\title{
Statement
}

for the Revision of the Resource Management Plans of the Western Oregon Bureau of Land Management

Salem, Eugene, Roseburg, Coos Bay, and

Medford Districts, and the Klamath Falls Resource Area of the Lakeview District

Volume II

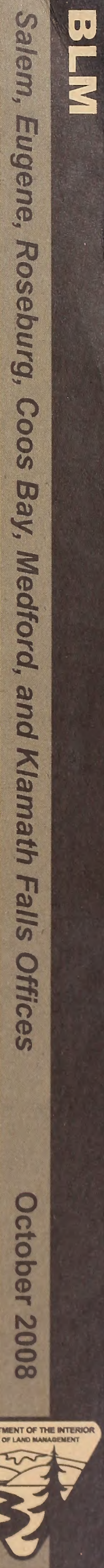


As the Nation's principal

conservation agency, the Department of the Interior has responsibility for most of our nationally owned public lands and natural resources. This includes fostering the wisest use of our land and water resources, protecting our fish and wildlife, preserving the environmental and cultural values of our national parks and historical places, and providing for the enjoyment of life through outdoor recreation. The Department assesses our energy and mineral resources and works to assure that their development is in the best interest of all our people. The Department also has a major responsibility for American Indian reservation communities and for people who live in Island Territories under U.S. administration. 


\section{Table of Contents - Volume II}

Chapter 4 - Environmental Consequences

Summary of Major Changes from Chapter 4 of the Draft EIS/Draft RMP.

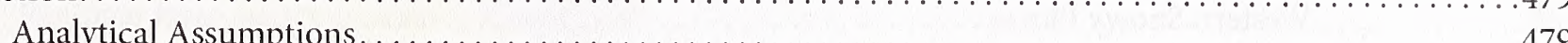

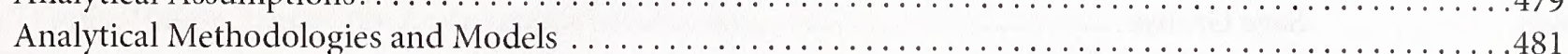

Geographic Information System Data . . . . . . . . . . . . . . . . . . . . . . . . . 483

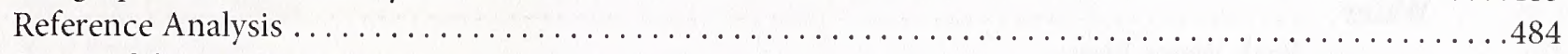

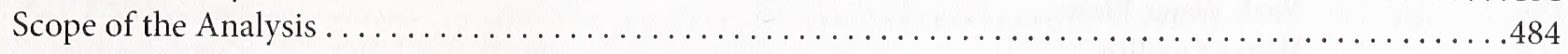

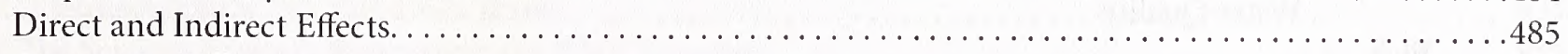

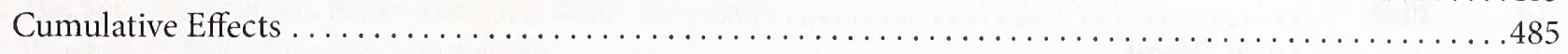

Spatial and Temporal Scales of Analysis . . . . . . . . . . . . . . . . . . . . . . . . 488

Potential Changes in Conditions Not Incorporated into the Analysis . . . . . . . . . . . . . . . 488

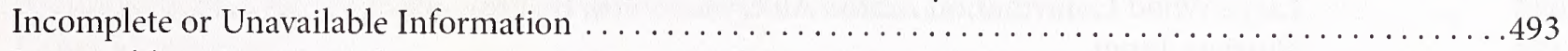

Irreversible or Irretrievable Commitment of Resources . . . . . . . . . . . . . . . . . . . 495

Adverse Effects That Cannot be Avoided . . . . . . . . . . . . . . . . . . . . . . . . . . . 495

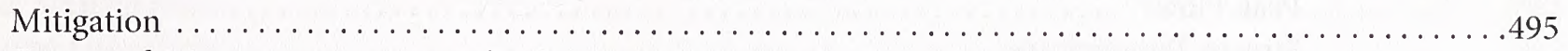

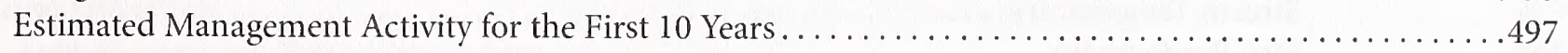

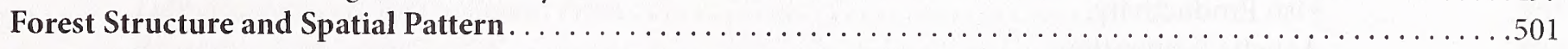

Forest Structure and Spatial Pattern on the BLM-Administered Lands across the Planning Area. . . . . . .502

Forest Structure and Spatial Pattern on the BLM- Administered Lands by Land Use Allocation . . . . . . . 517

Forest Structure and Spatial Pattern on the BLM- Administered Lands at the Province Scale.......... 519

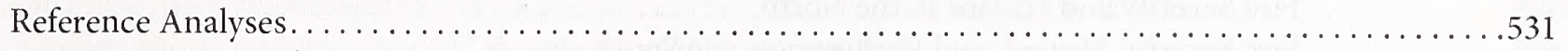

Carbon Storage

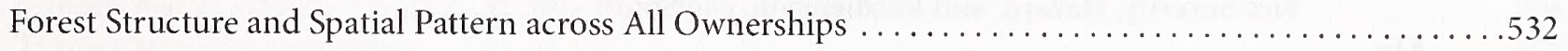

Socioeconomics . .

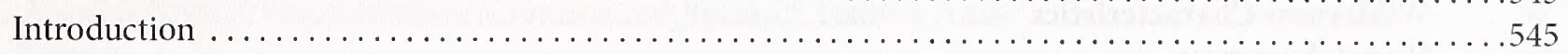

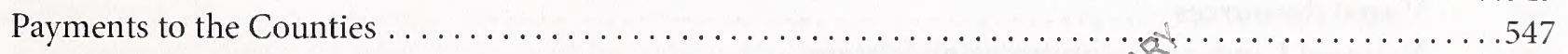

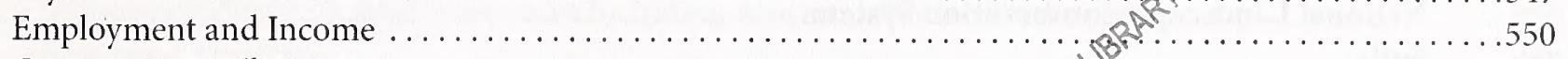

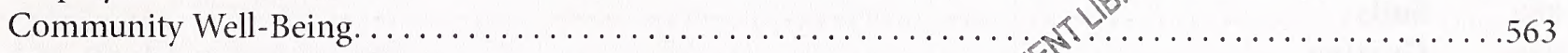

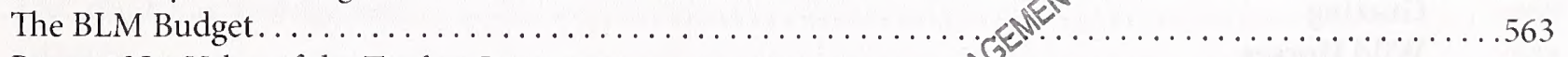

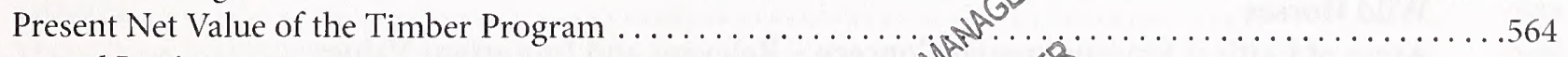

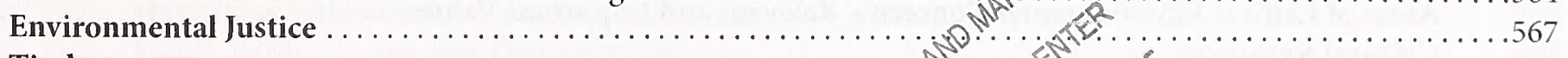

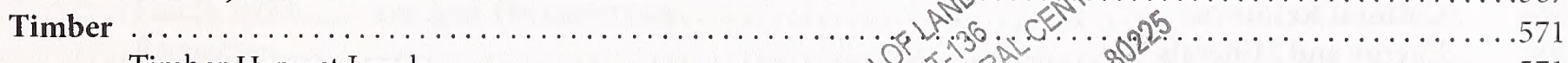

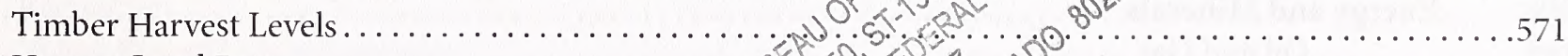

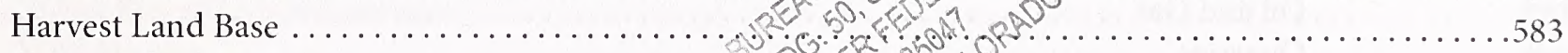

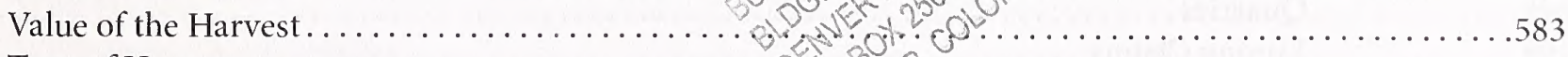

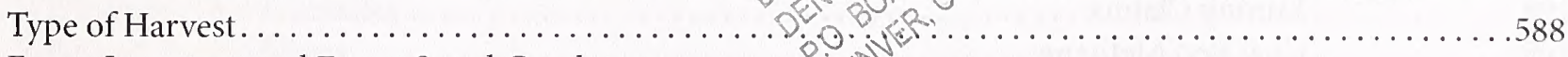

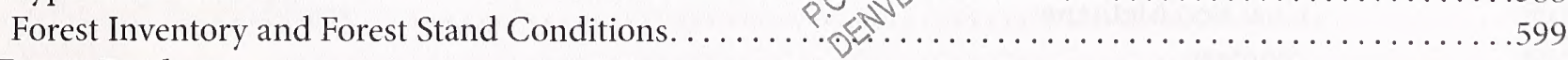

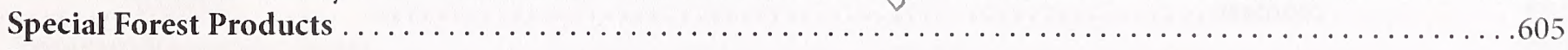

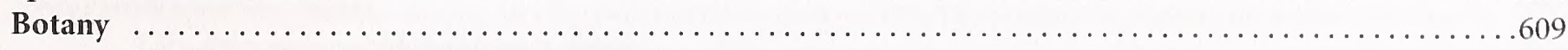

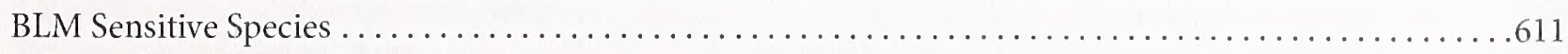

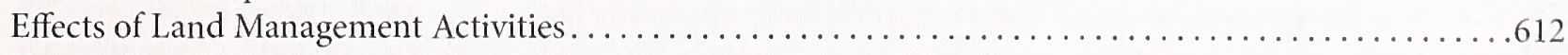

National Landscape Conservation System and Areas of Critical Environmental Concerns ...........6.621

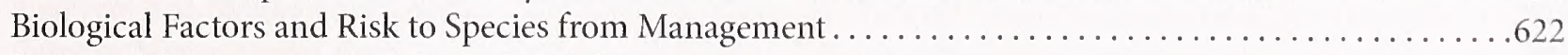

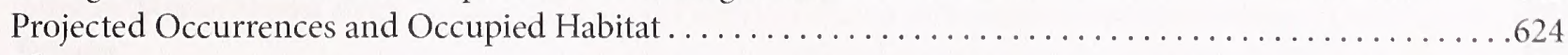

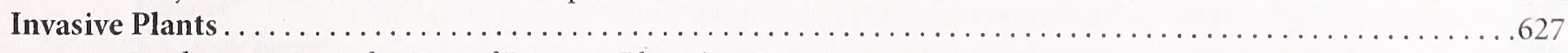

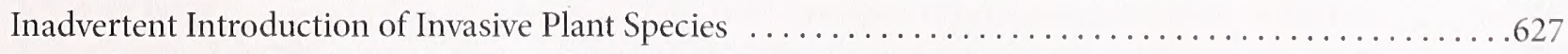

Wildlife .

Long-Term Introduction and Spread of Invasive Plant Species and Summary ................6. 640

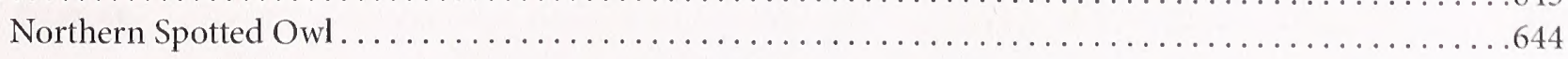




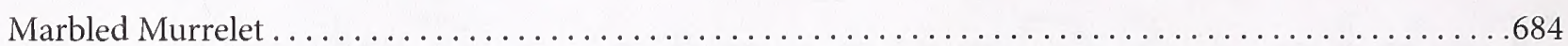

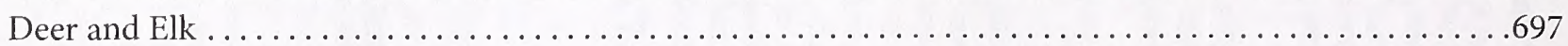

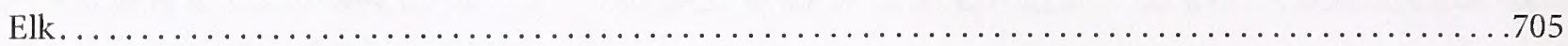

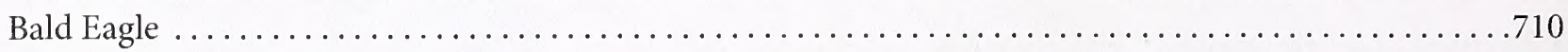

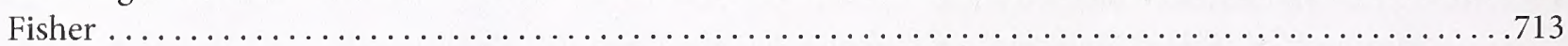

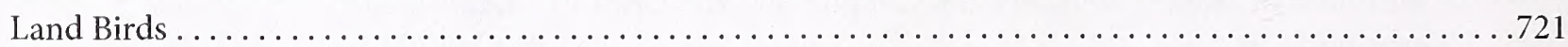

Western Snowy Plover . . . . . . . . . . . . . . . . . . . . . . . . . . . . . . . 743

Sage Grouse . . . . . . . . . . . . . . . . . . . . . . . . . . . . . . . . . . . . 744

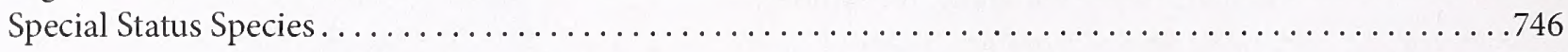

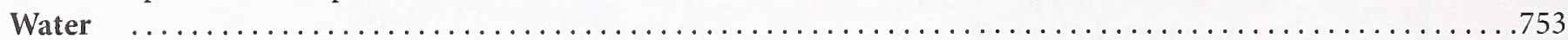

Peak Water Flow . . . . . . . . . . . . . . . . . . . . . . . . . . . . . . . . . 753

Water Quality . . . . . . . . . . . . . . . . . . . . . . . . . . . . . . . . . . . 759

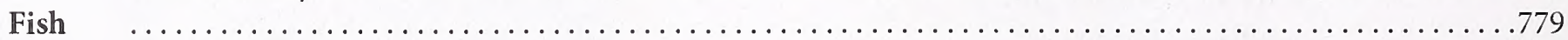

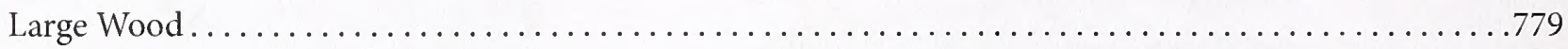

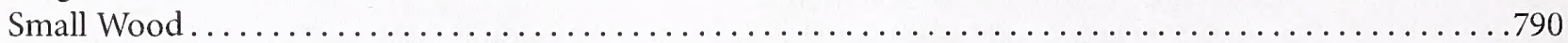

Large Wood Contribution Across All Ownerships, By Province. . . . . . . . . . . . . . . . . . . 794

Nutrient Input . . . . . . . . . . . . . . . . . . . . . . . . . . . . . . . . . . . 797

Fine Sediment Delivery . . . . . . . . . . . . . . . . . . . . . . . . . . . . . . . . . 799

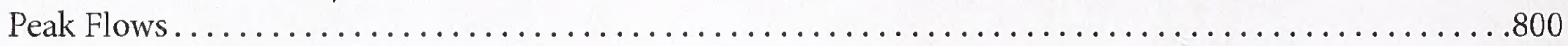

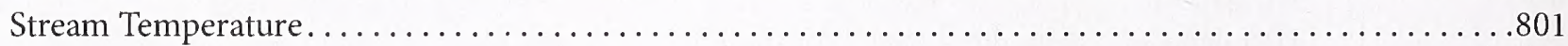

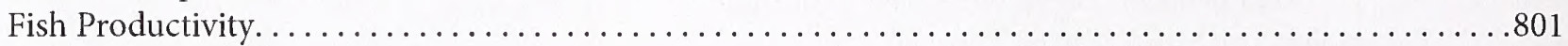

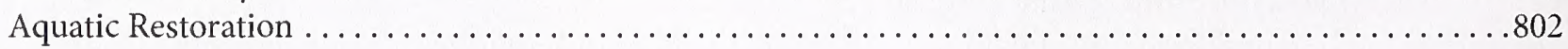

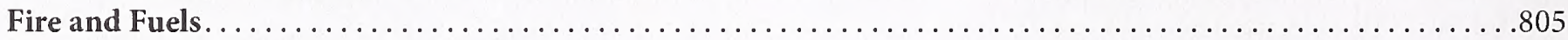

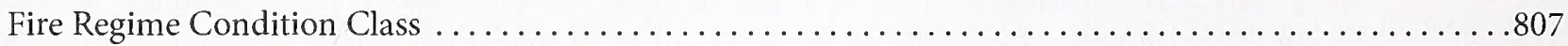

Fire Severity and Hazard in the North. . . . . . . . . . . . . . . . . . . . . . . . . 808

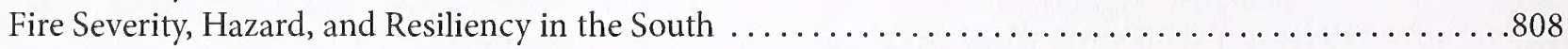

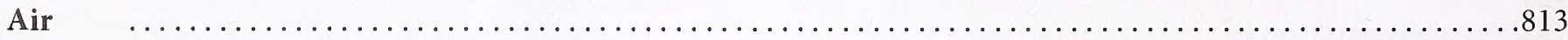

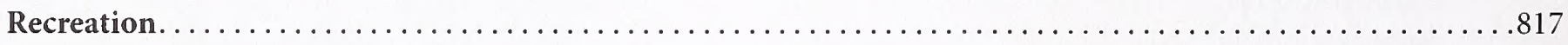

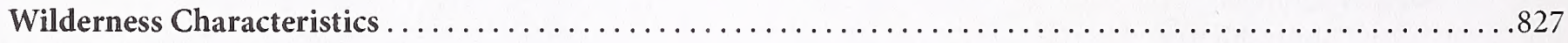

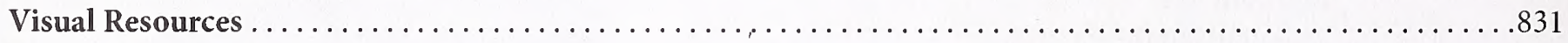

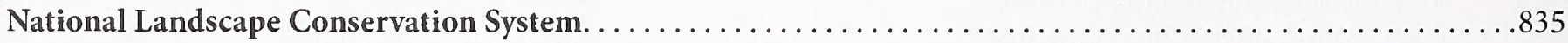

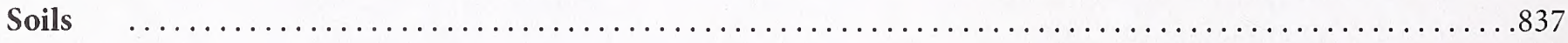

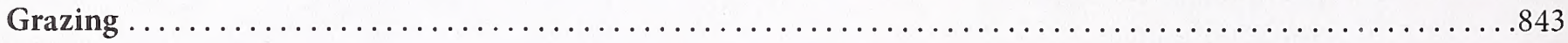

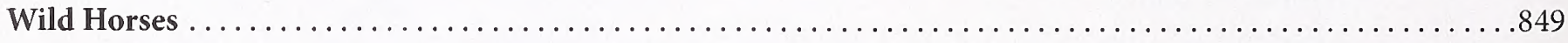

Areas of Critical Environmental Concern - Relevant and Important Values . . . . . . . . . . . . . . . 853

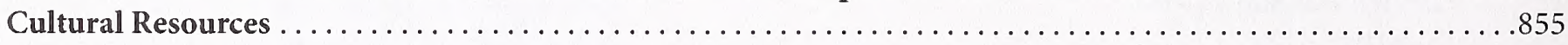

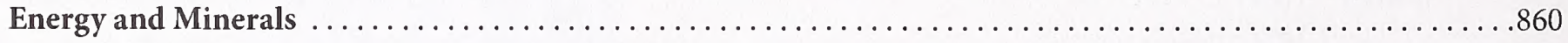

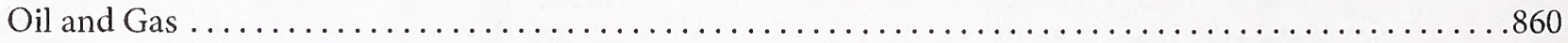

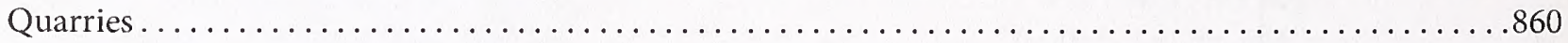

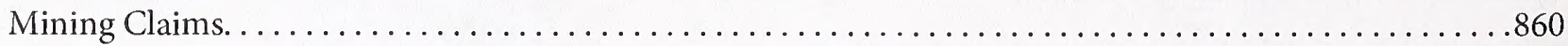

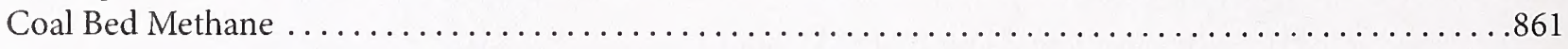

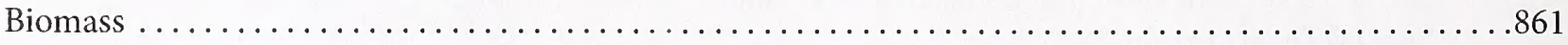




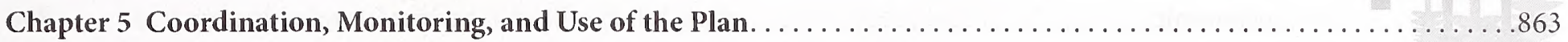

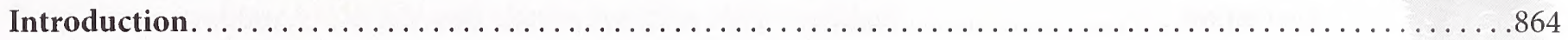

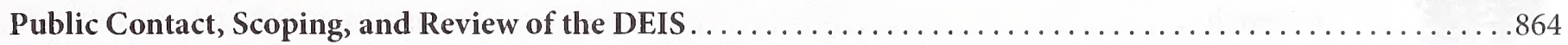

Protest Process. . . . . . . . . . . . . . . . . . . . . . . . . . . . . . . . . . . . . . . . . . . . . . 865

Relationship of the Proposed Resource Management Plan to Other Agency Plans and Programs .........885

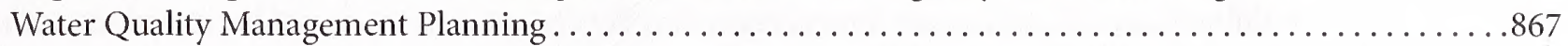

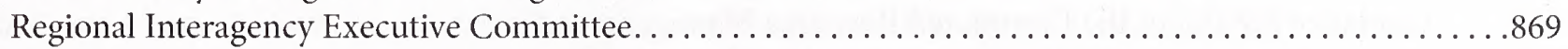

Section 7 Consultation Under the Endangered Species Act. . . . . . . . . . . . . . . . . . . . . . . 869

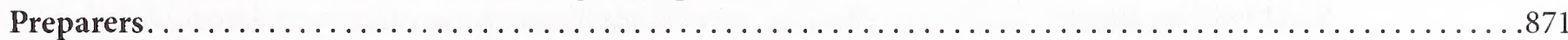

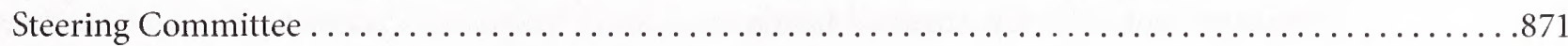

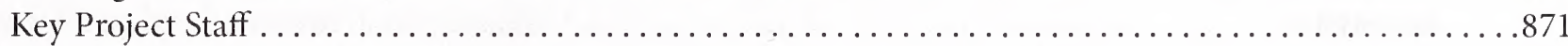

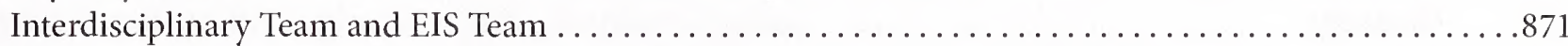

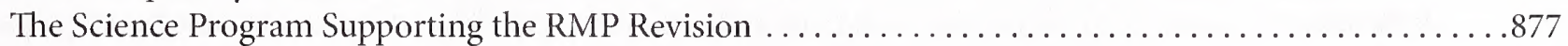

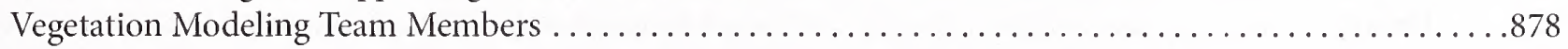

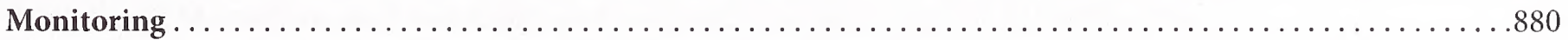

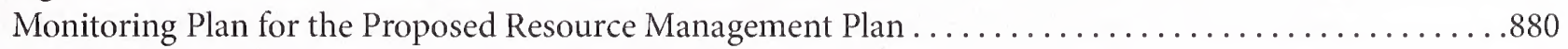

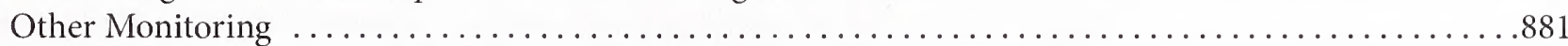

Plan Evaluations . . . . . . . . . . . . . . . . . . . . . . . . . . . . . . . . . . . . . . . . 881

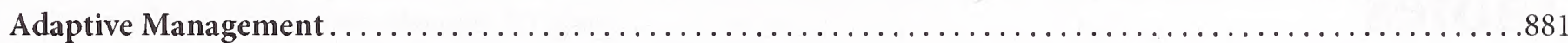

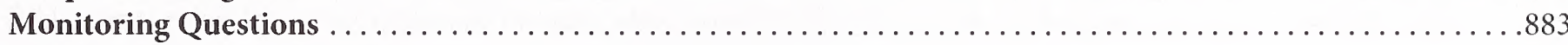

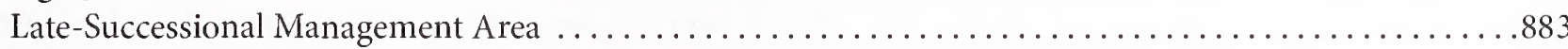

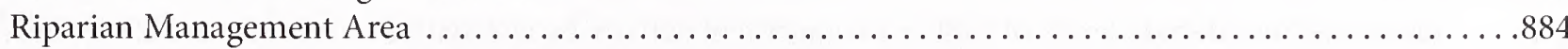

Eastside Forest Management Area . . . . . . . . . . . . . . . . . . . . . . . . . . . . . . . 886

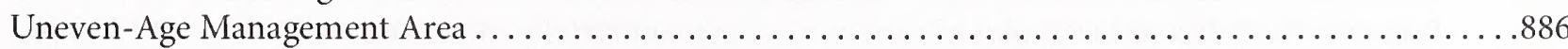

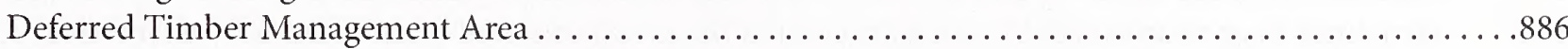

Timber Management Area and Uneven-Age Management Area $\ldots \ldots \ldots \ldots \ldots \ldots \ldots \ldots \ldots \ldots \ldots . \ldots . \ldots . \ldots . \ldots \ldots 6$

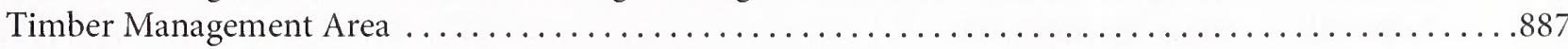

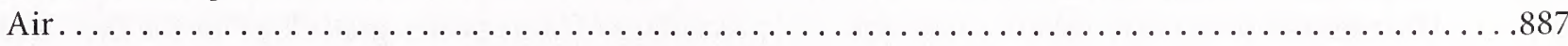

Areas of Critical Environmental Concern and Research Natural Areas . . . . . . . . . . . . . . . . . . 887

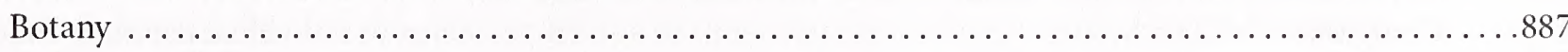

Cultural and Paleontological Resources Including American Indian Traditional Uses . . . . . . . . . . . 888

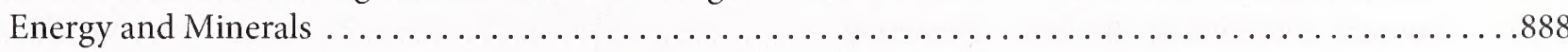

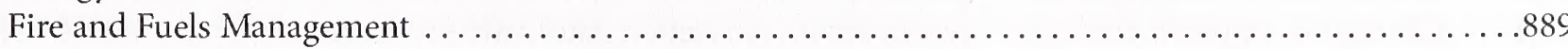

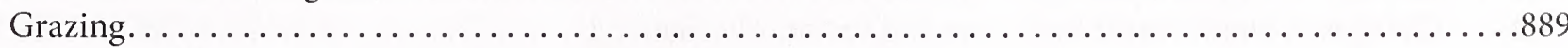

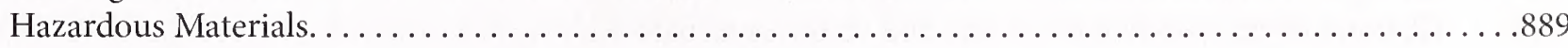

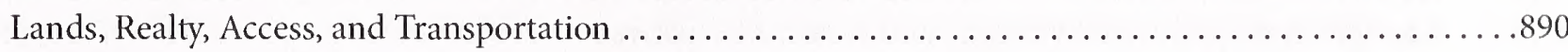

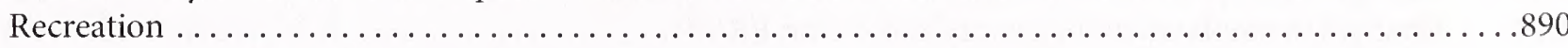

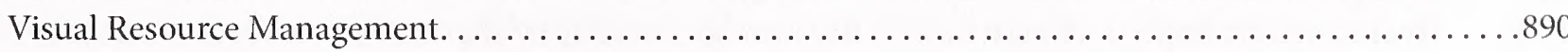

Wild Horses. . . . . . . . . . . . . . . . . . . . . . . . . . . . . . . . . . . . . . . . . . . . 890

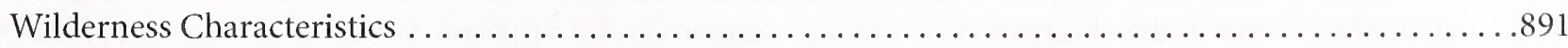

Wild and Scenic Rivers . . . . . . . . . . . . . . . . . . . . . . . . . . . . . . . . . 891

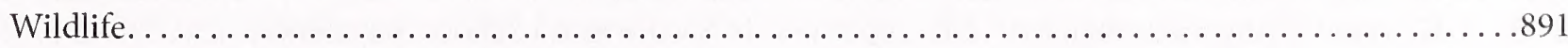

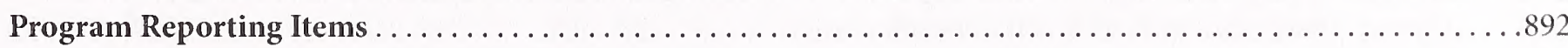

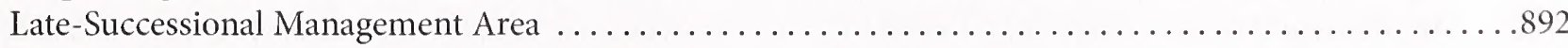

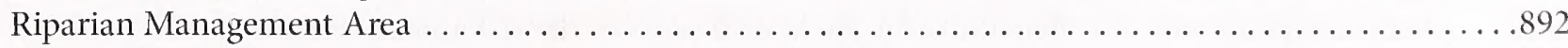

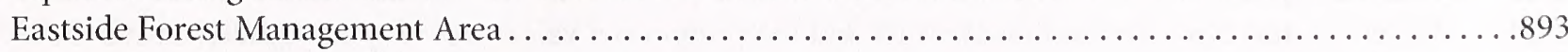

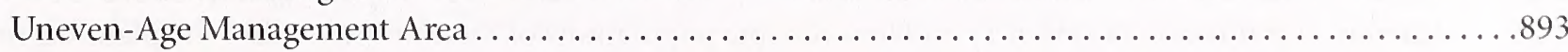

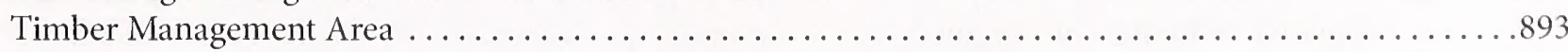

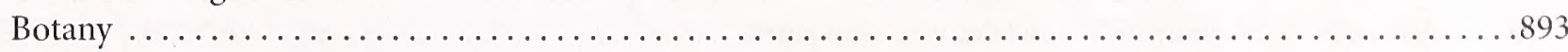

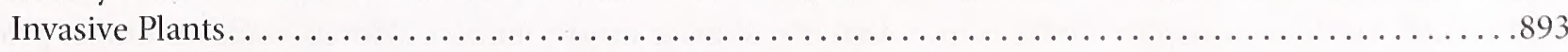

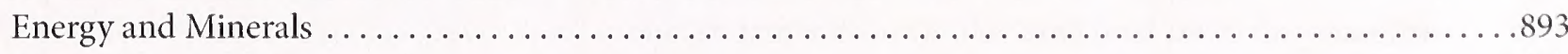

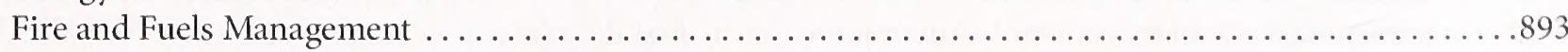

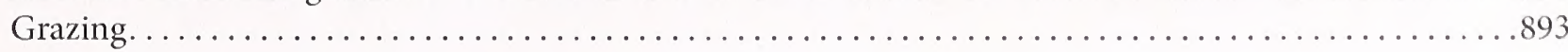

Table of Contents - iii 


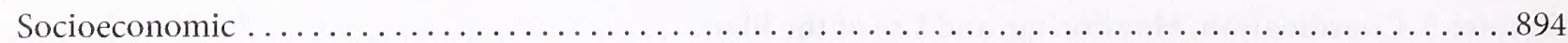

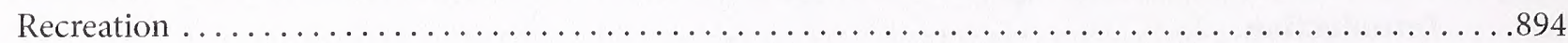

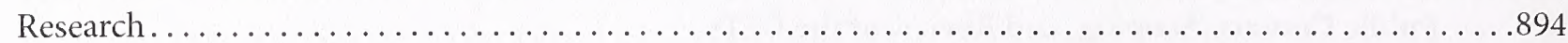

Special Forest Products . . . . . . . . . . . . . . . . . . . . . . . . . . . . . . 894

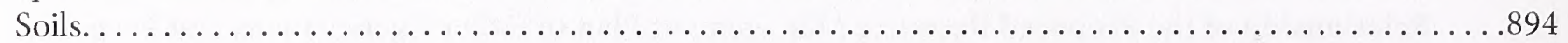

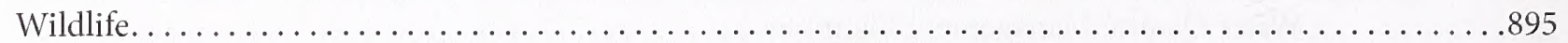

Guidance for Use of the Completed Resource Management Plans. . . . . . . . . . . . . . . . . . . . 895

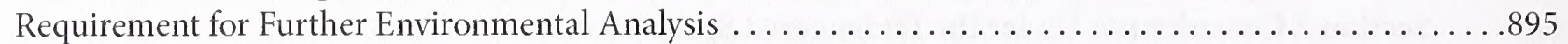

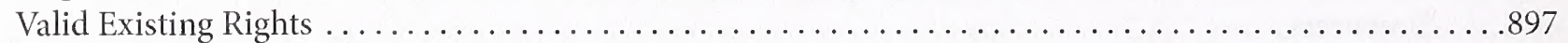

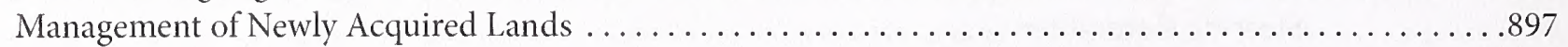

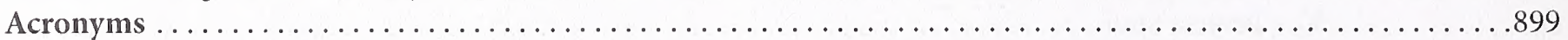

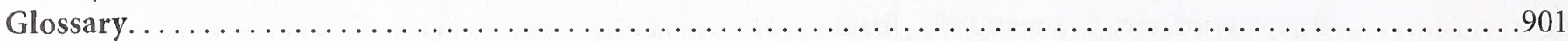

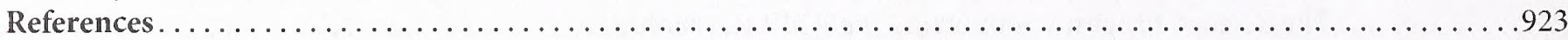

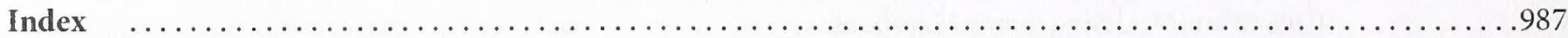

\section{Tables}

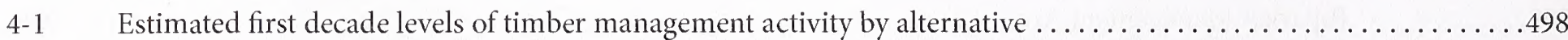

4-2 Estimated first decade levels of timber management activity by district under the PRMP . . . . . . . . . ....499

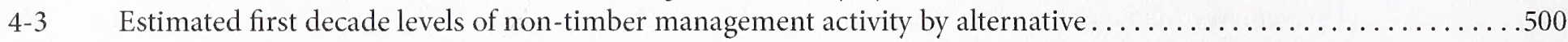

4-4 Structural stage abundances by percentage of the BLM-administered forested lands by alternative ...........504

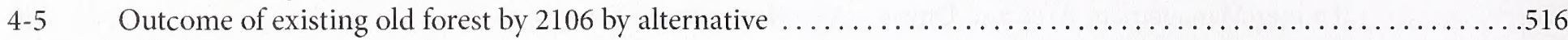

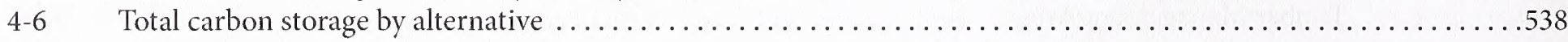

4-7 Distribution of harvest by harvesting type and percentage of large peeler-grade logs for the first decade .......547

4-8 Estimated annual payments to the counties for the first 10 years $\ldots \ldots \ldots \ldots \ldots \ldots \ldots \ldots \ldots \ldots \ldots \ldots \ldots \ldots \ldots \ldots \ldots \ldots \ldots$

4-9 Comparison of 2005 Secure Rural Schools payments to annual payments to individual counties under

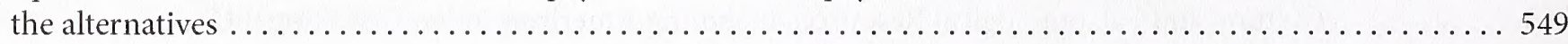

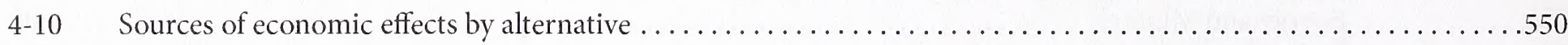

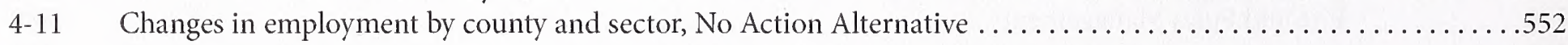

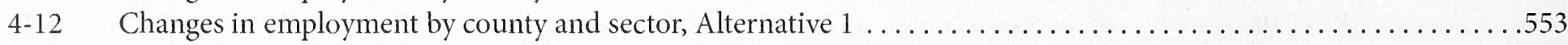

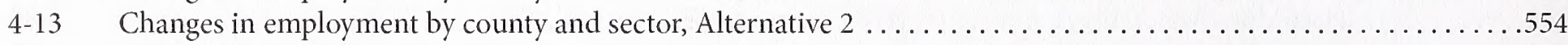

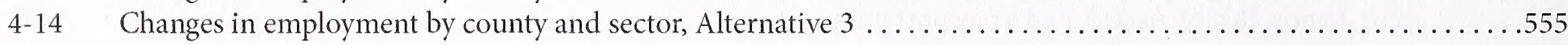

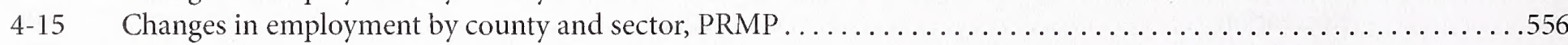

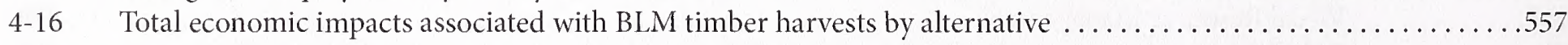

4-17 Counties in which the alternatives would compensate for other job losses. . . . . . . . . . . . . . . . . 558

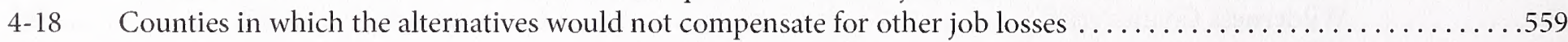

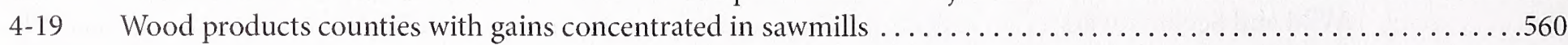

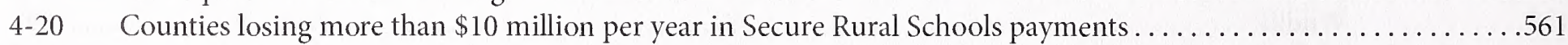

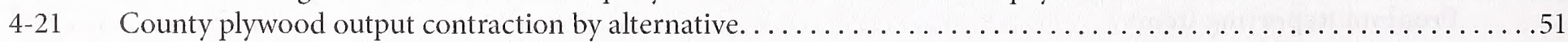

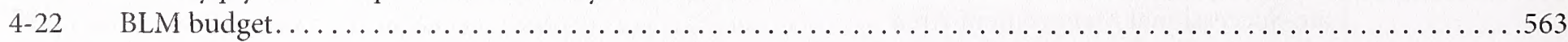

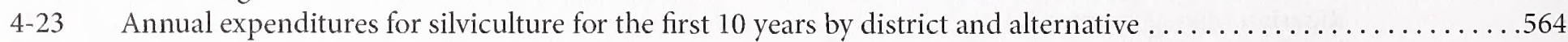

4-24 Revenues and costs for the first 10 years and the present net value over 50 years by alternative ...........565

4-25 Current composition of minority and low-income populations of the counties within the planning area

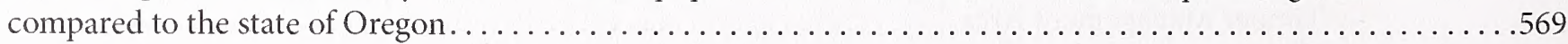

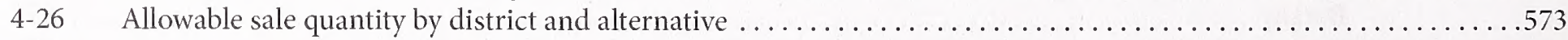

4-27 Allowable sale quantity for Reference Analysis: Manage most commercial forest lands for timber production .....574

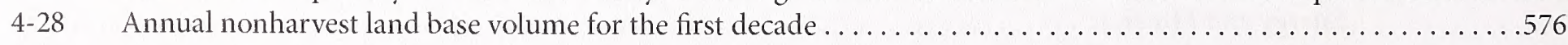

4-29 Annual Eastside Management Lands volume for the first decade. . . . . . . . . . . . . . . . . . . 577 


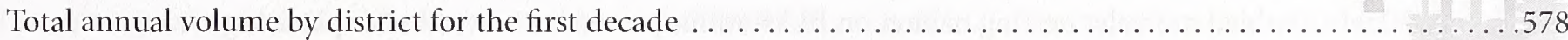

Total harvest volume by decade and alternative (first eight decades) . . . . . . . . . . . . . . . . . . . 579

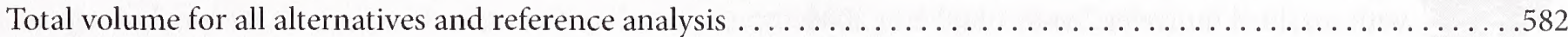

Estimated annual acres by harvest type over the first decade . . . . . . . . . . . . . . . . . . . . . . . 589

First decade acres harvested by age group in the harvest and nonharvest land base under the No Action Alternative .591

First ecade acres harvested by age in the harvest and nonharvest land base under Alternative $1 \ldots \ldots \ldots . \ldots . . . .591$

First decade acres harvested by age group in the harvest and nonharvest land base under Alternative $2 \ldots . . . .593$

First decade acres harvested by age group in the harvest and nonharvest land base under Alternative $3 \ldots \ldots . . .593$

First decade acres harvested by age group in the harvest and nonharvest land base under the PRMP . . . . . . . .594

Response of special forest products and acres of forest management activity and mature \& structurally

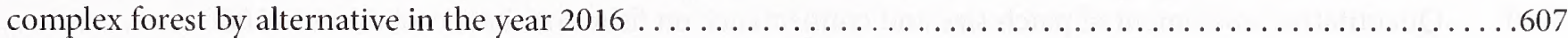

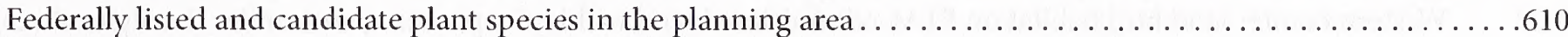

Forest management activities over the next 10 years that affect special status species plant occurrences........612

Projected occurrences that would be affected by forest management over the next 10 years . . . . . . . . . 625

Projected BLM sensitive plant and fungi species occurrences and occupied habitat by district. . . . . . . . . .625

Susceptibility comparison for the introduction of invasive plant species that are associated with timber

harvesting in the fifth-field watershed across the alternatives over the next 10 years . . . . . . . . . . 628

Matrix to determine the relative risk for the introduction of invasive plant species that are associated with timber

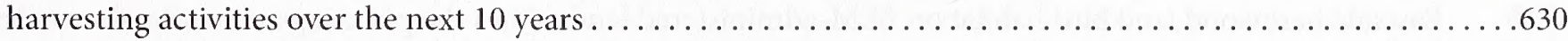

4-46 Risk comparison for introduction of invasive plant species associated with timber harvesting in the fifth-field

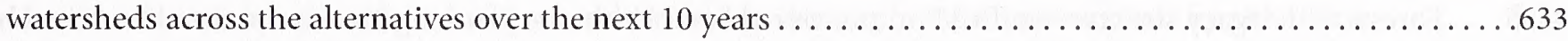

4-47 Susceptibility comparison for the introduction of invasive plant species into riparian habitats that are associated with timber harvesting in the fifth-field watersheds over the next 10 years $\ldots \ldots \ldots \ldots$

4-48 Risk comparison for the introduction of invasive plant species into riparian habitats associated with timber harvesting the fifth-field watersheds across the alternatives over the next 10 years $\ldots \ldots \ldots \ldots$

4-49 Risk comparison for the introduction of invasive plant species associated with new road construction by

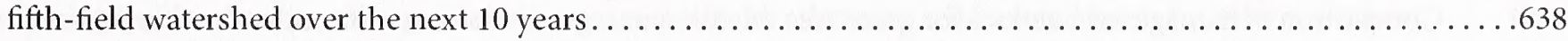

4-50 Relative risk of long and short-term introduction and spread of invasive plant species by analysis factor........ .641

4-51 Percent Change By Alternative Between 2006 And 2056, And Between 2006 And 2106, In The Acres Of Northern Spotted Owl Suitable Habitat With Low Or Mixed Fire Severity In The Medford District

And The Klamath Falls Resource Area . . . . . . . . . . . . . . . . . . . . . . . . . 669

4-52 Percent change, by alternative, between 2006 and 2056, and between 2006 and 2106, in the acres of northern spotted owl suitable habitat with low or mixed fire severity in the Coos Bay, Eugene,

Roseburg and Salem districts $\ldots \ldots \ldots \ldots \ldots \ldots \ldots \ldots \ldots \ldots \ldots \ldots \ldots \ldots \ldots \ldots \ldots \ldots \ldots \ldots \ldots$
Percent change, by alternative, between 2006 and 2056 , and between 2006 and 2106 , in the acres of northern spotted owl dispersal habitat with low or mixed fire severity in the Medford District and the

Klamath Falls Resource Area. . . . . . . . . . . . . . . . . . . . . . . . . . . . . 673

4-54 Percent change, by alternative, between 2006 and 2056, and between 2006 and 2106, in the acres of northern spotted owl dispersal habitat with low or mixed fire severity in the Coos Bay, Eugene and

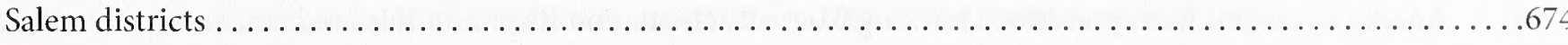

4-55 Percent change, by alternative, between 2006 and 2056, and between 2006 and 2106, in the acres of northern spotted owl suitable habitat with fire resiliency in the Medford District . . . . . . . . . . . . 676

4-56 Percent change, by alternative, between 2006 and 2056, and between 2006 and 2106, in the acres of northern spotted owl suitable habitat with fire resiliency in the Klamath Falls Resource Area . . . . . . . . . . 676

4-57 Percent change, by alternative, between 2006 and 2056, and between 2006 and 2106, in the acres of northern spotted owl dispersal habitat with fire resiliency in the Medford District. . . . . . . . . . . . 678

4-58 Percent change, by alternative, between 2006 and 2056, and between 2006 and 2106, in the acres of northern spotted owl dispersal habitat with fire resiliency in the Klamath Falls Resource Area . . . . . . . . . .678

4-59 The numbers of known and predicted northern spotted owl sites on BLM-administered lands in the planning area that currently occur in the nonharvest land base under each alternative $\ldots \ldots \ldots . \ldots . \ldots . \ldots 1$

4-60 Year at which the threshold age would be reached after which marbled murrelet sites would not be protected

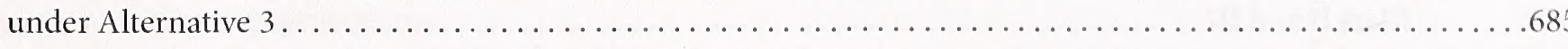


4-61

4-62

4-63

4-64

4-65

4-66

4-67

4-68

4-69

4-70

4-71

4-72

4-73

4-74

4-75

4-76

4-77

4-78

4-79

4-80

4-81

4-82

4-83

4-84

4-85

4-86

4-87

4-88

4-89

4-90

4-91

4-92

4-93

4-94

4-95

4-96

4-97

4-98

4-99

4-100

4-101

4-102

4-103

4-104

4-105
Available marbled murrelet nesting habitat on BLM-administered lands within the planning area ...........686

Comparison of the amounts of marbled murrelet nesting habitat and mature and structurally complex forests

with marbled murrelet Zones 1 and 2 in 2006 . . . . . . . . . . . . . . . . . . . . . . . . . . . . . . . . . 695

Open road density on BLM-administered lands within deer habitat management units . . . . . . . . . . . .704

Off-highway vehicle emphasis areas proposal for deer habitat management areas in the Medford District. . . . . .705

Open road density on BLM-administered lands in elk habitat management units . . . . . . . . . . . . . . . .709

Bald eagle nesting and roosting habitat development within the planning area $\ldots \ldots \ldots \ldots \ldots \ldots \ldots \ldots \ldots . \ldots \ldots 10$

Bald eagle nesting and roosting habitat in the west side of the Klamath Falls Resource Area ..............712

Available fisher natal habitat on BLM-administered lands within the planning area. . . . . . . . . . . . . . 714

Available fisher foraging habitat on BLM-administered lands within the planning area. . . . . . . . . . . . . 714

Quantitative assessment of patch size and connectance on fisher habitat condition in $2106 \ldots \ldots \ldots \ldots \ldots .720$

Western conifer land bird habitat on BLM-administered land within the planning area under the alternatives. . . .723

Western hardwood land bird habitat on BLM-administered land within the planning area under the

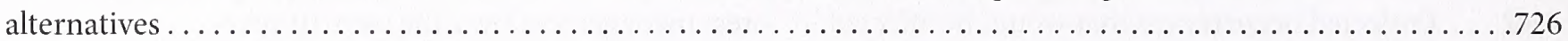

Eastside conifer forest land bird habitat on BLM-administered land within the planning area under the

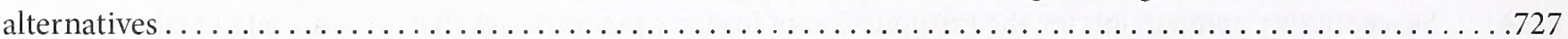

Eastside ponderosa pine land bird habitat on BLM-administered land within the planning area under the

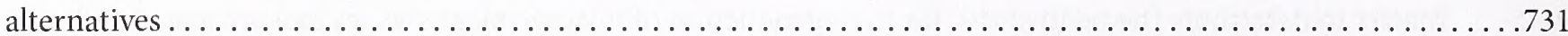

Eastside hardwood land bird habitat on BLM-administered land within the planning area under the

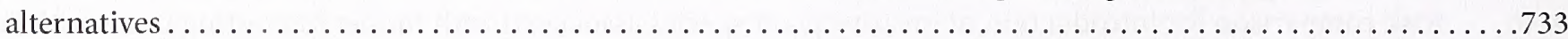

Forests with legacy structure on BLM-administered land within the planning area under the alternatives by

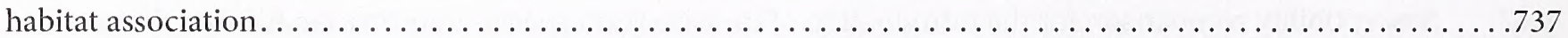

Comparison of management actions for snag retention or creation under the alternatives . . . . . . . . . . . 738

Snag density found in unharvested forests . . . . . . . . . . . . . . . . . . . . . . . . . . . . . . . . .

Comparison of management actions for downed wood retention or creation under the alternatives ............741

Coarse woody debris cover found in unharvested forests . . . . . . . . . . . . . . . . . . . . . . . 742

Comparison of management actions for green tree retention in regeneration harvests under the alternatives ....... 743

Federally listed candidate, threatened, and endangered species not associated with forested ecosystems........ 747

Riparian management areas across all land use allocations under the alternatives . . . . . . . . . . . . . . . . . .749

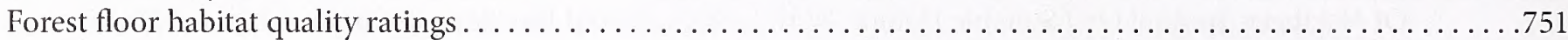

Projected acres of stand establishment forests on BLM-administered lands . . . . . . . . . . . . . . . . . . 754

Rain-dominated sixth-field subwatersheds susceptible to peak flows under the alternatives .............. 755

Potential delivery of fine sediment by new roads constructed by 2016 under the alternative. . . . . . . . . . . 767

Estimate of future fish passage barriers removed per decade by district in the planning area $\ldots \ldots \ldots \ldots \ldots . \ldots 802$

Estimate of future road improvement and decommissioning by district in the planning area $\ldots \ldots \ldots \ldots \ldots . \ldots 03$

Estimate of future instream restoration projects per decade by district . . . . . . . . . . . . . . . . . . . . 803

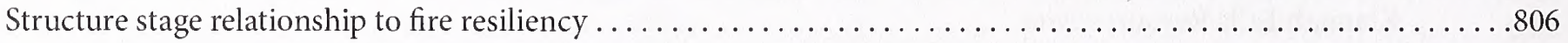

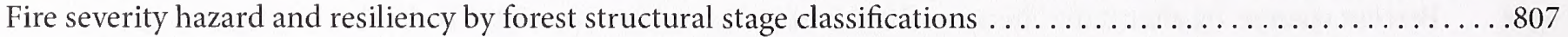

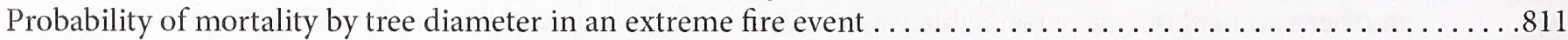

Annual emissions from prescribed burning from all activities on BLM-administered lands. . . . . . . . . . . 814

Annual emissions from prescribed burning from all activities on all ownerships $\ldots \ldots \ldots \ldots \ldots \ldots \ldots \ldots \ldots . \ldots . \ldots \ldots$

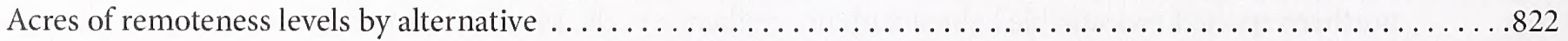

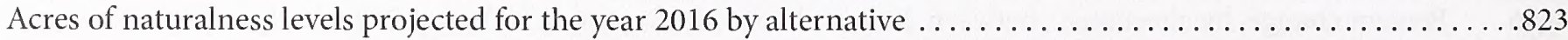

Special management to maintain wilderness characteristics under all action alternatives $\ldots \ldots \ldots \ldots \ldots \ldots \ldots 827$

BLM-administered lands with wilderness characteristics in the harvest land base by alternative $\ldots \ldots \ldots \ldots \ldots 828$

BLM-administered lands with wilderness characteristics in late-successional management areas and riparian

management areas by alternative . . . . . . . . . . . . . . . . . . . . . . . . . . . . . 829

BLM-administered lands with wilderness characteristics maintained by alternative . . . . . . . . . . . . . 829

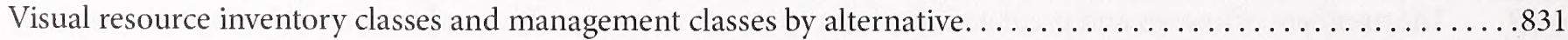

Harvest land base within each visual resource inventory class by alternative $\ldots \ldots \ldots \ldots \ldots \ldots \ldots \ldots \ldots \ldots . \ldots \ldots 32$

Percentage of existing visual resource quality maintained by alternative within areas inventoried as

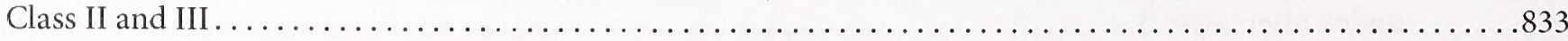

Residual detrimental soil disturbance compared to total acres harvested during the first 10 years ..........838 
4-106 Livestock grazing authorizations by district and by alternative. . . . . . . . . . . . . . . . . .

4-107 Range improvement construction by district and by alternative. . . . . . . . . . . . . . . . . . . 845

4-108 Changes in livestock forage production within lands allocated for grazing by alternative .............. 848

4-109 Changes in wild horse forage production by alternative. . . . . . . . . . . . . . . . . . . . . . . 852

4-110 Percent of total cultural resource sites damaged under the alternatives over the next 10 years ...........859

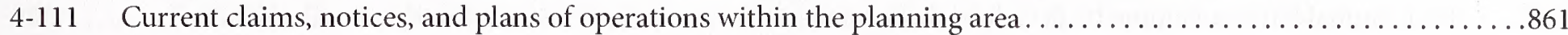

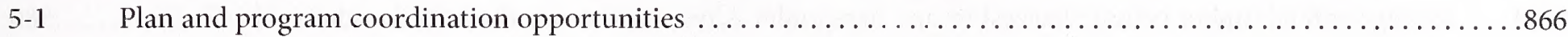

5-2 BLM plans and components of a total maximum daily load implementation plan $\ldots \ldots \ldots \ldots . \ldots . . . . . . .668$

5-3 Key project staff for the proposed resource management plan and final environmental impact statement .......875

\section{Figures}

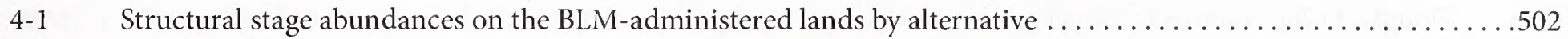

4-2 Comparison of the BLM-administered forested lands by 2106 with the average historic conditions and current

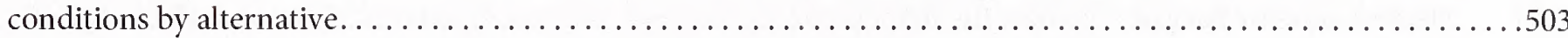

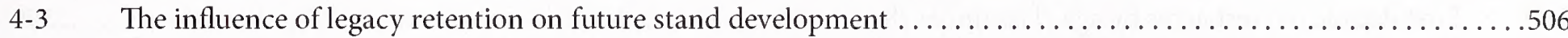

4-4 Stand establishment forests with and without structural legacies (e.g. retained green trees) by alternative........ 510

4-5 Young forests with and without structural legacies (e.g. retained green trees) by alternative...............511

4-6 Mature forest with multi-layered canopies or single canopies by alternative . . . . . . . . . . . . . . . 512

4-7 Structural stage abundances on the forested lands in the harvest land base by alternative .............. 18

4-8 Structural stage abundances in the harvest land base by land use allocation in the PRMP ..............519

4-9 Structural stage abundances on the forested lands in the nonharvest land base by alternative .............520

4-10 Comparison of the structural stage abundances on the BLM-administered forested lands by 2106 with the current conditions and the average historic conditions by alternative by province. ...............

4-11 Change in the mean patch size from the current conditions by 2106 by forest structural stage on the

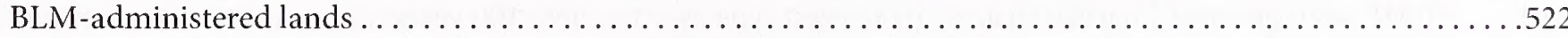

4-12 Change in the connectivity from the current conditions by 2106 by forest structural stage on the

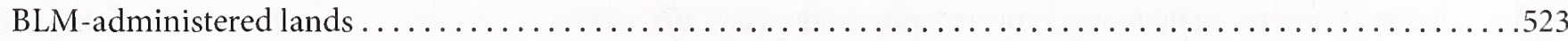

4-13 Structural stage abundances on BLM-administered forested lands in the Coast Range Province by alternative. ....525

4-14 Structural stage abundances on BLM-administered forested lands in the West Cascades Province by alternative...526

4-15 Structural stage abundances on BLM-administered forested lands in the Klamath Province by alternative ........528

4-16 Structural stage abundances on BLM-administered forested lands in the Eastern Cascades Province by alternative 529

4-17 Comparison of all ownerships by 2106 with average historic conditions and current conditions by alternative. ... 534

4-18 Comparison of all ownerships by 2106 with average historic conditions and current conditions by province by

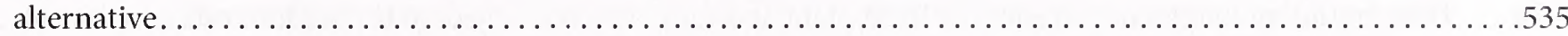

4-19 Change in the mean patch sizes from the current condition by 2106 by the forest structural stages

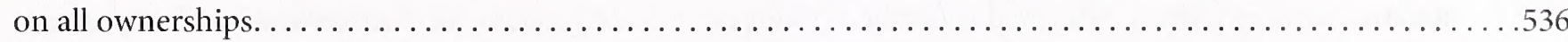

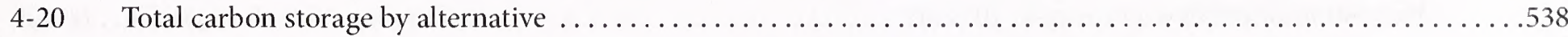

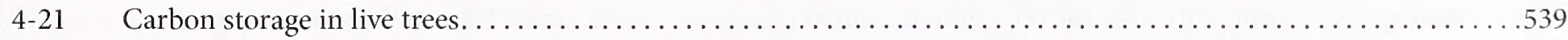

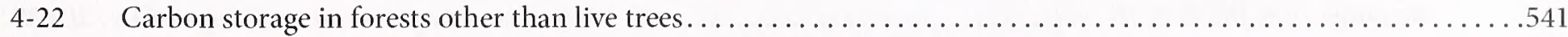

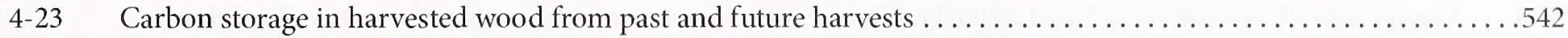

4-24 Historic and projected BLM payments to the counties for the first decade. . . . . . . . . . . . . . . . . . 549

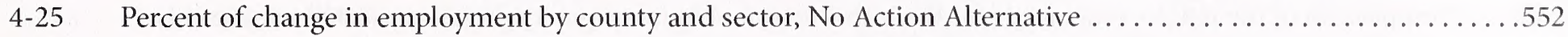

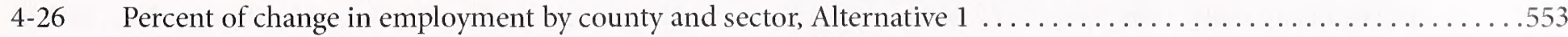

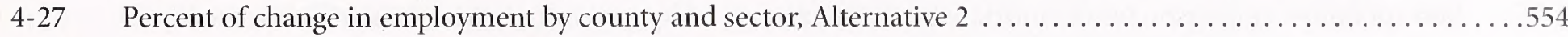

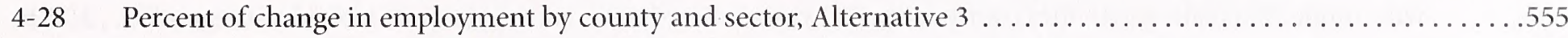

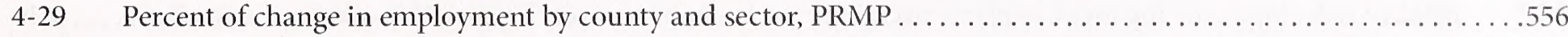

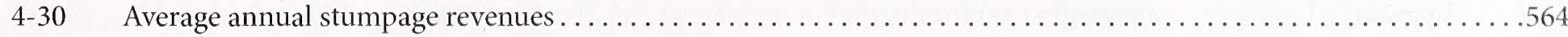

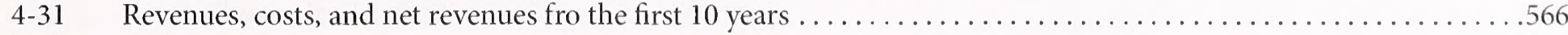




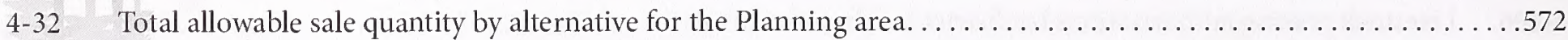

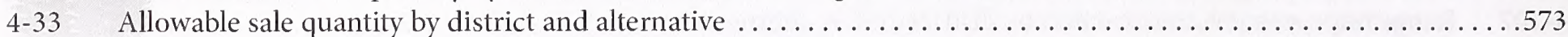

4-34 Reference analysis: Manage most commercial forest lands for maximizing timber production ...............574

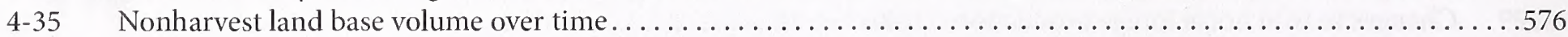

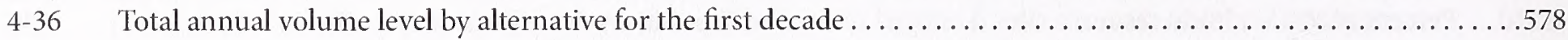

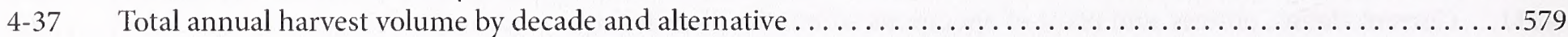

4-38 Average annual timber volume harvest by age class under the No Action Alternative over the next decade. . . . . 5580

4-39 Average annual timber volume harvest by age class under Alternative 1 over the next decade ..............5.50

4-40 Average annual timber volume harvest by age class under Alternative 2 over the next decade .............551

4-41 Average annual timber volume harvest by age class under Alternative 3 over the next decade .............581

4-42 Average annual timber volume harvest by age class under PRMP over the next decade................581

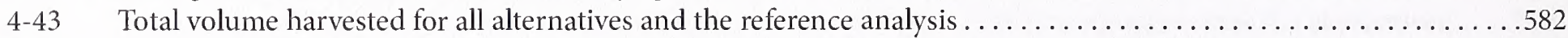

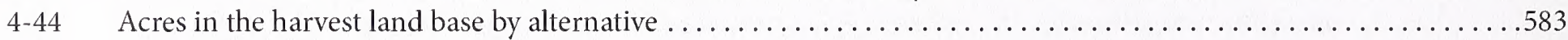

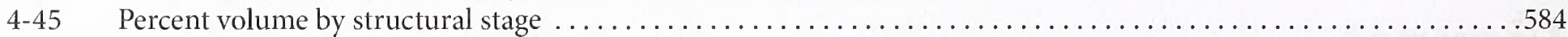

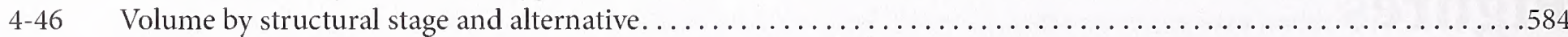

4-47 Percentage of number 3, peeler-grade and better Douglas fir logs by alternative $\ldots \ldots \ldots \ldots \ldots \ldots \ldots \ldots \ldots \ldots \ldots 5$

4-48 Douglas fir $\log$ volumes by peeler grade and sawlog grade by alternatives $\ldots \ldots \ldots \ldots \ldots \ldots \ldots \ldots \ldots \ldots \ldots \ldots \ldots \ldots$

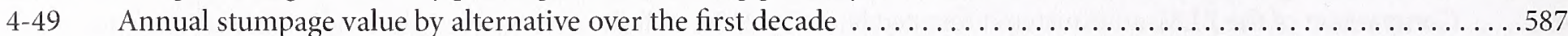

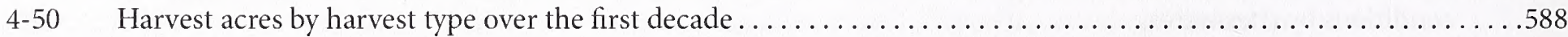

4-51 First decade harvest acres by age class under the No Action Alternative. . . . . . . . . . . . . . . . . . . . . . 590

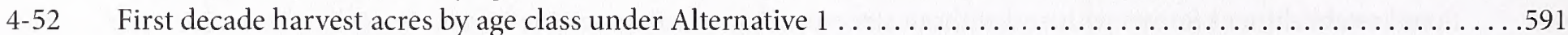

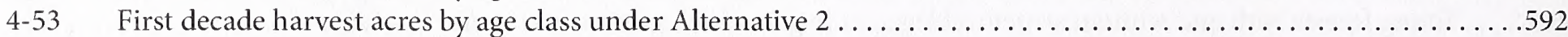

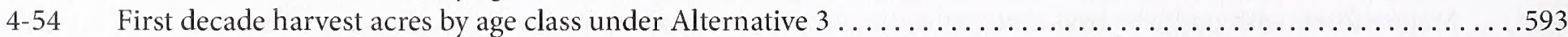

4-55 First decade harvest acres harvested by age class under the PRMP . . . . . . . . . . . . . . . . . . . . . . 594

4-56 First decade harvest types as a percentage of entire forest age class distribution . . . . . . . . . . . . . . . . . . 595

4-57 No Action Alternative, average annual harvested acres by harvest type over the next 100 years . . . . . . . . . . . 595

4-58 Alternative 1 , average annual harvested acres by harvest type over the next 100 years .................556

4-59 Alternative 2, average annual harvested acres by harvest type over the next 100 years ..................596

4-60 Alternative 3, average annual harvested acres by harvest type over the next 100 years ..................557

4-61 PRMP, average annual harvested acres by harvest type over the next 100 years . . . . . . . . . . . . . . . . 597

4-62 Miles of new permanent road construction under each alternative . . . . . . . . . . . . . . . . . . . . . . 598

4-63 Acres of new permanent road construction under each alternative . . . . . . . . . . . . . . . . . . . . . 598

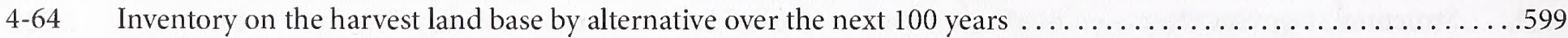

4-65 Age class distribution in the harvest land base under the No Action Alternative over the next 100 years .......601

4-66 Age class distribution in the harvest land base under Alternative 1 over the next 100 years ..............601

4-67 Age class distribution in the harvest land base under Alternative 2 over the next 100 years ..............602

4-68 Age class distribution in the harvest land base under Alternative 3 over the next 100 years .............602

4-69 Age class distribution in the harvest land base under the PRMP over the next 100 years.................603

4-70 Distribution of known occurrences of BLM plant and fungi species subject to timber harvest. . . . . . . . . . .613

4-71 Distribution of known populations of Bureau special status species by land ownership and habitat group. . . ...623

4-72 Relative susceptibility of fifth-field watersheds to invasive plant species introduction as a result of timber

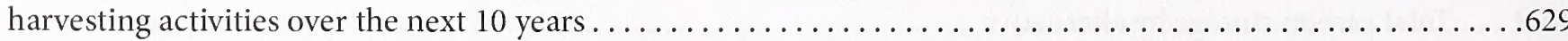

4-73 Susceptibility comparison for introduction of invasive plant species associated with timber harvesting

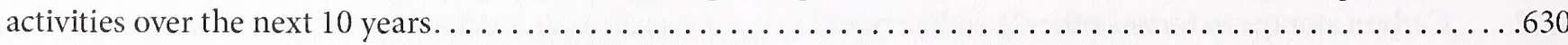

4-74 Comparison of the risk by mapped watershed for the introduction of invasive plant species associated with

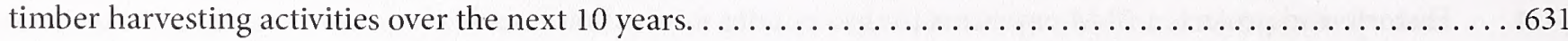

4-75 Comparison of the risk by watersheds for the introduction of invasive plant species associated with timber

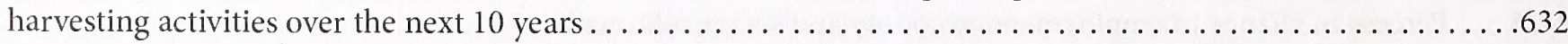

4-76 Susceptibility comparison for the introduction of invasive plant species into riparian habitats associated

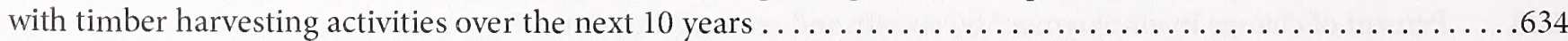

4-77 Relative risk of introducing invasive plant species in riparian habitats over the next 10 years............636

4-78 Riparian risk category comparison for introduction of invasive plant species over the next 10 years. . . . . . . .637 
4-79 Risk comparison for the introduction of invasive plant species associated with new road construction

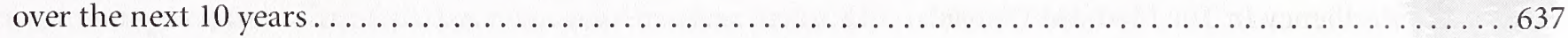

4-80 Relative risk for introduction of invasive plant species associated with off-highway vehicle designations.........639

4-81 Risk comparison for introduction of invasive plant species associated with off-highway vehicle use ..........640

The Distribution Of Large And Small Habitat Blocks At Year 2016 Under All Alternatives And According

To The No Harvest Reference Analysis . . . . . . . . . . . . . . . . . . . . . . . . . . 646

4-83 The Distribution Of Large And Small Habitat Blocks At Year 2026 Under All Alternatives And According

To The No Harvest Reference Analysis. . . . . . . . . . . . . . . . . . . . . . . . . . 648

4-84 The Distribution Of Large And Small Habitat Blocks At Year 2036 Under Alternative 2, The PRMP, And

According To The No Harvest Reference Analysis. . . . . . . . . . . . . . . . . . . . . . 650

4-85 The Distribution Of Large And Small Habitat Blocks At Year 2046 Under Alternative 2, The PRMP, And

According To The No Harvest Reference Analysis. . . . . . . . . . . . . . . . . . . . . . . 65

4-86 The Distribution Of Large And Small Habitat Blocks At Year 2056 Under All Alternatives And According

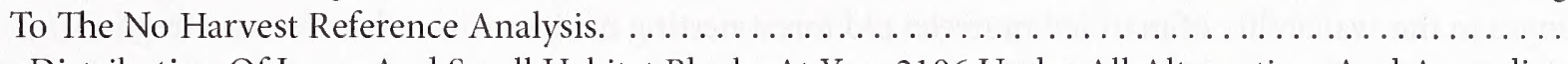

4-87 The Distribution Of Large And Small Habitat Blocks At Year 2106 Under All Alternatives And According

To The No Harvest Reference Analysis . . . . . . . . . . . . . . . . . . . . . . . . . . . . . . .

4-88 Changes In The Number Of Acres Contained Within All Large Habitat Blocks, On All Land Ownerships,

Under The Alternatives And According To The No Harvest Reference Analysis ...................656

4-89 Changes In The Acres Of Suitable Habitat On Federally-Administered Lands Under The Alternatives And

According To The No Harvest Reference Analysis. . . . . . . . . . . . . . . . . . . . . . . . 659

4-90 Changes In The Acres Of Suitable Habitat Within Small And Large Habitat Blocks On

Federally-Administered Lands Under The Alternatives And According To The No Harvest

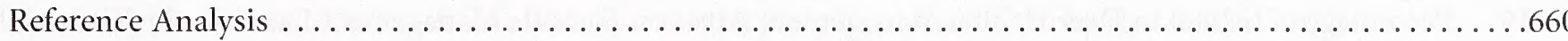

4-91 Changes In The Acres Of Suitable Habitat Within Large Habitat Blocks On Federally-Administered

Lands Under The Alternatives And According To The No Harvest Reference Analysis . . . . . . . . . . . . 66

4-92 A Comparison Of The Alternatives And The No Harvest Reference Analysis In 2056: The Proportion

Of Northern Spotted Owl Dispersal Habitat On All Land Ownerships In Each Fifth-Field Watershed ........ .662

4-93 A Comparison Of The Alternatives And The No Harvest Reference Analysis In 2056: The Proportion

Of Northern Spotted Owl Suitable Habitat On All Land Ownerships In Each Fifth-Field Watershed ........666

4-94 Changes By Alternative In Development Of Northern Spotted Owl Suitable Habitat With Low Fire

Severity In The Medford District And The Klamath Falls Resource Area . . . . . . . . . . . . . . 668

4-95 Changes By Alternative In Development Of Northern Spotted Owl Suitable Habitat With Mixed Fire

Severity In The Medford District And The Klamath Falls Resource Area . . . . . . . . . . . . . . . . . . . 669

4-96 Changes By Alternative In Development Of Northern Spotted Owl Suitable Habitat With Low Fire

Severity In The Coos Bay, Eugene, Roseburg And Salem Districts . . . . . . . . . . . . . . . 670

4-97 Changes By Alternative In Development Of Northern Spotted Owl Suitable Habitat With Mixed Fire

Severity In The Coos Bay, Eugene, Roseburg And Salem Districts . . . . . . . . . . . . . . . . 670

4-98 Changes By Alternative In The Development Of Northern Spotted Owl Dispersal Habitat With High Fire

Severity In The Medford And Roseburg Districts And The Klamath Falls Resource Area ..............672

4-99 Changes By Alternative In The Development Of Northern Spotted Owl Dispersal Habitat With Low Fire

Severity In The Medford And Roseburg Districts And The Klamath Falls Resource Area . . . . . . . . . . . 672

4-100 Changes By Alternative In The Development Of Northern Spotted Owl Dispersal Habitat With Mixed Fire

Severity In The Medford And Roseburg Districts And The Klamath Falls Resource Area . . . . . . . . . . . . 673

4-101 Changes By Alternative In Development Of Northern Spotted Owl Dispersal Habitat With High Fire

Severity In The Coos Bay, Eugene, Roseburg And Salem Districts . . . . . . . . . . . . . . . . . 674

4-102 Changes By Alternative In Development Of Northern Spotted Owl Dispersal Habitat With Low Fire

Severity In The Coos Bay, Eugene, Roseburg And Salem districts. . . . . . . . . . . . . . . . . 675

4-103 Changes By Alternative In Development Of Northern Spotted Owl Dispersal Habitat With Mixed Fire

Severity In The Coos Bay, Eugene, Roseburg And Salem Districts . . . . . . . . . . . . . . . . . 675

4-104 Changes By Alternative In Development Of Northern Spotted Owl Suitable Habitat With Fire

Resiliency In The Medford District . . . . . . . . . . . . . . . . . . . . . . . . . . . 677

4-105 Changes By Alternative In Development Of Northern Spotted Owl Suitable Habitat With Fire

Resiliency In The Klamath Falls Resource Area . . . . . . . . . . . . . . . . . . . . . . 677

Table of Contents - ix 
4-106 Changes By Alternative In The Development Of Northern Spotted Owl Dispersal Habitat With Fire Resiliency In The Medford District

4-107 Changes By Alternative In The Development Of Northern Spotted Owl Dispersal Habitat With Fire

Resiliency In The Klamath Falls Resource Area . . . . . . . . . . . . . . . . . . . . . . . . . 679

4-108 Changes In The Estimated Number Of Functional Northern Spotted Owl Nest Territories That Would

Occur On All Land Ownerships Under Each Alternative And According To The No Harvest

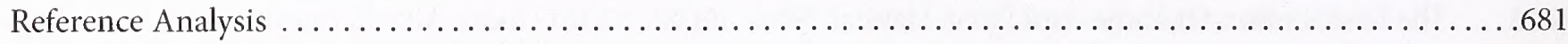

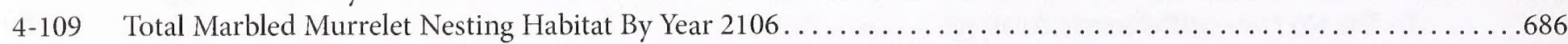

4-110 Old Forest Marbled Murrelet Nesting Habitat . . . . . . . . . . . . . . . . . . . . . . . . . . . 687

4-111 District Marbled Murrelet Nesting Habitat Fluctuations In Zone 1, Expressed As Percent Change From 2006.....689

4-112 Changes In The Availability Of Marbled Murrelet Old Forest Nesting Habitat Within The Planning

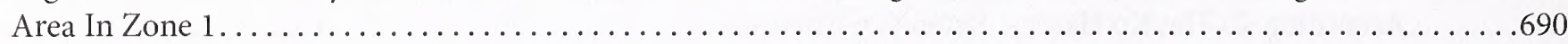

4-113 District Marbled Murrelet Nesting Habitat Fluctuations In Zone 2, Expressed As Percent Change From 2006 .....693

4-114 Changes in the availability of marbled murrelet old forest nesting habitat within the western Oregon

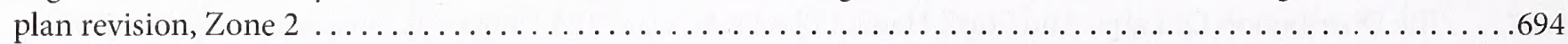

4-115 Average hiding cover availability on the deer habitat management units in the Coos Bay District. . . . . . . . . . 698

4-116 Percentage of deer habitat management area in the Coos Bay District greater than 492 feet from roads

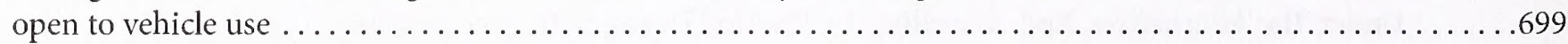

4-117 Foraging habitat availability on the deer habitat management units in the Medford District and Klamath Falls

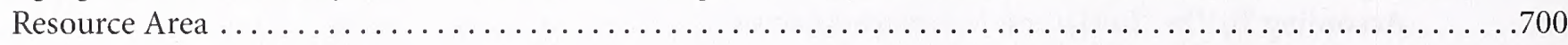

4-118 Percentage of deer habitat management area in the Medford District and western Klamath Falls Resource Area

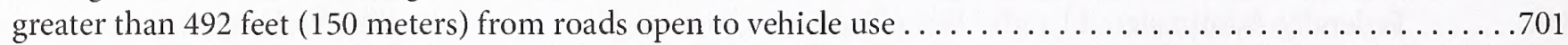

4-119 Percentage of habitat in Deer Habitat Management Areas on Eastside Management Lands in the Klamath Falls

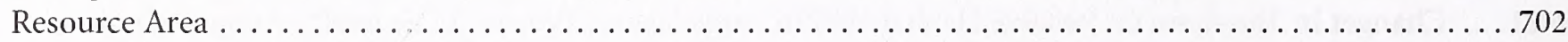

4-120 Elk Hiding Cover Availability On The Elk Habitat Management Units In the Coos Bay And Salem Districts ......705

4-121 Percentage Of Elk Habitat Management Area In The Coos Bay And Salem Districts, Greater Than 492 Feet From

Roads Open To Vehicle Use. . . . . . . . . . . . . . . . . . . . . . . . . . . . . . . . 706

4-122 Average Foraging Habitat On Elk Habitat Management Units In The Medford District..................707

4-123 Percentage Of Elk Habitat Management Area In The Medford District Greater than 492 Feet From Roads

Open To Vehicle Use. . . . . . . . . . . . . . . . . . . . . . . . . . . . . . . . . .

4-124 Bald eagle nesting and roosting habitat development within the planning area.....................

4-125 Summary of bald eagle nesting and roosting habitat development in the west side of the Klamath Falls

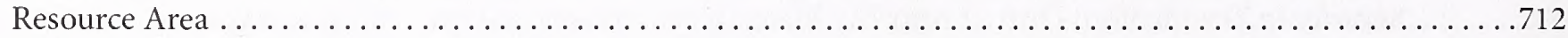

4-126 The abundance and development of bald eagle nesting and roosting habitat in bald eagle management areas......713

4-127 Fisher foraging habitat summarized for BLM-administered lands within the planning area . . . . . . . . . . . .714

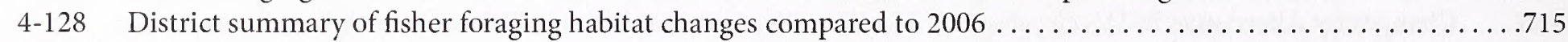

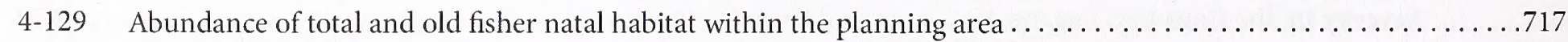

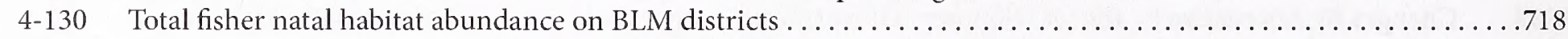

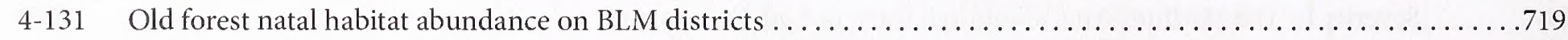

4-132 Western conifer forest land bird habitat trends on BLM-administered land within the planning area...........722

4-133 Western hardwood forest land bird habitat trends on BLM-administered land within the planning area ........725

4-134 Eastern conifer forest land bird habitat trends on BLM-administered land within the planning area ..........728

4-135 Eastern Ponderosa Pine Landbird Habitat Trends On BLM-Administered Land Within The Planning Area....... 730

4-136 Eastern Hardwood Landbird Habitat Trends For Hardwood Forests On BLM-Administered Land Within The

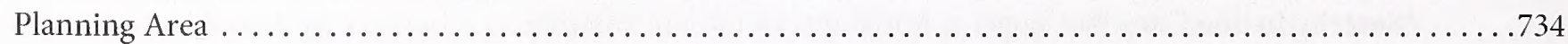

4-137 Total Number Of Western Snowy Plover Young Fledged Along the Oregon Coast From 1990 To 2006 ... ....744

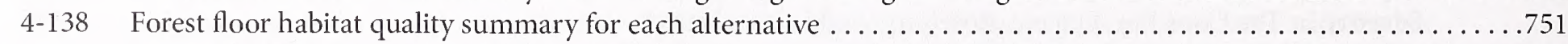

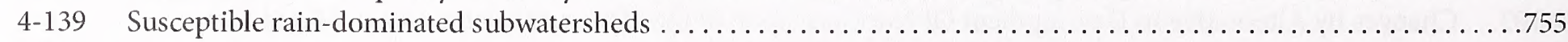

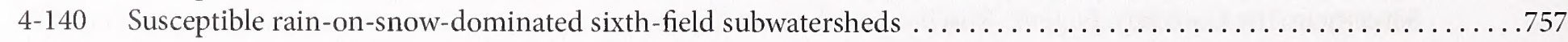

4-141 Potential For Sediment Transport, Based On Channel Gradient And Return Interval Streamflow. . . . . . . . . . 758

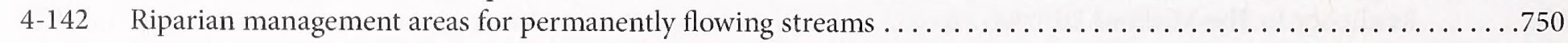

4-143 Structural stage classes of the riparian reserves under the No Action Alternative ....................

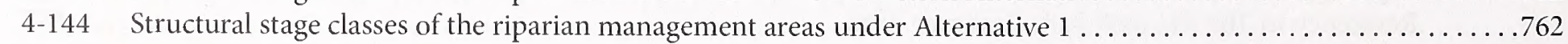

Table of Contents - x 
Structural stage classes of the riparian management areas under the PRMP $\ldots \ldots \ldots \ldots \ldots . \ldots \ldots$

Structural stage classes of the riparian management areas under Alternatives 2 and $3 \ldots \ldots \ldots \ldots$

Projected Newly Constructed Permanent Roads Within A Sediment Delivery Distance To Streams,

Compared To Total Newly Constructed Permanent Roads By 2016.

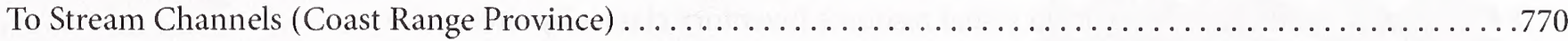

4-149 Relative Landslide Density By Alternative Across All Land-Use Allocations That Would Deliver

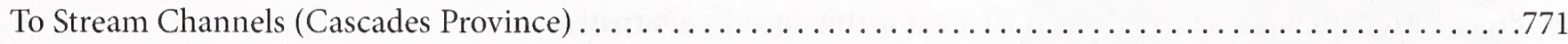

4-150 Relative Landslide Density By Alternative Across All Land-Use Allocations That Would Deliver

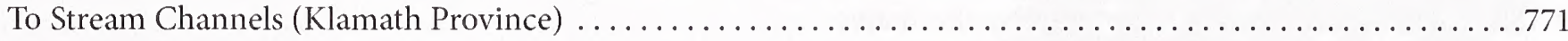

4-151 Relative Landslide Density By Alternative In The Harvest Land Base That Would Deliver To Stream

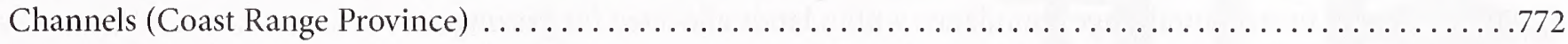

4-152 Relative Lndslide Density By Alternative In The Harvest Land Base That Would Deliver To Stream Channels

(Cascades Province) . . . . . . . . . . . . . . . . . . . . . . . . . . . . . . . . . . . .

4-153 Relative Landslide Density By Alternative In The Harvest Land Base That Would Deliver To Stream Channels

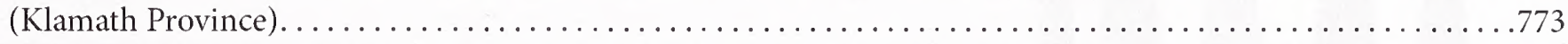

4-154 Timber productivity capability classification withdrawals within the Upper Smith River representative

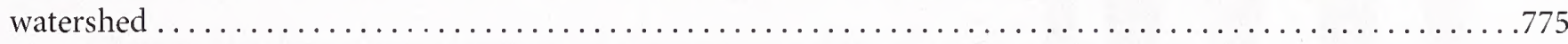

4-155 Potential large wood contribution from all sources for the planning area in 2106 by alternative and the

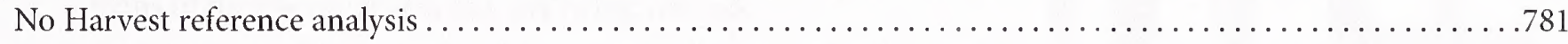

4-156 Potential small functional wood contribution from all sources for the planning area in 2106 by alternative

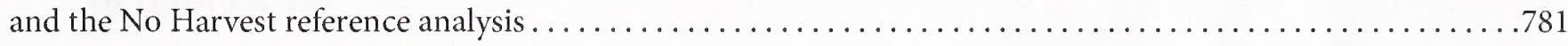

4-157 Potential large wood contribution from all sources for the planning area in 2106 by alternative and the

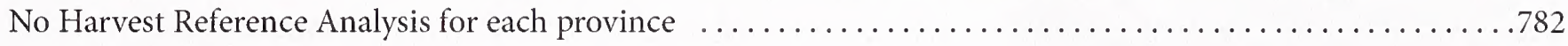

4-158

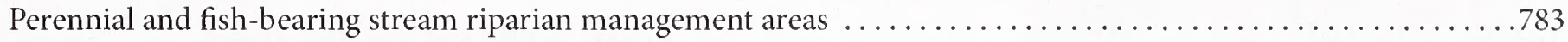

4-159

Forest structural stage in the riparian management areas by alternative $\ldots \ldots \ldots \ldots \ldots \ldots \ldots . \ldots \ldots$

4-160

Percent of riparian large wood contribution to fish-bearing streams by land use allocation at 2106 in the

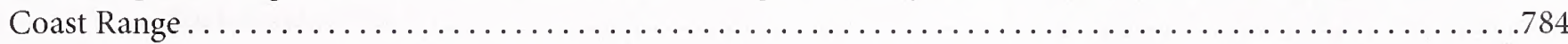

4-161 Boundaries riparian management areas for each alternative on non-fish-bearing intermittent channels ........785

4-162 Percent of riparian large wood contribution to non-fish-bearing streams by land use allocation at 2106

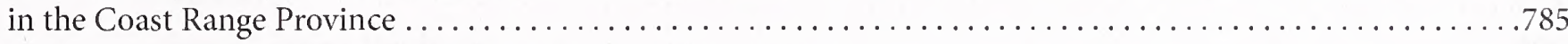

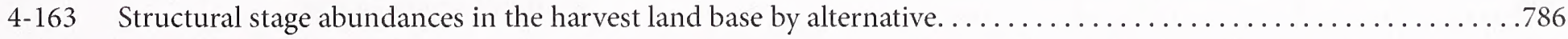

4-164 Percent of debris flow large wood contribution by land use allocation at 2106 in the Cascades Province ........788

4-165 Potential and relative debris flow large wood contribution to streams from BLM-administered lands in the Coast

Range Province . . . . . . . . . . . . . . . . . . . . . . . . . . . . . . . . . . . . .

4-166 Potential small functional wood contribution to stream channels for the planning area in 2106 by alternative and the No Harvest reference analysis for each province $\ldots \ldots \ldots \ldots \ldots \ldots \ldots$

4-167 Potential small functional riparian wood contribution to streams from BLM-administered lands for

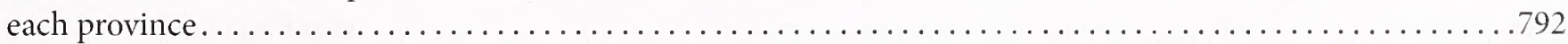

4-168 Potential debris flow small wood contribution from BLM-administered lands for each province ..............793

4-169 Potential large wood contribution comparison of all ownerships by 2106 with current and maximum

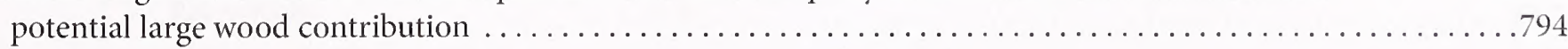

4-170 Potential large wood contribution in the Rogue-Horseshoe Bend watershed. . . . . . . . . . . . . . . . 795

4-171 Potential large wood contribution in the Evans Creek watershed . . . . . . . . . . . . . . . . . . . . 796

4-172 Potential large wood contribution in the Eagle Creek watershed . . . . . . . . . . . . . . . . . . . . 796

4-173 Potential large wood contribution in the Chetco watershed . . . . . . . . . . . . . . . . . . . . 797

4-174 Comparison of the structural stage abundance within riparian management areas on BLM-administered

forested lands by 2106 with the current and average historical conditions . . . . . . . . . . . . 978

4-175 Distribution of high intrinsic potential streams for chinook salmon, coho salmon, and steelhead trout

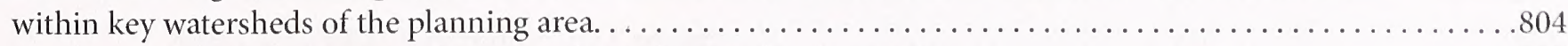

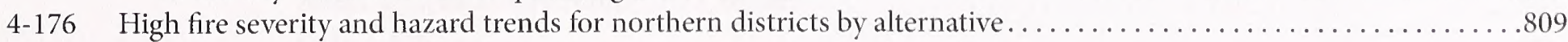

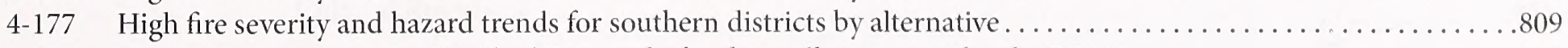

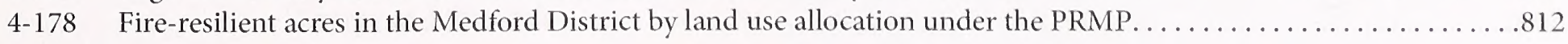




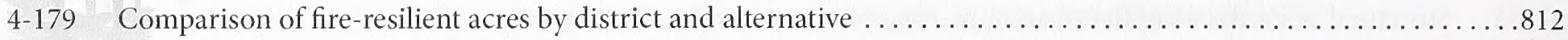

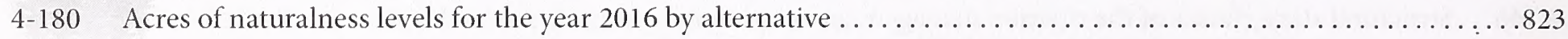

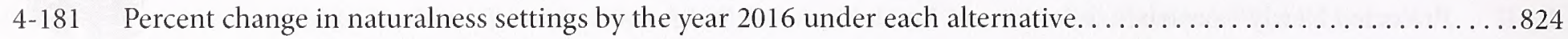

4-182 Acres of BLM-administered lands with wilderness characteristics maintained by alternative .............830

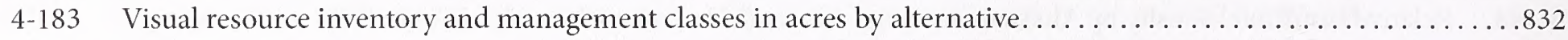

4-184 Harvest land base acres within visual resource inventory classes by alternative $\ldots \ldots \ldots \ldots \ldots \ldots \ldots \ldots \ldots . \ldots \ldots 33$

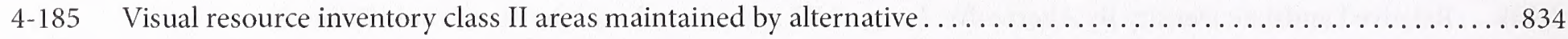

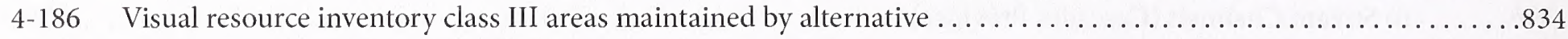

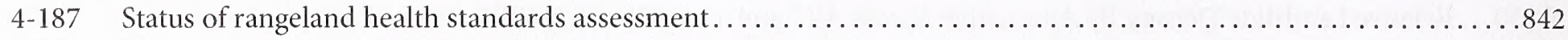

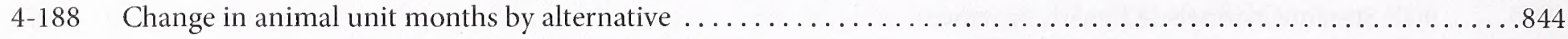

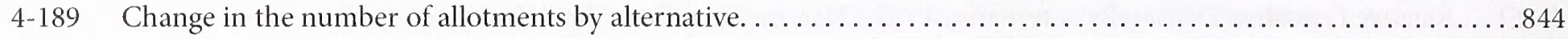

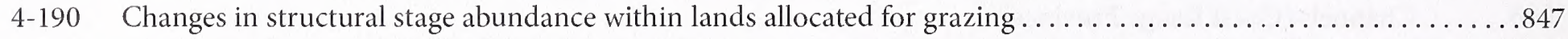

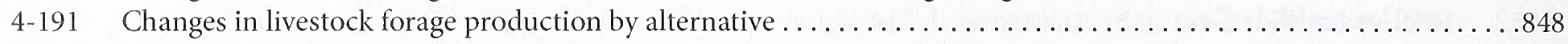

4-192 Changes in structural stage abundance within the Pokegama Herd Management Area . . . . . . . . . . . . . . . . . 851

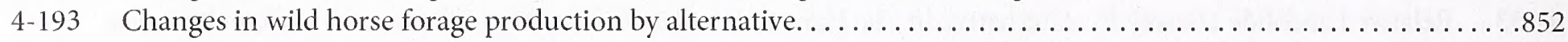

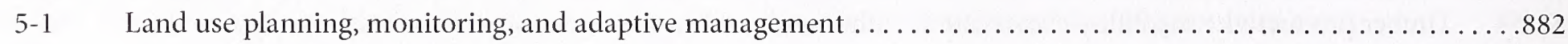




\section{Chapter 4 \\ Environmental \\ Consequences}

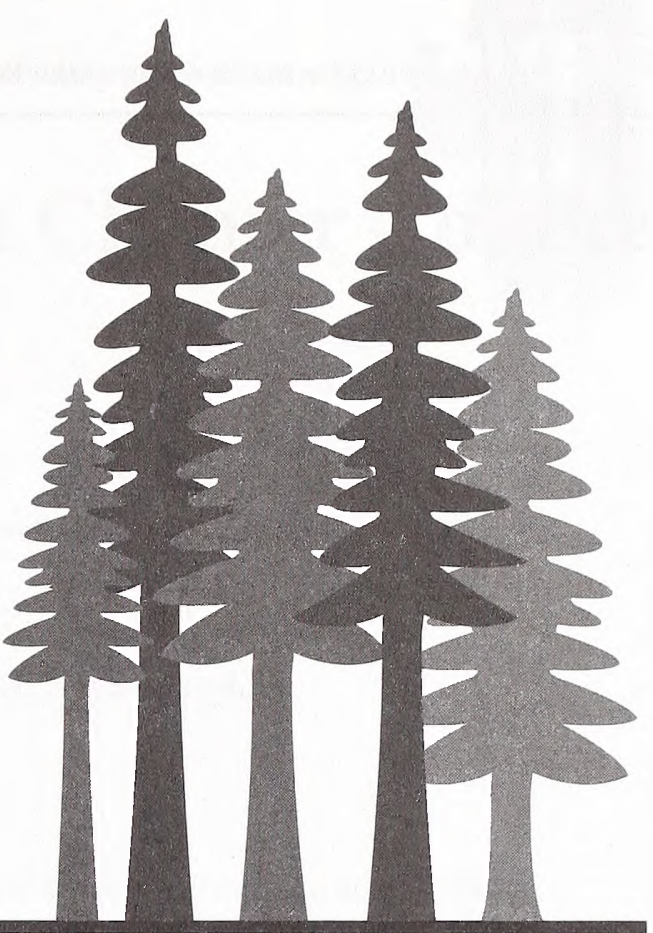

Chapter 4 analyzes the environmental consequences of the alternatives for the six resource management plans of the planning area that are being revised.

\section{In this chapter:}

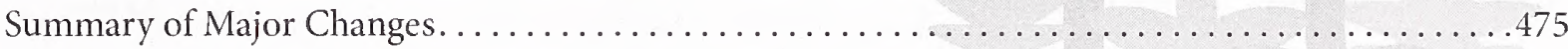

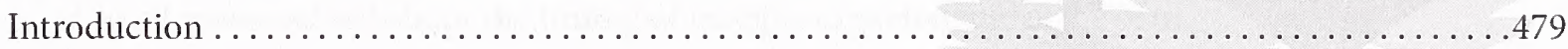

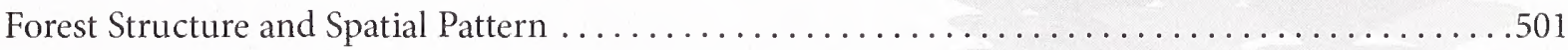

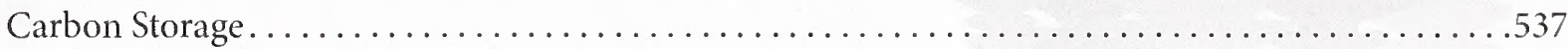

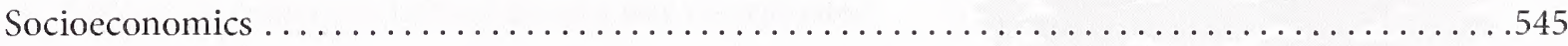

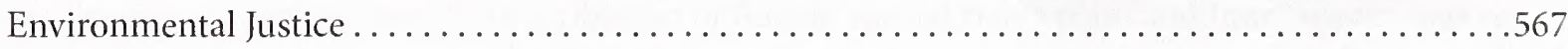

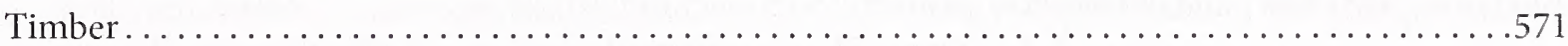

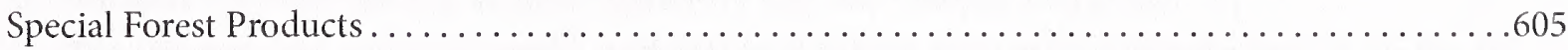

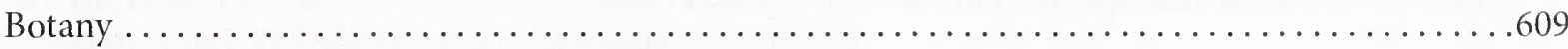

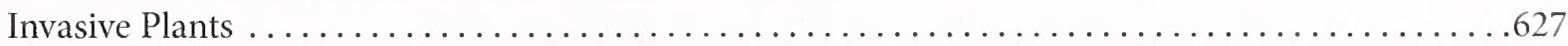

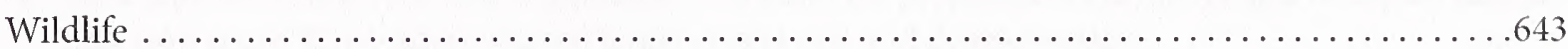

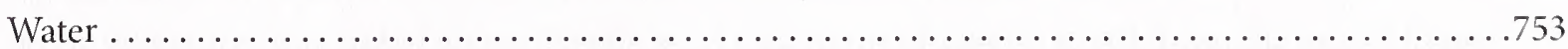

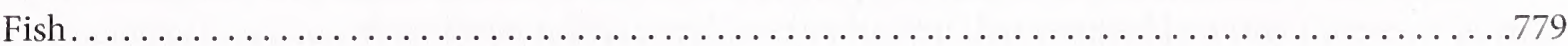

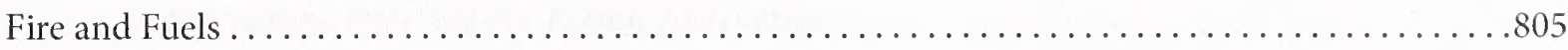

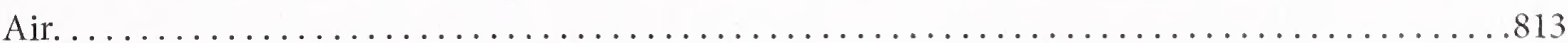

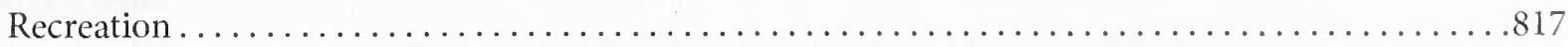

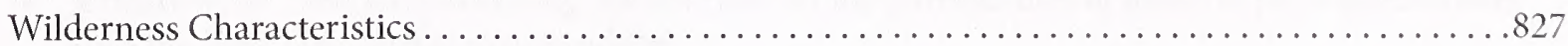

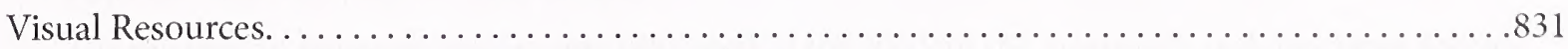

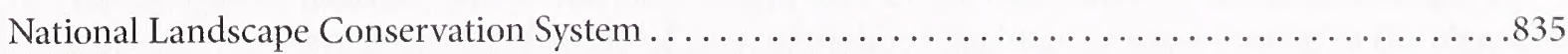

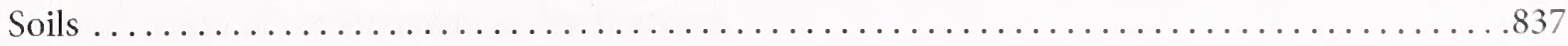

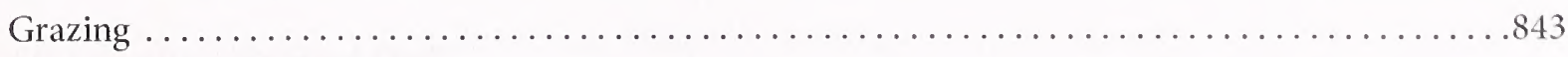

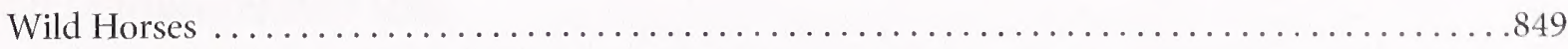

Areas of Critical Environmental Concern . . . . . . . . . . . . . . . . . . . . . . . . . . . . . . . 853

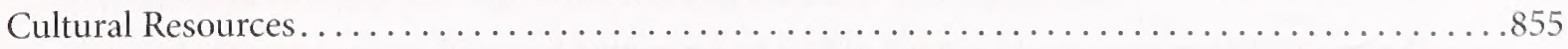

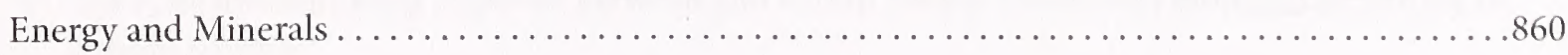




\section{Summary of Major Changes from Chapter 4 of the Draft EIS/Draft RMP}

\section{Forest Structure and Spatial Pattern}

- The section (formerly called Ecology) was re-titled to better reflect the content of the analysis.

\section{Carbon Storage}

- A section describing carbon storage on BLM-administered lands was added.

\section{$\underline{\text { Socioeconomics }}$}

- The display of employment impacts was expanded to show changes by county, sector, and alternative

\section{Timber}

- The volume from Eastern Management Lands was split out to differentiate this type of volume.

- A discussion on how changes in log prices or harvesting costs would affect stumpage prices was added.

- A section was added about the timing of receipts expected under the plan.

\section{Botany}

- Species placement in habitat groups was re-evaluated.

- Species occurrences and the distribution of Bureau special status plant and fungi species was reanalyzed, based on: new species list; number of occurrences; occupied habitat; and changes to land use allocations for the No-Action Alternative and Alternatives 1, 2, and 3.

- The effects to species, occurrences, and occupied habitat from management activities for the No Action and Alternatives 1,2, and 3 were re-analyzed.

- New data sets were used and remodeling was done for projected occurrences and occupied habitat on unsurveyed BLM-administered lands at regional and district scales.

- A discussion was added about the effects to subgroups of species at risk from the loss of forest biological legacies, older forest habitat, and interior habitat that resulted in a slight increase in risk for all alternatives from the No Action Alternative.

\section{Invasive Plants}

- A relative risk comparison among the alternatives for introduction of invasive plant species over both the long and short term was added.

- The mitigation measure section was relocated in the FEIS to the Summary and describes specific measures for preventing introduction of new infestations that may be incorporated in the planning and design of implementation-level actions.

\section{Wildlife (Northern Spotted Owl)}

- The evaluation of suitable habitat was refined to evaluate the actual locations, sizes, and spatial arrangement of stable nesting territories and blocks of nesting habitat.

- The scale for evaluating dispersal between and within habitat blocks was modified according to current science. 
- The analysis of "areas of concern" was refined to better identify potential barriers to owl movement and survival.

- Evaluations were added to address the impact of wildfire to owl habitat and conservation risks associated with the declining spotted owl population.

\section{Wildlife (other than Northern Spotted Owl)}

- The range of the marbled murrelet has been modified to reflect a needed correction in the Medford District, and an analysis of structurally complex forest greater than 200 years of age has been included to differentiate this habitat component from overall nesting habitat.

- The narrative describing fisher natal habitat has been revised to include an analysis of those structurally complex stands greater than 200 years of age, separate from the overall discussion of natal habitat.

- An expanded discussion of legacy components (i.e. snags, coarse woody debris, and green tree retention) has been added to the land bird section.

- The special status species analysis has been extensively revised to facilitate effect analysis based on five broad categories of habitat types: (1) westside forest habitats; (2) habitat on the Eastside Management Lands (i.e., east side of the Klamath Falls Resource Area); (3) non-forested habitats; (4) riparian habitats; and (5) forest floor habitats.

- The cover analysis in the deer and elk narrative has been revised to discuss hiding cover, not thermal cover.

Fish

- The wood delivery model was expanded to use highly detailed stand information rather than general structural classes.

- The wood delivery modeling and analysis was also expanded, from five representative watersheds to all fifth-field watersheds in the planning area.

- Expansion of the wood delivery model and analysis was done to include large and small wood contribution; contribution of fish-bearing and non-fish bearing streams; contribution from BLMadministered lands to non-BLM administered lands; contribution by source (riparian, debris flow, channel migration); and the contribution by land use allocation.

- The fish productivity index was replaced with a more comprehensive, qualitative discussion of the effects of the alternatives on fish productivity.

- A more quantitative analysis of nutrient input to stream channels was added.

- Estimates and assumptions regarding future levels of instream restoration, fish passage improvements, road improvement and road decommissioning were included.

Water

- An error was corrected for the peak flow planning criteria in the rain-dominated hydroregion. The number of susceptible subwatersheds increased from 1, to a range of 5-12 under the alternatives.

- Mortality of Port-Orford-cedar within riparian areas and its effect on stream temperature change has been previously analyzed under the FSEIS Management of Port-Orford-Cedar in Southern Oregon 2004, which is incorporated by reference.

- Landsliding susceptibility analysis was added for all land use allocations by calculating a relative landslide density that indicates the expected amount of landslides which could deliver sediment to streams. 


\section{Fire and Fuels}

- A discussion of changes in Fire Regime Condition Class under each alternative was addedsw

$\underline{\text { Air }}$

- Analysis of PM 2.5 emissions for each alternative was added.

- Analysis of current emissions was added to provide comparison for projected future emissions under each alternative.

- Annual emissions from prescribed burning on all ownerships were addressed.

\section{$\underline{\text { Soills }}$}

- A section on biomass removal/whole tree logging was added.

- A section on western juniper control was added.

- The outcome of the analysis for soils was clarified to show that the long-term conservation and the productive capacity of the forest and rangeland soils across the planning area would be maintained.

\section{Cultural Resources}

- The numbers and percentages of cultural sites damaged were recalculated, based on the revised number of disturbed acres under each alternative. 


\section{Introduction}

Chapter 4 describes the environmental consequences of the alternatives on the affected environment (described in Chapter 3) within the planning area (defined in Chapter 2). The five alternatives analyzed in detail (the PRMP, No Action Alternative, and Alternatives 1, 2, and 3) provide varying management direction with respect to the resources within the planning area, and would have varying effects on resources and programs. Also described in this chapter are the analytical assumptions, key assumptions, analytical methodology and modeling, and data that were used in the analyses of this final environmental impact statement. Finally, this chapter suggests mitigation measures that may be needed to reduce impacts to certain resources.

This final environmental impact statement describes the consequences of generalized management-level direction of a resource management plan. The final environmental impact statement is not intended to analyze fully the site-specific effects that may occur from all of site-specific implementation-level actions that may be conducted in the future under such a plan. Site-specific effects would be considered during the planning of implementation-level actions.

\section{Analytical Assumptions}

The analytical assumptions that were used in the analysis of the PRMP and alternatives are based on the science of, and the relationships within, the natural systems that exist within the planning area. The specific assumptions that were used for the analysis in this final environmental impact statement are contained within the specific sections of Chapter 4, appendices, and the 2006 Proposed Planning Criteria and State Director Guidance document and its subsequent updates (incorporated by reference). The details about the methodology, including assumptions, that was used to model vegetation, water, large wood source areas, timber valuation, and socioeconomics are included as appendices.

Following are the key assumptions common to the PRMP and all four alternatives. The assumptions that are specific to a resource or program are contained within the individual sections of Chapter 4 for those resources or programs.

\section{Key Assumptions and Information Common to All Alternatives}

\section{Terminology}

The following terms are used in this final environmental impact statement:

- Commercial forest lands - Those lands that are capable of producing 20 cubic feet per acre per year of wood of commercial species. These lands are identified in the timber productivity capability classification (see Appendix $R$ - Vegetation Modeling). These lands are biologically capable of producing a sustained yield of timber.

- Forested lands - Those lands that are capable of $10 \%$ tree stocking. This excludes roads and such nonforest areas as water, meadows, and rock outcrops that are identified in the GIS data.

- Long term - For the management directions of these resource management plan revisions, long term is considered to be 100 years.

- Short term - For the management directions of these resource management plan revisions, short term is considered to be 10 years. 


\section{Projection of Forest Conditions}

For the PRMP and all four alternatives, the lands that would be available for harvesting in support of the allowable sale quantity and sustained yield management (harvest land base) were mapped. Other lands (nonharvest land base) were also mapped and segregated into those lands where active management could occur and those lands where timber harvesting is prohibited. This mapping allowed the spatial application of the analytical assumptions of the alternatives, including timber harvesting, to model forest conditions over time. These modeled projections of forest conditions were expressed as classifications of habitat for the northern spotted owl, and as structural stages of forests, which were used by the interdisciplinary team in their analyses. See Appendix B - Forest Structure and Spatial Pattern and Appendix R-Vegetation Modeling.

As part of this revision effort, the BLM has modeled timber harvesting and the development of wildlife habitat on BLM-administered lands. See Appendix R - Vegetation Modeling. This modeling allowed projections to be made of the changes to the vegetation over time in the harvest land base. See the Forest Structure and Spatial Pattern section of this chapter.

\section{Information from the Northwest Forest's Plan 10-Year Monitoring Report}

Information from the Northwest Forest Plan's 10-year monitoring report was considered in the analyses in this final environmental impact statement. Some of the general key findings in this monitoring report were that:

- Watershed conditions improved.

- Late-successional and old-growth forest increased more than was anticipated.

- Less timber harvesting occurred on federal lands than was anticipated.

Specific information used from the report is referenced in the individual sections found in Chapters 3 and 4.

\section{BLM Budget and Implementation}

For analytical purposes, it is assumed that all alternatives would be adequately funded to implement the alternatives as designed.

It is expected that an organizational transition to the new allowable sale quantity levels would occur over a period of up to five years. Due to the speculative nature of the transition period, analysis of effects assumed full implementation from the date of the decision.

\section{Administrative Actions}

It is assumed that most of these types of routine transactions and activities (see Chapter 2 for details) would occur under all four alternatives at approximately the same level as during the past 10 years. Some variation from past levels for certain activities such as surveys and road maintenance would occur as the level of timber harvest varies by alternative. The effects of these actions have been generally incorporated into the analysis for each resource or program.

\section{Reasonably Foreseeable Mineral Development}

Minerals that can be reasonably foreseeable for development include:

- fluid minerals (from natural gas wells, oil wells, geothermal wells and plants, and coal bed natural gas wells) 
- salable minerals (from rock quarries and decorative stone collection)

- locatable minerals (from dredging and mines)

With the exception of natural gas and coal bed natural gas, it is assumed that these types of activities would occur at a rate consistent with the past 10 years and would not vary by alternative. Exploration and development of the Mist gas field in the Salem District and coal bed natural gas in the Coos Bay District is expected to increase in the next 10 years. Development scenarios would not vary by alternative. A detailed description of the reasonably foreseeable development scenario can be found in Appendix Q - Energy and Minerals. The effects of these actions have been generally incorporated into the analysis for each resource or program. Site-specific effects would be considered during the planning of implementation-level actions.

\section{Threatened and Endangered Species}

The environmental impact statement analyzes the effects of the alternatives on all species that are listed under the Endangered Species Act as threatened or endangered or have been identified as candidate species at the time of the preparation of this final environmental impact statement. This includes species that have recently been listed, including the Oregon Coast coho salmon, which was listed as threatened in 2008 . The environmental impact statement also includes analysis of species on which the U.S. Fish and Wildlife Service has recently made decisions on proposals for listing or delisting. For example, the environmental impact statement analyzes the effects of the alternatives on:

- fisher, for which the U.S. Fish and Wildlife Service found in 2004 that listing was "warranted but precluded"

- sage grouse, for which the U.S. Fish and Wildlife Service found in 2005 that listing was not warranted, but has initiated a status review in 2008 to re-examine its 2005 decision; and

- bald eagle, which the U.S. Fish and Wildlife Service removed from the endangered species list in 2007

Several recovery planning efforts and redesignations of critical habitat were underway at the time of the preparation of this final environmental impact statement. Information from these efforts was used in formulating the PRMP and alternatives, management objectives and directions, and effects analyses to the extent practical, because the design of the alternatives and the analyses anticipated that these efforts and redesignations would be completed prior to the publication of the final environmental impact statement.

\section{Analytical Methodologies and Models}

The analytical methodologies that were used in assessing the effects of the alternatives are described in detail in the specific sections of Chapter 4, appendices, and the 2006 Proposed Planning Criteria and State Director Guidance document and its subsequent updates (incorporated by reference). The public was requested to provide comments on the methodologies described in the 2006 Proposed Planning Criteria and State Director Guidance. Those comments were used to refine the methodologies used in the analysis. As a result, certain of the methodologies and assumptions of the Planning Criteria were subsequently updated. In addition, the details about the methodology, including assumptions, that was used to model vegetation, water, large wood source areas, timber valuation, and socioeconomics are included as appendices. The analyses are both qualitative and quantitative in nature. The methodologies consist of procedures or models from experimental forests, scientific papers, previous environmental impact statements, and procedures developed by BLM resource specialists.

Analytical models based on scientific principles have been used to assess and compare some of the environmental consequences of the alternatives. These models simplify the complexity of biological, physical, or economic systems. Although the analytical models are limited by current knowledge, they 
represent a synthesis of the knowledge of BLM resource specialists who are familiar with the subjects of concern. As detailed in Chapter 5, the interdisciplinary team members have the necessary scientific expertise, through education and experience, to provide high quality information and accurate analysis to the environmental impact statement.

\section{Forest Vegetation and Habitat Modeling}

The alternatives outline a range of approaches for managing the BLM-administered forest lands by varying the size and placement of land use allocations and varying the intensity with which the BLMadministered forest lands are managed. These different management approaches would result in a range of outcomes - forest characteristics, habitat types, and sustainable harvest levels. A model was used to simulate the development of the forest over time under each alternative. The model simulated the application of management practices and forest development assumptions to characterize what the forests would be like in $10,20,30,40,50$, and 100 years into the future. The outputs from this modeling form a quantitative basis for the analysis in this final environmental impact statement that compares the alternatives.

The OPTIONS model by D.R. Systems was used to model forest vegetation conditions, to model endangered species habitat, and to determine a sustainable harvest level. It is a scenario-based model and not an optimization model. A scenario-based model simulates the intensity of management and the analytical assumptions of the alternatives that produce a solution that satisfies both the resource objectives of the alternative and a sustainable harvest level. An optimization model seeks to find combinations of the types, timing, and intensity of harvests that increase the value of a forest in terms of its economic value from timber harvesting, as well as its ecological and social value from its composition.

The OPTIONS model is also a spatially explicit model. This allowed for the development of map-based scenarios for the estimation of the environmental consequences of the alternatives within the short term (10 years) and long term (100 years).

The OPTIONS model was applied to the approximately 2.6 million acres of BLM-administered lands within the planning area. The surrounding private, state, and other federal lands comprise approximately 22 million acres. Modeling the non-BLM-administered lands to the same level of detail as the BLM-administered lands is not possible, because there is inadequate information available on which to base such modeling. Data on existing forest stand conditions of sufficient precision and accuracy to support detailed modeling does not exist or is not readily available for other ownerships. In addition, the prediction of specific harvesting practices on state lands and private lands would be complex and largely speculative. Context vegetation modeling for the non-BLM-administered lands was done by applying broad assumptions regarding the future management of non-BLM-administered lands to the Interagency Vegetation Mapping Project satellite image vegetation classification, as discussed in Chapter 4 - Forest Structure and Spatial Pattern.

The OPTIONS model came with no data and was used only as a modeling tool. The BLM was responsible for the data, assumptions, and rules that were used in formulating the model for analyzing the alternatives. A complete description of the OPTIONS modeling effort can be found in Appendix $R$ - Vegetation Modeling.

The ORGANON growth and yield model was used to determine the volume outputs for the silviculture regimes of each alternative and was a key input into the OPTIONS model. A complete description of the growth and yield modeling effort can be found in Appendix $R$ - Vegetation Modeling.

The OPTIONS model provided an assessment of the changes to the structural stages of forests and the changes to the habitat of the northern spotted owl over time for each alternative. A detailed description of these vegetation classes may be found in Appendix B - Forest Structure and Spatial Pattern. The OPTIONS model also provided changes to key baseline vegetation conditions and northern spotted owl habitats. These outputs were used by resource specialists to estimate the environmental consequences of the alternatives. Outputs were also used as data inputs for other models (such as the modeling of hydrology and fire). 
The harvest treatments that were simulated in the model for the first 10 years were used to develop a first decadal scenario. This first decadal scenario was used to estimate short-term change to the forests and to display the types of treatments that would be applied. It also served as a basis to estimate road construction and harvesting methods. In addition, the first decadal scenario served as a quality control check of the sampled harvest units that were identified by the model. These harvest units were examined for the practicality of implementation. The first decadal scenario was not intended to be a plan for subsequent implementation on the ground. The environmental consequences from subsequent implementation of forest treatments through actual projects will be analyzed and disclosed in project-level environmental analysis. Project-level analysis will examine project-level impacts and determine if they are within those already anticipated and described in this environmental impact statement. Additional information about the first decadal scenario can be found in Appendix E - Timber.

\section{Sustained Yield Units}

Sustained yield units serve as the base geographical unit for which the allowable sale quantity is determined. The BLM recently revised sustained yield units to match the five western Oregon BLM District boundaries and the western portion of the Klamath Resource Area in the Lakeview District. The old sustained yield units had been established based on supplying marketing centers that are no longer relevant. Funding and implementing the resource management plans is done on a district basis, which provides a more logical basis for the sustained yield units. The revised sustained yield unit boundaries would result in slightly higher $(2 \%)$ allowable sale quantity level than would have occurred under the previous units. The larger sustained yield units would result in a slightly higher sustainable harvest level, because there would be more flexibility in placement and timing of harvest with a larger forest inventory. The amount of acres in the harvest land base under each alternative would not be affected by the sustained yield unit boundary change.

\section{Geographic Information System Data}

To support the western Oregon resource management planning effort in the mid-1980s, the BLM created an automated geospatial database, which is a geographic information system (GIS) database. Ongoing collaborative efforts in the collection, standardization, and acquisition of data have resulted in a substantial increase in the amount and accuracy of the geospatial data that is available for land use planning.

The quality, quantity, and management of the data that is contained within the GIS database have provided managers and resource professionals with the ability to analyze complex land management issues and scenarios. The western Oregon component of the GIS database includes many data layers such as forest vegetation, management units, roads, hydrology, elevation, ownership, and a wide range of wildlife habitat information (including the location of threatened and endangered species on BLM-administered lands).

Existing data was evaluated for accuracy, reliability, and limitations and also was updated. Of particular note is an update to the estimated amount of BLM-administered lands that are contained in the riparian reserve land use allocation under the No Action Alternative. Over the past 10 years, the extent of the hydrology network has been more fully mapped and the information regarding the presence of fish has increased. This improved GIS data about hydrology and the presence of fish on BLM-administered lands within the planning area made it possible to model the extent of the riparian reserves to a precision that was not feasible 10 years ago. For the 1995 resource management plans, it was estimated that $22 \%(522,000$ acres) of the BLM-administered lands within the planning area was contained in the riparian reserve land use allocation (the portion interspersed with the matrix and adaptive management areas after all other allocations were deducted). Based on the updated data, that number is now estimated at $15 \%$ (364,000 acres) for the No Action Alternative, which increases the acreage of the harvest land base, and, consequently, would increase the allowable sale quantity. 
Other updates that resulted from the improved accuracy of the GIS information included a mapping correction. A mapping error during the 1995 Medford District resource management plan revision resulted in the inaccurate reporting of the district's acres that were open to off-highway vehicle use. The 1995 resource management plan showed 391,400 acres were open to off-highway vehicle use when, in fact, only 139,878 acres were open to off-highway vehicle use.

Besides the improved GIS data, another important source of data that was used in the analysis of the alternatives included the recently completed decadal assessment of the Northwest Forest Plan. This decadal assessment generated more current, accurate, and detailed data on the existing condition of the environment across the area of the Northwest Forest Plan than was available in 1995.

The data used in this analysis is also at a far finer resolution than was previously available. In 1995, the Northwest Forest Plan analysis used a geographical information database that was limited to a resolution of units of 40 acres in size. The current database has a resolution of units of 10 square meters in size, which is more than 16,000 times finer in resolution. This finer data allows more detailed analysis than was previously possible. As a result, this analysis can more precisely map resource conditions and accurately include finescale features, such as streams and roads, in the analyses that could not previously be considered. The data used in the analyses of the alternatives was summarized at various scales, including the planning area, physiographic provinces, the BLM districts, and fifth-field watersheds. There are 260 fifth-field watersheds, averaging 87,000 acres in size, that are located all or partially within the planning area.

\section{Reference Analysis}

Two reference analyses are included in this final environmental impact statement. Reference analyses provide additional information that is useful to understand more fully the effects of one or more of the alternatives.

The reference analyses are focused and limited to specific analytical questions. The reference analyses are not selectable during decision making, because they would not meet the purpose and need for action.

The two reference analyses for this final environmental impact statement include:

1. Allow no harvesting. This reference analysis provides information about the vegetation condition that would occur naturally and the capacity of the BLM-administered lands to provide fish and wildlife habitat if management of those lands ceased.

2. Manage most commercial forest lands for timber production. This reference analysis provides information about the vegetation condition and timber production levels that would occur if most of the BLM-administered lands (except the National Landscape Conservation System lands, the administratively withdrawn lands, and lands within 25 feet of streams) were managed for intensive timber harvesting in a manner similar to private industrial lands.

\section{Scope of the Analysis}

The Council on Environmental Quality's regulations for implementing the National Environmental Policy Act (NEPA) direct that "NEPA documents must concentrate on the issues that are truly significant to the action in question, rather than amassing needless detail" (40 CFR 1500.1[b]). Issues are "truly significant to the action in question" if they are necessary to make a reasoned choice between alternatives (i.e., the issue relates to how the alternatives respond to the purpose and need). Issues are also "truly significant to the action in question" if they relate to significant direct, indirect, or cumulative impacts resulting from the alternatives. This analysis addresses the environmental consequences that are associated with the issues that are related to the purpose and need (see Chapter 1) or relate to significant impacts. For example, the 
analysis of fisheries focuses on the effects on listed fish species to address the issue of "How should the BLM manage federal lands in a manner that is consistent with the Endangered Species Act in order to contribute to the conservation of species." Other fish species occur within the planning area, and some have different habitat requirements and life histories than the listed fish species. However, this analysis does not attempt to analyze the effects of the alternatives on all fish species. Similarly, the analysis of plants and wildlife focuses on the effects on species listed under the Endangered Species Act, and effects are analyzed for BLM sensitive species to the extent necessary to evaluate changes in populations or habitat that would affect the conservation of these species. These sections do not attempt to analyze the effects of the alternatives on all plant and animal species.

\section{Direct and Indirect Effects}

The Council on Environmental Quality's regulations for implementing the National Environmental Policy Act require that both the direct and indirect effects on the quality of the human environment of a proposed action or alternative be disclosed. Direct effects and indirect effects are described below:

- Direct effects. Those effects "which are caused by the action and occur at the same time and place."

- Indirect effects. Those effects "which are caused by the action and are later in time or farther removed in distance, but are still reasonably foreseeable."

There is no requirement that direct and indirect effects be discussed individually. It can also be difficult to distinguish between direct and indirect effects, particularly at the scale of the planning area. Additionally, it does not make any difference to the resource affected whether the effects are directly or indirectly caused. Therefore, the terms direct and indirect are not used to differentiate the effects analyzed in this final environmental impact statement.

\section{Cumulative Effects}

Cumulative effects result from the incremental impact of an action when added to past actions, other present actions, and reasonably foreseeable actions (40 CFR 1508.7). Due to the nature of the analysis in this large-scale and long-term resource management plan/environmental impact statement, all environmental effects described in this environmental impact statement would have incremental impacts that would have a cumulative effect together with past actions, other present actions, and reasonably foreseeable actions. Therefore, there is not a discreet and separate section labeled as cumulative effects. The discussion of effects on each resource incorporates the effects of past actions, and describes other present actions and reasonably foreseeable actions to provide context in which the incremental effects are examined, thus revealing the cumulative effects of the alternatives.

As the Council on Environmental Quality points out, in guidance issued on June 24, 2005, the "environmental analysis required under NEPA is forward-looking," and review of past actions is required only "to the extent that this review informs agency decision making regarding the proposed action." Use of information on the effects of past actions may be valuable in two ways according to the Council on Environmental Quality guidance. One is for consideration of the proposed action's cumulative effects, and secondly as a basis for identifying the proposed action's direct and indirect effects.

The Council on Environmental Quality stated in this guidance that "[g]enerally, agencies can conduct an adequate cumulative effects analysis by focusing on the current aggregate effects of past actions without delving into the historical details of individual past actions." This is because a description of the current state of the environment inherently includes the effects of past actions. The Council on Environmental Quality guidance specifies that the "[Council on Environmental Quality] regulations do not require the consideration of the individual effects of all past actions to determine the present effects of past actions." 
The existing baseline information used in this analysis is a result of the aggregation of all past actions. The information on the current conditions is more comprehensive and more accurate for establishing a useful starting point for a cumulative effects analysis than attempting to establish such a starting point by adding up the described effects of individual past actions to some environmental baseline condition in the past, which unlike current conditions can no longer be verified by direct examination.

The second area in which the Council on Environmental Quality guidance states that information on past actions may be useful is in "illuminating or predicting the direct and indirect effects of a proposed action." Extrapolation of data from largely anecdotal information of past actions is not generally accepted as a reliable predictor of effects. The basis for predicting the direct and indirect effects of this proposed action and its alternatives is published empirical research, the general accumulated experience of the resource professionals in the agency with similar actions, and models based on current scientific knowledge regarding relationships of the proposed management directions and effects that are generally accepted by the scientific community in the various specialized fields. Information on past actions has been integral to the development of many of the analytical methods in the EIS; for example, timber sale costs are analyzed based on data on past timber sale costs, as detailed in Appendix E - Timber. However, cataloguing individual past timber sales and their individual costs would not provide a better basis for analyzing the timber sale costs of the alternatives.

Scoping for this project did not identify any need to list individual past actions nor to analyze, compare, or describe environmental effects of individual past actions in order to complete an analysis that would be useful for illuminating or predicting the effects of the proposed action.

The effects of other present actions have been incorporated into the description of the existing condition. For the purpose of this analysis, projects scheduled to be sold under the 1995 resource management plans that were proposed prior to December, 2008, are assumed for the purpose of this analysis to be completed as proposed. For example, the habitat on acreage included in a timber sale project proposed prior to that date would be displayed and analyzed as harvested, whether or not that harvest has yet been completed. This assumption may overestimate the actual acreage harvested from sold sales, because some sales have not yet been awarded or have been enjoined. This analytical assumption does not constitute a decision in principle about the disposition of these sales. On other ownerships, the effects of other present actions are integrated into the broader analysis of current condition and assumptions about continued management consistent with existing plans or current trends. Other specific actions that are proposed, but have not yet been decided at the time of the preparation of this EIS, are described below.

For BLM-administered lands, reasonably foreseeable future actions are those actions that would occur as described under the various alternatives. For U.S Forest Service and state of Oregon lands, reasonably foreseeable actions are those that would occur under their current land use plans from a broad-scale perspective. For private lands, reasonably foreseeable actions are those actions that would occur with the continuation of present management, also from a broad-scale perspective. It would be speculative for the analysis to presume knowledge of site-specific actions that would occur in the future on lands managed by others over the time period analyzed in the final environmental impact statement. These assumptions about future management on other ownerships are based on existing plans or current trends and are broad and general in nature. However, the broad assumptions are sufficient to provide context for evaluating the incremental effect of the alternatives.

There are other broad-scale analyses currently underway that are other present or reasonably foreseeable actions for purposes of analyzing cumulative effects. They include:

- Westwide Energy Corridor Project. This project, which is currently underway, is a national programmatic environmental impact statement mandated under the Energy Policy Act of 2005 to designate corridors for oil, gas, and hydrogen pipelines, as well as electricity transmission and distribution facilities on federal lands in 11 western states. The Westwide Energy Corridor Draft 
Programmatic Environmental Impact Statement was led by the Department of Energy (the BLM is a co-lead) and released in October 2007. The final environmental impact statement is scheduled for release in late 2008. After the environmental impact statement is completed, the BLM will issue a Record of Decision amending the relevant land use plans, as necessary, to implement corridor designations on the lands it administers. The U.S. Forest Service and Department of Defense are also cooperating agencies in the project. A decision is anticipated after the release of the Records of Decision for the Western Oregon Plan Revisions.

- Proposed Jordan Cove Energy (Liquid Natural Gas Terminal) Project and Proposed Pacific Connector Gas Pipeline Project. These two projects consist of an onshore liquid natural gas import and storage terminal located on the bay side of the North Spit of Coos Bay, Oregon, and an approximately 223-mile-long, 36-inch-diameter natural gas pipeline from the terminal southeastward across Coos, Douglas, Jackson, and Klamath counties to an interconnection with existing pipelines near Malin, Oregon. The Federal Energy Regulatory Commission will prepare an environmental impact statement to address the environmental consequences of the project. The Bureau of Land Management, U. S. Forest Service, and other governmental entities are formal cooperators in the environmental documentation. The current schedule calls for completion of the draft environmental impact statement by late 2008 and the final environmental impact statement by early 2009 .

- Proposed Bradwood Landing (Liquid Natural Gas Terminal) and Palomar Pipeline Projects. These two projects would consist of an onshore liquid natural gas import and storage terminal located on the south shore of the Columbia River at river mile 38 and an approximately 220mile-long, 36-inch-diameter natural gas pipeline extending from the terminal southeastward across Clatsop, Columbia, Washington, Yamhill, Marion, Clackamas and Wasco counties to an interconnection with an existing pipeline near Madras, Oregon. The Federal Energy Regulatory Commission has prepared a draft environmental impact statement to address the environmental consequences of the liquid natural gas terminal. The current schedule calls for completion of the final environmental impact statement by late 2008. The Federal Energy Regulatory Commission will prepare an environmental impact statement for the proposed pipeline once the pipeline project proponent files a complete application. The current schedule calls for completion of the draft environmental impact statement for the proposed pipeline by early 2009 and the final environmental impact statement by late 2009 .

- Proposed Ruby Pipeline. This project would consist of the construction of a buried natural gas pipeline between locations known as the Opal Hub in Lincoln County, Wyoming and the Malin Hub near Malin, Oregon, and crossing through the states of Utah, Idaho and Nevada. The proposed pipeline would consist of 680 miles of 42 -inch high pressure pipeline. The proposed location would pass through the eastern portion of the Klamath Falls Resource Area in the BLM's Lakeview District. The Federal Energy Regulatory Commission issued a Notice of Intent to prepare an Environmental Impact Statement in March 2008.

- EIS for Invasive Plant and Landscape Health Management Using Herbicides on BLMadministered lands in Oregon. An EIS team has initiated work on an Oregon-wide programmatic environmental impact statement for the use of 18 herbicide-active ingredients. The herbicides are those that were analyzed in the Final Programmatic EIS for Vegetation Treatments Using Herbicides in 17 Western States (2007). The Oregon-wide environmental impact statement will support all BLM districts in Oregon for use in their existing integrated weed management program and will further identify the details of how and when herbicides would be used as part of an integrated vegetation management program. Scoping is currently planned to be completed during summer 2008. 


\section{Spatial and Temporal Scales of Analysis}

Some resources are spread more broadly across the planning area than others. Therefore, the analysis of the alternatives at multiple spatial scales is necessary to examine those resources for which their geographic area differs from the planning area. For example, the analysis of certain animals or birds may require consideration of a geographic area that is broader than individual districts. In contrast, the geographic area appropriate for analysis of a rare plant that has a highly localized geographic range may be quite limited. Information presented at multiple spatial scales helps the BLM to understand issues, analyze cumulative impacts, and tailor decisions to specific needs and circumstances.

It is also necessary to consider various temporal scales. The Council on Environmental Quality's regulations require consideration of the relationships between the short-term uses of the human environment and the maintenance and enhancement of long-term productivity. Some natural processes and the implementation of management directions or their effects may occur over a relatively short time, whereas other natural processes and implementation of management directions or their effects occur over longer periods of time. Therefore, vegetation changes were analyzed at 10,20,30, 40,50, and 100 years. Effects are reported for different sets of time points for different analyses. Where possible, interim benchmarks and rates of progress or trends have been identified for those management objectives that may not be achieved for decades, a century, or longer.

In general, for these analyses, the short term is considered 10 years and the long term is considered 100 years. In the analysis of certain resources, the definition of short term and long term varies from this general definition. In those instances, the time period for short and long term is specified in the text.

\section{Potential Changes in Conditions Not Incorporated into the Analysis}

There are potential future events or changes in conditions that would alter the analysis of effects, for which there is insufficient information at this time to incorporate into the detailed quantitative analysis of future resource conditions. These future changes include climate change, Sudden Oak Death, and natural disturbance. For each of these, it is not speculative that some change in conditions will occur in the future, but it is not possible to reasonably foresee the specific nature or magnitude of the changes.

\section{Climate Change}

The global climate is becoming warmer, and there is strong evidence that this warming is resulting, at least in part, from human-caused production of greenhouse gases, including carbon dioxide (IPCC 2007). Climate interacts with vegetation and ecosystems; climate affects plant growth and ecosystem productivity; and ecosystem dynamics affect climate through the storage and release of greenhouse gases, including carbon dioxide.

In the past decades, the regional climate has become warmer and wetter with reduced snowpack (Scientific Consensus Statement 2004). Current climate conditions have changed from the climate conditions when the current old-growth stands were developing (Franklin et al. 2006). It is unknown whether these changes in climate have altered fundamental processes about tree regeneration and stand development in a way that changes the likely development of currently young stands.

The analysis does not incorporate changes in future climate conditions in the vegetation modeling, because the specific nature of regional climate change over the next decades remains speculative. Although an increase in average annual regional temperatures is likely, changes to the amount and timing of precipitation are too uncertain to predict (U.S. Global Change Research Program 2001, Climate Impacts Group 2004, 
and Scientific Consensus Statement 2004). Changes in the impact analysis as a result of climate change would be highly sensitive to changes in the amount and timing of precipitation. Furthermore, it would be very difficult to apply the results of climate change models to a finer scale than the entire Pacific Northwest, which limits the ability to apply the results of climate change models to the analysis of specific management strategies or actions.

Climate change could result in changes in vegetation types and species distributions, but the predicted effects vary with different climate change scenarios (Bachelet and Neilsen 2000). Increasing temperatures would likely result in expansion of forest vegetation into currently alpine areas (Field et al. 2007, Millar et al. 2006, Climate Impacts Group 2004, and Mote et al. 2003). Millar et al. (2006) predicted that several climate change scenarios would result in an increase in "warm temperate/sub-tropical mixed forest" in the Coast Range and Klamath Provinces. These shifts could result in an increase in madrone, tanoak, and other oak species in the drier sites, and maple and alder in the wetter sites, with a possible increase in southerly conifers such as redwood and some pines (Millar et al. 2006). In contrast, Busing et al. (2007) modeled future forest conditions in a western Cascades watershed within the planning area under two different climate change scenarios: (1) minor warming with drier summers, and (2) major warming with wetter conditions. For both scenarios, the modeling found that climate change would not result in rapid shifts in tree species dominance or total basal area, but that some tree species may shift their ranges to higher elevations. It is not known whether forests in southwestern Oregon, most of which receive less annual precipitation and longer summer drought, would respond similarly to the modeled watershed.

Either higher than previous temperatures or higher than previous atmospheric carbon dioxide levels could increase tree growth rates. However, the overall effects on regional forest growth are uncertain, especially because of the uncertainty of precipitation changes (Millar et al. 2006 and Smith 2004). At the broader scale, the IPCC report (2007) concluded:

"overall forest growth in North America will likely increase modestly (10-20\%) as a result of extended growing seasons and elevated $\mathrm{CO}_{2}$ over the next century, but with important spatial and temporal variations." (Field et al. 2007).

Higher temperatures could lead to increased drought stress on plants and could potentially result in some shift from forest to non-forest vegetation on currently dry sites (Climate Impacts Group 2004, Scientific Consensus Statement 2004, Mote et al. 2003). However, such shifts are difficult to predict and remain speculative. As noted by Millar et al. (2006):

"Hotter temperatures would enhance evaporative demand, tending to drought-stress the vegetation. However, that is somewhat countered, or even reversed, if it is also accompanied by increases in precipitation, as well as the increased water use efficiency of the vegetation from elevated $\mathrm{CO}_{2}$ concentrations."

Higher summer temperatures would likely extend the season of high fire risk and could result in increased frequency and intensity of wildfires (Field et al. 2007, Climate Impacts Group 2004, Scientific Consensus Statement 2004, Mote et al. 2003). However, the potential effects of increased fire risk on forests depend heavily on predictions about broad-scale patterns of ocean/atmosphere interactions, changes in precipitation, and fire suppression activities (Westerling et al. 2006, Millar et al. 2006, Mote et al. 2003).

Higher temperatures could result in changes to hydrologic processes, including reduced snowpacks, earlier snowmelt, shifting of the rain-on-snow zones, higher spring streamflows, and lower summer streamflows (Field et al. 2007). The overall effects on hydrologic processes are uncertain because of the uncertainty of precipitation changes. Increased winter precipitation could potentially mitigate or overwhelm the effects of increased temperatures on snowpack and the changes in the timing of streamflows. However, decreased summer precipitation, coupled with reduced snowpacks and earlier snowmelt, would reduce summer streamflow. Hydrologic processes are heavily influenced by broad-scale patterns of ocean/atmosphere interactions (such as El Nino/Southern Oscillation) (Mote et al. 2003). Changes to these broad-scale patterns remain speculative (Field et al. 2007, Climate Impacts Group 2004). 
Higher summer temperatures, especially if coupled with reduced summer streamflow, could contribute to degraded freshwater habitat conditions for salmon (Lawson et al. 2004, Climate Impacts Group 2004). Even if summer precipitation does not decrease, changes in seasonal patterns of precipitation and runoff could alter hydrologic characteristics of aquatic systems, such as the frequency and timing of floods, affecting species composition and ecosystem productivity (Field et al. 2007, Mote et al. 2003).

Changes in vegetation in response to increased temperature, altered precipitation, and altered fire regimes would alter wildlife habitat. However, because the changes in vegetation are uncertain, consequent changes in wildlife habitat are uncertain. The Sustainable Ecosystems Institute (SEI) report noted that an increase in fire frequency "may affect the capability of the west-side reserve network to recover Spotted Owls" (SEI 2008: 53). The Final Recovery Plan for the northern spotted owl suggested that "the spotted owl and its habitat probably will be affected by climate change through several pathways, including but not limited to changes in fire regime; patterns of rain and snowfall; wildlife diseases; and abundance and distribution of native and nonnative species of fish, wildlife, and plants." However, the Final Recovery Plan concluded that "at this time, we do not have adequate information to accommodate or specifically predict these possible future changes" (USDA USFWS 2008, 34:143).

\section{Sudden Oak Death}

The analysis does not incorporate future changes in forest structure and composition and wildlife habitat as a result of Sudden Oak Death, a recently recognized disease that is killing tanoak, oaks, and other plant species in California and southwestern Oregon. The disease is caused by the introduced pathogen, Phytophthora ramorum. The disease causes trunk cankers, which often directly lead to the death or weakening of a tree to the point that fungi or insects kill it (Rizzo et al. 2002). Tree mortality rates vary widely, even in susceptible species. A wide range of other species with visible branch cankers or foliar lesions is infected by the pathogen, but with uncertain effects on the plant. One of the most common oak species within the planning area, Oregon white oak (Quercus garryana), appears to be unaffected by the pathogen (Rizzo 2003). The long-term effect of sudden oak death on infected forest ecosystems is unknown.

The disease has been confirmed in Oregon at several locations near Brookings, in Curry County (Palmieri and Frankel 2006, Kanaskie et al. 2006). The state of Oregon and U.S. Forest Service are implementing eradication measures (Kanaskie 2007, Palmieri and Frankel 2006). Future spread of the disease into Oregon is uncertain. Models identify different levels of risk of sudden oak death spread across the planning area (Kelly et al. 2005). Widespread infections and mortality of tanoak and oak species could alter not only forest composition and structure, but also important forest processes such as nutrient cycling and wildlife habitat. For example, tanoak and oaks are important in many southwestern Oregon stands in providing cover and food for a wide variety of wildlife species. Widespread infections could affect suitable northern spotted owl habitat in southwestern Oregon through the removal of sub-dominant canopy tree and shrub species, thereby altering habitat structure and prey base numbers. The SEI report evaluated the effect of Sudden Oak Death on northern spotted owls and concluded that there is no reason at this time "to elevate [Sudden Oak Death] above the level of a potential threat, subject to continued monitoring" (SEI 2008:13). The final Recovery Plan for the northern spotted owl concluded that it was not necessary to do anything specific to address Sudden Oak Death, as it was not considered a significant threat (USDI USFWS 2008: 144). Because future spread of the disease and subsequent tree mortality in the planning area is speculative, there is no basis on which this analysis can assume future changes to forest composition, structure, and process as a result of Sudden Oak Death.

\section{Natural Disturbance}

This analysis does not include detailed estimates of future natural disturbances, such as wildfires, windstorms, disease, or insect infestations. These disturbances will occur in the future under all alternatives, but predicting their location, timing, severity, and extent would be speculative. Such disturbances would 
have the potential to alter the future abundance and spatial pattern of structural stages and habitat. There are no available theoretical approaches for estimating the location, timing, or severity of future natural disturbances at the scale of the planning area over the time frame of this analysis. A general discussion of various approaches to estimating the extent of future natural disturbances and the effects of natural disturbances is provided below.

\section{The Extent of Natural Disturbance}

Wildfire is the most predictable of these natural disturbances, yet predicting specific effects related to wildfires it is still impossible at the scale of the planning area. The effects are highly dependent on a wildfire's location, timing, severity, and extent, all of which depend on variables that cannot be reasonably foreseen. Those variables include weather, ignition sources, fuel conditions in the fire location, and the effectiveness of control efforts.

The FSEIS of the Northwest Forest Plan responded to this uncertainty about future wildfires with a theoretical approach, which assumed that $2.5 \%$ of late-successional forests would be lost to wildfires each decade (USDA USFS and USDI BLM 1994b, p. 3\&4:42). That theoretical approach was based on an assumption that forests in the Northwest Forest Plan area experienced a natural disturbance rotation of 250 years, which was extended to a 400-year disturbance rotation as a result of "partial fire suppression" (USDA USFS and USDI BLM 1994b, p. 3\&4:42). That analysis assumed an even rate of loss to wildfire over time and among provinces. The FSEIS of the Northwest Forest Plan also assumed that the rate of loss from natural disturbance of late-successional forests would not vary among the alternatives. Therefore, that theoretical approach to analyzing future disturbance would provide little information to help sharply define the issues or provide a clear basis for choice among the alternatives.

The Late-Successional/Old-Growth Monitoring Report found that the actual loss of late-successional forests over the past 10 years was lower than anticipated by the FSEIS for the Northwest Forest Plan: $1.8 \%$ for the entire Northwest Forest Plan area ${ }^{1}$ (Spies 2006: 84, 89; and Moeur et al. 2005). The Late- Successional/ Old-Growth Monitoring Report also found that there was high variation among the provinces in the loss of late-successional forest to wildfires in the past 10 years: the Coast Range Province had no loss, and the Klamath Province had a much higher loss rate (9.5\% for the decade) (Spies 2006: 84; Moeur et al. 2005), but most of this was on U.S. Forest Service lands, rather than BLM-administered lands, as explained below. The predictive power of that empirical data from the Late-Successional/Old-Growth Monitoring Report is uncertain, in part because of the overwhelming influence of individual wildfires in that data. More than three-quarters of the acreage lost to wildfires in the entire Northwest Forest Plan area were the result of a single fire (Moeur et al. 2005: 95). The Late-Successional/Old-Growth Monitoring Report described a $<1 \%$ decadal loss of late-successional forest from wildfire in the Eastern Cascades Province. However, if the monitoring period had been extended for one additional year, the decadal loss rate would have increased to $14.6 \%$ because of a single large fire (Spies 2006: 84; Moeur et al. 2005: 96). Attempts to provide detailed predictions of wildfire acreage are confounded by the high spatial and temporal variability, even at the scale of provinces and decades.

The actual total wildfire acreage on BLM-administered lands over the past decade has been less than the acreage of late-successional forest that had been anticipated to be lost by the FSEIS of the Northwest Forest Plan. From 1995 to 2004, wildfire occurred on 29,800 acres of BLM-administered lands in the planning area (1.2\% of BLM-administered lands). This acreage includes wildfires of all severities in all vegetation conditions, rather than just stand-replacing fires in late-successional forest. If this wildfire acreage were assumed to be entirely stand-replacing fire and also to have occurred in vegetation conditions proportional to their abundance (which is unlikely, given that stand establishment and young forests have higher fire hazard and fire severity than mature and structurally complex forest as addressed in the Fire and Fuels

${ }^{1}$ Note that the Late Successional/OId Growth Monitoring Report reported values for late-successional forest loss to wildfire by a variety of classifications of late-successional forest. The numbers reported here are from the summarization of the results of the Late-Successional/ Old-Growth Monitoring Report in the monitoring synthesis report (Spies 2006). 
section of Chapter 4), the decadal loss of mature \& structurally complex forest on BLM-administered lands would still have been less than half the amount anticipated to be lost by the FSEIS of the Northwest Forest Plan. The lower than expected rate of loss from wildfire may be a result of the BLM-administered lands having greater interspersion with private lands and greater access for fire suppression than Forest Service lands.

The information available for predicting future disturbances has not substantially changed since the FSEIS for the Northwest Forest Plan, and there are no better methods for incorporated disturbance predictions into detailed analysis of forest management strategies at the scale of this planning area. If the empirical data from the past 10 years is predictive of future conditions, the theoretical approach of assuming a $2.5 \%$ decadal loss of late-successional forest would be an overestimate of the acreage lost. Nevertheless, even if loss of this magnitude were to occur under the alternatives considered here, it would not alter the relative comparison of the effects of alternatives or the fundamental conclusions about the effects of the alternatives. However, incorporating such a loss into the quantitative analysis of structural stage abundance would alter the quantitative outcomes and obscure the effects of the alternatives. A $2.5 \%$ decadal loss of late-successional forest (if equated to mature \& structurally complex forest in this analysis) would result in a reduction over time in the abundance of mature \& structurally complex forest that would be comparable to the difference in the abundance of mature \& structurally complex forest that can be attributed to the effects of the alternatives.

Most other studies in the planning area that have modeled future forest conditions under different management regimes have not incorporated large-scale disturbance (see, e.g., Cissel et al. 1999; Kennedy 2005:103; Spies et al. 2007; and Torgersen et al. 2004:13; and). Busing et al. (2007) simultaneously modeled different management regimes and different disturbance scenarios. However, that simulation addressed only a single watershed and used extremely general descriptions of starkly contrasting management scenarios, which would not adequately provide for a reasoned choice among the alternatives in this plan.

In summary, it is not possible to accurately predict the total acreage of wildfires or other disturbances at the scale of the planning area (Spies 2006:84). To predict total acreage of wildfires for BLM-administered lands, which are highly dispersed among other ownerships, would be far more speculative. To attempt to predict wildfire acreage for BLM-administered lands at finer scales, or to predict wildfire severity, timing, or extent, would be so speculative as to be arbitrary. However, if wildfires and other disturbances occur at approximately the rate anticipated in the FSEIS in the Northwest Forest Plan or at the lower rate actually experienced over the past decade, the relative effects of the alternatives would not be substantially altered from the effects described in this analysis.

\section{Effects of Natural Disturbances}

Natural disturbances kill trees, creating snags and coarse woody debris. Some disturbances, such as wildfires, consume some portion of the trees that are killed, but other disturbances leave the killed trees intact. Disturbances drive the development of forest structure, composition, and process (Franklin et al. 2002). Disturbances have strong controls on the pattern of the landscape, nutrient cycling, hydrology, and habitat (Hutto 2006; Lindenmayer and Noss 2006; Reeves et al. 2006; Beschta et al. 2004; Ice et al. 2004; Karr et al. 2004; Lindenmayer et al. 2004; Robichaud et al. 2000; Perry 1998; Forman 1995). The analysis in the Biscuit Fire Recovery Project environmental impact statement described the effects of wildfire within the planning area, as detailed below, and that analysis is incorporated by reference. For example:

- Vegetation. Disturbances such as wildfire and windstorms alter vegetation conditions and influence forest composition, structure, and spatial pattern (Franklin et al. 2002 and Forman 1995). The environmental impact statement for the Biscuit Fire Recovery Project concluded that the wildfires had removed late-successional forest habitats and created early-successional habitats (USDA USFS/USDI BLM 2004d: III-153 - III-173). 
- Soil conditions and processes. The effects of fire on soils are variable depending on the intensity of the fire and the type of fuels consumed. If forest litter and the decomposed organic material on and in the soil are not totally consumed, then fire effects on soil are usually minimal. In areas of moderate to high burn severity, all the duff and litter on forested sites, including logs on the forest floor, may be consumed. This can heat the soil enough to make fine-textured soils, such as clays and silts, increase in coarseness. Fire has the potential to make soils hydrophobic, or resistant to the natural movement of water into and through the soil profile. This may impact summer water availability to sprouting and recently planted vegetation. At the same time, loss of all the vegetation and surface cover has the potential to decrease the movement of water into soil, increase the potential for overland flow of water, and increase the risk of erosion and mass wasting (USDA USFS/USDI BLM 2004d: III-81 and Robichaud et al. 2000). Fire recycles nutrients otherwise stored in organic matter on the forest floor and unavailable for plant use. After a fire, many nutrients are made available for use by vegetation. Usually following wildfire, there is a short-term increase in soil fertility lasting several years. However, if the organic matter of the mineral soil is lost or reduced, which can occur in hot long-duration fires, then the ability of the soil to hold nutrients leached from the ash is reduced. As a result, nutrients can be lost from the nutrient cycling system. The environmental impact statement for the Biscuit Fire Recovery Project concluded that wildfire altered the conditions and processes of the soil, but did not conclude that the wildfire had increased the risk of landslides (USDA USFS/USDI BLM 2004d: III-81 - III-85).

- Stream flow, sedimentation, and water temperature. Wildfires generally increase peak flows: water-repellent soils and cover loss causes flood peaks to arrive faster, rise to higher levels, and entrain significantly greater amounts of bedload and suspended sediments than unburned watersheds (Robichaud et al. 2000). Where fires remove streamside canopy, the increased solar radiation reaching the stream can increase water temperatures. The environmental impact statement for the Biscuit Fire Recovery Project concluded that the wildfires had increased stream flow, sedimentation, and water temperature (USDA USFS/USDI BLM 2004d: III-206 - III-211).

- Insect infestations. Disturbances such as wildfire and windstorms can lead to increased populations of insects, including bark beetles and wood borers that attack weakened, dying, or dead trees. Insects, in general, and associated disease organisms are integral parts of the forest ecosystem. They help decompose and recycle nutrients, build soils, and can help maintain genetic diversity within tree species. Wood borers start the decomposition process on downed wood by breaking down the dead wood, especially the downed material. The environmental impact statement for the Biscuit Fire Recovery Project concluded that the extensive insect infestations following the fire were possible, but not predictable (USDA USFS/USDI BLM 2004d: III-143 - III144).

\section{Incomplete or Unavailable Information}

If information that is relevant to reasonably foreseeable significant adverse impacts and essential to a reasoned choice among alternatives is incomplete or unavailable, the Council on Environmental Quality's regulations (40 CFR 1502.22[a]) require that an environmental impact statement:

- include a statement that the information is incomplete or unavailable.

- describe the relevance of this information to analyzing the impacts.

- summarize existing credible scientific evidence which is relevant to evaluating the impacts.

- evaluate such impacts based on theoretical approaches or research methods.

There is incomplete or unavailable information about salvage after natural disturbance that is relevant to reasonably foreseeable significant adverse impacts and essential to a reasoned choice among alternatives. 


\section{Salvage after Natural Disturbance}

The alternatives contain management directions related to salvaging of trees killed following disturbances, and those management directions vary among the alternatives. Information on the effects of salvage is incomplete or unavailable. The analysis of the effects of such salvage after natural disturbances (the location, timing, severity, and extent of which cannot be predicted, as discussed above) prior to their occurrence would require making so many speculative assumptions regarding specific circumstances that the conclusions of the analysis could not be used to make reasonably informed decisions regarding management directions. In addition to the summarization of existing scientific evidence and the evaluation of impacts provided below, the analysis of specific salvage actions would be addressed at the time of proposed implementation, when specific circumstances could be analyzed.

Salvaging after natural disturbances provides opportunities for timber harvesting. When such harvesting would occur in the non-harvest land base is not included in computing the allowable sale quantity (see Chapter 4 - Timber), because this harvesting would not be repeated over time. The economic return from harvesting in the non-harvest land base that would not otherwise occur in the absence of a natural disturbance cannot be analyzed because of the speculative nature of the timing and magnitude of the disturbance and the value of the timber that might be killed. When harvesting after natural disturbance occurs in the harvest land base, the harvests would be included as part of the allowable sale quantity. Therefore, any increase in the timber volume that would be offered for sale in a given year because of salvaging after a natural disturbance would result in lower programmed harvest in subsequent years, so that the total volume harvested in a decade would not exceed the decadal level of cut. Consequently, such salvage harvesting in the harvest land base area would create no economic benefit beyond that assumed from programmed harvesting in these areas.

Salvaging after natural disturbances can potentially reduce the risk of a future high-severity fire by reducing the quantity of large fuels (USDA USFS/USDI BLM 2004d: III-37 - III-38 and III-58; McIver and Starr 2000). In contrast, Donato et al. (2006) and Beschta et al. (2004) concluded that salvage logging increases fire risk by increasing surface fine fuels, and suggested that leaving snags standing could result in a lower fire hazard. More recent studies have found that salvage logging increases fine fuels in the short term, but reduces the quantity of large fuels a decade or more after salvage logging (Monsanto and Agee 2008, Mclver and Ottmar 2007). The large fuels in a fire release a large amount of energy over a sustained time period. This heat pulse contributes to long-term soil damage and root mortality (Monsanto and Agee 2008 and Robichaud et al. 2000: 5). All disturbances that kill trees increase the quantity of both fine and large fuels on the ground. Salvage logging reduces the quantity of large fuels, but can increase the quantity of fine fuels. Although the potential for reducing future fire severity by reducing large fuels is consistent with existing research on fire effects (Monsanto and Agee 2008; Brown et al. 2003), there is little research that directly evaluates the effectiveness of salvage logging in achieving this objective. As noted by Reeves et al. (2006): "reburn probability and reburn fire behavior are understood mostly in theory; there is little empirical evidence that would be useful for evaluating risks."

Salvaging after natural disturbances can potentially reduce insect and disease outbreaks (Ice et al. 2004, Sessions et al. 2004, McIver and Starr 2000). For example, windthrow can contribute to increases in Douglas fir bark beetle populations (Furniss and Carolin 1977). However, the effect of salvage logging on future insect and disease outbreaks, like the effect on reburns, is understood mostly in theory and without empirical evidence (USDA USFS/USDI BLM 2004d: III-143 - III-144).

Ground disturbances that are caused by salvage logging can mechanically break up hydrophobic soils (McIver and Starr 2000). However, some studies suggest that hydrophobic soils are temporary and would be naturally altered before salvage logging would typically occur (Reeves et al. 2006, Beschta et al. 2004, USDA USFS/USDI BLM 2004d: III-82). 
Salvaging can reduce safety hazards. Natural disturbances create snags and logs that can pose safety hazards to people and infrastructure (roads, trails, and recreation facilities). Salvaging can also reduce safety hazards during wildfire suppression, because large fuels contribute to the difficulty of suppression operations, and snags and logs pose direct safety hazards to firefighters (USDA USFS/USDI BLM 2004d: III-38 - III-41, III51 - III-53, and III-55 - III-56).

Salvage logging can disrupt natural tree regeneration (Donato et al. 2006, McIver and Starr 2000), but can improve access to disturbed sites to allow replanting and future silvicultural treatments (Sessions et al. 2004). Several studies have asserted that salvage logging necessarily causes forest degradation as a result of soil compaction, erosion, sedimentation to streams, and the spread of invasive species (Lindenmayer and Noss 2006, Reeves et al. 2006, Beschta et al. 2004, Karr et al. 2004). These adverse effects are only potential results of salvage logging, not certain results. As with other timber harvesting, proper logging design and implementation can avoid adverse effects on soil and water (Ice et al. 2004, Sessions et al. 2004, Duncan 2002, McIver and Starr 2000).

Salvaging does not directly contribute to the ecological recovery of disturbed forests and, in some respects, impairs or delays ecological recovery. Salvaging reduces snag and coarse woody debris levels, which reduces ecological functions and alters future stand development (Lindenmayer and Noss 2006, Noss et al. 2006, Reeves et al. 2006, Franklin et al. 2002). Salvage logging simplifies and homogenizes the post-disturbance early-successional forest, and several studies have asserted that early-successional forests with abundant structural legacies from the previous stand (as would occur typically in naturally-created early-successional forests) are becoming increasingly rare and are important sites for many biological and ecological processes (Hutto 2006, Lindemayer and Noss 2006, Spies 2006, Ohmann et al. 2005, Lindemayer et al. 2004, Franklin et al. 2002).

\section{Irreversible or Irretrievable Commitment of Resources}

The irreversible or irretrievable commitment of resources refers to those that cannot be reversed or that are lost for a long period of time. Examples include the extraction of minerals or the commitment of land to permanent roads. Although not specifically labeled, irreversible or irretrievable commitments of resources are described in the environmental consequences for each resource.

\section{Adverse Effects That Cannot be Avoided}

Under the National Environmental Policy Act (NEPA), an agency does not have to avoid adverse effects. However, an agency must identify adverse effects and disclose them. An agency must also identify the means to mitigate those adverse effects that can be mitigated - not all adverse effects can be mitigated. Adverse effects that cannot be avoided are those that would remain even after mitigation measures have been applied.

\section{Mitigation}

The Council of Environmental Quality regulations regarding the National Environmental Policy Act state that mitigation includes avoiding, minimizing, rectifying, reducing, eliminating or compensạting for adverse environmental impacts. Many relevant, reasonable mitigation measures that could avoid or reduce the adverse environmental impacts of the proposed action while still meeting the purpose and need were incorporated into the alternatives either specifically or programmatically. Many other reasonable mitigation measures that would be identified and considered in implementation project design and analysis have been described to the extent possible at this scale (see the Best Management Practices in Appendix I-Water). Where unmitigated adverse impacts remain at the programmatic scale, some relevant and reasonable 
measures have been identified (e.g., green tree retention for rain-on-snow watersheds susceptible to peak flow increases). In addition, there will be an opportunity in the Record of Decision to incorporate aspects of the various alternatives as mitigation in the Approved Resource Management Plan to avoid or reduce adverse environmental impacts.

Measures to avoid, rectify, or reduce environmental impacts were incorporated into the alternatives where practicable and consistent with meeting the purpose and need of the plan revision. The analysis of the PRMP in the Final EIS indicates that levels of impacts to the various resources would be very low. This is primarily a result of the incorporation of mitigation into the design of land use allocations and management direction of the PRMP to avoid, rectify, or reduce adverse environmental impacts. For example, the BLM Special Status Species Policy was incorporated into the PRMP as a result of adverse impacts identified in the Draft EIS. As a result, the environmental effects of the PRMP would be very low and, therefore, few additional specific mitigation measures were identified in the effects analysis for the PRMP

The following are a few examples of specific mitigation that has been incorporated as management direction into the PRMP to avoid, rectify, or reduce adverse environmental impacts:

- Livestock exclosures, or seasonal restrictions from streams or special status plant sites, to conserve species.

- Road improvement, storm-proofing, maintenance, or decommissioning to reduce chronic sediment inputs along stream channels and waterbodies.

- Application of uneven-age management to reduce fire hazard and increase fire resiliency of forest stands in southern Oregon.

- Seasonal restriction of motor vehicle use, or closure of roads, in deer and elk winter range to maintain healthy populations.

- Restriction of activities during nesting season of the northern spotted owl and marbled murrelet, where they have been found to be currently nesting, to increase nesting success.

Programmatic mitigation measures are those that may be appropriate at the time of project implementation of the Approved RMP. Programmatic mitigation measures were incorporated into the alternatives including the PRMP. These measures would be required through management direction and would be applied as determined necessary through analysis of site-specific circumstances at the project level. The following are a few examples of programmatic mitigation that have been incorporated into the PRMP as management direction and may be applied as determined necessary though project-level, site-specific analysis to avoid or reduce adverse environmental impacts:

- Altering the type, timing, extent, and intensity of actions to maintain populations of special status plant and animal species.

- Implementing Best Management Practices to maintain water quality.

- Implementing prescribed burns in accordance with the Oregon Smoke Management Plan to reduce emissions, to avoid smoke intrusions into designated areas, and to avoid degrading the visibility in Class I areas.

- Including stipulations in permits issued for collection of special forest products to limit adverse impacts on plant communities, individual plants, soil, and water.

- Altering the design of projects within Visual Resource Management Classes I, II, and III to preserve, retain, or partially retain the existing character of the landscape.

Management directions in the alternatives are mostly broad in nature and are not intended to provide an exhaustive list of project-level practices that could be implemented to accomplish management objectives. Specific project-level mitigation measures that are consistent with an alternative's management objectives or management direction may be implemented as determined necessary. The following are a few examples of project-level mitigation that are not specifically listed in the individual alternatives, but which are consistent 
with the management objectives and management direction of all alternatives including the PRMP and may be applied at the time of project implementation:

- Washing of vehicles to reduce the risk of introduction or spread of invasive plants.

- Using weed-free straw and mulch to reduce the risk of introduction or spread of invasive plants.

- Restricting ground-based harvesting equipment to slopes less than 35 percent to avoid detrimental soil disturbance.

- Restricting ground-based harvesting equipment to designated skid trails to reduce the extent of detrimental soil disturbance.

- Increasing initial plantation spacing to reduce the need to thin and thereby reduce the amount of slash that would contribute to fire hazard or require fuels treatment.

\section{Estimated Management Activity for the First 10 Years}

See Table 4-1 (Estimated first decade levels of timber management activity by alternative) for the assumed levels of timber management activities that were used in the analysis of the environmental consequences. See Table 4-2 (Estimated first decade levels of timber management activity by district under the PRMP) for the assumed levels of activity by individual district.

See Table 4-3 (Estimated first decade levels of non-timber management activity by alternative) for the assumed levels of certain non-timber related activities that were used in the analysis of the environmental consequences.

These assumed levels of activities are broad approximations used to compare the environmental consequences of the PRMP and the alternatives. The achievement of objectives and anticipated environmental consequences are not highly sensitive to short-term and relatively minor departures from the broad levels of assumed activities used as analytical assumptions. 
FEIS for the Revision of the Western Oregon RMPs

Table 4-1. Estimated First Decade Levels Of Timber Management Activity By Alternative

\begin{tabular}{|c|c|c|c|c|c|c|}
\hline \multirow{2}{*}{ Timber Management Activity } & \multirow{2}{*}{ Unit } & \multicolumn{5}{|c|}{ Alternative } \\
\hline & & No Action & Alt. 1 & Alt. 2 & Alt. 3 & PRMP \\
\hline Regeneration harvesting & acres & 60,500 & 90,600 & 143,400 & 3,900 & 76,600 \\
\hline Partial harvesting & acres & 0 & 0 & 0 & 124,600 & 0 \\
\hline Harvest land base thinning & acres & 36,800 & 45,400 & 43,300 & 160,300 & 146,400 \\
\hline Nonharvest land base thinning & acres & 63,200 & 68,000 & 33,400 & $0^{\mathrm{a}}$ & 73,900 \\
\hline Eastside Management Lands thinning & acres & 3,200 & 3,200 & 3,200 & 3,200 & 800 \\
\hline Allowable sale quantity (ASQ) volume & $\mathrm{mmbf}$ & 2,680 & 4,560 & 7,270 & 4,710 & 5,020 \\
\hline Nonharvest land base (NHLB) volume & $\mathrm{mmbf}$ & 870 & 810 & 400 & 20 & 860 \\
\hline Eastside Management Lands volume & $\mathrm{mmbf}$ & 20 & 20 & 20 & 20 & 5 \\
\hline Total harvest volume & $\mathrm{mmbf}$ & 3,570 & 5,390 & 7,690 & 4,750 & 5,885 \\
\hline Permanent road construction & miles & 360 & 520 & 610 & 550 & 700 \\
\hline Temporary road construction & miles & 460 & 310 & 400 & 510 & 570 \\
\hline $\begin{array}{l}\text { Right-of-way area for permanent road } \\
\text { construction }\end{array}$ & acres & 1,800 & 2,800 & 3,300 & 3,200 & 3,870 \\
\hline Ground-based yarding & acres & 31,100 & 38,700 & 36,500 & 58,500 & 56,700 \\
\hline Cable yarding & acres & 100,400 & 139,100 & 157,000 & 187,900 & 202,500 \\
\hline Aerial yarding & acres & 29,000 & 26,200 & 26,600 & 42,400 & 38,500 \\
\hline \multicolumn{7}{|l|}{ Site preparation: } \\
\hline Prescribed burning & acres & 48,200 & 71,700 & 109,300 & 60,800 & 70,900 \\
\hline Other & acres & 14,900 & 28,500 & 46,200 & 20,400 & 15,400 \\
\hline Release/precommercial thinning & acres & 54,600 & 54,600 & 54,600 & 54,600 & 57,700 \\
\hline Stand conversion & acres & 2,100 & 2,100 & 2,100 & 2,100 & 2,200 \\
\hline Planting/unimproved genetics & acres & 18,600 & 29,300 & 38,600 & 20,300 & 30,100 \\
\hline Planting/improved genetics & acres & 50,800 & 73,500 & 115,700 & 62,400 & 74,200 \\
\hline Fertilization & acres & 104,700 & 129,700 & 127,200 & 204,400 & 108,600 \\
\hline Stand maintenance/protection & acres & 112,500 & 161,400 & 259,900 & 134,400 & 153,200 \\
\hline Pruning & acres & 37,600 & 37,600 & 37,600 & 37,600 & 35,600 \\
\hline
\end{tabular}




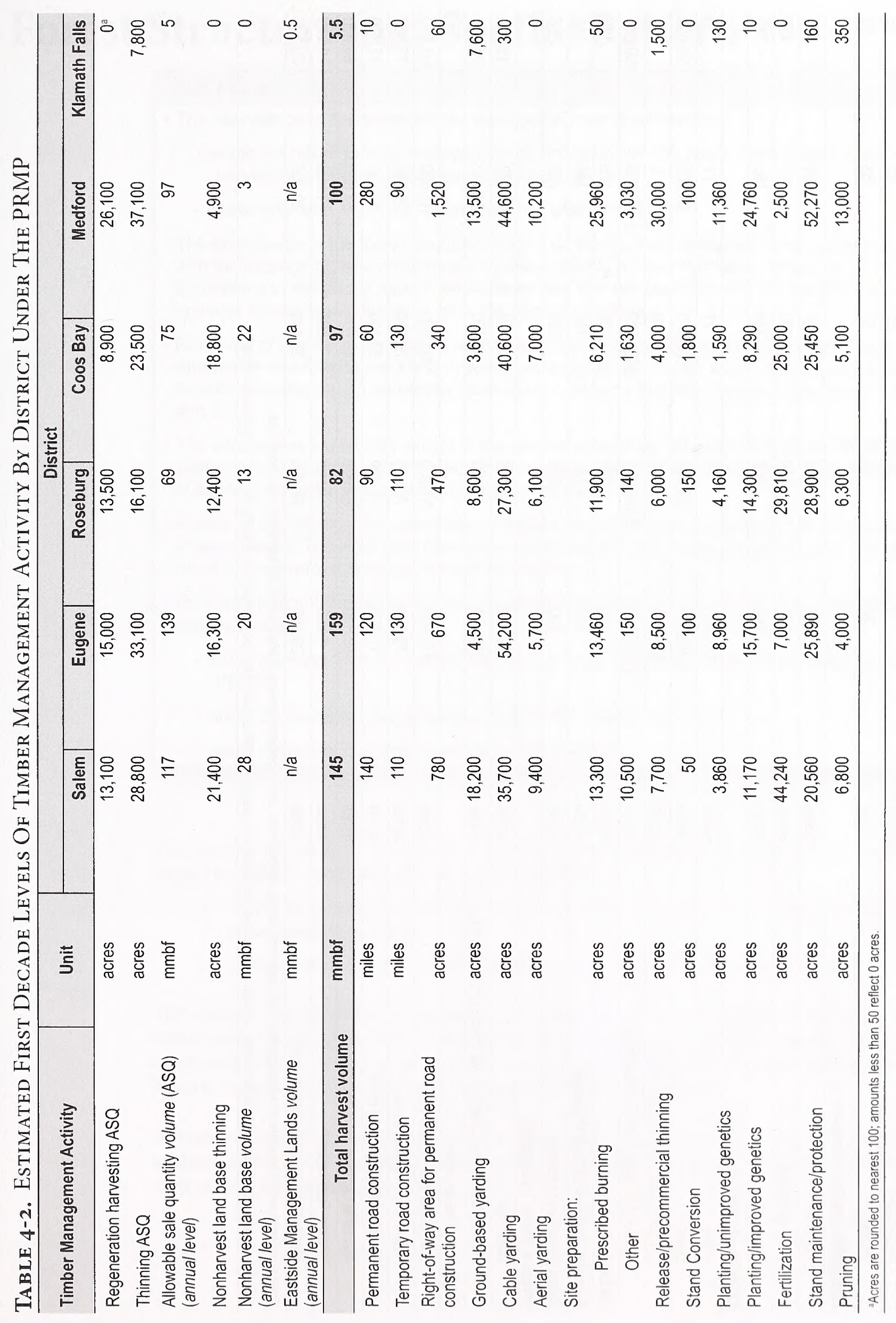




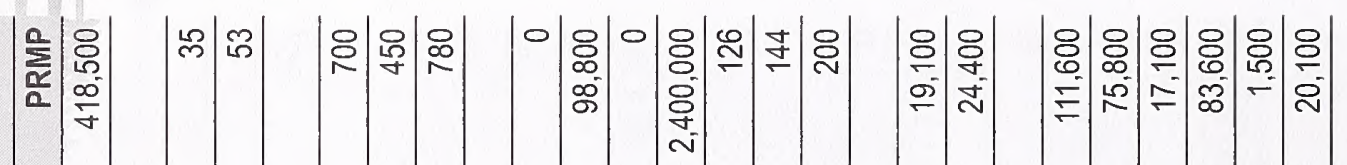

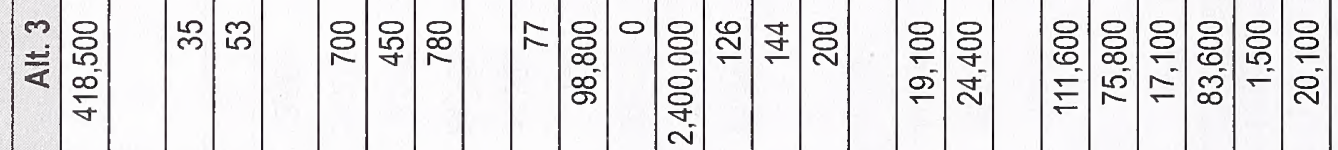

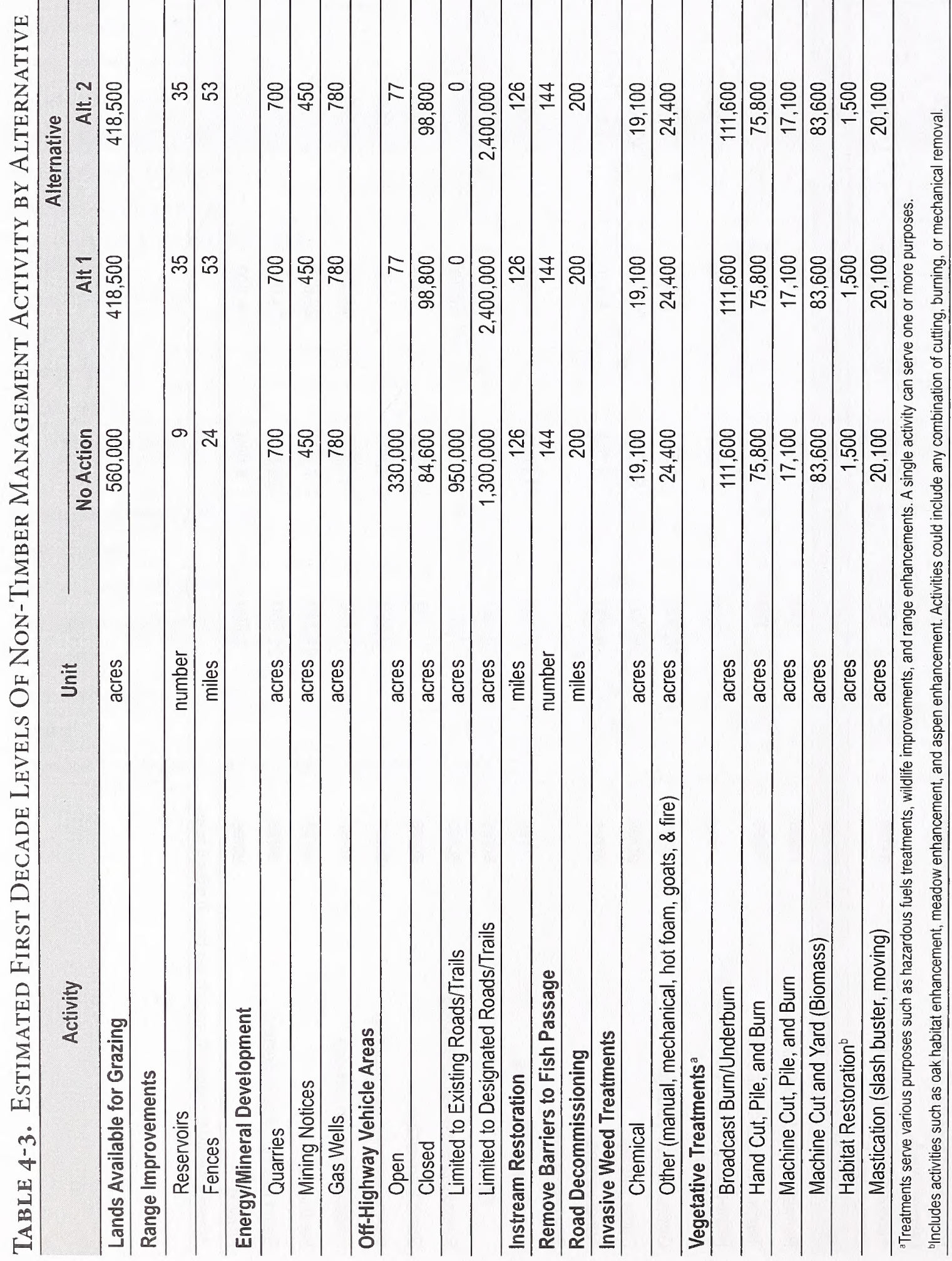




\section{Forest Structure and Spatial Pattern}

\section{Key Points}

- The abundance of the forest structural stages across all ownerships:

- would not return to their average historic conditions in 100 years, even if there were no timber harvesting on the BLM-administered lands, and

- would only shift $1 \%$ in 100 years under all alternatives.

- The abundance of the forest structural stages on the BLM-administered lands would be consistent with the average historic conditions only under the No Action Alternative. Under all alternatives, the abundance of the young forests would decrease, and the abundance of the mature \& structurally complex forests would increase from the current condition.

- Retention of structural legacies in regeneration harvests, which would occur under the No Action Alternative and Alternative 3 and in some areas under the PRMP, would result in structurally complex forests redeveloping on harvested lands almost twice as fast after harvesting as under Alternatives 1 and 2 .

- The alternatives would vary widely in the amount of existing old forest that would be harvested in 100 years - from 14\% under the No Action Alternative, to $63 \%$ under Alternative 3. Under the PRMP, $27 \%$ of existing old forest would be harvested in 100 years.

- Across all ownerships, the patch size of mature and structurally complex forests would increase under all alternatives. The No Action Alternative would result in the largest increase, and Alternative 3 would result in the smallest increase in most provinces.

- On the BLM-administered lands, the size and connectivity of the patches of the mature \& structurally complex forests:

- would increase from the current condition in most provinces under the No Action Alternative and the PRMP,

- would decrease in most provinces under Alternatives 1 and 2.

- would decrease in all provinces under Alternative 3.

This analysis describes the abundance and spatial patterns at various points in time of the forest structural stages that would exist under each of the alternatives:

- for the BLM-administered lands within the entire planning area, by land use allocation and by physiographic province

- across all ownerships for the entire planning area, by physiographic province

This analysis compares these abundances and spatial patterns to the average historic conditions. As explained in Chapter 3 (in Forest Structure and Spatial Pattern), this analysis uses the average historic conditions as a benchmark to provide context in comparing the effects of the alternatives. The average historic conditions do not represent a goal or target for management.

Although of interest in itself, this analysis is intended to serve as an important basis for other subsequent analyses in this EIS by providing a description of the forest at broad landscape scales that would occur at various time periods under the alternatives. 


\section{Forest Structure and Spatial Pattern on the BLM-Administered Lands across the Planning Area}

On the BLM-administered lands in 100 years, the abundance of:

- stand establishment forests would remain approximately constant under the No Action Alternative, and increase under the PRMP and Alternatives 1,2, and 3;

- young forests would decrease under the PRMP and all alternatives;

- mature forests would increase under the PRMP and all alternatives; and

- structurally complex forests would increase under the PRMP and all alternatives.

See Figure 4-1 (Structural stage abundances on the BLM-administered lands by alternative). ${ }^{2}$

Figure 4-1. Structural Stage Abundances on The BlM-Administered Lands By Alternative

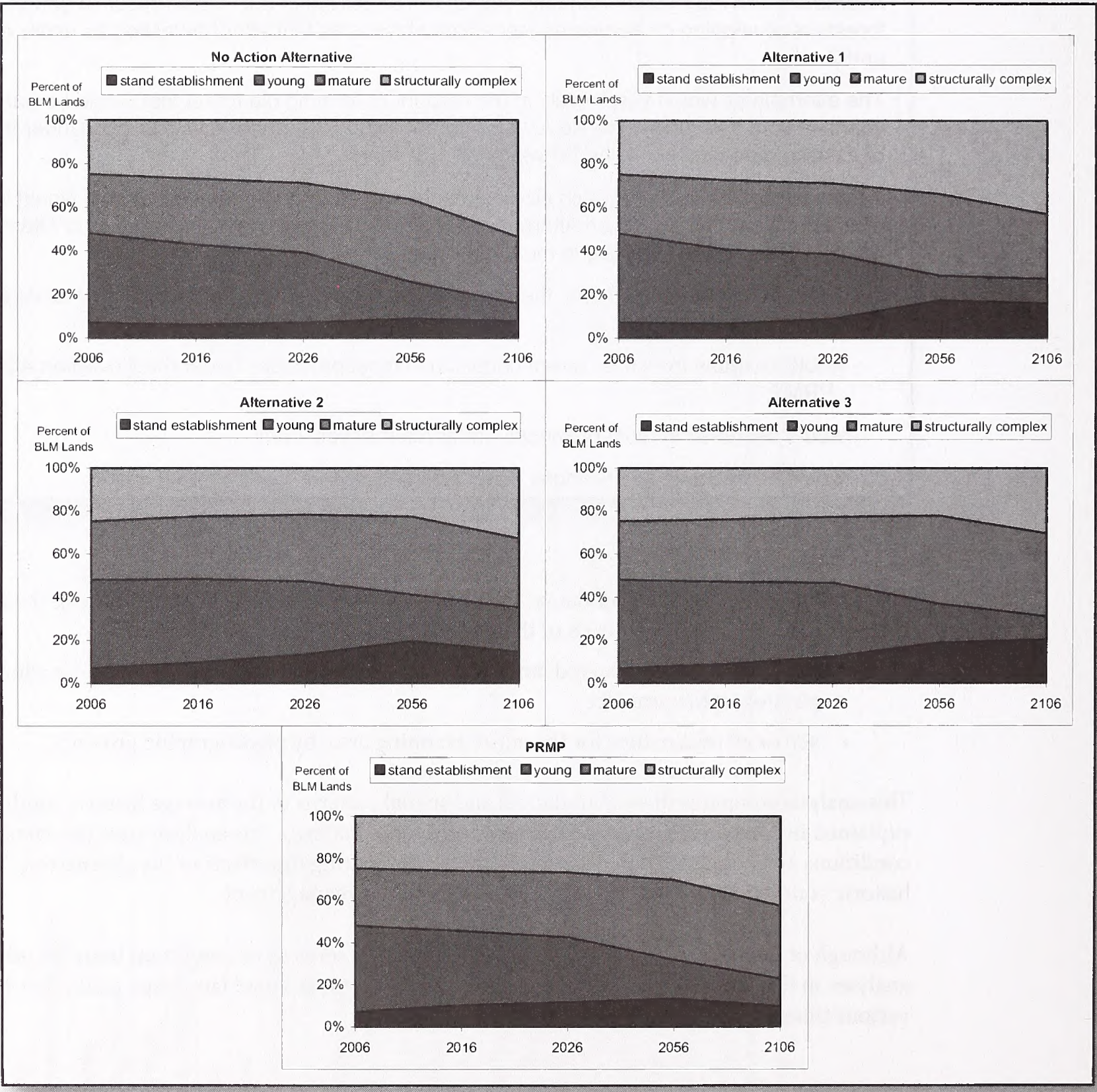

${ }^{2}$ The 2006 forest structural stage abundances differ slightly among the alternatives due to differences in how inventory information is assembled for modeling under each alternative and the changes in identification of nonforest. See the Forest Structure and Spatial Pattern section in Chapter 3 for further explanation. 
Under the No Action Alternative, the abundance of the forest structural stages on the BLM-administered lands would become roughly consistent with the estimates of the average historic conditions (Nonaka and Spies 2005) within 100 years. Under the PRMP and Alternatives 1, 2, and 3, the abundance of the forest structural stages on the BLM-administered lands would move toward the average historic conditions, but would not reach the average historic conditions within 100 years. See Figure 4-2 (Comparison of the

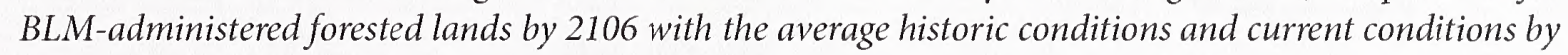
alternative) and Table 4-4 (Structural stage abundances by percentage of the BLM-administered forested lands by alternative).

The No Action Alternative would result in the BLM-administered lands being dominated by mature and structurally complex forests. The amount of the structurally complex forests would more than double in 100 years. The increase in structurally complex forests would be accompanied by a comparable decrease in the amount of young forests. The overall result of these changes would be to shift the BLM-administered lands from a condition in which the young forests are the most common, to a condition in which the structurally complex forests are the most common. This shift would occur largely as a result of four factors:

- The large acreage in the nonharvest land base would develop into mature and structurally complex forests. The nonharvest land base would develop similarly under all alternatives, but the nonharvest land base ( $73 \%$ of the forested acres) would be larger under the No Action Alternative than the PRMP or any other alternative. See Figure 4-9 (Structural stage abundances on the forested lands in the nonharvest land base by alternative) later in this section.

- The regeneration harvest rate would be too low to increase the amount of stand establishment forests, eventually resulting in a decrease in the young forests. Regeneration harvesting in the harvest land base would create an average of 6,100 acres of stand establishment forest per year in the first decade, but 8,400 acres of stand establishment forest would develop into young forests across all allocations. Meanwhile, an average of 15,600 acres of young forest would develop into mature forest per year the first decade, which would result in a substantial decrease in the total abundance of young forest. This net loss in young forest acreage would continue in the following decades. The net loss would slow between 2056 and 2106, but would not reach equilibrium in 2106. Young forest abundance would decrease over time under all alternatives, because fewer acres of stand establishment would develop into young forest than the acres of young forest that would develop into mature forest. However, the greatest decline in young forest abundance would occur

Figure 4-2. Comparison Of The BLM-Administered Forested Lands By 2106 With The Average Historic Conditions And Current Conditions By

\section{Alternative}

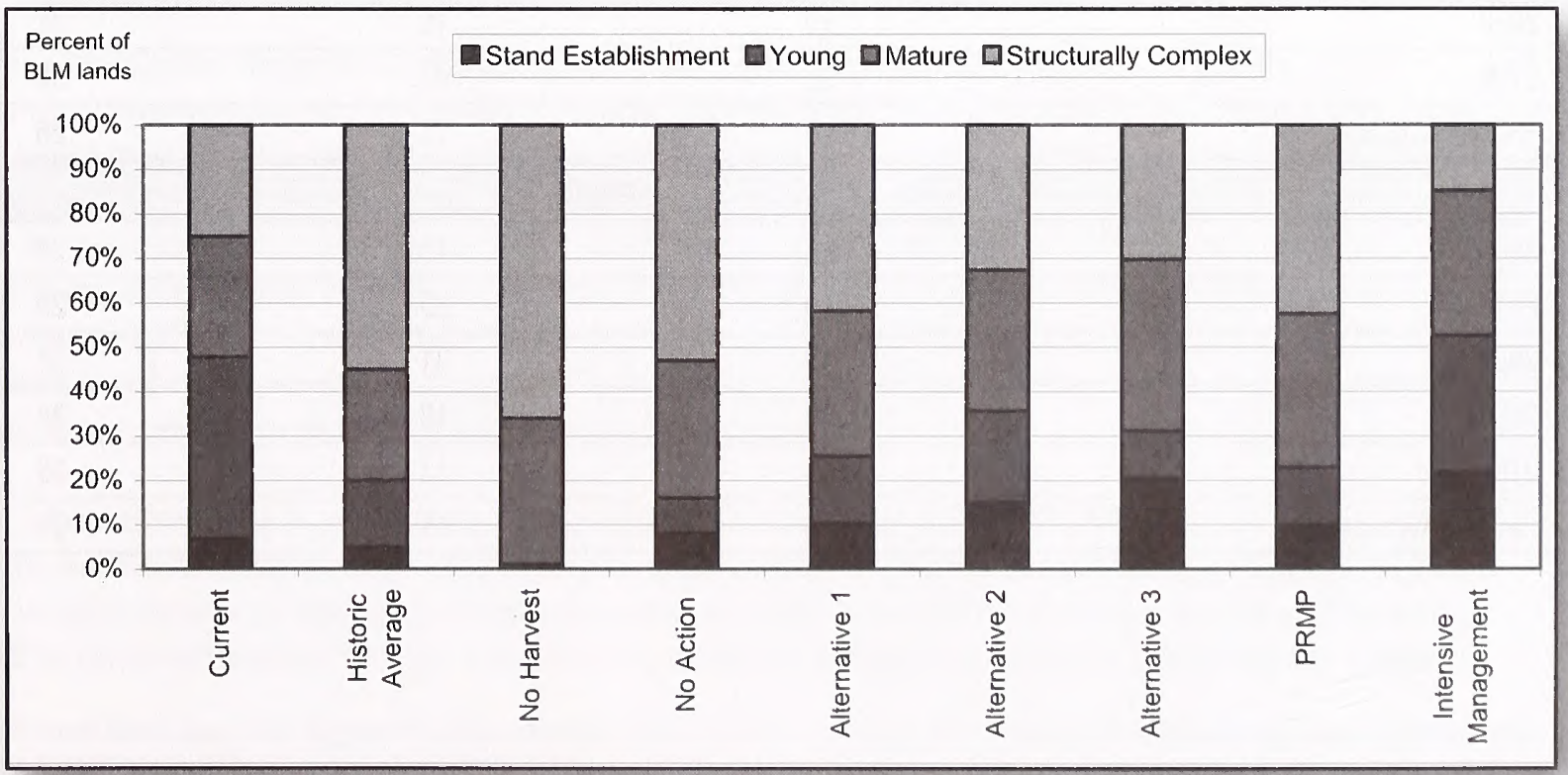


Table 4-4. Structural Stage Abundances By Percentages Of The BlM-Administered Forested Lands By Alternative

\begin{tabular}{|c|c|c|c|c|}
\hline \multirow[b]{2}{*}{ Year } & Stand Establishment & Young & Mature & Structurally Complex \\
\hline & \multicolumn{4}{|c|}{$(\%)$} \\
\hline \multicolumn{5}{|c|}{ No Action Alternative } \\
\hline 2006 & 7 & 41 & 27 & 25 \\
\hline 2016 & 6 & 36 & 30 & 27 \\
\hline 2026 & 7 & 32 & 32 & 29 \\
\hline 2056 & 9 & 17 & 38 & 36 \\
\hline 2106 & 8 & 8 & 31 & 53 \\
\hline Historic Averages & 5 & 15 & 25 & 55 \\
\hline \multicolumn{5}{|c|}{ Alternative 1} \\
\hline 2006 & 7 & 41 & 27 & 25 \\
\hline 2016 & 7 & 39 & 29 & 25 \\
\hline 2026 & 10 & 34 & 31 & 26 \\
\hline 2056 & 14 & 19 & 37 & 30 \\
\hline 2106 & 10 & 15 & 33 & 42 \\
\hline Historic Averages & 5 & 15 & 25 & 55 \\
\hline \multicolumn{5}{|c|}{ Alternative 2} \\
\hline 2006 & 7 & 41 & 27 & 25 \\
\hline 2016 & 10 & 39 & 29 & 22 \\
\hline 2026 & 13 & 34 & 31 & 22 \\
\hline 2056 & 20 & 22 & 36 & 23 \\
\hline 2106 & 15 & 21 & 32 & 33 \\
\hline Historic Averages & 5 & 15 & 25 & 55 \\
\hline \multicolumn{5}{|c|}{ Alternative 3} \\
\hline 2006 & 7 & 41 & 27 & 25 \\
\hline 2016 & 9 & 38 & 29 & 24 \\
\hline 2026 & 13 & 34 & 31 & 23 \\
\hline 2056 & 19 & 18 & 41 & 22 \\
\hline 2106 & 20 & 11 & 39 & 30 \\
\hline Historic Averages & 5 & 15 & 25 & 55 \\
\hline \multicolumn{5}{|c|}{ PRMP } \\
\hline 2006 & 7 & 41 & 27 & 25 \\
\hline 2016 & 10 & 35 & 29 & 26 \\
\hline 2026 & 12 & 31 & 31 & 27 \\
\hline 2056 & 13 & 18 & 38 & 30 \\
\hline 2106 & 10 & 13 & 35 & 43 \\
\hline Historic Averages & 5 & 15 & 25 & 55 \\
\hline
\end{tabular}


under the No Action Alternative compared to the other alternatives, because it would have the lower regeneration harvesting rate (and subsequently the lower abundance of stand establishment forest) of all alternatives.

- Green tree retention in regeneration harvests would speed redevelopment of the structurally complex stands after harvesting. Green tree retention in regeneration harvest units results in harvest stands with structural legacies. The green tree retention requirements in the harvest land base would result in harvested stands developing into structurally complex forest almost twice as quickly as stands without structural legacies. Stand establishment forests with structural legacies, such as those that would be produced under the No Action Alternative and Alternative 3, would develop into structurally complex forests in approximately 80 years for the most common stand conditions on productive sites. Stand establishment forests without structural legacies, such as those that would be produced under Alternatives 1 and 2 and the PRMP, would develop into structurally complex forests in approximately 150 years for common stand conditions on productive sites. See Figure 4-3 (The influence of legacy retention on future stand development). This finding is consistent with other studies that concluded that green tree retention would speed the redevelopment of the structurally complex forests (Spies 2006: 94, Zenner 2000 and 2005).

- The standards and guidelines of the Matrix land use allocation under the No Action Alternative would constrain harvesting of the structurally complex forests. The following Matrix standards and guidelines would contribute to retention of structurally complex forest within the harvest land base under the No Action Alternative:

- retention of late-successional forests in landscape areas where little late-successional forest persists ( $15 \%$ rule)

- maintenance of $25 \%$ to $30 \%$ of each connectivity/diversity block in late-successional forest

- management of connectivity/diversity blocks on a 150-year area control rotation (see Eugene RMP in USDI BLM 1994b: 35)

- a 120-year minimum regeneration harvest age in the Southern General Forest Management Area (see Medford RMPin USDI BLM 1994e:72-74)

The 120-year minimum regeneration harvest age in the Southern General Forest Management Area would contribute to retention of the structurally complex forest because some forests (7,700 acres in 2006) in the Medford District were identified in the inventory as less than 120 years old, but were classified as structurally complex forest. The green tree retention requirements in regeneration harvesting in the Southern General Forest Management Area would result in harvested stands developing back into structurally complex forests in less than 120 years on some sites.

Under the No Action Alternative, the size and connectivity of mature \& structurally complex forest ${ }^{3}$ patches would increase more than under any other alternative, when compared to the current condition, which would move the spatial patterns in the direction of historic conditions in the Coast Range, West Cascades, and Klamath Provinces. See Figure 4-11 (Change in the mean patch size from the current condition to 2106 by forest structural stage on the BLM-administered lands) later in this section. (As explained in the Forest Structure and Spatial Pattern section of Chapter 3, patch size is measured by the mean average of the distribution of patch sizes, and connectivity is measured by the connectance index.) The No Action Alternative is the only alternative under which the size and connectivity of the mature \& structurally complex forest patches in the West Cascades would increase.

Under Alternative 1, the overall change in the abundance of the forest structural stages would be similar to the No Action Alternative, in part because the large acreage in the late-successional management areas would be coincident with the mapped late-successional reserves of the No Action Alternative. However, the shift in the forest structural stage abundances would not be as pronounced as under the No Action

${ }^{3}$ As explained in Chapter 3 (Forest Structure and Spatial Pattern section), this analysis refers to the combined class as mature \& structurally complex forest where mature forest cannot be distinguished from structurally complex forest. 
Figure 4-3. The Influence Of Legacy Retention On Future Stand Development
No Action and Alternative 3
100-year-old stand developed
with legacies - Structurally
Complex

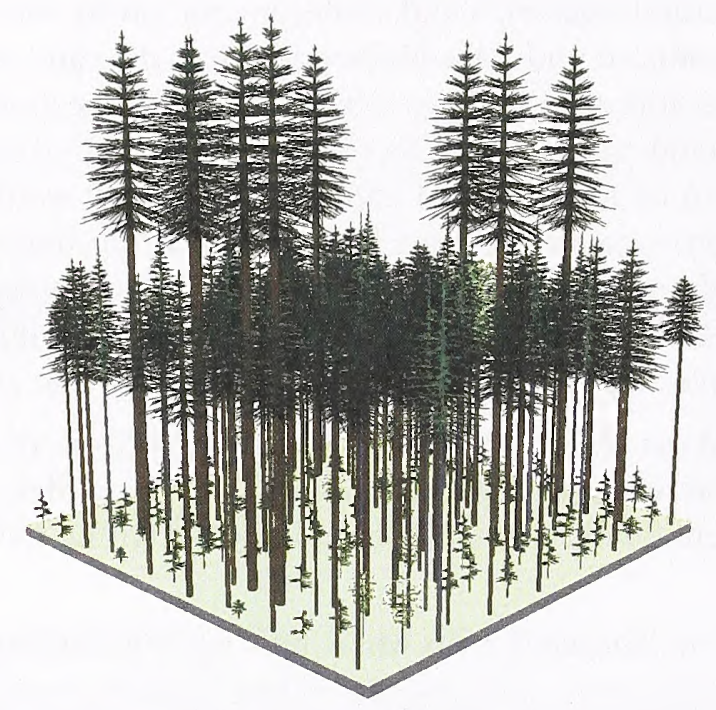

Alternatives 1, 2, and PRMP (in Timber Management Area)

100-year-old stand developed without structural legacies Mature with Single Canopy

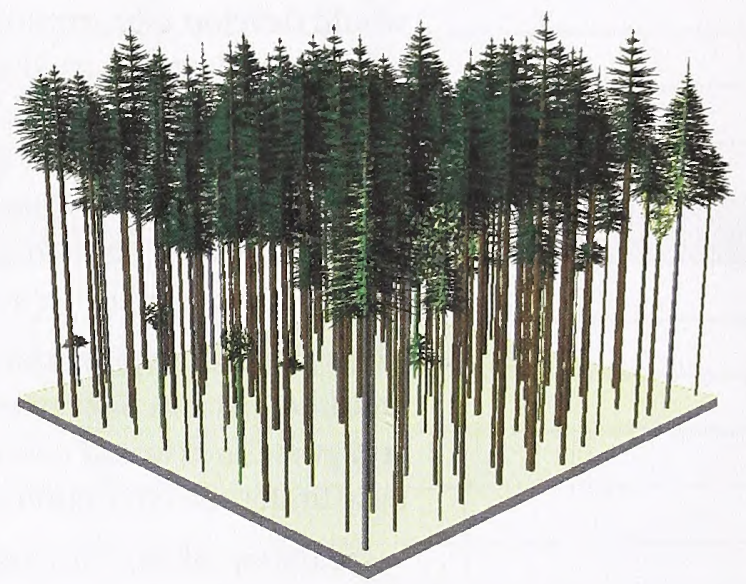

Alternative, because the total of the riparian management areas would be smaller than the riparian reserves of the No Action Alternative; the redevelopment of the structurally complex forests would be slower than under No Action because of the absence of green tree retention; and the regeneration harvest rate would be higher in the harvest land base.

The size and connectivity of the mature \& structurally complex forest patches in the Coast Range Province would increase under Alternative 1 compared to the current condition, but less so than under the No Action Alternative. See Figure 4-11 (Change in the mean patch size from the current condition by 2106 by forest structural stage on the BLM-administered lands). In all other provinces, the size and connectivity of the mature \& structurally complex forest patches would decrease under Alternative 1 compared to the current condition. Under Alternative 1, the BLM-administered lands would become dichotomous (i.e., divided into two parts), with the nonharvest land base being dominated by mature and structurally complex forests, and the harvest land base being dominated by stand establishment without structural legacies forest and young forest without structural legacies forests.

The edges between the harvest land base and nonharvest land base would be abrupt; the adjacent forests would contrast highly in their structure. Dichotomous landscape patterns with abrupt edges would be inconsistent with modeled historic conditions for western Oregon (Nonaka and Spies 2005, Wimberly et al. 2000), and some research has suggested that such a dichotomous landscape would pose a risk to species and ecological processes (Spies 2006, Cissel et al. 1999, Forman 1995). Little empirical research is available to evaluate the effects of a dichotomous landscape pattern on most species and ecological processes. However, at broad spatial scales, the ability of the BLM to re-create historic spatial patterns is limited by its checkerboard ownership pattern that likely would continue a dichotomous landscape pattern under all alternatives.

Under Alternative 2, the overall change in the abundance of the forest structural stages would also be similar to that projected to occur under the No Action Alternative. However, the shift in structural stage abundances from current conditions would be less than under Alternative 1, because the late-successional 
management areas and the riparian management area would be smaller than under Alternative 1. Similar to Alternative 1, the regeneration harvest rate under Alternative 2 would be higher in the harvest land base than under the No Action Alternative, and the redevelopment of the structurally complex forests would be slower than under No Action because of the absence of green tree retention in regeneration harvest units under Alternative 2.

Alternative 2 would decrease the size of the mature \& structurally complex forest patches compared to the current condition in all provinces, though less so than Alternative 3. See Figure 4-11 (Change in the mean patch size from the current condition by 2106 by forest structural stage on the BLM-administered lands). The connectivity of the mature \& structurally complex forest patches would decrease under Alternative 2 in all provinces, except the Coast Range Province where a smaller increase in connectivity would occur under Alternative 2 than under the PRMP, Alternative 1, and the No Action Alternative. Decreasing the size and connectivity would move the spatial pattern of the mature \& structurally complex forests further away from the historic conditions. The shift in the spatial patterns and the increase in the dichotomous nature of the landscape on the BLM-administered lands under Alternative 2 would be similar to that which would occur under Alternative 1.

A larger increase in the abundance of stand establishment forests and a smaller increase in the abundance of the structurally complex forest would occur under Alternative 3 than with all other alternatives. The development of the structural stages would be different under Alternative 3 from the other alternatives, because of the relatively small acreage that would be allocated to the nonharvest land base. As a result, there would not be a large acreage that would develop into mature \& structurally complex forests, as in the other alternatives. Nevertheless, there would be slightly less mature \& structurally complex forest by 2106 under Alternative 3 than under Alternative 1 and more than under Alternative 2. Mature \& structurally complex forest would redevelop more quickly after harvesting under Alternative 3 than under the other alternatives, because of the more extensive use of partial harvest and the green tree retention requirements in both partial and regeneration harvest units.

The size and connectivity of the mature \& structurally complex forest patches in all provinces would decrease under Alternative 3 more than any other alternative, which would move the spatial pattern of the mature \& structurally complex forest away from historic conditions. See Figure 4-11 (Change in the mean patch size from the current condition by 2106 by forest structural stage on the BLM-administered lands).

The harvest intervals under Alternative 3 are designed to mimic the historic average fire return interval, which might suggest that Alternative 3 would be effective at restoring average historic conditions. However, the conclusion here that the application of the harvesting based on the average fire return interval would not restore average historic conditions in 100 years is consistent with other analyses (Nonaka and Spies 2005, Wallin et al. 1994). The current structural stage abundances and spatial patterns are the result of extensive forest management, human-caused fires, and fire suppression policies in the twentieth century and are strongly inconsistent with the average historic conditions. The application of extensive active forest management-even management mimicking natural disturbances-to the current condition would initially move forests away from the average historic conditions and would likely take several centuries to return the BLM-administered lands to the average historic conditions.

Under the PRMP, the overall change in the abundance of the forest structural stages would be similar to Alternatives 1 and 2. Under the PRMP, the allocation of lands to late-successional management areas would be approximately comparable to Alternative 2 , and the allocation of lands to riparian management area would be approximately comparable to Alternative 1. Similar to Alternatives 1 and 2, the regeneration harvest rate under the PRMP would be higher in the harvest land base than under the No Action Alternative, and the absence of green tree retention in regeneration harvest units would slow the redevelopment of the structurally complex forests under the PRMP compared to the No Action Alternative. 
The size of the mature \& structurally complex forest patches would increase under the PRMP compared to the current condition in all provinces except the West Cascades Province. See Figure 4-11 (Change in the mean patch size from the current condition by 2106 by forest structural stage on the BLM-administered lands). Under the PRMP, the connectivity of the mature \& structurally complex forest patches in all provinces would increase. The PRMP is the only alternative under which the size and connectivity of the mature \& structurally complex forest patches would increase compared to the current condition in the Eastern Cascades Province. Increasing the size and connectivity would move the spatial pattern of the mature \& structurally complex forests towards historic conditions, though less so than the No Action Alternative in the Coast Range, West Cascades, and Klamath Provinces.

The stand establishment forests on the BLM-administered lands would be transformed under the No Action Alternative and Alternative 3 to a structural condition more like naturally created, early-successional forests than the current condition, or the condition that would occur under Alternatives 1 and 2. See Figure 4-4 (Stand establishment forests with and without structural legacies by alternative) and Figure 4-5 (Young forests with and without structural legacies by alternative). Under the No Action Alternative and Alternative 3 , the stand establishment forests would completely shift to dominance by stand establishment with structural legacies. This shift would occur because the current stand establishment without structural legacy forests would develop into young forests and would be replaced by new stand establishment with structural legacy forests resulting from green tree retention in regeneration harvest units under the No Action Alternative and Alternative 3.

Stand establishment forests would be created under Alternatives 1 and 2 and the PRMP that would lack the structural complexity of naturally created, early-successional forests. Stand establishment with structural legacy forests would almost completely disappear because of the absence of green tree retention in regeneration harvest units. A very small acreage of stand establishment with structural legacy would be created under Alternative 2 in regeneration harvest units within riparian management areas. These areas would be along intermittent non-fish-bearing streams that are not prone to debris flows and in the management area adjacent to the Coquille Forest, where green tree retention is required. Under the PRMP, in the Uneven-aged Management Area, the abundance of stand establishment forest would be reduced over time. See Figure 4-8 (Structural stage abundance in the harvest land base by land use allocation in the PRMP) later in this section.

In 100 years, the abundance of stand establishment forest on the BLM-administered lands would be slightly above the average historic conditions under the No Action Alternative, and well above the average historic conditions under Alternatives 1, 2, and 3, and the PRMP.

The abundance of young forests would drastically decline under all alternatives. The remaining young forests would slowly shift to an eventual dominance by young with structural legacy forests under the No Action Alternative and Alternative 3. This shift would occur because the young forests without structural legacies would develop into mature forests over time and then be replaced by young forests with structural legacies due to the continuous new supply of stand establishment forests with structural legacies under these two alternatives.

The proportion of young without structural legacy forests would increase under Alternatives 1 and 2 and the PRMP, because almost all new young forests would develop from stand establishment without structural legacy forests. In the Uneven-aged Management Area under the PRMP, very little stand establishment without structural legacy forests would be created, and harvesting in mature and structurally complex forest would create young with structural legacy forests. In the Timber Management Area under the PRMP, only stand establishment without structural legacy forests would be created.

In 100 years, the abundance of young forests on the BLM-administered lands would be slightly below the average historic conditions under the No Action Alternative, Alternative 3 , and the PRMP; equal to the 
average historic conditions under Alternative 1; and slightly above the average historic conditions under Alternative 2.

Figure 4-4 (Stand establishment forests with and without structural legacies [e.g., retained green trees] by alternative) displays stand conditions that would develop following regeneration harvest in the No Action Alternative (General Forest Management Area) or Alternative 3 (western hemlock retention levels). Partial harvesting under Alternative 3 would also create stand establishment with structural legacy forests, but with more overstory trees than shown here.

Figure 4-5 (Young forests with and without structural legacies [e.g., retained green trees] by alternative) displays stand conditions that would develop following regeneration harvest in the No Action Alternative (General Forest Management Area) or Alternative 3 (western hemlock retention levels). Partial harvesting under Alternative 3 would also create young with structural legacy forests, but with more overstory trees than shown here.

The overall abundance of mature forests would be more consistent among the alternatives than other structural stages. See Figure 4-6 (Mature forest with multi-layered canopies or single canopies by alternative). All alternatives would result in an overall increase in the abundance of mature forests over the next 50 years (as young forests develop into mature forests), and then a decrease after 50 years. However, the alternatives would differ in the proportion of mature forests with multi-layered canopies to mature forests with single canopies. Under all alternatives, mature forests with single canopies would predominate in 50 years, as the large acreage of young without structural legacy forest develops. The abundance of mature forest with multilayered canopies in 100 years would be influenced primarily by the effect of green tree retention in regeneration harvest units or uneven-aged management. These types of management would speed redevelopment of mature forest with multi-layered canopies after timber harvest, and, to a lesser extent, by the size of the harvest land base.

Compared to the other alternatives, the No Action Alternative (which would have the smallest harvest land base of all alternatives) and Alternative 3 (which would have the largest harvest land base of all alternatives), would have the highest proportion of mature forest in mature forest with multi-layered canopies ( $74 \%$ and $73 \%$, respectively) in 100 years. This would occur because both of these alternatives include green tree retention in regeneration harvest units. Under the PRMP, there would be slightly more mature forest with multi-layered canopies than mature forest with single canopies (58\%) in 100 years; mature forest with multilayered canopies would predominate in the non-harvest land base and the Uneven-Age Management Area, and mature forest with single canopy would predominate in the Timber Management Area due to the lack of green tree retention in regeneration harvest units. Under Alternative 1, there would be very slightly more mature forest with multi-layered canopies than mature forest with single canopies (53\%) in 100 years.

Although the harvest land base under Alternative 1 would be roughly similar to that under the PRMP, Alternative 1 would lack the Uneven-Age Timber Management Area. Under Alternative 2, there would be less mature forest with multi-layered canopies than mature forest with single canopies ( $38 \%$ ), because the harvest land base would be larger than that under the PRMP or Alternative 1 and would lack green tree retention in regeneration harvest units. The influence of timber harvest and green tree retention on mature forests is further demonstrated by the two reference analyses. The reference analysis of intensive management on most commercial timber lands, which would have no green tree retention, would have the most extreme outcome: $80 \%$ of all mature forests would be mature with single canopies in 100 years. Under the no harvesting reference analysis, the abundance of mature forest with multi-layered canopies would be approximately equal to the abundance of mature forest with single canopies in 100 years, as a result of the current abundance of young, high-density, even-aged managed stands (see Forest Structure and Spatial Pattern in Chapter 3).

In 100 years, the amount of mature forests on the BLM-administered lands would be above the average historic conditions under all alternatives. 
Figure 4-4. Stand Establishment Forests With And Without Structural Legacies (E.G., Retained Green Trees) By Alternative

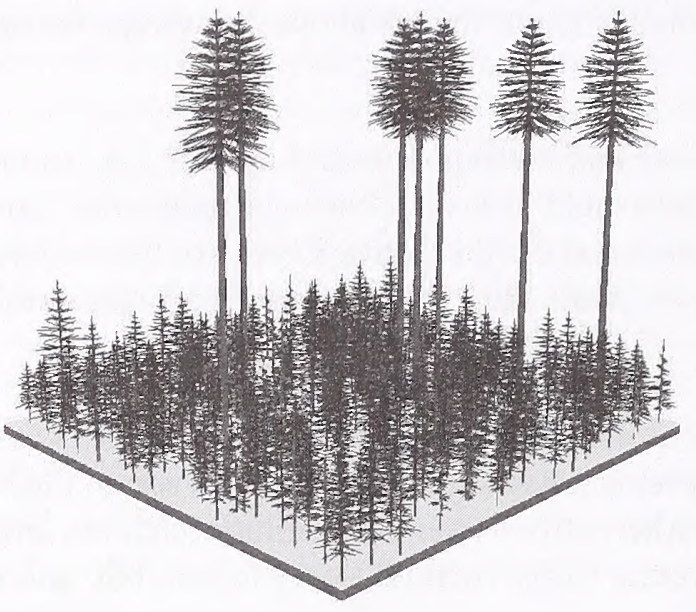

Stand Establishment with Structural Legacy

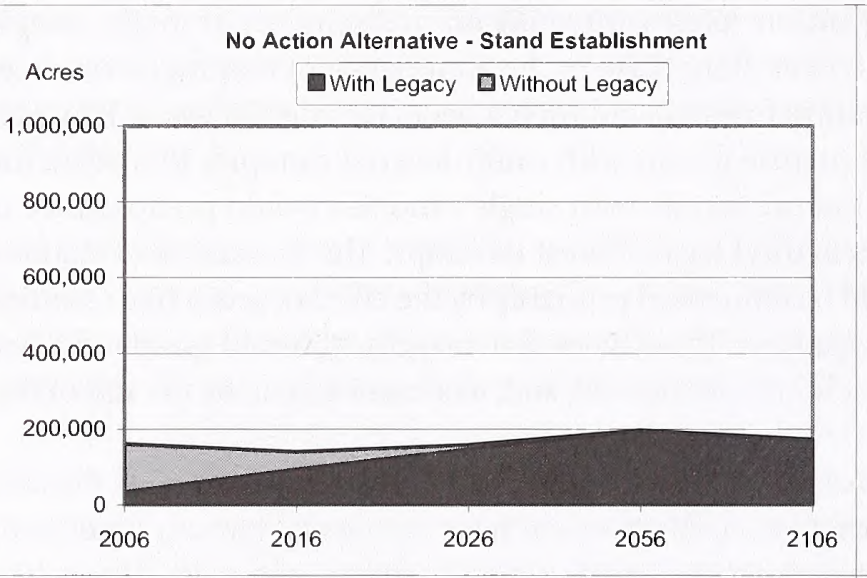

Alternative 2 - Stand Establishment

Acres $\square$ With Legacy $\square$ Without Legacy

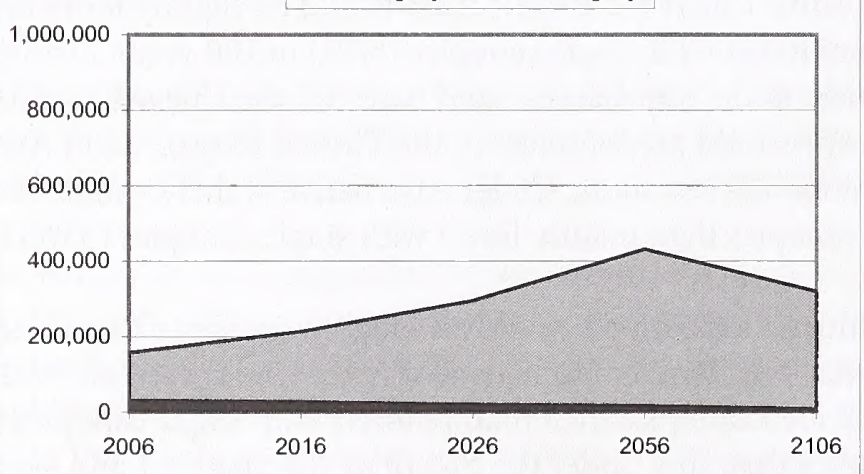

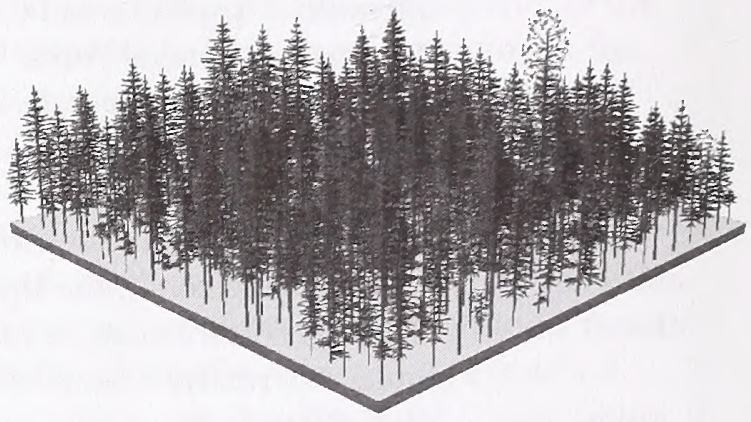

Stand Establishment without Structural Legacy
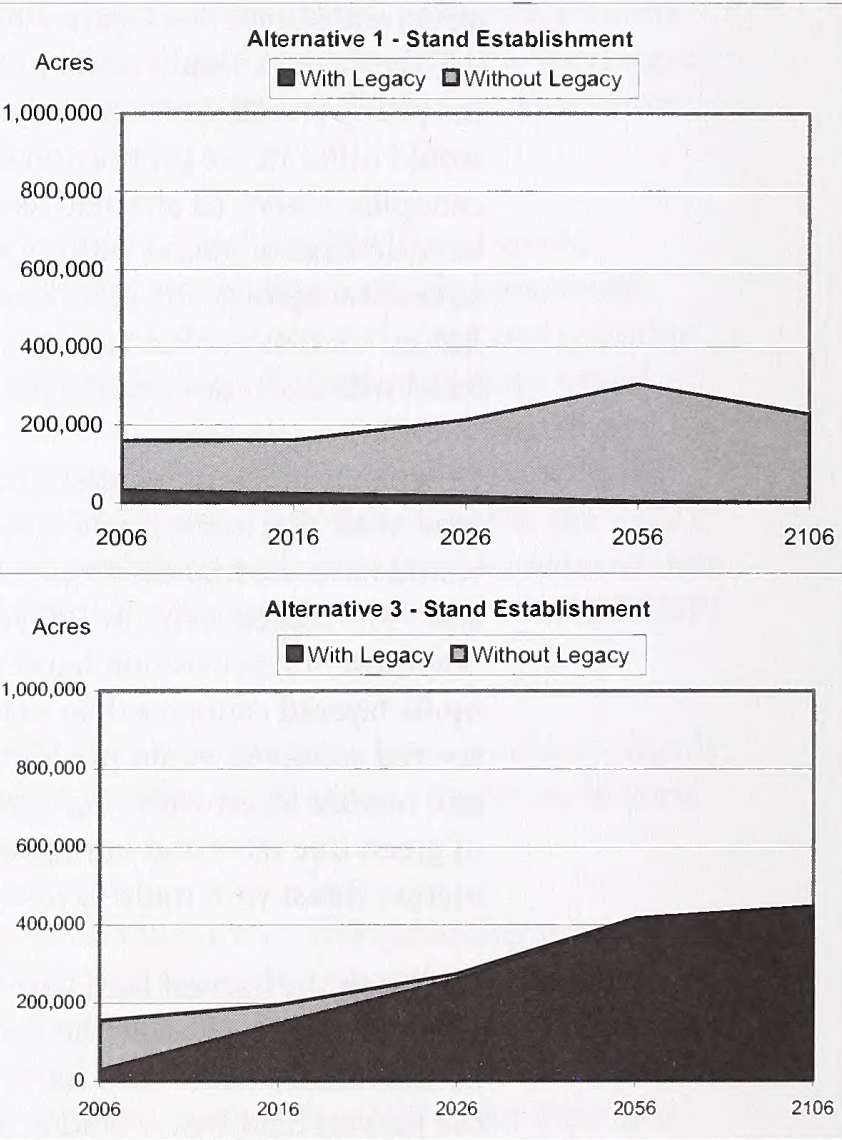

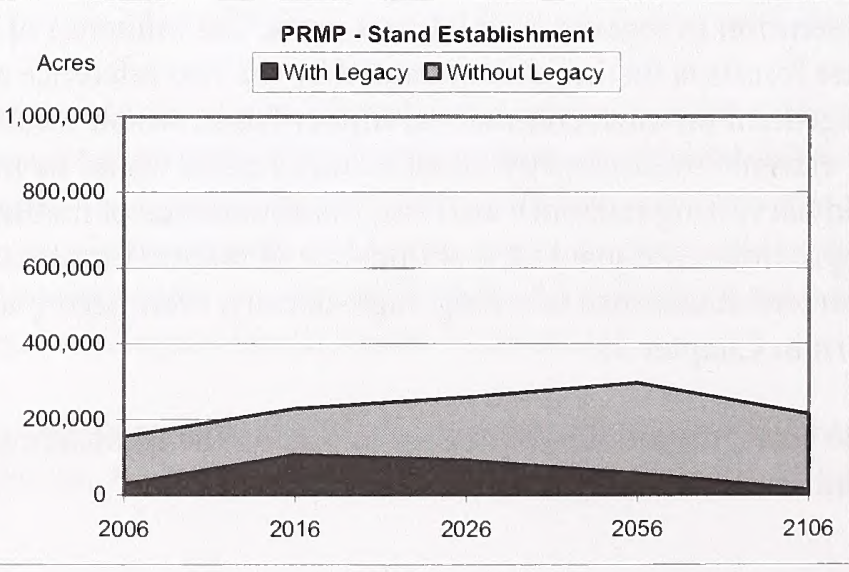




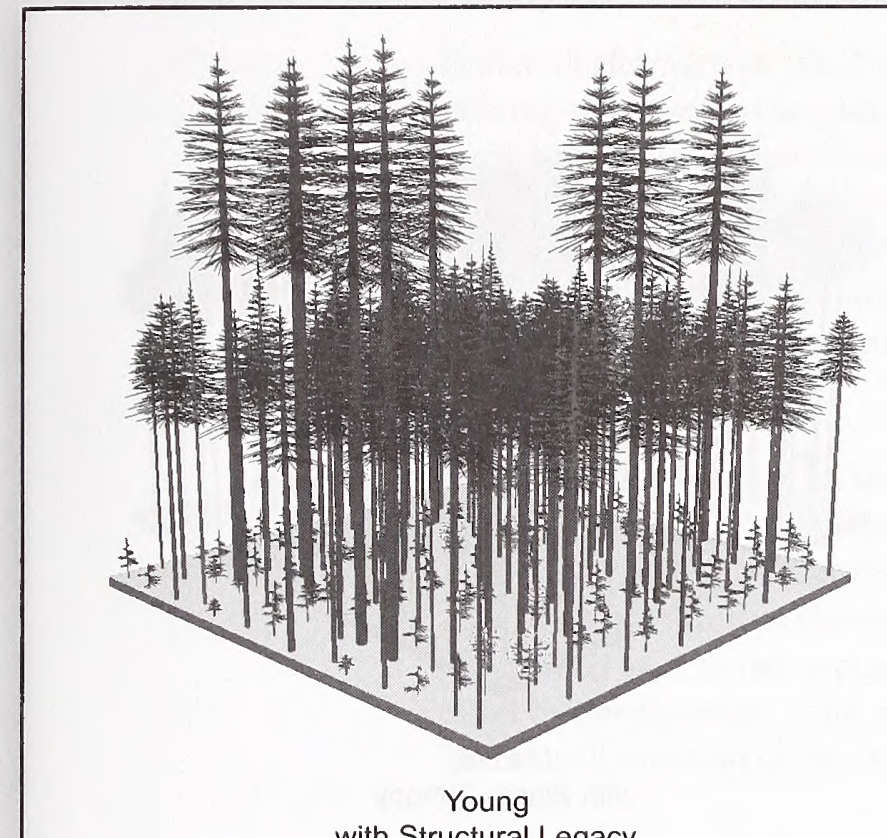

with Structural Legacy

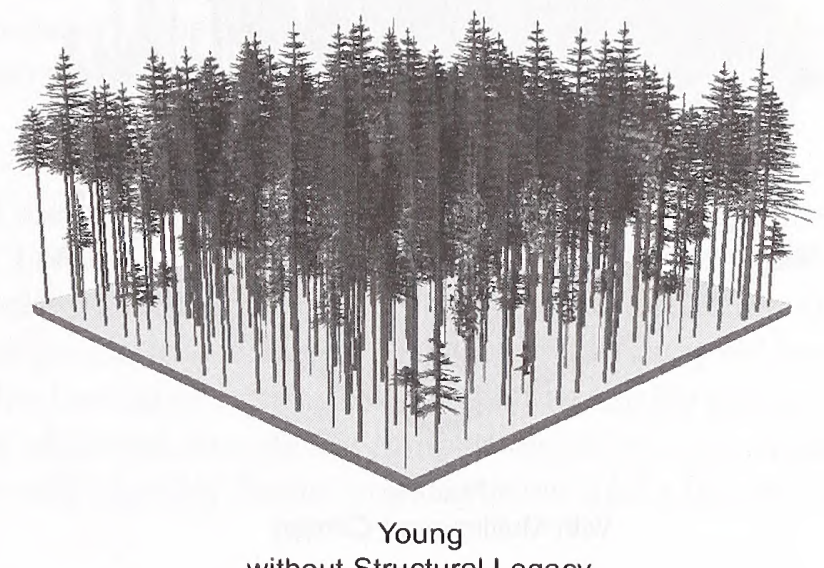

without Structural Legacy
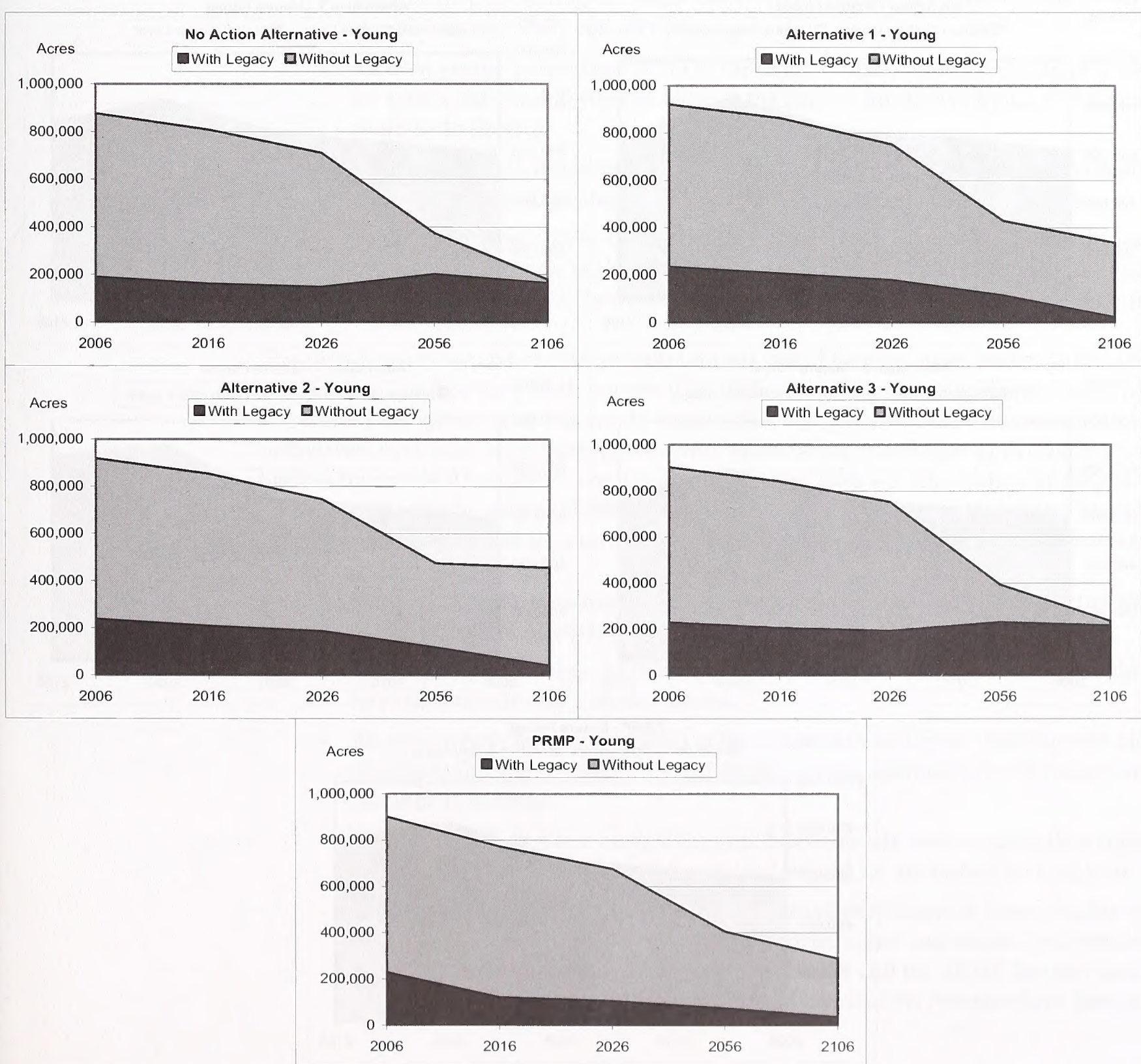
Figure 4-6. Mature Forest With Multi-Layered Canopies Or Single Canopies By Alternative

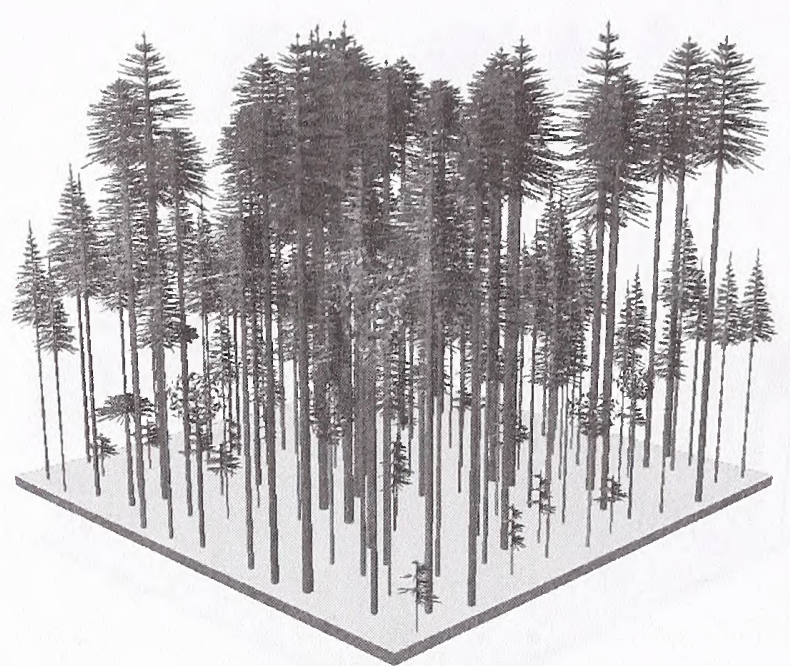

Mature with Multilayered Canopy
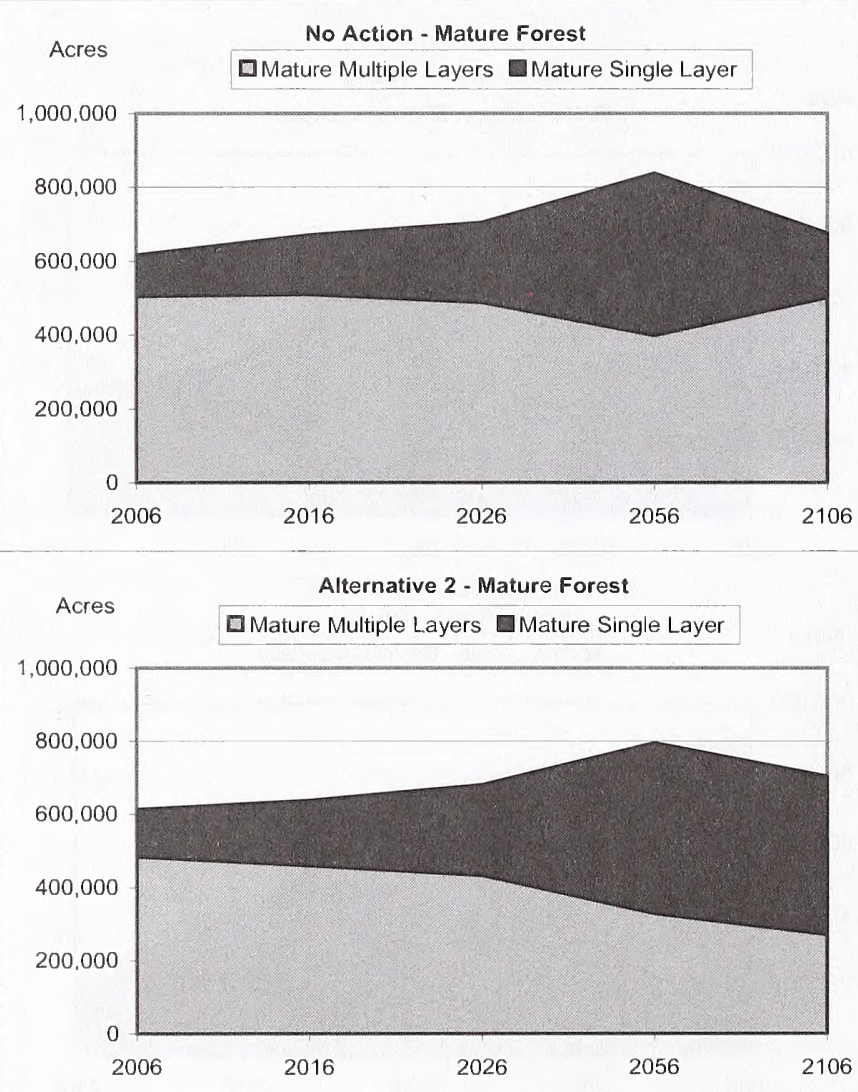

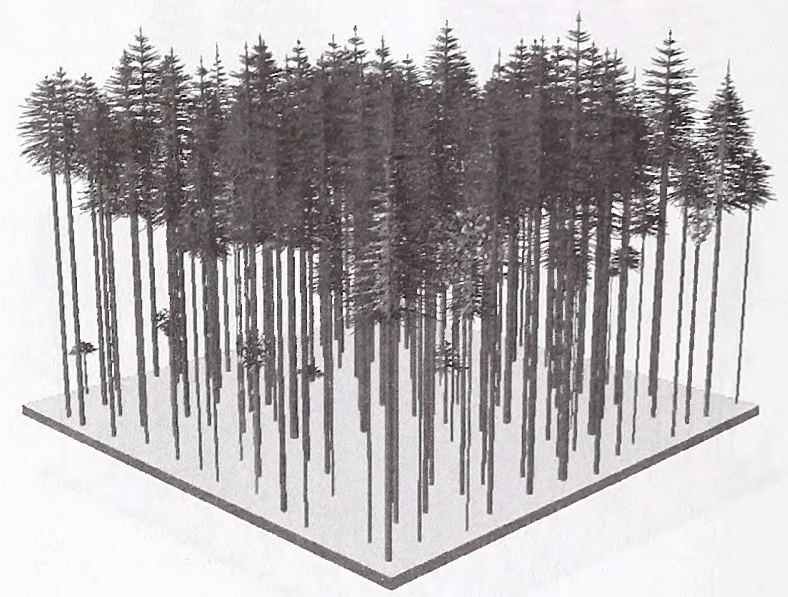

Mature with Single Canopy
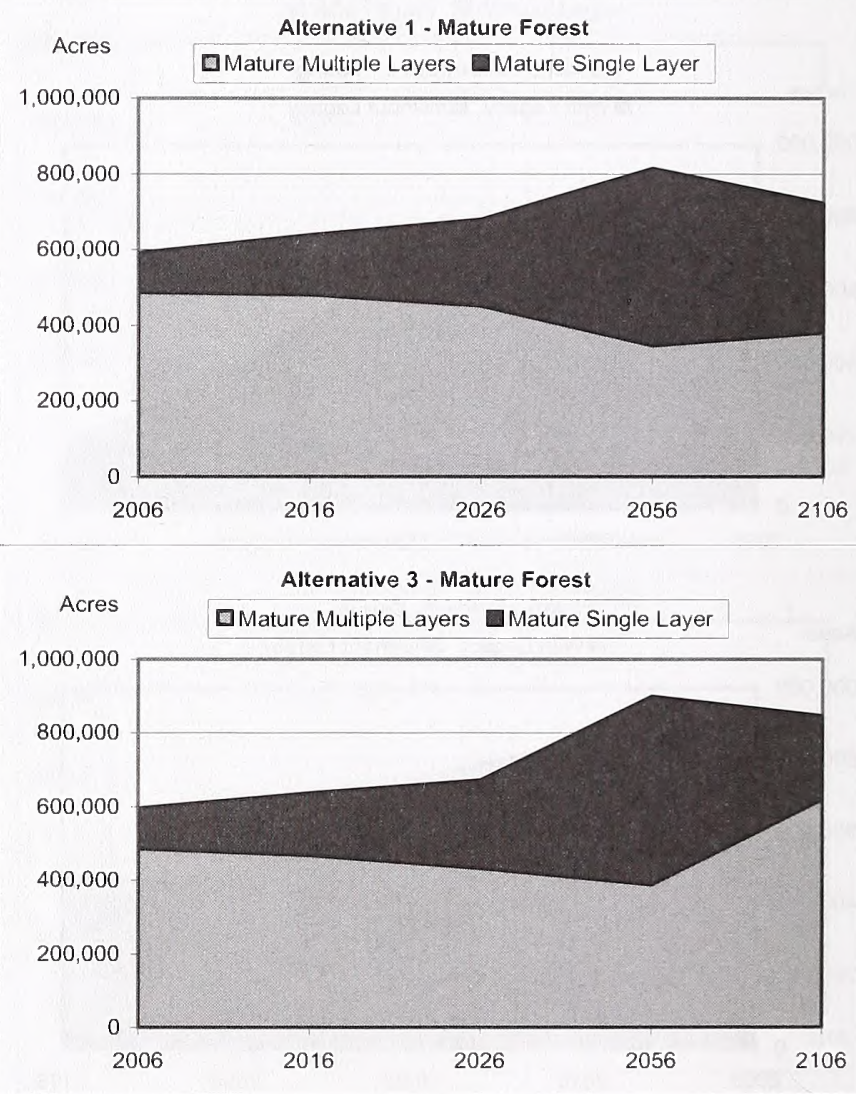

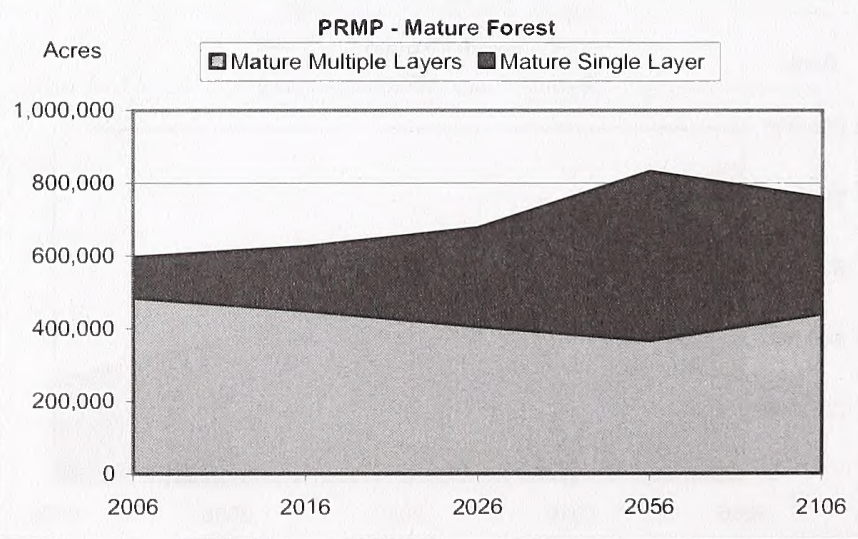


Under all alternatives, the abundance of the structurally complex forests would result from retention of existing structurally complex forests, coupled with future development of additional structurally complex forests. However, the alternatives would vary in both the amount of the existing structurally complex forest that would be retained and the amount of additional structurally complex forest that would develop. Under all alternatives, the additional structurally complex forest that would develop would initially be at the lower end of forest structural conditions meeting the definition of structurally complex forests; this is generally consistent with the implementation pattern of the No Action Alternative for the past decade (Moeur et al. 2005:100).

The No Action Alternative would result in a larger increase in the abundance of the structurally complex forests than any other alternative. Less existing old forest would be harvested under the No Action Alternative than any other alternative, because the No Action Alternative would have the smallest amount of existing old forest in the harvest land base. See Table 4-5 (Outcome of existing old forest by 2106 by alternative) later in this section. The harvest of existing old forest under the No Action Alternative would be offset by development of far more additional structurally complex forest, for a net increase of 624,800 acres. The overall function of the structurally complex forests would improve under the No Action Alternative, because:

- The majority of existing old forest (86\%) would remain unharvested and would continue to develop into older structurally complex forest.

- An even greater percentage (90\%) of the oldest of these forests (existing very old forest, which are stands that are 400 years or older in the current inventory) would remain unharvested and continue to develop.

- Approximately 15 times more acres would develop into new structurally complex forest by 2106 than the acreage of existing old forest that would be harvested by that year.

- The size and connectivity of the mature \& structurally complex forest patches would increase from the current condition in all provinces, except the Eastern Cascades. See text under Forest Structure and Spatial Pattern on the BLM-administered Lands at the Province Scale later in this section.

The abundance of the structurally complex forests would increase more under Alternative 1 than under Alternatives 2 or 3 or the PRMP, but less than under the No Action Alternative. Under Alternative 1, the structurally complex forests that would remain after 100 years would be almost entirely restricted to the nonharvest land base. More existing old forest would be harvested than under the No Action Alternative, but less than under Alternatives 2 or 3 or the PRMP. See Table 4-5 (Outcome of existing old forest by 2106 by alternative). The harvest of 88,800 acres of existing old forest under Alternative 1 would be offset by development of additional structurally complex forest for a net increase of 370,000 acres by 2106 .

The overall function of the structurally complex forests would improve under Alternative 1 (though less so than under the No Action Alternative) because:

- The majority of existing old forest (75\%) would remain unharvested and would continue to develop into older structurally complex forests.

- An even greater percentage (90\%) of the oldest of these forests (existing very old forest, which are the stands that are 400 years or older in the current inventory) would remain unharvested and continue to develop.

- Approximately six times more acres would develop into new structurally complex forest by 2106 than the acreage of existing old forest that would be harvested by that year,

- The size and connectivity of the mature \& structurally complex forest patches would increase from the current condition in the Coast Range Province. Size and connectivity would decrease in other provinces, but less than under Alternatives 2 and 3 and the PRMP. See text under Forest Structure and Spatial Pattern on the BLM-administered Lands at the Province Scale later in this section. 
Under Alternative 2, the abundance of the structurally complex forests would slightly decrease in the first 50 years and eventually increase in abundance in 100 years. As under Alternative 1 , the structurally complex forests remaining after 100 years would be almost entirely restricted to the nonharvest land base. More existing old forest would be harvested under Alternative 2 than under the No Action Alternative, Alternative 1, or the PRMP, but less than under Alternative 3. See Table 4-5 (Outcome of existing old forest by 2106 by alternative). Of the existing old forest, $57 \%$ would be allocated to the nonharvest land base (compared to $83 \%$ under the No Action Alternative, $74 \%$ under Alternative 1, and $52 \%$ under Alternative 3 ). The harvest of 152,400 acres of existing old forest under Alternative 2 would be offset by development of additional structurally complex forest; the abundance of the structurally complex forest would remain almost constant for the first 50 years with an eventual net increase of 210,100 acres by 2106 . The overall function of the structurally complex forests would increase in some aspects under Alternative 2 (though less than under the No Action Alternative, Alternative 1, or the PRMP), and decrease in other aspects because:

- The majority of existing old forest $(57 \%)$ would remain unharvested and would continue to develop into older structurally complex forests.

- A greater percentage (76\%) of the oldest of these forests (existing very old forest, which are the stands that are 400 years or older in the current inventory) would remain unharvested and continue to develop.

- Slightly more acres would develop into new structurally complex forest by 2106 than the acreage of the existing old forest that would be harvested by that year.

- The size of the mature \& structurally complex forest patches would decrease from the current condition in all provinces, and the connectivity of the mature \& structurally complex forests would decrease in all provinces, except the Coast Range Province. See text under Forest Structure and Spatial Pattern on the BLM-administered Lands at the Province Scale later in this section.

A lower acreage of structurally complex forests would occur under Alternative 3 than any other alternative. Under Alternative 3, the amount of the structurally complex forests would decrease slightly over the first 50 years, and then eventually increase slightly from current levels. The harvest of the structurally complex forests (including partial harvest) would be roughly balanced by development of additional structurally complex forest, which would result in a fluctuating total abundance over time. Alternative 3 would harvest more of the existing old forest than any other alternative. See Table 4-5 (Outcome of existing old forest by 2106 by alternative). A larger amount of the existing old forest would be allocated to the harvest land base under Alternative 3 than any other alternative. The harvest of 220,000 acres of existing old forest under Alternative 3 would be offset by development of additional structurally complex forest, but less than under other alternatives with a net increase of 122,000 acres by 2106 . The overall function of the structurally complex forests would decrease from the current condition under Alternative 3, because:

- The majority of existing old forest (63\%) would be harvested within 100 years.

- The majority (68\%) of the oldest of these forests (existing very old forest, which are stands that are 400 years or older in the current inventory) would be harvested within 100 years.

- The total abundance of the structurally complex forest would decline slightly for the first 50 years.

- The size and connectivity of the mature \& structurally complex forest patches would decrease from the current condition in all provinces. See text under Forest Structure and Spatial Pattern on the BLM-administered Lands at the Province Scale later in this section.

The abundance of the structurally complex forests would increase over time under the PRMP. The abundance of existing old forest would remain at current levels in 2016, higher than under any other alternative. More existing old forest would be harvested in 100 years under the PRMP than under the No Action Alternative or Alternative 1, but less than under Alternatives 2 or 3. See Table 4-5 (Outcome of existing old forest by 2106. by alternative). Thirty-five percent of the existing old forest would be allocated to the harvest land base under the PRMP (compared to 17\% under the No Action Alternative, 26\% under Alternative 1, $43 \%$ under Alternative 2, and $48 \%$ under Alternative 3). Under the PRMP, a lower percentage of the existing old forest 
that would be allocated to the harvest land base (79\%) would be harvested after 100 years than under any other alternative. The eventual harvest of 96,200 acres of existing old forest under the PRMP would be offset by development of additional structurally complex forest, for a net increase of 397,900 acres by 2106 . The overall function of the structurally complex forests would improve under the PRMP (though less than under the No Action Alternative) because:

- The majority of existing old forest (73\%) would remain unharvested and would continue to develop into older structurally complex forests.

- A greater percentage ( $86 \%$ ) of the oldest of these forests (existing very old forest, which are the stands that are 400 years or older in the current inventory) would remain unharvested and continue to develop.

- More acres would develop into new structurally complex forest by 2106 than the acreage of the existing old forest that would be harvested by that year.

- The size of the mature \& structurally complex forest patches would increase from the current condition in all provinces, except the West Cascades Province, and the connectivity of the mature \& structurally complex forests would increase in all provinces. See text under Forest Structure and Spatial Pattern on the BLM-administered Lands at the Province Scale later in this section.

In 100 years, the amount of the structurally complex forest on the BLM-administered lands would be approximately equal to the average historic condition under the No Action Alternative, and below the average historic condition under Alternatives 1,2, and 3, and the PRMP.

There is insufficient information to quantify the abundance of hardwood stands. See the Forest Structure and Spatial Pattern section in Chapter 3. Furthermore, there is insufficient information about hardwood stand development, especially red alder stands, to model future stand development and transition to mixed or conifer-dominated stands. Some researchers have hypothesized that riparian red alder stands might develop into shrub-dominated areas (especially salmonberry) where conifer tree regeneration is absent (Deal 2006, Harrington 2006, Hibbs and Bower 2001). Empirical evidence for this successional pathway is generally lacking. Although this successional development is possible for small patches, studies in the Coast Range did not find evidence of this successional development at the landscape scale (Kerns and Ohmann 2004). Red alder stands in the Coast Range would likely continue to decline in abundance because of restrictions or exclusion of timber harvest in riparian areas under all alternatives. Existing red alder stands would eventually develop into mixed or conifer-dominated stands (western hemlock, western red-cedar, and Douglas fir), except near large streams where growing conditions favor red alder (Spies et al. 2007, Kennedy and Spies 2005). Successional development into conifer stands would be accelerated where hardwood conversion actions would be implemented, but the rate of this successional development is unknown. Riparian and upland hardwood stands would persist under all alternatives where:

- natural disturbances maintain hardwoods

- activities to maintain or restore natural plant communities on nonforest and noncommercial forest lands are implemented to maintain hardwoods

- site conditions preclude succession to a conifer forest

As a result, hardwood forest abundance would decline under all alternatives. In addition, none of the alternatives would create additional hardwood stands because of the limited disturbance of the nonharvest land base and the intensive silvicultural practices to reestablish conifers following disturbances in the harvest land base. 
Table 4-5. Outcome Of Existing Old Forest By 2106 By Alternative

\begin{tabular}{|c|c|c|}
\hline & $\begin{array}{l}\text { All Land Use Allocations } \\
\text { Acres Harvested } \\
\text { (\% of Existing Old Forest harvested) }\end{array}$ & $\begin{array}{l}\text { Harvest Land Base Only } \\
\text { (\% of Existing Old Forest harvested) }\end{array}$ \\
\hline \multicolumn{3}{|l|}{ No Action } \\
\hline & 48,700 acres $(14 \%)$ & $(83 \%)$ \\
\hline \multicolumn{3}{|c|}{ Alternative 1} \\
\hline & 88,800 acres $(25 \%)$ & $(96 \%)$ \\
\hline \multicolumn{3}{|c|}{ Alternative 2} \\
\hline & 152,400 acres $(43 \%)$ & $(100 \%)$ \\
\hline \multicolumn{3}{|c|}{ Alternative 3} \\
\hline & 220,000 acres $(63 \%)$ & $(91 \%)$ \\
\hline \multicolumn{3}{|l|}{ PRMP } \\
\hline & 96,200 acres $(27 \%)$ & $(79 \%)$ \\
\hline unharvested & arvested & \\
\hline
\end{tabular}




\title{
Forest Structure and Spatial Pattern on the BLM- Administered Lands by Land Use Allocation
}

\author{
Harvest Land Base
}

In the harvest land base under all alternatives, the abundance of stand establishment forests and mature forests would increase, and the abundance of young forests and structurally complex forests would decrease. The abundance of structurally complex forests would be reduced in the harvest land base to $14 \%$ in 100 years (compared to the current condition of 19\%) under the No Action Alternative and Alternative 3. The abundance of structurally complex forests would be reduced in the harvest land base in 100 years more under the PRMP than under the No Action Alternative and Alternative 3 ( $10 \%$ of the harvest land base in 2106, compared to the current condition of $20 \%){ }^{4}$ The structurally complex forests in the harvest land base would be nearly eliminated under Alternatives 1 and 2 ( $2 \%$ and $1 \%$ in 2106, respectively, compared to the current condition of $19 \%$ ).

The combined abundance of the mature \& structurally complex forests in the harvest land base would stay approximately constant under the No Action Alternative and the PRMP, decrease under Alternatives 1 and 2, and increase under Alternative 3. The analysis of terrestrial habitats in the Northwest Forest Plan FSEIS, on which the current (1995) RMPs of the No Action Alternative relied, analyzed the abundance and connectivity of late-successional and old-growth forests (which approximates mature \& structurally complex forests in this analysis) based on the abundance and future development of forests in the nonharvest land base (USDA USFS/USDI BLM 1994b: 3\&4:39-43, 3\&4:238-241). That previous analysis did not account for the retention or development of late-successional and old-growth forests in the harvest land base. Nevertheless, the analysis if this EIS reveals that the mature \& structurally complex forest together would continue to constitute approximately half of the acres (289,000 acres) within the harvest land base over the next 100 years under the No Action Alternative. See Figure 4-7 (Structural stage abundances on the forested lands in the harvest land base by alternative).

A larger increase in the stand establishment forests and a larger decrease in the structurally complex forests in the harvest land base would occur under Alternatives 1 and 2 than under the No Action Alternative because of:

- higher regeneration harvest rate in the harvest land base than under the No Action Alternative. Alternatives 1 and 2 do not have any of the standards and guidelines of the No Action Alternative that would constrain the harvesting of the structurally complex forests in the harvest land base.

- absence of green tree retention, which would slow development of the structurally complex forests after harvesting. Alternatives 1 and 2 do not have management direction that would require green tree retention in regeneration harvest units. Without green tree retention in regeneration harvest units, stands would take approximately twice as long (e.g., 150 years instead of 80 years on the most common stand conditions on productive sites) to develop into structurally complex forest after regeneration harvesting.

These two factors would interact to decrease the abundance of the structurally complex forest in the harvest land base. The higher regeneration harvest rate combined with the slower development into structurally complex forests would increase the likelihood that a stand would be harvested before it would have time to develop into structurally complex forest. As a result, structurally complex forest would be almost eliminated from the harvest land base by 2106 , even though the total acreage of the structurally complex forests across all land use allocations would increase under Alternatives 1 and 2.

The harvest land base under Alternative 3 would have the most stand establishment forest, the least young forest, and the most mature forest of any alternative. The abundance of structurally complex forest would be

${ }^{4}$ The area allocated to the harvest land base would differ among the alternatives. Therefore, the percentage of the harvest land base currently in structurally complex forest differs slightly among the alternatives. 
maintained in the harvest land base under Alternative 3 similar to the No Action Alternative, even though under Alternative 3 the most existing old forest would be harvested of any alternative.

Under the PRMP, stand establishment forest would increase, and structurally complex forest would decrease in the harvest land base as a whole. The different allocations within the harvest land base would result in different patterns. In the Timber Management Area, under the PRMP an increase in the stand establishment forests and decrease in the structurally complex forests would occur, similar to under Alternatives 1 and 2. In the Uneven-Aged Management Area under the PRMP, a decrease in stand establishment forest and an increase in mature forest and structurally complex forest would occur. See Figure 4-8 (Structural stage abundances in the harvest land base by land use allocation in the PRMP).

Figure 4-7. Structural Stage Abundances On The Forested Lands In The Harvest Land Base By Alternative

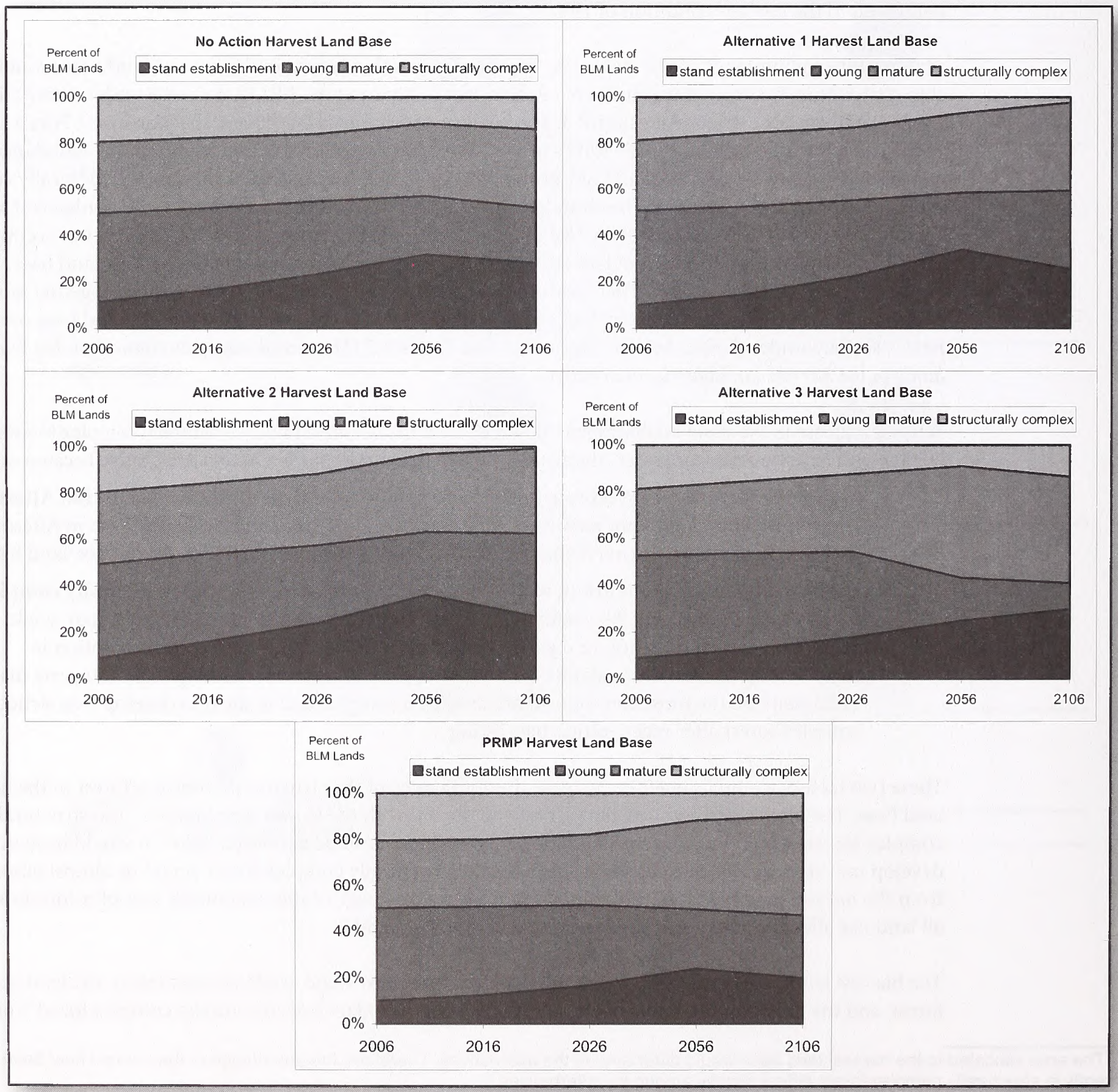


Figure 4-8. Structural Stage Abundances In The Harvest land Base By Land Use Allocation In THE PRMP

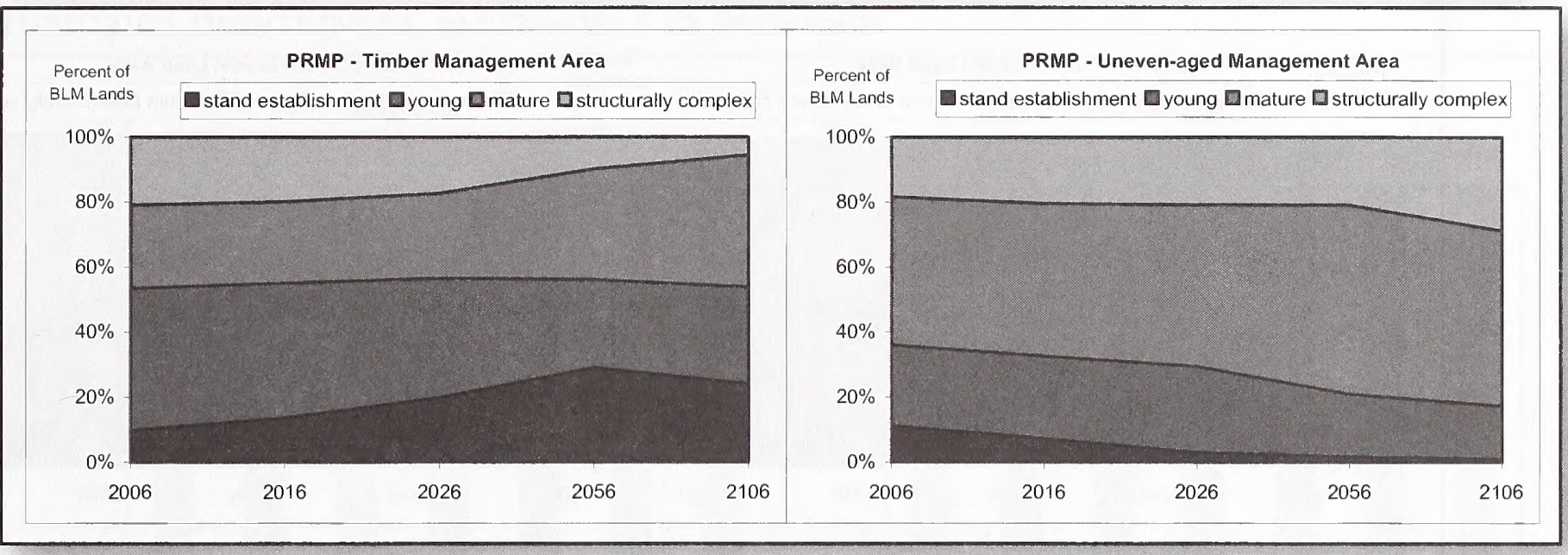

This analysis does not include estimates of future natural disturbances, but most natural disturbances in the harvest land base would have little effect on the abundance of the structural stages described here. Except in the most severe and extensive disturbances, salvage of naturally disturbed stands would result in the same eventual effect on the overall structural stage abundances in the harvest land base as scheduled timber harvesting under all alternatives.

\section{Nonharvest Land Base}

The structural stage development within the nonharvest land base would be similar under all alternatives, although the total acreage in the nonharvest land base would vary. The forest-capable portion of the nonharvest land base would become almost completely dominated by mature and structurally complex forest in 100 years. See Figure 4-9 (Structural stage abundances on the forested lands in the nonharvest land base by alternative).

This analysis does not include estimates of future natural disturbances, but natural disturbances would increase the amount of stand establishment and young forests from the abundances described here. The Northwest Forest Plan FSEIS assumed that $2.5 \%$ of the late-successional forests in the late-successional reserves would be lost to wildfire each decade (NWFP FSEIS, 3\&4:42). The actual rate of disturbance over the past decade has been lower on the BLM-administered lands. See text earlier in this chapter in the Introduction section, Incomplete or Unavailable Information - Salvage After Natural Disturbance.

\section{Forest Structure and Spatial Pattern on the BLM- Administered Lands at the Province Scale}

The effects of the alternatives on the structural stage abundances and spatial patterns in the Coast Range, West Cascades, and Klamath Provinces generally reflect the structural stage abundances and spatial patterns described for the planning area as a whole. The effects of the alternatives in the Eastern Cascades Province differ from the other provinces in many measures of the structural stage abundance and spatial pattern, in part because of the differing ecological conditions and management history. However, these different patterns have little effect on the overall pattern for the planning area, because the Eastern Cascades Province makes up only $2 \%$ of the BLM-administered forest lands modeled within the planning area.

See Figure 4-10, Figure 4-11, and Figure 4-12 on the next several pages. 
Figure 4-9. Structural Stage Abundances On The Forested Lands In The Nonharvest Land Base By Alternative

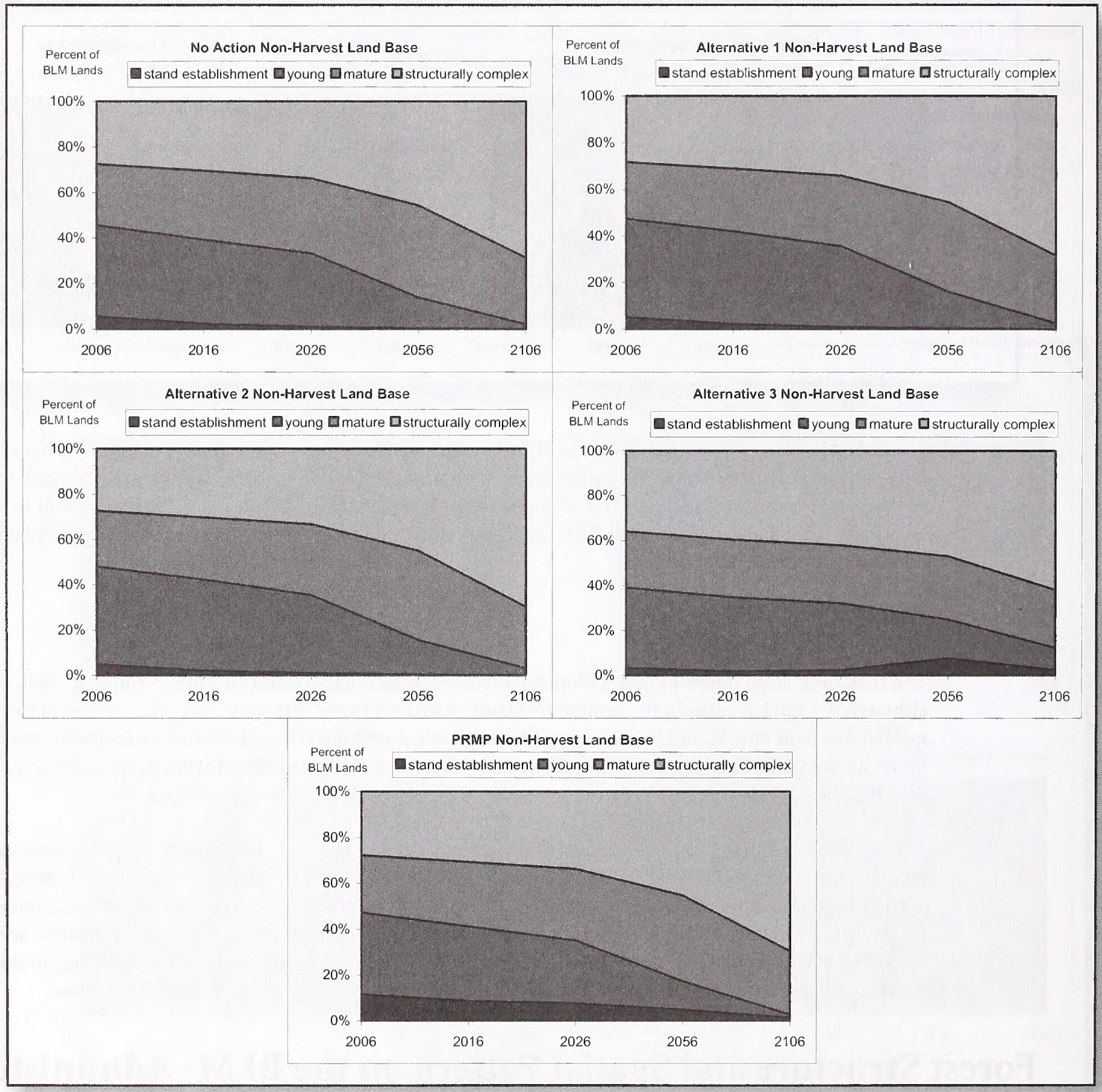


Figure 4-10. Comparison Of The Structural Stage Abundances On The BlmAdministered Forested Lands By 2106 With The Current Conditions And The Average Historic Conditions By Alternative By Province

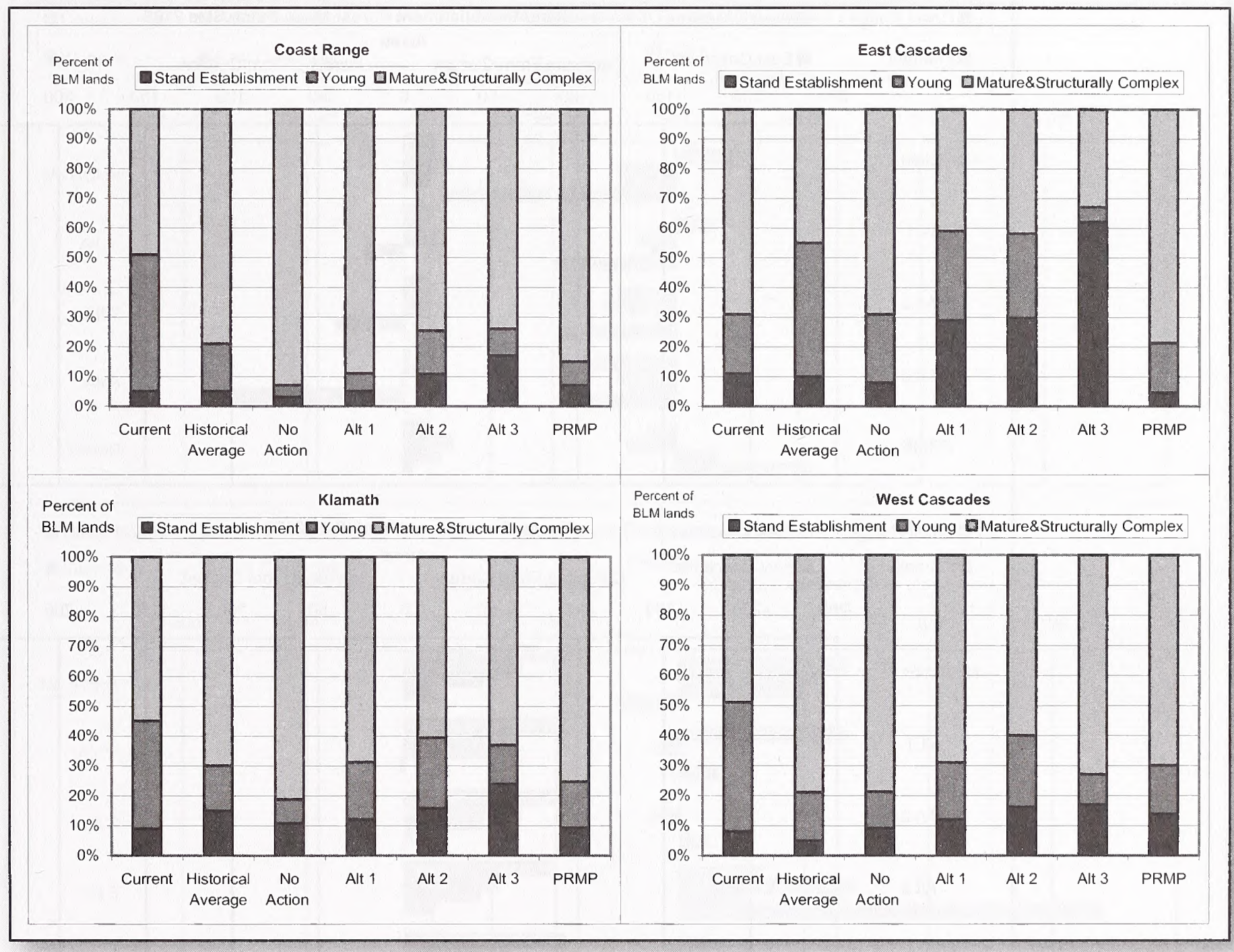


Figure 4-11. Change In The Mean Patch Size From The Current Condition By 2106 By Forest Structural Stage On The BLM-Administered Lands

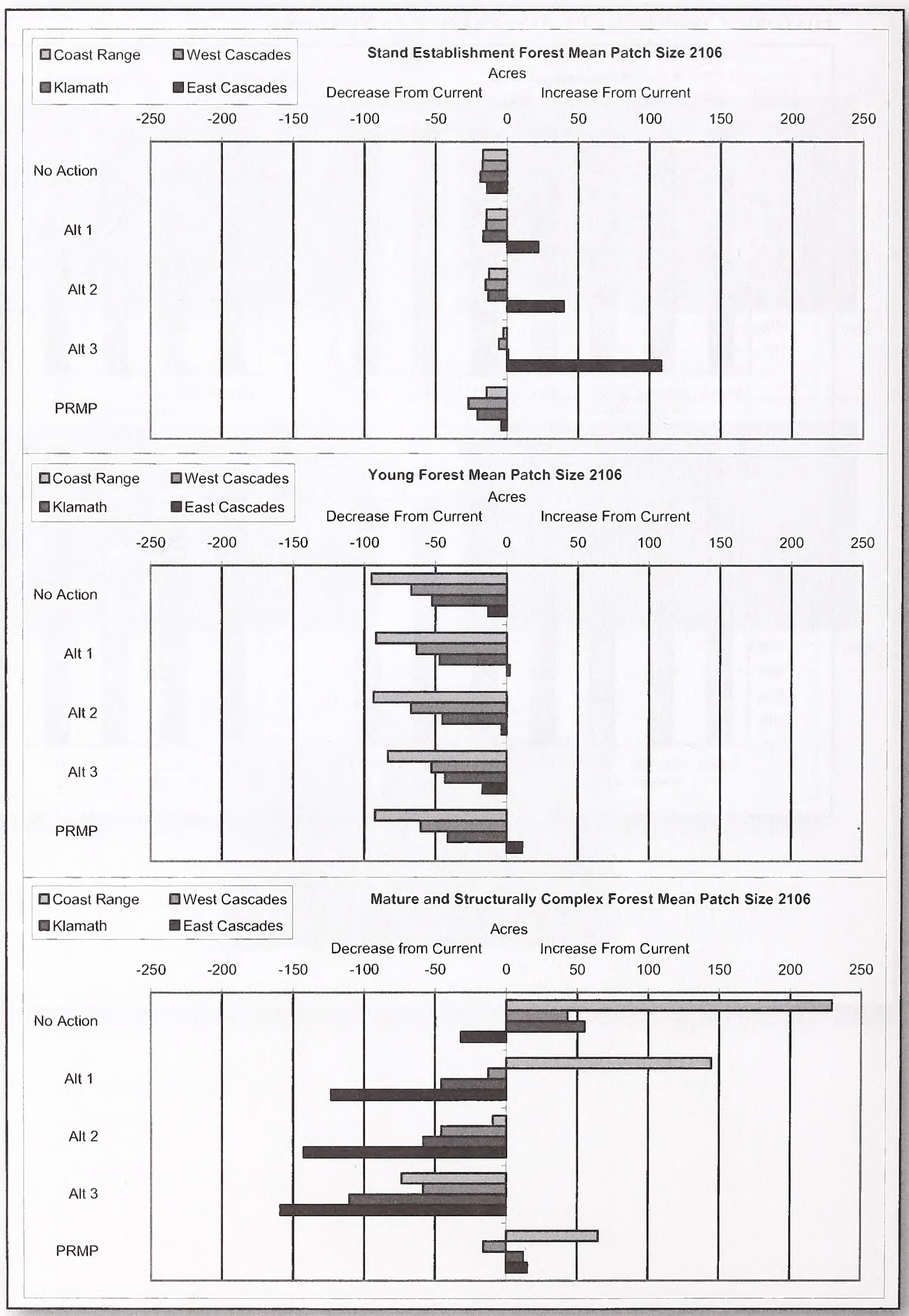


Figure 4-12. Change In The Connectivity From The Current Condition By 2106 By Forest Structure Stage On The BlM-Administered Lands.

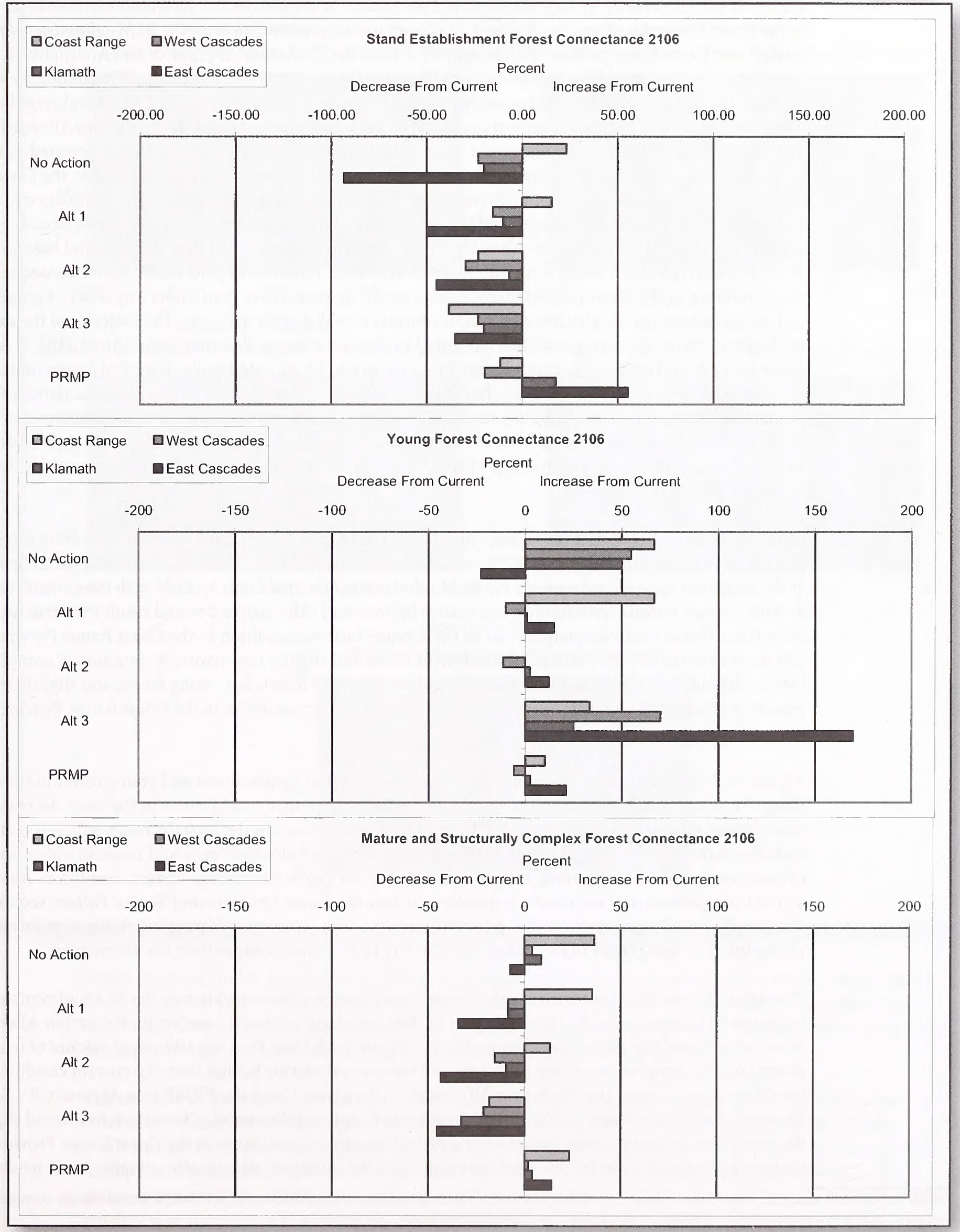




\section{Coast Range Province}

Under all alternatives, the young forests would decrease and the mature forests would increase in abundance in the Coast Range Province. See Figure 4-13 (Structural stage abundances on the BLM-administered forested lands in the Coast Range province by alternative). Under the No Action Alternative and Alternative 1, the abundance of stand establishment forests would remain approximately constant and the abundance of structurally complex forests would steadily increase to become the most abundant structural stage because of the predominance of the nonharvest land base in the Coast Range. Under the No Action Alternative and Alternative 1, very little of the existing old forest (less than $10 \%$ in 100 years) would be harvested in the Coast Range Province. Under Alternative 2, a larger harvest land base would be allocated in the Coast Range Province than under the No Action Alternative or Alternative 1, and consequently the abundance of stand establishment forests would increase and the abundance of the structurally complex forests would remain approximately constant for the first 50 years under Alternative 2. An even larger harvest land base would be allocated in the Coast Range Province under Alternative 3 than under Alternative 2, and consequently the abundance of the stand establishment forests would increase more than under any other alternative, and the abundance of the structurally complex forests would slightly decrease. The majority of the existing old forest (69\% in 100 years) would be harvested in the Coast Range Province under Alternative 3. A larger harvest land base in the Coast Range Province would be allocated under the PRMP than under the No Action Alternative or Alternative 1, but smaller than under Alternatives 2 or 3 . The abundance of the stand establishment forests would increase under the PRMP, but less so than under Alternatives 2 or 3 . The abundance of the structurally complex forests would increase under the PRMP, but less so than under No Action or Alternative 1. Approximately $11 \%$ of the existing old forest in the Coast Range would be harvested under the PRMP in 100 years.

In 100 years, the No Action Alternative, Alternative 1, and the PRMP would result in less young forest and more mature \& structurally complex forest than the average historic condition. ${ }^{5}$ See Figure 4-10 (Comparison of the structural stage abundances on the BLM-administered forested lands by 2106 with the current conditions and the average historic conditions by alternative by province). Alternative 2 would result in a structural stage abundance that is approximately similar to the average historic condition in the Coast Range Province in 100 years with slightly more stand establishment forest and slightly less mature \& structurally complex forest. Alternative 3 would result in more stand establishment forest, less young forest, and slightly less mature \& structurally complex forest than the average historic condition in the Coast Range Province in 100 years.

All alternatives would result in smaller patches of stand establishment forest and young forest in the Coast Range Province as shown in Figure 4-11. The No Action Alternative would result in the most decrease in the size of stand establishment patches, and Alternative 3 would result in the least decrease, which is consistent with the changes in the overall structural stage abundances. All alternatives would result in mean patch size of stand establishment and young forests that would be far below the average historic condition. Although a direct comparison of these results is problematic (see the Forest Structure and Spatial Pattern section in Chapter 3), Nonaka and Spies (2005) reported historic mean patch sizes of stand establishment forest and young forest ranging from 183 to 264 acres, which is 10 to 20 times larger than the alternatives.

The size and connectivity of the mature \& structurally complex forest patches on the BLM-administered lands would increase over the next 100 years in the Coast Range Province under the No Action Alternative, Alternative 1, and the PRMP. See Figure 4-11 and Figure 4-12. Over the next 100 years, patches of mature \& structurally complex forest that are larger and have more interior habitat than the current condition would be created under the No Action Alternative, Alternative 1, and the PRMP (see Appendix B - Forest Structure and Spatial Pattern). The size of the mature \& structurally complex forest patches would slightly decrease, and the connectivity would increase from the current condition in the Coast Range Province under Alternative 2. Both the size and connectivity of the mature \& structurally complex forest patches

${ }_{5}$ Note that for this analysis, the mature and structurally complex forests are combined (and referred to as mature \& structurally complex forest) because of the limitations in the description of the average historic conditions 
Figure 4-13. Structural Stage Abundances On The BlM-Administered Forested Lands In The Coast Range Province By Alternative

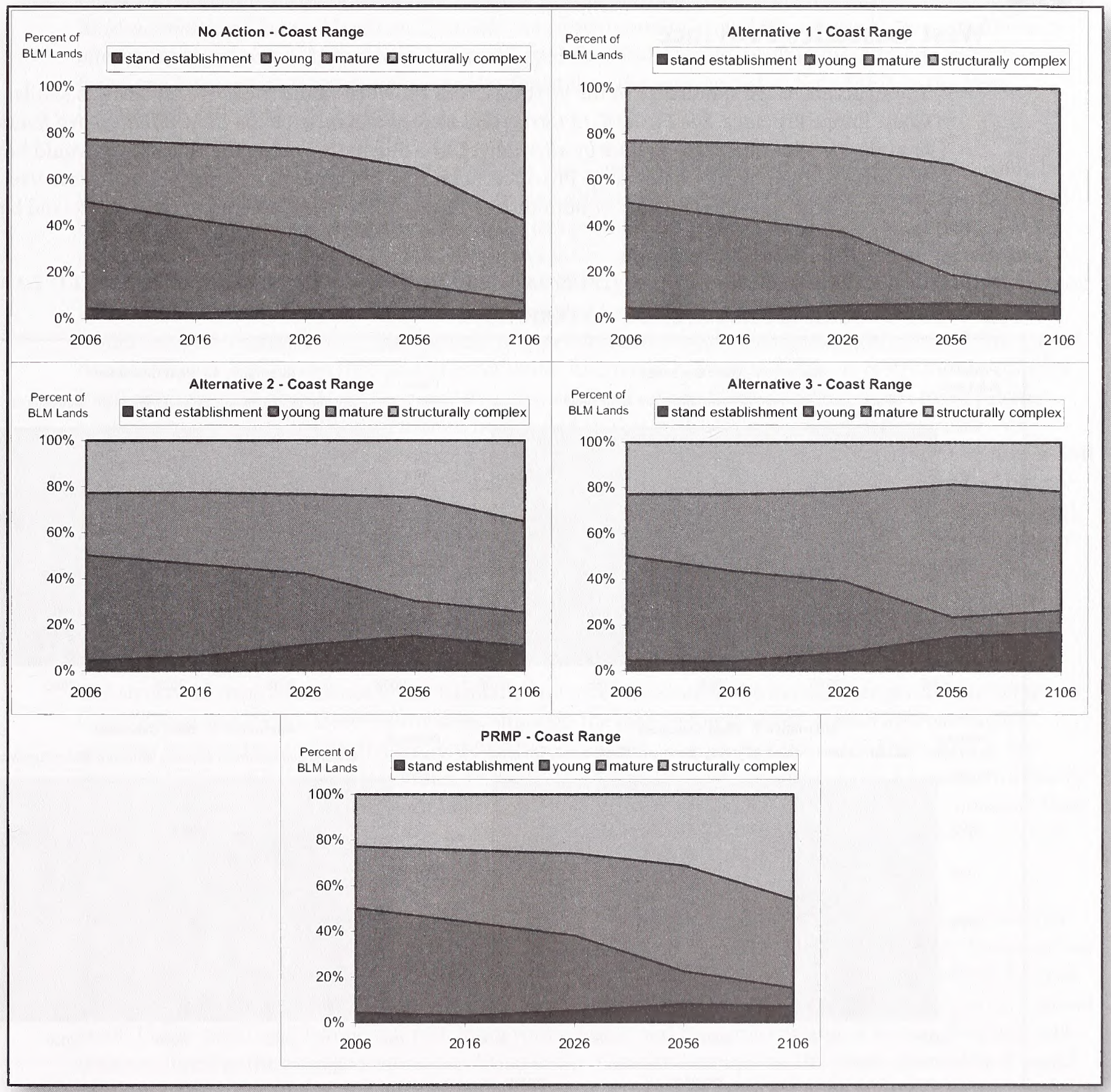

would decrease under Alternative 3. The spatial pattern of the mature \& structurally complex forest would move further away from the historic conditions under Alternative 3, which is consistent with the research concluding that the restoration of historic wildfire would move the Coast Range Province further away from the historic range of variability over the next 100 years (Nonaka and Spies 2005).

The increase in the mean patch size for the mature \& structurally complex forests under the No Action Alternative, Alternative 1, and the PRMP would be comparable to the estimates of the average historic mature forest patch size (Nonaka and Spies 2005). In their modeling of the average historic spatial patterns in the Coast Range Province, Nonaka and Spies reported the mean patch size of the mature forests as 272 acres, compared to a current mean patch size of 84 acres across all ownerships. From this analysis, the mean patch size of the mature \& structurally complex forest on the BLM-administered lands in the Coast Range 
Province is currently 110.8 acres and would increase to 340.2 acres under the No Action Alternative; 255.1 acres under Alternative 1; and 176.4 acres under the PRMP.

\section{West Cascades Province}

The structural stage abundance in the West Cascades Province would show overall changes similar to the Coast Range Province. See Figure 4-14 (Structural stage abundances on the BLM-administered forested lands in the West Cascades Province by alternative). The difference among the alternatives would be less pronounced than in the Coast Range Province, because the No Action Alternative and Alternative 1 would allocate a larger portion of the BLM-administered lands in the West Cascades to the harvest land base than in the Coast Range Province.

Figure 4-14. Structural Stage Abundances On BLM-Administered Forested Lands In The West Cascades Province By Alternative

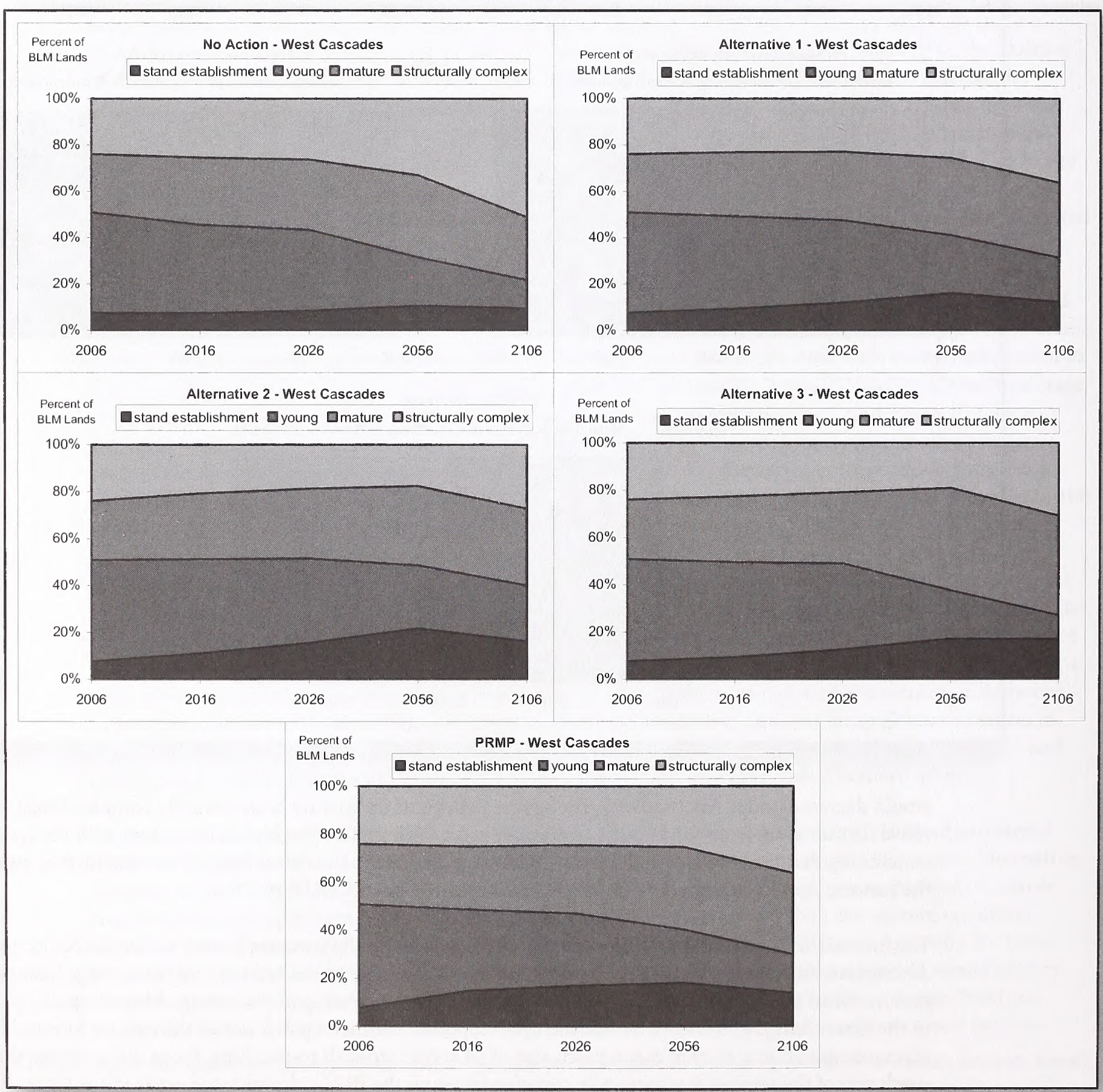


In 100 years, the No Action Alternative would result in a structural stage abundance that is approximately similar to the average historic condition in the West Cascades with slightly more stand establishment forest and slightly less young forest. See Figure 4-10 (Comparison of the structural stage abundances on the BLM-administered forested lands by 2106 with the current conditions and the average historic conditions by alternative by province). Alternatives 1,2, and 3, and the PRMP would result in more stand establishment forest and less mature \& structurally complex forest than the average historic condition in the West Cascades in 100 years.

Most of the changes in the spatial patterns in the West Cascades Province under the alternatives would be similar to the changes in the Coast Range Province, although the changes from the current condition and the differences among the alternatives would be less pronounced for all measures of spatial pattern. (See Figures 4-11 and 4-12). The No Action Alternative is the only alternative under which both the size and connectivity of the mature \& structurally complex forest patches would increase from the current condition in the West Cascades Province. The size and connectivity of mature \& structurally complex forest patches would decrease slightly under Alternative 1. A larger decrease would occur under Alternative 2. The largest decrease in size and connectivity would occur under Alternative 3 . The size of mature \& structurally complex forest patches would slightly decrease, and the connectivity of mature \& structurally complex forest patches would increase under the PRMP. There are no detailed studies of the historic spatial pattern in the West Cascades Province comparable to those in the Coast Range Province. However, studies of fire frequency and extent have suggested that the historic spatial pattern would have been larger and more connected mature \& structurally complex forest patches than the current condition (Weisberg and Swanson 2003, Cissel et al. 1999). Therefore, the spatial pattern of the mature \& structurally complex forest would move further away from the historic conditions in the West Cascades Province under Alternatives 1, 2, 3, and the PRMP.

\section{Klamath Province}

The structural stage abundance in the Klamath Province would show the overall changes similar to the Coast Range and West Cascades Provinces, although the mature forest would remain approximately constant in abundance under the No Action Alternative and decrease slightly under Alternative 3. See Figure 4-15 (Structural stage abundances on the BLM-administered forested lands in the Klamath Province by alternative). The difference among the alternatives in the Klamath Province would be less pronounced than in the Coast Range Province, because the No Action Alternative and Alternative 1 would allocate a larger portion of the Klamath Province to the harvest land base than in the Coast Range Province.

In 100 years, the No Action Alternative and the PRMP would result in less stand establishment forest and more mature \& structurally complex forest than the average historic condition in the Klamath Province. See Figure 4-10 (Comparison of the structural stage abundances on the BLM-administered forested lands by 2106 with the current conditions and the average historic conditions by alternative by province). Alternative 1 would result in less stand establishment forest, more young forest, and the same amount of mature \& structurally complex forest as the average historic condition in the Klamath Province in 100 years. Alternative 2 would result in more young forest and less mature \& structurally complex forest than the average historic condition in the Klamath Province in 100 years. Alternative 3 would result in more stand establishment forest and less mature \& structurally complex forest than the average historic condition in the Klamath Province in 100 years.

This analysis does not include the estimates of future natural disturbances, but natural disturbances would be more likely to alter the structural stage abundances in the nonharvest land base in the Klamath Province than in the Coast Range or West Cascades Provinces. The predominant high fire frequency regime and the effects of past fire suppression increase the likelihood that wildfires would increase the amount of stand establishment and young forests in the nonharvest land base from the abundances described here. However, as discussed under this chapter's Introduction, it is not possible to accurately predict the acreage, location, timing, severity, and extent of such disturbances. 
Figure 4-15. Structural Stage Abundances On The BlM-Administered Forested Lands In The Klamath Province By Alternative

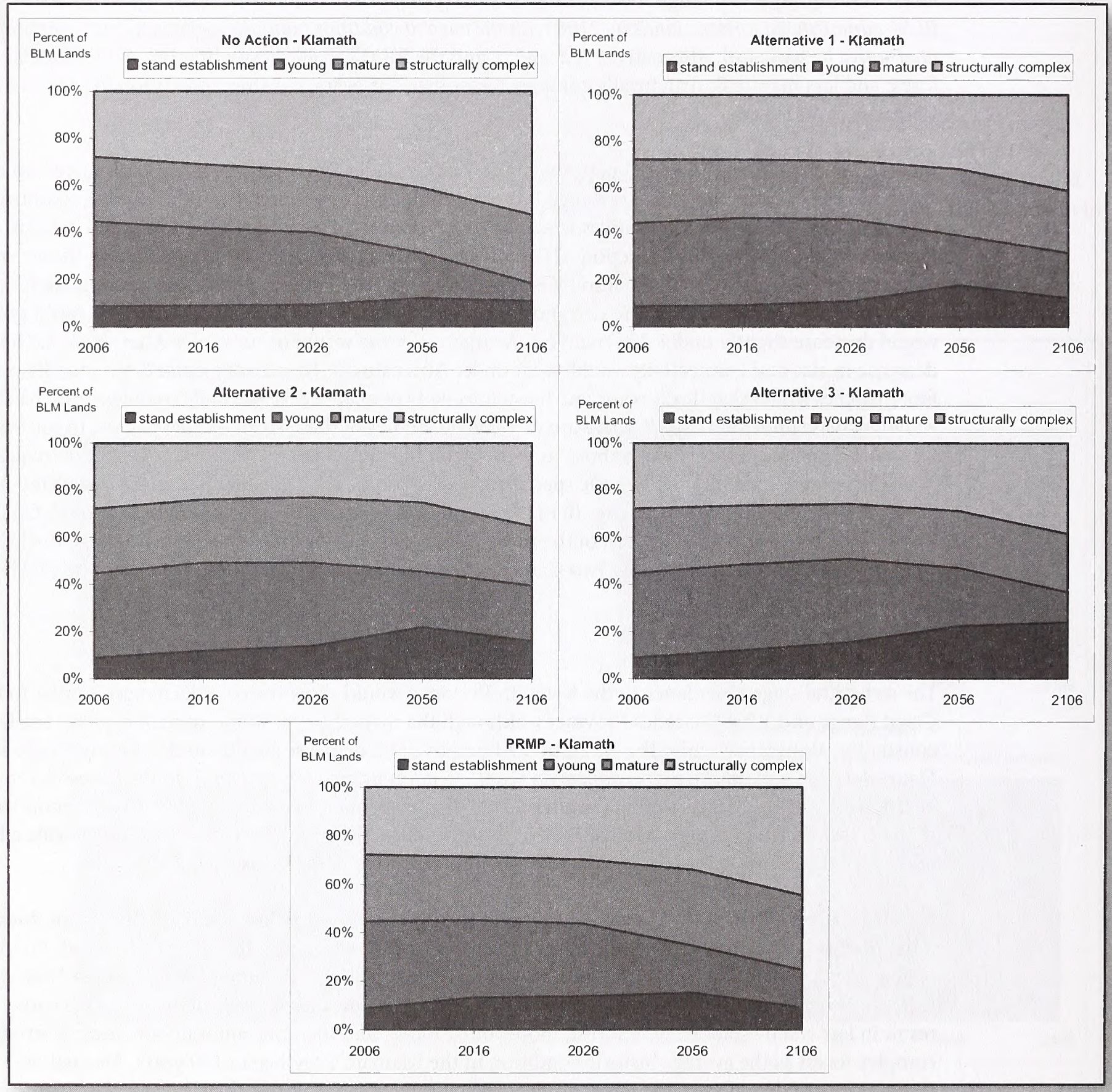

The size and connectivity of stand establishment forest patches would decrease under the No Action Alternative, Alternatives 1 and 2, and the PRMP. See Figure 4-11 (Change in the mean patch size from the current condition by 2106 by forest structural stage on the BLM-administered lands). Although there would be little change in the patch size under Alternative 3, the connectivity of stand establishment forest patches would decrease. Under the PRMP, the patch size would decrease but the connectivity of stand establishment forest patches would increase. The size of young forest patches would decrease under all alternatives. As in the West Cascades Province, the size and connectivity of the mature \& structurally complex forest patches would decrease compared to the current condition under Alternatives 1,2, and 3. Alternative 1 would result in the least decrease, and Alternative 3 would result in the most decrease. See Figures 4-10 and 4-11. The size and connectivity of mature \& structurally complex forest patches would increase under the PRMP. There are no 
detailed studies of the historic spatial pattern in the Klamath Province to compare these results. The historic spatial pattern was likely more variable than in the Coast Range or West Cascades Provinces, because of the complex interaction of highly variable geology and climate with the highly variable disturbance regimes (Frost and Sweeney 2000, Taylor and Skinner 2003).

\section{Eastern Cascades Province}

The structural stage abundances in the Eastern Cascades Province would differ from the other provinces and would differ strongly among the alternatives. See Figure 4-16 (Structural stage abundances on the BLMadministered forested lands in the Eastern Cascades Province by alternative).

\section{Figure 4-16. Structural Stage Abundances On The BLM-Administered Forested Lands} In The Eastern Cascades Province By Alternative

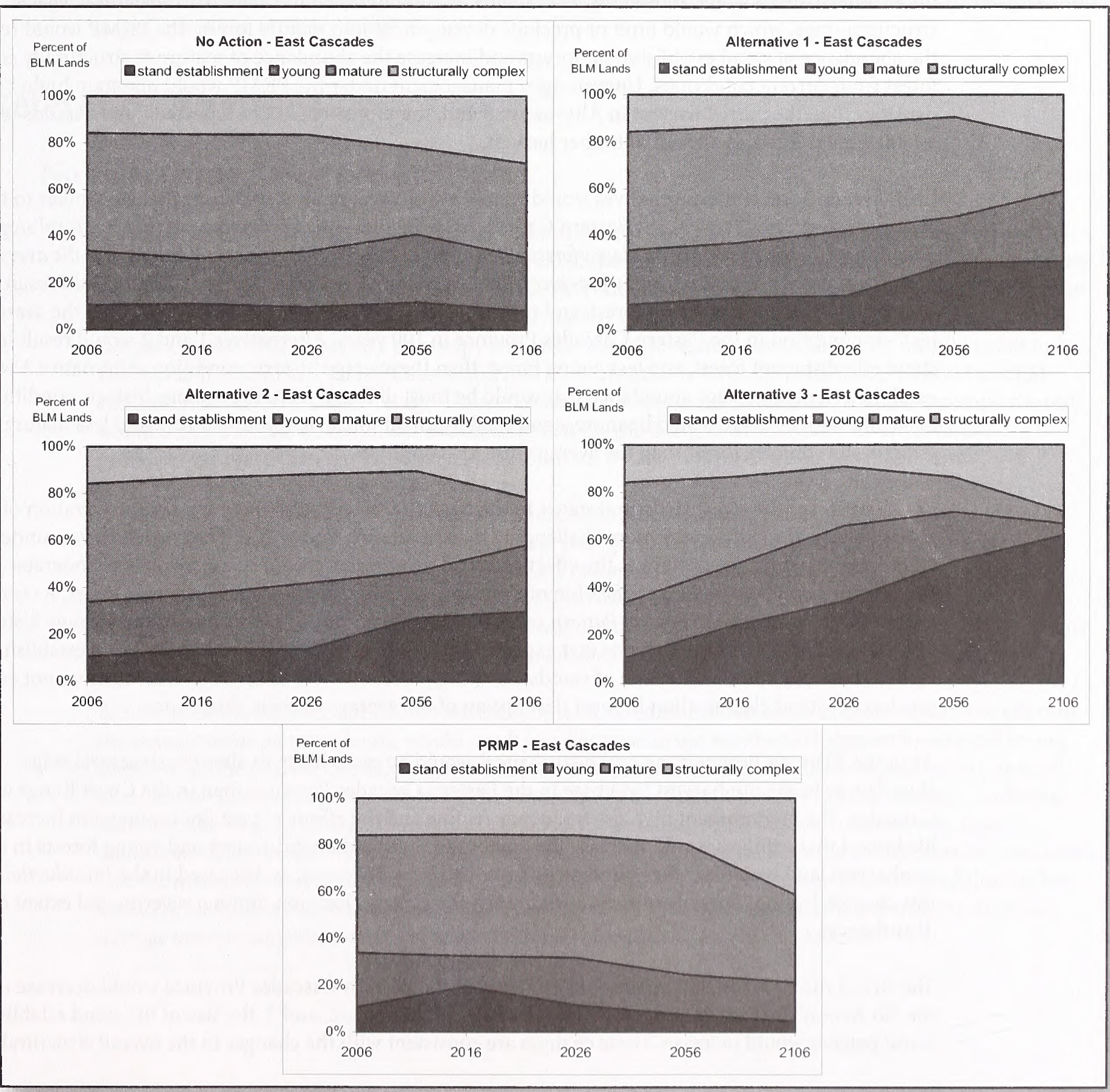


Under the No Action Alternative, the structural stage abundances in the Eastern Cascades Province would fluctuate, but remain approximately constant. The patterns in the Eastern Cascades Province would differ from the other provinces under the No Action Alternative because of the absence of the late-successional reserves and the small acreage of the riparian reserves in the Eastern Cascades Province. Overall, $69 \%$ of the BLM-administered forested acres in the Eastern Cascades Province would be in the harvest land base compared to the planning area average of $26 \%$. Similar acreage amounts would be allocated to the harvest land base under Alternatives 1 and 2, and consequently similar structural stage abundance would result under these alternatives: the abundance of stand establishment forests would increase, and the abundance of mature forests would decrease over the next 100 years.

The structural stage abundance under Alternative 3 in the Eastern Cascades would be a different pattern than the other alternatives, and different than Alternative 3 in the other provinces. The abundance of stand establishment forests would increase to become the most abundant structural stage, and the abundance of young forests and mature forests would decrease. The partial harvests in the Eastern Cascades Province under Alternative 3 would repeatedly reset stands to the stand establishment with structural legacies forest structural stage, which would limit or preclude development into mature forest. The PRMP would reduce the abundance of stand establishment forests and increase the abundance of mature \& structurally complex forest from current conditions. Uneven-aged management under the PRMP would maintain higher stand densities than the partial harvest in Alternative 3 and, therefore, would not repeatedly reset stands to stand establishment forest as a result of timber harvest.

In 100 years, none of the alternatives would result in structural stage abundances that are similar to the average historic condition in the Eastern Cascades. See Figure 4-10 (Comparison of the structural stage abundances on the BLM-administered forested lands by 2106 with the current conditions and the average historic conditions by alternative by province). The No Action Alternative and the PRMP would result in less stand establishment and young forest, and more mature \& structurally complex forest, than the average historic condition in the Eastern Cascades Province in 100 years. Alternatives 1 and 2 would result in more stand establishment forest, and less young forest, than the average historic condition. Alternative 3 would result in a structural stage abundance that would be most different from the average historic condition of all alternatives; there would be more stand establishment forest, less young forest, and less mature \& structurally complex forest than the average historic condition.

Classification of the forest structural stages in the Eastern Cascades Province and characterization of the average historic condition are more challenging than in any other province. The partial harvest under Alternative 3, which would mimic the effect on stand density that would occur following moderate- or lowseverity fire, would result in classification of the harvested stand as stand establishment forest. As noted in the Forest Structure and Spatial Pattern section of Chapter 3, most descriptions of the average historic abundance do not classify all stands that experience moderate- or low-severity fire as stand establishment forest. Therefore, the classification of stands following partial harvest under Alternative 3 does not equate precisely to stand classification in most description of the average historic abundance.

As in the Klamath Province, natural disturbances would be more likely to alter the structural stage abundances in the nonharvest land base in the Eastern Cascades Province than in the Coast Range or West Cascades. The predominant high fire frequency regime and the effects of past fire suppression increase the likelihood that wildfires would increase the amount of the stand establishment and young forests in the nonharvest land base from the abundances described here. However, as discussed in the Introduction to this chapter, it is not possible to accurately predict the acreage, location, timing, severity, and extent of such disturbances.

The size of the stand establishment forest patches in the Eastern Cascades Province would decrease under the No Action Alternative and the PRMP. Under Alternatives 1,2, and 3, the size of the stand establishment forest patches would increase. These changes are consistent with the changes in the overall structural stage 
abundance. See Figure 4-11 (Change in the mean patch size from the current condition by 2106 by forest structural stage on the BLM-administered lands).

All alternatives would result in only slight changes in the size of young forest patches compared to the current condition. The size of young forest patches would slightly decrease under the No Action Alternative and Alternatives 2 and 3, and would slightly increase under Alternative 1 and the PRMP.

The size and connectivity of the mature \& structurally complex forest patches would decrease in the Eastern Cascades Province under the No Action Alternative, and Alternatives 1, 2 and 3. See Figures 4-11 and 4-12. The No Action Alternative would result in the least decrease, and Alternative 3 would result in the most decrease of all the alternatives. Only under the PRMP would there be an increase in the size and connectivity of the mature \& structurally complex forest patches in the Eastern Cascades Province. There are no studies of historic spatial pattern to compare to these results. However, the historic spatial pattern in the Eastern Cascades likely differed from other provinces within the planning area because of the prevalence of a lowseverity/high-frequency fire regime that would have produced a fine-grained mosaic of the forest structural stages (Frost and Sweeney 2000).

\section{Reference Analyses}

\section{No Harvesting Reference Analysis}

Without any timber harvesting on the BLM-administered lands, the stand establishment forests would completely disappear and the young forests would almost completely disappear from the BLM-administered lands by 2106. See Figure 4-2 (Comparison of the BLM-administered forested lands by 2106 with the average historic conditions and current conditions by alternative) early in this section. The mature and structurally complex forests would increase to occupy almost all the BLM-administered lands. This would result in less stand establishment and young forests, and more mature and structurally complex forests on the BLMadministered lands than the average historic condition. Because the mature \& structurally complex forests would occupy almost all the BLM- administered lands, the size and connectivity would increase in all provinces far more than any alternative. See Appendix B - Forest Structure and Spatial Pattern.

This analysis does not include the estimates of future natural disturbances, but natural disturbances would increase the amount of the stand establishment and young forests from the abundances described here. The Northwest Forest Plan FSEIS assumed that $2.5 \%$ of the late-successional forests in the late-successional reserves would be lost to wildfires each decade (USDA USFS and USDI BLM 1994b, 3\&4:42). The actual rate of disturbance over the past decade has been lower on the BLM-administered lands (see text earlier in this chapter under Introduction - Incomplete or Unavailable Information - Salvage After Natural Disturbance).

Across all ownerships, no timber harvesting on the BLM-administered lands, combined with the effect of the management on other lands, would result in a decrease in the stand establishment forests and young forests from the current condition and an increase in the mature \& structurally complex forests, as in all alternatives. These changes would move the landscape in the direction of the historic average conditions. However, the structural stage abundances across all ownerships would not reach the average historic conditions in 100 years. The stand establishment forests would remain above the average historic condition, and the mature \& structurally complex forests would remain below the average historic condition as they would in all four alternatives and the PRMP. See Figure 4-17 (Comparison of all ownerships by 2106 with average historic conditions and current conditions by alternative) later in this section. 


\section{Intensive Management on Most Commercial Timber Lands Reference Analysis}

This reference analysis would result in more stand establishment forests, more young forests, and less structurally complex forests than any alternative. The structurally complex forests would be restricted almost entirely to the nonharvest land base, which would comprise $18 \%$ of the BLM-administered lands (compared to $40 \%$ under Alternative 3, which is the lowest of the alternatives). Although the mature forests would continue to comprise $33 \%$ of the BLM-administered lands, the majority $(80 \%)$ would be mature with single canopy forests (far higher than any other alternative). See Figure 4-6 (Mature forest with multi-layered canopies or single canopies by alternative) earlier in this section. This reference analysis would result in more stand establishment forests, more young forests, more mature forests, and less structurally complex forests than the average historic condition.

\section{Forest Structure and Spatial Pattern across All Ownerships}

The structural stages for all lands other than the BLM-administered lands were classified using Interagency Vegetation Mapping Project (IVMP) data (see text under Forest Structure and Spatial Pattern in Chapter 3). The IVMP data, however, only describes the current conditions. The BLM-administered lands are classified for both the current and future conditions based on modeling outputs rather than IVMP data. The modeling outputs provide the only available data on the future conditions under the different alternatives. It is not possible to conduct comparable modeling of future conditions on lands other than the BLM-administered lands. Therefore, the analysis relies on broad assumptions about the future conditions on other lands.

The analysis assumes that all forest-capable lands in the U.S. Forest Service late-successional reserves, administratively withdrawn, and congressionally reserved lands would develop through the structural stages by the following progression:

- In 2016, all stand establishment forests would become young forests.

- In 2056, all young forests that were young forests in 2006 would become mature \& structurally complex forests.

- In 2106, all young forests that were stand establishment forests in 2006 would become mature \& structurally complex forests.

The analysis assumes that all other lands would maintain their current abundances and spatial patterns. Although these assumptions are acknowledged to be broad and general in scope, it is not possible and would be inherently speculative to make more precise assumptions. The assumption about the U.S. Forest Service reserves does not account for natural disturbances (similar to the modeling of the BLM-administered lands) or the slow structural development on poor sites. The assumption on other lands overestimates harvesting on the U.S. Forest Service harvest base lands, because it does not account for riparian reserves. The prediction of specific harvesting practices on state lands and private lands would be complex and largely speculative (Spies et al. 2007, Kennedy and Spies 2005, Nonaka and Spies 2005). Nevertheless, the broad assumptions allow the analysis to provide context sufficient for making a reasonable evaluation of the relative effect of the different BLM management actions on the structural stage abundances and spatial patterns across all ownerships.

The value of the analysis across all ownerships is in the relative results that compare the future conditions under the different alternatives. Absolute results from the abundance and spatial analysis should be interpreted with great caution. Measurements of spatial patterns are strongly influenced by:

- definition of the elements of the analysis (e.g., the landscape boundaries)

- scale of the spatial analysis 
- definition of patch types

- basis for delineating patches

In addition, this analysis integrates two different data sources to construct the landscape: modeling outputs for the BLM-administered lands, and Interagency Vegetation Mapping Project data for all other lands. These two data sources use slightly different parameters to define structural stages and are measured at different scales; these differences influence the spatial pattern results. Therefore, these abundance and spatial pattern results should not be compared directly to results from other studies, but should only be used to describe relative effects of different alternatives.

All alternatives, combined with the effect of the management on other lands consistent with the assumptions described above, would contribute to a decrease in stand establishment forests and young forests from the current condition and an increase in the mature \& structurally complex forests. These changes would move the landscape in the direction of the historic average conditions. However, the structural stage abundance across all ownerships would not reach average historic conditions in 100 years under any alternative. The stand establishment forests would remain above the average historic condition, and the mature \& structurally complex forests would remain below the average historic condition in all alternatives. See Figure 4-17 (Comparison of all ownerships by 2106 with average historic conditions and current conditions by alternative). This conclusion is consistent with the research on the Coast Range landscape conditions that modeled alternative future management scenarios on all ownerships, rather than broad assumptions described above (Nonaka and Spies 2005). Modeling alternative future management scenarios on all ownerships across the planning area similar to the research in Nonaka and Spies (2005) is not possible or appropriate in this EIS, because Nonaka and Spies (2005) only addressed the Coast Range Province and used methods more appropriate to scientific research than an EIS. Also:

- There is less data available on existing forest conditions and forest growth and yield for other provinces in the planning area.

- The natural disturbance regime and historic conditions for other provinces are more complex and less well-studied in other provinces in the planning area.

- Detailed modeling on all ownerships across the planning area would be exorbitantly expensive and unreasonably time-consuming. The detailed modeling in Nonaka and Spies (2005) was part of, and also dependent on, a long-term joint research project begun in 1994 (Coastal Landscape Analysis and Modeling Study. Overview. URL: http://www.fsl.orst.edu/clams/overview.html [accessed June 2008]).

- Detailed modeling on all ownerships would require speculation about future management on other ownerships. Although such speculation may be appropriate in research, it would not be appropriate in an EIS analysis, which must be based on reasonably foreseeable actions.

The structural stage abundances across all ownerships would vary only slightly among the alternatives for two reasons:

- The BLM-administered lands comprise only $16 \%$ of all forested land within the planning area, which is too small an area to substantially shift the structural stage abundances across all ownerships.

- The effect of the alternatives on the BLM-administered lands, though quantitatively different, would make similar overall changes to the structural stage abundance, resulting in a decrease in the young forests and an increase in the mature \& structurally complex forests.

As a result, none of the alternatives would result in more than a $1 \%$ shift in the structural stage abundances across all ownerships. Even the reference analyses of no harvesting and intensive management on most commercial timber lands would result in only an additional 1 to $2 \%$ shift in the structural stage abundances across all ownerships. There are differences among the alternatives that are masked by grouping all mature and structurally complex forests together, and these differences are detailed in the analysis of the BLM- 


\section{Figure 4-17. Comparison Of All Ownerships By 2106 With Average Historic Conditions And Current Conditions By Alternative}

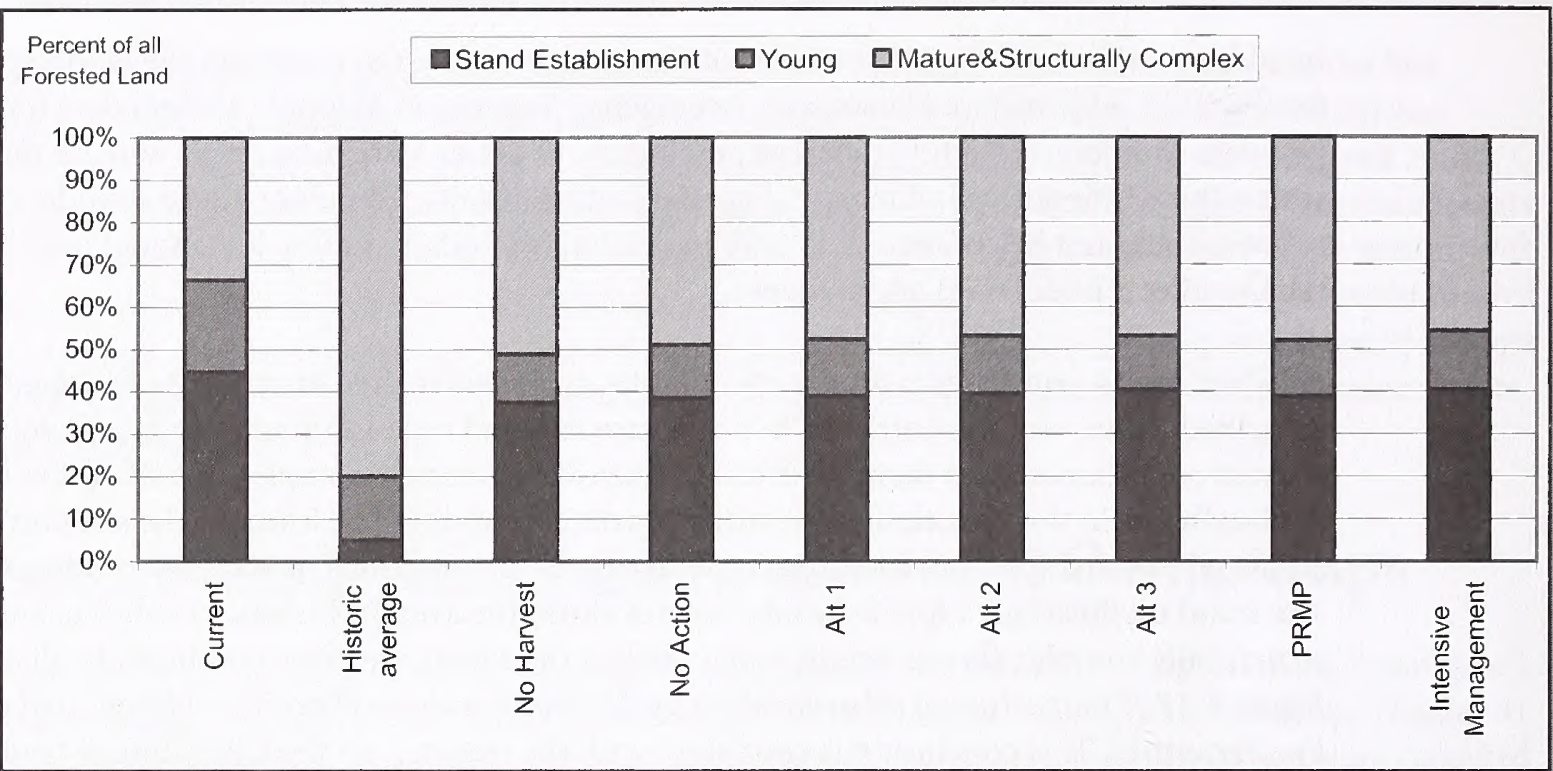

administered lands above. At the broad scale of analysis across all ownerships, however, the management of the BLM-administered lands does not substantially alter the condition of the entire forested landscape.

The principal controls on the condition of the entire forested landscape are the development of the U.S. Forest Service reserves into mature \& structurally complex forests and the continued intensive management of the nonfederal forests. For example, the No Action Alternative would add an additional 684,000 acres of mature \& structurally complex forest on the BLM-administered lands in 100 years, whereas development of the U.S. Forest Service reserves would add more than twice that amount $(1,786,000$ acres $)$ of mature \& structurally complex forest over the same time period.

The abundances of the structural stages over time shows slightly more difference among the alternatives at the province scale than for the entire planning area. Nevertheless, the alternatives still only shift the abundances at the province scale less than 3\% in 100 years. See Figure 4-18 (Comparison of all ownerships by 2106 with average historic conditions and current conditions by province by alternative).

The spatial patterns of the structural stages across all ownerships would reveal more differences among the alternatives than the abundances of the structural stages.

The stand establishment forest average patch size across all ownerships would decrease in some alternatives in some provinces and increase in others. ${ }^{6}$ See Figure 4-19 (Change in the mean patch sizes from the current condition by 2106 by the forest structural stages on all ownerships). Alternative 3 would contribute to an increase in the stand establishment patch size in all provinces. The PRMP would contribute to the largest increase in the stand establishment patch size in the Coast Range and West Cascades Provinces, and the largest decrease in the stand establishment patch size in the Klamath Province. This is consistent with the overall trend in the abundances across all ownerships. Nevertheless, the changes in stand establishment average patch size represent small relative changes in patch size over time under all alternatives.

The young forest average patch size across all ownerships would decrease in all alternatives in all provinces consistent with the overall trend in abundances.

${ }^{6}$ The mean patch size across all ownerships was calculated using eCognition for the PRMP and FRAGSTATS for the other alternatives. The two methods yield similar results and can be directly compared, as detailed in Appendix B - Forest Structure and Spatial Pattern. 
Figure 4-18. Comparison Of All Ownerships By 2106 With Average Historic Conditions And Current Conditions By Province By Alternative

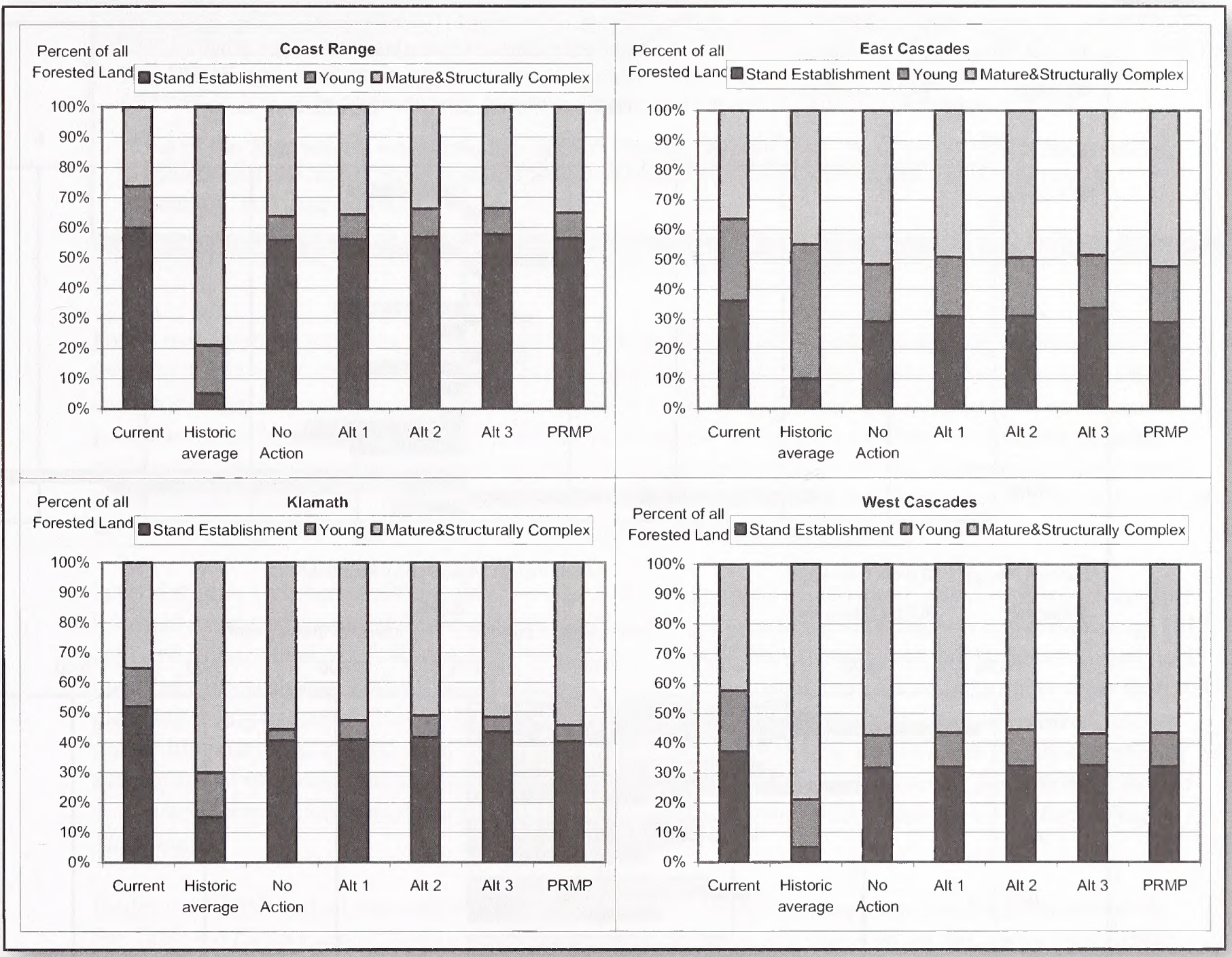

The mature \& structurally complex forest average patch size across all ownerships would increase in all alternatives in all provinces consistent with the overall trend in abundances. Development of the Forest Service reserves into mature \& structurally complex forests would produce very large mature \& structurally complex forest patches that would contribute to the increase in mean patch size, but there would still be a measurable difference among the alternatives. Among the alternatives, the No Action Alternative would contribute to the most increase in mature \& structurally complex forest patch size in most provinces, and Alternative 3 would contribute to the least increase in most provinces. The PRMP would contribute to the most increase in the East Cascades Province and the least increase in the West Cascades Province. The PRMP would contribute to almost as much increase as the No Action Alternative in the Klamath Province. The No Harvesting reference analysis would contribute to more difference in the mature \& structurally complex forest patch size than in the overall abundance of the mature \& structurally complex forest across all ownerships. The no harvesting reference analysis would contribute to mature \& structurally complex forest mean patch sizes that would be much larger than under Alternative 3 (i.e., $35 \%$ larger in the Coast Range Province, 23\% larger in the West Cascades Province, 120\% larger in the Klamath Province, and 32\% larger in the Eastern Cascades Province). The differences among the alternatives would be greatest in the Klamath Province, in part because the BLM-administered lands comprise a higher portion of the Klamath Province than any other province. 
Figure 4-19. Change In The Mean Patch Sizes From The Current Condition By 2106 By The Forest Structural Stages On All Ownerships

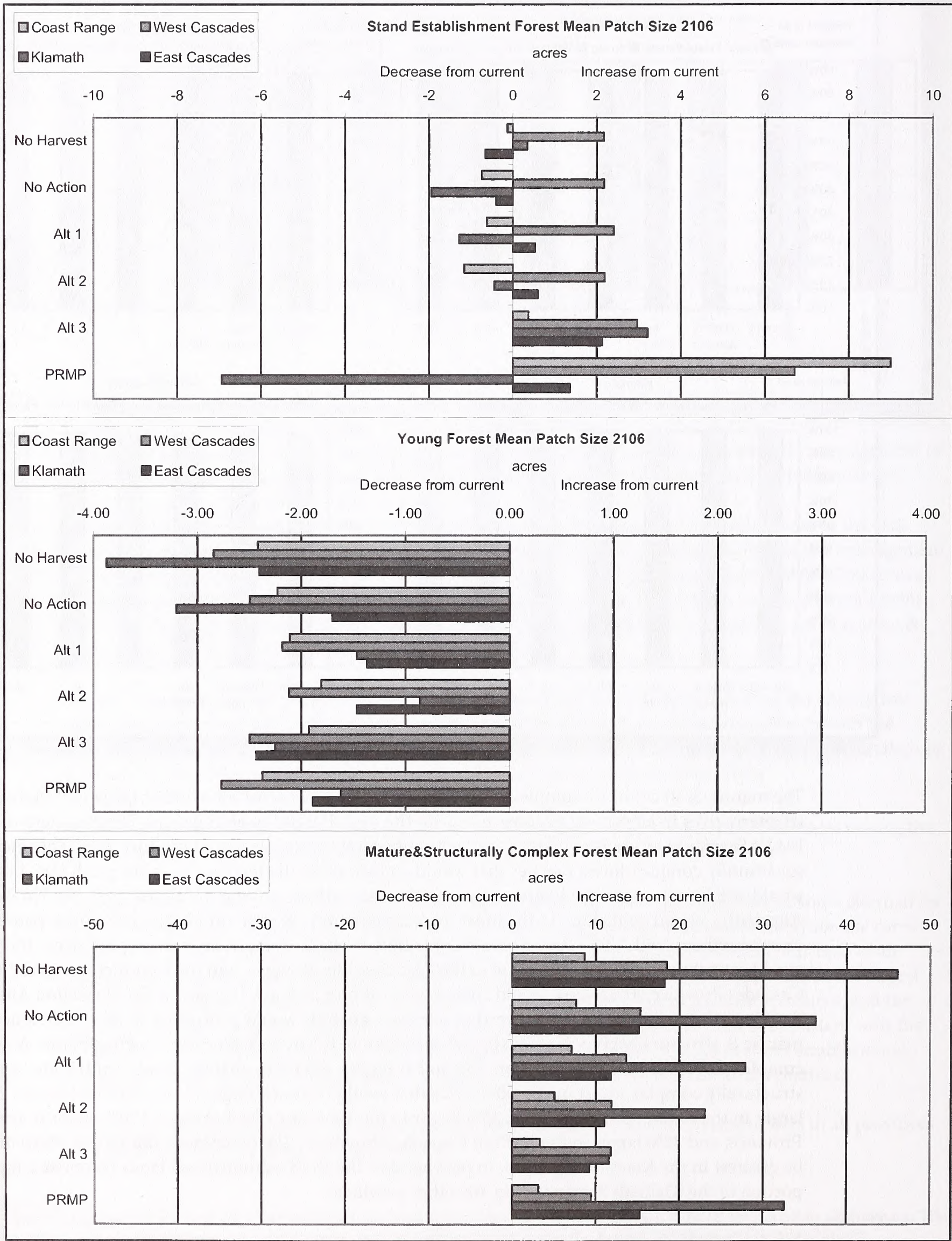




\section{Carbon Storage}

\section{Key Points}

- The PRMP and all alternatives would increase total carbon storage from current levels, ranging from 507 million tonnes in Alternative 3, to 596 million tonnes in the No Action Alternative in 2106.

- None of the alternatives would result in carbon storage of more than $1 \%$ of the current carbon stored in forests and harvested wood in the United States or $0.02 \%$ of current global carbon storage in vegetation, soil, and detritus.

Forest management activities, including timber harvest, prescribed burning, and biomass recovery, can result in losses of on-site carbon storage. Some losses move carbon from on-site carbon storage to off-site carbon storage: for example, timber harvest transfers some of the carbon in live trees to harvested wood products. Some losses may constitute substitution of one carbon loss for another: for example, biomass recovery for electricity generation may displace electricity generation from coal. Some losses may prevent potentially greater carbon losses: for example, prescribed burning for fuels reduction may reduce the risk of wildfire, causing much larger losses of carbon than the prescribed burning.

Several studies have inventoried carbon storage in forests at broad spatial scales and described trends, but have not attempted to model future effects of different forest management strategies on carbon storage (EPA 2007, Woodbury et al. 2007, Brown et al. 2004, Law et al. 2004, Smith and Heath 2004). Some studies have modeled carbon storage under different forest management practices, but over much smaller areas than this planning area (Baskent et al. 2008, Hoover and Stout 2007, Hoover et al. 2000). To model carbon storage under different forest management strategies at the scale of the planning area requires greatly simplifying assumptions and involves substantial areas of uncertainty in the analytical results, as described in Chapter 3 - Carbon Storage. Additional information on this analysis is provided in Appendix C-Carbon Storage Modeling.

Under the PRMP and all alternatives, total carbon storage would increase over time from current levels. See Table 4-6 (Total Carbon Storage by Alternative) and Figure 4-20 (Total Carbon Storage by Alternative). The No Action Alternative would result in the greatest increase in total carbon storage. In the first 50 years, Alternative 2 would result in the least increase in total carbon storage, but Alternative 3 would result in the least carbon storage of all alternatives by 2106 . The greatest difference among the alternatives in total carbon storage - between the No Action Alternative and Alternative 3 in 2106 - would be 15\%. The reference analysis of No Harvest would result in a greater increase in total carbon storage than any of the alternatives. By 2106, No Harvest would result in total carbon storage that would exceed the carbon storage under average historic conditions. This is consistent with previous text in this chapter (under Forest Structure and Spatial Pattern), which concluded that No Harvest would result in more mature and structurally complex forest in 2106 than average historic conditions. The reference analysis of Intensive Management on Most Commercial Timber Lands would result in a decrease in total carbon storage for the first 50 years. The total carbon storage under Intensive Management would increase from 2056 to 2106 , but would still remain lower than current levels.

The annual increase in carbon storage under all alternatives over the next 100 years would represent less than $1 \%$ of the current increase in carbon storage in forests and harvested wood nationally, ranging from $0.4 \%$ under Alternative 3, to $0.9 \%$ under the No Action Alternative. As described in Carbon Storage in Chapter 3, forest management in the United States currently represents an annual accumulation of 191 million tonnes of carbon. The No Action Alternative would average an annual accumulation of 1.69 million tonnes of carbon over the next 100 years, the highest of the alternatives. Alternative 3 would average an annual accumulation of 0.79 million tonnes of carbon over the next 100 years, the lowest of the alternatives. The PRMP would average an annual accumulation of 0.96 million tonnes of carbon over the next 100 years. 
Table 4-6. Total Carbon Storage By Alternative

\begin{tabular}{lrrrrrrr}
\hline Year & No Harvest & No Action & Alt. 1 & Alt. 2 & Alt. 3 & PRMP & $\begin{array}{r}\text { Intensive } \\
\text { Management }\end{array}$ \\
\hline 2006 & 427 & 427 & 427 & 427 & 427 & 427 & 427 \\
\hline 2016 & 459 & 450 & 437 & 429 & 431 & 430 & 407 \\
\hline 2026 & 491 & 467 & 449 & 429 & 437 & 437 & 389 \\
\hline 2056 & 588 & 520 & 488 & 445 & 473 & 458 & 364 \\
\hline 2106 & 703 & 596 & 564 & 513 & 507 & 523 & 395 \\
\hline
\end{tabular}

In general, the lower the harvest level in an alternative, the more carbon that would stored in live trees and forests (other than live trees), and the less carbon that would be stored in harvested wood, as described in detail below. The carbon stored in harvested wood would be insufficient to offset the difference in carbon stored in the forest following harvest. Nevertheless, all alternatives would result in an increase in total carbon storage, in large part because all alternatives would increase the abundance of mature and structurally complex forest, which store more carbon than young or stand establishment forests (see Carbon Storage in Chapter 3). By 2106, the No Action Alternative would result in total carbon storage 3\% higher than average historic conditions. By 2106, the other alternatives would store slightly less carbon than average historic conditions, ranging from $2 \%$ less under Alternative 1, to $12 \%$ less under Alternative 3. Despite these differences in the absolute values for the alternatives, all of the alternatives would continue to constitute $1 \%$ of the total carbon currently stored in forests and harvested wood in the United States and $0.02 \%$ of total carbon currently stored in vegetation, soil, and detritus globally. Therefore, the difference in carbon storage among the alternatives over time is too small to reveal a difference when placed in the context of nationwide or global carbon storage.

As described in Chapter 3, quantitative expressions of uncertainty are not available for most of these estimations of future carbon pools. Brown et al. (2004) estimated total error in describing current carbon storage and trends in California forests at 39\%. The EPA (2007) estimated total error in describing current carbon storage and trends in forest ecosystems nationwide at $31-32 \%$. The analysis here uses detailed forest inventory data to estimate current carbon in live trees, which would have less error than the procedures used in Brown et al. (2004) and EPA (2007). However, the estimation of total error from both of these sources

Figure 4-20. Total Carbon Storage By Alternative

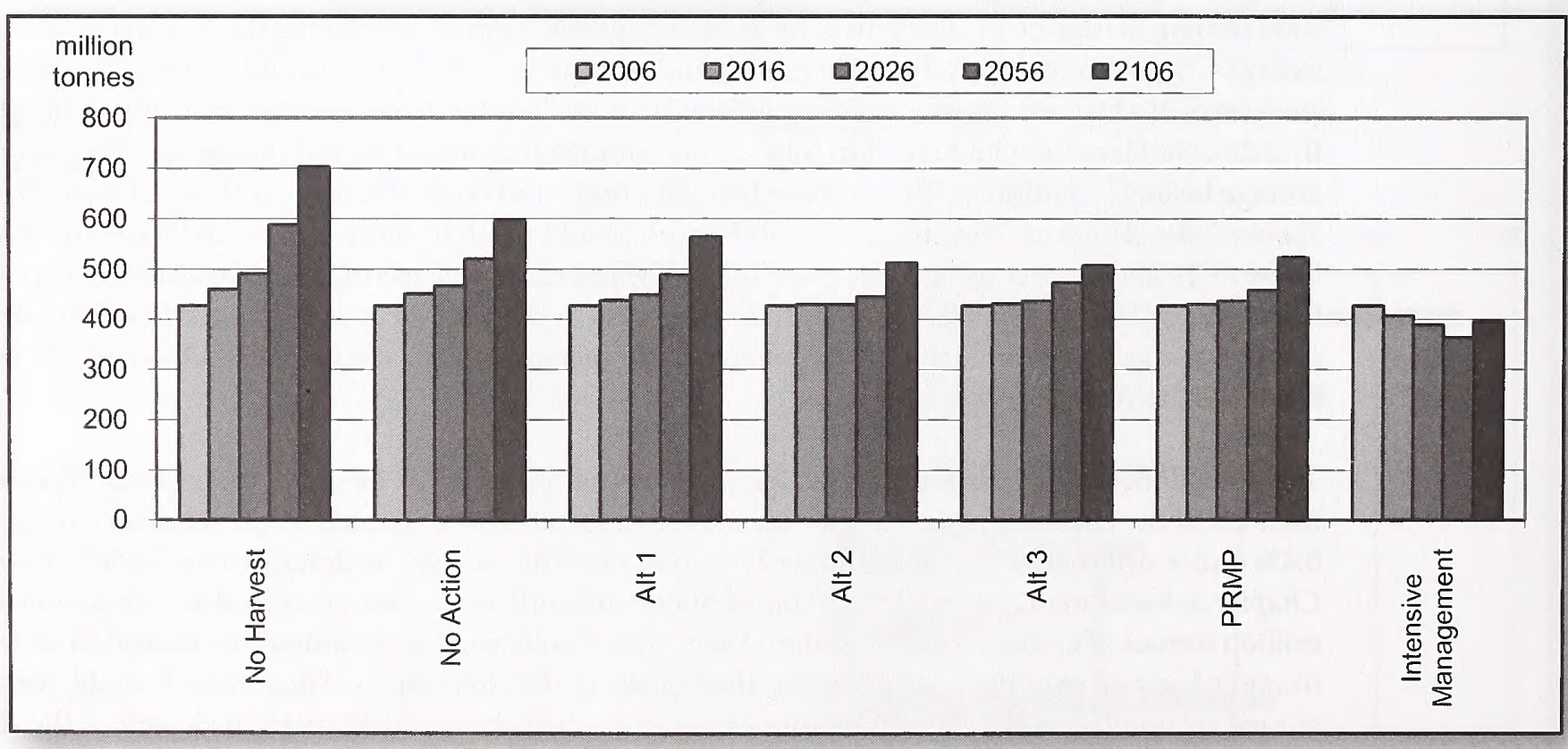


does not include sources of error associated with modeling future changes to forest carbon in response to the alternatives. The greatest source of error associated with this estimation is from the analysis of carbon stored in forests (other than live trees), as described below. Overall, the total error associated with these estimations, although it cannot be precisely quantified, is greater than the difference among the alternatives.

The PRMP and alternatives vary in the proportion of stored carbon in each of three carbon pools described in Chapter 3 - Carbon Storage:

- live trees

- forest carbon other than live trees

- harvested wood

Under the PRMP and all alternatives, the carbon storage in live trees would increase over time from current levels, similar to total carbon storage. See Figure 4-21 (Carbon Storage in Live Trees). In general, the lower the harvest level, the more carbon would be stored in live trees over time. However, Alternative 3 does not fit this overall pattern. Alternative 3 has a lower harvest level than Alternative 2 or the PRMP, but would result in less carbon storage in live trees, because the extensive use of partial harvest in Alternative 3 would result in slower tree growth rates after harvest and less efficient accumulation of carbon per acre than the regeneration harvest in the other alternatives. Additionally, Alternative 3 would have the least accumulation of carbon in live trees in the nonharvest land base of any of the alternatives, because it would allocate the fewest acres to the nonharvest land base of any alternative. As with total carbon storage, the No Harvest reference analysis would result in more carbon storage in live trees than any alternative, and the Intensive Management reference analysis would decrease the carbon storage in live trees over time.

The carbon storage on BLM-administered non-forest lands is calculated based on carbon values from Brown et al. (2004) for shrublands and woodlands and does not vary by alternative or over time, as noted in Chapter 3. The carbon in non-forest lands is added to the carbon in forests (other than live trees). Carbon storage in forests on BLM-administered lands in eastern Klamath Falls Resource Area is calculated based on carbon values from Smith et al. (2006) for Pacific Northwest East forest types. Because structural stage development is not modeled for these eastern Klamath Falls Resource Area lands in this environmental impact statement, the live tree carbon on these forests does not vary by alternative or over time and is added to the carbon in forests (other than live trees).

Figure 4-21. Carbon Storage In Live Trees

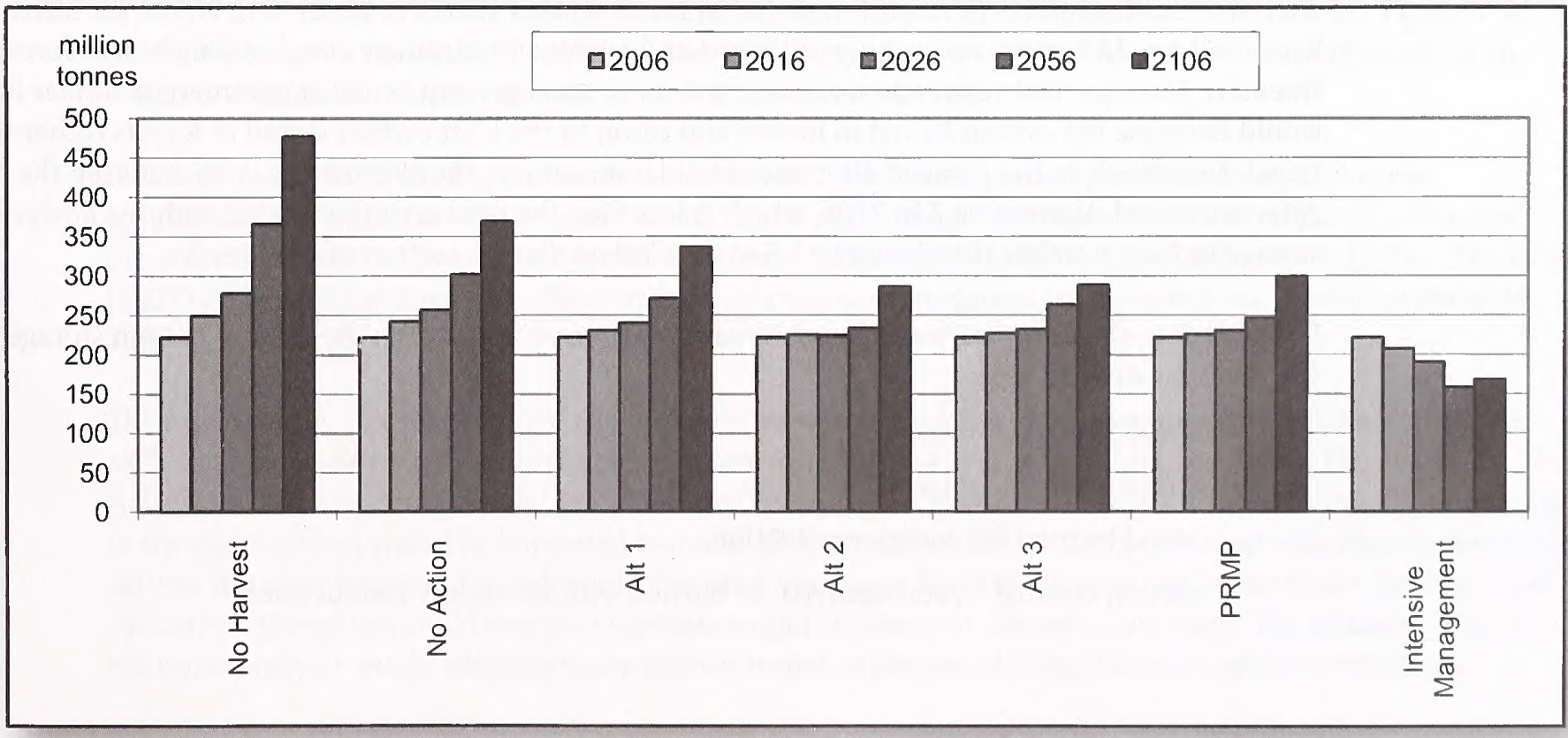


As explained in Chapter 3, this analysis models carbon stored in forests (other than live trees) using regional average values from DOE (2007) and Smithwick et al. (2002) for each structural stage. As noted by Smith et al. (2006), these regional average values reflect the current best available data for developing regional estimates, but these values do not account for variation among forest stands within these structural stages. Modeling future carbon storage in forests (other than live trees) under the PRMP and alternatives requires greatly simplifying assumptions and involves substantial areas of uncertainty in the analytical results. Accurate and precise modeling of future dead wood levels under the PRMP and alternatives is not possible at this scale of analysis (see Chapter 4, Forest Structure and Spatial Pattern). The PRMP and alternatives would likely alter future levels of plants other than trees and litter levels as a result of timber harvesting, site preparation, and prescribed burning (Long and Turner 1975). However, there is incomplete information to quantify such effects through direct modeling at the planning area scale. There is inadequate information to quantify the effects of the alternatives on soil organic carbon (Birdsey et al. 2006). As noted by EPA (2007):

"An important source of uncertainty is that there is little consensus from available data sets on the effect of land-use change and forest management activities (such as harvest) on soil [carbon] stocks ... Because soil [carbon] stocks are large, estimates need to be very precise, since even small relative changes in soil [carbon] sum to large differences when integrated over large areas." (EPA 2007: 7-11).

These values for carbon stored in forests (other than live trees) also do not account for variation among forest stands of the same structural stage that would result from variation among the alternatives. For example, the PRMP and Alternatives 1 and 2 include management direction for retention and creation of snags and coarse woody debris when thinning in Late-Successional Management Areas. This management practice would result in more carbon in dead wood than in otherwise similar stands that would not be thinned in the Late-Successional Management Areas or in other land use allocations. However, this variability is not reflected in these values, because the analysis cannot directly model these pools of carbon and instead must rely on regional average values.

The amount of carbon stored in forests (other than live trees) generally reflects the structural stage distribution that results under each alternative. See Figure 4-22 (Carbon Storage in Forests Other Than Live Trees). The No Action Alternative would result in the most carbon storage in forests (other than live trees) of all alternatives, because it would harvest the least existing old forest and would create the least stand establishment forests. Alternative 3 would result in the least carbon storage in forests (other than live trees) in 2106, because it would harvest the most existing old forest and create the most stand establishment forest by 2106. The PRMP would result in more carbon storage in forests (other than live trees) than Alternatives 2 or 3, but less than the No Action Alternative or Alternative 1. The No Harvest reference analysis would result in more carbon stored in forests (other than live trees) than any of the alternatives, because it would harvest no existing old forest and eventually eliminate stand establishment forests. The Intensive Management reference analysis of intensive management on most commercial timber lands would decrease the carbon stored in forests and result in the least carbon stored in forests (other than live trees). Nevertheless, the greatest difference in outcome among the alternatives is $8 \%$ between the No Action Alternative and Alternative 3 in 2106, which is less than the total error associated with the analysis of carbon storage in forests (other than live trees). See the Carbon Storage section of Chapter 3.

For modeling the future carbon storage in harvested wood under each alternative, carbon storage in harvest wood can be divided into:

- wood products in-use

- wood products in landfills

- wood burned for energy production

- carbon emitted (wood decayed or burned without energy production) 
Figure 4-22. Carbon Storage In Forests Other Than Live Trees

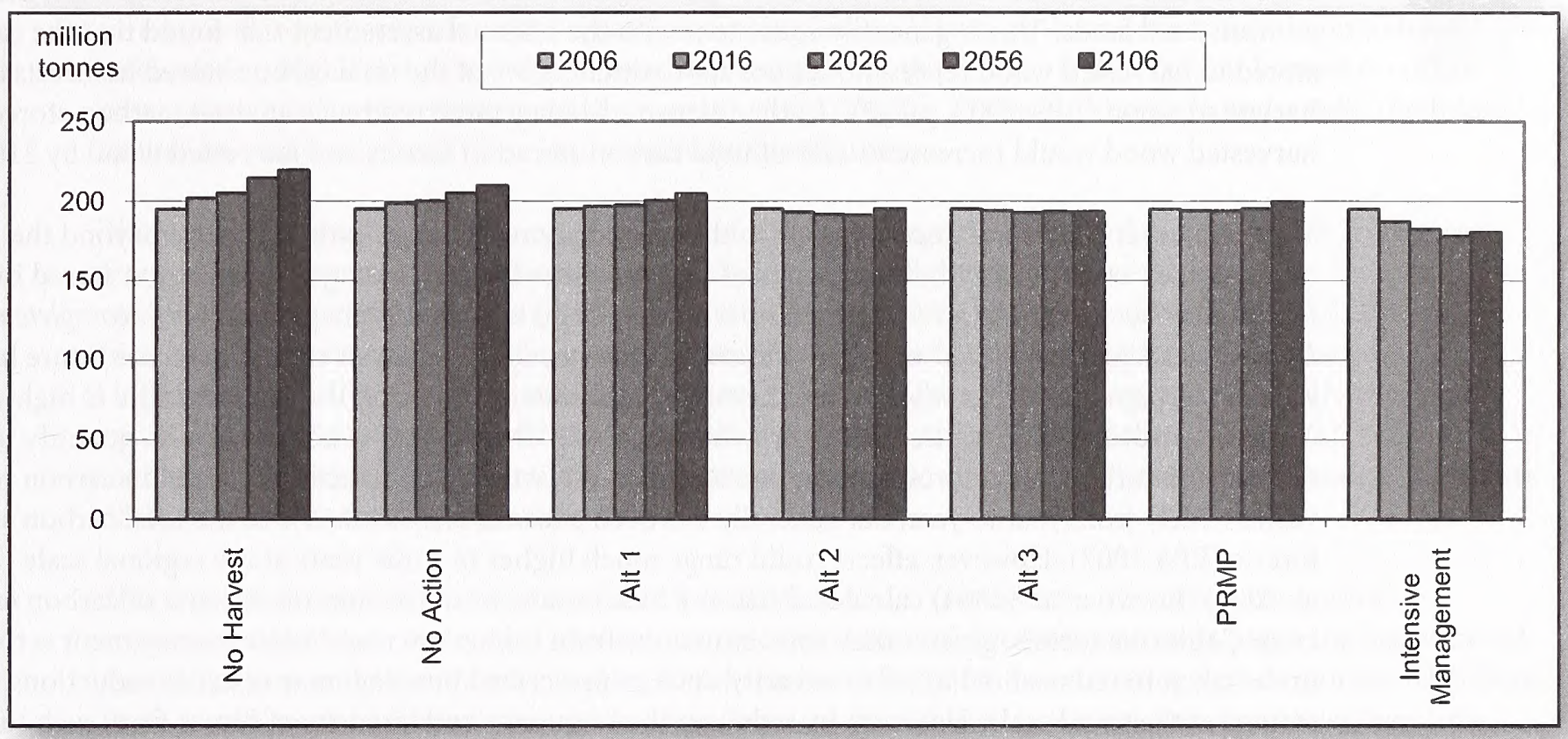

Harvested wood burned for energy production displaces the use of other carbon-emitting fuel sources, which distinguishes it from carbon emitted through decay or burning without energy production (Smith et al. 2006).

This analysis includes all harvested wood for each alternative. The conversion from harvested wood volume to carbon mass is used for softwood lumber from Smith et al. $(2006,35)$. Values for the portion of carbon in harvested wood that is in products in use, landfills, burned for energy, and emitted are derived from DOE (2007) and Smith et al. (2006). These values describe the change in these proportions over time since harvest. This analysis also includes the continued storage of carbon in wood harvested in harvests from 1962-2005, which is described in detail in Chapter 3 - Carbon Storage. The values from DOE (2007) and Smith et al. (2006) only address the portion of carbon in various pools for 100 years after harvest. This analysis treats the carbon stored in wood from past harvests as if it had been harvested in 2006 to provide an estimation of the change in carbon storage for the duration of the analysis period. This underestimates the carbon storage in wood from past harvests, because a much larger portion of carbon in harvested wood is lost in the first decade after harvest than in later decades (DOE 2007; Smith et al. 2006). See Figure 4-23 (Carbon Storage in Harvested Wood from Past and Future Harvests). However, there is no information on which to model carbon storage more than 100 years after harvest.

Estimating carbon storage in harvested wood necessarily involves broad generalizations and some speculation about the use of harvested wood, which may change over time. Brown et al. (2004) estimated the error associated with calculating carbon storage in harvested softwoods in California at $10.8 \%$. The EPA (2007) estimated the error associated with calculating carbon storage in harvested wood nationwide at 24$26 \%$.

The total amount of carbon stored in harvested wood reflects the overall amount of timber harvest under each alternative. See Figure 4-23 (Carbon Storage in Harvested Wood from Past and Future Harvests). The No Action Alternative would result in the least carbon stored in harvested wood, and Alternative 2 would result in the most carbon stored in harvested wood of all alternatives. Under the No Harvest reference analysis, the carbon stored in harvested wood would decrease over time, because there would be no future harvests, and the carbon stored in wood from past harvests would continue to decrease over time. The Intensive Harvest reference analysis would result in more carbon stored in harvested wood than any of the alternatives. 
The carbon stored in wood harvested from BLM-administered lands would range from $2 \%$ to $6 \%$ of the total amount of carbon stored in forests on BLM-administered lands and wood harvested from BLMadministered lands. This is generally consistent with the national assessment that found that the carbon stored in harvested wood represents a pool approximately $5 \%$ of the total carbon stored in forests and harvested wood (EPA 2007, p. 7-7). In the Intensive Management reference analysis, carbon stored in harvested wood would increase to $12 \%$ of total carbon stored in forests and harvested wood by 2106.

There are other sources of uncertainty with these estimations of future carbon storage beyond the uncertainties associated with descriptions of carbon values for each storage pool. Carbon stored in forests may be released as a result of wildfire. As described later in this chapter (under Incomplete and Unavailable Information, Salvage After Natural Disturbance), this analysis cannot estimate future broadscale disturbances, such as wildfire. Furthermore, the amount of carbon lost from wildfire is highly variable (Page-Dumroese and Jurgensen 2006, Brown et al. 2004). Therefore, it is not possible to quantify the effect of future disturbances on forest carbon pools. Nationally, wildfire has recently resulted in carbon release that varies widely from year to year, but generally has been a loss of $0.05 \%-0.10 \%$ of the total carbon stored in forests (EPA 2007). However, effects could range much higher in some years at the regional scale (Law et al. 2004). Brown et al. (2004) calculated that fire has recently been the dominant cause of carbon emissions from California forests, greater than total emissions from timber harvest. Forest management activities undertaken to reduce fire hazard or severity, such as prescribed burning, may result in reductions in carbon storage at the stand scale. However, by reducing the frequency and intensity of future fires, such fuels management could maintain higher carbon storage in the long term (Krankina and Harmon 2006).

It is not possible to quantify future changes in carbon storage on other ownerships in the planning area. As explained in previously in this chapter (see Forest Structure and Spatial Pattern), it is not possible to conduct comparable modeling of future vegetation conditions and timber harvesting on lands other than the BLM-administered lands. Analysis of vegetation condition relies on simple assumptions about future vegetation conditions on other lands. The environmental impact statement assumes that all forest-capable lands in the U.S. Forest Service late-successional reserves, administratively withdrawn, and congressionally reserved lands would develop through the structural stages according to broad assumptions. However, these simple assumptions about future condition of these U.S. Forest Service lands require combining mature and structurally complex forests together. Any attempt to calculate carbon storage based on this combined classification would be inaccurate because of the substantial difference in carbon storage per acre between mature and structurally complex forests (see Chapter 3 - Carbon Storage). The environmental impact

\section{Figure 4-23. Carbon Storage In Harvested Wood From Past And Future Harvests}

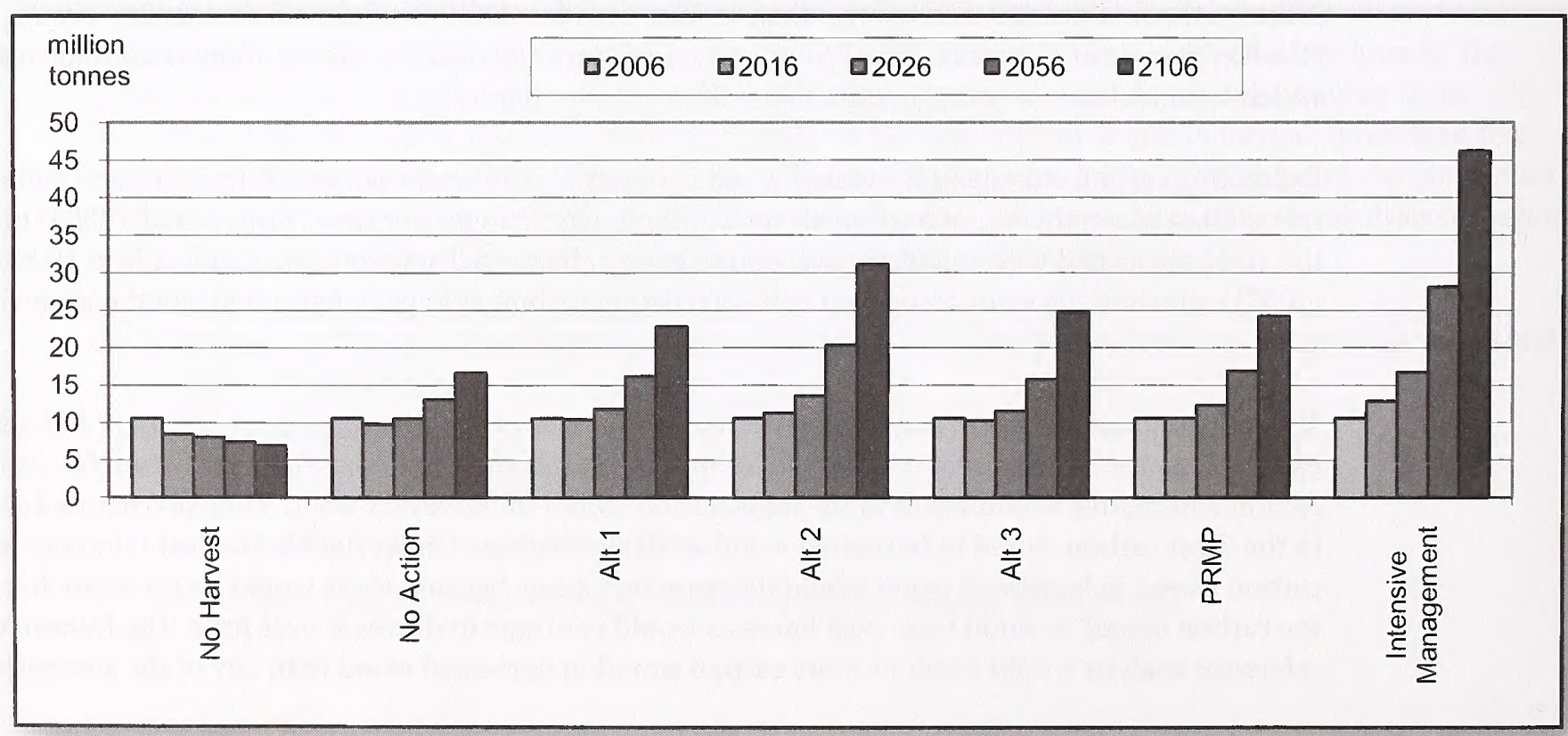


statement assumes that all other lands would maintain their current abundances and spatial patterns, as explained previously in Forest Structure and Spatial Pattern. Therefore, the carbon storage associated with forests on these other lands would remain at current levels. However, there is no information to base a calculation of the carbon storage in wood harvested from these other lands. Timber harvest on other ownerships has fluctuated substantially over time (see Chapter 3 - Socioeconomics), and predicting future timber harvest levels from these lands would be speculative.

There may be complicated, synergistic effects of climate change on the rate of carbon release from forests. For example, increased atmospheric carbon dioxide levels might increase tree growth rates, increasing the rate of carbon storage in forests (Field et al. 2007, Harmon 2006, Bachelet and Neilson 2000). However, increased temperatures would increase plant respiration, possibly offsetting increases in tree growth (Harmon 2006). Increased regional temperatures might increase wildfire frequency and intensity, which could escalate the release of carbon stored in forests (Field et al. 2007, Westerling et al. 2006). There is inadequate information to quantify these potential synergistic effects on carbon storage, because the nature of these effects remains speculative.

This analysis is based on the best available information and is consistent with current theoretical approaches. However, as detailed above, incomplete and unavailable information requires the use of broad generalizations and assumptions, leading to substantial uncertainty in estimating carbon storage. Therefore, these results must be interpreted with caution, because the differences among the alternatives over time would be less than the uncertainty associated with these estimations.

As noted in Chapter 3, carbon storage in forests can affect atmospheric concentrations of carbon dioxide, and thereby affect global climate. The effects of changes in carbon storage on atmospheric carbon dioxide concentration are manifested globally. Therefore, the changes in carbon storage in the planning area must be placed in the context of global carbon storage and atmospheric carbon dioxide levels. Under all alternatives over time, forests and harvested wood in the planning area would continue to constitute $0.02 \%$ of current global carbon storage in vegetation, soil, and detritus. The annual increase in carbon storage under all alternatives would continue to offset less than $0.0001 \%$ of the current annual increase in atmospheric carbon dioxide. In that context, it is not possible to discern any effect of the alternatives on global climate, because both the difference between current carbon storage and carbon storage in 100 years under all alternatives, and the difference in carbon storage in 100 years among the alternatives is too small a portion of global carbon storage to detect any change in global carbon storage. No climate models have sufficient precision to reflect the effects on climate from such a small fractional change in global carbon storage. 


\section{Socioeconomics}

This analysis examines the county-level economic impacts in terms of employment and income associated with the BLM's timber harvests, BLM's payments to counties, BLM's budget requirements, and the economic value of the BLM timber program that would result from the alternatives.

\section{Key Points}

- None of the alternatives would produce timber receipts sufficient to bring county payments to the level provided by the Secure Rural Schools payments of the Secure Rural Schools and Community SelfDetermination Act of 2000 . Alternative 2 would produce the highest payments to the counties at $94 \%$ of the O\&C portion of the 2005 Secure Rural Schools payment. The No Action Alternative would produce the lowest payments at $37 \%$ of the O\&C portion of the 2005 Secure Rural Schools payment.

- Alternative 2 would have the most favorable impact on local economies and result in a net increase of 3,442 jobs and $\$ 136.5$ million of wages. The PRMP would result in a net gain of 1,187 jobs and $\$ 52.1$ million in associated income. The No Action Alternative would have the least favorable impact on local economies and result in a net decrease of 3,768 jobs and $\$ 125.5$ million of wages.

- Economic activity created by the No Action Alternative would not offset jobs lost due to the loss of the Secure Rural Schools funding.

- Economic impacts would vary by county depending on:

- economic structure of the economy

- geographic distribution of the BLM timber sale program

- a county's share of the Secure Rural School payments

- projected changes in the wood products industry

- The BLM would require a budget increase to implement any of the five alternatives. The increase would range from $17 \%$ under the NoAction Alternative, to $60 \%$ under Alternative 2.

- The present net value of the BLM timber harvest would range from $\$ 46.1$ million under Alternative 3 , to $\$ 962.3$ million under Alternative 2 .

\section{Introduction}

Management of the BLM timber lands contributes to the economic activity in the western Oregon communities within the planning area. Timber harvesting and the manufacture of wood products create jobs and income in these sectors and also stimulate economic activity in other sectors of the local and regional economies. The BLM employees and BLM management expenditures also contribute to local economies. Approximately $50 \%$ of revenues received from the O\&C lands, furthermore, flows directly to county governments and funds a variety of social services and investments.

The BLM-administered lands contribute to employment and income in industries other than those related to lumber and wood products. Dispersed and developed recreation, commercial fishing, hunting, special forest products, mining, and grazing all contribute to the region's economies. The BLM's receipts from these activities in western Oregon are relatively minor compared to the timber program. Annual receipts from recreation are $\$ 1.2$ million; from special forest products are $\$ 300,000$; and from grazing are $\$ 30,000$ to $\$ 40,000$. Except for leasable minerals, non-timber resources and programs are not based on what the market will pay for these goods, opportunities, or services, but are intended to augment appropriated funds to support administration of the programs. 
Recreation on BLM-administered lands in western Oregon provides economic benefits to the planning area. However, detailed information regarding the economics of recreation is not provided here because none of the alternatives would have a material effect on recreation. A lower level of timber harvest in an alternative would not necessarily result in an increase in the level or value of recreation activities. The conclusion of this EIS in this respect is consistent with conclusions of the Northwest Forest Plan FSEIS and subsequent monitoring of that plan. In 1994, the Northwest Forest Plan reduced the harvest of timber on Forest Service and BLM-administered lands by approximately $80 \%$ of previous levels. However, recreation activity on these lands remained approximately the same after 10 years under the plan (Northwest Forest Plan: The First Ten Years, 2004).

This analysis does not include the economic effect of non-timber programs discussed above in the comparison of the alternatives, because the programs materially affected by any of the alternatives and the programs do not materially vary among the alternatives. Therefore, the overall economic and social effects and comparison of the alternatives would not be changed.

This analysis does not include the economic effect of non-market values such as wildlife, water quality, or the aesthetic value of forests. The analysis does not attempt to attach monetary values to such non-market values because to do so would be speculative and arbitrary. The NEPA regulations provide: "For purposes of complying with the Act (NEPA), the weighing of the merits and drawbacks of the various alternatives need not be displayed in a monetary cost-benefit analysis and should not be where there are important qualitative considerations (40 CFR 1502.23)."

The measures used for comparison of the alternatives are:

- employment - full-time equivalent jobs

- income - return to proprietors and wages associated with employment

- payments to counties - the O\&C counties' share of the revenues that are paid to the BLM

- BLM budget - money spent for the BLM's personnel, services, equipment, etc.

- present net value - sum of discounted revenues and costs associated with the timber sale program

The volumes and revenues of harvests for this analysis were derived from the OPTIONS model.

The Western Oregon Model (Adams and Latta 2007:8-14) was used to project delivery points for the projected harvest from OPTIONS. Developed at Oregon State University, this model relies on data about processing facilities, market prices, and private inventory to project log flows and production across western Oregon. County-level input/output models were constructed specifically for this analysis. Data specific to the economy of each county were incorporated into the model, resulting in employment and income projections tuned to the economy found in each county economy. The U.S. Forest Service's Timber Assessment Market Model was used to estimate the stumpage price impact of adding more BLM timber to the market.

Revenues, employment, and income reported herein are based on the total harvest volumes, including both the harvest land base (lands that contribute to the annual sale quantity) and non-harvest land base. See Appendix D - Socioeconomics for a more complete discussion of the analytical process and the assumptions for this analysis.

An increase in the BLM timber harvest would lead to an increase in the total timber harvest in the market area and increased activity in the wood-processing sectors. Under all alternatives, as the BLM sells more timber into the log market, log prices would fall an estimated 3.5\%, and timber harvests from price-sensitive private lands would fall slightly. Because of this price effect, the increase in the total harvest would be somewhat less than the increment of the BLM's timber. As manufacturing capacity adjusts to absorb the increased volume of the BLM's timber, prices and harvests from other owners would adjust to previous levels. See Chapter 3 for discussion of the timber market and wood products industry.

Differences in the economic effect of the harvests between the alternatives are due not only to the differences in the volume of timber that would be harvested, but also to differences in the location and characteristics 
of the timber that would be harvested. During the first 10-year period after implementation, for example, the harvest volume from Alternative 3 would be mostly from partial harvesting, whereas more regeneration harvesting would occur under the No Action Alternative, Alternatives 1 and 2, and the PRMP. Since thinning and partial harvesting cost more than regeneration harvesting, the average net revenue per thousand board feet would be highest under Alternative 2 and lowest under Alternative 3. The differences in the type of timber harvested would result in a difference in log quality. Large, peeler-grade logs, for example, would constitute more of the harvest volume under Alternative 2 than under the No Action Alternative. See Table 4-7 (Distribution of harvest by harvesting type and the percentage of large, peeler-grade logs for the first decade).

As a result of the differences in the type of harvesting (thinning, partial harvesting, regeneration harvesting, and uneven-aged management) and log quality, there is a difference in the projected average stumpage prices between the alternatives. See Table 4-8 (Estimated annual payments to the counties for the first decade); also see Figure 4-49 (Annual stumpage value by alternative over the first decade), which is in the Timber section of this chapter. This table and figure show that stumpage prices within the first 10 years would range from $\$ 280$ per mbf under Alternative 2, to $\$ 218$ per mbf under Alternative 3.

Decadal average stumpage price projections are used throughout this analysis. All impacts related to timber revenues, therefore, are based on decadal average revenue projections. Actual stumpage prices would fluctuate from year to year, primarily in response to changes in national and international markets for end products. These short-term fluctuations would affect all alternatives equally, but not the comparison between alternatives.

Differences in the type and quality of logs harvested could also lead to differences in employment projections. For example, larger and higher-quality logs can produce higher-valued specialty products that often require more labor-intensive milling procedures. Large logs, on the other hand, generally require less logging labor. Although there is a clear relationship in value and stumpage price to log size and quality, there is no clear established relationship between log size and quality to employment levels.

\section{Payments to the Counties}

Currently, the BLM-related revenues provide about $2.5 \%$ of the total revenue received by the $\mathrm{O} \& \mathrm{C}$ counties and $9.8 \%$ of the discretionary portion of the county budgets (see Chapter 3 ). These figures range from $0.1 \%$ of the total funding and $0.2 \%$ of the discretionary funding for the large metropolitan counties, to $20.5 \%$ of the total funding and $70.4 \%$ of the discretionary funding for the more rural southwestern Oregon counties. See the Socioeconomic section of Chapter 3.

Secure Rural Schools funding has expired and although there are proposals for a possible short-term renewal of some version of Secure Rural Schools funding, there are no proposals for a permanent or longterm extension. Therefore, this analysis assumes that the BLM payments to the counties would be based

Table 4-7. Distribution of Harvest By Harvesting Type And Percentage Of Large Peeler-Grade Logs For The First Decade

\begin{tabular}{lrrrrrr}
\hline Alternative & $\begin{array}{r}\text { Total Annual } \\
\text { Harvest (mmb) }\end{array}$ & $\begin{array}{r}\text { Regeneration } \\
\text { Harvest (\%) }\end{array}$ & Thinning (\%) & $\begin{array}{r}\text { Uneven-age } \\
\text { Harvest (\%) }\end{array}$ & $\begin{array}{r}\text { Partial } \\
\text { Cutting (\%) }\end{array}$ & $\begin{array}{r}\text { Peeler-size } \\
\text { Logs (\%) }\end{array}$ \\
\hline No Action & 355 & 65 & 34 & 1 & 0 & 0 \\
\hline Alternative 1 & 537 & 77 & 23 & 0 & 0 & 4.1 \\
\hline Alternative 2 & 767 & 89 & 11 & 0 & 62 & 7.7 \\
\hline Alternative 3 & 473 & 4 & 34 & 0 & 0 & 7.7 \\
\hline PRMP & 591 & 60 & 40 & & 4.0 \\
\hline
\end{tabular}


on the pre-existing formula with which the counties would receive $50 \%$ of the BLM stumpage receipts and some minor additional funding, as described in Chapter 3.

Table 4-8 (Estimated annual payments to the counties for the first decade) shows that Alternative 2 would have the most timber and generate the highest payments to counties ( $\$ 108$ million). That is equivalent to $94 \%$ of the 2005 Secure Rural Schools (SRS) funding associated with BLM-administered lands and $46 \%$ of the SRS funding from all federal lands. The PRMP would generate payments to counties of $\$ 75$ million, which is equivalent to $65 \%$ of the 2005 Secure Rural Schools (SRS) funding associated with BLM-administered lands and $32 \%$ of the SRS funding from all federal lands. The No Action Alternative would have the lowest total annual revenue ( $\$ 83.9$ million) and the lowest payment to counties ( $\$ 42$ million). That is equivalent to $37 \%$ of the 2005 Secure Rural Schools funding associated with the BLM-administered lands and $18 \%$ of the Secure Rural Schools funding from all federal lands.

Table 4-9 (Comparison of 2005 Secure Rural Public School payments to annual payments to individual counties under the alternatives) shows the payments to the counties for the first 10 years. The bulk of the projected payments is based on 50\% of the BLM stumpage receipts. Actual stumpage receipts may vary from year to year, as explained above. The BLM stumpage revenue is distributed between the counties based on historic valuation. The distribution of other revenues is fixed at the 2005 level and does not change between alternatives. Since this is a minor amount of revenue, the distribution of the total revenue between the counties on a percentage basis would be nearly identical under any alternative.

Table 4-9 also shows that the Secure Rural Schools funding associated with BLM-administered lands accounted for slightly less than half of the total Secure Rural Schools funding, and that the Secure Rural Schools funding associated with the U.S. Forest Service lands accounted for the other half. The distribution of USFS-related Secure Rural Schools funding differs from the distribution of the BLM-related Secure Rural School funding. The analysis of impacts on jobs and income is based on the assumption that the Secure Rural Schools funding would not be reauthorized. The U.S. Forest Service payments to counties (25\% of timber sale revenue) averaged $\$ 4.2 \mathrm{million} /$ year over the base period of 2000-2004. These results assume that National Forest timber harvests will not change significantly. Projecting a similar amount of payment into the future, however, would not make any substantive difference in projecting the effects of the BLM alternatives nor change the relative ranking of the alternatives.

Figure 4-24 (Historic and projected BLM payments to the counties for the first decade) compares the projected BLM payments to counties to the historic BLM payments. The No Action Alternative and Alternative 3 would provide average annual payments less than the lowest year in the 20 -year history. Alternative 1 would provide average annual payments in the range seen during the late 1990s. Alternative 2 would provide average annual payments in the range seen in the late 1980s and again after the passage of the Secure Rural Schools (SRS) legislation, which started in fiscal year 2001. The PRMP would provide average annual payments to counties similar to those received in the 1990s, prior to the SRS legislation.

Table 4-8. Estimated Annual Payments To The Counties For The First Decade

\begin{tabular}{|c|c|c|c|c|c|}
\hline & \multicolumn{5}{|c|}{ Alternative } \\
\hline & No Action & Alt. 1 & Alt. 2 & Alt. 3 & PRMP \\
\hline Harvest of Short Logs (mmbf) & 355 & 537 & 767 & 473 & 591 \\
\hline Adjusted Stumpage (\$/mbf) & 234 & 254 & 280 & 218 & 254 \\
\hline Total Revenue & 83.9 & 137.2 & 205.8 & 103.3 & 150.1 \\
\hline O\&C County Share & 42.0 & 68.7 & 108.0 & 51.7 & 75.1 \\
\hline$\%$ of 2005 BL.M payments & $37 \%$ & $60 \%$ & $94 \%$ & $45 \%$ & $65 \%$ \\
\hline $\begin{array}{l}\% \text { of } 2005 \text { BLM, USFS, and Secure } \\
\text { Rural School Payments }\end{array}$ & $18 \%$ & $29 \%$ & $46 \%$ & $22 \%$ & $32 \%$ \\
\hline
\end{tabular}


Table 4-9. Comparison Of 2005 Secure Rural School Payments To Annual Payments To Individual Counties Under The Alternatives

\begin{tabular}{l|rrr|rrrrr}
\hline \multirow{2}{*}{ Counties } & \multicolumn{3}{|c|}{ Secure Rural School Payments } & \multicolumn{4}{c}{ Alternatives (\$ million) } \\
\cline { 2 - 8 } & BLM & USFS & Totals & No Action & Alt. 1 & Alt. 2 & Alt. 3 & PRMP \\
\hline Benton & 3.2 & 0.5 & 3.7 & 1.2 & 1.9 & 3.0 & 1.5 & 2.1 \\
\hline Clackamas & 6.3 & 7.2 & 13.5 & 2.3 & 3.8 & 6.0 & 2.9 & 4.2 \\
\hline Columbia & 2.3 & 0.0 & 2.3 & 0.9 & 1.4 & 2.2 & 1.1 & 1.5 \\
\hline Coos & 7.6 & 0.8 & 8.4 & 2.5 & 4.1 & 6.4 & 3.0 & 4.4 \\
\hline Curry & 4.2 & 5.6 & 9.8 & 1.5 & 2.5 & 3.9 & 1.9 & 2.7 \\
\hline Douglas & 28.7 & 22.7 & 51.4 & 10.5 & 17.2 & 27.0 & 12.9 & 18.8 \\
\hline Jackson & 17.8 & 6.4 & 24.2 & 6.6 & 10.8 & 16.9 & 8.1 & 11.8 \\
\hline Josephine & 13.8 & 3.1 & 16.9 & 5.1 & 8.3 & 13.0 & 6.2 & 9.1 \\
\hline Klamath & 2.7 & 17.2 & 19.9 & 1.0 & 1.6 & 2.6 & 1.3 & 1.8 \\
\hline Lane & 17.4 & 34.2 & 51.6 & 6.4 & 10.5 & 16.5 & 7.9 & 11.5 \\
\hline Lincoln & 0.4 & 5.3 & 5.7 & 0.2 & 0.2 & 0.4 & 0.2 & 0.3 \\
\hline Linn & 3.0 & 11.4 & 14.4 & 1.1 & 1.8 & 2.8 & 1.4 & 2.0 \\
\hline Marion & 1.7 & 4.3 & 6.0 & 0.6 & 1.0 & 1.6 & 0.8 & 1.1 \\
\hline Multnomah & 1.2 & 1.1 & 2.3 & 0.5 & 0.7 & 1.2 & 0.6 & 0.8 \\
\hline Polk & 2.5 & 0.0 & 2.5 & 0.9 & 1.5 & 2.3 & 1.1 & 1.6 \\
\hline Tillamook & 0.6 & 2.8 & 3.4 & 0.2 & 0.4 & 0.6 & 0.3 & 0.4 \\
\hline Washington & 0.7 & 0.0 & 0.7 & 0.3 & 0.4 & 0.7 & 0.3 & 0.5 \\
\hline Yamhill & 0.8 & 0.8 & 1.6 & 0.3 & 0.5 & 0.8 & 0.4 & 0.5 \\
\hline Totals & 114.9 & 123.4 & 238.3 & 42.1 & 68.6 & 107.9 & 51.9 & 74.1 \\
\hline
\end{tabular}

Figure 4-24. Historic And Projected Blm Payments To The Counties For The First Decade

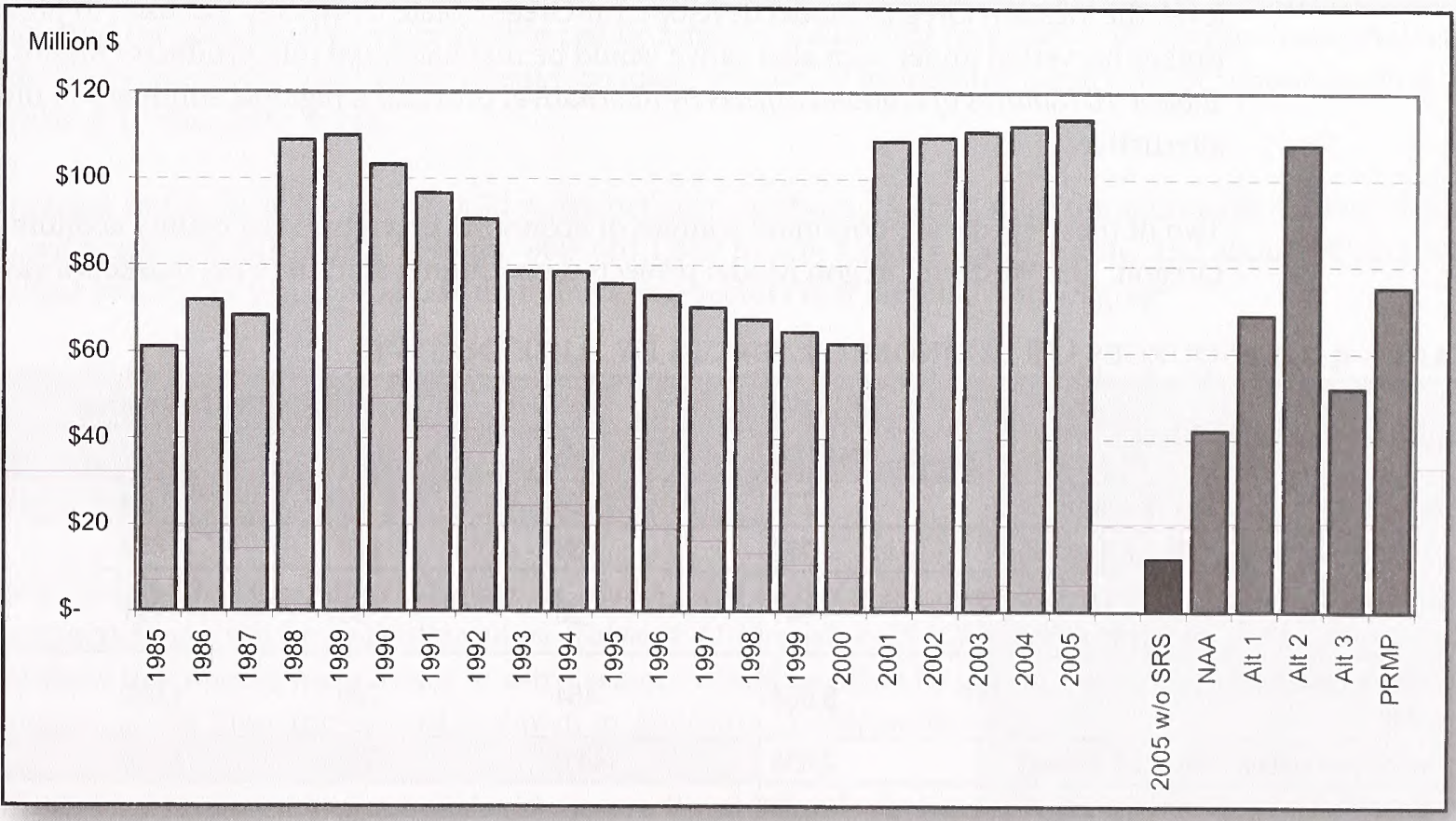




\section{Employment and Income}

The economic impact estimates for all alternatives were calculated from county-level input/output models. These models were tailored and field-calibrated to specifically address the types of impacts that are expected from the potential changes in the BLM timber harvest levels.

The economic impacts include the combination of direct effects due to:

- changes in BLM land management and county payments

- indirect effects associated with inter-industry transactions

- induced effects from payroll spending

The total effects are described in terms of changes in employment and earnings. Changes that would result from the alternatives are compared to a 2005 estimated baseline (labeled current in the following tables). The term (current) describes the amount of each county's 2005 economy that could be attributed to the combination of the BLM management actions and the Secure Rural Schools payments associated with both the BLM and the USFS. This analysis considers six principal sources of direct economic impacts on the O\&C counties, which are:

- loss of current Secure Rural Schools payments to counties

- changes to BLM timber harvest levels and associated changes in logging and log hauling

- changes in administrative and contracting expenditures by the BLM

- changes in sawmill operations in response to changes in timber harvest

- changes in the output of plywood mills in response to change in timber harvest

- changes in board and pulp mill operations as more chips and sawmill residuals come on the market

Each of these changes is considered at the county level. To forecast future economic impacts at the county level, the Western Oregon Model developed at Oregon State University was used to project where the BLM timber harvested under each alternative would be manufactured into products (Adams and Latta 2007, 8-14). Table 4-10 (Sources of economic effects by alternative) provides a regional summary of direct effects for each alternative.

Two of these effects are dominant sources of economic impacts to the county economies throughout western Oregon. The Western Oregon Model projects a continuing shift in panel markets away from plywood to less-

Table 4-10. Sources Of Economic Effects By Alternative

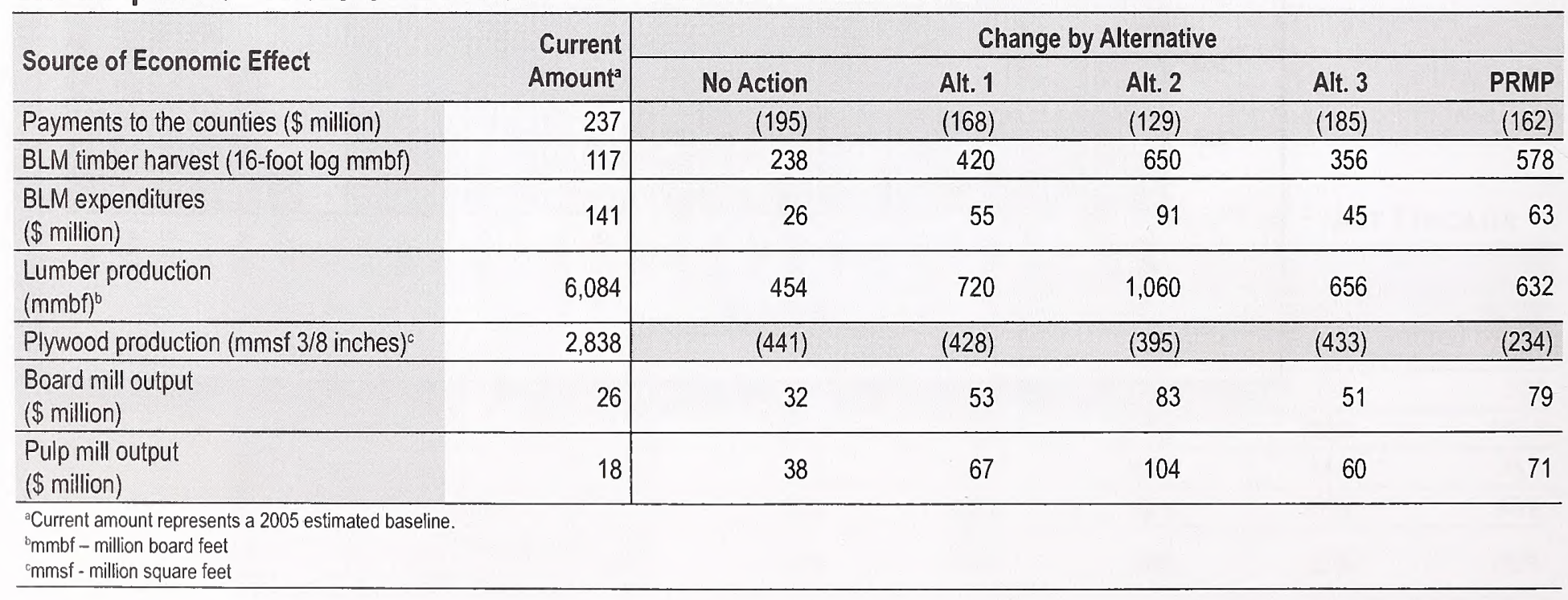


expensive oriented strand board (OSB). This shift would occur despite increased BLM timber harvests under the alternatives. Plywood production would decline by about $15-17 \%$ under all the alternatives.

Variations in BLM harvest are not a causal factor in the decline of plywood production; rather, projected declines are due to national market factors. Plywood production declines would occur even under the alternatives that would substantially increase the BLM's timber harvest. The projected decline in plywood production would reduce industry output more than $\$ 400$ million under all of the alternatives. In addition, approximately 1,500 to 2,000 plywood and veneer jobs, and additional job losses from a multiplier effect, would be lost as a result of that decline in plywood production.

Historically, counties shared in federal timber sales receipts. Western Oregon counties received $25 \%$ of U.S. Forest Service receipts, and O\&C counties received 50\% from the BLM timber sale receipts. Under the Northwest Forest Plan, federal timber sales declined substantially from historic levels (see Figure 3-28 in Chapter 3). The Secure Rural Schools funding that had compensated for lost timber receipt-sharing ended in 2006. These annual county payments had ranged from $\$ 0.7$ million in Washington County, to $\$ 51.5$ million in Lane County. This analysis assumes that a long-term or permanent reauthorization of the Secure Rural Schools and Community Self-Determination Act, or new similar legislation, would not occur.

Western Oregon counties would lose between 626 and 2,840 local government jobs from the loss of Secure Rural School payments; multiplier effects would double the total job loss. Losses would be the largest in the timber-dependent counties that have large federal land acreages. For example, under the No Action Alternative, Douglas County would lose more than 700 jobs in local government due to changes in county payments.

All alternatives would have an off-setting effect to the loss of Secure Rural School payments. Increased timber harvests in the PRMP would generate additional jobs in forestry, wood products, and related industries in most counties (see Table 4-11 through Table 4-15 below). In some counties, the increased income under the PRMP would help compensate for the loss of Secure Rural School payments. Increased industrial output and payroll under the PRMP would generate additional tax revenue for local government and demand for additional services such as public schools. Additional revenues from a larger industrial base would offset some of the local government jobs losses caused by terminated Secure Rural School funding (see Table 4-17 and Table 4-18).

The increase in the BLM harvests would range between $208 \%$ and $560 \%$ under the action alternatives. These increased harvests would create between 800 and 1,500 jobs in logging and trucking, and about 600 to 1,500 additional jobs in the wood products manufacturing sectors that are linked to logging.

Increased BLM harvests, plus the projected increased private harvests (estimated by the Western Oregon Model), would allow sawmills, board mills, and pulp mills to increase output. This increase would not be one-for-one, as some substitution of the additional BLM timber harvest for private timber harvest would occur.

Figure 4-25 through Figure 4-29 (Changes in employment by sector by county by alternative) show the sector level impacts by county for each alternative. Tables 4-11 through 4-15 (Changes in employment by county and sector) show that employment losses in some sectors would be offset by gains in other sectors. More detailed information about these projections is shown in Appendix D - Socioeconomics.

The BLM's land management, coupled with Secure Rural Schools payments, has played a large role in many western Oregon counties (refer to Sources of Economic Effects by Alternative). Together, in 2005, they accounted for 8,948 regional jobs and \$319.4 million in earnings. See Table 4-16 (Total economic impacts associated with BLM timber harvests by alternative). Under all alternatives, economic losses would be greatest in southwestern Oregon where the O\&C lands are concentrated. In Jackson and Douglas counties, revenues associated with the BLM-administered lands currently account for more than 3,000 jobs. Timber 
Figure 4-25. Percent Of Change In Employment By County And Sector - No Action Alternative

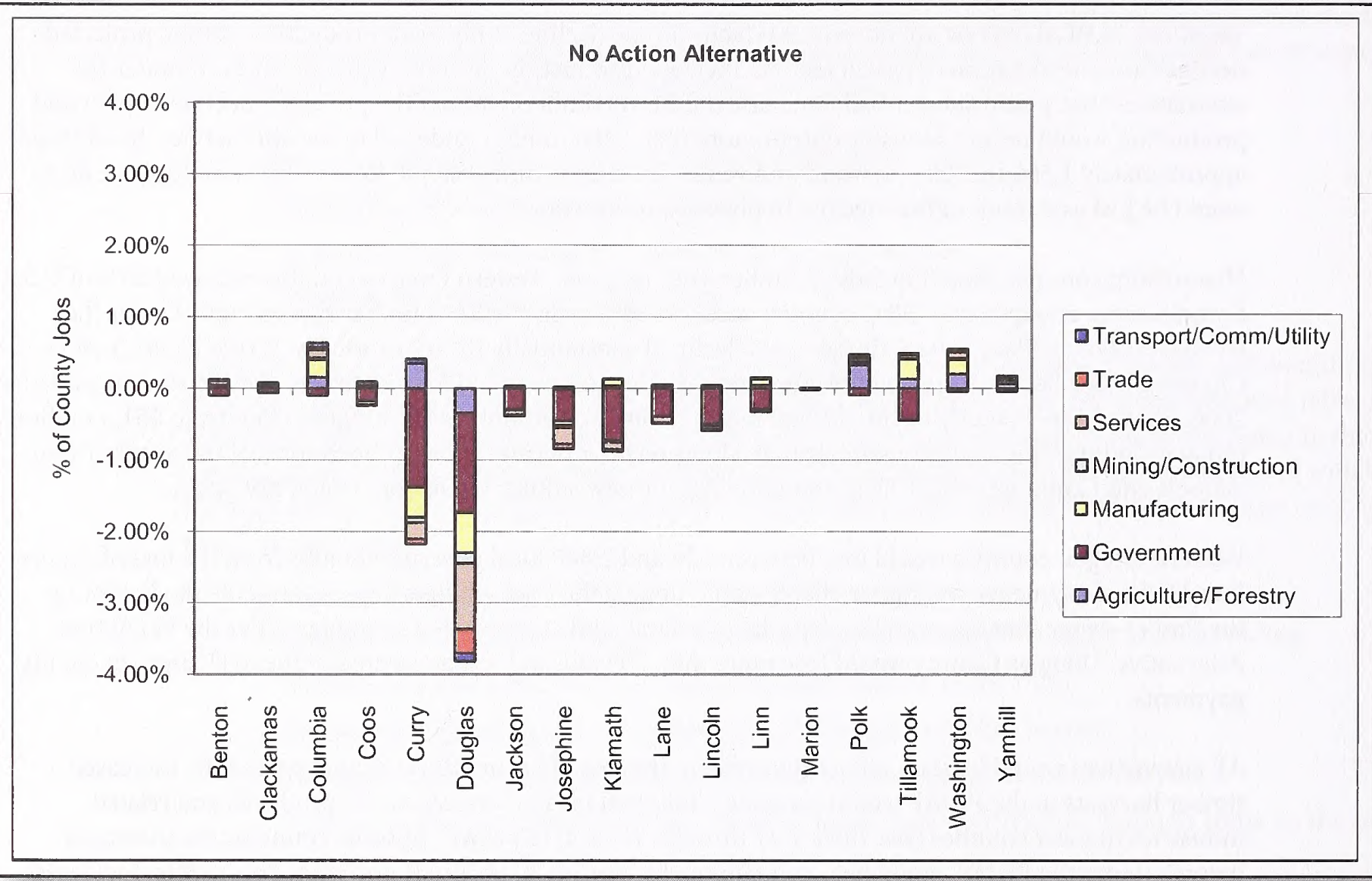

Table 4-11. Changes In Employment By County And Sector, No Action Alternative

\begin{tabular}{|c|c|c|c|c|c|c|c|c|}
\hline County & $\begin{array}{l}\text { Agriculture } \\
\text { and Forestry }\end{array}$ & Government & Manufacturing & $\begin{array}{l}\text { Mining and } \\
\text { Construction }\end{array}$ & Services & Trade & $\begin{array}{l}\text { Transport, } \\
\text { Communication, } \\
\text { and Utility }\end{array}$ & Total \\
\hline Benton & 19 & (35) & 0 & 1 & 19 & 4 & 4 & 12 \\
\hline Clackamas & 74 & (108) & 69 & - & 9 & 4 & 3 & 51 \\
\hline Columbia & 22 & (13) & 35 & 3 & 16 & 6 & 8 & 77 \\
\hline Coos & 11 & (49) & (17) & 0 & 0 & 0 & 15 & (39) \\
\hline Curry & 37 & (148) & (45) & (8) & (25) & (7) & 7 & (189) \\
\hline Douglas & (179) & $(736)$ & (297) & (76) & $(489)$ & $(176)$ & $(60)$ & $(2,012)$ \\
\hline Jackson & 39 & (304) & (3) & (4) & (66) & (10) & (3) & (351) \\
\hline Josephine & (4) & (164) & (22) & (14) & (84) & (25) & 8 & (306) \\
\hline Klamath & 12 & (247) & 33 & (8) & (35) & (7) & 2 & (251) \\
\hline Lane & 46 & (692) & 29 & (7) & $(151)$ & (19) & 28 & (767) \\
\hline Lincoln & 4 & (107) & 6 & (5) & (11) & (3) & 0 & (115) \\
\hline Linn & 26 & (142) & 44 & (5) & $(12)$ & (1) & 9 & $(82)$ \\
\hline Marion & 7 & (12) & 2 & (1) & (1) & 0 & 2 & (2) \\
\hline Polk & 74 & (20) & 10 & 1 & 11 & 4 & 7 & 87 \\
\hline Tillamook & 15 & (48) & 32 & 0 & 6 & 1 & 1 & 6 \\
\hline Washington & 22 & (4) & 23 & 1 & 10 & 2 & 3 & 57 \\
\hline Yamhill & 25 & (14) & 18 & 2 & 16 & 5 & 1 & 54 \\
\hline TOTAL & 249 & $(2,840)$ & (83) & (119) & (787) & (223) & 34 & $(3,768)$ \\
\hline
\end{tabular}


Figure 4-26. Percent Of Change In Employment By County And Sector - Alternative 1

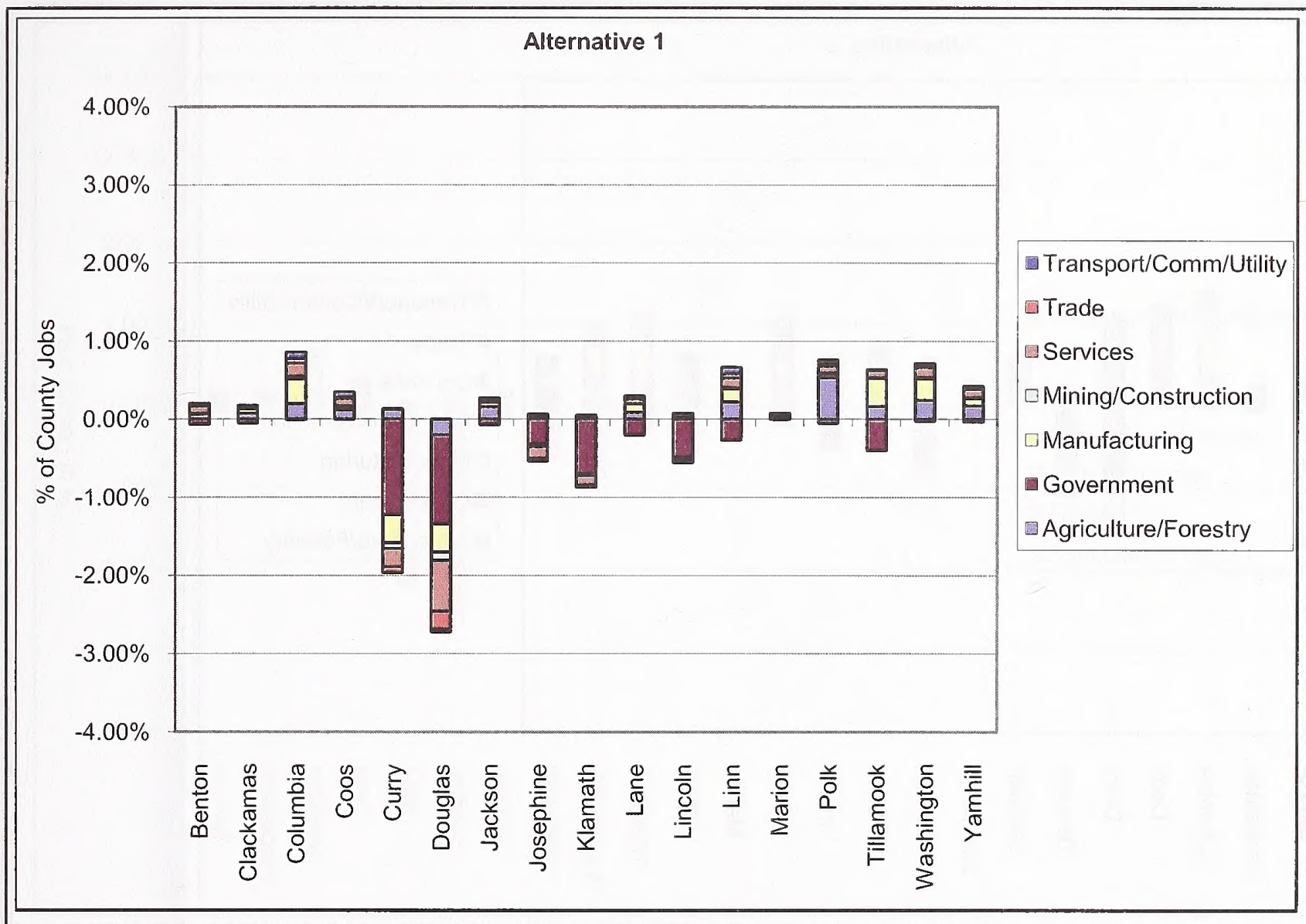

Table 4-12. Changes In Employment By County And Sector, Alternative 1

\begin{tabular}{|c|c|c|c|c|c|c|c|c|}
\hline \multirow[b]{2}{*}{ County } & \multicolumn{8}{|c|}{ Employment by Sector } \\
\hline & $\begin{array}{l}\text { Agriculture } \\
\text { and Forestry }\end{array}$ & Government & Manufacturing & $\begin{array}{l}\text { Mining and } \\
\text { Construction }\end{array}$ & Services & Trade & $\begin{array}{r}\text { Transport, } \\
\text { Communication, } \\
\text { and Utility }\end{array}$ & Total \\
\hline Benton & 26 & (23) & 0 & 2 & 34 & 7 & 7 & 53 \\
\hline Clackamas & 145 & (93) & 129 & 2 & 48 & 12 & 7 & 250 \\
\hline Columbia & 28 & (1) & 45 & 5 & 23 & 8 & 12 & 120 \\
\hline Coos & 34 & 8 & 6 & 0 & 27 & 4 & 21 & 100 \\
\hline Curry & 13 & (131) & (39) & (8) & (25) & (8) & 1 & (196) \\
\hline Douglas & (105) & $(600)$ & (192) & (55) & (342) & (122) & (20) & $(1,436)$ \\
\hline Jackson & 161 & (71) & 67 & 0 & 32 & 7 & 14 & 211 \\
\hline Josephine & 10 & $(116)$ & (7) & (8) & (54) & (13) & 15 & (174) \\
\hline Klamath & 9 & (238) & 8 & (9) & (41) & (9) & 1 & $(278)$ \\
\hline Lane & 155 & (354) & 200 & 0 & 102 & 18 & 64 & 184 \\
\hline Lincoln & 6 & $(104)$ & 10 & (4) & $(8)$ & (2) & 0 & (102) \\
\hline Linn & 113 & (132) & 84 & 7 & 63 & 27 & 43 & 205 \\
\hline Marion & 14 & 65 & 5 & 4 & 26 & 4 & 6 & 124 \\
\hline Polk & 120 & (11) & 11 & 3 & 20 & 7 & 10 & 160 \\
\hline Tillamook & 18 & (43) & 40 & 0 & 10 & 1 & 1 & 27 \\
\hline Washington & 27 & (2) & 31 & 2 & 14 & 3 & 2 & 76 \\
\hline Yamhill & 66 & (11) & 38 & 3 & 39 & 13 & 3 & 151 \\
\hline TOTAL & 840 & $(1,858)$ & 435 & (55) & (32) & (43) & 188 & (525) \\
\hline
\end{tabular}


FEIS for the Revision of the Western Oregon RMPs

Figure 4-27. Percent Of Change In Employment By County And Sector - Alternative 2

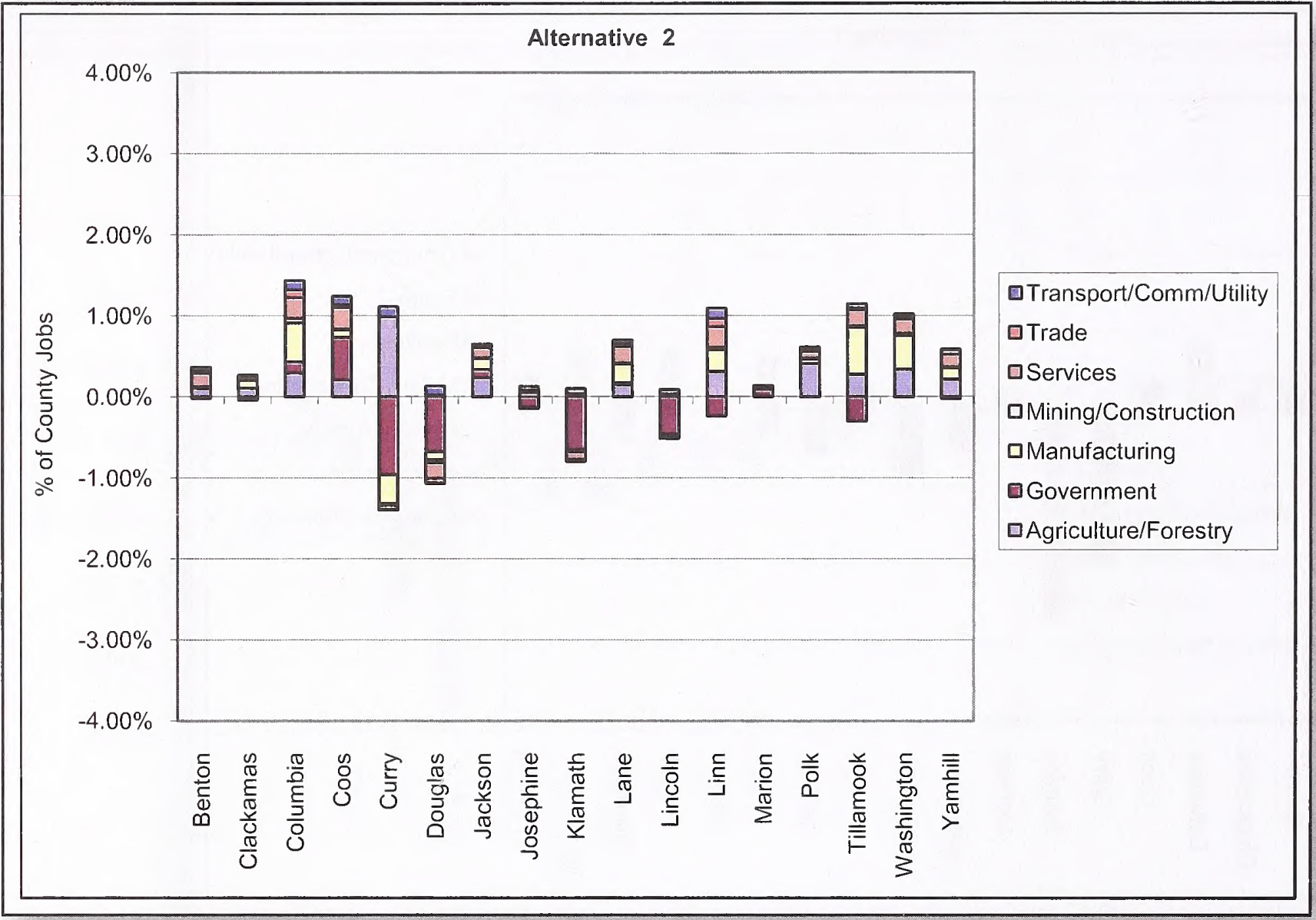

Table 4-13. Changes In Employment By County And Sector, Alternative 2

\begin{tabular}{|c|c|c|c|c|c|c|c|c|}
\hline \multirow[b]{2}{*}{ County } & \multicolumn{8}{|c|}{ Employment by Sector } \\
\hline & $\begin{array}{r}\text { Agriculture } \\
\text { and Forestry }\end{array}$ & Government & Manufacturing & $\begin{array}{l}\text { Mining and } \\
\text { Construction }\end{array}$ & Services & Trade & $\begin{array}{l}\text { Transport, } \\
\text { Communication, } \\
\text { and Utility }\end{array}$ & Total \\
\hline Benton & 41 & (6) & 1 & 4 & 63 & 12 & 16 & 132 \\
\hline Clackamas & 212 & (71) & 193 & 4 & 91 & 20 & 11 & 460 \\
\hline Columbia & 42 & 19 & 68 & 8 & 36 & 14 & 16 & 204 \\
\hline Coos & 60 & 151 & 27 & 2 & 77 & 10 & 30 & 358 \\
\hline Curry & 106 & (103) & (38) & (2) & (6) & (1) & 14 & (30) \\
\hline Douglas & 12 & (356) & (52) & (21) & $(100)$ & (34) & 58 & $(494)$ \\
\hline Jackson & 244 & 102 & 147 & 4 & 130 & 24 & 21 & 672 \\
\hline Josephine & 19 & (49) & 11 & (2) & (2) & 0 & 18 & (4) \\
\hline Klamath & 14 & (223) & 19 & (8) & (34) & (7) & 2 & (237) \\
\hline Lane & 271 & 36 & 423 & 7 & 380 & 59 & 85 & 1,261 \\
\hline Lincoln & 8 & (99) & 11 & (3) & (7) & (1) & 0 & (91) \\
\hline Linn & 158 & (120) & 135 & 17 & 128 & 51 & 63 & 432 \\
\hline Marion & 11 & 134 & 6 & 9 & 49 & 6 & 4 & 219 \\
\hline Polk & 93 & 0 & 12 & 3 & 18 & 6 & 7 & 139 \\
\hline Tillamook & 31 & (33) & 64 & 1 & 22 & 2 & 6 & 93 \\
\hline Washington & 37 & 0 & 46 & 3 & 19 & 4 & 3 & 112 \\
\hline Yamhill & 82 & (7) & 53 & 5 & 60 & 19 & 5 & 216 \\
\hline TOTAL & 1,440 & (626) & 1,127 & 31 & 924 & 186 & 360 & 3,442 \\
\hline
\end{tabular}

Chapter 4-554 
Figure 4-28. Percent Of Change In Employment By County And Sector - Alternative 3

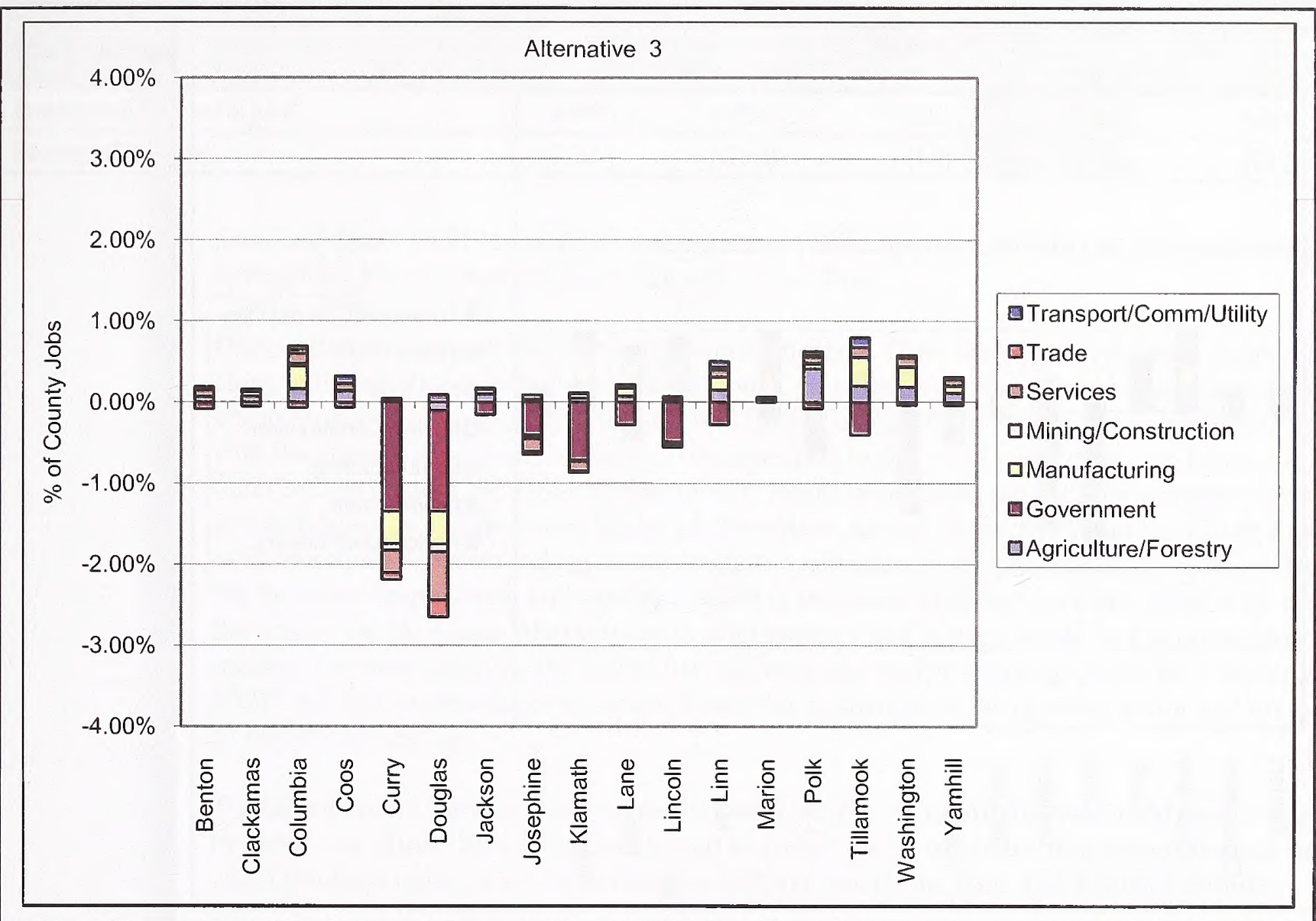

Table 4-14. Changes In Employment By County And Sector, Alternative 3

\begin{tabular}{|c|c|c|c|c|c|c|c|c|}
\hline \multirow[b]{2}{*}{ County } & \multicolumn{8}{|c|}{ Employment by Sector } \\
\hline & $\begin{array}{r}\text { Agriculture } \\
\text { and Forestry }\end{array}$ & Government & Manufacturing & $\begin{array}{l}\text { Mining and } \\
\text { Construction }\end{array}$ & Services & Trade & $\begin{array}{l}\text { Transport, } \\
\text { Communication, } \\
\text { and Utility }\end{array}$ & Total \\
\hline Benton & 25 & (31) & 1 & 1 & 28 & 6 & 10 & 39 \\
\hline Clackamas & 140 & $(104)$ & 118 & 1 & 39 & 10 & 6 & 210 \\
\hline Columbia & 23 & (10) & 40 & 4 & 18 & 7 & 6 & 88 \\
\hline Coos & 38 & (18) & 3 & 0 & 23 & 4 & 25 & 75 \\
\hline Curry & 4 & (144) & (43) & (9) & (29) & (9) & 1 & $(230)$ \\
\hline Douglas & (54) & (657) & $(212)$ & (53) & (311) & (109) & 46 & $(1,351)$ \\
\hline Jackson & 102 & (153) & 62 & (1) & (7) & 1 & 13 & 16 \\
\hline Josephine & 14 & (149) & (9) & (10) & (56) & (16) & 18 & (208) \\
\hline Klamath & 16 & (242) & 19 & (9) & (38) & (7) & 3 & (257) \\
\hline Lane & 136 & (489) & 172 & (3) & 14 & 6 & 52 & (111) \\
\hline Lincoln & 7 & $(104)$ & 8 & (4) & (8) & (2) & 0 & (103) \\
\hline Linn & 76 & (139) & 80 & 3 & 41 & 19 & 37 & 117 \\
\hline Marion & 13 & 47 & 3 & 3 & 21 & 3 & 6 & 95 \\
\hline Polk & 93 & (17) & 13 & 2 & 16 & 6 & 10 & 123 \\
\hline Tillamook & 22 & (44) & 38 & 1 & 13 & 1 & 12 & 43 \\
\hline Washington & 21 & (4) & 27 & 1 & 11 & 2 & 1 & 60 \\
\hline Yamhill & 44 & (13) & 31 & 3 & 29 & 10 & 3 & 106 \\
\hline TOTAL & 721 & $(2,271)$ & 351 & (70) & (197) & (70) & 248 & $(1,288)$ \\
\hline
\end{tabular}


Figure 4-29. Percent Of Change In Employment By County And Sector - PrMP

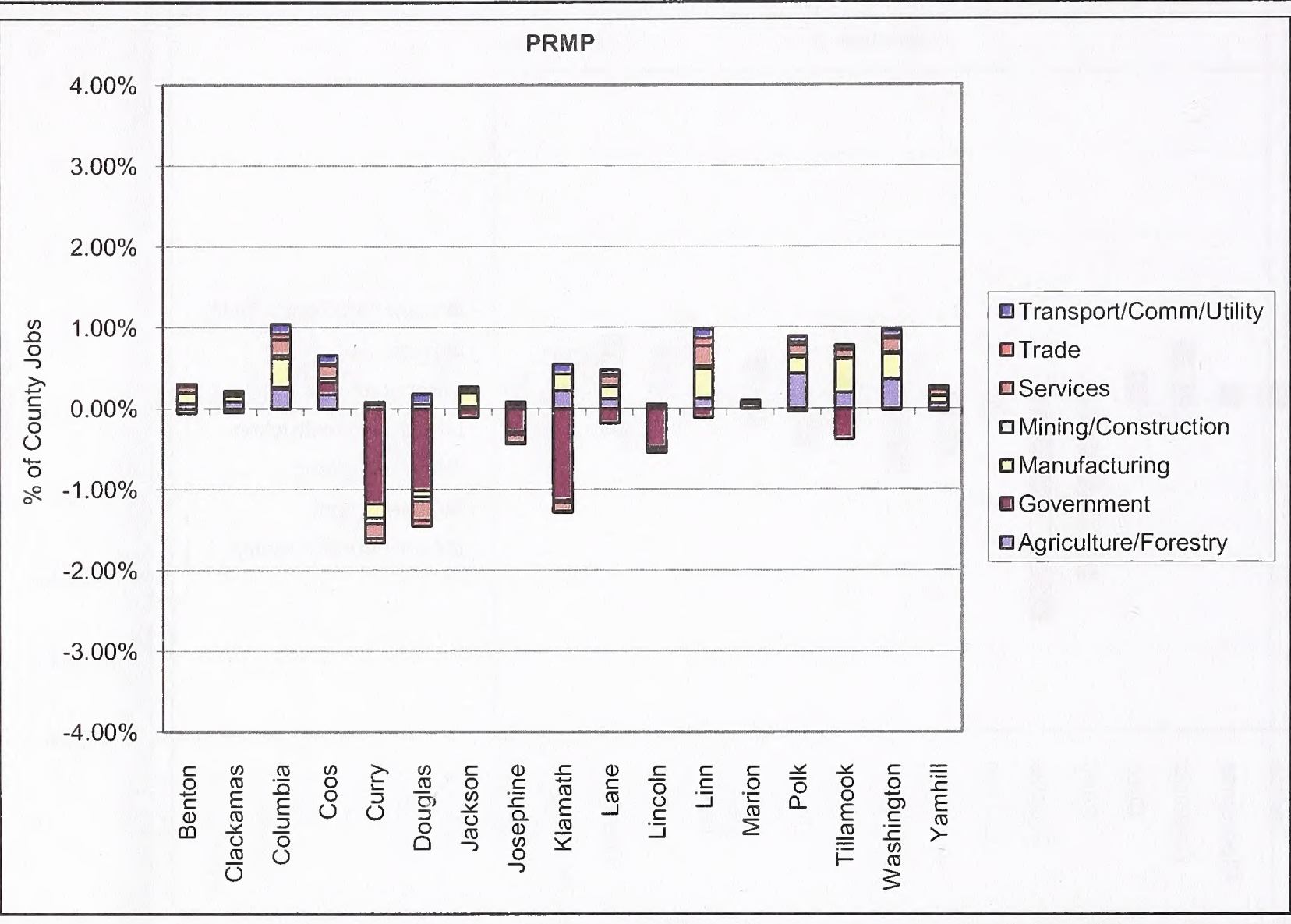

Table 4-15. Changes in Employment By County And Sector, PRMP

\begin{tabular}{|c|c|c|c|c|c|c|c|c|}
\hline \multirow[b]{2}{*}{ County } & \multicolumn{8}{|c|}{ Employment by Sector } \\
\hline & $\begin{array}{l}\text { Agriculture } \\
\text { and Forestry }\end{array}$ & Government & Manufacturing & $\begin{array}{l}\text { Mining and } \\
\text { Construction }\end{array}$ & Services & Trade & $\begin{array}{r}\text { Transport, } \\
\text { Communication, } \\
\text { and Utility }\end{array}$ & Total \\
\hline Benton & 22 & (21) & 50 & 2 & 29 & 6 & 7 & 94 \\
\hline Clackamas & 174 & (89) & 148 & 3 & 69 & 16 & 23 & 344 \\
\hline Columbia & 34 & 4 & 50 & 6 & 27 & 10 & 17 & 149 \\
\hline Coos & 51 & 44 & 14 & 1 & 44 & 6 & 30 & 190 \\
\hline Curry & 5 & $(126)$ & (19) & $(7)$ & $(20)$ & (6) & 4 & $(169)$ \\
\hline Douglas & 30 & (533) & (43) & (27) & (122) & (39) & 66 & (669) \\
\hline Jackson & 33 & $(106)$ & 178 & 1 & 41 & 8 & 19 & 173 \\
\hline Josephine & 15 & (104) & (9) & (7) & (34) & (9) & 16 & (132) \\
\hline Klamath & 75 & (386) & 71 & (11) & (37) & (4) & 41 & (251) \\
\hline Lane & 219 & (321) & 285 & 3 & 204 & 38 & 108 & 536 \\
\hline Lincoln & 7 & (103) & 5 & (4) & (8) & 0 & (2) & $(106)$ \\
\hline Linn & 62 & (55) & 188 & 17 & 124 & 48 & 59 & 444 \\
\hline Marion & 12 & 85 & 4 & 5 & 32 & 4 & 6 & 149 \\
\hline Polk & 98 & (9) & 45 & 4 & 28 & 10 & 15 & 192 \\
\hline Tillamook & 22 & (41) & 45 & 1 & 12 & 1 & 5 & 45 \\
\hline Washington & 40 & (2) & 34 & 3 & 18 & 4 & 9 & 105 \\
\hline Yamhill & 24 & (11) & 33 & 3 & 29 & 10 & 3 & 91 \\
\hline TOTAL & 923 & $(1,774)$ & 1,080 & (6) & 436 & 103 & 425 & 1,187 \\
\hline
\end{tabular}

Chapter $4-556$ 
Table 4-16. Total Economic Impacts Associated With BLM Timber Harvests By Alternative

\begin{tabular}{l|r|rrrrr}
\hline \multirow{2}{*}{ Economic Impact } & \multirow{2}{*}{ Current } & \multicolumn{5}{|c}{ Change in O\&C County Totals by Alternative } \\
\cline { 3 - 7 } & & No Action & Alt. 1 & Alt. 2 & Alt. 3 & PRMP \\
\hline Employment (number of jobs) & 8,948 & $(3,768)$ & $(525)$ & 3,442 & $(1,288)$ & 1,187 \\
\hline Earnings (\$ millions) & 319.4 & $(125.5)$ & $(7.3)$ & 136.5 & $(34.7)$ & 52.1 \\
\hline
\end{tabular}

harvested from the BLM-administered lands also plays important roles in the economies of EugeneSpringfield, Albany, Medford, Coos Bay, and Grants Pass.

Under all alternatives, timber harvesting would increase. There would be an increase in jobs and income along with a multiplier as impacts ripple through other sectors in the affected county economies. Economic effects would vary in proportion to increased timber harvest volumes. The economic effects would also vary with the amount of a county economy's concentration in the wood products sector. Economic activity in other sectors (caused indirectly by multipliers) would be based on the county's economic diversity and its self-sufficiency as a trade center. Under all alternatives except Alternative 2 and the PRMP, however, the loss of Secure Rural Schools funding coupled with the reduction in the plywood industry would be greater than the increased employment and earnings linked to increased BLM harvest levels. Table 4-16, therefore, shows that under the No Action Alternative and Alternatives 1 and 3, there would be a net reduction in jobs and income. For most counties, the higher harvest levels and higher stumpage prices for Alternative 2 and the PRMP would compensate for economic losses due to changes in the plywood sector and the loss of Secure Rural School funding.

The loss of Secure Rural Schools payments under the No Action Alternative would reduce regional earnings by about one-third. These reductions would be compounded by contraction in the plywood subsector of the wood products industry in Curry, Douglas, Jackson, Josephine, Linn, and Klamath counties.

Under the PRMP, there would be a net gain of 1,187 jobs in western Oregon with $\$ 52.1$ million in associated income. All counties except Curry, Douglas Josephine, Klamath, and Lincoln counties would see net job increases. In these counties, increased timber harvests and sawmill operations would not be sufficient to offset losses of county payments and declining plywood production. Job losses in these counties would vary from negligible impacts in Marion County, to 2 percent of total employment in Douglas County. These losses would cause noticeable impacts in southern Oregon County economies, concentrated in sectors linked to local government and wood products industries.

Under the PRMP, the O\&C timber harvests would shift geographically toward the Willamette Valley compared to the other alternatives. Because the harvest level would be proportionally higher in the northern districts compared to the other alternatives, there would be an accompanying increase in timber-related jobs and increased wood products manufacturing in these geographic area. See Table 4-26 (Allowable sale quantity by district and alternative) in the Timber section of this chapter.

Under Alternative 1, the increase of the BLM timber harvest would generate relatively small net economic impacts in western Oregon. Under Alternative 1, the jobs lost in some counties (Coos, Jackson, Lane, Linn, and Marion) would be offset by the jobs created in most other counties. However, Douglas and Klamath counties would have such large losses of jobs and earnings that there would still be a net loss overall in western Oregon.

Under Alternative 2, increased jobs and earnings would offset declines in most counties that would be caused by changes in the wood products industry and loss of Secure Rural Schools payments. Under Alternative 2, about 3,400 new jobs would be created and income would be increased by $\$ 137$ million across western Oregon. Substantial increases would occur in Clackamas, Coos, Jackson, Lane, Linn, Marion, and Yamhill counties. However, the increase in the BLM's harvest under Alternative 2 would still not be sufficient 
economic stimulus to overcome job losses in Curry, Douglas, Josephine, Klamath, and Lincoln counties. The job losses in these counties would be primarily in local government resulting mostly from losses of payments to the counties and contraction in the plywood sectors unrelated to the BLM's harvests.

For most counties, the economic impacts under Alternative 3 would be similar to those under Alternative 1. The exception would be Lane County, which would have considerably more jobs created in logging and wood products manufacturing. Under Alternative 3, there would be a net income loss of about $\$ 35$ million across western Oregon. The most substantial county losses would occur in southwestern Oregon (Curry, Douglas, Josephine, and Klamath counties). For example, Douglas County would lose about $\$ 40$ million in earnings. In the remaining counties, there would be enough economic increases resulting from the BLM's harvest to generally offset the loss of Secure Rural School payments. Nevertheless, many individual sectors, particularly those linked to plywood production, would still have income losses.

Only under Alternative 2 would there be sufficient economic gains from increased harvesting to offset the loss of Secure Rural Schools payments and the projected contractions in the plywood sub-sector. In some alternatives, particularly Alternative 2, the increased employment and income associated with the increased harvesting would be sufficiently large enough to offset the decreased employment and income caused by losses of Secure Rural Schools funding and the reduction in the plywood industry.

Jobs are an important indicator of the magnitude of the economic impact of the alternatives. A large set of O\&C counties would generally show net gains under most of the alternatives. See Table 4-17 (Counties in which the alternatives would compensate for other job losses). Note that under the No Action Alternative, however, harvest increases would be relatively small, so job losses resulting from other factors would not be offset in Coos, Jackson, and Linn counties.

Harvesting under any of the alternatives would not create sufficient jobs to compensate for job losses caused by the loss of Secure Rural Schools payments and the decline in plywood production in six counties. See Table 4-18 (Counties in which the alternatives would not compensate for other job losses). The group of counties shown in Table 4-18 is characterized by large losses in Secure Rural Schools payments and the presence of a large plywood subsector. Lane county would have mixed responses to the various alternatives due to more diversity in their forest products sector, but is included in this group due to large losses for the No Action Alternative and Alternative 3.

Douglas County would have the largest and most consistent economic loss among all the O\&C counties, because it would lose large Secure Rural Schools payments ( $\$ 51.1$ million annually from the USFS and BLM) and because it has a large plywood subsector.

Table 4-17. Counties In Which The Alternatives Would Compensate For Other JoB Losses

\begin{tabular}{lrrrrrr}
\hline \multirow{2}{*}{$\begin{array}{l}\text { Counties With Net } \\
\text { Gains }\end{array}$} & Current Jobs & \multicolumn{7}{c}{ Changes in Employment by Alternative } \\
\cline { 3 - 8 } & 118 & No Action & Alt. 1 & Alt. 2 & Alt. 3 & PRMP \\
\hline Benton & 265 & 51 & 53 & 132 & 39 & 94 \\
\hline Clackamas & 52 & 77 & 120 & 210 & 344 \\
\hline Columbia & 410 & $(39)$ & 100 & 358 & 75 & 149 \\
\hline Coos & 1,612 & $(351)$ & 211 & 672 & 16 & 190 \\
\hline Jackson & 396 & $(82)$ & 205 & 432 & 117 & 173 \\
\hline Linn & 272 & $(2)$ & 124 & 219 & 95 & 444 \\
\hline Marion & 54 & 87 & 160 & 139 & 123 & 149 \\
\hline Polk & 79 & 6 & 27 & 93 & 43 & 192 \\
\hline Tillamook & 22 & 57 & 76 & 112 & 60 & 45 \\
\hline Washington & 59 & 54 & 151 & 216 & 106 & 105 \\
\hline Yamhill & & & & & 91 & 91 \\
\hline
\end{tabular}


Table 4-18. Counties In Which The Alternatives Would Not Compensate For Other Job Losses

\begin{tabular}{l|r|r|r|r|r|r}
\hline \multirow{2}{*}{$\begin{array}{l}\text { Counties With Net } \\
\text { Losses }\end{array}$} & Current Jobs & \multicolumn{5}{|c}{ Changes in Employment by Alternative } \\
\cline { 3 - 7 } & & No Action & Alt. 1 & Alt. 2 & Alt. 3 & PRMP \\
\hline Curry & 235 & $(189)$ & $(196)$ & $(30)$ & $(230)$ & $(169)$ \\
\hline Douglas & 2.204 & $(2,012)$ & $(1,436)$ & $(494)$ & $(1,351)$ & $(669)$ \\
\hline Josephine & 470 & $(306)$ & $(174)$ & $(4)$ & $(208)$ & $(132)$ \\
\hline Klamath & 571 & $(251)$ & $(278)$ & $(237)$ & $(257)$ & $(251)$ \\
\hline Lane & 1,987 & $(767)$ & 184 & 1,261 & $(111)$ & 536 \\
\hline Lincoln & 143 & $(115)$ & $(102)$ & $(91)$ & $(103)$ & $(106)$ \\
\hline
\end{tabular}

A closer look at the estimated job impacts in Douglas County under the No Action Alternative illustrates the importance of considering all reasonably foreseeable sources of economic impact. If the economic analysis considered just the impacts of the changes to the harvest levels, the analysis would show that Douglas County employment would increase by 645 jobs simply as a result of increased harvest levels. If the analysis considered just the increased harvest levels and the contraction of the plywood industry, then the analysis would show a net loss of 936 jobs, because the plywood industry is heavily concentrated in Douglas County. If the analysis considered only the changes to the harvest levels and the loss of the Secure Rural Schools payments, then there would be a net increase of 163 jobs, which would result from an increase in the wood products sector offsetting losses in the government sector. When all three factors (the loss of the Secure Rural Schools payments, the contraction of the plywood industry, and the increase in BLM harvest levels) are considered together, there would be a net loss of 2,012 jobs. In other words, the increased employment in the wood products sector, specifically the sawmilling industry, would not be enough to offset losses in the government sector and the plywood industry. Similar relationships would occur in each county under each alternative, with the magnitude depending on the unique economic structure of each county and the specific harvest configuration of each alternative. Under the PRMP, there would be a $135 \mathrm{mmbf}$ increase in Douglas County timber harvest, and jobs linked to this increase would compensate for some jobs lost in plywood production and county government.

There would be a spectrum of county economic responses to timber harvest increases under the alternatives. For the purpose of analysis and discussion, counties are clustered into five categories that reflect the sensitivity of individual county economies. A county may fall into one or more of these categories.

\section{Sensitivity Categories of County Economies}

\section{Type 1}

Type 1 county economies would have little or no impact from the alternatives. These counties have small Secure Rural School payments, few BLM lands, or little reliance on the wood products industries relative to the size of their economies. Benton County and Polk County are examples of this, although the geographical harvest shift under the PMRP would marginally increase Polk County's wood products employment. Clatsop County has so few connections to all of the impact sources that it was not modeled.

\section{Type 2}

Type 2 counties have large diversified economies. In these counties, the economic effects of the alternatives would be small relative to the jobs and incomes generated by other sectors. Columbia and Washington counties have positive wood products sector responses, but they are primarily commuter adjuncts to Portland. Marion County is dominated by state and federal government sectors. The Portland metropolitan economy is so large that the Multnomah County model was not used. 


\section{Type 3}

These are counties in which the effects of the alternatives would be large enough to compensate for the loss of Secure Rural Schools payments-mostly from the higher levels of activity in the sawmill sectors and its multipliers. See Table 4-19 (Wood products counties with gains concentrated in sawmills). These counties would face internal trade-offs between job and budget losses in county governments and labor gains as sawmills expand. Even though Coos and Curry counties would have sawmill sector gains, the Secure Rural Schools payment loss effect would remain concentrated in local government and sectors. In some cases, resource-based economies such as Lincoln and Tillamook counties are reliant on non-BLM timber sources, so they would be only peripherally affected by the BLM timber harvest changes under the alternatives. The plywood counties (see Type 5) are shown here to indicate that some may have sawmill gains even when plywood jobs are declining.

\section{Type 4}

These counties have a large federal forest land base and significant wood products sectors. All counties had some reliance on federal Secure Rural Schools payments. The BLM harvest revenue sharing would offset losses somewhat under all alternatives. However, seven of these counties (Clackamas, Douglas, Jackson, Josephine, Klamath, Lane, and Linn) would be at large fiscal risk even considering higher BLM harvests. See Table 4-20 (Counties losing more than $\$ 10$ million per year in Secure Rural Schools payments). Job and budget losses would be concentrated in the county government sector and any multipliers tied to that sector.

Counties with large sawmill production value increases (e.g., Clackamas) and relatively small plywood subsectors would be most likely to have a neutral economic effect. Plywood counties have compounded economic losses from losses of payments to counties and adjustments in the wood products industry.

\section{Type 5}

These are counties that would have substantial or moderate losses from all of the alternatives. Three plywood counties (Douglas, Jackson, Lane) would have substantial economic losses. Four other counties (Coos, Curry, Josephine, and Linn) would have moderate economic losses where the plywood industry supplements instead of characterizes the wood products sectors. Large projected reductions in plywood and veneer output values worsen the Secure Rural Schools payment losses. See Table 4-21 (County plywood output contraction by alternative).

Table 4-19. Wood Products Counties With Gains Concentrated In Sawmills

\begin{tabular}{|c|c|c|c|c|c|c|}
\hline \multirow{2}{*}{$\begin{array}{l}\text { Counties With } \\
\text { Concentrated Sawmill } \\
\text { Gains }\end{array}$} & \multirow[b]{2}{*}{ Current } & \multicolumn{5}{|c|}{ Changes in Sawmill Sector Industrial Output $(\$ 1,000)$ by Alternative } \\
\hline & & No Action & Alt. 1 & Alt. 2 & Alt. 3 & PRMP \\
\hline Clackamas & 4,913 & 14,717 & 27,702 & 40,412 & 25,541 & 27,526 \\
\hline Columbia & 339 & 17,274 & 21,767 & 32,962 & 19,409 & 24,210 \\
\hline Coos & 2,638 & 6,185 & 11,781 & 16,782 & 11,083 & 8,526 \\
\hline Curry & 222 & 3,307 & 6,386 & 9,103 & 5,905 & 2,374 \\
\hline Josephine & 1,569 & 1,741 & 3,363 & 4,793 & 3,109 & 1,250 \\
\hline Lane & 15,711 & 30,573 & 58,205 & 91,352 & 55,606 & 54,922 \\
\hline Linn & 2,392 & 13,197 & 16,790 & 23,936 & 14,881 & 14,571 \\
\hline Polk & 462 & 9,160 & 11,905 & 16,588 & 10,504 & 10,114 \\
\hline
\end{tabular}


Table 4-20. Counties losing More Than $\$ 10$ Million Per Year In Secure Rural Schools PAYMENTS

\begin{tabular}{lrrrrrr}
\hline $\begin{array}{l}\text { Counties With Large } \\
\text { Secure Rural Public } \\
\text { School Funding Losses }\end{array}$ & $\begin{array}{r}\text { Current } \\
\text { (\$ million) }\end{array}$ & No Action & Alt. 1 & Alt. 2 & Alt. 3 & PRMP \\
\hline Clackamas & 13.5 & $(11.2)$ & $(9.7)$ & $(7.5)$ & $(10.8)$ & $(9.3)$ \\
\hline Douglas & 51.1 & $(40.7)$ & $(34.0)$ & $(24.1)$ & $(39.0)$ & $(32.4)$ \\
\hline Jackson & 24.3 & $(17.7)$ & $(13.5)$ & $(7.4)$ & $(16.7)$ & $(12.5)$ \\
\hline Josephine & 16.8 & $(11.7)$ & $(8.5)$ & $(3.8)$ & $(11.0)$ & $(7.7)$ \\
\hline Klamath & 19.9 & $(18.9)$ & $(18.3)$ & $(17.3)$ & $(18.7)$ & $(18.1)$ \\
\hline Lane & 51.5 & $(45.1)$ & $(41.1)$ & $(35.1)$ & $(44.2)$ & $(40.1)$ \\
\hline Linn & 14.4 & $(13.3)$ & $(12.6)$ & $(11.6)$ & $(13.1)$ & $(12.4)$ \\
\hline
\end{tabular}

Table 4-21. County Plywood Output Contraction By Alternative

\begin{tabular}{lrrrrrr}
\hline & & \multicolumn{5}{c}{ Changes in Plywood Output by Alternative (\$ million) } \\
\cline { 3 - 7 } $\begin{array}{l}\text { Counties With Plywood } \\
\text { Output Contraction }\end{array}$ & Current Output & No Action & Alt. 1 & Alt. 2 & Alt. 3 & PRMP \\
\hline Coos & 78.5 & $(12.2)$ & $(12.1)$ & $(12.2)$ & $(12.2)$ & $(14.9)$ \\
\hline Curry & 42.9 & $(6.6)$ & $(5.9)$ & $(5.9)$ & $(6.6)$ & $(7.4)$ \\
\hline Douglas & 438.7 & $(68.1)$ & $(65.9)$ & $(60.4)$ & $(67.2)$ & $(74.8)$ \\
\hline Jackson & 271.4 & $(42.0)$ & $(39.8)$ & $(37.3)$ & $(39.7)$ & $(22.9)$ \\
\hline Josephine & 59.9 & $(9.3)$ & $(9.3)$ & $(8.3)$ & $(9.3)$ & $(10.3)$ \\
\hline Lane & 211.2 & $(32.7)$ & $(32.7)$ & $(29.0)$ & $(32.7)$ & $(32.7)$ \\
\hline Linn & 55.6 & $(8.9)$ & $(8.7)$ & $(8.1)$ & $(8.7)$ & $(8.9)$ \\
\hline
\end{tabular}

This pattern of economic response would be caused by large compounded economic losses from two sources: elimination of Secure Rural Schools payments concentrates economic impacts in county government employment, and budgets. The plywood contraction projection reduces highly paid jobs and high value-added production. The BLM harvests directly increase logging, transportation, sawmill, pulpmill, and board plant jobs only where these subsectors exist. As each of these sectors has different patterns of purchases from other sectors, many of these counties have unique multiplier effects.

A discussion of the overall economic impacts does not capture the subtleties of the impacts within the individual counties or the specific sectors, such as the plywood and sawmill industries. Under all alternatives, Douglas County would have the most severe economic losses. It would have a sharp decline in plywood production and local government, along with secondary effects in other such sectors as logging and the retail trade. Most of these economic losses would occur in the Roseburg vicinity, where government and plywood manufacturing are concentrated.

Economic losses in Curry County would not be as large as those in the larger Douglas County economy, but would still be substantial given the small size of the county. Increased logging and sawmill operations in Brookings would be offset by declines in plywood manufacturing. The loss of government jobs would be most severe in Gold Beach, the county seat. The loss of local governmental services would be particularly difficult for this county because of the high proportion of retirees who need such specialized services as home health care. Only 10 counties in the United States have higher retiree proportions than Curry County (Census 2000, 2006). 
Klamath County would also experience substantial economic losses under all alternatives because of its large losses of Secure Rural Schools payment. Job losses in Klamath County under all alternatives would range from 237 to 278 jobs. Klamath County is a major plywood producer, so these job losses would be compounded by job losses resulting in adjustments in the wood products industry.

Josephine County and Jackson County have close economic ties and similarities. Both counties have plywood manufacturing operations that are projected to lose jobs; both counties have a large share of the O\&C lands; and both county governments received large Secure Rural Schools payments. Grants Pass would experience economic losses due to the loss of county payments. Jackson County would experience an increase in jobs under the action alternatives including the PRMP. See Table 4-17 (Counties in which the alternatives would compensate for other job losses). Cave Junction would experience improvements in its economy due to increased timber harvests from both the BLM and private forests. The Medford area is a major plywood manufacturing area and would experience large reductions in employment. Some of these economic losses would be offset by increased industry output in sawmills and board mills in White City. Local government services in both counties would shrink. The Medford economy is sufficiently diverse and robust that these job losses would be offset by growth in other economic sectors.

Lincoln County would experience economic losses under all alternatives. Almost all of these losses would be in local government, which would lose about 100 jobs. Newport would experience the most loss.

Lane and Linn County would experience similar economic losses, but Lane County's economic losses would be mostly the result of the loss of about $\$ 40$ million in Secure Rural Schools payments. The logging and sawmill sectors in these counties would grow, particularly under the PRMP and Alternative 2, with both counties showing large economic gains in that part of the wood products sector, even though both counties would concurrently experience losses associated with the decline in plywood production. There would be a large economic loss to local government in these two counties, especially in both county seats (Eugene and Albany). These larger, more urban economies, however, are more resilient than the county seats in more rural areas. Plywood mill closures in communities such as Lebanon are more likely to produce long-term localized changes than those caused by changes in the BLM timber harvests.

The two other coastal counties (Coos and Tillamook) would experience improvements in their logging and sawmill sectors, particularly under Alternative 2 and the PRMP. In Coos County, these economic gains would be partially offset by losses in plywood manufacturing. Coos County has a much larger proportion of federal lands, so increased federal jobs would offset the reduction in local government funding and services resulting in little net government sector change. There would be a proportionally larger economic loss to Coquille compared to other communities because it has both a plywood plant and it is the county seat.

Counties in and near the Portland metropolitan area (Clackamas, Washington, Yamhill, and Columbia) are part of a diversified and rapidly growing economy. None of these counties have a large proportion of federal lands; none are timber dependent; and none are dependent on Secure Rural School funds, even though Clackamas would lose $\$ 11.3$ million from this source. Economic impacts on these counties would be minimal and almost unrelated to the BLM's timber harvest changes. There are, however, some smaller communities within those counties that do have wood products-based economies. Willamina, Molalla, St. Helens, and Rainier would experience economic gain of varying degrees under all alternatives.

Central Willamette Valley counties (Benton, Marion, and Polk) would not experience a substantive economic effect as a result of any of the alternatives. They would have only lost $\$ 2.4$ million to $\$ 4.6$ million each from the termination of Secure Rural Schools payments. These counties are not major wood products processing counties and do not have significant shares of the O\&C lands. 


\section{Community Well-Being}

Donoghue et al. (USDA USFS 2006c) calculated a socioeconomic well-being index for 433 communities in western Oregon and noted how the index changed between 1990 and 2000 (see the Socioeconomics section of Chapter 3). The results suggest those communities with low and or declining socioeconomic well-being scores are most typically found in the more rural and more southern counties.

The county-level analysis of jobs and income indicates that counties with the greatest potential net loss of jobs and income under any alternative are similarly more rural and more southern.

The analysis of the economic impacts of the alternatives describes net changes in county-level jobs and income. Because employees in one sector of an economy often require specialized skills and knowledge, employees may not be able to move easily from a declining sector to a growing sector. Although job creation in one sector does not offset all of the social costs of job losses in another sector, a more detailed analysis of these social effects is beyond the scope of this analysis.

\section{The BLM Budget}

The BLM budget requirements would be higher under all alternatives, due to administrative costs of implementing higher timber harvest levels. For this analysis, budget requirements for nontimber resource programs and the state office, which were about $78 \%$ of the 2006 fiscal year budget, were held constant between alternatives. See Table 4-22 (BLM budget) for budget requirements at full harvest levels under each alternative.

All alternatives would require an increase from the current BLM budget to implement increased levels of timber harvesting. Compared to the current level, the BLM budget would increase $18 \%$ under the No Action Alternative, $37 \%$ under Alternative 1, 62\% under Alternative, 2, 31\%, under Alternative 3, and $43 \%$ for the PRMP.

In addition to the costs shown on Table 4-22, expenditures for contractors to perform silvicultural treatments (planting, fertilization, pruning, etc.) would also increase. See Table 4-23 (Annual expenditures for silviculture for the first 10 years by district). These expenditures would vary by alternative based on the types of harvest anticipated under each alternative. Alternative 2 would require the highest expenditure, since it includes the most regeneration harvesting.

TABLE 4-22. BLM Budget

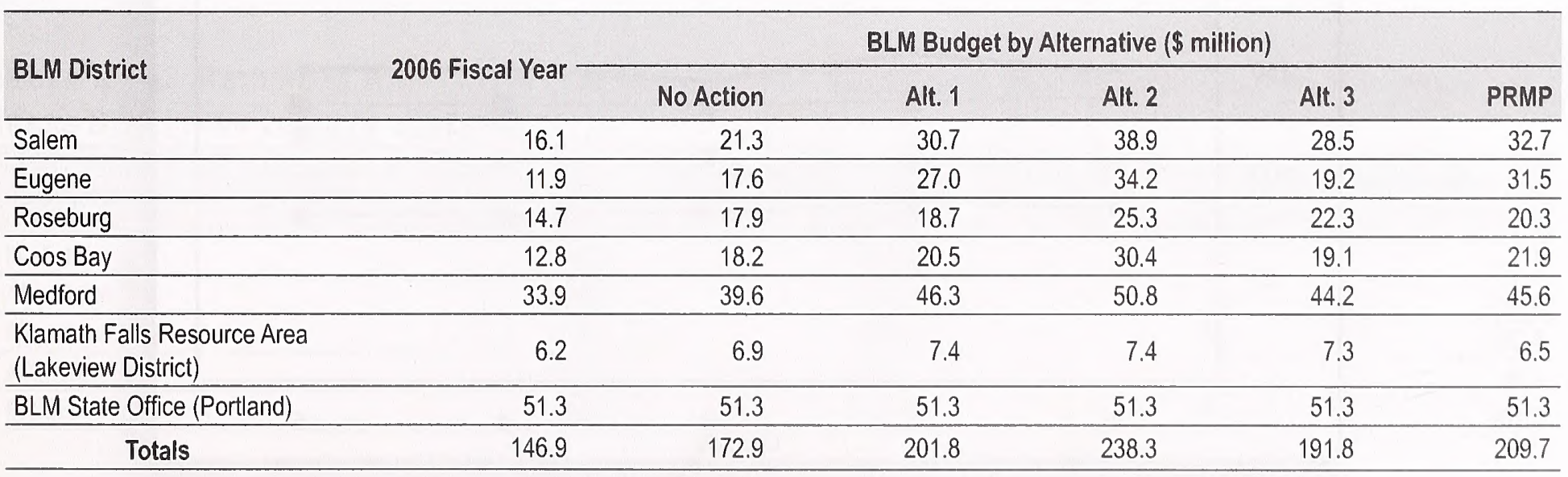


Table 4-23. Annual Expenditures For Silviculture For The First 10 Years By District And Alternative

\begin{tabular}{lrrrrr}
\hline \multirow{2}{*}{ BLM District } & \multicolumn{5}{c}{ Annual Expenditures for Silviculture For the First 10 Years (\$ million) } \\
\cline { 2 - 6 } & No Action & Alt. 1 & Alt. 2 & Alt. 3 & PRMP \\
\hline Salem & 0.5 & 0.9 & 1.2 & 1.0 & 1.3 \\
\hline Eugene & 0.8 & 1.2 & 1.6 & 1.1 & 1.5 \\
\hline Roseburg & 1.5 & 1.6 & 2.3 & 2.8 & 1.4 \\
\hline Coos Bay & 1.2 & 1.2 & 2.3 & 0.6 & 0.9 \\
\hline Medford & 3.0 & 4.1 & 4.9 & 3.1 & 3.2 \\
\hline Lakeview & 0.1 & 0.3 & 0.3 & 0.1 & 0.1 \\
\hline \multicolumn{1}{c}{ Totals } & 7.2 & 9.3 & 12.7 & 8.6 & 8.2 \\
\hline
\end{tabular}

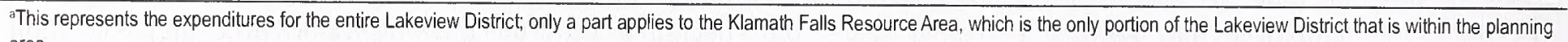
area.

\section{Present Net Value of the Timber Program}

Present net value is a measure of economic return. Future revenues and costs over a 50 - year period are discounted back to the present using a $5 \%$ discount rate.

Projections of the stumpage revenue for each alternative reflect the amount of timber harvested, the type of harvest (regeneration harvesting, partial harvesting, or thinning), and the age or size of the timber that would be harvested. Stumpage revenues would change over time, reflecting changes in the nature of the sale program under each alternative. See Figure 4-30 (Average annual stumpage revenues). These revenues include volume from both the harvest land base (from which the annual sale quantity is calculated) and volume from the nonharvest land base during the first five decades after implementation.

For the No Action Alternative, Alternatives 1 and 2, and the PRMP, for example, harvests past the first decade would have less thinning volume from the Late-Successional Reserves or Late-Successional

Figure 4-30. Average Annual Stumpage Revenues

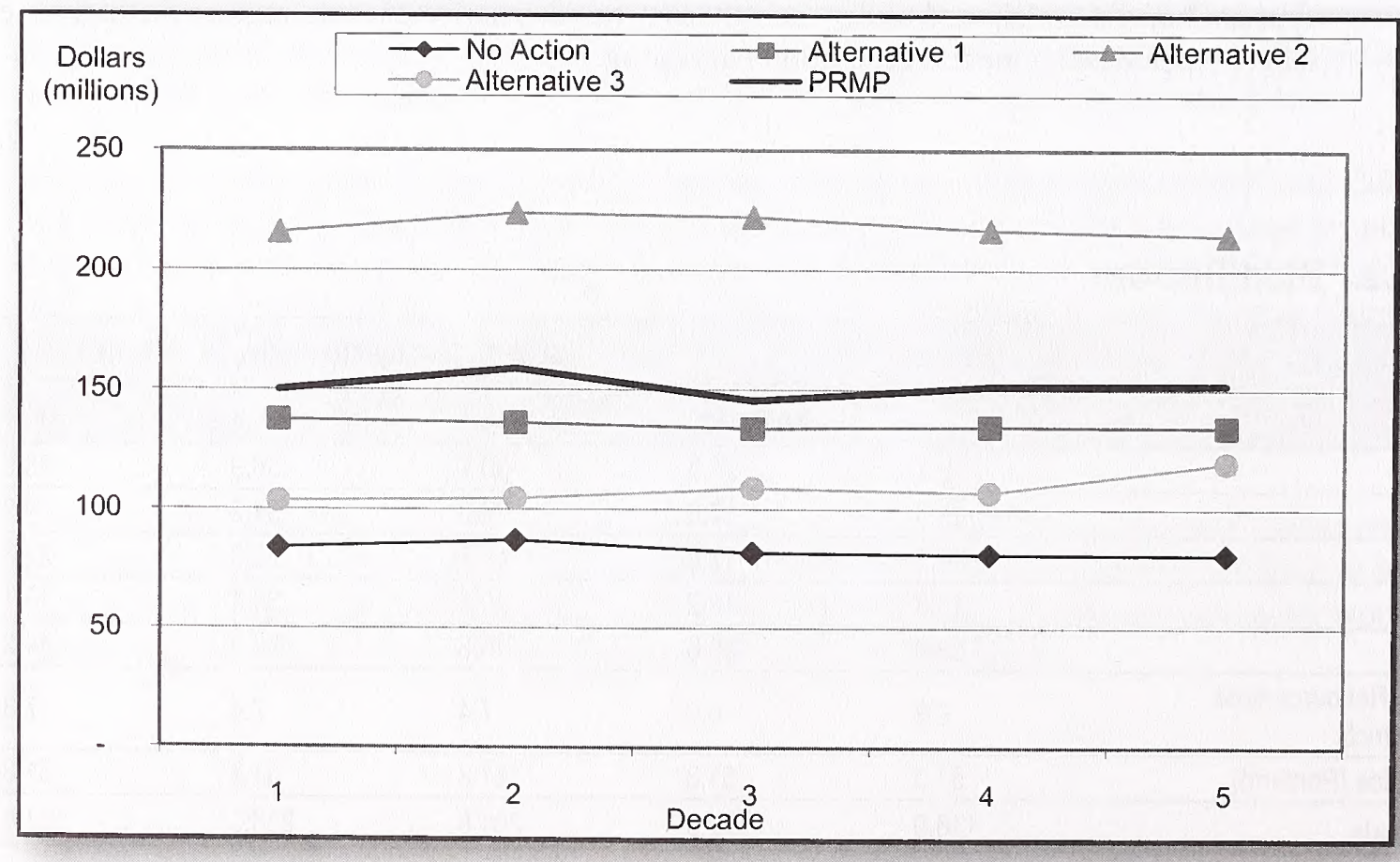


Management Areas, which would reduce the total volume and value of timber harvests over time. Under Alternatives 1 and 2, higher-valued harvests from the structurally complex forests would decline after the first couple of decades; the harvests would shift to more mature and less structurally complex forest types, which would reduce the average harvest value. Under the PRMP, higher-valued harvests from the structurally complex forests would be deferred for the first 15 years. The harvest of structurally complex forests in the harvest land base would then take place from 2023 to 2106 . Under Alternative 3, harvesting would shift from partial harvesting to regeneration harvesting with an accompanying reduction in costs, resulting in an increase in stumpage revenue.

Revenue projections are based on the 2005 average log price and do not include any future real price increase. Revenues under all alternatives are based on an assumption that stumpage prices in the market area would fall 3.5\% during the first 10-year period as the BLM adds more timber into the market. By the second decade, it is assumed that mill capacity would adjust to absorb the additional capacity, and the market adjustment is removed. Timber prices respond to markets for final products and vary from year to year. This analysis assumes that changes to the BLM timber sale program would not materially affect end product prices and that all alternatives would, therefore, experience the same market fluctuations. Based on these assumptions, the comparisons between alternatives are valid regardless of market fluctuations.

Under all alternatives, the cost of the BLM timber program is estimated to be $\$ 200$ per mbf. This includes all of the work associated with preparing, offering, and administering timber sales. It includes work done by members of a timber sale interdisciplinary team, National Environmental Policy Act compliance work, overhead, etc. The additional silvicultural costs specific to each alternative are also included in the calculation. See Table 4-23 (Annual expenditures for silviculture for the first 10 years by district) in the previous section (BLM Budget).

See Figure 4-31 (Revenues, costs, and net revenues for the first 10 years) for a comparison of the revenues, costs, and net revenues for the first 10 years. See Table 4-24 (Revenues and costs for the first 10 years and the present net value over 50 years by alternative).

Alternative 2 would have the highest total revenue of all alternatives because it would have both the highest harvest level and the highest stumpage value. First decade revenues under the No Action Alternative would be the lowest of all alternatives. This is because even though the No Action Alternative would have an $8 \%$ higher average stumpage value than Alternative 3, it would have 33\% less harvest volume.

The alternatives are ranked differently with respect to the 50 -year present net value calculation. From the highest to lowest present net value, the alternatives would be ranked Alternative 2, the PRMP, Alternative 1, the No Action Alternative, and Alternative 3. Because the average first decadal stumpage price under Alternative 3 is close to the average timber program cost, the net revenue under Alternative 3 would be negative in the first 10 years. Net revenues in subsequent decades would be slightly positive as capacity adjusted to the additional BLM volume and stumpage prices rebounded.

Table 4-24. Revenues And Costs For The First 10 Years And The Present Net Value Over 50 Years By Alternative (\$ Million)

\begin{tabular}{l|rrrr}
\hline \multirow{2}{*}{ Alternative } & \multicolumn{3}{|c|}{ Decade 1 } & \multicolumn{2}{l}{\begin{tabular}{l} 
Present Net Value Over 50 \\
\cline { 2 - 5 }
\end{tabular}} & Total Revenues & Total Costs & Net Revenues & Years \\
\hline No Action & 83.9 & $(78.7)$ & 5.2 & 107.5 \\
\hline Alternative 1 & 137.5 & $(117.7)$ & 19.8 & 342.8 \\
\hline Alternative 2 & 215.8 & $(166.9)$ & 48.9 & 962.3 \\
\hline Alternative 3 & 103.3 & $(103.8)$ & 23.0 & 46.1 \\
\hline PRMP & 150.1 & $(127.1)$ & 465.0 \\
\hline
\end{tabular}


Figure 4-31. Revenues, Costs, And Net Revenues For The First 10 Years

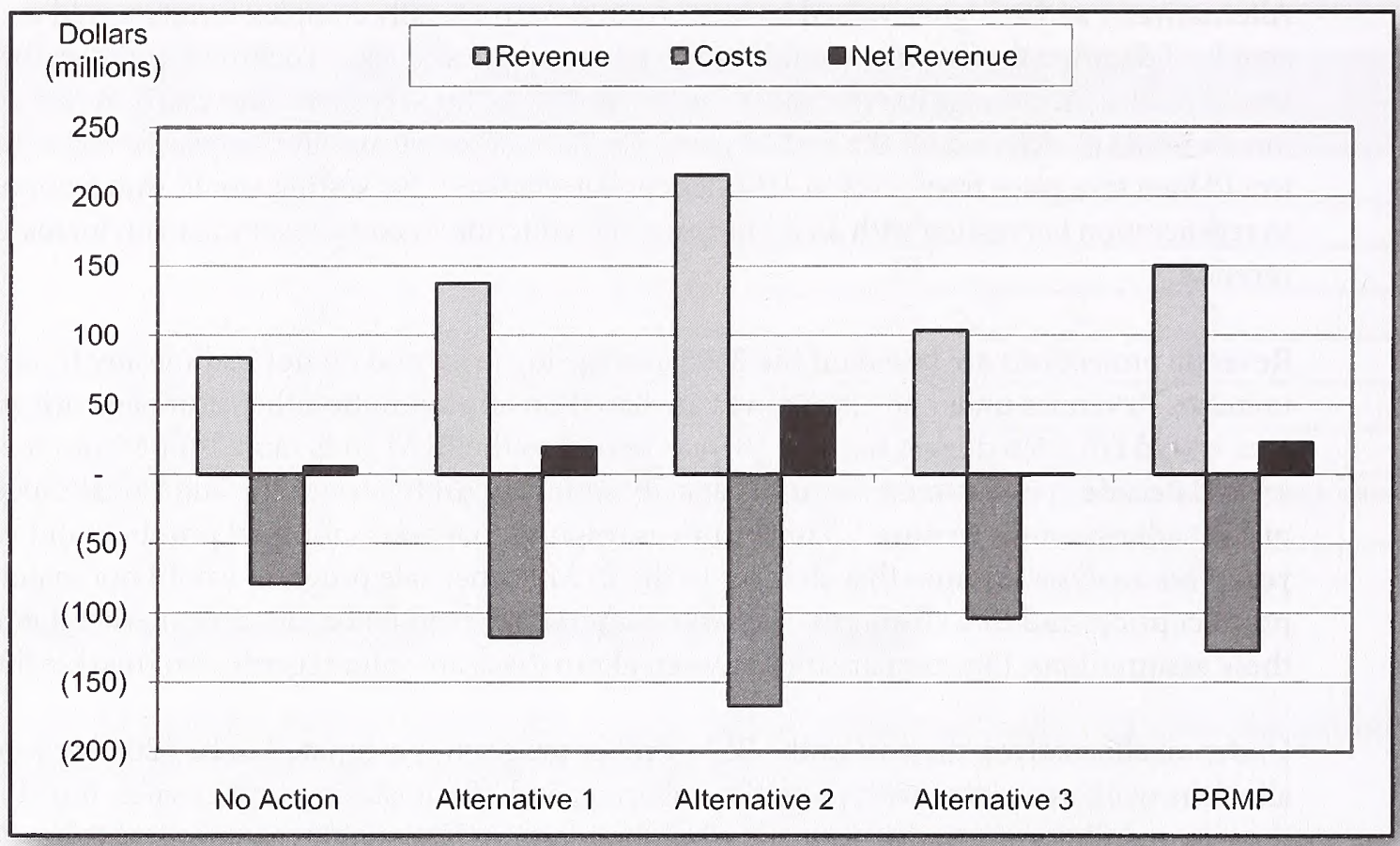

The present net value calculation shown here is based only on the costs and revenue of timber harvests. It does not include the value of the standing inventory, which would increase under all alternatives. (Growth would exceed harvest because of the amount of lands allocated to the nonharvest land base.) As discussed earlier in this Socioeconomics section, the present net value also does not include the cash revenues and costs associated with nontimber outputs, such as special forest products, nor any economic value associated with other commodity or amenity values. 


\section{Environmental Justice}

This analysis examines the disproportionate impacts on low-income and minority populations that would result from the alternatives.

\section{Key Points}

- No high or adverse human health or environmental effects have been identified for any of the alternatives.

- The effects of the alternatives are not expected to fall disproportionately on minority or low income populations.

Federal agencies are required to "identify and address... \{the \}disproportionately high and adverse human health or environmental effects of its programs, policies, and activities on minority populations and low-income populations in the United States" in accordance with Executive Order 12898 regarding environmental justice.

The guidelines described by the Council on Environmental Quality (CEQ 1997) were used to guide the analysis of the potential environmental justice issues associated with the western Oregon resource management plan revisions. The analysis included:

- a determination of the geographic distribution of low-income populations and minority populations within the affected area (i.e., the planning area)

- an assessment of whether the impacts of the alternatives produce impacts that are high and adverse

- if impacts are high and adverse, a determination as to whether these impacts would disproportionately impact low-income populations or minority populations

The following Council on Environmental Quality guidelines (CEQ 1997) are used to identify minority and low-income populations:

- Minority population. A minority population is identified for a geographic unit if the number of minority persons (Hispanic/Latino, Black/African American, American Indian/ Alaskan Native, Asian, Native Hawaiian/Other Pacific Islander, or some other race ) is:

- greater than $50 \%$ of the total population of that geographic unit, or

- meaningfully greater than the percentage of the minority population in the reference unit for that geographic unit.

For this analysis, each county is a geographic unit and the state of Oregon is the reference unit.

The first part of the Council on Environmental Quality's guidance on minority population provides a numeric measure, which is that the number of minority persons must exceed $50 \%$ of the total population for an affected area (i.e., a geographic unit). The remainder of the guidance calls for a judgment in evaluating the potential for environmental justice concerns. It is important to consider the circumstances of any one group that resides within the affected area, in addition to considering the percentage of the affected community that is composed of minority persons (EPA 1998).

- Low-income population. Low-income individuals are defined as individuals who fall below the poverty line. The poverty line takes into account the size of the family and the age of individuals in the family. In 1999, for example, the poverty line for a family of five with three children below the age of 18 was $\$ 19,882$. For any given family below the poverty line, all family members are considered as being below the poverty line for the purposes of analysis (Proctor and Dalaker 2002).

Although there are no quantitative guidelines by the Council on Environmental Quality regarding the percentages of low-income populations in reference to larger populations, the Council on Environmental Quality suggests a screen to determine if low-income populations are unevenly distributed in an affected area compared to the larger population. 
See Table 4-25 (Current composition of minority and low-income populations of the counties within the planning area compared to the state of Oregon) for the current composition of the minority and low-income populations for each of the 18 counties within the planning area and the state of Oregon based on 2000 census data and the Council on Environmental Quality's guidelines. Counties that exceed the state-wide averages for minority or low-income populations are highlighted.

According to Table 4-25:

- For minority populations:

- None of the minority populations in the counties exceeds $50 \%$ of the total population of the county.

- Three counties exceed the state average for the percentage of minorities. The percentage of minority individuals in these three counties exceeds the state average by 6 to 7 percentage points.

- These three counties are within large metropolitan areas with diverse economies (Portland and Salem). For these three counties, the BLM-administered lands constitute less than $3 \%$ of the county area.

- For low-income populations:

- There are 12 counties that exceed the state average for the percentage of low-income populations. They exceed the state average by 0.1 to 5.4 percentage points.

- One of the 12 counties (Klamath County) is more than 5 percentage points above the state average. Approximately $7 \%$ of the lands within Klamath County are BLM-administered lands. These BLM-administered lands are largely public domain lands east of the Cascade Mountains and are close to unincorporated populations. Low-income populations are not expected to be unevenly distributed in relationship to the BLM-administered lands.

No high or adverse human health or environmental effects have been identified for any of the alternatives, and effects are not expected to fall disproportionately on minority or low-income populations. 


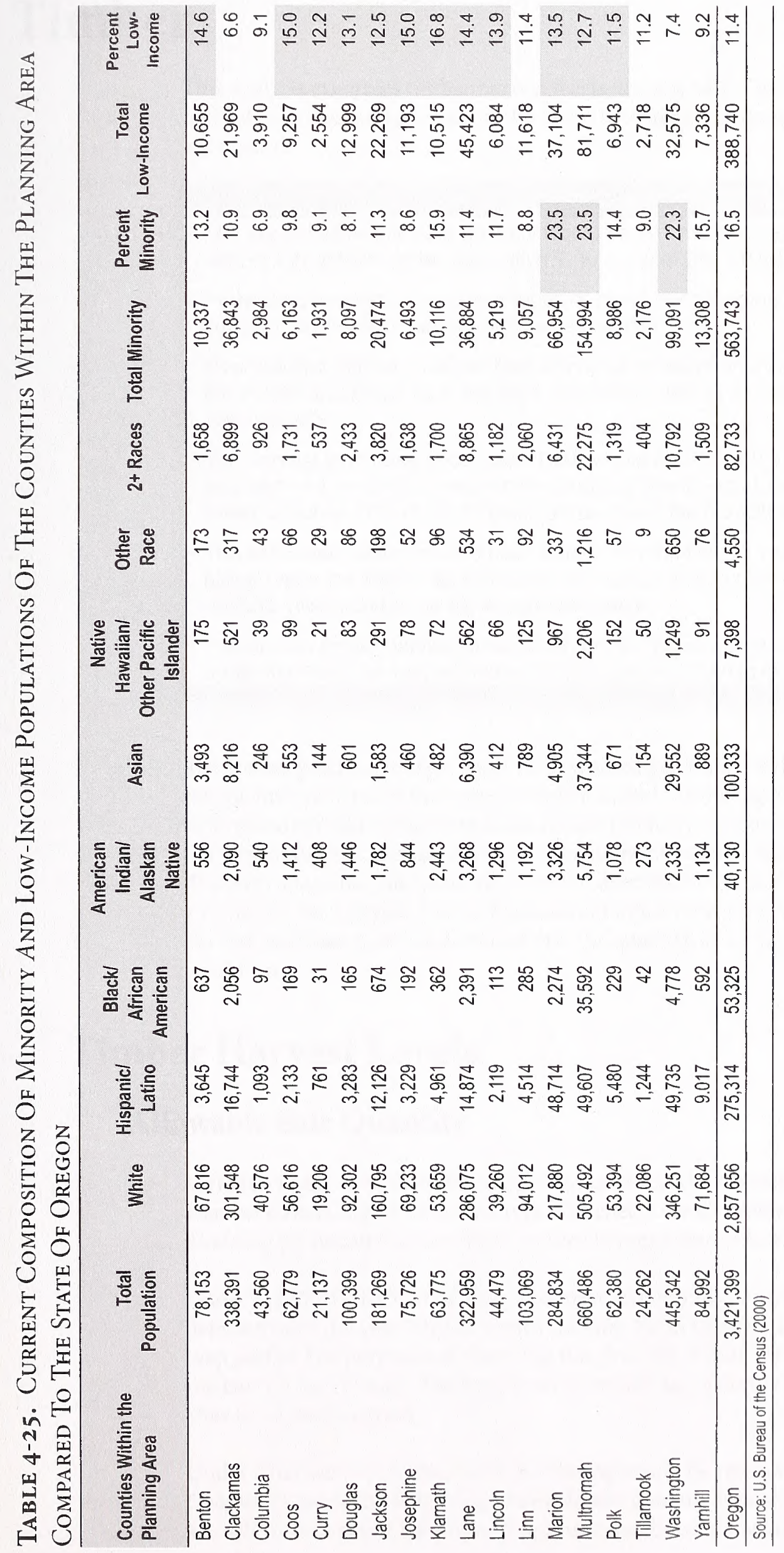




\section{Timber}

This analysis examines timber harvest levels, the size of the harvest land base, value of the harvest, acres of harvest activities, and changes to the forest inventory and forest stand conditions that would result from the alternatives.

\section{Key Points}

- The annual allowable sale quantity would be $502 \mathrm{mmbf}$ under the PRMP compared to a range from a high of $727 \mathrm{MMBF}$ under Alternative 2, to a low of $268 \mathrm{MMBF}$ under the No Action Alternative.

- Prohibiting harvesting in certain types of stands or changing the intensity of management has a substantial effect on the allowable sale quantity.

- Over the first decade, volume from thinnings in the nonharvest land base would be 86 MMBF under the PRMP and range from the No Action Alternative at $87 \mathrm{MMBF}$ per year, to virtually no volume under Alternative 3.

- The harvest land base under the PRMP would be 994,000 acres or $45 \%$ of the forested acres compared to a high of 1.4 million acres, which is $65 \%$ of the forested acres, under Alternative 3 ; to a low of 608,000 acres, which is $27 \%$ of the forested acres under the No Action Alternative.

- The estimated sale price of timber sold during the first 10 years after implementation would be $\$ 1.5$ billion under the PRMP as compared to a range from a high of $\$ 2.16$ billion under Alternative 2 , to a low of $\$ 839$ million under the No Action Alternative.

- The annual timber harvest acres of all harvest types would range from approximately 30,400 acres under the PRMP, to approximately 16,000 acres for the No Action Alternative.

The annual productive capacity of the sustained yield units is determined by the productivity of the land, the quantity of acres in the harvest land base, and the management intensity. The O\&C Act requires the determination and declaration of an annual productive capacity. It also requires, except under unusual market conditions, the sale annually of an amount equal to this level, which is the allowable sale quantity. The term allowable sale quantity is used to describe the annual level of sustainable harvest under each alternative. See Chapter 3 for a discussion of forest inventory. As areas are removed from or added to the harvest land base under the alternatives, the quantity, location, and the productivity of the harvest land base would vary.

\section{Timber Harvest Levels}

\section{Allowable Sale Quantity}

Variation in the acres of different age classes within the harvest land base affects the allowable sale quantity. Harvest scheduling by treatment type also affects the allowable sale quantity. See Appendix $R$ - Vegetation Modeling for detailed information on how harvests were modeled.

Under the PRMP, harvest of older and more structurally complex multi-layered conifer forests would be deferred until the year 2023 as shown on Map 2-2 in Chapter 2 and on Maps 2-2A, 2-2B, and 2-2C in the map packet. For purposes of modeling this deferral, stands 160 years of age and older were deferred from the harvest for 15 years. The long-term allowable sale quantity is based on harvest of these stands beginning after the deferral period.

Under Alternative 3, regeneration harvesting would be restricted until landscape thresholds are met (see Chapter 2). Since the long-term allowable sale quantity is based on the eventual harvest of all the areas that are within the harvest land base, this landscape threshold would temporarily suppress the allowable sale 
quantity. The allowable sale quantity shown for Alternative 3 in Figures 4-32 and 4-33 and Table 4-26 (below) is the initial reduced level. The allowable sale quantity would begin to rise in the $4^{\text {th }}$ decade and achieves the maximum level in the $8^{\text {th }}$ decade.

Under the No Action Alternative, harvest levels would also be restricted for periods of time. In the Matrix, including connectivity/diversity blocks and General Forest Management Area (both northern and southern), the level of harvest of late-successional forest would not occur in fifth-field watersheds in which federal forest lands are comprised of 15 percent or less late-successional forest. This restriction would be removed when stands in the watershed exceed 15 percent late-successional forest. Timber harvest in connectivity/diversity blocks would be restricted to maintain 25 to $30 \%$ of each block in late-successional forest at any point in time.

Requirements for retention of green trees in regeneration harvests would affect the allowable sale quantity. Retention trees would reduce the harvested volume on sale units. These retention trees would also reduce the growth of the subsequent stand through competition for light and water. The allowable sale quantity reduction varies by stand type, site quality, retention levels, and other factors but is expected to be in the range of 10 to $25 \%$. The No Action Alternative and Alternative 3 contain green tree retention requirements. Under the PRMP and Alternatives 1 and 2, there would be no requirement for green tree retention in regeneration harvest areas.

The allowable sale quantity for the planning area is shown in Figure 4-32 (Total allowable sale quantity by alternative for the planning area). Also see Figure 4-33 (Allowable sale quantity by district and alternative) and Table 4-26 (Allowable sale quantity by district and alternative).

The Eastside Forest Management Lands of the Klamath Falls Resource Area would not have an allowable sale quantity. These lands are public domain lands outside of the area covered by the O\&C Act, but the Federal Land Policy and Management Act (FLPMA) requires that timber harvest would not exceed the sustained yield capacity of those lands. The Eastside Management Lands are managed in accordance with the FLPMA. Their harvest level under the PRMP would be based on managing for healthy forests and fuels management, and this level of harvest would be well below the sustained yield capacity of those lands. With the exception of expected annual volume that may be harvested, and the expected miles of road constructed, these Eastside Management Lands are not shown in the subsequent analysis of allowable sale quantity.

Figure 4-32. Total Allowable Sale Quantity By Alternative For The Planning Area

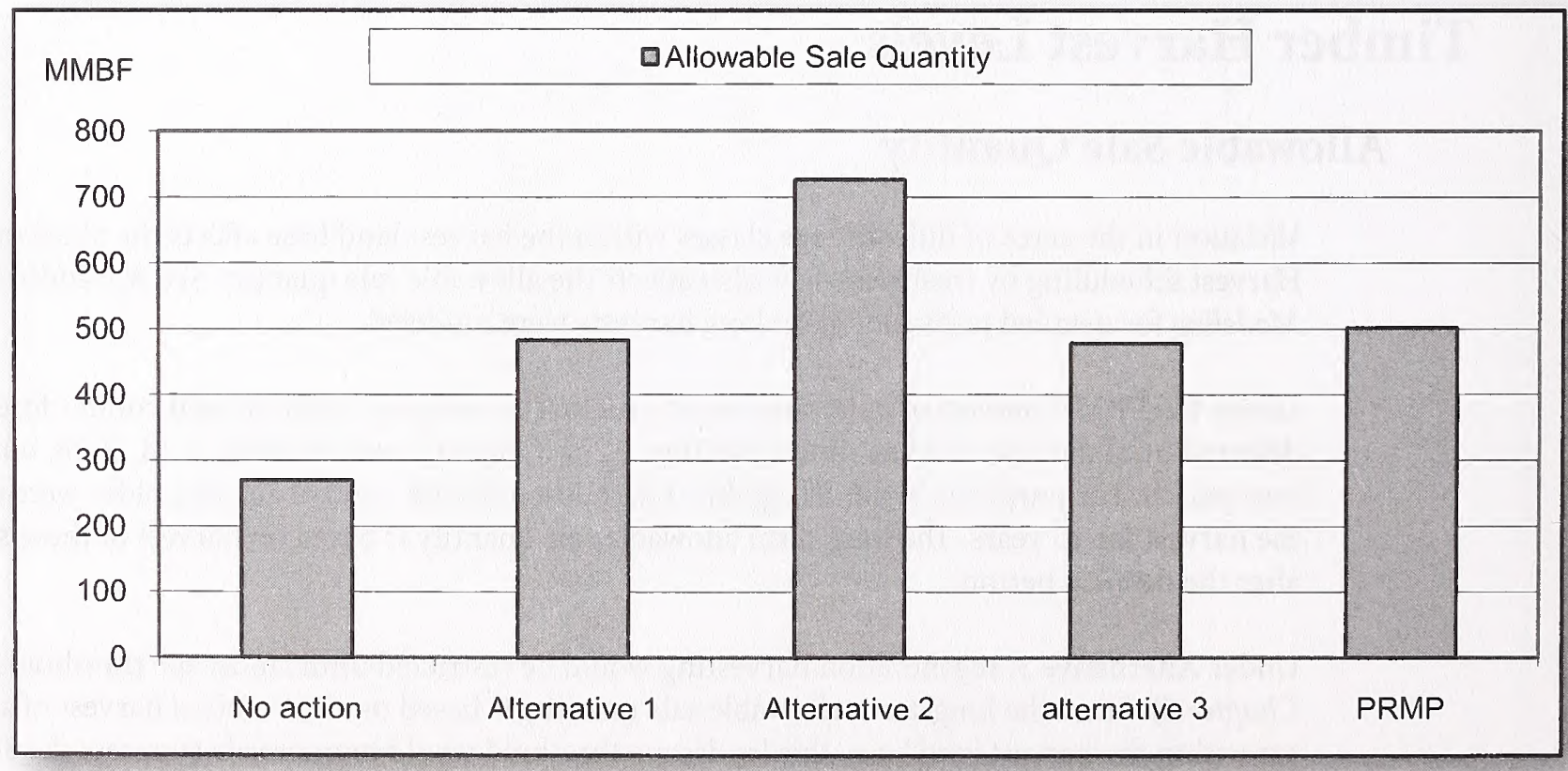


Figure 4-33. Allowable Sale Quantity By District And Alternative

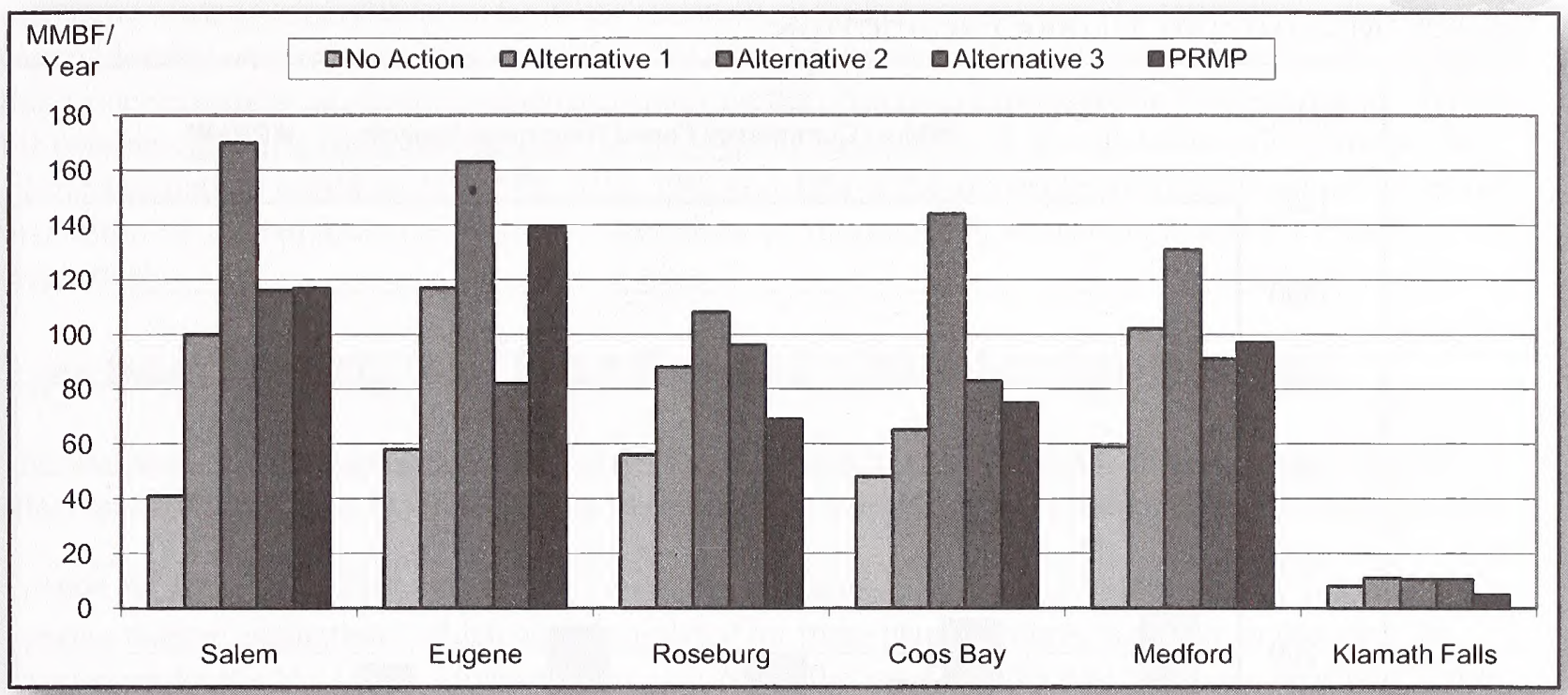

Table 4-26. Allowable Sale Quantity By District And Alternative

\begin{tabular}{l|r|r|r|r|r}
\hline \multirow{2}{*}{ BLM District } & \multicolumn{5}{c}{ Allowable Sale Quantity by Alternative (mmbflyear) } \\
\cline { 2 - 7 } & No Action & Alt. 1 & Alt. 2 & Alt. 3 & PRMP \\
\hline Salem & 41 & 100 & 172 & 116 & 117 \\
\hline Eugene & 58 & 117 & 165 & 82 & 139 \\
\hline Roseburg & 56 & 63 & 107 & 95 & 69 \\
\hline Coos Bay & 48 & 65 & 143 & 79 & 75 \\
\hline Medford & 59 & 102 & 131 & 91 & 97 \\
\hline $\begin{array}{l}\text { Klamath Falls Resource Area } \\
\text { (Lakeview District) }\end{array}$ & 6 & 9 & 9 & 8 & 5 \\
\hline \multicolumn{1}{c|}{ All District Totals } & 268 & 456 & 727 & 471 & 502 \\
\hline
\end{tabular}

\section{Reference Analysis}

Two reference analyses were completed. The first was no harvest. The second was a reference analysis of managing most commercial forest lands for maximizing timber production.

The results that would occur in the second reference analysis are shown and compared to the PRMP in Figure 4-34 (Reference Analysis: Manage most commercial forest lands for maximizing timber production). Also see Table 4-27(Allowable sale quantity for reference analysis: manage most commercial forest lands for timber production). 
Figure 4-34. Reference Analysis: Manage Most Commercial Forest Lands For Maximizing Timber Production

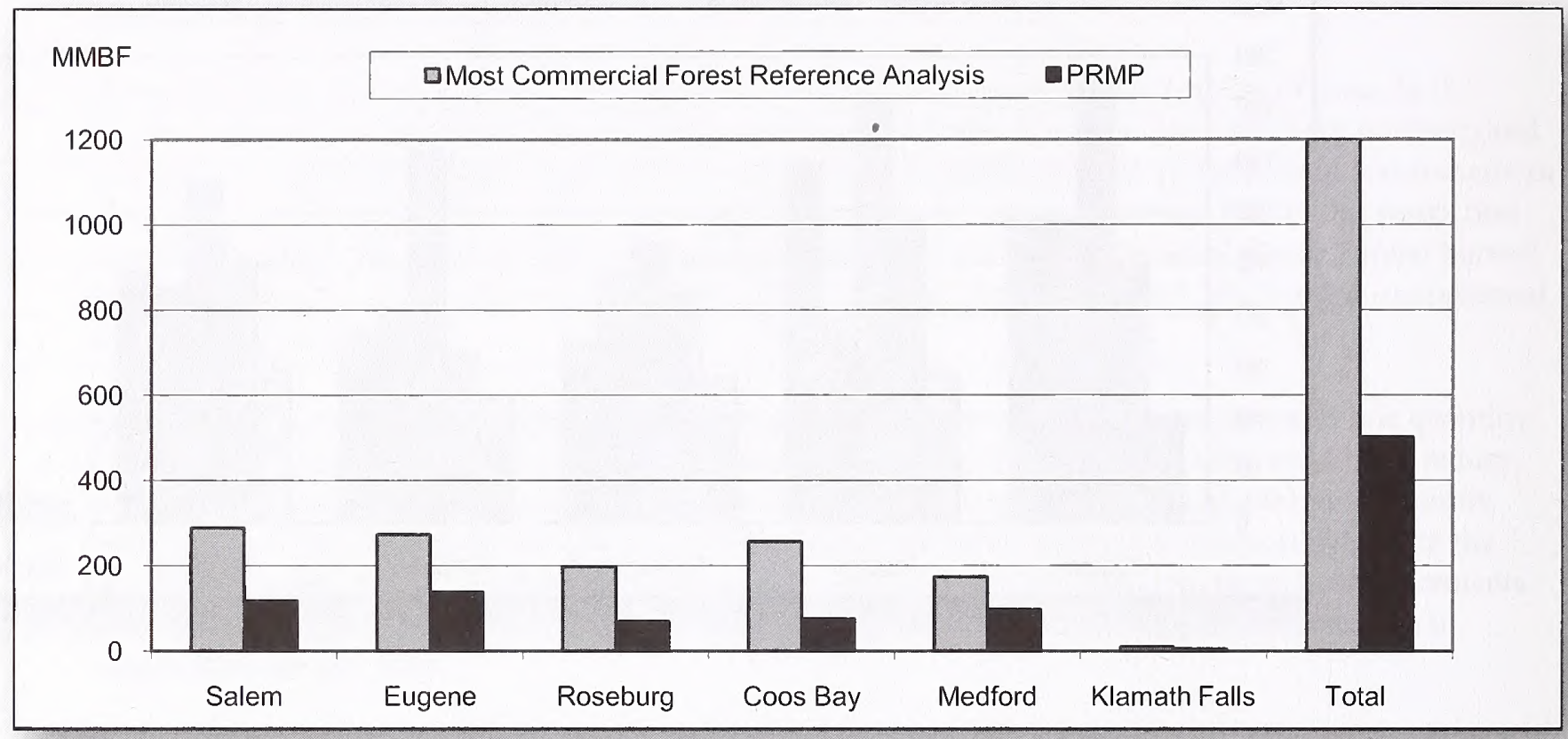

Table 4-27. Allowable Sale Quantity For Reference Analysis: Manage Most Commercial Forest Lands For Timber Production

\begin{tabular}{lr}
\hline District & $\begin{array}{r}\text { Allowable Sale Quantity } \\
\text { for Reference Analysis (mmbf) }\end{array}$ \\
\hline Salem & 289 \\
\hline Eugene & 273 \\
\hline Roseburg & 198 \\
\hline Coos Bay & 257 \\
\hline Medford & 174 \\
\hline Klamath Falls Resource Area & 10 \\
(Lakeview District) & 1,201 \\
\hline \multicolumn{1}{c}{ Totals } & 10 \\
\hline
\end{tabular}


The allowable sale quantity under all of the alternatives would be lower than the reference analysis of managing most commercial forest lands for maximizing timber production. The total for the planning area under this reference analysis would be 1,201 mmbf per year. Compared to the allowable sale quantity, this amount could be produced by focusing solely on the objective of maximizing timber production from the commercial forest lands managed by the BLM in the planning area. The allowable sale quantities for all five alternatives would be $22 \%, 38 \%, 61 \%, 39 \%$, and $42 \%$ of the allowable sale quantity of this potential maximum for the No Action Alternative, Alternative 1, Alternative 2, Alternative 3, and the PRMP, respectively.

\section{Changes from 1995 Harvest Land Base and Allowable Sale Quantity}

The alternatives would vary the portion of the forest allocated to the harvest land base, which has a direct effect on the harvest level by increasing or decreasing the acreage of lands available for sustained harvest.

In 1995, it was estimated that the riparian reserves contained approximately 522,000 acres. Improved riparian reserve estimations, which were completed for these plan revisions, have shown that riparian reserves under the No Action Alternative contain 364,000 acres. Over the past 10 years, the extent of the hydrology network has been more fully mapped and the information regarding fish presence has increased. This improved data allowed for GIS modeling of the extent of riparian reserves on BLM-administered lands that was not feasible 10 years ago. See Geographic Information System Data in the Introduction to this chapter.

The allowable sale quantity for the planning area is based on the improved GIS mapping of allocations, new inventory data, and revised growth and yield information. Because of the new acre calculations, reduction of modeling constraints, and a different timber inventory in the planning area, the level of allowable sale quantity has increased above the 1995 estimate. Therefore, the allowable sale quantity for the No Action Alternative would be $268 \mathrm{mmbf}$ per year, which would be $32 \%$ greater than the $203 \mathrm{mmbf}$ per year that was declared as the allowable sale quantity in the 1995 resource management plans 7 .

\section{Nonharvest Land Base Volume from Late Successionall Management Areas and the Riparian Management Areas}

Under all alternatives, timber would be offered each year as allowable sale quantity. In addition to the allowable sale quantity, volume from the nonharvest land base would be added to the allowable sale quantity and offered for sale each year. The nonharvest land base volume would result from applying thinning treatments in young stands to promote development of mature and structurally complex forest (see the Introduction section of this chapter). These thinning harvests would not be sustainable and would decline over time as the young stands in the nonharvest land base become too old for treatment, or as treatments are completed. Under the alternatives, nonharvest land base thinning treatments would occur in:

- Late-Successional Reserves and Riparian Reserves under the No Action Alternative

- Late-Successional Management Areas and Riparian Management Areas under Alternatives 1 and 2, and the PRMP

- Riparian Management Areas under Alternative 3

For some areas in the nonharvest land base, such as National Landscape Conservation System lands, or lands not suitable for sustained timber harvesting, no thinning harvesting is planned. See Figure 4-35 (Nonharvest land base volume over time) for the volume and duration of harvest from the nonharvest land base for all alternatives.

${ }_{7}^{7}$ The allowable sale quantity was reduced to $203 \mathrm{mmbf}$ per year in response to some of the findings in the $3 \mathrm{rd}$ year evaluation of the existing RMPs. A similar adjustment upward would be done in response to the latest findings in the evaluation of the existing RMPs, if they are not otherwise superseded by this proposed revision. 
Timber would be offered for sale from salvage operations in the Late-Successional Management Areas and in the wildland urban interface of the Riparian Management Areas. Additional timber would be offered for sale from these land use allocations as a result of the cutting of trees for safety and operational reasons, including but not limited to danger tree removal, creation of yarding corridors adjacent to nearby harvest units, and road construction or maintenance. It is not possible to make a reasonable estimate of the volume that would result from salvage because of the stochastic nature of disturbance. Therefore, although volume from salvage is anticipated, a specific amount of volume from salvage was not modeled or incorporated into the analysis.

Figure 4-35 shows that under all alternatives, the nonharvest land base harvest volume would decline over the entire planning area and would cease by the end of the $8^{\text {th }}$ decade. This decline over time is due to a combination of stands ageing beyond the point that treatments would be effective and completion of treatments on suitable stands.

See Table 4-28 for the first decade level of nonharvest land base volume that would occur for the alternatives.

Figure 4-35. Nonharvest Land Base Volume Over Time

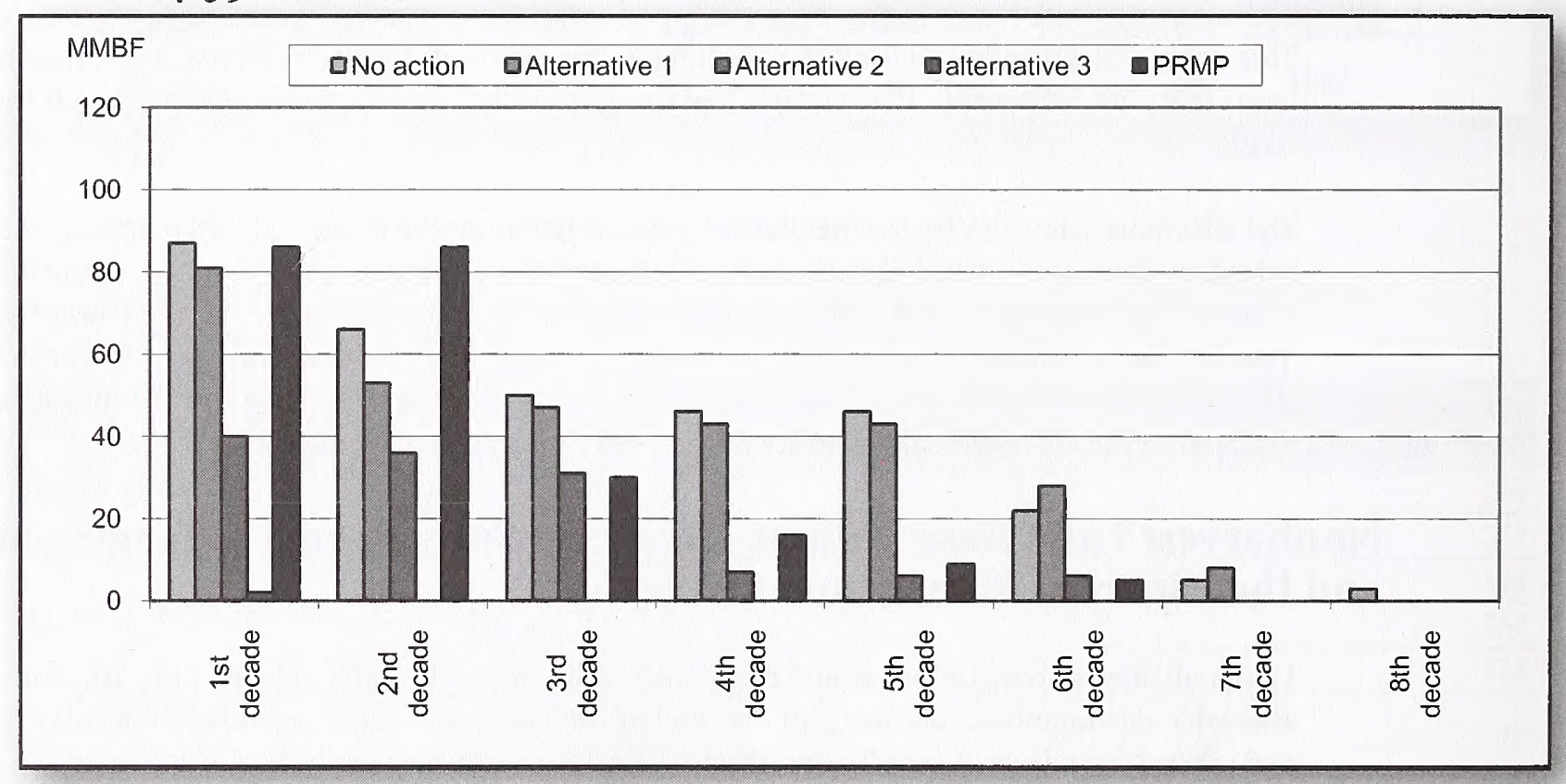

Table 4-28. Annual Nonharvest Land Base Volume For First Decade

\begin{tabular}{|c|c|c|c|c|c|}
\hline \multirow[t]{2}{*}{ BLM District } & \multicolumn{5}{|c|}{ 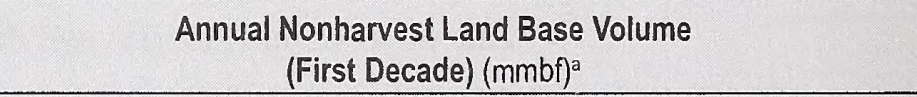 } \\
\hline & No Action & Alt. 1 & Alt. 2 & Alt. 3 & PRMP \\
\hline Salem & 32 & 32 & 12 & 2 & 28 \\
\hline Eugene & 14 & 14 & 12 & 0 & 20 \\
\hline Roseburg & 12 & 9 & 7 & 0 & 13 \\
\hline Coos Bay & 26 & 24 & 8 & 0 & 22 \\
\hline Medford & 3 & 2 & 1 & 0 & 3 \\
\hline $\begin{array}{l}\text { Klamath Falls Resource Area } \\
\text { (of the Lakeview District) }\end{array}$ & 0 & 0 & 0 & 0 & 0 \\
\hline Totals - All Districts & 87 & 81 & 40 & 2 & 86 \\
\hline
\end{tabular}


Table 4-29. Annual Eastside Management Lands Volume For The First Decade

\begin{tabular}{lrrrrrr}
\hline \multirow{3}{*}{ BLM District } & \multicolumn{5}{c}{$\begin{array}{c}\text { Annual Nonharvest Land Base Volume } \\
\text { (First Decade) (mmb) }\end{array}$} \\
\cline { 2 - 7 } & No Action & Alt. 1 & Alt. 2 & Alt. 3 & PRMP \\
\hline Klamath Falls Resource Area & 2 & 2 & 2 & 2 & 0.5 \\
\hline
\end{tabular}

Volume harvested from the nonharvest land base is added to the allowable sale quantity and the Eastside Management Lands volume to determine the total volume that would be annually harvested under the alternatives.

Under the PRMP, more timber volume from the nonharvest land base would be thinned than under the other alternatives except for the No Action Alternative during the first decade. Under the PRMP, an additional $17 \%$ of volume would be generated over the allowable sale quantity from the nonharvest land base during the first decade.

During the first eight decades, the largest thinning volume from the nonharvest land base would occur under the No Action Alternative compared to the other alternatives. This is because the No Action Alternative has the largest acreage in the nonharvest land base of all alternatives. The volume from these lands outside the harvest land base would be an additional $32 \%$ over the allowable sale quantity under the No Action Alternative during the first decade. Under the No Action Alternative, thinning would be restricted to stands less than 80 years of age (except for the North Coast Adaptive Management Area, where the limit would be 110 years). Under Alternatives 1, 2, 3, and the PRMP, nonharvest land base thinning would not be restricted by stand age as treatments would be scheduled when they are effective in developing stands to meet habitat needs.

Nonharvest land base thinning under Alternative 1 would generate an additional $18 \%$ during the first decade above the allowable sale quantity from the harvest land base.

The increase over the allowable sale quantity from thinning of the nonharvest land base under Alternative 2 would be $5 \%$ during the first decade.

Under Alternative 3, there would be less than $1 \%$ of additional nonharvest land base volume over the allowable sale quantity during the first decade.

In addition to the allowable sale quantity and nonharvest land base volume, the Eastside Management Lands of the Klamath Falls Resource Area would add an additional $2 \mathrm{mmbf}$ under the No Action Alternative, and Alternatives 1, 2 and 3. Under the PRMP, the volume coming from the Eastside Management Lands of the Klamath Falls Resource Area would be 0.5 mmbf/year. See Table 4-29.

\section{Total Harvest Volume Level}

The allowable sale quantity, nonharvest base volume, and Eastside Management Lands volume comprise the total harvest volume level. This level is shown by district and alternative for the first decade in Figure 4-36 (Total annual volume level by alternative for the first decade) and in Table 4-30 (Total annual volume by district over the first decade). 
Figure 4-36. Total Annual Volume Level By Alternative For The First Decade

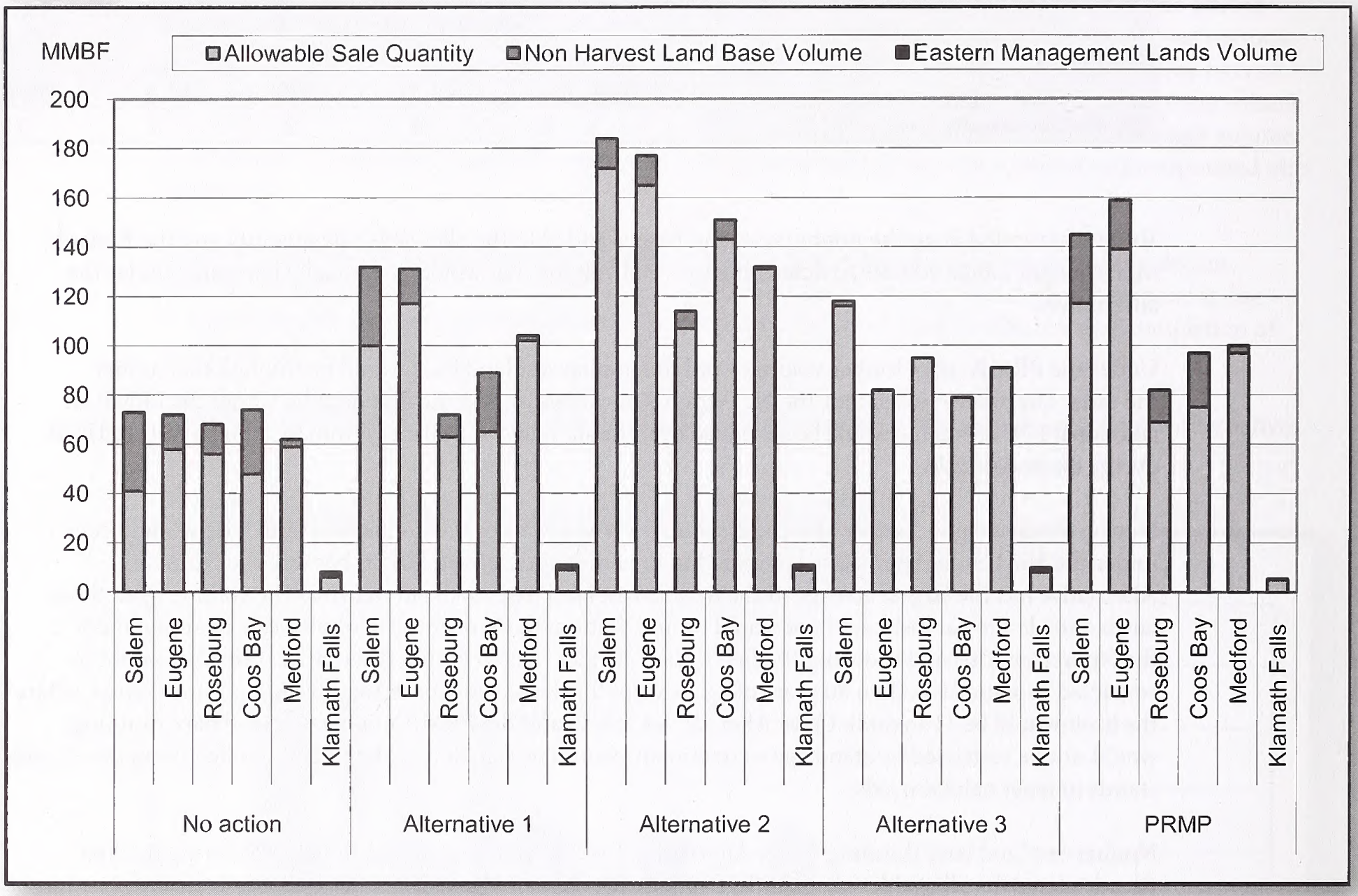

Taile 4-30. Total Annual Volume By District For The First Decade

\begin{tabular}{|c|c|c|c|c|c|c|c|}
\hline \multirow{2}{*}{ Alternative } & \multicolumn{7}{|c|}{$\begin{array}{l}\text { Annual Harvest Volume by BLM District } \\
\text { (First Decade) (mmbf) }\end{array}$} \\
\hline & Salem & Eugene & Roseburg & Coos Bay & Medford & $\begin{array}{r}\text { Klamath } \\
\text { Falls }^{a}\end{array}$ & Totals \\
\hline No Action & 73 & 72 & 68 & 74 & 62 & 8 & 357 \\
\hline Alternative 1 & 132 & 131 & 72 & 89 & 104 & 11 & 539 \\
\hline Alternative 2 & 184 & 177 & 114 & 151 & 132 & 11 & 769 \\
\hline Alternative 3 & 118 & 82 & 95 & 79 & 91 & 10 & 475 \\
\hline PRMP & 145 & 159 & 82 & 97 & 100 & 5.5 & $588^{b}$ \\
\hline
\end{tabular}

As a result of the declining nonharvest land base volume, the total volume harvested would decrease over the first eight decades, except under Alternative 3 where the attainment of landscape objectives would permit the sustainable allowable sale quantity to increase. This increase would begin in the third decade. The volume harvested by decade is shown in Figure 4-37 (Total annual harvest volume by decade and alternative) and Table 4-31 (Total harvest volume by decade and alternative).. 
Figure 4-37. Total Annual Harvest Volume By Decade And Alternative

\begin{tabular}{|c|c|c|c|c|c|}
\hline MMBF/Year & 口No action & 口Alternative 1 & 口Alternative 2 & Alternative 3 & $\triangle P R M P$ \\
\hline \multicolumn{6}{|l|}{900} \\
\hline \multicolumn{6}{|l|}{800} \\
\hline \multicolumn{6}{|l|}{700} \\
\hline \multicolumn{6}{|l|}{600} \\
\hline \multicolumn{6}{|l|}{500} \\
\hline \multicolumn{6}{|l|}{400} \\
\hline \multicolumn{6}{|l|}{300} \\
\hline \multicolumn{6}{|l|}{200} \\
\hline \multicolumn{6}{|l|}{100} \\
\hline 0 & 용 & कृ & 点 & ث & $\subsetneq \frac{0}{0}$ \\
\hline
\end{tabular}

Table 4-31. Total Harvest Volume By Decade And Alternative (First Eight Decades)

\begin{tabular}{crrrrr}
\hline \multirow{2}{*}{ Decade } & \multicolumn{5}{c}{ Annual Harvest Volume by Decade and Alternative (mmbf) } \\
\cline { 2 - 6 } & No Action & Alt. 1 & Alt. 2 & Alt. 3 & PRMP \\
\hline 1 & 355 & 537 & 767 & 473 & 588 \\
\hline 2 & 334 & 509 & 763 & 471 & 588 \\
\hline 3 & 318 & 503 & 758 & 471 & 532 \\
\hline 4 & 314 & 499 & 734 & 473 & 518 \\
\hline 5 & 314 & 499 & 733 & 522 & 511 \\
\hline 6 & 290 & 484 & 733 & 594 & 507 \\
\hline 7 & 273 & 464 & 727 & 594 & 502 \\
\hline 8 & 271 & 456 & 727 & 597 & 502 \\
\hline
\end{tabular}

\section{Ages of Stands Harvested}

The ages of stands that would be harvested vary by alternative. Under the No Action Alternative, proportionally less mature and structurally complex forest and a higher amount of younger forest than the action alternatives would be harvested. Specifically:

- Under the No Action Alternative, the allowable sale quantity harvest volume from forests older than 200 years during the first decade would be $19 \mathrm{mmbf}$ per year, which would be $7 \%$ of the allowable sale quantity harvest volume. 
- Under the PRMP, there would be no scheduled harvest from stands 200 years and older during the first decade. Harvest of older and more structurally complex multi-layered conifer forests (modeled as stands 160 years of age and older) would be deferred for 15 years, until the year 2023 as shown on Map 2-2 (in Chapter 2).

- For Alternatives 1, 2, and 3, the allowable sale quantity (ASQ) harvest volume from forests older than 200 years during the first decade would be:

- Alternative 1: $98 \mathrm{mmbf}$ per year (21\% of the ASQ)

- Alternative 2: $175 \mathrm{mmbf}$ per year (24\% of the ASQ)

- Alternative 3: 99 mmbf per year (21\% of the ASQ)

Figures 4-38 through Figure 4-42 show the average annual timber volumes that would be harvested by 10year age class by alternative during the first decade. These figures include both allowable sale quantity and nonharvest land base volumes.

Figure 4-38. Average Annual Timber Volume Harvest By Age Class Under The No Action Alternative Over The First Decade

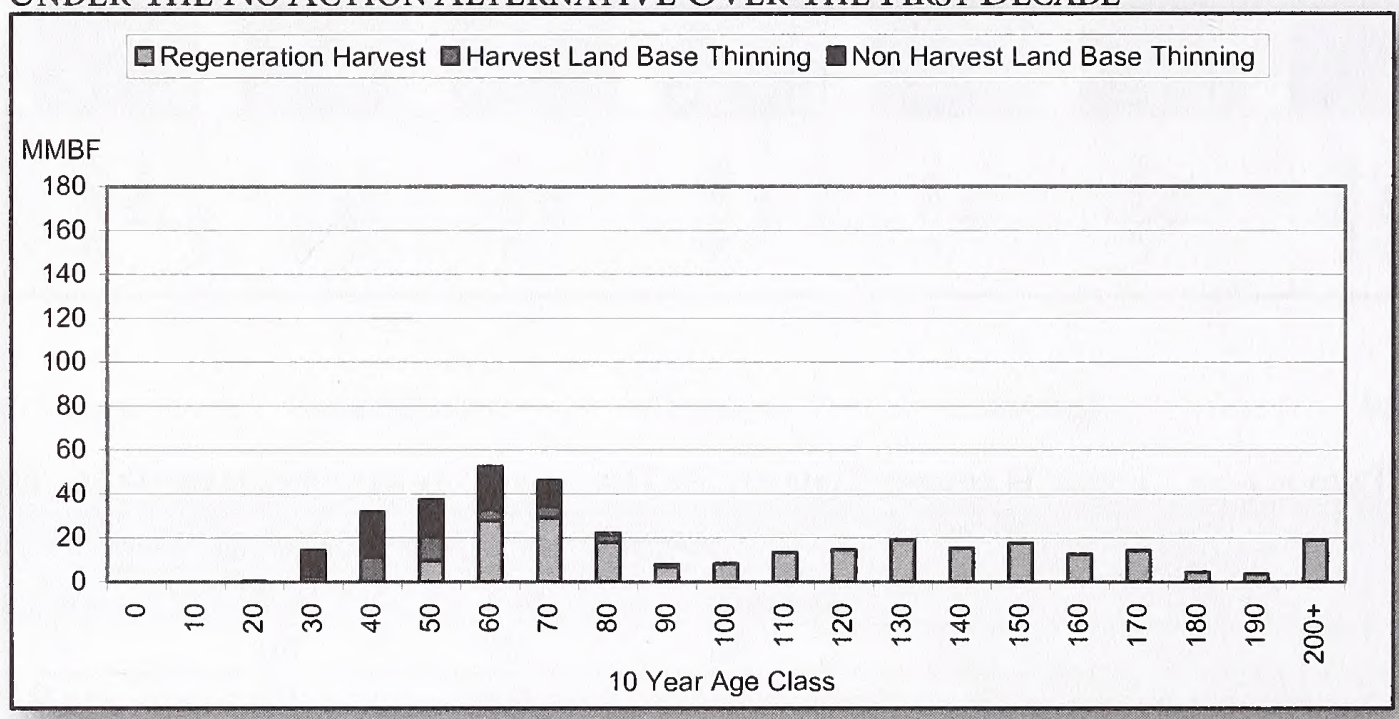

Figure 4-39. Average Annual Timber Volume Harvest By Age Class Under Alternative 1 Over The First Decade

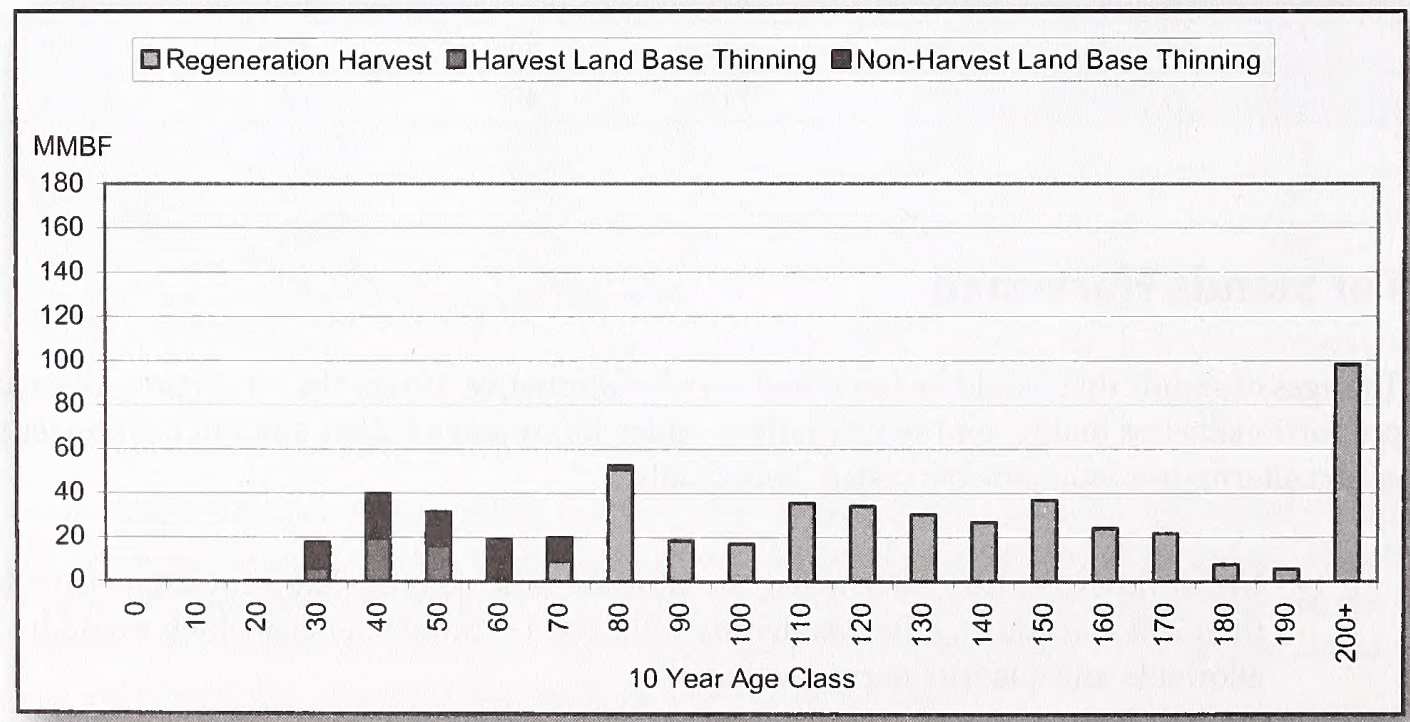


Figure 4-40. Average Annual Timber Volume Harvest By Age Class Under Alternative 2 Over The First Decade

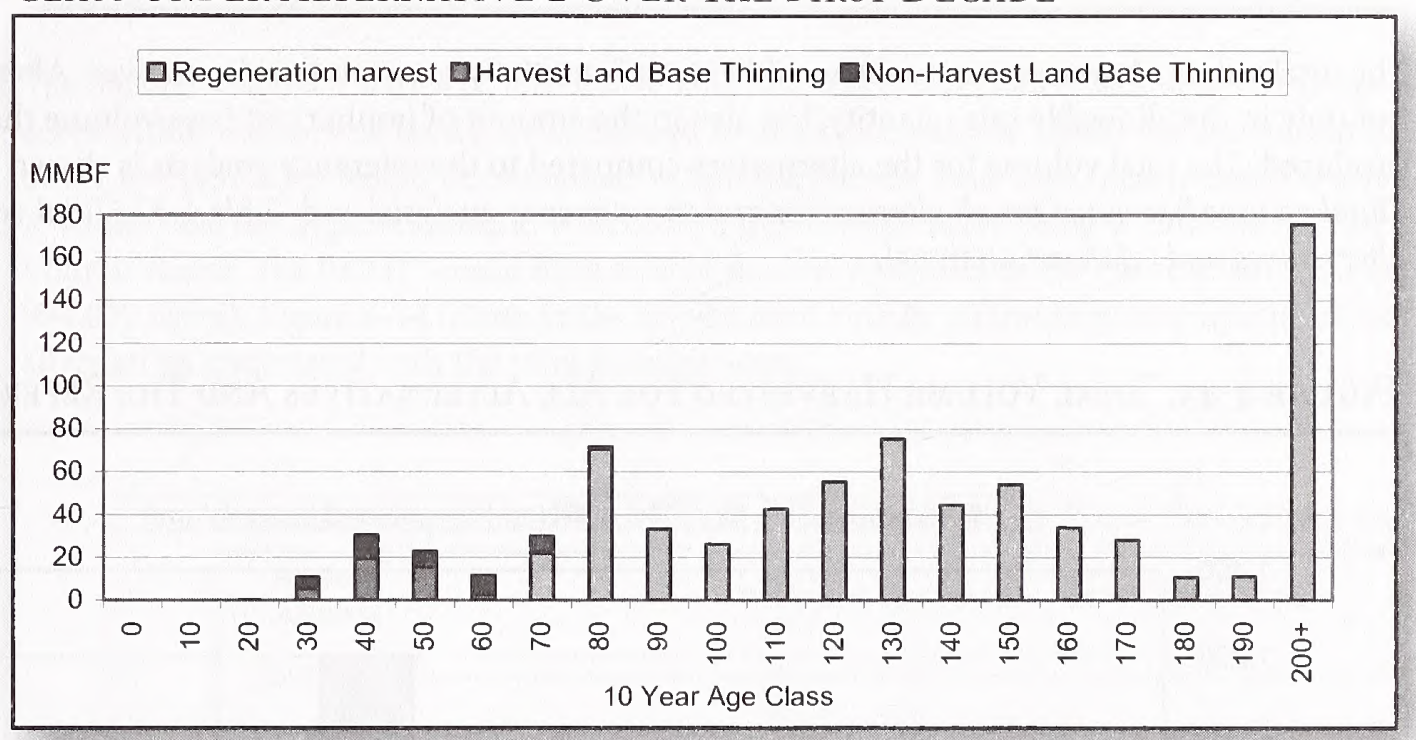

Figure 4-41. Average Annual Timber Volume Harvest By Age Class Under Alternative 3 Over The First Decade

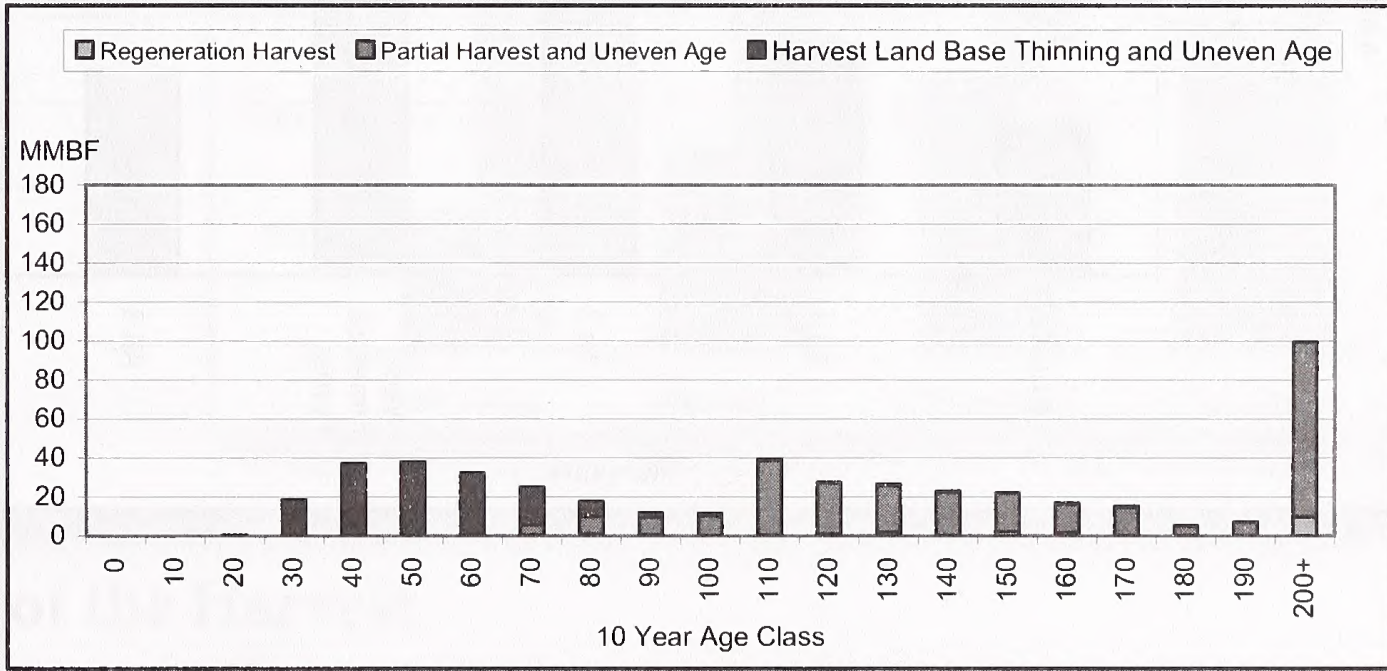

Figure 4-42. Average Annual Timber Volume Harvest By Age Class Under The PrMP Over The First Decade

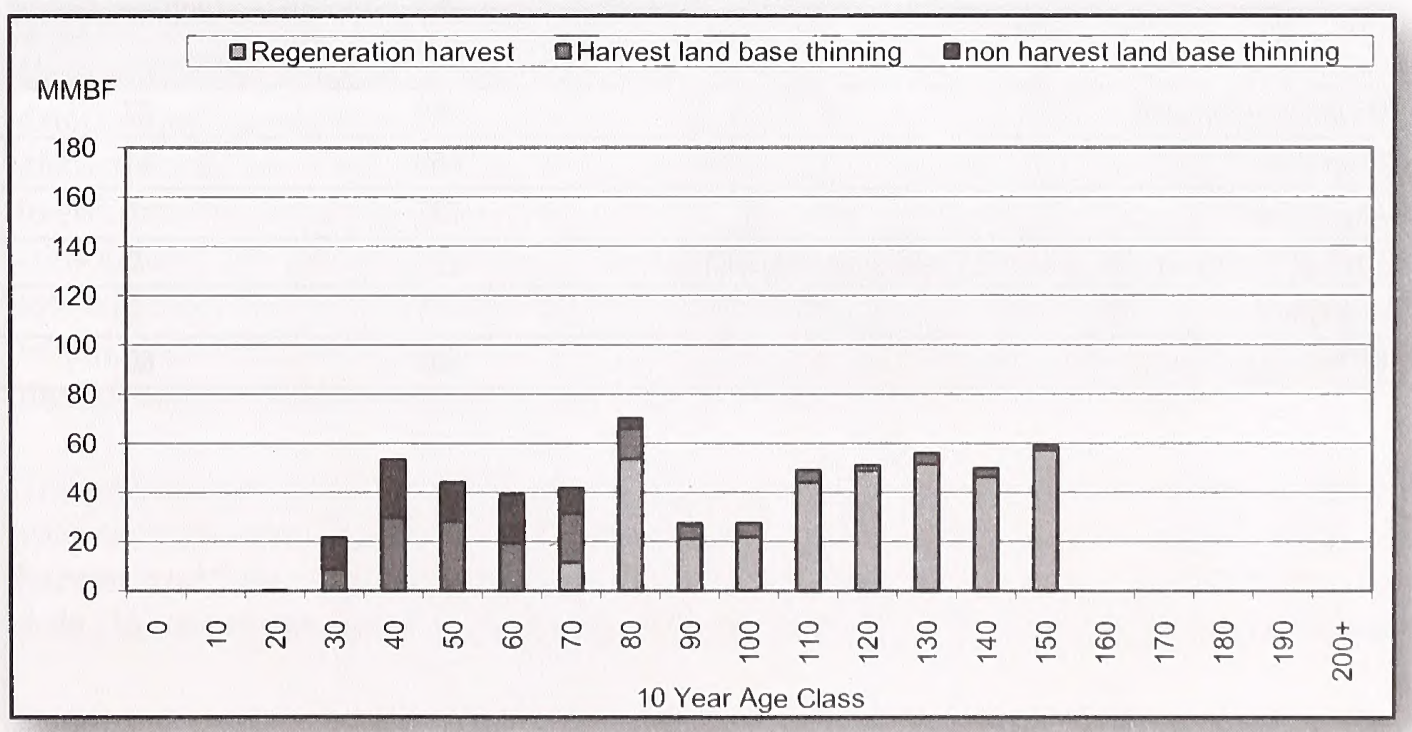




\section{Summary of Timber Harvest Levels}

The total volume harvested annually would vary substantially between the alternatives. Alternatives vary not only in the allowable sale quantity, but also in the amount of nonharvest base volume that would be produced. The total volume for the alternatives compared to the reference analysis is shown in Figure 4-43 (Total volume harvested for all alternatives and the reference analysis) and Table 4-32 (Total volume for all alternatives and reference analysis).

Figure 4-43. Total Volume Harvested For All Alternatives And The Reference Analysis

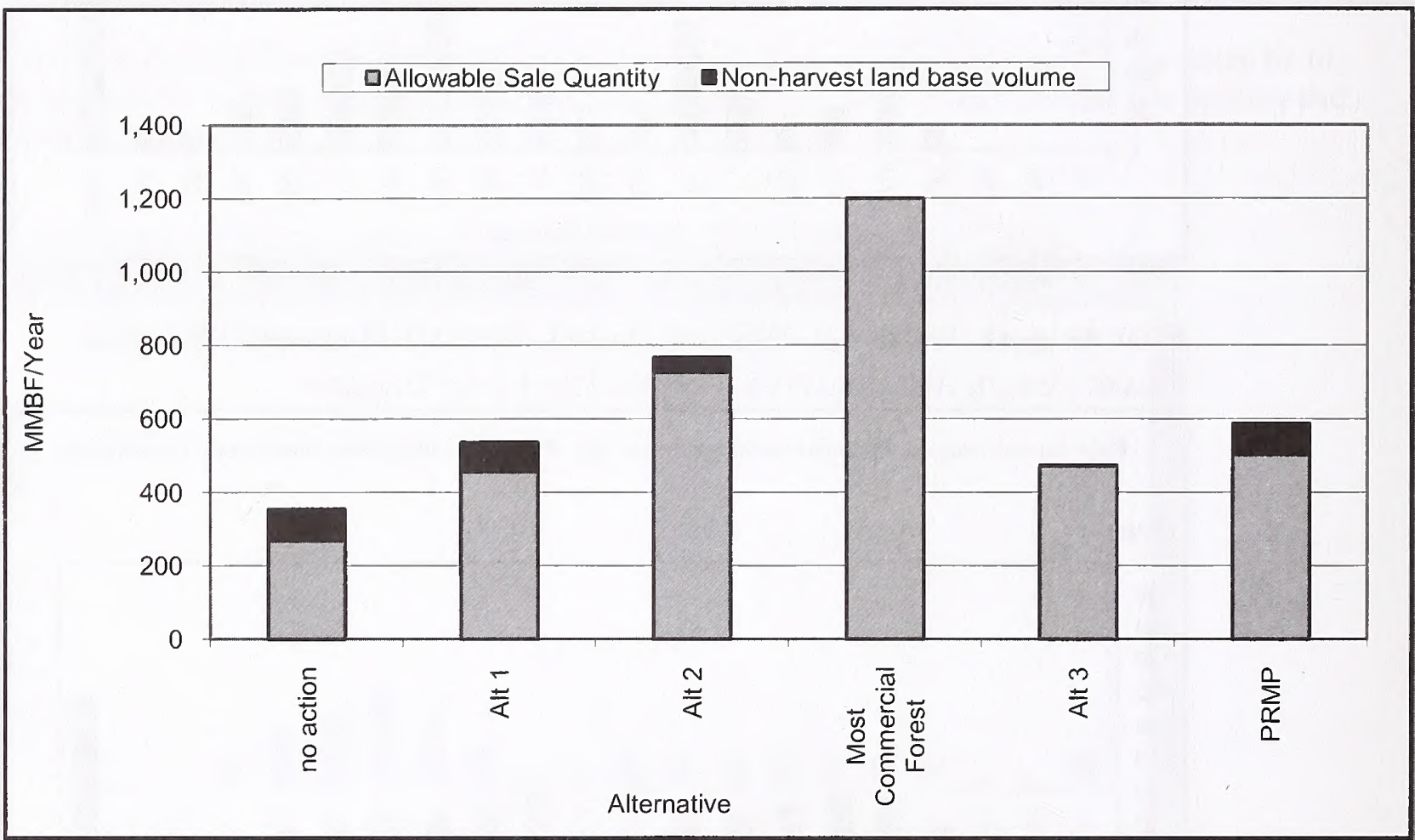

Table 4-32. Total Volume For All Alternatives And Reference Analysis

\begin{tabular}{lrrr}
\hline \multirow{2}{*}{ Alternative or reference analysis } & \multicolumn{1}{c}{$\begin{array}{c}\text { Allowable Sale } \\
\text { Quantity }\end{array}$} & $\begin{array}{c}\text { Non-harvest Land } \\
\text { Base Volume } \\
\text { (mmbf) }\end{array}$ & $\begin{array}{r}\text { Eastern Land } \\
\text { Management Volume }\end{array}$ \\
\cline { 2 - 5 } No Action Alternative & 268 & 87 & 2 \\
\hline Alternative 1 & 456 & 81 & 2 \\
\hline Alternative 2 & 727 & 40 & 2 \\
\hline Manage Most Commercial Lands (Reference Analysis) & 1201 & 0 & 2 \\
\hline Alternative 3 & 471 & 2 & 2 \\
\hline PRMP & 502 & 86 & 0.5 \\
\hline
\end{tabular}




\section{Harvest Land Base}

The harvest land base varies by alternative. The No Action Alternative would have the lowest number of acres within the harvest land base compared to other alternatives. Under the No Action Alternative, 27\% of the forested acres would be contained within the harvest land base (nearly 608,000 acres). Alternative 3 would have the highest amount, with $65 \%$ of the forested acres being within the harvest land base (1.4 million acres). The PRMP would have $45 \%$ of the forested acres in the harvest land base (approximately 994,000 acres). Figure 4-44 (Acres in the harvest land base by alternative) displays the acres for the alternatives contrasted with the total forested acres.

Figure 4-44. Acres In The Harvest Land Base By Alternative

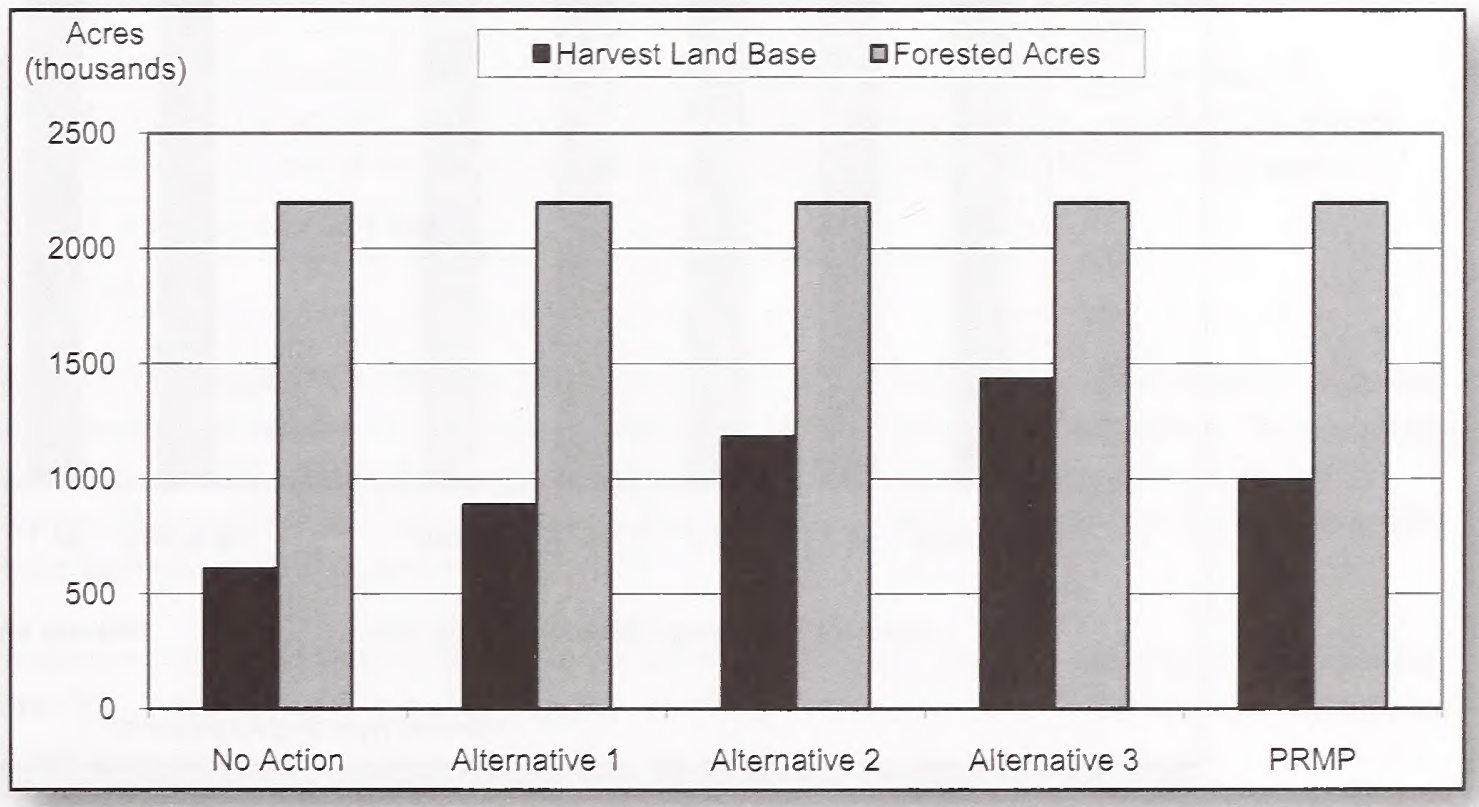

\section{Value of the Harvest}

\section{Log Quality}

The differences in the ages of the stands and the species composition of those stands that would be harvested under the alternatives would result in different types and grades of logs being harvested. The structural stage classification described in the Forest Structure and Spatial Pattern section of Chapter 3 is used as one basis for determining $\log$ quality and the value resulting from these harvests. Differences in species that occur in each district would also affect the value of the harvests for each alternative. Historical sales data has been used to estimate the percentage of harvest volume by species or groups of species. Individual species have been consolidated into groupings typical of those quoted for prices, such as true firs and hemlock being grouped into whitewoods. Historical sales data has also been used to estimate the amount of different log grades that would result from harvesting each structural stage. See Appendix E - Timber for further discussion on the methodology to value the timber that would be produced under each alternative.

The percentages of volume by structural stage that would be harvested are shown in Figure 4-45 (Percent volume by structural stage) as the average annual level for the first 10-year period. Volume is from both the harvest land base and nonharvest land base. The volumes of harvest by structural stage are shown in Figure 4-46 (Volume by structural stage and alternative). Under the PRMP, an average annual level of $83 \mathrm{mmbf} /$ year 
would be harvested from the structurally complex structural stage, slightly more than under the No Action Alternative, which would have an average harvest level of $79 \mathrm{mmbf} / \mathrm{year}$ from structurally complex stands. This similar harvest level is largely due to deferral of older and more structurally complex multi-layered conifer forests until the year 2023 under the PRMP. Under Alternative 2, the highest amount of structurally complex forest would be harvested at an average annual level of $317 \mathrm{mmbf}$.

Figure 4-45. Percent Volume By Structural Stage

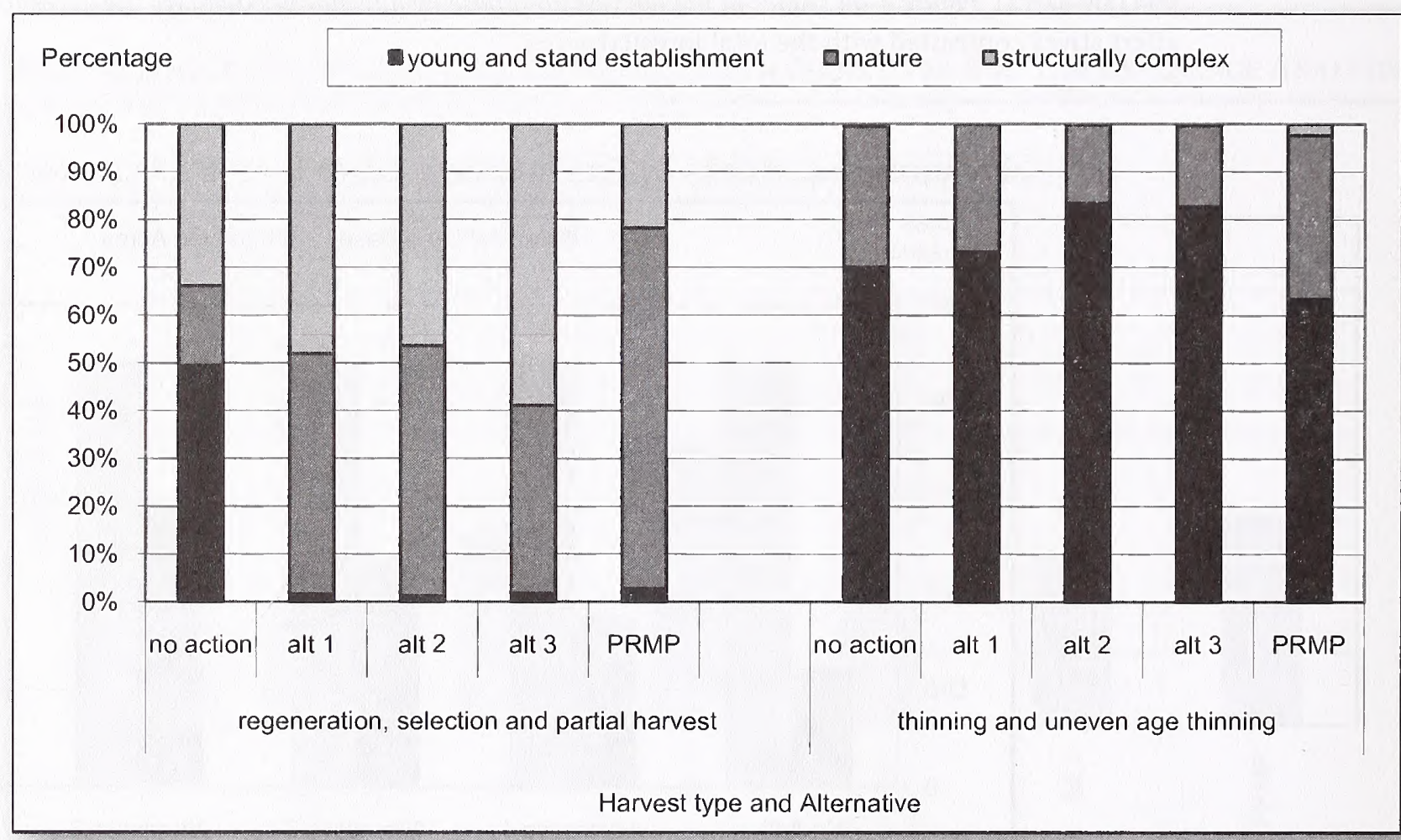

Figure 4-46. Volume By Structural Stage And Alternative

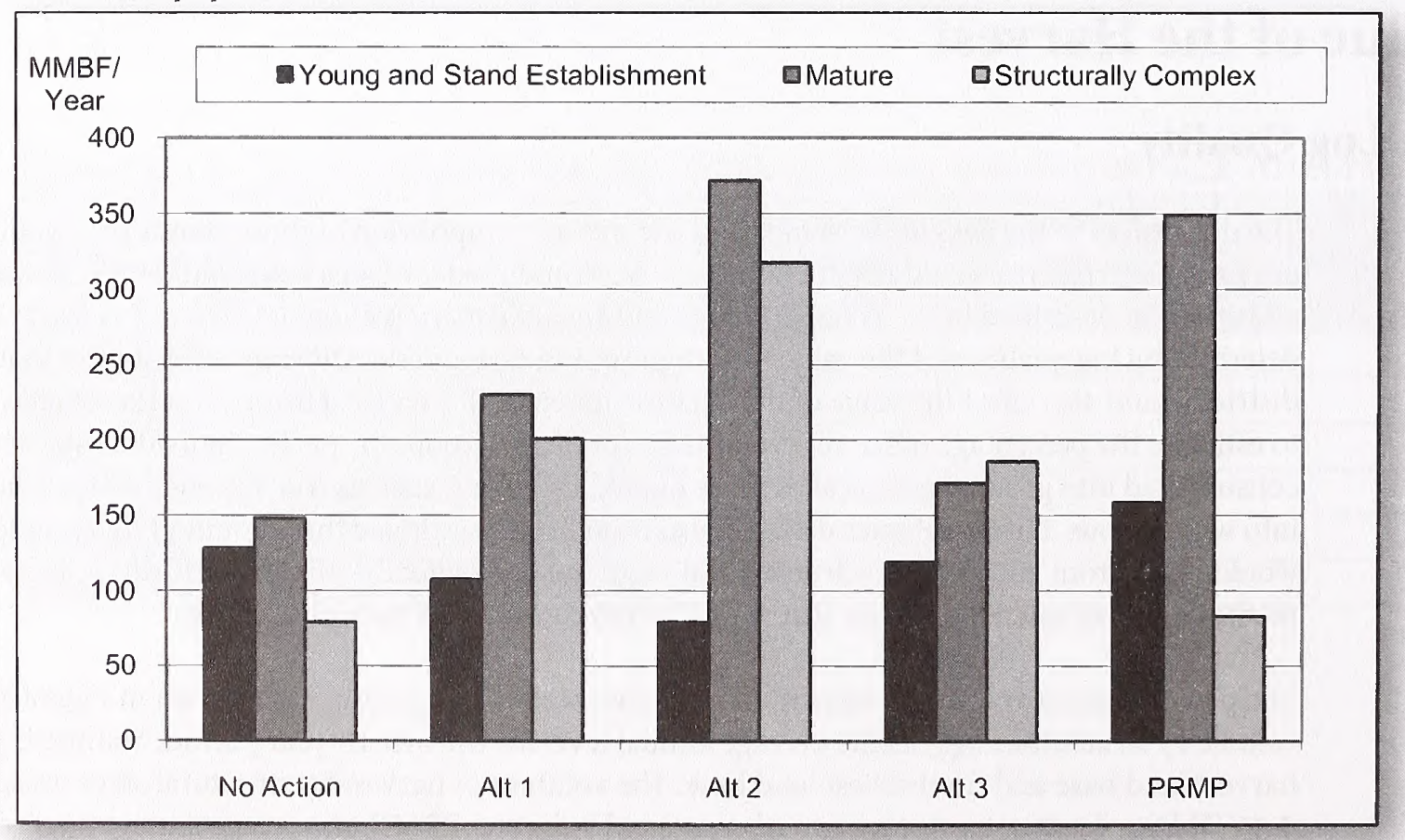


As a percentage, the PRMP would have the lowest level of regeneration harvest of structurally complex forest would occur compared to the other alternatives. However, because the overall harvest level of the PRMP is higher than the No Action, the total quantity would exceed the No Action Alternative as noted above. The PRMP would have the highest percentage of regeneration harvest in the mature structural stage compared to the other alternatives, but would be lower in quantity than Alternative 2 because of the higher level of harvest in Alternative 2. The highest level of regeneration harvesting of young forest would occur under the No Action Alternative compared to the other alternatives.

Alternatives 1,2, and 3 would have a similar percentage of harvest from structurally complex forest, but harvest would vary in quantity. As a result, the percentage of higher-grade logs (number 3, peeler-grade and better Douglas fir) would be higher under Alternatives 1,2 and 3 than under the No Action Alternative. Under the PRMP, there would be a very similar percentage of higher grade logs to that under the No Action Alternative.

Log quality for the first 10-year period is determined only for Douglas fir due to the dominance of Douglas fir in all districts. Historically, except for the Klamath Falls Resource Area, Douglas fir has been approximately $80 \%$ of the volume of timber sold. Two log grade groups are used for log quality analysis:

- number 3, peeler-grade and better

- sawlog grade

The percentage level of Douglas fir volume by peeler grade that would be harvested by alternative is shown in Figure 4-47 (Percentage of number 3, peeler-grade and better Douglas fir logs by alternative) The percentage of peeler grade for the PRMP and the No Action Alternative are similar, at approximately $4 \%$ of the Douglas fir volume. Alternatives 1,2, and 3 are similarly grouped at around $8 \%$ of Douglas fir volume, with Alternative 2 the highest percentage at $8.5 \%$.

Under the alternatives, there would be differing levels of harvest volume. The quantities of peeler-grade logs compared to sawlog-grade logs are shown in Figure 4-48 (Douglas fir log volumes by peeler grade and sawlog grade by alternative)

Figure 4-47. Percentage Of Number 3, Peeler-Grade And Better Douglas Fir Logs By Alternative

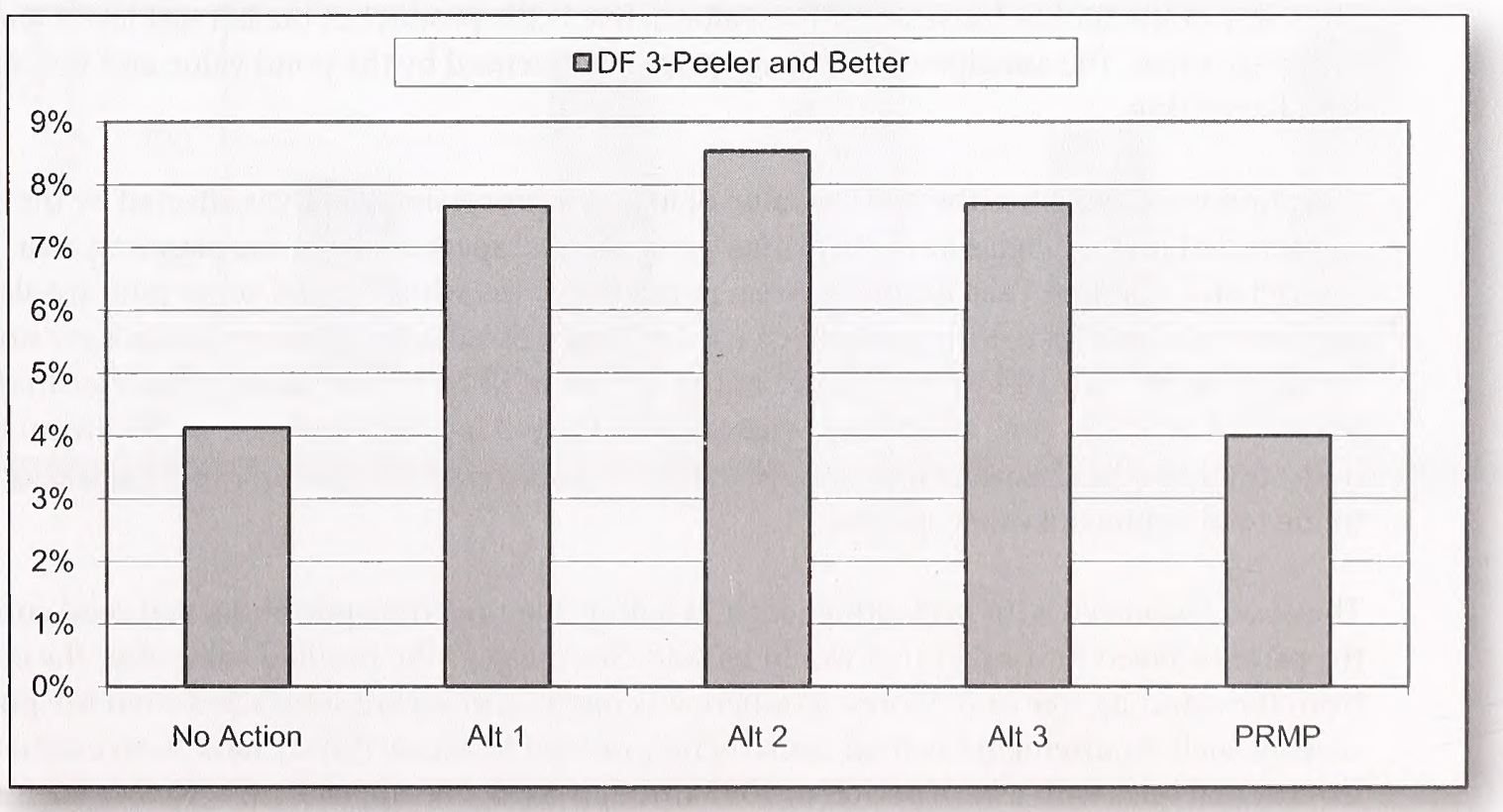


Figure 4-48. Douglas Fir Log Volumes By Peeler Grade And Sawlog Grade By Alternative

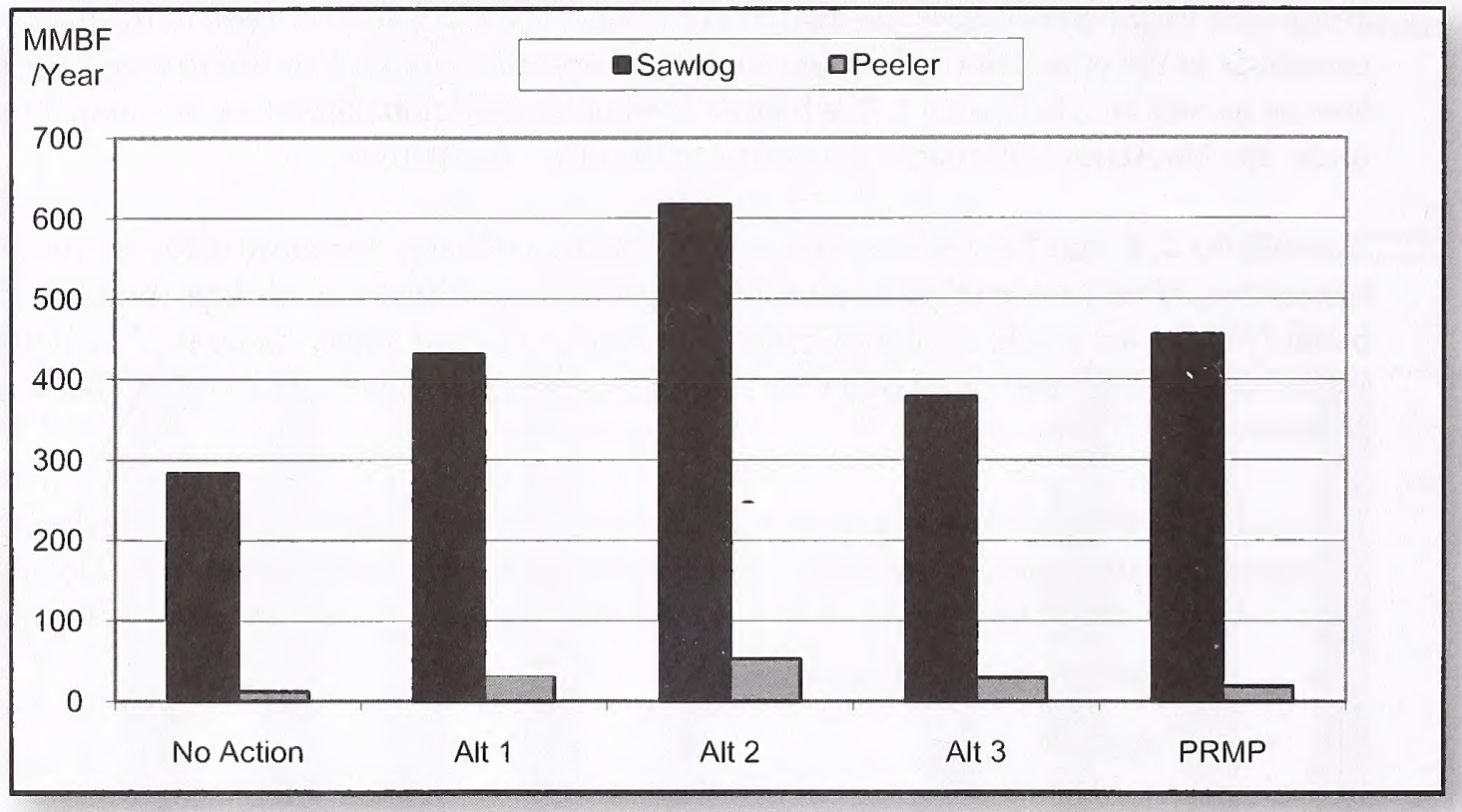

Under the No Action Alternative, there would be a reduced level in the quality of logs as a percentage and in the quantity harvested compared to the action alternatives, because of the higher proportion of thinning and the lower proportion of the structurally complex forest that would be harvested. Under the PRMP, there would be the second lowest harvest of peeler grade logs compared to the other alternatives due to the deferral of older and more structurally complex multi-layered conifer forests until the year 2023 . Most regeneration harvest would occur in the mature structural stage. This structural stage contains some peeler grade, but it is limited in quantity and consists of mostly 3 grade peeler. Under Alternative 2 , there would be the highest level of peeler logs compared to the other alternatives due to the higher harvest level and harvest of structurally complex forest.

\section{Stumpage Value}

The value of the timber harvests for each alternative is the product of the harvest levels and the anticipated stumpage price. The anticipated stumpage price is influenced by the pond value and the costs associated with harvesting.

The pond value, which is the market value of logs at a processing facility, is affected by the quality and species of harvested logs. Douglas fir is the primary commercial species within the planning area. In the Medford District and Klamath Falls Resource Area, ponderosa pine, white fir, and sugar pine are also important. Only for these four species has log grade been used as a part of valuation. Other species have not been valued by $\log$ grade because of low occurrence of the species in BLM timber sales, or because they are typically purchased as "camp run" where one price is quoted for all log sizes and grades. Historical information indicates that other than the four species mentioned above, the volume of higher grade logs was low relative to the total volume of other species.

The costs associated with harvesting (such as falling, logging, transportation, and road construction) reduce the price received for timber that would be sold. Stumpage is the residual value after the costs to get the $\log$ from the standing tree in the forest to where it is manufactured are subtracted from the pond value. The costs of such requirements as road construction needed to access timber have been estimated using costs from actual sales with a base period of 1995 through 2006. See Appendix E - Timber for further information. 
The stumpage value of the harvests over the first 10 years is determined by multiplying the volumes for each type of harvest (i.e., thinning, partial harvesting, regeneration harvesting, and uneven-aged management) by the estimated value of the logs as determined by the harvested structural stage (i.e., stand establishment, young, mature, and structurally complex), and then subtracting the costs of harvest for each combination. Stumpage prices for each harvest type are developed from historical costs and log prices.

The values shown in Figure 4-49 (Annual stumpage value by alternative over the first decade) are calculated using $2005 \log$ prices. Values are in 2005 dollars without adjustment for inflation.

Stumpage value would change in response to market conditions. Reductions or increases in log prices at manufacturing facilities would have a corresponding effect on stumpage prices.

Stumpage value is less sensitive to changes in prices between grades, since only a fraction of volume sold consists of higher graded logs. If all premiums for Douglas fir logs over a special mill grade disappeared, stumpage value under Alternative 2 would only decrease between 3-4 percent. The stumpage value under the No Action Alternative and the PRMP would decrease less than the other alternatives since a lower fraction of trees harvested under these alternatives consist of higher graded logs.

Costs also would affect the value of stumpage prices. An increase in costs would result in approximately an equivalent reduction in stumpage prices for all alternatives.

The changes in log prices or costs shown above would change the amount of stumpage value, but would all act in a similar manner across all alternatives. Reasonably foreseeable price changes would not change the ranking of the alternatives with respect to stumpage value.

\section{Figure 4-49. Annual Stumpage Value By Alternative Over The First Decade}

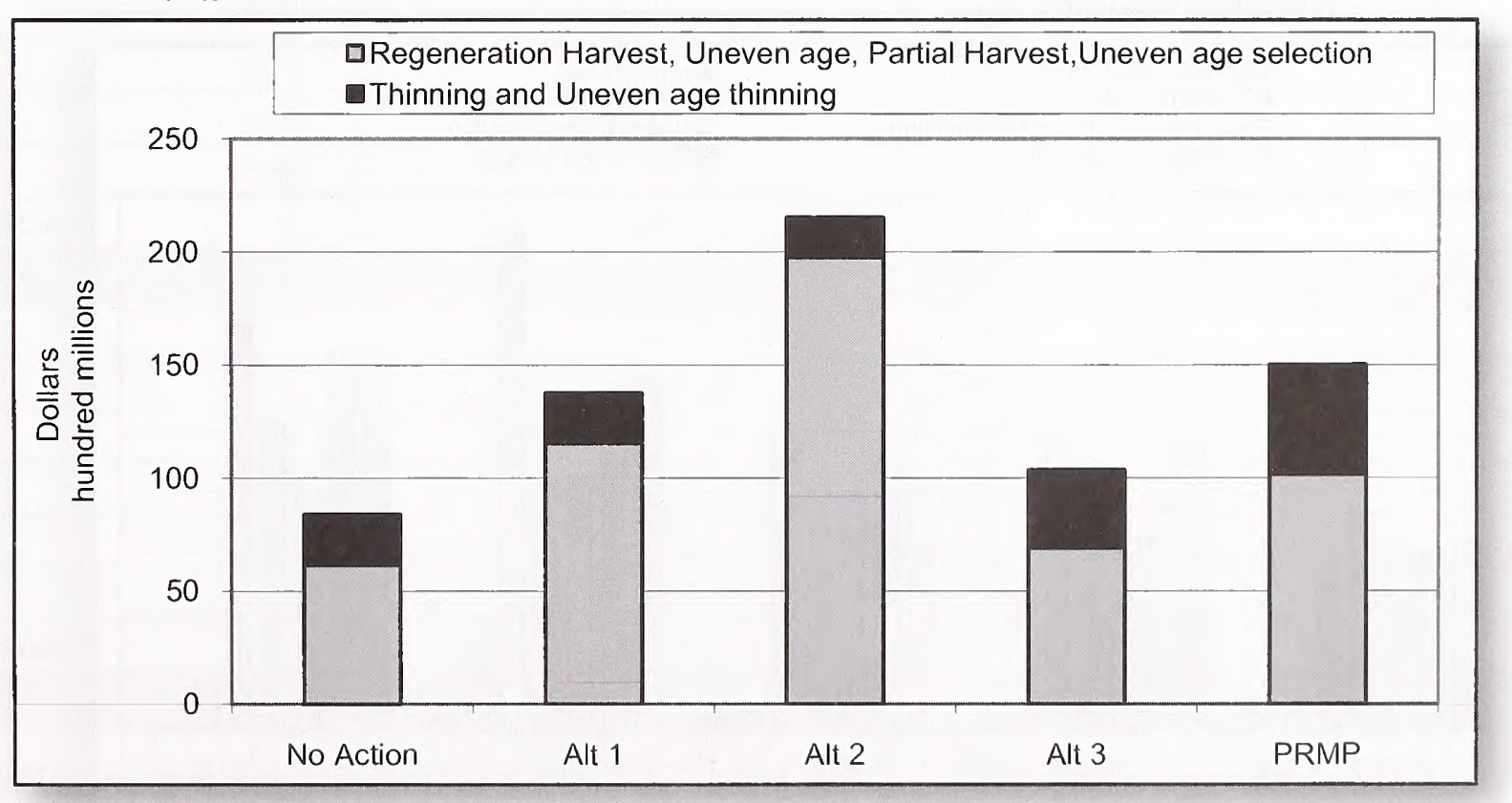




\section{Receipt Timing}

Historical data indicate that a lag occurs between the time that a timber sale is sold and the time that harvest occurs. Data over the last decade indicate that of volume offered in a fiscal year:

- $3 \%$ is harvested the fiscal year of the sale.

- $28 \%$ is harvested the next fiscal year after the sale.

- $41 \%$ is harvested two fiscal years after the sale.

- The remaining $28 \%$ volume is harvested more than two fiscal years beyond the sale.

This harvest lag potentially will result in a lag in the volume-related receipt changes. This harvest lag depends on market conditions, with sale operations commencing more quickly in times of high wood product demand and less quickly in market downturns. For timber sales with a contract length of more than 18 months, anniversary payments are due at 12 months after contract approval, and if applicable, at 24 months after approval regardless of whether timber has been cut. These anniversary payments are designed to encourage timely performance and are treated as receipts from timber sales. In addition, contract length can be designed to encourage rapid harvest for sales of limited size or lower complexity. Finally, ongoing sales from prior years' sales create receipts over the term of the contract. This lag in receipts is more pronounced as the level of harvest under the alternative increases compared to current harvest levels.

\section{Type of Harvest}

The different types of harvest that would occur under the alternatives include thinning, uneven-aged management, partial harvesting, and regeneration harvest. Thinning would occur in both the harvest land base and the nonharvest land base.

The harvest levels by harvest type under each alternative over the first decade are shown in Figure 4-50 (Harvest acres by harvest type over the first decade) and Table 4-33 (Estimated Annual Acres by harvest type over the first decade.

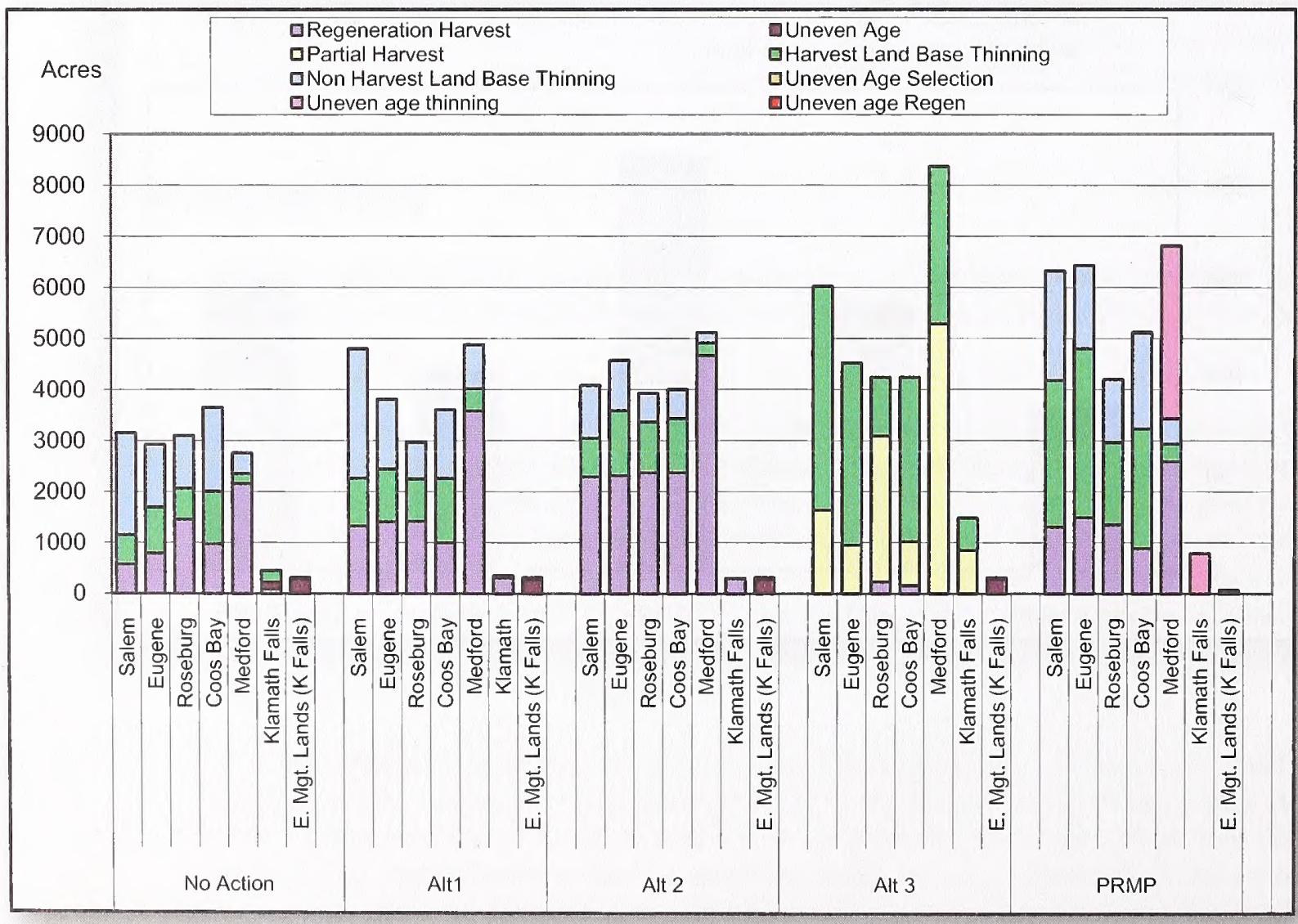

FIGURE 4-50. HARVEST ACRES By Harvest Type Over The First Decade 
Chapter 4 - Environmental Consequences

Table 4-33. Estimated Annual Acres By Harvest Type Over The First Decade

\begin{tabular}{|c|c|c|c|c|c|c|c|c|}
\hline \multirow[b]{2}{*}{ District and Alternative } & \multicolumn{8}{|c|}{ Harvest Acres } \\
\hline & $\begin{array}{r}\text { Regeneration } \\
\text { Harvest }\end{array}$ & $\begin{array}{r}\text { Regeneration } \\
\text { harvest with Green } \\
\text { Tree Retention }\end{array}$ & $\begin{array}{r}\text { Uneven- } \\
\text { Age }\end{array}$ & $\begin{array}{r}\text { Partial } \\
\text { Harvest }\end{array}$ & $\begin{array}{l}\text { Harvest } \\
\text { Land Base } \\
\text { Thinning }\end{array}$ & $\begin{array}{r}\text { Non-Harvest } \\
\text { Land Base } \\
\text { Thinning }\end{array}$ & $\begin{array}{r}\text { Uneven- age } \\
\text { thinning }\end{array}$ & $\begin{array}{r}\text { Uneven-age } \\
\text { Regen }\end{array}$ \\
\hline \multicolumn{9}{|l|}{ No Action Alternative } \\
\hline Salem & & 580 & & & 580 & 2,000 & & \\
\hline Eugene & & 790 & & & 900 & 1,240 & & \\
\hline Roseburg & & 1,460 & & & 610 & 1,040 & & \\
\hline Coos Bay & & 980 & & & 1,030 & 1,640 & & \\
\hline Medford & & 2,160 & & & 200 & 410 & & \\
\hline Klamath Falls & & 90 & 140 & & 230 & & & \\
\hline Eastside Management Lands & & & 290 & & 30 & & & \\
\hline \multicolumn{9}{|l|}{ Alternative 1} \\
\hline Salem & 1,329 & & & & 940 & 2,530 & & \\
\hline Eugene & 1,414 & & & & 1,040 & 1,360 & & \\
\hline Roseburg & 1,421 & & & & 830 & 710 & & \\
\hline Coos Bay & 1,001 & & & & 1,260 & 1,350 & & \\
\hline Medford & 3,585 & & & & 440 & 850 & & \\
\hline Klamath & 309 & & & & 50 & & & \\
\hline Eastside Management Lands & & & 290 & & 30 & & & \\
\hline \multicolumn{9}{|l|}{ Alternative 2} \\
\hline Salem & 2,295 & & & & 760 & 1,030 & & \\
\hline Eugene & 2,318 & & & & 1,270 & 980 & & \\
\hline Roseburg & 2,375 & & & & 990 & 560 & & \\
\hline Coos Bay & 2,375 & & & & 1,060 & 570 & & \\
\hline Medford & 4,666 & & & & 250 & 200 & & \\
\hline Klamath Falls & 295 & & & & 10 & & & \\
\hline Eastside Management Lands & & & 290 & & 30 & & & \\
\hline
\end{tabular}

Alternative 3

\begin{tabular}{lrrr}
\hline Salem & & 1,637 & 4,390 \\
\hline Eugene & 230 & 950 & 3,570 \\
\hline Roseburg & 160 & 2,860 & 1,150 \\
\hline Coos Bay & & 870 & 3,220 \\
\hline Medford & & 5,290 & 3,070 \\
\hline Klamath Falls & 290 & 860 & 630 \\
\hline Eastside Management Lands & & 30
\end{tabular}

\begin{tabular}{lr}
\hline PRMP & \\
\hline Salem & 1,310 \\
\hline Eugene & 1,500 \\
\hline Roseburg & 1,350 \\
\hline Coos Bay & 890 \\
\hline Medford & 2,600
\end{tabular}

Klamath Falls

Eastside Management Lands

70

\begin{tabular}{rr}
2,880 & 2,140 \\
\hline 3,310 & 1,630 \\
\hline 1,610 & 1,240 \\
\hline 2,350 & 1,880 \\
\hline $470^{a}$ & 420
\end{tabular}

ancludes both thinnings and 129 acres of shelterwood prep cut. 
Under the PRMP, within the Uneven-Age Management Area, treatments that preferentially remove smaller trees are shown as uneven age thinning in Table 4-33. For the first decade, no selection harvests (treatments that remove trees proportionally to their occurrence) are estimated. For the Klamath Falls Resource Area, an estimated 11 annual acres of regeneration harvest in the Uneven Age Management Area for the first decade is included.

Regeneration harvest under the PRMP would occur without green tree retention as shown in Table 4-33. Shelterwood cuts would be applied on an estimated 129 acres per year within the Timber Management Area in the Medford District.

The alternatives would vary in the age classes that receive regeneration harvesting, partial harvesting, uneven-aged management, and thinning. The acres harvested over the first decade by age class grouping are shown in Figure 4-51 through Figure 4-55 and Table 4-34 through Table 4-38.

During the first decade under the No Action Alternative, approximately $10 \%$ of the harvest land base would be regeneration harvested, which is $2.7 \%$ of the total forested acres within the planning area. Harvest land base thinning would occur on $6 \%$ of the harvest land base, with both types of thinning (harvest land base and nonharvest land base) occurring on 4.6\% of the total forested acres. See Figure 4-51 and Table 4-34.

During the first decade under Alternative 1, approximately $10 \%$ of the harvest land base would be regeneration harvested, which is $4.1 \%$ of the total forested acres within the planning area. Harvest land base thinning would occur on $5 \%$ of the harvest land base and both types of thinning (harvest land base and nonharvest land base) would occur on 5.1\% of the forested acres. See Figure 4-52 and Table 4-35.

Figure 4-51. First Decade Harvest Acres By Age Class Under The No Action Alternative
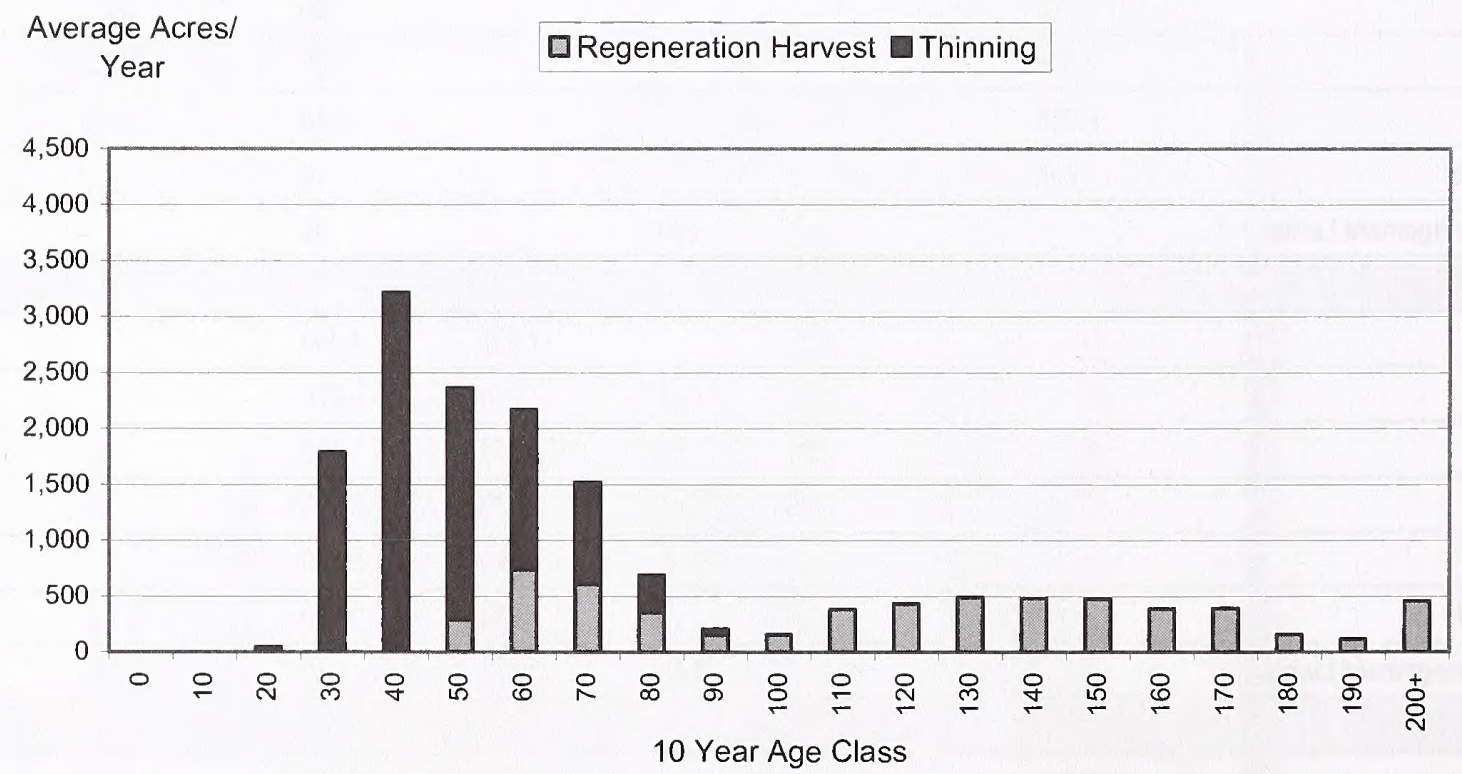
Table 4-34. First Decade Acres Harvested By Age Group In The Harvest And Nonharvest Land Base Under The No Action Alternative

\begin{tabular}{|c|c|c|c|c|}
\hline \multirow{3}{*}{$\begin{array}{l}\text { Age Group } \\
\text { (years) }\end{array}$} & \multirow{3}{*}{$\begin{array}{r}\text { Total Harvest } \\
\text { Land Base }\end{array}$} & \multicolumn{3}{|c|}{ First Decade Harvest (No Action Alternative)(acres) } \\
\hline & & \multicolumn{2}{|c|}{ Harvest Land Base } & \multirow{2}{*}{$\begin{array}{r}\begin{array}{r}\text { Nonharvest } \\
\text { Land Base }\end{array} \\
\text { Thinning }\end{array}$} \\
\hline & & Regeneration Harvesting & Thinning & \\
\hline 0 to 30 & 151,800 & 0 & 3,200 & 15,100 \\
\hline 40 to 70 & 190,900 & 16,300 & 28,900 & 47,500 \\
\hline 80 to 110 & 101,000 & 10,400 & 3,700 & 600 \\
\hline 120 to 150 & 71,800 & 18,700 & 400 & 0 \\
\hline 160 to 190 & 33,300 & 10,500 & 100 & 0 \\
\hline \multirow[t]{2}{*}{$200+$} & 58,800 & 4,600 & 500 & 0 \\
\hline & 607,600 & 60,500 & 36,800 & 63,200 \\
\hline
\end{tabular}

Figure 4-52. First Decade Harvest Acres By Age Class Under Alternative I

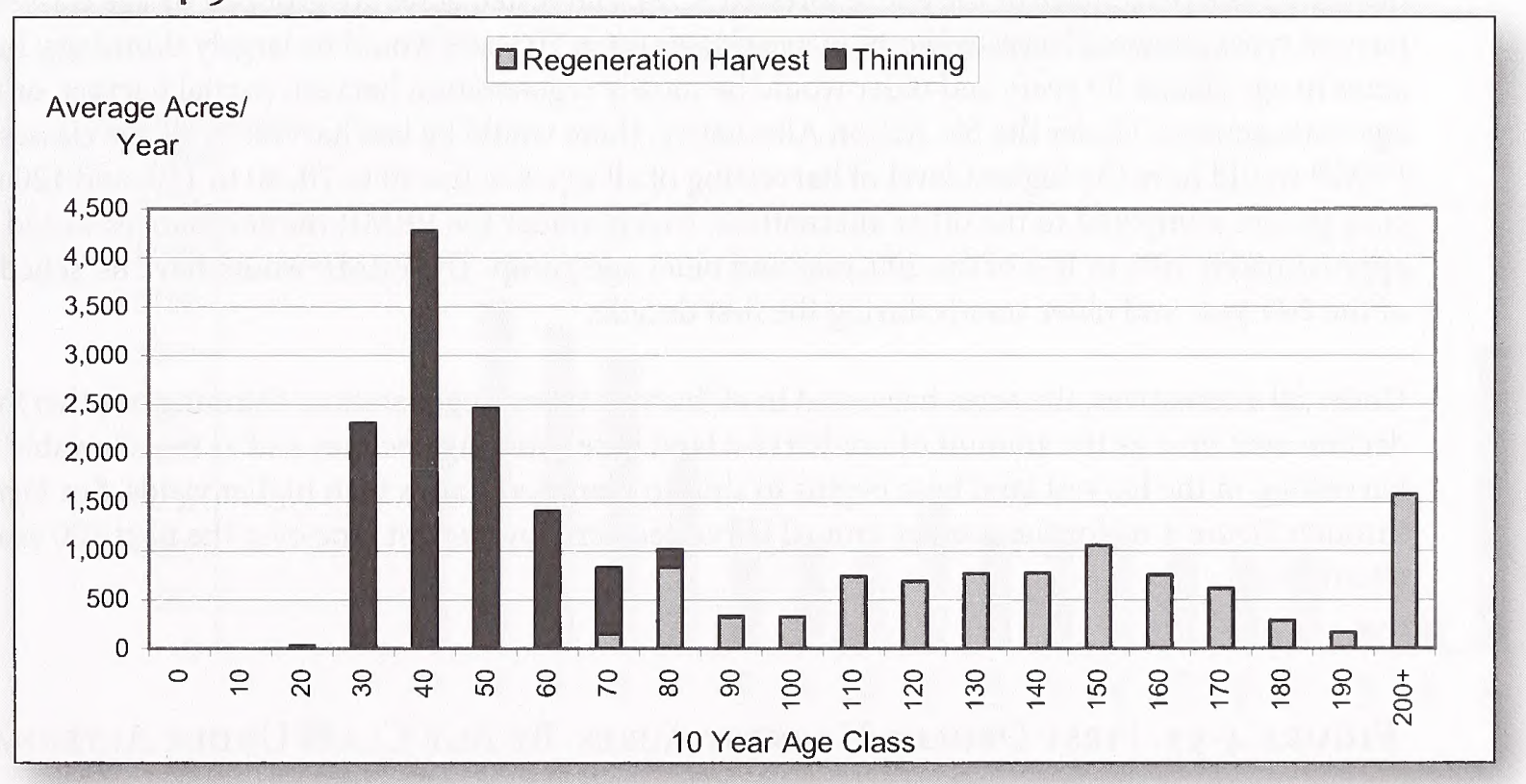

Table 4-35. First Decade Acres Harvested By Age In The Harvest And Nonharvest Land Base Under Alternative 1

\begin{tabular}{|c|c|c|c|c|}
\hline \multirow{3}{*}{$\begin{array}{l}\text { Age Group } \\
\text { (years) }\end{array}$} & \multirow{3}{*}{$\begin{array}{r}\text { Total Harvest Land } \\
\text { Base } \\
\text { (acres) }\end{array}$} & \multicolumn{3}{|c|}{$\begin{array}{l}\text { First Decade Harvest } \\
\text { Alternative } 1 \text { (acres) }\end{array}$} \\
\hline & & \multicolumn{2}{|c|}{ Harvest Land Base } & \multirow{2}{*}{$\begin{array}{r}\text { Nonharvest Land Base } \\
\text { Thinning }\end{array}$} \\
\hline & & Regeneration Harvesting & Thinning & \\
\hline 0 to 30 & 204,600 & 0 & 7,400 & 16,000 \\
\hline 40 to 70 & 282,400 & 1,500 & 37,500 & 50,600 \\
\hline 80 to 110 & 144,100 & 22,200 & 500 & 1,400 \\
\hline 120 to 150 & 109,500 & 32,900 & 0 & 0 \\
\hline 160 to 190 & 53,100 & 18,200 & 0 & 0 \\
\hline $200+$ & 92,100 & 15,800 & 0 & 0 \\
\hline & 885,800 & 90,600 & 45,400 & 68,000 \\
\hline
\end{tabular}


During the first decade under Alternative 2, approximately $12 \%$ of the harvest land base would be regeneration harvested, which is $6.5 \%$ of the total forested acres in the planning area. Harvest land base thinning would occur on $3.6 \%$ of the harvested land base and both types of thinning (harvest land base and nonharvest land base) would occur on 3.5\% of the forested acres. See Figure 4-53 and Table 4-36.

During the first decade under Alternative 3, approximately $0.3 \%$ of the harvest land base would be regeneration harvested, which is $0.2 \%$ of the total forested acres within the planning area. Harvest land base thinning including partial harvest would occur on $20 \%$ of the harvest land base, which is $13 \%$ of the forested acres. See Figure 4-54 and Table 4-37.

During the first decade under the PRMP, 7.7\% of the harvest land base would be regeneration harvested, which is $3.5 \%$ of the total forested acres within the planning area. Harvest land base thinning would occur on $14.7 \%$ of the harvest land base and both types of thinning (harvest land base and nonharvest land base) would occur on $10 \%$ of the forested acres, See Figure 4-55 and Table 4-38.

When compared against the entire forested acres, including the reserves, the alternatives vary in the percentage of age classes that would be harvested in all harvest types (including regeneration, thinning, and other) during the first decade. Figure 4-56 shows the percentage of age groupings that would be harvested as a percentage of the entire forested acres. Harvested acres are grouped by age classes, with all harvest types shown. Harvested acres in age classes up to 70 years would be largely thinnings; harvested acres in age classes 80 years and older would be mostly regeneration harvest, partial harvest, or unevenage management. Under the No Action Alternative, there would be less harvest in all age classes. The PRMP would have the highest level of harvesting of all types in the 40 to 70,80 to 110 , and 120 to 150 -age class groups compared to the other alternatives. Except under the PRMP, the alternatives would harvest approximately $10 \%$ or less of the 200 -year and older age group. The PRMP would have no scheduled harvest of the 200-year and older stands during the first decade.

Under all alternatives, the acres harvested in all harvest types (regeneration, thinning or other) would decline over time as the amount of nonharvest land base thinning declines and as the allowable sale quantity harvesting in the harvest land base begins to shift to managed stands with higher yields. See Figure 4-57 through Figure 4-61 for the average annual harvested acres by harvest type over the next 100 years for each alternative.

\section{Figure 4-53. First Decade Harvest Acres By Age Class Under Alternative 2}

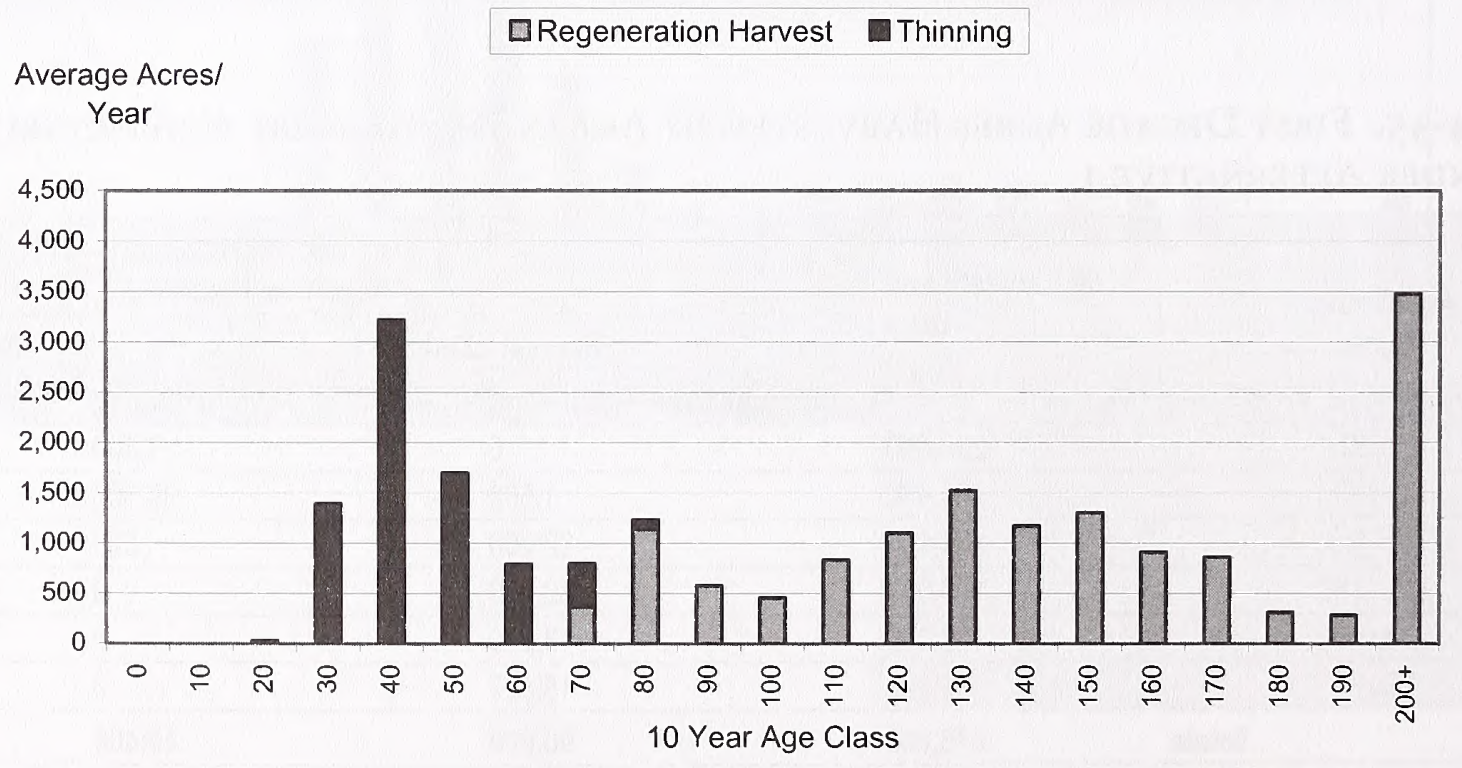


Table 4-36. First Decade Acres Harvested By Age Group In The Harvest And Nonharvest Land Base Under Alternative 2

\begin{tabular}{c|r|r|r|r}
\hline \multirow{2}{*}{$\begin{array}{c}\text { Age Group } \\
\text { (years) }\end{array}$} & Total Harvest Land & \multicolumn{3}{|c}{$\begin{array}{c}\text { First Decade Harvest } \\
\text { Alternative 2 (acres) }\end{array}$} \\
\cline { 3 - 5 } & $\begin{array}{r}\text { Base } \\
\text { (acres) }\end{array}$ & $\begin{array}{r}\text { Harvest Land Base } \\
\text { Regeneration } \\
\text { Harvesting }\end{array}$ & Thinning & Nonharvest Land Base \\
\cline { 3 - 6 } & & 3,700 & 3,800 & Thinning \\
\hline 0 to 30 & 279,000 & 30,100 & 200 & 7,400 \\
\hline 40 to 70 & 346,600 & 51,100 & 0 & 800 \\
\hline 80 to 110 & 169,300 & 23,700 & 0 & 0 \\
\hline 120 to 150 & 163,600 & 34,800 & 0 & 0 \\
\hline 160 to 190 & 72,100 & 143,400 & 43,300 & 33,400 \\
\hline $200+$ & 152,400 & & & 0 \\
\hline
\end{tabular}

Figure 4-54. First Decade Harvest Acres By Age Class Under Alternative 3 $\square$ Regeneration Harvest $\square$ Partial $\square$ Thinning

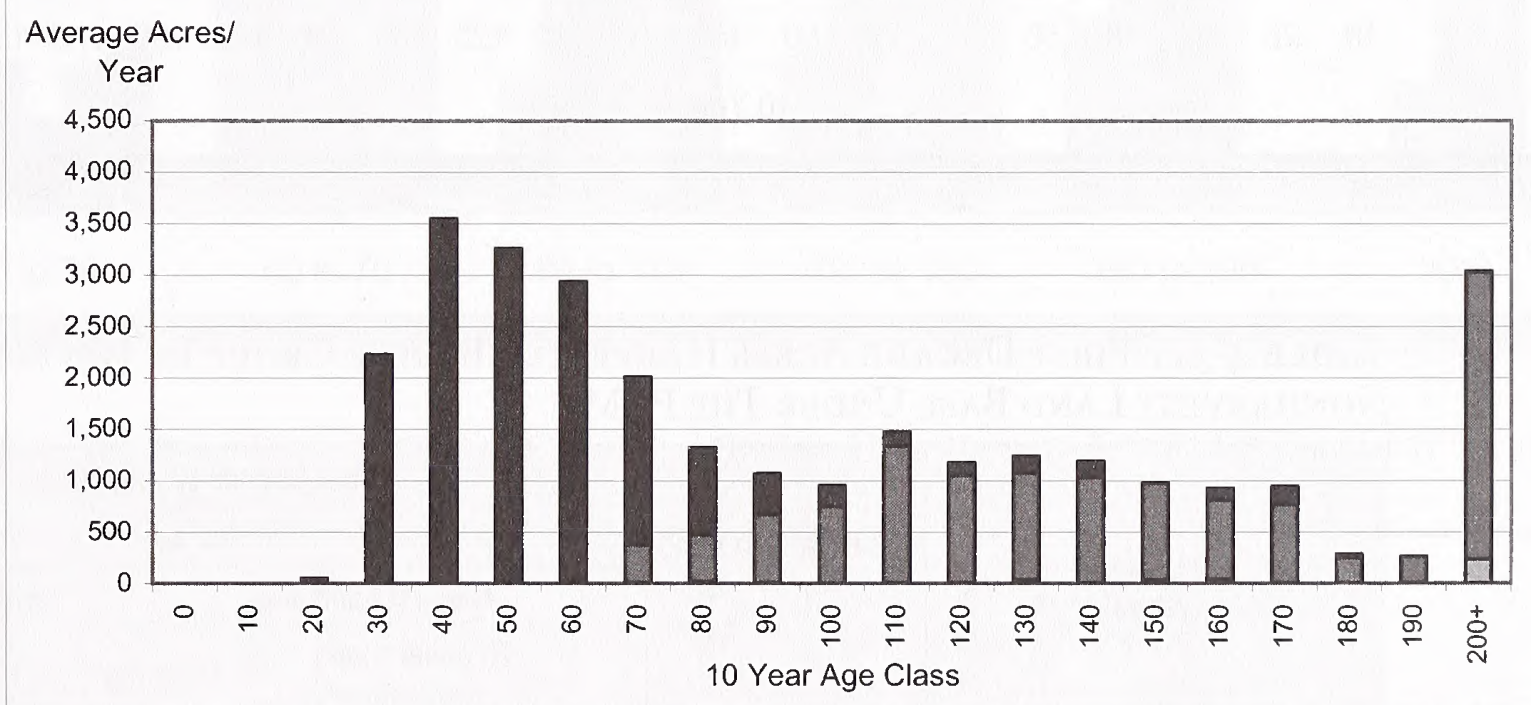

Table 4-37. First Decade Acres Harvested By Age Group In The Harvest And Nonharvest Land Base Under Alternative 3

\begin{tabular}{|c|c|c|c|c|}
\hline \multirow{3}{*}{$\begin{array}{l}\text { Age Group } \\
\text { (years) }\end{array}$} & \multirow{3}{*}{$\begin{array}{r}\text { Total Harvest Land } \\
\text { Base } \\
\text { (acres) }\end{array}$} & \multicolumn{3}{|c|}{$\begin{array}{c}\text { First Decade Harvest (acres) } \\
\text { Alternative } 3\end{array}$} \\
\hline & & \multicolumn{2}{|c|}{ Harvest Land Base } & \multirow{2}{*}{$\frac{\text { Nonharvest Land Base }}{\text { Thinning }}$} \\
\hline & & Regeneration Harvesting & Thinning $^{\mathrm{a}}$ & \\
\hline 0 to 30 & 377,100 & 0 & 22,800 & 0 \\
\hline 40 to 70 & 445,700 & 100 & 117,500 & 0 \\
\hline 120 to 150 & 160,100 & 800 & 44,900 & 0 \\
\hline 160 to 190 & 83,200 & 400 & 23,800 & 0 \\
\hline \multirow[t]{2}{*}{$200+$} & 166,700 & 2,300 & 28,100 & 0 \\
\hline & $1,434,200$ & 3,900 & 284,900 & 0 \\
\hline
\end{tabular}


Figure 4-55. First Decade Harvest Acres Harvested By Age Class Under The PrMP

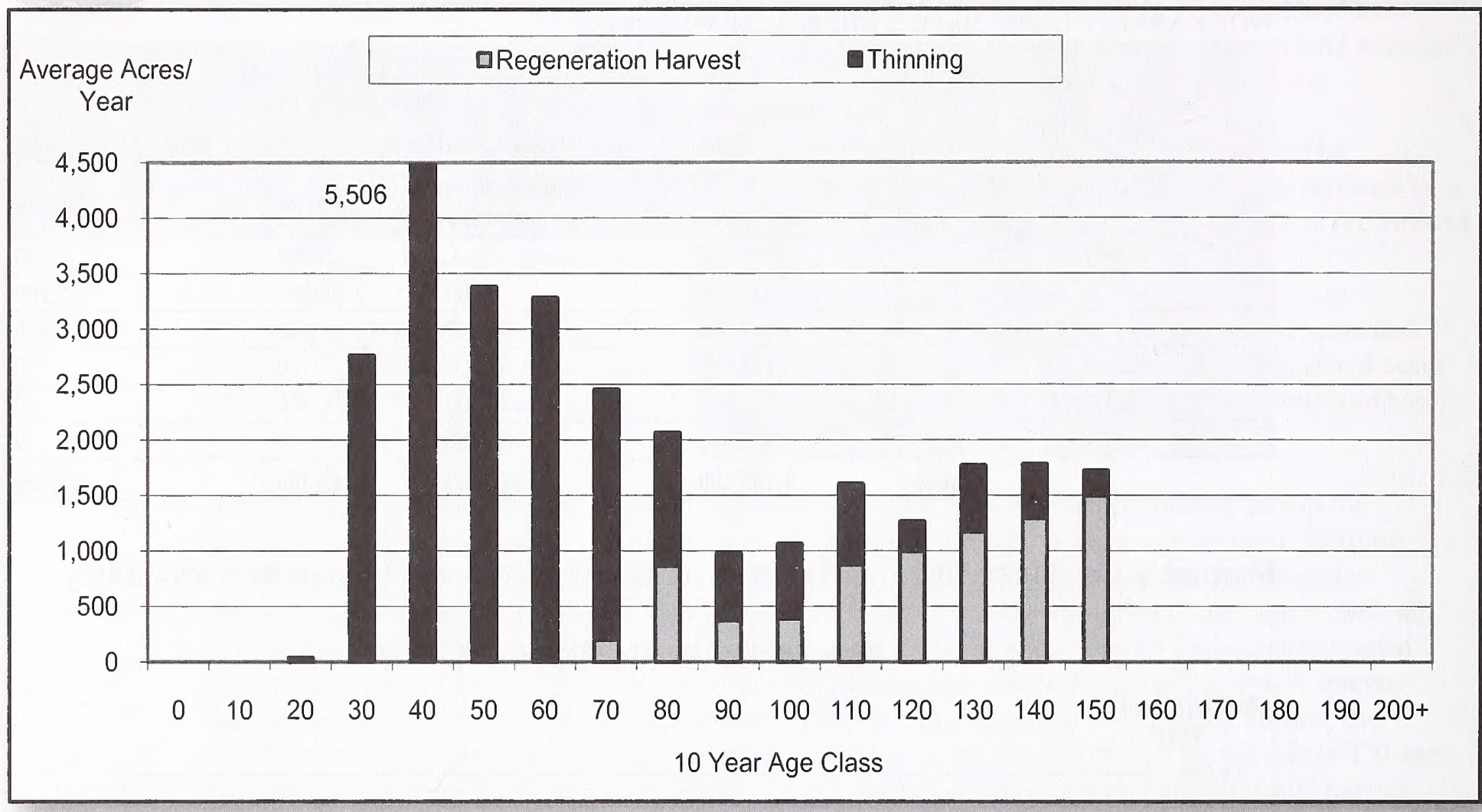

Table 4-38. First Decade Acres Harvested By Age Group In The Harvest And Nonharvest Land Base Under The PRMP

\begin{tabular}{|c|c|c|c|c|}
\hline \multirow{3}{*}{$\begin{array}{l}\text { Age Group } \\
\text { (years) }\end{array}$} & \multirow{3}{*}{$\begin{array}{r}\text { Total Harvest Land } \\
\text { Base } \\
\text { (acres) }\end{array}$} & \multicolumn{3}{|c|}{$\begin{array}{c}\text { First Decade Harvest (acres) } \\
\text { PRMP }\end{array}$} \\
\hline & & \multicolumn{2}{|c|}{ Harvest Land Base } & \multirow{2}{*}{$\begin{array}{r}\text { Nonharvest Land Base } \\
\text { Thinning }\end{array}$} \\
\hline & & $\begin{array}{r}\text { Regeneration } \\
\text { Harvesting }^{\mathrm{a}}\end{array}$ & Thinning & \\
\hline 0 to 30 & 243,200 & 0 & 11,300 & 16,700 \\
\hline 40 to 70 & 293,200 & 1970 & 90,300 & 54,000 \\
\hline 80 to 110 & 149,300 & 25,000 & 29,000 & 3100 \\
\hline 120 to 150 & 124,900 & 49,600 & 15,800 & 80 \\
\hline 160 to 190 & 61,700 & 0 & 0 & 0 \\
\hline $200+$ & 121,400 & 0 & 0 & 0 \\
\hline & 993,700 & 76,570 & 146,400 & 73,880 \\
\hline
\end{tabular}


Figure 4-56. First Decade Harvest (All Harvest Types) As A Percentage Of Entire Forest Age Class Distribution

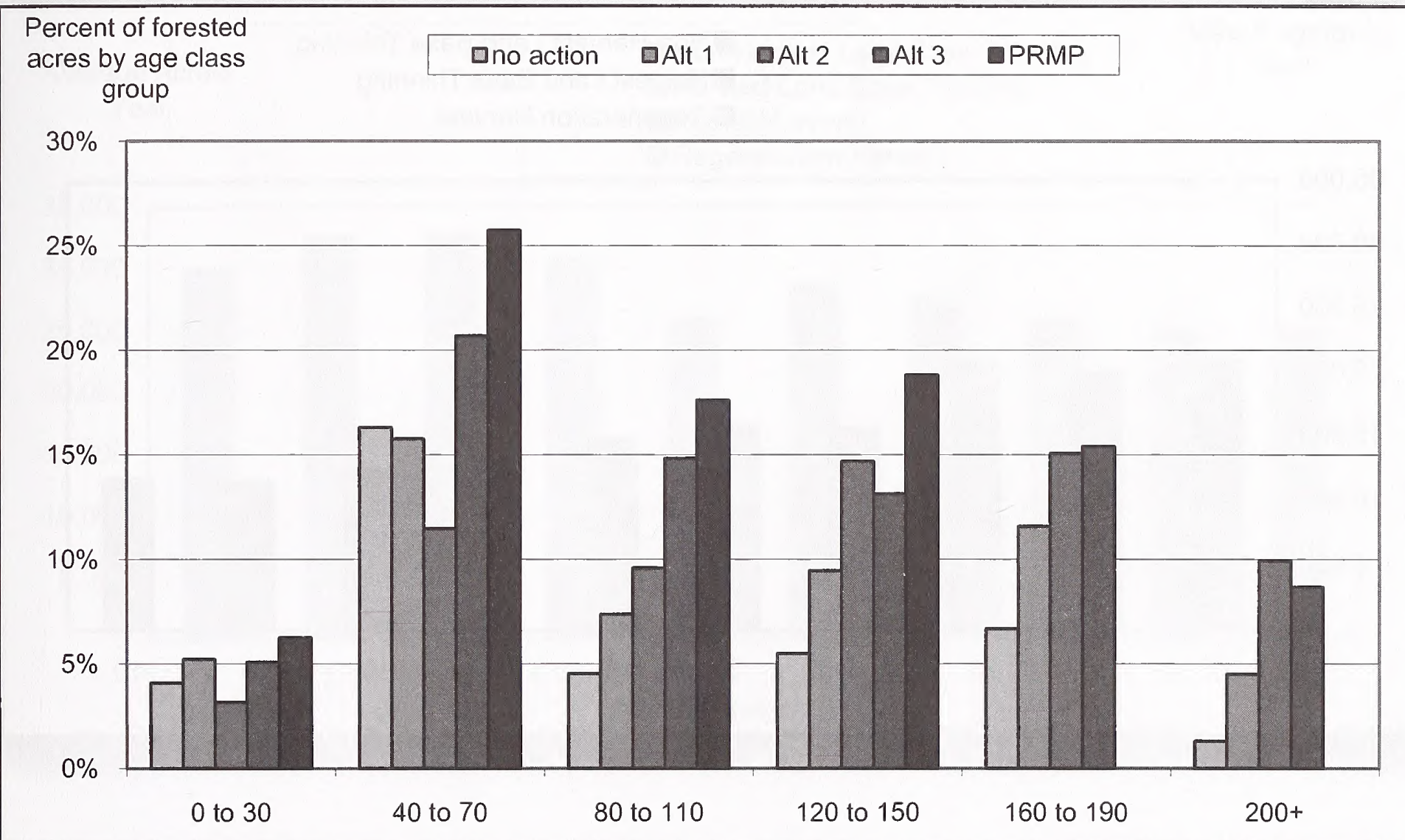

Figure 4-57. No Action Alternative, Average Annual Harvested Acres By Harvest Type Over The Next 100 Years

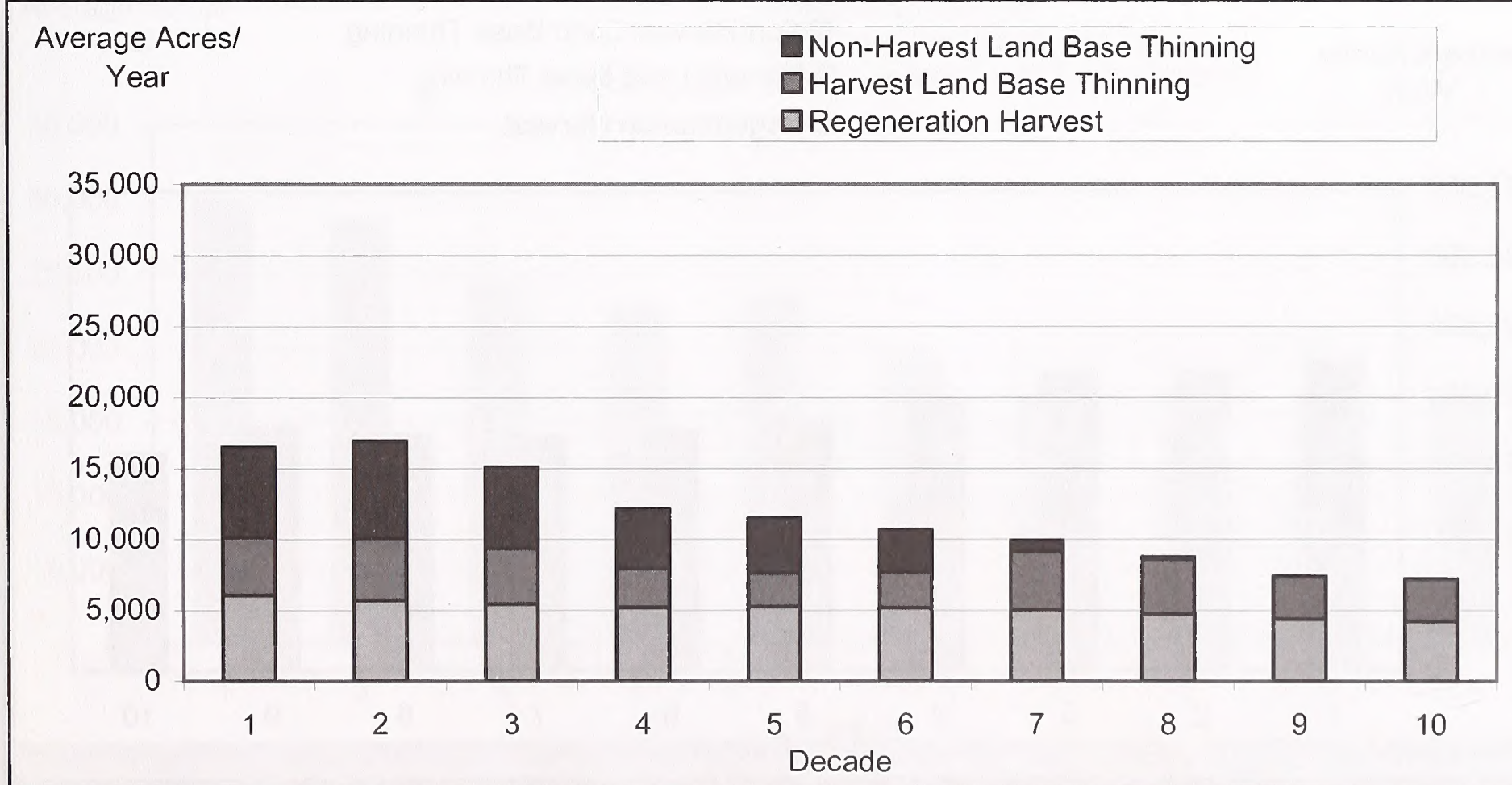


Figure 4-58. Alternative 1, Average Annual Harvested Acres By Harvest Type Over The NEXT 100 YEARS

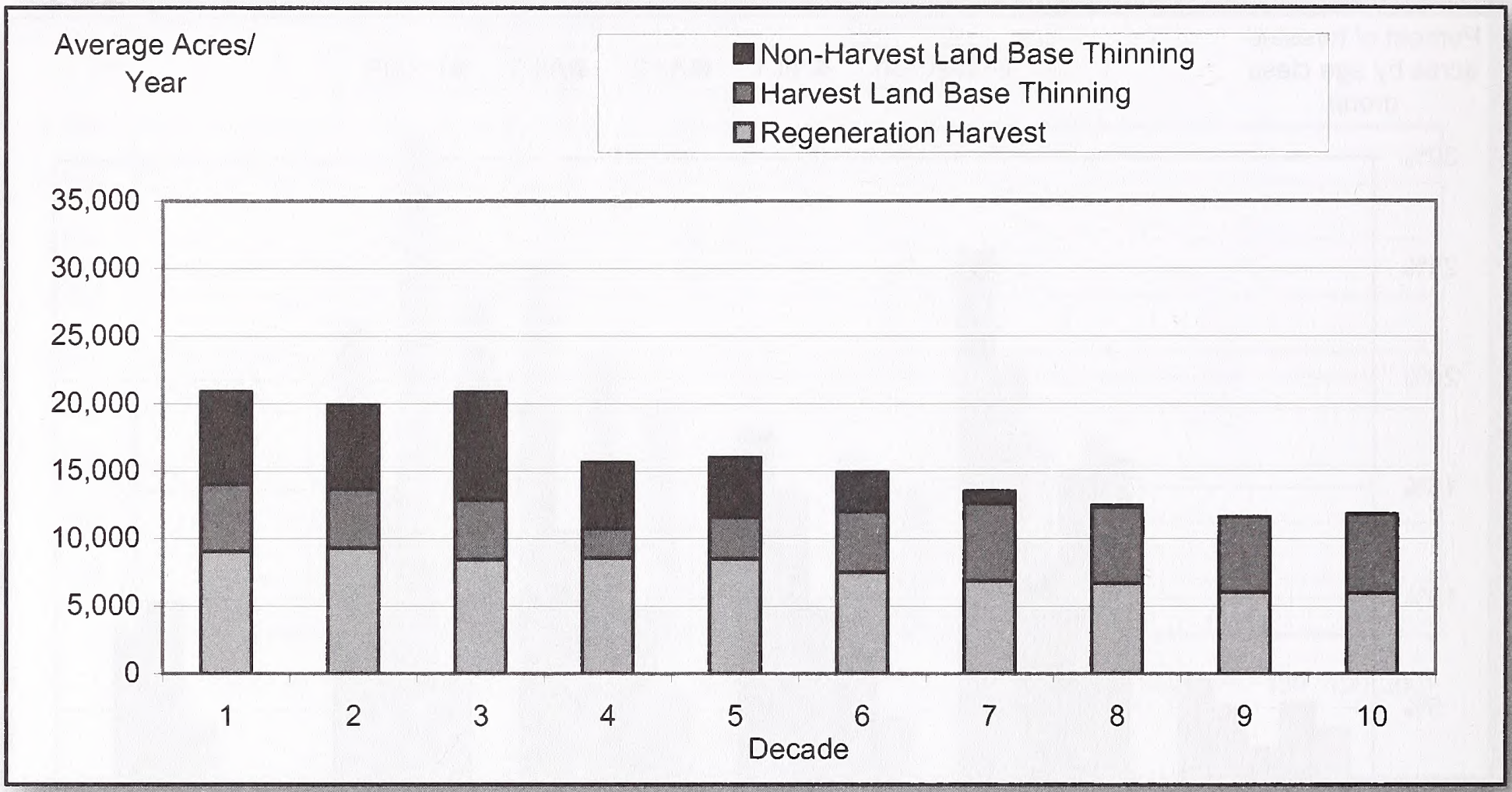

Figure 4-59. Alternative 2, Average Annual Harvested Acres By Harvest Type Over The NEXT 100 YeARS

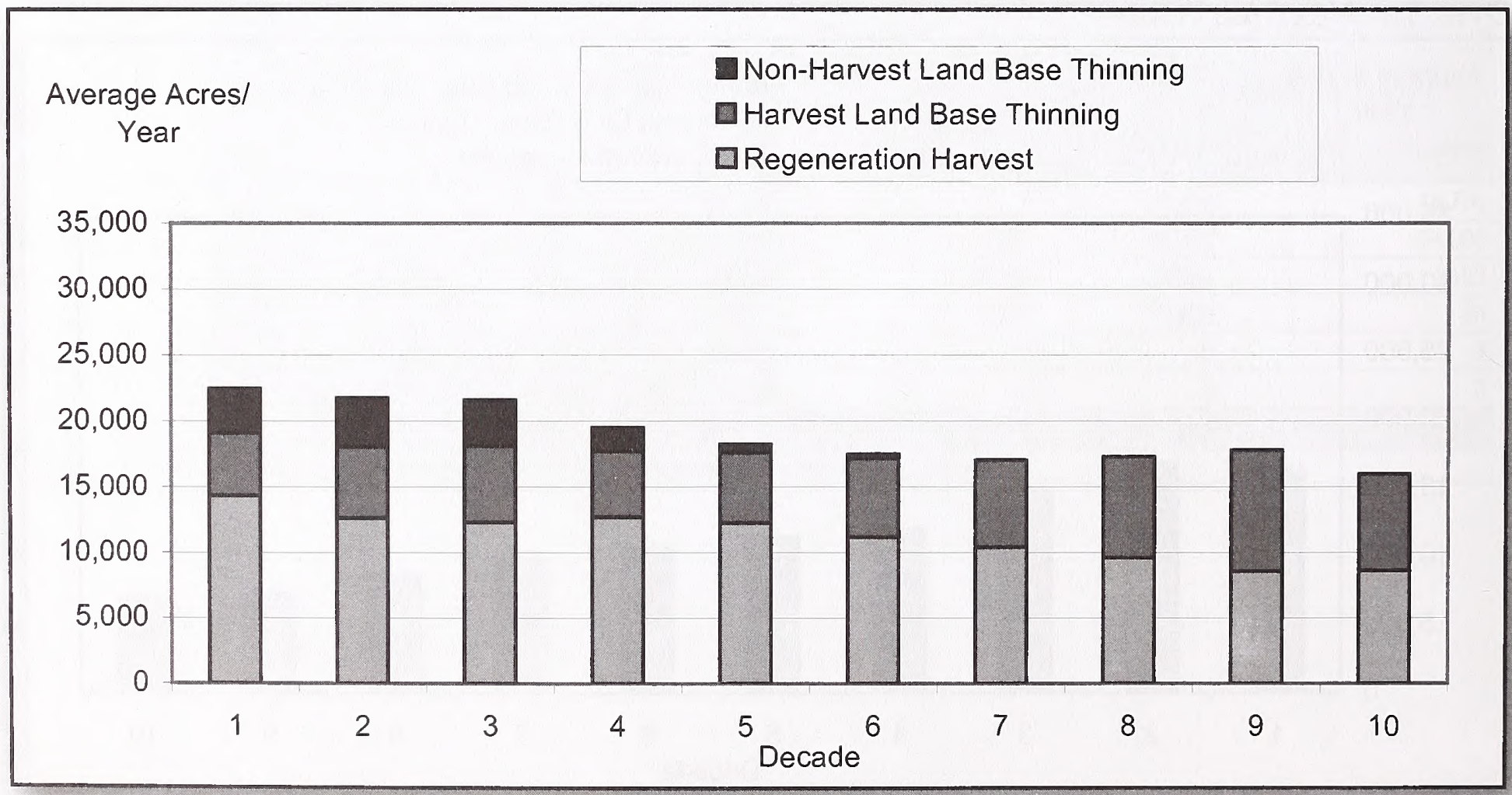


Figure 4-60. Alternative 3, Average Annual Harvested Acres By Harvest Type Over The NEXT 100 YEARS

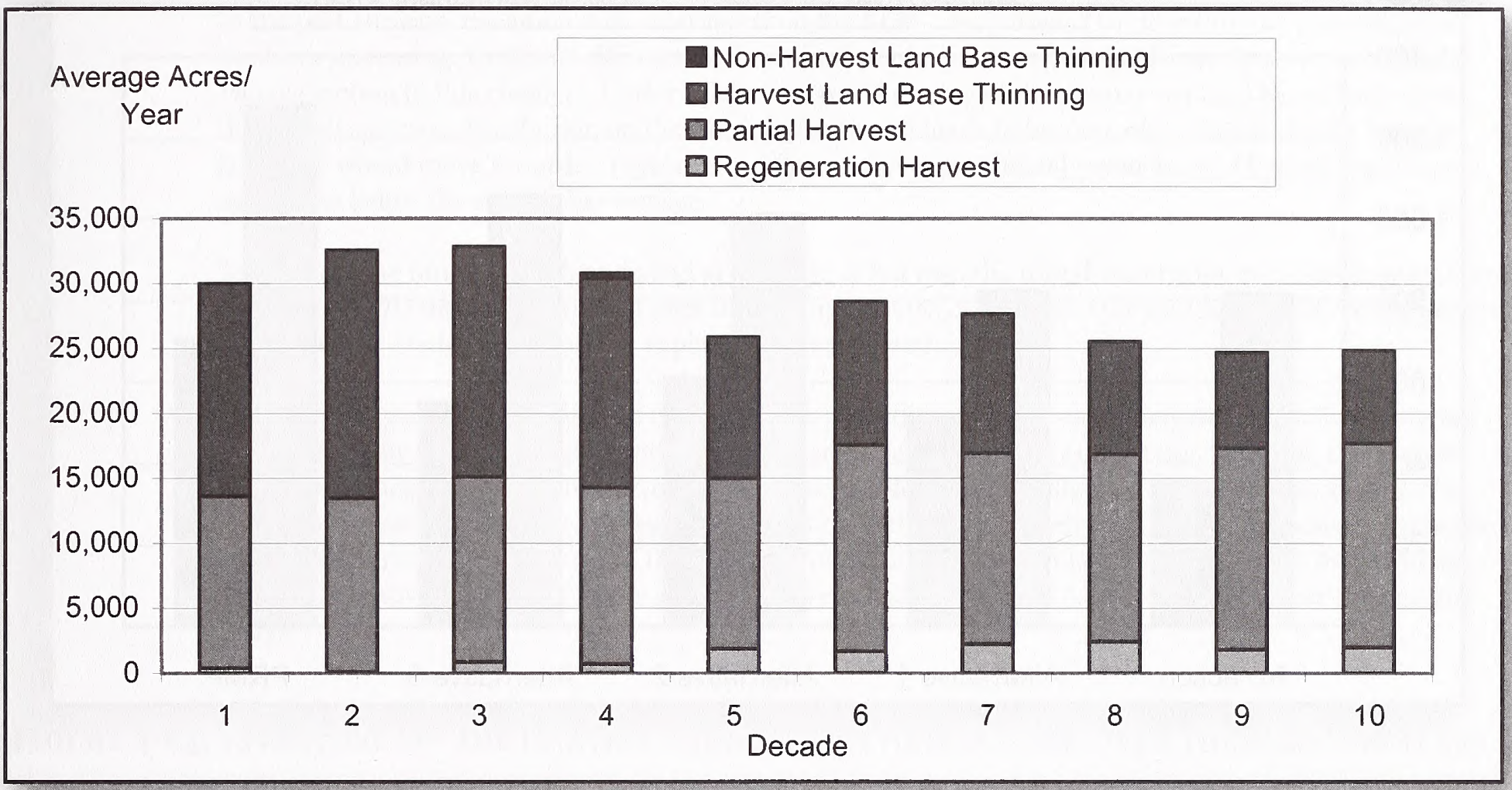

Figure 4-61. PrMP, Average Annual Harvested Acres By Harvest Type Over The Next 100 Years

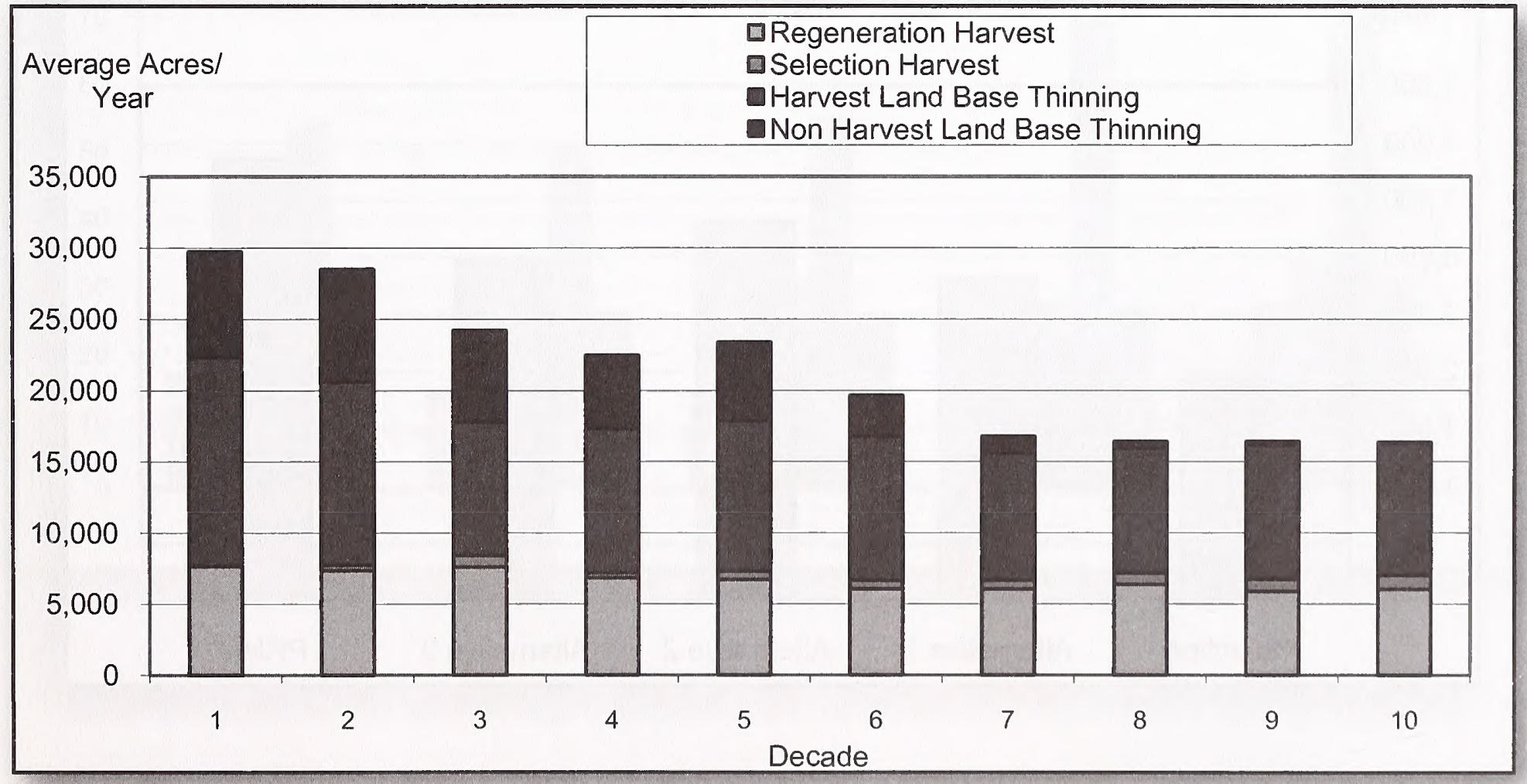


Figure 4-62. Miles Of New Permanent Road Construction Under Each Alternative

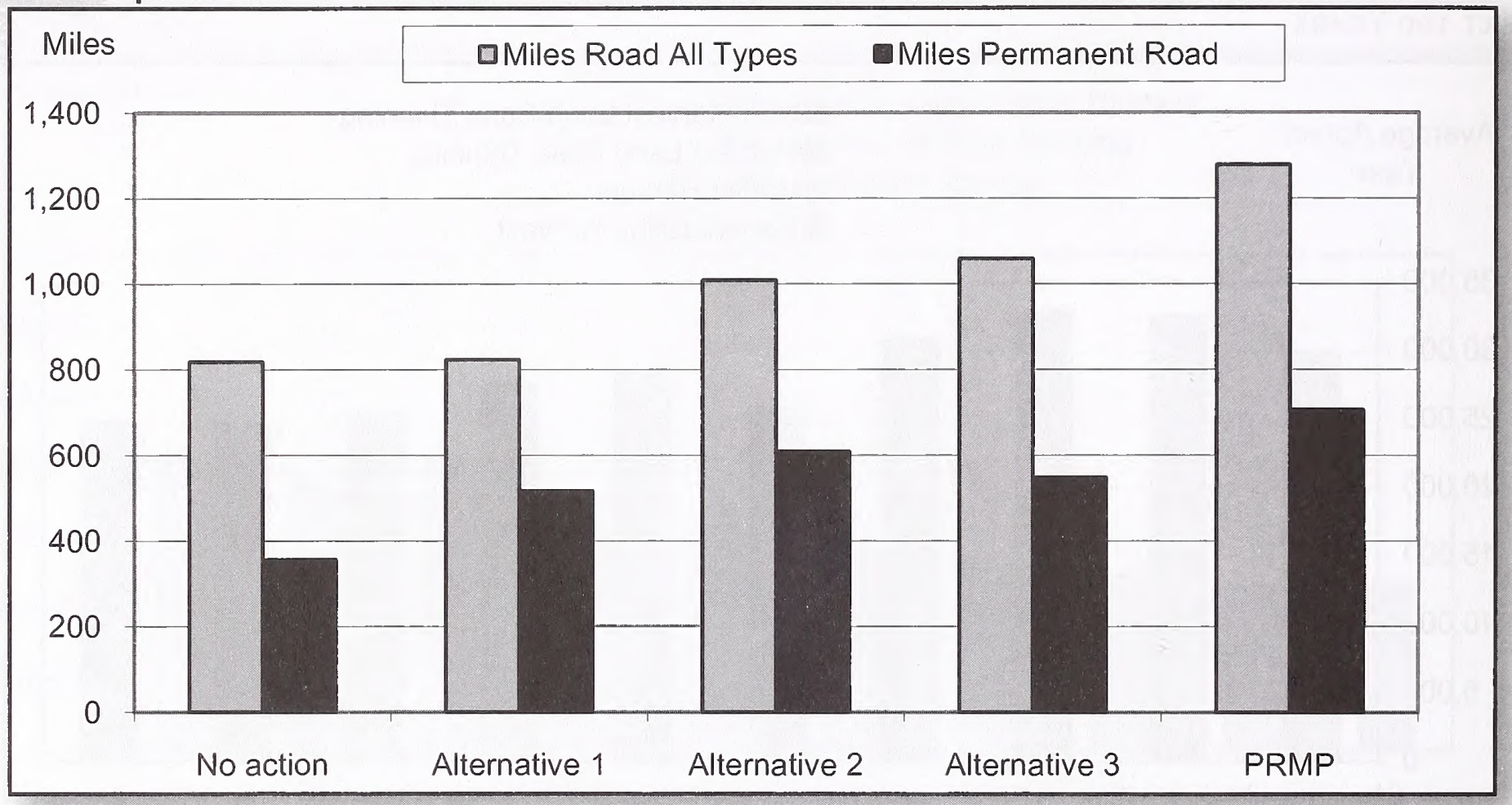

Figure 4-63. Acres Of New Permanent Road Construction Under Each Alternative

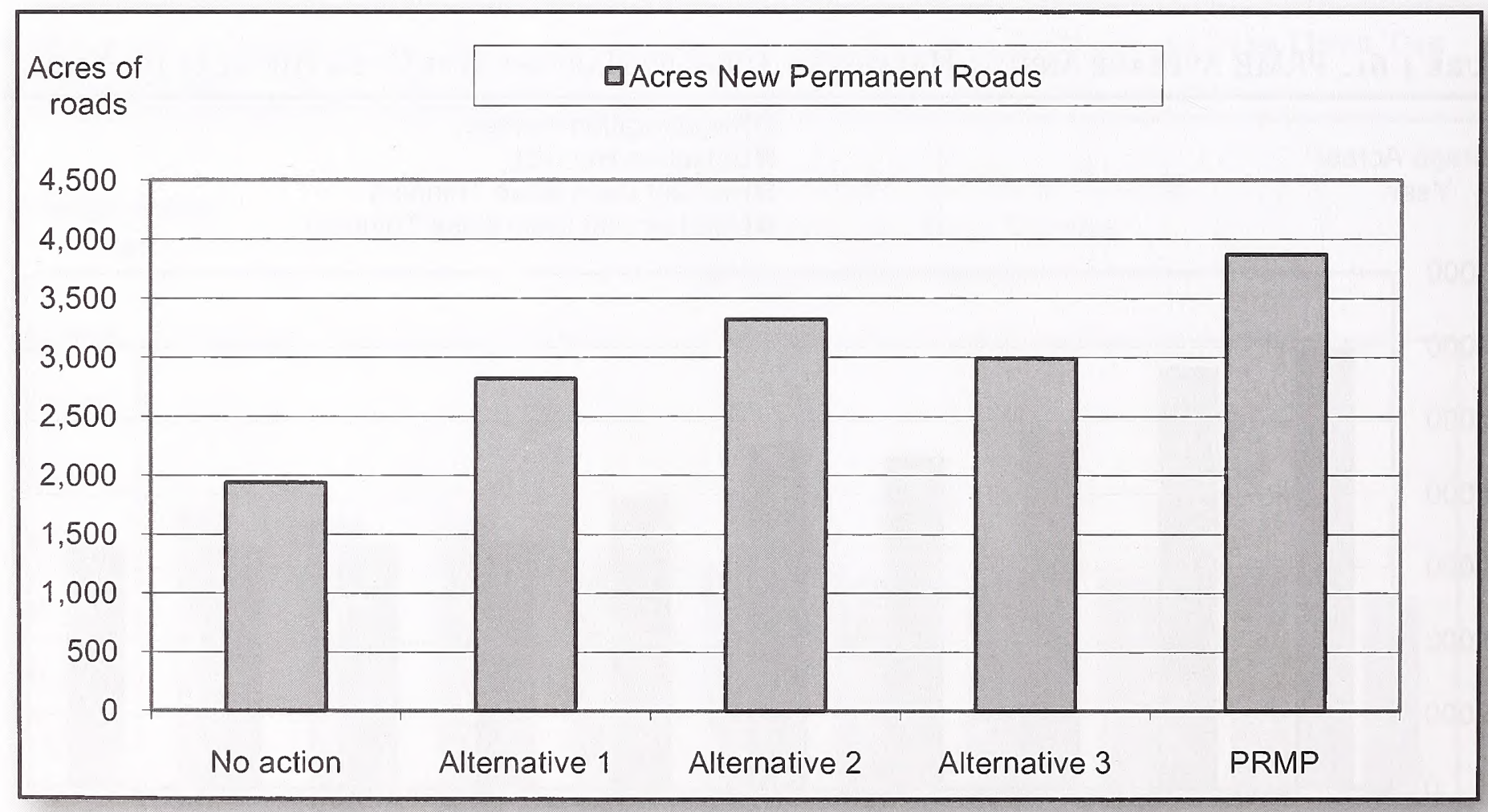




\section{Forest Inventory and Forest Stand Conditions}

In the past 10 years, the amount of older forest on the BLM-administered lands within the planning area has been increasing. Under all alternatives, this trend would continue (see the Forest Structure and Spatial Pattern section in this chapter). Under all alternatives, the aging of the nonharvest land base would cause the overall age class distribution on the BLM-administered lands to become older. Generally, the harvest land base would move towards a regulated condition with approximately even acres of harvest land base in age classes below the average harvest age.

To estimate the future growth and yield at the time of harvest, the initial volume for each forest operations inventory (FOI) unit was projected over time using the ORGANON and OPTIONS models. See Appendix $R$ - Vegetation Modeling for further explanation of this methodology.

For the entire planning area (all land use allocations), standing volume would increase under all alternatives. This is primarily due to the stands within the nonharvest land base increasing in age. Under all alternatives, the total standing volume on the harvest land base would decrease initially, then recover and increase as the harvest land base moves towards a regulated condition with approximately even levels of age classes below the anticipated harvest age. The trend of the standing volume for the harvest land base portion of the planning area by alternative is shown in Figure 4-64 (Inventory on the harvest land base by alternative over the next 100 years).

Figure 4-64. Inventory On The Harvest Land Base By Alternative Over The Next 100 Years

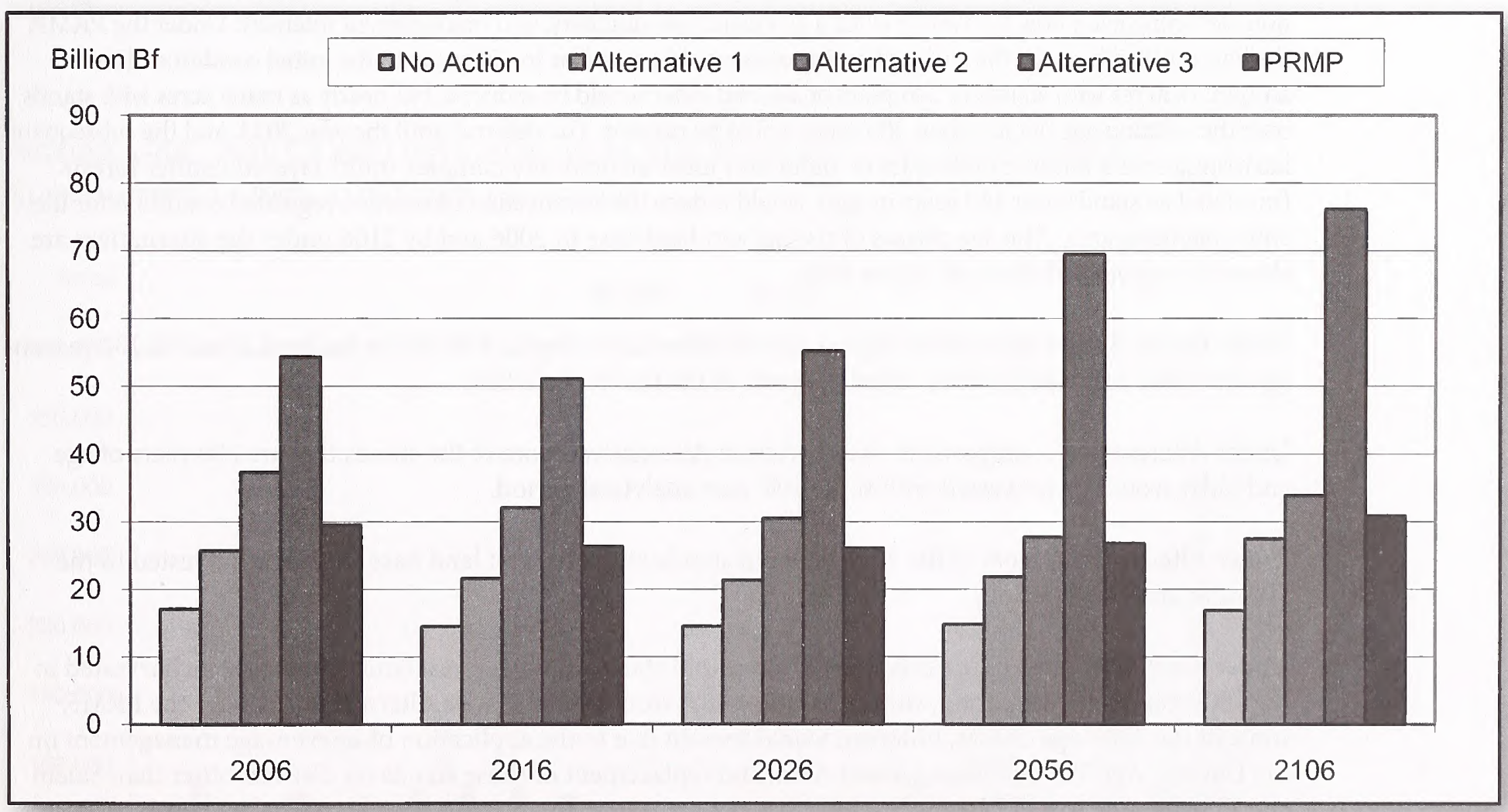


The standing volume for the different alternatives varies due to the different sizes of harvest land base for the alternatives. Under all alternatives, the standing volume in the harvest land base would dip and then rise as mature and structurally complex stands are harvested and replaced with rapidly growing stand establishment and young stands; the standing volume in the nonharvest land base would increase. By 2106, under the PRMP, the harvest land base would just have returned to the initial inventory level; under Alternatives 1 and 3, the starting condition would be exceeded; under the No Action Alternative, the harvest land base would have nearly reached the starting standing volume; and under Alternative 2, the harvest land base would not have yet returned to the starting standing volume level.

Under all alternatives, the growth rates for stands would change in the harvest land base over time. Mature and structurally complex stands would be harvested and replaced with more rapidly growing stand establishment and young stands. As young stands progress in age within the nonharvest land base, the growth on these stands would change as a result of increasing age and response to thinning.

The standing volume on the nonharvest land base indicates that the 100 -year analytical period is not long enough to reach the time when the nonharvest land base growth rate would be expected to slow due to advancing age. Nonharvest land base areas, such as the Late-Successional Management Areas, contain acres of stand establishment and young stands that have not yet reached culmination of mean annual increment. The growth rates on these stand establishment and young stands would remain high beyond 100 years.

Under all alternatives, except the PRMP, the harvest land base would move towards, but not reach, a regulated condition. Maintaining a nondeclining even flow of harvest volume reduces the ability to rapidly achieve regulation, since changes in the harvest level cannot be used to rapidly adjust the portion of the harvest land base in different age classes. For the harvest land base, a regulated condition provides the largest non-declining even flow harvest level for a given size, productivity, and management intensity. Under the PRMP, the harvest land base for the entire planning area would be similar in 100 years to the initial condition. The amount of acres with stands of 200 years of age and older would be reduced, but nearly as many acres with stands over the rotation age but less than 200 years would be present. The deferral until the year 2023 , and the subsequent harvesting over a number of decades of older and more structurally complex multi-layered conifer forests (modeled as stands over 160 years in age), would reduce the advancement towards a regulated condition for the entire planning area. The age classes of the harvest land base in 2006 and by 2106 under the alternatives are shown in Figure 4-65 through Figure 4-69.

Under the No Action Alternative, the age class distribution in Figure 4-65 shows the level of stands 200 years of age and older that would remain after 100 years in the harvest land base.

Under Alternative 1, compared to the No Action Alternative, more of the stands that are 200 years of age and older would be harvested within the 100 -year analytical period.

Under Alternative 2, most of the $200+$ year old stands in the harvest land base would be harvested in the 100 -year analytical period.

Under the PRMP, most of the existing 200+ year-old stands in the harvest land base would be harvested in the 100-year analytical period, similar to that which would occur under Alternative 2. Under the PRMP, some of the $200+$ age classes, however, would remain due to the application of uneven-age management on the Uneven-Age Timber Management Area, and replacement of those stands on districts other than Salem and Eugene. Age would become less effective as a measurement of stand condition for the Uneven-Age Timber Management Area under the PRMP for reasons similar to those described below for Alternative 3.

Under Alternative 3, age should be used with caution when describing stands that would develop. This is because application of a silvicultural system consisting of partial harvests causes stand age to be a less applicable measurement of stand condition. As partial harvesting is applied to stands, they would increase in variability in age with different ages included within the stands. They would develop into multi-storied stands. 
Figure 4-65. Age Class Distribution In The Harvest land Base Under The No Action Alternative Over The Next 100 Years

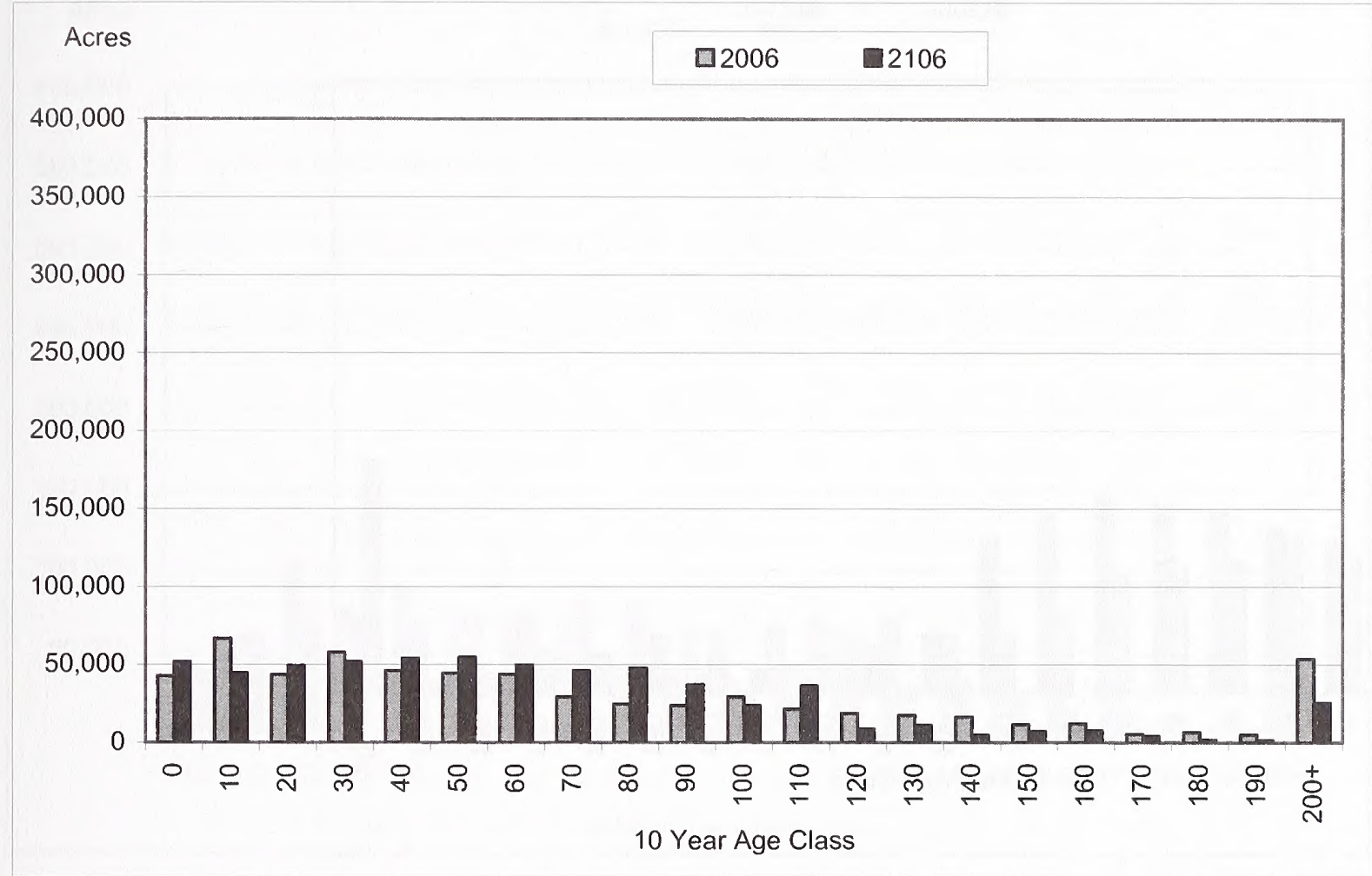

Figure 4-66. Age Class Distribution In The Harvest Land Base Under Alternative 1 Over The Next 100 years

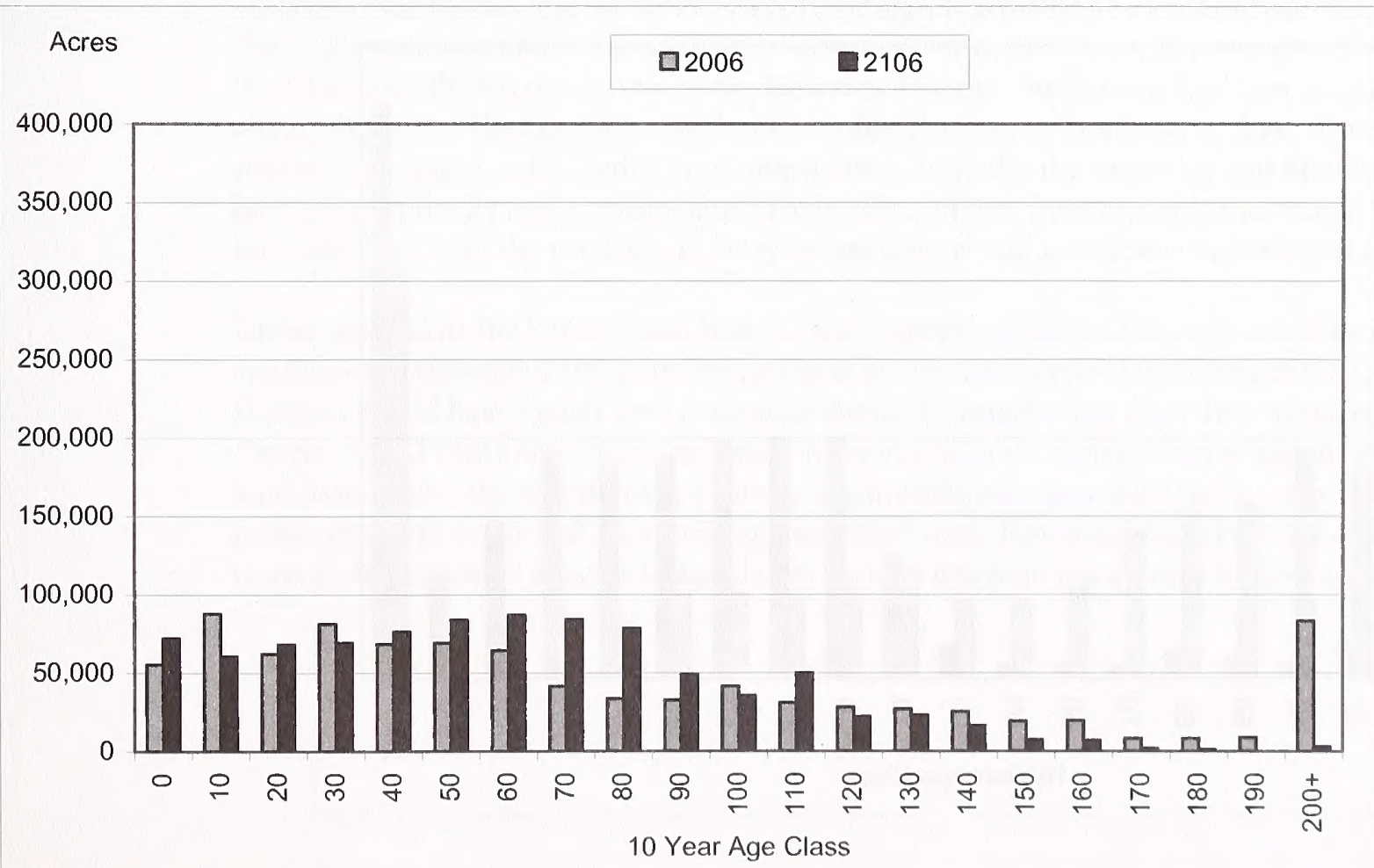


Figure 4-67. Age Class Distribution In The Harvest Land Base Under Alternative 2 Over The Next 100 years

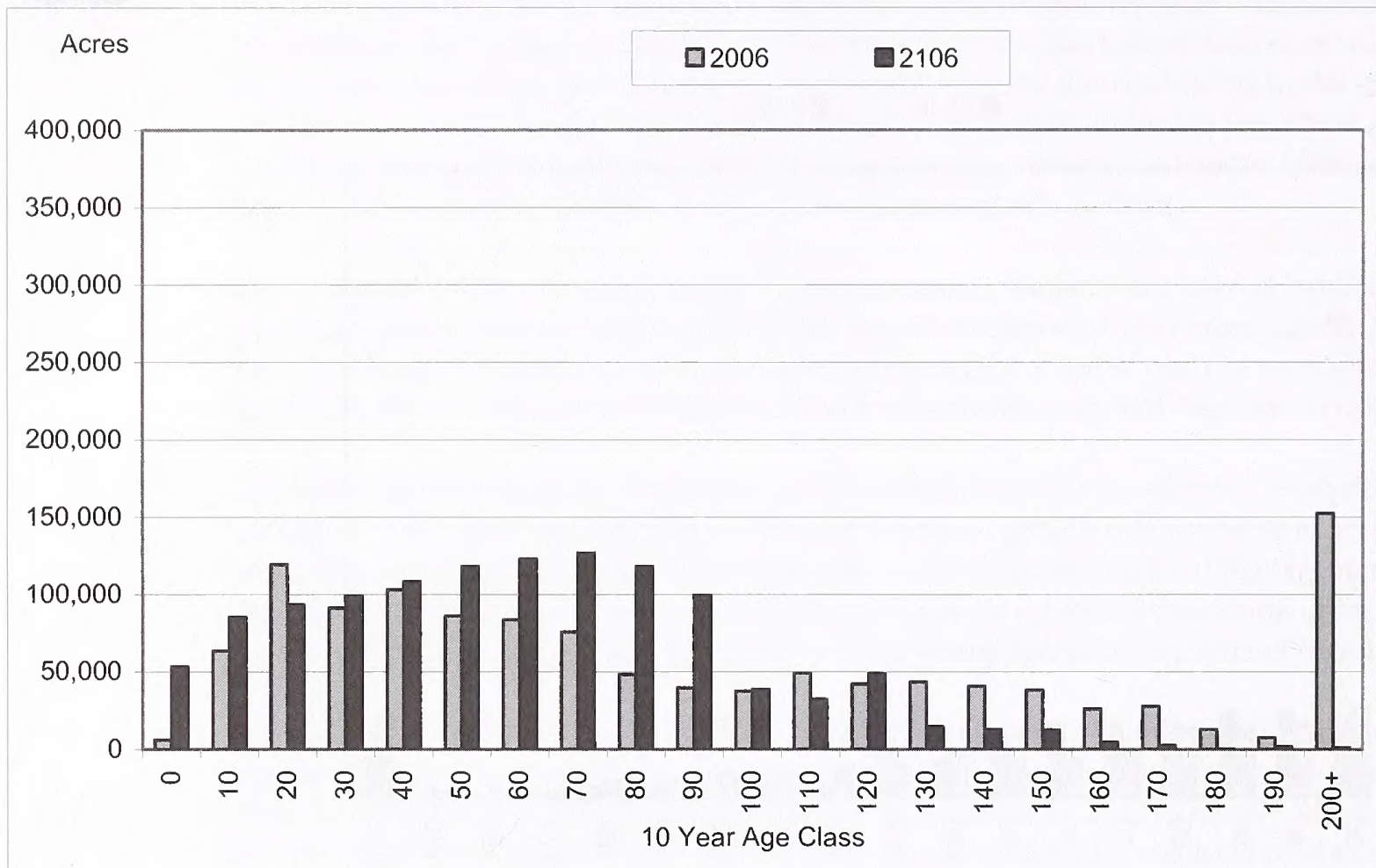

Figure 4-68. Age Class Distribution In The Harvest land Base Under Alternative 3 Over The Next 100 Years

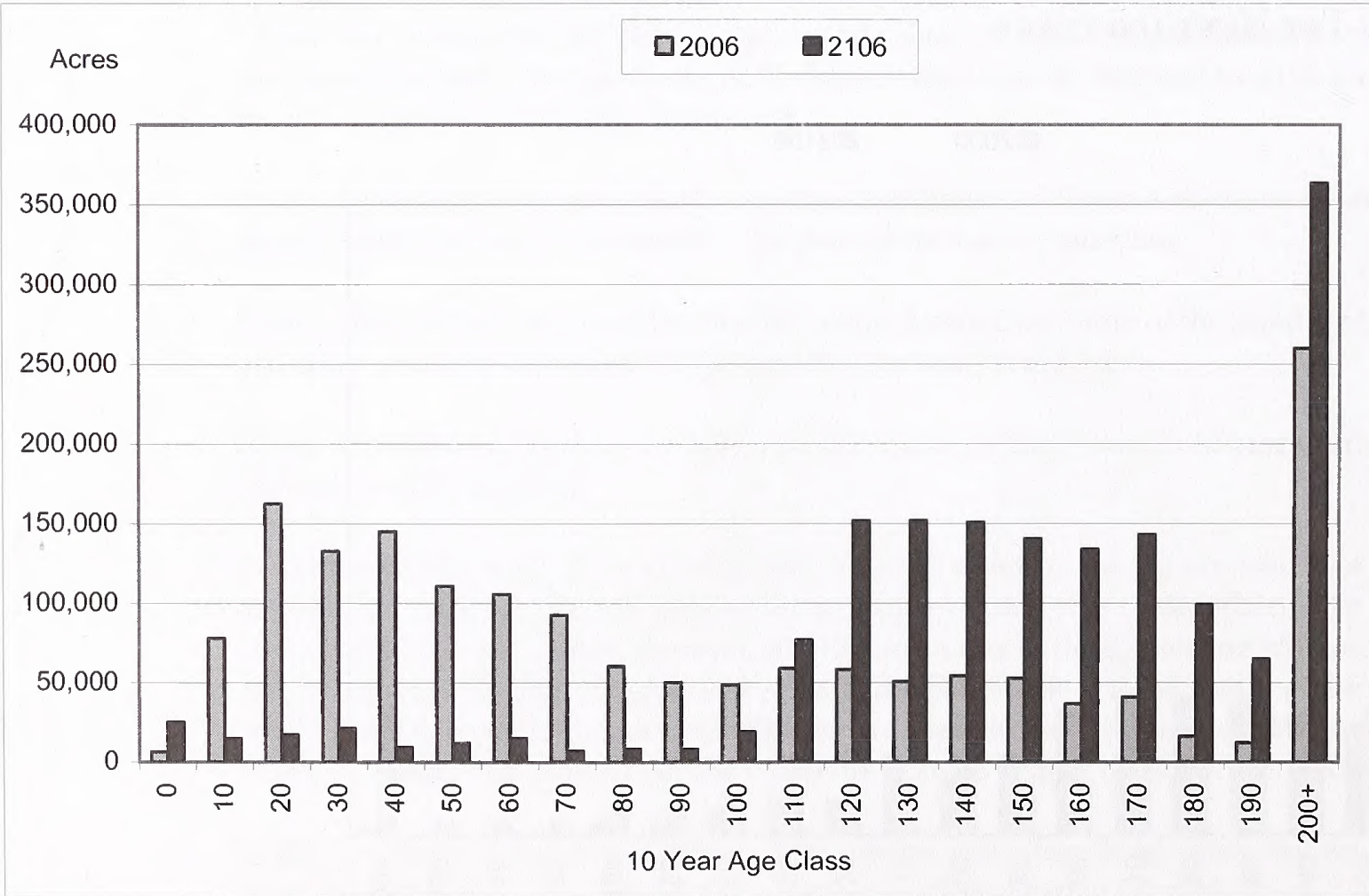


Figure 4-69. Age Class Distribution In The Harvest land Base Under The PRMP Over The NeXT 100 YeARS

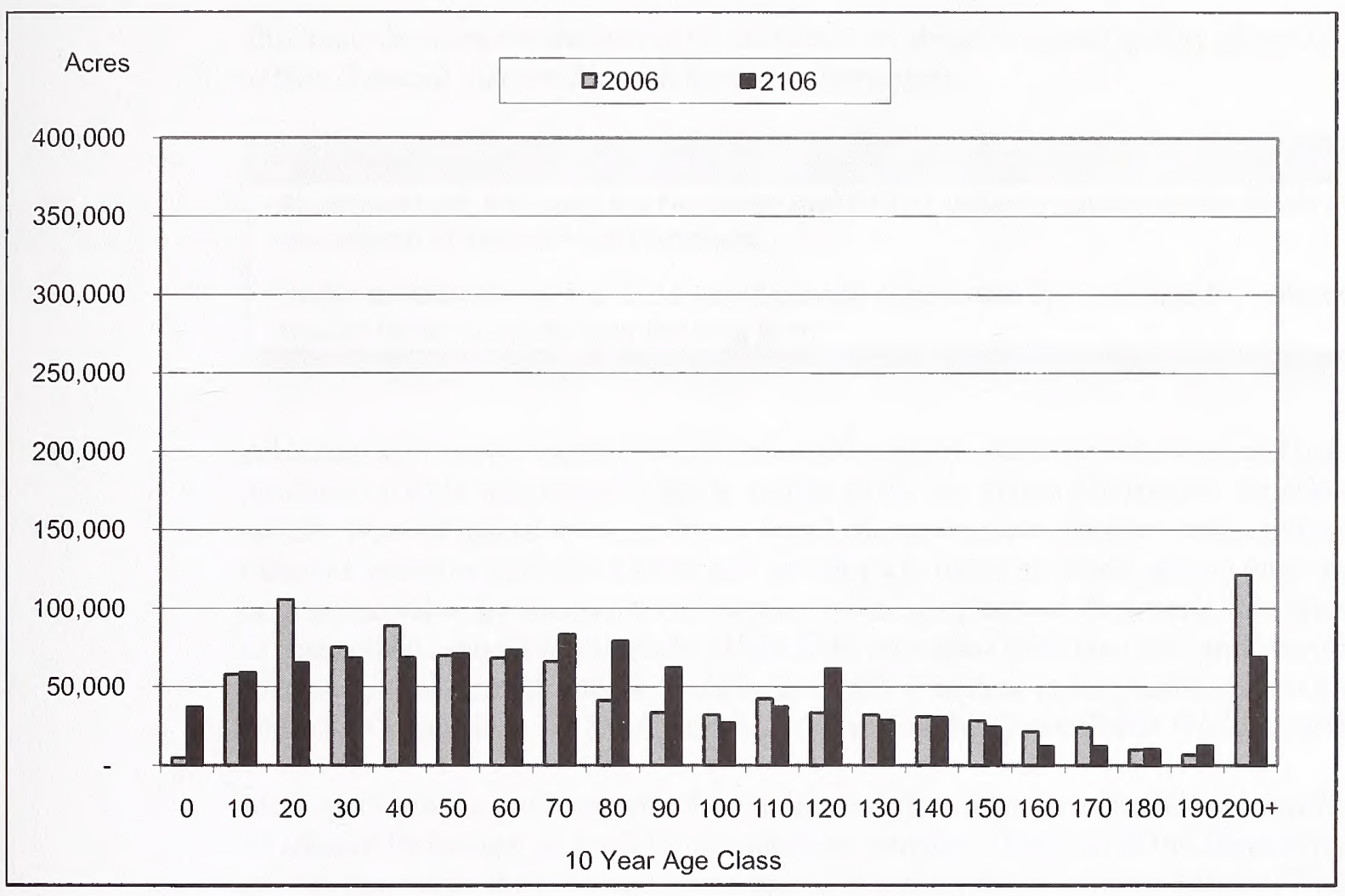

Although stands harvested using partial harvesting have their ages adjusted to provide a blended age, age is an accurate metric only for those stands that are regeneration harvested.

Under all alternatives, except for the PRMP, the age class distribution for the harvest land base in the districts would respond in two distinct manners. First, in the Salem, Eugene, and Coos Bay Districts, and the Klamath Falls Resource Area of the Lakeview District, the harvest land base is currently approaching a regulated state. The age class distribution within the harvest land base of these districts would remain relatively even and stable under these alternatives. Secondly, the Roseburg and Medford Districts currently have proportionally more mature and structurally complex forests stands that would be harvested over the next 100 years, and the variation in acres by age class would persist beyond 100 years.

Under the PRMP, the harvest land bases of the Eugene and Salem Districts would be nearly at regulated conditions at the end of 100 years, behaving as above. The harvest land bases of the Coos Bay and Roseburg Districts would have higher levels of stands above the rotation age than their initial conditions. The Medford District would continue to have persistent unevenness in the distribution of ages of stands within its harvest land base. Under the alternatives, a variety of allowable sale quantities and a range of values for those timber products would occur and on a varying amount of acres. However, the harvest land base would move toward even amounts of acres in age classes that are less than the average harvest age under all alternatives. 


\section{Special Forest Products}

This analysis examines changes to the distribution, abundance, and quality of special forest products relative to their demand that would result from the alternatives.

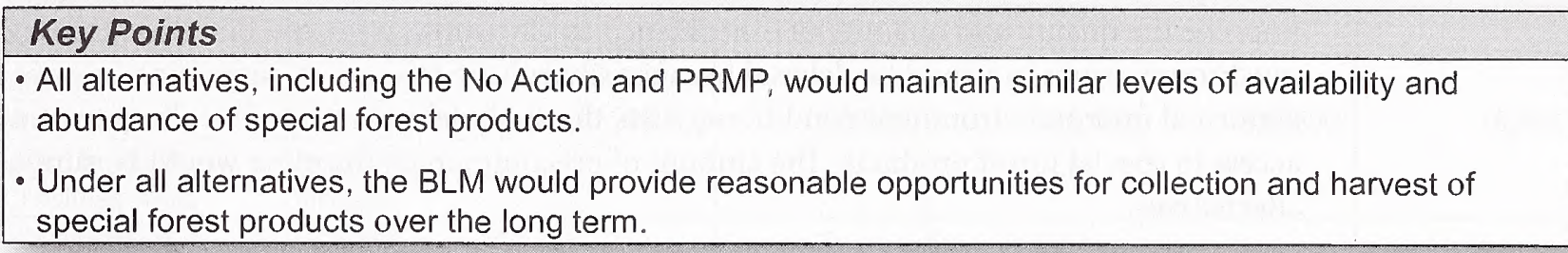

All action alternatives would provide reasonable opportunities for collection and harvest of special forest products on BLM-administered lands, similar to the No Action Alternative. Some harvest locations of specific types of special forest products would change over time as forest management activities occur in different locations. Collectors focus harvest efforts in locations where special forest products of commercial or personal value are abundant, easy, and economical to harvest. In general, it is expected that, similar to past activity, special forest products would be harvested from common and abundant plant or fungus species. Special forest products would be generally abundant in the planning areas under all action alternatives, similar to the No Action Alternative. See the Special Forest Products section in Chapter 3.

Most special forest products are collected in small quantities for personal or commercial use and would not be affected by changes in levels of management activities. Under all of the alternatives, the management activity that varies the most and affects special forest products is timber harvest. Timber harvest would be distributed across the harvest land base over time and would result in an increase in abundance and quality for some special forest products and a decrease for others at the site scale, but not at larger landscape scales. Regeneration and thinning harvests modify the condition of conifer forest stands and stand components (such as substrates and species that support mats of mosses), disturb the forest ground floor, and remove conifer trees that are host species and support mushrooms. The harvest of firewood, fungi, floral, and greenery would shift either into, or away from, regeneration timber harvest areas. The relative availability of Christmas trees would increase as the amount of regeneration harvest and stand establishment acres increase. The relative availability and quantity of firewood would increase as timber harvest increases. Many floral products, mushrooms, and mosses would decline in availability and quality in regeneration timber harvest areas in the short term.

The amount of habitat abundance of special forest products affected by forest management activities relative to their overall extent and abundance is unknown. Extent and abundance of special forest products inventories are generally lacking. Special forest products are harvested and collected from common species distributed throughout the planning area within the forest products' specific ranges and habitat type restrictions.

Although the habitat abundance of specific forest products increases or decreases at the harvest unit scale, these effects diminish at watershed and regional scales. The increase in harvest of timber under all alternatives (by 43,500; 59,600; 128,800; and 136,900 acres under Alternatives 1, 2, 3, and the PRMP, respectively; as shown in Table 4-39 below) from the No Action Alternative would change the habitat of forest products. The amount of habitat change relative to the total amount of special forest product areas within the range of specific special forest products is unknown. The remaining forest stands would continue to develop and support habitat for special forest products.

Commercial thinning would disturb the forest stand, forest floor, and micro-environment (amount of sunlight, temperature, and humidity change) less than regeneration harvest. Most special forest products would respond positively shortly after the initial disturbance and increase in abundance and quality 
within a few years. Older conifer trees would be retained and act as host species for mushrooms, allowing mushrooms to recover and fruit within approximately 5 to 10 years (Pilz et al. 2006). Floral and greenery products would generally respond quickly to increased light and lower competition levels.

Silvicultural treatments (e.g., stand maintenance and precommercial thinning) would retard the development of some special forest products (such as mushrooms and floral and greenery), but would improve the quality and quantity of others (such as Christmas trees and boughs). The development of most mushroom products would be delayed because silviculture treatments target host species and lengthen abnormal micro-environment conditions. Also, the slash debris left by silviculture treatments would prevent access to special forest products. The amount of precommercial thinning would be similar under all action alternatives.

Timber harvest, new road construction, and silvicultural treatments under all action alternatives would not alter the overall availability, abundance, and sustainability of special forest products from the No Action Alternative at the landscape scale and within each forest product's specific range. Nearly all special forest products occur, and are also available for harvest, on neighboring public lands managed by the Forest Service and the state of Oregon. Other opportunities, although more limited, occur on other federal, state, and private lands. Although overall availability and abundance would be maintained, the availability, abundance and quality at smaller spatial scales such as harvest units or watersheds would vary in the short term as a result of timber harvest activities. See Table 4-33 (Estimated annual acres by harvest type over the first decade) in the Timber section of this chapter.

Non-harvest related vegetation treatments, livestock grazing, recreation, watershed restoration, and wildfire suppression activities would be similar under all action alternatives. These activities would not change the availability, quantity, and abundance of special forest products from the No Action Alternative. Non-harvest related vegetation treatments would amount to approximately 310,000 acres over 10 years. These treatments would normally target small diameter wood products and either chip or cut unwanted fuels, but would not affect the overall availability and quantity of special forest wood products.

Under all action alternatives, the overall amount of stands in the mature and structurally complex structural stage would not change. The relative availability and abundance of mushrooms, mosses, and floral and greenery associated with these stand types would not change. See Table 4-39 (Response Of Special Forest Products And Acres Of Forest Management Activity And Mature \& Structurally Complex Forest By Alternative In The Year 2016).

Under all action alternatives, the availability and abundance of five special forest product categories (transplants, seeds and seed cones, edibles and medicinals, burls and miscellaneous, and coniferous boughs) would be similar to past levels. The specific distribution and abundance of most special forest products, as well as the actual amount harvested, is relatively unknown. The response of some special forest products to increased activity levels would be either an increase or decrease in their availability and abundance, or no change. However, these changes are expected to be relatively slight compared to the No Action Alternative. Similar levels of abundant and readily available quality products would be maintained under all alternatives.

There are five special forest product categories (Christmas trees, floral and greenery, mosses, mushrooms, and wood products) that would increase or decrease as the amount of activity acres increase and as older forest types develop at the site scale. At larger landscape scales, the responses may not represent every individual product within the categories. Differing levels of timber harvest and silviculture activities, based on the amount of acres treated, would not increase or decrease the overall abundance or availability of forest products at regional scales from the current level. These forest products are generally abundant throughout the region or within the vegetative community where they occur. In general, the distribution of these special forest products over the planning area is extensive, the amount of acres of forest habitat that exists is large, and ample opportunities to harvest and collect are available. 
Table 4-39. Response Of Special Forest Products And Acres Of Forest Management Activity And Mature \& Structurally Complex Forest By Alternative In The Year 2016

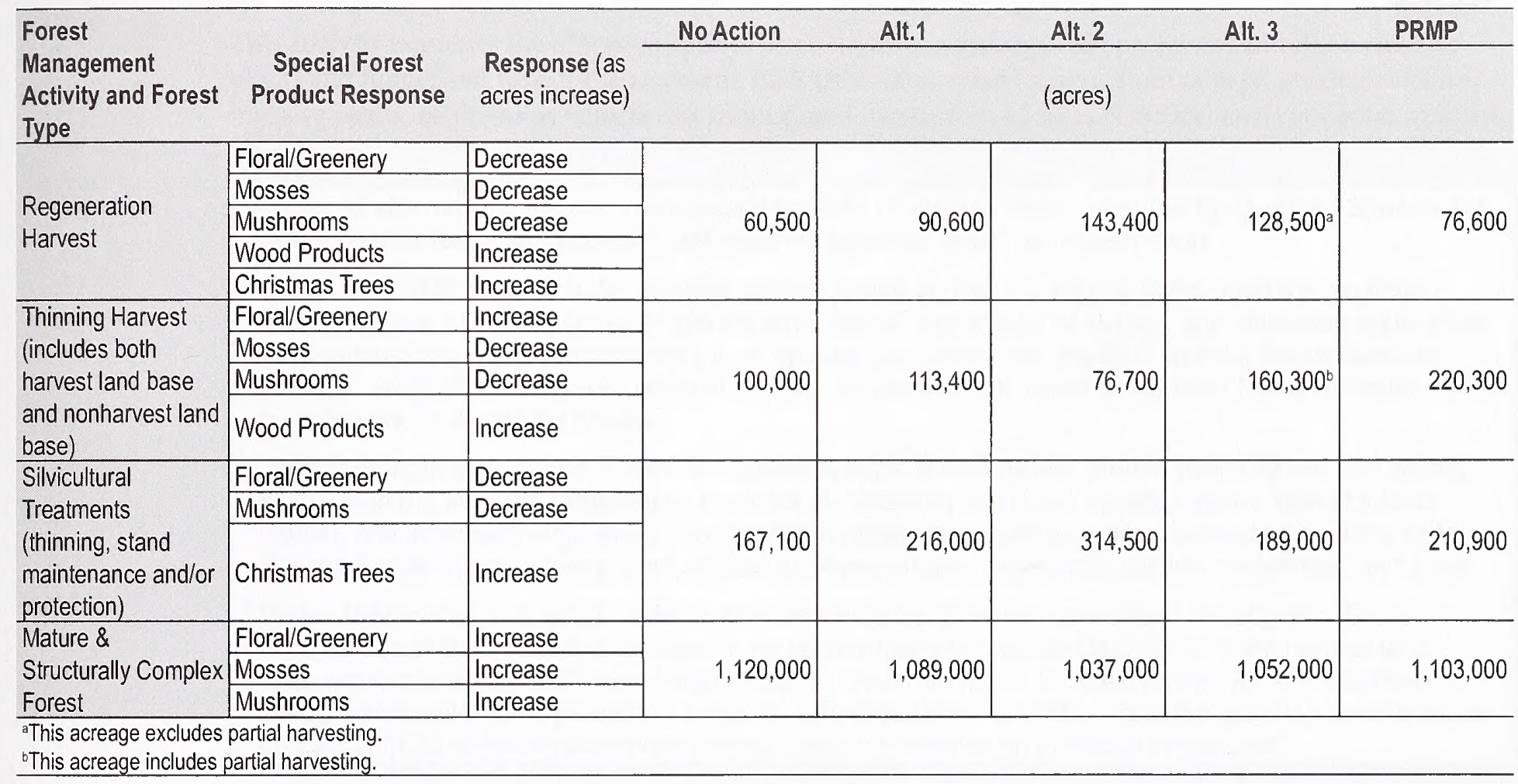

Natural disturbances, such as wildfires and wind storms, that shape the types and availability of special forest products are unpredictable in time and location, but are expected to occur across the landscape similar to levels experienced in the past. Natural disturbances change local conditions for special forest products. In general, most special forest products would be lost in wildfires, although the availability of firewood and some mushrooms that respond to fire would increase. Windstorms that blow down large amounts of trees would reduce the quality of special forest products and would limit access for harvest. Natural disturbances would reduce the availability and abundance of special forest products only at the local level. Availability and abundance of special forest products would not be substantially affected at larger landscape scales. 


\section{Botany}

This analysis examines the effects on species listed under the Endangered Species Act and BLM sensitive plants and fungi from timber management, fuels treatments, road construction, salvage, grazing, wildfire, invasive plants, off-highway vehicle use, mining, and designation of areas of critical environmental concern.

Key Points
- Under all alternatives, the occurrences and habitats of species listed under the Endangered Species Act
- Under the PRMP, risks to BLM sensitive species would be low, but slightly higher than the No Action
Alternative due to increased risks from invasive plants, loss of interior habitat, and increased edge effect.
Application of conservation measures to all species consistent with the BLM Special Status Species
Policy on all BLM-administered lands in the planning area would result in low risk of local extirpation of
occurrences for all habitat groups.
- Under Alternatives 1,2 , and 3 , risks to species in eight of nine habitat groups would be low, but slightly
higher than the No Action Alternative because of increased risks from invasive plants, loss of interior
habitat, and increased edge effect. Conservation measures would be applied consistent with the BLM
Special Status Species Policy since habitat for these groups largely falls outside the harvest land base.
- Under Alternatives 1,2 , and 3, risks to species would increase for the conifer habitat group. Some
occurrences of BLM sensitive species in the conifer habitat group on O\&C lands in the harvest land
base would be extirpated. There would be low to moderate risk of local extirpation for some species in
the conifer forest habitat group, but a low risk of extirpation or extinction from the planning area because
species with 20 or fewer occurrences would receive conservation protection measures.

\section{Federally Listed Plant Species}

Under all alternatives, conservation and recovery measures would be applied to federally listed, proposed, and candidate species. Habitat and occurrences would be managed for the conservation and recovery of the species on BLM-administered lands. These measures are required by recovery plans, biological opinions, or conservation agreements and would contribute to the recovery of species.

The species shown in Table 4-40 (Federally listed and candidate plant species in the planning areas) that may be found in the planning area are listed as threatened or endangered, or are candidates for listing under the Endangered Species Act.

There are seven federally listed species and one federal candidate species found on BLM-administered lands. The listed species that are not found on BLM-administered land would not be affected by BLM actions under the alternatives. The number of occurrences and amount of occupied area are two primary demographic metrics that characterize relative rarity and partially characterizes the species condition. Modifying management activities on BLM-administered lands when occurrences exist within activity areas would protect or improve the condition of the population. The general trend in the total number of occurrence and amount of occupied habitat since the species were federally listed is characterized below:

- Remained constant: Rough popcorn flower, Bradshaw's desert parsley, Western lily, and Siskiyou mariposa-lily

- Increased slightly: Cook's lomatium, Willamette Valley daisy, and Kincaid's lupine

- Increased substantially: Gentner's fritillary

The number of discovered sites where these plants occur has generally increased as surveys over the past several years have proceeded. The number of occurrences by species that have been found on BLMadministered lands ranges from more than 100 occurrences of Gentner's fritillary, to only one known 
Table 4-40. Federally Listed And Candidate Plant Species In The Planning Area

\begin{tabular}{|c|c|c|c|}
\hline \multirow{2}{*}{$\begin{array}{l}\text { Federal } \\
\text { Status }\end{array}$} & \multicolumn{3}{|c|}{ Federally Listed and Candidate Plant Species } \\
\hline & Scientific Name & Common Name & BLM Districts \\
\hline FTO & Castilleja levisecta & Golden paintbrush & Salem, Eugene \\
\hline FTO & Howellia aquatilis & Water howellia & $\begin{array}{l}\text { Salem, Eugene, Roseburg, } \\
\text { Medford }\end{array}$ \\
\hline FTO & $\begin{array}{l}\text { Lupinus sulphureus ssp. } \\
\text { kincaidii }\end{array}$ & Kincaid's lupine & Eugene, Roseburg \\
\hline FTO & Sidalcea nelsoniana & Nelson's checker-mallow & Salem \\
\hline FEO & Arabis mcdonaldiana & McDonald's rock-cress & Medford, Coos Bay \\
\hline FEO & Astragalus applegate & Applegate's milk-vetch & Klamath Resource Area \\
\hline FEO & $\begin{array}{l}\text { Erigeron decumbens var. } \\
\text { decumbens }\end{array}$ & Willamette valley daisy & Eugene, Salem \\
\hline FEO & Fritillaria gentneri & Gentner's fritillary & Medford \\
\hline FEO & Lilium occidentale & Western lily & Coos Bay \\
\hline FEO & $\begin{array}{l}\text { Limnanthes floccosa ssp. } \\
\text { grandiflora }\end{array}$ & $\begin{array}{l}\text { Large-flowered wooly } \\
\text { meadowfoam }\end{array}$ & Medford \\
\hline FEO & Lomatium bradshawii & Bradshaw's desert parsley & Salem, Eugene \\
\hline FEO & Lomatium cookii & Cook's lomatium & Medford \\
\hline FEO & Plagiobothrys hirtus & Rough popcorn flower & Roseburg \\
\hline FCO & Calochortus persistens & Siskiyou mariposa-lily & Medford \\
\hline FTO (federally threatened Oregon) & FEO (federally endangered Oregon) & (federal candidate Oregon) & \\
\hline
\end{tabular}

occurrence of Western lily. A complete list of federally listed species and the number of extant (currently existing) occurrences are found on Table 3-20 in Chapter 3 and in Appendix F - Botany. The number of occurrences would likely increase over the next 10 years on BLM-administered lands for Gentner's fritillary and Kincaid's lupine as additional suitable habitat is surveyed and new populations are established to meet recovery objectives. Few new occurrences would be expected to be found for Cook's lomatium, Willamette valley daisy, Rough popcorn flower, Bradshaw's desert parsley, Western lily, and Siskiyou mariposa-lily because most suitable habitat for these species has already been surveyed.

Occurrences of federally listed species also are found on private lands. It is assumed that these occurrences are unprotected, not secure, and would not contribute to recovery of the species (USDI USFWS 1993, 2003b, and 2006b). This is because no protection for federally listed plant species is provided by state or federal laws on private lands.

Under all alternatives, the application of conservation measures recommended under recovery plans for all management activities would maintain or improve habitat where known occurrences and occupied habitat of federally listed and candidate species are found on BLM-administered lands. Conservation and recovery activities would be implemented consistent with recovery plans and conservation agreements for each federally listed plant species. Generally, the conservation measures recommended under recovery plans that would occur on BLM-administered lands include:

- habitat assessments

- field surveys prior to activities in suitable habitat

- conservation protection measures of existing occurrences and habitat

- habitat restoration

- augmentation of existing occurrences

- establishment of new occurrences 
Recovery activities are described in recovery plans individually by species (see Appendix F - Botany). Similar types of conservation measures would be applied for federally listed species and federally proposed species without recovery plans, and for candidate species.

Under all alternatives, the introduction and spread of invasive plant species would increase incrementally over 10 years relative to the increase in the amount of management activities in suitable habitat for each species. (See Chapter 4 - Invasive Species.) Invasive plants are found in all habitat types where federally listed plants are found and compete for light, moisture, and other resources.

There are 44 occurrences of Gentner's fritillary found in grazing allotments on the Medford District. The National Landscape Conservation System includes 22 of these occurrences. Grazing has been allowed where occurrences of Gentner's fritillary are found. Yearly monitoring has not detected any damage to plants or habitat as a result of utilization by cattle. These populations are generally small, ranging from a few individuals to 30 or more in a population and generally occupy 0.5 acres or less. Application of conservation protections measures (fence exclusion, release date adjustments etc.) would prevent grazing utilization, damage to plants, or extirpation of occurrences.

Occasionally, immediate response to emergency operations such as wildfire suppression would result in the damage or loss of occupied habitat or occurrences. When these occasional situations occur, the application of conservation measures would minimize damage or loss of occurrences or habitat to the extent the wildfire emergency conditions allow the measures to be applied.

\section{BLM Sensitive Species}

Most plant and fungi species are considered common and are of no conservation concern. This analysis focuses on the BLM's sensitive species, which include state-listed species. Species are grouped according to habitat associations to facilitate analysis of a large number of species (see the Botany section of Chapter 3).

The analysis examines the risks to these species given the type and amount of expected management activities and the conservation measures to be applied under each of the alternatives. Under the No Action Alternative and the PRMP, where conservation measures would be applied to all species consistent with the BLM Special Status Species Policy on all BLM-administered lands in the planning area, the known occurrences would likely survive. Occurrences and habitat characteristics would be managed for the specific biological requirements of each species. Application of conservation measures would provide protection from management activities that would modify site conditions and occupied habitat. Typically, conservation measures are designed for management activities and implemented as seasonal or operational restrictions and changes in treatment methods, or habitat protection buffers. Management activities may affect these species by altering vegetative and environmental conditions, compacting or displacing soil, altering hydrologic conditions, introducing and spreading invasive plants, or trampling or damaging individual plants or occurrences. Species conservation protection measures would alter the area, extent, or timing of the activity, the type of operation, and the degree of disturbance to counter these effects.

Under Alternatives 1, 2, and 3, conservation measures consistent with the BLM Special Status Species Policy would be applied to species occurrences and habitat on Public Domain lands and O\&C lands that are not in the harvest land base. With the exception of the conifer habitat group, all other habitat groups occur primarily on lands outside of the harvest land base.

Under Alternatives 1,2, and 3, occurrences of Bureau sensitive species would be extirpated and occupied habitat lost in the harvest land base if and when management activities intersect with species occurrences. Conservation measures would not be applied to species occurrences or habitat in the conifer habitat group that occur within the O\&C harvest land base unless 20 or fewer occurrences of a species are known to exist. See Appendix F - Botany for a list of species on BLM-administered land with 20 or fewer occurrences. 
Under the No Action Alternative and the PRMP, which provide for applying conservation measures consistent with BLM Special Status Species Policy to all species occurrences on all land use allocations, the Bureau sensitive species occurrences would likely survive.

Under all action alternatives, the amount of timber harvest (including subsequent silviculture treatments, hazardous fuels treatments, and road construction) would increase compared to the No Action Alternative (see Table 4-41). This would affect Bureau sensitive species occurrences primarily in the conifer habitat group. Under all action alternatives, these management activities would result in the potential introduction and spread of invasive plant species, loss of forest biological legacy (i.e., large trees, snags, and down wood) in regeneration harvest areas, and decreases in the amount of interior habitat in the harvest land base.

The level of forest management activities that would occur under the alternatives is shown in Table 4-41 (Forest management activities that potentially affect special status species plant occurrences over the next 10 years).

\section{Effects of Land Management Activities}

\section{Timber Harvest}

Timber harvesting modifies forest vegetation including species composition, stand age, density, canopy, and legacy components such as snags and large down wood that serve as substrate and hosts for some species associated with the conifer habitat group. Timber harvesting also alters environmental conditions. The amount of physical disturbance of the site from timber harvest activities varies widely, depending on factors such as terrain, access, type of equipment, and skills of the operator. These factors contribute to the total area disturbed and the survival of any species occurrence in the area. For some species and occurrences, the effects of the physical disturbance of the harvest method would have more consequence than modification of the habitat without application of conservation measures.

Under Alternatives 1,2,3, and the PRMP, the acres with known occurrences of BLM sensitive species in the conifer forest habitat group that would be subject to timber harvest would increase compared to the No Action Alternative. Figure 4-70 (Distribution of occurrences of BLM sensitive botany species subject to timber harvest) shows that when all known BLM sensitive species occurrences are aggregated and compared between alternatives, the most notable pattern is the increase in the number of occurrences in the harvest land base under the action alternatives compared to the No Action Alternative.

Table 4-41. Forest Management Activities Over The Next 10 Years That Affect Special Status Species Plant Occurrences

\begin{tabular}{lrrrrr}
\hline Activity & No Action & Alt. 1 & Alt. 1 & Alt. 3 & PRMP \\
\hline Regeneration Harvest (acres) & 60,500 & 90,600 & 143,400 & 3,900 & 76,000 \\
\hline Partial Harvest (acres) & 0 & 0 & 0 & 124,600 & 0 \\
\hline $\begin{array}{l}\text { Thinning (Harvest Land Base } \\
\text { and Non-Harvest Land Base) } \\
\text { (acres) }\end{array}$ & 100,000 & 113,400 & 76,700 & 160,300 & 221,100 \\
\hline $\begin{array}{l}\text { Timber Slash and Non-Timber } \\
\text { Vegetation Treatments (acres) }\end{array}$ & 110,000 & 110,000 & 110,000 & 110,000 & 291,000 \\
\hline Road Construction (miles) & 820 & 830 & 1,010 & 1,060 & 1,280 \\
\hline
\end{tabular}


Figure 4-70. Distribution Of Known Occurrences Of BLM Plant And Fungi Species Subject To Timber Harvest

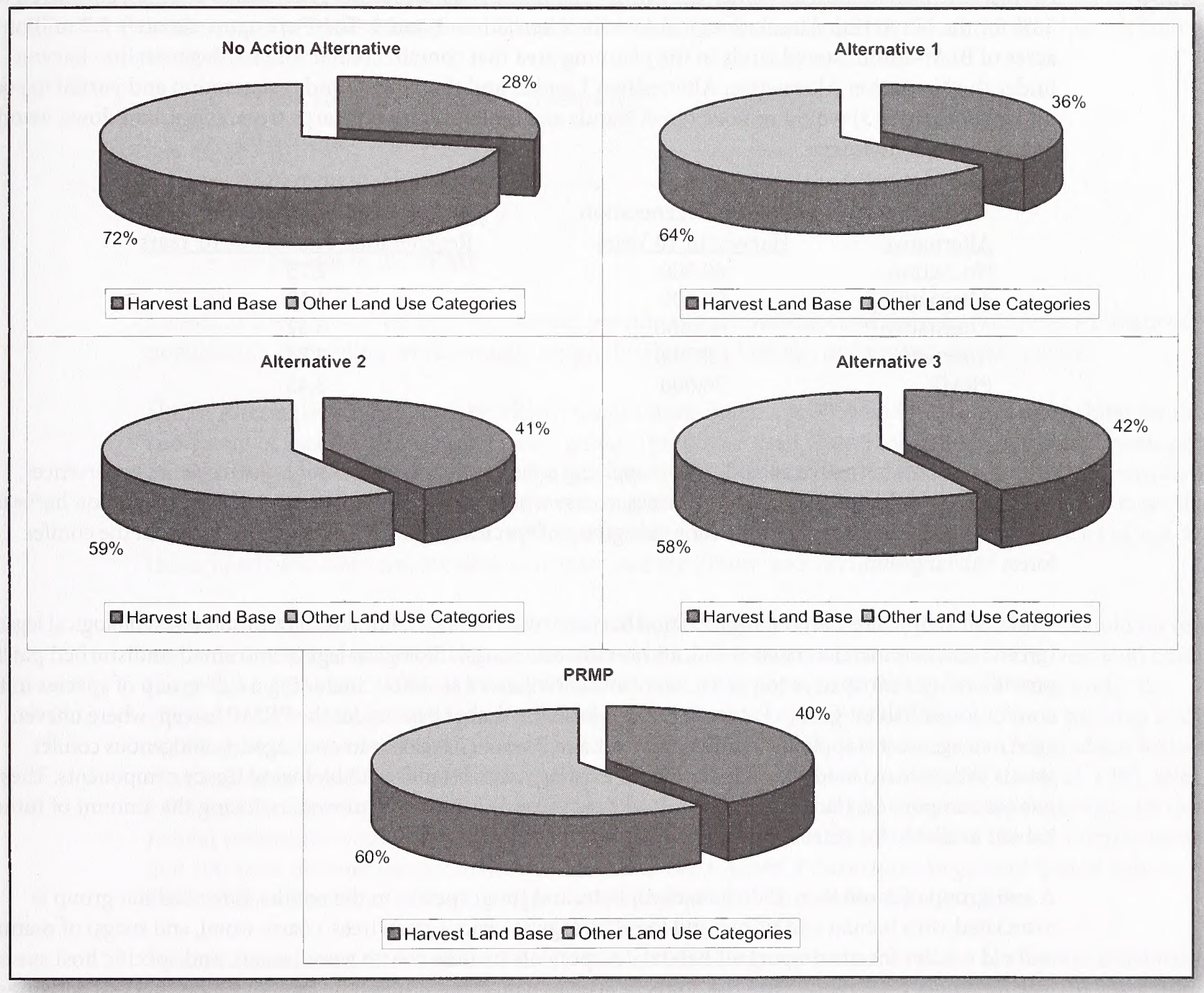

Approximately 3,700 total known occurrences of BLM sensitive species have been recorded on BLMadministered lands. The percentage of known species occurrences in the conifer habitat group that are within the harvest land base would be $28 \%, 36 \%, 41 \%, 42 \%$ and $40 \%$ under the No Action Alternative and Alternatives 1, 2, 3 and the PRMP, respectively. A disproportionate number of known occurrences is likely to be within the land use categories that are more available for projects. Therefore, known occurrences should not be cited to establish actual distribution or use patterns for these species. Known occurrences of species in the conifer habitat group that are within the harvest land base would be subject to greater risk of occurrence extirpation and habitat losses through management actions under Alternatives 1,2, and 3 compared to the No Action Alternative. Under the PRMP, timber harvesting activities would not directly affect occurrences and occupied habitat within the timber harvest land base, because conservation measures would be applied to all BLM sensitive species and occurrences and the species would likely survive. 
Four general timber harvest types would occur under the various alternatives: regeneration, partial, unevenaged, and thinning. Under the alternatives, the amount of regeneration harvest acres as a portion of total harvest acres would be least under the PRMP (26\%) and the most under Alternative $2(65 \%)$, compared to $38 \%$ for the No Action Alternative, and 44\% for Alternatives 1 and 3 . There are approximately 2.2 million acres of BLM-administered lands in the planning area that contain conifer forests. Regeneration harvest under the No Action Alternative, Alternatives 1 and 2, and the PRMP (and regeneration and partial harvest under Alternative 3 ) would remove forest stands and biological legacy (large trees, snags, and down wood) components, as follows:

$\begin{array}{lcc}\text { Alternative } & \begin{array}{c}\text { Acres of Regeneration } \\ \text { Harvest in 10 Years }\end{array} & \begin{array}{c}\text { Percent of all BLM Conifer Forest } \\ \text { Regeneration Harvest in 10 Years }\end{array} \\ \text { No Action } & 60,500 & 2.75 \\ \text { Alternative 1 } & 90,600 & 4.12 \\ \text { Alternative 2 } & 143,400 & 6.52 \\ \text { Alternative 3 } & 128,500 & 5.84 \\ \text { PRMP } & 76,000 & 3.45\end{array}$

The No Action Alternative, in addition to applying conservation measures for known species occurrences, would retain biological legacies (green trees, coarse wood, and large diameter snags) in regeneration harvest areas and provide future substrate for a sub-group of species (lichen, bryophytes and fungi) in the conifer forest habitat group.

Under all action alternatives, regeneration harvest would remove commercial trees and forest biological legacy (green trees, commercial coarse wood, and commercial snags). Biological legacy and small undisturbed patches provide refugia for species to persist over time (Franklin et al. 2002), including a sub-group of species in the conifer forest habitat group. Future forest stands on the timber base under the PRMP (except where unevenaged management is applied) and Alternatives 1 and 2 would develop into even-aged, homogenous conifer stands with reduced biodiversity compared to existing natural stands with biological legacy components. These habitat components (large trees, snags, and down wood) would be removed, reducing the amount of future habitat available for recruitment of populations for many decades.

A sub-group of more than 25 lichen, bryophyte, and fungi species in the conifer forest habitat group is associated with habitat conditions and forest biological legacy (green trees, coarse wood, and snags) of mature and old conifer forests. Important habitat components include coarse wood, snags, and specific host species (see Appendix F - Botany). The risk to these species would increase as the level of timber harvest activities increases, biological legacies are lost, and interior habitat conditions are reduced in the harvest land base over time. Development of large dead wood in forest stands does not begin for about 100 years after harvest removal and does not culminate for more than 400 years (Spies et al. 1988). Although each species has a unique distribution, biology, and ecology and the amount of information relative to these life requirement features is limited, the biological legacy components appear to be one of many components essential to persistence of these species. Biological legacies play important roles in perpetuating species during ecosystem reorganization and recovery following disturbance (Franklin et al. 2000, Franklin and MacMahon 2000, and Lindenmayer and Franklin 2002). Some species (Bryoria pseudocapillaris and Hypogymnia duplicata) are only known to occur on the bark of old coastal spruce trees and other conifer forests (coastal maritime). Other species (Calicium adspersum and Tetraphis geniculata) are associated with coarse wood in interior habitat conditions of old conifer forests.

Under Alternatives 1, 2, 3, and the PRMP, regeneration harvests of forest stands would not develop replacement biological legacies (large trees, snags, and down wood) suitable for a sub-group of coniferassociated species before the next timber harvest is scheduled. Under all action alternatives, these forest stands would permanently lose host and substrate habitat for these species in regeneration harvest units in the harvest land base. However, a substantial amount of forest stands with biological legacy would 
remain on BLM-administered lands in the non-harvest land base (e.g., Congressional reserves, National Conservation System lands, Late-Successional Management Areas, and Riparian Management Areas), and in the Uneven-age Timber Management Area under the PRMP, as well as on Forest Service lands. Of the 2.2 million acres of BLM-administered land in the conifer forest lands, the portion in the non-harvest land base by alternative is:

- 73 percent in the No Action Alternative

- 60 percent in Alternative 1

- 46 percent in Alternative 2

- 36 percent in Alternative 3

- 55 percent in the PRMP

Forests in the non-harvest land base would provide suitable habitat conditions for future recruitment of populations, depending on the unique range, distribution, biology, and ecology of the species.

Under Alternatives 1, 2, 3, and the PRMP, forest stands under age 30 would not be suitable habitat for this sub-group of species in the conifer forest group. This is true even when biological legacy components persist because only a few relic occurrences of all species have been discovered in these stands. Stands between 30 and 80 years of age provide mixed but improving habitat conditions for these species. Currently, more than 1.0 million of the 2.2 million acres of BLM-administered conifer forest lands are under 80 years of age. Of these, nearly 450,000 acres are under 30 years (see the Timber section in Chapter 3).

Under Alternatives 1,2,3, and the PRMP, forest fragmentation of stands 80 years and older would increase and interior habitat conditions would decrease on BLM-administered lands within the harvest land base over the next 10 years. Suitable habitat would be reduced by between 30,000 to 64,000 acres under the alternatives for a sub-group of plant and fungi species in the conifer forest habitat group. A growing body of literature demonstrates that micro-climate changes from multiple interactions across a gradient between edge and interior habitat conditions affect species diversity, abundance, and vigor (Chen et al. 1995, Jules 1998, and Stewart et al. 2006). Depending on the edge characteristics and surrounding stand age, interior habitat conditions would require a forest stand patch size of approximately 50 acres for any interior habitat and 100 acres or more for any substantial amounts. See Chapter 4 (Structural Stages and Spatial Pattern section) for a discussion of the forest patch sizes that would occur under the alternatives.

Under Alternatives 1,2,3, and the PRMP, risks for this sub-group of species in the conifer forest habitat group associated with mature and older conifer forest would increase slightly over the next 10 years from the No Action Alternative. Biological legacy (large trees, snags, and down wood) would be lost from stands during regeneration harvests. This loss would reduce the amount of future suitable habitat for dispersal and survival of populations of species. Under the PRMP, regeneration harvests would not occur in the Unevenage Timber Management Area. Under the PRMP, which would apply conservation measures to all known occurrences of species consistent with the BLM Special Status Species Policy, all known occurrences would likely survive. Under the PRMP, the harvest of older and more structurally-complex multi-layered conifer forest stands within the harvest land base would be deferred through 2023. Risks to this sub-group of species would increase slightly under the PRMP and moderately under Alternatives 1,2, and 3 . Risks to the other subgroups of species would be similar to the No Action Alternative.

Partial harvest under Alternative 3 would be a type of regeneration harvest that would create even-aged stands in the understory, but retain portions of the existing overstory stand, aggregated or distributed within the harvest area. Partial harvests would occur only under Alternative 3 and create approximately 125,000 acres of stands with biological legacy and 4,000 acres of stand establishment forests similar to regeneration harvest without biological legacy. 
Uneven-age management would occur under the PRMP on 41,300 acres in the southern Cascades and Klamath Provinces. Uneven-age and partial harvests would retain biological legacy and host species in forest stands, although at a lower amount, at smaller diameter sizes, and at different distributions than natural stands.

Thinning would occur under all alternatives. Thinning is an intermediate stand harvest that retains larger diameter trees distributed evenly over the harvest area. Generally, thinning forest stands modifies stand characteristics, structure, and vegetation less than other harvest types. Also, with thinning, forest stands recover quicker from disturbance and would have minimized risks to occurrences and species in the conifer forest habitat group.

\section{Salvage Harvest}

Under Alternatives 1, 2, 3, and the PRMP, salvage timber harvest would occur following disturbance both inside and outside of the timber harvest land base. Salvage harvest would primarily affect plant and fungi species in the conifer and mixed evergreen forests, riparian and aquatic, serpentine areas, and oak and hardwood woodlands habitat groups. It is not possible to predict the locations and amount of salvage harvest that would occur over the next 10 years (see the Introduction in Chapter 4). The Eastern Cascades, the southern West Cascades, and the Klamath Provinces have high fire frequency, with low severity return intervals where salvage harvest would occur (see the Fire and Fuels section of Chapter 3). Where high severity wildfires occur, they would consume most occurrences and suitable habitat of rare plant and fungi species, although some would likely survive below ground as propugules or in unburned areas or islands of low intensity burns (Kaye et al. 2005; Botany section of Chapter 3).

Under Alternatives 1, 2, and 3, no conservation protection measures would be applied to species and occurrences within the salvage areas. Risks to species and occurrences would increase moderately from the No Action Alternative. Although not all occurrences would be extirpated as a result of wildfires, subsequent ground disturbance from salvage activities could contribute to additional occurrence extirpations. Under the PRMP, with the application of conservation measures to species occurrences on all BLM-administered lands, the species would likely survive, with risks to species and occurrences similar to the No Action Alternative.

\section{Silviculture Treatments}

Under Alternatives 1, 2, 3, and the PRMP, the amount and location of silviculture treatments would be associated primarily with the amount and location of regeneration, partial, and uneven-age harvest acres within the harvest land base as shown in Table 4-41 (Forest management activities that affect plant occurrences over the next 10 years). Silvicultural treatments associated with regeneration harvest would modify newly established, young forest stands through cutting and scalping vegetation, conifer thinning, converting hardwood stands to conifers, and fertilization. Treatments associated with regeneration harvests would result in young stands that are generally even-aged with reduced stand structure and species diversity, and lacking small micro-habitat patches. Structural components and small undisturbed patches remaining in the unit from previous treatments would allow some species occurrences in the conifer habitat group to persist within the harvest units. Silviculture treatments would occur over a 20 -year period of time on the forest stands where regeneration harvests occurred.

Occasionally, occurrences of rare plant species have survived the combination of harvest, fuels reduction, and silviculture treatments in the past when no conservation measures were applied. Forests in the stand establishment and young forest structural stage classification are suitable habitat for a sub-group of species in the conifer habitat group. As long as populations were not completely extirpated during timber harvest activities, this sub-group of species would benefit from more frequent habitat disturbances when conservation measures are integrated with activities. Species such as Tall bugbane and Wayside aster respond positively 
by increasing growth, flowering, and fruiting from more open conditions (e.g., Cimicifuga elata, Kaye and Kirkland 1999; Eucephalus vialis, Thorpe and Kaye 2006). Other occurrences of species have survived the combination of treatments in the past, but do not appear to benefit biologically to the disturbance with increased growth and reproduction (Cypripedium fasciculatum, Knorr and Martin 2003). These are considered relic occurrences that survived the activity and habitat disturbance in micro-habitat patches but are neither tolerant nor adapted to harvest disturbances.

Under Alternatives 1, 2, and 3, few rare plant and fungi occurrences that survived the initial timber harvest would survive subsequent silviculture treatments without the application of conservation measures. Under either of these three alternatives, risks to species and occurrences would increase slightly compared to the No Action Alternative because most populations would have been extirpated as a result of habitat loss and activity disturbance during timber harvest. Species with 20 or fewer occurrences would receive conservation protection measures. Under the PRMP, risks to species and occurrences would be similar to the No Action Alternative. Under both the PRMP and No Action Alternative, species would likely survive due to application of conservation measures to occurrences and species on all BLM-administered lands consistent with Bureau Special Status Species Policy.

\section{Site Preparation and Non-Timber Related Vegetation Treatments}

Under all action alternatives, hazardous fuel reduction treatments and biomass treatments would reduce slash from timber harvest and silviculture activities, remove hazard fuels in the Wild Urban Interface, and harvest fuels for biomass. Non-timber related vegetation treatment activities would occur on approximately 219,000 acres, and site preparation after timber harvest would occur on 71,000 acres over the next 10 years. More than 270,000 acres would occur in the Klamath, Eastern Cascades, and the southern portion of the West Cascades Provinces. These treatments would affect plant and fungi species in the conifer and mixed evergreen forests, shrub communities, serpentine areas, and oak and hardwood woodlands habitat groups. Fuel reduction treatments associated with timber harvest (approximately $50 \%$ of total acres) would primarily affect the conifer forest habitat group and oak and hardwood woodlands habitat groups. More rare plant and fungi species and occurrences are found in the Klamath Province than any other province; the fewest number of occurrences are found in the Eastern Cascades Province. Species would no longer occur in these treatment units if the substrate, host species, or micro-environment upon which the species depends is removed by the treatments.

The prescribed fire and fuel treatments to reduce fire hazard are done under spring-like conditions and designed not to consume soil duff, large logs, or snags. Under all of the alternatives, substrate consisting of large down logs or snags would generally be retained in hazardous fuel treatments. A projection of the number of acres or intensity of biomass removal that would take place under the alternatives is speculative (see the Energy and Minerals section of Chapter 4). Vascular plant species not in the conifer habitat group are generally shade-intolerant and respond to increased light and reduction in plant competition with increased growth, flowering and fruiting (Kaye and Thorpe 2006, USDA USDI 2004b, USDA and USDI BLM and NPS 2004, USDI USFWS 2005 and 2006b).

Under Alternatives 1, 2, and 3, conservation protection measures would not be applied to fuels reduction treatments associated with timber harvest on $\mathrm{O} \& \mathrm{C}$ lands in the timber harvest land base. Consequently, under these three alternatives, few rare plant and fungi occurrences would survive in timber harvest units that receive fuels reduction treatments. Risks to species and occurrences would increase slightly to moderately compared to the No Action Alternative because most occurrences would be extirpated as a result of timber harvest. Species with 20 or fewer occurrences would receive conservation protection measures. Since species and occurrences on lands not in the O\&C harvest land base would receive conservation measures, most occurrences there would likely survive. Under the PRMP, where conservation protection measures would be applied to all species and occurrences on all BLM-administered lands, the species would likely survive. Risks to species and occurrences under the PRMP would be similar to the No Action Alternative. 


\section{Road Construction}

Under all action alternatives, road construction associated with forest management activities would increase compared to the No Action Alternative and occur predominantly in the conifer habitat group. Road construction would occur to a lesser amount in areas where all the other habitat groups are found. The increase in new roads would disproportionately affect the Klamath Province on the Medford District because of the higher density of such plant occurrences relative to other provinces. Roads there would be more likely to cross habitat types such as meadows or serpentine areas with rare plant occurrences. The total miles of new permanent and temporary roads and the percent that occurs in the Klamath Province (Medford District) are as follows:

- No Action Alternative:

- Alternative 1

- Alternative 2

- Alternative 3

- PRMP

\section{$\underline{\text { Road Miles }}$}

820

830

1,010

1,060

1,280

\begin{tabular}{c} 
Medford District \% \\
\hline $19 \%$ \\
$34 \%$ \\
$27 \%$ \\
$31 \%$ \\
$29 \%$
\end{tabular}

Conservation measures would be applied under all alternatives to species occurrences and occupied habitat in the path of road construction for all nine habitat groups in areas outside of the harvest land base. Under Alternative 1,2, and 3, most occurrences of species in the conifer habitat group that occur in the path of road construction would likely be extirpated in areas within the timber harvest land base since conservation measures would not be applied. Since conservation measures would be applied to species with 20 or fewer occurrences, these species occurrences would likely survive. Under the PRMP, the risks to species and occurrences would be similar to the No Action Alternative where all occurrences would likely survive since conservation protection measures would be applied to all species and occurrences on all BLM-administered lands consistent with Bureau Special Status Species Policy.

\section{Invasive Plants}

Under all action alternatives, the risk of introducing and spreading invasive plants would increase as a result of the combination of activities that include timber harvest activities, salvage harvest, fuels treatments, silviculture activities, road construction, and grazing, but would decrease as a result of limiting off-highway vehicle activity to designated roads and trails (see Table 4-41). The level of risk would increase the risk of introducing invasive species relative to the amount of activity proposed by alternative, with the highest risks under Alternatives 2 and the PRMP. These activities disturb vegetation and expose soils for invasive species introduction and spread (see the Invasive Plants sections in Chapters 3 and 4). Invasive plants occur throughout the planning area, but are less prominent on serpentine soils in the Klamath Province. Invasive plants are found on habitat occupied by all nine habitat groups. Invasive plants would primarily affect the vascular plant group of species. There is very little information about the adverse effects of invasive plant species (e.g., false brome and knotweeds) to fungi and terrestrial lichens and bryophytes (Kaye, pers. com. 2008). The interactions between the type, amount, and location of activities with invasive plants are key factors in determining the magnitude of effects to species occurrences.

Invasive plants alter the existing native plant community and reduce rare plant growth and vigor, flowering, and fruiting. They also limit the expansion and migration of occurrences (Kaye et al. 2006, USDA USDI 2005). Under all action alternatives, the risk of invasive plant introductions and spread would increase moderately compared to the No Action Alternative (see the Invasive Plants section of Chapter 4). Impacts to rare plant occurrences would vary depending on many factors, but primarily the invasive species and its biology, site characteristics, and the rare plant species and its biology. There is not a reliable way to predict actual location of invasive species introductions relative to occurrences of rare species as a result of activities. Actions to control invasive plant species that eradicate or reduce competition would benefit 
rare plant occurrences. Generally, larger rare plant occurrences would be more resilient to invasive species invasion and persist longer than small occurrences that are less robust.

Under all action alternatives, measures to prevent and control new invasive plant infestations would be applied on all BLM-administered land. Although these measures would reduce the likelihood of the introduction of invasive plants and treat their spread, it is assumed these actions would not be completely successful. Under all action alternatives, the risk to rare vascular plant species occurrences and habitat in all habitat groups would increase moderately compared to the No Action. Alternative.

\section{Wildfire Suppression}

All habitat groups would be subject to wildfire suppression activities, but primarily activities would occur in the southern half of the West Cascades, Eastern Cascades, and Klamath Provinces. Under all action alternatives, risks to species occurrences from wildfire suppression activities would be similar to the No Action Alternative. Rare plant and fungi species in the planning area evolved in ecosystems that included periodic natural fires, but not wildfire suppression activities. Immediate response wildfire suppression activities that involve bull-dozing (such as fireline access and construction, safety zone construction, and staging centers) often make more fundamental and longer-lasting changes to habitat than the wildfire itself, although on a much smaller area. On the recent Timber Rock wildfire, only 27 of 27,100 acres (0.1\%) were disturbed by fire lines (USDI BLM 2004). The acres of wildfire suppression activity are low relative to other management activities, but where suppression activities occur on the sites of BLM sensitive species occurrences, the species would likely be extirpated from those sites. Suppression efforts that prevent or reduce habitat loss of habitat from uncharacteristic wildfire would preserve occurrences that would otherwise be lost.

\section{Locatable Mining Activities}

The existing laws in regard to mining activities on the public lands are equally applicable to all the alternatives; therefore, the level of mining operations would also be the same under all alternatives. Whatever effects on botanical species occur from mining activities would be part of the existing condition and projected effects of the No Action Alternative. This discussion, therefore, does not compare alternatives regarding mining activities, but rather for consideration for cumulative effects. Mining operations occur throughout the planning area, but would occur primarily in areas occupied by species in the rocky areas/ outcrops/scree, serpentine, conifer, and riparian and aquatic habitat groups.

The majority of claims, notices, and plans occur on Medford District (Klamath Province) where more rare plant occurrences are located. There are approximately 2,500 mining claims of active record in the planning area. Mining notices allow ground disturbance for exploration of locatable minerals. Plans of operation are required for commodity extraction operations or explorations greater than 5 acres. The number of occurrences that intersect with mining operations would be few, although some would be consequential. Mining claims, notices, and plans exist on areas where there are known rare plant occurrences such as French Flat (Medford District) and Hunter Bog (Coos Bay District), which also are areas of critical environmental concern. Seven BLM's sensitive species and numerous occurrences are found on these two areas alone. Because conservation measures for Bureau sensitive species would not be applied to mining notices and plans of operations, some species occurrences would likely be extirpated and occupied habitat destroyed as a result of equipment operations and ground disturbance.

\section{Rock Quarries}

Under all action alternatives, the level of rock quarry operations would increase slightly compared to the No Action Alternative. The amount of quarry operation activity would be associated with the level of road construction and maintenance under each alternative. Quarry operations occur in areas occupied by species 
in the rocky areas/ outcrops/scree, serpentine, and conifer groups. There are approximately 370 existing quarries located on 700 acres. Existing quarries would be expanded, and a few new rock quarries would be developed to meet new road construction and maintenance rock needs. The location of new quarries is uncertain and would depend on the location of the activities and suitable rock sources. This would affect a relatively small percentage of the planning area and would possibly intersect with only a small number of plant occurrences. The overall risk of occurrence extirpation to species in these four habitat groups from quarry activities would be low under all alternatives. Conservation measures would be applied to all species and occurrences on all BLM-administered lands consistent with Bureau Special Status Species Policy since quarry sites are outside of the harvest land base.

\section{Grazing}

Under all alternatives, livestock grazing would occur in the southern half of the West Cascades, the Eastern Cascades, and the Klamath Provinces. Risks to occurrences and species would be similar to the No Action Alternative. Grazing would occur in areas occupied by upland meadows/grasslands, oak and hardwood woodlands, conifer, seasonal wetlands fens/vernal pools, and riparian and aquatic habitat groups. Under the No Action Alternative, approximately 560,000 acres would be authorized for grazing. Under all action alternatives, the number of grazing allotment acres would be reduced by 141,000 acres to 420,000 acres. Since these 141,000 acres of allotments are currently vacant (no cattle grazing occurring), there would be no change in the effects to the known occurrences of the BLM's sensitive species in this area.

Under all alternatives, there are 9 species in the Klamath Falls Resource Area and 46 species in the Medford District that include over 700 occurrences on 1,080 acres within allotments authorized for grazing.

Livestock graze and trample vegetation, including BLM sensitive species. Species assessments and monitoring of rangeland conditions and trends indicate that relatively few occurrences are extirpated due to grazing within the planning area. (ODA 2005, Meinke 2007, Menke et al. 2007, Kaye 2002).

Not all areas within grazing allotments are grazed and not all occurrences in grazing allotments are affected by grazing or trampling. Some occur in inaccessible locations, areas of low forage and use, or where grazing and trampling is seasonal, transient, and low. A few annual species such as Bellinger's meadow-foam, disappearing monkeyflower, and sculptured allocarya can tolerate light-to-moderate levels of trampling and grazing, as long as they can produce seed and maintain stable germination and occupancy levels (Whiteaker, pers. com. 2007).

Generally, the areas of higher grazing utilization occur in close proximity to abundant forage, grassland meadows, water sources, and flat ground. Areas of higher disturbance from trampling occur around holding pens, watering areas, and salt blocks. These high disturbance areas allow invasive plants to establish, increase occupancy, and spread. Occurrences of BLM sensitive species occur in areas of high utilization and high disturbance as well as low utilization. Although occurrences would normally withstand low-to-moderate amounts of grazing and trampling damage, high levels of disturbance (especially when repeated over multiple years) would reduce plant vigor, prevent reproduction, damage individual plants and occurrences, and increase the introduction and spread of invasive plants. Where high levels of disturbance occur in proximity to rare species, the risk to occurrences increases and may result in the extirpation of populations (Menke and Kaye 2007).

Under all alternatives, occurrences and occupied habitat of BLM's sensitive species that occur in the five habitat groups (upland meadows/grasslands, oak and hardwood woodlands, conifer, seasonal wetlands fens/vernal pools, and riparian and aquatic) would be protected from grazing and trampling through conservation measures associated with the application of the BLM's Special Status Species Policy. Since expected grazing usage is the same under all alternatives, including the No Action Alternative, and conservation measures would be equally applied under all alternatives, the effects regarding grazing activities on botanical species is not relevant to the choice to be made among the alternatives. 


\section{Off-Highway Vehicle Use}

Under the No Action Alternative, approximately 330,000 acres of BLM-administered lands would be designated as open to off-highway vehicle use in the Salem, Eugene, and Medford Districts, and the Klamath Falls Resource Area. Approximately 85,000 acres would be designated as closed. Species in all nine habitat groups are found in these areas. A majority of these open areas are located on steep, densely-forested terrain, which is not conducive to cross-country motor vehicle travel. However, where cross-country travel occurs, vehicles would crush vegetation, displace soils, and create trails that could potentially degrade occupied habitat and damage occurrences of rare plant species that may be scattered throughout the area.

High concentrations of off-highway vehicle activities occur around campgrounds, recreation areas, existing trails, and adjacent to private lands and fan outwards for hundreds of acres. Off-highway vehicle activities occur across a wide area, including 140,000 acres in the Klamath Province where the highest density of species occurrences are found.

Under Alternatives 1, 2, and 3, off-highway vehicle activity would be closed on an additional 14,000 acres and designated as "limited to designated roads and trails" on an additional 1.3 million acres. Only 77 acres would remain open to off-highway vehicles. Risks to occurrences and species would be reduced moderately compared to the No Action Alternative. A designation of "limited to designated roads and trails" would result in a reduction to the amount of potential damage to occupied habitat and occurrences for all habitat groups compared to the No Action Alternative. Populations would likely still experience some reductions and extirpations, but at lower rates. The 77 acres that would remain open include coastal sand dune areas in the Coos Bay District. An abundance of rare plant occurrences (mostly lichens in forested areas) are found in surrounding habitat, but off-highway vehicle activities would not result in loss or damage to occurrences or degrade habitat. The 77 acres which would be designated as open under Alternatives 1,2, and 3 would be designated as limited to designated roads and trails under the PRMP.

\section{National Landscape Conservation System and Areas of Critical Environmental Concerns}

Under all action alternatives, risks to occurrences and species in the National Landscape Conservation System would be similar to the No Action Alternative. A small portion of these lands have been surveyed, but approximately 300 occurrences and 307 acres of occupied habitat of special status plant and fungi species are known from the National Landscape Conservation System.

Areas of critical environmental concern are designated where special management attention is required to maintain and protect relevant and important values. Under the No Action Alternative, 131 existing and potential areas of critical environmental concern would be managed to maintain and protect relevant and important values. This would result in the conservation of approximately 560 known occurrences of BLM's sensitive plant species. These species occur in a wide range of habitats throughout the planning area, with over 400 occurrences in the Klamath Province. More occurrences are likely to exist in areas of critical environmental concern because of the unique nature of the habitat.

Under Alternatives 1, 2, and 3, there are 40 Areas of Critical Environmental Concern that contain special status species as a relevant and important value; these areas would not be designated under one or more of these three alternatives. These areas contain approximately 60 known occurrences. There are 28 additional Areas of Critical Environmental Concern with the BLM's sensitive species that would be reduced in size under one or more of these alternatives. Occurrences of species in the conifer habitat group would be subject to forest management activities. Some occurrences of these species would likely be extirpated as a result of future forest management activities because they would not receive special management attention or conservation protection measures (except for those species with 20 or fewer occurrences). An example 
of these species (Cupressus bakeri) is one of eight populations in Oregon; this species is found in the Baker Cypress Area of Critical Environmental Concern (Medford District). It is the only occurrence on BLMadministered lands and is the northern most population of cypress in North America.

Under the PRMP, there are six areas of critical environmental concern that contain special status species as a relevant and important value that would not be designated, and 22 others that would be reduced in size. Conservation measures would be applied to species occurrences on all BLM-administered lands consistent with Bureau Special Status Species Policy. There would be a low risk of extirpation of occurrences and species, similar to the No Action Alternative.

\section{Biological Factors and Risk to Species from Management}

For many species, there is insufficient information at the level of plan decision-making to determine the significance of the loss of one or more occurrences to a BLM sensitive plant or fungi species. The Bureau special status plant and fungi species have diverse life histories and respond differently to habitat change and disturbances. The unique biological requirements, ecology, and threats of each species shape the number of individuals, patch size, and distribution. Biological factors interact with environmental factors to determine population and species rarity and trends (Gurevitch et al. 2006, Kaye et al. 1997).

Various studies discuss specific factors that influence population trends relative to plant life-form and life history, breeding systems and effective breeding occurrences, seed dormancy, recruitment, colonal growth, colonization, genetic factors, and models of extinction risks and disturbance (Ellestrand and Elam 1993, Lennartsson 2002, Menges 2000, Schemske et al. 1994). Although each species requires individual biological, ecological, and risk assessments and the threshold of many species is higher, at a minimum any occurrence losses from management activities to species with 20 or fewer occurrences would contribute to the trend toward local extirpation or extinction of the species within the planning area (Ellstrand and Elam 1993, Freidman 2007, Kaye 2007, and USDI USFWS 2003). For some species, this threshold is higher. However, the threshold is consistent with general biological, environmental, and risk factors for species rankings in Oregon Natural Heritage Plan (2007) and Nature Serve (2008).

Under Alternatives 1,2 and 3, there would be little risk of the extirpation of occurrences to BLM's sensitive species in the nine habitat groups in areas outside of the harvest land base on BLM-administered O\&C lands and on Public Domain lands. This is because conservation measures associated with the BLM Special Status Species Policy would be applied and occurrences would likely survive. The BLM Special Status Species Policy would be applied in all land use allocations under the No Action Alternative and the PRMP.

Under all alternatives, 90 of the BLM's sensitive species with 20 or fewer known occurrences and containing at least one occurrence would occur on BLM-administered lands (excluding species in the Cascade Siskiyou National Monument and West Eugene Wetlands). Of these species, 41 occur entirely on BLM-administered lands. ${ }^{8}$ Specifically:

- 42 of the 90 species have 1 to 5 known occurrences.

- 48 of the 90 species have 6 to 20 known occurrences.

The conifer habitat group, where forest management activities would occur, includes 54 of the 90 species as shown in Figure 4-71 (Distribution of known populations of Bureau special status species by land ownership and habitat group). Of these 54 species:

- 27 species have 1 to 5 known occurrences.

- 27 species have 6 to 20 known occurrences.

${ }^{8}$ There is some uncertainty when combining records from two data sets related to double counting and undercounting. Geobob was the primary data source for BLM lands. Heritage data was the source for state, private, and other federal lands. 
Figure 4-71. Distribution Of Known Populations of Bureau Special Status Species By Land Ownership And Habitat Group

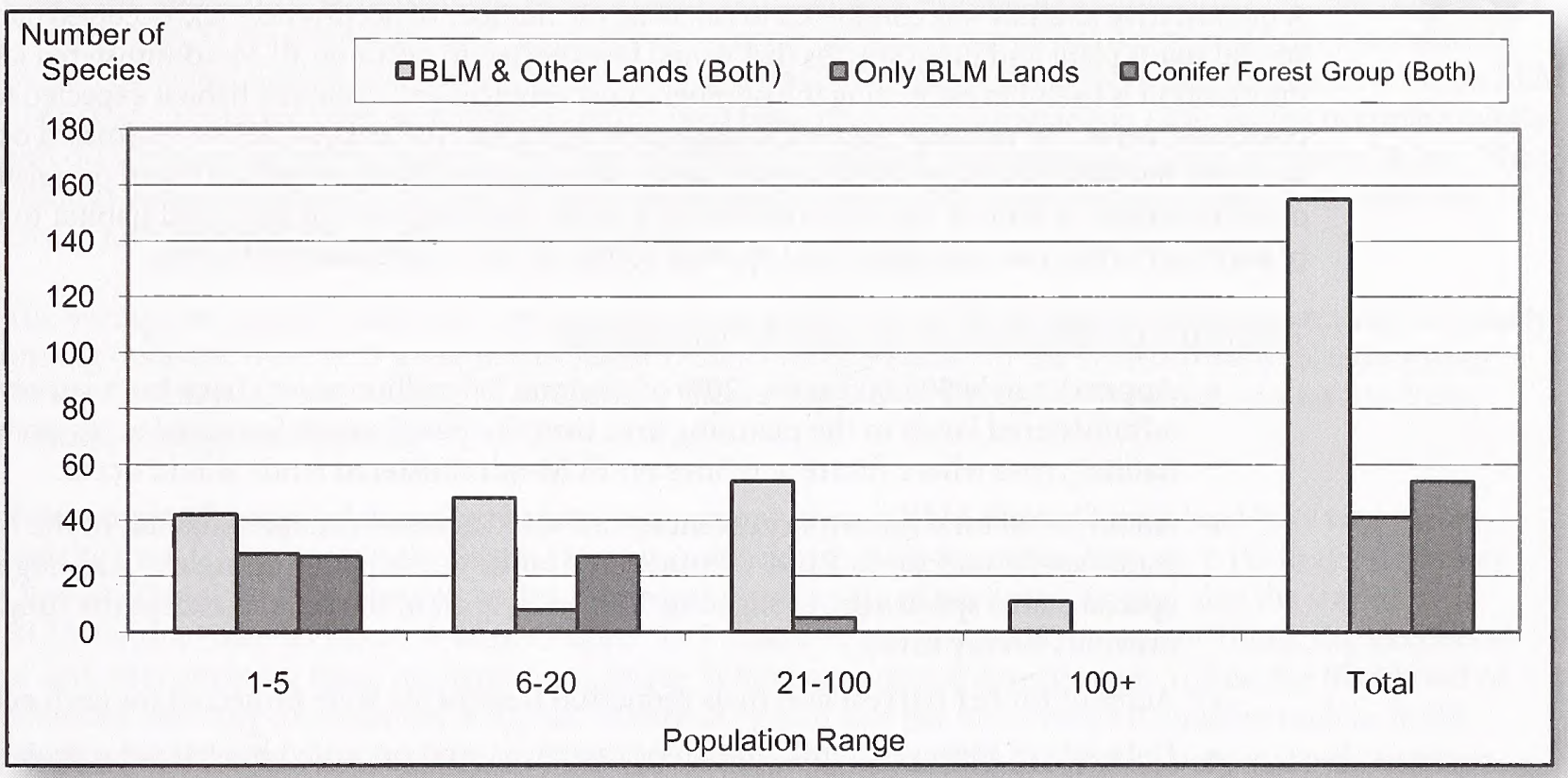

Any occurrence losses from management activities would be critical for species with fewer than 20 occurrences (Ellstrand and Elam 1993, USDI USFWS 2003c, Kaye pers. com., 2007). Conservation measures would be applied to species with 20 or fewer occurrences to prevent extirpation in the planning area under all alternatives.

There are another 65 sensitive species that are known from more than 21 occurrences. Although five of these species occur entirely on BLM-administered lands, none occur in the conifer habitat group.

Under Alternatives 1,2, and 3, species with 21 to 100 known occurrences in the conifer habitat group would have an increased risk of extirpation of occurrences. Any occurrence losses would contribute to a trend toward extirpation within the planning area. However, conservation measures would be applied to prevent extirpation and extinction if occurrences drop to 20 or fewer known occurrences.

Under Alternatives 1, 2, and 3, occurrences of species on private lands would not be considered when determining the total number of species occurrences for applying conservation measures. It is assumed that no protection of the BLM's sensitive species would occur on private lands; however, if BLM sensitive species occur on private lands, the circumstances that have permitted its continued existence on the private lands may or may not continue. It would be speculative to predict the change in those circumstances and likewise the outcome of such occurrences. Therefore, the assumption is made in this analysis that no change would occur to any species occurrences on private lands. Occurrences of these species, as well as federally listed plants, have been damaged and extirpated on private lands (USDI USFWS 2003b and 2006b, Brock and Callagan 2006). The loss of habitat is documented in various monitoring reports and recovery plans for federally listed plant species (USDI USFWS 1998c, 2000, 2003a, and 2003b).

Under the No Action Alternative and the PRMP, due to application of conservation measures to occurrences and species on all BLM-administered lands consistent with Bureau Special Status Species Policy, there would be a low risk of extirpation to occurrences and species similar to the No Action Alternative. 


\section{Projected Occurrences and Occupied Habitat}

A quantitative analysis was conducted to calculate the number of occurrences and occupied habitat of BLM's special status plant and fungi species that would be expected to occur on BLM-administered lands. This information is useful in estimating the number of occurrences and occupied habitat expected to occur and the potential intersect of occurrences and management activities. The analysis derives estimated occurrences and occupied habitat on all BLM-administered lands using a single linear projection based on existing survey and occurrence data. A ratio of the total number of known occurrences and occupied habitat to the total number of acres surveyed was calculated and applied across all BLM-administered lands.

The following information was used for the analysis:

- Approximately 509,600 acres (20\% of the total 2.6 million acres) have been surveyed on BLMadministered lands in the planning area over the past 7 years. Surveyed acres occur in areas and habitat types where future activities on BLM-administered lands would occur.

- About 3,700 total known occurrences and 4,250 acres of occupied habitat of the BLM's special status species occur on BLM-administered lands in the planning area. ${ }^{9}$ (Although the Bureau special status species list changed in 2007 , nearly all of the species except the fungi were included in previous survey lists.)

- Acres of timber harvest and fuels reduction treatments were projected for each action alternative.

- Data sets of surveyed acres, known occurrences, and occupied habitat were projected for all unsurveyed BLM-administered lands and each BLM district.

The following statements apply to the projection of occurrences and occupied habitat:

- The BLM special status species are not homogenously distributed throughout the planning area and tend to have a clumpy or patchy distribution. They are often associated with poorly understood biotic, edaphic (soil), and climatic patterns.

- The pattern of distribution is based on the survey information and provides only a broad approximation of the number of occurrences and the pattern of occupied habitat at the planning area scale.

- There is incomplete information on the distribution of the BLM's special status plant and fungi species in the planning area, as well as the specific location of future management actions that could affect these occurrences.

- The pattern that results from the acres surveyed, occurrences found, and acres of occupied habitat cannot be used to predict the location of BLM special status species. The analysis is limited to broad-scale estimates of the aggregate of all occurrences and occupied habitat and is not applicable to any specific species.

- The analysis assumes a similar level of discovery in the future as the past.

The results of the analysis, including the number and percentage of projected occurrences that would be affected by forest management activities under the alternatives, are shown in Table 4-42 (Projected occurrences that would be affected by forest management over the next 10 years).

Under Alternatives 1,2, and 3, the percentage of projected species occurrences that would be affected by management activities would range from 8 to 11 percent over 10 years. The projected occurrences in the harvest land base would intersect with forest management activities over decades, and most occurrences would be extirpated unless the species is known from 20 or fewer occurrences. In this case, occurrences would be protected by conservation measures under the BLM Special Status Species policy. The relationship between occurrences affected does not necessarily equate to the percentage of risk to a specific species. Under the No Action Alternative and the PRMP, species occurrences would not be affected due to the application of conservation measures under the BLM Special Status Species policy.

${ }_{9}^{9}$ These species and occurrences are based on the 2008 BLM special status species list and the records in GeoBob on October $22,2007$.

They do not include occurrences in the West Eugene Wetlands nor lands in the National Landscape and Conservation System. 
A similar calculation of projected occurrences and occupied habitat was estimated for each BLM district using local data for survey acres, species occurrence, and occupied habitat. The results of the analysis show that $0.8 \%$ of all BLM-administered lands in the planning area would be occupied habitat. See Table 4-43 (Projected BLM sensitive plant and fungi species occurrences and occupied habitat by district). The ratio of known occupied habitat and known occurrences as a fraction of surveyed acres, when calculated for each BLM district and projected over each district's entire land base, provides a comparison of projected occupied habitat and occurrences between districts. The total number of projected occurrences is approximately 18,395 . The amount varies across districts and ranges from approximately 1,000 projected occurrences in Coos Bay District, to nearly 9,500 in the Medford District.

The average occupied habitat size per occurrence, or patch size, of BLM special status species varies broadly among districts, from 0.21 acres in the Salem District to 12.89 acres in the Klamath Falls Resource Area. Differences in patch size among BLM districts largely depend on the types of species, species life-form, biology, ecology, and habitat.

The percent of projected occupied habitat as a percent of each BLM district's total land base also varies widely, from 0.1 percent in the Salem District and Klamath Falls Resource Area, to $4.1 \%$ in the Coos Bay District. The differences are due to the number and patch size of occurrences, and also the size of each BLM district (refer to Figure 3-48 in Chapter 3). In areas where few occurrences are found, the likelihood of activities affecting these occurrences is lower. Where occurrence densities are higher, the likelihood of activities affecting occurrences is higher. Where the patch size per occurrence is smaller, such as in the Medford and Salem Districts, the likelihood of population loss would increase as activity levels increase because smaller size occurrences would be more susceptible to disturbances such as invasive species invasion or changes to interior habitat conditions.

Table 4-42. Projected Occurrences That Would Be Affected By Forest Management Over The NeXt 10 Years

\begin{tabular}{crrrrr}
\hline Alternative & $\begin{array}{r}\text { Planning Area } \\
\text { (BLM Acres) }\end{array}$ & $\begin{array}{r}\text { Number of Projected } \\
\text { Occurrences }\end{array}$ & $\begin{array}{r}\text { Acres of Timber } \\
\text { Harvest Treatments }\end{array}$ & $\begin{array}{r}\text { Number of Projected } \\
\text { Occurrences Affected }\end{array}$ & $\begin{array}{r}\text { Percent of Projected } \\
\text { Occurrences Affected }\end{array}$ \\
\hline No Action & $2,557,800$ & 18,395 & 160,500 & 1,154 & $6 \%$ \\
\hline Alt. 1 & $2,557,800$ & 18,395 & 204,000 & 1,467 & $8 \%$ \\
\hline Alt. 2 & $2,557,800$ & 18,395 & 220,100 & 1,583 & $9 \%$ \\
\hline Alt. 3 & $2,557,800$ & 18,395 & 288,800 & 2,077 & $11 \%$ \\
\hline PRMP & $2,557,800$ & 18,395 & 296,900 & 2,135 & $12 \%$ \\
\hline
\end{tabular}

Table 4-43. Projected BlM Sensitive Plant And Fungi Occurrences And Occupied Habitat BY DISTRICT

\begin{tabular}{|c|c|c|c|c|c|c|c|}
\hline & Planning Area & Salem & Eugene & Roseburg & Coos Bay & Medford & Klamath \\
\hline Total Acres & $2,557,800$ & 403,000 & 315,100 & 426,300 & 322,700 & 865,800 & 224,900 \\
\hline $\begin{array}{l}\text { Projected Occupied } \\
\text { Area (acres) }\end{array}$ & 21,331 & 429 & 5,027 & 4,755 & 13,344 & 5,178 & 251 \\
\hline Occupied Area (\%) & $0.8 \%$ & $0.1 \%$ & $1.6 \%$ & $1.1 \%$ & $4.1 \%$ & $0.6 \%$ & $0.1 \%$ \\
\hline $\begin{array}{l}\text { Projected Number of } \\
\text { Occurrences }\end{array}$ & 18,395 & 2,085 & 3,276 & 2,705 & 1,051 & 9,473 & 19 \\
\hline $\begin{array}{l}\text { Average Acres Per } \\
\text { Number of Occurrences }\end{array}$ & 1.16 & 0.21 & 1.53 & 1.76 & 12.70 & 0.55 & 13.21 \\
\hline
\end{tabular}




\section{Invasive Plants}

This analysis examines timber harvesting, road management activities, and off-highway vehicle use for the potential to introduce and spread invasive plant species would result from the alternatives.

\section{Key Points}

- The risk of introducing and spreading invasive plant species over the next 10 years would be lowest under the No Action Alternative, and highest under Alternative 2.

- The risk of introducing and spreading invasive plant species over the long term would be lowest under the No Action Alternative, and highest under Alternative 3.

The effects of timber harvesting, road management activities, and off-highway vehicle use on the introduction and spread of invasive plant species is measured in terms of susceptibility or risk at the scale of fifth-field watersheds. Timber harvesting, road management activities, and off-highway vehicle use generally can create susceptibility for invasive plant species introduction and spread. Under any of the actions, including action alternatives and no action, infestations would be introduced and spread more readily in areas that would have greater intensity and extent of human activity (e.g., high recreational use areas).

Management activities on other land ownerships would also contribute to the amount of lands made susceptible to the introduction and spread of invasive plant species. In addition, other management actions such as grazing and recreational activities on BLM-administered lands would also contribute to the introduction and spread of invasive plant species. The analysis assumes that actions on other ownerships and actions other than timber harvesting, road management activities, and off-highway vehicle use would continue to contribute to invasive plant species introduction and spread at current levels. Any future changes in the contribution from these other activities to the risk of introduction and spread of invasive plant species would be speculative and depend largely on site-specific factors that cannot be analyzed at this scale of analysis. However, there is no basis for speculating that such changes would vary among the alternatives. Therefore, information on the contribution of these other management actions to the risk of introduction and spread of invasive plant species is not necessary for a reasoned choice among the alternatives.

\section{Inadvertent Introduction of Invasive Plant Species}

The factors that were considered in the analysis of the relative levels of risk for the inadvertent introduction of invasive plant species on the BLM-administered lands include:

- distribution and abundance of species

- types of timber harvesting and logging methods

- proximity of harvesting activity to streams

- intensity and distribution of management activities

- designations for off-highway vehicle use

Species group distributions are categorized and displayed in maps as abundant, limited, or low by fifth-field watershed (see the Invasive Plant section in Chapter 3). For analysis purposes, species groups are combined to represent invasive plant species. 


\section{Risk of Introduction}

The relative risk of invasive plant species being introduced over the next 10 years as an inadvertent result of timber harvesting activities would vary by alternative. The differences are based on the distribution of invasive plant species, the acres of the different timber harvesting types (thinning, partial harvesting, regeneration harvesting, and uneven-aged management), and the methods of logging that would be used. See Appendix $G$ - Invasive Plants for methodology used in determining risk of, or susceptibility to, invasive plant introductions. Timber harvesting types and logging methods would alter the conditions that affect the introduction and spread of invasive weeds. For example:

- Regeneration harvests under all alternatives and partial harvests under Alternative 3 would create higher light levels than commercial thinning and uneven-aged management.

- Soil would be disturbed more by ground-based logging methods, less by skyline cable systems, and least by aerial logging systems.

A comparison of the relative susceptibility among the alternatives can be seen in Figure 4-72 (Relative susceptibility of fifth-field watersheds to invasive plant species introduction as a result of timber harvesting activities over the next 10 years), Figure 4-73 and Table 4-44 (Susceptibility comparison for introduction of invasive plant species associated with timber harvesting activities over the next 10 years). Watersheds with no potential for timber harvesting activities in the first 10 years of implementation, or which have no BLMadministered lands do not have an assigned susceptibility category.

Figure 4-72 is based on estimates derived from the Ten-Year Scenario Quality Check (Appendix E - Timber) and should not be interpreted as a product of actual site-specific project planning.

Susceptibility to the introduction of invasive plant species would be greatest under Alternative 2, which would have 171 watersheds with some level of susceptibility that is associated with timber harvesting activities over the next 10 years. The No Action Alternative would have the least susceptibility to the introduction of invasive plant species, with 156 watersheds having some level of susceptibility. Alternatives 1,3 , and the PRMP would be intermediate in susceptibility, with 158,160 , and 168 watersheds, respectively, having some level of susceptibility.

Table 4-44. Susceptibility Comparison For The Introduction Of Invasive Plant Species That Are Associated With Timber Harvesting In The Fifth-Field Watersheds Across The Alternatives Over The Next 10 Years

\begin{tabular}{lrrrrr}
\hline Susceptibility Ranking & No Action & Alt. 1 & Alt. 2 & Alt. 3 & PRMP \\
\hline High & 0 & 0 & 2 & 1 & 0 \\
\hline Moderate & 2 & 6 & 13 & 8 & 9 \\
\hline Low & 154 & 152 & 156 & 151 & 159 \\
\hline Total Susceptible & 156 & 158 & 171 & 160 & 168 \\
\hline Total Not Susceptible & 104 & 102 & 89 & 100 & 92 \\
\hline Total Watersheds & 260 & 260 & 260 & 260 & 260 \\
\hline
\end{tabular}


Figure 4-72. Relative Susceptibility Of Fifth-Field Watersheds To Invasive Plant Species Introduction As a Result Of Timber Harvesting Activities Over The Next 10 Years

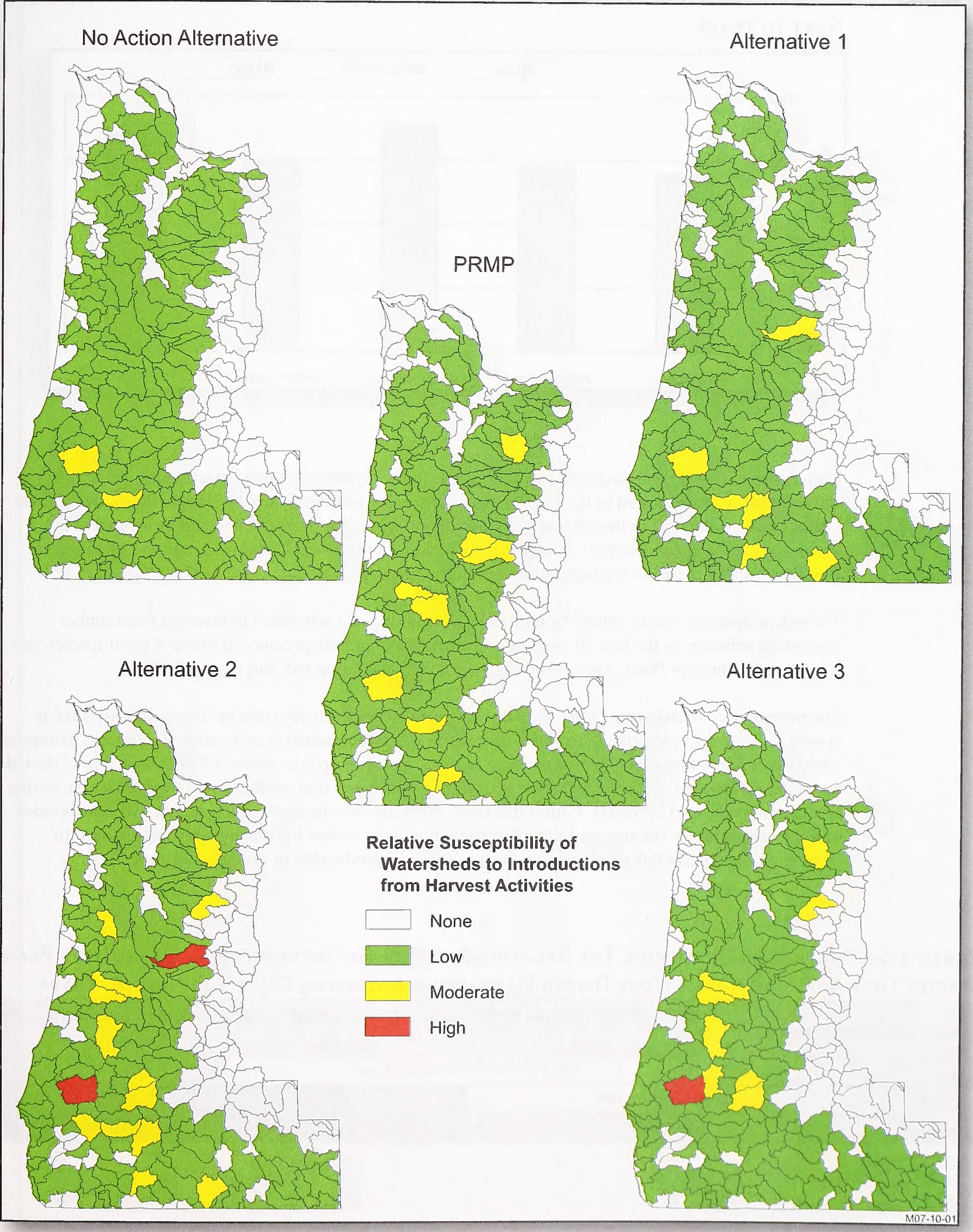


Figure 4-73. Susceptibility Comparison For Introduction Of Invasive Plant Species Associated With Timber Harvesting Activities Over The NeXT 10 YeARS

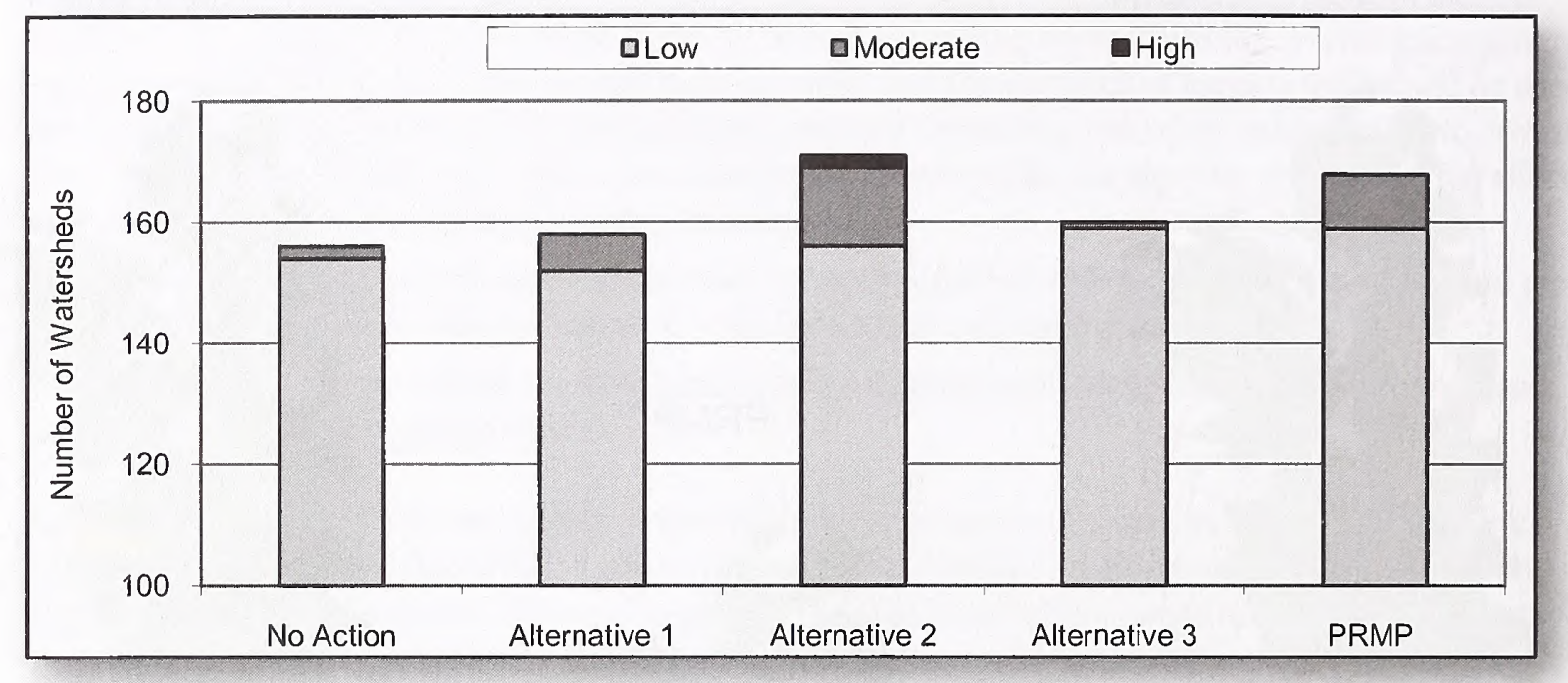

Under Alternative 2, there would be two watersheds in the highest susceptibility category. These two watersheds would be located in the Eugene, Roseburg, and Coos Bay Districts. Under Alternative 3, there would be one watershed in the highest susceptibility category. This watershed would be located in the Roseburg and Coos Bay Districts. Under the No Action Alternative, Alternative 1, and the PRMP, there would be no watersheds in the highest susceptibility category.

The risk of invasion is determined by both the susceptibility of a watershed to invasion from timber harvesting activities in the first 10 years of implementation and the presence of invasive plant species. See Appendix G-Invasive Plants for methodology used in determining risk and susceptibility.

The process used to determine the risk of invasive plant species introduction by fifth-field watershed is shown in Table 4-45 (Matrix to determine the relative risk for introduction of invasive plant species associated with timber harvesting activities over the next 10 years) and displayed in Figure 4-74 (Comparison of the risk by mapped watershed for the introduction of invasive plant species that are associated with timber harvesting activities over the next 10 years). Within this table, categories for the distribution of invasive plant species and the categories for the susceptibility of introduction from timber harvesting activities are used to determine the relative risk categories for the inadvertent introduction of invasive plant species.

Table 4-45. Matrix To Determine The Relative Risk For The Introduction Of Invasive Plant Species That Are Associated With Timber Harvesting Activities Over The Next 10 Years

\begin{tabular}{|c|c|c|c|}
\hline \multirow{2}{*}{ Species Distribution Categories } & \multicolumn{3}{|c|}{ Susceptibility Categories for Introduction of Invasive Plant Species From Timber Harvesting Activities } \\
\hline & Low & Moderate & High \\
\hline Low & Low & Moderately Low & Moderate \\
\hline Limited & Moderately Low & Moderately High & High \\
\hline Abundant & Moderate & High & Highest \\
\hline
\end{tabular}


Figure 4-74. Comparison Of The Risk By Mapped Watershed For The Introduction Of Invasive Plant Species Associated With Timber Harvesting Activities Over The Next 10 Years

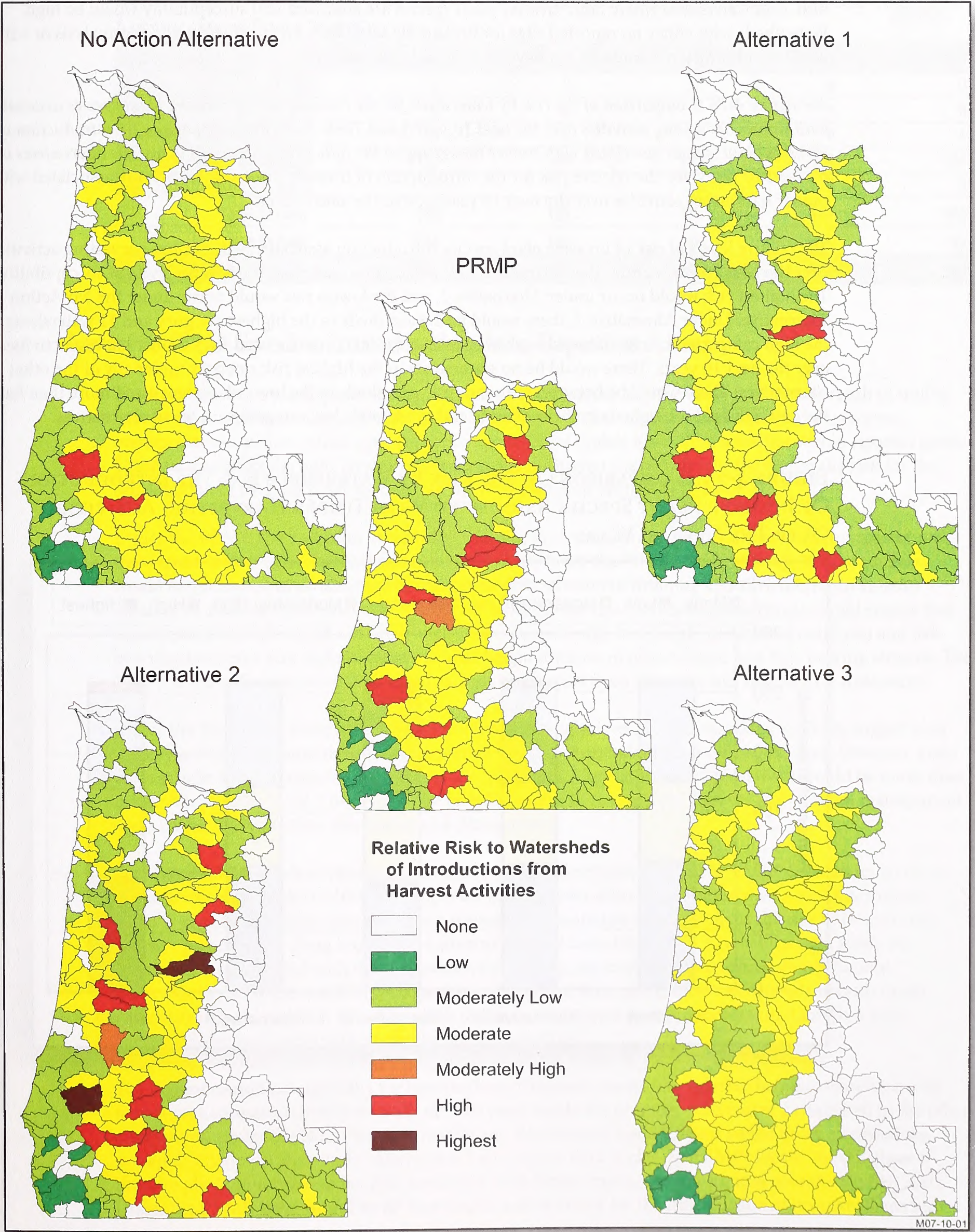


Watersheds with a low distribution of invasive plant species and low susceptibility for the introduction of invasive plant species would have the lowest risk of invasion. The greatest risk of invasion would be in fifth-field watersheds where both invasive plant species are abundant and susceptibility would be high. Watersheds with either no reported sites for the sample set of invasive plant species in the analysis or with no BLM-administered lands do not have an assigned risk category.

See Figure 4-75 (Comparison of the risk by watersheds for the introduction of invasive plant species associated with timber harvesting activities over the next 10 years) and Table 4-46 (Risk comparison for introduction of invasive plant species associated with timber harvesting in the fifth-field watersheds across the alternatives over the next 10 years) for the relative risk for the introduction of invasive plant species that are associated with timber harvesting activities over the next 10 years across the alternatives.

The relative levels of risk of invasive plant species introduction associated with timber harvesting activities over the next 10 years under the alternatives follow the same pattern as the relative levels of susceptibility: The highest risk would occur under Alternative 2, and the lowest risk would occur under the No Action Alternative. Under Alternative 2, there would be 2 watersheds in the highest category and 12 watersheds in the high categories for risk of invasive plant species introduction associated with timber harvest activities over the next 10 years. There would be no watersheds in the highest risk category under any of the other alternatives. There would be between four and five watersheds in the low risk category and more than half of the 260 fifth field watersheds in the moderate and moderately low categories under all alternatives.

\section{Figure 4-75. Comparison Of The Risk By Watersheds For The Introduction Of Invasive Plant Species Associated With Timber Harvesting Activities Over The Next 10 Years}

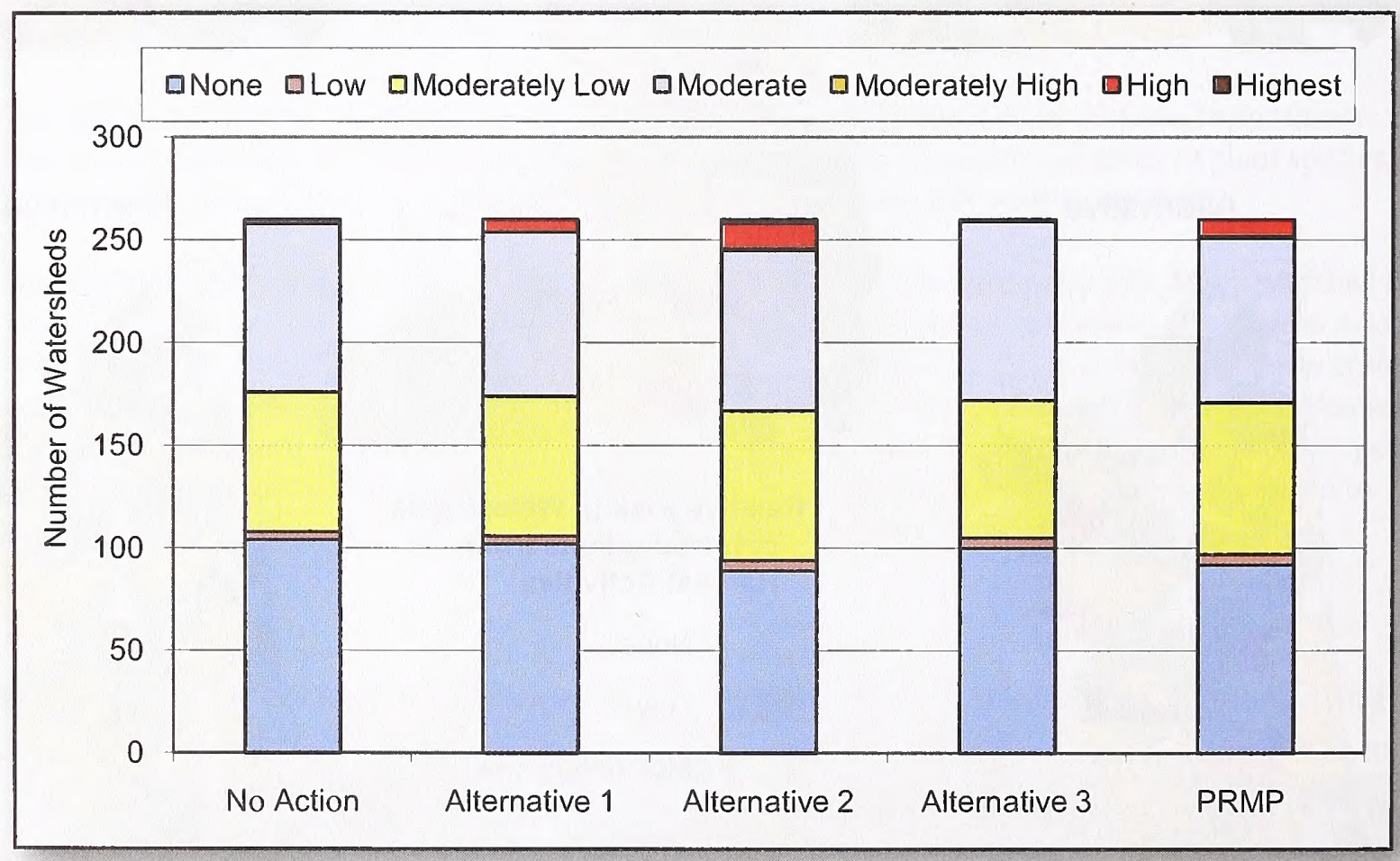


Table 4-46. Risk Comparison For The Introduction Of Invasive Plant Species Associated With Timber Harvesting In The Fifth-Field Watersheds Across The Alternatives Over The Next 10 Years

\begin{tabular}{|c|c|c|c|c|c|}
\hline Risk Ranking & No Action & Alt. 1 & Alt. 2 & Alt. 3 & PRMP \\
\hline Highest & 0 & 0 & 2 & 0 & 0 \\
\hline High & 2 & 6 & 12 & 1 & 8 \\
\hline Moderately high & 0 & 0 & 1 & 0 & 1 \\
\hline Moderate - Moderately low & 150 & 148 & 151 & 154 & 154 \\
\hline Low & 4 & 4 & 5 & 5 & 5 \\
\hline Total At Risk & 156 & 158 & 171 & 160 & 168 \\
\hline Total Not At Risk & 104 & 102 & 89 & 100 & 92 \\
\hline Total Watersheds & 260 & 260 & 260 & 260 & 260 \\
\hline
\end{tabular}

\section{Invasive Plant Species Introduction into Riparian Areas}

The risk of invasive plant species being introduced into riparian habitats as an inadvertent result of timber harvesting activities would vary with: the widths of riparian management areas or riparian reserves; management direction within riparian areas; and levels of timber harvesting activities within riparian areas. These factors affect the light levels in riparian areas: the higher the light levels, the higher the risk for the introduction of invasive plant species (see the Invasive Plants section in Chapter 3).

Under the PRMP, the exclusion of thinning adjacent to streams would result in light levels in riparian areas that would remain at or decrease from current levels. Under the PRMP, the light levels in riparian areas would be the lowest of all alternatives because of the exclusion of thinning and silvicultural treatments adjacent to streams. Also, under the PRMP, the width of the riparian management areas would ensure that regeneration harvest would not occur within one site-potential tree-height distance of perennial and fishbearing streams or one-half site-potential tree-height distance of intermittent, non-fish-bearing streams. The PRMP is the only alternative that would exclude these areas from thinning and silvicultural treatments.

Under the No Action Alternative and Alternative 1, the light levels in riparian areas would be higher than under the PRMP, because these two alternatives would not exclude thinning along streams. However, postharvest light levels in riparian areas under the No Action Alternative and Alternative 1 would be lower than under Alternatives 2 and 3 because of the broader widths of the riparian reserves and riparian management areas under the No Action Alternative and Alternative 1.

Post-harvest light levels in riparian areas under Alternatives 2 and 3 would be higher than under all other alternatives, because the widths of the riparian management areas would be narrower, and Alternatives 2 and 3 would not exclude thinning along streams. The analytical assumption for the risk of introducing invasive plant species along intermittent streams under Alternatives 2 and 3 is that the light levels for riparian areas associated with these streams would mimic the levels in surrounding timber harvest units. This is due to the width of the riparian management areas along most intermittent streams under Alternatives 2 and 3 , which would result in regeneration harvest (and the increase in light from such harvest) closer to streams than under the other alternatives.

The highest overall susceptibility for introduction of invasive plants into riparian habitats associated with timber management activities over the next 10 years would occur under Alternative 2 compared to the other alternatives. Under the No Action Alternative and Alternatives 1 and 3, there would be an intermediate susceptibility (lower than under Alternative 2 and higher than under the PRMP) for the introduction of invasive plants into riparian habitats associated with timber management activities over the next 10 years. Under the PRMP, there would be no measurable susceptibility for the introduction of invasive plants into 
riparian habitats associated with timber management activities over the next 10 years, because the exclusion of thinning and silvicultural treatments along streams would prevent an increase in light from current conditions within riparian areas.

See Figure 4-76 (Susceptibility comparison for the introduction of invasive plants species into riparian habitats associated with timber harvesting activities over the next 10 years) and Table 4-47 (Susceptibility comparison for introduction of invasive plant species into riparian habitats associated with timber harvesting activities in the fifth-field watersheds over the next 10 years) for a comparison of the relative susceptibility among the alternatives.

Figure 4-76. Susceptibility Comparison For The Introduction Of Invasive Plant Species Into Riparian Habitats Associated With Timber Harvesting Activities Over The Next 10 Years

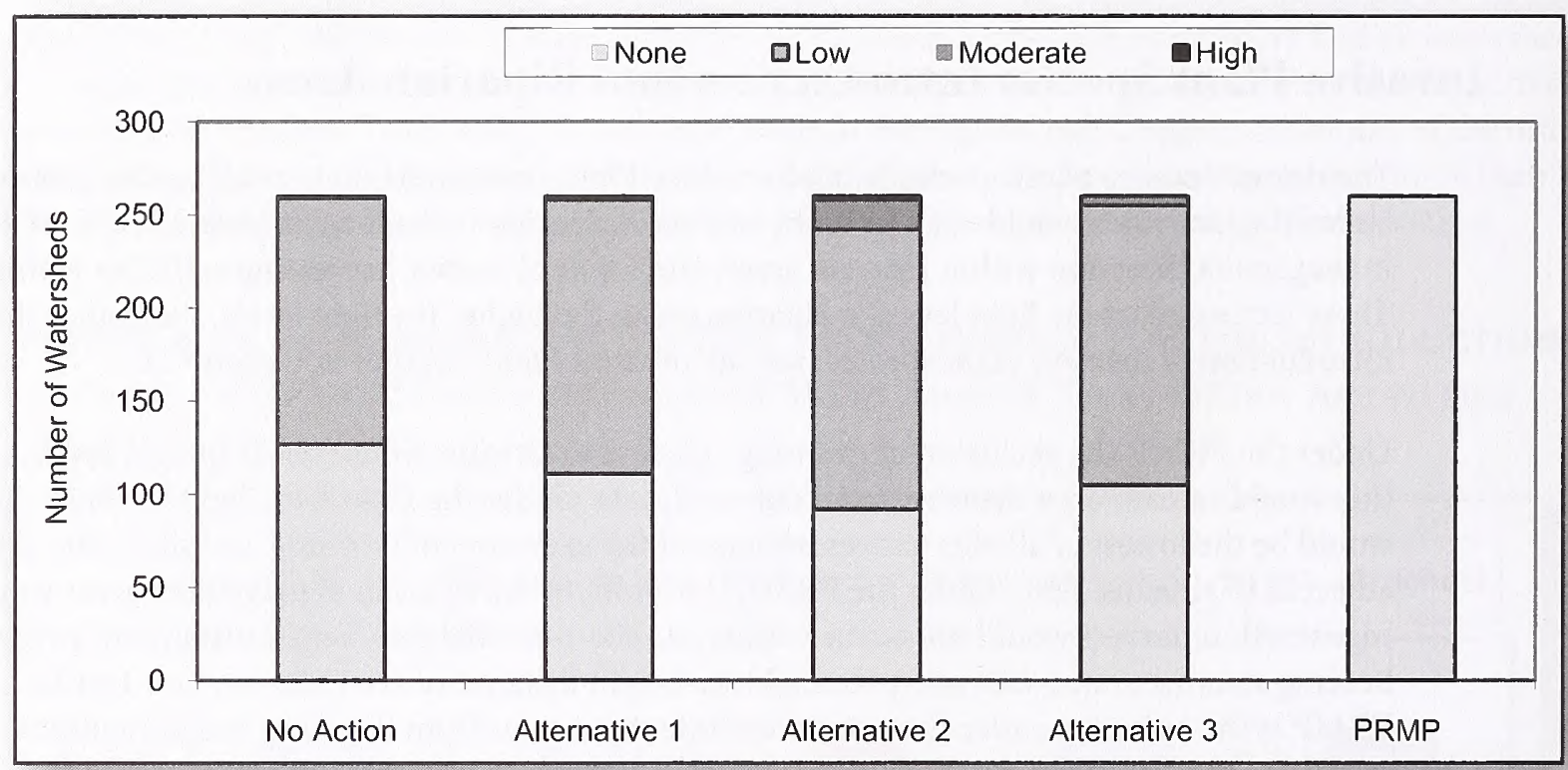

Table 4-47. Susceptibility Comparison For The Introduction Of Invasive Plant Species Into Riparian Habitats That Are Associated With Timber Harvesting In The Fifth-Field Watersheds Over The NeXt 10 Years

\begin{tabular}{|c|c|c|c|c|c|}
\hline Susceptibility & No Action & Alt.1 & Alt. 2 & Alt. 3 & PRMP \\
\hline Post-thinning light levels & lower & lower & higher & higher & lowest \\
\hline $\begin{array}{l}\text { Widths of riparian reserves or riparian } \\
\text { management areas }\end{array}$ & broadest & broader & narrower & narrower & broader \\
\hline $\begin{array}{l}\text { Thinning and silvicultural treatment } \\
\text { exclusion areas }\end{array}$ & no & no & no & no & yes \\
\hline Overall susceptibility & moderate & moderate & highest & next highest & least \\
\hline Low & 132 & 147 & 150 & 150 & 0 \\
\hline Total Susceptible & 133 & 149 & 166 & 155 & 0 \\
\hline Total Not Susceptible & 127 & 111 & 94 & 105 & 260 \\
\hline Total Watersheds & 260 & 260 & 260 & 260 & 260 \\
\hline
\end{tabular}


The highest overall risk of the introduction of invasive plant species into riparian habitats that are associated with timber harvesting activities over the next 10 years would occur under Alternative 2, because there would be narrower riparian management areas under Alternative 2 than under the No Action Alternative, Alternative 1, or the PRMP. The most acres of regeneration harvest in or near riparian areas over the next 10 years would occur under Alternative 2 compared to the other alternatives See Appendix G - Invasive Plants for methodology used in determination of risks.

The second highest risk of introducing invasive plants into riparian areas over the next 10 years would occur under Alternative 3. This risk is based on establishment of the narrowest riparian management areas under Alternative 3 of all alternatives, and also the relatively high number of acres of thinning and partial harvests adjacent to riparian areas that would occur under Alternative 3 over the next 10 years.

The second lowest risk of introducing invasive plants into riparian areas over the next 10 years would occur under the No Action Alternative, compared to the other alternatives because the broadest riparian reserves would be established under the No Action Alternative of all alternatives and because of the relatively fewer acres of timber harvest activities within riparian areas that would occur under the No Action Alternative.

Under the PRMP, there would be no measurable risk of introducing invasive plant species into riparian areas as an inadvertent result of timber harvesting over the next 10 years, because the exclusion of thinning and silvicultural treatments along streams would prevent an increase in light within riparian areas. In addition, because there would be no thinning in the exclusion areas, there would be no harvest activities that would bring in invasive plant seed or plant parts into the riparian areas. There would be some risk of introducing invasive plant species into riparian areas as an inadvertent result of other actions related to timber harvesting, such as tree felling for safety and operational reasons. However, the resultant risk of such potential invasive plant species introductions would be highly localized and cannot be discerned at this scale of analysis.

The risk of introducing invasive plant species into riparian habitats is shown in Figure 4-77 (Relative risk of introducing invasive plant species in riparian habitats over the next 10 years) and based on riparian susceptibility values and invasive plant species distribution. The risk comparison for invasion into riparian habitats among the alternatives is presented in Figure 4-78 (Riparian risk category comparison for the introduction of invasive plant species over the next 10 years) and Table 4-48 (Risk comparison for introduction of invasive plant species into riparian habitats associated with timber harvesting in the fifth-field watersheds over the next 10 years)

Table 4-48. Risk Comparison For The Introduction Of Invasive Plant Species Into Riparian Habitats Associated With Timber Harvesting In The Fifth-Field Watersheds Across The Alternatives Over The Next 10 Years

\begin{tabular}{|c|c|c|c|c|c|}
\hline Risk Ranking & No Action & Alt. 1 & Alt. 2 & Alt. 3 & PRMP \\
\hline Highest to Moderately High & 1 & 5 & 18 & 5 & 0 \\
\hline Moderate to Moderately Low & 129 & 140 & 145 & 148 & 0 \\
\hline Low & 3 & 4 & 5 & 2 & 0 \\
\hline Total at Risk & 133 & 149 & 168 & 155 & 0 \\
\hline Total Not at Risk & 127 & 111 & 92 & 105 & 260 \\
\hline Total Watersheds & 260 & 260 & 260 & 260 & 260 \\
\hline
\end{tabular}


Figure 4-77. Relative Risk Of Introducing Invasive Plant Species In Riparian Habitats Over The Next 10 Years
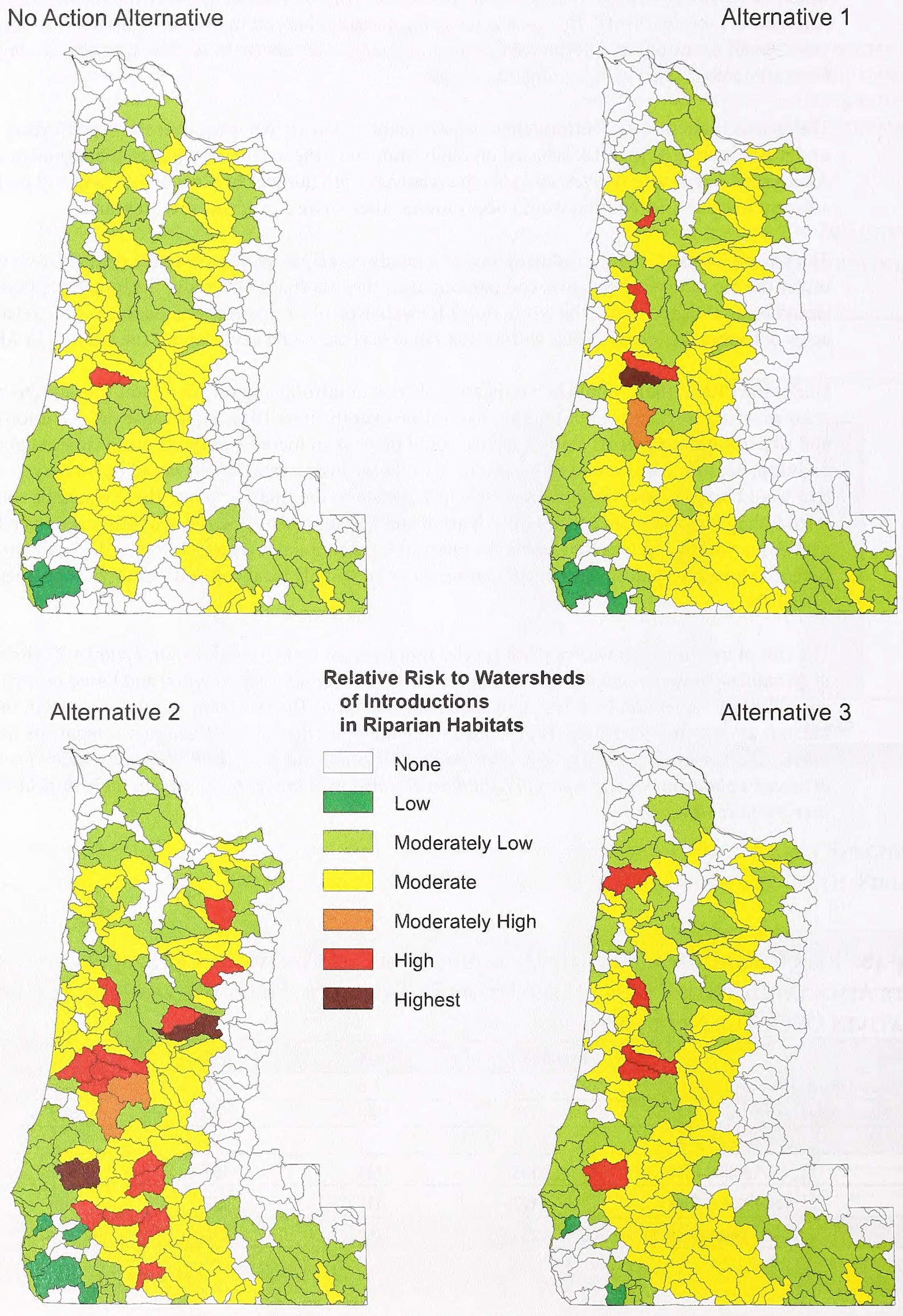


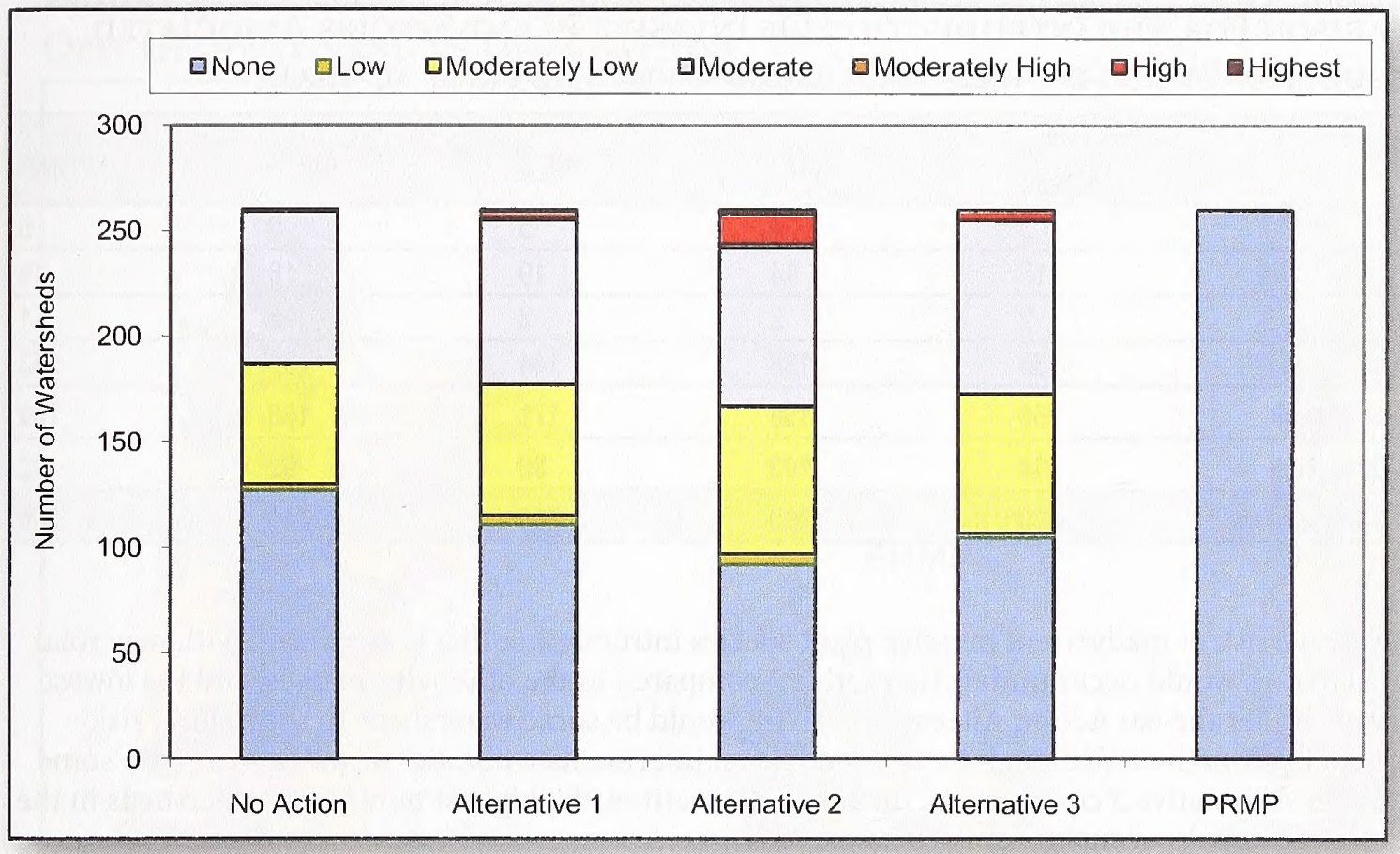

FIGURE 4-78.

RIPARIAN RISK

Category

COMPARISON FOR

INTRODUCTION OF

InVASIVE PLANT

Species Over the

NeXt 10 Years

\section{Invasive Plant Species Introduction Associated with New Road Construction}

This analysis uses levels of new road construction associated with timber harvesting activities over the next 10 years to compare the relative risk of invasive plant introduction associated with road construction across the alternatives.

See Figure 4-79 and Table 4-49 (Risk comparison for the introduction of invasive plant species associated with new road construction over the next 10 years) for the risk comparison for the introduction of invasive plant species into fifth-field watersheds as a result of new road construction activities among the alternatives. See Appendix $G$-Invasive Plants for methodology used in determining risks. .

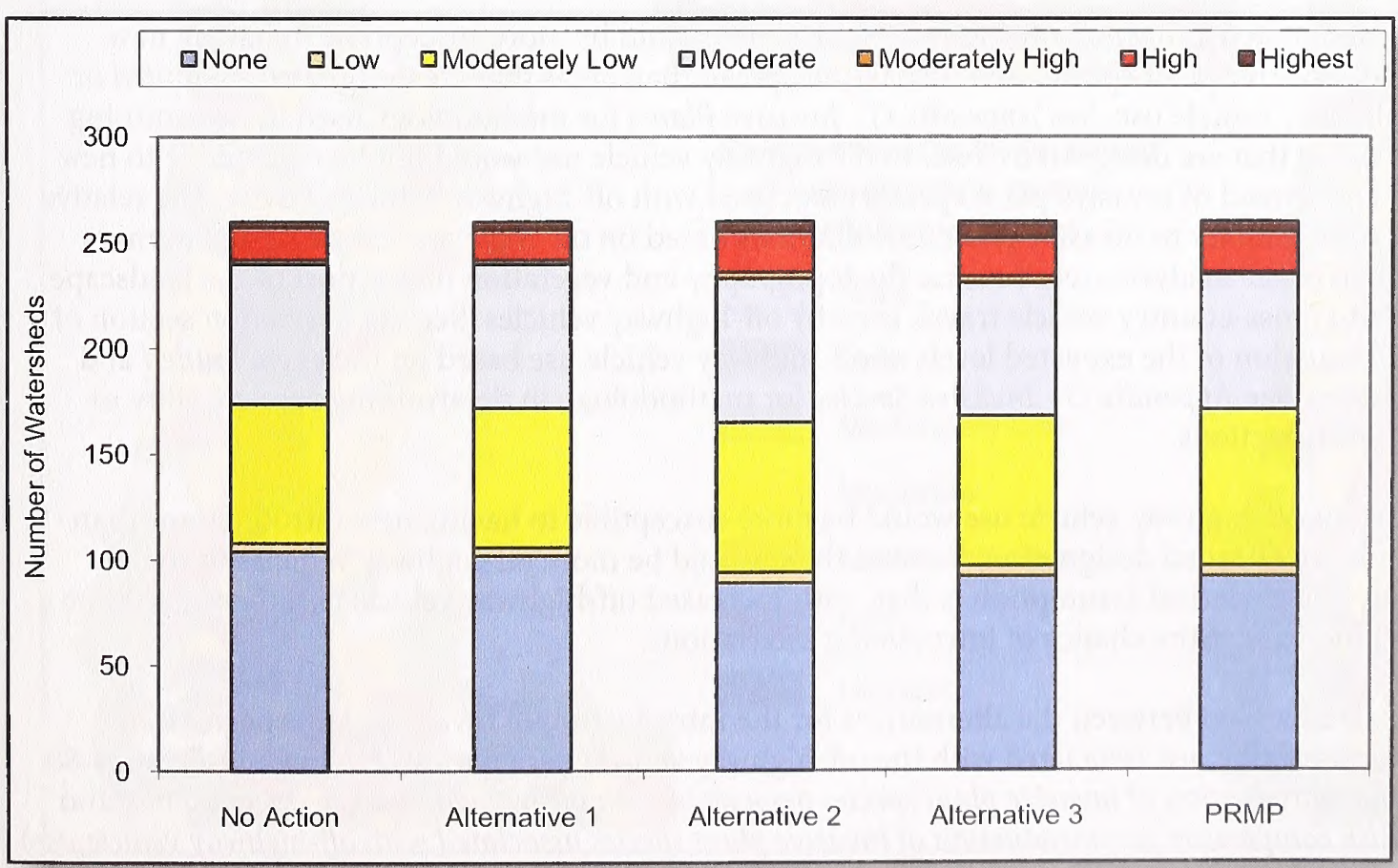

FiguRE 4-79. RISK COMPARISON FOR The INTRODUCTION Of Invasive Plant Species Associated WiTH NEW ROAD Construction Over The Next 10 Years 
Table 4-49. Risk Comparison For The Introduction Of Invasive Plant Species Associated With New Road Construction By Fifth-Field Watershed Over The Next 10 Years

\begin{tabular}{|c|c|c|c|c|c|}
\hline Risk Ranking & $\begin{array}{r}\text { No } \\
\text { Action }\end{array}$ & Alt. 1 & Alt. 2 & Alt. 3 & PRMP \\
\hline Highest & 3 & 4 & 5 & 8 & 5 \\
\hline High & 15 & 14 & 19 & 18 & 19 \\
\hline Moderately high & 2 & 2 & 3 & 3 & 1 \\
\hline Moderate or lower & 136 & 138 & 144 & 139 & 143 \\
\hline Total at Risk & 156 & 158 & 171 & 168 & 168 \\
\hline Total Not at Risk & 104 & 102 & 89 & 92 & 92 \\
\hline Total Watersheds & 260 & 260 & 260 & 260 & 260 \\
\hline
\end{tabular}

The greatest relative risk of inadvertent invasive plant species introduction that is associated with new road construction activities would occur under Alternative 2 compared to the other alternatives, and the lowest risk would occur under the No Action Alternative. There would be some watersheds in the highest risk category under all alternatives. Although there would be an intermediate number of watersheds with some level of risk under Alternative 3 compared to the other alternatives, the highest number of watersheds in the highest risk category would occur under Alternative 3.

Although the most new road construction would occur under the PRMP compared to the other alternatives, there would be an intermediate number of total watersheds at risk of invasive plant introduction among the alternatives and an intermediate number of individual fifth-field watersheds in the highest risk ranking over the next 10 years under the PRMP. These results indicate that the combination of estimated timber harvest activities and associated new road construction in fifth-field watersheds under the PRMP would result in a lower risk of introducing invasive plants into the affected fifth-field watersheds than would occur under Alternatives 2 and 3 over the next 10 years, and a greater risk than would occur under the No Action Alternative or Alternative 1.

\section{Invasive Plant Species Introduction Associated with Off-Highway Vehicle Use}

There would be little difference among the alternatives in the relative risk for introduction of invasive plant species associated with off-highway vehicle use.

Areas that are designated as open to off-highway vehicle use would be more susceptible to having new introductions of invasive plant species and infestation spread than areas that are designated as limited or closed to off-highway vehicle use. See Appendix G - Invasive Plants for methodology used in determining susceptibility. Areas that are designated closed to off-highway vehicle use would not be susceptible to new introductions and spread of invasive plant species associated with off-highway vehicle activity. The relative differences in susceptibility to invasive plant introductions based on off-highway vehicle designations is minor over much of the analysis area, because the topography and vegetation make most of the landscape non-conducive to cross-country vehicle travel, even by off-highway vehicles. See the Recreation section of Chapter 4 for discussion of the expected levels of off-highway vehicle use based on the open, limited and closed designations. See Appendix G - Invasive Species for methodology in determining susceptibility to invasive plant introductions.

Emphasis areas for off-highway vehicle use would be more susceptible to having new introductions than other areas under the limited designation, because there would be more off-highway vehicles in the emphasis areas. The analytical assumption is that, with increased off-highway vehicle use, there would be a corresponding increase in the chance of introducing infestations.

A relative risk comparison between the alternatives for the introduction of invasive plant species into fifth-field watersheds that are associated with the off-highway vehicle designations is shown in Figure 4-80 (Relative risk for introduction of invasive plant species associated with off-highway vehicle designations) and Figure 4-81 (Risk comparison for introduction of invasive plant species associated with off-highway vehicle use) 
Figure 4-80. Relative Risk For Introduction Of Invasive Plant Species Associated With OfF- Highway Vehicle Designations

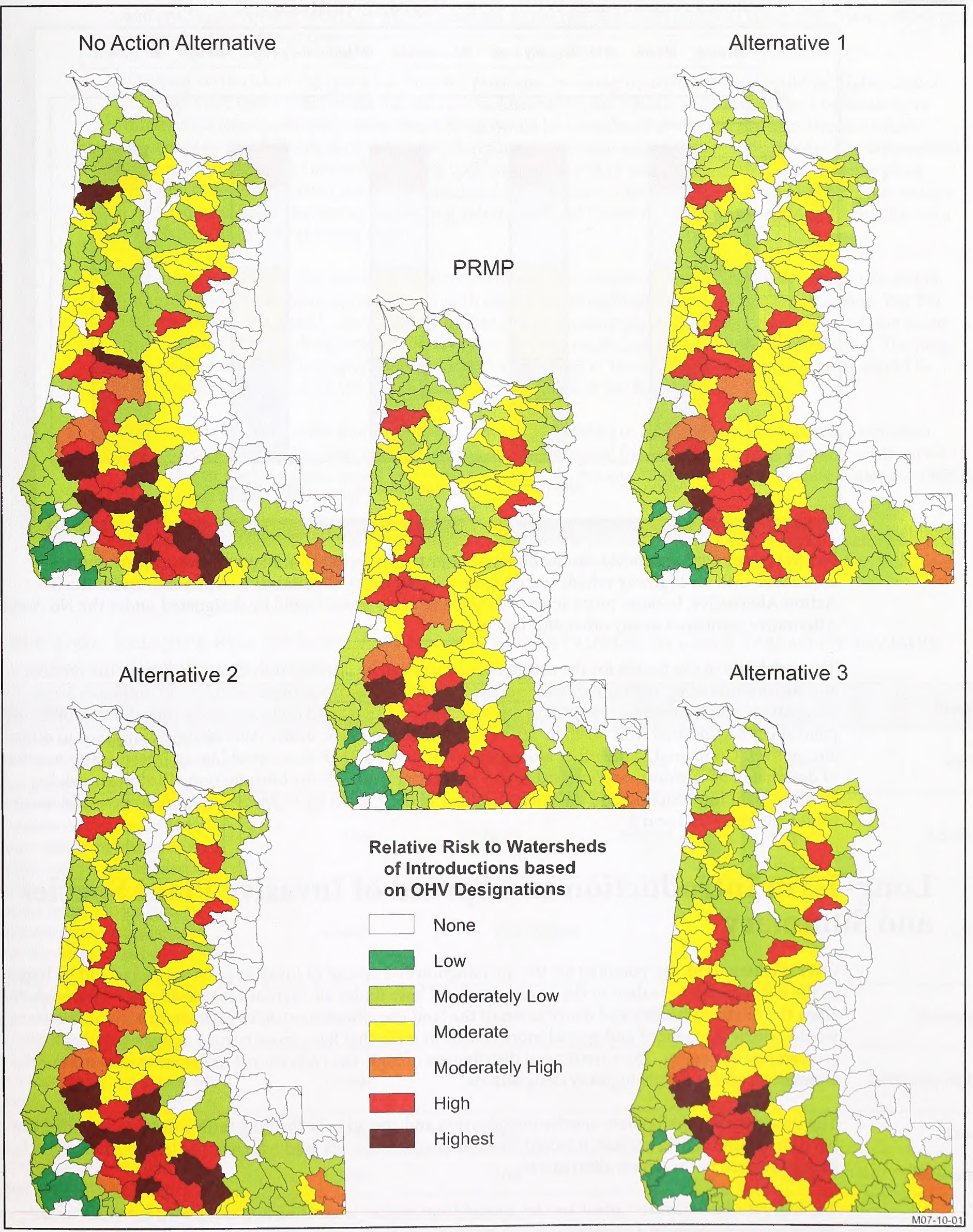


Figure 4-81. Risk Comparison For Introduction Of Invasive Plant Species Associated With Off-Highway Vehicle Use

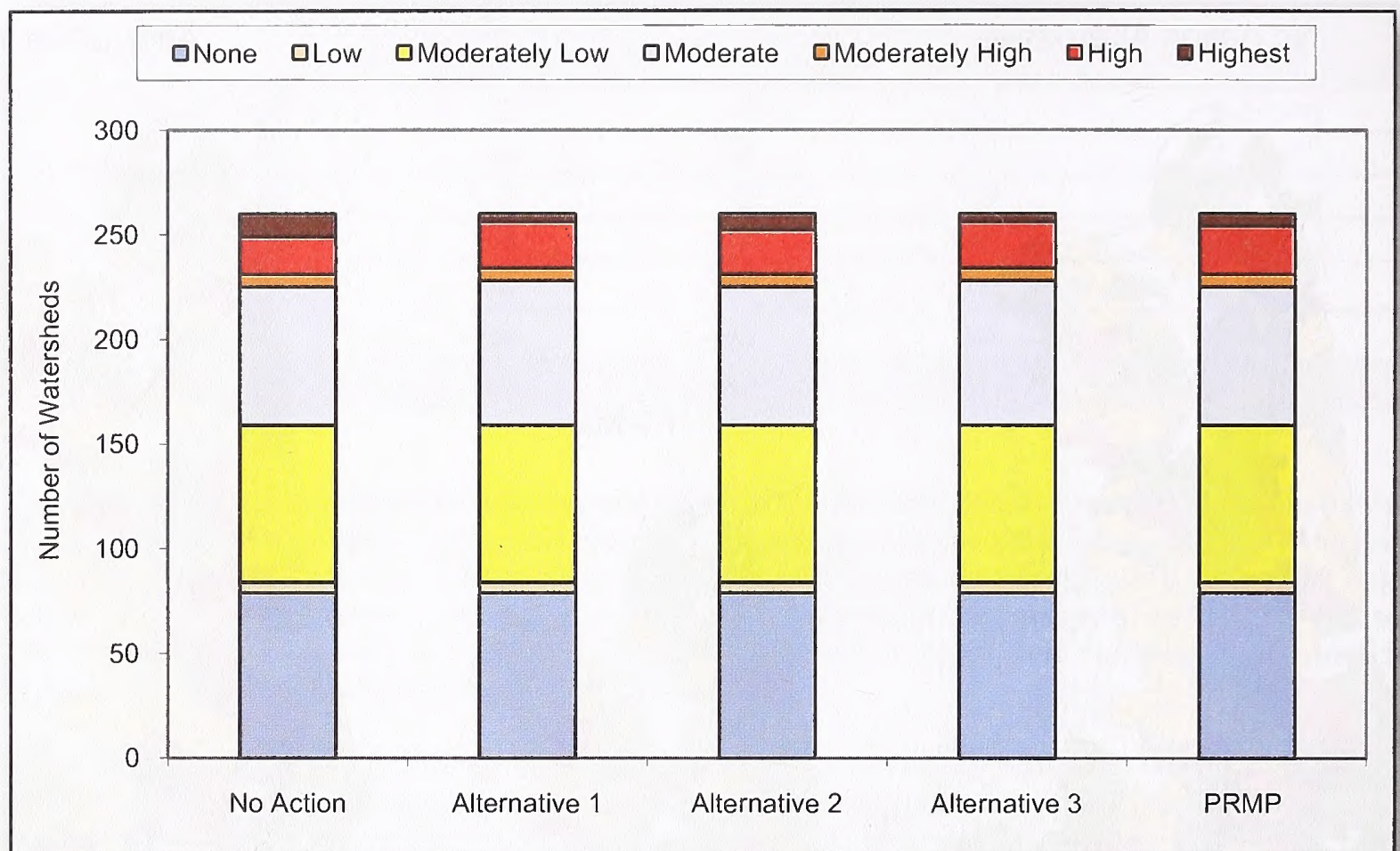

The most fifth-field watersheds in the highest risk category for introduction of invasive plant species associated with off-highway vehicle use compared to the other alternatives would occur under the No Action Alternative, because more acres open and less acres closed would be designated under the No Action Alternative compared to any other alternative.

The variability in the results for the action alternatives can be attributed to the variability in the number and distribution of off-highway emphasis areas. Under Alternative 2, there would be 17 emphasis areas designated, which would be the most of any alternative. The second highest risk for introduction of invasive plant species associated with off-highway vehicle use would occur under Alternative 2 compared to other alternatives. Compared to the other alternatives, under the PRMP there would be an intermediate number of designated off-highway emphasis areas and an intermediate risk for introduction. The lowest risk for invasive plant introduction and the lowest number of designated off-highway emphasis areas would occur under Alternatives 1 and 3.

\section{Long-Term Introduction and Spread of Invasive Plant Species and Summary}

Over the long term, the potential for the introduction and spread of invasive plant species would be higher in the harvest land base than in the nonharvest land base under all alternatives. See Chapter 2 for maps that show the relative amounts and distribution of the land use allocations under each alternative. Infestations would also be introduced and spread more readily in areas that have more human activity (such as high recreational use areas). The amount and distribution of high-use recreational use areas would not vary by alternative, except for off-highway designations.

The least risk of invasive plant species introduction and spread over the long term would occur under the No Action Alternative, because it would have the smallest harvest land base and the largest nonharvest land base compared to the action alternatives.

The highest risk of invasive plant species spread from timber harvesting and associated activities would occur under Alternative 3 compared to the other alternatives over the long term, even though under 
Alternative 2 there would be a higher risk over the next 10 years. The highest risk in the long term would occur under Alternative 3, which would have the largest harvest land base, and because timber harvesting and road construction would be more dispersed across the BLM-administered lands with Alternative 3 than under the other alternatives.

The long-term risk of the spread of invasive plant species along riparian habitats would be higher under Alternatives 2 and 3 than under the No Action Alternative, the PRMP, and Alternative 1 because more infestations associated with timber harvesting would be introduced along intermittent streams under Alternatives 2 and 3 with their narrower riparian management areas widths along most of the intermittent streams. Although the timber harvesting itself under the PRMP would create no risk of invasive plant introductions into riparian areas, the associated road construction and level of road use and maintenance expected to support the timber harvesting activities would create risk for invasive plant introduction into riparian habitats over the long term.

The long-term risk of the spread of invasive plant species associated with off-highway vehicle use would be similar among all alternatives, except with regard to off-highway emphasis area designations. The No Action Alternative would have a slightly higher risk of invasive plant introductions and spread due to the more acres with open designations and fewer acres designated closed to off-highway vehicle use. The longterm risk of invasive plant species introduction and spread in the off-highway emphasis areas would be consistently higher than in the surrounding areas because of the higher level of use.

When the effects of timber harvesting activities are considered in combination with the effects of road construction and off-highway vehicle use, the overall potential for introduction and spread over the next 10 years and in the long term would be lowest under the No Action Alternative, intermediate under the PRMP, and highest under Alternative 3.

A relative risk comparison between the alternatives for the introduction of invasive plant species over both the long and short term is shown in Table 4-50 (Relative risk of long and short-term introduction and spread of invasive plant species by analysis factor).

Table 4-50. Relative Risk Of Long And Short-Term Introduction And Spread Of Invasive Plant Species By Analysis Factor

\begin{tabular}{|c|c|c|c|c|c|}
\hline Risk Analysis Factor & $\begin{array}{r}\text { No } \\
\text { Action } \\
\end{array}$ & Alt. 1 & Alt. 2 & Alt. 3 & PRMP \\
\hline $\begin{array}{l}\text { Number of highest and high risk fifth- } \\
\text { field watersheds from timber harvest } \\
\text { activities over the next } 10 \text { years. }\end{array}$ & Low & Moderate & Highest & Lowest & High \\
\hline $\begin{array}{l}\text { Number of highest and high risk fifth- } \\
\text { field watersheds for introduction into } \\
\text { riparian habitats from timber harvest } \\
\text { activities over the next } 10 \text { years. }\end{array}$ & Low & Moderate & Highest & Moderate & Lowest \\
\hline $\begin{array}{l}\text { Number of fifth-field watersheds } \\
\text { assigned risk categories from new } \\
\text { road construction associated with } \\
\text { timber harvest activities over the next } \\
10 \text { years. }\end{array}$ & Lowest & Low Highest & & High & High \\
\hline $\begin{array}{l}\text { Introduction into fifth-field watersheds } \\
\text { associated with off-highway vehicle } \\
\text { use (long and short term). }\end{array}$ & Highest & Low & High & Low & Moderate \\
\hline $\begin{array}{l}\text { Long-term introduction associated } \\
\text { with timber harvest and associated } \\
\text { activities. }\end{array}$ & Lowest & Low & High & Highest & Moderately High \\
\hline $\begin{array}{l}\text { Long-term introduction and spread } \\
\text { along riparian habitats. }\end{array}$ & Lowest & Low & High & Highest & Low \\
\hline $\begin{array}{l}\text { Overall potential to introduce and } \\
\text { spread invasive plant species. }\end{array}$ & Lowest & Low & High & Highest & Moderate \\
\hline
\end{tabular}


All alternatives include management direction to "prevent, detect, and rapidly control new invasive plant infestations." This management direction is general in nature, as is appropriate to the scope and scale of this action. More specific measures to prevent the introduction of new infestations may be incorporated in the planning and design of implementation-level actions. These specific measures may include, but are not limited to, the following:

- Use cable or aerial logging methods in fifth-field watersheds that are at high risk for the introduction of invasive plant species.

- Clean vehicles and heavy equipment that would operate off roads and in the rights-of-way. In infested areas, where the transport of invasive plant species seeds or propagules on heavy equipment is likely, clean the heavy equipment before leaving the project site, except in emergency situations.

- Use sterile material or native species weed-free straw and mulch.

- Use native plant species to promote competitive exclusion of invasive plant species.

- Consistent with project objectives, retain native vegetation in and around project locations and minimize soil disturbance. 


\section{Wildlife}

\section{Key Points}

Northern Spotted Owl:

Between 2006 and 2056:

- Under the No Action Alternative, Alternative 1, and the PRMP, habitat development on BLM-administered lands would contribute sufficiently to the development, distribution and spacing of large blocks of suitable spotted owl habitat, with the exception of spacing between large habitat blocks on either side of the Klamath-Coast Range provincial boundary.

- Under Alternative 2, habitat development on BLM-administered lands would not contribute sufficiently to the distribution and spacing of large habitat blocks.

- Under Alternative 3, habitat development on BLM-administered lands would not contribute sufficiently to the spacing of large habitat blocks

- Habitat conditions that facilitate spotted owl movement and survival would improve under all alternatives. In parts of the planning area, the distribution of BLM-administered lands is insufficient to achieve adequate dispersal conditions under any alternative.

- The acres of spotted owl suitable habitat in the low and mixed fire severity regimes, and the acres of fire-resilient habitat, would increase under the No Action Alternative, and decrease under Alternatives 1,2 and 3. Under the PRMP, the acres of spotted owl suitable habitat in the low and mixed fire severity regimes would decrease in the northern portion of the planning area and increase in the southern portion of the planning area; the acres of fire-resilient habitat would increase.

- The number of functional northern spotted owl nest territories would increase from current conditions under all alternatives.

\section{Marbled Murrelet and Other Wildlife:}

- Marbled murrelet nesting habitat on BLM-administered lands would increase under all alternatives. Under the PRMP, the quantity of marbled murrelet nesting habitat would increase $60 \%$ on BLM-administered lands, compared to the 68 and $93 \%$ increases that would occur under Alternative 1 and the No Action alternative.

- The mean patch size of mature \& structurally complex forest would increase from 111 acres to 338 acres under the No Action Alternative and to 176 acres under the PRMP in the Coast Range, and from 137 acres to 199 and 152 acres under the No Action Alternative and the PRMP, respectively, in the Klamath Province. The increases in patch size and total nesting habitat would be indicative of an increase in overall marbled murrelet nesting habitat condition.

- The No Action and PRMP would retain $99 \%$ of all marbled murrelet nesting habitat greater than 200 years old on BLM-administered lands through 2026.

- Fisher habitat condition would improve under the No Action, Alternative 1, and the PRMP on BLM-administered lands in the Coast Range Province; a result of the increase in the amount of natal habitat coupled with the increase in mean patch size and connectance of mature \& structurally complex forests. Similarly, fisher habitat condition would improve on BLM-administered lands in the Western Cascades Province under the No Action Alternative, on BLM-administered lands in the Klamath province under the PRMP and No Action Alternatives, and on BLM-administered lands in the East Cascades Province under the PRMP.

- The BLM-administered lands would continue to provide adequate hiding cover on deer and elk habitat management areas under all alternatives in the Coos Bay and Salem Districts

- The BLM-administered lands would not meet forage requirements of deer and elk under all alternatives in the habitat management areas in the Medford District and Klamath Falls Resource Areas.

- Within westside conifer forests, land bird habitat quantities would surpass Partners-in-Flight recommendations for old-growth and mature forests on BLM-administered lands, though not on the landscape as a whole. For Partners-in-Flight recommendations on young and earlyseral forests, they would be surpassed on the landscape as a whole, though they would not on BLM-administered lands alone. Due to the small percentage of the landscape managed by the BLM, these statements apply to all alternatives.

- Westside hardwood and eastside conifer land bird habitat quantities would not meet Partners-in-Flight recommendations under any alternative.

- Eastside ponderosa pine, eastside hardwoods, nonforest, and Eastside Management Lands land bird habitat quantities would meet or surpass Partners-in-Flight recommendations under all alternatives.

- For species dependent on mature and structurally complex forest, the principal determining factors on the condition of the entire forested landscape are the development of the U.S. Forest Service reserves into mature and structurally complex forests under current forest plans, and the continued intensive management of the nonfederal forests. These factors are so dominant that BLM has very little ability to influence the outcome to these species one way or the other. 


\section{Northern Spotted Owl}

This analysis examines how BLM-administered lands in the planning area would contribute to the four conservation needs of the northern spotted owl, which are described in Chapter 3 (see Northern Spotted Owl). To accomplish this, the analysis examines the following:

- development, distribution and spacing of large blocks of suitable spotted owl habitat

- quality and distribution of habitat that supports spotted owl movement and survival through and between habitat blocks, including in areas of concern

- development of spotted owl habitat in the low and mixed fire severity regimes, and with fire resiliency

- development of functional spotted owl nest territories

Although, in most instances, the analysis evaluates habitat changes through the year 2106 , it focuses on habitat changes between 2006 and 2056, as this period spans the recovery timeframe suggested by the Final Recovery Plan for the Northern Spotted Owl (USFWS 2008a:36).

Under the Northwest Forest Plan (USDA USDI 1994), which would remain in effect on U.S. Forest Service lands, the federal contribution to large blocks of suitable habitat would be provided by the Late-Successional Reserves and managed Late-Successional Areas, including the Riparian Reserves interspersed with those land use allocations. The Northwest Forest Plan established these land use allocations, in association with existing congressionally reserved areas, to support the formation of large blocks of suitable habitat. The analysis assumes that all forest-capable lands in the U.S. Forest Service Late-Successional Reserves, Administratively Withdrawn, and Congressionally Reserved areas would develop through the structural stages over time, as detailed in Chapter 4 (see Forest Structure and Spatial Pattern). The analysis assumes that all other non-BLM-administered lands would maintain their current abundances and spatial patterns of habitat.

The analysis makes frequent comparisons of the habitat development under the alternatives to habitat development under the No Harvest reference analysis. As explained in Chapter 4 -Introduction, the reference analysis is not a reasonable alternative, because it would not meet the purpose and need for the action. The reference analysis is included to provide additional information that is useful to understand more fully the effects of the alternatives. Specifically in this analysis, the No Harvest reference analysis helps identify where the contribution of BLM-administered lands to achieving northern spotted owl conservation needs is limited or precluded by the land ownership pattern, regardless of the management of BLMadministered lands under the alternatives.

As explained in Chapter 3 (see Forest Structure and Spatial Pattern), the classification of 2006 structural stage and northern spotted owl habitat conditions differ slightly among the alternatives because of differences in how the inventory information is assembled for modeling under each alternative. The classifications for Alternative 2 and the PRMP for 2006 are largely similar, except that the classification for the PRMP resulted in the shift of acreage from "young with structural legacy" to "stand establishment with structural legacy" in the Medford District and the Klamath Falls Resource Area as a result of new growth curves developed for uneven-aged management. The descriptions of current conditions in Chapter 3 (see Forest Structure and Spatial Pattern) use the 2006 data from Alternative 3. However, this section provides conditions for the year 2006, as described for each alternative in the modeling to accurately depict the relative short-term changes in habitat abundance. Although this variability in starting conditions among the alternatives does not prevent a reasonable comparison of the alternatives, the absolute abundance of habitat may not be precisely compared among alternatives, especially for the years 2006 and 2016.

Analysis of habitat conditions in years 2036 and 2046 is included for Alternative 2, the PRMP, and the No Harvest reference analysis to evaluate modifications made to Alternative 2 (which was identified as 
the preferred alternative in the draft EIS) in developing the PRMP. The draft EIS concluded that under Alternative 2, the acreage of suitable habitat outside of large blocks would decrease between 2006 and 2056 and then increase thereafter. The addition of analysis in 2036 and 2046 provides information on the efficacy of the PRMP in modifying the magnitude and timing of the habitat decline that would occur under Alternative 2. Analysis of the No Harvest reference analysis for these years provides context for evaluating the relative difference between habitat development under Alternative 2 and the PRMP. Analyzing the habitat conditions under the No Action Alternative, and Alternatives 1 and 3 for these years would not provide relevant information for evaluating the efficacy of the PRMP in modifying the magnitude and timing of the habitat decline that would occur under Alternative 2.

\section{CONSERVATION NEED 1}

The formation of large blocks of suitable habitat that support clusters of reproducing owls are distributed across a variety of ecological conditions and are spaced to facilitate owl movement between the blocks.

\section{Large Block Formation}

- Would habitat development under the alternative, when supporied by the Congressionally Reserved lands, and the Late-Successional Reserves and managed Late-Successional Areas on U.S. Forest Service lands, contribute to large blocks of suitable habitat to support clusters of reproducing northern spotted owls?

Habitat development under all alternatives would contribute to large blocks of suitable habitat during all decades, but the level of those contributions would differ substantially among the alternatives. Map 3-4 in Chapter 3 shows current large habitat blocks. Figures 4-82 - 4-87 compare how large and small habitat blocks would change under the alternatives.

Figure 4-88 shows changes in number of acres contained within large habitat blocks on all land ownerships, under each alternative and according to the No Harvest reference analysis. As discussed in Chapter 3 (see Northern Spotted $\mathrm{Owl}$ ), not all acres within large habitat blocks support suitable habitat or dispersal habitat. However, each large habitat block contains the minimum quantity and spatial arrangement of suitable habitat needed to support at least 20 breeding pairs of northern spotted owls.

Under the No Action Alternative, the acres contained within large habitat blocks would increase by $9 \%$ through 2026, then, at 2056, exceed the current level by $167 \%$. Under Alternative 1, the acres contained within large habitat blocks would increase slightly through 2026, then at 2056 exceed the current level by $147 \%$. Under Alternative 2, the acres contained within large habitat blocks would decline by $16 \%$ through 2036, remain relatively stable through 2046 and at 2056 exceed the current level by 133\%. Under Alternative 3 , the acres contained within large habitat blocks would decline by $11 \%$ through 2026 , but at 2056 would exceed the current level by $141 \%$. Under the PRMP, the acres contained within large habitat blocks would decline by $9 \%$ through 2036, match the current level by 2046, and then at 2056 exceed the current level by 148\%. See Figure 4-88. 


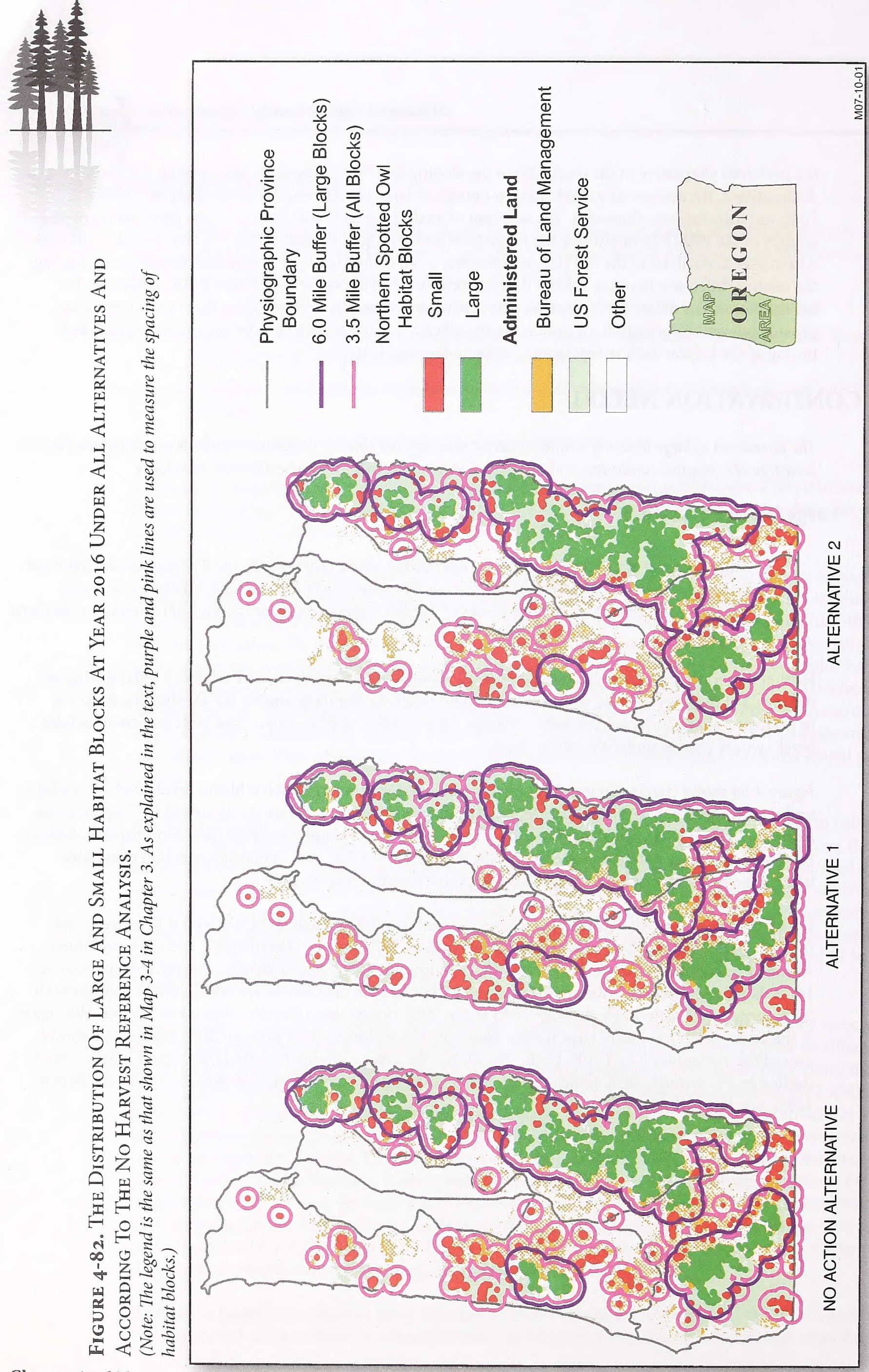




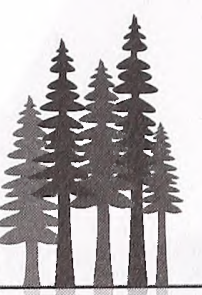

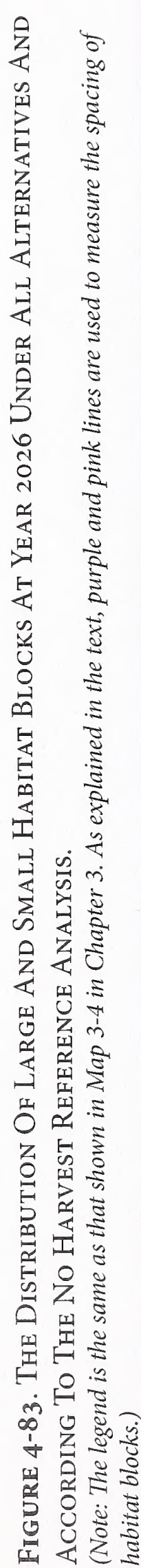
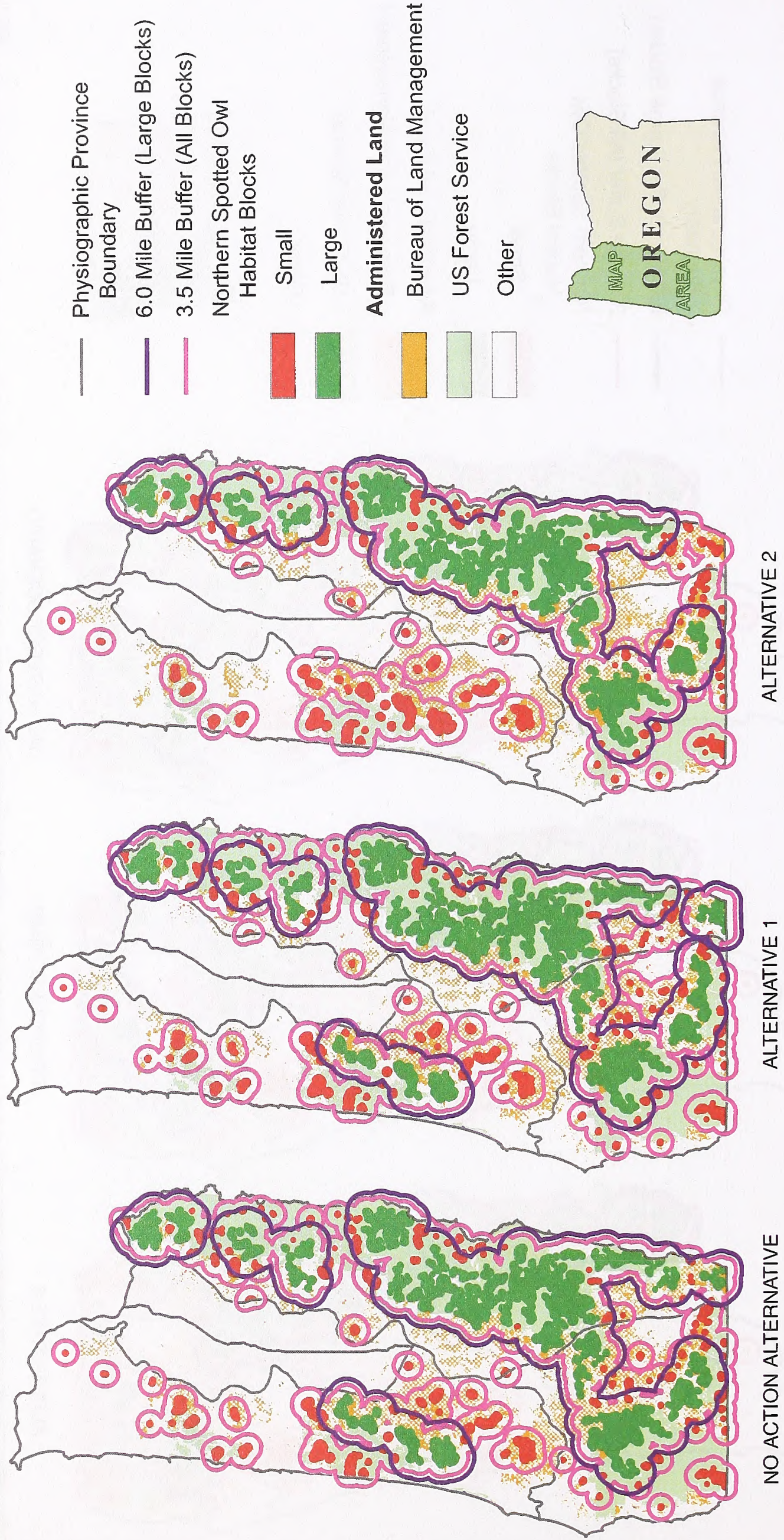


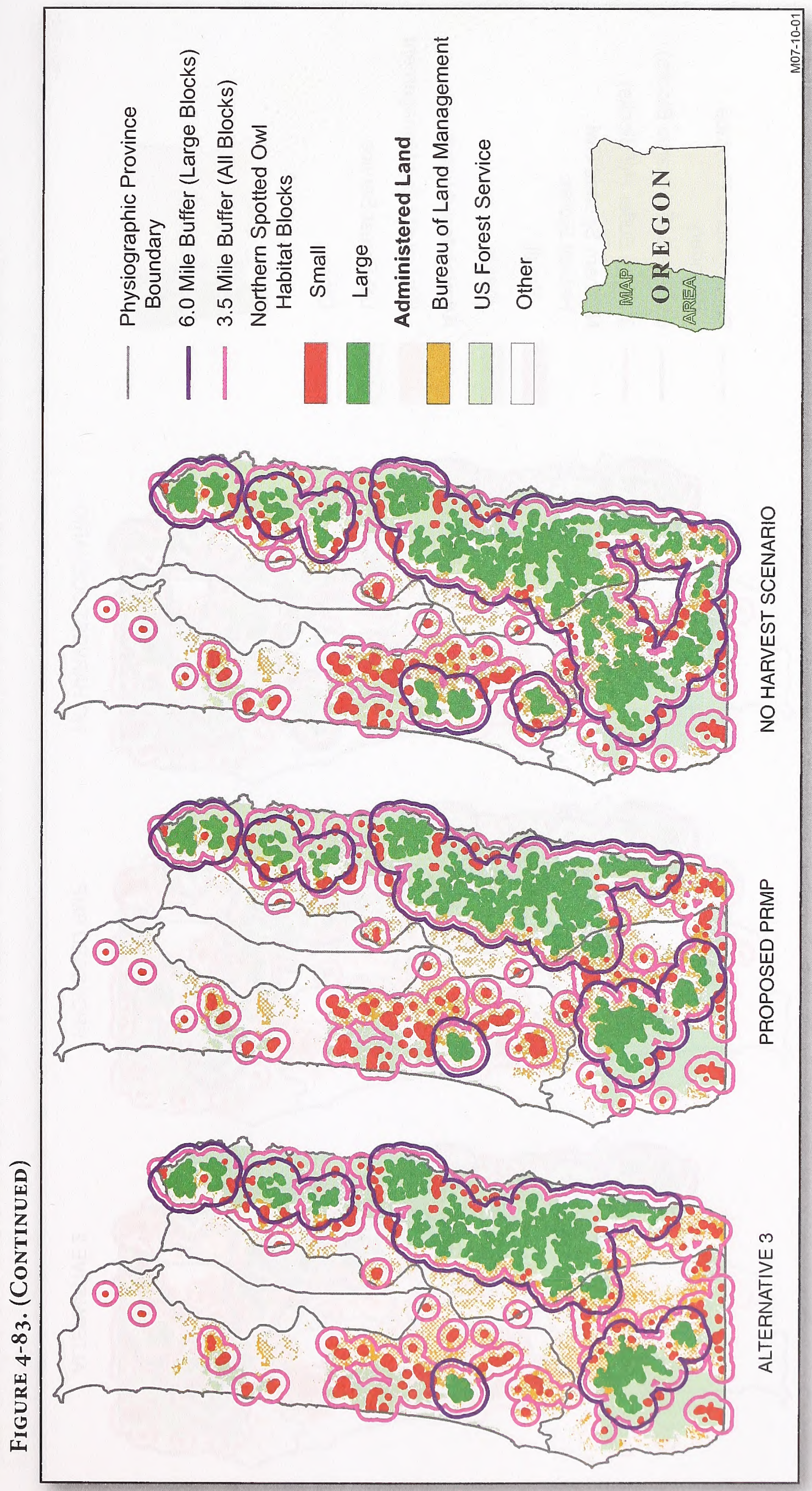




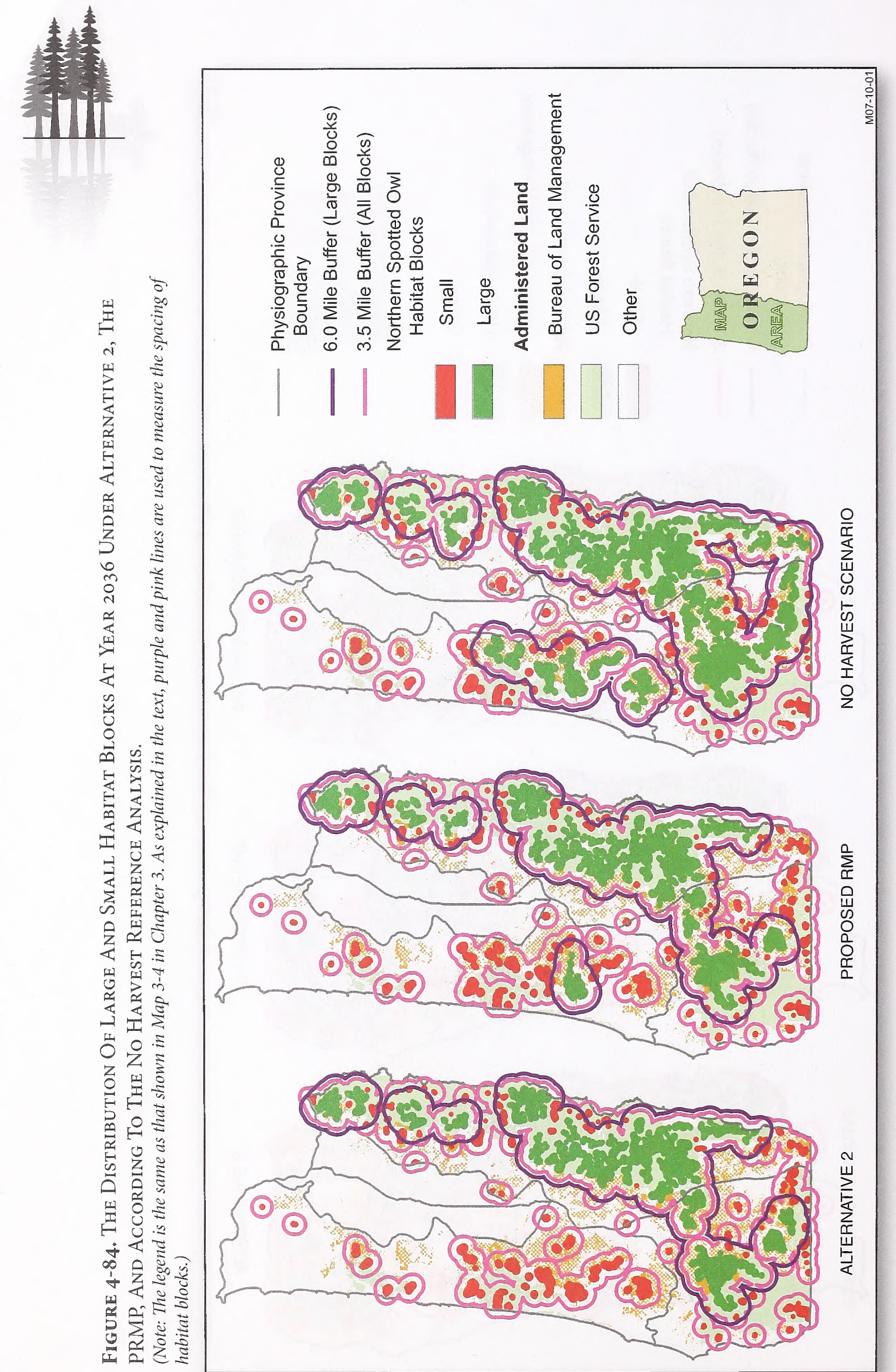




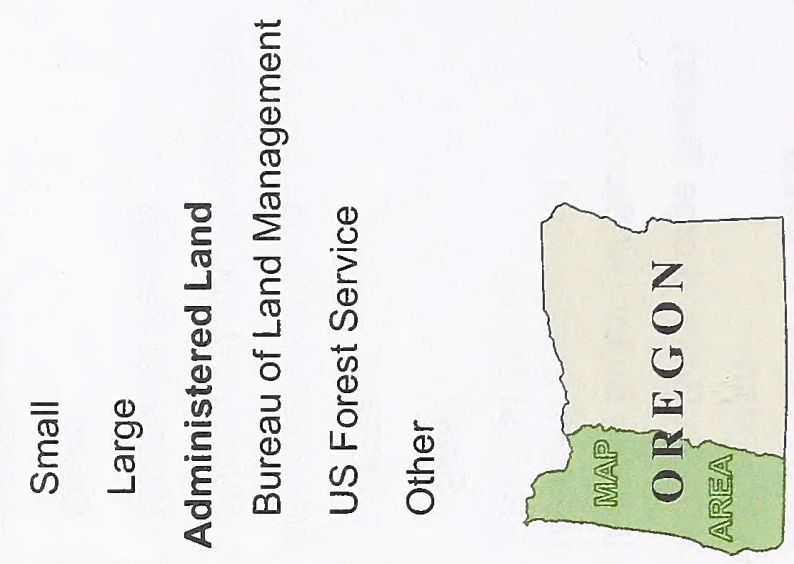

艺

至<smiles>C=CC1CC1</smiles>
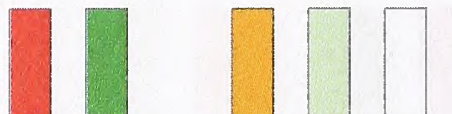

स

是

戦 है

号 @

ㄴํํ

$\approx$ ह

凷

㟧吉

范

0

की $\equiv$

岁

i $\frac{\overrightarrow{0}}{0}$

ए

12

\&

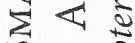

ए ड

z

य $\cong$

덤 됟

$\approx$ 되 क

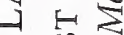

단.

$7 \geq$

논 $\frac{5}{5}$

号芯

尡

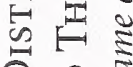

A 0 .

던

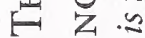

๑ $\frac{2}{2}$

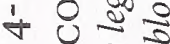

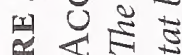

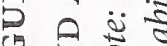

先云造造

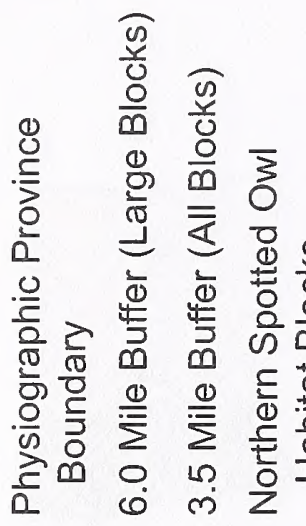
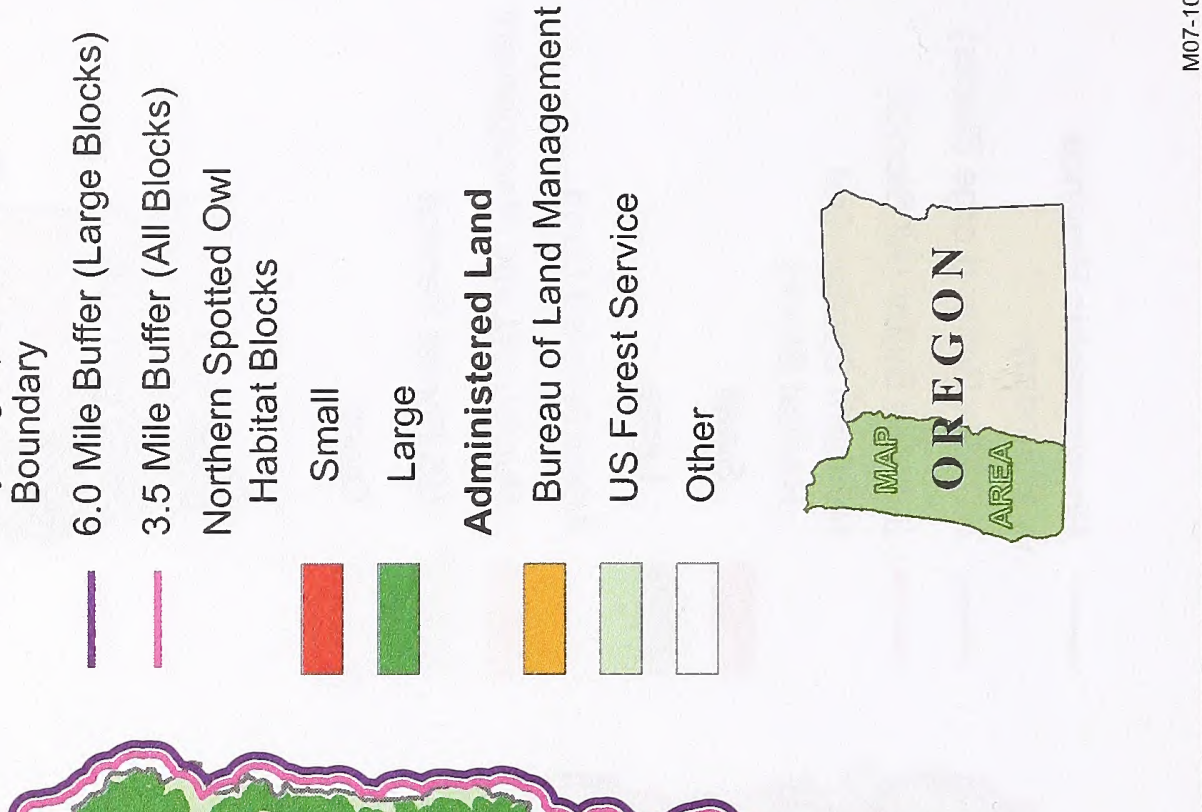

ras
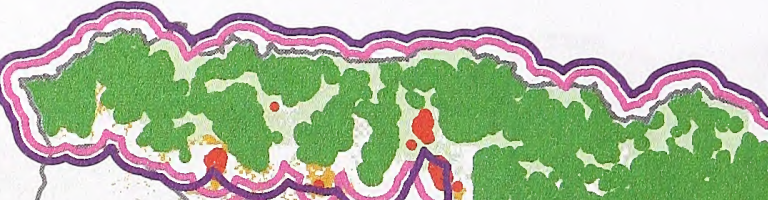

$2 \approx 2$

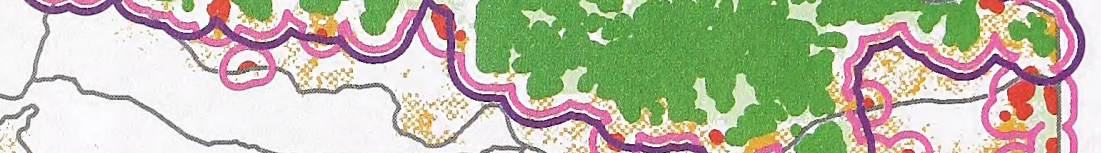

$\stackrel{\sim}{\longrightarrow}$
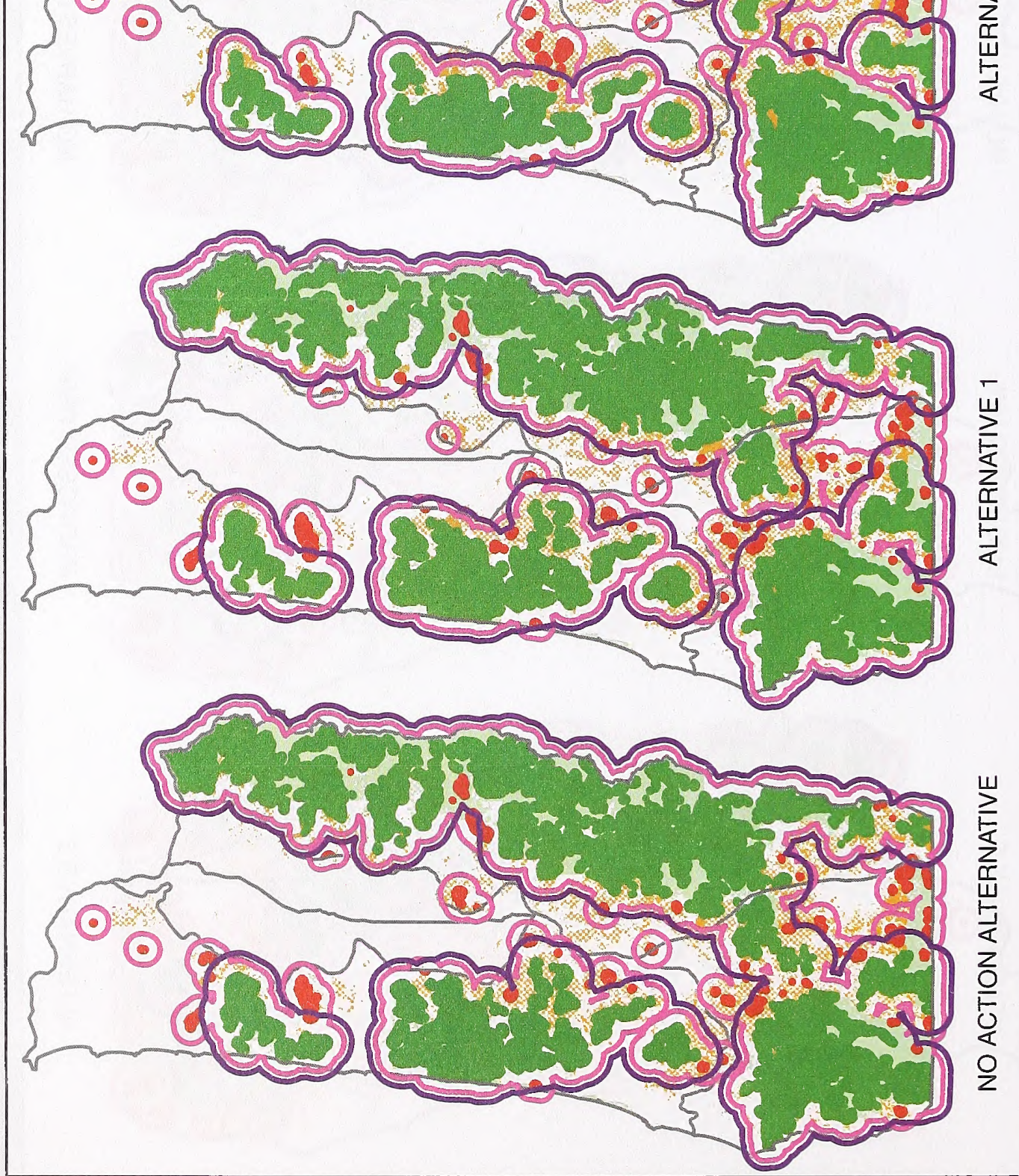


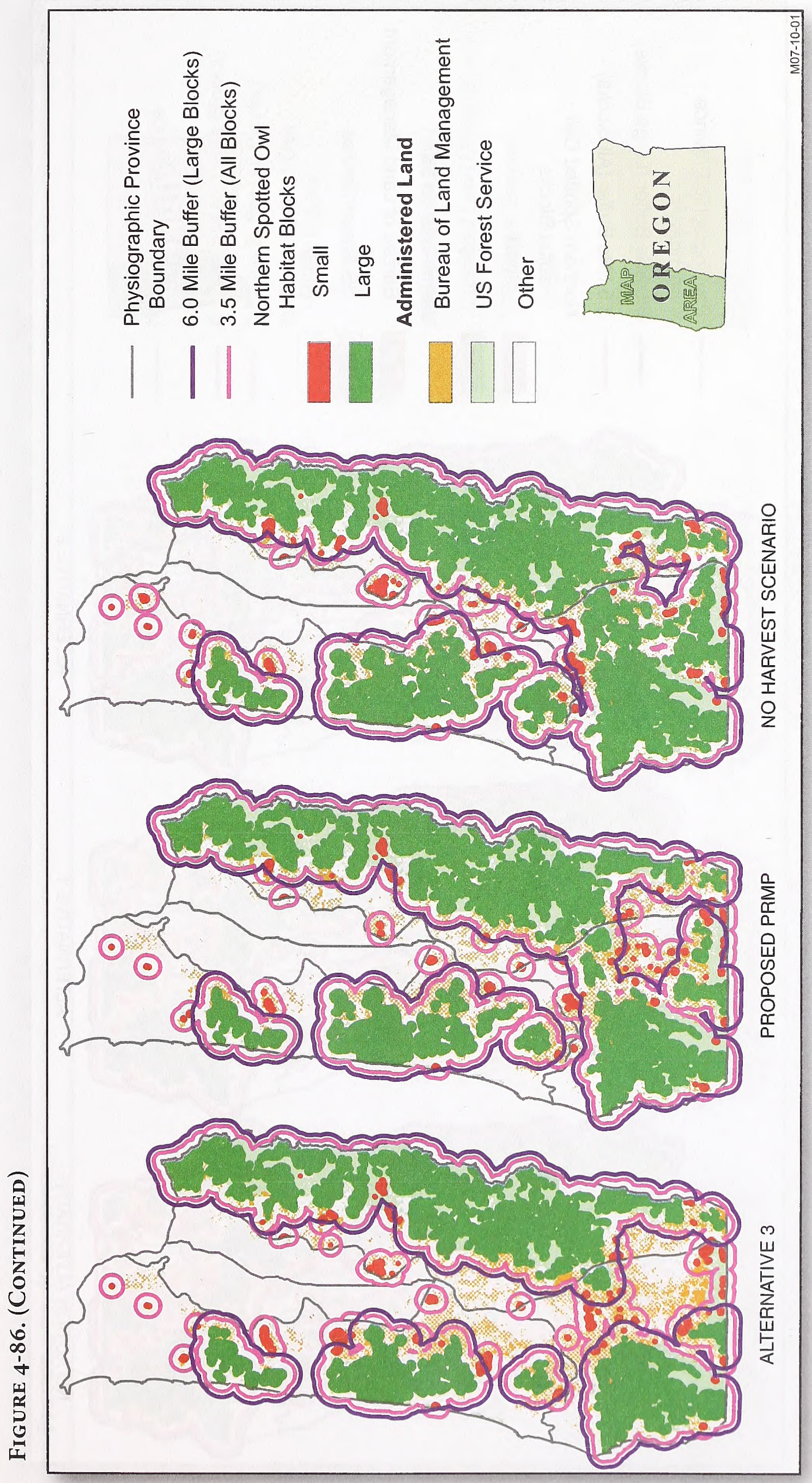


擊静

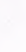

子

4

䒚 离

है

号芯

$\underset{-1}{0}$

ณ है

近

年 इ

水

0 ะ

$\stackrel{11}{ \pm}$

苨芯

衰告

II

焉官

出离

公范

< 뙤 इ

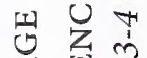

政

$\rightarrow$ 贸昰

出要 $\equiv$

Z $\begin{aligned} & 0 \\ & 0\end{aligned}$

点茎造

造变

点吕

-

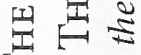

F 0

$\therefore=$

$\infty$ 我

떠

क्ष

号

6

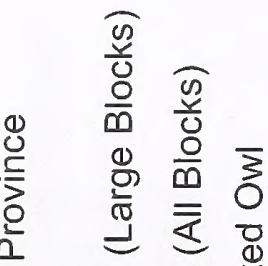

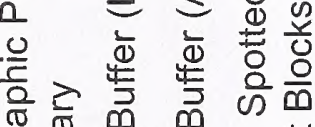

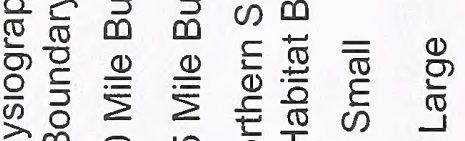

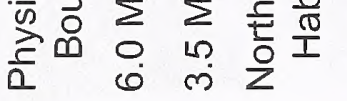

|
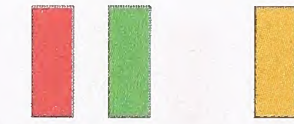

$\square$

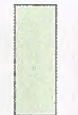

(c)
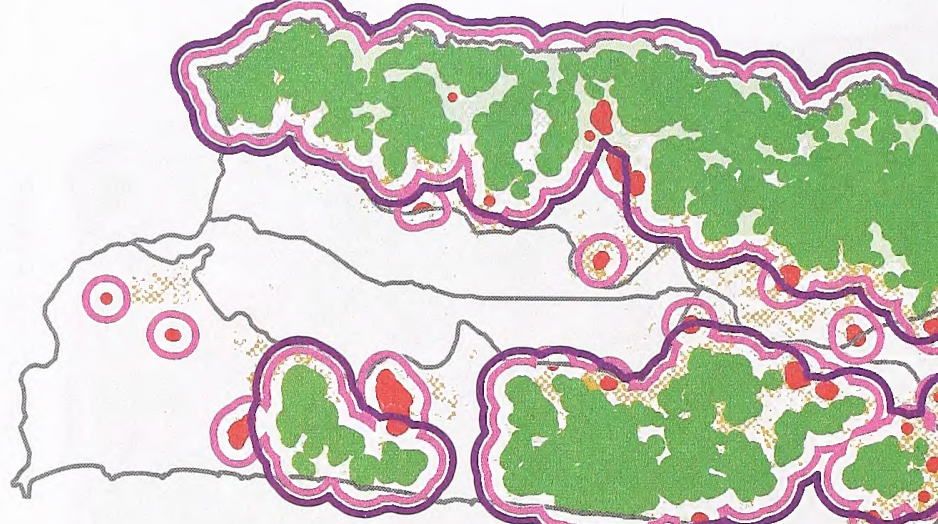
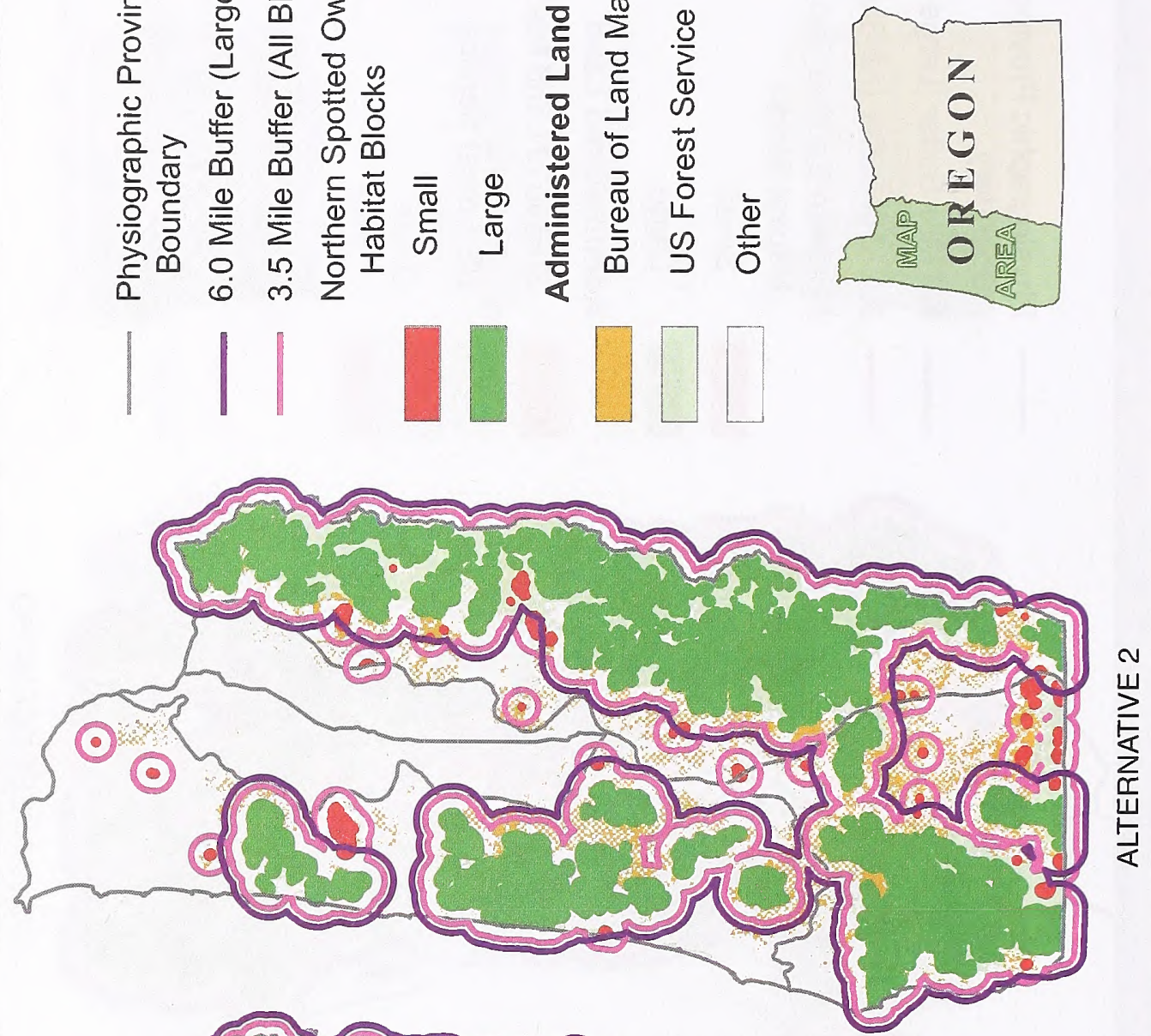

崖
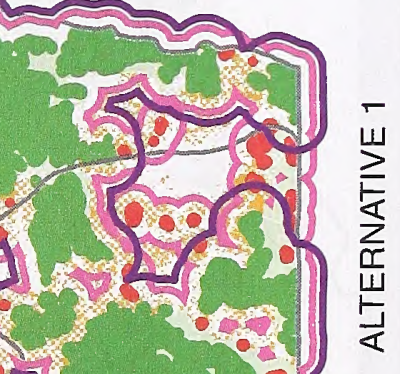

N

कxon

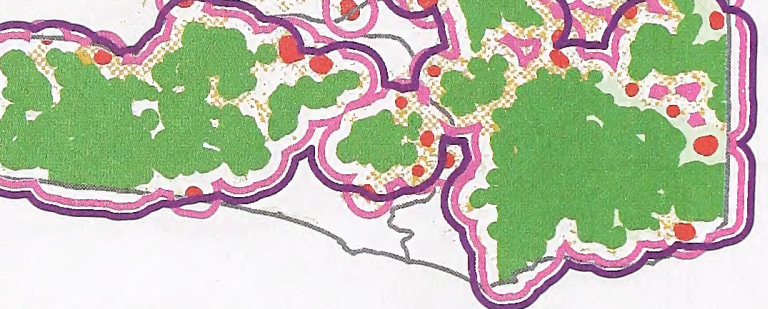


Figure 4-88. Changes In The Number Of Acres Contained Within All Large Habitat Blocks, On All Land Ownerships, Under The Alternatives And According To The No Harvest Reference Analysis.

(Note: For the years 2036 and 2046, data are not included for the No Action Alternative or Alternatives 1 and 3.)

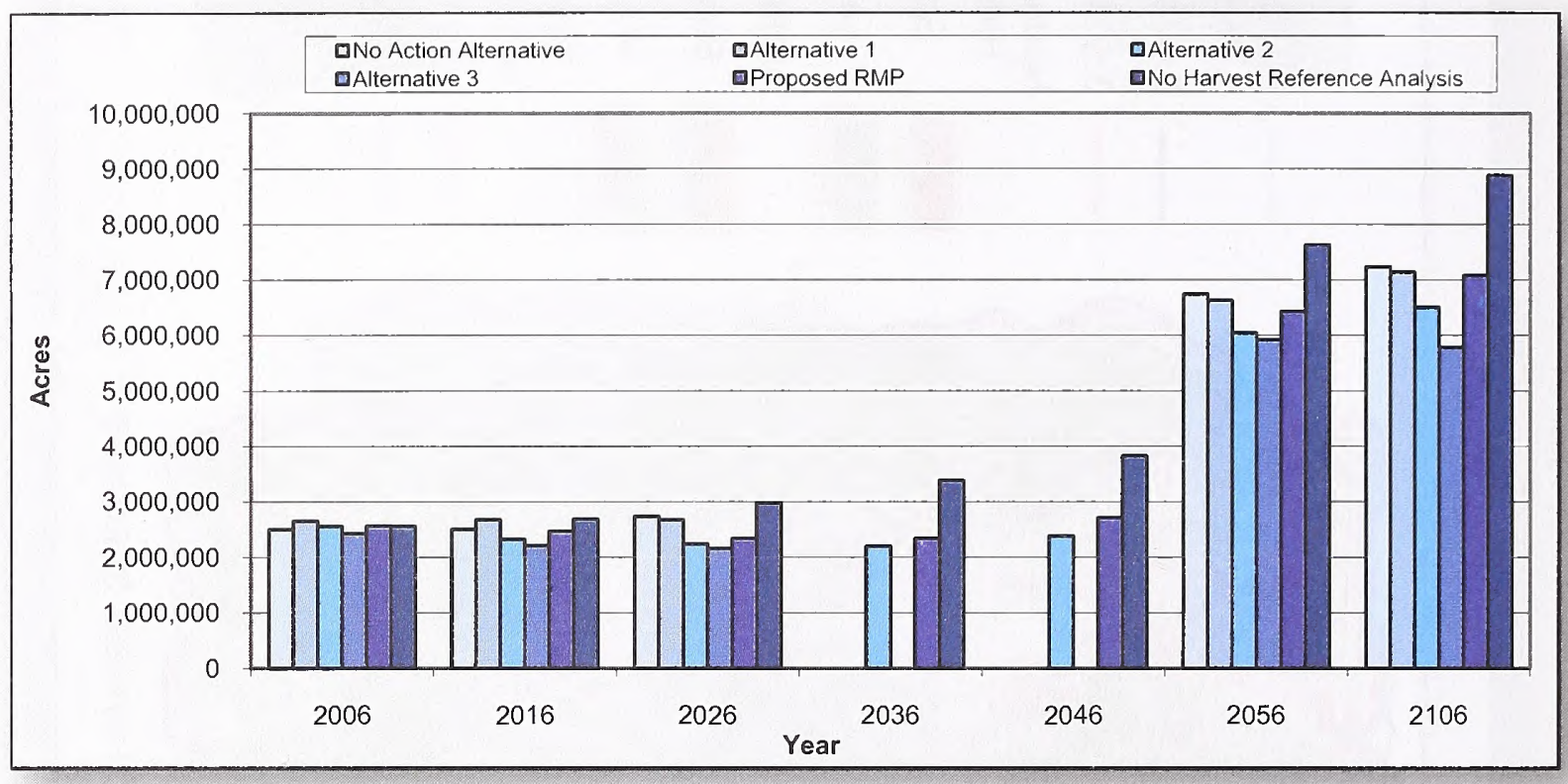

\section{Large Block Distribution}

- Would habitat development under the alternative, when supported by the congressionally reserve lands, and the late-successional reserves and managed late-successional areas on U.S. Forest Service lands, contribute to large blocks of suitable habitat in each physiographic province ${ }^{10}$ of the planning area?

Habitat development under all alternatives except Alternative 2 would contribute to a landscape that supports large habitat blocks distributed across a variety of ecological conditions. As described in Chapter 3 - Northern Spotted Owl, large habitat blocks are distributed sufficiently when they occur in all physiographic provinces during all decades.

Although the landscape would support large habitat blocks in all provinces in all decades under the PRMP, No Action Alternative, and Alternatives 1 and 3, there would be differences among these alternatives in the number of large habitat blocks in each province at various times. There would be more large habitat blocks in the Coast Range Province, where large habitat blocks are most limited, between 2006 and 2026 under the No Action Alternative and Alternative 1 than under the other alternatives (Figures 4-82 and 4-83). Through 2056, there would be fewer large habitat blocks in the Coast Range Province under Alternative 3 than under the No Action Alternative and Alternative 1, and fewer large habitat blocks in the Klamath Province than under the PRMP, No Action Alternative, and Alternative 1 (Figures 4-82, 4-83 and 4-86). Although, through year 2026, there would be more large habitat blocks in the Coast Range Province under the No Action Alternative and Alternative 1 than under the PRMP (Figures 4-82 and 4-83), by year 2056, there would be as many large blocks in the Coast Range Province under the PRMP as under these alternatives, and more large blocks in the Klamath Province with the formation of an additional large block (Figure 4-86).

${ }^{10}$ The Willamette Valley Physiographic Province is not capable of supporting habitat blocks under any alternative (Lint 2005:Figure 3-7). 
Under Alternative 2, all large habitat blocks in the Coast Range Province would disappear by 2026 (Figures 4-83 and 4-84). By 2046, habitat development under Alternative 2 again would provide sufficient contribution to achieve large habitat blocks in all provinces (Figure 4-85). However, large blocks of suitable habitat are needed to maintain clusters of reproducing spotted owls - a criterion of population stability. Therefore, the multi-year loss of large habitat blocks in the Coast Range Province almost certainly would cause a provincial population decline, and possibly local extirpations, that would negatively affect spotted owl colonization of the large habitat blocks that would later form in this province. Thus, the contribution of habitat development under Alternative 2 to the development of large habitat blocks would be insufficient to meet Conservation Need 1.

\section{Large Block Spacing}

- Would habitat development under the alternative, when supported by the congressionally reserved areas, and the late-successional reserves and managed late-successional areas on U.S. Forest Service lands, contribute to large blocks of suitable habitat spaced no more than 12 miles apart and small blocks of suitable habitat spaced no more than 7 miles apart?

With one exception, by year 2056, habitat development under the PRMP, No Action Alternative, and Alternative 1 would be sufficient to support the target spacing between habitat blocks. Habitat development under Alternatives 2 and 3 would not be sufficient to support the target spacing between habitat blocks.

By year 2056, the spacing between habitat blocks would achieve most target spacing distances under the PRMP, No Action Alternative, and Alternative 1, but there would be some differences among these alternatives in when the target spacing would be achieved between specific blocks (Map 3-4 and Figures 4-82 - 4-87). The purple and pink lines on Map 3-4 and Figures 4-82 - 4-87 measure the spacing between habitat blocks. Purple lines are plotted 6 miles from large habitat blocks; overlapping purple lines indicate that large habitat blocks are spaced no more than 12 miles apart. Pink lines are plotted 3.5 miles from all habitat blocks; overlapping pink lines indicate that small habitat blocks are spaced no more than 7 miles from other small or large habitat blocks.

In all decades, there would be a gap greater than the target spacing between habitat blocks within the northern portion of the Coast Range Province, and a gap greater than the target spacing across the boundary between the southern portion of the Coast Range and central portion of the West Cascades Provinces. The No Harvest reference analysis indicates that the BLM land ownership pattern precludes development of target spacing between these habitat blocks, even by year 2106 (Figure 4-87).

Block spacing would be similar under the No Action Alternative and Alternative 1. By 2026, more blocks in the Coast Range and Klamath Provinces would have the target spacing under the No Action Alternative and Alternative 1 than under the PRMP (Figure 4-83). However, by 2056, more blocks would have the target spacing under the PRMP than the No Action Alternative or Alternative 1, especially because of the smaller gaps between large habitat blocks in the southern portion of the Klamath Province under the PRMP (Figure 4-86).

At 2056, there would be a gap greater than the target spacing between habitat blocks on either side of the Klamath-Coast Range provincial boundary under all of the alternatives. The No Harvest reference analysis indicates that, in the absence of active management, the target spacing across this boundary would be achieved by 2056. Under the PRMP, No Action Alternative, and Alternative 1 (but not under Alternatives 2 or 3), small habitat blocks would develop in this area that would help support owl movement across this boundary without meeting the target spacing.

By 2106, habitat blocks would achieve the target spacing in the southern portion of the Klamath Province under the PRMP, the No Action Alternative or Alternative 1 (Figure 4-87). Under the PRMP, the target spacing would be achieved with large habitat blocks; the target spacing would be achieved with small habitat blocks under the No Action Alternative and Alternative 1. 
Under Alternatives 2 and 3, the contribution from BLM-administered lands would be insufficient to achieve a landscape that supports proper spacing between habitat blocks. By 2056, substantial spacing gaps would remain between habitat blocks on each side of the Coast Range-Klamath provincial boundary under both Alternatives 2 and 3 (Figure 4-86). Unlike the other alternatives, small habitat blocks would not develop in this area to help support owl movement. Even by 2106, Alternative 3 would not contribute to a landscape that supports proper spacing between habitat blocks (Figure 4-87).

\section{Interim Nesting Habitat}

The spotted owl was listed in 1990 due to the widespread loss of suitable habitat across its entire home range; habitat loss continues to be one of the "most-pressing threats to the spotted owl" (USFWS 2008a:6-7). For this reason, and because large blocks of suitable habitat require time to develop under each alternative, the analysis examines how suitable habitat would persist and develop at various scales across the landscape and within habitat blocks under each alternative. The amount of suitable habitat within habitat blocks reflects how suitable habitat within functional nest territories would change. As described in Chapter 3 (see Northern Spotted $\mathrm{Owl}$ ), a functional nest territory contains the type, quantity and spatial arrangement of habitat needed to support a nesting spotted owl pair, whether or not that habitat actually is occupied by nesting spotted owls. The amount of suitable habitat within large habitat blocks reflects how suitable habitat that is capable of supporting clusters of breeding spotted owl pairs would change, whether or not that habitat actually is occupied by nesting spotted owls. As described in Chapter 3 (see Northern Spotted Owl), clusters of 20 or more spotted owl breeding pairs that support each other demographically are needed for population stability. Because this analysis assumes that nonfederal lands would maintain their current abundances and spatial patterns of habitat, the analysis is confined to federally-administered lands.

- Would there be a stable or increasing acreage of suitable habitat on all federal lands under the alternative until large blocks of suitable habitat form?

- Would there be a stable or increasing acreage of suitable habitat within large or small habitat blocks on federal lands under the alternative until large blocks of suitable habitat form?

- Would there be a stable or increasing acreage of suitable habitat within large habitat blocks on federal lands under the alternative until large blocks of suitable habitat form?

By 2056, the acreage of suitable habitat would increase from current levels under all alternatives at the scales of:

- all federal lands

- federal lands within all habitat blocks

- federal lands within large habitat blocks

However, between 2006 and 2056, the alternatives would differ in whether they would provide stable or increasing acreage of suitable habitat at these various scales.

Under the No Action Alternative and Alternative 1, the acreage of suitable habitat would be stable or increasing in all decades between 2006 and 2056 at the scales of:

- all federal lands

- federal lands within all habitat blocks

- federal lands within large habitat blocks

Under the PRMP, the acreage of suitable habitat would be stable or increasing in all decades between 2006 and 2056 at the scales of:

- all federal lands

- federal lands within large habitat blocks 
but not at the scale of:

- federal lands within all habitat blocks

Under Alternatives 2 and 3, the acreage of suitable habitat would be stable or increasing in all decades between 2006 and 2056 at the scale of:

- all federal lands

but not at the scales of:

- federal lands within all habitat blocks

- federal lands within large habitat blocks

The development of spotted owl suitable habitat on all federal lands, on federal lands within large and small habitat blocks, and on federal lands within large blocks, is shown in Figures 4-89, 4-90 and 4-91, respectively.

At the scale of all federal lands, the acreage of suitable habitat would be stable or increasing in all decades under all alternatives (Figure 4-89). Through 2026, the acreage of suitable habitat on all federal lands would remain approximately stable under all alternatives (Figure 4-89): increasing from current levels by 5\% under the No Action Alternative, 3\% under Alternative 1, and 1\% under Alternative 3 and the PRMP, and decreasing by $1 \%$ under Alternative 2 . By 2056, the quantity of suitable habitat on all federal lands would increase from current levels under all alternatives: by $61 \%$ under the No Action Alternative, $56 \%$ under Alternative 1, 47\% under Alternative 2, 53\% under Alternative 3 and 54\% under the PRMP.

Figure 4-89. Changes In The Acres Of Suitable Habitat On FederallyAdministered Lands Under The Alternatives And According To The No Harvest Reference Analysis.

(Note: For the years 2036 and 2046, data are not included for the No Action Alternative or Alternatives 1 and 3.)

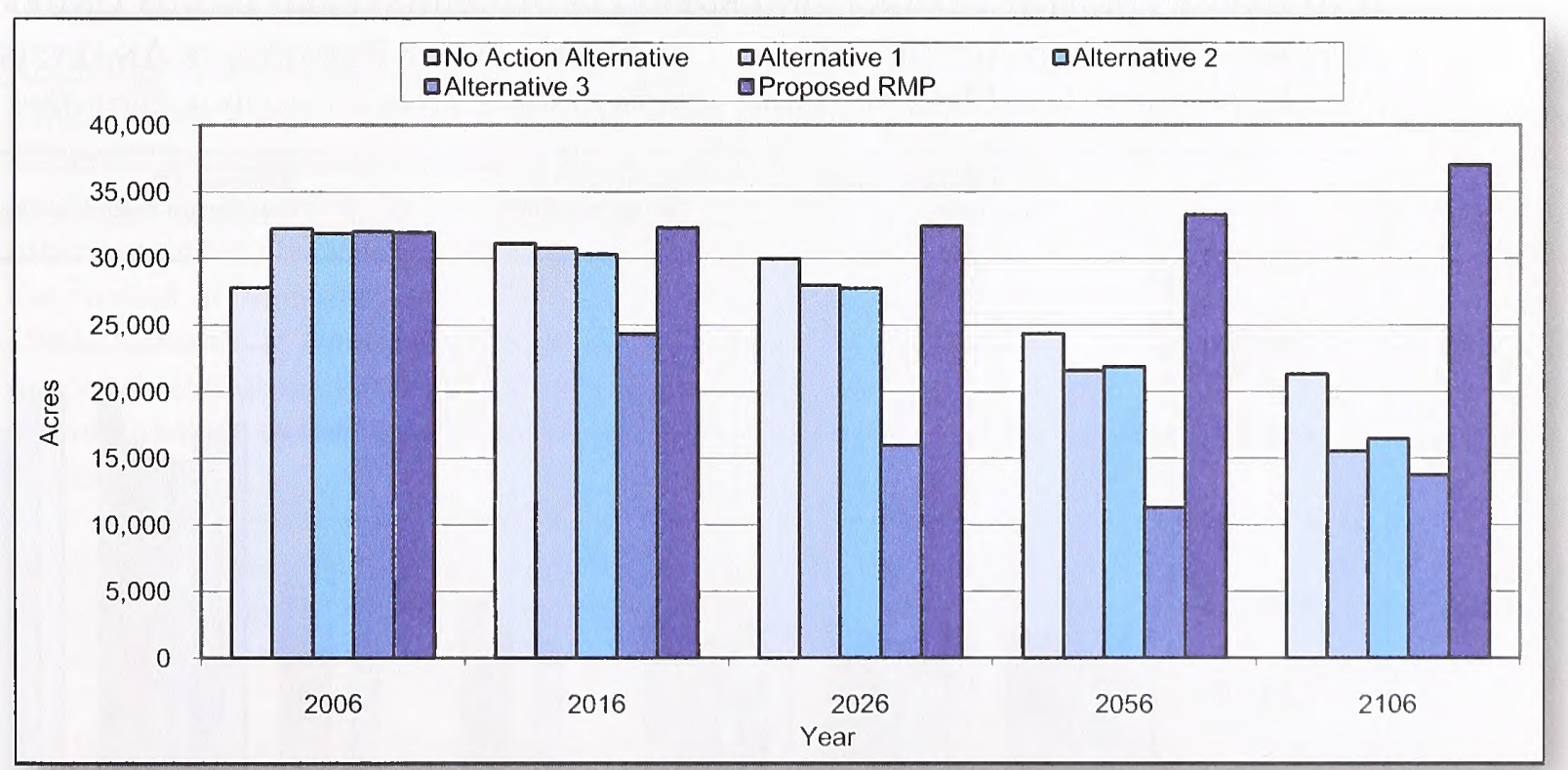


At the scale of all habitat blocks (including both small and large habitat blocks), the acreage of suitable habitat would be stable or increasing in all decades under the No Action Alternative and Alternative 1, but not under the PRMP, Alternative 2, or Alternative 3 (Figure 4-90). Through 2026, the acreage of suitable habitat in all habitat blocks would increase from current levels by $6 \%$ under the No Action Alternative and $1 \%$ under Alternative 1, but would decrease by $7 \%$ under Alternative 2, $4 \%$ under Alternative 3, and 3\% under the PRMP. That is, the acreage of suitable habitat in all habitat blocks would decrease between 2006 and 2026 under Alternatives 2 and 3, and the PRMP, even though the acreage of suitable habitat would be stable on the federal landscape as a whole. By 2056, the acreage of suitable habitat within all habitat blocks would increase substantially from current levels under all alternatives: $138 \%$ under the No Action Alternative, $125 \%$ under Alternative 1, 113\% under Alternative 2, $120 \%$ under Alternative 3, and 124\% under the PRMP.

At the scale of large habitat blocks, the acreage of suitable habitat would be stable or increasing in all decades under the No Action Alternative, Alternative 1, and the PRMP, but not under Alternatives 2 or 3 (Figure 4-91). Through 2026 the amount of suitable habitat within large habitat blocks would increase from current levels by $8 \%$ under the No Action Alternative, $1 \%$ under Alternative 1 and $6 \%$ under the PRMP, but decline by $11 \%$ under Alternative 2 and $10 \%$ under Alternative 3. That is, under Alternatives 2 and 3 , the decrease in the acreage of suitable habitat in large habitat blocks (which represent habitat blocks that can support breeding clusters) would be greater than the decrease for all habitat blocks, even though the acreage of suitable habitat would be stable on the federal landscape as a whole. In contrast, under the No Action Alternative and the PRMP, the increase in suitable habitat would be disproportionately higher within large habitat blocks (which represent habitat blocks that can support breeding clusters) than from within all habitat blocks or across the entire federal landscape. By 2056, the acreage of suitable habitat within large blocks would increase substantially from current levels under all alternatives: $228 \%$ under the No Action Alternative, 207\% under Alternative 1; 193\% under Alternative 2; $203 \%$ under Alternative 3; and 253\% under the PRMP.

Figure 4-90. Changes In The Acres Of Suitable Habitat Within Small And Large Habitat Blocks On Federally-Administered Lands Under The Alternatives And According To The No Harvest Reference Analysis. (Note: For the years 2036 and 2046, data are not included for the No Action Alternative or Alternatives 1 and 3.)

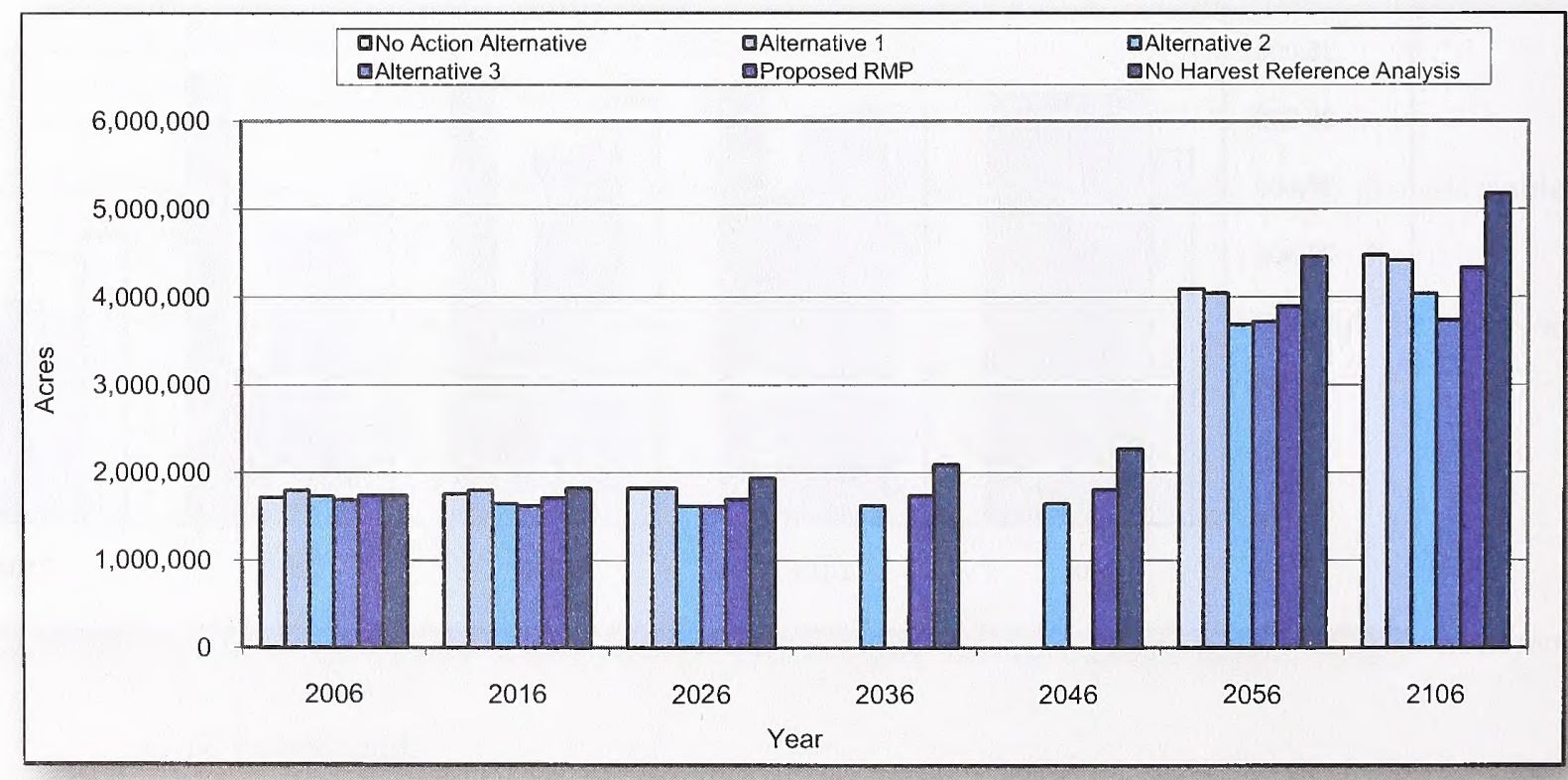


Figure 4-91. Changes In The Acres Of Suitable Habitat Within Large Habitat Blocks On Federally-Administered Lands Under The Alternatives And According To The No Harvest Reference Analysis.

(Note: Data for 2036 and 2046 is not included for the No Action Alternative or Alternatives 1 and 3.)

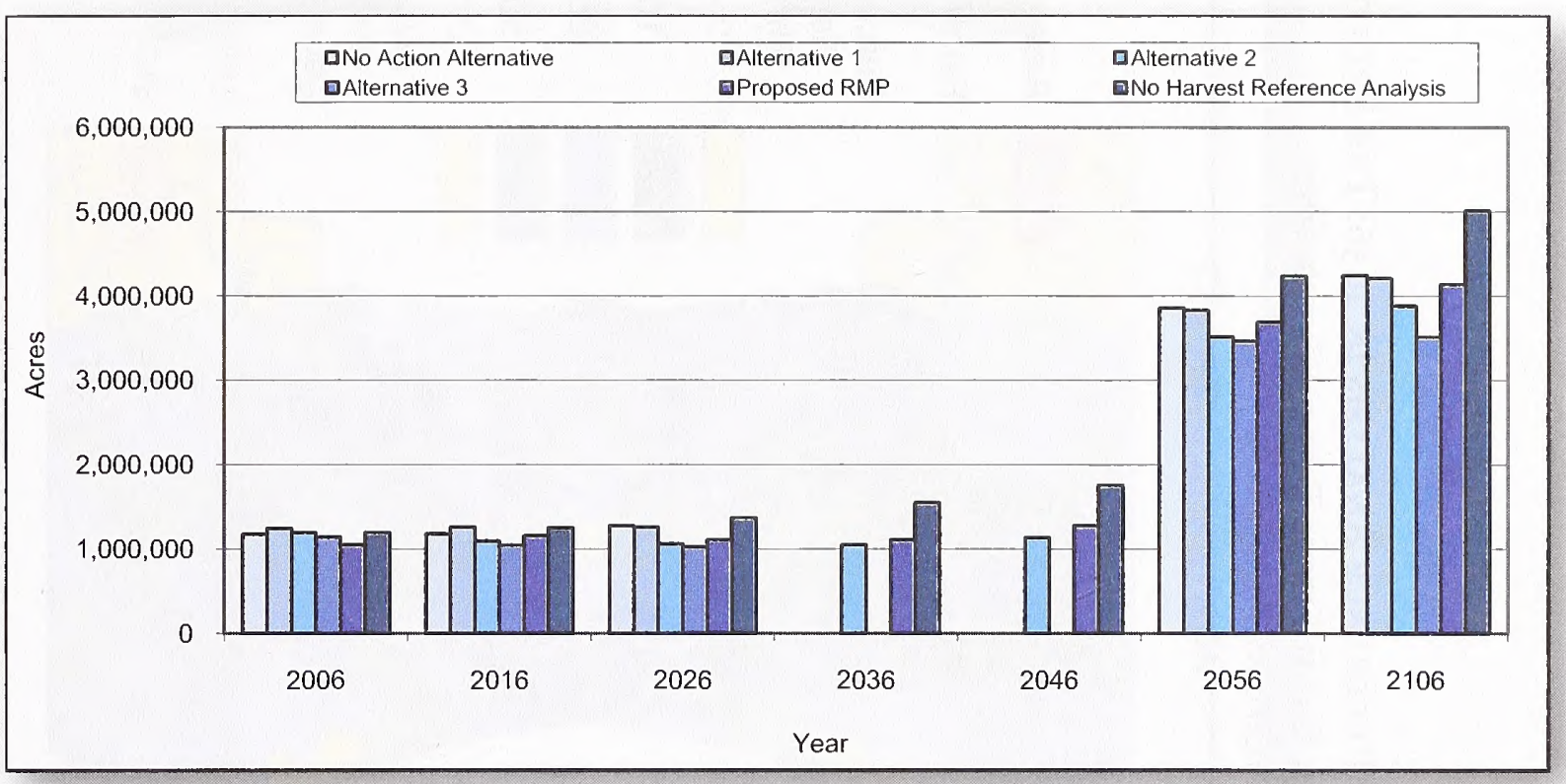

\section{CONSERVATION NEED 2}

Habitat conditions within and surrounding large blocks of suitable habitat that facilitate owl movement between the blocks and ensure the survival of dispersing owls

\section{Dispersal Habitat}

According to the criteria discussed in Chapter 3 (see Northern Spotted Owl), 50\% or more dispersal habitat within a watershed indicates that the watershed is likely to be "functional," or supports spotted owl dispersal (movement and survival). By this standard, 58 watersheds currently are functional (see Map 3-5 in Chapter 3). The West Cascades Province has disproportionately more functional watersheds than the other provinces. Only five functional watersheds currently occur in the Coast Range Province. The greater the number of functional watersheds, the better the landscape would support owl dispersal (Thomas et al. 1990). However, as detailed in Chapter 3 (see Northern Spotted Owl), there is no defined minimum quantity or spatial arrangement of dispersal habitat needed to support owl movement between the blocks. Therefore, it is not possible to define a minimum or target number of functional watersheds needed to support owl dispersal.

Spotted owl dispersal conditions would improve substantially under all alternatives. By 2036 there would be at least 80 functional watersheds under each alternative. However, by 2056 , more evident differences among the alternatives would appear (Figure 4-92).

The No Harvest reference analysis indicates that, in the absence of active management on BLMadministered lands, by 2056 (Figure 4-92), habitat conditions for spotted owl dispersal on all land ownerships would closely parallel the development of blocks of suitable habitat (Figure 4-86). The No Harvest reference analysis indicates that BLM-administered lands are not capable of substantially affecting spotted owl dispersal conditions throughout most of the northern half of the Coast Range Province, 


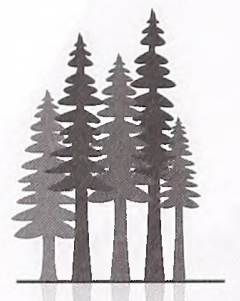

5
2
0
0
0
0

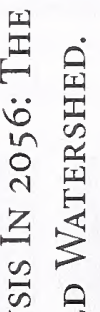

焉完

公它

约舆弯

开

空

工兵 项

5 is

क्य कै है

㲾

ये

○

乙 3

焉 $9 \frac{9}{3}$

<

㲾。

运是总

$\sum^{1} z$

是 $0 \frac{5}{5}$

安焉

空

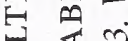

安言

㱏

is

0 至 :

乙类

ค 2 S

出

㐘

卷

$\circlearrowleft$ 논

य 0.

त

iे $z$ o

न

IE

它苍苛
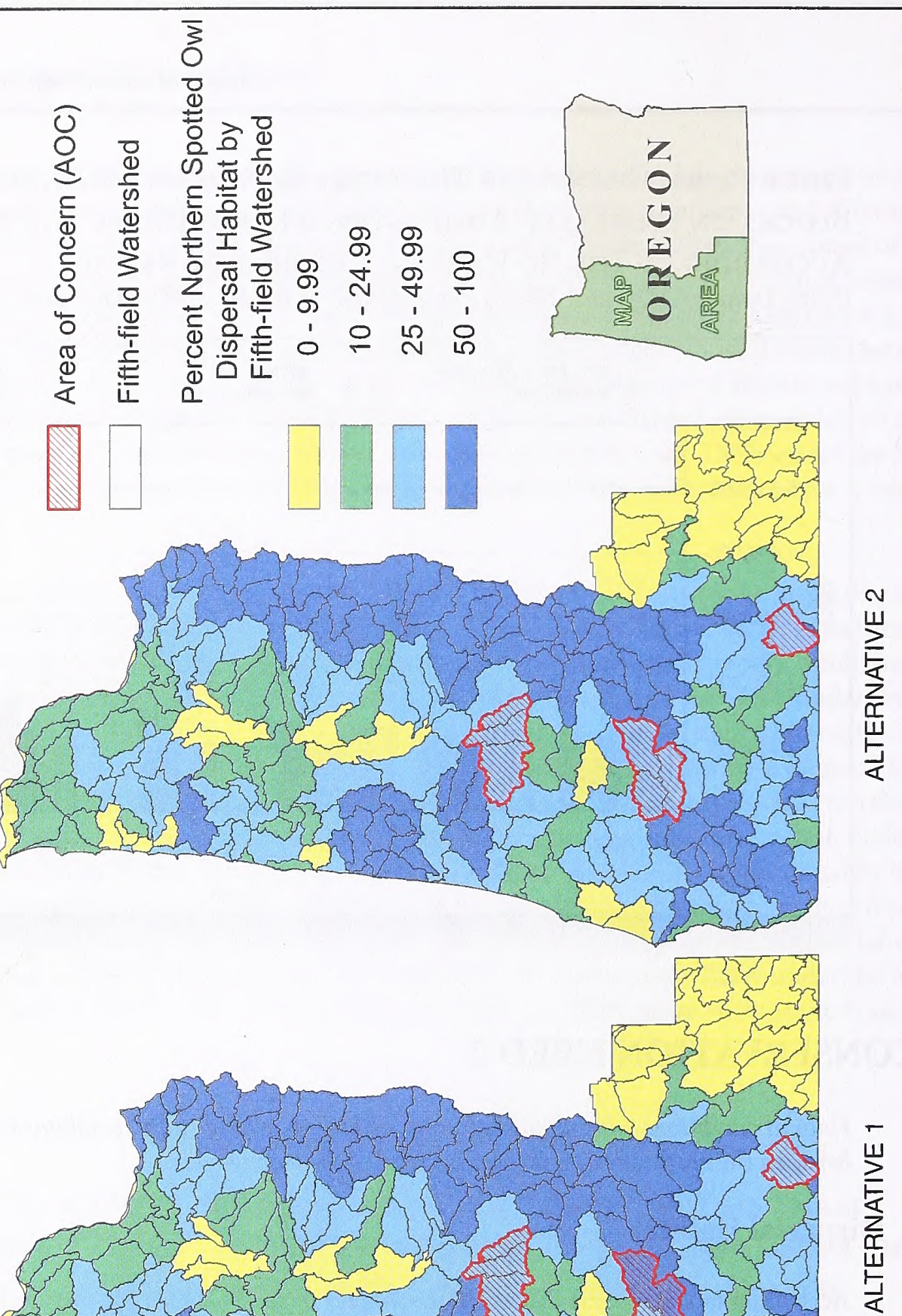


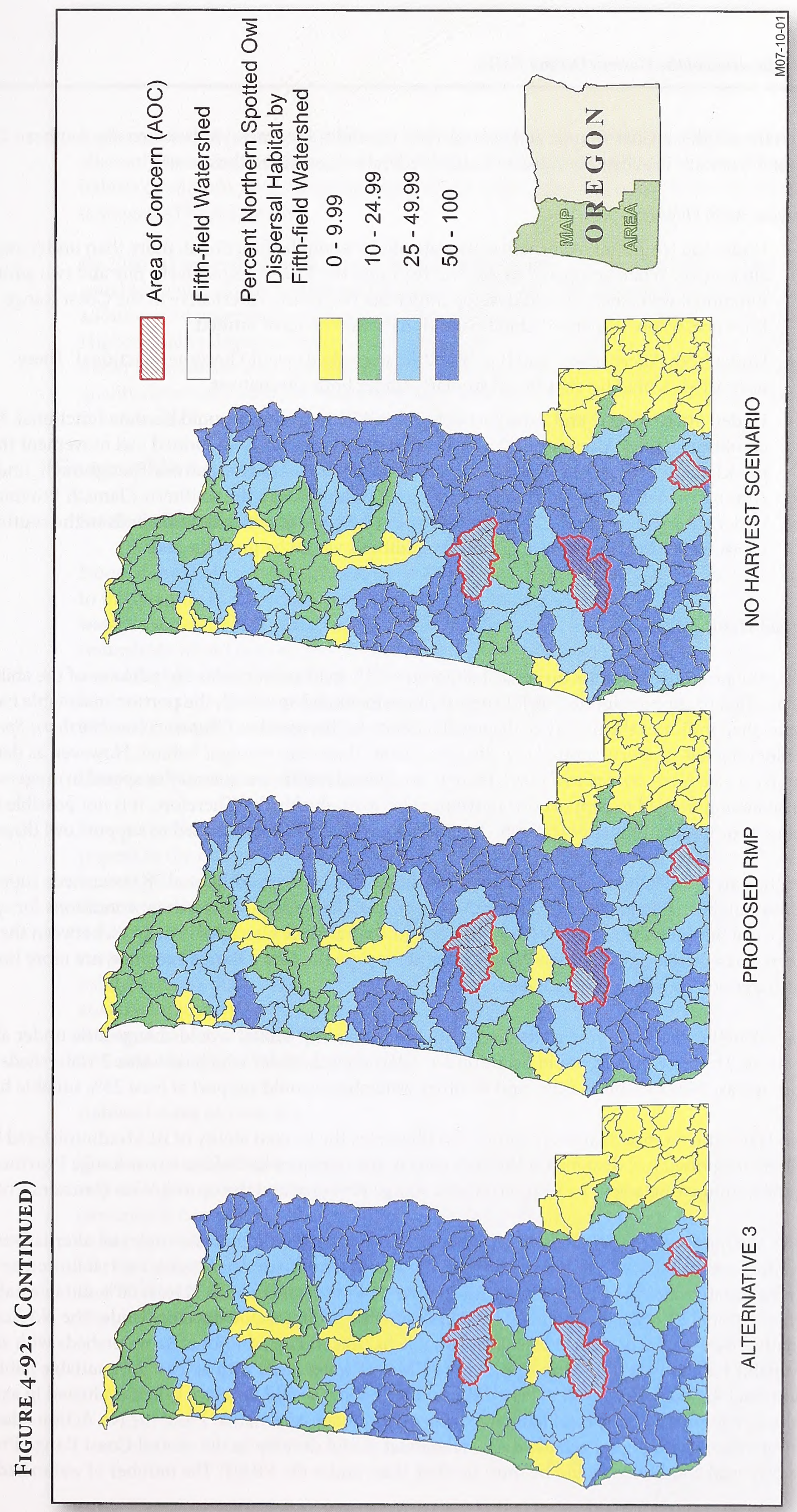


between the southern Coast Range and central West Cascades Provinces, or between the southern Coast Range and Klamath Provinces because of limited federal ownership in these areas.

By the year 2056 (Figure 4-92):

- Under the No Action Alternative, 84 watersheds would be functional, more than under any other alternative. When compared to Alternative 1 and the PRMP, respectively, one and two additional functional watersheds would develop under the No Action Alternative in the Coast Range Province, where dispersal habitat conditions would be most limited.

- Under both Alternative 1 and the PRMP, 82 watersheds would become functional. These watersheds would be distributed similarly under both alternatives.

- Under Alternatives 2 and 3, respectively, 77 and 78 watersheds would become functional. Habitat conditions under Alternatives 2 and 3 would not foster east-west spotted owl movement through the Klamath Province as well as they would under the other alternatives. Even though, under Alternative 3, there would be more functional watersheds in the southern Klamath Province than under Alternative 1 or the PRMP, there would be fewer functional watersheds in the southern Coast Range Province where dispersal conditions would be most limited.

\section{Dispersal Habitat Quality}

Whereas the proportion of total dispersal habitat in a fifth-field watershed is an indicator of the ability of that watershed to support spotted owl dispersal (movement and survival), the portion of suitable habitat in a watershed indicates the quality of dispersal habitat. As discussed in Chapter 3 (see Northern Spotted Owl), older habitat supports spotted owl dispersal better than does younger habitat. However, as detailed in Chapter 3 (see Northern Spotted Owl), there is no defined minimum quantity or spatial arrangement of dispersal habitat needed to support owl movement between the blocks. Therefore, it is not possible to define a minimum or target number of watersheds with higher-quality habitat needed to support owl dispersal.

Currently, only 2 watersheds support at least $50 \%$ suitable habitat; an additional 78 watersheds support at least 25\% suitable habitat (see Map 3-6 in Chapter 3). Map 3-6 suggests that habitat conditions for spotted owl dispersal between the southern Coast Range and central West Cascades Provinces, between the southern Coast Range and Klamath Provinces, and through the Coast Range Province, are more limited than is suggested by Map 3-5 (in Chapter 3)

By year 2036, the distribution of watersheds with higher-quality habitat would change little under all alternatives. The least change would occur under Alternative 2, under which the same 2 watersheds would support at least $50 \%$ suitable habitat, and 84 other watersheds would support at least $25 \%$ suitable habitat.

The No Harvest reference analysis (Figure 4-90) illustrates the limited ability of BLM-administered lands to contribute to spotted owl dispersal at the $50 \%$ level in the northern half of the Coast Range Province and along the boundary between the southern Coast Range Province and the central West Cascades Province.

By 2056, the number of watersheds with higher-quality habitat would increase under all alternatives (Figure 4-93). More watersheds with higher-quality habitat would develop under Alternative 1 , followed by the No Action Alternative and the PRMP. Under Alternative 1, 45 watersheds with at least 50\% suitable habitat and an additional 81 watersheds with at least $25 \%$ suitable habitat would develop. Under the No Action Alternative, 44 watersheds with at least $50 \%$ suitable habitat and an additional 82 watersheds with at least $25 \%$ suitable habitat would develop. Under the PRMP, 41 watersheds with at least $50 \%$ suitable habitat and an additional 82 watersheds with at least $25 \%$ suitable habitat would develop. When evaluated in association with the development of dispersal habitat (Figure 4-92), under Alternative 1 and the No Action Alternative, more watersheds with higher-quality dispersal habitat would develop in the central Coast Range Province, where dispersal conditions would be most limited, than under the PRMP. The number of watersheds with 
higher-quality dispersal habitat in the extreme south of the West Cascades Province, throughout most of the Klamath Province, and throughout the southern half of the Coast Range Province, suggests that dispersal habitat conditions would develop better under Alternative 1, the No Action Alternative, and the PRMP, than is suggested by Figure 4-92.

By 2056, 41 watersheds with at least $50 \%$ suitable habitat and an additional 73 watersheds with at least $25 \%$ suitable habitat would develop under Alternative 3;39 watersheds with at least $50 \%$ suitable habitat and an additional 74 watersheds with at least $25 \%$ suitable habitat would develop under Alternative 2 (Figure 4-93). Higher-quality dispersal habitat conditions in the southern Klamath Province would not develop as well under Alternatives 2 or 3 as under the other alternatives. When compared to the other alternatives, higherquality dispersal condition would develop less well in the northern Coast Range Province under Alternative 2 , and in the southern West Cascades Province under Alternative 3.

\section{Geographic Areas of Concern}

\section{South Willamette-North Umpqua Area of Concern}

None of the three watersheds used to represent this Area of Concern currently are functional with respect to the quantity of dispersal habitat (see Map 3-5 in Chapter 3), and less than 25\% of the habitat in each watershed currently is comprised of higher-quality dispersal habitat (see Map 3-6 in Chapter 3). These three watersheds would not become functional for dispersal or support at least $25 \%$ suitable habitat by 2056 under any of the alternatives (Figure 4-92 and Figure 4-93). The No Harvest reference analysis indicates that the land ownership pattern precludes these three watersheds from providing for dispersal at the $50 \%$ level by 2056 (Figure 4-92) under any of the alternatives.

\section{Umpqua-Rogue Area of Concern}

One of the three watersheds that are used to represent this Area of Concern currently is functional with respect to the quantity of dispersal habitat (Map 3-5), and more than $25 \%$ of the habitat in each watershed currently is comprised of higher-quality dispersal habitat (see Map 3-6 in Chapter 3). By 2056, two of the three watersheds would be functional under the No Action Alternative, Alternative 1 and the PRMP (Figure 4-92). Under Alternatives 2 and 3, dispersal habitat conditions would not measurably improve from the current conditions by 2056. By 2056, all three watersheds would continue to have more than $25 \%$ suitable habitat but less than $50 \%$ suitable habitat under all alternatives (Figure 4-93). The No Harvest reference analysis indicates that the land ownership pattern precludes one of the watersheds from providing for dispersal habitat at the 50\% level (Figure 4-92) and precludes all three watersheds from developing at least 50\% suitable habitat by 2056 (Figure 4-93).

\section{Ashland Area of Concern}

The one watershed used to represent this Area of Concern currently is not meeting the $50 \%$ level with respect to the quantity of dispersal habitat (Map 3-5), but more than $25 \%$ of the habitat in each watershed currently is comprised of higher-quality dispersal habitat (Map 3-6). By 2056, the watershed would continue to have more than $25 \%$ suitable habitat but still less than $50 \%$ suitable habitat under all alternatives. The No Harvest reference analysis indicates that the land ownership pattern precludes this watershed from meeting the "50-11-40" level of dispersal habitat (Figure 4-92) or developing at least 50\% suitable habitat by 2056 (Figure 4-93) under any of the alternatives. 


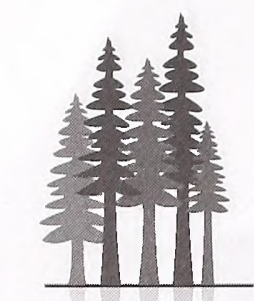

5
0
2
0
0
0
0
0

$\ddot{0}$

经量

ते

总

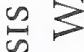

䔰

至䛼

떤

出

空

焉

虫

น

氙艺

प्र को

密

要

인

乙

咭 $0 \frac{3}{3}$

品

究。

实

我星

安

范

$z_{5}$

至廷

ज

ये

䛼 I

圷完

E

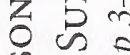

娄是

造

盗留

$\varangle 5$

ले क

1.z

되도 일

䢵

曷苍造
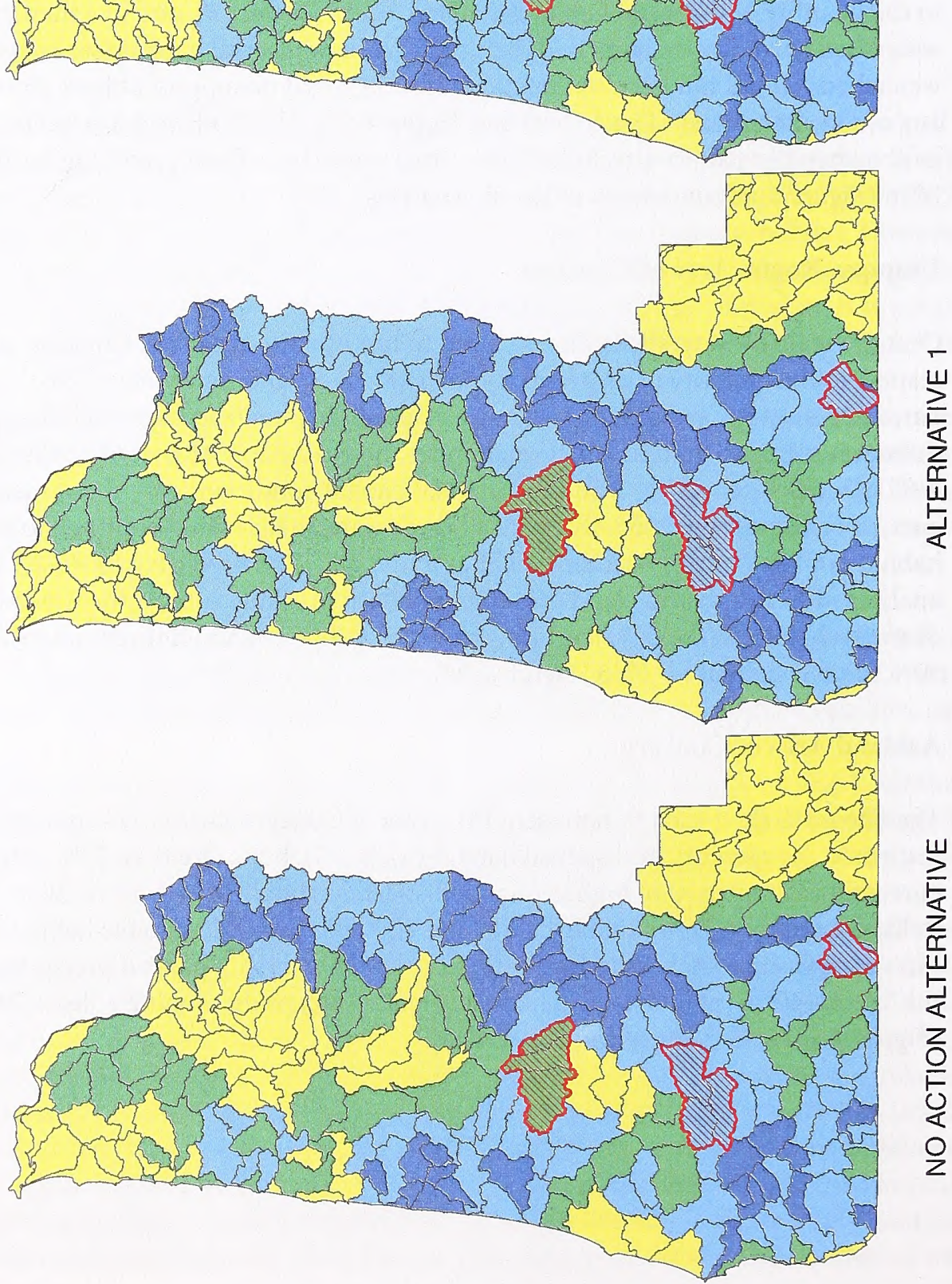


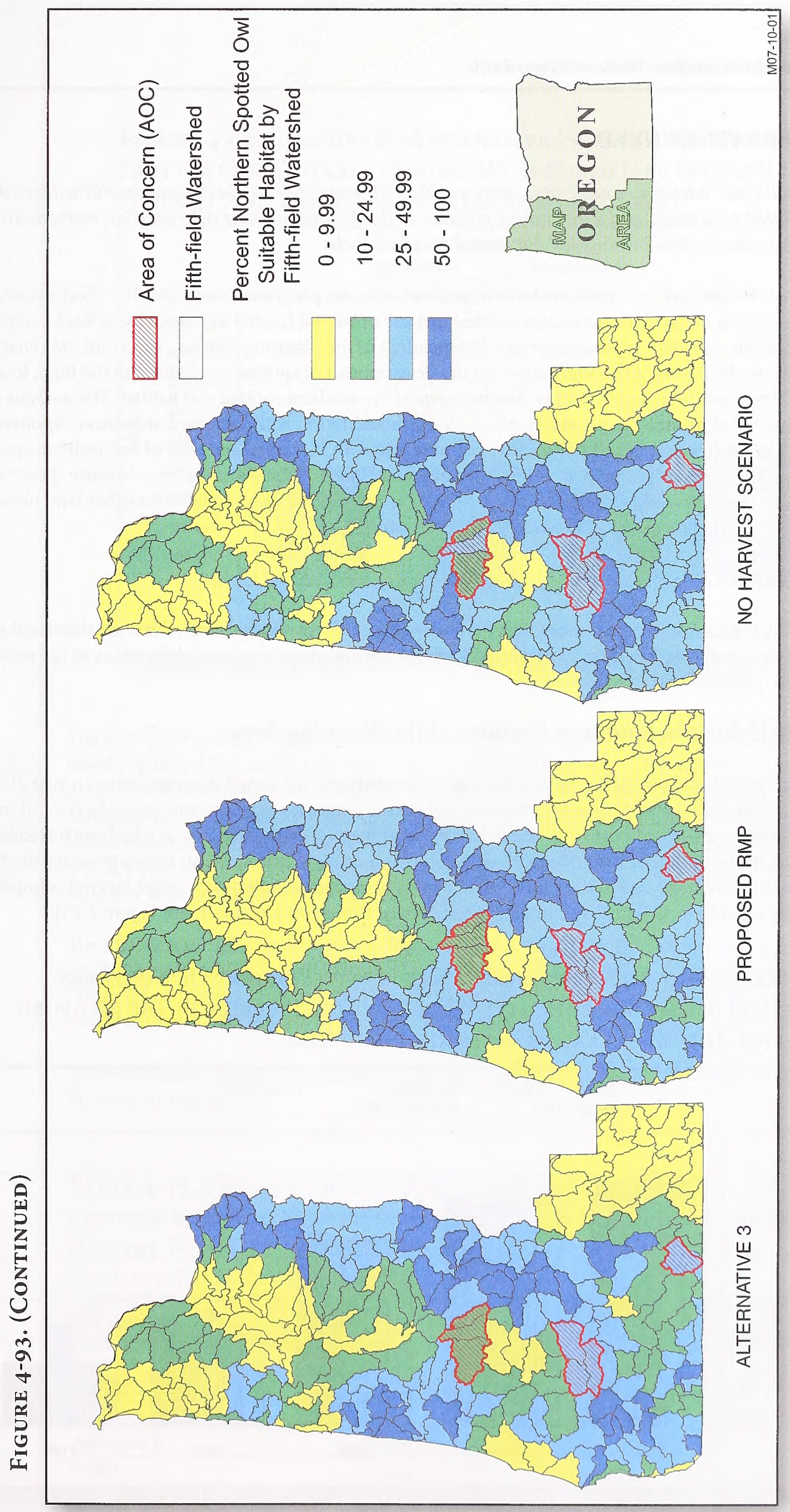




\section{CONSERVATION NEED 3}

A coordinated, adaptive management effort to reduce the loss of habitat due to catastrophic wildfire throughout the spotted owl's range, and a monitoring program to clarify whether these risk reduction methods are effective and to determine how owls use habitat treated to reduce fuels

None of the alternatives would establish or preclude specific programs to evaluate the effectiveness of fire risk reduction methods or determine spotted owl use of habitat treated to reduce fuels. Such programs would occur, as needed and appropriate, independent of the planning process. Therefore, this analysis focuses on the effects of the alternatives on the development of spotted owl habitat in the high, low and mixed fire severity regimes, and the development of fire-resilient spotted owl habitat. The analysis assumes that the risk of habitat loss to catastrophic wildfire would lessen with increased amounts of spotted owl habitat in the low and mixed fire severity regimes, and with increased amounts of fire-resilient spotted owl habitat. This analysis is confined to BLM-administered lands in the planning area, because these metrics pertain to individual forest stands, for which there is not specific data available for other land ownerships (see Forest Structure and Spatial Pattern in this chapter).

\section{Fire Severity}

The effects that would occur under the alternatives on northern spotted owl habitat are discussed separately for the southern and northern portions of the planning area due to regional differences in fire regimes (see Northern Spotted Owl in Chapter 3).

\section{Suitable Habitat in Southern Portions of the Planning Area}

The acreage of suitable habitat within the low fire severity regime would decrease between year 2006 and 2056 under all alternatives (see Figure 4-94). These decreases would be due to the harvest of mature forest with multi-layered canopies in the harvest land base exceeding the rate at which such stands would develop in the nonharvest land base. In addition, a substantial portion of this decrease under the No Action Alternative would be due to the transition of stands from mature forest with multi-layered canopies (low fire severity regime) to structurally complex forest (mixed fire severity regime) (see Figure 4-95).

Figure 4-94. Changes By Alternative In Development Of Northern Spotted Owl Suitable Habitat With Low Fire Severity In The Medford District And The Klamath Falls Resource Area

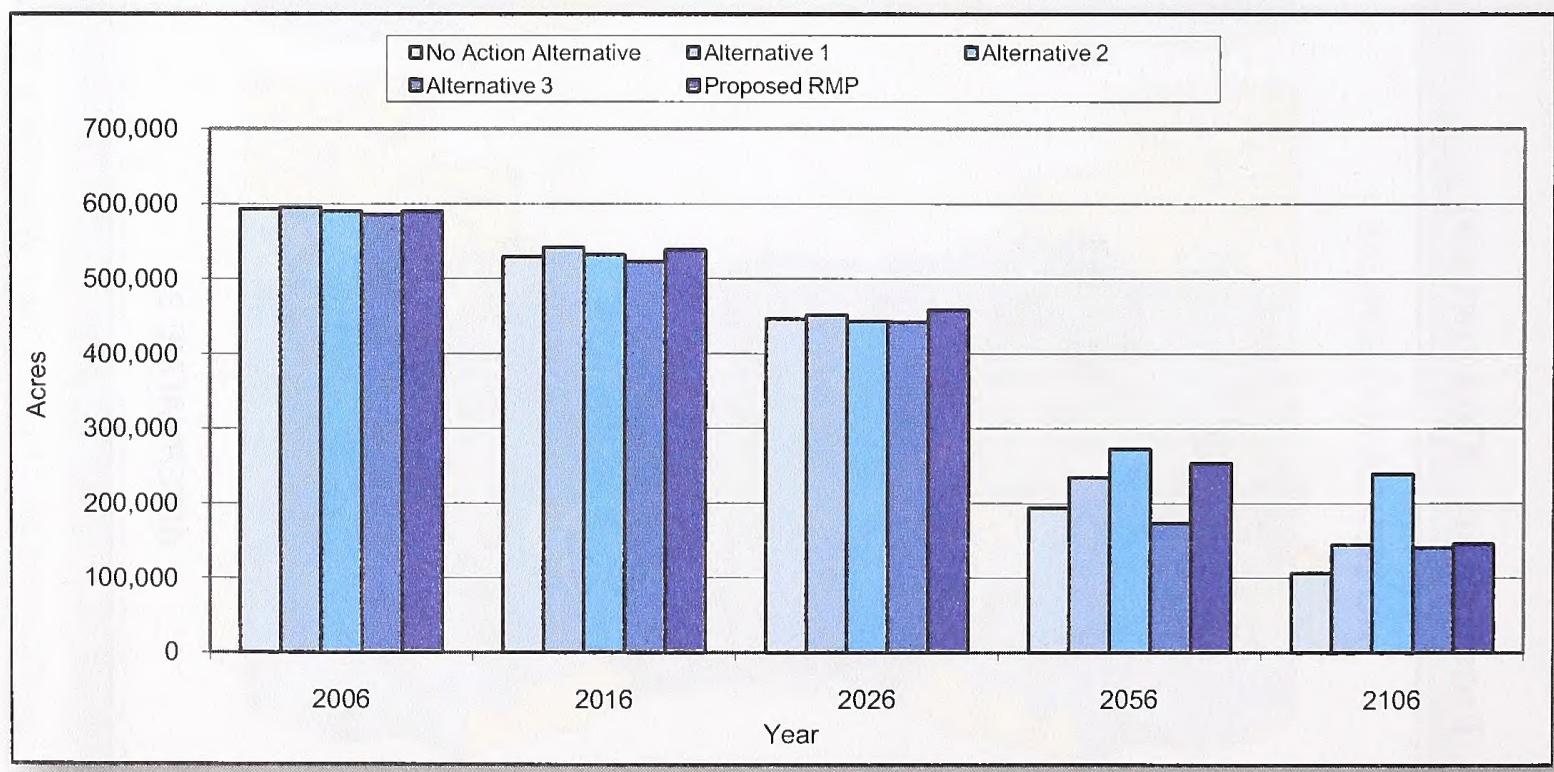


Figure 4-95. Changes By Alternative In Development Of Northern Spotted Owi, Suitable Habitat With Mixed Fire Severity In The Medford District And The Klamath Falls Resource Area

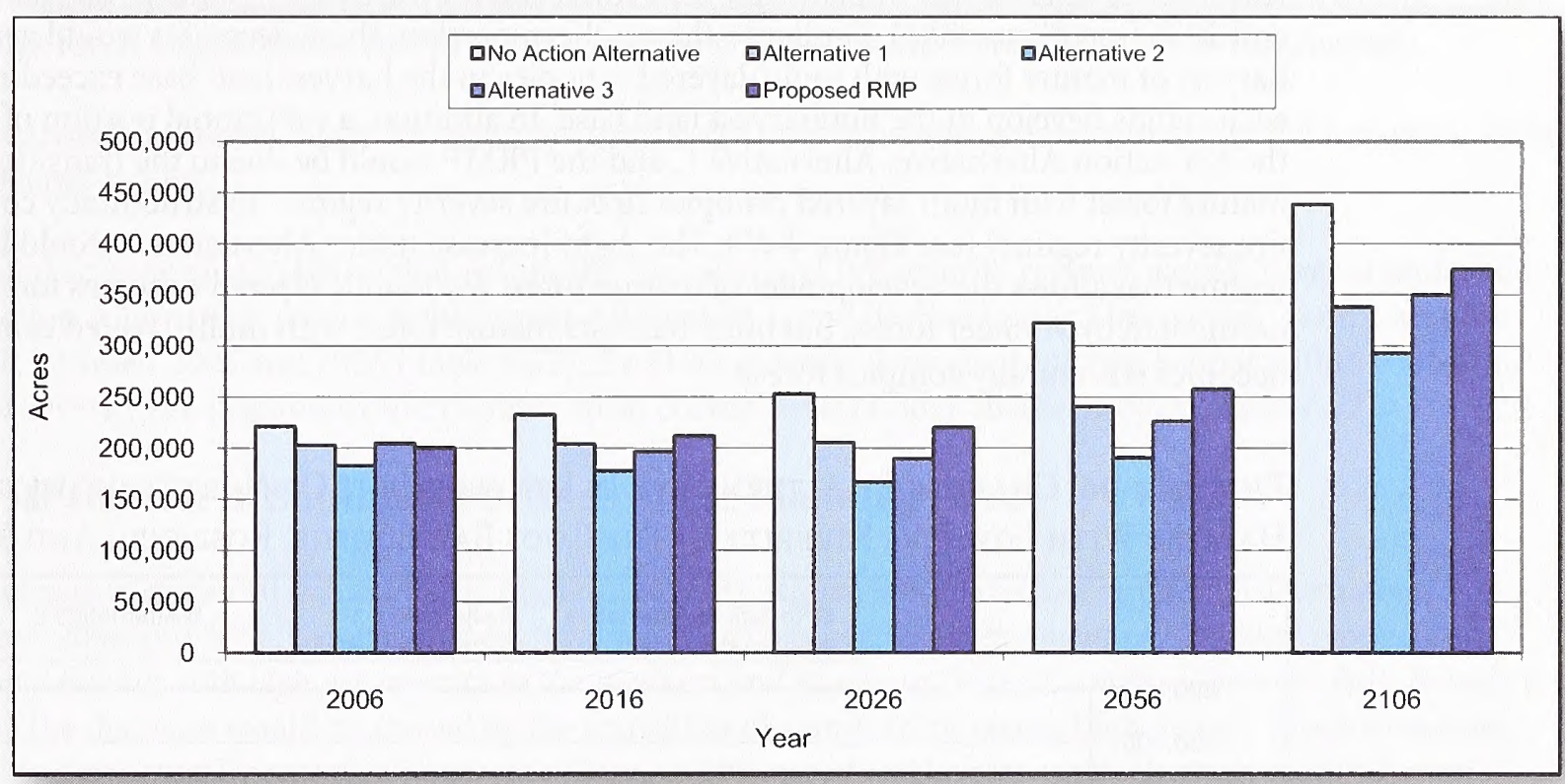

The acreage of suitable habitat within the mixed severity regime would increase during each decade under the No Action Alternative, Alternative 1 and the PRMP, between 2006 and 2056 (Figure 4-95). During this same period, the acreage of suitable habitat within the mixed severity regime under Alternatives 2 and 3 would decrease through 2026 before increasing by 2056 (Figure 4-95). These differing rates of change would reflect differences among the alternatives in the acreage of land allocated to the nonharvest land base, which would foster the development of structurally complex forest (mixed fire severity regime) (see Forest Structure and Spatial Pattern in this chapter).

The total acreage of suitable habitat within the low or mixed fire severity regimes would increase under the No Action Alternative and the PRMP, and decrease under Alternatives 1, 2, and 3, between 2006 and 2056 (Table 4-51). By year 2106, the total acreage of suitable habitat within the low or mixed severity fire regimes would increase from current levels under all alternatives except Alternative 2 (Table 4-51).

As discussed in Chapter 3 (see Northern Spotted $O w l$ ), suitable habitat generally does not fall within the high fire severity regime.

Table 4-51. Percent Change By Alternative Between 2006 And 2056, And Between 2006 And 2106, In The Acres Of Northern Spotted Owl Suitable Habitat With Low Or Mixed Fire Severity In The Medford District And The Klamath Falls Resource Area

\begin{tabular}{|c|c|c|}
\hline Alternative & $\begin{array}{r}\text { Percent Change } \\
2006-2056\end{array}$ & $\begin{array}{r}\text { Percent Change } \\
2006-2106\end{array}$ \\
\hline No Action & +5 & +34 \\
\hline Alternative 1 & -4 & +3 \\
\hline Alternative 2 & -11 & -9 \\
\hline Alternative 3 & -17 & +9 \\
\hline PRMP & +5 & +23 \\
\hline
\end{tabular}




\section{Suitable Habitat in Northern Portions of the Planning Area}

The acreage of suitable habitat within the low fire severity regime would decrease under the No Action Alternative, Alternatives 1 and 2, and the PRMP, and increase slightly under Alternative 3, between 2006 and 2056 (see Figure 4-96). Similar to the southern portion, these decreases would generally be due to the harvest of mature forest with multi-layered canopies in the harvest land base exceeding the rate at which such stands develop in the nonharvest land base. In addition, a substantial portion of the decreases under the No Action Alternative, Alternative 1, and the PRMP would be due to the transition of stands from mature forest with multi-layered canopies (low fire severity regime) to structurally complex forest (mixed fire severity regime) (see Figure 4-97). The slight increase under Alternative 3 would be due to a harvest regime that allows the development of mature forest with multi-layered canopies forest in a landscape dominated by younger forest, but often harvests mature forest with multi-layered canopies forest before it becomes structurally complex forest.

Figure 4-96. Changes By Alternative In Development Of Northern Spotted Owl Suitable Habitat With Low Fire Severity In The Coos Bay, Eugene, Roseburg And Salem Districts

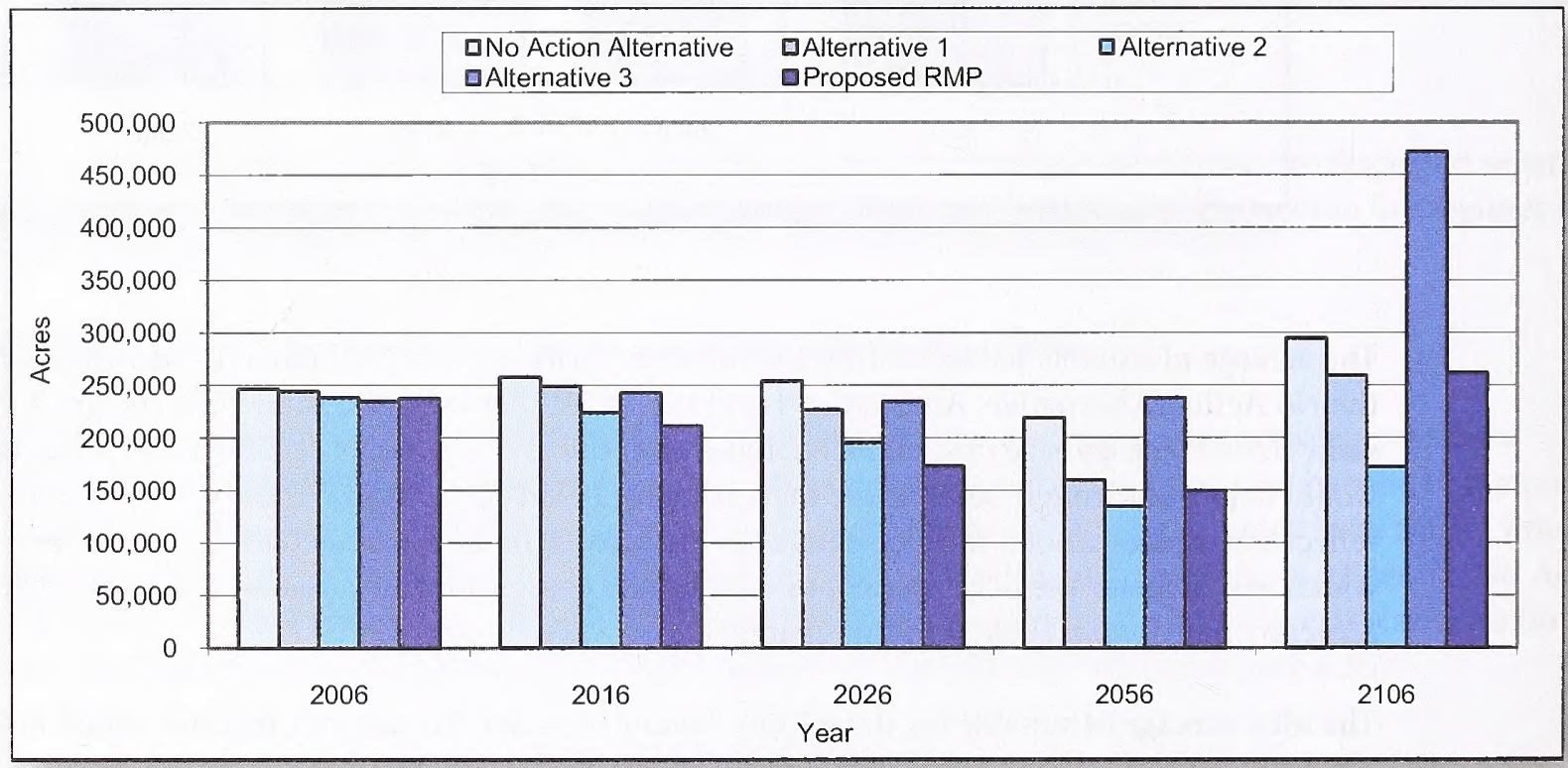

Figure 4-97. Changes By Alternative In Development Of Northern Spotted Owl Suitable Habitat With Mixed Fire Severity In The Coos Bay, Eugene, Roseburg And Salem Districts

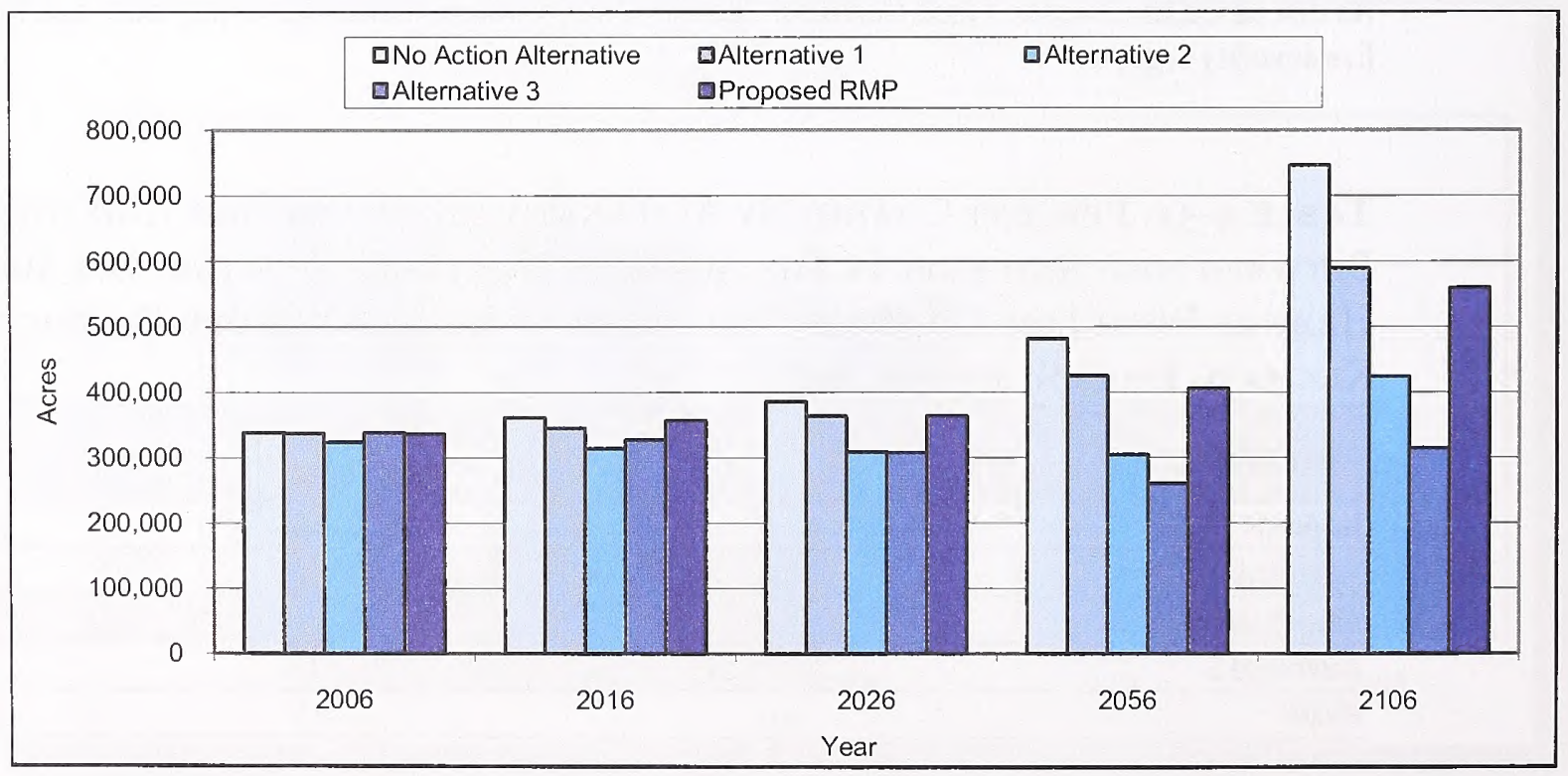


The acreage of suitable habitat within the mixed fire severity regime would increase under the No Action Alternative, Alternatives 1 and 2, and the PRMP, and decrease under Alternative 3, between 2006 and 2056 (Figure 4-97). As in the southern portion, these changes would reflect the differences among the alternatives in acreage of land allocated to the nonharvest land base, which would foster the development of structurally complex forest (mixed fire severity regime) (see Forest Structure and Spatial Pattern in this chapter).

As discussed in Chapter 3 (see Northern Spotted Owl), suitable habitat generally does not fall within the high fire severity regime.

The total acreage of suitable habitat within the low or mixed fire severity regimes would increase under the No Action Alternative, remain stable under Alternative 1, and decline under Alternatives 2 and 3 and the PRMP, between 2006 and 2056 (Table 4-52). By 2106, the total acreage of suitable habitat within the low or mixed severity fire regimes would increase from current levels under all alternatives (Table 4-52).

\section{Dispersal Habitat in Southern Portions of the Planning Area}

The acreage of dispersal habitat in the high fire severity regime would decrease under all alternatives between 2006 and 2056. See Figure 4-98 (Changes by alternative in development of Northern Spotted Owl dispersal habitat with high fire severity in the Medford and Roseburg Districts and the Klamath Falls Resource Area). The decrease would be caused by the transition of stands from young high density forest to mature forest and structurally complex forest (see Figure 4-99) exceeding the rate at which stand establishment forest would transition into young high density forest (see Figure 4-100). Figure 4-99 shows "Changes by alternative in development of Northern Spotted Owl dispersal habitat with low fire severity in the Medford and Roseburg Districts and the Klamath Falls Resource Area." Figure 4-100 shows "Changes by alternative in development of Northern Spotted Owl dispersal habitat with mixed fire severity in the Medford and Roseburg Districts and the Klamath Falls Resource Area." The alternatives would differ according to the quantity of habitat within young high density forest that would be harvested, thus delaying or preventing its transition into mature forest and structurally complex forest and, in many cases, causing it later to become young high density forest.

Table 4-52. Percent Change By Alternative Between 2006 And 2056, And Between 2006 And 2106, In The Acres Of Northern Spotted Owl Suitable Habitat With Low Or Mixed Fire Severity In The Coos Bay, Eugene, Roseburg And SAlem Districts

\begin{tabular}{lrr}
\hline Alternative & Percent Change & Percent Change \\
& $2006-2056$ & $2006-2106$ \\
\hline No Action & +20 & +78 \\
\hline Alternative 1 & 0 & +46 \\
\hline Alternative 2 & -22 & +6 \\
\hline Alternative 3 & -13 & +37 \\
\hline PRMP & -3 & +43 \\
\hline
\end{tabular}


Figure 4-98. Changes By Alternative In The Development Of Northern Spotted Owl Dispersal Habitat With High Fire Severity In The Medford And Roseburg Districts And The Klamath Falls Resource Area

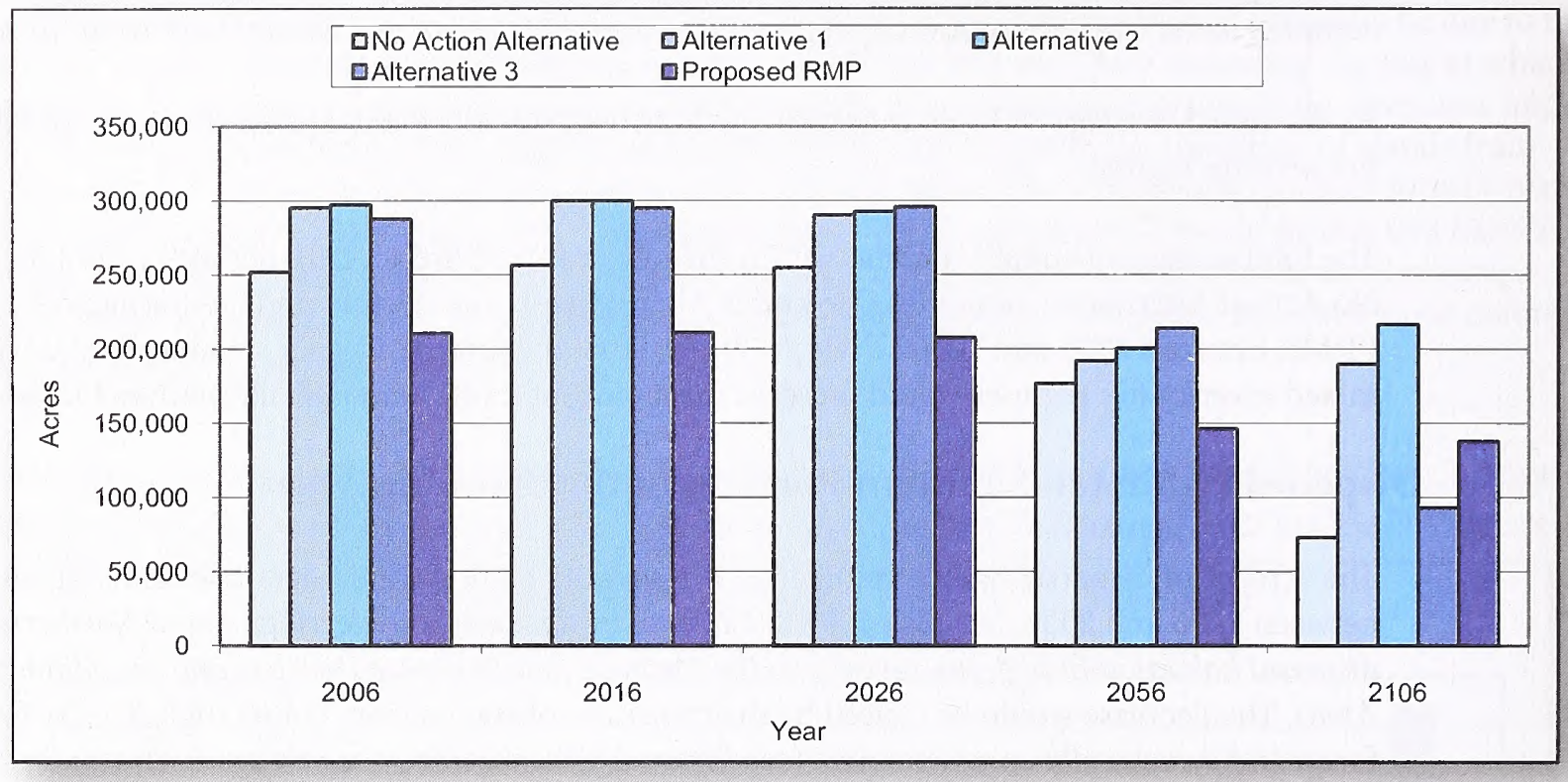

Figure 4-99. Changes By Alternative In The Development Of Northern Spotted Owl Dispersal Habitat With Low Fire Severity In The Medford And Roseburg Districts And The Klamath Falls Resource Area

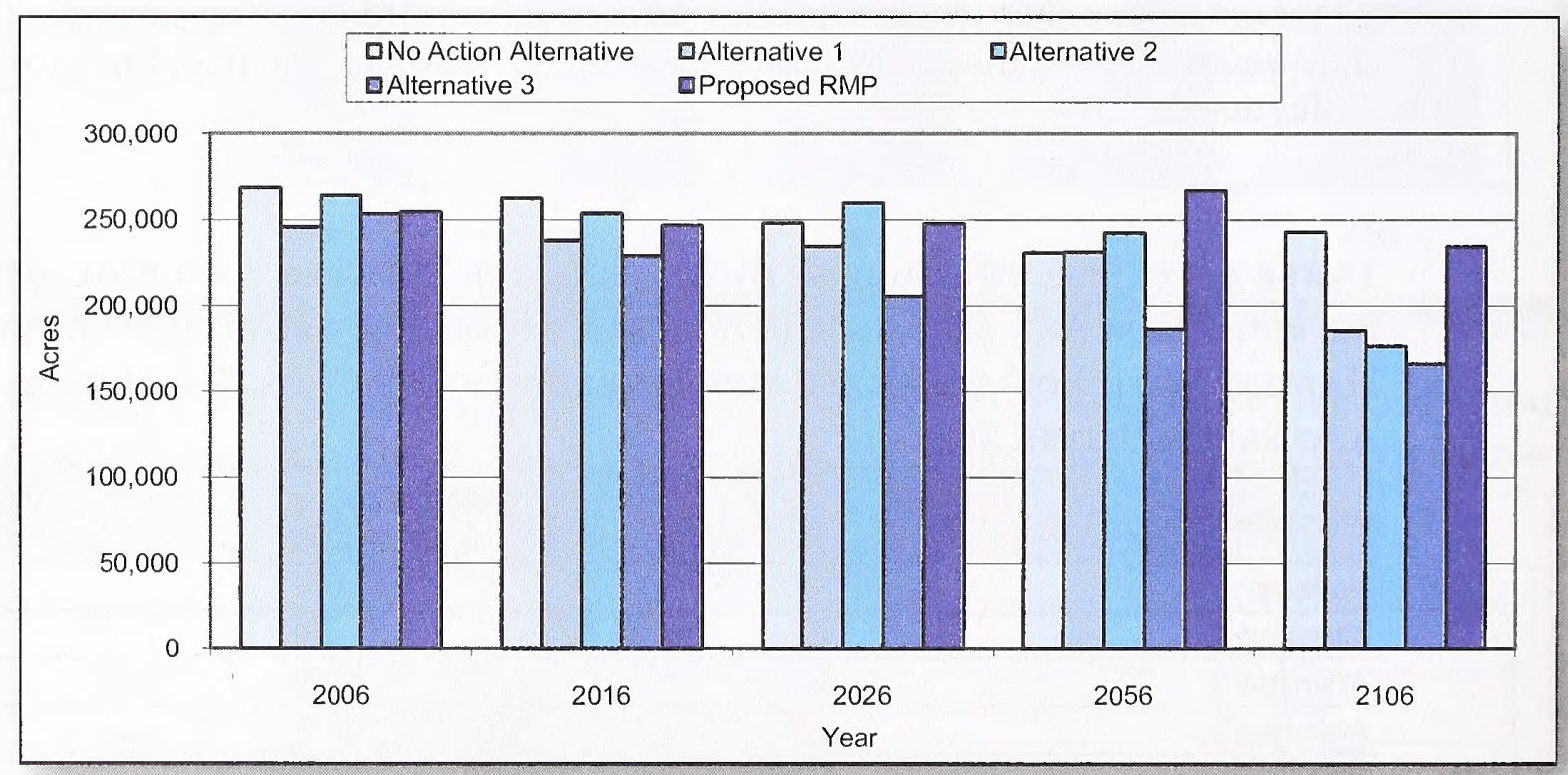

The acreage of dispersal habitat within the low or mixed fire severity regimes would increase under the No Action Alternative, Alternative 1, and the PRMP and decrease under Alternatives 2 and 3 between 2006 and 2056 (Table 4-53). By 2106, the acreage of dispersal habitat within the low or mixed fire severity regimes would increase from current levels under all alternatives (Table 4-53). 
Figure 4-100. Changes By Alternative In The Development Of Northern Spotted Owl Dispersal Habitat With Mixed Fire Severity In The Medford And Roseburg Districts And The Klamath Falls Resource Area

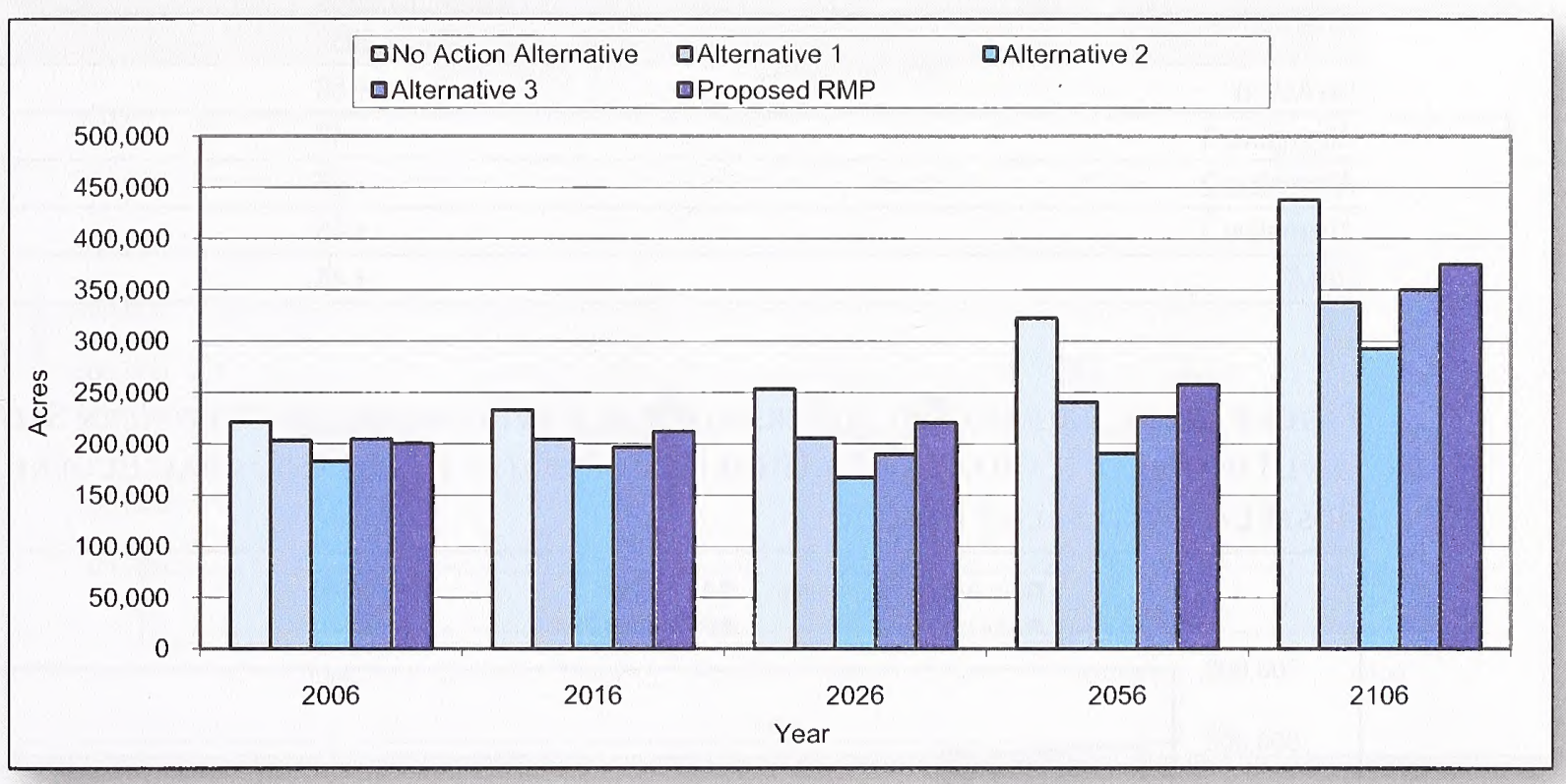

Table 4-53. Percent Change By Alternative Between 2006 And 2056, And Between 2006 And 2106, In The Acres Of Northern Spotted Owl Dispersal Habitat With low Or Mixed Fire Severity In The Medford District And the Klamath Falls Resource Area

\begin{tabular}{lrr}
\hline Alternative & Percent Change & Percent Change \\
$2006-2106$ \\
\hline No Action & $2006-2056$ & +13 \\
\hline Alternative 1 & +5 & +39 \\
\hline Alternative 2 & -3 & +17 \\
\hline Alternative 3 & -10 & +5 \\
\hline PRMP & +15 & +13 \\
\hline
\end{tabular}

\section{Dispersal Habitat in Northern Portions of the Planning Area}

The acreage of dispersal habitat within the low or mixed fire severity regimes would increase under all alternatives. See Table 4-54 (Percent change, by alternative, between 2006 and 2056, and between 2006 and 2106, in the acres of northern spotted owl dispersal habitat with low or mixed fire severity in the Coos Bay, Eugene and Salem Districts). Changes through 2056 would be similar to those that would occur in the southern portion of the planning area and would occur because the transition of stands from young high density forest to mature forest and structurally complex forest would exceed the rate at which stand establishment forest would transition into young high density forest. The principal differences between the northern and southern portions of the planning area are that changes in the quantity of dispersal habitat in each fire severity regime would be greater in the northern portion. This reflects the higher proportion of stands in the northern part of the planning area that currently are in young high density forest and mature with single canopy forest.

Figures 4-101-4-103 show changes in development of northern spotted owl dispersal habitat by alternative in the high, low, or mixed fire severity regimes in the northern portion of the planning area. 
Table 4-54. Percent Change By Alternative Between 2006 And 2056, And Between 2006 And 2106, In The Acres Of Northern Spotted Owl Dispersal Habitat With Low Or Mixed Fire Severity In The Coos Bay, Eugene And Salem Districts

\begin{tabular}{lrr}
\hline Alternative & $\begin{array}{r}\text { Percent Change } \\
2006-2056\end{array}$ & $\begin{array}{r}\text { Percent Change } \\
\text { 2006-2106 }\end{array}$ \\
\hline No Action & +59 & +72 \\
\hline Alternative 1 & +47 & +65 \\
\hline Alternative 2 & +27 & +41 \\
\hline Alternative 3 & +43 & +46 \\
\hline PRMP & +44 & +61 \\
\hline
\end{tabular}

Figure 4-101. Changes By Alternative In Development Of Northern Spotted Owl Dispersal Habitat With High Fire Severity In The Coos Bay, Eugene, Roseburg And Salem Districts

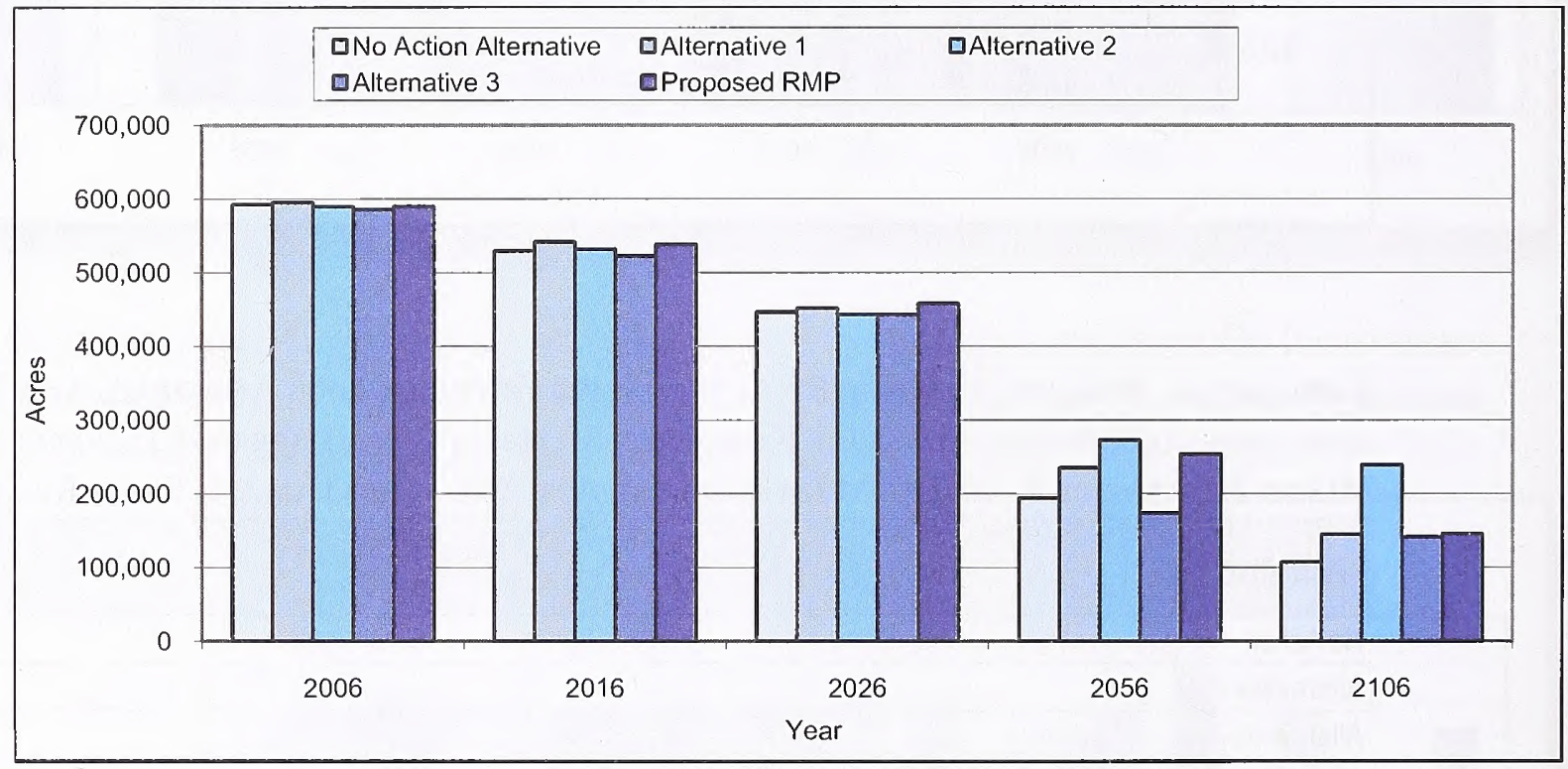

Figure 4-102. Changes By Alternative In Development Of Northern Spotted Owl Dispersal Habitat With Low Fire Severity In The Coos Bay, Eugene, Roseburg And Salem districts

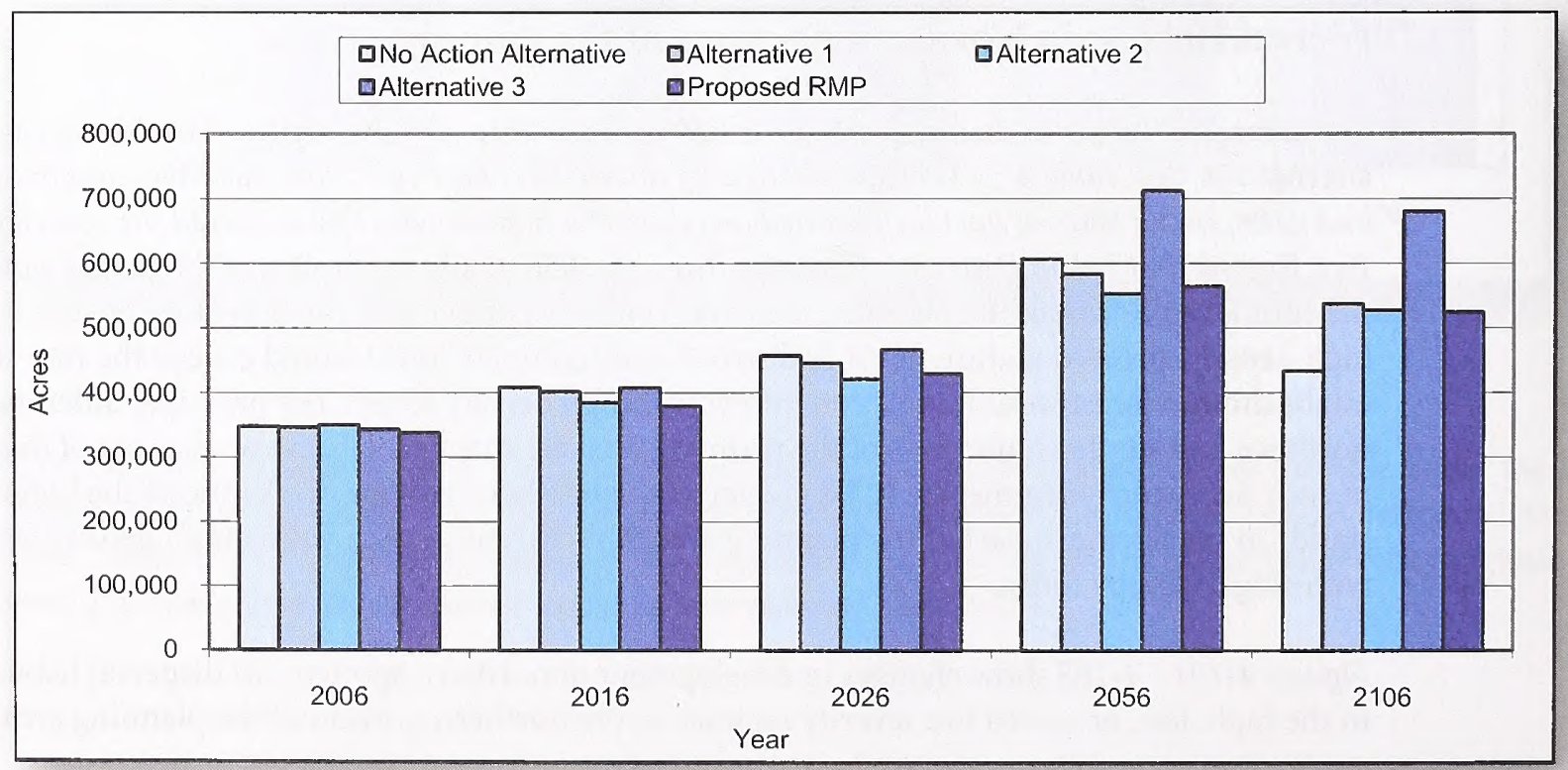


Figure 4-103. Changes By Alternative In Development Of Northern Spotted Owl Dispersal Habitat With Mixed Fire Severity In The Coos Bay, Eugene, Roseburg And Salem Districts

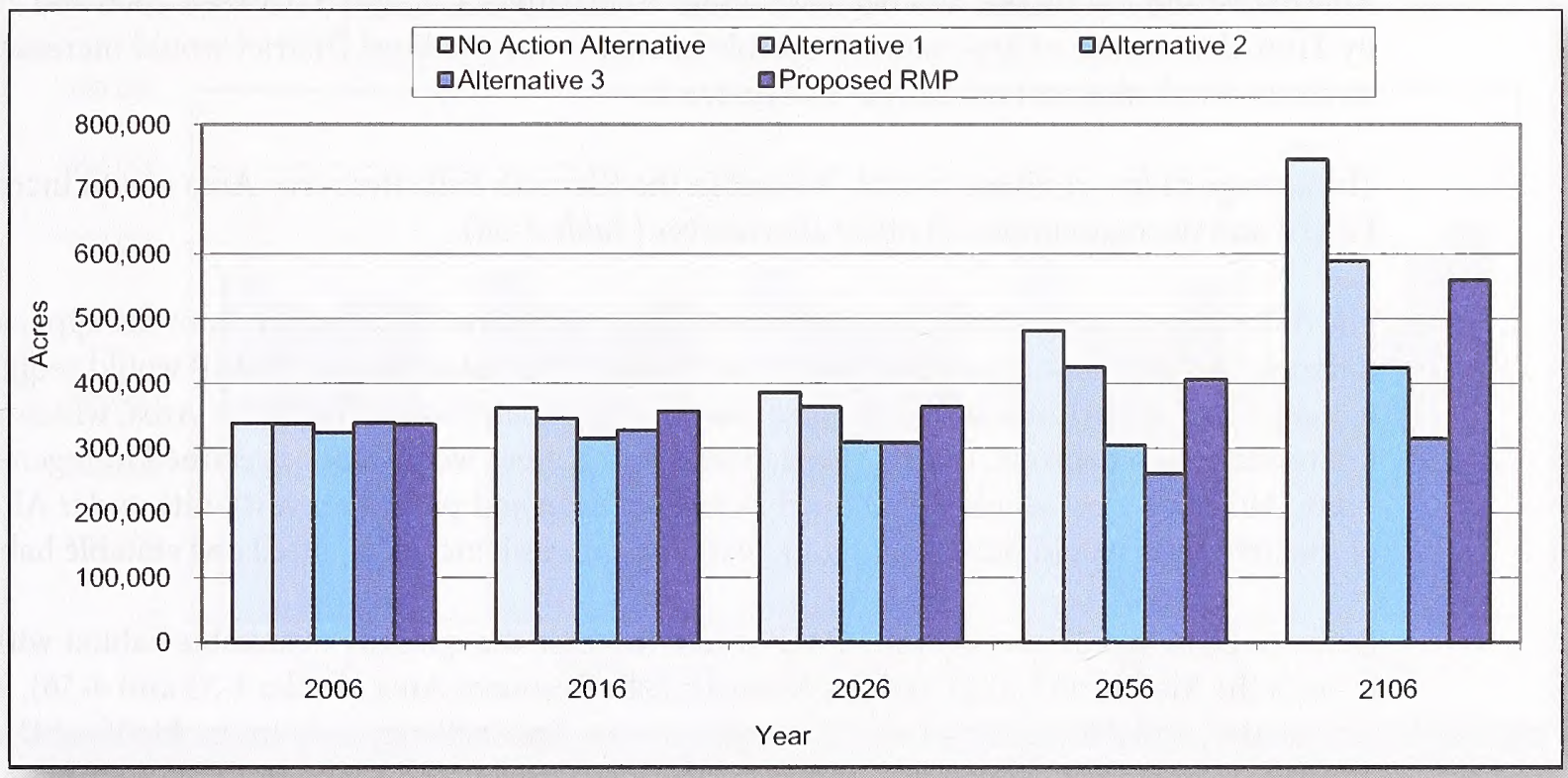

\section{Conclusions for Fire Severity}

On BLM-administered lands, between 2006 and 2056:

- The No Action Alternative would contribute to Conservation Need 3, because the acres of spotted owl suitable and dispersal habitats in the low and mixed fire severity regimes would increase throughout the planning area.

- Alternative 1 would not contribute to Conservation Need 3, because the acres of spotted owl suitable habitat in the low and mixed fire severity regimes in the southern portion of the planning area would decrease where the risk to spotted owl habitat is higher.

- Alternatives 2 and 3 would not contribute to Conservation Need 3, because the acres of spotted owl suitable habitat in the low and mixed fire severity regimes throughout the planning area would decrease, with substantial decreases in the southern portion of the planning area where the risk to spotted owl habitat is higher. Also, the acres of dispersal habitat in the low and mixed fire severity regime would decrease in the southern portion of the planning area.

- The PRMP would contribute to Conservation Need 3. Even though the acres of spotted owl suitable habitat in the low and mixed fire severity regimes would decrease in the northern portion of the planning area, it would increase in the southern portion of the planning area where the risk to spotted owl habitat is higher. The acres of dispersal habitat in these regimes would substantially increase throughout the planning area under the PRMP.

\section{Fire Resiliency}

As detailed in Chapter 3 (see Northern Spotted Owl), fire resiliency is the ability of a vegetative community to withstand or recover from a fire disturbance. The stand structural classes that exhibit fire resiliency are stand establishment with structural legacies, young forest with structural legacies, mature forest, and structurally complex forest. It is evaluated in this analysis only in the Klamath Falls Resource Area and the Medford District. 


\section{Northern Spotted Owl Suitable Habitat}

The acreage of fire-resilient suitable habitat in the Medford District would increase under the No Action Alternative and the PRMP, and decrease under Alternatives 1, 2, and 3 between 2006 and 2056 (Table 4-55). By 2106, the acreage of fire-resilient suitable habitat in the Medford District would increase from current levels under all alternatives except Alternative 2.

The acreage of fire-resilient suitable habitat in the Klamath Falls Resource Area would increase under the PRMP, and decrease under all other alternatives (Table 4-56).

The differences among alternatives in fire resiliency would result primarily from the application of different management prescriptions to retain trees in harvest units. The PRMP would require uneven-age management in portions of the Medford District and Klamath Falls Resource Area, which would improve fire resiliency. In contrast, under Alternatives 1 and 2, trees would not be retained in regeneration harvest units. Although trees would be retained in regeneration and partial harvest units under Alternative 3 , little of this retention would occur in, and increase the fire resiliency of, spotted owl suitable habitat.

Between 2006 and 2106, only the PRMP would increase the quantity of suitable habitat with fire resiliency in both the Medford District and the Klamath Falls Resource Area (Tables 4-55 and 4-56). The No Action Alternative, and Alternatives 1 and 3, would increase fire resiliency only in the Medford District. Alternative 2 would decrease fire resiliency in both the Medford District and Klamath Falls Resource Area.

Figures 4-104 and 4-105, respectively, show changes in development of northern spotted owl suitable habitat, by alternative, with fire resiliency in the Medford District and the Klamath Falls Resource Area.

Table 4-55. Percent Change By Alternative Between 2006 And 2056, And Between 2006 And 2106, In The Acres Of Northern Spotted Owl Suitable Habitat With Fire Resiliency In The Medford District

\begin{tabular}{lrr}
\hline Alternative & Percent Change & Percent Change \\
No Action & $2006-2056$ & 2006-2106 \\
\hline Alternative 1 & +6 & +38 \\
\hline Alternative 2 & -2 & +7 \\
\hline Alternative 3 & -9 & -6 \\
\hline PRMP & -14 & +14 \\
\hline
\end{tabular}

Table 4-56. Percent Change By Alternative Between 2006 And 2056, And Between 2006 And 2106, In The Acres Of Northern Spotted Owl Suitable Habitat With Fire Resiliency In The Klamath Falls Resource Area

\begin{tabular}{lrr}
\hline Alternative & Percent Change & Percent Change \\
& $\mathbf{2 0 0 6 - 2 0 5 6}$ & $\mathbf{2 0 0 6}-\mathbf{2 1 0 6}$ \\
\hline No Action & -13 & -23 \\
\hline Alternative 1 & -33 & -52 \\
\hline Alternative 2 & -31 & -48 \\
\hline Alternative 3 & -65 & -57 \\
\hline PRMP & +4 & +16 \\
\hline
\end{tabular}


Figure 4-104. Changes By Alternative In Development Of Northern Spotted Owl Suitable Habitat With Fire Resiliency In The Medford District

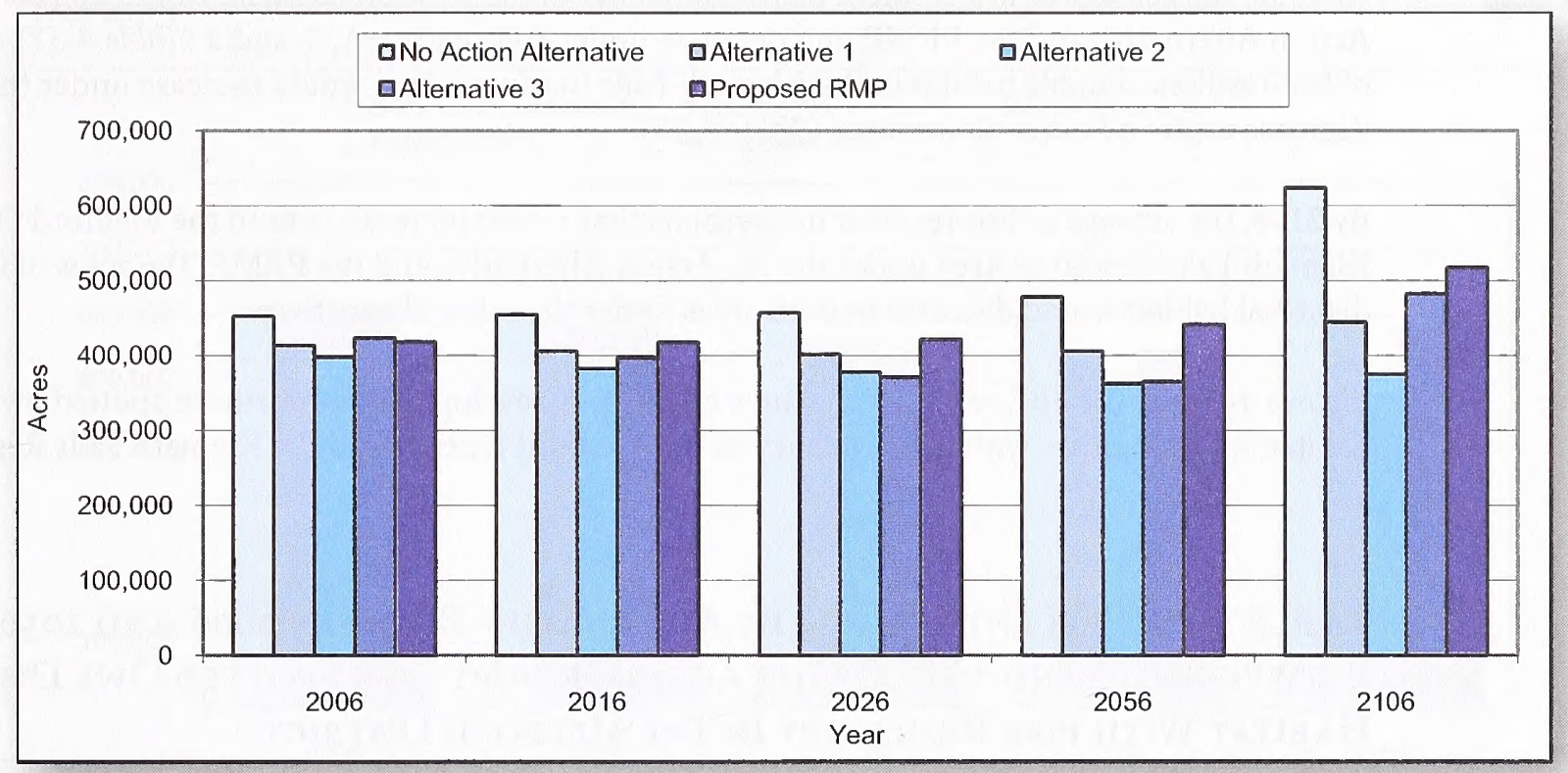

Figure 4-105. Changes By Alternative In Development Of Northern Spotted Owl Suitable Habitat With Fire Resiliency In The Klamath Falls Resource Area

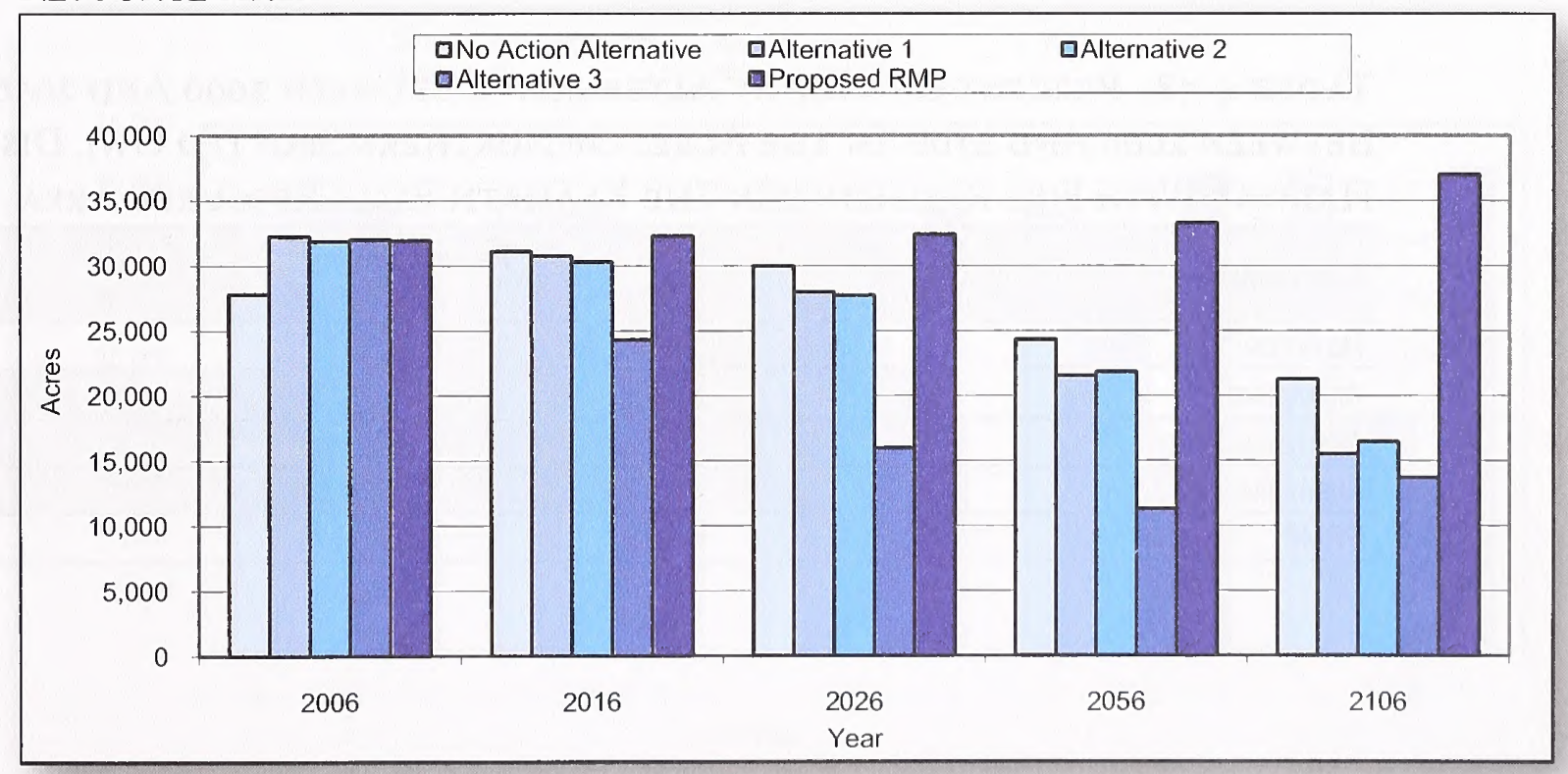




\section{Northern Spotted Owl Dispersal Habitat}

By 2056, the acreage of fire-resilient dispersal habitat in the Medford District would increase under the No Action Alternative and the PRMP, and decrease under Alternatives 1, 2, and 3 (Table 4-57). The acreage of fire-resilient suitable habitat in the Klamath Falls Resource Area would increase under the PRMP and decrease under all other alternatives (Table 4-58).

By 2106, the acreage of fire-resilient dispersal habitat would increase in both the Medford District and Klamath Falls Resource Area under the No Action Alternative and the PRMP. The acres of fire-resilient dispersal habitat would decrease in both areas under the other alternatives.

Figures 4-106 and 4-107, respectively, show changes in development of northern spotted owl dispersal habitat, by alternative, with fire resiliency in the Medford District and the Klamath Falls Resource Area.

Table 4-57. Percent Change By Alternative Between 2006 And 2056, And Between 2006 And 2106, In The Acres Of Northern Spotted Owl Dispersal Habitat With Fire Resiliency In The Medford District

\begin{tabular}{lrr}
\hline Alternative & Percent Change & Percent Change \\
& $2006-2056$ & $2006-2106$ \\
\hline No Action & +5 & +16 \\
\hline Alternative 1 & -10 & -13 \\
\hline Alternative 2 & -16 & -21 \\
\hline Alternative 3 & -11 & -5 \\
\hline PRMP & +3 & +12 \\
\hline
\end{tabular}

Table 4-58. Percent Change By Alternative Between 2006 And 2056, And Between 2006 And 2106, In The Acres Of Northern Spotted Owl Dispersal Habitat With Fire Resiliency In The Klamath Falls Resource Area

\begin{tabular}{|c|c|c|}
\hline Alternative & $\begin{array}{r}\text { Percent Change } \\
2006=2056 \\
\end{array}$ & $\begin{array}{r}\text { Percent Change } \\
2006=2106 \\
\end{array}$ \\
\hline No Action & -3 & +6 \\
\hline Alternative 1 & -25 & -49 \\
\hline Alternative 2 & -23 & -47 \\
\hline Alternative 3 & -52 & -60 \\
\hline PRMP & +18 & +20 \\
\hline
\end{tabular}


Figure 4-106. Changes By Alternative In Development Of Northern Spotted Owl Dispersal Habitat With Fire Resiliency In The Medford DISTRICT

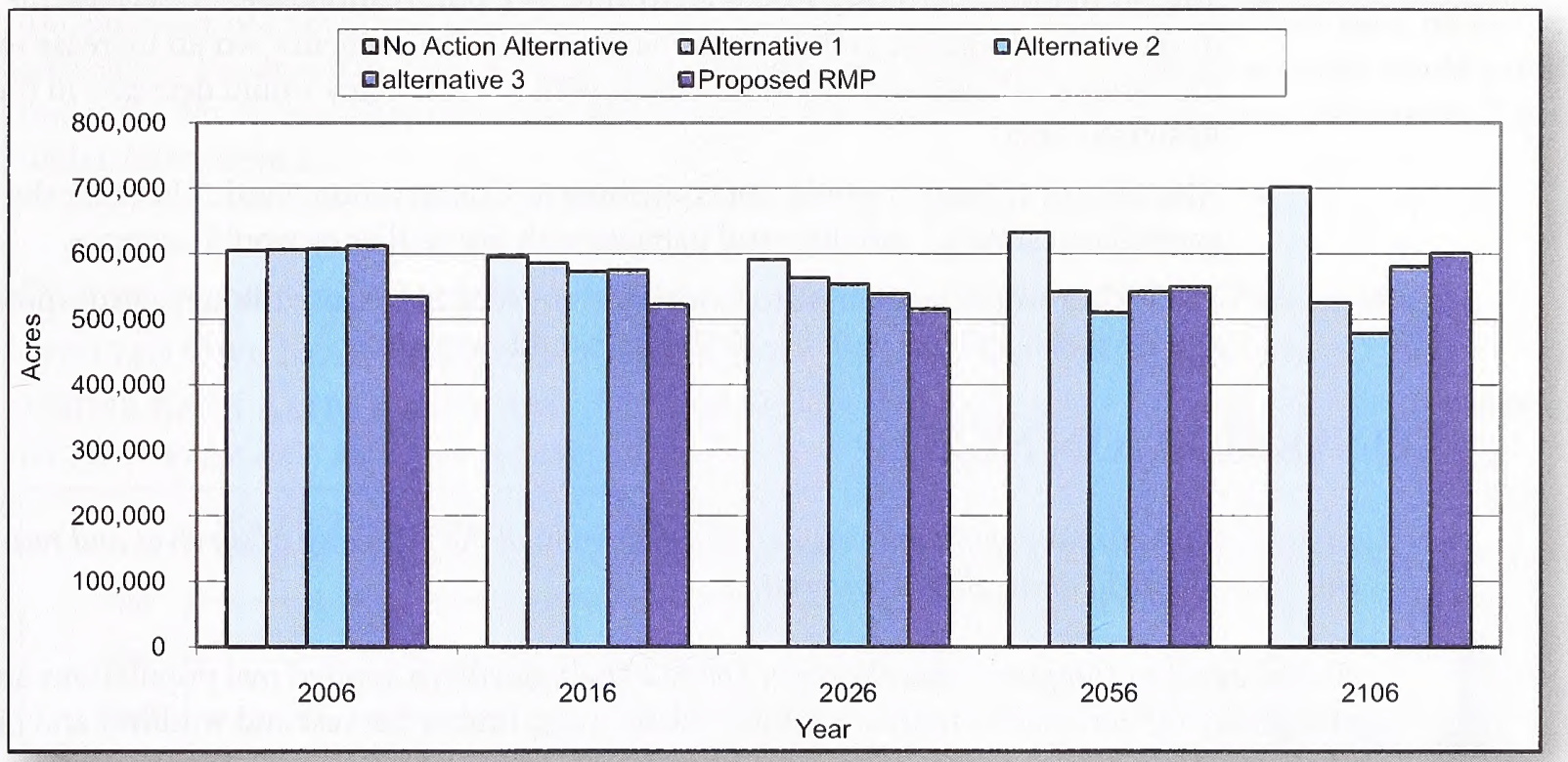

Figure 4-107. Changes By Alternative In Development Of Northern Spotted Owl Dispersal Habitat With Fire Resiliency In The Klamath Falls Resource Area

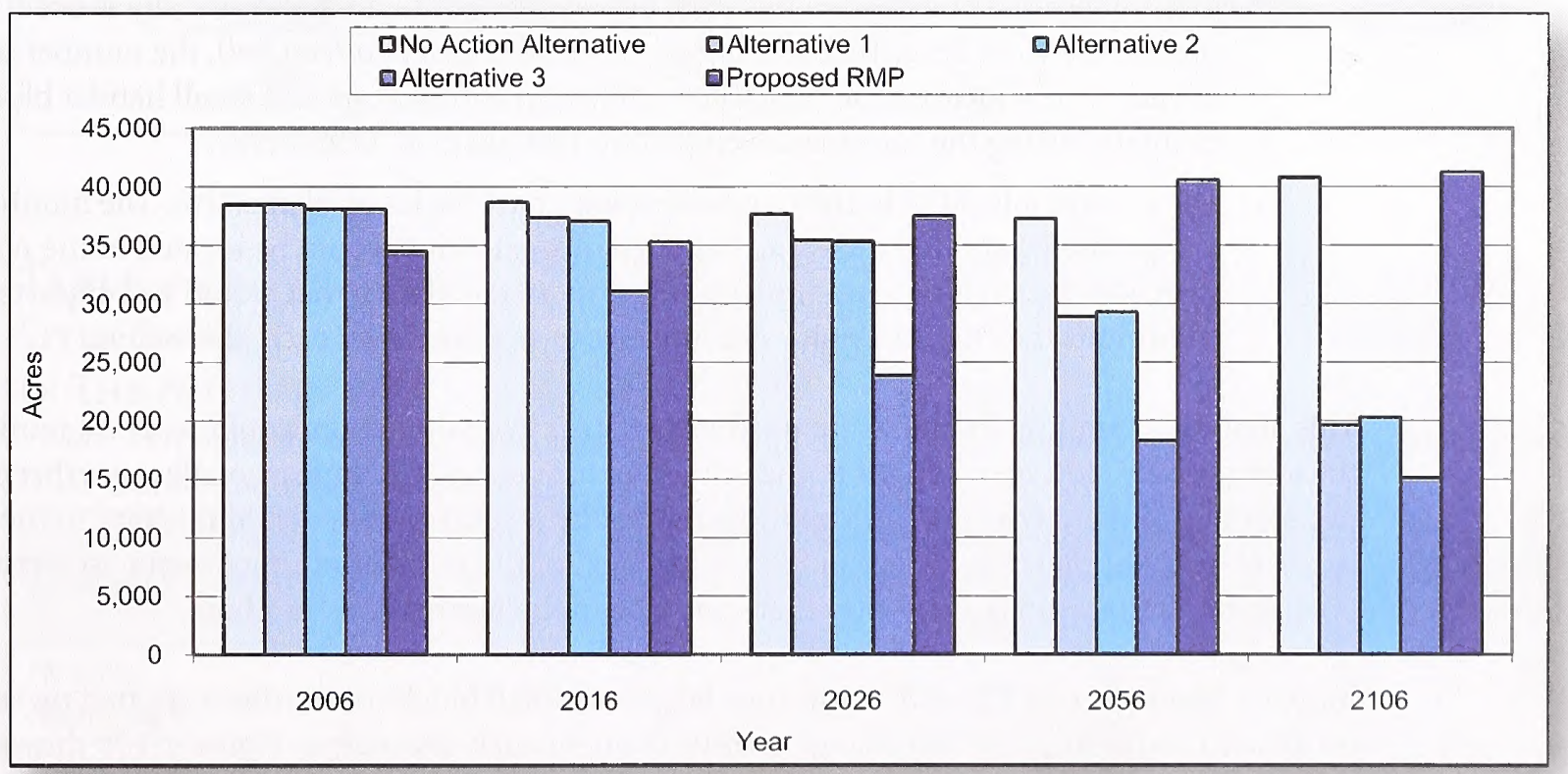




\section{Conclusions for Fire Resiliency}

On BLM-administered lands, between 2006 and 2056:

- The No Action Alternative would contribute to Conservation Need 3, because the total acreage of spotted owl suitable and dispersal habitats with fire resiliency would increase (even though the acres of suitable and dispersal habitat with fire resiliency would decrease in the Klamath Falls Resource Area).

- Alternatives 1,2 and 3 would not contribute to Conservation Need 3, because the acreage of spotted owl suitable and dispersal habitats with fire resiliency would decrease.

- The PRMP would contribute to Conservation Need 3, because the acreage of spotted owl suitable and dispersal habitats with fire resiliency would increase.

\section{CONSERVATION NEED 4}

In areas of significant population decline, the application of the full range of survival and recovery options for this species in light of significant uncertainty

As discussed in Chapter 3 (see Northern Spotted $O w l$ ), northern spotted owl populations appear to be affected by influences that both are habitat-related (e.g., timber harvest and wildfire) and not directly related to habitat (e.g., competition from barred owls and West Nile virus). Since scientists currently cannot separate the effects of these influences on spotted owl populations, the BLM has no credible means to evaluate how the alternatives (which would affect primarily habitat) alone would affect those populations. Instead, this analysis examines how the alternatives would affect: (1) the estimated number of functional northern spotted owl nest territories on all land ownerships, and (2) the number of known and predicted spotted owl sites on BLM-administered lands in the nonharvest land base.

- A functional nest territory contains the type, quantity, and spatial arrangement of habitat needed to support a nesting spotted owl pair, whether or not that habitat actually is occupied by nesting spotted owls. As described in Chapter 3 (see Northern Spotted Owl), the number of functional territories is a measure of the habitat contained within large and small habitat blocks and is estimated using the formula developed by Thomas et al. (1990:198).

- The acreage allocated to the nonharvest land base varies by alternative. The number of known and predicted spotted owl sites that currently exist that would be located in the nonharvest land base under each alternative reflects those spotted owl sites that would be supported by habitat conditions that would persist and improve over time under each alternative.

This analysis cannot predict how the northern spotted owl population would respond numerically to the alternatives. However, in light of the myriad of influences that appear to affect northern spotted owl populations, this analysis provides an indication of how spotted owls would respond to the alternatives, to the extent that their response would be a function of the number of functional nest territories and the portion of existing spotted owl sites that would be in the nonharvest land base.

Map 3-4 and Figures 4-82 - 4-87 show how large and small blocks of northern spotted owl suitable habitat, on all land ownerships, would change over time under each alternative. Figure 4-108 shows how the number of functional northern spotted owl nest territories that would occur within these habitat blocks would change by alternative.

Between 2006 and 2026, the number of functional nest territories would increase from current conditions under the No Action Alternative and Alternative 1: 6\% under the No Action Alternative and 1\% under Alternative 1. During this same period, the number of functional nest territories would decrease from current conditions under Alternatives 2 and 3 and the PRMP: $-8 \%$ under Alternative 2, $-4 \%$ under 
Alternative 3, and $-3 \%$ under the PRMP. By 2056, the number of functional nest territories would increase under all alternatives: $89 \%$ under the No Action Alternative, $77 \%$ under Alternative 1, 64\% under Alternative 2,71\% under Alternative 3 and $76 \%$ under the PRMP.

The numbers of known and predicted northern spotted owl sites in the nonharvest land base, under each alternative, are shown in Table 4-59. At least $40 \%$ of known and predicted spotted owl sites would persist under the No Action Alternative and Alternative 1; 37\% under the PRMP; 27\% under Alternative 2, and 6\% under Alternative 3.

Figure 4-108. Changes In The Estimated Number Of Functional Northern Spotted Owl Nest Territories That Would Occur On All Land Ownerships Under Each Alternative And According To The No Harvest Reference Analysis (Note: Data for 2036 and 2046 are not included for the No Action Alternative or Alternatives 1 and 3.)

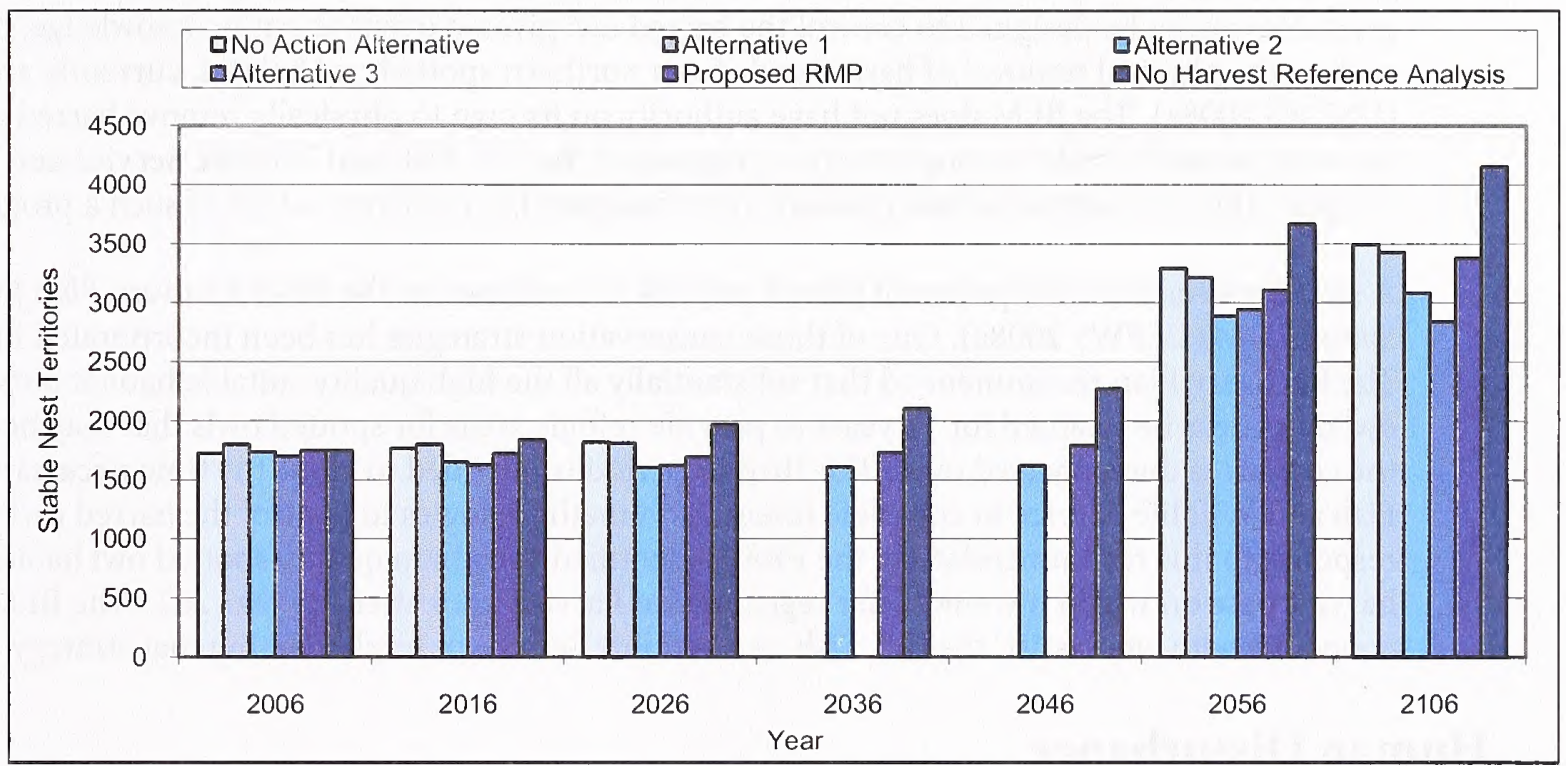

Table 4-59. The Numbers Of Known And Predicted Northern Spotted Owl Sites On BlM-Administered Lands In The Planning Area That Currently Occur In The Nonharvest Land Base Under Each Alternative.

(Note: Percentages are those portions of the known $(1,110)$ and predicted (196) spotted owl sites that occur on $B L M$-administered lands in the planning area.)

\begin{tabular}{lrr}
\hline Alternative & $\begin{array}{r}\text { Number (percent) of Known Spotted } \\
\text { Owl Activity Sites In the Nonharvest } \\
\text { Land Base }\end{array}$ & $\begin{array}{r}\text { Number (percent) of Predicted Spotted } \\
\text { Owl Sites In the Nonharvest Land Base }\end{array}$ \\
\hline No Action & $474(43 \%)$ & $44(22 \%)$ \\
\hline Alternative 1 & $524(47 \%)$ & $45(23 \%)$ \\
\hline Alternative 2 & $317(29 \%)$ & $42(21 \%)$ \\
\hline Alternative 3 & $66(6 \%)$ & $18(9 \%)$ \\
\hline PRMP & $442(40 \%)$ & $47(24 \%)$ \\
\hline
\end{tabular}




\section{Effects of the Alternatives on the Barred Owl}

The barred owl is a species that is capable of displacing northern spotted owls from their nest territories (Gremel 2005, Anthony et al. 2006 and Forsman et al. 2006). The Final Recovery Plan for the Northern Spotted Owl (USFWS2008a:64-66, 107-108) describes the potential threat that the barred owl poses to the northern spotted owl and the difficulties of verifying relationships between barred owl occupancy and habitat management. That discussion is incorporated here by reference. This EIS does not conduct a detailed analysis of the effects of the alternatives on the barred owl, because the current knowledge of the barred owl, and of how barred owls and northern spotted owls interact, is insufficient to design habitat management practices that control or lessen the potential effect of the barred owl on spotted owl conservation. Because of this, the BLM has no credible means to evaluate how the alternatives would influence the potential effect of the barred owl on spotted owl conservation.

Although barred owl occupancy might pose a risk to the conservation of the northern spotted owl, the level of that risk has yet to be determined scientifically. Since land use allocations and habitat management practices cannot be designed to control the barred owl given current scientific knowledge, other practices, such as the physical removal of barred owls from northern spotted owl habitat, currently are being evaluated (USFWS 2008a). The BLM does not have authority on its own to physically remove barred owls. The BLM, however, would be able to cooperate in a program of the U.S. Fish and Wildlife Service and the State of Oregon. The alternatives neither preclude nor anticipate the implementation of such a program.

A strategy to address the potential barred owl risk is contained in the Final Recovery Plan for the Northern Spotted Owl (USFWS 2008a). One of those conservation strategies has been incorporated into the PRMP. The Recovery Plan recommended that substantially all the high quality suitable habitat outside the managed owl core areas be retained for 10 years to provide refugia areas for spotted owls that may be dispersing from the core areas due to barred owls. The 10-year period is intended to allow the time necessary for the U.S. Fish and Wildlife Service to complete research on methodologies to control the barred owl incursion. In response to this recommendation, the PRMP identified such high quality spotted owl habitat in the timber harvest base on which it would defer regeneration harvest until after the year 2023. The BLM will continue to cooperate with, and assist, the U.S. Fish and Wildlife Service in implementing that strategy.

\section{Human Disturbance}

Disturbances associated with a variety of land use actions can negatively affect northern spotted owls. Such disturbances would be most likely to include: elevated (above ambient ${ }^{11}$ ) levels of noise in occupied nesting habitat during breeding periods (e.g., from the use of chainsaws or the felling and yarding of trees in adjacent stands); increased human intrusions into occupied habitat; and mechanical shaking of occupied trees (e.g., by the rotor-wash of hovering helicopters, or the movement of yarding cables). Such disturbances are more likely to disrupt normal behavior in a manner that would affect individual spotted owls when the disturbances occur during the breeding period and in proximity to an active nest (USFWS 2003 and 2007b). Examples of disrupted behavior include abandonment of a nest or territory, interrupted foraging, and delayed feeding of the young.

Normally, potential disruptions are of short duration (i.e., hours or days during a single breeding period), and they commonly are substantially reduced or completely eliminated during project planning by the application of protection measures (e.g., timing restrictions). For these reasons, the effects of disturbances on northern spotted owls generally are considered to be less significant than the effects of habitat loss (USFWS 2003).

\footnotetext{
${ }^{11}$ In this context, ambient refers to the level of pre-project disturbance. For example, log hauling along a road that normally receives substantial use by the public probably would not cause disturbances that exceed the ambient level. However, that same hauling along a road that receives no or infrequent public use might cause disturbances that exceed the ambient level because resident owls are less habituated to those disturbances. Determinations of whether disturbances would affect northern spotted owls can only be made by examining individual projects.
} 
The potential effects to spotted owl populations from disturbances associated with the alternatives are not evaluated here because: (1) all of the alternatives restrict activities that require a BLM permit and could disrupt normal behaviors during the breeding period, and (2) the application of those restrictions, and the potential effects of proposed site-specific disturbances, are more accurately evaluated during project planning and, when affects are anticipated, associated Section 7 consultation with the U.S. Fish and Wildlife Service.

There would be no substantive disturbance effects from BLM management activities to known nesting northern spotted owls under any of the alternatives because, under all alternatives, the BLM would restrict activities that would disrupt nesting northern spotted owls, including, if necessary, the casual uses of BLM facilities. The BLM normally does not control most casual use of BLM-administered lands and facilities (i.e., lawful activities that do not require a BLM permit), such as recreational activities, because they tend to be dispersed and rarely cause more than temporary effects to individual northern spotted owls. 


\section{Marbled Murrelet}

This analysis describes the abundance and development of marbled murrelet nesting habitat and the patch dynamics of marbled murrelet nesting habitat. This focus on nesting habitat instead of population levels is necessary and appropriate for several reasons. First, effects in terms of population levels cannot be analyzed based on habitat changes because population size is affected by numerous factors other than habitat. A large portion of the marbled murrelet life cycle is tied to at-sea conditions including food supplies and mortality due to oil spills and other sea conditions. Changes in sea conditions are likely to vary widely over the next 100 years. The interaction of sea conditions and habitat changes is unknown. Consequently, a model is not available that can predict population levels based on habitat amounts and configuration. Although it is not possible to predict what population levels would be supported by a particular amount or configuration of habitat, the characteristics of the habitat that is used by murrelets for nesting is known, and the relative abundance of such habitat among the alternatives can be analyzed. It is reasonable to assume that an alternative that would provide more nesting habitat opportunities for murrelets than another alternative would also support a potentially higher population of marbled murrelets. This is true even though the population level is affected by so many other factors unrelated to nesting habitat conditions, which is the only element of the species' life requirements that would be affected by BLM's management under the alternatives.

\section{Surveys and Marbled Murrelet Sites}

Under all alternatives, known occupied marbled murrelet sites would receive protection from harvest. There are currently 226 known occupied marbled murrelet sites on BLM-administered lands, which were found between 1993 and 2006.

Marbled murrelet surveys prior to any nesting habitat-disturbing activities would be required through management action under the No Action Alternative and the PRMP. Protection from harvest of occupied murrelet sites would be required through management action under Alternatives 1 and 3 , and surveys are assumed to occur as an analytical assumption. The analysis for the No Action Alternative, Alternative 1, and Alternative 3 predicts discovery and protection of future marbled murrelet sites based on past detection rates of sites found per acre of planned harvest, by murrelet zone, since it is reasonable to assume future detection rates will reflect current experience. Based on past detection rates, 560 new sites would be located and protected under the No Action Alternative, 599 new sites under Alternative 1, and 868 new sites under Alternative 3 through 2016.

Under Alternative 3, occupied marbled murrelet sites would be protected from harvest until $50 \%$ of the acres in an assessment area are older than defined threshold stand ages. The year at which the $50 \%$ threshold would be met and the protection of the marbled murrelet sites would be removed under Alternative 3 are shown in Table 4-60 (Year at which the threshold age would be reached after which marbled murrelet sites would not be protected under Alternative 3).

There would be no protection from timber harvests of occupied marbled murrelet sites through management actions under Alternative 2; therefore, it was assumed for analytical purposes that predisturbance surveys would not occur. Because of the secretive nature of nesting marbled murrelets, it is not reasonable to expect that additional sites would be found without surveys. Applying the same modeling assumptions as for No Action Alternative and Alternatives 1 and 3, which were based on past detection rates, approximately 1,650 murrelet sites would be harvested under Alternative 2 through 2016, in the absence of pre-project surveys.

The analysis used to project the discovery and protections of additional occupied marbled murrelet habitat for the PRMP involved a description of the minimum stand ages for existing occupied murrelet sites. It also involved calculation of detection rates by district, resource area (physiographic provinces were used in the Coos Bay District), and marbled murrelet zone ( 0 to 25 miles and $25+$ miles from the coast were used in the Coos Bay District). This analysis projected 18,700 acres that would be protected from timber harvest in the next 10 years around occupied marbled murrelet sites under the PRMP. 
Table 4-60. Year At Which The Threshold Age Would Be Reached After Which Marbled Murrelet Sites Would Not Be Protected Under Alternative 3

\begin{tabular}{lll}
\hline $\begin{array}{l}\text { Sustained Yield Unit } \\
\text { (BLM District) }\end{array}$ & Province & Year \\
\hline Salem & Coast Range & 2046 \\
\hline Eugene & Coast Range & 2046 \\
\hline Roseburg & Coast Range & 2016 \\
\hline Roseburg & Klamath & 2106 \\
\hline Coos Bay & Coast Range & 2056 \\
\hline Coos Bay & Klamath & 2026 \\
\hline Medford & Klamath & 2056 \\
\hline
\end{tabular}

\section{Marbled Murrelet Nesting Habitat}

There are 881,000 acres of BLM-administered lands capable of growing nesting habitat for the marbled murrelet: 641,000 acres occur within marbled murrelet Zone 1, and 250,000 acres occur within marbled murrelet Zone 2. A map of these two zones is in the Wildlife section of Chapter 3. See Table 4-61 (Available marbled murrelet nesting habitat on BLM-administered lands within the planning area).

For this analysis, marbled murrelet habitat is classified as the mature, multiple canopy, and structurally complex structural stage classifications. This classification is based on marbled murrelet nesting suitability category 4 from Raphael et al. (2006). Category 4 structural classifications are stands with a greater than 20 inches quadratic mean diameter with complex canopy structures. Raphael et al. (2006) also classified simple canopy stands with a quadratic mean diameter greater than 30 inches as nesting suitability class 4 . Although the data used for this analysis does not distinguish between the 30-inch and greater diameter class, the assumption is that the majority of those stands would fall into the structurally complex structural stage classification. Marbled murrelet nesting habitat is assumed to include all stands in the mature, multicanopied, and structurally complex structural stages.

By the year 2106, marbled murrelet nesting habitat would increase from the current condition of 367,000 acres, which is $41 \%$ of the total area on BLM-administered lands capable of providing marbled murrelet nesting habitat, to:

- 707,000 acres under the No Action Alternative (79\% of habitat capable)

- 618,000 acres under Alternative 1 (69\% of habitat capable)

- 431,000 acres under Alternative 2 (48\% of habitat capable)

- 489,000 acres under Alternative 3 (55\% of habitat capable)

- 588,000 acres under PRMP ( $66 \%$ of habitat capable)

Figure 4-109 (Marbled murrelet nesting habitat by the year 2106) shows how habitat develops over time. In the first 50 years, there would be a $14-16 \%$ decrease in marbled murrelet nesting habitat under Alternatives 2 and 3 on BLM-administered lands, within the range of the marbled murrelet, from the current condition of 367,000 acres. Marbled murrelet nesting habitat on BLM-administered lands would decrease $2 \%$ in 20 years under the PRMP, but would recover to show a net $5 \%$ increase by 2056 . Even though all five districts exhibit long-term increases in marbled murrelet nesting habitat, short-term declines in available nesting habitat are important to consider in evaluating the effects on the marbled murrelet. This is because a short-term decline of habitat, if large enough, could depress the population to a level from which the marbled murrelet would not recover. 
FEIS for the Revision of the Western Oregon RMPs

Table 4-61. Available Marbled Murrelet Nesting Habitat On BlM-Administered Lands

Within The Planning Area

\begin{tabular}{|c|c|c|c|c|c|c|c|c|c|}
\hline \multirow[b]{2}{*}{ Year } & \multicolumn{3}{|c|}{ Marbled Murrelet Zone 1} & \multicolumn{3}{|c|}{ Marbled Murrelet Zone 2} & \multicolumn{3}{|c|}{ Total } \\
\hline & Developed & Old Forest & Total & Developed & Old Forest & Total & Developed & Old Forest & Total \\
\hline \multicolumn{10}{|c|}{ No Action Alternative } \\
\hline 2006 & 148,000 & 96,000 & 244,000 & 66,000 & 57,000 & 123,000 & 214,000 & 153,000 & 367,000 \\
\hline 2016 & 174,000 & 96,000 & 270,000 & 69,000 & 56,000 & 125,000 & 242,000 & 153,000 & 395,000 \\
\hline 2026 & 192,000 & 96,000 & 288,000 & 70,000 & 56,000 & 126,000 & 262,000 & 152,000 & 414,000 \\
\hline 2056 & 234,000 & 96,000 & 330,000 & 85,000 & 54,000 & 139,000 & 319,000 & 149,000 & 468,000 \\
\hline 2106 & 423,000 & 95,000 & 518,000 & 138,000 & 52,000 & 189,000 & 561,000 & 146,000 & 707,000 \\
\hline
\end{tabular}

Alternative 1

\begin{tabular}{l|r|r|r|r|r|r|r|r|r}
\hline 2006 & 148,000 & 96,000 & 244,000 & 66,000 & 57,000 & 123,000 & 214,000 & 153,000 & 367,000 \\
\hline 2016 & 168,000 & 94,000 & 261,000 & 66,000 & 55,000 & 121,000 & 233,000 & 149,000 & 382,000 \\
\hline 2026 & 173,000 & 94,000 & 267,000 & 63,000 & 55,000 & 117,000 & 236,000 & 148,000 & 384,000 \\
\hline 2056 & 193,000 & 93,000 & 286,000 & 72,000 & 50,000 & 122,000 & 265,000 & 143,000 & 408,000 \\
\hline 2106 & 364,000 & 92,000 & 457,000 & 114,000 & 47,000 & 161,000 & 478,000 & 139,000 & 618,000 \\
\hline
\end{tabular}

Alternative 2

\begin{tabular}{l|r|r|r|r|r|r|r|r|r}
\hline 2006 & 148,000 & 96,000 & 244,000 & 66,000 & 57,000 & 123,000 & 214,000 & 153,000 & 367,000 \\
\hline 2016 & 144,000 & 90,000 & 234,000 & 59,000 & 52,000 & 111,000 & 202,000 & 142,000 & 345,000 \\
\hline 2026 & 140,000 & 86,000 & 226,000 & 55,000 & 47,000 & 101,000 & 194,000 & 133,000 & 327,000 \\
\hline 2056 & 145,000 & 69,000 & 214,000 & 57,000 & 36,000 & 93,000 & 203,000 & 105,000 & 307,000 \\
\hline 2106 & 244,000 & 69,000 & 313,000 & 82,000 & 36,000 & 118,000 & 327,000 & 105,000 & 431,000 \\
\hline
\end{tabular}

Alternative 3

\begin{tabular}{|c|c|c|c|c|c|c|c|c|c|}
\hline & & & & & & & & & \\
\hline 2006 & 148,000 & 96,000 & 244,000 & 66,000 & 57,000 & 123,000 & 214,000 & 153,000 & 367,000 \\
\hline 2016 & 166,000 & 89,000 & 254,000 & 61,000 & 53,000 & 114,000 & 227,000 & 141,000 & 368,000 \\
\hline 2026 & 173,000 & 80,000 & 254,000 & 54,000 & 48,000 & 102,000 & 228,000 & 128,000 & 356,000 \\
\hline 2056 & 166,000 & 60,000 & 226,000 & 58,000 & 33,000 & 92,000 & 224,000 & 93,000 & 317,000 \\
\hline 2106 & 314,000 & 34,000 & 348,000 & 123,000 & 18,000 & 141,000 & 437,000 & 52,000 & 489,000 \\
\hline \multicolumn{10}{|c|}{ PRMP } \\
\hline 2006 & 148,000 & 96,000 & 244,000 & 66,000 & 57,000 & 123,000 & 214,000 & 153,000 & 367,000 \\
\hline 2016 & 157,000 & 96,000 & 253,000 & 59,000 & 57,000 & 116,000 & 216,000 & 153,000 & 369,000 \\
\hline 2026 & 154,000 & 96,000 & 250,000 & 53,000 & 55,000 & 108,000 & 207,000 & 151,000 & 358,000 \\
\hline 2056 & 185,000 & 93,000 & 277,000 & 62,000 & 45,000 & 108,000 & 247,000 & 138,000 & 385,000 \\
\hline 2106 & 351,000 & 93,000 & 444,000 & 104,000 & 40,000 & 144,000 & 455,000 & 133,000 & 588,000 \\
\hline
\end{tabular}

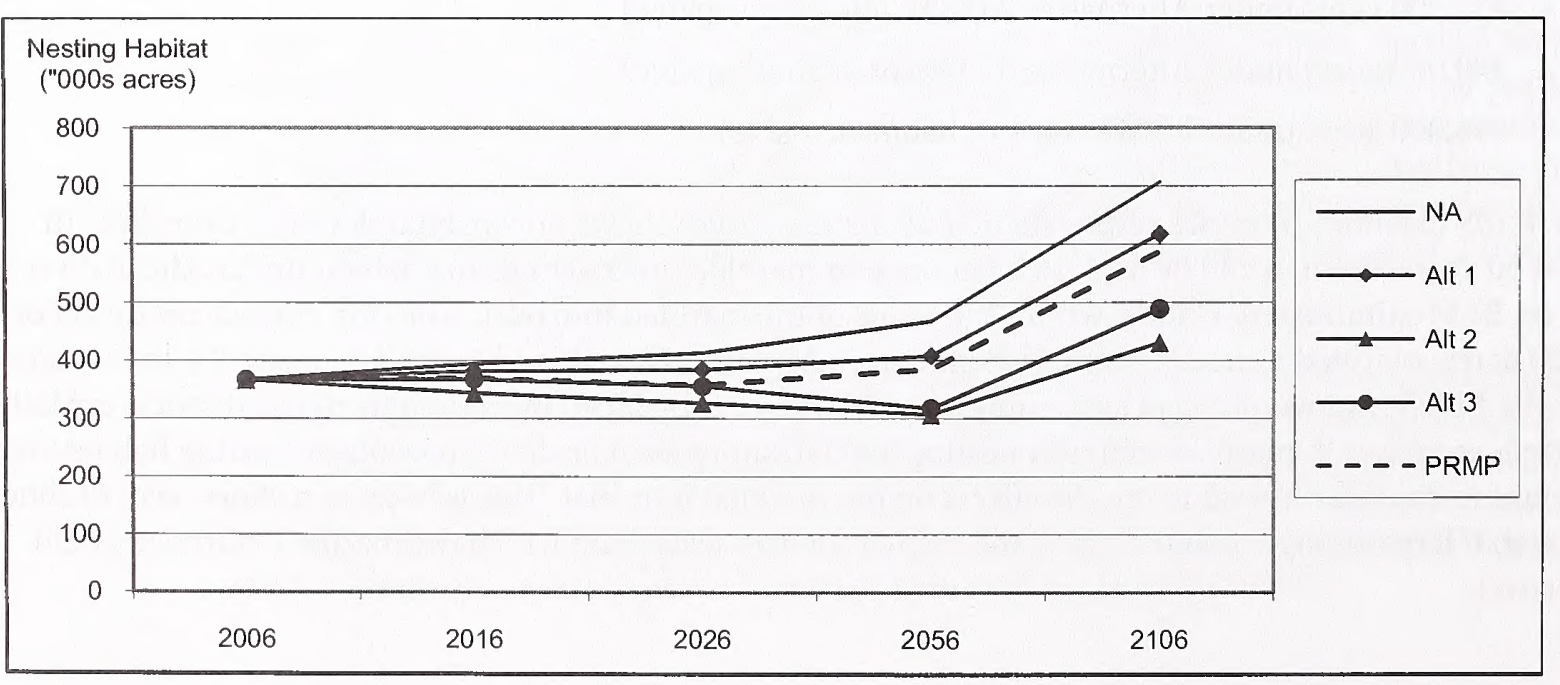

Figure 4-109.

TOTAL MARBLED

MURRELET

Nesting Habitat

BY YEAR 2106 
There are marbled murrelet habitat components that cannot be modeled. These components depend on time for their development and include nesting platform development and canopy gap development. For this reason, old forests structurally complex stands greater than 200 years of age have been analyzed as a component of the overall quantity of marbled murrelet nesting habitat

Structurally complex forests greater than 200 years of age (existing old forest and existing very old forest), as described in Appendix B - Forest Structure and Spatial Patterns, cannot increase. Marbled murrelet, old forest nesting habitat would decline from 153,000 acres under all alternatives. Marbled murrelet, old forest nesting habitat would decline $10 \%$ or less under the No Action Alternative, Alternative 1, and the PRMP. Marbled murrelet, old forest nesting habitat would follow a similar declining trajectory under Alternative 2, in which habitat would decline $31 \%$ by 2056 before it would stabilize by 2106 . Marbled murrelet, old forest habitat would decline under Alternative 3 continuously through 2106 , by $66 \%$ from 153,000 acres to 93,000 acres. See Figure 4-110. (Old forest marbled murrelet nesting habitat).

\section{Marbled Murrelet Habitat in Zone 1}

Marbled murrelet nesting habitat would increase under all alternatives, by 2106 in Zone 1 . The increase in marbled murrelet nesting habitat would range from 65,000 acres (a 28\% increase) under Alternative 2 to 277,000 acres (112\% increase) under the No Action Alternative. Zone 1 is important because it represents the approximate area identified in the marbled murrelet recovery plan as the recovery area for the species (USDI USFWS 1997). See Figure 4-111 (District marbled murrelet nesting habitat fluctuations in Zone 1, expressed as percent change from 2006.) for more information.

Under the No Action Alternative, marbled murrelet nesting habitat would increase in all BLM districts within Zone 1. Increases in marbled murrelet nesting habitat would range from $54 \%$ in the Roseburg District, to $151 \%$ in the Eugene District. There would be no time periods during which marbled murrelet nesting habitat would exhibit a net decline from the 2006 levels.

Under Alternative 1, marbled murrelet nesting habitat would increase $85 \%$ ( 213,000 acres) by 2106 in Zone 1. In all districts under Alternative 1, marbled murrelet nesting habitat would increase. These increases would range from 40 to $117 \%$. The Coos Bay and Roseburg Districts would be the only districts that would exhibit 30 and 50-year declines, respectively, in marbled murrelet nesting habitat. Marbled murrelet nesting habitat would decline 3.3\% over the next 20 years in the Coos Bay District and 3\% in the Roseburg District in the next 50 years.

Under Alternative 2, marbled murrelet nesting habitat would increase in all BLM districts except the

\section{Figure 4-110. Old Forest Marbled Murrelet Nesting Habitat}

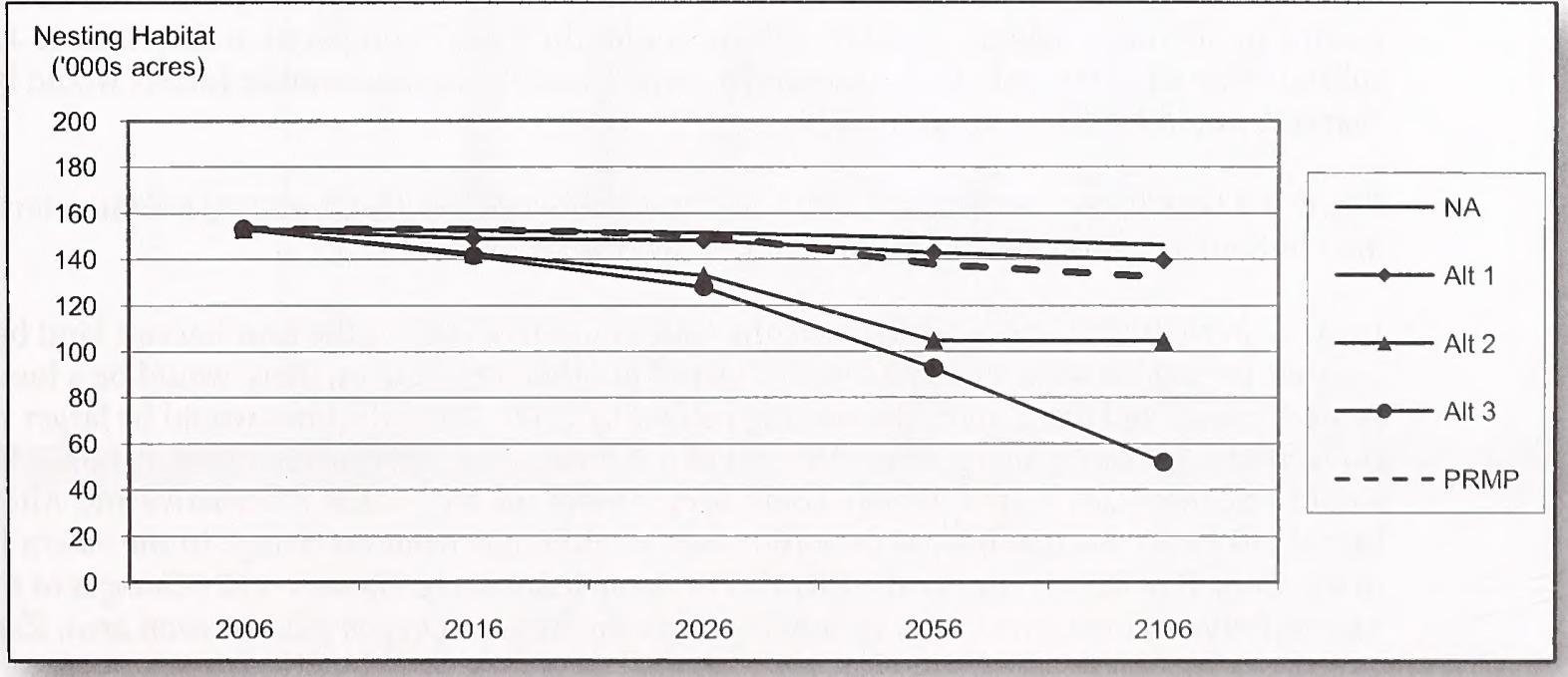


Medford District, by 2106 in Zone 1. Nesting habitat in the Medford District would decline 230 acres during this period. Western Oregon BLM would exhibit an 11\% decline in marbled murrelet nesting habitat for the first 50 years under Alternative 2. Individually, marbled murrelet nesting habitat in the Roseburg and Coos Bay Districts would decline 12 and 30\%, respectively; and would increase in the Salem and Eugene Districts, 71 and 33\%, respectively, in the same time period.

Under Alternative 3, marbled murrelet nesting habitat would decrease $8 \%$ in the first 50 years, for BLM as a whole, but would recover to a net increase in available marbled murrelet nesting habitat of $43 \%(104,000$ acres) in Zone 1 by 2106. Murrelet nesting habitat in the Salem and Eugene Districts would increase 70 and $86 \%$ (respectively) by 2106 . The Roseburg and Coos Bay Districts would exhibit a net decrease in available murrelet nesting habitat for the first 50 years. This decrease would be up to $50 \%$ in the Roseburg District and $12 \%$ for the Coos Bay District before available marbled murrelet nesting habitat would increase by 17 and 18 $\%$, respectively, by 2106 .

Marbled murrelet nesting habitat would increase $82 \%$ under the PRMP on western Oregon BLMadministered lands. District-specific increases in murrelet nesting habitat would vary from 55 to $122 \%$ under the PRMP. The Coos Bay District is the only district that would exhibit a decline in murrelet nesting habitat in Zone 1 under the PRMP. Marbled murrelet habitat would initially decline $8 \%$ in the Coos Bay District by 2026, but additional habitat development thereafter would lead to a 63\% increase by 2106 .

Because of the increased amount of late-successional management areas and the increased Riparian Management Areas under the PRMP compared to Alternative 2, and because substantially all older and more structurally complex, multi-layered conifer forests would be maintained (deferred from harvest) until 2023 under the PRMP, more murrelet nesting habitat would be maintained and more would develop over time compared to Alternative 2. Marbled murrelet nesting habitat would increase from 38 to $55 \%$ in the various districts under the PRMP, compared to nesting habitat fluctuations ranging from a decrease of $47 \%$ to an increase of $71 \%$ in the various districts under Alternative 2. See Figure 4-111 - District marbled murrelet nesting habitat fluctuations in Zone 1, expressed as percent change from 2006. The decline in the amount of marbled murrelet nesting habitat in Alternatives 2 and 3 would be caused by the increase in the amount of lands that would be harvested each decade, compared to No Action, Alternative 1, and the PRMP.

Figure 4-111 (District marbled murrelet nesting habitat fluctuations in Zone 1, expressed as percent change from 2006.) compares habitat fluctuations by district in Zone 1.

Old forest, marbled murrelet nesting habitat would decline under all alternatives. The scale of the decline varies with the amount of non-harvest land base and the cutting intensity on the harvest land base under the various alternatives (In Zone 1 the Medford District has so little available old forest, nesting habitat [314 acres] that any loss causes a large percentage change that is out of proportion to the actual importance of the few acres in question and is not considered in this analysis, although it is graphed for comparison.) Under the No Action Alternative and Alternative 1, which have the largest amount of Late-Successional Management Areas and Riparian Management Areas compared to the other alternatives, there would be less than $10 \%$ decline in the amount of old forest, marbled murrelet nesting habitat in all districts. The decline in old forest habitat would be delayed under the PRMP compared to Alternatives 1,2, and 3, because substantially all older and more structurally complex, multi-layered conifer forests would be maintained (harvest would be deferred) until 2023.

Figure 4-112 (Changes in the availability of marbled murrelet old forest, nesting habitat within the planning area in Zone 1.) compares habitat fluctuations by district in Zone 1.

Under Alternatives 2 and 3, which have the least amount of land in the non-harvest land base and the shortest period between stand entries compared to other alternatives, there would be a loss of $29 \%$ and $65 \%$, respectively, of old forest murrelet nesting habitat by 2106 . These declines would be larger than what would occur under the other alternatives. The loss of old forest, marbled murrelet nesting habitat under the PRMP would be comparable to that which would occur under the No Action Alternative and Alternative 1 . The loss of old forest, nesting habitat over 100 years would range from no change in the Salem District, to 6\% in the Coos Bay District under the PRMP. For comparisons, see Figure 4-112 (Changes in the availability of marbled murrelet old forest, nesting habitat within the western Oregon plan revision area, Zone 1). 
Figure 4-111. District Marbled Murrelet Nesting Habitat Fluctuations In Zone 1, Expressed As Percent Change From 2006

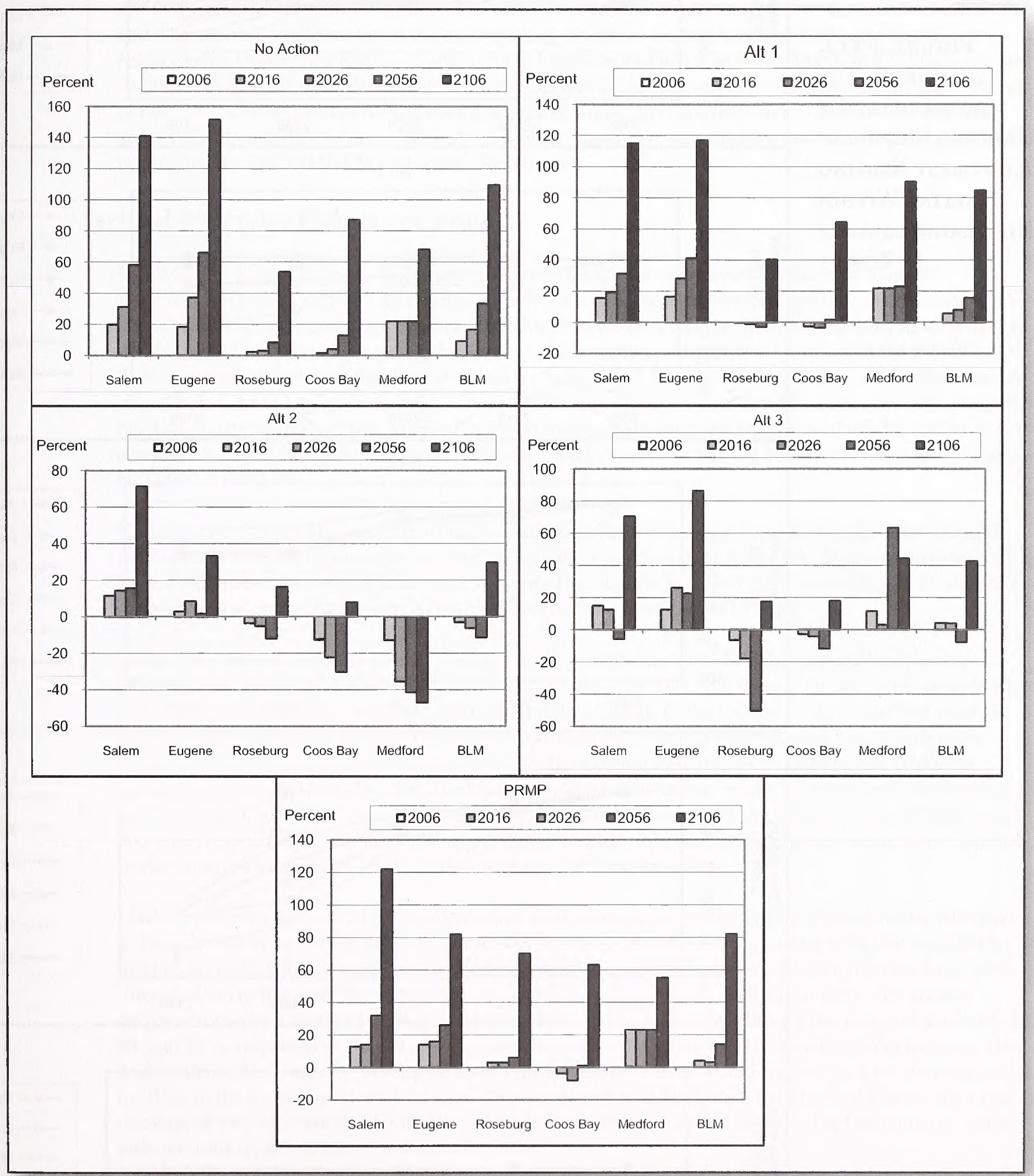


FIGURE 4-112. Changes In The Availability OF Marbled Murrelet Old Forest Nesting Habitat Within The Planning Area IN ZONE 1

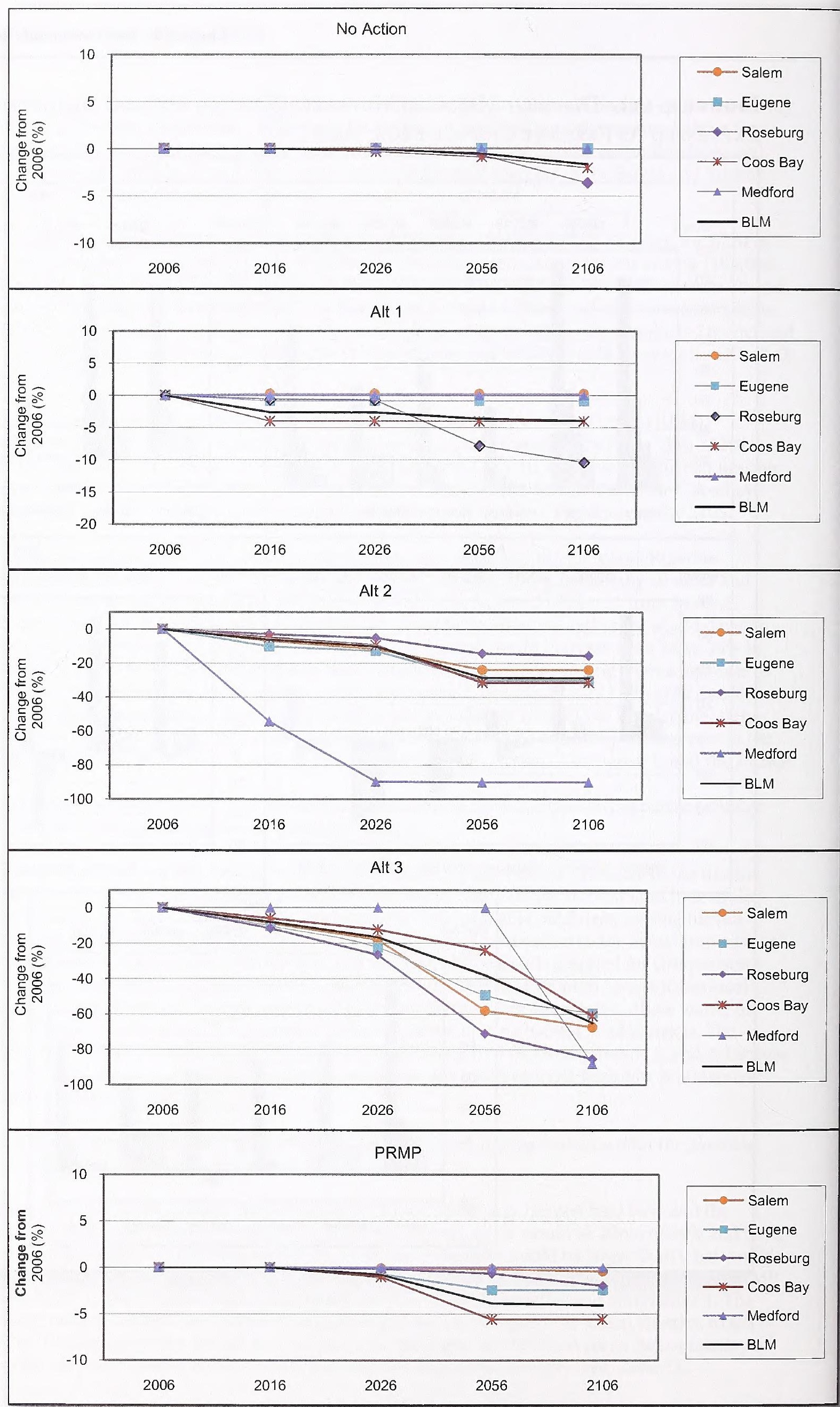


The largest increase among the alternatives of marbled murrelet nesting habitat on all BLM-administered lands in Zone 1 would occur under the No Action Alternative and Alternative 1: an increase from 244,000 acres, to 518,000 acres and 457,000 acres, respectively. In addition, the No Action Alternative and Alternative 1 would maintain the most existing old forest, nesting habitat (95,000 and 92,000 acres, respectively). Under the PRMP, murrelet nesting habitat would increase from 244,000 to 444,000 acres, and 93,000 acres of existing old forest marbled murrelet nesting habitat would be maintained. The least amount of marbled murrelet nesting habitat would be created under Alternatives 2 and 3 (313,000 and 348,000 acres, respectively). In addition, Alternatives 2 and 3 would maintain the least amount of existing old forest, nesting habitat $(69,000$ and 34,000 acres, respectively).

\section{Marbled Murrelet Habitat in Zone 2}

Lands within Zone 2 have not been identified as crucial for the recovery of the marbled murrelet. Approximately $5 \%$ of marbled murrelet sites known on BLM-administered lands occur within Zone 2 . There are no other murrelet sites known to occur in Zone 2 in western Oregon. Marbled murrelet nesting habitat within Zone 2 would increase under the No Action Alternative, Alternatives 1 and 3, and the PRMP by 2106. Marbled murrelet nesting habitat would increase from 123,000 acres available in 2006. The increases in available marbled murrelet nesting habitat would range from $15 \%$ under Alternative 3, to $54 \%$ under the No Action Alternative by 2106. Marbled murrelet nesting habitat under Alternative 2 would decline by 5,000 acres $(0.3 \%)$ by 2106 . Under the PRMP, available marbled murrelet nesting habitat in Zone 2 would increase by 21,000 acres $(19 \%)$.

Under the No Action Alternative marbled murrelet nesting habitat in all BLM districts in Zone 2 would increase by 2106 . The increases in the districts would range between 41 and $150 \%$. Marbled murrelet nesting habitat would decrease on the Salem and Roseburg Districts $4 \%$ by 2026 before recovering. A $4 \%$ decrease in marbled murrelet nesting habitat would occur on the Coos Bay District by 2056.

Under Alternative 1, overall marbled murrelet nesting habitat on all BLM-administered lands in the planning area would decline from 123,000 to 117,000 acres by 2026. The Eugene District is the only district that would not exhibit any decrease in murrelet nesting habitat. In the Eugene District, marbled murrelet habitat would increase from 12,000 acres to 25,000 acres by 2106 . Marbled murrelet nesting habitat in Medford District would decline less than 1\% from the existing 19,000 acres by 2026 before exhibiting a net increase of 23,000 acres by 2106. Marbled murrelet nesting habitat would decline in both the Roseburg and Coos Bay Districts ( $1 \%$ and $37 \%$, respectively) by 2056 before exhibiting a net increase of 24,000 and 600 acres, respectively, ( $30 \%$ and $42 \%$, respectively) by 2106 . Murrelet nesting habitat in the Salem District would decline a total of $32 \%$, from 10,000 acres to 7,000 acres by 2106 .

Marbled murrelet nesting habitat would decline in all districts except the Eugene District under Alternative 2. There would be an overall decrease of available marbled murrelet nesting habitat of 26,000 acres (21\%) by 2056 on BLM-administered lands in Zone 2. Marbled murrelet habitat would then increase from 2056 through 2106 to the point that would approximate the levels of habitat available in 2006. The greatest declines in marbled murrelet nesting habitat would occur by 2056 in Roseburg, Coos Bay, and Medford (23, 68 , and $24 \%$, respectively) before available marbled murrelet nesting habitat would begin to increase. The decline in marbled murrelet nesting habitat in the Roseburg District would recover for a net decrease of $2 \%$ by 2106 , in the Coos Bay District for a net decrease of $54 \%$ by 2106 , and in the Medford District for a net decrease of $19 \%$ by 2106 . Similar to Alternative 1, there would be a decline of nesting habitat in the Salem District from 10,000 acres to 3,000 acres by 2106 .

Under Alternative 3, marbled murrelet nesting habitat on all BLM- administered lands within Zone 2 would increase by $15 \%$ ( 18,000 acres) by 2106 . The increases in the individual districts would range from $2 \%$ to $100 \%$ by 2106 . The largest increases in habitat would occur in the Eugene, Coos Bay, and Salem Districts. Within western Oregon BLM, marbled murrelet nesting habitat would decrease $25 \%$ in Zone 2 by 2056 , from 123,000 to 92,000 acres. Marbled murrelet nesting habitat would decline $8 \%$ by 2056 in the Salem 
District, by $28 \%$ in the Roseburg District, by $36 \%$ in the Coos Bay District, and by 6\% in the Medford District. The Eugene District is the only district where marbled murrelet nesting habitat would increase in all time periods. Marbled murrelet nesting habitat would increase $100 \%$, from 12,000 to 24,000 acres, in the Eugene District by 2106.

Marbled murrelet nesting habitat would increase 21,000 acres (19\%) by 2106 under the PRMP in the western Oregon BLM, but would decline by 15,000 acres (11\%) through 2056. Marbled murrelet nesting habitat would decline $47 \%$ in the Salem District under the PRMP by 2106. Nesting habitat would decline in the Eugene and Roseburg Districts by 41 and 7\%, respectively, by 2056 before increasing by 3 and 29\%, respectively, by 2106 .

Figure 4-113 (District marbled murrelet nesting habitat fluctuations in zone 2) compares habitat fluctuations by district.

Old forest marbled murrelet nesting habitat would decline under all alternatives. The scale of this decline would depend on the amount of the non-harvest land base, as well as the periods between and the amount of timber removed in each stand entry on the harvest land base under each alternative. The Salem District contains no old forest; therefore, nesting habitat in Zone 2 will not be discussed further for that district.

The No Action Alternative and Alternative 1 would establish the largest amount of late-successional management areas and Riparian Management Areas and have the largest amount of lands in the nonharvest land base compared to the other alternatives. As a result of the large amount of lands in the nonharvest land base in these alternatives, there would occur the smallest decline in the amount of old forest nesting habitat in Zone 2 among the alternatives. This decline would consist of less than $10 \%$ under the No Action Alternative and 18\% under Alternative 1. The decrease of this habitat in Zone 2 in the various districts would range from 3\% in the Eugene District, to $25 \%$ in the Medford District by 2106 under the No Action Alternative. The decrease of this habitat in Zone 2 in the individual districts would range from $7 \%$ in the Eugene District, to 37\% in the Medford District under Alternative 1 by 2106.

Alternatives 2 and 3 would establish the fewest acres in the nonharvest land base compared to the other alternatives. As a result, the largest decline in the amount of old forest marbled murrelet nesting habitat in Zone 2 would occur under Alternatives 2 and 3 compared to the other alternatives. This decline would be $37 \%$ under Alternative 2 and $68 \%$ under Alternative 3 by 2106. The declines in this habitat in Zone 2 by 2106 in individual BLM districts would range from 11 to $76 \%$ under Alternative 2, and from 59 to $73 \%$ under Alternative 3. For comparisons, see Figure 4-114 (Changes in the availability of marbled murrelet old forest, nesting habitat within the western Oregon plan revision area, Zone 2). Under the PRMP, old forest marbled murrelet nesting habitat would decline $30 \%$ by 2106 . This decline would vary among individual districts from 21 to $66 \%$.

Marbled murrelet nesting habitat in Zone 2 on all BLM-administered lands would increase to the highest amounts under the No Action Alternative and Alternative 1 compared to the other alternatives. There are currently 123,000 acres of marbled murrelet habitat in Zone 2 on BLM-administered lands. This habitat would increase to 189,000 acres under the No Action Alternative and to 161,000 acres under Alternative 1. In addition, the No Action Alternative would maintain 52,000 acres of existing old forest marbled murrelet habitat in Zone 2; Alternative 1 would maintain 47,000 acres of this existing habitat in Zone 2. Marbled murrelet nesting habitat would increase under the PRMP to levels similar to that in Alternative 3; however, under Alternative 3 the existing old forest component in Zone 2 would decrease $68 \%$, and under the PRMP this habitat in Zone 2 would decrease $30 \%$. The decrease in existing old forest murrelet nesting habitat in Zone 2 under Alternative 1 would be $18 \%$, and under Alternative 2 the decrease would be $37 \%$. Under Alternative 3, marbled murrelet nesting habitat would increase to 141,000 acres; however, only 18,000 acres of old forest murrelet nesting habitat in Zone 2 would be maintained. 
Figure 4-113. District Marbled Murrelet Nesting Habitat Fluctuations In Zone 2, Expressed As Percent Change From 2006

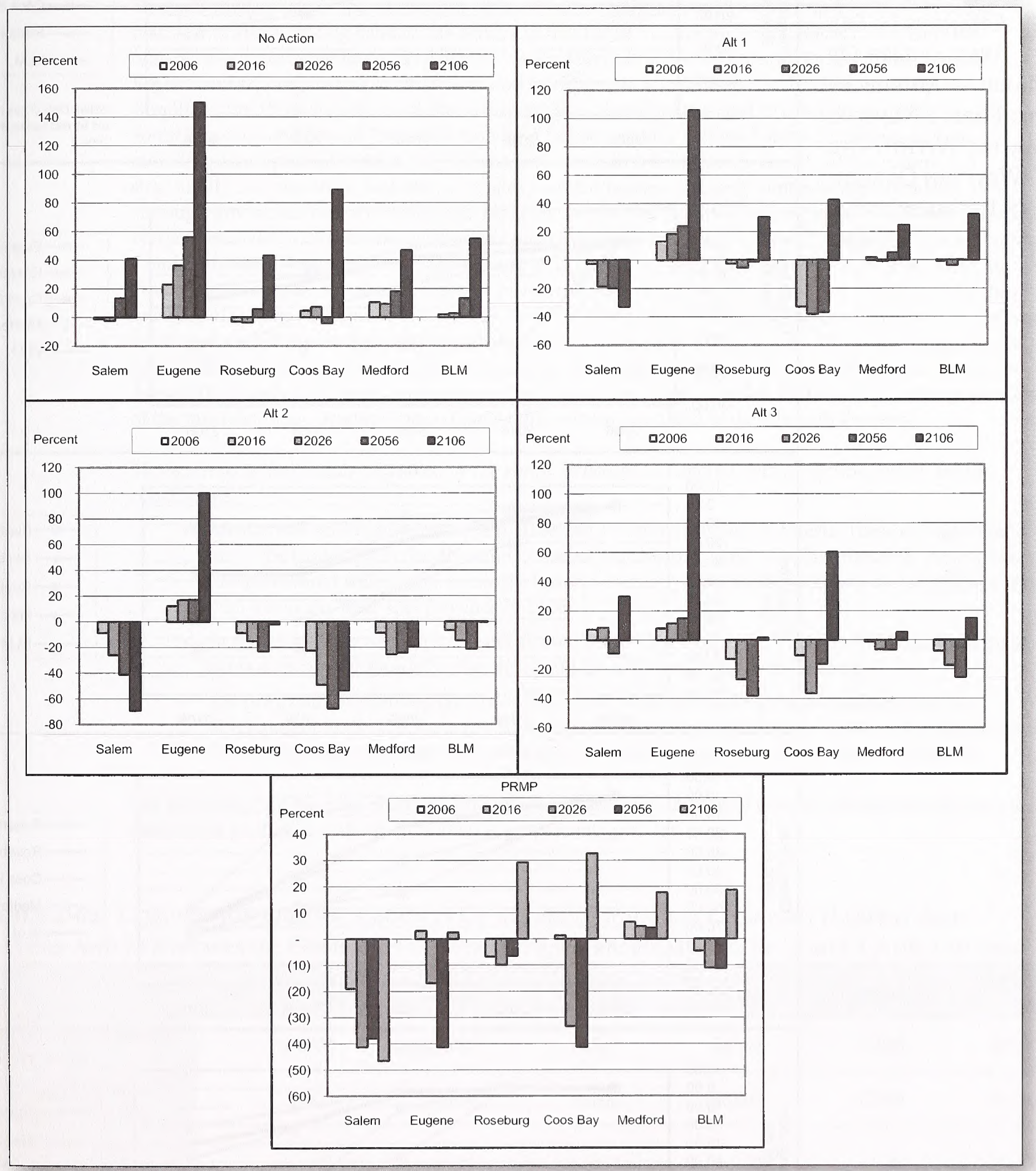


FIGURE 4-114. Changes In The Availability OF Marbled Murrelet Old Forest Nesting Habitat Within The Western Oregon Plan Revision Area, ZONE 2

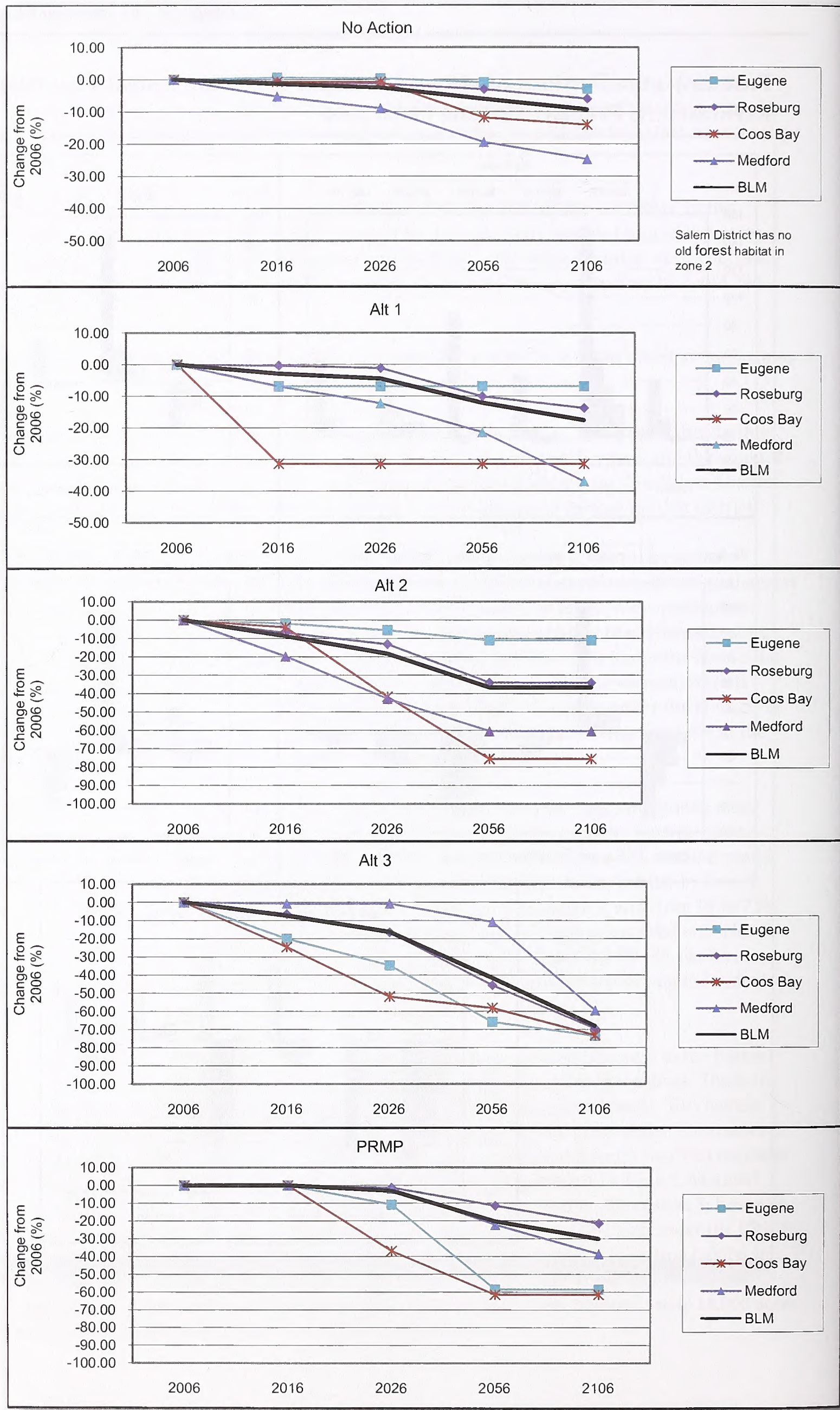




\section{Marbled Murrelet Habitat in All Ownerships}

To assess the impacts of the alternatives on marbled murrelet across all ownership is difficult because marbled murrelet nesting habitat data similar to that for BLM-administered lands is unavailable for non-BLM-administered lands. As described in the Forest Structure and Spatial Pattern, the Interagency Vegetation Mapping Project (IVMP) was used to categorize non-BLM lands. Habitat structure was simplified into three classes: stand establishment; young; and mature and structurally complex (see the Forest Structure and Spatial Pattern section for a full description of these habitat conditions and the modeling assumptions for projecting habitat conditions into the future.). The use of the mature and structurally complex stage data over-estimates marbled murrelet nesting habitat by approximately $19 \%$, although this varies from 0 to $45 \%$, depending on district. See Table 4-62 (Comparison of the amounts of marbled murrelet nesting habitat and mature and structurally complex forests within marbled murrelet zones 1 and 2 in 2006). Nevertheless, the mature and structurally complex stage serves as a good surrogate to evaluate and compare the alternatives on a provincial scale over time. The analysis in the Forest Structure and Spatial Pattern section was not specifically implemented for the range of the marbled murrelet, but the findings for the Coast Range and Klamath Provinces can be used as a surrogate. The Coast Range closely approximates the range of the marbled murrelet in the Salem and Eugene Districts, Swiftwater Resource Area of the Roseburg District, and Umpqua Resource Area of the Coos Bay District. The southern portion of the murrelet range overlays approximately the western one-third of the Klamath Province.

This analysis is thoroughly discussed in the Forest Structure and Spatial Pattern section; below are the conclusions.

- All alternatives would increase in mature and structurally complex forests. These changes would move the landscape in the direction of the average historic condition, but mature \& structurally complex would still remain below the historic averages. Structural conditions do not differ by more than $4 \%$ in any west-side province in 2106.

- At the broad scale of analysis across all ownerships, the management of the BLM-administered lands does not substantially alter the condition of the entire forested landscape.

- The principal determining factors on the condition of the entire forested landscape are the development of the U.S. Forest Service reserves into mature and structurally complex forests under the current forest plans and the continued intensive management of the nonfederal forests.

The BLM does not have the ability to influence the overall distribution of mature and structurally complex habitat at a provincial scale by more than a few percentage points.

Table 4-62. Comparison Of The Amounts Of Marbled Murrelet Nesting Habitat And Mature And Structurally Complex Forests With Marbled Murrelet Zones 1 And 2 In 2006

\begin{tabular}{lcccccr}
\hline & $\begin{array}{r}\text { Coos } \\
\text { Bay }\end{array}$ & Eugene & Medford & Roseburg & Salem & $\begin{array}{r}\text { Grand } \\
\text { Total }\end{array}$ \\
\hline $\begin{array}{l}\text { Marbled murrelet nesting } \\
\text { habitat (acres) }\end{array}$ & 124,000 & 49,000 & 20,000 & 98,000 & 77,000 & 367,000 \\
\hline $\begin{array}{l}\text { Mature and Structurally } \\
\text { Complex forest (acres) }\end{array}$ & 139,000 & 69,000 & 20,000 & 98,000 & 112,000 & 437,000 \\
\hline $\begin{array}{l}\text { \% difference between } \\
\text { nesting habitat and mature }\end{array}$ & 12 & 41 & 0 & 0 & 45 & 19 \\
\& structurally complex & 12 & & & & & \\
\hline
\end{tabular}




\section{Patch and Core Area Size}

The Forest Structure and Spatial Patterns section of this chapter analyzed the development of patch size over time for the mature and structurally complex forest structural stage classifications. Marbled murrelet habitat includes the mature, structurally complex forest structural stage classification, so although the absolute patch sizes would be different, the relative relationships would be similar. In the Coast Range physiographic province, the current patch size is 111 acres. The mean patch size of mature and structurally complex forest that would exist in 2106 on BLM- administered lands in the planning area would be:

- 338 acres under the No Action Alternative

- 254 acres under Alternative 1

- 101 acres under Alternative 2

- 37 acres under Alternative 3

- 176 acres under the PRMP

The mean core area size would follow the same trends as the mean patch size. An increase in the size of core areas would indicate that more nesting opportunities further from edge habitat would develop. This would result in a decrease in potential nest predation (Raphael et al. 2002a and 2002b, Meyer et al. 2002). Zharikov et al. (2006) concluded that fragmentation itself does not cause increased nest predation, but the impact of fragmentation on potential nest predators causes concerns. As stands treated with regeneration harvest age, production of berries and seeds would increase, which would lead to an increasing predator population (birds and small mammals). Zharikov et al. (2006) further cite evidence that populations of nest predators rarely increase in forested landscapes managed for timber production compared to data from more suburban or agricultural settings that indicates increases in nest predators does follow timber harvest activities.

The influences of patch dynamics on differing landscapes are often conflicting and reflect local situations more than concrete certainties. There have been no critical thresholds established for any of these criteria. Assumptions used in this analysis to base conclusions on regarding murrelet habitat, even when considering apparently conflicting research, include:

- More habitat is better for the murrelet.

- Larger blocks of habitat are better for the murrelet.

- Less edge is better for the murrelet (whether or not it contributes to predation).

Edge density ${ }^{12}$ of mature and structurally complex stand in the Coast Range would increase under all alternatives. The increase compared to the current condition of 40 feet per acre would range from $35 \%$ under the No Action Alternative and Alternative 1, to 80 feet per acre under Alternative 3. Edge density of mature and structurally complex stands would increase from $59 \%$ under the PRMP, comparable to the $63 \%$ increase that would occur under Alternative 2.

In the Klamath Province, the current patch size is 137 acres. The mean patch size of mature and structurally complex forest in 2106 on BLM-administered lands in the planning area would be:

- 192 acres under the No Action Alternative

- 91 acres under Alternative 1

- 79 acres under Alternative 2

- 27 acres under Alternative 3

- 152 acres under the PRMP

\footnotetext{
${ }^{12}$ Edge density is defined as the length of stand edge between the target habitat type and others; it is expressed as a linear length per unit area and can range from 0 to infinity.
} 
Edge density of Mature and Structurally Complex stands in the Klamath Province would increase under all alternatives. The increase compared to the current condition of 62 feet per acre would range from $19 \%$ under Alternative 2, to $50 \%$ under Alternative 3 . Edge density of mature and structurally complex stands would increase from 35\% under the PRMP; comparable to the 32 and $43 \%$ increases that would occur under the No Action Alternative and Alternative 1.

The quantity of marbled murrelet nesting habitat on BLM-administered lands in the planning area would increase under all alternatives by 2106 . There would be decreases, however, in the quantity of marbled murrelet nesting habitat under Alternatives 2 and 3 through 2056.

The quality of marbled murrelet nesting habitat (as measured by patch and core area size and edge density) would vary under the alternatives. Under the PRMP and the No Action Alternative, patch and core area size would increase by 2106 in mature and structurally complex stands in the Coast Range and Klamath Provinces. This increase would indicate improving nesting habitat conditions for the marbled murrelet. The increase in core area size would offset increases in edge density. Edge density would become a limiting factor to improving murrelet reproduction only in those instances in which it is not offset with patch size increases.

Under Alternative 1, patch size and core area size would increase by 2106 in mature and structurally complex stands in the Coast Range Province, which would indicate improving habitat conditions. In the Klamath Province, the increase in the quantity of marbled murrelet nesting habitat and the decrease in patch size area would result in no change to the overall habitat conditions in the Klamath Province.

Under the No Action Alternative, Alternative 1, and the PRMP there would be short-term effects (20-50 years) due to decreases in available nesting habitat that would be small (less than $5 \%$ available habitat). Marbled murrelet nesting habitat conditions would remain stable in both the Coast Range and Klamath Provinces for the next 50 years due to habitat quantity changing little (less than 5\%) and no measurable change in Mature and Structurally complex forest patch and core area size.

Under Alternatives 2 and 3, in the Coast Range and Klamath Provinces, a decline in habitat conditions would occur due to the decrease in mature and structurally complex patch and core area size, the increase in edge density of mature and structurally complex forests, and a decrease in the amount of nesting habitat over the next 50 years.

Increases in the amount of available nesting habitat in both the Coast Range and Klamath Provinces, combined with increases in mean patch size and core area, would result in increasing habitat conditions for the marbled murrelet on BLM-administered lands under the PRMP.

\section{Deer and Elk}

\section{Columbian White-tailed Deer}

The Douglas County population segment of the Columbian white-tailed deer would continue to be managed on the North Bank Habitat Management Area in accordance with the habitat management plan (BLM 2001c).

Management that converts forest from the mature and structurally complex forest structural stages to the stand establishment stage would result in the loss of hiding cover. This would occur only in those stands adjacent to the valley bottom habitats utilized as foraging habitat. Management of the BLM's forests that are adjacent to the Umpqua Valley and Columbia River, where the deer are located, would have little effect on the survival of the species. This is because recovery of the Douglas County population is tied to the presence of secure valley habitat and not the upland coniferous forest where timber harvest under the alternatives would occur. Recovery of the Columbia River population is tied to habitat conditions on the Julia Butler Hansen National Wildlife Refuge and surrounding valley bottom habitat. 


\section{Mule/Black-Tailed Deer}

Mule deer and black-tailed deer occur across BLM-administered lands within the planning area. However, BLM (with input from the Oregon Department of Fish and Wildlife) has identified 26 deer habitat management areas where management consideration is given to important wintering areas and areas that provide hiding cover for this species. Hiding cover is provided when stand conditions are capable of concealing $90 \%$, or more of the animal at 200 feet. For analytical purposes, three structural stages (young, high density; mature; and structurally complex) are considered to provide hiding cover.

\section{Deer Habitat Management Areas in the Coos Bay District}

Five of the 26 deer habitat management areas (approximately 30,000 acres) are designated in the Coos Bay District to provide hiding cover. Changes in the amount of hiding cover, on BLM-administered lands, in these five habitat management areas would vary less than 10\% through 2106 under all alternatives, except Alternative 2. Deer hiding cover in Alternative 2 would decline from $92 \%$ of the deer habitat management areas providing cover in 2006 , to $78 \%$ in 2026 . The hiding cover would recover to $83 \%$ by 2106 , which is approximately the amount of hiding cover that would develop under Alternative 3 . The No Action Alternative and Alternative 1 would result in stable levels of hiding cover at approximately $90 \%$ of the deer habitat management areas. The amount of hiding cover under the PRMP would fluctuate between 91 and $94 \%$ of BLM-administered lands within the deer habitat management areas, over the next 100 years. See Figure 4-115 (Average hiding cover availability on deer habitat management units in the Coos Bay District.) for more details.

However, Wisdom et al. (2004), citing work by others (Black et al. 1976 and Thomas et al. 1979), stated that the optimum cover to forage ratio for elk was $60: 40$ (60\% cover habitat to $40 \%$ forage habitat). Although this number may not be prescriptive for deer, it would indicate that the amount of available cover on BLMadministered lands is currently extremely high; is projected to be extremely high under all alternatives; and is not and would not be a limiting factor on BLM-administered lands within in the deer habitat management areas even when considering the effects from roads.

Figure 4-1 15. Average Hiding Cover Availability On The Deer Habitat Management Units In The Coos Bay District

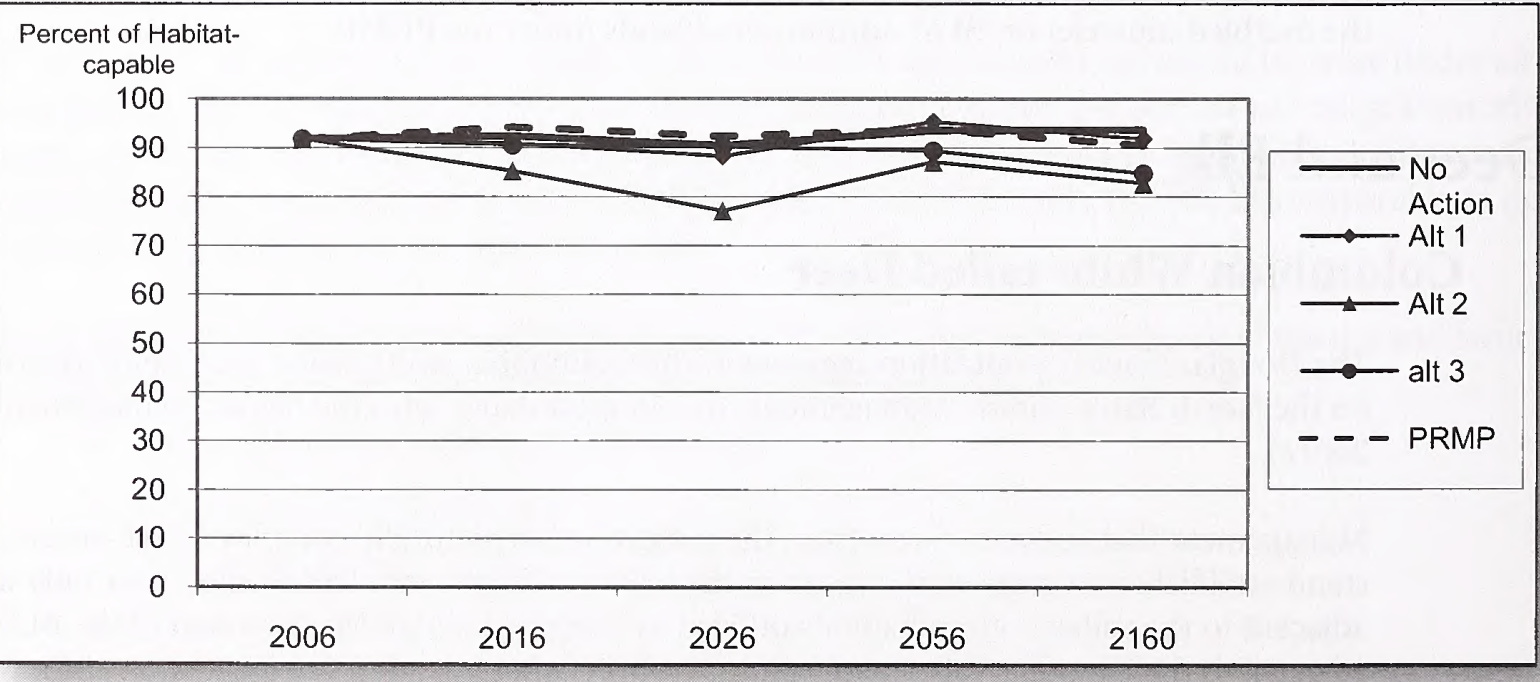


Other habitat factors that contribute to the overall value of hiding cover include core area size (or distance from edge) and distance from a road open to vehicle use. Habitat models indicate that cover values increase with distance from the edge and from roads open to vehicles. Cole (1996) found that elk, on BLMadministered lands in the Oregon Coast Range, used habitat significantly more when it was greater than 492 feet ( 150 meters) from roads open to vehicles. Similar studies are not available for deer within the planning area, but 492 feet is a reasonable threshold distance to apply to deer as well. Deer habitat management areas in the Coos Bay District currently contain between 33 and $72 \%$ of their area more than 492 feet from roads that are open to vehicle traffic. See Figure 4-116 (Percentage of deer habitat management area, in the Coos Bay District, greater than 492 feet from roads open to vehicle use).

Areas more than 492 feet from open roads provide the deer respite from disturbance caused by road use (Wisdom et al. 2004). The effective loss of foraging habitat and hiding cover within 492 feet of open roads due to disturbance increases the vulnerability of deer to both legal and illegal harvest, and also increases stress and movement rates (Rowland et al. 2004). Although BLM has an estimate of the amount of new road construction in the next 10 years, it is not a geographic or spatial estimate and, therefore, changes in the amount of land in deer habitat management areas within 492 feet of roads cannot be estimated. As the amount of roads open to vehicle use increase there would be a decrease in the amount of land greater than 492 feet from open roads, which would increase deleterious impacts (such as those described previously) to deer. See the Road Density in Deer Habitat Management Areas section for a discussion of the effects of the alternatives on road density within the deer habitat management areas.

Figure 4-116. Percentage Of Deer Habitat Management Area In The Coos Bay District, Greater Than 492 Feet From Roads Open To Vehicle Use

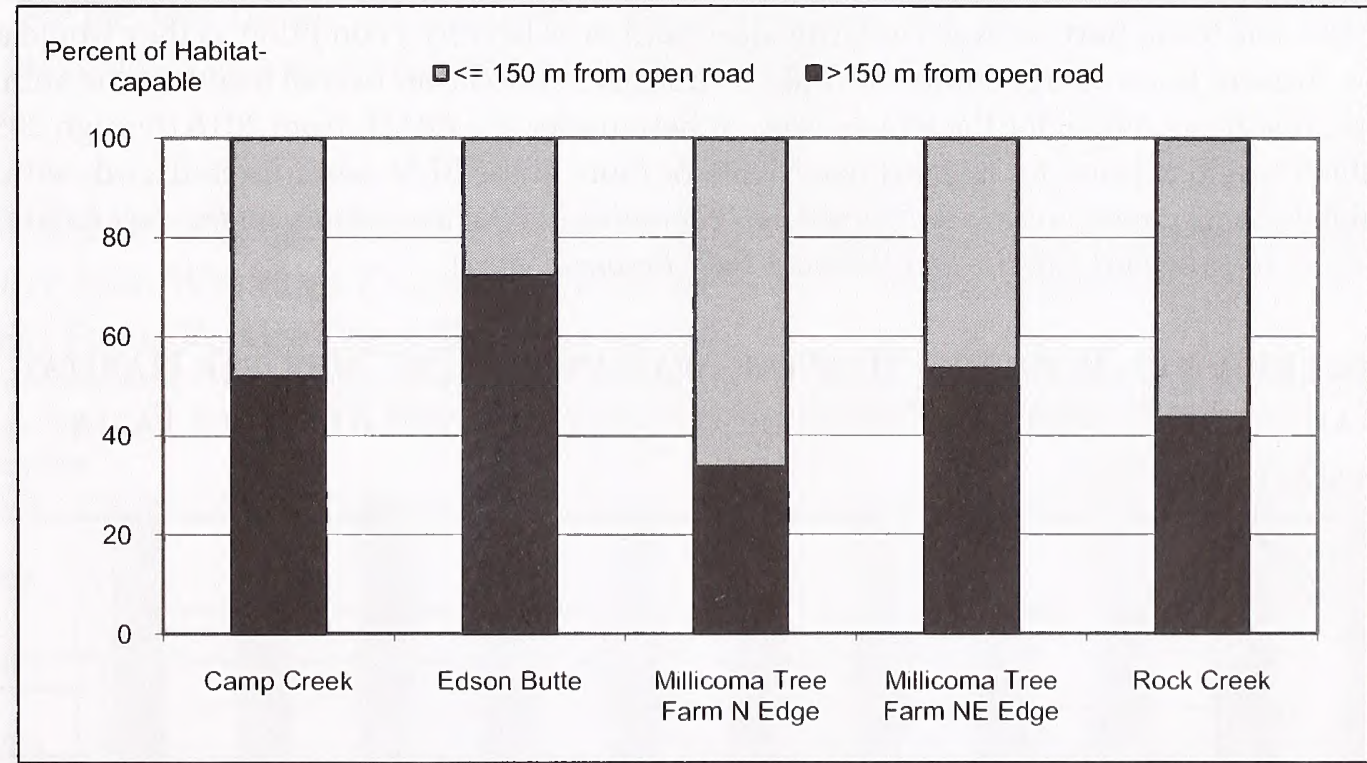




\section{Deer Habitat Management Areas (Medford District \& Western Klamath Falls Resource Area)}

There are 12 deer habitat management areas totaling 143,000 acres that provide important winter foraging habitat on BLM-administered land in the Medford District and western Klamath Falls Resource Area Deer foraging habitat levels would fluctuate around 9\% through 2106 under the No Action Alternative. Under Alternatives 1 and 2, foraging habitat would decline from the highs of 19 and 23\% in 2056, to approximately the starting condition of $10 \%$ by 2106 . Foraging habitat would increase from $10 \%$, to $37 \%$ of BLMadministered lands in the deer habitat management areas under Alternative 3. Under the PRMP, there would be a rapid increase in available foraging habitat on BLM-administered lands, which would peak in 2016 at $36 \%$. By 2106 , available foraging habitat under the PRMP would decline to $10 \%$ of the habitat-capable lands in the deer habitat management areas in the Medford District and Klamath Falls Resource Area. See Figure 4-117 (Foraging habitat availability on the deer habitat management units in the Medford District and Klamath Falls Resource Area).

Intensive forest management on intermingled private forestlands would provide more foraging habitat per unit area than on BLM-administered lands. This is due to shorter harvest rotations on private forestlands resulting in more land being in an early-seral stage than would be provided under a longer harvest rotation.

Wisdom et al. (2004), citing work by others (Black et al. 1976 and Thomas et al. 1979), stated that the optimum cover to forage ratio for elk was 60:40 (60\% cover habitat to $40 \%$ forage habitat). Although optimum cover to forage ratio of 60:40 is not prescriptive for deer (see discussion above), it indicates that the amount of available foraging habitat on these deer habitat management areas is currently extremely low $(10 \%)$ and would continue to be low under all alternatives. Winter foraging habitat is the limiting factor to deer management on BLM-administered lands in the deer habitat management areas in the Medford District and Klamath Falls Resource Area. Without adequate forage, the habitat management areas would not be able to support an over-wintering deer herd in as healthy a condition as they would at the 60:40 level. The stress of lower forage amounts would be translated into lower overall health of the animals and lower reproductive potential for the female deer. At best, under the PRMP, from 2016 through 2056, foraging habitat would account for approximately $28 \%$ or more of the BLM-administered lands within these deer habitat management areas. See Figure 4-117 (Foraging habitat availability on the deer habitat management units in the Medford District and Klamath Falls Resource Area).

Figure 4-117. Foraging Habitat Availability On The Deer Habitat Management Units In The Medford District and Klamath Falls Resource Area

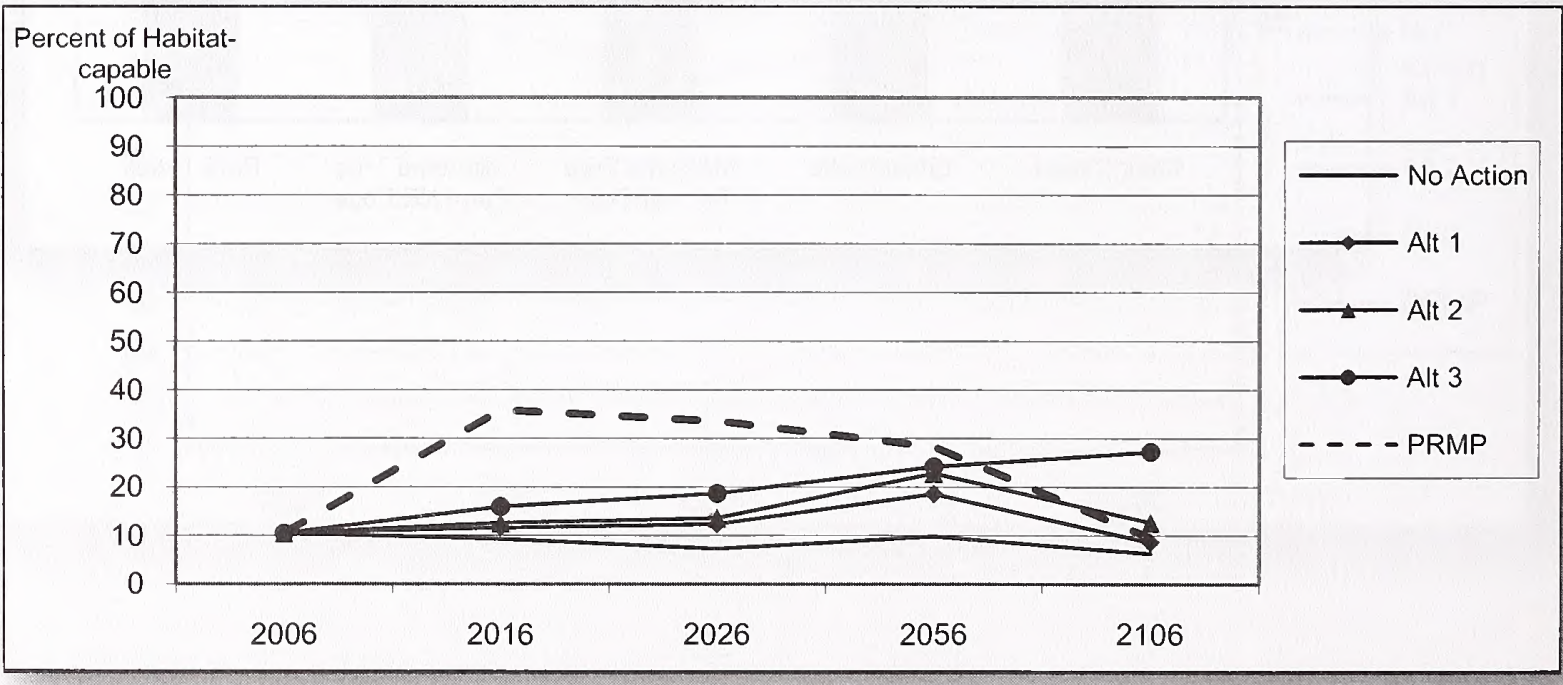


Winter foraging habitat would be better met on the industrial forest lands intermingled with BLMadministered lands in many of the deer habitat management areas. The intensive forest management on those lands would leave a higher percentage in early-seral conditions that would provide forage. However, due to the management practices on private industrial timberlands (such as large clearcuts and aggressive brush control), the foraging habitat created would be of differing quality than those on BLM-administered lands. There is no data to indicate whether or not intermingled private lands would tip the overall cover:forage ratio one way or the other. More accurate analysis of the cover to forage ratio that considers the specifics of intermingled private lands would need to occur at the project scale where the analysis could better account for specific circumstances of habitat juxtaposition and better forecast habitat changes over time on private lands.

As discussed previously under Deer Habitat Management Areas in the Coos Bay District, deer are assumed to use habitat more when it is greater than 492 feet ( 150 meters) from roads open to vehicles. Deer habitat management areas in the Medford District and western Klamath Falls Resource Area currently contain between 53 and $96 \%$ of their lands more than 492 feet from roads open to vehicle traffic. See Figure 4-118 (Percentage of deer habitat management area, in the Medford District and western Klamath Falls Resource Area, greater than 492 feet [150 meters] from roads open to vehicle use).

Areas more than 492 feet from open roads provide deer respite from disturbance caused by road use (Wisdom et al. 2004). The effective loss of foraging habitat and hiding cover within 492 feet of open roads due to disturbance increases vulnerability of deer to both legal and illegal harvest, and increases in stress and movement rates (Rowland et al. 2004). Although the BLM does have an estimate of the amount of new road construction in the next 10 years, it is not a geographic or spatial estimate and, therefore, changes in the amount of land in deer habitat management areas within 492 feet of roads cannot be estimated. As the amount of roads open to vehicle use increase, there would be a decrease in the amount of land greater than 492 feet from open roads deleterious impacts (such as those described previously) to deer would increase. See the Road Density in Deer Habitat Management Areas section for a discussion of the effects of the alternatives on road density within the deer habitat management areas.

\section{Figure 4-118. Percentage Of Deer Habitat Management Area In The Medford District And Western Klamath Falls Resource Area, Greater Than 492 Feet (150 Meters) From Roads Open To Vehicle Use}

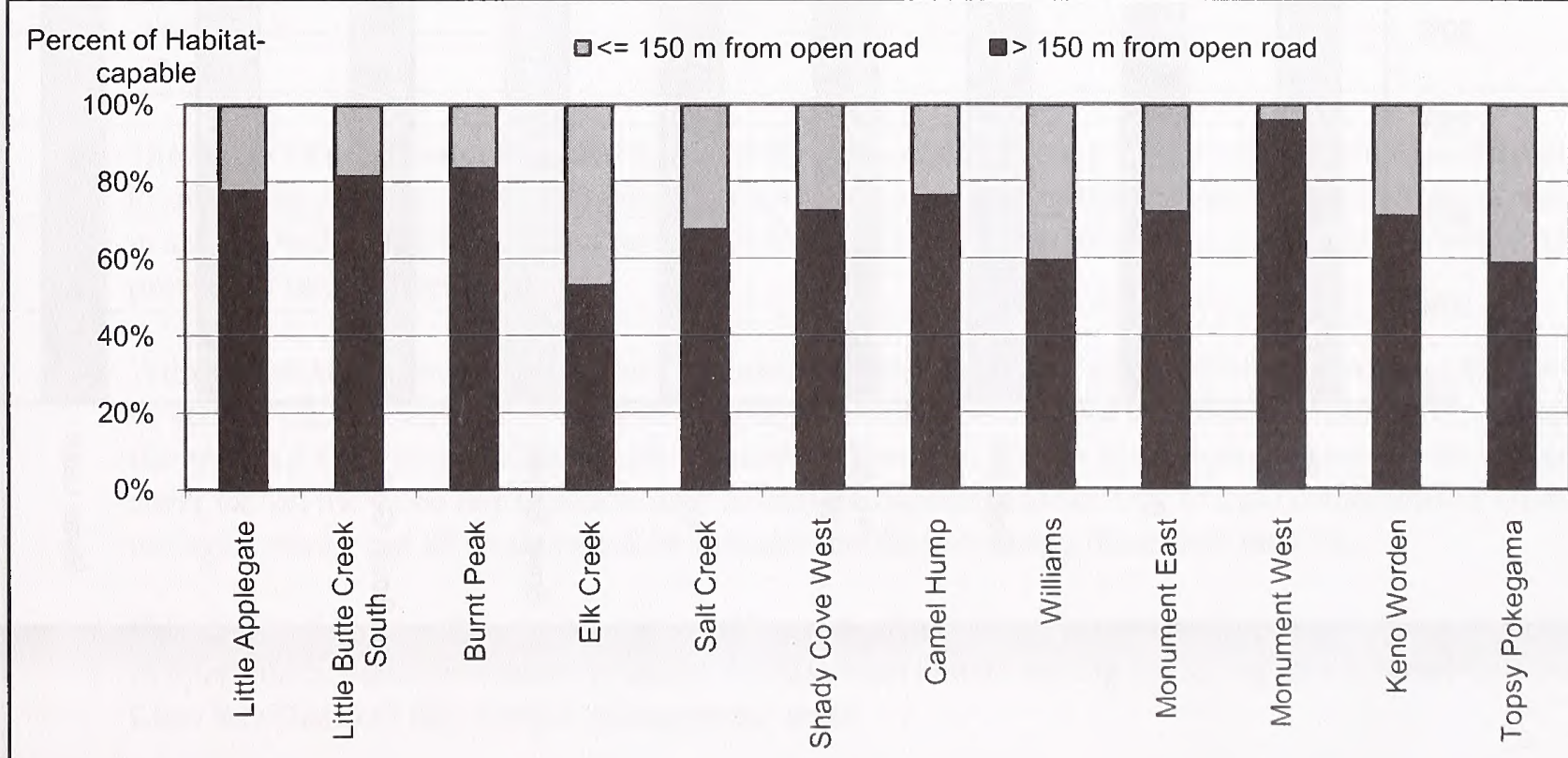




\section{Deer Management Areas in Eastside Management Lands}

There are nine deer habitat management areas on Eastside Management Lands in the Klamath Falls Resource Area managed for winter forage habitat. Forests in those areas would be managed with an unevenaged management under all alternatives. Range and other non-forest types would continue to provide a similar habitat function for deer as they currently provide. The overall distribution of forest structural stages would not change in this area as a result of uneven-aged management. Conditions on the deer management areas on the Eastside Management Lands in 2006 vary from approximately 20 to $90 \%$ foraging habitat as shown in Figure 4-119 (Percent of foraging habitat in deer habitat management areas on Eastside Management Lands in the Klamath Falls Resource Area).

Foraging habitat would be created as harvested stands regenerate, but would not persist as long as foraging habitat created under even-aged management. This is because the openings created through harvest under uneven-age management would typically be much smaller than those created under even-aged management.

Intensive forest management on intermingled private forestlands would provide more foraging habitat per unit area than on BLM-administered lands, due to shorter harvest rotations resulting in more land being in an early-seral stage than a longer rotation would provide. However, due to management practices on private forestlands such as larger clearcut harvest units and aggressive brush control, the foraging habitat would differ in quality from foraging habitat on BLM-administered lands. There is no data to indicate whether or not intermingled private lands would change the overall cover to forage ratio one way or the other. More accurate analysis of the cover to forage ratio that considers the specifics of intermingled private lands would need to occur at the project scale where the analysis could better account for specific circumstances of habitat juxtaposition and better forecast habitat changes over time on private lands.

\section{Figure 4-11 19. Percentage Of Habitat In Deer Habitat Management Areas On} Eastside Management Lands In The Klamath Falls Resource Area

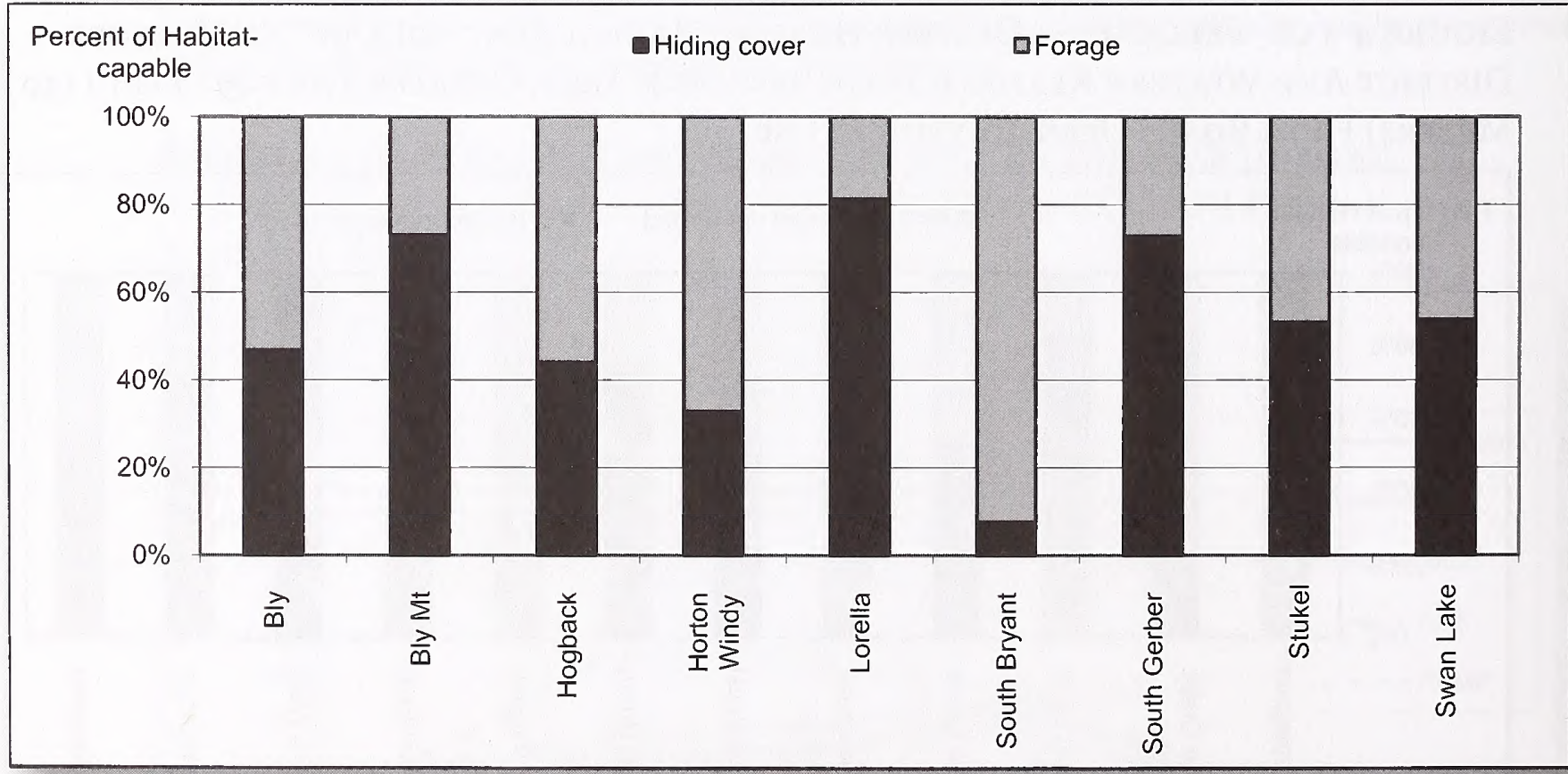




\section{Road Density in Deer Habitat Management Areas}

In the first 10 years, the approximate miles of new roads open to public use that would be built in deer habitat management areas, by alternative, are:

- 12.2 miles of new roads under the No Action Alternative

- 32 miles under Alternative 1, Alternative 2, and Alternative 3

- 55 miles under the PRMP

New road construction would taper off in the future; however, the decade in which that would occur cannot be determined. There is enough detailed information available to analyze the first decade of anticipated levels of road construction for comparison of the alternatives. This level of construction would not continue indefinitely, because at some time the potential maximum road development would be reached. On average, for the first decade, open road density would increase from approximately 1.8 miles per square mile, to 1.9 miles per square mile under the No Action Alternative and Alternatives 1,2, and 3.

Changes in individual habitat management areas range from 0 to $62 \%$. Of 27 habitat management areas, 11 areas would exhibit no change in average road density. Under the PRMP, average road density would increase to 2 miles per square mile, and changes on individual habitat management areas would range from 0 to $77 \%$. New roads that are open to public use would increase by 2016 by approximately $2 \%$ under the No Action Alternative; 4 to 5\% under Alternatives 1, 2, and 3; and 8\% under the PRMP. See Table 4-63 (Open road density on BLM-administered lands within deer habitat management units).

The density of roads open to public vehicle use within deer habitat management areas on Eastside Management Lands varies between 0.64 and 1.53 miles per square mile and does not vary by alternative or time period.

The average road density would change by alternative, as follows:

\begin{tabular}{lcc}
\hline Alternative & $\begin{array}{c}\text { Number of Deer HMAs (of 27 HMAs) With Less } \\
\text { Than 1\% Increase in Average Road Density }\end{array}$ & $\begin{array}{c}\text { Number of Deer HMAs (of 27 HMAs) With } \\
5 \% \text { Increase in Average Road Density }\end{array}$ \\
\hline No Action & 12 & 7 \\
\hline Alternative 1 & 15 & 8 \\
\hline Alternative 2 & 12 & 7 \\
\hline Alternative 3 & 17 & 3 \\
\hline PRMP & 12 & 10 \\
\hline
\end{tabular}

The effects of new roads on habitat use are difficult to evaluate based only on changes in road density. Road location compared to available habitat is critical to accurate forecasting of effects. For example, a road built in an area with already high road density would have relatively minor effects compared to a road built in previously undisturbed habitat.

Winter closures of open roads under all alternatives would remove or reduce the disturbance effects caused by vehicle use of roads and allow deer to gain maximum benefit from the available forage near roads within the Medford District and Klamath Falls Resource Area deer habitat management areas and on winter hiding cover within the Coos Bay District's deer habitat management areas. Due to legal constraints of binding road use agreements, not all roads would be closed to public use during these time periods.

Vehicles would cause disturbance to available cover adjacent to open roads As a result, the cover adjacent to open roads would be utilized to less than maximum benefit during the spring and summer seasons in the Coos Bay District's deer habitat management areas. 
Table 4-63. Open Road Density On BlM-Administered Lands Within Deer Habitat Management Units

\begin{tabular}{|c|c|c|c|c|c|c|c|}
\hline \multirow{2}{*}{ District } & \multirow{2}{*}{$\begin{array}{l}\text { Deer Habitat Management } \\
\text { Area }\end{array}$} & \multicolumn{6}{|c|}{$\begin{array}{l}\text { Density of Open roads } \\
\text { (road miles per square mile) }\end{array}$} \\
\hline & & 2006 & $\begin{array}{l}2016 \\
\text { Alt } 1\end{array}$ & $\begin{array}{l}2016 \\
\text { Alt } 2\end{array}$ & $\begin{array}{l}2016 \\
\text { Alt } 3\end{array}$ & $\begin{array}{r}2016 \\
\text { No Action }\end{array}$ & $\begin{array}{r}2016 \\
\text { PRMP }\end{array}$ \\
\hline \multirow{5}{*}{ Coos Bay } & Camp Creek & 3.03 & 3.20 & 3.26 & 3.10 & 3.12 & 3.21 \\
\hline & Edson Butte & 1.55 & 1.57 & 1.65 & 1.58 & 1.59 & 1.75 \\
\hline & $\begin{array}{l}\text { Millicoma Tree Farm } \\
\text { N Edge }\end{array}$ & 4.34 & 4.35 & 4.34 & 4.34 & 4.34 & 4.34 \\
\hline & $\begin{array}{l}\text { Millicoma Tree Farm NE } \\
\text { Edge }\end{array}$ & 2.97 & 3.05 & 2.98 & 3.20 & 3.01 & 3.05 \\
\hline & Rock Creek & 3.83 & 4.24 & 4.18 & 3.97 & 4.06 & 3.98 \\
\hline \multirow{10}{*}{$\begin{array}{l}\text { Klamath Falis } \\
\text { (Eastern } \\
\text { Management } \\
\text { Lands) }\end{array}$} & Bly & 1.39 & 1.39 & 1.39 & 1.39 & 1.39 & 1.39 \\
\hline & Bly Mountain & 1.42 & 1.42 & 1.42 & 1.42 & 1.42 & 1.42 \\
\hline & Hogback & 0.98 & 0.98 & 0.98 & 0.98 & 0.98 & 0.98 \\
\hline & Horton Windy & 1.09 & 1.09 & 1.09 & 1.09 & 1.09 & 1.09 \\
\hline & Keno Worden & 1.40 & 1.43 & 1.40 & 1.44 & 1.41 & 1.53 \\
\hline & Lorella & 0.94 & 0.94 & 0.94 & 0.94 & 0.94 & 0.94 \\
\hline & South Bryant & 1.53 & 1.53 & 1.53 & 1.53 & 1.53 & 1.53 \\
\hline & South Gerber & 0.64 & 0.64 & 0.64 & 0.64 & 0.64 & 0.64 \\
\hline & Stukel & 1.14 & 1.14 & 1.14 & 1.14 & 1.14 & 1.14 \\
\hline & Swan Lake & 0.65 & 0.65 & 0.65 & 0.65 & 0.65 & 0.65 \\
\hline Klamath Falis & Topsy Pokegama & 2.91 & 2.92 & 2.93 & 2.94 & 2.95 & 3.02 \\
\hline \multirow{11}{*}{ Medford } & Burnt Peak & 0.59 & 0.67 & 0.95 & 0.68 & 0.64 & 0.59 \\
\hline & Camel Hump & 1.47 & 1.55 & 1.58 & 1.53 & 1.48 & 1.60 \\
\hline & Elk Creek & 3.34 & 3.40 & 3.48 & 3.50 & 3.36 & 3.42 \\
\hline & Little Applegate & 1.30 & 1.38 & 1.37 & 1.37 & 1.34 & 1.60 \\
\hline & Little Butte Creek South A & 1.12 & 1.15 & 1.17 & 1.21 & 1.13 & 1.38 \\
\hline & Little Butte Creek South B & 0.25 & 0.29 & 0.28 & 0.31 & 0.27 & 0.45 \\
\hline & Monument East & 1.58 & 1.58 & 1.58 & 1.58 & 1.58 & 1.58 \\
\hline & Monument West & 0.53 & 0.54 & 0.53 & 0.53 & 0.53 & 0.53 \\
\hline & Salt Creek & 2.01 & 2.11 & 2.10 & 2.08 & 2.05 & 2.14 \\
\hline & Shady Cove West & 1.61 & 1.67 & 1.75 & 1.75 & 1.61 & 1.92 \\
\hline & Williams & 2.74 & 2.96 & 2.89 & 2.98 & 2.77 & 3.13 \\
\hline & Average & 1.83 & 1.91 & 1.91 & 1.92 & 1.86 & 1.97 \\
\hline
\end{tabular}

Under all alternatives, off-highway vehicle travel would be limited to designated roads and trails. These limitations, along with the closure of roads in deer management areas, would limit the amount of disturbance to wintering animals. Reduced disturbance would decrease the amount of unnecessary movements animals make and, therefore, reduce their energy expenditure. Additionally, road closures that occur through limiting off-highway vehicles to designated roads and trails would result in more available foraging habitat, since animals would not need to move away from their former frequently used roads and trails that would not be designated for off-highway vehicle use.

Off-highway vehicle emphasis areas would be designated that would overlap four deer habitat management areas under Alternatives 2 and the PRMP. See Table 4-64 (Off-highway vehicle emphasis areas proposal for deer habitat management areas in the Medford District). Off-highway vehicle emphasis areas would be managed to accommodate vehicle use that is more concentrated. Off-highway vehicles would be limited to designated roads and trails. Comprehensive travel management plans that would be completed for each off highway emphasis area would accommodate the needs of deer habitat management areas by restricting offhighway vehicle activity, such as identifying closures of certain roads and trails and seasonal restrictions. 
Table 4-64. Off Highway Vehicle Emphasis Areas Proposal For Deer Habitat Management Areas In The Medford District

\begin{tabular}{|c|c|c|}
\hline \multirow{2}{*}{ Deer Habitat Management Area } & Alternative 2 & PRMP \\
\hline & (acres) & \\
\hline Little Applegate & 5,344 & 1,334 \\
\hline Little Butte Creek & 6,550 & 0 \\
\hline Salt Creek & 8,429 & 0 \\
\hline Williams & 4,377 & 6,067 \\
\hline Total Acres & 24,700 & 7,401 \\
\hline
\end{tabular}

Elk

There are 16 elk habitat management areas on BLM-administered lands (see the Wildlife section of Chapter 3). These areas provide specific limited habitat needs for elk, including important winter foraging areas and areas that provide hiding cover. Elk forage on grasses, forbs, shrubs, and trees species that are characteristic of the stand establishment and young low density forest structural stage classifications. Additional forage (e.g., lichens) would be found in older structural stages. Hiding cover is provided when stand conditions are capable of concealing $90 \%$ or more of the animal at 200 feet. For analytical purposes, the young, high density; mature; and structurally complex structural stages are considered to provide hiding cover.

\section{Elk Management Areas on the Coos Bay and Salem Districts}

Seven of the 16 elk habitat management areas would be managed to provide hiding cover for elk in the Coos Bay and Salem Districts. Currently, hiding cover constitutes $92 \%$ of BLM-administered lands in the elk habitat management areas in the Coos Bay and Salem Districts. The percentage of hiding cover in elk habitat management areas would remain stable, between 90 and 95\%, through 2106 under the No Action Alternative, Alternative 1, and the PRMP. Hiding cover would decrease to approximately $85 \%$ of the elk habitat management areas in the Coos Bay and Salem Districts by 2106 under Alternative 3. The largest decline in elk hiding cover among all alternatives would occur under Alternative 2 in which this habitat would decline to $60 \%$ of BLM-administered lands in elk habitat management areas by 2106 . See Figure 4-120 (Elk hiding cover availability on the elk habitat management units in the Coos Bay and Salem Districts) for trends in the abundance of elk hiding cover. Intermingled industrial forest lands would undoubtedly contribute to the hiding cover available to elk in these habitat management areas. There is no data to indicate whether or not intermingled private lands would change the overall cover to forage ratio one way or the other. More accurate analysis of the cover to forage ratio that considers the specifics of intermingled private lands would need to occur at a project scale where the analysis could better account for specific circumstances of habitat juxtaposition and better forecast habitat changes over time on private lands.

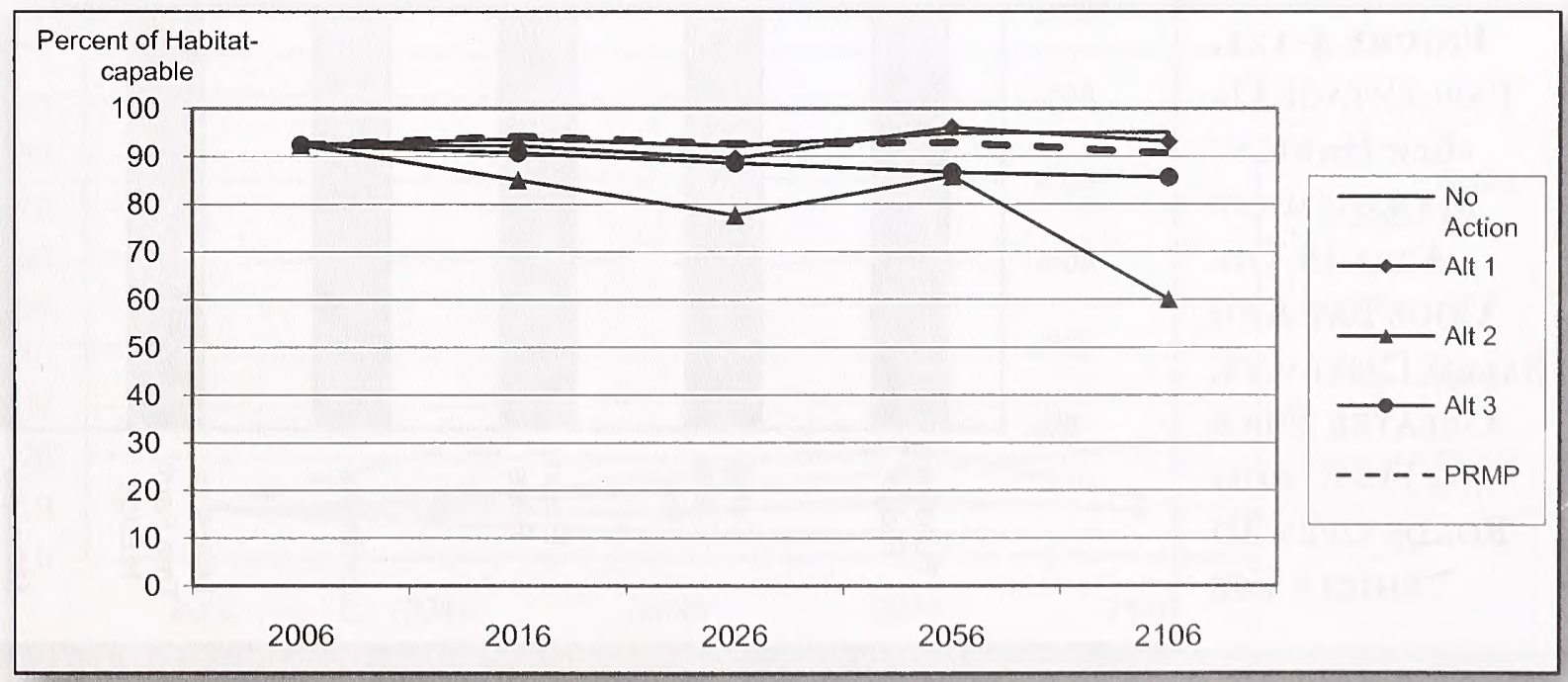


The functionality of hiding cover is affected by core area size (or distance from edge) and open road density. Habitat models indicate that cover value increases from the edge up to 200 yards into a stand. Cover value decreases with increasing density of roads that are open to vehicles (Wisdom et al. 2004). Using the mature and structurally complex analysis as a surrogate for hiding cover, mean patch size on BLM-administered lands would decrease by 9 acres under Alternative 2 and by 73 acres under Alternative 3 in the Coast Range by 2106 . There would be increases in mean patch size in the other alternatives: 229 acres increase under the No Action Alternative; 144 acres increase under Alternative 1; and 26 acres increase under the PRMP.

For more information, see Table 4-70 (Quantitative assessment of patch size and connectance on fisher habitat condition in 2106) later in this section.

The loss of hiding cover would not reduce the ratio of cover to forage below the optimum in the elk management areas in the Coos Bay and Salem Districts. Wisdom et al. (2004), citing work by others (Black et al. 1976 and Thomas et al. 1979), stated that the optimum cover to forage ratio for elk was 60:40 ( $60 \%$ cover habitat, to $40 \%$ forage habitat). Analysis indicates that the amount of available hiding cover is extremely high (e.g., greater than 85\%) under the PRMP and all alternatives, except Alternative 2. See Figure 4-120 (Elk hiding cover availability on the elk habitat management units in the Coos Bay and Salem Districts) for trends in the abundance of elk hiding cover.

As discussed previously under Deer Habitat Management Areas in the Coos Bay District, elk use habitat more when it is greater than 492 feet (150 meters) from roads open to vehicles. Elk habitat management areas in the Coos Bay and Salem Districts currently contain between 30 and $85 \%$ of their lands more than 492 feet from roads open to vehicle traffic. See Figure 4-121 (Percentage of elk habitat management area, in the Coos Bay and Salem Districts, greater than 492 feet from roads open to vehicle use).

Areas more than 492 feet from open roads provide elk respite from disturbance caused by road use (Wisdom et al. 2004). The effective loss of foraging habitat and hiding cover within 492 feet of open roads due to disturbance increases vulnerability of elk to both legal and illegal harvest, and increases in stress and movement rates (Rowland et al. 2004). Although BLM does have an estimate of the amount of new road construction in the next 10 years, it is not a geographic or spatial estimate and, therefore, changes in the amount of land in elk habitat management areas within 492 feet of roads cannot be estimated. As the amount of roads open to vehicle use increase the amount of land greater than 492 feet from open roads would decrease and deleterious impacts (such as those described previously) to elk would increase. See the Road Density in Elk Habitat Management Areas section for a discussion of the effects of the alternatives on road density within the elk habitat management areas.

FigURE 4-121. Percentage OF

ElK Habitat MANAGEMEN'T Area In The Coos Bay And Salem Districts, Greater Than 492 Feet From Roads Open To Vehicle Use

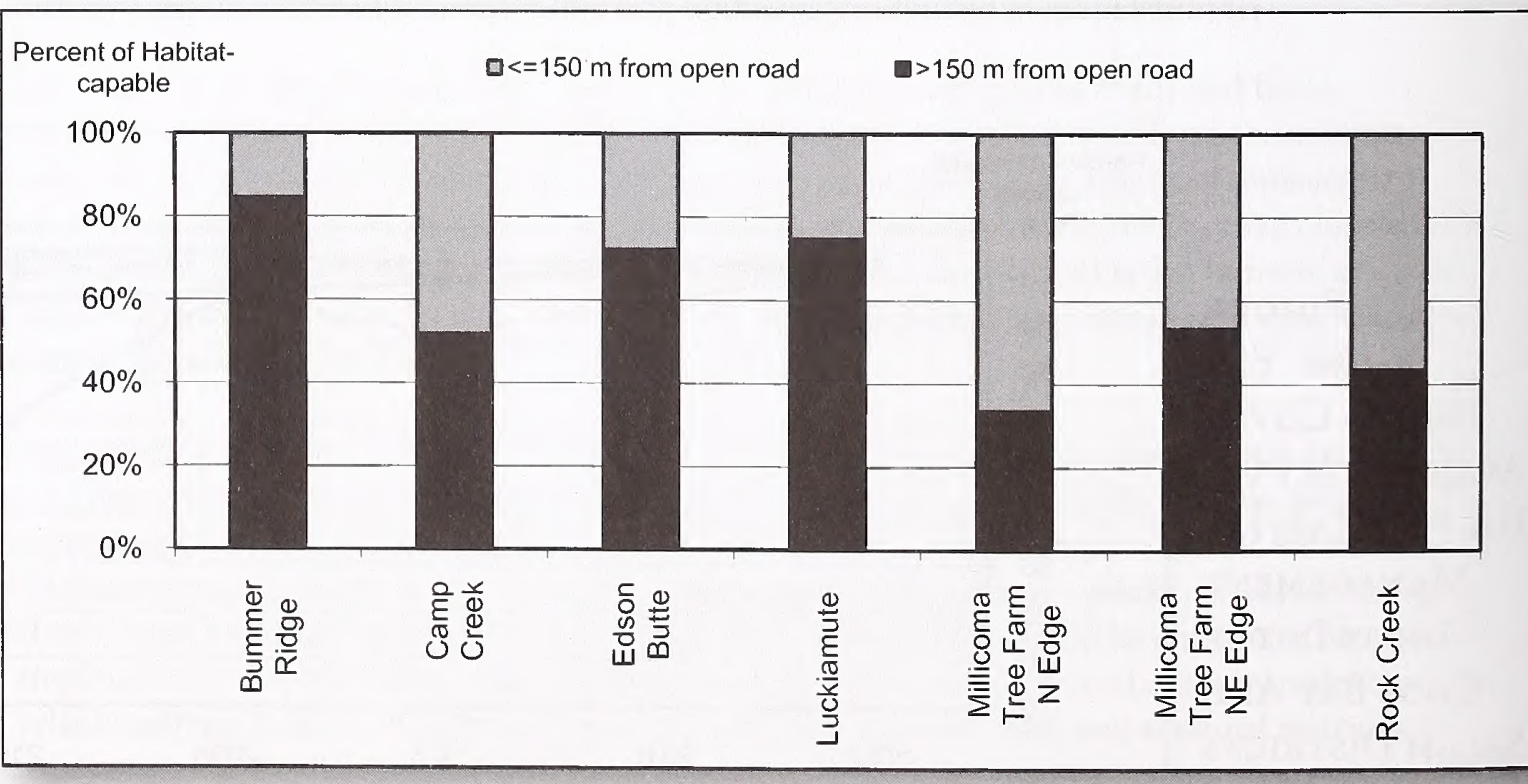




\section{Elk Habitat Management Areas on the Medford District}

Under all alternatives, nine elk habitat management areas (totaling 123,700 acres) would be managed in areas of important winter foraging habitat in the Medford District. Following are several factors that affect the quality of elk foraging habitat:

- effect that fuels treatments have on vegetation, after harvesting and site preparation

- size of the forage units. Elk use decreases with increased distance (greater than 100 yards) from hiding cover (Wisdom et al. 2004)

- disturbance caused by vehicles. Forage habitat quality decreases with increasing density of roads open to vehicle traffic (Wisdom et al. 2004)

The creation of foraging habitat would occur as a result of regeneration harvests. Forest stands would remain in the stand establishment phase and provide foraging habitat for elk for up to two to three decades following regeneration harvest. The differences among alternatives would be a result of the different amounts of regeneration harvests and partial harvests under the alternatives that would create the stand establishment forest structural stage classification. Natural grasslands and woodland areas would provide foraging habitat that would not vary among the alternatives. Intensive forest management on intermingled private forestlands would provide additional foraging habitat. It is assumed that the amount of forage habitat on privately owned commercial forest lands would remain approximately stable over time.

Foraging habitat availability on the Medford District elk habitat management areas would vary little amongst the alternatives. Foraging habitat would remain stable at approximately the current condition of $9 \%$ under Alternative 1. Foraging habitat would decline through 2106 from $9 \%$, to $4 \%$ of the BLM-administered lands under the No Action Alternative. Foraging habitat would increase 12\% by 2056 under Alternative 2 and the PRMP before decreasing to a more modest increase of $3 \%$ by 2106 . Under Alternative 3 , the amount of elk foraging habitat would increase to $22 \%$ of the BLM-administered lands within the elk habitat management areas by 2106. Figure 4-122 (Average foraging habitat on the elk habitat management units in the Medford District) shows the trends in foraging habitat on elk management areas in the Medford District.

Intensive forest management on intermingled private forestlands would provide more foraging habitat per unit area than on BLM-administered lands due to shorter harvest rotations resulting in more land being in an early seral than a longer rotation would provide. However, since management practices on private forestlands include larger clearcut harvest units and aggressive brush control, the foraging habitat would differ in quality from foraging habitat on BLM-administered lands. There is no data to indicate whether or

Figure 4-122. Average Foraging Habitat On Elk Habitat Management Units In The Medford District

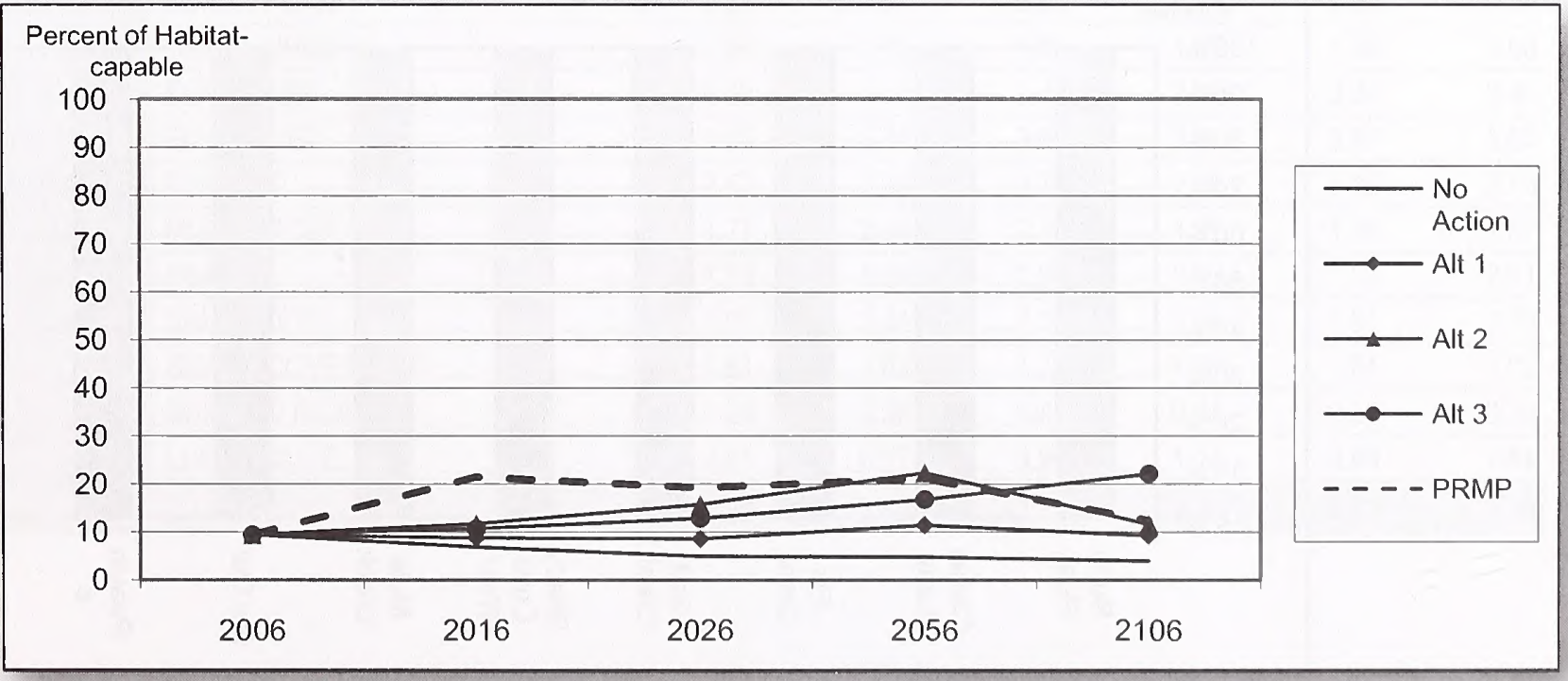


not intermingled private lands would change the overall cover to forage ratio one way or the other. More accurate analysis of the cover to forage ratio that considers the specifics of intermingled private lands would need to occur at a project scale where the analysis could better account for specific circumstances of habitat juxtaposition and better forecast habitat changes over time on private lands.

As discussed previously in Elk Habitat Management Areas on the Coos Bay and Salem Districts, Wisdom et al. (2004) stated that the optimum cover to forage ratio for elk was $60 \%$ cover habitat to $40 \%$ forage habitat. Under the PRMP, from 2016 to 2056, foraging habitat would account for $20 \%$ of the BLM-administered lands within the elk habitat management areas in the Medford District. None of the alternatives would provide elk foraging habitat at levels close to the $40 \%$ recommended by Wisdom et al. (2004). Winter foraging habitat would be better met on the industrial forestlands intermingled with BLM-administered lands in many of the elk habitat management areas where intensive forest management would leave a higher percentage of those lands in early-seral conditions. Management on industrial forest lands would create foraging habitat of differing quality than those on BLM-administered lands. There is no data to indicate whether or not intermingled private lands would change the overall cover to forage ratio one way or the other. More accurate analysis of the cover to forage ratio that considers the specifics of intermingled private lands would need to occur at a the project scale where the analysis could better account for specific circumstances of habitat juxtaposition and better forecast habitat changes over time on private lands.

As discussed previously under Deer Habitat Management Areas in the Coos Bay District, elk use habitat more when it is greater than 492 feet (150 meters) from roads open to vehicles. Elk habitat management areas in the Medford District currently contain between 15 and $50 \%$ of their lands more than 492 feet from roads open to vehicle traffic. See Figure 4-123 (Percentage of deer habitat management area, in the Medford District greater than 492 feet from roads open to vehicle use).

Areas more than 492 feet from open roads provide elk respite from disturbance caused by road use (Wisdom et al. 2004). The effective loss of foraging habitat and hiding cover within 492 feet of open roads due to disturbance increases vulnerability of elk to both legal and illegal harvest, and increases their stress and movement rates (Rowland et al. 2004). Although the BLM does have an estimate of amount of new road construction that would occur in the next 10 years, it is not a geographic or spatial estimate and, therefore, changes in the amount of land in elk habitat management areas within 492 feet of roads cannot be estimated. As the amount of roads open to vehicle use increases, the amount of land greater than 492 feet from open roads would decrease and deleterious impacts (such as those described previously) to elk would increase. See the Road Density in Elk Habitat Management Areas section for a discussion of the effects of the alternatives.

Figure 4-1123. Percentage Of Elk Habitat Management Area In The Medford District Greater than 492 Feet From Roads Open To Vehicle Use

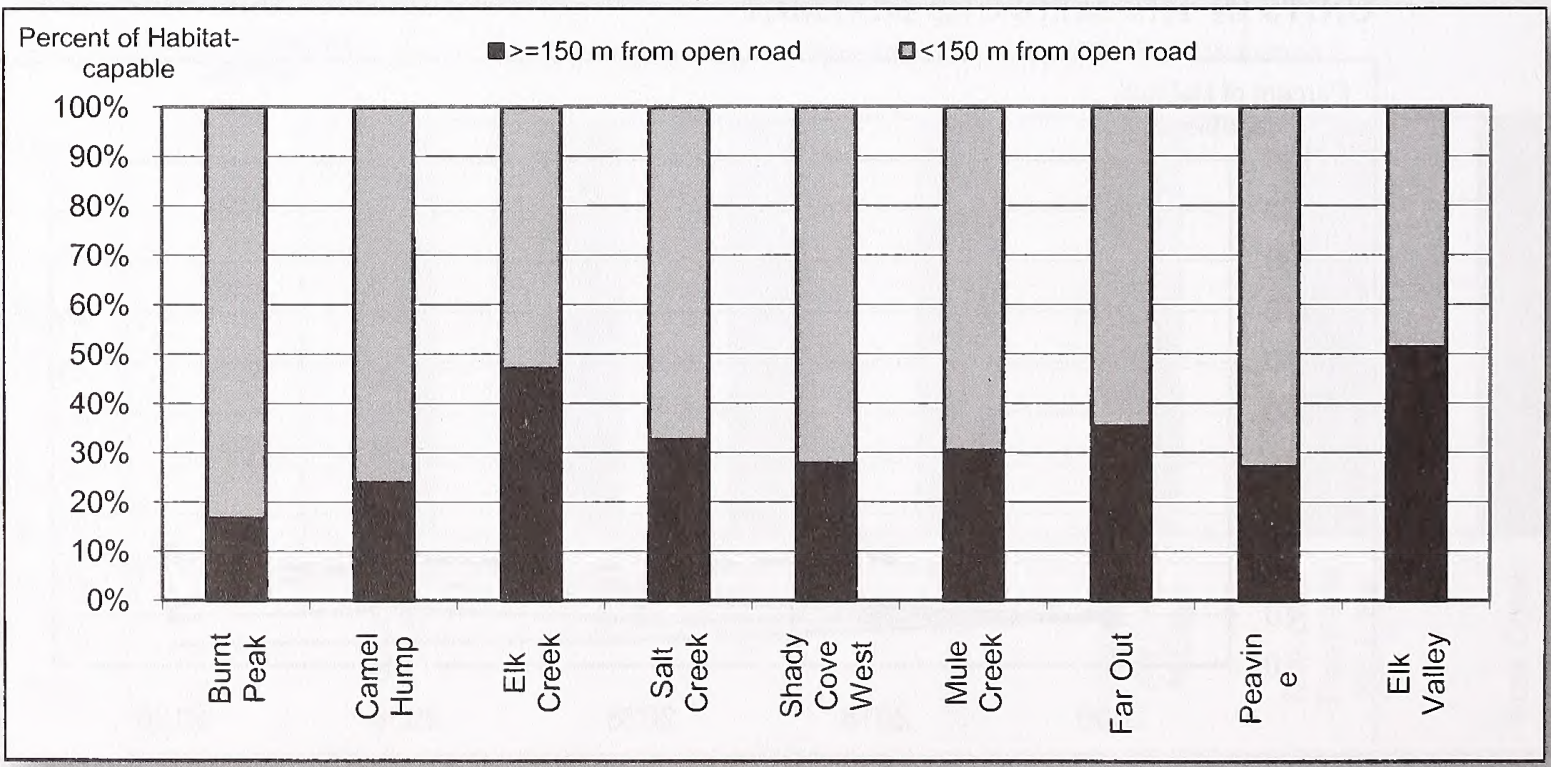




\section{Road Density Within Elk Habitat Management Areas}

The density of roads open to the public within elk habitat management areas on the Coos Bay, Salem, and Medford Districts currently varies from 0.24 to 4.35 road miles per mile and averages 2.35 road miles per mile. See Table 4-65 (Open road density on BLM-administered lands in elk habitat management units). Construction of new roads that would be open to public use would vary from 17 miles under the No Action Alternative, to more than 36 miles under the PRMP. The open road density in elk habitat management areas would increase $6 \%$ under the PRMP, from 2.35 to 2.49 road miles per square mile. Under Alternatives 1, 2, and 3 , there would be a 6 to $7 \%$ increase in open road density. Under the No Action Alternative, open road density would increase $3 \%$ to 2.42 road miles per square mile.

The average road density would change by alternative, as follows:

\begin{tabular}{lcc}
\hline Alternative & $\begin{array}{c}\text { Number of Elk HMAs (of } 16 \text { HMAs) With Less } \\
\text { Than 1\% Increase in Average Road Density }\end{array}$ & $\begin{array}{c}\text { Number of Elk HMAs (of 16 HMAs) With 5\% Increase } \\
\text { in Average Road Density }\end{array}$ \\
\hline No Action & 1 & 9 \\
\hline Alternative 1 & 2 & 10 \\
\hline Alternative 2 & 1 & 8 \\
\hline Alternative 3 & 4 & 4 \\
\hline PRMP & 1 & 9 \\
\hline
\end{tabular}

Table 4-65. Open Road Density On BLM-Administered Lands In Elk Habitat Management Units

\begin{tabular}{|c|c|c|c|c|c|c|c|}
\hline \multirow{3}{*}{ District } & \multirow{3}{*}{ Elk Habitat Management Area } & \multicolumn{6}{|c|}{ Density of Open Roads (road miles per square mile) } \\
\hline & & Year & 2016 & 2016 & 2016 & 2016 & 2016 \\
\hline & & 2006 & Alt. 1 & Alt. 2 & Alt. 3 & No Action & PRMP \\
\hline \multirow{6}{*}{ Coos Bay } & CAMP CREEK & 3.03 & 3.20 & 3.26 & 3.10 & 3.12 & 3.21 \\
\hline & EDSON BUTTE & 1.55 & 1.57 & 1.65 & 1.58 & 1.59 & 1.75 \\
\hline & $\begin{array}{l}\text { MILLICOMA TREE FARM } \\
\text { N EDGE }\end{array}$ & 4.34 & 4.35 & 4.34 & 4.34 & 4.34 & 4.34 \\
\hline & MILLICOMA TREE FARM & & & & & & \\
\hline & NE EDGE & 2.97 & 3.05 & 2.98 & 3.20 & 3.01 & 3.05 \\
\hline & ROCK CREEK & 3.83 & 4.24 & 4.18 & 3.97 & 4.06 & 3.98 \\
\hline \multirow{9}{*}{ Medford } & BURNT PEAK & 0.59 & 0.67 & 0.95 & 0.68 & 0.64 & 0.59 \\
\hline & CAMEL HUMP & 1.47 & 1.55 & 1.58 & 1.53 & 1.48 & 1.60 \\
\hline & ELK CREEK & 3.32 & 3.39 & 3.47 & 3.49 & 3.34 & 3.40 \\
\hline & ELK VALLEY & 3.46 & 3.76 & 3.69 & 3.54 & 3.62 & 3.57 \\
\hline & FAR OUT & 2.42 & 2.59 & 2.73 & 2.65 & 2.45 & 2.75 \\
\hline & MULE CREEK & 1.77 & 2.06 & 2.11 & 1.92 & 1.95 & 1.87 \\
\hline & PEAVINE & 1.93 & 1.99 & 1.97 & 2.10 & 1.96 & 2.01 \\
\hline & SALT CREEK & 2.01 & 2.11 & 2.10 & 2.08 & 2.05 & 2.15 \\
\hline & SHADY COVE WEST & 1.61 & 1.67 & 1.75 & 1.75 & 1.61 & 1.92 \\
\hline \multirow{3}{*}{ Salem } & BUMMER RIDGE & 0.24 & 0.36 & 0.45 & 0.34 & 0.28 & 0.38 \\
\hline & LUCKIAMUTE & 0.91 & 0.97 & 0.94 & 1.13 & 0.93 & 1.54 \\
\hline & Average & 2.35 & 2.50 & 2.52 & 2.48 & 2.42 & 2.49 \\
\hline
\end{tabular}


The effects of new roads on habitat use are difficult to evaluate based only on changes in road density. Road location compared to available habitat is critical to accurate forecasting of effects. A road built in an area with already high road density would have relatively minor effects compared to a road built into previously undisturbed habitat.

Winter closures of open roads under all alternatives would remove or reduce the disturbance effects caused by vehicle use of existing and new roads and allow deer to gain maximum benefit from available forage near roads within the Medford District's elk habitat management areas and on winter hiding cover within the Coos Bay and Salem Districts' elk habitat management areas. Due to legal constraints of binding road use agreements, not all roads would be closed to public use during these time periods.

Vehicles would cause disturbance to available cover adjacent to open roads. As a result, the cover adjacent to open roads would be utilized to less than maximum benefit during the spring and summer seasons in the Coos Bay District's deer habitat management areas.

Under all alternatives, off-highway vehicles would be limited to designated roads and trails. These limitations, along with the seasonal closure of roads in elk management areas, would limit the amount of disturbance and risks of illegal hunting. Reduced disturbance would allow elk to make maximum use of foraging habitat and hiding cover, as well as lower the risk of illegal harvests.

\section{Bald Eagle}

Within the planning area (except the Klamath Falls Resource Area), the amount of area where nesting and roosting habitat exists for bald eagles would increase by 2106 under all alternatives, including the PRMP. This would provide opportunities for the movement of existing bald eagle pairs and the establishment of new nest sites. Under Alternative 2, there would be a $2 \%$ decrease in nesting and roosting habitat between 2006 and 2016 (from 239,583 acres in 2006, to 234,775 acres in 2016) before increasing steadily from 2016 through 2106. The remaining alternatives, including the PRMP, would have a steady, gradual increase in the amount of nesting and roosting habitat. See Table 4-66 (Bald eagle nesting and roosting habitat development within the planning area) and Figure 4-124 (Bald eagle nesting and roosting habitat development within the planning area).

Table 4-66. Bald Eagle Nesting And Roosting Habitat Development Within The Planning Area

\begin{tabular}{l|rr|r|r|r}
\hline \multirow{2}{*}{ Alternative } & 2006 & 2016 & 2026 & 2056 & 2106 \\
\cline { 2 - 6 } & \multicolumn{5}{|c|}{ (acres) } \\
\hline No Action & 240,000 & 263,000 & 281,000 & 331,000 & 374,000 \\
\hline Alternative 1 & 240,000 & 250,000 & 262,000 & 298,000 & 332,000 \\
\hline Alternative 2 & 240,000 & 235,000 & 242,000 & 258,000 & 282,000 \\
\hline Alternative 3 & 240,000 & 244,000 & 243,000 & 277,000 & 313,000 \\
\hline PRMP & 240,000 & 249,000 & 264,000 & 306,000 & 349,000 \\
\hline
\end{tabular}


Figure 4-124. Bald Eagle Nesting And Roosting Habitat Development Within The Planning Area

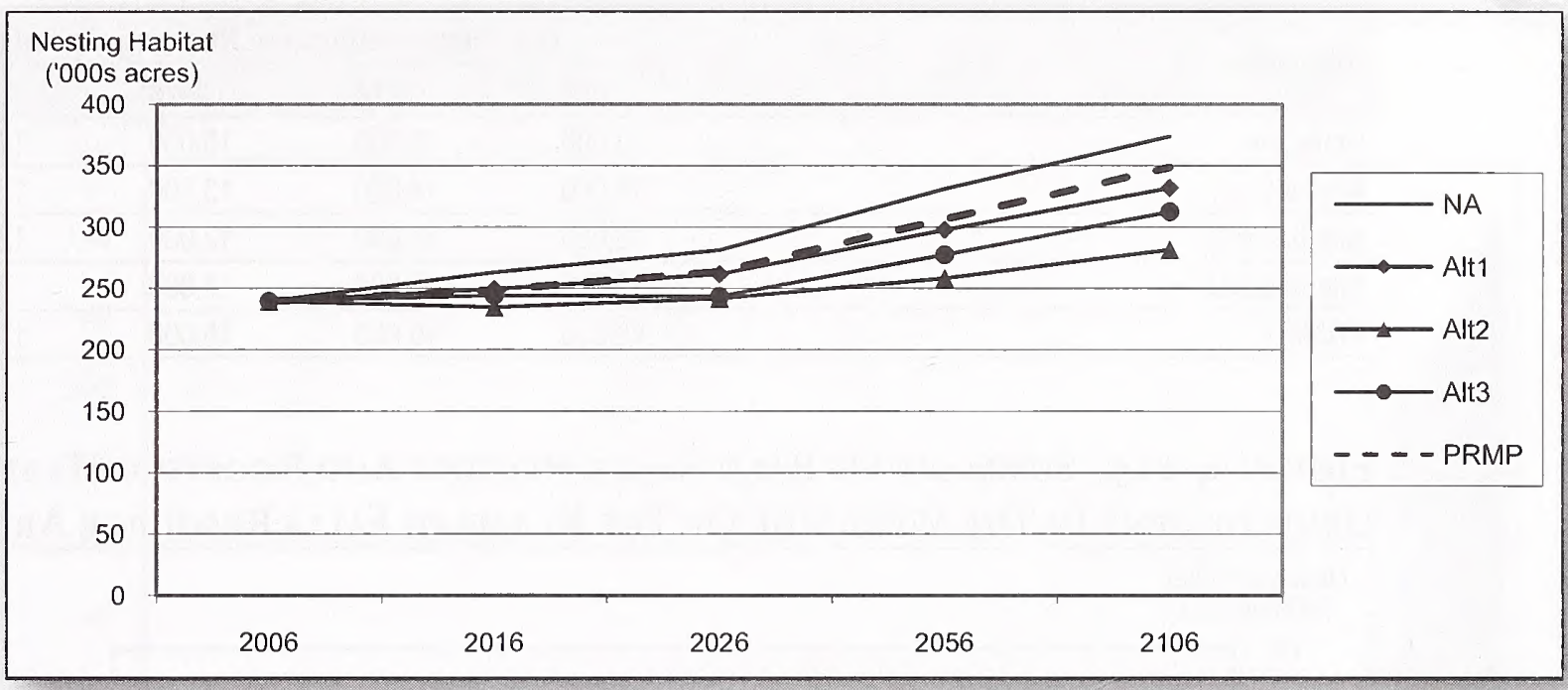

In the Klamath Falls Resource Area, the analysis and the effects to bald eagle nesting and roosting habitat would differ between the western and eastern portions of the resource area. The western portion of the Klamath Falls Resource Area contains bald eagle nesting and roosting habitat on the forested lands in the Klamath Physiographic Province (such as those described in Forest Structure and Spatial Pattern).

Under Alternatives 1,2, and 3, bald eagle nesting and roosting habitat would decrease by 26 to $43 \%$ (4,000 to 7,000 acres) by 2106 in the western portion of the Klamath Falls Resource Area. See Table 4-67 (Bald eagle nesting and roosting habitat in the west side of the Klamath Falls Resource Area) and Figure 4-125 (Summary of bald eagle nesting and roosting habitat development in the west side of the Klamath Falls Resource Area). Bald eagle nesting and roosting habitat would decline under Alternatives 1 and 2 due to lower site classes of the forest stands in the Klamath Falls Resource Area, which recover slower than high site classes after harvest and the increase in habitat loss due to increased regeneration harvests. Under Alternative 3, unevenaged management coupled with the higher rate of stand entry would cause a higher rate of habitat loss compared to the other alternatives. Uneven-aged management under Alternative 3 would remove trees equally from all size classes, and stands would be entered more frequently, which would result in the largest reduction of bald eagle nesting and roosting habitat. Under Alternatives 1,2, and 3, the opportunities for establishment of additional bald eagle nest sites and movement of the existing pairs of bald eagles on BLMadministered lands in the west side of the Klamath Falls Resource Area would diminish from the current condition; such opportunities would increase under the No Action Alternative and the PRMP.

Under the No Action Alternative, bald eagle nesting and roosting habitat would increase by $7 \%$ in the west side of the Klamath Falls Resource Area by 2106, and by 13\% under the PRMP by 2106 . See Table 4-67 (Bald eagle nesting and roosting habitat in the west side of the Klamath Falls Resource Area) and Figure 4-125 (Summary of bald eagle nesting and roosting habitat development in the west side of the Klamath Falls Resource Area). Under the No Action Alternative and PRMP, the opportunities for the movement of existing bald eagle pairs and the establishment of new nest sites in the Klamath Falls Resource Area would be increasing, similar to those in the rest of the planning area. 
Table 4-67. Bald Eagle Nesting And Roosting Habitat In The West Side Of The Klamath Falls Resource Area

\begin{tabular}{lrrrrr}
\hline \multirow{2}{*}{ Alternative } & \multicolumn{5}{c}{ Bald Eagle Nesting and Roosting Habitat (acres) } \\
\cline { 2 - 6 } & 2006 & 2016 & 2026 & 2056 & 2106 \\
\hline No Action & 15,000 & 16,000 & 15,000 & 14,000 & 16,000 \\
\hline Alternative 1 & 15,000 & 14,000 & 13,000 & 12,000 & 11,000 \\
\hline Alternative 2 & 15,000 & 14,000 & 13,000 & 12,000 & 10,000 \\
\hline Alternative 3 & 15,000 & 12,000 & 7,000 & 7,000 & 8,000 \\
\hline PRMP & 15,000 & 15,000 & 15,000 & 17,000 & 17,000 \\
\hline
\end{tabular}

Figure 4-125. Summary Of Bald Eagle Nesting And Roosting Habitat Development In The West Side Of The Klamath Falls Resource Area

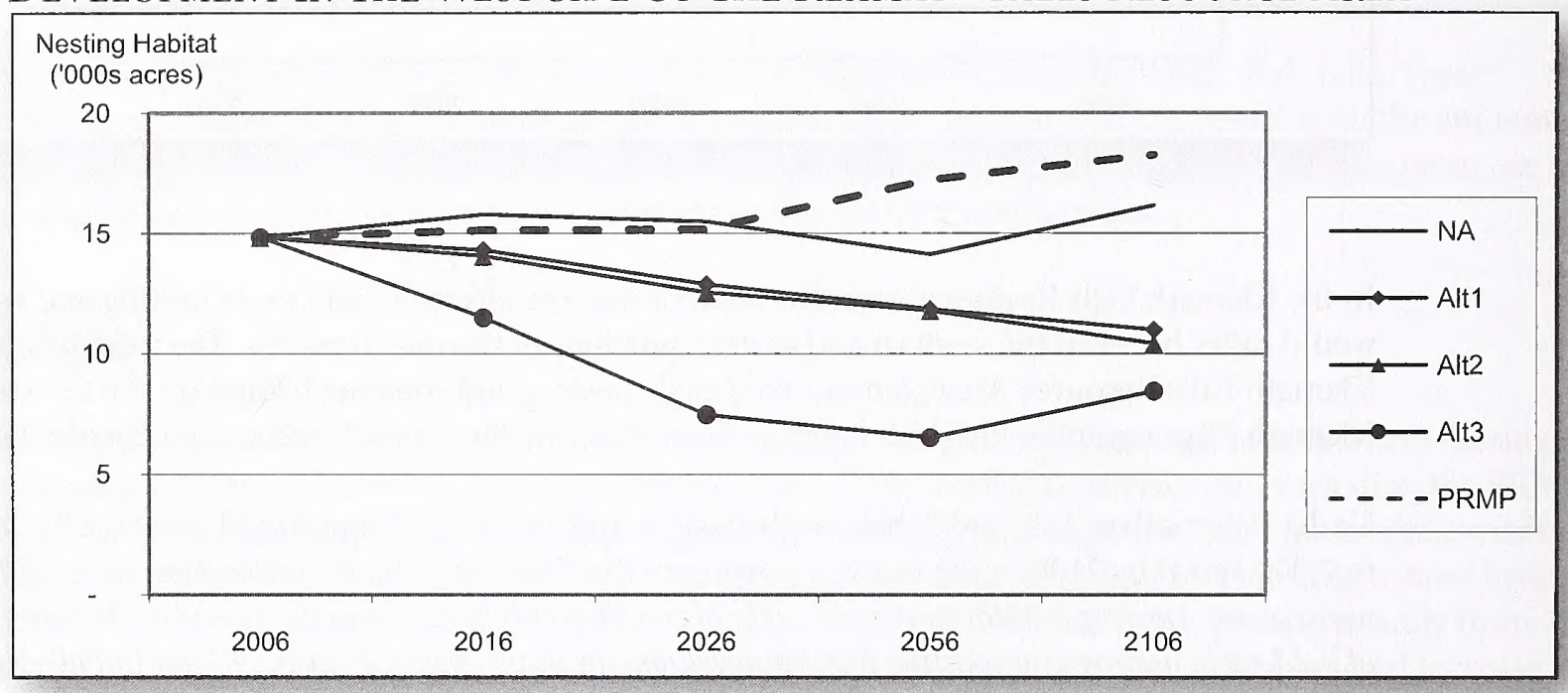

Forested lands in the eastern portion of the Klamath Falls Resource Area, within the Eastside Management Lands area, contain approximately 37,000 acres of bald eagle nesting and roosting habitat. Even though forest stands were not modeled through time for the Eastside Management Lands, no changes to the current management are anticipated. The effects to bald eagle nesting and roosting habitat are assumed to be similar to those described for the west side of the Klamath Falls Resource Area under the No Action Alternative.

Under all alternatives, occupied bald eagle nest sites, historic sites, potential sites, and wintering and congregation areas would be protected on BLM-administered lands. Management of these lands in compliance with the Bald Eagle Protection Act would provide protection for sites on both federal and private lands. The effects to the designated bald eagle management areas are common to all alternatives, including the PRMP.

Under all alternatives, the only management activity that would occur in bald eagle management areas would be treatments to reduce fire risk and thinning to promote development of larger trees. The amount of available eagle nesting and roosting habitat would increase within each bald eagle management area over time as stands continue to develop. The number of bald eagle management areas that have at least $90 \%$ nesting and roosting habitat would increase from 100 management areas in 2006, to 144 management areas by 2106. See Figure 4-126 (The abundance and development of bald eagle nesting and roosting habitat in bald eagle management areas). In addition, the "taking" of bald eagles is prohibited under the Bald and Golden Eagle Protection Act and the Migratory Bird Treaty Act. Noise disturbance and physical disturbance of nesting bald eagles would be considered an unlawful taking of the species and would be prohibited under these acts. The BLM activities that would disturb nesting bald eagle pairs would be restricted during the critical nesting period (January 1 to August 31). 
Figure 4-126. The Abundance And Development Of Bald Eagle Nesting And Roosting Habitat In Bald Eagle Management Areas

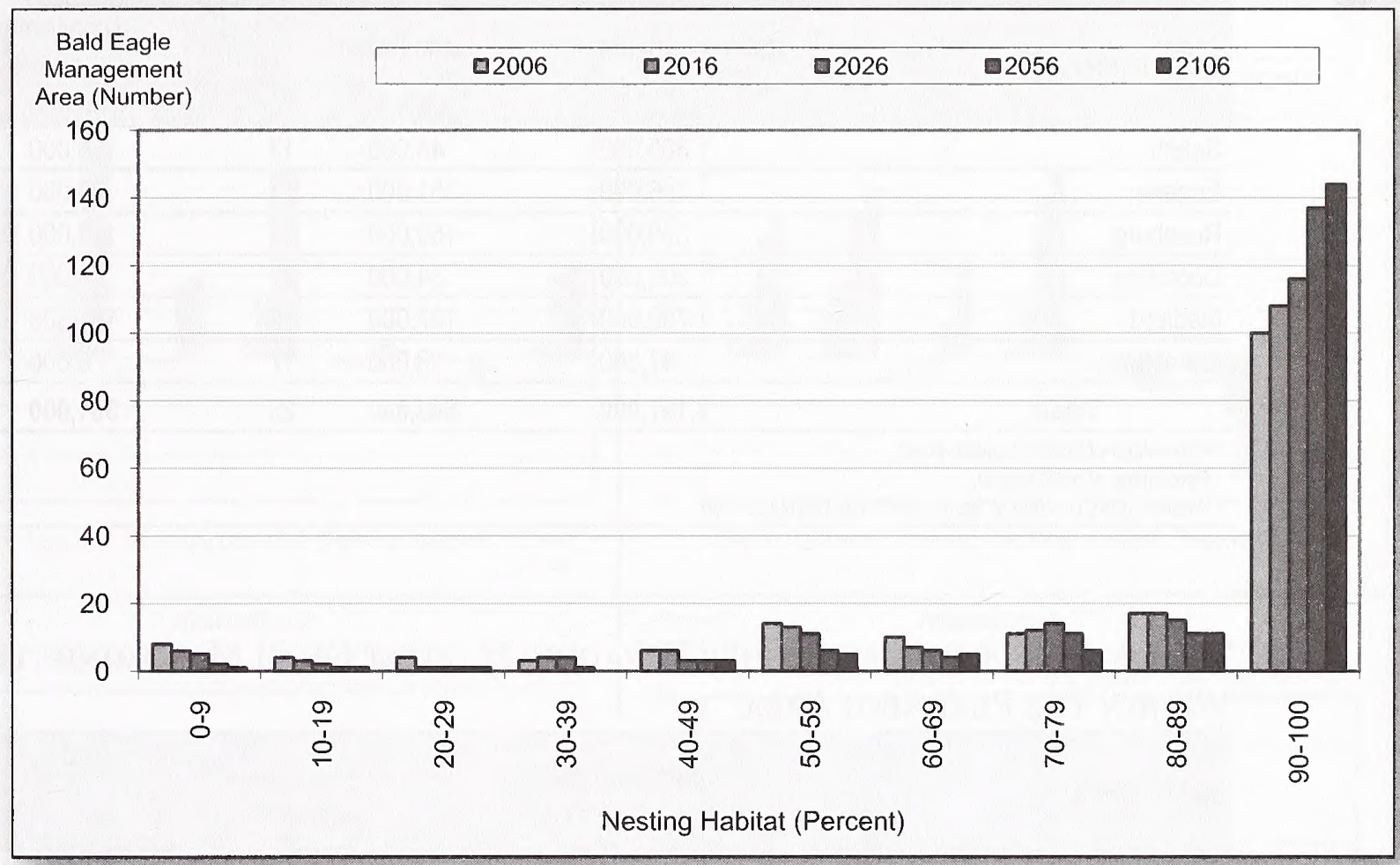

\section{Fisher}

Fisher historically ranged throughout BLM-administered lands within the planning area. The only remaining recognized population centers are in the southern Cascade Mountains and the northern Siskiyou Mountains of the Medford and Coos Bay Districts. There are currently 543,000 acres of natal habitat on BLM-administered lands within the planning area and 1,356,000 acres of foraging habitat (includes overlap with natal habitat). See Table 4-68 (Available fisher natal habitat on BLM-administered lands with the planning area) and Table 4-69 (Available fisher foraging habitat on BLM-administered lands with the planning area).

Fisher forage in all habitat types that are capable of providing high canopy cover and that have some legacy component (Fed. Reg. 69[68]:18770-18792, and Powell 1981). Across BLM-administered lands, within the planning area, fisher foraging habitat would increase under all alternatives as shown in Figure 4-127 (Fisher foraging habitat summarized for BLM-administered lands within the planning area). Under the No Action Alternative, there would be a $37 \%$ increase in fisher foraging habitat. There would be a similar trend under Alternatives 1, 3, and the PRMP, resulting in an increase of 23 to $27 \%$. Under Alternative 2, foraging habitat would increase $8 \%$. Under Alternative 2 and the PRMP, foraging habitat would decline by $3 \%$ by 2016 ; however, by 2056 fisher foraging habitat would increase by $15 \%$ over 2006 levels.

Figure 4-128 (District summary of fisher forging habitat changes, compared to 2006.) illustrates the response of fisher foraging habitat development to the alternatives in each district.

Fisher foraging habitat would increase under all alternatives and in all time intervals in the Salem, Eugene, and Coos Bay Districts. The PRMP would increase fisher foraging habitat by $74 \%$ by 2106 on BLMadministered lands in the Coos Bay District; this percentage would provide slightly less foraging habitat than the No Action Alternative at $77 \%$ and Alternative 1 with $79 \%$. However, the PRMP increase in fisher 
Table 4-68. Available Fisher Natal Habitat On BLM-Administered Lands Within The Planning Area

\begin{tabular}{|c|c|c|c|c|c|}
\hline \multirow{2}{*}{ BLM District } & \multirow{2}{*}{$\begin{array}{r}\text { Habitat-capable } \\
\text { (acres) }\end{array}$} & \multicolumn{2}{|c|}{ Natal Habitat } & \multicolumn{2}{|c|}{$\begin{array}{l}\text { Natal habitat } 200 \text { years } \\
\text { of age and older }\end{array}$} \\
\hline & & (acres) & $(\%)^{a}$ & (acres) & $(\%)^{b}$ \\
\hline Salem & 365,000 & 48,000 & 13 & 30,000 & 63 \\
\hline Eugene & 296,000 & 51,000 & 17 & 38,000 & 75 \\
\hline Roseburg & 399,000 & 156,000 & 39 & 119,000 & 75 \\
\hline Coos Bay & 302,000 & 84,000 & 28 & 57,000 & 68 \\
\hline Medford & 788,000 & 197,000 & 25 & 101,000 & 51 \\
\hline Klamath $^{\circ}$ & 47,000 & 8,000 & 17 & 6,000 & 75 \\
\hline Totals & $2,197,000$ & 543,000 & 25 & 351,000 & 65 \\
\hline
\end{tabular}

a Percentage of habitat-capable acres.

${ }^{\mathrm{D}}$ Percentage of natal habitat.

c Western (O\&C) portion of the Klamath Falls Resource Area.

Table 4-69. Available Fisher Foraging Habitat On BlM-Administered Lands Within The Planning Area

\begin{tabular}{lrrr}
\hline BLM District & $\begin{array}{r}\text { Habitat-capable } \\
\text { (acres) }\end{array}$ & $\begin{array}{c}\text { Foraging Habitat } \\
\text { (acres) }\end{array}$ & $(\%)^{a}$ \\
\hline Salem & 365,000 & 196,000 & 54 \\
\hline Eugene & 296,000 & 134,000 & 45 \\
\hline Roseburg & 399,000 & 227,000 & 57 \\
\hline Coos Bay & 302,000 & 149,000 & 49 \\
\hline Medford & 788,000 & 612,000 & 78 \\
\hline Klamath & 47,000 & 38,000 & 81 \\
\hline Totals & $2,197,000$ & $1,356,000$ & 62 \\
\hline $\begin{array}{l}\text { a Percentage of habitat-capable acres } \\
\text { bWestern (O\&C) portion of the Klamath Falls Resource Area }\end{array}$ & & \\
\hline
\end{tabular}

Figure 4-1 27. Fisher Foraging Habitat Summarized For BLMAdministered Lands Within The Planning Area

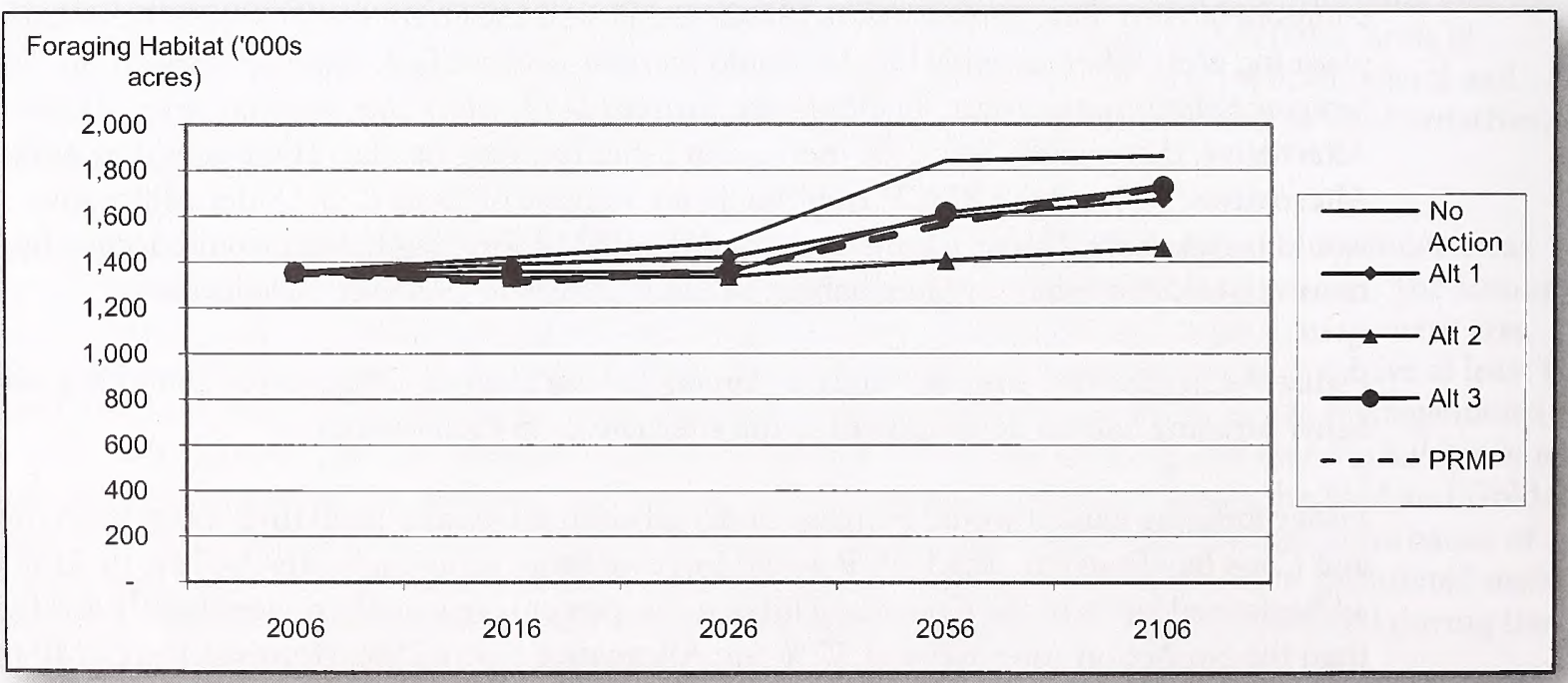


Figure 4-128. District Summary Of Fisher Foraging Habitat Changes Compared To 2006

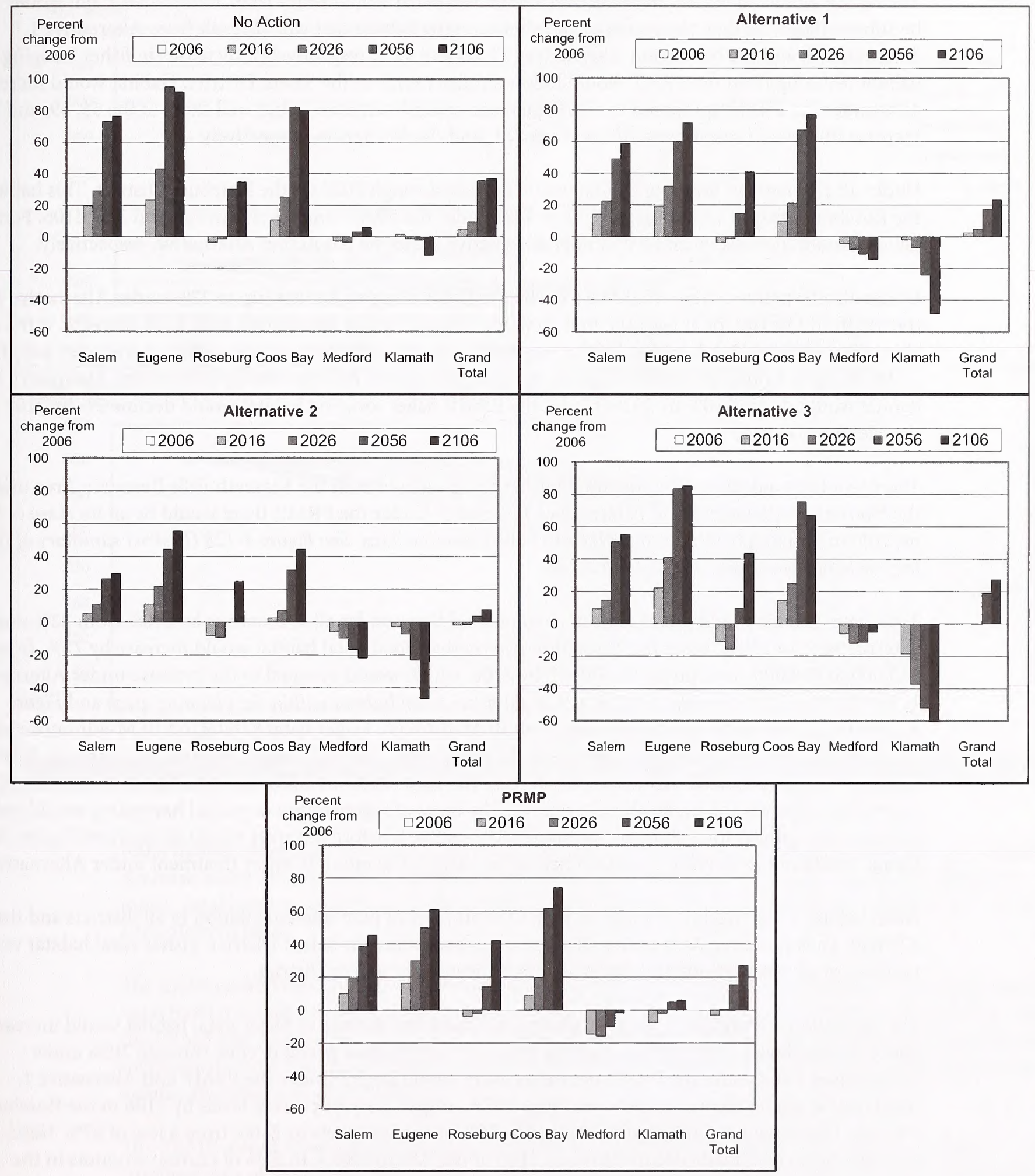


foraging habit would be well above the $44 \%$ increase that would occur under Alternative 2 . Fisher foraging habitat would increase $61 \%$ on BLM-administered lands in Eugene under the PRMP. The PRMP would have a $6 \%$ increase over the increase that would result from Alternative 2, but would be substantially less than the increases in fisher foraging habitat that would result from Alternative 1 , Alternative 3, and the No Action Alternative (72, 85 and 92\%, respectively). Increases in fisher foraging habitat resulting from the PRMP would follow similar trends in the Salem District. Habitat would increase $45 \%$ under the PRMP compared to a $30 \%$ increase underAlternative 2, but well short of the 56,59 , and $77 \%$ increase that would result from Alternatives 3,1 , and the No Action, respectively.

Under all alternatives, foraging habitat would decline through 2026 on the Roseburg District. This habitat on the Roseburg District would increase 41 to 44\% under the PRMP and Alternatives 1 and 3 by 2106. Foraging habitat would increase 25 and $35 \%$ under Alternative 2 and the No Action Alternative, respectively.

Under all alternatives, there would be a decline in fisher foraging habitat (up to $22 \%$ under Alternative 2) in the Medford District for at least the first 20 years. The No Action Alternative, with a $6 \%$ increase, is the only alternative under which foraging habitat would increase by 2106 . This increase would occur after a decline of $3 \%$ by 2026 . Under the PRMP, fisher foraging habitat would decline $16 \%$ by 2026 ; under Alternative 2 this habitat would decline $10 \%$ by 2026 . Under the PRMP, fisher foraging habitat would decline $2 \%$ by 2106 in the Medford District.

There would be a decline of up to $60 \%$ in fisher foraging habitat in the Klamath Falls Resource Area under the No Action Alternative and Alternatives 1,2, and 3. Under the PRMP, there would be an increase of $10 \%$ by 2106 in foraging habitat in the Klamath Falls Resource Area. See Figure 4-128 (District summary of fisher forging habitat changes, compared to 2006).

Total natal habitat would increase from current conditions under all alternatives by 2106 , from $22 \%$ under Alternative 2, to $118 \%$ under the No Action Alternative. Total natal habitat would increase by $72 \%$, from 543,000 to 934,000 acres under the PRMP by 2106 , which would be equal to the increase under Alternative 1. See Figure 4-129 (Abundance of total and old fisher natal habitat within the planning area) and Figure 4-130 (Total fisher natal habitat abundance on BLM districts). Fisher natal habitat, on BLM-administered lands, would decline 12\% under Alternative 2 through 2026, and 10\% under Alternative 3 through 2056. Under Alternative 3, natal habitat would increase the least (22\%) by 2106 due to the areas of partial and regeneration harvesting under this alternative. The areas of regeneration or partial harvesting would only provide natal habitat for a short period under Alternative 3 before the areas would be harvested again. Some stands would not re-develop into natal habitat because of the multiple-entry treatment under Alternative 3.

Natal habitat would decline during the first 20 to 50 years of plan implementation in all districts and the Klamath Falls Resource Area under all alternatives except for the Salem District. Fisher natal habitat would increase in all time periods and under all alternatives in the Salem District.

The No Action Alternative is the only alternative where the amount of fisher natal habitat would increase above current levels, 17\%, in the Roseburg District. Natal habitat would decline through 2056 under Alternatives 1 and 2 and the PRMP before recovery would begin. Under the PRMP and Alternative 1, natal habitat would recover to between 99 and 97\%, respectively, of current levels by 2106 in the Roseburg District. Fisher natal habitat would rebound to $76 \%$ of current levels by 2106 , from a low of $67 \%$. Natal habitat would continually decline through 2106 under Alternative 3, to $51 \%$ of current amounts in the Roseburg District. 
Figure 4-129 Abundance Of Total And Old Fisher Natal Habitat Within The Planning Area

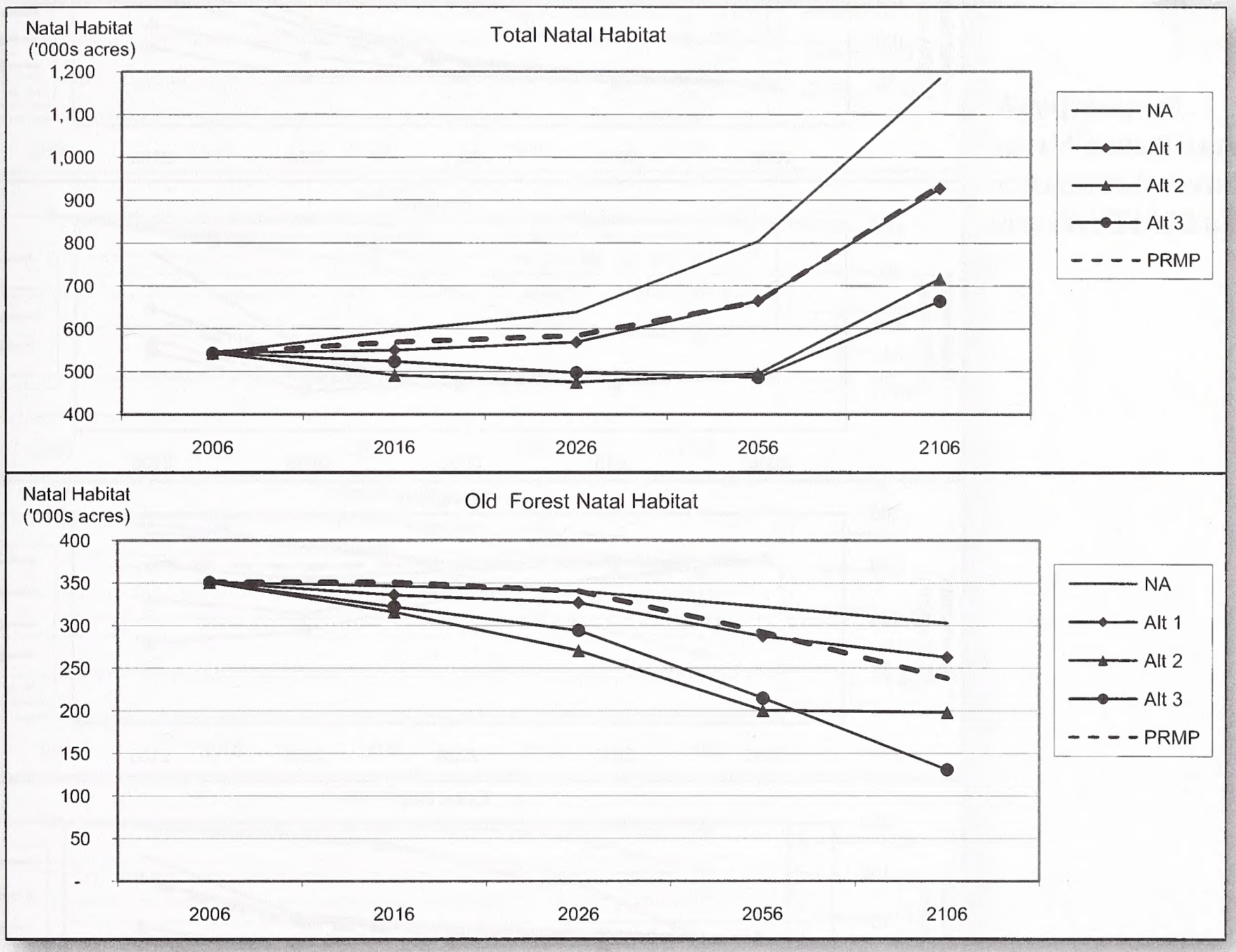

Natal habitat older than 200 years (defined as structurally complex old forest and very old forest) would decrease under all alternatives, on all districts within the planning area by 2106 . Under the PRMP, old forest, natal habitat would be reduced to $68 \%$ (238,000 acres) of the existing level (351,000 acres) on BLMadministered lands.

The most marked loss of old natal habitat would occur in the Klamath Falls Resource Area where old forest natal habitat would decline more than 50\% from current levels under all alternatives and the PRMP. Under the PRMP and Alternative 3, the most old forest natal habitat in the Klamath Fall Resource Area would be maintained under the PRMP and Alternative 3 (41 and 47\%, respectively). See Figure 4-131 (Old forest natal habitat abundance on BLM Districts).

The PRMP would retain an intermediate amount of old forest natal habitat when compared to the combinations of No Action/Alternative 1 (the high end) and Alternative 2/Alternative 3 (the low end) in various districts, and BLM (as a whole). Under the PRMP, between 60 and 75\% of the existing old forest, natal habitat would be maintained in all districts except the Klamath Falls Resource Area as discussed above. 
Figure 4-130. Total Fisher Natal Habitat Abundance ON BLM DISTRICTS

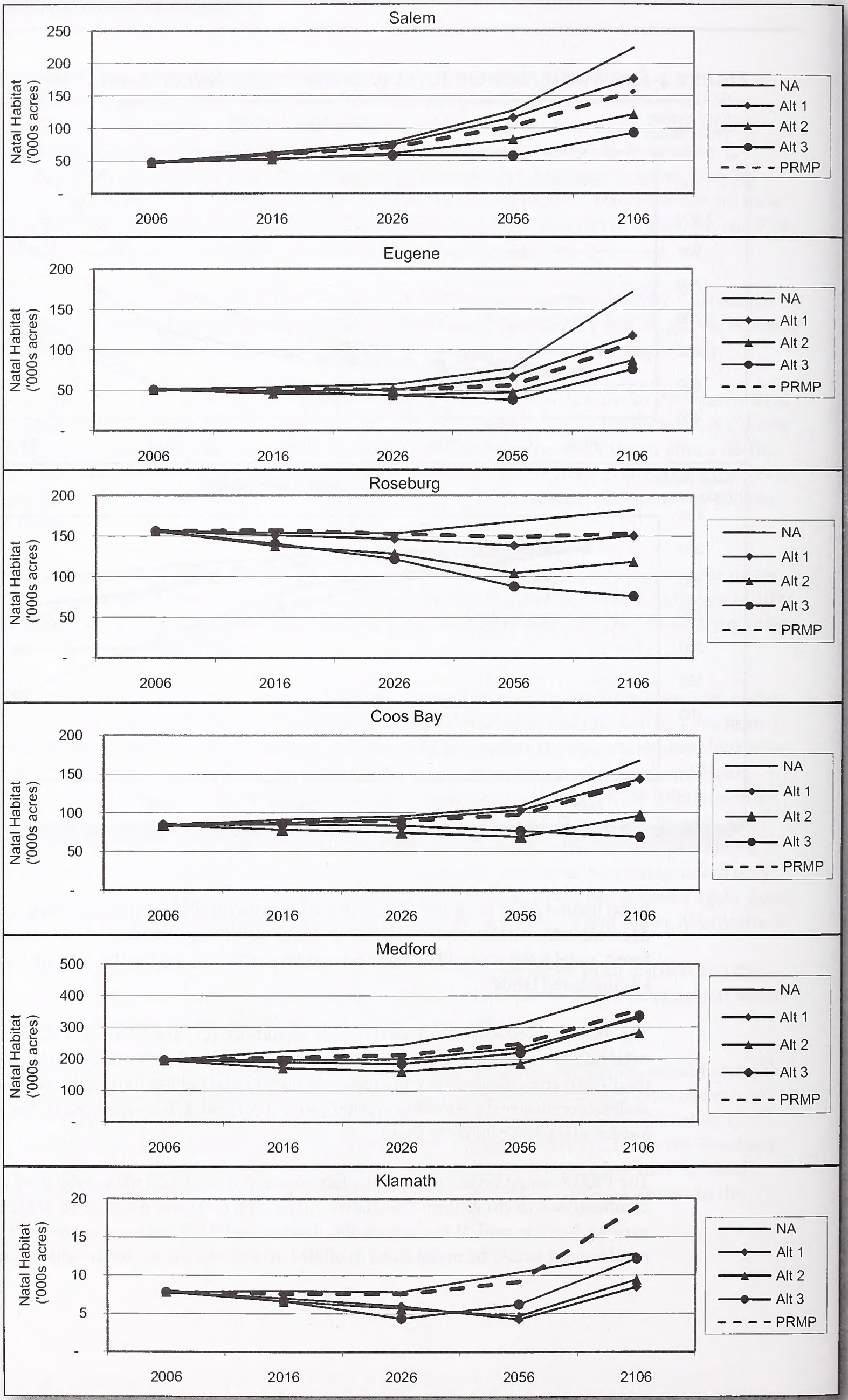




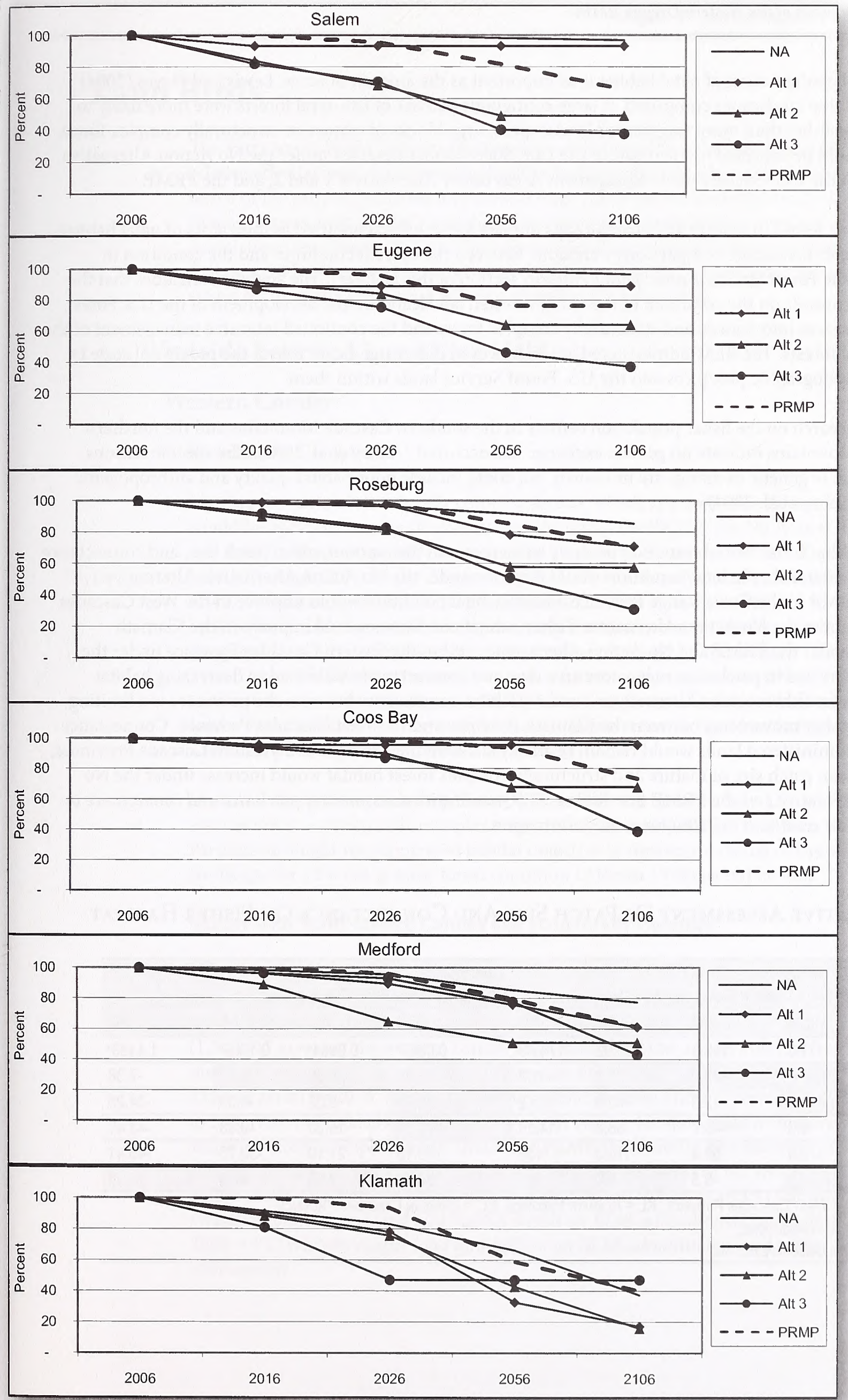

FIGURE 4-131.

Old Forest Natal

HABITAT ABUNDANCE

ON BLM DISTRICTS 
The spatial configuration of natal habitat is as important as the amount of acres. Lewis and Hayes (2004) concluded that landscapes comprised of large contiguous patches of late-seral forests were more likely to support the fisher than more fragmented landscapes. Large blocks of mature or structurally complex forest habitat would be expected to form within the Late-Successional Reserves under the No Action Alternative and within the Late-Successional Management Areas under Alternatives 1 and 2, and the PRMP.

The patterns found in mature and structurally complex forest habitat are used as indicators of natal habitat development. Landscape comparisons were done between the current condition and the condition in 2106 (see the Forest Structure and Spatial Patterns section of this chapter). The analysis concludes that the principal controls on the condition of the entire forested landscape are the development of the U.S. Forest Service reserves into mature and structurally complex forest and the continued intensive management of the nonfederal forests. The BLM-administered lands, however, play a significant role at the provincial scale by linking physiographic provinces and the U.S. Forest Service lands within them.

Genetic research on the fisher population centers in the southern Cascade Mountains and the northern Siskiyou Mountains indicate no genetic exchange has occurred (Aubry et al. 2004). The specific reasons for this lack of genetic exchange are unknown, but could include poor habitat quality and anthropogenic barriers (Aubry et al. 2004).

Assuming that fisher would respond positively to increases in the amount, mean patch size, and connectance of natal habitat, fisher habitat condition would improve under the No Action Alternative, Alternative 1, and the PRMP in the Coast Range Province. Fisher habitat condition would improve in the West Cascades Province under the No Action Alternative. Fisher habitat conditions would improve in the Klamath Province under the PRMP and No Action Alternatives, and in the Eastern Cascades Province under the PRMP. Decreases in patch size, mean core area size, and connectance would lead to decreasing habitat conditions for fishers under Alternatives 2 and 3. Habitat connectivity between the provinces is a limiting factor for fisher movements between the Klamath Province and the West Cascades Province. Connectance on BLM-administered lands would remain relatively stable in the Klamath and Western Cascade Provinces, and the mean patch size of mature and structurally complex forest habitat would increase under the No Action Alternative and the PRMP. See Table 4-70 (Quantitative assessment of patch size and connectance on fisher habitat condition in 2106) for more information.

Table 4-70. Quantitative Assessment Of Patch Size And Connectance On Fisher Habitat CONDITION IN 2106

\begin{tabular}{|c|c|c|c|c|c|c|c|c|}
\hline \multirow{2}{*}{ Alternative } & \multicolumn{4}{|c|}{$\begin{array}{l}\text { Mean Patch Size } \\
\text { (Change From Current Condition)(acres) } \\
\end{array}$} & \multicolumn{4}{|c|}{$\begin{array}{l}\text { Connectance } \\
\text { (Percent Change From Current Condition) }\end{array}$} \\
\hline & $\mathrm{CR}^{\mathrm{A}}$ & WC & $\mathrm{KL}$ & EC & CR & WC & $\mathrm{KL}$ & EC \\
\hline CuRrent Condition & 111.5 & 103.3 & 123.92 & 174.49 & $0.0883^{8}$ & $0.0984^{6}$ & $0.1009^{8}$ & $1.4433^{\circ}$ \\
\hline No ACTION & $229.4^{c}$ & 43.2 & 55.1 & -31.9 & 36.36 & 4.00 & 8.70 & -7.38 \\
\hline Alternative 1 & 144.3 & -12.5 & -45.6 & -123.2 & 35.29 & -8.33 & -8.33 & -34.25 \\
\hline Alternative 2 & -9.3 & -45.7 & -58.3 & -142.6 & 13.33 & -15.20 & -9.33 & -43.40 \\
\hline Alternative 3 & -73.4 & -58.4 & -110.3 & -159 & -18.18 & -21.10 & -32.75 & -45.41 \\
\hline PRMP & 26.3 & -6.5 & 5.0 & 6.1 & 30.35 & 2.03 & 4.26 & 16.38 \\
\hline
\end{tabular}

${ }^{a} C R=$ Coast Range Province, WC = West Cascades Province, KL = Klamath Province, EC = Eastern Cascades Province

${ }^{\circ}$ CONNECTANCE EXPRESSED AS NUMBER OF CONNECTIONS.

'SHADING INDICATES POSITIVE CHANGES IN LANDSCAPE METRIC. 


\section{Land Birds}

The Partners-in-Flight habitat objectives are useful for comparing the effects of the alternatives and their relative effectiveness of maintaining healthy bird populations. The analysis for land birds is expressed in terms of the proportion of each structural stage (for westside land bird habitat), or age class (for Eastside Management Lands habitat) available, referred to as "percent habitat-capable," within each habitat association (see Chapter 3, Land Birds section for discussion of habitat associations). The maximum value that percent habitat-capable can attain is $100 \%$, but this does not generally occur because multiple structural stages occur at any given time within a given habitat association.

\section{Westside Forested Land Bird Habitat}

\section{Western Conifer}

\section{Structurally Complex}

Varying amounts of structurally complex forests, which approximates Partners-in-Flight's "old growth," would be harvested under all alternatives, including the PRMP. The No Action Alternative, Alternative 1, and the PRMP would provide a continuous increase in the amount of structurally complex, western conifer habitat through 2106. Under Alternatives 2 and 3, structurally complex forests that currently comprise $26 \%$ or 447,576 acres of western conifer forest would decline 23 to $24 \%$ (397,611 to 405,110 acres), respectively, by 2056 before further stand development of structurally complex forest would occur such that it would comprise 26 to $30 \%$ ( 436,090 to 506,560 acres), respectively, of the western conifer habitat association by 2106. Under the PRMP, structurally complex forest would increase to $40 \%$ ( 709,020 acres) of the western conifer forest by 2106. See Figure 4-132 (Western conifer forest land bird habitat trends on BLM-administered land within the planning area) and Table 4-71 (Western conifer land bird habitat on BLM-administered land within the planning area under the alternatives).

Under all alternatives, including the PRMP, there would be more than $15 \%$ of the western conifer habitat association in a structurally complex stage during all time periods. Therefore, the Oregon/Washington Partners-in-Flight recommended habitat objective to maintain existing old-growth forests and manage the landscape for $15 \%$ old-growth forest condition (Altman 1999) would be met.

\section{Mature with Multi-layered Canopy and Structurally Complex}

Mature with multi-layered canopy and structurally complex forests currently comprise $47 \%$ or 793,982 acres of the western conifer habitat association. Mature with multi-layered canopy and structurally complex forest would not decline during any decadal period under the No Action Alternative and would increase to $77 \%$ $(1,312,717$ acres) of the western conifer association by 2106 . Under Alternatives 1,2 , and 3 , mature with multi-layered canopy and structurally complex forest would decline to between 35 and 43\% (591,039 to 735,043 acres) by 2056. Additional habitat would develop under Alternatives 1, 2, and 3 by 2106 , so that 43 to $59 \%$ ( 739,116 to $1,009,874$ acres) of western conifer habitat would be mature with multi-layered canopy and structurally complex forest. Under the PRMP, there would be a decrease in mature with multi-layered canopy and structurally complex forest to $43 \%$ ( 754,368 acres) of the western conifer association by 2026 before stand development would raise that proportion to $62 \%$ (1,093,218 acres) by 2106 . See Figure 4-132 (Western conifer forest land bird habitat trends on BLM-administered land within the planning area) and Table 4-71 (Western conifer land bird habitat on BLM-administered land within the planning area under the alternatives). 
Figure 4-132. Western Conifer Forest Land Bird Habitat Trends On BLM-Administered Land Within The Planning Area

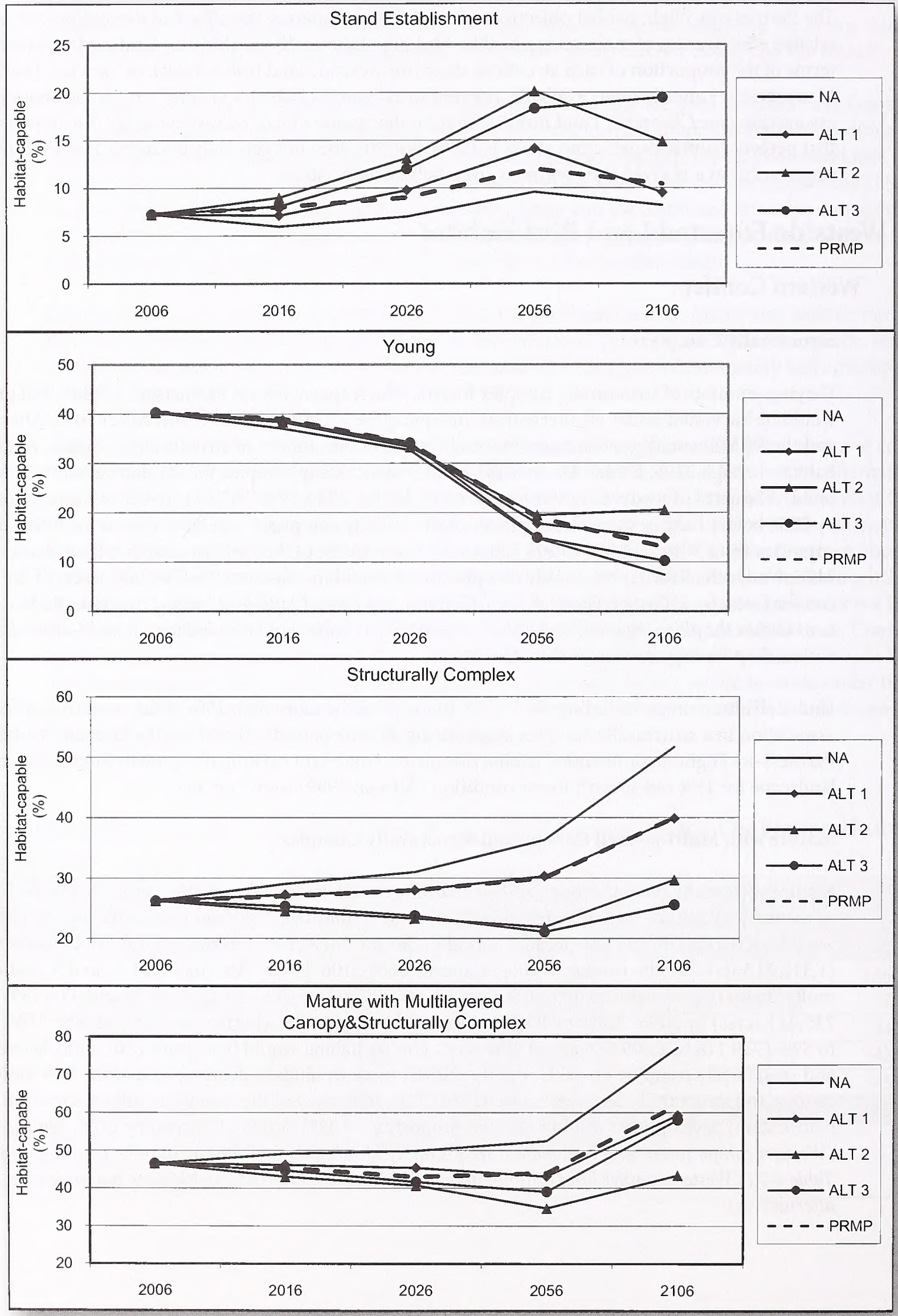


Table 4-71. Western Conifer Land Bird Habitat On BLM-administered Land Within The Planning Area Under The Alternatives

\begin{tabular}{|c|c|c|c|c|c|c|c|c|c|c|c|}
\hline \multirow{2}{*}{ Structural Stage } & \multirow{2}{*}{ Alternative } & 2006 & 2006 & 2016 & 2016 & 2026 & 2026 & 2056 & 2056 & 2106 & 2106 \\
\hline & & (acres) & $(\%)^{a}$ & (acres) & $(\%)$ & (acres) & $(\%)$ & (acres) & $(\%)$ & (acres) & $(\%)$ \\
\hline \multirow{3}{*}{ Stand Establishment } & No Action & 123,605 & 7 & 101,605 & 6 & 119,388 & 7 & 163,416 & 10 & 139,710 & 8 \\
\hline & \begin{tabular}{|l} 
Alternative 2 \\
\end{tabular} & 123,605 & 7 & 153,288 & 9 & 223,801 & 13 & 343,281 & 20 & 253,412 & 15 \\
\hline & Alternative 3 & 123,605 & 7 & 137,641 & 8 & 204,652 & 12 & 312,269 & 18 & 331,646 & 19 \\
\hline \multirow{4}{*}{ Young } & \begin{tabular}{|l|} 
Alternative 1 \\
\end{tabular} & 686,733 & 40 & 660,357 & 39 & 571,653 & 34 & 303,426 & 18 & 252,769 & 15 \\
\hline & Alternative 2 & 686,733 & 40 & 653,073 & 38 & 567,675 & 33 & 332,557 & 20 & 350,756 & 21 \\
\hline & \begin{tabular}{|l} 
Alternative 3 \\
\end{tabular} & 686,733 & 40 & 654,175 & 38 & 581,791 & 34 & 255,100 & 15 & 174,824 & 10 \\
\hline & PRMP & 686,733 & 40 & 682,225 & 39 & 605,929 & 34 & 343,466 & 19 & 233,550 & 13 \\
\hline \multirow{2}{*}{$\begin{array}{l}\text { Mature With Multi- } \\
\text { layered Canopy \& } \\
\text { Structurally Complex }\end{array}$} & No Action & 793,982 & 47 & 837,168 & 49 & 850,013 & 50 & 893,956 & 52 & $1,312,717$ & 77 \\
\hline & PRMP & 793,982 & 47 & 785,708 & 45 & 754,368 & 43 & 781,218 & 44 & $1,093,218$ & 62 \\
\hline \multirow{5}{*}{ Structurally Complex } & No Action & 447,576 & 26 & 495,357 & 29 & 528,261 & 31 & 619,342 & 36 & 881,063 & 52 \\
\hline & \begin{tabular}{|l|} 
Alternative 1 \\
\end{tabular} & 447,576 & 26 & 464,439 & 27 & 477,304 & 28 & 516,752 & 30 & 679,786 & 40 \\
\hline & \begin{tabular}{|l} 
Alternative 2 \\
\end{tabular} & 447,576 & 26 & 418,340 & 25 & 397,611 & 23 & 373,415 & 22 & 506,560 & 30 \\
\hline & Alternative 3 & 447,576 & 26 & 432,041 & 25 & 405,110 & 24 & 359,684 & 21 & 436,090 & 26 \\
\hline & PRMP & 447,576 & 26 & 477,043 & 27 & 485,247 & 28 & 523,347 & 30 & 709,020 & 40 \\
\hline
\end{tabular}

${ }^{\mathrm{a}}$ For all years, percent is habitat-capable acres

Under all alternatives including the PRMP, there would be more than $15 \%$ of the western conifer habitat association in a mature with multi-layered canopy and structurally complex forest stage. Therefore, the Oregon/Washington Partners-in-Flight habitat objective to maintain 15\% or more of the landscape in a mature forest condition (Altman 1999) would be met.

\section{Young Forest}

Under all alternatives including the PRMP, the amount of young forest would steadily decline from the current level of $40 \%$ (686,733 acres) of the western conifer habitat association to between 7 and $21 \%$ ( 126,128 to 350,756 acres) by 2106 . This decline would be related to the relative size of the non-harvest land base in No Action Alternative, Alternative 1, Alternative 2, and the PRMP. See Figure 4-132 (Western conifer forest land bird habitat trends on BLM-administered land within the planning area) and Table 4-71 (Western conifer land bird habitat on BLM-administered land within the planning area under the alternatives).

The Oregon/Washington Partners-in-Flight habitat objective of maintaining 20 to $40 \%$ of the western conifer habitat association in a young forest structural stage (Altman 1999) would not be achieved under any alternative on BLM-administered lands. However, intensive forest management on intermingled industrial, private lands would provide forest habitat in both the young and stand establishment structural stages. It is assumed that the amount of young and stand establishment habitat on privately owned commercial forestlands would remain approximately the same over time. Therefore, it is assumed that when both BLM-administered lands and private industrial forest lands are considered that the Partners-in-Flight habitat objective of maintaining 20 to $40 \%$ of the western conifer habitat association in a young forest structural stage would be met. 


\section{Stand Establishment}

The proportion of stand establishment forest within western conifer habitat association would increase from the current level of 7\% (123,605 acres), to between 8 and 19\% (139,710 to 331,646 acres) by 2106 under all alternatives. Under the PRMP, stand establishment forest would increase from the current level to $10 \%$ (172,301 acres) by 2106 . See Figure 4-132 (Western conifer forest land bird habitat trends on BLMadministered land within the planning area) and Table 4-71 (Western conifer land bird habitat on BLMadministered land within the planning area under the alternatives).

None of the alternatives, including the PRMP, would achieve the Oregon/Washington Partners-in-Flight habitat objective to maintain 20 to $40 \%$ of the landscape in a stand establishment condition for western conifer habitat. However, intensive forest management on intermingled industrial, private lands would provide forest habitat in both the young and stand establishment structural stages. It is assumed that the amount of young and stand establishment habitat on privately owned commercial forest lands would remain approximately the same over time. Therefore, it is assumed that when both BLM-administered lands and private, industrial forest lands are considered that the Partners-in-Flight habitat objective of maintaining 20 to $40 \%$ of the western conifer habitat association in a stand establishment structural stage would be met.

\section{Western Hardwood}

The amount of western hardwood habitat in a stand establishment structural stage would increase from the current level of $5 \%$ (17,651 acres), to between 7 and $17 \%(27,557$ to 67,228 acres) by 2106 . An increase in the amount of habitat in the stand establishment stage would indicate that either existing young, mature, and/or structurally complex western hardwood habitat was reduced in abundance. The increase in stand establishment would be derived mainly from the conversion of young forest to stand establishment; although the amount of young forest would also decrease as it develops into mature with multi-layered canopy and structurally complex structural stage. See below for a more detailed discussion of the trends in individual structural stages within the western hardwood habitat association.

Therefore, the habitat objective recommended by the Oregon/Washington Partners-in-Flight to maintain existing western hardwood habitat (Altman 2000b) would not be achieved under any of the alternatives, including the PRMP. However, mature with multi-layered canopy and structurally complex forest would comprise a greater proportion of the western hardwood habitat association under all alternatives in 2106 ( $51 \%$ to $77 \%$, or 198,536 to 298,407 acres) than in 2006 ( $49 \%$ or 188,575 acres).

\section{Structurally Complex}

The amount of structurally complex forest within the western hardwood association would increase from the current level of $22 \%(83,612$ acres) in 2006 to between 45 and $66 \%$ (173,534 to 255,372 acres) by 2106 under the alternatives, including the PRMP. However, under Alternatives 1, 2, and 3, there would be an initial decline in the abundance of structurally complex forest within the western hardwood association to 16 to $21 \%$ (63,831 to 81,115 acres) during the first decade (i.e., by 2016). Under the PRMP, structurally complex habitat would increase from the current level to $53 \%$ (206,539 acres) in 2106. See Figure 4-133 (Western hardwood forest land bird habitat trends on BLM-administered land within the planning area) and Table 4-72 (Western hardwood land bird habitat on BLM-administered land within the planning area under the alternatives).

\section{Mature with Multi-layered Canopy and Structurally Complex}

Under the No Action Alternative, Alternative 1, and the PRMP, there would be a steady increase in the amount of mature with multi-layered canopy and structurally complex forest habitat from the current level of $49 \%$ or 188,575 acres of the western hardwood association, to between 63 and $77 \%$ ( 244,249 to 298,407 acres) by 2106 . Under Alternatives 2 and 3, the amount of multi-layered canopy and structurally complex forest habitat would drop from the current level to $45 \%$ (175,092 to 175,515 acres) by 2026 and 2056, respectively before increasing to between 51 and $64 \%$ (198,536 to 247,550 acres) by 2106. See Figure 4-133 (Western hardwood forest land bird habitat trends on BLM-administered land within the planning area) and Table 4-72 (Western hardwood land bird habitat on BLM-administered land within the planning area under the alternatives). 
Figure 4-133. Western Hardwood Forest Land bird Habitat Trends On BLM-Administered Land Within The Planning Area
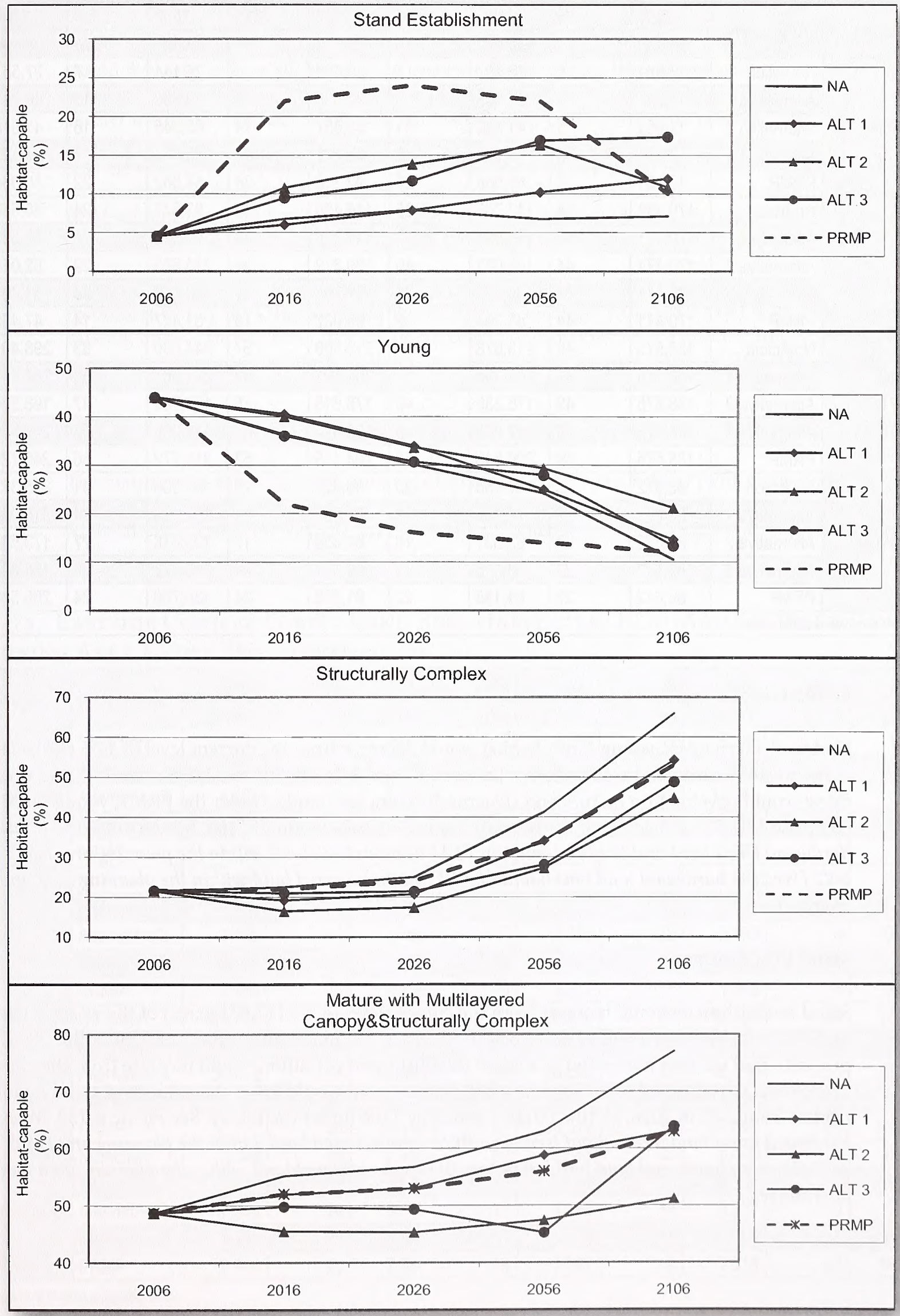
Table 4-72. Western Hardwood Land Bird Habitat On BlM-administered Land Within The Planning Area Under The Alternatives

\begin{tabular}{|c|c|c|c|c|c|c|c|c|c|c|c|}
\hline \multirow{2}{*}{ Structural Stage } & \multirow{2}{*}{ Alternative } & 2006 & 2006 & 2016 & 2016 & 2026 & 2026 & 2056 & 2056 & 2106 & 2106 \\
\hline & & (acres) & $(\%)^{a}$ & (acres) & $(\%)$ & (acres) & $(\%)$ & (acres) & $(\%)$ & (acres) & $(\%)$ \\
\hline \multirow{5}{*}{ Stand Establishment } & No Action & 17,651 & 5 & 26,237 & 7 & 30,662 & 8 & 26,144 & 7 & 27,557 & 7 \\
\hline & Alternative 1 & 17,651 & 5 & 23,313 & 6 & 30,535 & 8 & 39,588 & 10 & 46,240 & 12 \\
\hline & Alternative 2 & 17,651 & 5 & 41,802 & 11 & 53,657 & 14 & 63,345 & 16 & 41,918 & 11 \\
\hline & Alternative 3 & 17,651 & 5 & 36,653 & 9 & 45,316 & 12 & 65,467 & 17 & 67,228 & 17 \\
\hline & PRMP & 17,651 & 5 & 85,568 & 22 & 92,318 & 24 & 84,862 & 22 & 40,054 & 10 \\
\hline \multirow{5}{*}{ Young } & No Action & 170,471 & 44 & 140,707 & 36 & 116,486 & 30 & 93,677 & 24 & 40,556 & 10 \\
\hline & Alternative 1 & 170,471 & 44 & 156,988 & 41 & 131,595 & 34 & 96,592 & 25 & 56,525 & 15 \\
\hline & \begin{tabular}{|l|} 
Alternative 2 \\
\end{tabular} & 170,471 & 44 & 155,082 & 40 & 130,372 & 34 & 113,585 & 29 & 82,016 & 21 \\
\hline & Alternative 3 & 170,471 & 44 & 139,545 & 36 & 118,798 & 31 & 108,004 & 28 & 51,393 & 13 \\
\hline & PRMP & 170,471 & 44 & 85,204 & 22 & 60,987 & 16 & 54,427 & 14 & 47,465 & 12 \\
\hline \multirow{5}{*}{$\begin{array}{l}\text { Mature With Multi- } \\
\text { layered Canopy \& } \\
\text { Structurally Complex }\end{array}$} & No Action & 188,575 & 49 & 213,678 & 55 & 219,906 & 57 & 244,030 & 63 & 298,407 & 77 \\
\hline & Alternative 1 & 188,575 & 49 & 201,190 & 52 & 205,392 & 53 & 227,667 & 59 & 244,249 & 63 \\
\hline & Alternative 2 & 188,575 & 49 & 176,235 & 46 & 175,515 & 45 & 183,786 & 47 & 198,536 & 51 \\
\hline & Alternative 3 & 188,575 & 49 & 192,866 & 50 & 191,024 & 49 & 175,092 & 45 & 247,550 & 64 \\
\hline & PRMP & 188,575 & 49 & 200,545 & 52 & 204,135 & 53 & 215,772 & 56 & 245,724 & 63 \\
\hline \multirow{5}{*}{ Structurally Complex } & No Action & 83,612 & 22 & 87,153 & 23 & 96,826 & 25 & 160,008 & 41 & 255,372 & 66 \\
\hline & Alternative 1 & 83,612 & 22 & 74,156 & 19 & 80,006 & 21 & 132,128 & 34 & 210,096 & 54 \\
\hline & Alternative 2 & 83,612 & 22 & 63,831 & 16 & 67,458 & 17 & 105,678 & 27 & 173,534 & 45 \\
\hline & Alternative 3 & 83,612 & 22 & 81,115 & 21 & 82,841 & 21 & 108,823 & 28 & 188,823 & 49 \\
\hline & PRMP & 83,612 & 22 & 84,158 & 22 & 91,326 & 24 & 130,798 & 34 & 206,539 & 53 \\
\hline
\end{tabular}

\section{Young Forest}

Under all alternatives, young forest habitat would decrease from the current level of $44 \%$ (170,471 acres) of the western hardwood association to between 10 and $21 \%$ ( 40,556 to 82,016 acres) by 2106 since young forest would develop into mature and structurally complex stands. Under the PRMP, young forest would comprise $12 \%$ (47,465 acres) of the western hardwood association in 2106. See Figure 4-133 (Western hardwood forest land bird habitat trends on BLM-administered land within the planning area) and Table 4-72 (Western hardwood land bird habitat on BLM-administered land within the planning area under the alternatives).

\section{Stand Establishment}

Stand establishment would increase from the current level of 5\% (17,651 acres) of the western hardwood association to between 7 and $17 \%$ (27,557 to 67,228 acres) under all alternatives. Under the PRMP, the proportion of western hardwood in a stand establishment condition would increase from the current level to $24 \%$ (92,318 acres) in 2026. Further stand development would lower the amount of stand establishment habitat from $24 \%$ in 2026, to $10 \%$ ( 40,054 acres) by 2106 under the PRMP. See Figure 4-133 (Western hardwood forest land bird habitat trends on BLM-administered land within the planning area) and Table 4-72 (Western hardwood land bird habitat on BLM-administered land within the planning area under the alternatives). 


\section{Eastern Conifer}

\section{Structurally Complex}

Under all alternatives, the amount of structurally complex habitat within the eastern conifer association would decrease, at least slightly for the first two decades; from the current level of $20 \%$ (7,344 acres) to between 11 and $20 \%$ (or 3,886 to 7,148 acres) by 2026 . Structurally complex habitat within the eastern conifer association would continue to decrease through 2106 under Alternative 1 and Alternative 2, to $13 \%$ (4,618 acres) and 16\% (5,702 acres), respectively. Under the No Action Alternative, Alternative 3, and the PRMP, by 2106 between 22 and 40\% (8,058 to 14,411 acres) of the eastern conifer forest would be in a structurally complex condition. See Figure 4-134 (Eastern conifer forest land bird habitat trends on BLM-administered land within the planning area) and Table 4-73 (Eastern conifer land bird habitat on BLMadministered land within the planning area under the alternatives).

Based on structurally complex habitat alone, none of the alternatives would meet the habitat objective recommended by the Oregon/Washington Partners-in-Flight (Altman 2000a) to provide at least 25\% of existing mixed conifer forest in a mature or older condition by 2025 . However, under the PRMP, $40 \%$ of eastern mixed conifer forest would be in a structurally complex stage by 2106 , which would meet the Partners-in-Flight recommended habitat objective by that time.

\section{Mature with Multi-layered Canopy and Structurally Complex}

The mature with multi-layered canopy and structurally complex habitat (which currently comprises $84 \%$ or 30,762 acres of the habitat in the eastern conifer association) would decrease under the No Action Alternative and Alternatives 1, 2, and 3 between 26 and 34\% (9,299 to 12,287 acres). Under the PRMP, the

Table 4-73. Eastside Conifer Forest land Bird Habitat On BlM-Administered Land Within The Planning Area Under The Alternatives

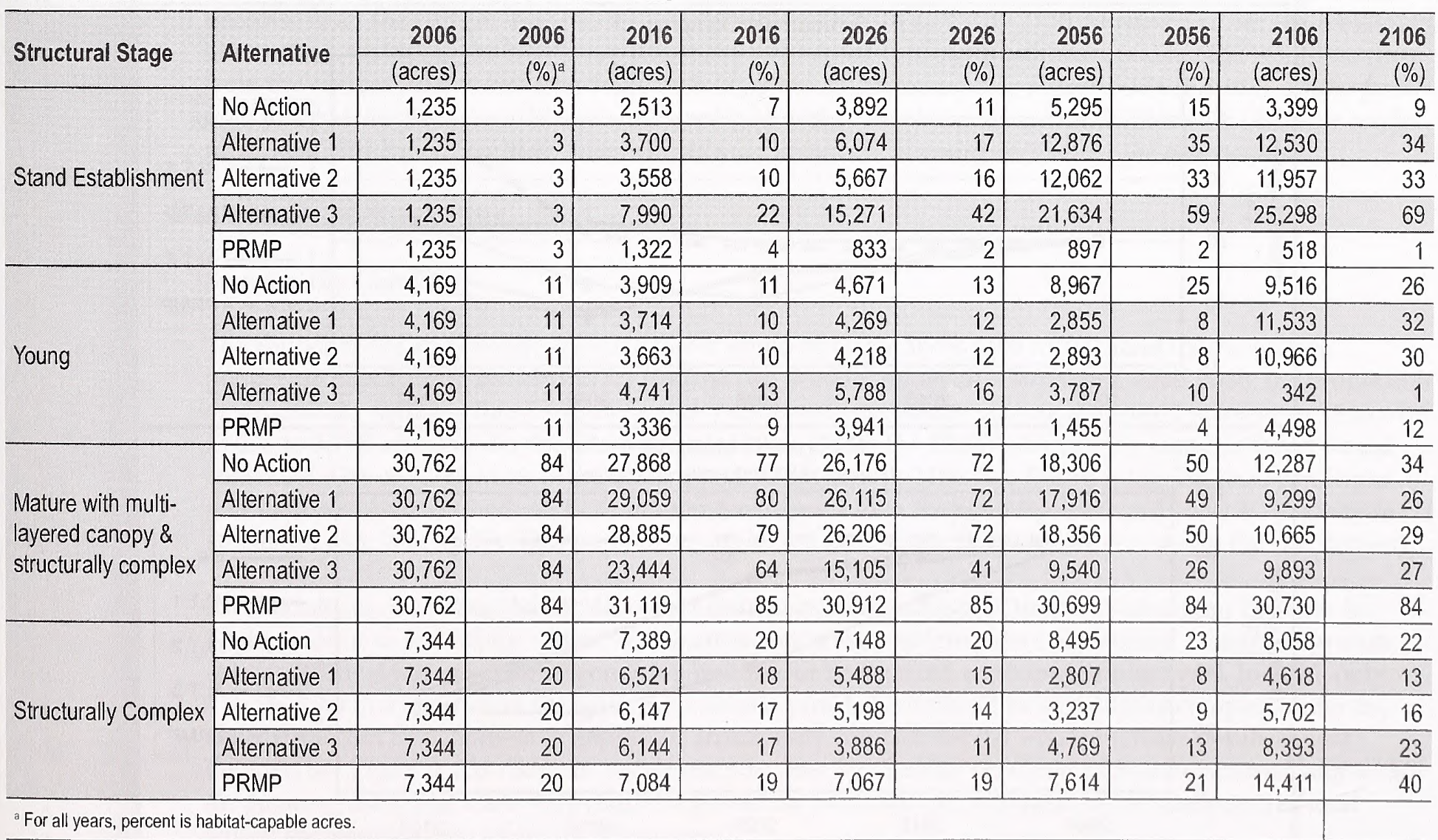


Figure 4-134. Eastern Conifer Forest Land bird Habitat Trends On BLMAdministered Land Within The Planning Area
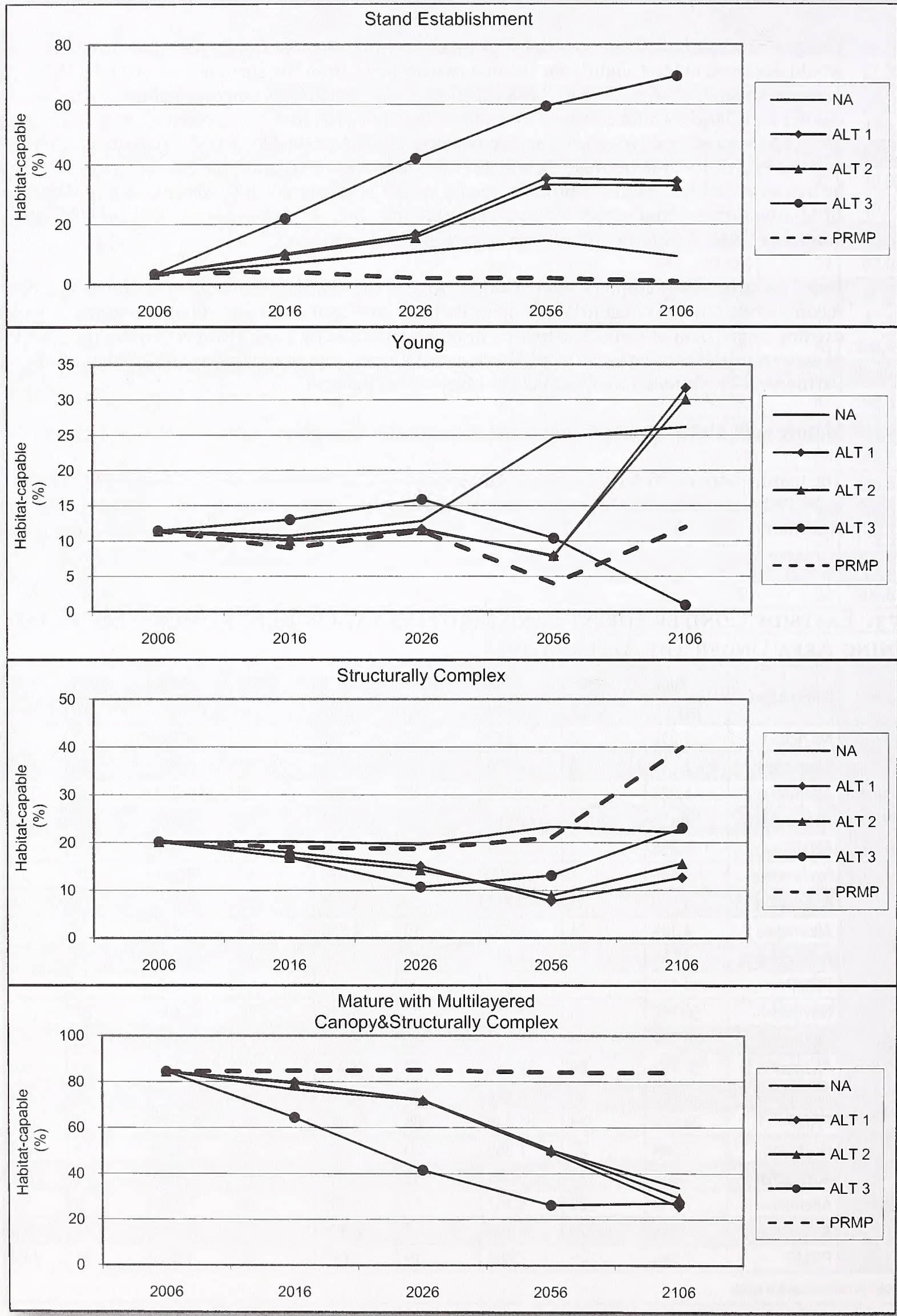
proportion of eastern conifer forest in a mature with multi-layered canopy and structurally complex stage would be relatively stable at 84 to $85 \%$ (30,699 to 31,119 acres) through 2106. See Figure 4-134 (Eastern conifer forest land bird habitat trends on BLM-administered land within the planning area) and Table 4-73 (Eastern conifer land bird habitat on BLM-administered land within the planning area under the alternatives).

The Oregon/Washington Partners-in-Flight recommended habitat objectives for eastern Oregon forests to maintain existing mixed conifer forests and manage to provide at least $25 \%$ in a mature or older condition (i.e., which approximates mature with multi-layered canopy and structurally complex) by 2025 would be met under all alternatives. In 2026, between 41 and $85 \%$ (15,105 to 30,912 acres) of the eastern conifer habitat association would be in a mature with multi-layered canopy and structurally complex stage.

By 2106, mature with multi-layered canopy and structurally complex stands would decline under the No Action Alternative, and Alternatives 1, 2, and 3 to between 26 and 34\% of the eastern conifer habitat association, but would still exceed the $25 \%$ habitat objective. The amount of mature with multi-layered canopy and structurally complex habitat within eastern conifer forest under the PRMP (i.e., 84\%) would far exceed the Partners-in-Flight habitat objective of $25 \%$.

\section{Young Forest}

Young forest would increase from the current level of 11\% (4,169 acres) of eastern conifer forest habitat under the No Action Alternative, Alternatives 1 and 2, and the PRMP to 12 to $32 \%$ (4,498 to 11,533 acres) by 2106 . Under Alternative 3, young forest would decrease from the current level to $1 \%$ ( 342 acres) by 2106. See Figure 4-134 (Eastside conifer forest land bird habitat trends on BLM-administered land within the planning area) and Table 4-73 (Eastside conifer forest land bird habitat on BLM-administered land within the planning area under the alternatives).

\section{Stand Establishment}

Under the PRMP, the proportion of eastside conifer forest in a stand establishment structural stage would decrease from the current level of 3\% (1,235 acres) to $1 \%$ ( 518 acres) by 2106 . However, under the remaining alternatives, including the No Action Alternative, the amount of stand establishment habitat would increase from the current level to between 9 and 69\% (3,399 to 25,298 acres). See Figure 4-134 (Eastside conifer forest land bird habitat trends on BLM-administered land within the planning area) and Table 4-73 (Eastside conifer forest land bird habitat on BLM-administered land within the planning area under the alternatives).

\section{Eastern Ponderosa Pine}

\section{Structurally Complex}

The abundance of structurally complex forest would be stable at $4 \%$ (300 to 400 acres) of the eastern ponderosa pine habitat association for the first two decades under all alternatives. After 2026, the proportion of structurally complex forest within eastern ponderosa pine habitat association would increase to 35 to $44 \%$ (3,028 to 3,798 acres) under the alternatives by 2106 . Under the PRMP, structurally complex forest would constitute $43 \%$ or 3,783 acres of the eastern ponderosa pine in 2106. See Figure 4-135 (Eastside ponderosa pine land bird habitat trends on BLM-administered land within the planning area) and Table 4-74 (Eastside ponderosa pine land bird habitat on BLM-administered land within the planning area under the alternatives).

All alternatives, including the PRMP, would contribute to meeting the Oregon/Washington Partners-inFlight recommended habitat objective to maintain existing ponderosa pine forests and manage to provide at least $30 \%$ in a mature or older condition by 2025 , or be on trend to accomplish that goal. In 2026 , only 4 to $5 \%$ (349 to 414 acres) of the eastern ponderosa pine habitat would be structurally complex under the alternatives, but development of additional structurally complex habitat would increase in subsequent decades. See Figure 4-135 (Eastside ponderosa pine land bird habitat trends on BLM-administered land within the planning area) and Table 4-74 (Eastside ponderosa pine land bird habitat on BLM-administered land within the planning area under the alternatives). 
Figure 4-135. Eastside Ponderosa Pine Land bird Habitat Trends On BLM-Administered Land Within The Planning Area

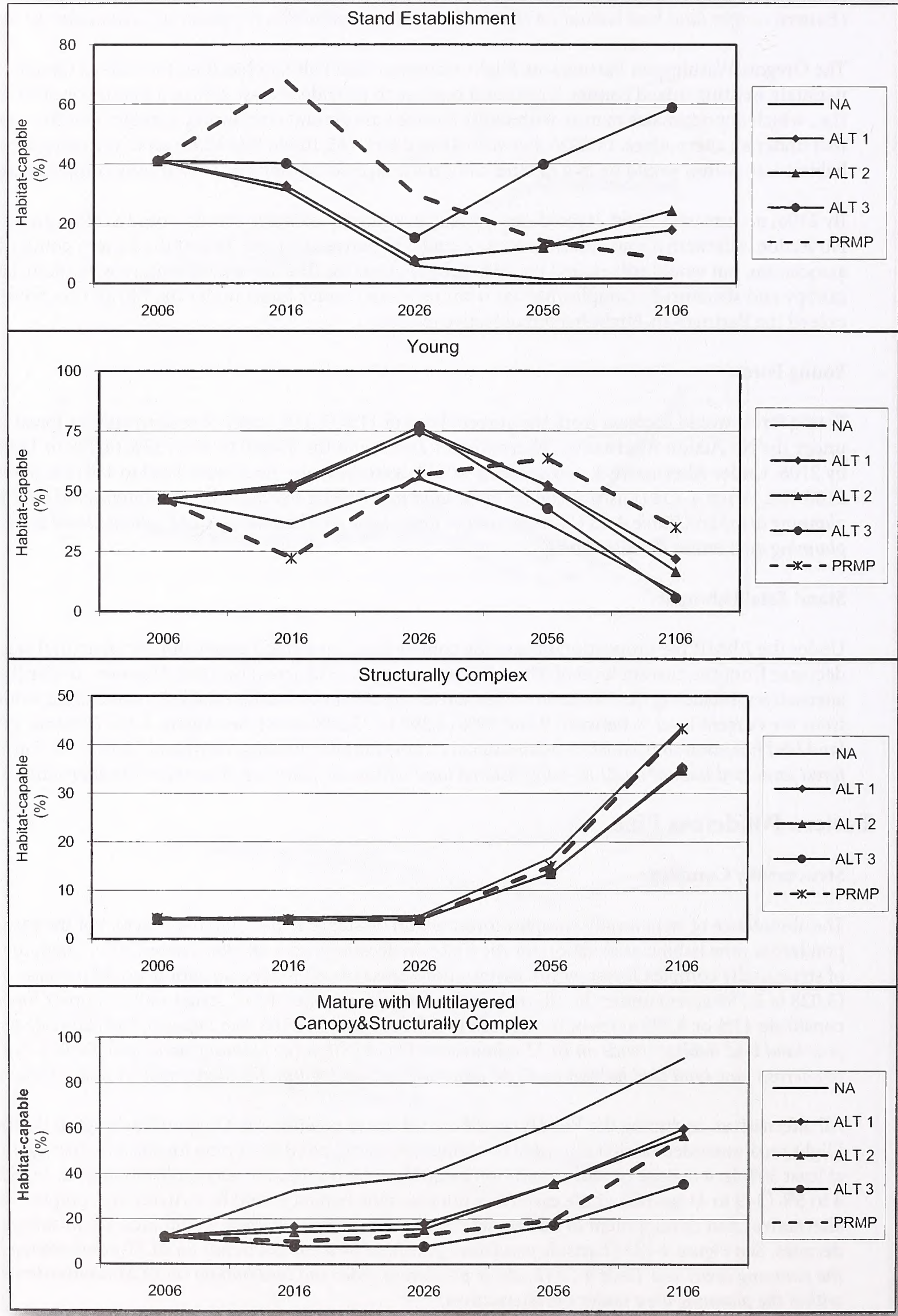




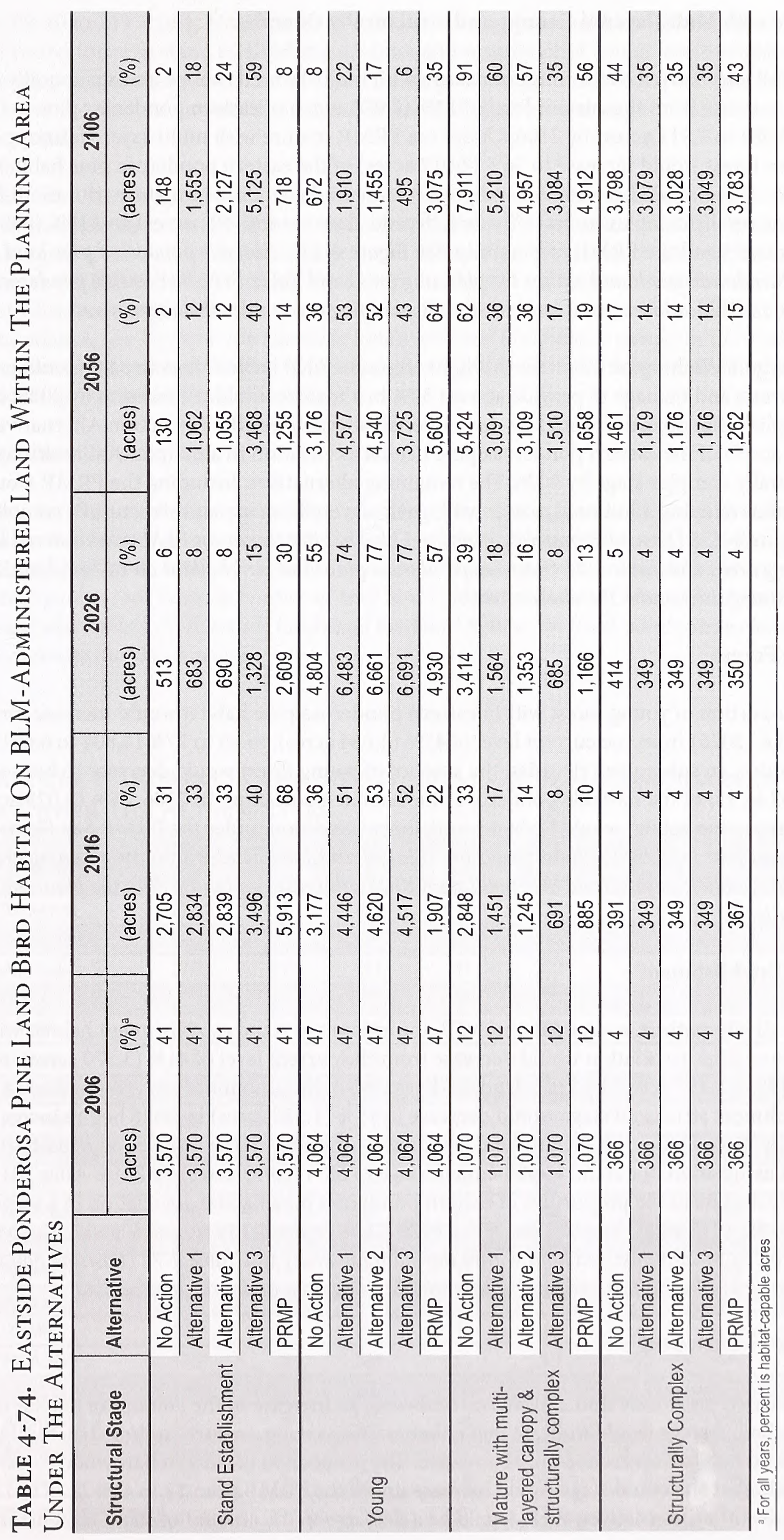




\section{Mature with Multi-layered Canopy and Structurally Complex}

Under all alternatives, the amount of mature with multi-layered canopy and structurally complex forest would increase from the current level of $12 \%$ ( 1,070 acres) of eastern ponderosa pine to between 35 to $91 \%$ (3,084 to 7,911 acres) by 2106 . Under the PRMP, mature with multi-layered canopy and structurally complex forest would increase to $56 \%$ (4,912 acres) of the eastern ponderosa pine habitat association by 2106 . There would be, however, a slight decrease in the amount of mature with multi-layered canopy and structurally complex forest in the first decade, down to 8\% (691 acres) and 10\% (885 acres), under Alternative 3 and the PRMP, respectively. See Figure 4-135 (Eastside ponderosa pine land bird habitat trends on BLM-administered land within the planning area) and Table F102.9 (Eastside ponderosa pine land bird habitat on BLM-administered land within the planning area under the alternatives).

The Oregon/Washington Partners-in-Flight recommended habitat objective to maintain existing ponderosa pine forests and manage to provide at least $30 \%$ in a mature or older condition by 2025 , or be on a trend to accomplish that objective would be met under all alternatives. The No Action Alternative would have $39 \%$ $(3,414$ acres $)$ of the eastern ponderosa pine habitat association in a mature with multi-layered canopy and structurally complex stage by 2026 . The remaining alternatives, including the PRMP, would be on an upward trend of developing additional mature with multi-layered canopy and structurally complex habitat by 2025 . See Figure 4-135 (Eastside ponderosa pine land bird habitat trends on BLM-administered land within the planning area) and Table 4-74 (Eastside ponderosa pine land bird habitat on BLM-administered land within the planning area under the alternatives).

\section{Young Forest}

The proportion of young forest within eastern ponderosa pine habitat would increase for the first 20 years (i.e., 2026) from the current level of $47 \%$ (4,064 acres), to 55 to $77 \%$ (4,804 to 6,691 acres) under all alternatives. In subsequent decades, the amount of young forest would decrease to between 6 and $44 \%$ (495 to 3,802 acres) of the Eastside ponderosa pine habitat association. In $2106,35 \%$ (3,075 acres) of eastern ponderosa pine habitat would be in a young forest condition under the PRMP. See Figure 4-135 (Eastside ponderosa pine land bird habitat trends on BLM-administered land within the planning area) and Table 4-74 (Eastside ponderosa pine land bird habitat on BLM-administered land within the planning area under the alternatives).

\section{Stand Establishment}

Under all alternatives, except Alternative 3, the amount of stand establishment habitat within the Eastside ponderosa pine association would decrease from the current level of $41 \%$ (3,570 acres), to between 2 and $24 \%$ ( 148 to 2,127 acres) by 2106 . Under Alternative 3 , the amount of eastern ponderosa pine in a stand establishment structural stage would decrease to $15 \%$ (1,328 acres) by 2026 before increasing to $59 \%(5,125$ acres) by 2106 . Under the PRMP, there would be an increase in the proportion of eastern ponderosa pine habitat association in a stand establishment stage to $68 \%$ (5,913 acres) by 2016 . After 2016, there would be a steady decline in the proportion of eastern ponderosa pine habitat association in a stand establishment stage to $8 \%$ (718 acres) by 2106 under the PRMP. See Figure 4-135 (Eastside ponderosa pine land bird habitat trends on BLM-administered land within the planning area) and Table 4-74 (Eastside ponderosa pine land bird habitat on BLM-administered land within the planning area under the alternatives).

\section{Eastside Hardwood}

As discussed previously under Western Hardwood, an increase in the amount of habitat in the stand establishment stage would indicate that either existing young, mature, and/or structurally complex eastern hardwood habitat was reduced in abundance. The proportion of eastern hardwood forest in a stand establishment structural stage would increase under the PRMP from 17 to $45 \%$ ( 278 to 732 acres) by 2106 ; under the other alternatives, there would be a decrease in the amount of stand establishment habitat to 0 
to $9 \%$ ( 0 to 149 acres). The increase in stand establishment would be derived mainly from the conversion of young forest to stand establishment, although the amount of young forest would also decrease as it developed into mature with multi-layered canopy and structurally complex structural stage. See below for a more detailed discussion of the trends in individual structural stages within the eastern hardwood habitat association.

Therefore, the Oregon/Washington Partners-in-Flight recommended habitat objective to maintain existing oak-pine forests in eastern hardwood habitat (Altman 2000a) would be achieved under the No Action Alternative, Alternative 1, Alternative 2, and Alternative 3, but would not be achieved under the PRMP. Under the PRMP, young forest of the eastern hardwood association would be converted to the stand establishment stage, but mature and structurally complex eastern hardwood forest would increase in abundance. See Figure 4-136 (Eastside hardwood land bird habitat trends on BLM-administered land within the planning area) and Table 4-75 (Eastside hardwood land bird habitat on BLM-administered land within the planning area under the alternatives).

\section{Structurally Complex}

Structurally complex forest would increase from the existing level of $8 \%$ or 125 acres of the eastern hardwood habitat association, to between 44 and 61\% (722 to 987 acres) by 2106 under all alternatives. Under the PRMP, 46\% (741 acres) of eastern hardwood association would be structurally complex by 2106. See Figure 4-136 (Eastside hardwood land bird habitat trends on BLM-administered land within the planning area) and Table 4-75 (Eastside hardwood land bird habitat on BLM-administered land within the planning area under the alternatives).

Table 4-75. Eastside Hardwood Land Bird Habitat On BLM-Administered Land Within The Planning Area Under The Alternatives

\begin{tabular}{|c|c|c|c|c|c|c|c|c|c|c|c|}
\hline \multirow{2}{*}{ Structural Stage } & \multirow{2}{*}{ Alternative } & 2006 & 2006 & 2016 & 2016 & 2026 & 2026 & 2056 & 2056 & 2106 & 2106 \\
\hline & & (acres) & $(\%)^{\mathrm{a}}$ & (acres) & $(\%)$ & (acres) & $(\%)$ & (acres) & $(\%)$ & (acres) & $(\%)$ \\
\hline \multirow{5}{*}{ Stand Establishment } & No Action & 278 & 17 & 171 & 11 & 171 & 11 & 0 & 0 & 0 & 0 \\
\hline & Alternative 1 & 278 & 17 & 171 & 11 & 171 & 11 & 74 & 5 & 0 & 0 \\
\hline & Alternative 2 & 278 & 17 & 171 & 11 & 202 & 12 & 61 & 4 & 1 & 0 \\
\hline & Alternative 3 & 278 & 17 & 171 & 11 & 171 & 11 & 42 & 3 & 149 & 9 \\
\hline & PRMP & 278 & 17 & 1,253 & 77 & 1,214 & 75 & 872 & 54 & 732 & 45 \\
\hline \multirow{5}{*}{ Young } & No Action & 1,168 & 72 & 1,278 & 79 & 1,278 & 79 & 1,222 & 75 & 735 & 45 \\
\hline & Alternative 1 & 1,168 & 72 & 1,417 & 87 & 1,342 & 82 & 1,202 & 74 & 809 & 50 \\
\hline & Alternative 2 & 1,168 & 72 & 1,275 & 78 & 1,239 & 76 & 1,182 & 73 & 792 & 49 \\
\hline & Alternative 3 & 1,168 & 72 & 1,275 & 78 & 1,270 & 78 & 1,320 & 81 & 731 & 45 \\
\hline & PRMP & 1,168 & 72 & 194 & 12 & 228 & 14 & 342 & 21 & 43 & 3 \\
\hline \multirow{5}{*}{$\begin{array}{l}\text { Mature with multi- } \\
\text { layered canopy \& } \\
\text { structurally complex }\end{array}$} & No Action & 180 & 11 & 380 & 23 & 380 & 23 & 608 & 37 & 1094 & 67 \\
\hline & Alternative 1 & 180 & 11 & 241 & 15 & 316 & 19 & 554 & 34 & 1020 & 63 \\
\hline & Alternative 2 & 180 & 11 & 180 & 11 & 186 & 11 & 384 & 23 & 833 & 51 \\
\hline & Alternative 3 & 180 & 11 & 180 & 11 & 186 & 11 & 264 & 16 & 747 & 46 \\
\hline & PRMP & 180 & 11 & 181 & 11 & 186 & 11 & 414 & 25 & 747 & 46 \\
\hline \multirow{5}{*}{ Structurally Complex } & No Action & 125 & 8 & 186 & 11 & 261 & 16 & 447 & 27 & 987 & 61 \\
\hline & Alternative 1 & 125 & 8 & 125 & 8 & 125 & 8 & 275 & 17 & 774 & 48 \\
\hline & Alternative 2 & 125 & 8 & 125 & 8 & 125 & 8 & 258 & 16 & 722 & 44 \\
\hline & Alternative 3 & 125 & 8 & 125 & 8 & 125 & 8 & 258 & 16 & 740 & 45 \\
\hline & PRMP & 125 & 8 & 125 & 8 & 125 & 8 & 258 & 16 & 741 & 46 \\
\hline
\end{tabular}


Figure 4-136 Eastside Hardwood Land bird Habitat Trends For Hardwood Forests On BLMAdministered Land Within The Planning Area

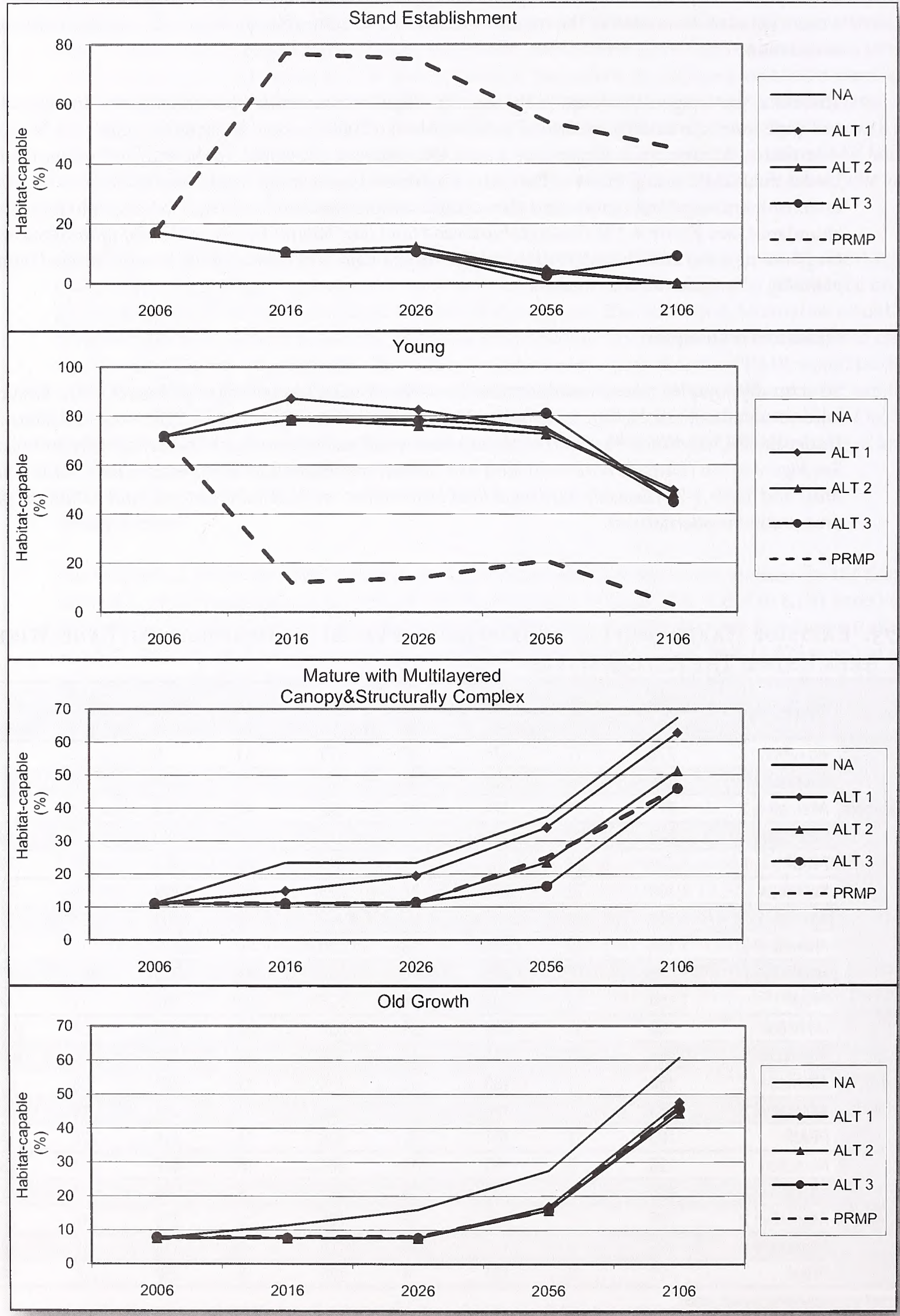




\section{Mature with Multi-layered Canopy and Structurally Complex}

The amount of eastern hardwood habitat in a mature with multi-layered canopy and structurally complex stage would increase under the alternatives from the current level of $11 \%$ or 180 acres to between 46 and $67 \%$ (747 to 1,094 acres). Under the PRMP, 46\% (747 acres) of eastern hardwood forest would be mature with multi-layered canopy and structurally complex. See Figure 4-136 (Eastside hardwood land bird habitat trends on BLM-administered land within the planning area) and Table 4-75 (Eastside hardwood land bird habitat on BLM-administered land within the planning area under the alternatives).

\section{Young Forest}

Under the No Action Alternative and Alternatives 1,2, and 3, the amount of eastern hardwood habitat in a young forest condition would initially increase from the current level of $72 \%(1,168$ acres), to between 78 and $89 \%$ (1,275 to 1,417 acres) in the first decade (by 2016) before dropping to between 45 and $50 \%$ (735 to 809 acres) by 2106 . Under the PRMP, the amount of young forest in the eastern hardwood association would decrease from the current level, to 3\% or 43 acres by 2106. See Figure 4-136 (Eastside hardwood land bird habitat trends on BLM-administered land within the planning area) and Table 4-75 (Eastside hardwood land bird habitat on BLM-administered land within the planning area under the alternatives).

\section{Stand Establishment}

Stand establishment habitat would decrease from the current level of $17 \%$ or 278 acres of eastern hardwood forest, to between 0 and 9\% ( 0 to 149 acres) under the No Action Alternative and Alternatives 1, 2, 3. Under the PRMP, the proportion of eastern hardwood in a stand establishment structural stage would increase from the current level to $77 \%$ or 1,253 acres in the first decade before decreasing to $45 \%$ or 732 acres by 2106. See Figure 4-136 (Eastside hardwood land bird habitat trends on BLM-administered land within the planning area) and Table 4-75 (Eastside hardwood land bird habitat on BLM-administered land within the planning area under the alternatives).

\section{Nonforest Habitat}

As previously discussed in the Wildlife; Special Status Species section of Chapter 4, the availability of nonforest habitat would be unchanged from its availability in 2006 under all alternatives, including the PRMP. Nonforest habitats tend to be comprised of features that are generally noncommercial. Habitat conversion would occur in the harvest land base under all alternatives where commercial timberland has not been successfully reforested to a desirable species mix. The amount of this activity would be inconsequential and, therefore, would have little to no impact on nonforest habitat.

All action alternatives contain a management objective to support natural species composition and vegetation on noncommercial areas, including: noncommercial forests, oak woodlands, shrublands, grasslands, cliffs, rock outcrops, talus slopes, meadows, wetlands, springs, fens, ponds, and vernal pools. With this management objective, the availability of nonforest habitat for land birds would, in general, be maintained.

Therefore, the Oregon/Washington Partners-in-Flight recommended habitat objective to maintain existing grassland-savannah, oak woodland, and chaparral habitats for nonforest habitat (Altman 2000b) would be met under the action alternatives, including the PRMP. 


\section{Land Bird Habitat on Eastside Management Lands}

Under all alternatives, including the PRMP, Ponderosa pine and eastern conifer forests (e.g., juniper and white fir forests) on Eastside Management Lands would receive uneven-aged management. Uneven-aged forest management would cause little change in the structural condition of the Ponderosa pine and conifer forests on Eastside Management Lands. The availability of these conifer forests as habitat for land birds would also be changed little from the current condition.

The Oregon/Washington Partners-in-Flight recommended habitat objectives to maintain existing shrub-steppe habitats, manage to provide at least $50 \%$ in a late-seral condition, and maintain existing riparian habitats (Altman and Holmes 2000) would be met under all alternatives, including the PRMP. Approximately 65\% (50,902 acres) of the 77,818 acres of habitat on Eastside Management Lands is old, which approximates the Partners-in-Flight late-seral condition. Little change in the structural condition would occur under all alternatives; therefore, existing habitats should be maintained under all alternatives.

It is assumed that woodland and rangeland management activities would occur at approximately the same rate under all action alternatives as under the 1995 resource management plan in the Klamath Falls Resource Area. Western juniper that is encroaching and competing and displacing native vegetation on rangelands and juniper woodlands would be treated utilizing a variety of treatments including: cutting, piling, burning, and utilization for biomass and other forest products. These treatments would remove competing vegetation and allow grassland and sagebrush habitats that are more typical of the native habitats to re-establish. Land birds associated with grassland and sagebrush habitats would have additional habitat made available to them through this re-establishment.

Under all alternatives, understocked forestlands would be reforested and rangeland would be converted from juniper back into the historical sagebrush or grassland communities. This conversion would cause an inconsequential reduction in hardwood habitat. Riparian hardwood communities would be maintained by controlling encroaching conifers and other activities to restore riparian hardwood communities (i.e., controlled grazing, burning, and planting).

It is assumed that under all action alternatives oil and gas exploration and development, mining and quarries, and infrastructure development such as roads, communication sites and recreation sites would occur at the same rate as under the 1995 resource management plans. These actions have caused an inconsequential loss of habitat and therefore under all alternatives, an inconsequential amount of habitat would be lost due to these activities within the planning area.

\section{Legacy Components}

Overall, there would be an increase in the amount of forests with legacy components (i.e., stands that are mature and structurally complex, young with structural legacies, or stand establishment with structural legacies) under all alternatives from the current level of $62 \%(1,327,973$ acres) of the planning area to between 66 and $92 \%(1,421,858$ to $1,971,964$ acres $)$ in 2106 . The proportion of forests with legacy components in the western conifer, western hardwood, Eastside Ponderosa pine, and Eastside hardwood habitat associations would generally increase from current levels by 2106. The amount of Eastside conifer association with legacy components would decline under the No Action Alternative, Alternatives 1 and 2, and the PRMP. Under Alternative 2, the amount of western hardwood and Eastside Ponderosa pine habitat associations with legacy components would also decline. See Table 4-76 (Forests with legacy structure on BLM-administered land within the planning area under the alternatives by habitat association).

The value of legacy structure in the stand establishment forests persists from stand establishment into the more advanced structural stages, typically providing larger diameter structure, a broader array of decay classes, and retention trees that provide a source of larger diameter snags and down wood than would otherwise develop in the subsequent structural stages. The influence of this initial input of snags, down wood, and remnant trees would be expected to provide habitat value for wildlife for approximately 100 years or longer. 
Table 4-76. Forests With Legacy Structure On BLM-Administered Land Within The Planning Area Under The Alternatives By Habitat Association

\begin{tabular}{|c|c|c|c|c|c|c|c|c|c|c|c|}
\hline \multirow{2}{*}{ Habitat Association } & \multirow{2}{*}{ Alternative } & 2006 & 2006 & 2016 & 2016 & 2026 & 2026 & 2056 & 2056 & 2106 & 2106 \\
\hline & & (acres) & $(\%)^{a}$ & (acres) & $(\%)$ & (acres) & $(\%)$ & (acres) & $(\%)$ & (acres) & $(\%)$ \\
\hline \multirow{5}{*}{ Western Conifer } & No Action & 992,816 & 58 & $1,026,458$ & 60 & $1,078,219$ & 63 & $1,393,452$ & 82 & $1,565,732$ & 92 \\
\hline & Alternative 1 & 992,816 & 58 & $1,001,039$ & 59 & $1,026,181$ & 60 & $1,194,248$ & 70 & $1,299,793$ & 76 \\
\hline & \begin{tabular}{|l} 
Alternative 2 \\
\end{tabular} & 992,816 & 58 & 971,646 & 57 & 974,096 & 57 & $1,056,565$ & 62 & $1,118,306$ & 66 \\
\hline & Alternative 3 & 992,816 & 58 & 994,103 & 58 & 991,360 & 58 & $1,252,158$ & 73 & $1,358,452$ & 80 \\
\hline & PRMP & 992,816 & 58 & $1,062,635$ & 60 & $1,090,384$ & 62 & $1,265,205$ & 72 & $1,380,835$ & 78 \\
\hline \multirow{5}{*}{ Western Hardwood } & No Action & 293,840 & 76 & 319,945 & 83 & 333,784 & 86 & 358,627 & 93 & 362,329 & 94 \\
\hline & \begin{tabular}{|l|} 
Alternative 1 \\
\end{tabular} & 293,840 & 76 & 318,905 & 82 & 328,956 & 85 & 326,720 & 84 & 310,398 & 80 \\
\hline & \begin{tabular}{|l} 
Alternative 2 \\
\end{tabular} & 293,840 & 76 & 292,271 & 75 & 297,408 & 77 & 278,863 & 72 & 283,233 & 73 \\
\hline & Alternative 3 & 293,840 & 76 & 301,436 & 78 & 309,708 & 80 & 306,930 & 79 & 313,624 & 81 \\
\hline & PRMP & 293,840 & 76 & 317,808 & 82 & 327,065 & 84 & 317,066 & 82 & 319,530 & 83 \\
\hline \multirow{5}{*}{ Eastern Conifer } & No Action & 34,560 & 95 & 34,937 & 96 & 34,949 & 96 & 35,623 & 98 & 33,965 & 93 \\
\hline & \begin{tabular}{|l} 
Alternative 1 \\
\end{tabular} & 34,560 & 95 & 32,035 & 88 & 29,077 & 80 & 21,927 & 60 & 12,637 & 35 \\
\hline & \begin{tabular}{|l} 
Alternative 2 \\
\end{tabular} & 34,560 & 95 & 31,922 & 88 & 29,252 & 80 & 22,509 & 62 & 13,576 & 37 \\
\hline & \begin{tabular}{|l} 
Alternative 3 \\
\end{tabular} & 34,560 & 95 & 34,177 & 94 & 33,845 & 93 & 35,207 & 97 & 35,921 & 99 \\
\hline & PRMP & 34,560 & 95 & 34,529 & 95 & 34,506 & 95 & 35,438 & 97 & 35,178 & 97 \\
\hline \multirow{5}{*}{$\begin{array}{l}\text { Eastern Ponderosa } \\
\text { Pine }\end{array}$} & No Action & 5,794 & 67 & 5,739 & 66 & 5,739 & 66 & 6,929 & 80 & 8,669 & 100 \\
\hline & \begin{tabular}{|l|} 
Alternative 1 \\
\end{tabular} & 5,794 & 67 & 5,666 & 65 & 5,670 & 65 & 5,768 & 66 & 5,809 & 67 \\
\hline & \begin{tabular}{|l} 
Alternative 2 \\
\end{tabular} & 5,794 & 67 & 5,638 & 65 & 5,641 & 65 & 5,830 & 67 & 5,736 & 66 \\
\hline & Alternative 3 & 5,794 & 67 & 5,716 & 66 & 5,739 & 66 & 7,363 & 85 & 8,702 & 100 \\
\hline & PRMP & 5,794 & 67 & 5,795 & 67 & 5,795 & 67 & 5,800 & 67 & 6,636 & 76 \\
\hline \multirow{5}{*}{ Eastern Hardwood } & No Action & 960 & 59 & 1,159 & 71 & 1,159 & 71 & 1,266 & 78 & 1,266 & 78 \\
\hline & Alternative 1 & 960 & 59 & 1,094 & 67 & 1,266 & 78 & 1,181 & 73 & 1,192 & 73 \\
\hline & Alternative 2 & 960 & 59 & 960 & 59 & 929 & 57 & 1,006 & 62 & 1,005 & 62 \\
\hline & Alternative 3 & 960 & 59 & 960 & 59 & 960 & 59 & 961 & 59 & 1,067 & 66 \\
\hline & PRMP & 960 & 59 & 961 & 59 & 961 & 59 & 1,068 & 66 & 1,068 & 66 \\
\hline \multirow{5}{*}{ Total } & No Action & $1,327,973$ & 62 & $1,388,241$ & 65 & $1,453,852$ & 68 & $1,795,898$ & 84 & $1,971,964$ & 92 \\
\hline & Alternative 1 & $1,327,973$ & 62 & $1,358,742$ & 64 & $1,391,151$ & 65 & $1,549,846$ & 72 & $1,629,831$ & 76 \\
\hline & \begin{tabular}{|l} 
Alternative 2 \\
\end{tabular} & $1,327,973$ & 62 & $1,302,439$ & 61 & $1,307,328$ & 61 & $1,364,775$ & 64 & $1,421,858$ & 66 \\
\hline & Alternative 3 & $1,327,973$ & 62 & $1,336,395$ & 62 & $1,341,614$ & 63 & $1,602,620$ & 75 & $1,717,769$ & 80 \\
\hline & PRMP & $1,327,973$ & 62 & $1,421,727$ & 65 & $1,458,711$ & 66 & $1,624,576$ & 74 & $1,743,248$ & 79 \\
\hline
\end{tabular}

\section{Snags}

Snag retention or creation would occur at varying densities under the alternatives as shown in Table 4-77 (Comparison of management actions for snag retention or creation under the alternatives).

Mellen et al. (2006) compiled forest inventory data from across Oregon and Washington and described snag density in terms of "tolerance levels." A tolerance level is the specific value at the edge of a tolerance interval. A tolerance interval is the range of values that represent a specific proportion or percentage of some sample or population. For example, if a $50 \%$ tolerance level of snag density used by wildlife species in a specific vegetation condition is, for example, 2.1 snags per acre, this means that $50 \%$ of all inventory plots had a density of 2.11 snags per acre or less. An $80 \%$ tolerance level of 7.98 snags per acre would be interpreted as $80 \%$ of the inventory plots had 7.98 snags per acre or less. A $100 \%$ tolerance interval corresponds to the maximum observed value, such as the highest snag density observed to be used by a wildlife species. Observed tolerance levels for snag density in the wildlife habitat types within the planning area are shown in Table 4-78 (Snag density found in unharvested forests). 
Table 4-77. Comparison Of Management Actions For Snag Retention Or Creation UNDER THE ALTERNATIVES

\begin{tabular}{|c|c|c|c|c|}
\hline No Action & Alternative 1 & Alternative 2 & Alternative 3 & PRMP \\
\hline $\begin{array}{l}\text { In the Matrix and } \\
\text { Riparian Reserve: } \\
\text { - } 1.1 \text { snags per acre } \\
\text { - In the LSR: } \\
\text { - Per LSRA guidance }\end{array}$ & $\begin{array}{l}\text { - In the TMA and RMA: } \\
\text { - Noncommercial snags } \\
\text { only } \\
\text { - In the LSMA in stands } \\
\text { with QMD > } 14 \text { inches: } \\
\text { - In the Western hemlock } \\
\text { series: } \\
\text { - } 6 \text { snags per acre > } 14 \\
\text { inches dbh } \\
\text { - In the Douglas fir series: } \\
3 \text { snags per acre > } 14 \\
\text { inches dbh } \\
\text { - In the tanoak series: } \\
4 \text { snags per acre > } 14 \\
\text { inches dbh } \\
\\
\text { In the LSMA in stands } \\
\text { with QMD < } 14 \text { inches: } \\
\text { - In the Western hemlock } \\
\text { series: } \\
\text { - } 3 \text { snags per acre > } 12 \\
\text { inches dbh } \\
\text { - In the Douglas fir series: } \\
2 \text { snags per acre > } 10 \\
\text { inches dbh } \\
\text { - In the tanoak series: } \\
2 \text { snags per acre > } 10 \\
\text { inches dbh }\end{array}$ & $\begin{array}{l}\text { - In the TMA and RMA: } \\
\text { - None } \\
\text { - In the LSMA in stands } \\
\text { with QMD > } 14 \text { inches: } \\
\text { - In the Western hemlock } \\
\text { series: } 6 \text { snags per acre } \\
>14 \text { inches dbh } \\
\text { - In the Douglas fir series: } \\
3 \text { snags per acre }>14 \\
\text { inches dbh } \\
\text { - In the tanoak series: } \\
4 \text { snags per acre >14 } \\
\text { inches dbh } \\
\\
\text { In the LSMA in stands } \\
\text { with QMD }<14 \text { inches: } \\
\text { - In the Western hemlock } \\
\text { series: } 3 \text { snags per acre } \\
>12 \text { inches dbh } \\
\text { - In the Douglas fir series: } \\
2 \text { snags per acre > } 10 \\
\text { inches dbh } \\
\text { - In the tanoak series: } \\
2 \text { snags per acre }>10 \\
\text { inches dbh }\end{array}$ & 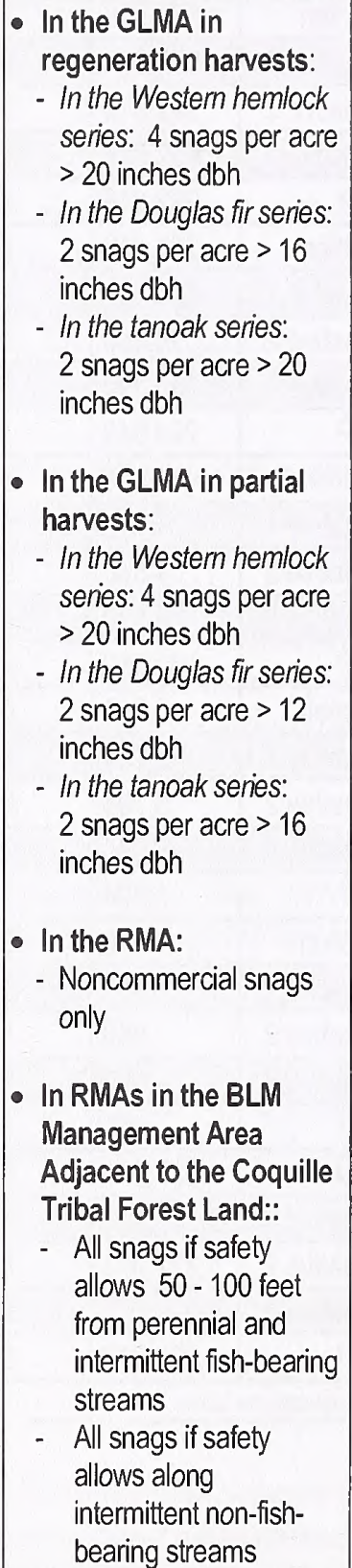 & $\begin{array}{l}\text { - In the TMA and RMA: } \\
\text { - Noncommercial snags } \\
\text { only } \\
\text { - In the Deferred TMA: } \\
\text { - All snags retained } \\
\text { - In the LSMA in stands } \\
\text { with QMD > } 14 \text { inches: } \\
\text { - In the Westem hemlock } \\
\text { series: } 6 \text { snags per acre } \\
>14 \text { inches dbh } \\
\text { - In the Douglas fir series: } \\
3 \text { snags per acre > } 14 \\
\text { inches dbh } \\
\text { - In the tanoak series: } \\
4 \text { snags per acre > } 14 \\
\text { inches dbh } \\
\text { - In the LSMA in stands } \\
\text { with QMD < } 14 \text { inches: } \\
\text { - In the Western hemlock } \\
\text { series: } 3 \text { snags per acre } \\
>12 \text { inches dbh } \\
\text { - In the Douglas fir series: } \\
2 \text { snags per acre > } 10 \\
\text { inches dbh } \\
\text { - In the tanoak series: } \\
2 \text { snags per acre > } 10 \\
\text { inches dbh } \\
\text { In the Eastside Forest } \\
\text { Management Area: } \\
\text { - } 2 \text { snags per acre > } 16 \\
\text { inches dbh }\end{array}$ \\
\hline
\end{tabular}

LSR - Late-Successional Reserve; LSRA - Late-Successional Riparian Area; TMA - Timber Management Area; LSMA - Late-Successional Management Area; GLMA - General Land Management Area; RMA - Riparian Management Area; QMD - quadratic mean diameter; dbh - diameter breast height

Tolerance levels of snag density were used to facilitate comparison of the different management actions for snags under the alternatives against the data for unharvested forests synthesized by Mellen et al. (2006). Under the alternatives, management actions for snag retention or creation are differentiated based on vegetation series (see Figure 2-1 - Forest vegetation series in Chapter 2, and Appendix B - Forest Structure and Spatial Pattern). Snag density requirements for the western hemlock vegetation series were compared with the tolerance levels for the Coast Range and West Cascades wildlife habitat types from Mellen et al. (2006). Snag density requirements for the tanoak vegetation series and the Douglas fir vegetation series were compared with the tolerance levels for the Southwest Oregon wildlife habitat type from Mellen et al. (2006). 
Table 4-78. Snag Density Found In Unharvested Forests

\begin{tabular}{|c|c|c|c|c|c|c|c|}
\hline \multirow{3}{*}{ Wildlife Habitat Type ${ }^{a}$} & \multicolumn{6}{|c|}{ Tolerance Levels ${ }^{a}$} & \multirow{3}{*}{ Comparable Vegetation Series } \\
\hline & \multicolumn{3}{|c|}{$\begin{array}{l}\text { Density of snags } \\
>10 \text { inches } \mathrm{dbh} \\
\text { (snags/acre) }\end{array}$} & \multicolumn{3}{|c|}{$\begin{array}{l}\text { Density of Snags } \\
>20 \text { inches } \mathrm{dbh} \\
\text { (snags/acre) }\end{array}$} & \\
\hline & $30 \%$ & $50 \%$ & $80 \%$ & $30 \%$ & $50 \%$ & $80 \%$ & \\
\hline $\begin{array}{l}\text { Coast Range } \\
\text { (Westside Lowland Conifer-Hardwood Forest Oregon Coast) }\end{array}$ & 2.1 & 6.5 & 17.0 & 1.1 & 2.1 & 10.1 & Western Hemlock \\
\hline $\begin{array}{l}\text { West Cascades } \\
\text { (Westside Lowland Conifer-Hardwood Forest Oregon West } \\
\text { Cascades) }\end{array}$ & 8.3 & 14.6 & 29.2 & 2.1 & 4.4 & 10.6 & Western Hemlock \\
\hline $\begin{array}{l}\text { Eastern Cascades } \\
\text { (Eastside Mixed Conifer Forest E Cascades/Blue Mnts.) }\end{array}$ & 4.0 & 9.1 & 22.2 & 0.0 & 2.0 & 6.4 & $\begin{array}{l}\text { Tanoak; Douglas Fir (Klamath Falls } \\
\text { Resource Area) }\end{array}$ \\
\hline $\begin{array}{l}\text { Southwest Oregon } \\
\text { (Southwest Oregon Mixed Conifer-Hardwood Forest) }\end{array}$ & 3.2 & 6.4 & 14.6 & 1.1 & 2.1 & 5.3 & Tanoak; Douglas Fir (Medford District) \\
\hline
\end{tabular}

aFrom stands of small/medium trees (QMD = 10 to 19 inches dbh) based on Mellen et al. (2006).

\section{No Action Alternative}

Under the No Action Alternative, snags would be provided at densities at or below the $30 \%$ tolerance level on approximately $47 \%$ of BLM-administered lands within the planning area (i.e., within the Matrix, Adaptive Management Areas, and Riparian Reserves land use allocations). Within the Late-Successional Reserves (36\% of BLM-administered lands in the planning area), Late-Successional Reserve assessments provide guidance and/or recommendations on the density of snags to be provided and that density varies among the Late-Successional Reserves. On the remaining $17 \%$ of BLM-administered lands within the planning area (i.e., Congressionally Withdrawn or Administratively Withdrawn lands), current snag density would not change due to management actions. See Table 4-77 (Comparison of management actions for snag retention or creation under the alternatives) and Table 4-78 (Snag density found in unharvested forests).

\section{Alternative 1}

Under Alternative 1, the management action for snags in the Western hemlock vegetation series would provide snags at densities between the $30 \%$ and $50 \%$ tolerance levels in the Coast Range and below the $30 \%$ tolerance level in the West Cascades within the late-successional management areas which constitute $28 \%$ of BLM-administered lands within the planning area. Management actions in the Late-Successional Management Area for snags in the Douglas fir vegetation series and the tanoak vegetation series would generally provide snag densities below the 30\% tolerance level for observed densities in Southwestern Oregon.

Within the Timber Management Areas and Riparian Management Areas, which constitute $46 \%$ of BLMadministered lands within the planning area, noncommercial snags would be retained except where they would be removed for safety or operational reasons. Snag density within the Timber Management Area and Riparian Management Area would be provided below the 30\% tolerance level. Snag density would not be altered by management actions on the remaining $26 \%$ of BLM-administered lands within the planning area (i.e., National Landscape Conservation System and Administratively Withdrawn lands). See Table 4-77 (Comparison of management actions for snag retention or creation under the alternatives) and Table 4-78 (Snag density found in unharvested forests).

\section{Alternative 2}

Under Alternative 2, the management action for snags in the Western hemlock vegetation series would provide snags at densities between the 30\% and 50\% tolerance levels in the Coast Range and below the 30\% tolerance level in the West Cascades within the Late-Successional Management Area (i.e., 19\% of BLMadministered lands within the planning area). Management actions in the Late-Successional Management Area for snags in the Douglas fir vegetation series and the tanoak vegetation series would generally provide snag densities below the $30 \%$ tolerance level for observed densities in Southwestern Oregon. 
Within the Riparian Management Areas (i.e., 6\% of BLM-administered lands within the planning area), noncommercial snags would be retained, except where they would be removed for safety or operational reasons. No snags would be retained or created within the Timber Management Area (i.e., $48 \%$ of BLMadministered lands within the planning area). Snag density within the Riparian Management Areas and Timber Management Areas would be provided below the 30\% tolerance level. Snag density would not be altered by management actions on the remaining $27 \%$ of BLM-administered lands within the planning area (i.e., National Landscape Conservation System lands and Administratively Withdrawn lands). See Table 4-77 (Comparison of management actions for snag retention or creation under the alternatives) and Table 4-78. (Snag density found in unharvested forests).

\section{Alternative 3}

Under Alternative 3, the management action for snags in the Western hemlock vegetation series would provide snags at densities above the $30 \%$ tolerance level in the Coast Range, but below the $30 \%$ tolerance level in the West Cascades within the General Landscape Management Area (i.e., 66\% of BLM-administered lands in the planning area). Management actions in the General Landscape Management Area for snags in the Douglas fir vegetation series and the tanoak vegetation series would provide snag densities below the $30 \%$ tolerance level for observed densities in southwestern Oregon.

Within the Riparian Management Area (i.e., 7\% of BLM-administered lands within the planning area), noncommercial snags would be retained, except where they would be removed for safety or operational reasons. Snag density within the Riparian Management Area would be below the $30 \%$ tolerance level. In Riparian Management Areas within the BLM Management Area adjacent to Coquille Tribal Forest Land (i.e., $1 \%$ of BLM-administered lands within the planning area), snag densities retained would be variable since all existing snags would be retained except those removed for safety reasons. Snag density would not be altered by management actions on the remaining $26 \%$ of BLM-administered lands within the planning area (i.e., National Landscape Conservation System and Administratively Withdrawn lands). See Table 4-77 (Comparison of management actions for snag retention or creation under the alternatives) and Table 4-78 (Snag density found in unharvested forests).

\section{PRMP}

Under the PRMP, the management action for snags in the Western hemlock vegetation series would provide snags at densities between the 30\% and 50\% tolerance levels in the Coast Range and below the $30 \%$ tolerance level in the West Cascades within the Late-Successional Management Areas and the LateSuccessional Management Areas murrelet critical habitat units (i.e., 23\% of BLM-administered lands in the planning area). Management actions in the late successional management areas for snags in the Douglas fir vegetation series and the tanoak vegetation series would generally provide snag densities below the $30 \%$ tolerance level for observed densities in Southwestern Oregon.

Within the Riparian Management Areas (i.e., 10\% of BLM-administered lands within the planning area), noncommercial snags would be retained, except where they would be removed for biomass recovery or for safety or operational reasons. No snags would be retained or created within the Timber Management Areas (i.e., 27\% of BLM-administered lands in the planning area). Snag density within Riparian Management Areas and Timber Management Areas would be provided below the $30 \%$ tolerance level.

Within the forest management areas of the Eastside Management Lands land use allocation (i.e., 1\% of BLM-administered lands within the planning area), snags would be provided below the $30 \%$ tolerance level. Within the Uneven-aged Management Areas (i.e., 8\% of BLM-administered lands within the planning area), there is no management direction for snag retention or creation. However, a reasonable analytical assumption is that existing non-merchantable snags would be retained, except where they would be removed for safety or operational reasons. Snag density would not be altered by management actions on the remaining $24 \%$ of BLM-administered lands within the planning area (i.e., Deferred Timber Management Areas, National Landscape Conservation Systems Lands, and Administratively Withdrawn Lands). See Table 4-77 (Comparison of management actions for snag retention or creation under the alternatives) and Table 4-78 (Snag density found in unharvested forests). 


\section{Down Wood}

For this analysis, the minimum diameters and lengths of down wood as prescribed by the management actions under the alternatives were assumed to be retained. The prescribed amounts of downed wood are summarized in Table 4-79 (Comparison of management actions for downed wood retention or creation under the alternatives).

Tolerance levels of coarse woody debris cover were used to facilitate comparison of the different management actions for coarse woody debris under the alternatives against the data for unharvested forests synthesized by Mellen et al. (2006). Under the alternatives, management actions for coarse woody debris retention or creation are differentiated based on vegetation series. See Figure 2-1 (Forest Vegetation Series in Chapter 2) and Appendix B - Forest Structure and Spatial Pattern. Coarse woody debris requirements for the western hemlock

\section{TAble 4-79. Comparison Of Management Actions For Downed Wood Retention OR} Creation Under The Alternatives

\begin{tabular}{|c|c|c|c|c|}
\hline No Action & Alternative 1 & Alternative 2 & Alternative 3 & PRMP \\
\hline $\begin{array}{l}\text { - In Northern GFMA and } \\
\text { Connectivity/Diversity } \\
\text { Blocks: } \\
\text { - } 240 \text { feet per acre } \\
(0.7 \% \text { cover }) \\
\text { - In Southern GFMA: } \\
\text { - } \quad 120 \text { feet per acre } \\
(0.3 \% \text { cover }) \\
\text { - In the LSR: } \\
\text { - Per LSRA guidance }\end{array}$ & $\begin{array}{l}\text { - In the TMA and RMA: } \\
\text { - Noncommercial coarse } \\
\text { woody debris only } \\
\text { - In the LSMA in stands } \\
\text { with QMD > } 14 \text { inches: } \\
\text { - In the Western hemlock } \\
\text { series: } 240 \text { feet per acre } \\
\text { (0.6\% cover) } \\
\text { - In the Douglas fir series: } \\
120 \text { feet per acre }(0.3 \% \\
\text { cover) } \\
\text { - In the tanoak series: } \\
120 \text { feet per acre }(0.3 \% \\
\text { cover) } \\
\\
\text { In the LSMA in stands } \\
\text { with QMD } 14 \text { inches: } \\
\text { - In the Western hemlock } \\
\text { series: } 120 \text { feet per acre } \\
\text { (0.2\% cover) } \\
\text { - In the Douglas fir series: } \\
60 \text { feet per acre }(0.1 \% \\
\text { cover) } \\
\text { - In the tanoak series: } \\
60 \text { feet per acre }(0.1 \% \\
\text { acre) }\end{array}$ & $\begin{array}{l}\text { - In the TMA and RMA: } \\
\text { - None } \\
\text { - In the LSMA in stands } \\
\text { with QMD > } 14 \text { inches: } \\
\text { - In the Western hemlock } \\
\text { series: } 240 \text { feet per acre } \\
\text { (0.6\% cover) } \\
\text { - In the Douglas fir series: } \\
120 \text { feet per acre (0.3\% } \\
\text { cover) } \\
\text { - In the tanoak series: } \\
120 \text { feet per acre (0.3\% } \\
\text { cover) } \\
\\
\text { In the LSMA in stands } \\
\text { with QMD } \leq 14 \text { inches: } \\
\text { - In the Western hemlock } \\
\text { series: } 120 \text { feet per acre } \\
\text { (0.2\% cover) } \\
\text { - In the Douglas fir series: } \\
60 \text { feet per acre (0.1\% } \\
\text { cover) } \\
\text { - In the tanoak series: } \\
60 \text { feet per acre (0.1\% } \\
\text { acre) }\end{array}$ & $\begin{array}{l}\text { - In the GLMA in } \\
\text { regeneration harvests: } \\
\text { - In the Western hemlock } \\
\text { series: } 240 \text { feet per } \\
\text { acre (0.9\% cover) } \\
\text { - In the Douglas fir series: } \\
120 \text { feet per acre (0.3\% } \\
\text { cover) } \\
\text { - In the tanoak series: } \\
120 \text { feet per acre }(0.4 \% \\
\text { cover) } \\
\\
\text { - In the GLMA in partial } \\
\text { harvests: } \\
\text { - In the Western hemlock } \\
\text { series: } 240 \text { feet per acre } \\
\text { (0.9\% cover) } \\
\text { - In the Douglas fir series: } \\
120 \text { feet per acre (0.3\% } \\
\text { cover) } \\
\text { - In the tanoak series: } \\
120 \text { feet per acre (0.3\% } \\
\text { cover) } \\
\text { - In the BLM Management } \\
\text { Area Adjacent to the } \\
\text { Coquille Tribal Forest } \\
\text { Land:: } \\
\text { woody debris only } \\
\text { cover) } \\
\text { in RMAs }\end{array}$ & $\begin{array}{l}\text { - In the TMA and RMA: } \\
\text { - Noncommercial coarse } \\
\text { woody debris only } \\
\text { - In the Deferred TMA: } \\
\text { - All coarse woody debris } \\
\text { retained } \\
\text { - In the LSMA in stands } \\
\text { with QMD > } 14 \text { inches: } \\
\text { - In the Western hemlock } \\
\text { series: } 240 \text { feet per acre } \\
\text { (0.6\% cover) } \\
\text { - In the Douglas fir series: } \\
120 \text { feet per acre (0.3\% } \\
\text { cover) } \\
\text { - In the tanoak series: } \\
120 \text { feet per acre }(0.3 \% \\
\text { cover) } \\
\text { - In the LSMA in stands } \\
\text { with QMD } 14 \text { inches: } \\
\text { - In the Western hemlock } \\
\text { series: } 120 \text { feet per acre } \\
\text { (0.2\% cover) } \\
\text { - In the Douglas fir series: } \\
60 \text { feet per acre (0.1\% } \\
\text { cover) } \\
\text { - In the tanoak series: } \\
60 \text { feet per acre ( } 0.1 \% \\
\text { acre) } \\
\text { (n) cover) }\end{array}$ \\
\hline
\end{tabular}


vegetation series were compared with the tolerance levels for the Coast Range and West Cascades wildlife habitat types from Mellen et al. (2006). Coarse woody debris requirements for the tanoak vegetation series and the Douglas fir vegetation series were compared with the tolerance levels for the Southwest Oregon wildlife habitat type from Mellen et al. (2006).

Under all alternatives, except for Late-Successional Reserves under the No Action Alternative, the amount of down wood that would be provided by the management actions on BLM-administered lands would generally be below the $30 \%$ tolerance level described by Mellen et al. (2006). The amount of down wood provided in late-successional reserves under the No Action Alternative and how that amount compares to the tolerance levels from Mellen et al. (2006) would vary among the Late-Successional Reserves because the guidance for down wood retention and/or creation varies among the individual Late-Successional Reserve assessments. In addition, existing down wood present in Riparian Management Areas in the BLM management area adjacent to the Coquille tribal forest land under Alternative 3 would be retained, and existing down wood present in the deferred Timber Management Area under the PRMP would be retained, except where removed for operational reasons.

Under the No Action Alternative and Alternative 3, slightly more down wood would be provided than under Alternatives 1 and Alternative 2, or the PRMP, but down wood would still be provided at levels below the 30\% tolerance level. See Table 4-79 (Comparison of management actions for downed wood retention or creation under the alternatives) and Table 4-80 (Coarse woody debris cover found in unharvested forests).

\section{Green Tree Retention}

The proportion of BLM-administered lands within the planning area that would contain green retention trees as a legacy component following regeneration harvest and the density of those retention trees would vary across the alternatives. All BLM-administered lands within the planning area would have green tree retention provided under the No Action Alternative following regeneration harvest. Under Alternative 3, zero green trees could be retained following regeneration on the BLM Management Area adjacent to the Coquille tribal forest land ( $1 \%$ of BLM-administered lands), since the management action would provide a range of retention from 0 to 6 trees per acre. Within the Timber Management Areas under Alternatives 1 and 2, and the PRMP, there would be zero green tree retention following regeneration harvest on 37,48 , and $27 \%$ of BLM-administered lands within the planning area, respectively. In addition, under the PRMP after the deferral of harvest is lifted in 2023 within the Deferred Timber Management Area (7\% of BLMadministered lands in the planning area), there would be zero green tree retention following regeneration harvest.

Table 4-80. Coarse Woody Debris Cover Found In Unharvested Forests

\begin{tabular}{|c|c|c|c|c|}
\hline \multirow{3}{*}{ Wildlife Habitat Type } & \multirow{2}{*}{\multicolumn{3}{|c|}{$\begin{array}{c}\text { Tolerance Levels } \\
\begin{array}{c}\text { Coarse Woody Debris } \\
(\% \text { cover })\end{array}\end{array}$}} & \multirow{3}{*}{$\begin{array}{l}\text { Comparable } \\
\text { Vegetation Series }\end{array}$} \\
\hline & & & & \\
\hline & $30 \%$ & $50 \%$ & $80 \%$ & \\
\hline $\begin{array}{l}\text { Coast Range } \\
\text { (Westside Lowland Conifer-Hardwood Forest OR Coast) }\end{array}$ & 2.9 & 5.0 & 9.4 & Western Hemlock \\
\hline $\begin{array}{l}\text { Western Cascades } \\
\text { (Westside Lowland Conifer-Hardwood Forest OR W Cascades) }\end{array}$ & 2.1 & 4.0 & 8.7 & Western Hemlock \\
\hline $\begin{array}{l}\text { Eastern Cascades } \\
\text { (Eastside Mixed Conifer Forest E Cascades/Blue Mnts.) }\end{array}$ & 0.6 & 2.1 & 4.9 & $\begin{array}{l}\text { Tanoak; Douglas } \\
\text { Fir (Klamath Falls } \\
\text { Resource Area) }\end{array}$ \\
\hline $\begin{array}{l}\text { Southwest Oregon } \\
\text { (Southwest Oregon Mixed Conifer-Hardwood Forest) }\end{array}$ & 0.8 & 1.7 & 4.1 & $\begin{array}{l}\text { Tanoak; Douglas Fir } \\
\text { (Medford District) }\end{array}$ \\
\hline
\end{tabular}


Following regeneration harvest, the stand establishment structural stage would have greater numbers of remnant green trees and, therefore, a greater number of legacy habitat features for land birds and other wildlife under the No Action Alternative and Alternative 3 compared to Alternatives 1, Alternative 2, and the PRMP. Alternatives 1 and 2, and the PRMP would provide stand establishment habitat of lower value for those species that use legacy structures than the No Action Alternative or Alternative 3, due to the lack of requirements in Alternatives 1,2 and the PRMP to retain green trees in regeneration harvests. See Table 4-81 (Comparison of management actions for green tree retention in regeneration under the alternatives).

\section{Western Snowy Plover}

Under all alternatives, including the PRMP, existing plans for western snowy plover habitat at the Coos Bay North Spit and the New River Area of Critical Environmental Concern would continue to be implemented. These plans are designed to prevent disturbance to known snowy plover nest sites, restore natural dune processes with a goal of providing additional nesting habitat, and provide predator control. Designated critical habitat for the western snowy plover is located within the Coos Bay North Spit and New River Area of Critical Environmental Concern.

The Pacific Coast distinct population segment of the western snowy plover has exhibited "significant" progress towards recovery as shown in Figure 4-137 (Total number of western snowy plover young fledged along the Oregon Coast from 1990 to 2006) (Lauten et al. 2006). Since the management that has led to this recovery would continue under all alternatives, it is anticipated that population numbers and nesting success in the long term would remain stable or increase under all alternatives.

Table 4-81. Comparison Of Management Actions For Green Tree Retention In REGENERATION HARVESTS UNDER THE ALTERNATIVES

\begin{tabular}{|c|c|c|c|c|}
\hline No Action & Alternative 1 & Alternative 2 & Alternative 3 & PRMP \\
\hline $\begin{array}{l}\text { In Northern GFMA: } \\
-6-8 \text { tpa } \\
\text { - In Southern GFMA: } \\
-18-25 \text { tpa } \\
\text { - In Connectivity/Diversity } \\
\text { Blocks: } \\
-12-18 \text { tpa }\end{array}$ & $\begin{array}{l}\text { - In the TMA: } \\
-0 \text { tpa }\end{array}$ & $\begin{array}{l}\text { - In the TMA: } \\
\text { - O tpa }\end{array}$ & $\begin{array}{l}\text { - In the GLMA in } \\
\text { regeneration harvests: } \\
\text { - In the Western hemlock } \\
\text { series: } \\
6 \text { tpa } \\
\text { - In the Douglas fir series: } \\
9 \text { tpa } \\
\text { - In the tanoak series: } \\
6 \text { tpa } \\
\text { - In the GLMA in partial } \\
\text { harvests: } \\
\text { - In the Western hemlock } \\
\text { series: } \\
30 \text { tpa } \\
\text { - In the Douglas fir series: } \\
20 \text { tpa } \\
\text { - In the tanoak series: } \\
20 \text { tpa } \\
\\
\text { - In the BLM Management } \\
\text { Area Adjacent to the } \\
\text { Coquille Tribal Forest } \\
\text { Land: } \\
0 \text { - } 6 \text { tpa }\end{array}$ & $\begin{array}{l}\text { - In the TMA: } \\
\text { - } 0 \text { tpa } \\
\text { - In the deferred TMA after } \\
2023 \text { : } \\
\text { - } 0 \text { tpa } \\
\text { - In the Eastside Forest } \\
\text { Management Area: - } \\
\text { Relative Density (Curtis) of } \\
\text { green trees between } 15 \\
\text { and } 55 \\
\text { - In the Uneven-Aged } \\
\text { Management Area: } \\
\text { Relative Density (Curtis) of } \\
\text { green trees between } 25 \\
\text { and } 55\end{array}$ \\
\hline
\end{tabular}


Figure 4-137. Total Number Of Western Snowy Plover Young Fledged Along the Oregon Coast From 1990 To 2006

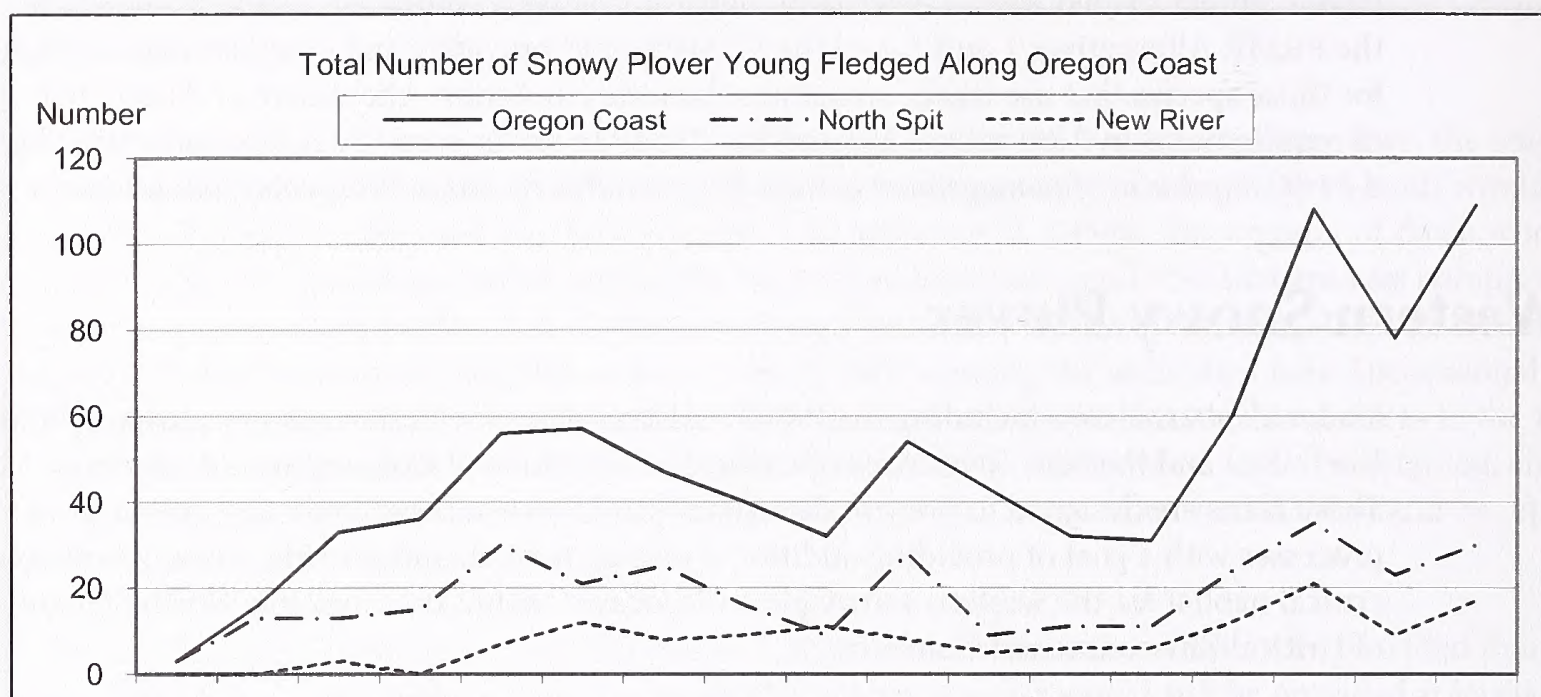

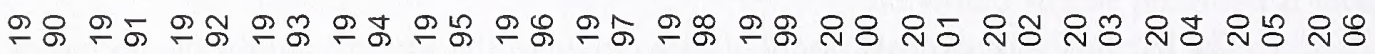

\section{Sage Grouse}

The treatment of sage grouse habitat, which only occurs east of Highway 97 in the Klamath Falls Resource Area, would not vary between the alternatives. Therefore, the following impacts would occur under all alternatives, including the PRMP.

The Oregon conservation strategy for sage grouse was completed in 2005. The BLM was a partner in that process, along with the U.S. Forest Service and state agencies (Hagen et al. 2005). The conservation strategy includes managing at least $70 \%$ of the sage grouse habitat-capable lands in a suitable habitat condition and the remaining habitat-capable lands in a potential-habitat condition. Within the Gerber block this would equate to managing approximately 33,000 acres ( $70 \%$ of the 47,000 acres of habitat-capable land) in a suitable habitat condition. Currently, there are approximately 28,000 acres of suitable sage grouse habitat (59\% of habitat-capable land) within the Gerber block.

Juniper encroachment prevents sage grouse non-habitat from developing into suitable habitat because it competes for moisture and light. Juniper encroachment is a major cause of the loss of sage grouse habitat in the Gerber block. Juniper woodlands occupy approximately 40,000 acres within the Gerber block. Juniper expansion has increased by a factor of 10 since the 1880s (Miller and Tausch 2001, as cited in Hagen 2005).

Current levels of vegetative treatments (e.g. juniper removal to enhance range and wildlife habitat) would increase the amount of sage grouse habitat. See Table 4-3 (Estimated first decade levels of non-timber management activity by alternative). These activities would continue at approximately the same levels under all alternatives, including the PRMP.

It is assumed that woodland and rangeland management activities in the next decade would occur at approximately the same rate as in the past decade under the 1995 resource management plan in the Klamath Falls Resource Area. Western juniper that is encroaching and competing and displacing native vegetation on rangelands and juniper woodlands would continue to be treated utilizing a variety of treatments including: cutting, piling, burning, and utilization for biomass and other forest products. Removal of juniper would remove competing vegetation and allow sage grouse habitat to re-establish. 
Operations associated with ground disturbance that are used to remove encroaching junipers can also incidentally remove native vegetation and encourage the spread of invasive non-native grasses. The spread of invasive non-native grasses also causes the loss of sage grouse habitat. Site-disturbing activities can include the use of heavy equipment or burning, which allows the spread of invasive non-native grasses. These nonnative grasses prevent establishment of sagebrush and other native forage species for sage grouse. Similar to juniper, non-native grasses limit the availability of food source and hiding cover for the sage grouse. However, because the amount of non-timber vegetative treatments would not vary among the alternatives, the incidence of spreading invasive, non-native grasses through these treatments would also not vary among the alternatives. See Table 4-3 (Estimated first decade levels of non-timber management activity by alternative),

Grazing allotments overlay the entire Gerber block. Rangeland surveys in the Gerber block have shown that range conditions have been on an upward trend towards late-successional forest and potential natural community since the late 1930s. In 1938, surveys indicated that $68 \%$ of range was dominated by cheatgrass communities. A 2004 report states: "[n] ative perennial bunchgrasses, desirable shrub species, and native forbs have all increased in abundance [since 1938], leaving only $4.5 \%$ dominated by cheatgrass (and other non-native annual grasses) and in an early to mid- seral successional forest state (USDI unpublished)." Grazing under the No Action Alternative has been compatible with the maintenance and the creation of sage grouse habitat. Grazing levels and practices in the Gerber block would not change under the action alternatives; therefore, grazing would not result in the loss of sage grouse habitat under any of the alternatives.

Forested areas do not provide suitable sage grouse habitat; therefore, timber harvest on the Eastside Management Lands in the Klamath Falls Resource Area would have no impact on the sage grouse habitat. Under all alternatives, understocked forestlands would be reforested and rangeland would be converted from juniper back into historic sagebrush or grassland communities.

It is assumed that under all action alternatives, oil and gas exploration and development, mining and quarries, and infrastructure development (such as roads, communication sites and recreation sites) would occur at the same rate as under the 1995 resource management plan. These actions have caused an inconsequential loss of sage grouse habitat; therefore under all alternatives, an inconsequential amount of habitat would be lost due to these activities within the planning area.

Sage grouse do not currently occur within the planning area; therefore, effects to sage grouse populations are difficult to predict. Disturbances, such as noise and activities associated with human developments, would limit suitable habitat from becoming occupied. Conservation measures to reduce or restrict disturbances would be implemented if a site were to become occupied or if reintroduction were attempted. Off-highway vehicle use in the Gerber block would be restricted to designated roads and trails. This would result in a reduction of disturbance due to off-highway vehicle use. No new campground or other large-scale recreation developments would occur under any of the alternatives within the Gerber block. There would be 18.2 miles of potential trail development for non-motorized users in the action alternatives. Avoiding historic lekking areas and seasonal trail closures would limit disturbance impacts to any new leks that may be established in the future.

West Nile virus in sage grouse was first documented in Oregon in 2006 from Malheur County (ODFW 2008) and Harney County (Hagen 2008). The prevalence of West Nile virus in wild populations of sage grouse in Oregon is unknown. None of the alternatives, including the PRMP, would affect the likelihood of West Nile virus from spreading. 


\section{Special Status Species}

\section{Federally Listed Threatened and Endangered Species}

Under all alternatives, including the PRMP, the 12 federal candidate and listed species identified in Table 4-82 (Federally listed candidate, threatened, and endangered species not associated with forested ecosystems) would be managed to provide for the conservation of the species. These 12 species occur in habitat types that are considered non-forest. In general, the availability of nonforest habitat would be unchanged from the current availability under all alternatives, including the PRMP. Nonforest habitats tend to be comprised of features that are generally noncommercial. All action alternatives contain a management objective to support natural species composition and vegetation on noncommercial areas. With this management objective, the availability of nonforest habitat for the 12 federal candidate and listed species identified in Table 4-82 (Federally listed candidate, threatened, and endangered species not associated with forested ecosystems) would, in general, be maintained.

\section{Bureau Sensitive}

Under the No Action Alternative and the PRMP, the Oregon/Washington Special Status Species policy for sensitive species would be applied to O\&C lands and public domain lands administered by the BLM within the planning area. Within the harvest land base under Alternatives 1,2, and 3, sensitive species would be managed on public domain lands and on O\&C lands where protection does not conflict with sustained yield forest management. Under Alternatives 1, 2, and 3, where conflicts with sustained yield management occur, protections on O\&C lands would only be applied to prevent extinction of a species even if it is not yet listed under the Endangered Species Act.

Application of the current Oregon/Washington Special Status Species policy would include assessment and review of the effects of proposed actions on Bureau sensitive species. This assessment and review would be done by the districts during their project planning of individual projects. Application of this policy would not equate to guaranteed protection for individuals of a sensitive species, only that the conservation needs of the species would be further assessed at the project or implementation level in light of proposed actions.

When conservation measures are determined to be necessary at the project or implementation level, options for conservation would include, but not be limited to: (a) modifying a project (e.g., timing, placement, and/ or intensity), (b) using buffers to protect sites, and/or (c) implementing habitat restoration actions (IM-OR2003-054 Oregon/Washington Special Status Species Policy).

\section{Westside Forest Habitat}

The effects to westside forested habitat (i.e., Coast Range, West Cascades, Klamath, Eastern Cascades physiographic provinces) were previously described in this chapter under Forest Structure and Spatial Pattern. Refer to Figure 4-10 (Comparison of the structural stage abundances on the BLM-administered forested lands by 2106 with the current conditions and the average historic conditions by alternative by province).

In the Coast Range, West Cascades, and Klamath Provinces, there would be an increase in the amount of mature and structurally complex forest habitat under all alternatives, including the PRMP by 2106 . In these physiographic provinces, Bureau sensitive wildlife species that are associated with mature and structurally complex forest habitat would have more habitat available. In the Eastern Cascades Province, mature and structurally complex habitat would become less abundant under Alternatives 1,2, and 3 by 2106 , but would become more abundant under the PRMP by 2106. Under the No Action Alternative, the amount of mature and structurally complex habitat would be unchanged. Refer to Figure 4-10 (Comparison of the structural stage abundances on the BLM-administered forested lands by 2106 with the current conditions and the average historic conditions by alternative by province). 
Table 4-82. Federally listed Candidate, Threatened, And Endangered Species Not Associated With Forested Ecosystems

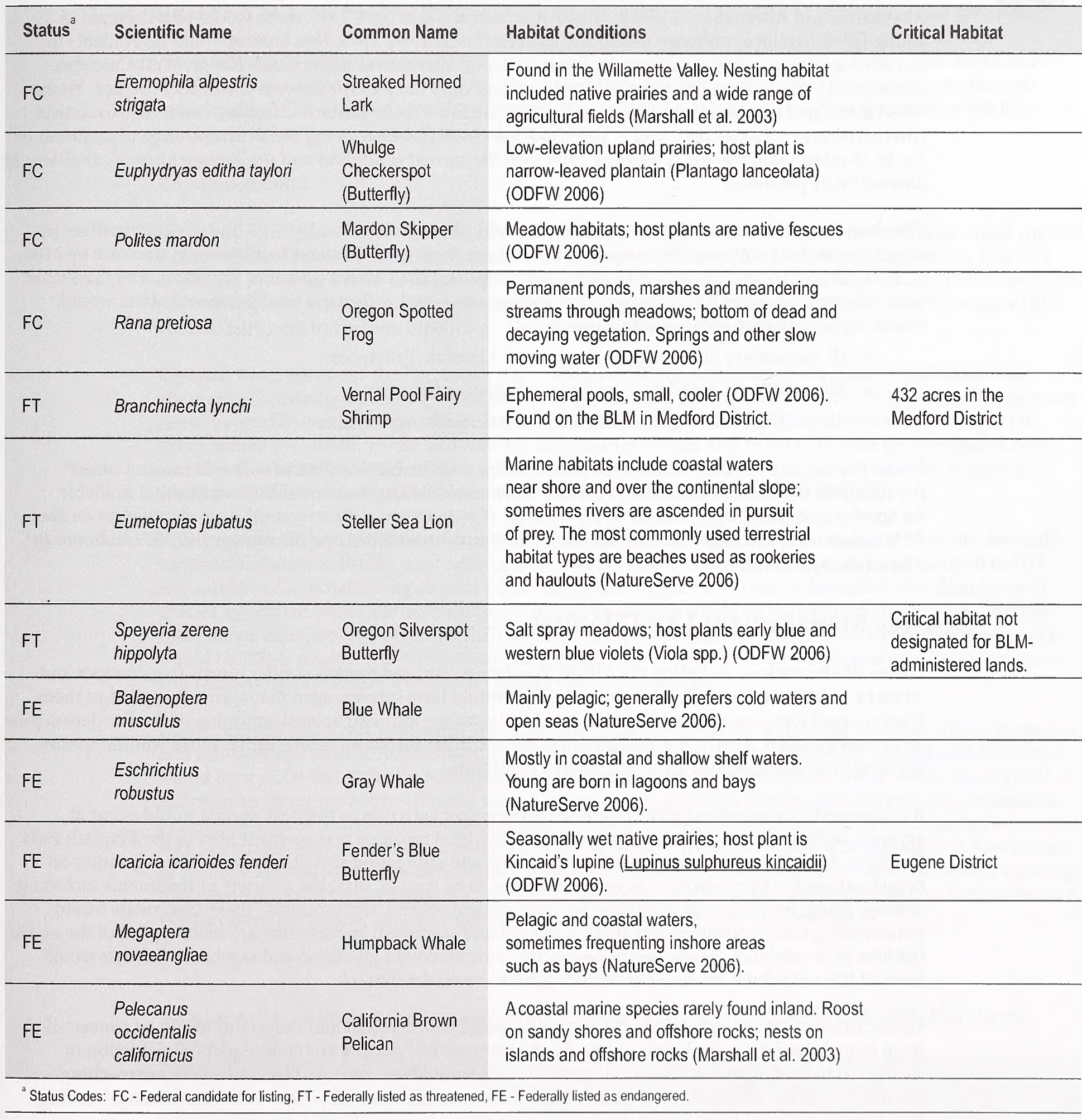


There would be a decrease in the amount of young forest habitat under all alternatives, including the PRMP by 2106 in the Coast Range, West Cascades, and Klamath Provinces. In the Eastern Cascades Province, there would be an increase in the abundance of young forest habitat under the No Action Alternative and Alternatives 1 and 2. Under Alternative 3 and the PRMP, there would be a decrease in young forest habitat abundance within the Eastern Cascades by 2106. Less habitat would be available to sensitive species associated with young forest under all alternatives in the Coast Range, West Cascades, and Klamath Provinces; and under Alternative 3 and the PRMP in the Eastern Cascades Province. Young forest associated species would have more habitat available in the Eastern Cascades under the No Action Alternative and Alternatives 1 and 2. Refer to Figure 4-10 (Comparison of the structural stage abundances on the BLM-administered forested lands by 2106 with the current conditions and the average historic conditions by alternative by province).

The abundance of stand establishment habitat would generally increase by 2106 under all alternatives in all physiographic provinces. Exceptions to this, where stand establishment habitat would decrease by 2106 , include the No Action Alternative in the Coast Range and the Eastern Cascades Provinces, and the PRMP in the Eastern Cascades Province. Sensitive species associated with stand establishment habitat would, therefore, have more habitat available under:

- all alternatives in the West Cascades and Klamath Provinces

- Alternatives 1, 2, and 3 in the Eastern Cascades Province

- Alternatives 1, 2, 3, and the PRMP in the Coast Range Province

Under the No Action Alternative in the Coast Range and the Eastern Cascades Provinces, and under the PRMP in the Eastern Cascades Province, there would be less stand establishment habitat available for species associated with it. Refer to Figure 4-10. (Comparison of the structural stage abundances on the $B L M-a d m i n i s t e r e d$ forested lands by 2106 with the current conditions and the average historic conditions by alternative by province).

\section{Eastside Management Land Habitat}

Under all alternatives, including the PRMP, Ponderosa pine and eastern conifer forests (e.g., juniper and white fir forests) on Eastside Management Lands would have uneven-aged management applied to them. Uneven-aged forest management would cause little change in the structural condition of the Ponderosa pine and eastern conifer forests. The availability of these conifer forests as habitat for sensitive wildlife species would also be changed little from the current condition.

It is assumed that woodland and rangeland management activities in the next decade would occur at approximately the same rate as in the past under the 1995 resource management plan in the Klamath Falls Resource Area. Western juniper that is encroaching and competing and displacing native vegetation on rangelands and juniper woodlands would continue to be treated, utilizing a variety of treatments including: cutting, piling, burning, and utilization for biomass and other forest products. These treatments would remove competing vegetation and allow grassland and sagebrush habitats that are more typical of the native habitats to re-establish. Bureau sensitive species associated with grassland and sagebrush habitats would have additional habitat made available through this re-establishment.

Under all alternatives, understocked forestlands would be reforested and rangeland would be converted from juniper back into sagebrush or grassland communities, causing an inconsequential reduction in hardwood habitat. Riparian hardwood communities would be maintained by controlling encroaching conifers and other activities to restore riparian hardwood communities (i.e., controlled grazing, burning, and planting).

It is assumed that under all action alternatives, oil and gas exploration and development, mining and quarries, and infrastructure development such as roads, communication sites and recreation sites would occur at the same rate as under the 1995 resource management plans. These actions have caused an inconsequential loss of habitat; therefore, under all alternatives, an inconsequential amount of habitat would be lost due to to these activities within the planning area. 


\section{Nonforest Habitat}

In general, the availability of nonforest habitat would be unchanged from the current availability under all alternatives, including the PRMP. Nonforest habitats tend to be comprised of features that are generally noncommercial. All action alternatives contain a management objective to support natural species composition and vegetation on noncommercial areas, including: noncommercial forests, oak woodlands, shrublands, grasslands, cliffs, rock outcrops, talus slopes, meadows, wetlands, springs, fens, ponds, and vernal pools. With this management objective, the availability of nonforest habitat for sensitive wildlife species would, in general, be maintained.

\section{Riparian Habitat}

Riparian Management Areas would constitute approximately $37 \%$ of BLM-administered lands under the No Action Alternative, 20\% under Alternative 1,13\% under Alternative 2, 11\% under Alternative 3, and 10\% under the PRMP as shown in Table 4-83 (Riparian management areas across all land use allocations under the alternatives). For a discussion of environmental consequences regarding water quality and fisheries, which are also pertinent to riparian habitat, see the Water and Fish sections of Chapter 4.

Riparian Reserves under the No Action Alternative and Riparian Management Areas under the action alternatives are designated along streams. Although the areas in Riparian Reserves or Riparian Management Areas beyond the width of one site-potential tree (generally greater than 150 feet in western Oregon) on either side of the stream would add little to maintenance of lotic and riparian species assemblages (Cockle and Richardson 2003, McComb et al. 1993, Vessely and McComb 2002, Haggerty et al. 2004, Gomez and Anthony 1996), studies found differences for at least some species out to 150-300 feet.

Vesely and McComb (2002) found buffer strips 66 feet wide contained approximately $80 \%$ of the detectable torrent salamanders, Pacific giant salamanders, and Dunn's salamanders. Additional width out 90 to 100 feet would assist in stabilizing diurnal variations in temperature and relative humidity. The abundance of species associated with riparian areas and streams abundance would be maintained under the No Action Alternative, Alternative 1, and the PRMP along intermittent streams, because Riparian Management Areas would be 100-feet wide; this width would be sufficient to maintain the environmental conditions, moisture, and temperature necessary to support riparian-associated species.

Under Alternatives 2 and 3, Riparian Management Areas would extend to 100 feet on either side of perennial and fish-bearing streams. Additionally, under Alternative 2, intermittent streams at high risk of debris flows would have a 100-feet Riparian Management Area. These Riparian Management Areas would be managed to maintain stream temperature, organic matter inputs, and large wood. Stands would be managed to maintain or develop mature or structurally complex forest structural stage classifications. Habitat for species associated with the stream channel and the area immediately adjacent to the streams would be maintained. Species not as strongly associated with the near-stream habitat would decline in abundance, because the canopy openings that would occur in the area between 25 and 100 feet from the stream and the regeneration of habitat beyond 100 feet from the stream channel would create habitat unfavorable to those species.

Table 4-83. Riparian Management Areas Across All Land Use Allocations Under The Alternatives

\begin{tabular}{lc}
\hline Alternative & $\begin{array}{c}\text { Riparian Management Area } \\
\text { (\% Total BLM-administered Lands) }\end{array}$ \\
\hline NoAction & 37 \\
\hline Alternative 1 & 20 \\
\hline Alternative 2 & 13 \\
\hline Alternative 3 & 11 \\
\hline PRMP & 10 \\
\hline
\end{tabular}


Riparian Management Areas under Alternative 2 would allow harvest within 25 feet of intermittent streams, except for debris-flow prone areas which would allow no harvest within 25 feet. The noncommercial vegetation that would be retained within 25 feet of intermittent streams (except debris- flow prone) would not maintain the thermal regime of the habitat within the Riparian Management Area. Amphibians associated with streams are especially susceptible to desiccation in dry environments, and they would be susceptible to localized declines in Riparian Management Areas. Harvesting in the adjacent forest within the shade zone of the stream (e.g., within 25 feet) would have effects on stream amphibian populations that last from 25 to over 50 years post harvest (Bury 2005, Karraker and Welsh 2006, Bury and Pearl 1999, Ashton et al. 2006).

Retention of trees in the 25-feet Riparian Management Area of intermittent non-fish-bearing streams under Alternative 3 would have similar effects to those described in the previous paragraph under Alternative 2. This is because the canopy provided by trees within 25 feet of the stream channel would be sparse, and the forest edges created between Riparian Management Areas and upland regeneration harvest would increase diurnal and seasonal temperature fluctuation and decrease the relative humidity and the microclimate within the Riparian Management Area (Vesely and McComb 2002, Anderson et al. in press). Amphibians associated with streams are especially susceptible to desiccation in dry environments, and they would be susceptible to localized declines in Riparian Management Areas that would be treated under Alternative 3. Harvesting in the adjacent forest within the shade zone of the stream (e.g., within 25 feet) would have effects on stream amphibian populations that last from 25 to over 50 years post harvest (Bury 2005, Karraker and Welsh 2006, Bury and Pearl 1999, Ashton et al. 2006).

Approximately 4,000 acres of harvest would occur over the next 10 years along non-debris flow prone, non-fish-bearing intermittent streams under Alternative 2 (approximately $1 \%$ of the total area within 100 feet of all intermittent streams) on BLM-administered lands within the planning area. A similar amount of harvest would occur within Riparian Management Areas under Alternative 3. At the local scale, Riparian Management Areas under Alternatives 2 and 3 adjacent to these intermittent streams would not maintain a stable assemblage of stream and riparian associated wildlife species. At the fifth-field watershed or larger scale, impacts to species assemblages and their connectivity are not anticipated under Alternative 2 or Alternative 3, because approximately $1 \%$ of the total area within 100 feet of intermittent streams would be impacted per decade.

\section{Forest Floor Habitat}

Regeneration harvests and the associated impact to adjacent forests would result in the loss of forest floor habitat. This loss would be a result of the breakage and removal of existing forest structure during harvest and the decreases in soil and down wood moisture levels because of increases light and wind penetration into adjacent stands.

Twenty random watersheds were modeled to evaluate the effects of regeneration harvests and legacy retention direction on forest floor habitat. Structural stage sub-divisions as described in Appendix B - Forest Structure and Spatial Pattern were scored based on habitat values as shown in Table 4-84 (Forest floor habitat quality ratings). Structural stage scores were decreased if there was a lack of legacy, if canopy cover was low, and if location occurred within 50 feet of a stand in the stand establishment structural stage. Habitat values for young stands (without legacy) were increased one point when they reached 50 years of age to account for natural development of legacy. The habitat quality scores have no proportional relationship to each other. A stand with a score of 4 would not provide twice as much habitat benefit as a score of 2 .

As shown in Figure 4-138 (Forest floor habitat quality summary for each alternative), under all alternatives at least $50 \%$ of the forested habitat would receive a habitat quality score of 4 or 5 by 2056. Differences between the alternatives in the amount of forest floor habitat within habitat quality categories 0 to 3 would occur as a result of legacy retention and the amount of harvesting activities. Since Alternative 1, Alternative 2, and the PRMP do not have legacy retention requirements in their land use allocations associated with the harvest land base (Timber Management Area, Deferred Timber Management Area, and Uneven-Age Timber Management Area), they would have more forest floor habitat with a 0 to 3 score (i.e., lower habitat quality) compared to the No Action Alternative and Alternative 1. Habitat quality 2 under Alternative 3 would be comprised mainly of young, low density forest stands with legacy. Under Alternative 3 , this category would drop to $1 \%$ of the BLM-administered lands in 2056 . This would be due primarily to the fact that harvested 
Table 4-84. Forest Floor Habitat Quality Ratings

\begin{tabular}{lc}
\hline Structural Stage Condition & Habitat Quality Score \\
\hline Road and non-forest & 0 \\
\hline Stand establishment with legacy & 1 \\
\hline Stand establishment without legacy & 0 \\
\hline Young low density with legacy & 2 \\
\hline Young low density without legacy & 1 \\
\hline Young low density without legacy, >50 years old & 2 \\
\hline Young high density with legacy & 3 \\
\hline Young high density without legacy & 2 \\
\hline Young high density without legacy, >50 years old & 3 \\
\hline Mature single canopy & 4 \\
\hline Mature multiple canopy & 5 \\
\hline Structurally complex & 5 \\
\hline
\end{tabular}

Figure 4-138. Forest Floor Habitat Quality Summary For Each Alternative

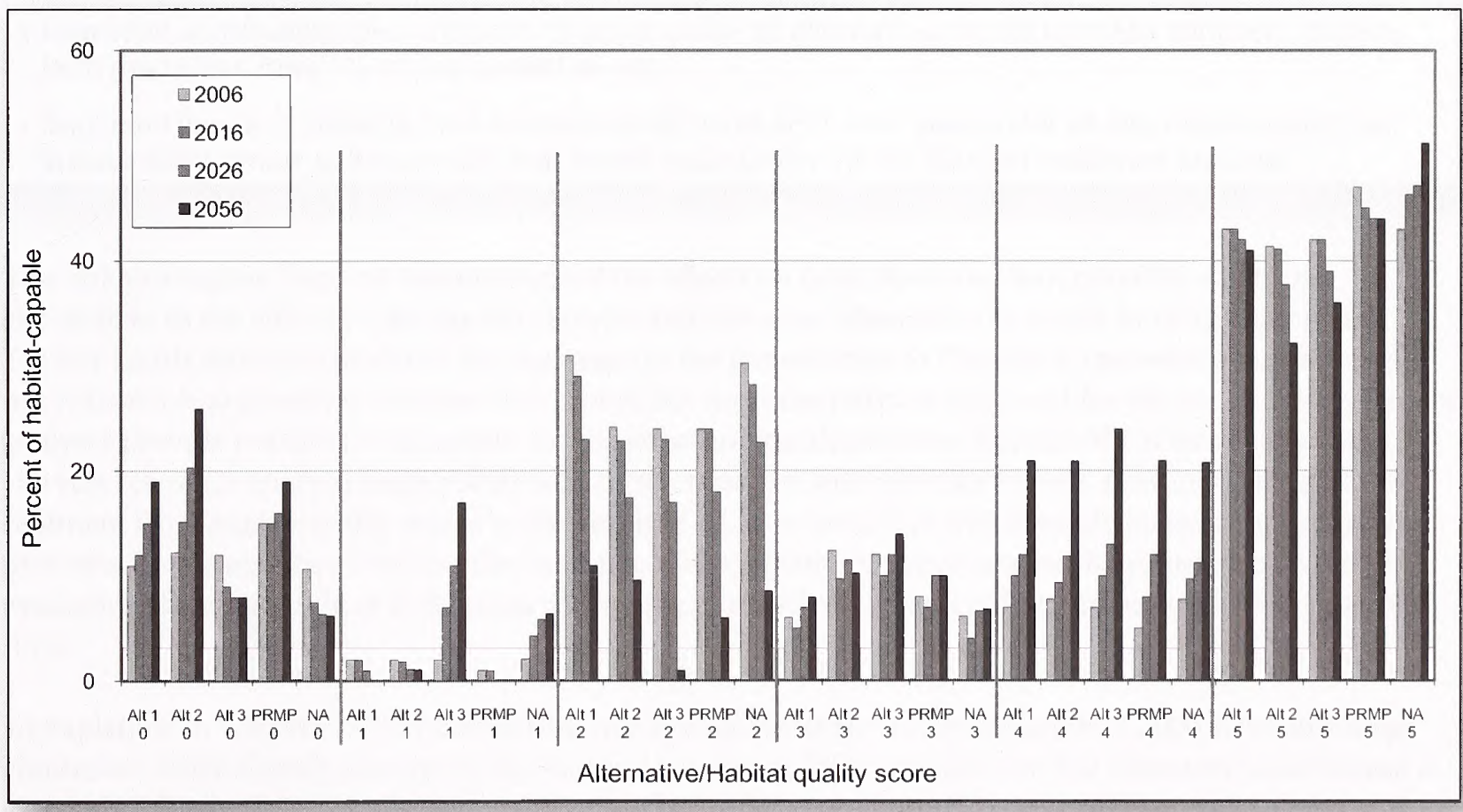

stands under Alternative 3 would move more quickly from the stand establishment (with legacy) structural stage directly to the mature, or structurally complex structural stages. Legacy structures (downed wood and snags) are key habitat features in enabling forest floor species to maintain a presence in a stand when regeneration harvests occur.

Under all alternatives, trends in each physiographic province would resemble those displayed in Figure 4-138 (Forest floor habitat quality summary for each alternative). The model assumes that forest floor associates persist through harvest activities or recolonize from adjacent habitats, either Riparian Management Areas or upland areas. Based on the results of this modeling, at least $50 \%$ of the forest floor habitat would persist in habitat quality category 4 or 5 under all alternatives. Therefore, forest floor associated species would persist on BLM-administered lands under all alternatives, including the PRMP. 
This analysis examines the effects of management actions on peak water flow and water quality in terms of water temperature and fine sediment.

\begin{abstract}
Key Points
- In the rain-dominated hydroregion, the PRMP would have the highest number of subwatersheds susceptible to peak flow increases, and the No Action Alternative would have the fewest. However, the susceptibility to peak flows under all alternatives would be more similar to the effects of the No Harvest reference analysis than to the effects of the Intensive Management on the Most Commercial Timber Lands reference analysis.

- In the rain-on-snow hydroregion, only three subwatersheds would be susceptible to peak flow increases in most time periods, which would be the same as under the No Harvest reference analysis.

- None of the alternatives would affect stream temperature, because effective shade under all alternatives would be near potential natural shade. Under the No Action Alternative, Alternative 1, and the PRMP, the risk of natural tree mortality from blowdown that could affect stream shading would be lower than under Alternatives 2 and 3.
\end{abstract}

- New road construction over the next 10 years under all alternatives would increase sediment delivery from roads less than $1 \%$ above current levels. .

- Sediment inputs to streams from harvest-related landslides over time under all alternatives would be substantially similar to the amount that would occur under the No Harvest reference analysis.

This analysis makes frequent comparisons of the effects on peak flows and water quality under the alternatives to the effects under the No Harvest and Intensive Management on the Most Commercial Timber Lands reference analyses. As explained in the Introduction to Chapter 4, the reference analyses are not reasonable alternatives, because they would not meet the purpose and need for the action. The reference analyses provide points of comparison for the effects of the alternatives. Specifically in this analysis, the No Harvest reference analysis helps clarify which effects on the susceptibility to peak flow increases and the sediment from mass wasting would be the result of BLM actions, and which would be the result of natural processes or the actions of others. The Intensive Management reference analysis helps provide context for evaluating the magnitude of differences among the alternatives in susceptibility to peak flow increase over time.

As explained in Chapter 3 (Forest Structure and Spatial Pattern), the classification of 2006 structural stage conditions differ slightly among the alternatives because of differences in how the inventory information is assembled for modeling under each alternative. The differences in the assembly of inventory information have a lesser effect on 2016 modeling results, and a negligible effect on modeling results for later years. Consistent with the descriptions of current conditions in Chapter 3 (in Forest Structure and Spatial Pattern), this analysis uses the 2006 data from Alternative 3 for all alternatives. Therefore, the effects on peak flows and water quality in 2016 cannot be precisely compared to the 2006 data for some alternatives, for the sake of providing a consistent description of current conditions.

\title{
Peak Water Flow
}

This analysis evaluates the effect of timber harvest on increases to peak flows. Timber harvest would have the dominant influence on peak flow susceptibility from BLM actions, and can be addressed at this scale of analysis. This analysis evaluates the amount of timber harvest on all ownerships in sixth-field subwatersheds for each alternative at time periods of $10,20,50$, and 100 years. The results of this analysis do not identify specific increases in peak flows that would depend on the timing and magnitude of 
future storms (which cannot be predicted) and site-specific conditions (which cannot be addressed at this scale of analysis). Instead, the results of this analysis describe susceptibility to peak flow increases at the subwatershed scale as a result of timber harvest.

Roads that extend the stream network can also influence the advances in the timing of water runoff or increases in peak flow (Wemple 1994, Jones and Grant 1996, and Grant et al. 2008). However, the effect of road construction on peak flow susceptibility is not included in this analysis, because new road construction under all of the alternatives would extend the stream network by less than 0.006 mile/mile of stream of the BLM's stream miles within the sediment delivery buffer along riparian areas. Analysis at this scale is not sufficiently sensitive to detect differences in changes in timing of peak flows that would result from this slight increase in the stream network.

In the rain-dominated hydroregion, timber harvesting influences peak flows only where a large proportion of the timber has been harvested within a short period of time in a watershed. The magnitude of the effect is scaled by the type of harvesting (thinning or regeneration harvesting) and the amount and distribution of harvesting at the stand level. It is also important to consider the treatment area in relation to watershed, scale, basin physical characteristics, and prior forest management history. After a harvested stand has reestablished a substantial basal area, the area is considered hydrologically recovered. This usually occurs by the time a regenerated stand of timber is about 10 to 30 years in age (Miller and Burnett 2007, Stednick 1991). The stand establishment structural stage forest class is therefore used as a surrogate for open conditions where the majority of the basal area has been removed through timber harvesting.

Acres of stand establishment forests are shown in Table 4-85 (Projected acres of stand establishment forests on BLM-administered lands).

Grant et al. (2008) showed that for the rain-dominated hydroregion, 45\% of an area harvested was the mean of the data when detectable peak flow effects appear in drainage areas with roads (see Chapter 3-Water). If this means that response level is used as a screen to determine peak flow susceptibility in the rain-dominated hydroregion, only two subwatersheds with BLM-administered lands would be susceptible under any alternative and any time period to a peak flow increase: Cooper Creek and Elk Creek-Flat Creek. Cooper Creek subwatershed on the Roseburg District is susceptible primarily because of the openness of the vegetation community type (oak savannah). Elk Creek-Flat Creek on the Medford District east of Brookings, Oregon, is currently susceptible because of the 2002 Biscuit fire, which burned approximately, 500,000 acres.

Based on experimental studies at the catchment scale, Grant et al. (2008) indicate that when 29\% of an area is harvested in the rain-dominated hydroregion, detectable effects on peak flows in watersheds with roads begin to appear (see the Water section in Chapter 3). If this minimally detectable response level is used as a screen to determine peak flow susceptibility (instead of the mean response level used above), up to 12 subwatersheds with BLM-administered lands would be susceptible under any alternative in the

Table 4-85. Projected Acres Of Stand Establishment Forests On BLM-Administered Lands

\begin{tabular}{l|r|r|r|r|r|r|r|r|r|r}
\hline \multirow{2}{*}{ Alternatives } & \multicolumn{9}{|c|}{ Stand Establishment Forests on BLM-Administered Lands } \\
\cline { 2 - 10 } & \multicolumn{2}{|c|}{2006} & \multicolumn{2}{|c|}{2016} & \multicolumn{2}{|c|}{2026} & \multicolumn{2}{|c|}{2056} & \multicolumn{2}{|c}{2106} \\
\cline { 2 - 10 } & acres & $\%$ & acres & $\%$ & acres & $\%$ & acres & $\%$ & acres & $\%$ \\
\hline PRMP & 155,000 & 7 & 229,000 & 10 & 259,000 & 12 & 296,000 & 13 & 214,000 & 10 \\
\hline Alternative 1 & 155,000 & 7 & 161,000 & 7 & 213,000 & 10 & 305,000 & 14 & 228,000 & 10 \\
\hline Alternative 2 & 155,000 & 7 & 213,000 & 10 & 295,000 & 13 & 431,000 & 20 & 319,000 & 15 \\
\hline Alternative 3 & 155,000 & 7 & 195,000 & 9 & 274,000 & 12 & 417,000 & 19 & 450,000 & 20 \\
\hline No Action Alternative & 155,000 & 7 & 140,000 & 6 & 159,000 & 7 & 198,000 & 9 & 173,000 & 8 \\
\hline
\end{tabular}

aStand establishment acres are shown as a percent of BLM-administered lands, based on a gross forested area 2,197,000 acres. 
rain-dominated hydroregion. ${ }^{13}$ The number of susceptible subwatersheds at the $29 \%$ response level would vary among alternatives and over time. The effects of timber harvesting on peak flows in rain-dominated subwatersheds are shown in Figure 4-139 (Susceptible rain-dominated subwatersheds) and in Table 4-86 (Rain-dominated sixth-field subwatersheds susceptible to increases in peak flows under the alternatives).

Figure 4-139. Susceptible Rain-Dominated Subwatersheds

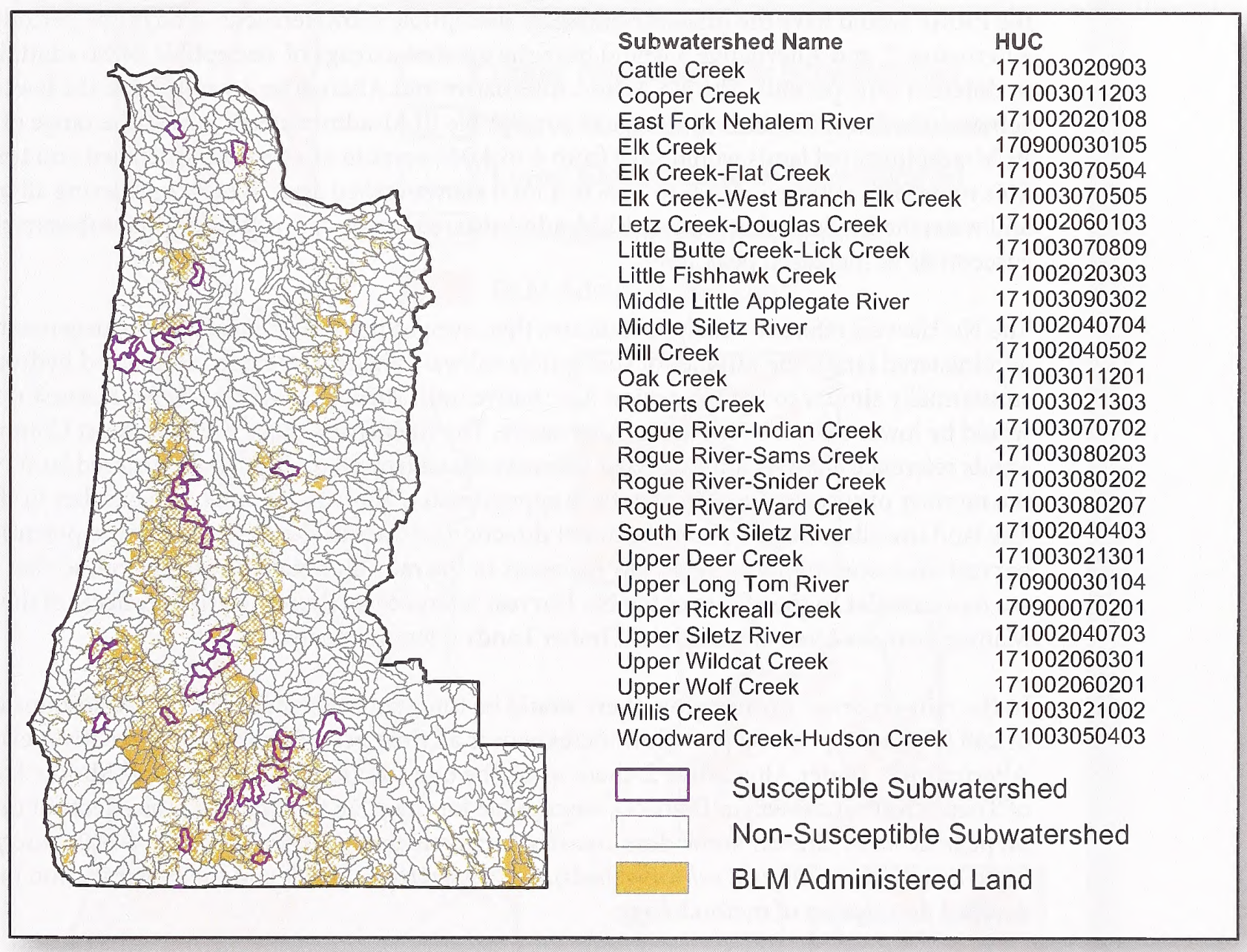

Table 4-86. Rain-Dominated Sixth-Field Subwatersheds Susceptible To Peak Flows Under The Alternatives

\begin{tabular}{lrrrrr}
\hline Alternative & $\begin{array}{r}\text { Range of BLM } \\
\text { Susceptible } \\
\text { Subwatersheds (all } \\
\text { time periods) }\end{array}$ & $\begin{array}{r}\text { Total BLM Susceptible } \\
\text { Subwatersheds, (all } \\
\text { time periods) }\end{array}$ & $\begin{array}{r}\text { Maximum Susceptible } \\
\text { BLM Acres }\end{array}$ & $\begin{array}{r}\text { Year That Maximum } \\
\text { Susceptible BLM Acres } \\
\text { is Reached }\end{array}$ & $\begin{array}{r}\text { Range of BLM } \\
\text { Susceptible Acres } \\
\text { (\% of total }\end{array}$ \\
\hline PRMP & 9 to 12 & 18 & 12,000 & 2016 & 1.8 to 6.6 \\
\hline Alternative 1 & 7 to 8 & 11 & 4,000 & 2016,2026 & 0.5 to 2.6 \\
\hline Alternative 2 & 7 to 10 & 15 & 11,000 & 2026 & 1.3 to 5.3 \\
\hline Alternative 3 & 6 to 12 & 16 & 12,000 & 2106 & 1.7 to 5.0 \\
\hline No Action & 5 to 8 & 9 & 4,000 & 2016 & 1.5 to 4.0 \\
\hline No Harvest & 1 to 7 & 9 & 4,000 & 2016,2026 & 0.5 to 2.7 \\
\hline Intensive & 30 to 95 & 110 & 163,000 & 2056 & 3.5 to 9.0 \\
\hline Management & & & & \\
\hline
\end{tabular}

${ }^{a}$ Year is based on the level and distribution of forest harvest.

${ }^{13}$ This analysis assumes that most non-BLM-administered lands would maintain their current amount of equivalent clearcut area (see Chapter 4 section on Forest Structure and Spatial Pattern). Future changes in the amount of equivalent clearcut area on non-BLM-administered lands and effects on peak flow susceptibility would be considered during the planning of implementation-level actions. 
Table 4-86 shows the range of susceptible subwatersheds under the alternatives equaling and exceeding $29 \%$ equivalent clearcut area, which is the minimally detectable peak flow response level. A total of 27 out of 634 rain-dominated subwatersheds (4\%) in the planning area with BLM-administered lands would be susceptible at time periods of $10,20,50$, and 100 years. However, susceptibility varies with the pattern and intensity of timber harvest in subwatersheds over time, meaning that subwatersheds may be susceptible in some time periods, but not in other time periods. When compared to the other action alternatives, the PRMP would have the highest number of susceptible subwatersheds in any time period; the PRMP, Alternative 2, and Alternative 3 would have the greatest acreage of susceptible BLM-administered lands, but in different time periods. The No Action Alternative and Alternative 1 would have the fewest susceptible subwatersheds and the lowest acreage of susceptible BLM-administered lands. The range of affected BLM-administered lands would vary from 4 to 4,021 acres in any one subwatershed and time period. This represents between $<0.1 \%$ to $16 \%$ of a total subwatershed area. When considering all ownerships and watersheds where there are no BLM-administered lands, up to 20 additional subwatersheds would be susceptible to increased peak flows.

The No Harvest reference analysis indicates that, even in the absence of active management on BLMadministered lands, the number of susceptible subwatersheds in the rain-dominated hydroregion would be substantially similar to the No Action Alternative until 2056, after which the No Harvest reference analysis would be lower than the No Action Alternative. The Intensive Management on Most Commercial Timber Lands reference analysis indicates that intensive management on BLM-administered lands would increase the number of susceptible subwatersheds approximately three to ten times the number in the alternatives. The land use allocations and management direction under the alternatives limit the potential effect of timber harvest on susceptibility to peak flow increases in the rain-dominated hydroregion, so that the alternatives are more similar to the effects of the No Harvest reference analysis than to the effects of the Intensive Management on Most Commercial Timber Lands reference analysis.

In the rain-on-snow hydroregion, there would be three subwatersheds with BLM-administered lands out of $248(1 \%)$ susceptible to peak flow increase over all time periods under all alternatives except under Alternative 2. Under Alternative 2, there would be one additional subwatershed (Middle Fork of North Fork of Trask River on the Salem District), susceptible for the 2056 time period. The effects of timber harvesting on peak flows in rain-on-snow-dominated subwatersheds are shown in Figure 4-140 (Susceptible rain-onsnow-dominated sixth-field subwatersheds). See Appendix I - Water and the Water section in Chapter 3 for a detailed description of methodology.

The No Harvest reference analysis indicates that, even in the absence of active management on BLMadministered lands, the number of susceptible subwatersheds in the rain-on-snow hydroregion would be the same as under all alternatives except Alternative 2. The Intensive Management on Most Commercial Timber Lands reference analysis indicates that intensive management on BLM-administered lands would result in one subwatershed more than the No Harvest reference analysis that would be susceptible in the 2026 and 2056 time periods.

Variations of climate can affect the melting of snow as stored water and peakflows during runoff events in the rain-on-snow hydroregion. To evaluate the sensitivity of these results to climate variations, the analysis also analyzed peak flow susceptibility using daily average air temperatures and wind speeds that are exceeded less than $2 \%$ of the time, instead of the average conditions used above (i.e., exceeded $50 \%$ of the time). Under these extreme conditions, 4 to 10 subwatersheds out of 248 (up to 4\%) with BLMadministered lands would be susceptible to peak flow increases. This involves approximately 78,000 acres (3\%) of BLM-administered lands within the planning area. There would be more affected subwatersheds under Alternatives 1,2 and the PRMP during the 2026 and 2056 and 2106 time periods using these extreme climate conditions: there would be no difference under the No Action Alternative and Alternative 3. Green tree retention under the No Action and Alternative 3 in regeneration harvest units and partial 
Figure 4-1 40. Susceptible Rain-On-Snow-Dominated Sixth-Field SUBWATERSHEDS

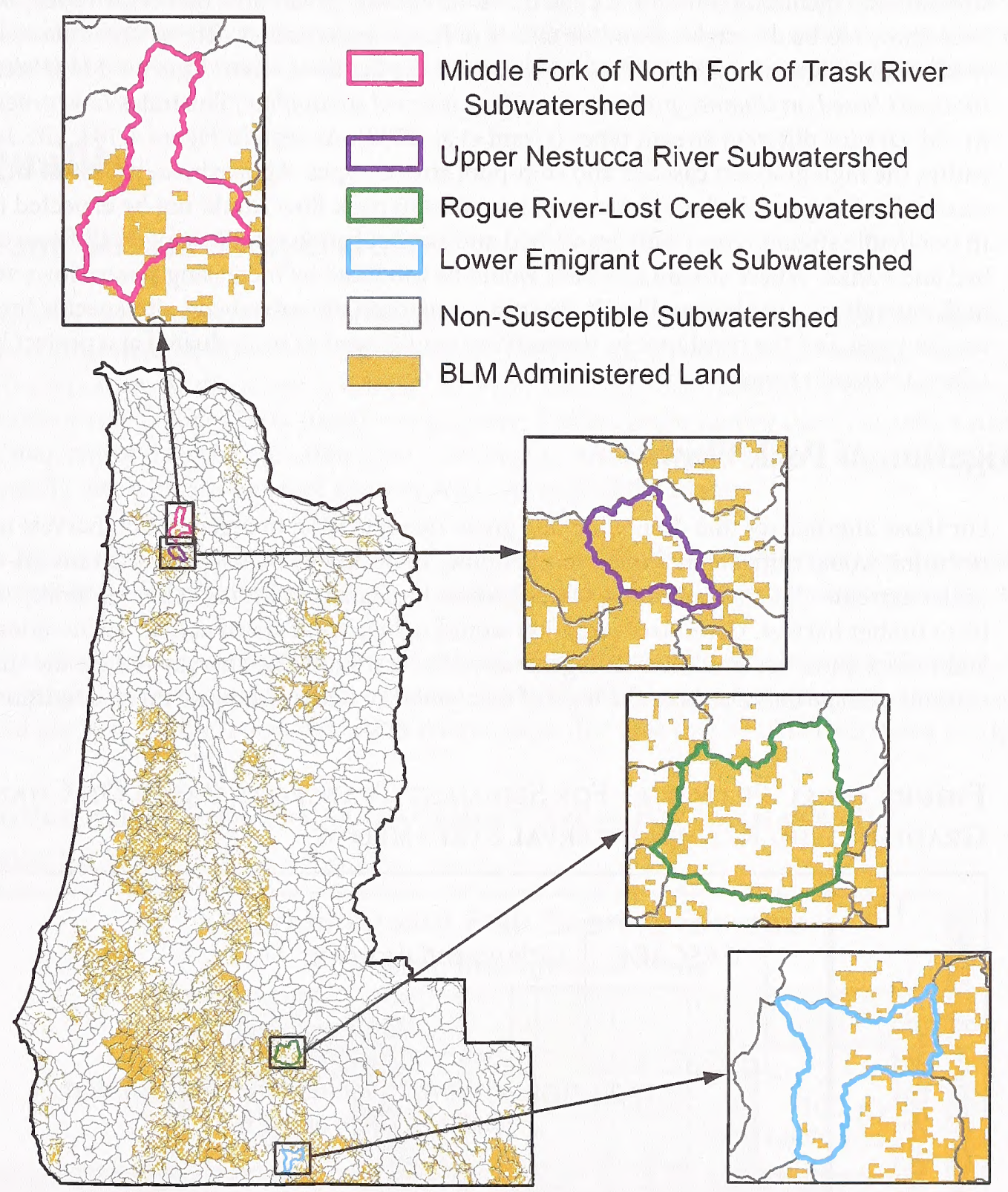

(Note: Peak flow susceptibility for sixth-field watersheds is where the 2-year, 24-hour bankfull channel forming peak flow is greater than the 5-year, 24-hour peak flow. Includes the current rate of harvesting on private land from the 1996 IVMP satellite imagery, applied to all time periods.)

harvesting under Alternative 3 would lessen the effect of increased wind speeds in the mechanics of rapid melt of shallow snowpacks, resulting in little difference in peak flow susceptibility under extreme climate conditions.

In the rain-on-snow hydroregion, variations in climate conditions would have more effect on susceptibility to peak flow increases than timber harvest. The similarity in peak flow susceptibility under the two reference analyses demonstrates that timber harvest on BLM-administered lands would not have any substantial effects on peak flow susceptibility in the rain-on-snow hydroregion that can be detected at this scale of analysis. 
The results of this analysis that show some subwatersheds would be susceptible to increases in peak flows under the alternatives do not automatically imply adverse effects on stream form. This is because streamflow runoff normally fluctuates with climate, and channels have developed over time under a wide range of streamflows, including infrequent peak flows. Moreover, streamflow that return every one to six years have been shown to be detectable from the effects of forest management. These streamflows have the potential to affect the frequency of sediment transport and the depth of scour. Figure 4-141 (Potential for sediment transport based on channel gradient and return interval streamflow) illustrates how potential peak flow effects would vary for different stream types (Grant et al. 2008). As seen in Figure 4-141, effects are not expected within the high gradient cascade and step-pool stream types. Approximately $80 \%$ of BLM streams are cascade and step-pool where short-term increases in peak flow would not be expected to cause changes. In pool/riffle stream types, with gravel-bed and sand substrates, increasing peak flows can rearrange the bed and banks. Where stream channels would be modified by increasing stream lows and stream energies high enough to cause bed and bank shear in susceptible subwatersheds, site-specific information regarding stream types and the resistance to streamflows would need to be evaluated at a project level to describe effects to stream form.

\section{Mitigation of Peak Flows}

For those alternatives that do not include green tree retention in regeneration harvest units, green tree retention would mitigate increased susceptibility to peak flow increases in the rain-on-snow hydroregion under extreme climate conditions, where project level analysis indicates susceptibility to peak flow increases from timber harvest. Green tree retention would reduce wind speed across regeneration harvest units and reduce snow accumulation in regeneration harvest units and thereby reduce the susceptibility under extreme climate conditions to the level of susceptibility under average climate conditions.

Figure 4-141 Potential For Sediment Transport, Based On Channel Gradient And Return Interval Streamflow

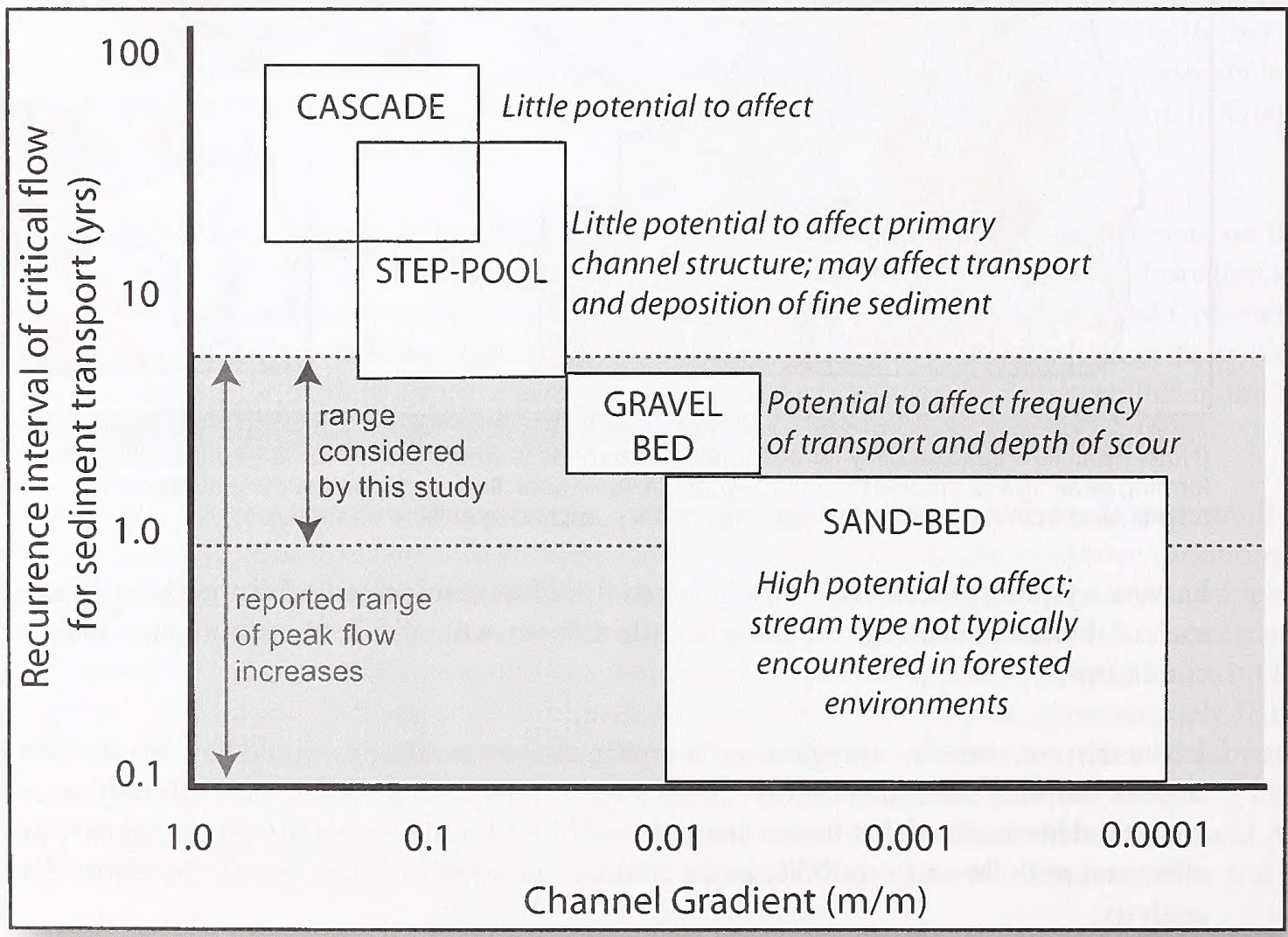

From Grant et al. 2008, used by permission 
Other potential mitigation measures, such as altering the arrangement, distribution, timing, and patch size of regeneration harvest units within susceptible subwatersheds, cannot be evaluated at this scale of analysis. Whether adverse effects from peak flow increases would occur in any given sub-watershed from implementation-level actions and whether adverse effects could be lessened or avoided by such potential mitigation measures would depend on sub-watershed-specific conditions at the time of project implementation and would need to be considered in planning and design of implementation-level actions.

\section{Water Quality}

\section{Shade and Stream Temperature}

This analysis evaluates the effect of management activities on stream temperature by assessing the shading of perennial streams that would develop under the land use allocations and management direction of each alternative. As discussed in Chapter 3 (Water section), solar radiation is the most important source of radiant energy that affects stream temperature, and the forest canopy that is nearest a stream blocks the majority of the solar radiation from reaching the stream. Eighty percent effective shade or greater is normally met within a 100 -foot distance from the edge of the stream.

See Figure 4-142 (Riparian Management Areas for permanently flowing streams) for the width of the riparian reserves or the Riparian Management Areas along permanently flowing streams under the alternatives.

Under all alternatives, allocation of, and management direction for, the Riparian Management Areas (or riparian reserves) would result in the retention of sufficient shade during the summer months to avoid any measurable increase in water temperature. The area that would be allocated to Riparian

Figure 4-142. Riparian Management Areas For Permanently FLOWING STREAMS

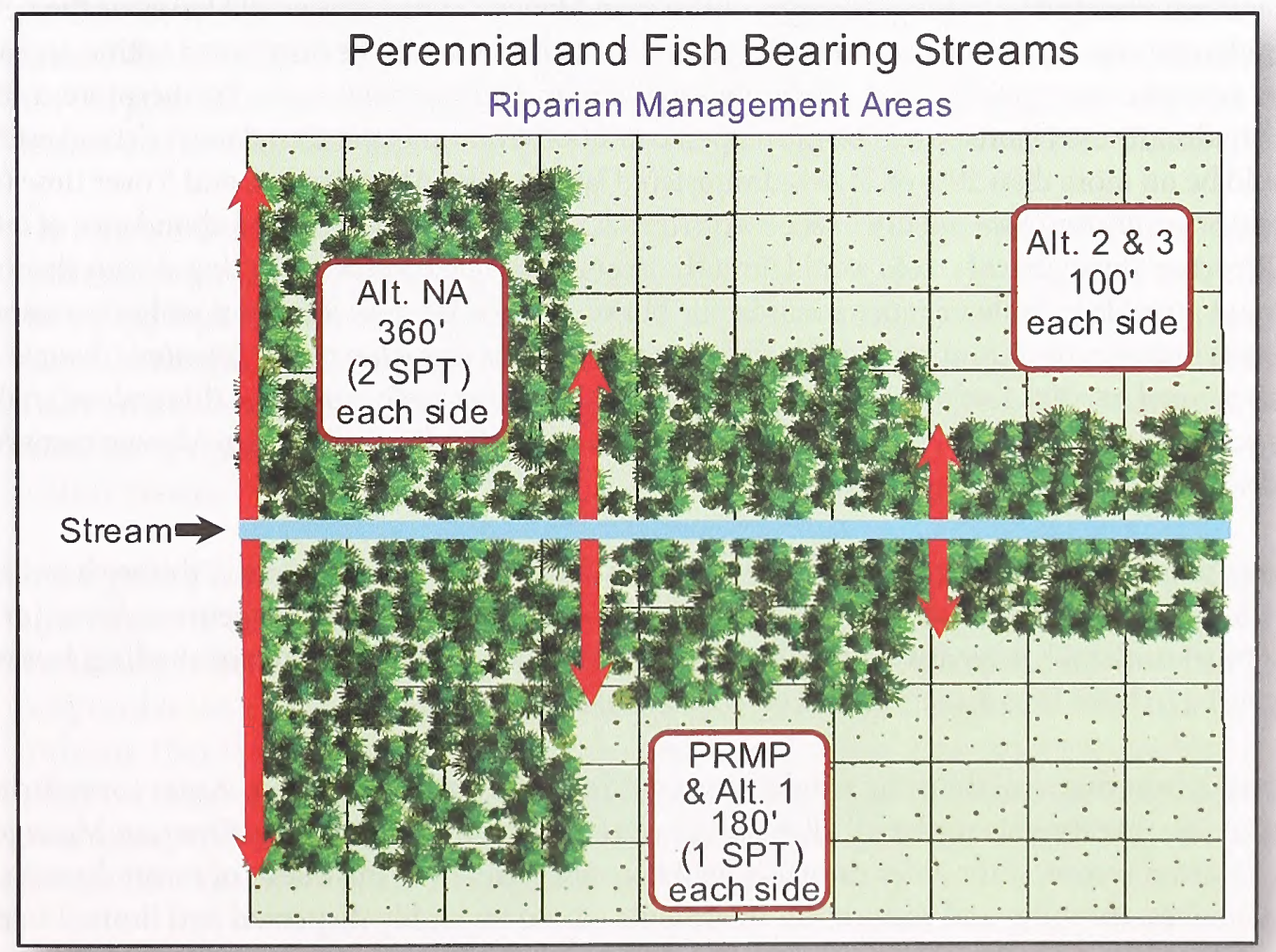

Note: SPT (site-potential tree) example shown for mid-range of conifer forest site productivity (site class III) 
Management Areas (or riparian reserves) along perennial streams has already attained a forest structural condition that provides a high complement of shade: currently, $54 \%$ is mature or structurally complex, and less than $5 \%$ is stand establishment forest. Shade quality would further improve with time under all alternatives as stand establishment and young forests would decline in abundance, and mature and structurally forests would increase. Furthermore, under all alternatives, management direction for the Riparian Management Areas (or riparian reserves) would maintain the primary and secondary shade zones, and management direction would result in $80 \%$ effective shade or potential natural shade, whichever is less (see Chapter 3 - Water for definitions of the primary and secondary shade zones, and discussion of effective shade).

Under the No Action Alternative, Alternative 1, and the PRMP, the Riparian Management Area (or riparian reserve) width would extend beyond the primary and secondary shade zones. This additional width of Riparian Management Areas (or riparian reserves) would provide less than $5 \%$ increase in effective shade beyond the shading provided within 100 feet of streams. However, this additional width would provide a buffer against natural tree mortality from blowdown that could affect stream shading. Blowdown can occur anywhere in a Riparian Management Area or (riparian reserve), but may be more prevalent at the edge of the Riparian Management Area (or riparian reserve), particularly where high contrast edges exist between stand types (e.g., between mature forest and stand establishment forest). Steinblums et al. (1984) found that a riparian buffer of at least 120 feet from streams would maintain stream shading even where blowdown occurs. This is because the trees most likely to blow down would be outside the primary and secondary shade zones and would buffer the trees in the primary and secondary shade zones from the effects of wind. Under the No Action Alternative, Alternative 1, and the PRMP, the Riparian Management Area (or riparian reserve) width would extend beyond 120 feet from streams and, therefore, would maintain stream shading even where blowdown occurs.

Under Alternatives 2 and 3, the Riparian Management Area would not extend beyond the primary and secondary shade zones. Therefore, the Riparian Management Areas under Alternatives 2 and 3 would not provide a buffer against natural tree mortality from blowdown that could affect stream shading. The blowdown risk within Riparian Management Areas would increase where recent regeneration harvests would border Riparian Management Areas, creating an open area for wind acceleration and forest edges that face prevailing winds. Blowdown susceptibility along the edges of Riparian Management Areas would lessen as the new forest grows in the adjacent regeneration harvest area. Regeneration harvests would be distributed within and among watersheds over a range of topographies and proximities to Riparian Management Areas. Furthermore, a small portion of the BLM-administered lands would be in an open condition over time: the abundance of stand establishment forest would be no more than $20 \%$ of BLM-administered lands under Alternatives 2 and 3 over time (see Chapter 4 Forest Structure and Spatial Pattern section). The dispersed pattern and limited abundance of open areas adjacent to Riparian Management Areas would limit the overall risk of blowdown affecting stream shading. Nevertheless, it is not possible to evaluate more precisely the blowdown risk because it is not possible to reasonably foresee the specific location, timing, or magnitude of future windstorms (see Chapter 4 - Potential Changes in Conditions Not Incorporated into the Analysis section). Also, there is insufficient information at this scale of analysis to evaluate the combined effects from the design of regeneration harvests adjacent Riparian Management Areas, topography and soils, and vegetation type and age.

Along perennial streams, tree falling for road construction and maintenance, timber harvest and restoration would occur within varying areas (described below) of the Riparian Management Areas (or riparian reserves) under all alternatives. These activities could alter reach level stream shading, but would have little potential to have broad-scale effects on stream shading.

Under all alternatives, thinning would occur within Riparian Management Areas (or riparian reserves). Restoration treatments under all alternatives would include felling trees in Riparian Management Areas (or riparian reserves) for alder or brush field conversions, or for treatment of forest diseases. Under all alternatives, thinning and restoration treatments would be highly dispersed and limited in extent because of the highly localized and limited conditions to which the treatments would be responding (see Chapter 3 - Water and Fish sections), and, therefore, would have little potential for broad-scale effects on stream 
shading. In addition, management direction under some alternatives would preclude broad-scale effects on stream shading:

- Under the No Action Alternative, thinning and restoration treatments would be designed to attain Aquatic Conservation Strategy objectives, which include maintaining and restoring water quality.

- Under Alternatives 2 and 3, thinning would be excluded within 25 feet of streams; thinning would maintain at least $80 \%$ effective or site-potential shade in the primary shade zone; and thinning would maintain at least $50 \%$ of the forest canopy cover after harvesting in the secondary shade zone.

- Under the PRMP, thinning would be excluded from the primary shade zone, and thinning would maintain at least $50 \%$ of the forest canopy cover after harvesting in the secondary shade zone.

Site-specific and highly localized effects on stream shading from thinning or restoration treatments would depend on site-specific stream and riparian conditions and the specific design of thinning or restoration treatments, which cannot be analyzed more precisely at this scale of analysis. Site-specific effects of thinning or restoration treatments on stream shading would be considered during the planning of implementationlevel actions.

Tree felling or timber harvest for safety or operational reasons, such as danger tree removal, creation of yarding corridors adjacent to nearby harvest units, and road construction and improvement, would occur within Riparian Management Areas (or riparian reserves) under all alternatives. Such actions would be highly dispersed, limited in extent, and highly localized in their effects. Site-specific and highly localized effects on stream shading from tree falling or timber harvest for safety or operational reasons would depend on site-specific stream and riparian conditions and the specific design of tree falling or timber harvest, which cannot be analyzed more precisely at this scale of analysis. Site-specific effects of tree falling or timber harvest on stream shading would be considered during the planning of implementation-level actions.

Salvage harvest following natural disturbance within the Riparian Management Areas (or riparian reserves) would occur under all alternatives, but would not alter stream shading. Salvage harvest would cut trees that are dead or dying, and therefore the shading of these trees would have already been lost as a result of the natural disturbance. It is not possible to estimate the loss of stream shading from natural disturbance, because it is not possible to reasonably foresee the specific location, timing, or magnitude of future disturbances (see the section on Potential Changes in Conditions Not Incorporated into the Analysis in Chapter 4).

See Figure 4-143 (Structural stage classes of the riparian reserves under the No Action Alternative) for the distribution of acres by structural stage class within the riparian reserves. The preponderance of acres within the young high-density and mature forest structural stage classes indicates that the riparian areas currently have tree heights and crown areas that would provide effective shading. See the Water section in Chapter 3. There would be a gradual decline of the small percentage of stand establishment acres over time and would result in riparian forest structure that would improve shade quality as more acres move into the young and mature classes.

See Figure 4-144 (Structural stage classes of the Riparian Management Areas under Alternative 1) and Figure 4-145 (Structural stage classes of the Riparian Management Areas under the PRMP) for the distribution of acres by structural stage class within the Riparian Management Areas. The preponderance of acres within the young high-density and mature forest structural stage classes indicate that the riparian areas already have tree heights and crown areas that would provide effective shading. There would be a gradual decline in the amount of stand establishment acres over time, which would result in riparian forest structure that would improve shade quality as more acres move into the young and mature classes. 
Figure 4-143. Structural Stage Classes Of The Riparian Reserves Under The No Action Alternative

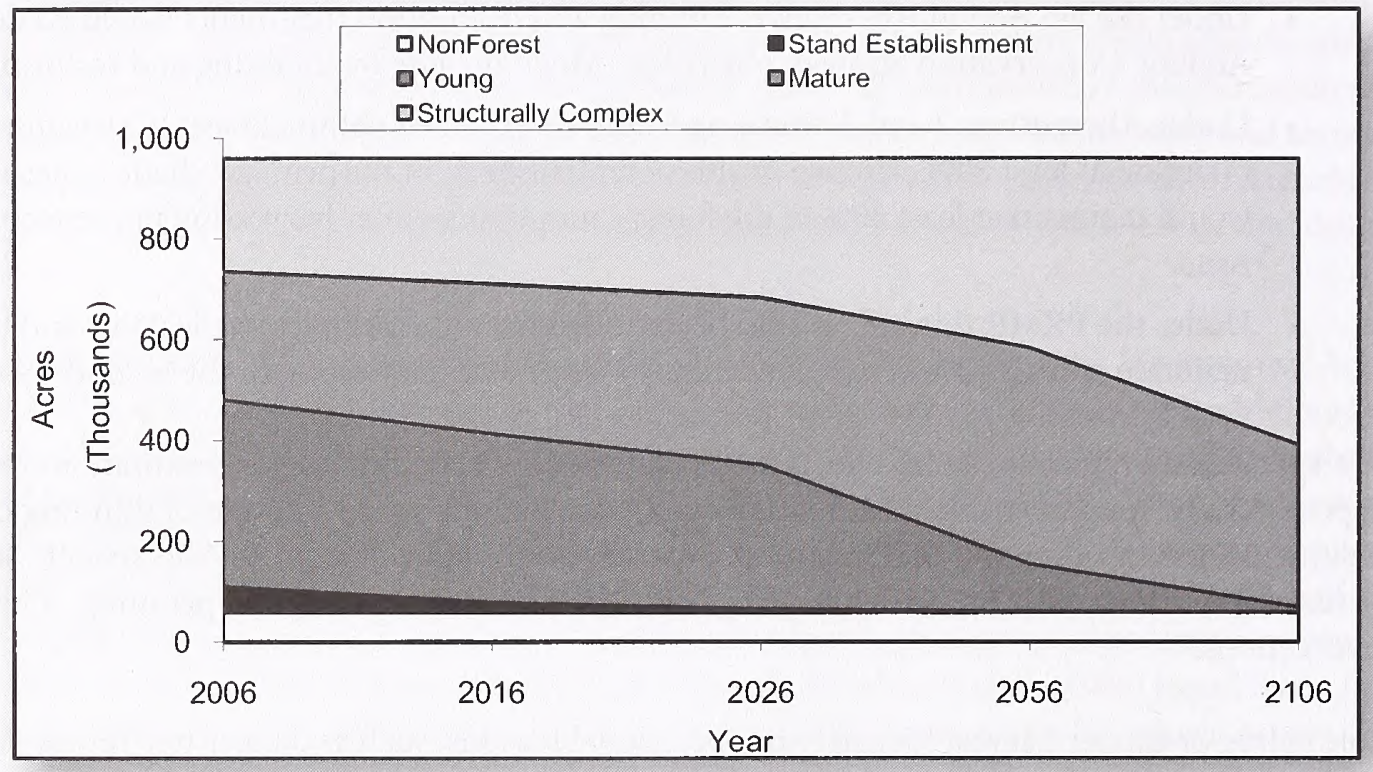

See Figure 4-146 (Structural stage classes of the Riparian Management Areas under Alternatives 2 and Figure 4-144. Structural Stage Classes Of The Riparian Management Areas Under Alternative 1

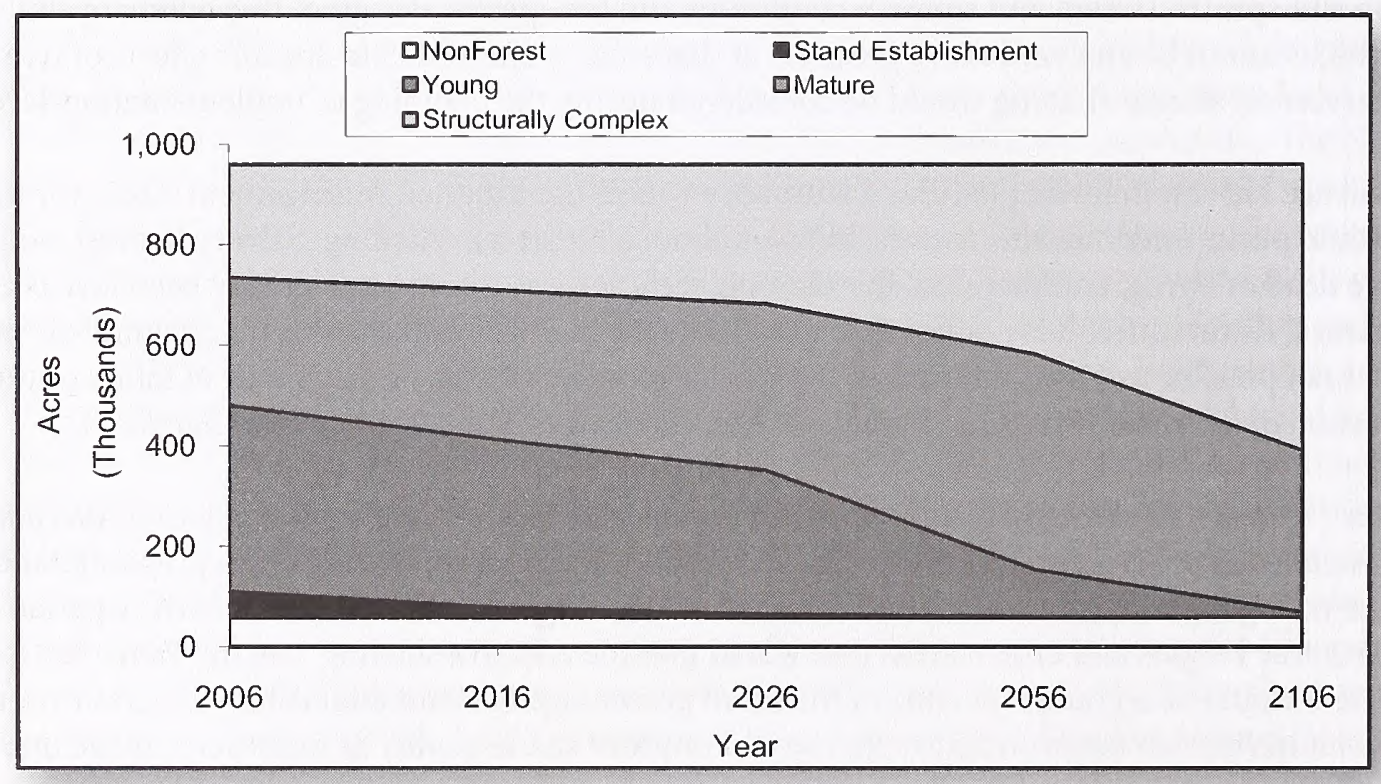

3) for the distribution of acres by structural stage class within the Riparian Management Areas. The preponderance of acres within the young stage which are high-density and mature forest structural stage classes indicate that the riparian areas already have tree heights and crown areas that would provide effective shading. There would be a gradual decline of the small percentage of stand establishment acres over time, which would result in riparian forest structure that would improve shade quality as more acres move into the young and mature classes.

The conclusions above regarding effective shade levels and effect on stream temperature do not include the management area adjacent to the Coquille Forest under Alternatives 2 and 3, where there would be an increase in stream temperatures following timber harvest. There are 31 miles of perennial streams on BLMadministered lands adjacent to the Coquille Forest, which include scattered land parcels totaling 10 miles 
Figure 4-145. Structural Stage Classes Of The Riparian Management Areas Under The PrmP

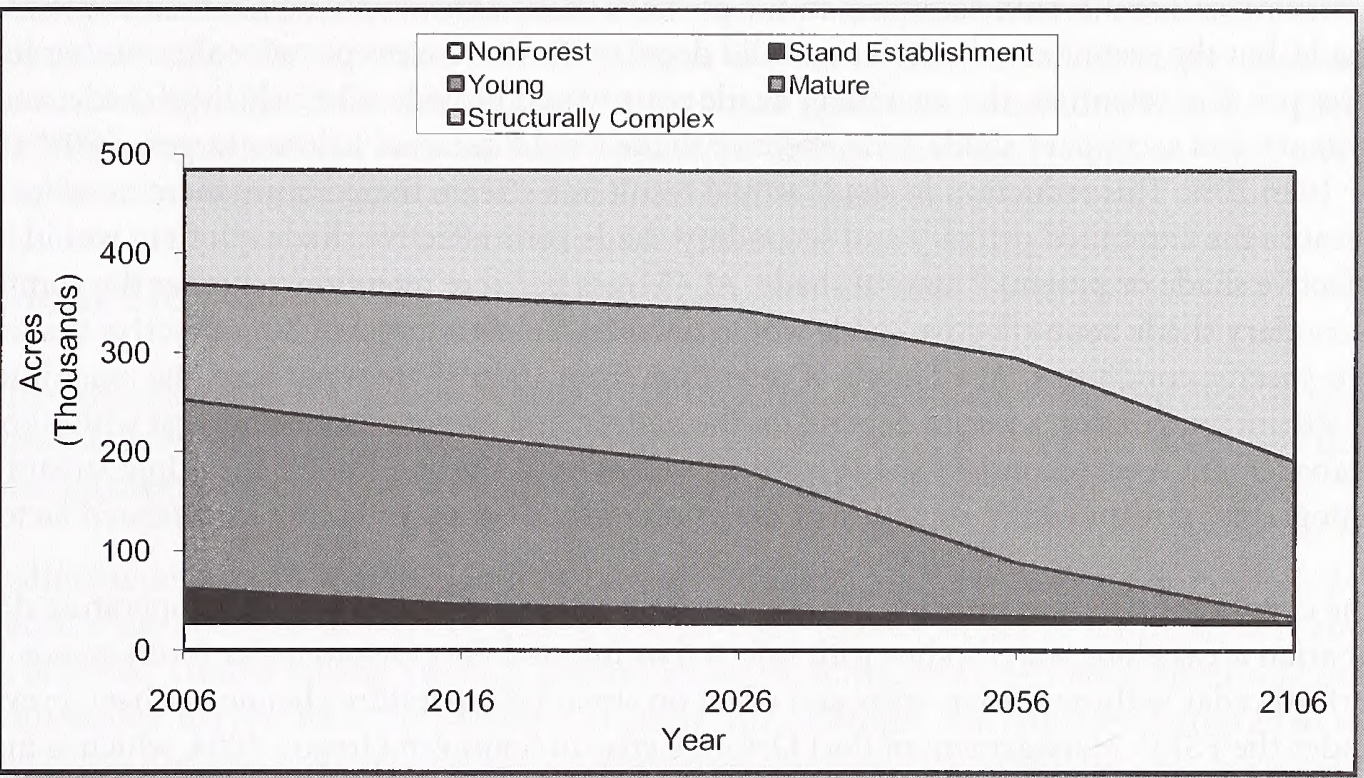

Figure 4-146. Structural Stage Classes Of The Riparian Management Areas Under Alternatives 2 And 3

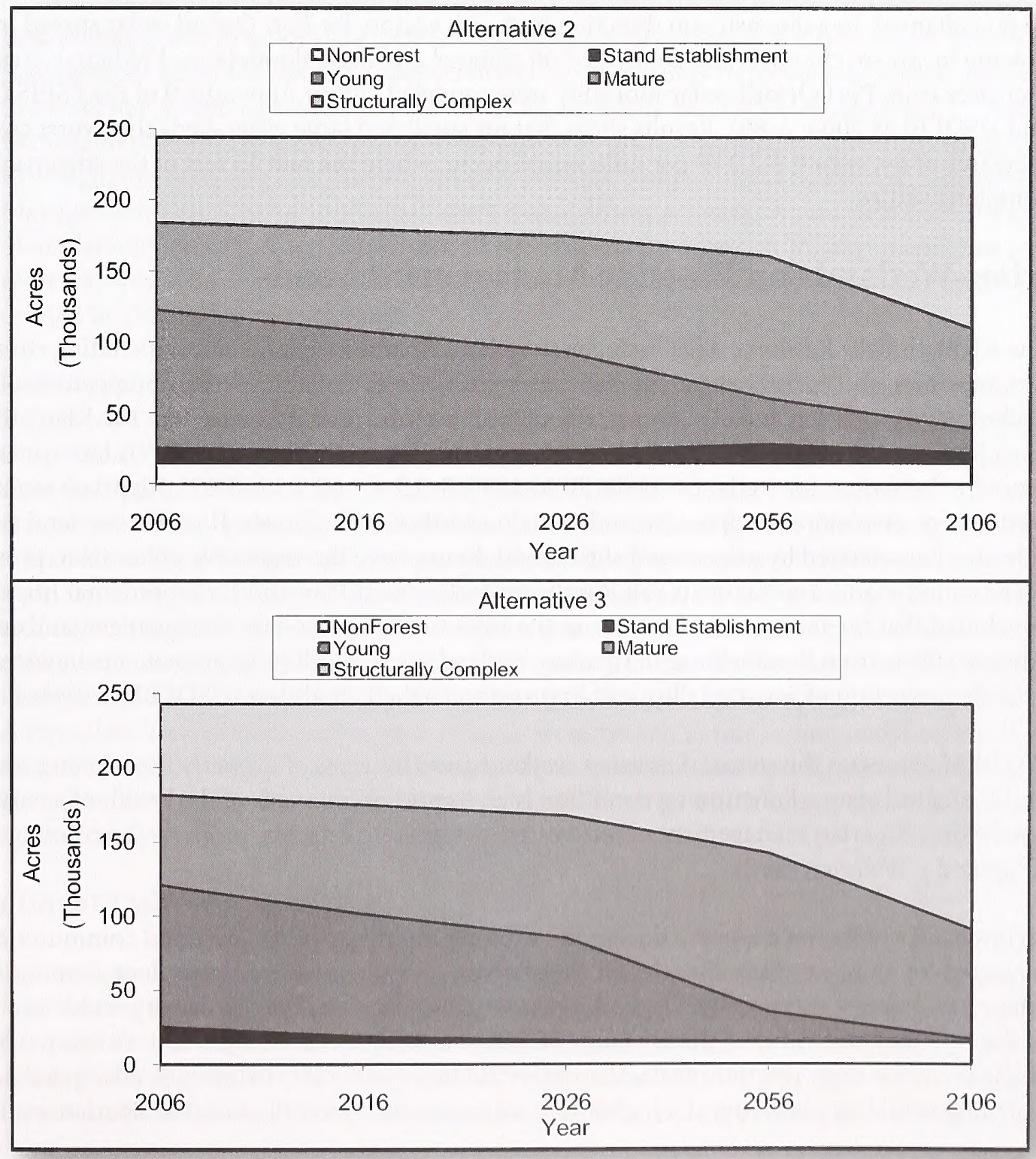


within the East Fork Coquille watershed and 20 miles within the Middle Fork Coquille Watershed. Under Alternatives 2 and 3, sufficient trees in the primary shade zone would be retained to maintain $80 \%$ effective shade, but the secondary shade zone would decrease to 10-45 trees per acre after timber harvest. At 10 trees per acre retention, the secondary shade zone would provide relatively little shade, and the combined primary and secondary shade zone effective shade would decrease below a target of $80 \%$ effective shade by 10 to $20 \%$. This reduction in shade would result in a stream temperature increase of up to $1^{\circ} \mathrm{F}$ per mile, because the combined primary and secondary shade zone effective shade quotient would be below $80 \%$ effective shade or potential natural shade. At 45 trees per acre retention, whether the combined primary and secondary shade zone effective shade would decrease below a target of $80 \%$ effective shade would depend on site-specific conditions. At all levels of retention, from 10 to 45 trees per acre, the magnitude of any increase in stream temperatures would depend on the pattern and extent of forest harvest within the Riparian Management Area secondary shade zone, as well as local site conditions; including stream orientation, topography, stream width, structure of the primary shade zone and other interrelated factors.

The conclusions above regarding effective shade levels and effect on stream temperature do not include riparian areas along waterbodies with infected or infested Port Orford cedar forest stands. Mortality of Port Orford cedar within riparian areas and effect on stream temperature change has been previously analyzed under the FSEIS Management of Port Orford Cedar in Southern Oregon 2004, which is incorporated by reference. This FSEIS concluded that Port Orford cedar infestations are limited to no more than 40 feet downslope from roads, except where streams or wet areas are present to facilitate further movement (USDA USFS and USDI BLM 2004: 3\&4-76). Further, infestations of Port Orford cedar occur lineally, close to the stream channel. In a downstream direction high risk vectors for Port Orford cedar spread include water flowing in stream channels and connected off channel areas and floodplains. Predicted stream temperature increases from Port Orford cedar mortality were modeled within Appendix 9 of the FSEIS (USDA USFS and USDI BLM 2004: A-80). Results show that for small and large watersheds that worst case temperature increases of between $0.9-2.2^{\circ} \mathrm{F}$ per mile would occur, where the first 15 feet of the streamside stand is completely killed.

\section{Riparian-Wetlands on Eastside Management Lands}

The Klamath Falls Resource Area includes rangeland riparian-wetland lands, including streams, marshes, wet meadows, and spring/seep areas, but varies greatly in extent and species composition on a west-east declining precipitation and elevation gradient with increasing arid rangelands. The Klamath Falls Resource Area Resource Management Plan and Environmental Impact Statement, which is incorporated by reference, describe these riparian-wetlands (USDI BLM 1994: 3-3,3-4, and 3-11-3-37). Riparian-wetland areas on the west side receive more precipitation and contain mostly conifer forests. Riparian-wetland areas on the east side are characterized by grasses and shrubs and do not have the vegetative potential to provide for more than limited shade. The Klamath Fall Resource Management Plan and Environmental Impact Statement concluded that the management actions in the 1994 RMP for east-side management lands would reduce adverse effects from livestock use in riparian-wetland areas; result in improvements in water temperature; provide protection of water quality; and improve watershed condition (USDI BLM 1994: 4-16-4-24).

The BLM expresses the status of riparian-wetland areas in terms of properly functioning condition and ecological status. Functioning condition is an important measure of the health of riparian-wetland conditions. Riparian management objectives are designed to improve properly functioning condition (see Chapter 2 - Water section).

To limit solar radiation exposure during the summer months, riparian-wetland communities would be managed for an upward trend under all alternatives, consistent with the prevalent community type and where ecologically appropriate. Depending on vegetation species height, density, width and physical aspects of the riparian-wetland area, a wide range of effective shade levels would result. On east-side lands, effective shade levels for most riparian-wetland areas would be considerably below $80 \%$ effective shade and stream warming would be occurring at a higher rate when compared to fully forested riparian-wetland areas 
elsewhere in the planning area. However, these riparian-wetland areas would reach system potential shade, when proper functioning condition and maximum upward trend is attained for the prevalent vegetation community type. Stream state, including degree of channel incision, width, depth, streambank stability, scour and deposition of sediments, and frequency of floodplain inundation would be evaluated along with riparian vegetation, because these physical attributes are related to proper functioning condition to determine an upward trend.

\section{Sediment Delivery}

This analysis focuses on sediment delivery to stream channels from roads and from landslides, because these sources would likely yield more fine sediment than other sources; are most likely to be affected by the management actions in the alternatives; and can be addressed at this scale of analysis.

Sediment delivery to streams as a direct result of timber harvest activities is not included in this analysis, because the potential delivery of sediment from these sources would be immeasurably small at this scale of analysis. Timber falling, yarding, ground-based skidding, and other land-disturbing practices associated with timber harvest have the potential to create fine sediment that could be delivered to streams. However, the combined effect of applying Best Management Practices that would prevent or contain deliverable sediments and the Riparian Management Areas (or riparian reserves) that would prevent surface soil disturbance and intercept and filter any deliverable sediments from timber harvest activities would limit or avoid delivery of fine sediment to streams as a result of timber harvest activities under all alternatives. Best Management Practices that prevent water quality degradation address timber harvest and associated management activities would be applied under all alternatives to prevent or contain deliverable sediments to a level that would be similar to that which would occur naturally (see Appendix I - Water). Specific Best Management Practices are identified to minimize or prevent sediment delivery to streams and waterbodies to a negligible level (e.g., log suspension over streams, ground based equipment limitation zones). Best Management Practices for individual forest management activities would be specified during the planning of implementation-level actions. Under all alternatives, the Riparian Management Area (or riparian reserves) would be of sufficient width to intercept and filter all or most of any fine sediment that could be created by timber harvest activities.

Rashin et al. (2006) found that for 157 erosion features that delivered sediment to streams where forest buffers were not present and that did not utilize any Best Management Practices, that $94 \%$ of them were closer than 33 feet (slope distance) from stream channels. All alternatives include Riparian Management Area (or riparian reserves) that are greater than 33 feet wide, except for intermittent stream channels that are not debris-flow prone under Alternative 2 and intermittent stream channels under Alternative 3. Under Alternatives 2 and 3, Riparian Management Areas along these intermittent stream channels would be 25 feet wide, which is most of the distance indicated by Rashin et al. (2006) as being effective to intercept and filter sediment. It is possible that timber harvest activities under Alternatives 2 and 3 near intermittent streams could result in some fine sediment delivery to streams, but only where application of Best Management Practices would not completely prevent sediment delivery. Whether specific timber harvest activities under Alternatives 2 and 3 near intermittent streams would result in fine sediment delivery and, if so, how much fine sediment delivery, would depend on site-specific stream and riparian conditions and the specific design of timber harvest activities and Best Management Practices, which cannot be analyzed more precisely at this scale of analysis.

\section{Sediment Delivery from Roads}

This analysis is based on the use of a reference road (WA State DNR 1997) and the spatially-explicit road locations for new construction during the first decade. The road locations for new construction are derived from the 10-year scenario, in which modeled harvest units locations are mapped and BLM specialists develop road locations and harvest methods for the selected units (see Appendix E-Timber). The mapped harvest units in the ten-year scenario are a sample of the entire planning area, and road construction 
results were expanded from this sample to estimate results for the entire planning area. It is not possible to analyze the road construction in future decades, because identifying specific harvest units and road locations beyond the first decade would be too speculative to be informative. However, the mileage of road construction in future decades would generally decline from the first decade under all alternatives because as road density would increase over time, less new road construction would be required for timber harvest. Additionally, the proportion of timber harvest from thinning and the total harvest acres would decline in future decades under all alternatives (see Chapter 4 - Timber). Therefore, the sediment delivery from roads for future decades under each alternative would generally be less than the amount analyzed here for the first decade.

Roads that are within a 200-foot delivery distance to streams are the primary sites in the Pacific Northwest for mobilizing chronic fine sediment to streams as concentrated ditch flow during heavy rainfall or snowmelt (see Chapter 3 - Water section). Under all alternatives, new roads would be located inside a sediment delivery distance to a lesser extent than upslope areas, because most primary transportation routes that parallel streams within a sediment delivery distance to streams have already been constructed. Timber planning harvest and road location projections in the first decade show that intrusions into the 200 -foot sediment delivery zones and riparian areas surrounding streams would be limited to necessary stream crossings and shorter sections of road to access favorable upslope topography to forest stands where there would be no other reasonable routes. Approximately $36 \%$ of existing permanent roads on BLMadministered lands are within a 200 -foot sediment delivery distance to streams. In contrast, an average of less than $2 \%$ increase ( 97 miles) in new permanent road construction under the alternatives would be within a 200-foot sediment delivery distance to streams. Moreover, there would be an average of less than $2 \%$ increase in roads within a sediment delivery distance to streams channels among the alternatives, compared to an average $6 \%$ increase in upland areas outside a sediment delivery distance for planned permanent roads. See Figure 4-147 (Projected newly constructed permanent roads within a sediment delivery distance to streams, compared to total newly constructed permanent roads by 2016).

The incremental increase in fine sediment delivery from new road construction over the next 10 years would range from 1,567 tons/year under the No Action Alternative, to 2,811 tons/year under the PRMP. See Table 4-87 (Potential delivery of fine sediment by new roads constructed by 2016 under the alternatives) for the results for road segments that could contribute to fine sediment delivery over the next 10 years under each

\section{Figure 4-147. Projected Newly Constructed Permanent Roads Within A Sediment Delivery Distance To Streams, Compared To Total Newly Constructed Permanent Roads By 2016}

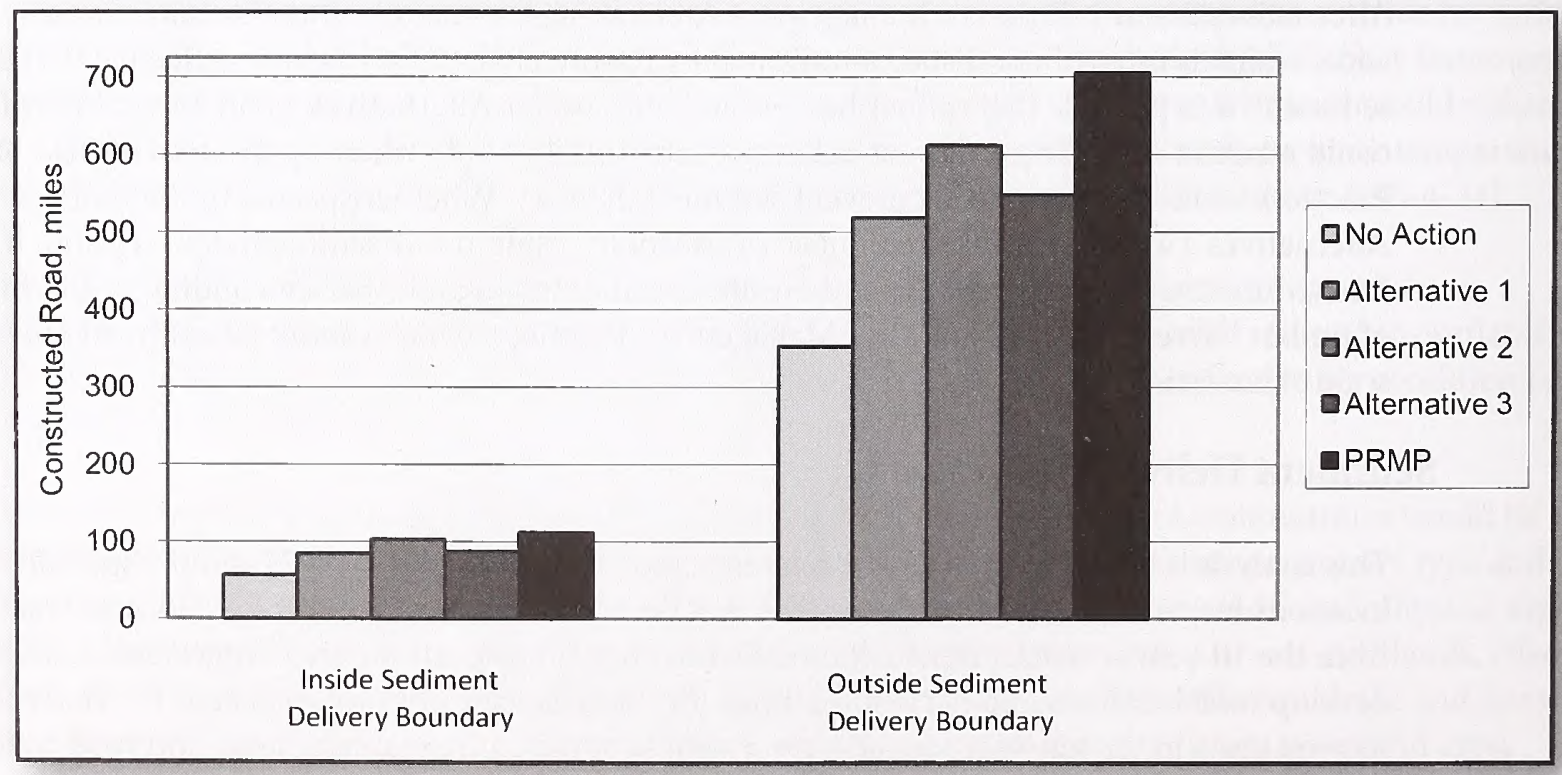


alternative. The current condition is shown for comparison. Under all alternatives, this increase would constitute less than a $1 \%$ increase in watersheds above current levels of fine sediment delivery from existing roads.

The increase in fine sediment delivery from new road construction over the next ten years would be lower under the No Action Alternative than all other alternatives, because fewer miles of road would be

Table 4-87. Potential Delivery Of Fine Sediment By New Roads Constructed By 2016 Under The Alternatives

\begin{tabular}{|c|c|c|c|c|c|c|}
\hline $\begin{array}{l}\text { Current Condition and } \\
\text { Condition under the } \\
\text { Alternatives by } 2016 \\
\end{array}$ & \multicolumn{2}{|c|}{$\begin{array}{c}\text { Roads Within Fine Sediment Delivery } \\
\text { Distance } \\
\text { (miles) }\end{array}$} & \multicolumn{2}{|c|}{$\begin{array}{l}\text { Potential Fine Sediment Delivery } \\
\text { (tons/year) }\end{array}$} & \multicolumn{2}{|c|}{$\begin{array}{c}\text { Watershed Average Potential Fine } \\
\text { Sediment Delivery } \\
\text { (tons/square mile/year) }^{b}\end{array}$} \\
\hline \multirow{2}{*}{ Existing Roads ${ }^{c}$} & \multicolumn{6}{|c|}{ Current Condition } \\
\hline & BLM & Other & BLM & Other & BLM & Other \\
\hline Natural & 1,738 & 15,874 & 23,050 & 233,054 & 0.86 & 8.75 \\
\hline Aggregate & 2,590 & 22,938 & 28,938 & 30,765 & 1.09 & 1.15 \\
\hline Paved & 767 & 2,436 & 8,277 & 33,807 & 0.31 & 1.27 \\
\hline Totals & 5,096 & 21,249 & 60,265 & 297,626 & 2.8 & 11.3 \\
\hline New Roads (by 2016) ${ }^{d}$ & \multicolumn{6}{|c|}{ No Action Alternative } \\
\hline Natural & 11.5 & & 326 & & 0.01 & \\
\hline Aggregate & 45.4 & & 1241 & & 0.05 & \\
\hline Paved & 0.0 & & 0 & & 0 & \\
\hline Totals & 56.9 & & 1,567 & & 0.06 & \\
\hline New Roads (by 2016) & \multicolumn{6}{|c|}{ PRMP } \\
\hline Natural & 30.4 & & 857 & & 0.03 & \\
\hline Aggregate & 81.5 & & 1,954 & & 0.07 & \\
\hline Paved & 0 & & 0 & & 0 & \\
\hline Totals & 112.9 & & 2,811 & & 0.10 & \\
\hline New Roads (by 2016) & \multicolumn{6}{|c|}{ Alternative 1} \\
\hline Natural & 15.6 & & 421 & & 0.02 & \\
\hline Aggregate & 69.9 & & 1,725 & & 0.06 & \\
\hline Paved & 0 & & 0 & & 0 & \\
\hline Totals & 85.5 & & 2,146 & & 0.08 & \\
\hline New Roads (by 2016) & \multicolumn{6}{|c|}{ Alternative 2} \\
\hline Natural & 13.3 & & 404 & & 0.02 & \\
\hline Aggregate & 89.7 & & 1,859 & & 0.07 & \\
\hline Paved & 0 & & 0 & & 0 & \\
\hline Totals & 103 & & 2,263 & & 0.09 & \\
\hline New Roads(by 2016) & \multicolumn{6}{|c|}{ Alternative 3} \\
\hline Natural & 16.0 & & 436 & & 0.02 & \\
\hline Aggregate & 71.4 & & 1,655 & & 0.06 & \\
\hline Paved & 0 & & 0 & & 00 & \\
\hline Totals & 87.4 & & 2,091 & & 0.08 & \\
\hline
\end{tabular}

${ }^{a}$ Delivery distances include the road segments within 200 feet of stream channels, where ditchflow carrying fine sediment could enter streams.

${ }^{b}$ These estimates were calculated by surface type for each fifth-field watershed and summed for the planning area.

${ }^{c}$ BLM includes the BLM-controlled roads and the private roads within the planning area from BLM GIS GTRN (roads) coverage.

Includes BLM new roads only. Information is not available to predict the number of miles of new roads on other lands. 
constructed over then next ten years within the sediment delivery distance to streams. Fine sediment delivery would be similar under Alternatives 1,2, and 3 even though Alternative 2 would have the highest timber harvest volume of all alternatives. Alternative 2 would have a greater proportion of regeneration harvest to thinning harvest than the other alternatives (see Chapter 4 - Timber), and regeneration harvest requires less road construction than thinning. Additionally, most new road construction under Alternative 2 would be short extensions of existing roads in upslope areas because of the prevalence of regeneration harvest and conventional logging systems generally yard uphill.

The increase in fine sediment delivery from new road construction over the next 10 years would be greater under the PRMP than all other alternatives because of the greater acreage of thinning under the PRMP (see Chapter 4 - Timber), that would require more road construction than regeneration harvest. Additionally, the PRMP would include approximately twice the length of permanent natural surface road within the 200 -foot sediment delivery distance than the other alternatives. Natural surface road would yield higher sediment delivery per mile than aggregate road in typical topography near streams (See Chapter 3 - Water).

Under all alternatives, Best Management Practices would be applied to the design of permanent and temporary road construction (see Appendix I - Water) to maintain or improve water quality. The Best Management Practices include methods that limit the delivery of sediment to streams. These practices would be applied during such management activities as timber harvesting, road maintenance and construction, road decommissioning, energy and mineral development, and fuel treatments.

Some of the Best Management Practices that are related to roads include:

- Design transportation system to limit the number of new roads and reduce the stream fine sediment delivery points to the extent practicable.

- Design new stream crossings to pass flows of water, sediment and debris without overtopping or failure.

- Improve road systems to reduce the flow of concentrated water and entrainment of fine sediment in roadside ditches by increasing the frequency of drainage relief culverts.

- Disconnect road flow paths from streams by performing road restoration actions where roads are permanently decommissioned.

These results in Table 4-87 over-estimate the fine sediment delivery from new road construction under all alternatives, because the basic erosion rates for new roads would decrease typically as much as $50 \%$ after two years of construction as a result of vegetation establishment along cut and fill slopes (see Chapter 3-Water). Therefore, the expected sediment delivery to streams would decrease rapidly after road construction and stabilization. The average sediment delivery to streams from new road segments being constructed in different years during the first decade while others are re-vegetating during the same period means that there would be less sediment delivery from road than the results reported in Table 4-87 for all alternatives. The effect of vegetation establishment in reducing sediment delivery from roads would depend on site-specific conditions and the specific road design, which cannot be analyzed more precisely at this scale of analysis. Therefore, the reduction in sediment delivery after road construction from vegetation establishment cannot be quantified in this analysis.

This analysis assumes that approximately 270 miles of road decommissioning, 38,115 miles of road maintenance, and 2,184 miles of road improvement per decade would occur under all alternatives. This assumed level of road decommissioning is based on the level of activity that has occurred under the 1995 resource management plans adjusted for the anticipated reduction in opportunities for decommissioning in the future (see Chapter 4 - Fish). All alternatives include management direction to decommission roads specifically to reduce chronic sediment inputs, but it is not possible to identify specifically where future road decommissioning would occur. If future road decommissioning were to occur within the sediment delivery distance proportional to the total abundance of new BLM roads within the sediment delivery distance, 
97 miles of road within the sediment delivery distance would be decommissioned each decade under all alternatives. Table 4-87 shows that 5,096 miles (36\%) of the 14,273 miles of total BLM's roads occur within a sediment delivery distance. On a proportional basis, 97 miles (i.e., $36 \%$ of 270 miles) of roads within the sediment delivery distance would be decommissioned each decade under all alternatives.

Therefore, there would be little net increase in road miles within a 200-foot sediment delivery distance under Alternative 2 and the PRMP, and a net decrease in road miles under the other alternatives. See Figure 4-147 (Projected newly constructed permanent roads within a sediment delivery distance to streams, compared to total newly constructed permanent roads by 2016). This likely under-estimates the amount of road decommissioning that would occur within the sediment delivery distance because management direction under all alternatives directs road decommissioning to reduce chronic sediment inputs to streams. The specific effects of road decommissioning on sediment delivery from roads would depend on sitespecific conditions of roads, streams and riparian areas and the specific design of road decommissioning, all of which cannot be analyzed more precisely at this scale of analysis. Nevertheless, the estimated road decommissioning within the sediment delivery distance would result in an immeasurably small increase in sediment delivery from BLM roads under the PRMP and Alternative 2 and a net decrease in sediment delivery from BLM roads under the No Action Alternative, Alternative 1, and Alternative 3.

\section{Sediment Delivery from Mass Wasting}

This analysis evaluates the effects of management activities on sediment delivery from mass wasting by calculating a relative landslide density that indicates the expected amount of landslides that could deliver sediment to streams. Mass wasting refers to any down-slope movement of a mass of sediment or rock. This analysis will specifically address shallow, colluvial landslides that occur when loose, heterogeneous soils on steep slopes become saturated and slide. Shallow, colluvial landslides ("landslides" hereafter) are the type of mass wasting most likely to be affected by the management actions in the alternatives and can be addressed at this scale of analysis. Landslides can occur in all forest types, but not in all forest locations. Some portions of the landscape are not prone to landslides, regardless of management actions. On landslide-prone portions of the landscape, timber harvest can increase the probability of landslide, but only if a damaging storm occurs in the vegetation re-growth period: up to 10 years following harvest (see Chapter 3 - Water).

This analysis calculates an average relative density of landslides that could deliver to a stream channel in the planning area from BLM-administered lands using geospatial and analytical methods developed by Miller and Burnett (2007). Topographic weighting functions were developed for the Coast Range Cascades, and Klamath Provinces. Vegetation was classified into recent regeneration harvest $(<10$ years), mixed forest and hardwoods (10-100 years) and older forest ( $>100$ years). The relative landslide density was calculated for all combinations of topography and classified vegetation, including the susceptibility from roads. Because this analysis is designed to evaluate the delivery of sediment to streams, the relative landslides density includes only those areas that could deliver to stream channels, based on the model calibration described in Miller and Burnett (2007) (see Appendix I - Water). The relative landslide density is an indication of the expected amount of landslides for a time period, based on a calibration dataset. For this analysis, the calibration time period is the expected relative landslide density based on 1996 floods, which were extreme storms that have a return interval of 70-100 years (see Chapter 3 - Water).

It is not possible at this scale of analysis to quantify the amount of sediment that would be delivered from landslides to streams over time under each of the alternatives. The amount of sediment delivered to streams from landslides would depend on the volume of each landslide and site-specific geologic and topographic factors, which cannot be addressed at this scale of analysis. The relative landslide density provides a basis to compare qualitatively the potential sediment delivery among the alternatives, and to compare the effects of the alternatives to current conditions and to the potential sediment delivery that the No Harvest reference analysis indicates would occur in the absence of active management. 
Over the planning timeframe, relative landslide density across the planning area would decline from the current condition under all alternatives, in part because the abundance of older forest would increase under all alternatives.

In all provinces, relative landslide density across all land use allocations would decline from the current condition by 2106. Similar to the current condition, relative landslide density over time would remain highest in the Klamath Province, slightly lower in the Coast Range, and substantially lower in the Cascades Province $^{14}$ (see Figures 4-148, 4-149, and 4-150). In the Coast Range Province by 2106, relative landslide density would range from 2.8 landslides per square mile under Alternative 3, to 2.9 landslides per square mile under Alternative 1. In the Cascades Province by 2106, relative landslide density would range from 0.6 landslides per square mile under the PRMP, to 0.7 landslides per square mile under Alternative 1 . In the Klamath Province by 2106 , relative landslide density would range from 3.6 landslides per square mile under Alternative 2, to 4.0 landslides per square mile under Alternative 1. In the Klamath Province, relative landslide density under Alternative 1 would slightly increase from current conditions until 2056, and then would decline to below current conditions by 2106; this is the only alternative in any province during any timber period under which relative landslide density would increase from current conditions. The No Harvest reference analysis indicates that, even in the absence of active management on BLM-administered lands, the relative landslide density by 2106 would be 2.8 landslides per square mile in the Coast Range Province; 0.6 landslides per square mile in the Cascades Province and 3.5 landslides per square mile in the Klamath Province.

There is little if any correlation between relative landslide density under the alternatives over time and the acres of timber harvest under the alternatives. For example, in the Klamath Province, Alternative 1 and the No Action Alternative would have the highest relative landslide density and would have the lowest Allowable Sale Quantity of any alternatives; Alternative 2 and the PRMP would have the lowest relative

Figure 4-148. Relative Landslide Density by Alternative Across All LandUse Allocations That Would Deliver To Stream Channels (Coast Range Province)

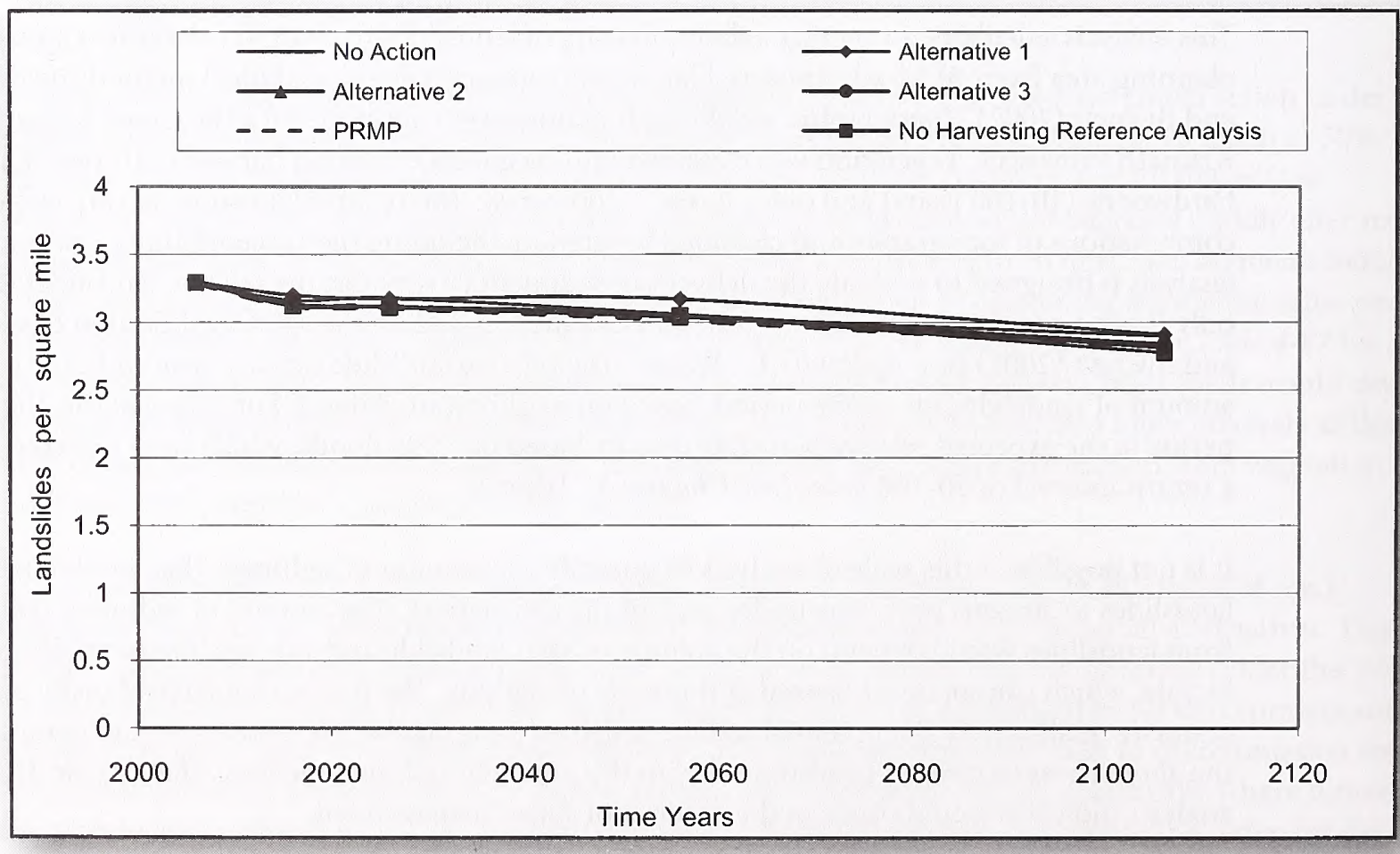

${ }^{14}$ The "Cascades Province" in this analysis includes the West Cascades, East Cascades, and Willamette Valley Provinces. 
Figure 4-149. Relative Landslide Density By Alternative Across All Land-Use Allocations That Would Deliver To Stream Channels (Cascades Province)

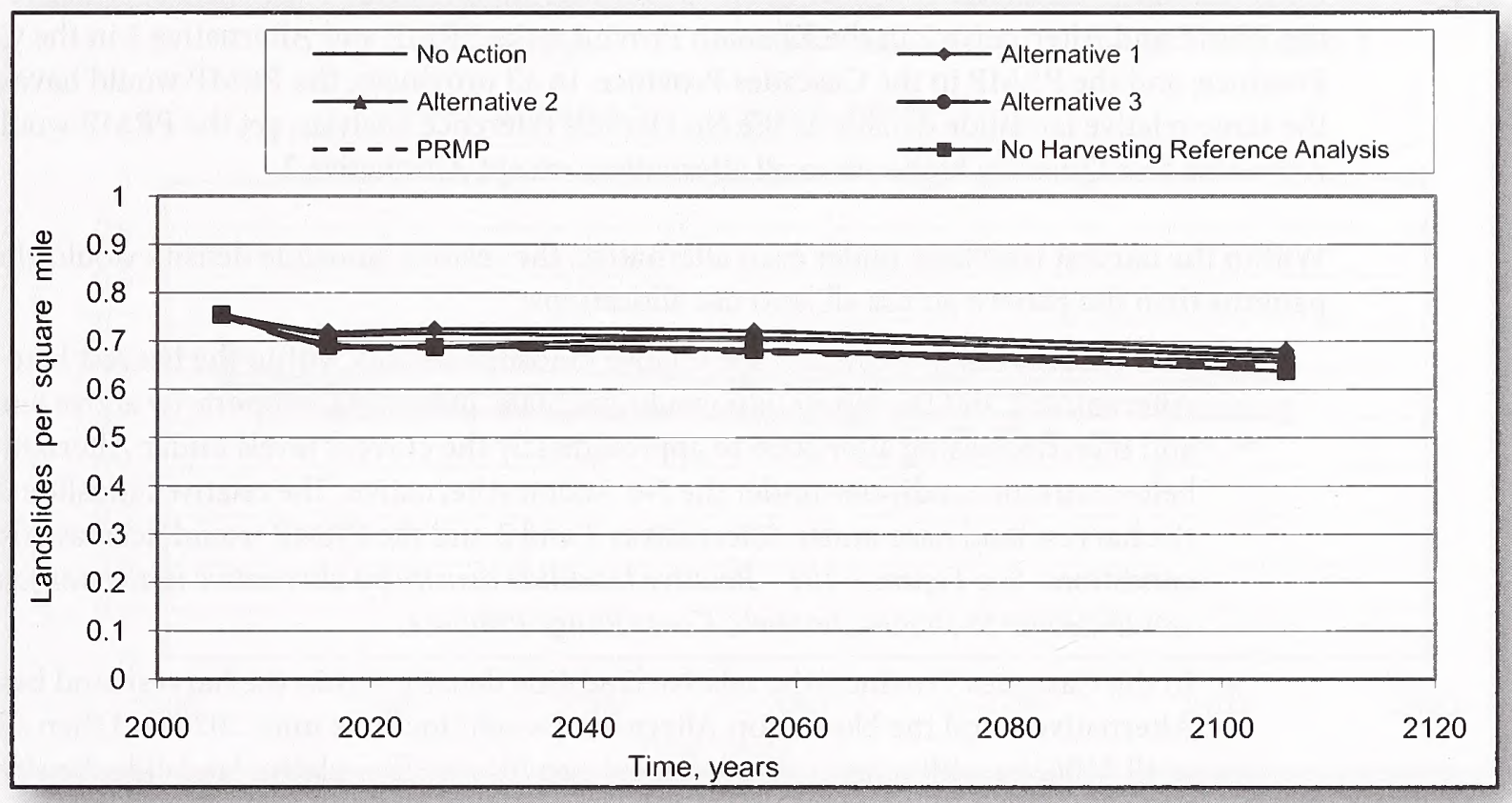

Figure 4-150. Relative Landslide Density By Alternative Across All Land-Use Allocations That Would Deliver To Stream Channels (Klamath Province)

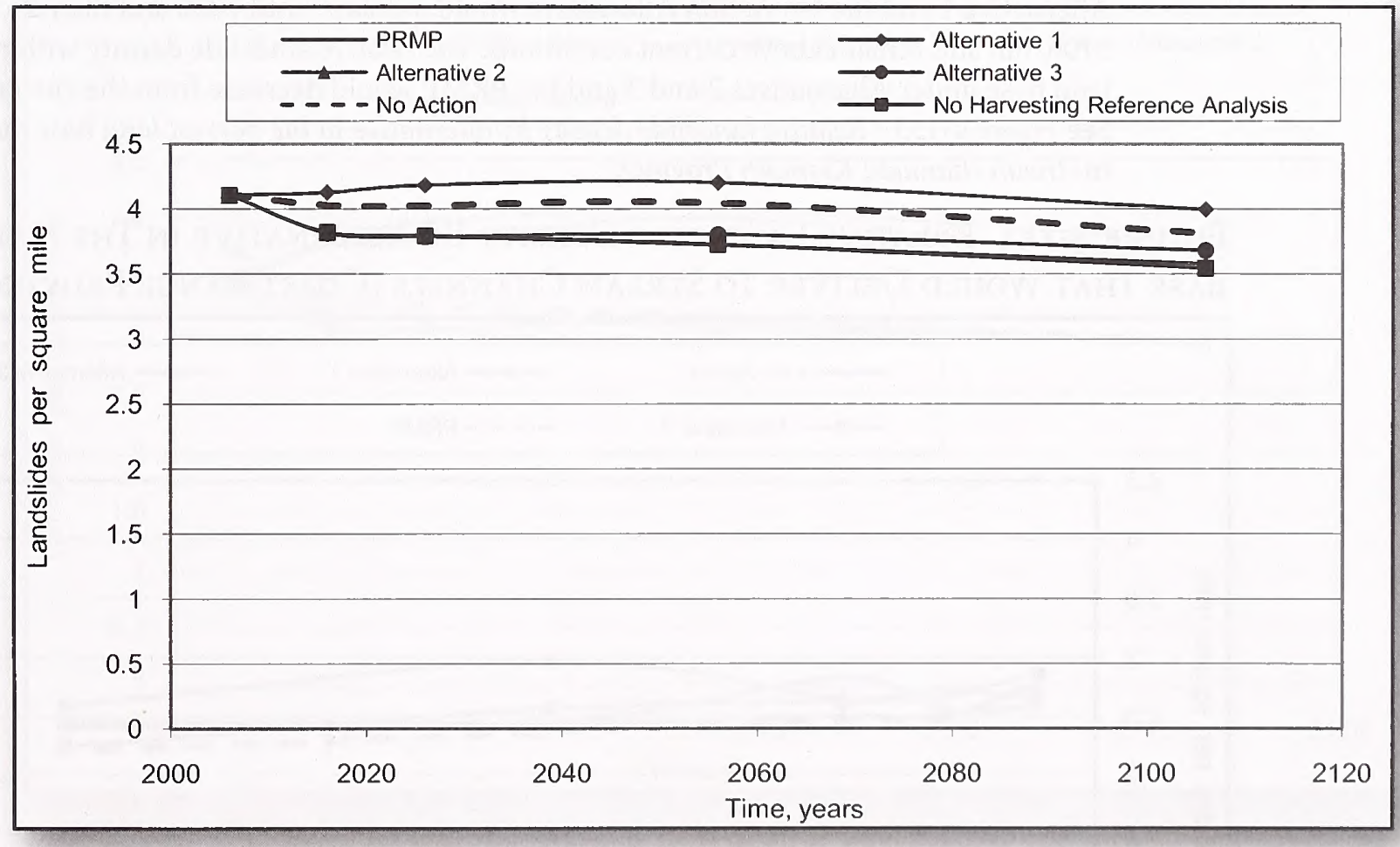

Relative landslide densities are weighted averages, as modeled by Miller 2008, for non-forest, recent harvest areas, young forest, and older forest for a set of watersheds comprising each province. Landslide delivery is to stream channels $<20 \%$ gradient. 
landslide density and would have the highest Allowable Sale Quantity (see Chapter 4 - Timber). In each province, the relative landslide density under at least one alternative would be virtually indistinguishable from what the No Harvest reference analysis indicates would occur in the absence of active management: the PRMP and Alternative 2 in the Klamath Province; the PRMP and Alternative 3 in the Coast Range Province; and the PRMP in the Cascades Province. In all provinces, the PRMP would have approximately the same relative landslide density as the No Harvest reference analysis, yet the PRMP would have an Allowable Sale Quantity higher than all alternatives except Alternative 2.

Within the harvest land base under each alternative, the relative landslide density would show different patterns than the pattern across all land use allocations:

- In the Coast Range Province, the relative landslide density within the harvest land base under Alternative 1 and the No Action would fluctuate, increasing temporarily above current conditions, and then decreasing after 2056 to approximately the current levels under Alternative 1 and to below current conditions under the No Action Alternative. The relative landslide density within the harvest land base under Alternatives 2 and 3 and the PRMP would decrease from the current conditions. See Figure 4-151 - Relative landslide density by alternative in the harvest land base that would deliver to stream channels; Coast Range Province.

- In the Cascades Province, the relative landslide density within the harvest land base under Alternative 1 and the No Action Alternative would increase until 2026 and then slightly decrease until 2106, but still remain above current conditions. The relative landslide density within the harvest land base under Alternatives 2 and 3 and the PRMP would decrease from the current conditions. See Figure 4-152 - Relative landslide density by alternative in the harvest land base that would deliver to stream channels; Cascades Province.

- In the Klamath Province, the relative landslide density within the harvest land base under Alternative 1 and the No Action Alternative would increase until 2056 and then decrease until 2106 , but still remain above current conditions. The relative landslide density within the harvest land base under Alternatives 2 and 3 and the PRMP would decrease from the current conditions. See Figure 4-153 - Relative landslide density by alternative in the harvest land base that would deliver to stream channels; Klamath Province.

Figure 4-151 Relative Landslide Density By Alternative In The Harvest Land Base That Would Deliver To Stream Channels (Coast Range Province)

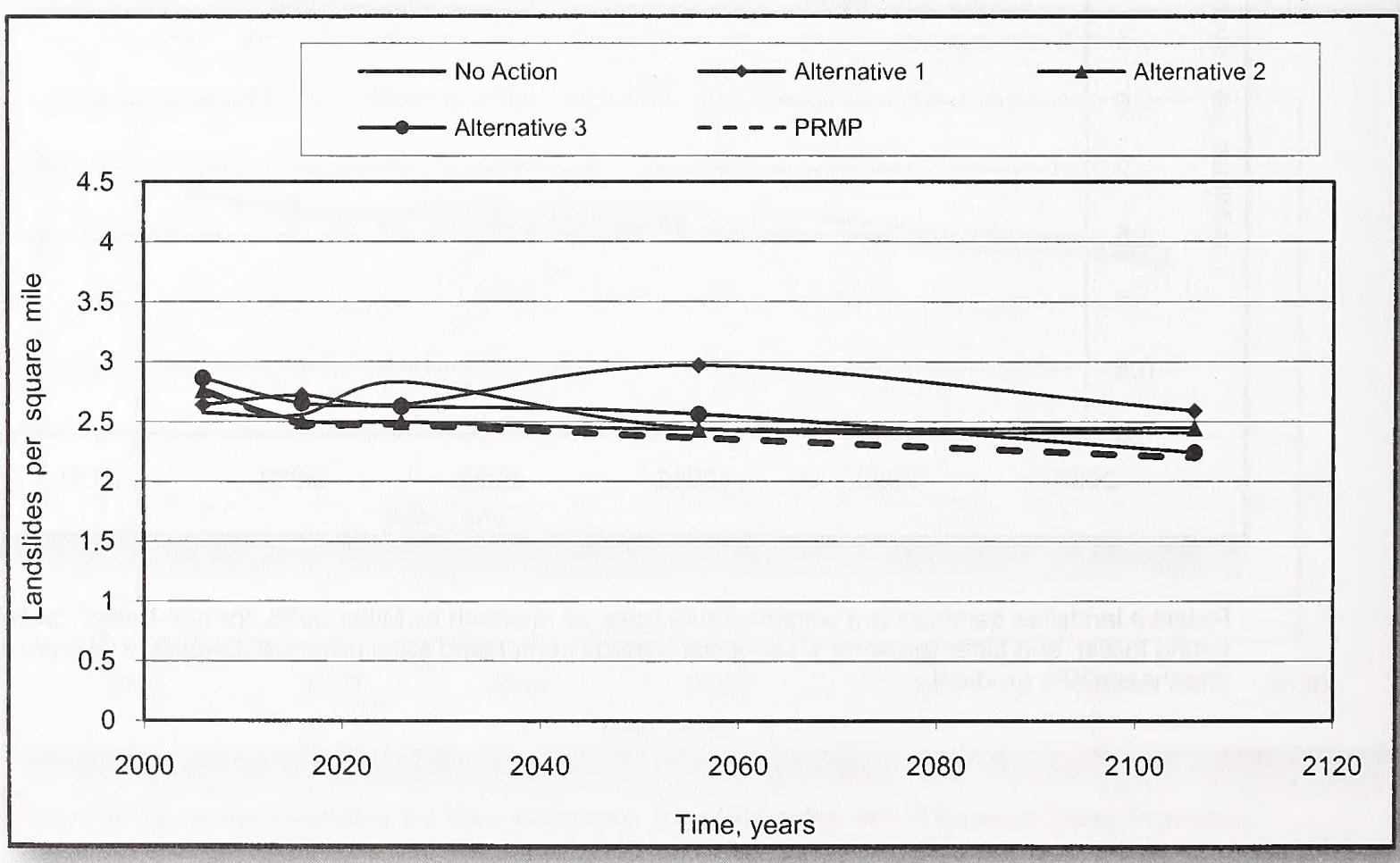


Figure 4-152 Relative Landslide Density By Alternative In The Harvest Land Base That Would Deliver To Stream Channels (Cascades Province)

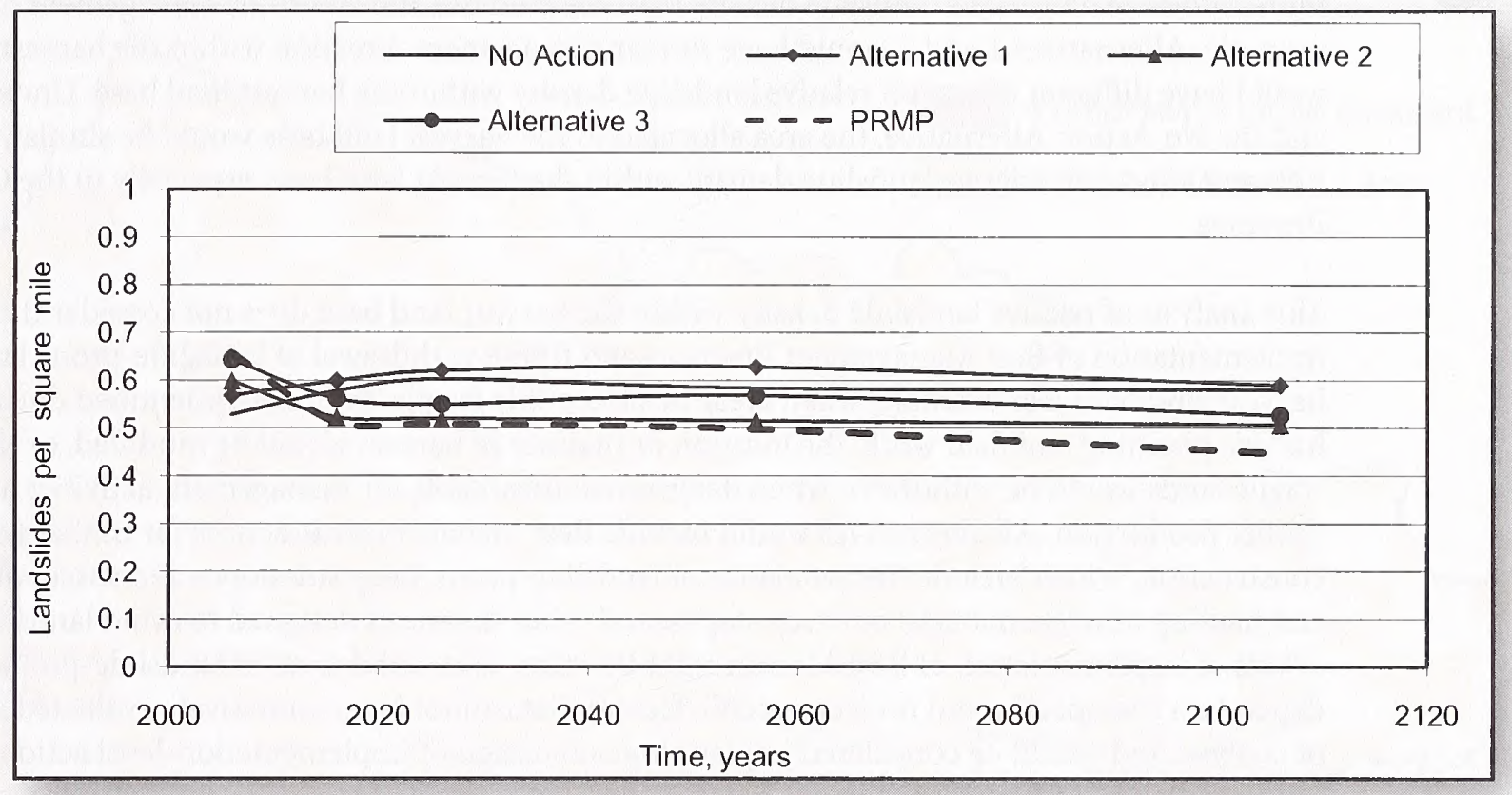

Figure 4-153 Relative Landslide Density By Alternative In The Harvest Land Base That Would Deliver To Stream Channels (Klamath Province)

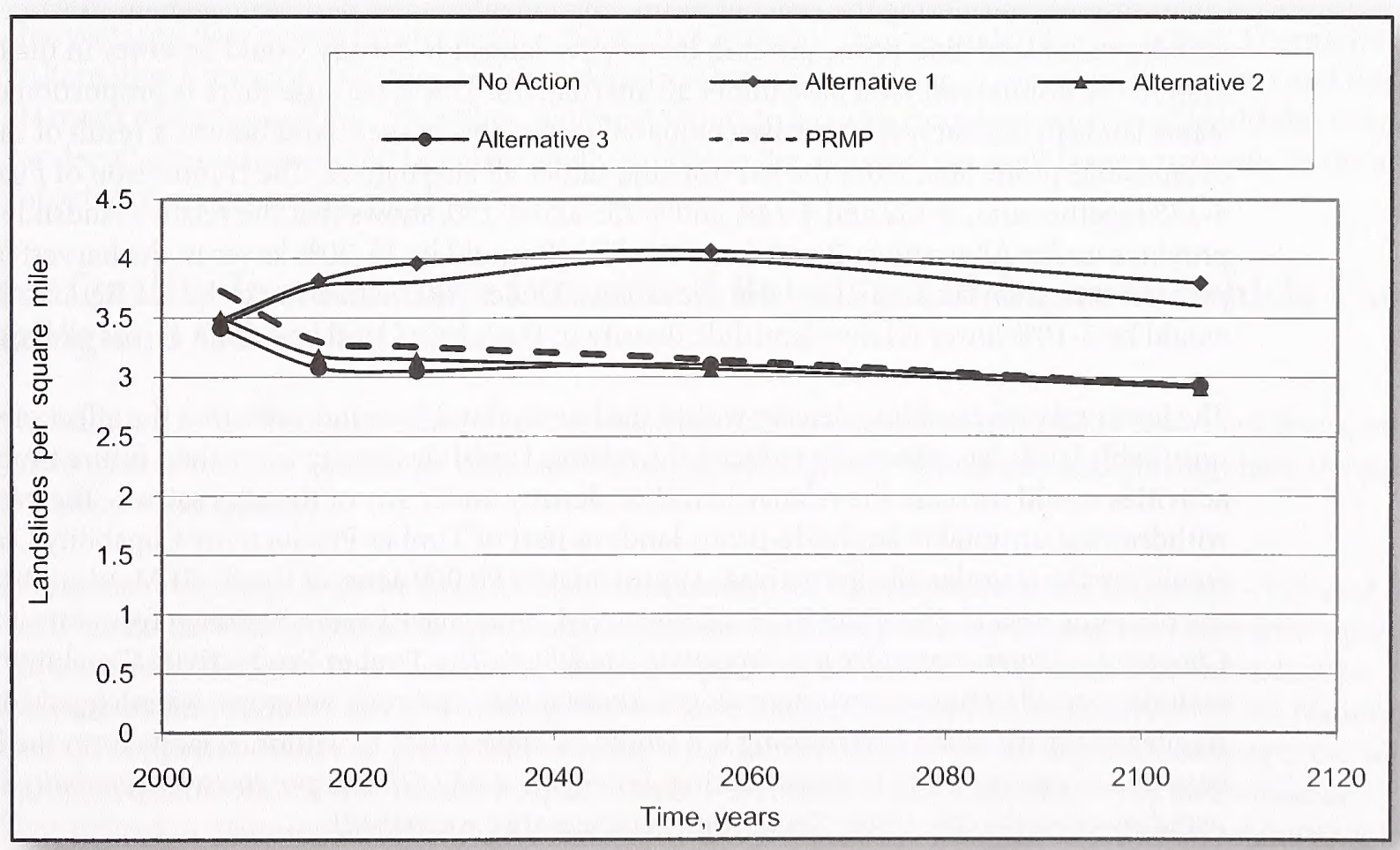

Relative landslide densities are weighted averages, as modeled by Miller 2008, for non-forest, recent harvest areas, young forest, and older forest for a set of watersheds comprising each province. Landslide delivery is to stream channels $<20 \%$ gradient. Relative landslide densities do not have the same starting point on Figures $4-151,4-152$, and 4-153, because the harvest land base varies from 620,822 acres under the No Action Alternative to 1,434,248 acres under Alternative 3. 
The variation in effects on relative landslide density among the alternatives within the harvest land base indicates that the specific location of management actions in relation to landslide-prone ground would have more influence on relative landslide density than the land use allocations or management direction. For example, Alternatives 1 and 2 would have similar management direction within the harvest land base, yet would have different effects on relative landslide density within the harvest land base. Under Alternative 1 and the No Action Alternative, the area allocated to the harvest land base would be similar, yet would have different effects on relative landslide density within the harvest land base, especially in the Coast Range Province.

This analysis of relative landslide density within the harvest land base does not consider the effect of future implementation of Best Management Practices and future withdrawal of landslide-prone lands from the harvest land base. For example, when areas of susceptible fragile ground are identified during timber harvest planning and field work, the location or manner of harvest would be modified, or the susceptible fragile lands would be withdrawn when determined unsuitable for management activities associated with timber production. All alternatives would include Best Management Practices for timber harvest and road construction, which include the avoidance of landslide-prone steep sideslopes and susceptible headwalls; end hauling of waste material on steep slopes; and other measures designed to avoid landslides. The specific effects of implementation of Best Management Practices and withdrawal of landslide-prone lands would depend on site-specific and project-specific factors that cannot be quantitatively evaluated at this scale of analysis and would be considered in planning and design of implementation-level actions. However, implementation of Best Management Practices and withdrawal of landslide-prone lands would have the general effect of reducing the relative landslide density of all alternatives to a level substantially similar to the level of the No Harvest reference analysis.

Even without considering the effect of future implementation of Best Management Practices and future withdrawal of landslide-prone ground, the relative landslide density would be lower in the harvest land base than in the nonharvest land base under all alternatives. This is because there is proportionally more area of stable lands in the harvest land base compared to the non-harvest land base as a result of the withdrawal of landslide-prone land from the harvest land under all alternatives. The comparison of Figures 4-151 and 4-148 together and, 4-152 and 4-149, and 4-153 and 4-150, shows that the relative landslide density by province under Alternatives 2 and 3 and the PRMP would be 15-30\% lower in the harvest land base at any point in time than across all land use allocations. Under Alternative 1 and the No Action Alternative, there would be $3-10 \%$ lower relative landslide density in the harvest land base than across all land use allocations.

The lower relative landslide density within the harvest land base indicates that the effect of withdrawing unsuitable lands has effectively reduced the relative landslide density more than future timber harvest activities would increase the relative landslide density under any of the alternatives. The past practice of withdrawing unsuitable landslide-prone lands as part of Timber Productivity Capability Classification would continue under all alternatives. Approximately 90,000 acres of fragile BLM-administered lands within the planning area (3.5\% of the BLM-administered lands) have been withdrawn from forest management (see Chapter 3 - Water; Appendix R - Vegetation Modeling). The Timber Productivity Capability Classification includes consideration of very steep slopes, skeletal soils and rock outcrops, waterlogged soils, and other fragile landforms when determining if it would be appropriate to withdraw lands from the harvest land base due to susceptibility to mass wasting. See Figure 4-154 (Timber productivity capability classification withdrawals within the Upper Smith River representative watershed).

Although it is not possible at this scale of analysis to reasonably quantify the amount of sediment that would be delivered from landslides to streams, the amount over time would be substantially similar to the amount that the No Harvest reference analysis indicates would occur naturally in the absence of active management. Even without including the effect of future implementation of Best Management Practices and future withdrawal of landslide-prone lands from the harvest land base, the relative landslide density under the PRMP, Alternative 2, and Alternative 3 would be substantially similar to the No Harvest reference analysis. Implementation of Best Management Practices and future withdrawal of landslide-prone lands from the 
Figure 4-154. Timber Productivity Capability Classification Withdrawals Within The Upper Smith River Representative Watershed

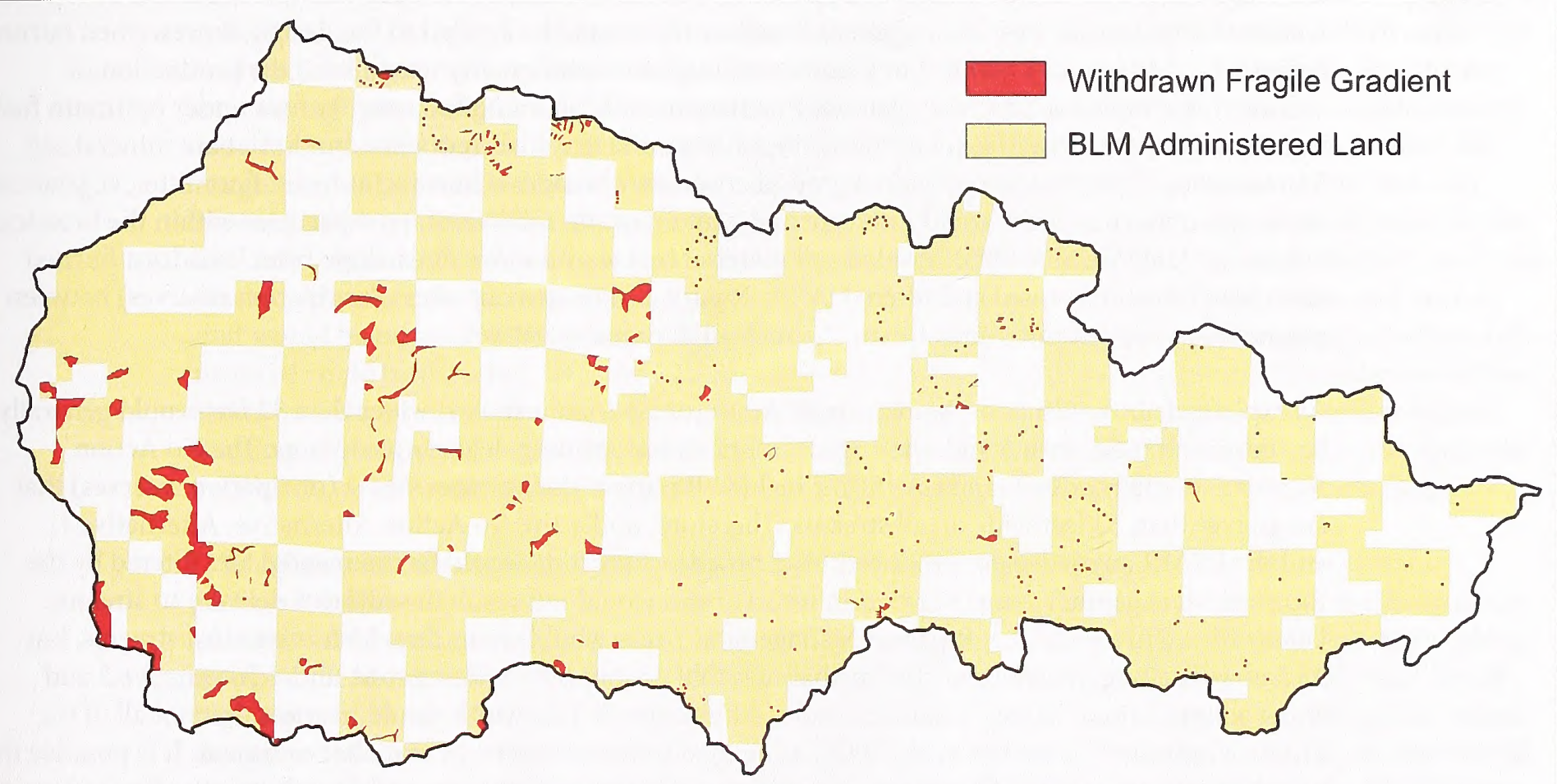

harvest land base would further reduce the relative landslide density under the No Action Alternative and Alternative 1 towards a relative landslide density substantially similar to the other alternatives and the No Harvest reference analysis. Therefore, sediment inputs to streams from harvest-related landslides over time under all alternatives would be substantially similar to the amount that would occur naturally in the absence of active management on BLM-administered lands.

\section{Water Quality Impacts from Prescribed Burning, Off-highway Vehicle Use, Grazing and Other Activities}

In addition to the effects of timber harvest and road construction on water quality described above, other management actions (including prescribed burning, off-highway vehicle use, and grazing) have the potential to affect water quality.

Prescribed burning would be used under all alternatives for slash treatment (see Chapter 4 - Fire and Fuel) and would have the potential to create soil erosion and sediment delivery to streams. There are a variety of slash reduction practices that may be utilized depending on harvest type, stand and fuel reduction objectives, and climatic and fuel loading differences, from the northern to southern end of the planning area. The specific effects of prescribed burning on sediment delivery would depend on site-specific and project-specific factors that cannot be quantitatively evaluated at this scale of analysis and would be considered in planning and design of implementation-level actions. Nevertheless, broadcast burning for site preparation after regeneration harvesting would involve higher fuel loadings, longer duration, and higher intensity fires compared to other types of prescribed burning, and therefore would have more potential for effects on sediment delivery.

It is projected that $50 \%$ of the regeneration harvest units from the first decade levels of regeneration harvest would be broadcast burned (see Chapter 4 - Fire and Fuels) on an annual basis. At this rate, there would be approximately 3,000 acres broadcast burned under the No Action Alternative; 4,500 acres under Alternative 1; 7,200 under Alternative 2; 200 acres under Alternative 3; and 3,800 acres under the PRMP. Soil erosion 
after broadcast burning can be expected to vary from 0.4 to 2.6 tons per acre per year on a burned forest floor until vegetation is established (Megahan and Molitor 1975), and this is not appreciably different than the range of erosion in an undisturbed forest of 0.01 to 2.47 tons per acre per year (USDA USFS 2005). Under all alternatives, Best Management Practices that would be applied to the design of prescribed burning projects (see Appendix I - Water) to maintain or improve water quality would limit the production of sediment. Examples of Best Management Practices include planning low severity fires under optimum fuel moisture content (spring-like conditions) to achieve sufficient fuels reduction but limit bare mineral soil. Maintenance of patchiness of residual ground cover after broadcast burning as forest floor litter, vegetation, rocks and unburned fuels would intercept and contain onsite soil loss of most particles within the broadcast burn area (USDA USFS 2005). Eroded soil material that would move downslope from broadcast burned areas would be intercepted and filtered by the Riparian Management Areas (or riparian reserves) between regeneration harvest units and stream channels under all alternatives.

As explained above, Riparian Management Areas (or riparian reserves) wider than 33 feet would generally be effective at intercepting and filtering sediment and precluding delivery to streams. The No Action Alternative, Alternative 1, and the PRMP include Riparian Management Areas (or riparian reserves) that are greater than 33 feet wide on all streams. Therefore, under the No Action Alternative, Alternative 1, and the PRMP, any sediment produced from broadcast burning would be intercepted and filtered by the Riparian Management Area (or riparian reserve) and would not result in sediment delivery to streams. Under Alternatives 2 and 3, Riparian Management Areas would wider than 33 feet on most streams, but 25 feet wide along intermittent stream channels that are not debris-flow prone under Alternative 2 and along all intermittent stream channels under Alternative 3. This width would be most, but not all of the distance indicated by Rashin et al. (2006) as being effective to intercept and filter sediment. It is possible that broadcast burning under Alternatives 2 and 3 near intermittent streams could result in some fine sediment delivery to streams, but only where application of Best Management Practices would not completely prevent sediment production and delivery. Whether specific broadcast burning projects under Alternatives 2 and 3 near intermittent streams would result in fine sediment delivery, and if so, how much fine sediment delivery, would depend on site-specific stream and riparian conditions and the specific design of broadcast burning and Best Management Practices, which cannot be analyzed more precisely at this scale of analysis. Nevertheless, any sediment delivery to streams from broadcast burning under Alternatives 2 and 3 would be temporary and decrease to natural levels in on to two growing seasons (USDA USFS 2005), highly localized, and limited in magnitude.

Any sediment delivery from broadcast burning under Alternatives 2 and 3 would be highly localized because of the limited extent of broadcast burning near the riparian areas of intermittent streams. Alternative 3 would have less than 5 acres of broadcast burned area adjacent to the riparian areas of intermittent stream channels each year along less than 1 mile of intermittent stream channel. Alternative 2 would involve approximately 200 acres per year of broadcast burning along the riparian areas of 33 miles on non-debris-flow intermittent stream channels, which is less than $0.2 \%$ of the total BLM intermittent stream miles. Any sediment delivery from broadcast burning under Alternatives 2 and 3 would be limited in magnitude because of the effect of Best Management Practices to limit fire severity and sediment production; the interception of eroded sediment within the broadcast burn area; and the interception of remaining eroded sediments that move downslope within the Riparian Management Area. Under Alternative 3, the Riparian Management Area would be undisturbed. Under Alternative 2, the Riparian Management Area includes a 25-foot streambank zone that would be retained including forbs, shrubs, noncommercial trees and 12 conifers per acre (refer to Table-2-53 in Chapter 2). Even though there would be less conifer trees retained than other Riparian Management Area allocations, the understory vegetation and surface litter would be as effective as an unharvested Riparian Management Area in intercepting and filtering sediment.

Prescribed burning would be used under all alternatives within Riparian Management Areas (or riparian reserves) to reduce fuel hazard loadings or for restoration purposes and would have the potential to create soil erosion and sediment delivery to streams. Prescribed burning within Riparian Management Areas 
(or Riparian Reserves) would likely be limited to the Medford District and Klamath Falls Resource Area. Whether specific prescribed burning projects for fuel treatment or restoration would result in fine sediment delivery, and if so, how much fine sediment delivery, would depend on site-specific stream and riparian conditions and the specific design of prescribed burning and Best Management Practices, which cannot be analyzed more precisely at this scale of analysis. Due to rapid establishment of grasses, forbs, and shrubs, any fine sediment delivery would be temporary (generally less than 1-2 years), and the deliverable amount of sediment would depend on the residual vegetation, organic material and duff, soil organic matter, site roughness, soil type, and slope steepness. Best Management Practices for soil and water protection and meeting water quality standards would require fuel prescriptions to be low-intensity, short-duration burns and only where fuel loads are light (up to 12 tons per acre) under favorable moisture and weather conditions that would reduce the potential for sediment delivery. Residual vegetation, unburned debris, and surface duff would be retained with an expectation that no more than $5 \%$ of bare soil would be exposed where soil material could be detached. This residual groundcover would effectively intercept and filter most or all fine sediment before it could be delivered to stream channels. Additional Best Management Practices include limiting of fire ignition within Riparian Management Areas and distributing treatment areas (see Appendix $I$ - Water), which would reduce the potential magnitude of any sediment delivery to stream channels.

Off-highway vehicle use under all alternatives would have the potential to result in contaminant and sediment delivery to streams. These potential effects on water quality would be reduced by the designation of limited or closed areas and the application of Best Management Practices. Under the action alternatives, nearly all BLM-administered lands would be designated as "limited to designated roads and trails" for offhighway vehicle use. Under the No Action Alternative, there would be 300,000 acres of off-highway vehicle designated as open, and 950,000 acres designated as "limited to existing roads and trails." Under the PRMP, there would be no acres designated as "open," while under Alternatives 1, 2, and 3 there would be 77 acres designated as "open." There would be no effect on water quality in the 77-acre "open" area (Heceta Dunes) under Alternatives 1, 2 and 3, because this area is wind blown sand dunes that do not drain to stream channels. There would be an increase of $58 \%$ as "limited to designated roads and trails" for off-highway vehicle use under the action alternatives compared to the No Action Alternative.

Limiting off-highway vehicle use to designated roads and trails compared to off highway use in open areas would prevent oil and grease and other contaminants from entering waterbodies and also prevent wheeltrack surface disturbance and consequent gullying in erodible soils and sediment delivery to waterbodies. Erosion and sedimentation of streams would be reduced by "limiting off-highway vehicles to designated roads and trails" compared to "limited to existing roads and trails," because roads with surfaces that may erode from off-highway vehicle use or roads where off-highway vehicle use cannot reasonably avoid crossing through stream channels would not be designated. Therefore, the potential for water quality effects from off-highway vehicle use would be lower under all of the action alternatives than under the No Action Alternative. In addition, 17 Best Management Practices are identified that address the maintenance or improvement of water quality as related to off-highway vehicle use, including measures that would avoid creation of contaminants or sediment within riparian areas and measures that would reduce the potential for delivery of contaminants or sediment to stream channels (See Appendix I - Water).

The grazing of cattle along rangeland streams would contribute contaminants to water (fine sediment and bacteria) and elevate stream temperatures. This analysis assumes that the Standards for Rangeland Health (1997), particularly standard II (riparian area function) and standard IV (water quality) would be achieved at the earliest possible date, or when permits or leases are renewed. Under all alternatives, the general guidelines for grazing management and Best Management Practices for water quality would be expected to meet the proper functioning condition of streams and water quality standards in the long term. These measures would include:

- Providing adequate cover and plant community structure to promote stream bank stability, debris and fine sediment capture, and floodwater energy dissipation in riparian areas. 
- Maintaining or restoring plant communities to promote photosynthesis throughout the growing season.

- Completing range improvements including riparian pasture fencing, development of off-stream watering, and the relocation of animal holding facilities away from riparian areas.

Placement of culverts and instream structures (e.g., for fish habitat restoration projects) could result in an increase in turbidity and potential downstream sediment delivery. Under all alternatives, culvert placements and other instream activities would cause short-term, localized increases in turbidity (less than eight hours in duration and less than 300 feet from the culvert replacement or instream activity). The potential increase in turbidity would be the same under every alternative, and effects on water quality would be limited or avoided by the application of Best Management Practices, such as diverting water around a site, use of containment and filtering techniques (e.g., silt curtains), and limiting mechanized equipment along streambanks, which would be applied to meet water quality standards. Site-specific and highly localized effects on sediment delivery from placement of culverts and instream structures would depend on sitespecific stream conditions and the specific project design, which cannot be analyzed more precisely at this scale of analysis. Site-specific effects of placement of culverts and instream structures on sediment delivery would be considered during the planning of implementation-level actions.

\section{Source Water Watersheds for Public Drinking Water}

There are 80 source water watersheds for public drinking water within the planning area. The potential contaminant sources that would impact the surface water have been identified as part of the Oregon Department of Environmental Quality Source Water Assessments (see Chapter 3 - Water). Potential sources of water quality impairment under all alternatives would include: timber harvest, construction, maintenance, and use of roads and stream crossings, river recreation, construction and maintenance of transmission lines, grazing, prescribed burning, off-highway vehicle use, and quarry operations. Under all alternatives, Riparian Management Areas (or riparian reserves) would limit disturbance near streams and waterbodies and would intercept and filter potential contaminants. In addition, the application of Best Management Practices during management activities under all alternatives would limit or avoid the delivery of contaminants to streams and waterbodies (see Appendix I - Water). Under all alternatives, forest management activities would occur in source water watersheds for public drinking water within the 1,000foot sensitive zones identified by the Oregon Department of Environmental Quality (see Chapter 3-Water). All alternatives would have little or no effect on the parameters of concern from forest operations, including increases in stream temperature and sediment delivery, in source water watersheds for public drinking water as described above in this section.

Management activities on BLM-administered lands would maintain stream shade under all alternatives and, therefore, would not contribute to an increase in stream temperatures. The incremental increase in fine sediment delivery to stream channels from new road construction would be less than $1 \%$ above current conditions under all alternatives. Relative landslide density across the planning area would decline from the current condition under all alternatives, and sediment inputs to streams from harvest-related landslides over time under all alternatives would be substantially similar to the amount that would occur naturally in the absence of active management on BLM-administered lands. Other potential sources of sediment would not result in delivery of fine sediment to streams that would be measurable at this scale of analysis, because of the interception and filtration of sediments by the Riparian Management Areas (or riparian reserves) and the effect of the application of Best Management Practices. Therefore, BLM activities under all alternatives would have a low risk for changing the suitability of these waters for public source waters. 


\section{Fish}

This analysis examines how the alternatives would affect fish habitat by the delivery of large wood, nutrients, and fine sediments to streams and by alterations to peak stream flows and stream temperature.

A variety of anadromous and resident fish species occur throughout the planning area (see the Fish section of Chapter 3). The habitat requirements and the responses to habitat changes vary by species and among age groups within species. However, the fish species that would be affected by BLM management are similar enough in their habitat requirements to permit an analysis of how any changes to large wood, nutrient input, sediment, flow, or temperature would affect fish habitat in general.

\section{Key Points}

- The potential large wood contribution to streams would increase over time under all alternatives. The greatest increase would occur under the PRMP and the No Action Alternative, and the smallest increase would occur under Alternative 2.

- Fine sediment delivery to stream channels would not increase more than $1 \%$ above existing rates under any alternative and would not decrease fish survival.

- The PRMP would have the highest number of susceptible subwatersheds, but Alternative 2 would have the greatest acreage of susceptible BLM-administered lands. The susceptibility to peak flows under all alternatives would be more similar to the effects of the No Harvest reference analysis than to the effects of the Intensive Management on Most Commercial Timber Lands reference analysis.

- The risk of adverse effects to fish from an increase in peak flow would be very low under all alternatives, because of the small proportion of the planning area identified as susceptible to peak flow increases, the small proportion of the stream types in which streambed scour would occur, and the low likelihood that all factors required for adverse effects on fish would occur simultaneously.

- None of the alternatives would contribute to an increase in stream temperature that would affect fish.

\section{Large Wood}

This analysis uses a spatially explicit, GIS-based, wood recruitment model to estimate potential wood recruitment to stream channels in all fifth-field watersheds within the planning area from BLM and nonBLM-administered lands. See Chapter 3 (Fish section) and Appendix J - Fish for details on the wood recruitment model. The potential wood contribution is not a prediction of actual instream conditions at a specific point in time, but represents a potential contribution to instream wood based on forest conditions over time. The analysis describes:

- large wood contribution to fish-bearing streams from BLM-administere ${ }^{15}$ lands for the entire planning area, by physiographic province ${ }^{16}$

- large wood to non-fish-bearing streams from BLM-administered lands for the entire planning area, by physiographic province

- small functional wood contribution to fish-bearing and non-fish-bearing streams for the entire planning area, by physiographic province

- large wood contribution to fish-bearing stream channels across all ownerships for the entire planning area, by physiographic province

\footnotetext{
${ }^{15}$ For this analysis, the wood contribution from BLM-administered lands is the contribution from BLM-administered lands to streams on both BLM-administered lands and non-BLM-administered lands.

${ }^{16}$ See Appendix I - Water for a description of physiographic provinces.
} 
For this analysis, trees greater than 20 inches diameter (i.e., dbh - diameter at breast height) are considered large wood. The analysis uses this size threshold to maintain consistency with the structural stage classification of forests, which uses the density of trees greater than 20 inches in diameter as a threshold for the definition of mature \& structurally complex forests (see Forest Structure and Spatial Pattern in Chapter 3). Depending on stream size, trees less than 20 inches diameter can also function in smaller streams if they are "pool-forming" and are hereafter referred to as small functional wood (see the Fish section of Chapter 3). Because larger pieces have a greater influence on fish habitat and physical processes in stream channels than smaller pieces (Dolloff and Warren 2003), large wood and small functional wood are analyzed separately.

The results in this analysis describe potential wood recruitment in pieces/mile/year. Depending on the lifespan of the wood recruited and the rate of depletion, the differences in annual potential wood recruitment among alternatives could accumulate over time, so that relatively small differences in annual potential wood recruitment among alternatives would result in larger differences in in-stream accumulations over longer time periods.

This analysis makes frequent comparisons of the potential wood recruitment under the alternatives to potential wood contribution under the No Harvest reference analysis. As explained in the Introduction of Chapter 4, the reference analysis is not a reasonable alternative, because it would not meet the purpose and need for the action. There are no standards or thresholds for potential wood recruitment, but the No Harvest reference analysis provides a point of comparison for the effects of the alternatives. Specifically in this analysis, the No Harvest reference analysis helps provide context for evaluating the magnitude of differences among the alternatives in potential wood recruitment over time.

As explained in Chapter 3, in Forest Structure and Spatial Pattern, the classification of structural stage conditions for 2006 differ slightly among the alternatives because of differences in how the inventory information is assembled for modeling under each alternative. The differences in the assembly of inventory information have a lesser effect on 2016 modeling results, and a negligible effect on modeling results for later years. Consistent with the descriptions of current conditions in the Forest Structure and Spatial Pattern section of Chapter 3 , this analysis uses the 2006 data from Alternative 3 for all alternatives. Therefore, the potential wood recruitment in 2016 cannot be precisely compared to the 2006 data for some alternatives, for the sake of providing a consistent description of current conditions. This does not prevent a reasonable comparison of the alternatives, because effects on potential wood recruitment are inherently long term, and effects in 10 years do not provide a reasonable basis for comparing the effects of the alternatives.

On BLM-administered lands:

- The large wood contribution to fish-bearing and non-fish-bearing streams would increase from current conditions under all alternatives. In 2106, the large wood contribution would be similar under the No Action Alternative and the PRMP, and under these two alternatives would be greater than under the other alternatives. See Figure 4-155 (Potential large wood contribution from all sources to all streams for the entire planning area). The differences in potential large wood recruitment among the alternatives in 2106 would be less than the difference between all of the alternatives and the current condition.

- The small functional wood contribution to fish-bearing and non-fish-bearing streams would very slightly increase from current conditions under the No Action Alternative and very slightly decrease under the PRMP and Alternatives 1, 2 and 3. In 2106, the small functional wood contribution would be greatest under the No Action Alternative, followed by the PRMP, Alternative 1, Alternative 2, and Alternative 3. See Figure 4-156 (Potential small wood contribution from all sources to all streams for the entire planning area).

The wood recruited from different source areas (riparian, debris flow, and channel migration) varies both temporally and spatially. Therefore, this analysis also determines the potential wood contribution from each source separately, rather than a combined annual average, in order to evaluate the effects of the alternatives on these processes separately. The analysis compares the wood contribution under each alternative over time to the current condition and to the wood contribution under the No Harvest reference analysis. 
Figure 4-155. Potential large Wood Contribution From All Sources For The Planning Area In 2106 By Alternative And The No Harvest Reference Analysis

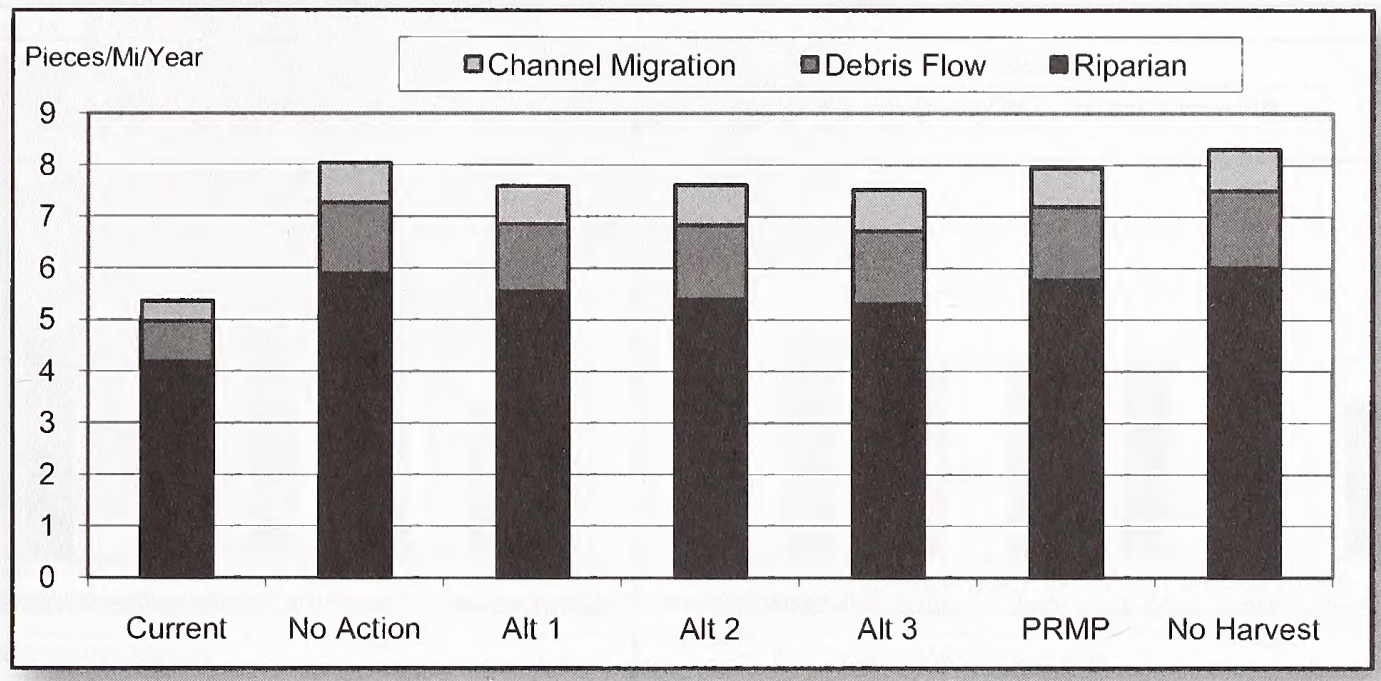

Figure 4-156. Potential Small Functional Wood Contribution From All Sources For The Planning Area In 2106 By Alternative And The No Harvest Reference Analysis

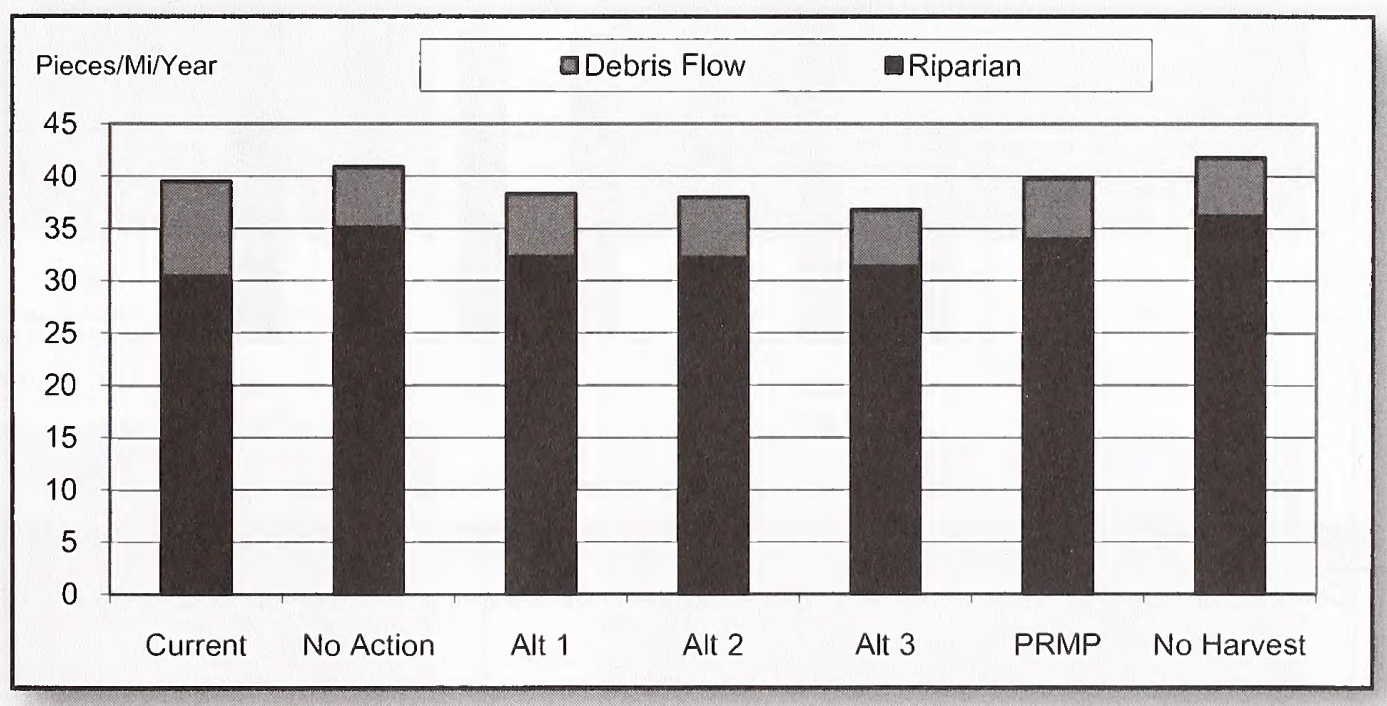

\section{Large Wood Contribution to Fish-bearing and Non-Fish-bearing Streams}

In all provinces, the potential large wood contribution to fish-bearing and non-fish-bearing stream channels would increase over time from BLM-administered lands under all alternatives, although the rate of increase would vary by alternative. See Figure 4-157 (Potential large wood contribution from all sources for the planning area in 2106 by alternative and the No Harvest reference analysis for each province).

\section{Riparian Sources}

Over long time periods, riparian sources would be the largest source of potential large wood contribution in all provinces under all alternatives. The potential large wood contribution to fish-bearing and non fishbearing stream channels from riparian sources would increase over time from BLM-administered lands in all provinces under all alternatives, although the rate of increase would vary by alternative. The potential 
Figure 4-157. Potential Large Wood Contribution From All Sources For The Planning Area In 2106 By Alternative And The No Harvest Reference Analysis For EACH PROVINCE

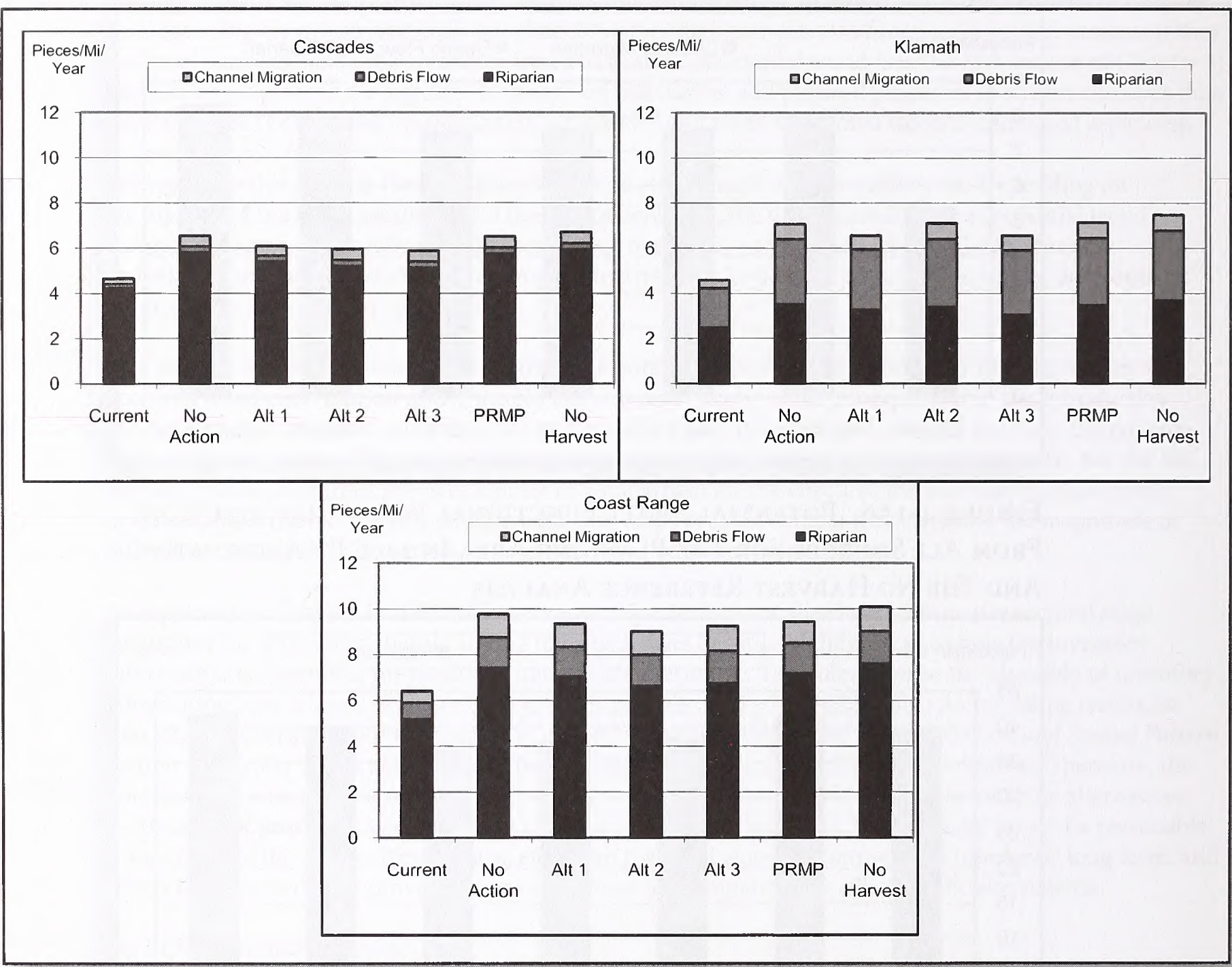

NOTE: The "Cascades Province" in this analysis includes the West Cascades, Eastern Cascades, and Willamette Valley Provinces.

large wood contribution to fish-bearing streams would increase to a greater degree under the PRMP, No Action Alternative, and Alternative 1, than under Alternatives 2 and 3.

The potential large wood contribution from riparian sources would increase under all alternatives, because the riparian management areas (or riparian reserves) under every alternative would include all or most of the riparian wood source areas, particularly along fish-bearing and perennial stream channels (see the Fish section of Chapter 3). See Figure 4-158 (Perennial and fish-bearing stream riparian management areas).

Under all alternatives, the Riparian Management Areas (or Riparian Reserves) would become dominated by mature \& structurally complex forest over time. See Figure 4-159 (Forest structural stage in the riparian management areas by alternative). As the amount of mature \& structurally complex forests increases within these source areas, the availability of trees that could potentially be delivered to stream channels would also increase. 
Although the large wood contribution would increase under all alternatives, it would increase the most under the No Action Alternative, Alternative 1, and the PRMP, because the riparian management areas (or riparian reserves) under these alternatives would include more of the riparian wood source area than under Alternatives 2 and 3. The majority of wood delivered to stream channels from riparian wood source areas is recruited from within a slope distance equal to one tree height from the stream (FEMAT 1993, Everest and Reeves 2007). The Riparian Management Areas (or riparian reserves) under the No Action Alternative, Alternative 1, and the PRMP would be at least one site-potential tree height in width along perennial and fish-bearing streams. For example, in the Coast Range Province, nearly all the potential large wood contribution to fish-bearing streams under the PRMP, No Action Alternative, and Alternative 1 would come from within the riparian management area (or riparian reserve) land use allocation. See Figure 4-160 (Percent of riparian large wood contribution to fish-bearing streams by Land Use Allocation at 2106 in the Coast Range).

On intermittent, non-fish-bearing streams, the Riparian Management Areas under all action alternatives would be less than one site-potential tree height. See Figure 4-161 (Boundaries of riparian management areas for each alternative on non-fish-bearing intermittent channels).

Under Alternatives 2 and 3, a greater portion of the potential wood contribution to streams from riparian wood source areas would be recruited from within the harvest land base than under the No Action Alternative, Alternative 1, or the PRMP. For example, in the Coast Range Province in 2106, the percentage of the potential large wood contribution to non-fish-bearing streams from riparian sources to all streams that would come from the harvest land base would be $3 \%, 5 \%, 19 \%, 20 \%$, and $5 \%$, under the No Action Alternative, Alternatives 1, 2, and 3, and the PRMP, respectively. See Figure 4-162 (Percent of riparian large wood contribution to non-fish-bearing streams by Land Use Allocation at 2106 in the Coast Range Province).

Timber harvest would reduce the number of trees available for potential delivery as large wood from riparian wood source areas within the harvest land base. The portions of the riparian wood source areas within the harvest land base under Alternatives 2 and 3 would still be capable of delivering large wood to the extent they would be in mature \& structurally complex forest. Under Alternative 2, there would be $37 \%$ of the harvest land base in mature \& structurally complex forest in 2106 . Alternative 3 would have $59 \%$ of the harvest land base in mature \& structurally complex forest in 2106. See Figure 4-163 (Structural stage abundances in the harvest land base, by alternative).

Figure 4-160. Percent Of Riparian Large Wood Contribution To Fish-Bearing Streams By Land Use Allocation At 2106 In The Coast Range

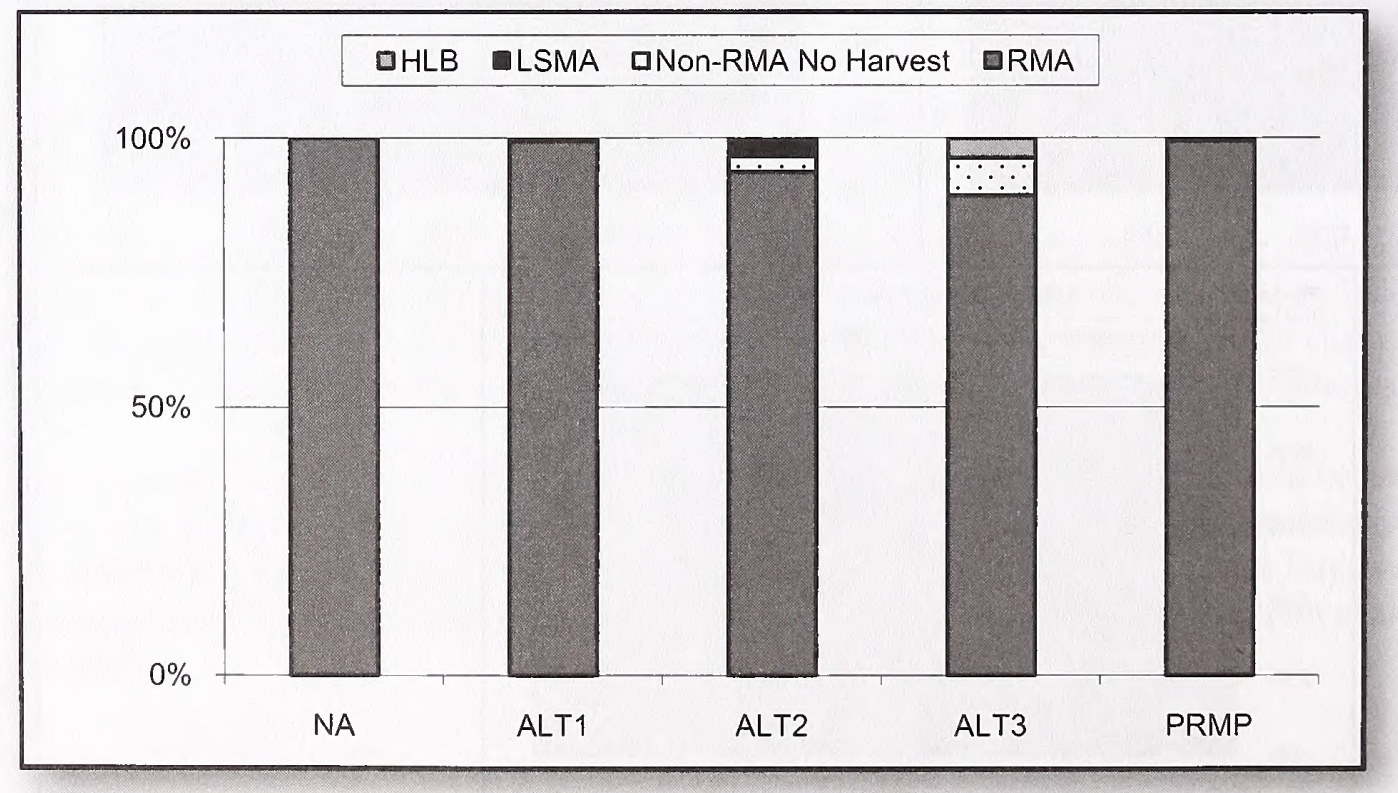


Figure 4-161. Boundaries Of Riparian Management Areas For Each Alternative On Non-Fish-Bearing Intermittent Channels

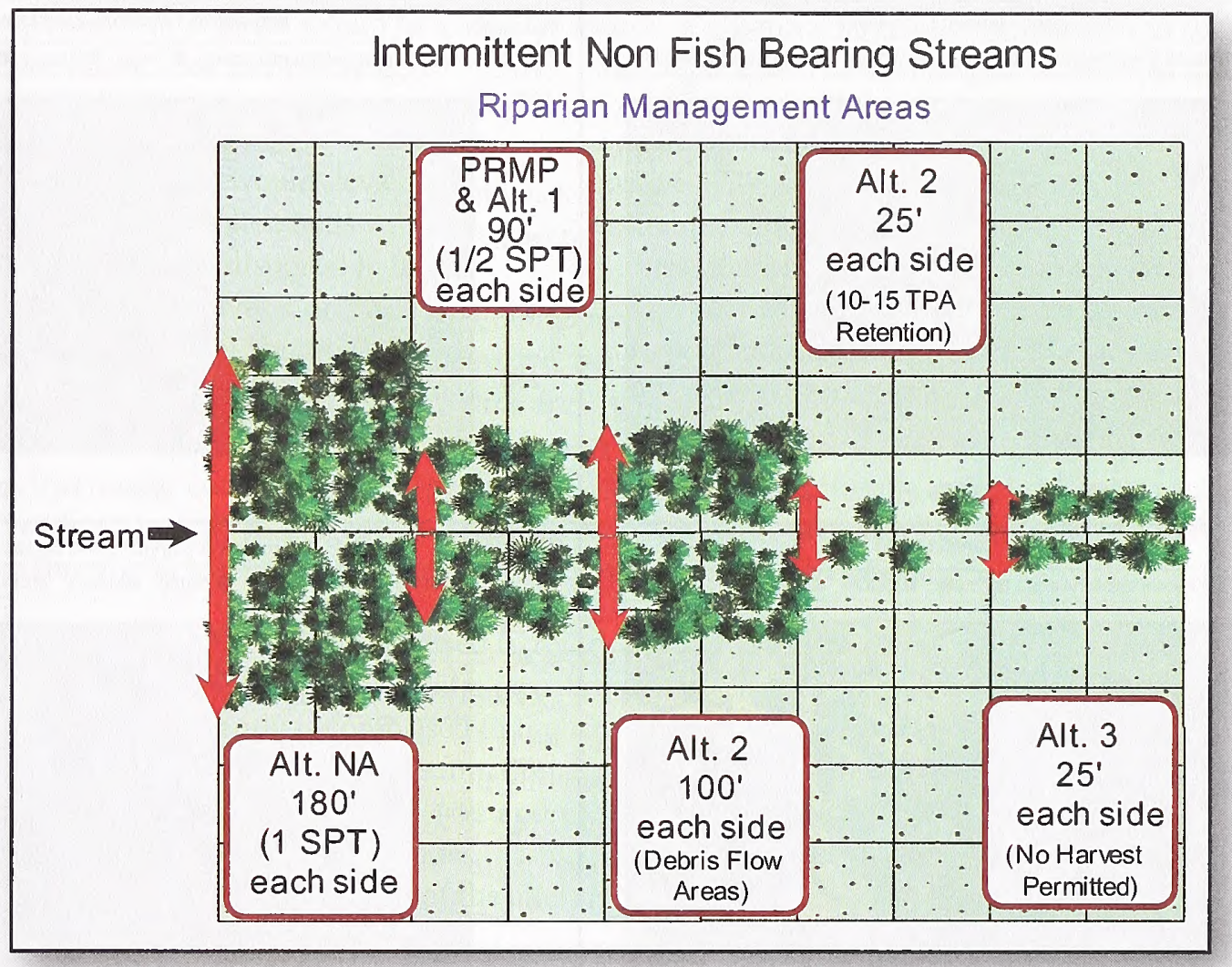

Figure 4-162. Percent Of Riparian Large Wood Contribution To Non-FishBearing Streams By Land Use Allocation At 2106 In The Coast Range Province

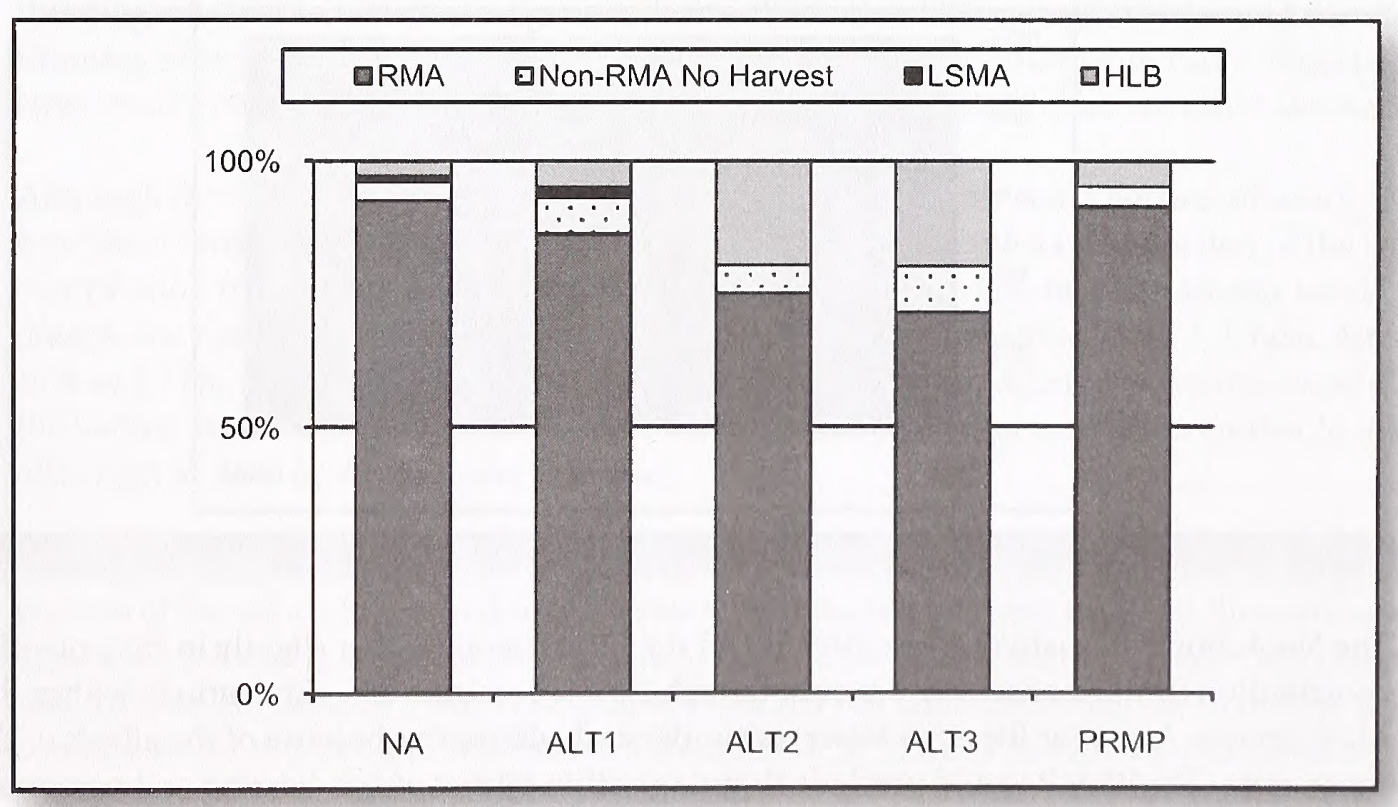


Figuire 4-163. Structural Stage Abundances In The Harvest land Base By Alternative

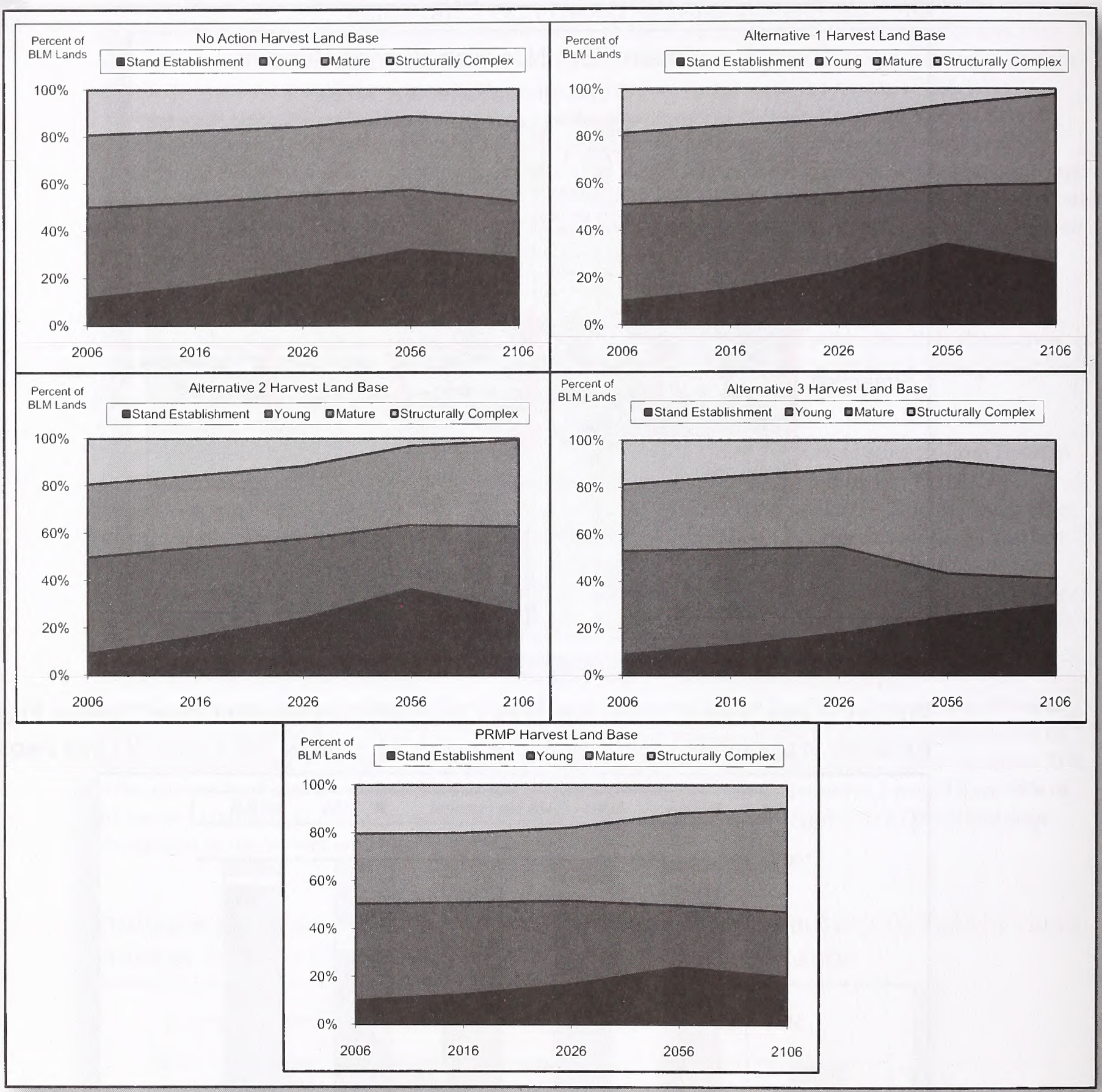

The No Action Alternative, Alternative 1, and the PRMP would differ slightly in the potential large wood contribution from riparian sources even though riparian sources areas are entirely within Riparian Management Areas (or Riparian Reserves) under each alternative because of the effects of thinning within those areas. The PRMP would preclude thinning within 60 feet of fish-bearing and perennial stream channels, and 35 feet of intermittent channels. These areas closest to streams have a larger effect on riparian recruitment rates than areas further from the streams. See Appendix J-Fish, Figure J-29 (Riparian wood recruitment at year 2106 under the PRMP with and without No Harvest buffers in the Cascades Province). The exclusion of thinning near streams under the PRMP would result in higher potential wood contribution from riparian sources than Alternative 1 in some provinces, even though the riparian management areas are the same width. 


\section{Debris Flow Sources}

Debris flow sources would be a smaller source of potential large wood contribution than riparian sources over long time periods (e.g., 100 years), ${ }^{17}$ but larger than channel migration sources under all alternatives. Refer to Figure 4-155 (Potential large wood contribution from all sources for the planning area in 2106 by alternative and the No Harvest reference analysis). The potential large wood contribution to stream channels from debris flow sources would increase in all provinces under every alternative, although the rate of increase would vary by alternative and province.

Similar to riparian sources, the potential large wood contribution stream channels from debris flow sources would increase under every alternative, because the abundance of mature \& structurally complex forests would increase in large wood source areas under every alternative over time, and because the areas outside the riparian management area would contribute large wood to the extent they would be in mature \& structurally complex forest. The amount of mature \& structurally complex forests would increase similarly within Riparian Management Areas (or Riparian Reserves) under all alternatives. Refer to Figure 4-159 (Forest structural stage in the riparian management areas by alternative).

The rate of increase in potential large wood contribution to fish-bearing stream channels from debris flow sources would vary among alternatives, because the amount of debris-flow prone headwater stream channels allocated to riparian management areas (or riparian reserves) would vary among alternatives. Headwater stream channels also differ in their susceptibility to debris flows. Research from the Coastal Landscape Analysis and Modeling Study (CLAMS) indicates that a relatively small portion of headwater streams in a watershed deliver the majority of large wood to stream channels (Miller and Burnett 2007b). These steep, loworder streams have a higher probability of providing wood to debris flows than other parts of the landscape. Management actions along these streams would have a disproportionately greater influence on the potential delivery of wood from debris flows than management actions elsewhere in debris-flow source areas. The amount of thinning near these steep, low-order streams would vary among the alternatives, causing some variation in the potential large wood contribution among alternatives. Because the PRMP would exclude thinning adjacent to streams to a greater degree than other alternatives, there would therefore be less thinning near steep, low-order streams than other alternatives, which would contribute to greater potential large wood contribution from debris flow sources under the PRMP than the other alternatives.

Although the PRMP and all other alternatives would incorporate some portion of debris-flow prone headwater stream channels into riparian management areas, a substantial portion of the large wood contribution from debris flow sources to fish-bearing and non-fish-bearing streams would come from outside the riparian management area, particularly under Alternatives 2 and 3. Under Alternatives 2 and 3 , $17 \%$ and $22 \%$, respectively, of the large wood contribution from debris flow sources would be delivered from the harvest land base. See Figure 4-164 (Percent of debris flow large wood contribution to streams by land use allocation at 2106 in the Cascades Province).

Timber harvest would reduce the number of trees available for potential delivery as large wood in the portion of the debris flow wood source areas within the harvest land base, but these areas would still be capable of delivering large wood to the extent they would be in mature \& structurally complex forest. As noted above, Alternative 2 would have $37 \%$ of the harvest land base would be in mature \& structurally complex forest in 2106, and Alternative 3 would have 59\%. Refer to Figure 4-163 (Structural stage abundances in the harvest land base, by alternative).

The analysis segregates the potential large wood contribution from debris flow sources by the diameter of the large wood and the size of the channel to which the wood would be potentially delivered. The amount of larger diameter trees ( $>30$ inches) is important in debris flow source areas where larger trees can be

${ }_{17}^{7}$ Debris flows vary spatially and temporally. At the watershed or reach scale, some years may have no debris flow wood contribution because recurrence intervals span centuries. When averaged out to an annual rate, the contribution would be smaller than riparian inputs, but the volume of wood delivered in any debris flow may be greater than the riparian input for many years following the debris flow. 
Figure 4-164. Percent Of Debris Flow Large Wood Contribution By Land Use Allocation At 2106 In The Cascades Province

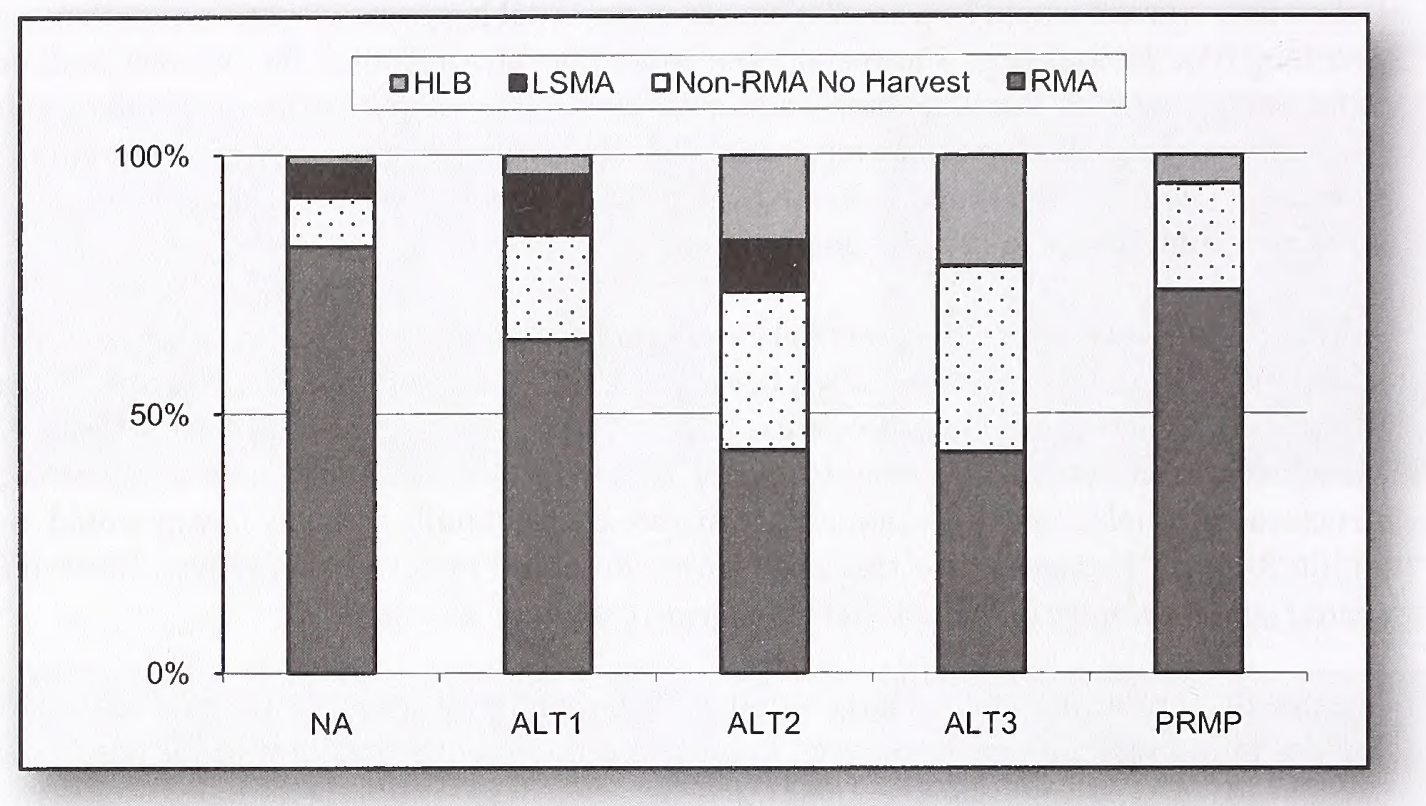

delivered to larger stream channels (greater than 66 feet wide), because larger diameter trees are necessary to be functional in larger stream channels (Beechie and Sibley 1997). The inherent potential for large wood to be delivered to larger streams from debris flow sources depends on topography and the amount of larger streams, which varies by province. Debris flows are one of the dominant geomorphic processes in steep mountainous terrain in the Coast Range Province, (May and Greswell 2004), and there are more large streams (greater than 66 feet wide) in the Coast Range Province than in the Klamath or Cascades Provinces. In the Cascades and Klamath Provinces, the majority of large wood is delivered to stream channels less than 66.6 feet wide from debris flow sources. Therefore, the potential delivery of large diameter wood to large streams from debris flow sources is of most relevance in the Coast Range Province.

In the Coast Range Province, the potential large wood contribution of trees greater than 30 inches in diameter to larger streams from debris flow sources under all alternatives would be greater than the contribution that the No Harvest reference analysis indicates would occur if no active management were to occur on BLM-administered lands. See Figure 4-165 (Potential and relative debris flow large wood contribution to streams from BLM-administered lands in the Coast Range Province). Although this seems counter-intuitive, there is a reasonable explanation. Thinning within debris flow wood source areas that would occur in a managed forest would shift forest stands in debris-flow-prone areas to fewer but larger diameter trees, compared to unthinned areas that would take place in an unmanaged forest that would occur in the No Harvest reference analysis. The greatest shift in the diameter of trees available for potential delivery would occur under the PRMP. Although the PRMP would exclude thinning from along streams, as described above, it would have more thinning elsewhere on the landscape than the other alternatives and, therefore, shift more stands with debris flow source areas to fewer, but larger diameter trees. This would result in more potential for large wood contribution of trees greater than 30 inches in diameter to larger streams from debris flow sources than other alternatives.

In the Klamath Province, there would be a greater amount of larger diameter trees under the PRMP and No Action Alternative than under the other alternatives, in part because thinning would result in larger diameter trees in debris flow source areas. However, in the Klamath Province, trees greater than 30 inches in diameter would generally not be capable of being delivered to larger streams (greater than 66 feet wide) from debris flow sources, because BLM-administered lands are generally not located near larger streams in the province. In this province, there is a greater importance of trees delivered to streams less than 66 feet 
Figure 4-165. Potential And Relative Debris Flow Large Wood Contribution To Streams From BlM-Administered Lands In The Coast Range Province

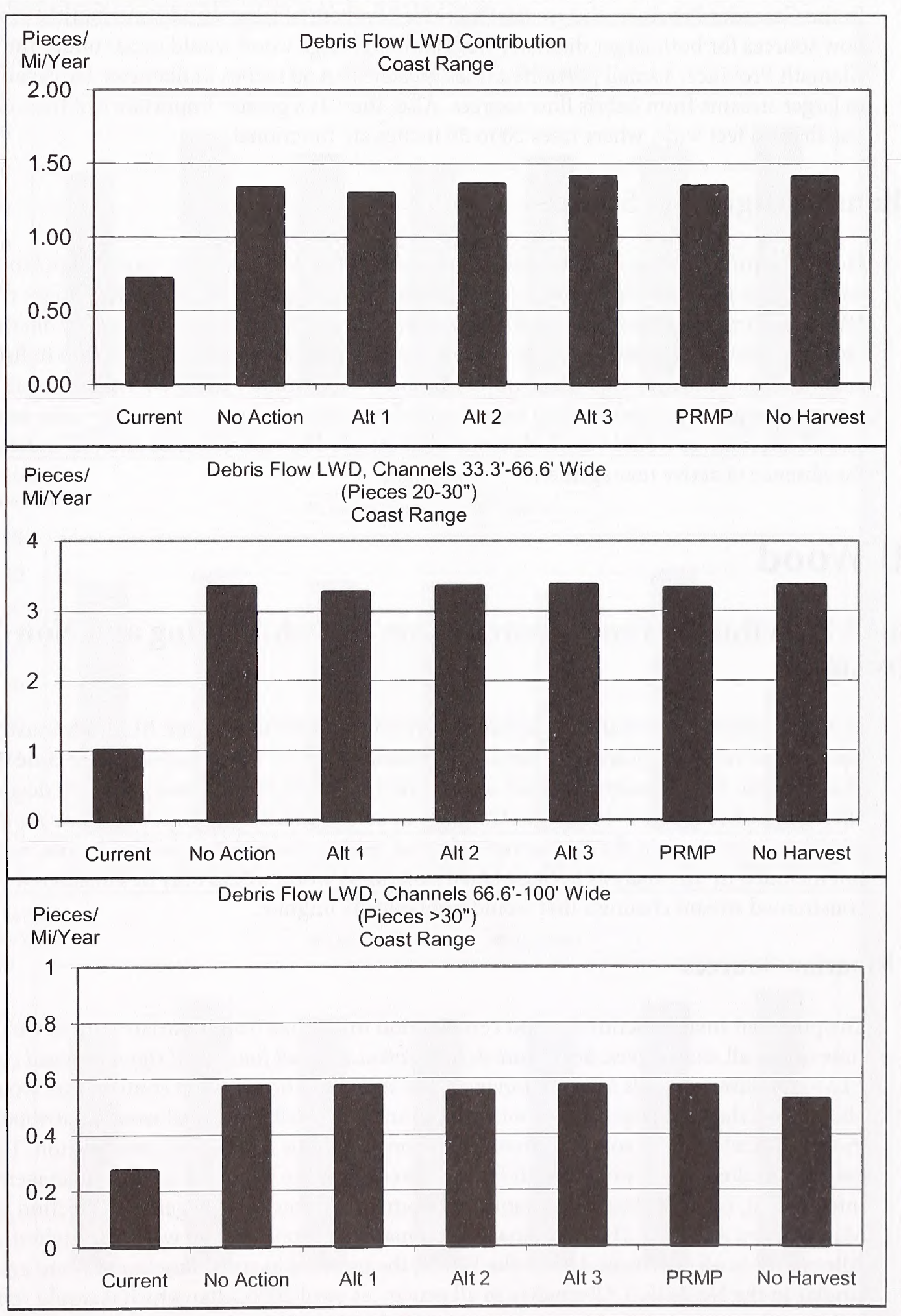


wide, where trees 20 to 30 inches in diameter are functional, and the greatest increase of total potential large wood contribution to streams from debris flow sources would occur under Alternative 2.

In the Cascades Province, the greatest increase of potential large wood contribution to streams from debris flow sources for both larger diameter trees and total large wood would occur under the PRMP. Similar to the Klamath Province, a small portion of trees greater than 30 inches in diameter are capable of being delivered to larger streams from debris flow sources. Also, there is a greater importance of trees delivered to streams less than 66 feet wide, where trees 20 to 30 inches are functional.

\section{Channel Migration Sources}

Over long time periods, channel migration sources would be a smaller source of potential large wood contribution than riparian sources or debris flow sources under all alternatives. Refer to Figure 4-155 (Potential large wood contribution from all sources for the planning area in 2106 by alternative and the No Harvest reference analysis). In all provinces, the potential large wood contribution to fish-bearing stream channels from channel migration sources would increase under every alternative. In all provinces, the potential large wood contribution from channel migration sources would vary little among the alternatives, and all alternatives would vary little from what the No Harvest reference analysis indicates would occur in the absence of active management.

\section{Small Wood}

\section{Small Functional Wood Contribution to Fish-bearing and Non-Fish-bearing Streams}

In all provinces, the potential small functional wood contribution from BLM-administered lands to fishbearing and non-fish-bearing streams from riparian sources would increase over time under all alternatives. The potential small functional wood contribution from debris flow sources would decrease under all alternatives. See Figure 4-166 (Potential small wood contribution to stream channels for the planning area in 2106 by alternative and the No Harvest reference analysis for each province). Channel migration sources are not included in this analysis because small functional wood would only be considered functional in smaller constrained stream channels that would not typically migrate.

\section{Riparian Sources}

The potential small functional wood contribution to streams from riparian sources would increase over time under all alternatives. See Figure 4-167 (Potential small functional riparian wood contribution from BLM-administered lands for each province).The small functional wood contribution would vary more among alternatives than the large wood contribution, and the small functional wood contribution would decrease in some decades under some alternatives, in contrast to the large wood contribution. The differences among the alternatives would result from differences in the widths of riparian management areas along intermittent, non-fish-bearing streams and from differences in management direction within Riparian Management Areas. In 2106, the small functional wood contribution would be highest under the No Action Alternative in all provinces. Under the PRMP, the increase in small functional wood contribution would be similar to the No Action Alternative in all provinces until 2056, after which it would remain approximately stable or decrease slightly. The increase in small functional wood contribution under the PRMP would be greater than under Alternative 1 in all provinces, even though the Riparian Management Area would be the same width under each alternative, because the PRMP would exclude thinning adjacent to streams, from where the majority of smaller functional wood would recruited. In all provinces, the small functional wood contribution would be lowest in 2106 under Alternatives 2 and 3, because regeneration harvest would occur within the riparian source area near intermittent non-fish-bearing streams, which 
Figure 4-166. Potential Small Functional Wood Contribution To Stream Channels For The Planning Area In 2106 By Alternative And The No Harvest Reference Analysis For Each Province

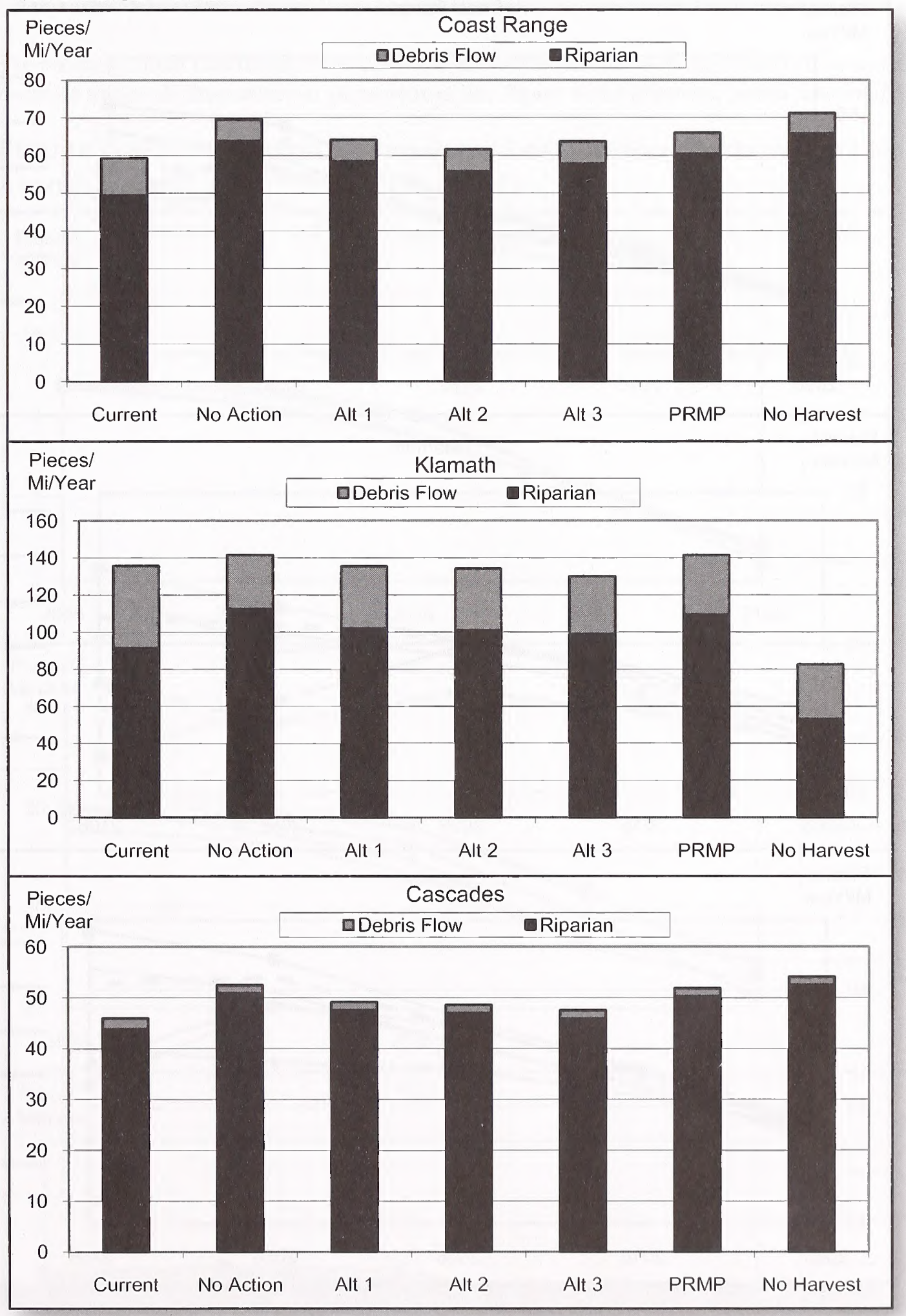


Figure 4-167. Potential Small Functional Riparian Wood Contribution To Streams From BLM-Administered Lands For Each Province

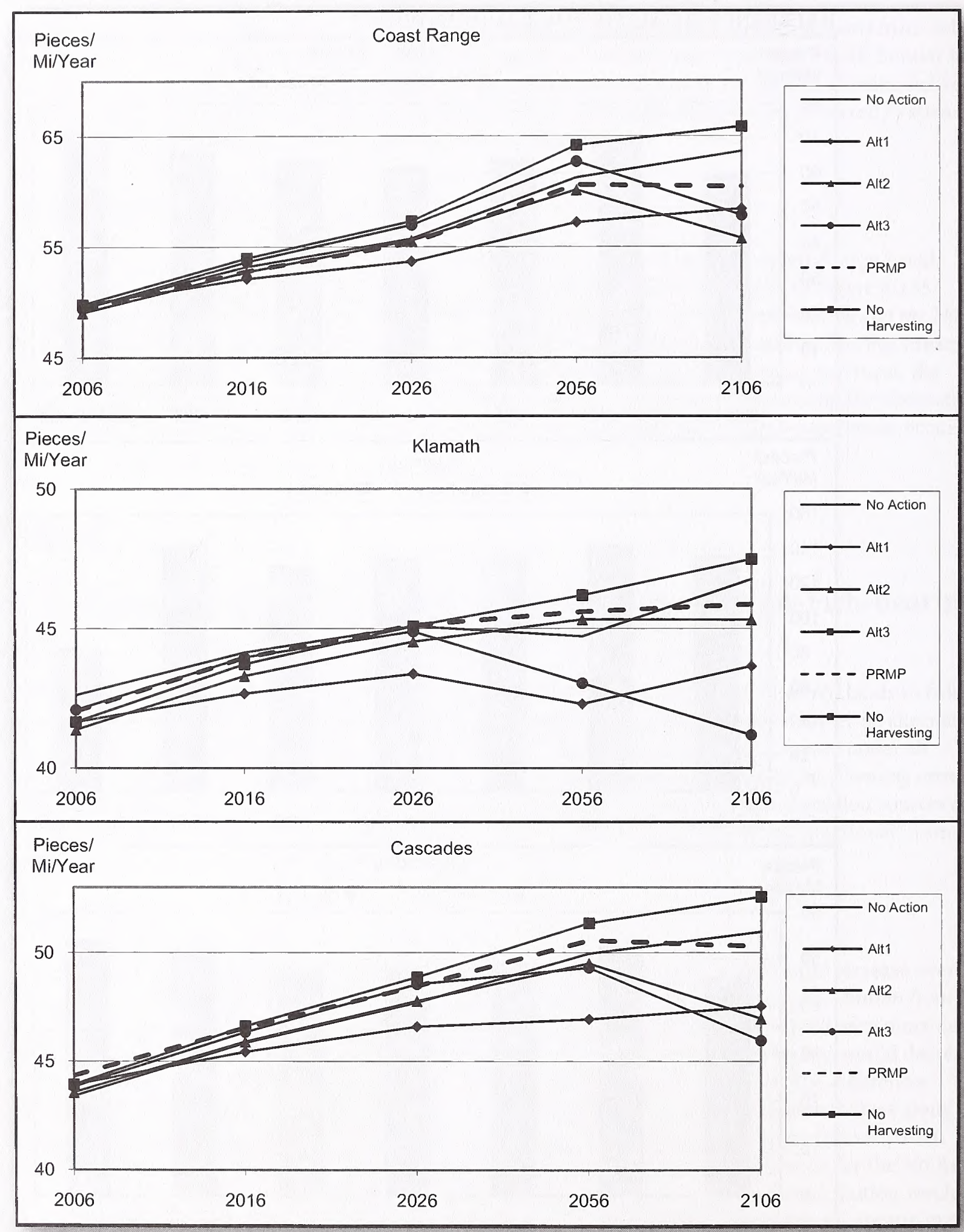


would have a 25-foot wide Riparian Management Area. Regeneration harvest within the riparian source area would temporarily reduce the supply of small functional wood following harvest.

\section{Debris Flow Sources}

The potential small functional wood contribution to stream channels from debris flow sources would decrease under all alternatives in all provinces. See Figure 4-168 (Potential debris flow small wood

Figure 4-168. Potential Debris Flow Small Wood Contribution From BlMAdministered Lands For Each Province

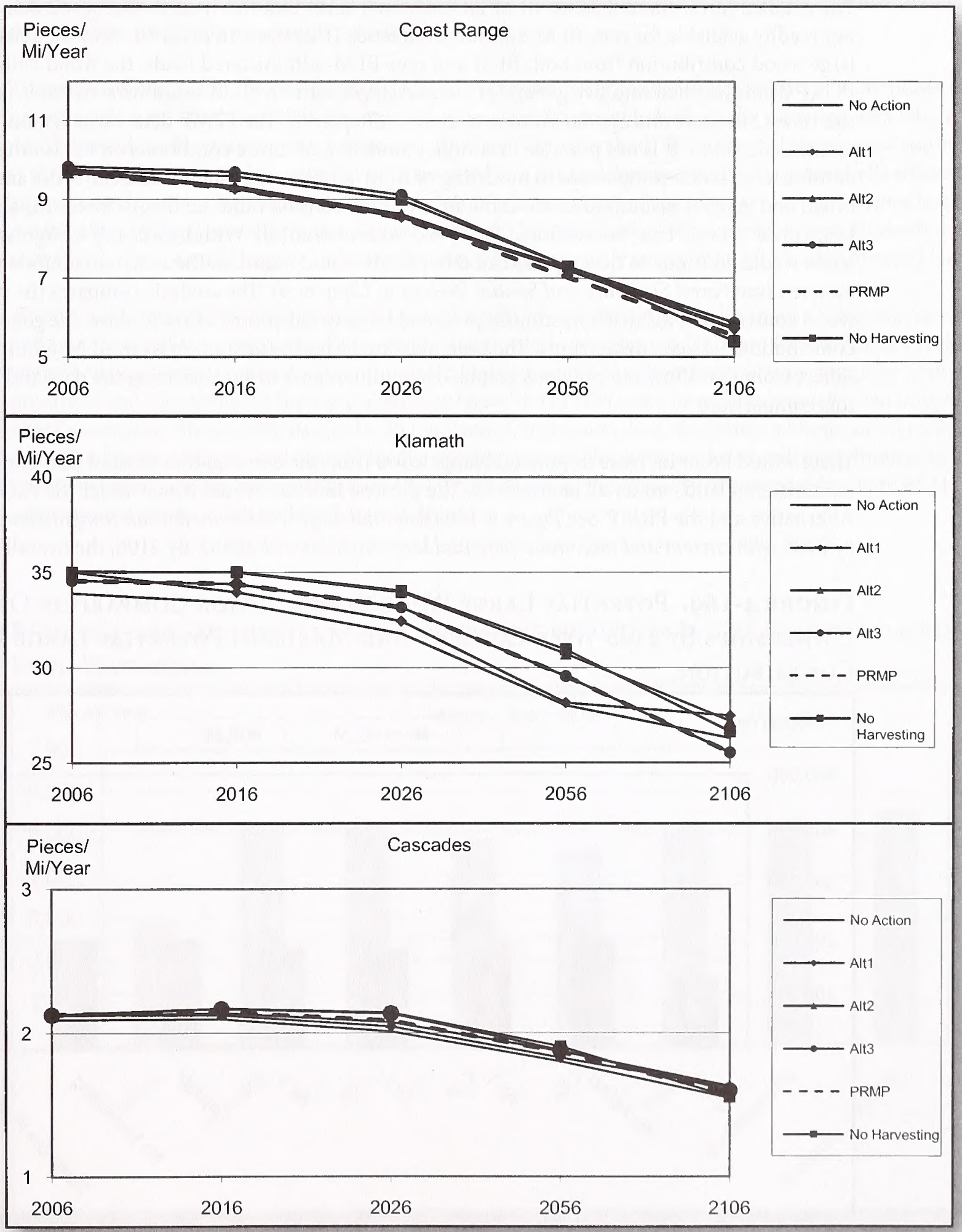


contribution from BLM-administered lands for each province). Young forests provide more small functional wood than mature \& structurally complex forests, and the abundance of young forests would decrease, and mature \& structurally complex forest would increase over time under all alternatives in all provinces (see the Forest Structure and Spatial Pattern section of Chapter 4). The No Harvest reference analysis indicates that the small functional wood contribution would decrease similarly to the alternatives, even in the absence of active management on BLM-administered lands.

\section{Large Wood Contribution Across All Ownerships, By Province}

The detailed forest stand data for BLM-administered lands that was used for the wood delivery model is not readily available for non-BLM-administered lands. Therefore, in order to show the relative potential large wood contribution from both BLM and non-BLM-administered lands, the wood delivery model used IVMP data, classified into five general structural stages for non-BLM-administered lands (as described in the Forest Structure and Spatial Pattern section of Chapter 3). The IVMP data, however, only describes the current condition. It is not possible to conduct modeling of future conditions on lands other than the BLMadministered lands comparable to modeling of BLM-administered lands. Therefore, the analysis relies on broad and general assumptions about the future conditions on other lands: All forest-capable lands in the U.S. Forest Service Late-Successional Reserves, Administratively Withdrawn, and Congressionally Reserve lands would continue to develop, and all other lands would maintain their current abundances and spatial patterns (see Forest Structure and Spatial Pattern in Chapter 4). The analysis compares the relative large wood contribution against a maximum potential large wood contribution to show the general relative contribution between ownerships. The potential large wood contribution from BLM-administered lands differs from that shown in previous graphs due to differences in summarizing the data and using the data for this comparison.

There would be an increase in potential large wood from the combination of BLM and non BLMadministered lands under all alternatives. The greatest increase would occur under the No Action Alternative and the PRMP. See Figure 4-169 (Potential large wood contribution comparison of all ownerships by 2106 with current and maximum potential large wood contribution). By 2106 , the overall potential large

Figure 4-169. Potential Large Wood Contribution Comparison Of All Ownerships By 2106 With Current And Maximum Potential Large Wood Contribution

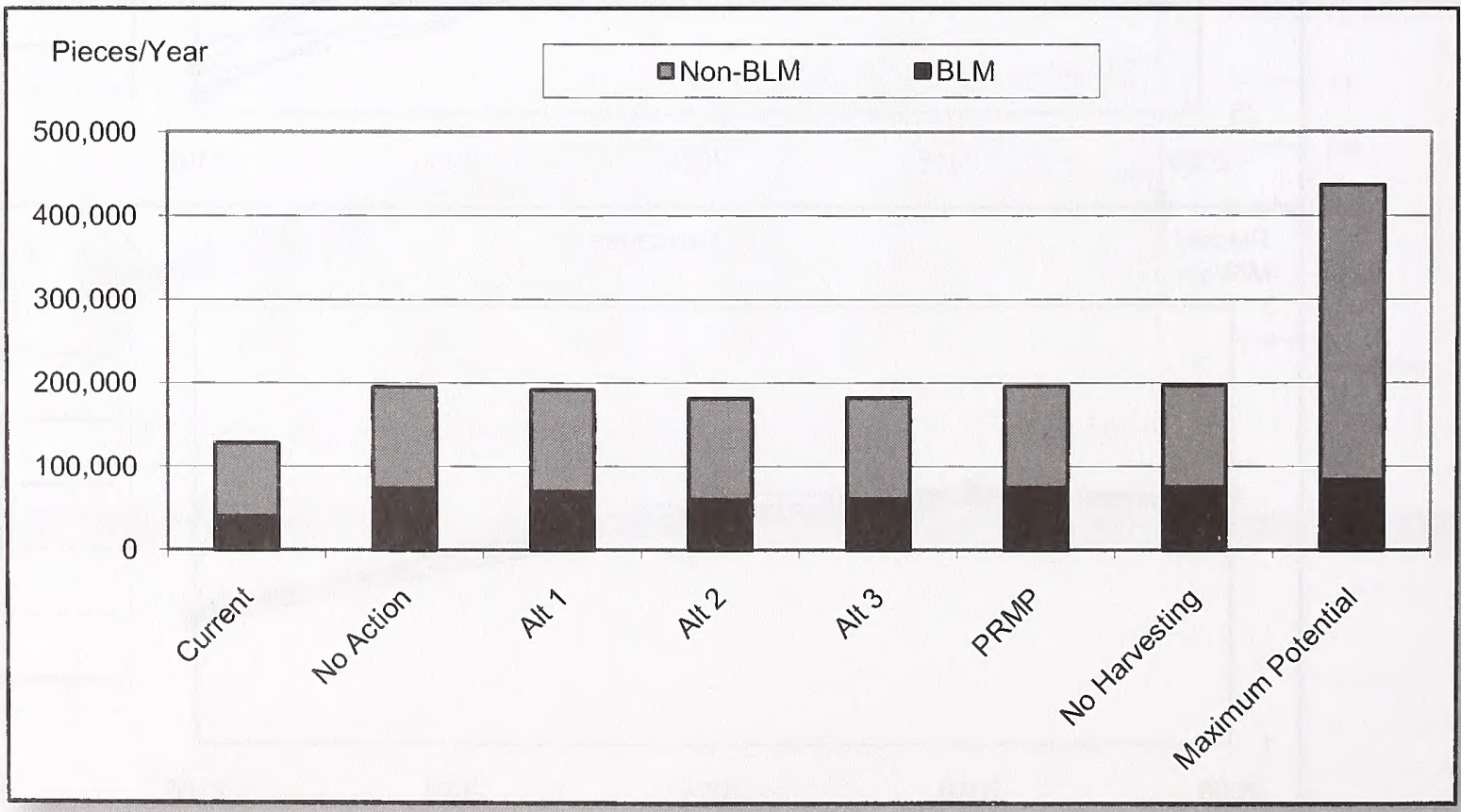


wood contribution from all sources, across all ownerships, would increase from the current condition. Although, the potential large wood contribution from BLM-administered lands would increase by 2106 similar to the contribution under the No Harvest reference analysis under every alternative, the overall large wood contribution would be substantially less than the maximum potential. This occurs because not all forests that are capable of delivery to streams would be within a mature \& structurally complex forest on non-BLM-administered lands by year 2106 , and because the BLM is rarely the predominant landowner within fifth-field watersheds in the planning area. The BLM-administered lands comprise only $16 \%$ of all forested lands within the planning area, which is too small an area to substantially increase the overall large wood contribution in a watershed to a level similar to the maximum potential. The No Harvest reference analysis indicates that, even if there were no active management on BLM-administered lands, the overall potential large wood contribution for all ownerships to streams at year 2106 would still be less than the contribution under the maximum potential.

There are differences in the overall increases in the potential large wood contribution that are masked by grouping all watersheds together. For example, there are three watersheds in the planning area where BLMadministered lands comprise more than two-thirds of the watershed. The potential large wood contribution is shown for the Rogue-Horseshoe Bend watershed as a general representation for watersheds where BLMadministered lands comprise more than two-thirds of the watershed. See Figure 4-170 (Potential large wood contribution in the Rogue-Horseshoe Bend watershed). In watersheds similar to the Rogue-Horseshoe Bend watershed, the potential large wood contribution would primarily occur from BLM-administered lands.

There are 30 watersheds in the planning area where BLM-administered lands comprise between one-third and two-thirds of the watershed. The potential large wood contribution is shown for the Evans Creek watershed as a general representation for watersheds where BLM-administered lands comprise between one-third and two-thirds of the watershed. See Figure 4-171 (Potential large wood contribution in the Evans Creek watershed). In watersheds similar to the Evans Creek watershed, the potential large wood contribution from BLM-administered lands would have a greater potential to increase the overall contribution in the watershed compared to the contribution that would occur in the majority of watersheds where BLMadministered lands comprise less than one-third.

Figure 4-170. Potential Large Wood Contribution In The Rogue-Horseshoe BEND WATERSHED

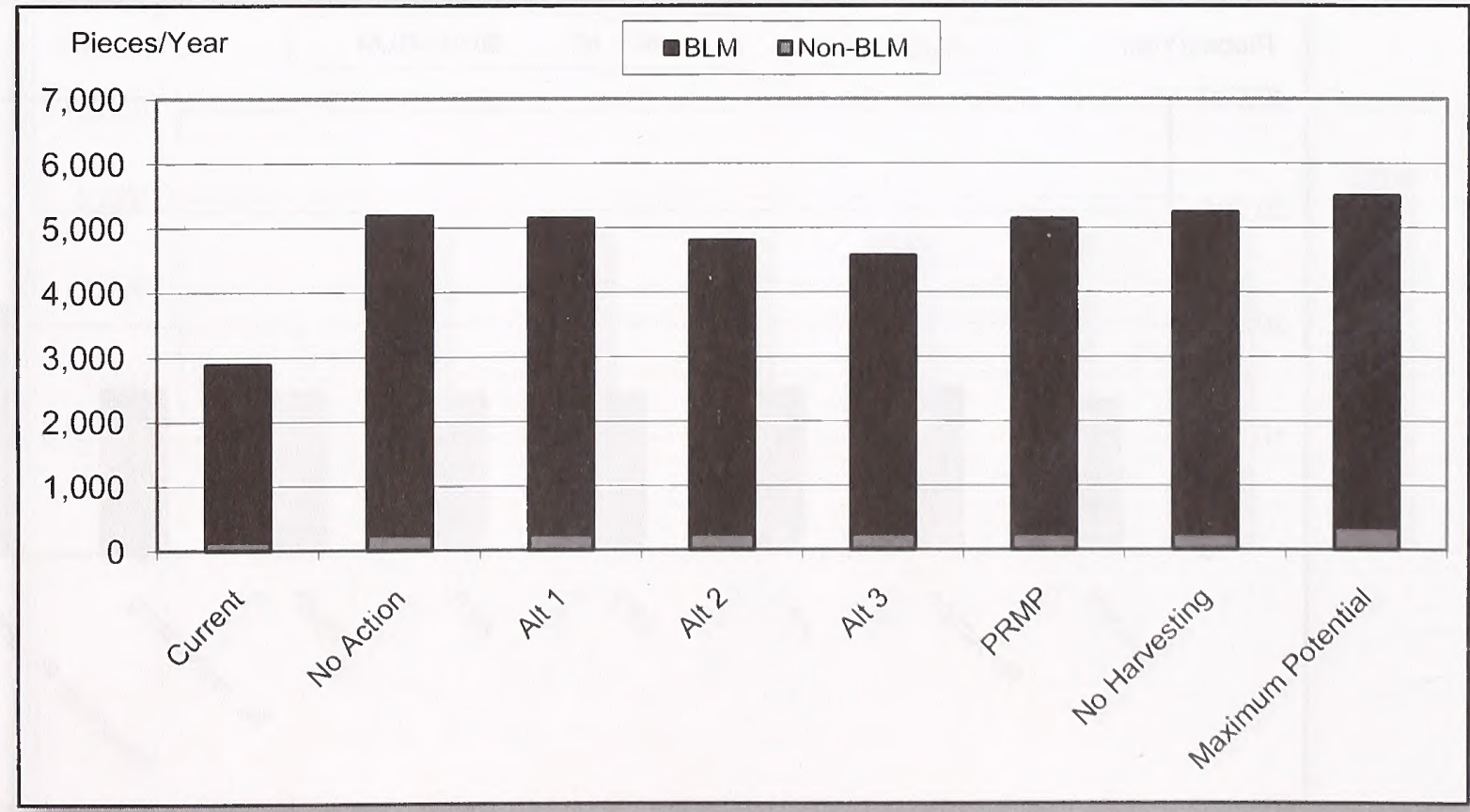


Figure 4-171. Potential Large Wood Contribution In The Evans Creek WATERSHED

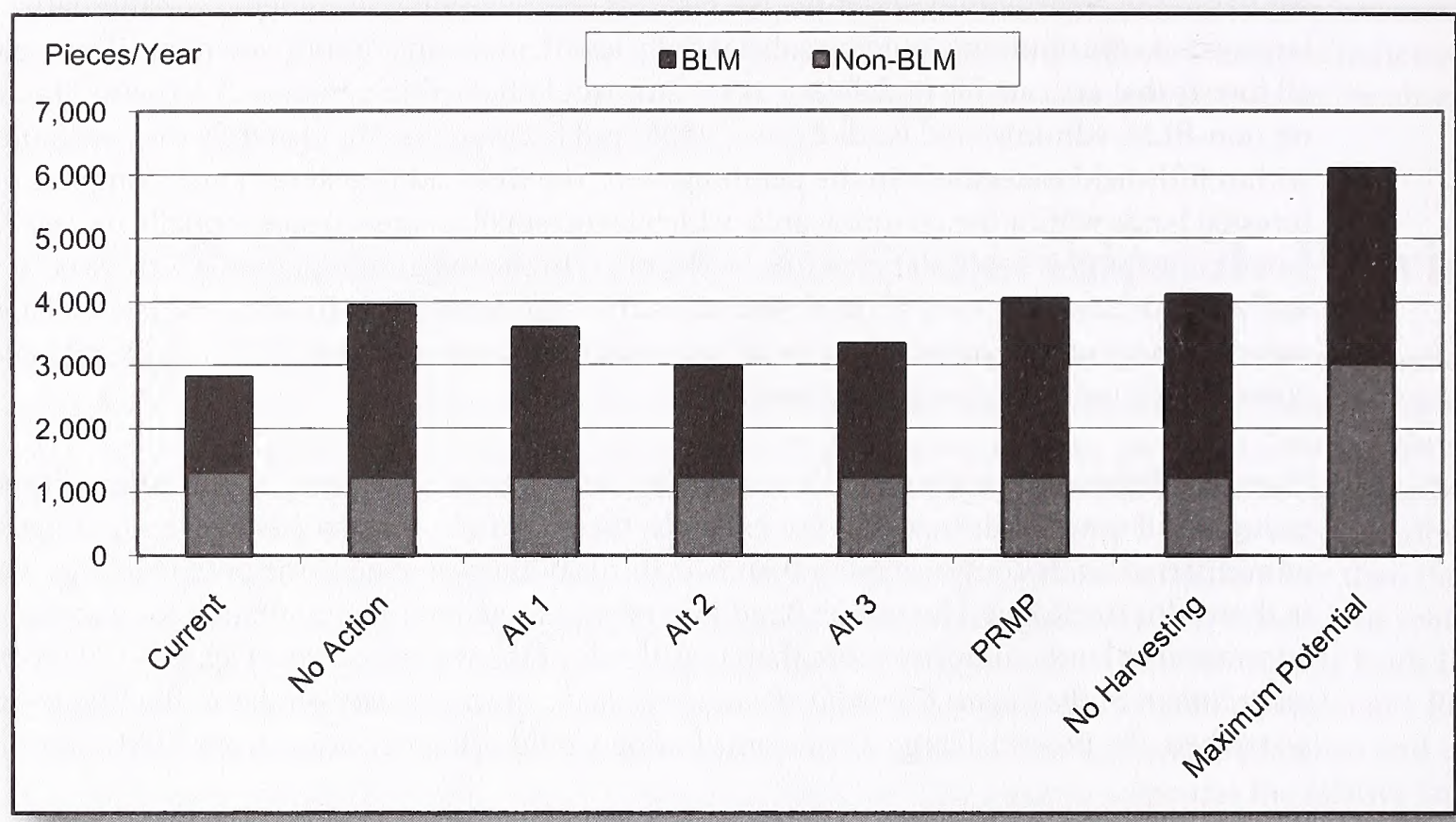

In the majority of watersheds, the BLM-administered lands comprise less than one-third of watersheds in the planning area (138 watersheds). The large wood contribution is shown for the Eagle Creek watershed as a general representation for watersheds where BLM-administered lands would not be the predominant landowner. In the majority of watersheds, the potential large wood contribution would increase slightly above current conditions. This occurs because BLM-administered lands comprise too small of an area to substantially increase the overall large wood contribution in a watershed to a level similar to the maximum potential. See Figure 4-172 (Potential large wood contribution in the Eagle Creek watershed).

Figure 4-172. Potential Large Wood Contribution In The Eagle Creek WATERSHED

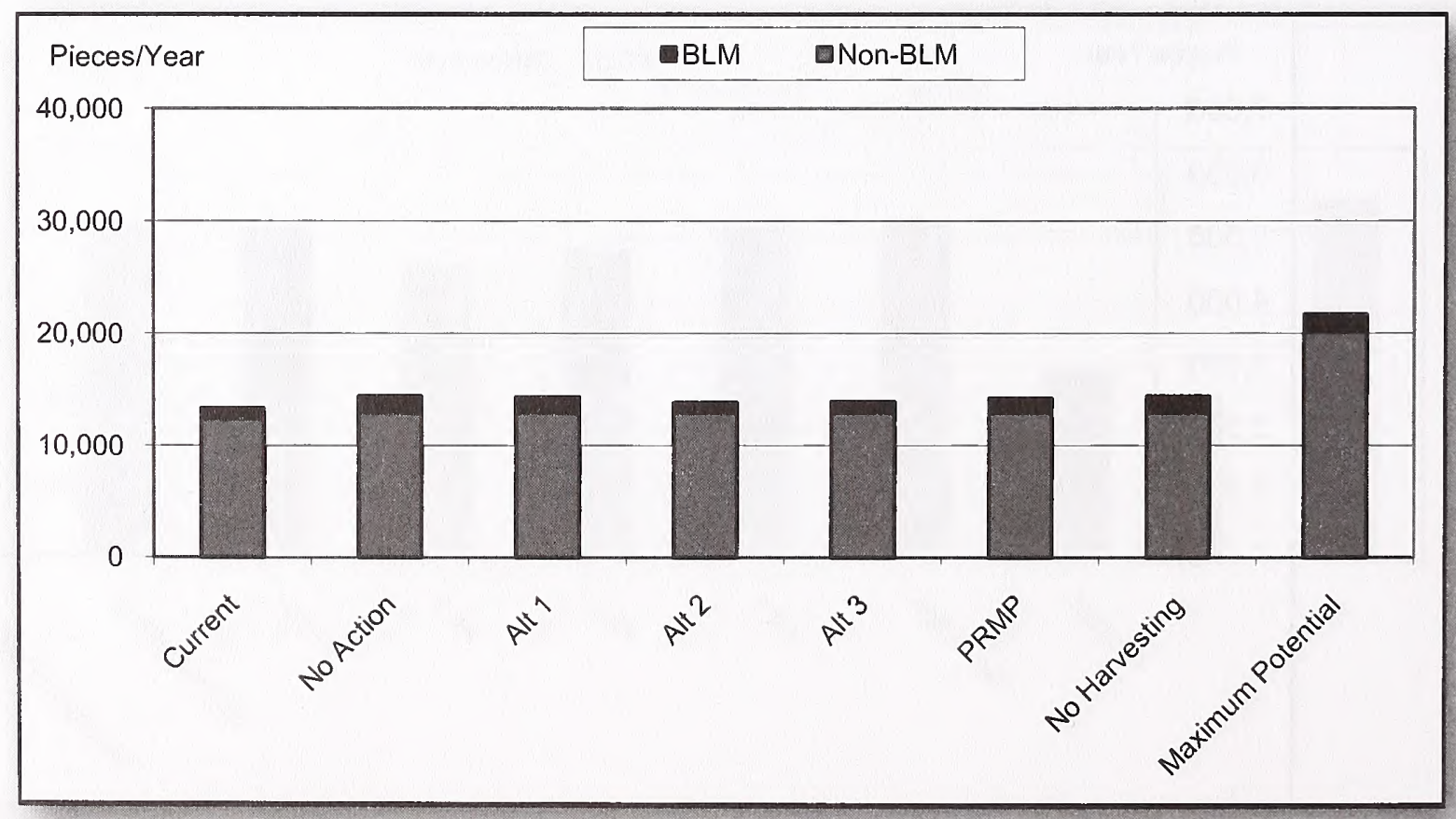


In some cases, federal ownerships other than BLM-administered lands would be the predominant landowner. The large wood contribution is shown for Chetco watershed as a general representation of the potential large wood contribution that would be typical in watersheds with a greater amount of other federal ownership. See Figure 4-173 (Potential large wood contribution in the Chetco watershed). In these watersheds, the overall potential large wood contribution would increase to a greater degree from non-BLM-

administered lands than BLM-administered lands, because the modeling relies on the assumption that all forest-capable lands in the Riparian, Administratively Withdrawn, Late-Successional, and Congressionally Reserved lands of the U.S. Forest Service would develop into mature \& structurally complex forests over time (See Chapter 4-Forest Structure and Spatial Pattern).

\section{Nutrient Input}

As described in the Fish section of Chapter 3, the type, successional stage, size, abundance, and overall stand composition of riparian vegetation within one-half site-potential tree height distance from the stream channel determines the amount of nutrient input to the stream channel from litterfall. The input of solar radiation to stream channels also contributes to stream energy and production and is also dependent on the forest structure near the stream channel. At the scale of this analysis, thresholds have not been established to determine the amount of organic input necessary to maintain food supplies for fish. Therefore, this analysis compares the abundance and spatial patterns of the riparian forest structure to the average historic conditions of forest structure in the planning area to determine effects of each alternative on the potential stream productivity from nutrient input, based on correlations of forest structure stage and stream productivity from O'Keefe and Naiman (2006). See the Fish section of Chapter 3. Average historic conditions do not represent a target or standard for management, but are used here to provide context for comparing relative effects of the alternatives in the absence of thresholds for nutrient input.

The Riparian Management Areas (or Riparian Reserves) under all of the alternatives have more stand establishment forests and less mature \& structurally complex forests currently than it did historically. Over time, the structural stage abundance within Riparian Management Areas would shift from being dominated by stand establishment and young forests, to mature \& structurally complex forests. The overall result of

Figure 4-173. Potential Large Wood Contribution In The Chetco Watershed

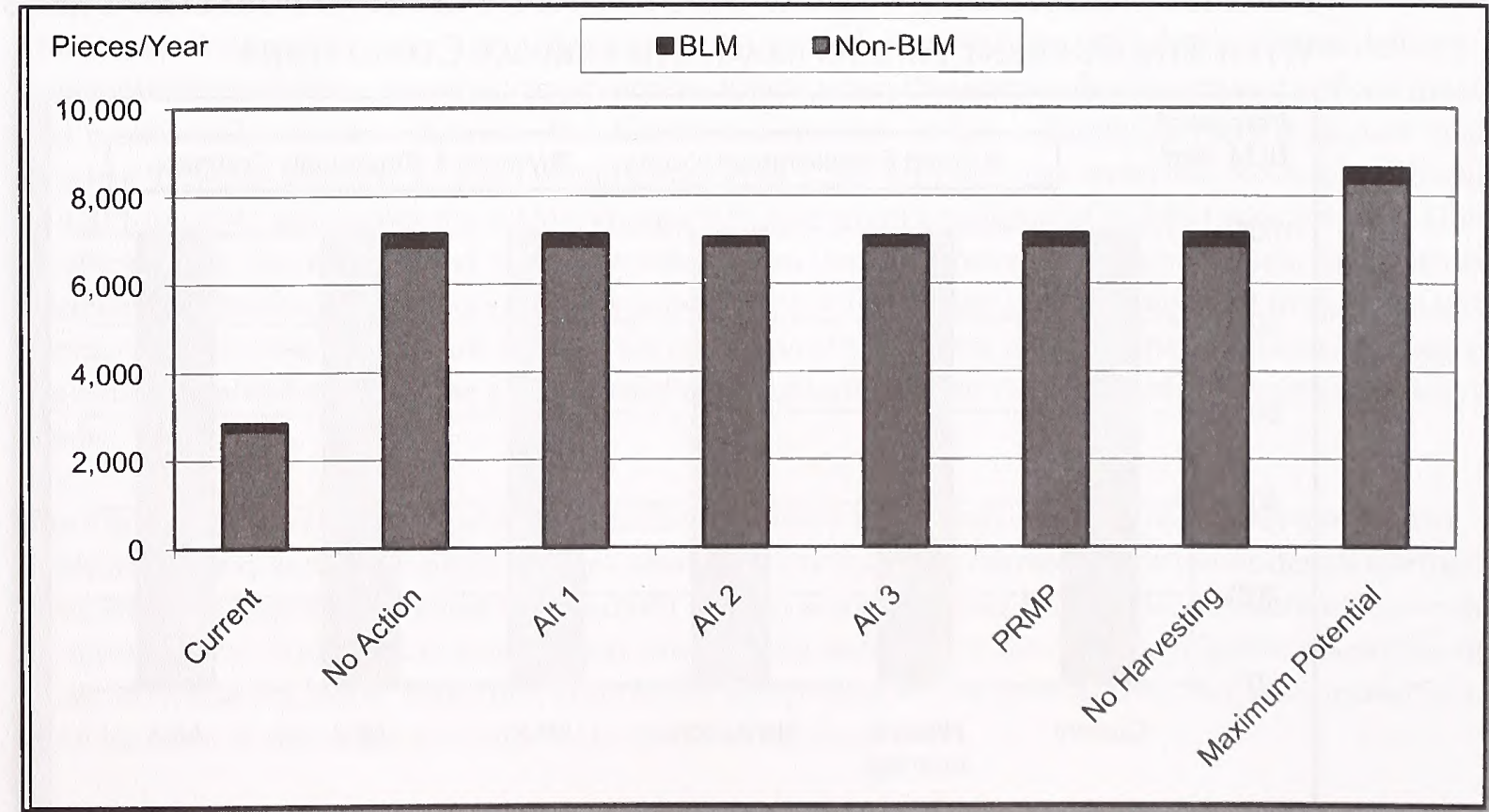


these changes would be a shift on BLM-administered lands from a condition where stream productivity from solar radiation in stand establishment and younger forests would dominate, to a condition where nutrient input from litterfall in mature \& structurally complex forests would dominate. Under the PRMP, No Action Alternative, Alternative 1, and Alternative 3, the amount of nutrient input to stream channels would increase over time from litterfall sources to above average historic conditions and decrease over time from solar radiation to below average historic condition as Riparian Management Areas (or Riparian Reserves) would become almost completely dominated by mature \& structurally complex forests. See Figure 4-174 (Comparison of the structural stage abundance within riparian management areas on BLM-administered forested lands by 2106 with the current and average historical conditions).

The abundance of structural stages within Riparian Management Areas under Alternative 2 would be most similar to the average historical conditions. Because of the more narrow riparian management widths areas along non-debris flow prone headwater channels, localized shifts in vegetation from timber harvest would occur in areas near the stream channel. Therefore, the amount of stand establishment within the Riparian Management Area would decrease to a lesser degree under Alternative 2 than under the other alternatives. Under Alternative 2, there would be a greater contribution to stream productivity from solar radiation and less nutrient input from litterfall sources than under the other alternatives.

However, BLM-administered lands comprise less than one-third of the majority of watersheds in the planning area and are typically intermingled with other ownerships where there would be a greater amount of stand establishment and young forests near stream channels. Therefore, increasing nutrient input from litterfall sources is likely more important than maintaining the historic condition on BLM-administered lands.

Thinning within Riparian Management Areas (or Riparian Reserves) would have little effect on nutrient input under all alternatives, because trees near the stream channel would be retained. Danehy et al. (2007) found little effect on instream flora, fauna, or macroinvertebrate assemblages due to thinning. Additionally, periphyton biomass was larger in thinned stands than in mature stands, and macroinvertebrate assemblages, biotic metrics, functional feeding group composition, and biomass measures were the same in both mature and thinned riparian stands (Danehy et al. 2007). This occurs because changes in abiotic and biotic features of these systems are less dramatic with the retention of trees near the channel than if all trees were removed

\section{Figure 4-174. Comparison Of The Structural Stage Abundance Within Riparian Management Areas On BLM-Administered Forested Lands By 2106 With The Current And Average Historical Conditions}

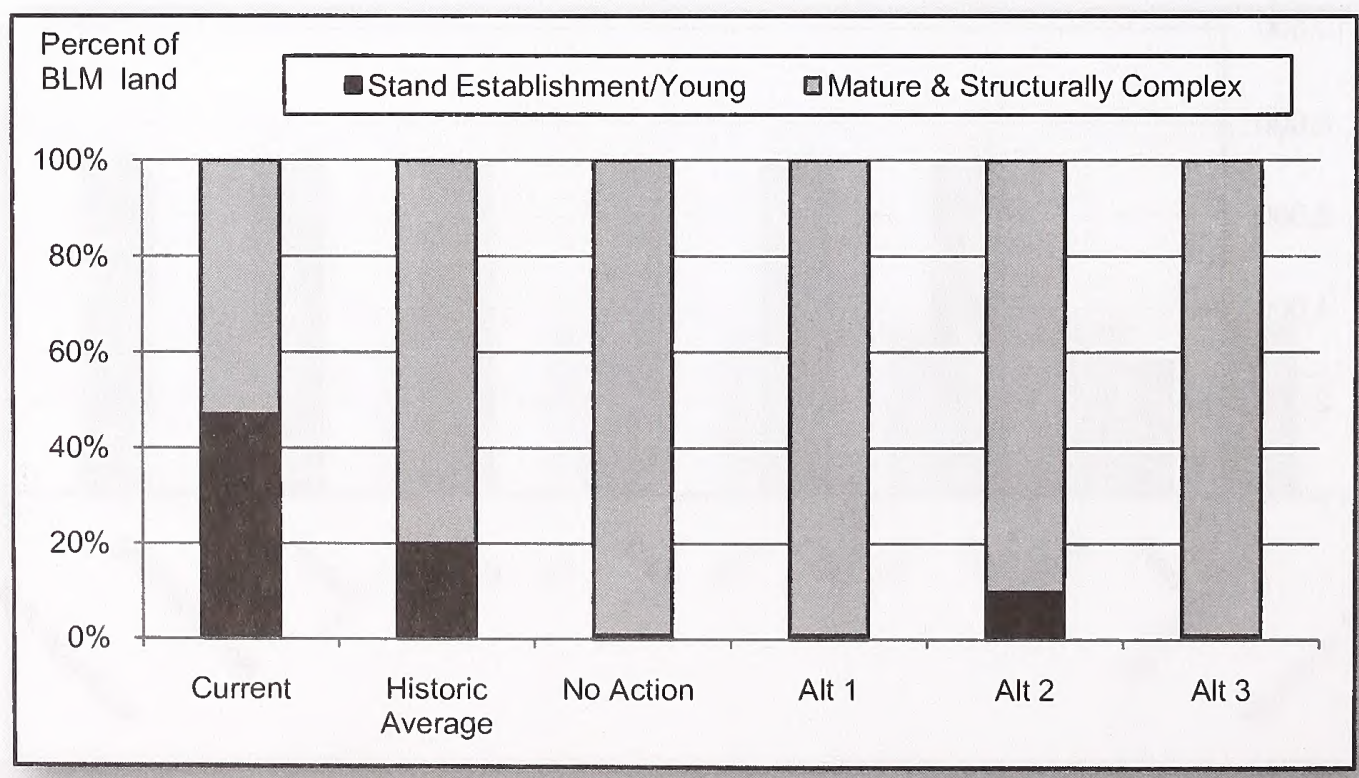


(Danehy et al. 2007). Under the PRMP, thinning within the Riparian Management Area would have little if any effect on nutrient inputs, because the PRMP would exclude thinning from within 60 feet of fish-bearing and perennial stream channels, and 35 feet of intermittent channels. Therefore, under the PRMP, nutrient inputs would be the most dominated by litterfall sources, with the least contribution from solar radiation of any alternative.

\section{Fine Sediment Delivery}

Under all alternatives, the increase in fine sediment delivery to streams would not increase more than $1 \%$ above the current conditions, and would therefore be below the threshold for measurable effects on fish survival at this scale of analysis.

As noted in the Fish section of Chapter 3, thresholds beyond general levels at which lethal and sublethal effects have not been well established in terms of the levels of sediment delivery that would cause impairment to fish at the scale of this analysis. Suttle et al. (2004) suggest there is no threshold below which fine sediment is harmless to fish, and the deposition of fine sediment in the stream channel (even at low concentrations) can decrease the growth of salmonids. Such sub-lethal effects on individual fish would occur under every alternative from timber harvest activities, broadcast burning, grazing, culvert replacements, and other management activities. Chapter 3 (Fish section) provides a qualitative description of potential sublethal effects to fish from sediment, but it is not possible to describe quantitative changes in sub-lethal effects under the alternatives over time at this scale of analysis. Therefore, this analysis focuses on the sediment levels that would affect fish survival. This analysis assumes that every $1 \%$ increase in fine sediment from management activities would result in a 3.4\% decrease in fish survival (see Chapter 3, Fish section).

This analysis assumes that, like the watersheds used in the Cederholm study, existing fine sediment levels in watersheds in the planning area are not currently above background rates. The assumption is based on the current condition of fine sediment in streams within the planning area on BLM-administered lands (see Chapter 3, Fish section). For this analysis, sediment yields are calculated at a fifth-field scale and expressed as tons per square mile per year (see Chapter 3 , Water section). Since this output (tons/square mile/year) cannot be directly equated to a percent embeddedness, using the assumption above ( $>1 \%$ increase above natural levels) provides the ability to utilize a comparison of the relative increase expected under each alternative in order to evaluate the relative effects of fine sediment delivery on fish species at the watershed scale for each alternative.

The Water section of Chapter 4 provides a quantitative analysis of the potential fine sediment delivery to stream channels from new road construction, which typically accounts for the majority of sediment that is delivered to stream channels. The incremental increase in fine sediment delivery from new road construction over the next 10 years would range from 1,567 tons per year under the No Action Alternative, to 2,811 tons per year under the PRMP, compared to a current condition of 357,891 tons per year. Under all alternatives, this incremental increase would be less than $1 \%$ above current conditions. As explained in Chapter 4 (Water section), these results over-estimate the future fine sediment delivery from roads under the alternatives, because they do not account for reductions in sediment delivery after road construction from vegetation establishment, or the effect of road decommissioning on reducing overall sediment delivery from roads.

The Chapter 4 (Water section) analyzes sediment delivery from landslides and concludes that relative landslide density across the planning area would decline from the current condition under all alternatives. Also, sediment inputs to streams from harvest-related landslides over time under all alternatives would be substantially similar to the amount that would occur naturally in the absence of active management on BLM-administered lands. Therefore, none of the alternatives would have an effect on fish survival as a result of an increase in fine sediment delivery to streams from landslides. 
Chapter 4 (Water section) qualitatively analyzes other potential sources of fine sediment delivery to streams, and none of these other sources would result in delivery of fine sediment to streams that would be measurable at this scale of analysis.

Restoration activities, such as instream restoration and fish passage improvements that are beneficial to fish habitat, would also result in short-term increases in sediment delivery to stream channels. Under all alternatives, instream restoration would improve habitat complexity. Removal of fish-passage barriers would increase access for adults to reach spawning habitat, and also increase the ability for juveniles to move within the stream channel during winter high flows and access cooler stream reaches during summer months.

Placement of culverts and instream structures could result in an increase in turbidity and potential downstream sediment delivery, and often would occur during low flow periods when fish are most vulnerable to fine sediment. Under all alternatives, culvert replacements and other instream activities would cause short-term localized increases in turbidity (less than eight hours in duration, and less than 300 feet from the culvert placement or instream activity). The potential increase in turbidity would be the same under every alternative and would not affect entire fish populations because Best Management Practicessuch as diverting water around a site, use of containment and filtering techniques (e.g., silt curtains), and limiting mechanized equipment along streambanks-would be applied to meet water quality standards. Site-specific and highly localized effects on sediment delivery from placement of culverts and instream structures would depend on site-specific stream conditions and the specific project design, which cannot be analyzed more precisely at this scale of analysis. Site-specific effects of placement of culverts and instream structures on sediment delivery and attendant effects on fish would be considered during the planning of implementation-level actions. Additionally, the overall benefit to fish species and fish habitat from these activities would outweigh the potential for short-term localized increases in turbidity.

Under all alternatives, grazing in riparian areas would reduce and eliminate streambank vegetation and contribute fine sediments to stream channels (see Water in Chapter 4). (USDI USFWS 2003d). Sedimentation is a limiting factor for endangered Lost River and Shortnose suckers. Under all of the action alternatives, up to 29 reservoirs and 48 miles of fence would be constructed within the Klamath Falls Resource Area of the Lakeview District. These range improvements would be used to improve livestock distribution by shifting the grazing pressure from riparian and wetland areas to upland areas, and by shifting the grazing distribution on the upland areas (including those areas that are not currently used). These range improvement actions would be consistent with conservation measures of the recovery plan for the Lost River and Shortnose suckers to fence portions of streams to reduce cattle-caused erosion and to replant streambanks with native vegetation (USDI USFWS 2003d).

\section{Peak Flows}

Chapter 4 (Water section) identifies subwatersheds that would be susceptible to peak flow increase under the alternatives. Peak flow increases can scour streambeds, which can potentially result in fish egg mortality (see Fish in Chapter 3). The Chapter 4 (Water section) concludes that, in the rain-dominated hydroregion, the PRMP would have the highest number of susceptible subwatersheds, but Alternative 2 would have the greatest acreage of susceptible BLM-administered lands. The No Action Alternative would have the fewest susceptible subwatersheds and the lowest acreage of susceptible BLM-administered lands. However, the susceptibility to peak flows under all alternatives would be more similar to the effects of the No Harvest reference analysis than to the effects of the Intensive Management on Most Commercial Timber Lands reference analysis. In the rain-on-snow hydroregion, there would be three subwatersheds with BLM-administered lands out of 248 (1\%) susceptible to peak flow increase over all time periods under all alternatives except under Alternative 2, under which there would be one additional subwatershed susceptible for the 2056 time period. Chapter 4 (Water section) concludes that timber harvest on BLM- 
administered lands would not have any substantial effects on peak flow susceptibility in the rain-on-snow hydroregion that can be detected at this scale of analysis.

Whether susceptibility to peak flow increases identified in Water (Chapter 4) would result in fish egg mortality would depend on watershed and stream-specific characteristics and the timing of peak flow increases, making it impossible to make a reasonable prediction of precise effects on fish from peak flow increases under each alternative over time. For example, streambed scour that would result in egg mortality would generally occur in lower gradient stream channels with gravel and sand-bed substrates, and would not typically occur within cascade and step-pool stream types (Grant et al. 2008). On BLM-administered lands within the planning area, $80 \%$ of the streams are stream types where increases in peak flows would not cause streambed scour (see Chapter 4, Water section). Increases in peak flow susceptibility would result in adverse effects on fish only if all of the following conditions would occur in concert: a storm that would increase flow would occur during the time period a subwatershed would be susceptible; the increase in flows would occur in pool/riffle stream types with gravel-bed and sand substrates; and the increase in flows would occur when fish would be spawning. Where and when storms would occur in relation to the susceptible subwatersheds and fish spawning cannot be predicted.

Therefore, it is not possible to make a reasonable prediction of the adverse effects to fish from increases in susceptibility to peak flows under the alternatives. However, the risk of adverse effects to fish from an increase to peak flow would be very low under all alternatives, because of the small proportion of the planning area identified as susceptible to increase in peak flows, the small proportion of the stream types in which streambed scour would occur, and the low likelihood that all factors required for adverse effects on fish would occur simultaneously. Furthermore, there would be no identifiable difference among the alternatives in the effects on fish from peak flow increases, because of the relatively small difference in peak flow susceptibility among the alternatives and the difficulty in directly ascribing adverse effects to fish from susceptibility to increases in peak flow.

\section{Stream Temperature}

Under all alternatives, management activities on BLM-administered lands would maintain stream shade and, therefore, would not contribute to an increase in stream temperatures (see Water in Chapter 4). Because none of the alternatives would contribute to an increase in stream temperatures, this component of fish habitat would not be affected under any alternatives.

\section{Fish Productivity}

The ecosystem processes that affect habitat complexity for fish species in the planning area include large wood delivery, nutrient inputs, fine sediment delivery, stream temperature, and peak flows. This analysis determines the effect of the alternatives on each of these processes (wood, nutrients, sediment, stream temperature, peak flows) in terms of fish habitat independently. These processes do not act independently in terms of fish productivity. However, existing models cannot accommodate the synergistic interactions among these processes at the spatial scale of the planning area; therefore, the cumulative effects to fish productivity are described qualitatively.

All alternatives would provide for riparian and aquatic conditions that supply stream channels with shade, sediment filtering, leaf litter and large wood, and streambank stability, but to varying degrees. All alternatives would improve the riparian and aquatic conditions that affect fish productivity from current conditions. Although sub-lethal effects of fine sediment delivery to stream channels would occur under all alternatives, the increase in fine sediment delivery would be below the threshold for effects on fish survival under all alternatives. Of all riparian and aquatic conditions affecting fish productivity, increasing large wood and habitat complexity would have the greatest benefit (Nickelson 2001). 
The PRMP, No Action Alternative, and Alternative 1 would provide more improvement to aquatic habitat and subsequent fish productivity than Alternatives 2 or 3. Under the PRMP, No Action Alternative, and Alternative 1, Riparian Management Area (or Riparian Reserve) widths would include the distances in which most ecological functions of riparian forests for streams are fulfilled (Reeves and Burnett 2007, FEMAT 2003). Overall, Alternatives 2 and 3 would have lower likelihood of providing habitat complexity and fish productivity than the other alternatives, because the large wood contribution to fish-bearing streams would be less over time than the contribution under the PRMP, No Action Alternative, and Alternative 1.

\section{Aquatic Restoration}

The analysis assumes that the levels of aquatic restoration described below would occur within the planning area. However, these levels are projections used for analytical assumptions, not targets. The amount of aquatic restoration that would occur would depend on future funding and site-specific conditions.

\section{Fish Passage}

For this analysis, it is assumed that activities to modify or replace fish passage barriers would decrease in the future, because the majority of fish passage barriers have already been corrected on BLM-administered lands for anadromous and/or listed fish. The priority may shift to barriers that occur on resident fish-bearing streams as opportunities to remove barriers for anadromous and listed fish would decrease. See Table 4-88 (Estimate of future fish passage barriers removed per decade by district in the planning area).

Removing fish passage barriers increases access for adults to reach spawning habitat and increases the ability for juveniles to move within the stream channel during winter high flows and to access cooler stream reaches during summer months. Although many fish passage barriers on BLM-administered lands have been corrected, many barriers still exist on non BLM-administered lands. Refer to Map 3-8 (Fish passage barriers) in Chapter 3. Therefore, working with watershed partnerships would be critical to improve fish passage in these watersheds.

\section{Roads}

The BLM controls approximately 14,000 miles of roads in the planning area. Approximately, 588 miles of BLM-controlled roads were decommissioned from 1995 to 2004. Although there are over 14,000 miles of roads on BLM-administered lands, most cannot be closed or decommissioned because of road right-of-way agreements (see the Fish section of Chapter 3).

As a result of these legal road right-of-way requirements and the amount of roads that have previously been decommissioned, opportunities on BLM-administered land to decommission roads have decreased over the last five years (2000-2005). Because improving roads can reduce sediment delivery to stream channels, road projects in the future would focus on improving existing roads to minimize their potential impact to

Table 4-88. Estimate Of Future Fish Passage Barriers Removed Per Decade By District In The Planning Area

\begin{tabular}{|c|c|c|c|c|c|c|c|}
\hline Activity & Salem & Eugene & Roseburg & $\begin{array}{c}\text { Coos } \\
\text { Bay }\end{array}$ & Medford & Klamath Falls & Plan-wide Summary \\
\hline $\begin{array}{l}\text { Number of Fish } \\
\text { Passage Barriers } \\
\text { Removed Per } \\
\text { Decade }\end{array}$ & 23 & 58 & 20 & 20 & 20 & 3 & 144 \\
\hline
\end{tabular}


the aquatic system. Actions such as the replacement of aging stream crossing culverts, adding ditch-line drainage culverts, road surface improvements, and outsloping of roads would be used in addition to road decommissioning. For this analysis, it is assumed that approximately 270 miles of road decommissioning; 38,115 miles of road maintenance; and 2,184 miles of road improvement would occur in the future. See Table 4-89 (Estimate of future road restoration and decommissioning by district in the planning area).

\section{Instream Restoration}

For this analysis, it is assumed that instream restoration would continue at a similar rate per decade as the previous decade (1995-2004). See Table 4-90 (Estimate of future instream restoration by district). Due to BLM's ownership pattern, it is assumed that the BLM would also continue to complete projects through partnerships on non BLM-administered lands to support the Oregon Plan for Salmon and Watersheds.

Under the No Action Alternative, key watersheds would continue to be high priority areas for instream restoration. Management activities in key watersheds under the No Action Alternative would focus on limiting road construction and would place priority for instream restoration activity in key watersheds in order to contribute to anadromous salmonid and bull trout conservation. However, a relatively small portion of the key watersheds under the No Action Alternative coincide with high intrinsic potential streams. See Figure 4-175 (Distribution of high intrinsic potential streams for chinook salmon, coho salmon, and steelhead trout within key watersheds of the planning area).

Under all action alternatives, an emphasis for instream restoration would be placed on streams that have high intrinsic potential for fish, high priority fish populations (such as those defined in recovery plans), or high levels of chronic sediment inputs. Increasing habitat complexity in streams with high priority fish populations or occupied high intrinsic potential streams would be more effective in improving habitat complexity in those streams with a greater potential to support salmonids than others. Therefore, aquatic restoration under the PRMP and Alternatives 1, 2, and 3 would be more effective than the No Action Alternative in improving fish habitat on BLM-administered lands.

Table 4-89. Estimate Of Future Road Improvement And Decommissioning By District In The Planning Area

\begin{tabular}{|c|c|c|c|c|c|c|c|c|}
\hline \multirow[b]{2}{*}{ Activity } & \multirow[b]{2}{*}{ Unit } & \multicolumn{7}{|c|}{ Districts } \\
\hline & & Salem & Eugene & Roseburg & Coos Bay & Medford & Klamath Falls & $\begin{array}{l}\text { Plan-wide } \\
\text { Summary }\end{array}$ \\
\hline $\begin{array}{l}\text { Road Improvement } \\
\text { (Continuous Use) }\end{array}$ & $\begin{array}{l}\text { Miles/ } \\
\text { Decade }\end{array}$ & 233 & 98 & 214 & 298 & 1,224 & 117 & 2,184 \\
\hline Road Maintenance & $\begin{array}{c}\text { Miles/ } \\
\text { Decade }\end{array}$ & 6,500 & 7,660 & 7,580 & 6,940 & 8,860 & 575 & 38,115 \\
\hline $\begin{array}{l}\text { Road Decommissioning } \\
\text { (Non-continuous use) }\end{array}$ & $\begin{array}{c}\text { Miles/ } \\
\text { Decade }\end{array}$ & 30 & 60 & 30 & 30 & 20 & 30 & 270 \\
\hline
\end{tabular}

${ }^{a}$ Road improvement includes road renovation, stormproofing and improvement.

Table 4-90. Estimate Of Future Instream Restoration Projects Per Decade By District

\begin{tabular}{lrrrrrrr}
\hline & \multicolumn{5}{c}{ Districts } \\
\cline { 2 - 7 } & Salem & Eugene & Roseburg & Coos Bay & Medford & Klamath Falls & $\begin{array}{l}\text { Plan-wide } \\
\text { Summary }\end{array}$ \\
\hline $\begin{array}{l}\text { Number of Instream Restoration } \\
\text { Projects Per Decade }\end{array}$ & 19 & 42 & 30 & 25 & 8 & 2 \\
\hline
\end{tabular}




\section{Fire and Fuels}

This analysis examines how the alternatives would affect fire severity and fire hazard on all BLMadministered lands, and also fire resiliency in the Medford District and Klamath Falls Resource Area.

\footnotetext{
Key Points

- In the Salem, Eugene, Coos Bay, and Roseburg Districts, compared to the current condition, all alternatives would reduce the fire hazard and would reduce the acres of high severity fire when wildfires occur.

- In the Medford District, compared to the current condition, all alternatives would reduce the fire hazard and would decrease the acres of high severity fire when wildfires occur. The No Action Alternative would result in the largest decrease and Alternative 2 would result in the smallest decrease.

- In the Klamath Falls Resource Area, compared to the current condition, the No Action Alternative and the PRMP would reduce the fire hazard and the acres of high severity fire when wildfires occur. Alternatives 1,2 , and 3 would increase the fire hazard and would increase the acres of high severity fire when wildfires occur.

- In the Medford District and Klamath Falls Resource Area, the No Action Alternative, Alternatives 1, and 2 would create stand establishment and young stands consisting of even-aged plantations, which would be highly susceptible to stand-replacing crown fires. Alternative 3 and the PRMP would reduce crown fire hazard and increase fire resiliency.

- Across the planning area, the No Action Alternative and the PRMP would be most effective in reducing fire hazards, decreasing the risk of large wildfires, and reducing the risk of resource damage due to high severity wildfire. Alternative 2 would be the least effective.
}

The analysis of fire and fuels divides the planning area into two geographic areas:

- Salem, Eugene, Coos Bay, and Roseburg Districts (the North), which generally have a low frequency/high severity fire regime (although the southern portion of the Roseburg District begins the transition to the southern area)

- Medford District and Klamath Falls Resource Area (the South), which generally have a high frequency/low severity fire regime

Fire severity, hazard, and resiliency can generally be equated to broad descriptions of vegetation conditions. This analysis uses the standard 13 fuel models (Andersen 1982), which are assigned to the forest structural stage classifications described in Forest Structure and Spatial Pattern in Chapter 3. However, fire severity, hazard, and resiliency are also influenced by site-specific or stand-specific factors, which are evaluated qualitatively in this analysis. Environmental conditions such as temperature, wind, and relative humidity can cause extreme variations in fire behavior within the fuel models. See the Fire and Fuels section of Chapter 3 for specific discussion of weather, risk, hazard and ignition patterns, and how they contribute to fire severity and fire hazard.

The Wildland Urban Interface constitutes a large portion of BLM-administered acres in the planning area, and the trends described here would be reflected within the Wildland Urban Interface.

Fire severity is a function of both ground and surface fuel loading. As a young forest develops into a mature forest, the fire severity drops from high to low. As a mature forest develops into a structurally complex forest, ground fuels, surface fuels and ladder fuels increase, and fire severity changes to a mixed severity rating. Very heavy amounts of ground and surface fuels increase the probability of a crown fire, which would occur under extreme conditions (weather that exceeds the 90 th percentile). Weather factors that influence fire behavior are temperature, relative humidity, and wind speed. Under moderate and extreme conditions, 
the primary source of high severity fire would be in stand establishment and young forest that consist of even aged plantations. Under extreme conditions, structurally complex forest could also burn with high severity.

In stand establishment and young forest in the North, slash levels created by timber harvest have a strong influence on fire behavior. In stand establishment and young forest in the South, live vegetation also provides a large influence on fire behavior.

Slash levels would be highly variable, depending on site-specific conditions such as:

- pre-harvest stand condition and composition

- harvesting methods

- timber merchantability standards

- market prices

Post-harvest slash treatment can greatly reduce slash levels. The effects of this treatment can be expected to last approximately 15 years. Because slash levels cannot be predicted at this scale of analysis, the effect of slash on fire severity and hazard is evaluated qualitatively.

For analysis purposes, this analysis assumes that the majority of the acreage within regeneration harvest units in the North would receive slash treatment, and thinning units would not receive slash treatment, based on experience with similar harvests over the past decade. In the South, however, based on this experience, it is projected that $90 \%$ of harvest units would receive some form of slash treatment. The remaining $10 \%$ would not have enough slash to require treatment.

The assignment of structural stages to fire severity and hazard levels reflects the severity and hazard of surface fires. At this scale of analysis, it is not possible to categorize the structural stages by crown fire hazard, or otherwise quantitatively evaluate crown fire hazard. This is because the hazard of crown fire depends in large part on site-specific stand conditions such as tree height-to-live crown and canopy density which cannot be modeled at this scale of analysis. There is no available information at this scale of analysis for evaluating these highly stand-specific characteristics which cannot accurately be inferred from the structural stage classification. Therefore, the analysis qualitatively evaluates crown fire hazard based on the amount and types of stand treatments and the expected stand conditions that would result from treatment based on past experiences with treatments. This qualitative evaluation provides a sufficient basis for evaluating the relative effects of the alternatives on crown fire hazard in order to make a reasoned choice among the alternatives, given the broad, programmatic nature of the management direction in the alternatives that would affect crown fire hazard. Site-specific effects on crown fire hazard would be considered during the planning of implementation-level stand management projects.

Fire resiliency depends in part on some of the same site-specific factors as crown fire hazard. However, surface fuels and the presence of large trees also affect fire resiliency, and these factors can be reflected in relationship of structural stages to fire resiliency levels as shown in Table 4-91 (Structure stage relationship to fire resiliency) and Table 4-92 (Fire severity, hazard, and resiliency by forest structural stage classifications).

Table 4-91. Structure Stage Relationship To Fire Resiliency

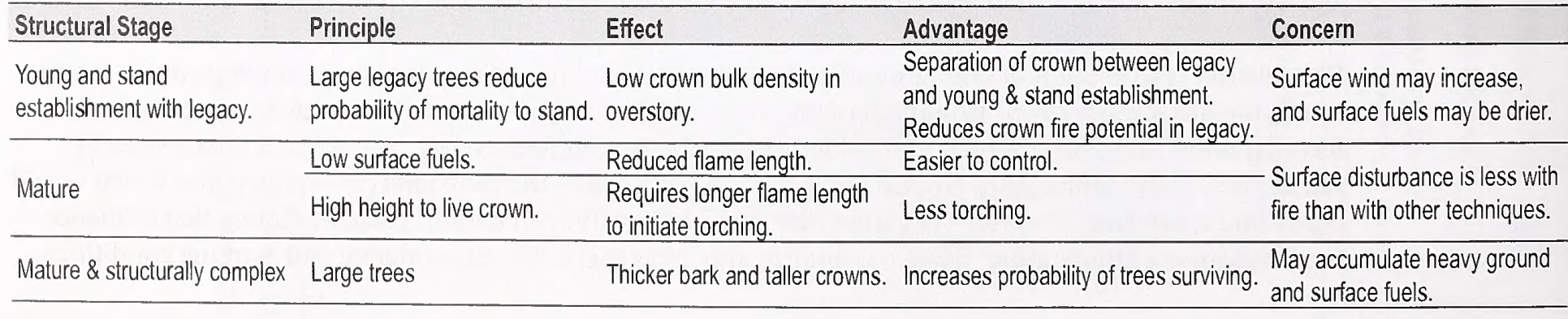


Table 4-92. Fire Severity, Hazard, And Resiliency By Forest Structural Stage Classifications

\begin{tabular}{llll}
\hline Structural Stage & Severity & Hazard & Resiliency \\
\hline $\begin{array}{l}\text { Stand establishment without structural legacies; and young } \\
\text { without structural legacies }\end{array}$ & High & High & Low \\
\hline $\begin{array}{l}\text { Stand establishment with structural legacies; and young with } \\
\text { structural legacies }\end{array}$ & High & High & Moderate \\
\hline Mature & Moderate & Moderate & Moderate \\
\hline Structurally complex & Mixed & Moderate & Moderate \\
\hline
\end{tabular}

\section{Fire Regime Condition Class}

Chapter 3 analyzed current conditions using LANDFIRE data to describe fire regimes and Fire Regime Condition Class at a stand level scale for all ownerships within the planning area (see the Fire and Fuels section in Chapter 3). There is no LANDFIRE data on which to analyze future conditions under each alternative because data to build such projections is unavailable. The structural stage classification in the vegetation modeling in this analysis does not directly equate to information needed to derive LANDFIRE forest classifications. Therefore, it is not possible to analyze quantitatively the future Fire Regime Condition Class at a stand level under each alternative. Instead, this analysis broadly and qualitatively describes the future Fire Regime Condition Class under each alternative on BLM-administered lands based on general principles described in the LANDFIRE project (USDA Forest Service and USDI. URL: http://www.landfire. gov/index.php [accessed March 2008]), changes in forest structural stages; and changes in fire severity, fire hazard, and fire resiliency.

Throughout the planning area, all alternatives would reduce the departure from reference conditions in comparison to current conditions on BLM-administered lands, because all alternatives would decrease the high severity acres and would result in forest structural stages on BLM-administered lands that would more closely resemble historic conditions in 100 years than the current conditions (see the Forest Structure and Spatial Pattern section in Chapter 4).

In the northern districts (Salem, Eugene, Coos Bay, and Roseburg Districts), the No Action Alternative would have the most change in fire condition of all alternatives and would result in fire conditions similar to reference conditions in 100 years. The No Action Alternative would result in forest structural stages on BLM-administered lands that would approximate average historic conditions in 100 years and would have the largest decrease in high severity acres of all alternatives in most of the northern districts. Alternative 2 would result in the least change of all alternatives from current fire conditions in most of the northern districts. The PRMP would be intermediate in the amount of change from current fire conditions in most of the northern districts. In the Salem, Eugene, and Coos Bay Districts, the PRMP would have less of a decrease in high severity acres than the No Action Alternative, but more of a decrease than Alternative 2. In the Roseburg District, the PRMP would have the most decrease of all of the alternatives.

In the southern districts (Medford District and Klamath Falls Resource Area), the No Action Alternative and PRMP would have the most change in fire condition of all alternatives and would result in fire conditions more similar to reference conditions in 100 years than current conditions. The No Action Alternative would result in the largest decrease in high severity acres of all alternatives, followed by the PRMP. Both the PRMP and the No Action Alternative would result in more acres of mature and structurally complex forest on BLM-administered lands than average historic conditions in 100 years.

Under all alternatives, forests in the nonharvest land base would develop into closed canopy mature and structurally complex stands (see Forest Structure and Spatial Pattern in Chapter 4). Regeneration harvesting in the matrix and adaptive management areas under the No Action Alternative, and in the Timber Management Area under Alternatives 1 and 2, and the PRMP would create blocks of even-aged 
stand establishment and young forests. These stands would consist of dense canopies that would favor stand replacement fires and would not resemble typical historic stand conditions in southern districts. The No Action Alternative would create the least acreage of stand establishment and young forests in southern districts. The PRMP would create the second least acreage of stand establishment and young forests. Alternative 2 would create the most acreage of stand establishment and young forests of all alternatives. The No Action Alternative and the PRMP would result in less combined acreage of stand establishment and young forests in 100 years than average historic conditions in the southern districts. Alternatives 1,2 , and 3 would result in the more combined acres of stand establishment and young forests in 100 years than average historic conditions in the southern districts.

In the Uneven-Age Timber Management Area in the PRMP, forest conditions would better meet reference conditions over time than all other alternatives. The forest management in the Uneven-Age Timber Management Area in the PRMP would harvest trees across all age classes. This type of forest management would most closely mimic the historic disturbance patterns with which these forests developed. The forest management in the Uneven-Age Timber Management Area in the PRMP would result in mature \& structurally complex stands with a mosaic of age classes and a relatively open stand structure in both the understory and the overstory, which would more closely resemble historic stand conditions than any other alternative. In the Timber Management Area in the PRMP, stand conditions over time would be similar to the Timber Management Area in Alternatives 1 and 2.

The overall ranking of the alternatives from most effective to least effective in reducing fire hazards, decreasing the risk of large wildfires, and reducing the risk of resource damage due to high severity fire would be the No Action Alternative, the PRMP, Alternative 1, Alternative 3, and Alternative 2.

\section{Fire Severity and Hazard in the North}

Over the next 100 years, all alternatives would reduce fire severity and hazard in the North, because all alternatives would reduce the combined abundance of stand establishment and young forest. See Figure 4-176 (High fire severity and hazard trends for northern districts by alternative). The reductions in acres susceptible to high severity fire during wildfires and reduction of fire hazard would vary among districts. In general, the No Action Alternative would result in the largest decrease of high severity acres, and Alternative 2 would result in the smallest decrease of high severity acres. The PRMP would rank in the middle. There are no established thresholds for evaluating changes in fire severity and hazard. As detailed in Chapter 3 (in the Fire and Fuels section), the majority of acres in the North currently have a moderate or lower fire hazard, and all alternatives would reduce the fire severity and hazard from current conditions.

\section{Fire Severity, Hazard, and Resiliency in the South}

Over the next 100 years, fire severity and hazard would decrease in the Medford District under all alternatives, but the amount of decrease would vary widely among the alternatives. The amount of decrease would be relative to the reduction in acreage of stand establishment and young forest compared to the current condition. The No Action Alternative would have the greatest decrease in high fire severity acres, followed by the PRMP. In the Timber Management Area under the PRMP, high fire severity acres would slightly decrease and fire resiliency would steadily decrease. In the Uneven-Age Timber Management Area under the PRMP, high fire severity acres would steadily decrease and fire-resilient acres would steadily increase. Alternative 2 would have the least decrease, maintaining the acres of high severity fire when wildfires occur and fire hazard at only slightly less than the current condition. See Figure 4-177 (High fire severity for southern districts by alternative). 
Figure 4-176. High Fire Severity and Hazard Trends For Northern Districts By Alternative

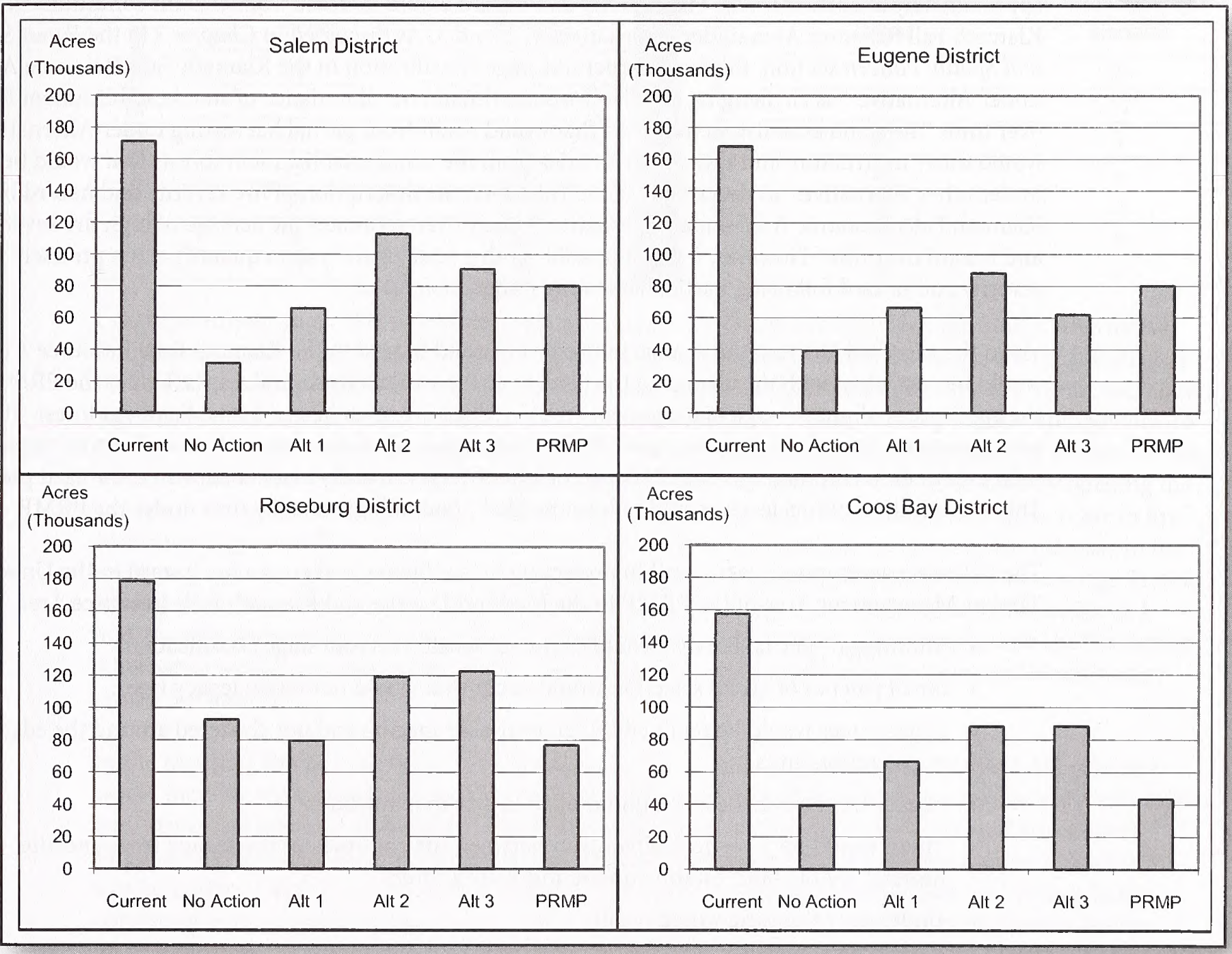

Figure 4-177. High Fire Severity And Hazard Trends For Southern Districts By Alternative

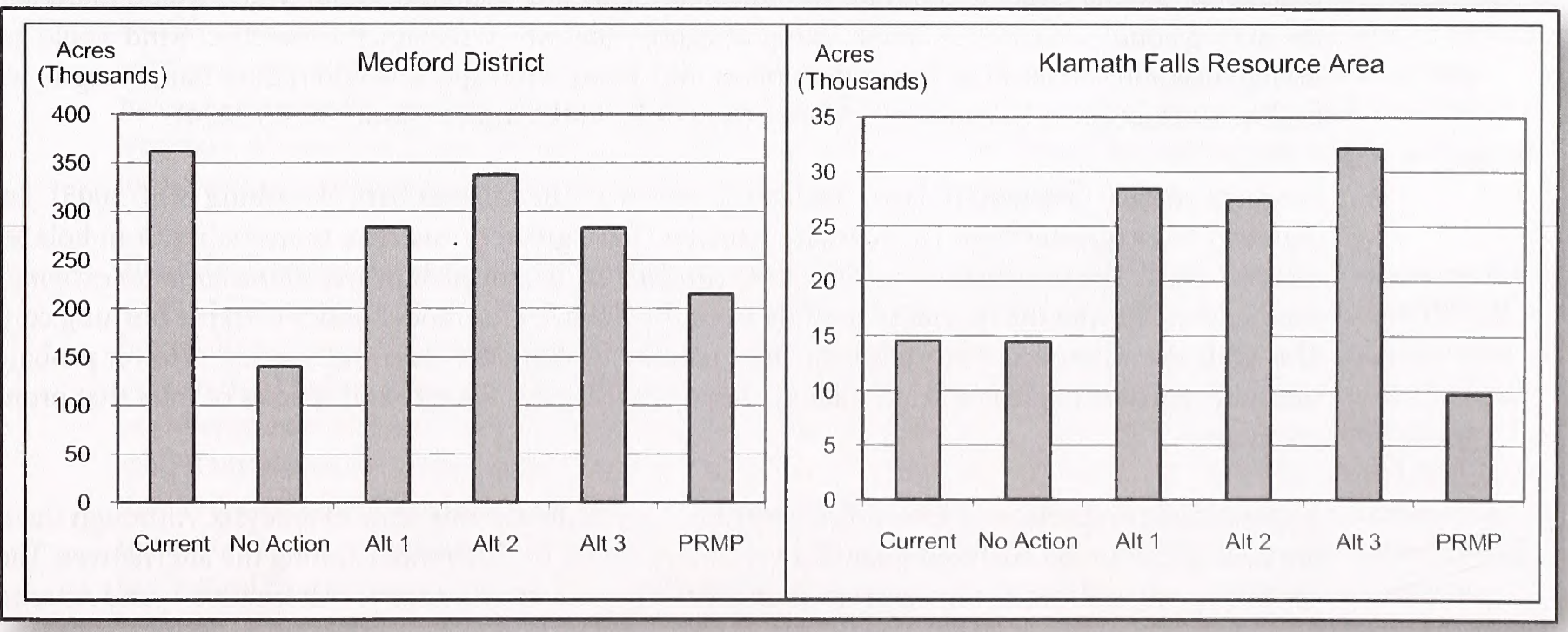


In the Klamath Falls Resource Area, the PRMP is the only alternative that would show a decrease in fire severity and hazard over time. The No Action Alternative would maintain fire severity and hazard approximately at current levels. Fire severity and hazard would increase from current conditions in the Klamath Fall Resource Area under Alternatives 1, 2, and 3. As discussed in Chapter 3 in the Forest Structure and Spatial Pattern section, the forest structural stage classification in the Klamath Falls Resource Area under Alternative 3 is challenging and likely over-estimates the abundance of stand establishment forests over time. The stand establishment forests that would result from partial harvesting under Alternative 3 would differ in structure and fuel characteristics from the stand establishment forests that would be created under other alternatives, as described below. Therefore, the description of fire severity and hazard in the Klamath Falls Resource Area under Alternative 3 likely over-estimates the acreage of high fire severity and hazard over time. However, it is not possible at this scale of analysis to quantify more precisely the fire severity and hazard following partial harvesting under Alternative 3.

As in the Medford District, the change in fire severity and hazard in the Klamath Falls Resource Area would be consistent with the change in the acreage of the various structural stages. Under the PRMP, the application of uneven-age management would reduce the acres in stand establishment forest. The management action in the Uneven-Aged Timber Management Area would reduce understory vegetation with every entry, eliminating dense buildups of ladder fuels normally associated with even-aged plantations. This modification of fuel levels would reduce the likelihood of high severity fires under the PRMP.

The following assumptions were used in projecting fire resiliency and crown fire hazard in the Uneven-Age Timber Management Area of the PRMP in the Medford District and Klamath Falls Resource Area:

- Thinning or partial harvest would occur across all structure stage classifications.

- Small patches of group selection would occur that would not retain legacy trees.

- Legacy trees would be retained under a variable spacing and not clustered around the edges of regeneration units.

- Legacy trees would be a minimum of 16 inches in diameter.

- There would be a vertical separation between the canopies of the legacy trees and the understory of stand establishment and young forest.

- Understory thinning would occur.

- Surface fuels would be treated whenever a management action occurs that would increase existing surface fuel loads.

In general, leaving larger green trees would create a partially sheltered stand, which would materially alter the drying conditions of the stands. The more canopy that would remain, the less effect wind would have on drying fuels and surface fires. This reduction in mid-flame wind speed would reduce flame length, which can lead to a reduction in tree mortality (Fire Behavior Field Reference Guide: NFES 2224).

Frequent surface fires tend to favor the largest trees with the thickest bark (Hessburg et al. 2005). Large diameter trees (greater than 16 inches in diameter) have greater resistance to mortality from bole and crown scorch. The information in Table 4-93 (Probability of mortality by tree diameter in an extreme event) was generated using the mortality module from the Behave Plus model under extreme burning conditions. This table shows expected mortality during a wildfire by diameter class and species. A lower probability of mortality equates to greater fire resiliency. Table 4-93 displays the size and species of trees that promote fire resiliency.

A quantified comparison of crown fire hazard is not possible at this scale of analysis. Although the crown fire hazard cannot be analyzed quantitatively, there would be differences among the alternatives. The stand establishment and young forests created under the No Action Alternative, Alternative 1, and Alternative 2 would consist of even-aged plantations, which would be highly susceptible to stand-replacing crown fires, because even-aged plantations would have high canopy bulk density with continuous, single-storied 
Table 4-93. Probability Of Mortality By Tree Diameter In An Extreme Fire Event

\begin{tabular}{|c|c|c|c|c|c|}
\hline \multirow{8}{*}{ 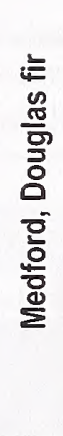 } & $\begin{array}{c}\text { Tree Diameter in } \\
\text { inches }\end{array}$ & $\begin{array}{c}\text { Probability of } \\
\text { Mortality }\end{array}$ & \multirow{8}{*}{ 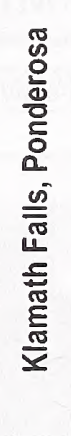 } & $\begin{array}{l}\text { Tree Diameter in } \\
\text { inches }\end{array}$ & $\begin{array}{c}\text { Probability of } \\
\text { Mortality }\end{array}$ \\
\hline & 10 & 71 & & 10 & 25 \\
\hline & 15 & 49 & & 15 & 12 \\
\hline & 20 & 34 & & 20 & 7 \\
\hline & 25 & 24 & & 25 & 4 \\
\hline & 30 & 18 & & 30 & 3 \\
\hline & 35 & 15 & & 35 & 2 \\
\hline & 40 & 13 & & 40 & 2 \\
\hline
\end{tabular}

canopies without gaps. This would maintain or increase the crown fire hazard in the South. Alternative 3 would also create stand establishment and young forests, but there would be less crown fire hazard as a result of the use of partial harvest or uneven-aged management. Alternative 3 and the PRMP in the UnevenAge Timber Management Area would increase the tree height-to-live crown ratio, create multiple-storied canopies with gaps, reduce canopy bulk density, and treat both surface and ladder fuels. All of these actions would increase fire resiliency. Any increase in wind or reduction of fuel moistures created by opening the canopy in the partial harvests would likely be offset by a reduction in fire severity and an increase in fire resiliency (Agee and Skinner 2005). As a combined result of the reduction in fire severity, increase in fire resiliency, and changes in stand canopy structure, Alternative 3 and the PRMP in the Uneven-Age Timber Management Area would be the only alternatives that would reduce crown fire hazard. Alternatives 1 and 2 would decrease fire resiliency from current conditions, and Alternatives 1 and 2 and the No Action Alternative would not alter stand canopy structure as described above, and therefore would not reduce crown fire hazard.

In the Medford District and Klamath Falls Resource Area, the No Action Alternative and Alternative 3 would increase the acreage of fire-resilient forest from current conditions, because they would create forests with structural legacies. Although the No Action Alternative would increase the acres of fire-resilient forest similar to Alternative 3, other aspects of fire resiliency would differ from Alternative 3. Similar to Alternatives 1 and 2, the No Action Alternative would create stand establishment and young forests, consisting of even-aged plantations that would be highly susceptible to stand-replacing crown fires as described above. The increased crown fire hazard under the No Action Alternative would partially offset the increase in fire resiliency from the retention of structural legacies.

Alternatives 1 and 2 would decrease the acres of fire-resilient forest from current conditions, because they would create forests without structural legacies, which would have lower fire resiliency compared to forests with such structural legacies. Increased crown fire hazard under Alternatives 1 and 2 would exacerbate the reduction in fire resiliency (resulting from stand establishment and young forests that lack structural legacies). Alternative 2 would have the greatest reduction in fire resiliency by creating the largest acreage of forest without structural legacies, combined with high crown fire hazard.

The PRMP would decrease the acres of fire-resilient forest in the Medford District overall and increase the acres of fire-resilient forest in the Klamath Falls Resource Area. In the Medford District under the PRMP, fire resiliency would increase over time in the Uneven-Age Timber Management Area, and decrease over time in the Timber Management Area. See Figure 4-178 (Fire-resilient acres in the Medford District by land use allocation under the PRMP). Fire resiliency would decrease in the Timber Management Area under the PRMP similarly to the Timber Management Area in Alternatives 1 and 2. As in Alternatives 1 and 2, the increased crown fire hazard in the Timber Management Area under the PRMP would exacerbate the reduction in fire resiliency. In the Uneven-Age Timber Management Area, the PRMP would reduce crown fire hazard by maintaining large trees while reducing crown bulk density, which would interact with the increase in fire-resilient acres to further improve overall fire resiliency. See Figure 4-179 (Comparison of fireresilient acres by district and alternative). 
Figure 4-178. Fire-Resilient Acres In The Medford District By Land Use Allocation Under The PRMP

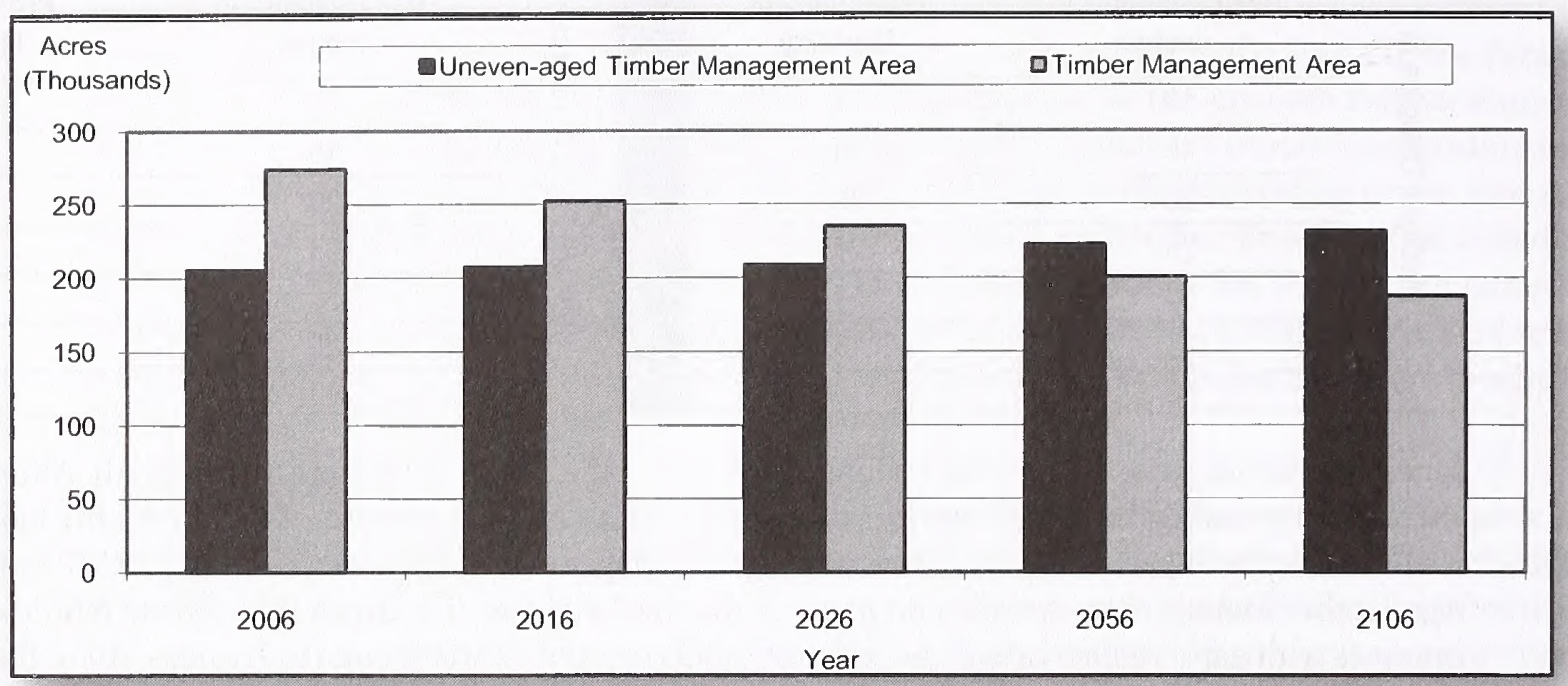

Figure 4-179. Comparison Of Fire-Resilient Acres By District And Alternative

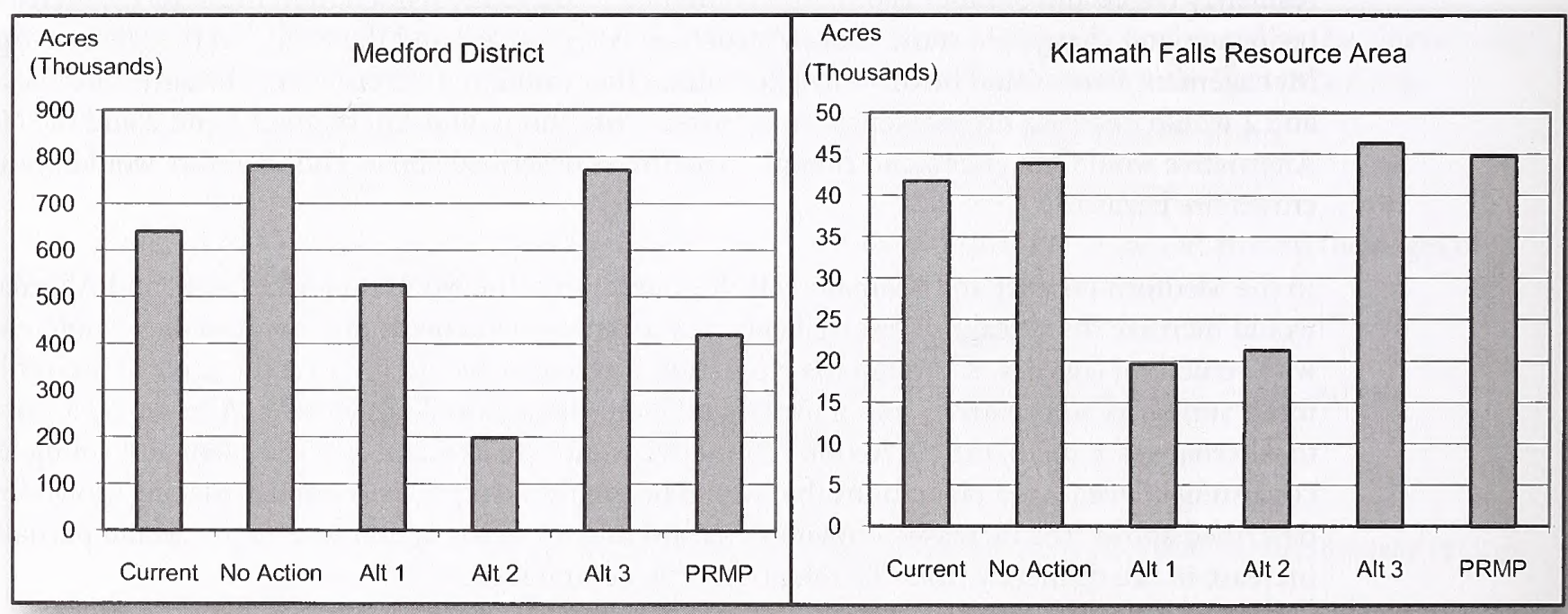


This analysis examines the effects of prescribed burning and wildfire on air quality that would result from the alternatives.

\section{Key Points}

- Emissions from prescribed burning from all activities in the northern districts would be highest under Alternative 2, and lowest under the No Action Alternative. Emissions from prescribed burning from all activities in the southern districts would be highest under the PRMP, and lowest under the No Action Alternative.

- Under all alternatives, compliance with the Oregon Smoke Management Plan would prevent particulate matter from prescribed burning from reaching levels considered a health hazard and would protect Class 1 visibility areas.

Prescribed burning for the purpose of hazardous fuels treatments and site preparation would be the only management action under the alternatives that would have a notable effect on air quality. This effect would be largely at the local level, because prescribed burning would be implemented in accordance with the Oregon Smoke Management Plan. Adhering to the guidance in the Oregon Smoke Management Plan minimizes smoke impacts from prescribed fires on local communities and directs smoke away from Smoke Sensitive Receptor Areas (see the Air section of Chapter 3).

The analysis of future emissions is based on the acreage treated and the amount of slash per acre expected to be burned in such treatments. The emissions shown in this analysis assume that all acres projected to receive treatment would be treated. This may overestimate actual emissions, because weather conditions and compliance with the Oregon Smoke Management Plan may prevent some treatments. Thus, the emissions from prescribed burning, which are based on an annual average of the first 10 years of activities projected under each alternative in this analysis, present an upper limit to what could reasonably be expected. The annual emissions would fluctuate in future decades, making it impossible to predict emissions into the future. However, the relative differences in emissions from prescribed burning forecast for the first decade among the alternatives would continue in future decades.

The acreage of BLM-administered lands that would be burned by prescription for the purpose of hazardous fuels treatment would remain at current levels in the northern districts (Salem, Eugene, Roseburg, and Coos Bay Districts) under all alternatives. Therefore, emissions from hazardous fuels treatments would not vary in the northern districts among the alternatives. The hazardous fuels treatment acreage would remain at current levels in the southern districts (Medford District and Klamath Falls Resource Area) under all alternatives except the PRMP, under which the hazardous fuels treatment acreage would increase from current levels.

Emissions from the treatment of timber harvest units would vary by alternative, because both the acreage treated and the slash per acre would vary by alternative. Therefore, the total emissions from all activities would vary by alternative. See Table 4-94 (Annual emissions from prescribed burning from all activities on $B L M$-administered lands). At this scale of analysis, it is not possible to relate the average annual emissions from prescribed burning under the alternatives to standards of the Environmental Protection Agency (EPA) for particulate matter (PM) 2.5 or PM 10, which are defined at the scale of cubic meters. How emissions from a specific prescribed burn would relate to EPA standards would depend on highly localized conditions, weather conditions, and project-specific features that cannot be predicted at this scale of analysis. Whether 
such emissions would actually cause any health or visibility concerns cannot be assumed from the projections of annual emissions at the plan level. Compliance with the Oregon Smoke Management Plan would prevent particulate matter caused by prescribed burning from reaching levels considered a health hazard and would protect Class 1 visibility areas.

Under the No Action Alternative, annual PM10 emissions from prescribed burning in the northern districts would be a substantial increase from current emissions. Annual emissions in southern districts would also increase from current emissions. These increased emissions would result from the difference between the actual implementation of the 1995 resource management plans over the past 10 years, and the management actions and analytical assumptions in those plans regarding timber harvest methods. Implementation of the 1995 district resource management plans has resulted in not only less overall timber harvest than anticipated, as described in Chapter 1, but also disproportionately less regeneration harvest than anticipated in the 1995 RMPs. The analysis in this EIS of the future effects of the No Action Alternative assumes that the management actions and analytical assumptions described in the 1995 resource management plans regarding timber harvest methods would be implemented in the future (see the Timber section of Chapter 4). Therefore, the analysis in this EIS assumes that more regeneration harvest would occur under the No Action Alternative than has been implemented over the past 10 years, and concludes that emissions from treatment of timber harvest units would increase under the No Action Alternative from current levels.

Alternative 1 would have more emissions than the No Action Alternative, because Alternative 1 would have more acres of regeneration harvest, which would create heavier slash loadings than thinning and would be treated with prescribed burning.

Alternative 2 would have more emissions than any other alternative, because Alternative 2 would have the most acres of regeneration harvest.

Alternative 3 would have more emissions than the No Action Alternative, but less than Alternative 1, Alternative 2, and the PRMP. This difference would result from the interaction of the large acreage of partial harvest under Alternative 3 and the lower amounts of slash that would result from partial harvest compared to regeneration harvest. Alternative 3 would have little regeneration harvest in the first 10 years. However, the partial harvest acreage under Alternative 3 would be greater than the regeneration harvest acreage in the Roseburg and Medford Districts under all alternatives, and similar or greater than the regeneration harvest acreage in all districts under the No Action Alternative (see the Timber section of Chapter 4). Partial harvest would produce less slash per acre than regeneration harvest and therefore lower emissions per acre.

Table 4-94. Annual Emissions From Prescribed Burning From All Activities On BLM-Administered Lands

\begin{tabular}{|c|c|c|c|c|c|c|}
\hline \multicolumn{7}{|c|}{ Annual Particulate Emissions (tons/year) } \\
\hline \multicolumn{7}{|c|}{ PM 10 Emissions } \\
\hline BLM Districts & Current $^{\mathrm{a}}$ & No Action ${ }^{b}$ & Alt. 1 & Alt.2 & Alt.3 & PRMP \\
\hline $\begin{array}{l}\text { Northern } \\
\text { Districts }\end{array}$ & 368 & 3,443 & 4,090 & 7,414 & 3,979 & 4,989 \\
\hline $\begin{array}{l}\text { Southern } \\
\text { Districts }\end{array}$ & 1,486 & 2,004 & 3,094 & 3,137 & 3,138 & 3,975 \\
\hline \multicolumn{7}{|c|}{ PM 2.5 Emissions } \\
\hline $\begin{array}{l}\text { Northern } \\
\text { Districts }\end{array}$ & 225 & 2,410 & 2,863 & 5,189 & 2,785 & 4,203 \\
\hline $\begin{array}{l}\text { Southern } \\
\text { Districts }\end{array}$ & 930 & 1,402 & 2,004 & 2,195 & 1,949 & 2,782 \\
\hline \multicolumn{7}{|c|}{$\begin{array}{l}\text { Average emissions over the past } 10 \text { years of implementing the current RMPs, which has included less regeneration harvest than assumed in the RMPs and less total } \\
\text { harvest volume than the declared ASQ. } \\
\text { bAverage emissions modeled into the future for implementing the current RMPs as they are written, including assumptions about the mix of harvest types. In addition, } \\
\text { these emissions are based on the adjustment of the ASQ under the No Action Alternative described in the Timber section of Chapter } 4 \text {. }\end{array}$} \\
\hline
\end{tabular}


The PRMP would have more emissions in the northern districts than the No Action Alternative and Alternatives 1 and 3, because the PRMP would have more acres of regeneration harvest. The PRMP would have more emissions in the southern districts than the No Action Alternative and Alternatives 1 and 3 , because the PRMP would have more emissions from both hazardous fuels treatments and timber harvest units. The PRMP would have more acres of regeneration harvest than the No Action Alternative and would also treat areas of uneven-aged management with prescribed fire treatments. In addition, the acres of hazardous fuels treatment would be higher under the PRMP than all other alternatives, as described above.

The analysis in this EIS assumes that emissions from prescribed burning on all other lands would maintain their current levels. There is no information on which to model future changes in emissions from other ownerships, because it would be speculative to assume changes in acres harvested or treated on other ownerships, and there is no specific data available on slash per acre on other ownerships. Nevertheless, the broad assumptions are sufficient to provide context for evaluating the relative effect of the different BLM management actions on the total emissions across all ownerships. If emissions from other landowners remain at current levels, based on the average annual emissions over the past 10 years, total emissions from non-BLM-administered lands from prescribed burning would be 15,119 tons of PM 10, of which 9,076 tons would be PM 2.5. When combined with current emissions from BLM-administered lands, based on the average annual emissions over the past 10 years, total emissions from all ownerships from prescribed burning would be 17,009 tons of PM 10, of which 10,254 tons would be PM 2.5. When combined with the future emissions from BLM-administered lands under each alternative, the cumulative total emissions for the entire planning area would range from 20,566 tons of PM 10 and 12,888 tons of PM 2.5 under the No Action Alternative, to 25,670 tons of PM 10 and 16,460 tons of PM 2.5 under Alternative 2. The PRMP would contribute total emissions that would be less than under Alternative 2, but more than under all other alternatives. See Table 4-95 (Annual emissions from prescribed burning from all activities on all ownerships).

Wildfire emissions are greater than those from prescribed burning (Huff 1995). For example, the Timbered Rock wildfire produced an estimated 12,000 tons of PM 10 emissions and 11,000 tons of PM 2.5 over a twomonth period. These emissions over two months from one wildfire were more than the annual emissions that would occur from prescribed fire for all BLM-administered lands in the planning area under any of the alternatives. The prediction of the amount of emissions from future wildfires would be speculative, because the location, timing, severity, and extent of future wildfires cannot be reasonably foreseen (see the Introduction of Chapter 4). There is no basis for belief that future emissions from wildfire would vary among the alternatives. Therefore, future wildfire emissions do not provide a reasonable basis for choice among the alternatives. Wildfires and prescribed burns do not usually occur at the same time, and smoke produced from wildfires would dissipate before smoke would be produced from prescribed burns. Therefore, there would be no cumulative effect of the emissions from these two sources.

Smoke from prescribed burning and wildfire has potential indirect effects on human health. Whether smoke from prescribed burning or wildfire would result in health effects would depend on site-specific conditions and weather, which cannot be predicted at this level of analysis. In the planning of implementation-level prescribed burning projects, site-specific effects would be considered, and mitigation measures to reduce or avoid health effects from smoke could be designed.

Table 4-95. Annual Emissions From Prescribed Burning From All Activities On All Ownerships

\begin{tabular}{lccccrr}
\hline \multicolumn{7}{c}{ Annual Emissions (tons/year) } \\
\hline $\begin{array}{l}\text { Particulate } \\
\text { Emissions Level }\end{array}$ & Current & No Action & Alt. 1 & Alt. 2 & Alt. 3 & PRMP \\
\hline PM 10 & 17,009 & 20,566 & 22,303 & 25,670 & 22,236 & 24,083 \\
\hline PM 2.5 & 10,254 & 12,888 & 13,943 & 16,460 & 13,810 & 16,061 \\
\hline
\end{tabular}


There are many pollutants associated with smoke, but the primary pollutant of concern from both wildfire and prescribed fire is particulate matter. The health effects of smoke vary from the irritation of the eyes and respiratory tract to more serious disorders, including asthma, bronchitis, reduced lung function, and premature death. Studies have found that fine particulate matter (PM 2.5) is linked (alone or with other pollutants) to a number of significant respiratory-related and cardiovascular-related effects, including increased mortality and the aggravation of existing respiratory and cardiovascular diseases (Therriault 2001). Airborne particles are respiratory irritants, and laboratory studies show that high concentrations of particulate matter cause persistent coughing, phlegm, wheezing, and physical discomfort in breathing (Therriault 2001).

Particulate matter can also alter the body's immune system and affect the removal of foreign materials, such as pollen and bacteria, from the lungs (Therriault 2001). Smoke from prescribed burning and wildfire also contains carbon monoxide. The health threat from lower levels of carbon monoxide is most serious for those who suffer from cardiovascular disease. At higher levels, carbon monoxide exposure can cause headaches, dizziness, visual impairment, reduced work capacity, and reduced manual dexterity. For the general population, levels of carbon monoxide would not rise to the level to be considered a health hazard (Therriault 2001). People exposed to toxic air pollutants at sufficient concentrations and durations may have an increased chance of cancer or other serious health problems.

Smoke from prescribed burning under all alternatives would have the potential to reach nuisance levels for a short duration in a highly localized area. However, compliance with the Oregon Smoke Management Plan under all alternatives would prevent particulate matter from reaching levels that would be considered a health hazard and would protect Class 1 visibility areas. 


\section{Recreation}

\section{Key Points}

- All action alternatives would meet overall projected recreational demand and improve the quality of visitor experiences.

- Redesignation of off-highway vehicle areas under all action alternatives would improve off-highway vehicle opportunities, public safety, and visitor experiences compared to the No Action Alternative.

- In the Medford District, management of 13 off-highway vehicle emphasis areas under Alternative 2 , and 7 off-highway vehicle emphasis areas under the PRMP, would improve off-highway vehicle opportunities and would result in fewer visitor conflicts, thereby improving the quality of experiences for all visitors compared to the other alternatives.

- All action alternatives would continue to maintain a mix of recreation settings that provide a variety of opportunities and experiences for visitors.

This analysis examines the recreational demand and the quality of visitor experiences under each alternative as measured by the availability of recreational developments, recreational management areas, off-highway vehicle designations, and the variety of recreational settings.

All action alternatives would carry forward 211 existing recreation developments on BLM-administered lands, except for two day-use areas in the Coos Bay District that would be discontinued due to insufficient local demand. However, two new environmental education areas would be designated in the Coos Bay District (see the Recreation section in Chapter 2).

Under all action alternatives, no new recreation developments were analyzed. Existing developments would continue to support the increasing level of recreation use on BLM-administered lands. This is because visitors are not solely dependent on recreation developments for their recreation pursuits. For example, dispersed recreation uses (e.g., hunting, fishing, and sightseeing) do not require recreation developments.

It is probable, however, that visitors would experience localized crowding at certain existing recreation developments as demand for these sites increases. Although potential recreation developments are not included in the analysis of effects (since there is no certainty of their future development), a list of potential sites, trails, and byways is included under all action alternatives (see the Recreation section in Chapter 2). Future overcrowding could be offset by developing potential recreation sites.

Under all action alternatives (within the Salem, Eugene, Roseburg, Coos Bay Districts and the Klamath Falls Resource Area), the designation of special recreation management areas would not vary by alternative. Within these four districts and one resource area, four new special recreation management areas would be designated, and two existing special recreation management areas would be consolidated. In addition, the boundaries of nine special recreation management areas would be adjusted. As a result, within these four districts and one resource area there would be 28 special recreation management areas on BLMadministered lands in the planning area, for a total of 272,438 acres under all action alternatives. This would be an increase of 150,800 acres from the No Action Alternative. A majority of this change in acreage would be a result of designating the Gerber Special Recreation Management Area (104,400 acres) in the Klamath Falls Resource Area and Tioga Special Recreation Management Area (34,000 acres) in the Coos Bay District.

Special recreation management areas would only vary by alternative on the Medford District where under the PRMP, seven new special recreation management areas (67,944 acres) focusing on off-highway vehicle recreation would be designated. Under the No Action Alternative and Alternatives 1,2 and 3, none of 
these areas would be designated as special recreation management areas. Hyatt Lake, Pacific Crest National Scenic Trail, and the Rogue National Wild and Scenic River special recreation management areas would be designated under the No Action Alternative and all of the action alternatives.

See the Recreation section in Chapter 2 for information about individual recreation management areas for each BLM district by alternative.

The Row River Trail special recreation management area in the Eugene District would be 15,100 acres under the No Action Alternative. This area would be reduced from 15,100 acres to 230 acres under all action alternatives in order to focus recreation management on the trail corridor itself, rather than the entire Row River fifth-field watershed as established under the No Action Alternative. Since intensive recreation management only occurs within the trail corridor, there would be no loss of existing opportunities or experiences for visitors.

Under all action alternatives, the overall increase in the number and total acres of special recreation management areas compared to the No Action Alternative would improve the BLM's ability to provide quality visitor experiences. This is because special recreation management areas, by definition, are designed to provide specific recreation opportunities, experiences, and benefits to visitors. See Appendix $K$ - Recreation for the planning frameworks that are designed to enhance the quality of visitor experiences within these special recreation management areas.

Under all action alternatives, 2.4 million acres (93\%) of BLM-administered lands in the planning area would be designated as "limited to designated roads and trails" for off-highway vehicle use. This is an increase from 1.1 million acres under the No Action Alternative. For all action alternatives, this change would eliminate all off-highway vehicle open areas (330,000 acres) and areas designated as "limited to existing roads and trails" (950,000 acres). On the other hand, a 77-acre area in the Heceta Dunes would be designated as "open" under Alternatives 1, 2 and 3. Under the PRMP and the No Action Alternative, the Heceta Dunes ACEC would be managed as a closed area.

Under all action alternatives, there would also be an increase of 14,200 acres (less than $1 \%$ of the total land base) in areas that are closed to off-highway vehicle use compared to the No Action Alternative. This would bring the total amount of closed area to 98,800 acres. A majority of this increase in acreage would be the result of closing off-highway vehicle use in three elk emphasis areas (the Bull Run Watershed Management Unit and the Mt. Hood Corridor in the Salem District, and the North Bank Habitat Management Unit in the Roseburg District). Although this small increase in closed area would lose site-specific off-highway vehicle operations, it would not measurably affect off-highway vehicle opportunities when considering the overall planning area, and would improve nonmotorized recreational experiences in these areas.

An improvement in nonmotorized recreational experiences is based on the assumption that some motorized and nonmotorized activities have limited compatibility. This is especially true when high levels of both types of use are confined to the same area. For example, motorcycle riders and horseback riders using a narrow, single-track trail would likely result in visitor conflicts and safety concerns. Spatial separation of these activities reduces encounters, thereby improving the overall experience for visitors. This is also true of areas that are managed specifically for off-highway vehicle opportunities, which results in fewer visitor conflicts by not encouraging nonmotorized recreation activities within these areas.

Under all action alternatives, a reduction of 330,000 acres of open areas compared to the No Action Alternative would not result in a substantial loss of off-highway vehicle opportunities. This is because a majority of the open areas are located on steep, densely-forested terrain, which is not conducive to crosscountry motor vehicle travel. (Only $7 \%$ of these lands are classified as nonforest habitat.) For this reason, existing off-highway vehicle use is primarily limited to existing roads and trails in these areas. These existing 
routes would continue to be available to off-highway vehicle use until route designations are completed through subsequent transportation management plans. Some of these roads and trails would eventually be closed to off-highway vehicle use if warranted for resource or social concerns.

Under all action alternatives, the "limited to designated roads and trails" off-highway vehicle area designation would increase public safety and decrease visitor conflicts compared to the No Action Alternative. This would result from the onsite managenent of designated trails and other related developments that are associated with this designation type (e.g., improved signing, construction of parking areas with off-loading ramps, placement of stream crossing structures, and trail construction and maintenance based on standards for off-highway vehicle use). Therefore, although the quantity of area open for off-highway vehicle use would decrease, the quality of the experience for off-highway vehicle users would increase.

Improving off-highway vehicle management under all the action alternatives would primarily be accomplished through subsequent route designations, which would identify specific roads and trails to provide off-highway vehicle opportunities for the public. These routes would be improved or expanded to enhance visitor experiences or to meet increasing demand. Routes that are not designed or suitable for off-highway vehicle use (or are only compatible for certain types of motor vehicles) would be closed or restricted to reduce visitor conflicts and improve public safety.

Appendix $K$ - Recreation includes interim off-highway vehicle management guidelines for the districts. They provide the basis for managing off-highway vehicle use until subsequent transportation management plans are completed.

Under the No Action Alternative, there would be three off-highway vehicle emphasis areas in the Salem, Eugene, and Roseburg Districts, totaling 34,200 acres. Under all action alternatives, these existing emphasis areas would be carried forward with some minor acreage adjustments in the Salem and Eugene Districts.

In addition, under all action alternatives, an off-highway vehicle emphasis area (Blue Ridge) would be designated in the Coos Bay District, for a total of 1,600 acres. This area currently provides a multiple-use, off-highway vehicle trail system for the public. The new emphasis area designation would improve the BLM's management of the area for off-highway vehicle use. This would result from an increase in off-highway vehicle related developments and management presence (e.g., parking areas, restroom facilities, and BLM employees or rangers onsite), which would better accommodate off-highway vehicle riders.

Under all action alternatives, these small changes in off-highway vehicle emphasis areas in the BLM districts would not appreciably increase off-highway vehicle opportunities when considering the entire planning area, but it would improve local opportunities near Coos Bay and Eugene compared to the No Action Alternative.

Off-highway vehicle emphasis areas would vary under all action alternatives on the Medford District. Under the No Action Alternative, there would be three existing off-highway vehicle emphasis areas on this district, totaling 25,600 acres. Under Alternatives 1 and 3, none of these would be designated. Under Alternative 2, the 3 emphasis areas under the No Action Alternative would be designated with some minor acreage adjustments, and 10 additional areas would be designated. Under the PRMP, two of the three existing emphasis areas under the No Action Alternative would be designated as special recreation management areas with some acreage adjustments, and five additional emphasis areas would be designated as special recreation management areas with an off-highway vehicle focus.

The overall feasibility of managing each of these emphasis areas for focused off-highway vehicle recreation was a key factor in evaluating the alternatives. Feasibility was based on the pattern of public and private 
ownership within each emphasis area and the complexity of management and enforcement created by these patterns. The distribution of off-highway vehicle opportunities across the district, access from population centers, and known areas of user and adjacent landowner conflict were evaluated.

Alternative 2 would provide the greatest increase in off-highway vehicle opportunities and result in the least amount of user conflict outside of the emphasis areas. However, there would be some redundancy in the distribution of opportunities across the district. Also, the large number of off-highway vehicle emphasis areas would result in the most complex management and enforcement. Alternatives 1 and 3 would provide the least off-highway vehicle opportunities in the Medford District compared to other alternatives. Since it is likely that off-highway vehicle recreation will continue to increase, these two alternatives would result in the continued dispersal of off-highway vehicle use across the district. These two alternatives also would result in the highest level of user conflict, as well as the most complex situation for management and enforcement needed to mitigate these issues. Focused off-highway vehicle opportunities at seven areas distributed across the district would be provided under the PRMP, which would enable the BLM to concentrate management and enforcement efforts better than Alternative 2. There would be a moderate increase in recreation opportunities under the PRMP to accommodate growing demand for off-highway vehicle use area.

Alternatives 1 and 3 would result in a mix of outcomes in the Medford District. Since off-highway vehicle emphasis areas neither allow nor prevent off-highway vehicle use of a particular area (that is only determined through the broader off-highway vehicle area designations of open, limited, and closed), eliminating emphasis areas would simply result in less concentrated off-highway vehicle use. Under these alternatives, off-highway vehicle recreation would not receive the same level and degree of focused management as under Alternative 2 or the PRMP, but would be managed in a more dispersed and diluted manner across the entire Medford District. Off-highway vehicle riders who prefer a more structured recreation experience (i.e., designed trails and other amenities) would be displaced to other areas that offer such an experience. As a result, visitor conflicts and safety concerns would increase due to a lack of onsite management controls. Thus, these alternatives would not improve the quality of off-highway vehicle user experiences compared to the other alternatives, which would potentially lead to the greatest level of social and resource conflict because off-highway vehicle use would be dispersed across a larger area.

As with most recreation developments, dissemination of information to the public about the presence of the recreation developments typically results in higher levels of use. Under Alternatives 1 and 3, the elimination of off-highway vehicle emphasis areas that exist under the No Action Alternative would likely reduce public awareness of these areas, leading to a gradual reduction in off-highway vehicle use over time in these areas at the expense of increasing use in other areas.

The highest increase in higher quality off-highway vehicle opportunities would be provided under Alternative 2 compared to the other alternatives. Under Alternative 2, a total of 13 off-highway vehicle emphasis areas would be designated in the Medford District, for a total of 105,800 acres. This would result in a four-fold increase in acres of off-highway vehicle emphasis areas compared to the No Action Alternative and would result in some excess supply in the distribution of off-highway vehicle opportunities across the district. All of these areas are currently receiving moderate to high levels of off-highway vehicle use; however, 10 of these areas currently receive limited management presence. The large number of off-highway vehicle emphasis areas under Alternative 2 would result in the most complex management and enforcement.

Under the PRMP, seven emphasis areas distributed across the district would be designated as special recreation management areas focused on managing off-highway vehicle recreation, for a total of 67,944 acres. This would result in an increase of 22,344 acres of recreation areas emphasizing off-highway vehicle use compared to the No Action Alternative. All of these areas support moderate to high levels of offhighway vehicle use; however, five of them currently receive limited onsite management under the No Action Alternative. These designations would result in more concentrated levels of off-highway vehicle 
use within these areas and likely cause a reduction in dispersed off-highway vehicle use on other Medford District BLM-administered lands. It is assumed that dispersed off-highway vehicle use would decrease, because riders would be attracted to greater opportunities within these off-highway vehicle emphasis areas.

Alternative 2 and the PRMP would result in a loss of nonmotorized recreation opportunities in the Medford District compared to the No Action Alternative. This loss is due to the larger portion of BLM-administered lands that would be designated as off-highway vehicle emphasis areas, which would be managed for focused motorized recreation use (12\% larger compared to Alternative 2, and $7 \%$ larger compared to the PRMP). Since these areas would be managed to accommodate motorized recreational activities, visitors seeking nonmotorized forms of recreation would be displaced from these areas. This would be especially pronounced for people seeking solitude as an important element in their overall recreation experience. In general, however, off-highway vehicle emphasis areas would tend to focus this activity within specific areas, which would result in an overall improvement in the quality of experiences for all visitors.

Management actions that change the remoteness and naturalness aspects of the recreation setting of areas cause corresponding changes in the public use of those areas. This is because certain settings are more conducive to certain types of recreation activities and preferred by visitors who engage in them (see the Recreation section in Chapter 3). Since recreation use occurs on the BLM-administered lands that are managed for timber production, modifying these recreation setting characteristics would improve or diminish the BLM's ability to provide opportunities that contribute to meeting recreation demand and quality recreation experiences.

Visitors engage in a wide variety of recreation activities on BLM-administered lands, each with a unique combination of recreation setting preferences. See the Recreation section in Chapter 3 for an illustration of the diversity of settings preferred by each activity. These setting preferences are based on a combination of physical, administrative, and social setting characteristics. When combined together, these primary setting characteristics establish the overall recreation setting of an area. However, this analysis only considers the physical setting characteristics of remoteness and naturalness, because they provide the most direct measure of timber management effects under each alternative.

The effects of future management actions on the levels of recreation demand are projected through 2016. A 10 -year period is used because a reasonably accurate projection of road construction and recreation demand beyond 10 years is not possible. For recreation demand, this is due to the continually changing variables, such as regional demographics and new technologies, that influence outdoor recreation trends.

Timber management actions that require new road construction affect the level of remoteness of an area. Increasing the amount or improving the type of access into an area can lead to higher levels of certain types of use. Such changes can also displace certain types of visitors who preferred the area before access was modified. This dynamic relationship between recreation settings, recreation demand, and the distribution of recreation demand is the basis for analyzing the effects of alternatives (Clark and Stankey 1979).

The total amount of roads (including new road construction that would be projected to occur under the alternatives over the next 10 years) is used to classify levels of remoteness. This is done by buffering the different road types that occur on BLM-administered lands. Table 4-96 (Acres of remoteness levels by alternative) shows the results of this classification process by alternative. This analysis does not consider the proximity of non-BLM roads located on adjacent lands, since their influence on recreational use of the public lands would be indistinguishable among the alternatives.

Under No Action and all action alternatives, including the PRMP, the front country and rural settings would be static. This is because new road construction for timber harvesting under each alternative would only require additional local and resource roads (often referred to as logging roads). These road types would be developed within the middle country setting or further into the back country or primitive settings. These settings vary by less than $0.5 \%$ among all action alternatives. Because of the extensive road network that 
Table 4-96. Acres Of Remoteness Levels By Alternative

\begin{tabular}{lccccc}
\hline \multirow{2}{*}{ Alternative } & \multicolumn{4}{c}{ Remoteness Level (acres) } \\
\cline { 2 - 6 } & Primitive & Back Country & Middle Country & Front Country & Rural \\
\hline No Action & 8,000 & 463,000 & $1,735,000$ & 279,000 & 70,000 \\
\hline Alternative 1 & 14,000 & 461,000 & $1,731,000$ & 279,000 & 70,000 \\
\hline Alternative 2 & 13,000 & 455,000 & $1,739,000$ & 279,000 & 70,000 \\
\hline Alternative 3 & 13,000 & 447,000 & $1,746,000$ & 279,000 & 70,000 \\
\hline PRMP & 14,000 & 461,000 & $1,731,000$ & 279,000 & 70,000 \\
\hline
\end{tabular}

already exists on BLM-administered lands, new road construction under the action alternatives would not measurably change these existing levels of remoteness.

Under all alternatives, there would be no effect to the variety of recreational opportunities that exist on BLM-administered lands when considering remoteness levels. As a result, the majority of BLMadministered lands ( $82 \%$ ) would continue to be located within a quarter mile of roads, which are more conducive to motorized forms of recreation. Under all action alternatives, approximately $18 \%$ of BLMadministered lands would continue to be within the primitive and back country settings, which are favored by those seeking nonmotorized recreational opportunities.

As with remoteness, timber management activities affect the naturalness aspects of the recreation setting (i.e., forest stand structure and age). This in turn affects where visitors recreate based on their setting preferences.

The amount of timber harvest by type and acres that would occur over the next 10 years is used to classify degrees of naturalness along the continuum of recreation settings from primitive to rural. This analysis is based on forest stand types that are characteristic of these areas. For example, timber harvest that involves thinning dense young stands would shift the naturalness of an area from the front country to the middle country setting. In contrast, the regeneration harvesting of older stands would modify the naturalness of an area from primitive to rural. These changes would influence the distribution of recreation demand for visitors who prefer these different settings.

The scale of this analysis is at the forest-stand level, which varies greatly across BLM-administered lands. In fact, within a one-square-mile block of ownership, there can be more than a dozen different stand types. This results in an equal number of recreation settings, some of which can be relatively small and disjointed. For example, small patches of old forest scattered throughout young even-aged stands can result in the primitive setting being obscured by a more predominate front country setting.

The intermixing of setting types affects visitor experiences, depending on their individual preferences. Since setting preferences are subjective and vary from one person to the next, this interrelationship is not considered in the analysis. Rather, all forest stands on BLM-administered lands within the planning area are analyzed to calculate the total number of acres within each setting type.

This analysis does not consider nonforested lands or BLM-administered lands occupied by existing roads, since the naturalness of these areas are not affected by timber harvesting. Nonforest habitat and roads account for approximately $4 \%$ and $3 \%$, respectively, of the BLM's total land base.

See the Recreation section of Chapter 3 for a series of stand visualizations that illustrate these individual setting types.

Table 4-97 (Acres of naturalness levels projected for the year 2016 by alternative) and Figure 4-180 (Acres of naturalness levels for the year 2016 by alternative) show the naturalness component of the recreation setting by alternative. 
Table 4-97. Acres Of Naturalness Levels Projected For The Year 2016 By Alternative

\begin{tabular}{lccccc}
\hline \multirow{2}{*}{ Alternative } & \multicolumn{5}{c}{ Naturalness Levels (acres) } \\
\cline { 2 - 6 } & Primitive & Back Country & Middle Country & Front Country & Rural \\
\hline No Action & 595,000 & 671,000 & 176,000 & 632,000 & 140,000 \\
\hline Alternative 1 & 550,000 & 640,000 & 222,000 & 641,000 & 161,000 \\
\hline Alternative 2 & 491,000 & 638,000 & 223,000 & 630,000 & 213,000 \\
\hline Alternative 3 & 563,000 & 595,000 & 223,000 & 626,000 & 196,000 \\
\hline PRMP & 568,000 & 626,000 & 140,000 & 633,000 & 229,000 \\
\hline
\end{tabular}

Figure 4-180. Acres Of Naturalness Levels For The Year 2016 By Alternative

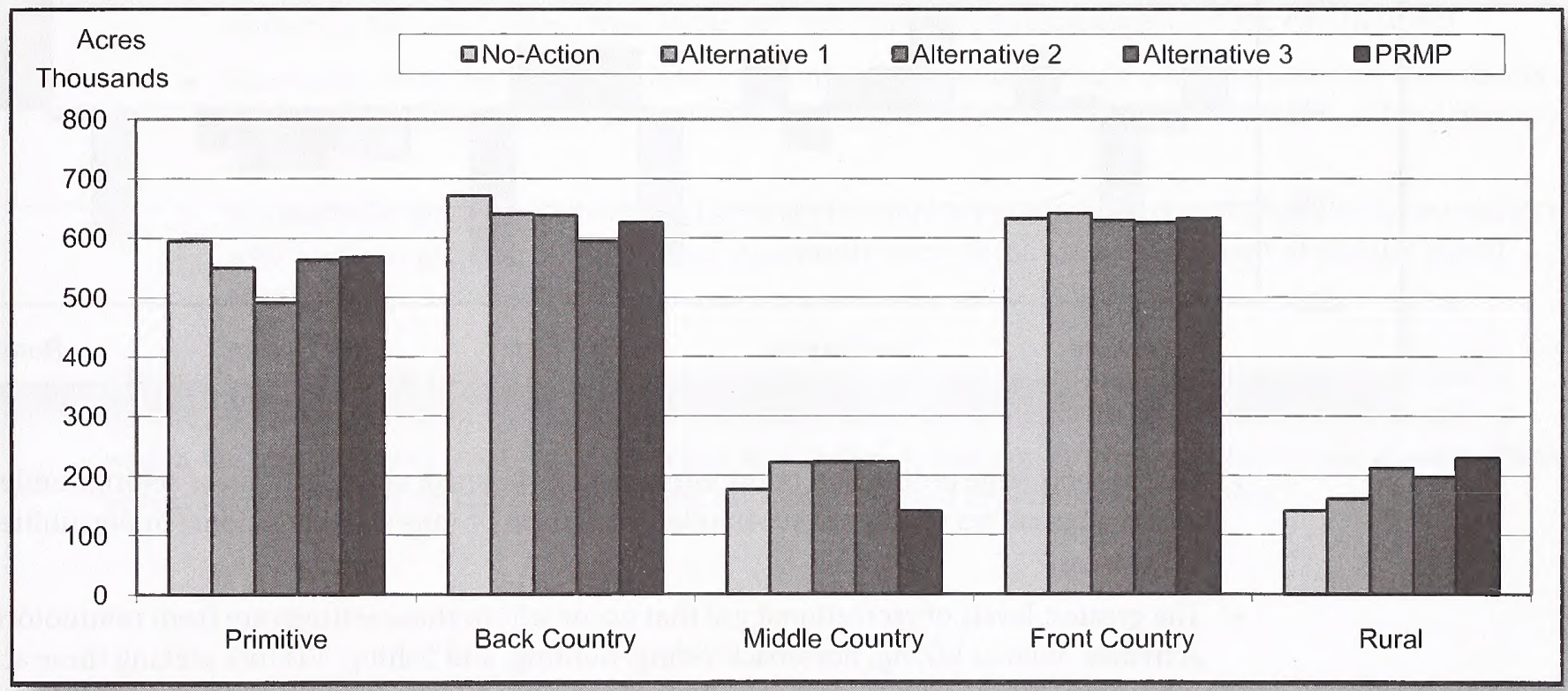

When considering the entire land base, under all alternatives there would be a relatively minor effect on naturalness settings by the year 2016. This is largely due to the short duration, approximately $20-25$ years, for which timber harvest practices would modify forest stands under each alternative. As a result, the action alternatives would continue to maintain a mix of naturalness settings that provide a variety of recreational opportunities and experiences for visitors.

The alternatives would have some minor effects on visitor use patterns when comparing visitors' setting preferences for different recreational activities (see the Recreation section of Chapter 3) with changes to individual naturalness settings. This analysis assumes that visitor preferences for naturalness would be similar to their overall recreation setting preferences, which includes physical, administrative, and social setting characteristics.

Figure 4-181 (Percent change in naturalness settings by the year 2016 under each alternative) illustrates changes to individual naturalness settings by alternative when using the existing condition for the year 2006 as the baseline.

The action alternatives would have varied effects on the existing levels of primitive and back country settings. The No Action Alternative would result in less than $1 \%$ of change within the primitive and backcountry settings. Under the PRMP, primitive and backcountry settings would increase by $6 \%$ above existing levels. The more marked changes would occur under Alternative 2, which would decrease primitive settings by $18 \%$, and under Alternative 3 which would decrease back country settings by $11 \%$.

- Existing levels of primitive settings account for $25 \%$, and back country settings for $28 \%$, of all BLMadministered lands in the planning area. 
Figure 4-181. Percent Change In Naturalness Settings By The Year 2016 Under Each Alternative

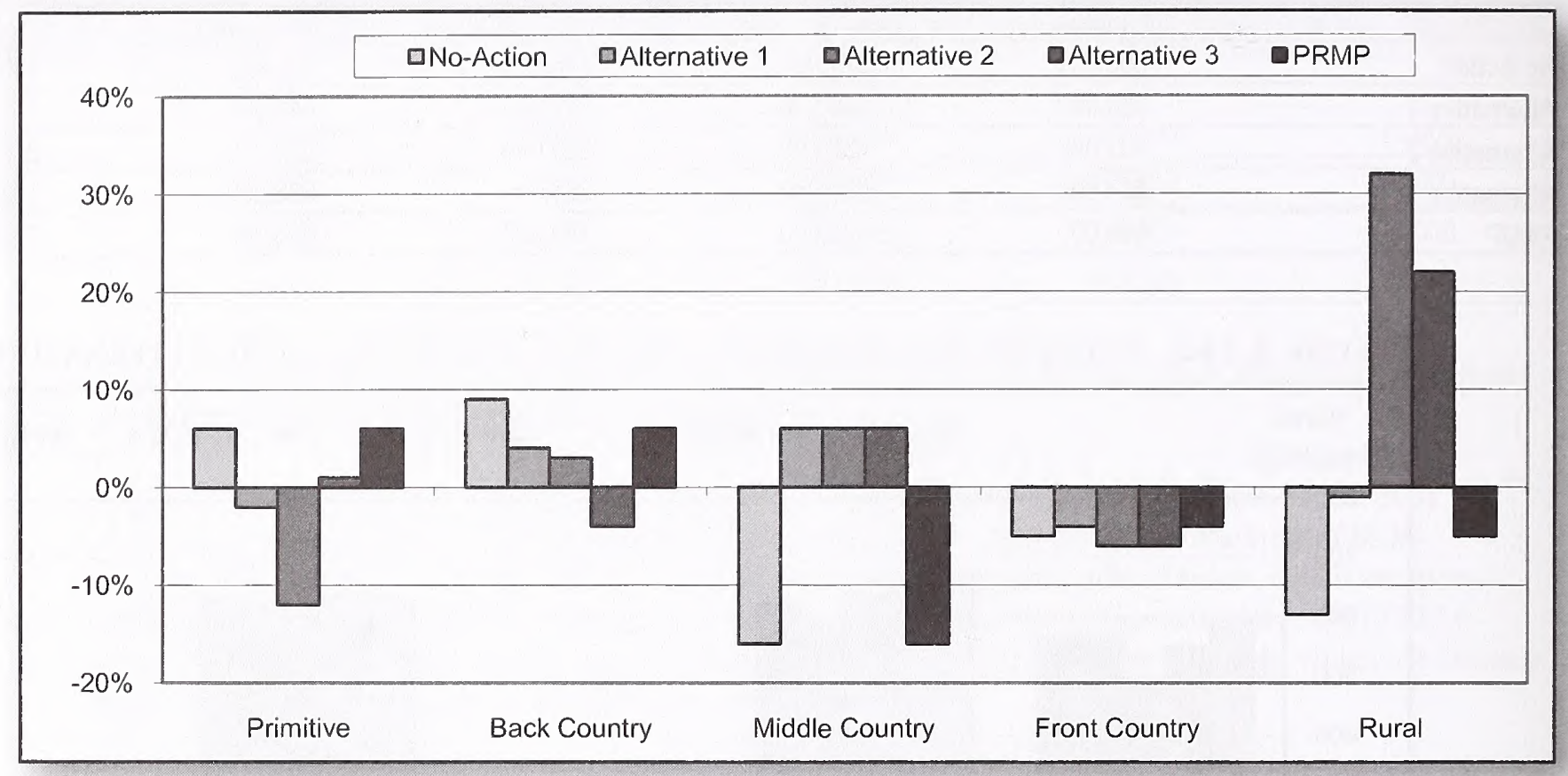

- Due to their large proportion of the entire land base, small changes to these settings under the action alternatives would not substantially diminish or improve recreational opportunities within these areas.

- The greatest levels of recreational use that occur within these settings are from nonmotorized activities, such as hiking, horseback riding, hunting, and fishing. Visitors seeking these activities may experience localized changes within these settings, but visitor use patterns associated with these activities would not be affected when considering the entire land base.

The action alternatives would increase the middle country settings by $6 \%$. Under the PRMP and the No Action Alternative, middle country settings would decrease by $16 \%$.

- The highest percentage of almost every recreational activity occurs within the middle country setting, which is likely due to a combination of both naturalness and remoteness characteristics.

- Middle country provides the highest level of naturalness within close proximity to roads, which is preferred by visitors who are seeking nature-based experiences that are easily accessible.

- Of BLM-administered lands in the planning area, $68 \%$ is classified as middle country based on remoteness levels. However, only $9 \%$ is classified as middle country when considering naturalness.

- The action alternatives would slightly increase the proportion of middle country (based on naturalness levels), thereby improving recreational opportunities and experiences for visitors who prefer this setting.

Under all alternatives, the front country setting would be reduced by no more than $6 \%$.

- Of BLM-administered land in the planning area, $31 \%$ is classified as front country (based on existing naturalness levels), which is proportionally more than all of the other settings.

- Due to its extensiveness throughout the planning area, small reductions under each of the alternatives would not affect recreational use that occurs within this setting type. 
Under the No Action Alternative, the rural setting acreage would decrease by $13 \%$. Under Alternatives 2 and 3 , acreage within the rural setting would increase by $32 \%$ and $22 \%$, respectively. Under the PRMP, rural settings would increase by $44 \%$.

- Although these increases under the PRMP and Alternatives 2 and 3 appear to be considerable, the rural setting only accounts for $5 \%$ of the BLM's total land base.

- The naturalness aspect of this setting is classified as a substantially modified environment, which is typical of an area following a regeneration harvest.

- These areas are generally not conducive to dispersed recreational use; however, high levels of recreation use occur within the developed recreation sites that are located within the rural setting. This is likely due to the experiences derived from improved access, amenities, and social interactions within developed recreation sites. These experiences are generally more important to visitors in the rural setting than those derived from the physical aspects of the environment.

- Since only $5 \%$ of the BLM-administered lands are classified as rural when considering naturalness levels, these changes would not noticeably affect overall recreational opportunities and experiences for visitors.

- Substantially modifying the natural setting of certain areas would have a localized effect on visitors who prefer to recreate in those areas. As a result, some localized displacement of visitors would occur.

Although some localized effects would occur within each of these settings, none of the changes would be measurable enough to influence visitor use patterns that are associated with any single recreation activity within the planning area. As a result, all action alternatives would continue to maintain a mix of naturalness settings that provide a variety of recreational opportunities and experiences for visitors. 


\section{Wilderness Characteristics}

This analysis examines the wilderness characteristics of the BLM-administered lands based on the timber harvesting treatments under each alternative.

\footnotetext{
Key Point

- The PRMP would cause the least amount of long-term alteration (17\%) of wilderness characteristics from regeneration harvesting when compared to all other alternatives.

- Alternative 3 would have the highest degree of long-term alternation of wilderness characteristics $(46 \%)$ when compared to all other alternatives.

- The PRMP would maintain wilderness characteristics on the greatest percentage of BLM-administered lands compared to the other action alternatives.
}

The identification of BLM-administered lands with wilderness characteristics is the result of an evaluation of 146 public wilderness proposals received during scoping. Nine areas (26,123 acres) contain the following wilderness characteristics: sufficient size, naturalness, and either outstanding opportunities for solitude or outstanding opportunities for primitive and unconfined recreation (see the Recreation section in Chapter 3 and Appendix K - Recreation).

Under all action alternatives, the BLM districts would apply special management to maintain the wilderness characteristics on five of these nine units. See Table 4-98 (Special management to maintain wilderness characteristics under all action alternatives) for a summary of this management direction by district.

Except for designated wilderness areas and wilderness study areas, the BLM-administered lands with wilderness characteristics are not identified in the existing (1995) resource management plans. Because of this, the effects of the No Action Alternative on these lands are considered without the application of special management to maintain their identified wilderness characteristics. Under all action alternatives, the special management to maintain wilderness characteristics would not apply to portions of these units that occur on O\&C lands in the harvest land base. For analytical purposes, it is assumed that areas in the harvest land base would eventually be harvested in accordance with the management direction contained in the alternatives. Depending on the land use allocation and management direction of the alternative, lands in the harvest land base would receive regeneration harvest, partial harvest, thinning, or uneven-age management (see The Alternatives section in Chapter 2). Timber harvest would result in a long-term loss of wilderness

Table 4-98. Special Management To Maintain Wilderness Characteristics Under All Action Alternatives

\begin{tabular}{|c|c|c|c|}
\hline BLM District & Unit Name & Acres & $\begin{array}{l}\text { Special Management to Maintain } \\
\text { Wilderness Characteristics }\end{array}$ \\
\hline Coos Bay & Wasson Creek & 3,408 & Yes \\
\hline \multirow{4}{*}{ Salem } & Bull of the Woods/Opal Creek Additions & 3,203 & Yes \\
\hline & South Fork Clackamas River & 919 & Yes \\
\hline & Salmon Huckleberry Additions & 637 & Yes \\
\hline & Mount Hebo & 81 & Yes \\
\hline \multirow{3}{*}{ Medford } & Berry Creek & 6,433 & No \\
\hline & Whiskey Creek & 5,667 & No \\
\hline & Wellington Mountain & 5,659 & No \\
\hline Roseburg & Williams Creek & 116 & No \\
\hline
\end{tabular}


characteristics. Under the action alternatives, any existing wilderness characteristics on public domain lands and those portions of $\mathrm{O} \& \mathrm{C}$ lands not in the harvest land base would be retained (see Table 4-98).

Of the total amount of the lands with identified wilderness characteristics, the portion that would be in the harvest land base varies by alternative. Table 4-99 (BLM-administered lands with wilderness characteristics in the harvest land base by alternative) shows the amount of lands with wilderness characteristics that would be in the harvest land base by alternative.

Timber harvest associated with Late-Successional Management Areas and Riparian Management Areas would diminish the naturalness of wilderness characteristics to a varying degree under the action alternatives, including the PRMP. This would also be the case under the No Action Alternative within Late-Successional Reserves and Riparian Reserves. Limited timber harvest to promote the development of structurally complex forests and to protect streams would occur within all of these land use allocations and would only slightly diminish naturalness if no road construction is necessary. The diminished naturalness would occur initially after treatment, but the long-term implications of such practices would eventually result in a higher degree of naturalness because of the development of structurally complex forest conditions.

Under all action alternatives, opportunities for solitude and primitive unconfined recreation would be diminished within Late-Successional Management Areas and Riparian Management Areas due to the visible evidence of limited timber harvesting. This would also be the case under the No Action Alternative where limited timber harvest would occur within Late-Successional Reserves and Riparian Reserves. Ultimately, to retain these wilderness characteristics, the "imprint of man's work [should be] substantially unnoticed," as defined by the Wilderness Act of 1964. Even with the limited timber harvest associated with LateSuccessional Management Areas and Riparian Management Areas, this would not be entirely possible to achieve. For example, evidence of thinning operations includes slash piles, yarding corridors, and stumps, which can take decades to become indiscernible.

Because of these effects to wilderness characteristics, timber harvest would be excluded within these areas on public domain lands and those portions of O\&C lands not in the harvest land base. Table 4-100 (BLM-administered lands with wilderness characteristics in late successional management areas and riparian management areas by alternative) shows the proportion of each unit of BLM-administered land with wilderness characteristics that contain Late-Successional and Riparian Management Areas by alternative.

Table 4-99. BlM-Administered Lands With Wilderness Characteristics In The Harvest Land Base By Alternative

\begin{tabular}{lrrrrrr}
\hline Unit Name & Total Acres & No Action & Alt. 1 & Alt. 2 & Alt. 3 & PRMP \\
\hline Wasson Creek & 3,408 & 0 & 0 & 1,989 & 2,154 & 0 \\
\hline Bull of the Woods & 3,203 & 144 & 239 & 634 & 641 & 371 \\
\hline South Fork Clackamas River & 919 & 246 & 363 & 389 & 388 & 286 \\
\hline Salmon Huckleberry Additions & 637 & 88 & 121 & 144 & 141 & 102 \\
\hline Mount Hebo & 81 & 0 & 0 & 17 & 19 & 0 \\
\hline Berry Creek & 6,433 & 563 & 1,658 & 3,512 & 3,465 & 1,859 \\
\hline Whiskey Creek & 5,667 & 2,074 & 1,949 & 0 & 2,701 & 0 \\
\hline Wellington Mountain & 5,659 & 1,680 & 2,185 & 2,258 & 2,311 & 1,922 \\
\hline Williams Creek & 116 & 22 & 54 & 54 & 54 & 4 \\
\hline Totals & 26,123 & 4,817 & 6,569 & 8,997 & 11,874 & 4,544 \\
\hline Percentage of Total Acres & $100 \%$ & $18 \%$ & $25 \%$ & $34 \%$ & $46 \%$ & $17 \%$ \\
\hline
\end{tabular}


Table 4-100. BLM-Administered Lands With Wilderness Characteristics In LateSuccessional Management Areas And Riparian Management Areas By Alternative

\begin{tabular}{lrrrrrr}
\hline Unit Name & Total Acres & No Action & Alt. 1 & Alt. 2 & Alt. 3 & PRMP \\
\hline Wasson Creek & 3,408 & 3,408 & 3,408 & 442 & 10 & 3,408 \\
\hline Bull of the Woods & 3,203 & 414 & 430 & 127 & 38 & 846 \\
\hline South Fork Clackamas River & 919 & 134 & 118 & 64 & 42 & 320 \\
\hline Salmon Huckleberry Additions & 637 & 69 & 9 & 2 & 2 & 199 \\
\hline Mount Hebo & 81 & 63 & 19 & 5 & 0 & 80 \\
\hline Berry Creek & 6,433 & 1,342 & 1,902 & 170 & 29 & 899 \\
\hline Whiskey Creek & 5,667 & 2,198 & 1,052 & 2,350 & 138 & 5,667 \\
\hline Wellington Mountain & 5,659 & 495 & 308 & 329 & 72 & 583 \\
\hline Williams Creek & 116 & 0 & 0 & 0 & 0 & 0 \\
\hline Totals & 26,123 & $\mathbf{8 , 1 2 3}$ & $\mathbf{7 , 2 4 6}$ & 3,489 & 331 & 12,009 \\
\hline Percentage of Total Acres & $100 \%$ & $31 \%$ & $28 \%$ & $13 \%$ & $1 \%$ & $46 \%$ \\
\hline
\end{tabular}

See Table 4-101 (BLM-administered lands with wilderness characteristics maintained by alternative) and Figure 4-182 (Acres of BLM-administered lands with wilderness characteristics maintained by alternative) for the amount of lands with wilderness characteristics that would be maintained when excluding those portions in the harvest land base, Late-Successional Management Areas, or Riparian Management Areas under all of the action alternatives, and within Late-Successional Reserves and Riparian Reserves under the No Action Alternative.

The PRMP would maintain 2\% less wilderness characteristics when compared to the No Action Alternative. Limited timber harvest to promote the development of structurally complex forests would occur within these areas; however, these activities would only slightly diminish naturalness if no road construction is necessary.

Under Alternatives 1, 2, and 3, fewer acres with wilderness characteristics would be maintained than under the No Action Alternative. Alternative 1 would maintain wilderness characteristics on slightly more lands compared to Alternatives 2 and 3. Under Alternative 1, 4\% less would be maintained than under the No Action Alternative. Under Alternatives 2 and 3, approximately $6 \%$ and $7 \%$ less, respectively, would be maintained. Under Alternative 3, timber harvest would occur in $46 \%$ of the areas with wilderness characteristics; under the PRMP, timber harvest would occur in $17 \%$ of the areas with wilderness characteristics.

Table 4-101. BLM-Administered Lands With Wilderness Characteristics Maintained By Alternative

\begin{tabular}{|c|c|c|c|c|c|c|}
\hline Unit Name & Total Acres & No Action & Alt. 1 & Alt. 2 & Alt. 3 & PRMP \\
\hline Wasson Creek & 3,408 & 2,220 & 2,220 & 977 & 1,244 & 2,220 \\
\hline Bull of the Woods & 3,203 & 2,645 & 2,534 & 2,445 & 2,524 & 1,986 \\
\hline South Fork Clackamas River & 919 & 539 & 438 & 466 & 489 & 313 \\
\hline Salmon Huckleberry Additions & 637 & 480 & 507 & 491 & 491 & 179 \\
\hline Mount Hebo & 81 & 81 & 81 & 22 & 62 & 81 \\
\hline Berry Creek & 6,433 & 4,528 & 2,873 & 2,751 & 2,939 & 3,675 \\
\hline Whiskey Creek & 5,667 & 1,395 & 2,666 & 3,317 & 2,828 & 5,293 \\
\hline Wellington Mountain & 5,659 & 3,484 & 3,166 & 3,072 & 3,276 & 3154 \\
\hline Williams Creek & 116 & 94 & 62 & 62 & 62 & 112 \\
\hline Totals & 26,123 & 15,466 & 14,547 & 13,603 & 13,915 & 14,817 \\
\hline Percentage of Total Acres & $100 \%$ & $59 \%$ & $55 \%$ & $52 \%$ & $53 \%$ & $57 \%$ \\
\hline
\end{tabular}


Figure 4-182. Acres Of BLM-Administered Lands With Wilderness Characteristics Maintained By Alternative

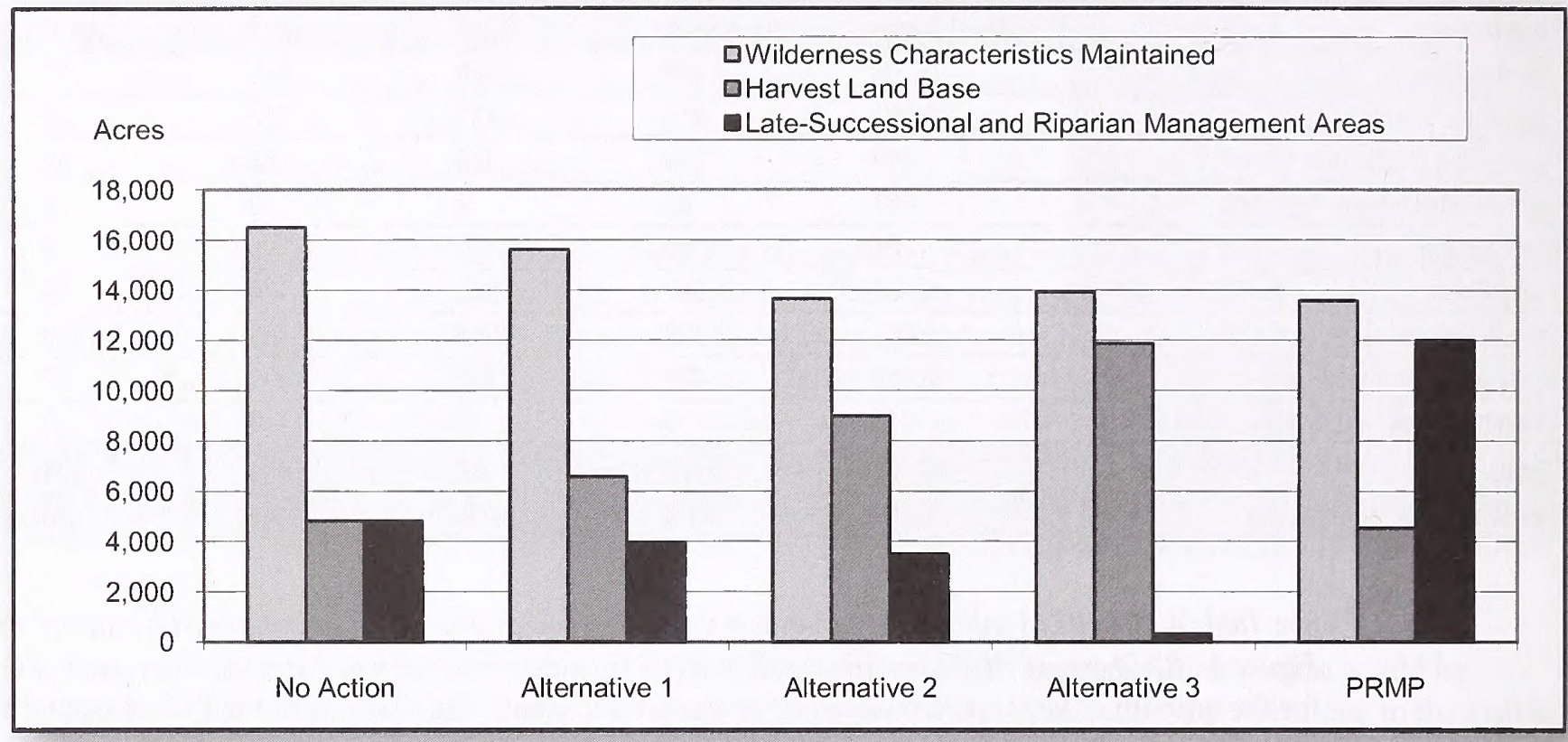

Under all action alternatives, management direction would protect the wilderness characteristics of the five selected units from all discretionary management actions (e.g., recreation developments and road building). However, the wilderness characteristics of these areas would not be protected from nondiscretionary actions, such as road construction associated with reciprocal right-of-way agreements or mining. 


\section{Visual Resources}

This analysis examines the maintenance of the visual resource quality of the BLM-administered lands under each alternative.

\section{Key Point}

The No Action Alternative would maintain existing visual resource quality on the greatest portion of BLMadministered lands in the planning area, followed second by the PRMP, and then by Alternatives 1, 2, and 3 .

Visual resource quality is determined through the visual resource inventory process, which is based on a combination of scenic quality, sensitivity levels, and distance zones. The results of this inventory process classified all BLM-administered lands in the planning area as Class I, II, III, or IV. Class I areas have the highest level of visual resource quality, and Class IV areas have the lowest level (see the Recreation section of Chapter 3).

The BLM also designates visual resource management classes through the land use planning process, and these classes also range from Class I to IV. Class I areas are managed to preserve visual resource quality and Class IV areas allow for major modifications. Except for Class I areas, management classes can vary from the original inventory classes to be consistent with resource management plan goals and objectives (see the Visual Resources section of Chapter 2).

For the purposes of this analysis, visual resource quality would be retained when an area's visual resource management objectives are either the same or more restrictive than the area's inventoried classification. For example, an area inventoried as Class III that is managed with either Class I, II or III management objectives would retain its inventoried visual resource quality. Conversely, areas that are managed under less restrictive visual resource management objectives than their inventoried classification would potentially have diminished visual resource quality over time due to management actions. An example would be an area inventoried as Class II that is managed under less restrictive Class III or IV management objectives. Table 4-102 (Visual resource inventory classes and management classes by alternative) and Figure 4-183 (Visual resource inventory and management classes in acres by alternative) show the relationship between visual resource inventory and management classes by alternative.

The relationship between inventory and management classes cannot be used exclusively to analyze the effects of alternatives on visual resource quality. Effects depend on the level and type of surface disturbing activities that would occur under each alternative. Major modifications of visual resource quality would take place on forest lands that are in the harvest land base. Therefore, the amount of harvest land base within each visual resource inventory class is used to determine the degree to which existing visual resource quality would likely be affected under each alternative. However, until projects are actually planned and site-specific visual simulations and analyses are completed, the visual effects of management actions cannot be fully

Table 4-102. Visual Resource Inventory Classes And Management Classes By Alternative

\begin{tabular}{lr|r|r|r}
\hline $\begin{array}{l}\text { Visual Resource } \\
\text { Inventory Classes }\end{array}$ & Inventoried & No Action & $\begin{array}{r}\text { Alternatives } \\
1,2,3\end{array}$ & PRMP \\
\cline { 2 - 5 } & \multicolumn{5}{c}{ (acres) } \\
\hline Class I & 79,000 & 29,000 & 36,000 \\
\hline Class II & 477,000 & 199,000 & 59,000 & 65,000 \\
\hline Class III & 573,000 & 587,000 & 45,000 & $2,402,000$ \\
\hline Class IV & $1,404,000$ & $1,717,000$ & $2,420,000$ & 2,000 \\
\hline
\end{tabular}


Figure 4-183. Visual Resource Inventory And Management Classes In Acres By Alternative

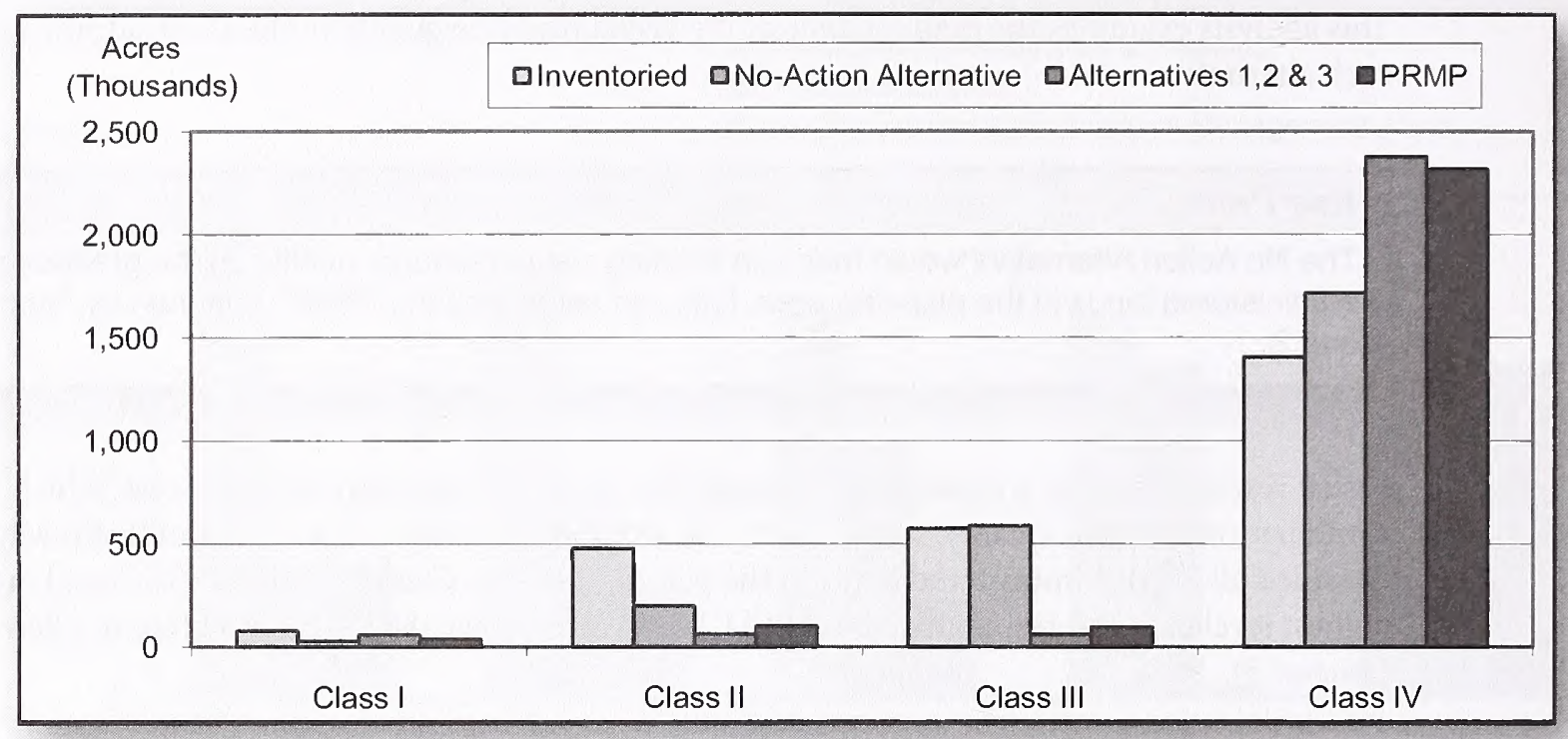

predicted. See Table 4-103 (Harvest land base within each visual resource inventory class by alternative) and Figure 4-184 (Harvest land base acres within visual resource inventory classes by alternative) for the amount of BLM-administered lands by inventory class in the harvest land base by alternative.

Existing visual resource quality on BLM-administered lands inventoried as Class I would be maintained under all alternatives. Class I is unique from the other inventory classes, because it is assigned to areas where a management decision has been made to preserve a natural landscape (see the Visual Resources section of Chapter 3). Because of this, no timber harvest would occur within these areas. All action alternatives would protect existing visual resource quality on lands inventoried and managed as Class I.

The existing visual resource quality on BLM-administered lands inventoried as Class IV would also be maintained under all action alternatives. Major modifications that would occur within the harvest land base portions of these areas would not diminish their existing visual resource quality. Areas inventoried as Class IV have low scenic quality or low sensitivity levels (based on indicators of public concern); or they are seldom seen (based on the relative visibility from travel routes or observation points). Because of these factors, regeneration harvest practices are compatible in areas inventoried as Class IV.

Areas inventoried as Classes II and III have higher degrees of scenic quality and sensitivity levels than areas inventoried as Class IV. Because of this, regeneration harvests would diminish existing visual resource quality within these areas. Table 4-104 (Percentage of existing visual resource quality maintained by alternative

Table 4-103. Harvest Land Base Within Each Visual Resource Inventory Class By Alternative

\begin{tabular}{lrrrr}
\hline $\begin{array}{l}\text { Visual Resource } \\
\text { Inventory Classes }\end{array}$ & No Action & Alt. 1 & Alt. 2 & Alt. 3 \\
\cline { 2 - 5 } & & & PRMP \\
\hline Class I & 4,000 & 1,000 & 3,000 & 5,000 \\
\hline Class II & 127,000 & 173,000 & 217,000 & 256,000 \\
\hline Class III & 180,000 & 245,000 & 325,000 & 350,000 \\
\hline Class IV & 324,000 & 474,000 & 668,000 & 1,000 \\
\hline $\begin{array}{l}\text { a Some harvest land base acres overlap Class I areas. This is due to mapping errors associated with the original inventory, which does not align exactly with congressional and administrative areas } \\
\text { designated as Class I. }\end{array}$
\end{tabular}


Figure 4-184. Harvest Land Base Acres Within Visual Resource Inventory Classes By Alternative

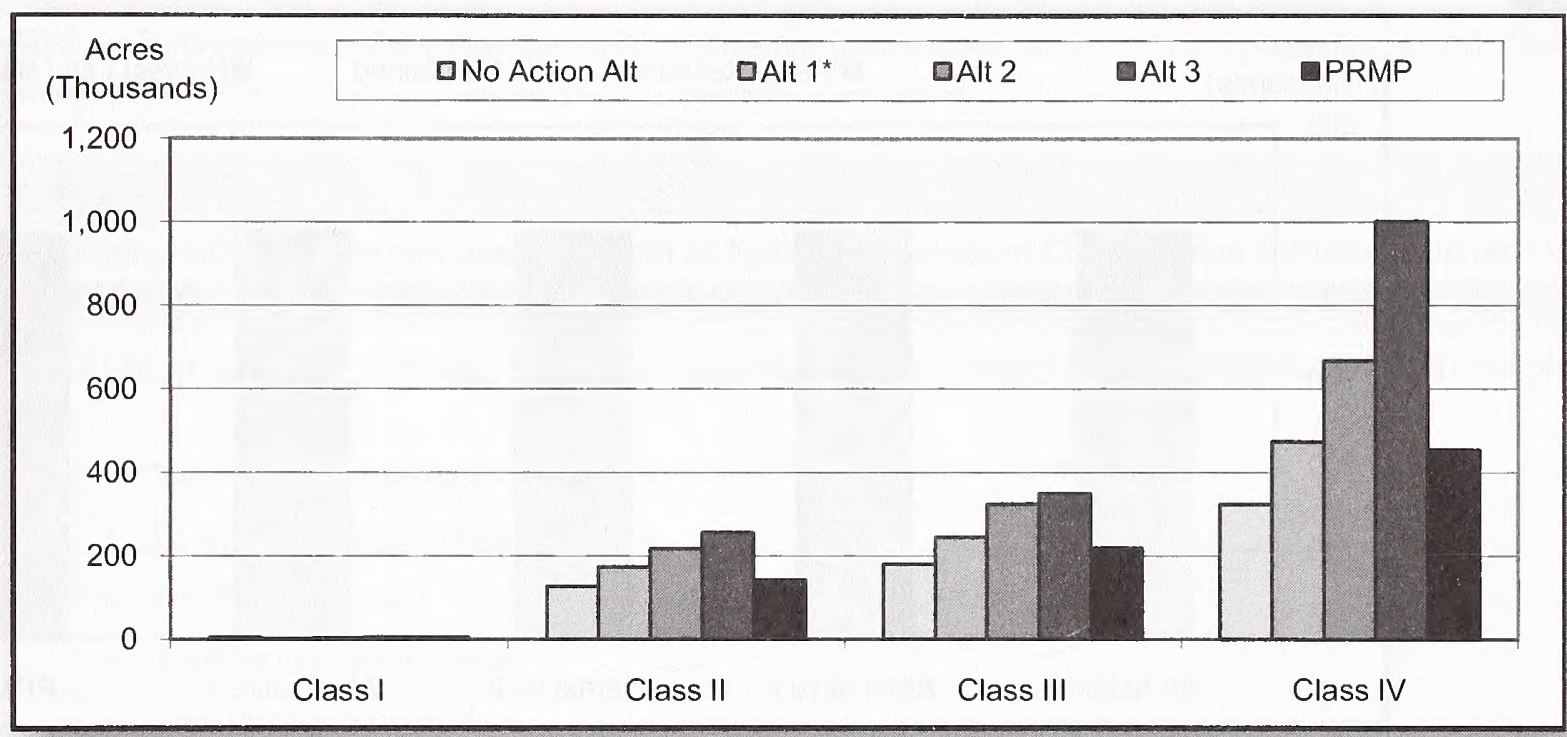

within areas inventoried as class II and III) shows the percentage of these inventory classes that would be maintained under each alternative based on the portion of these areas that are not within the harvest land base.

Slightly less existing visual resource quality within areas inventoried as Class II and Class III would be maintained under the PRMP compared to the No Action Alternative. The other action alternatives would maintain less existing visual resource quality within areas inventoried as Class II and Class III than the PRMP or the No Action Alternative. The highest portion of existing visual resource quality within these areas would be maintained under the PRMP compared to the other action alternatives. Figure 4-185 (Visual resource inventory Class II areas maintained by alternative) shows the proportion of areas inventoried as Class II that are within the harvest land base by alternative. Figure 4-186 (Visual resource inventory Class III areas maintained by alternative) shows the proportion of areas inventoried as Class III that are within the harvest land base by alternative.

Table 4-104. Percentage Of Existing Visual Resource Quality Maintained By Alternative Within Areas Inventoried As Class II And III

\begin{tabular}{lccccc}
\hline Visual Resource Inventory Classes & No Action & Alt. 1 & Alt. 2 & Alt.3 & PRMP \\
\hline Class II & $73 \%$ & $64 \%$ & $55 \%$ & $46 \%$ & $71 \%$ \\
\hline Class III & $69 \%$ & $57 \%$ & $43 \%$ & $39 \%$ & $62 \%$ \\
\hline
\end{tabular}


Figure 4-185. Visual Resource Inventory Class II Areas Maintained By Alternative

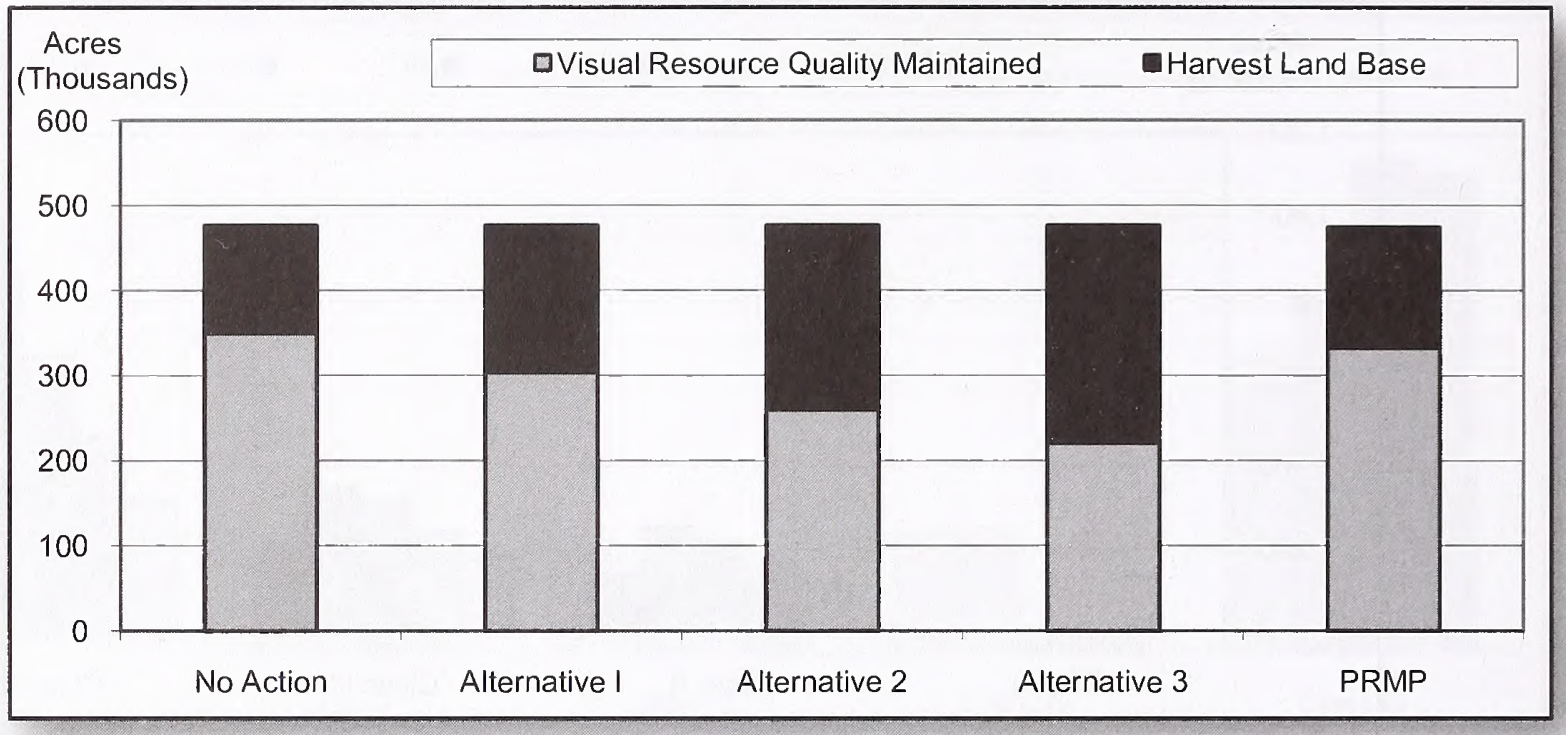

Figure 4-1186. Visual Resource Inventory Class III Areas Maintained By Alternative

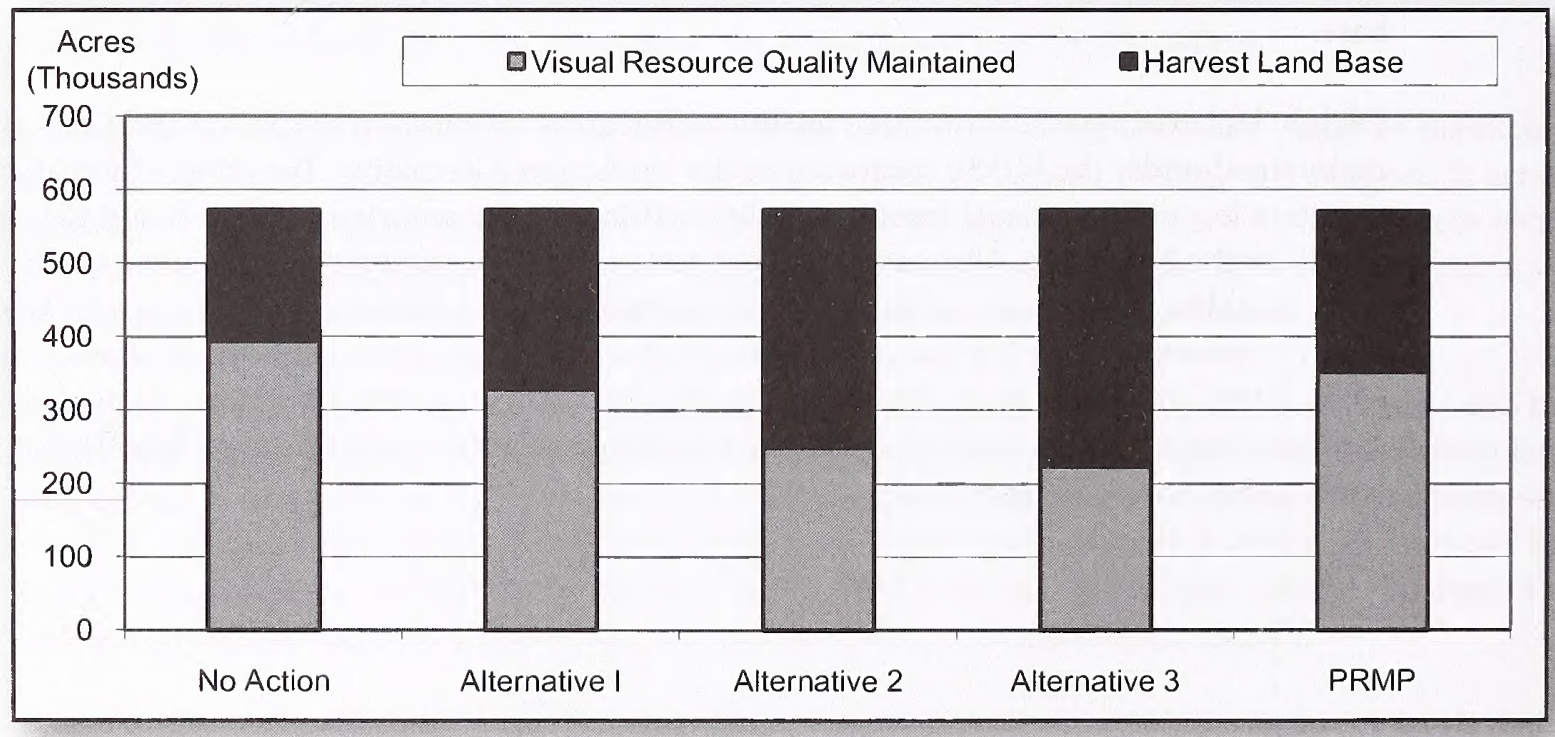




\section{National Landscape Conservation System}

This analysis examines the protection of the National Landscape Conservation System lands under each alternative.

\section{Key Point}

- All alternatives would continue to protect all National Landscape Conservation System designations.

The BLM manages the following National Landscape Conservation System designations within the planning area:

- 1 national monument

- 12 wild and scenic river segments

- 2 wilderness areas

- 5 wilderness study areas

- 1 national scenic trail

- 1 outstanding natural area

The BLM also manages portions of the Mount Hood Corridor and the Bull Run Watershed Management Unit, along with 57 eligible and suitable wild and scenic river segments, which are related to, but not part of, the National Landscape Conservation System. See Chapter 2 for a list of these individual designations in the planning area.

All of these designations are withdrawn from timber harvest with the exception of designated, suitable, and eligible wild and scenic rivers that are classified as scenic or recreational. Therefore, only the wild and scenic rivers classified as scenic or recreational are considered in the analysis, because they are the only elements in the National Landscape Conservation System that have the potential to be affected by the actions under the alternatives.

Under all alternatives, limited timber harvesting would be allowed within designated, suitable, and eligible wild and scenic river corridors that are classified as scenic or recreational. Harvesting would be done in a manner that would not impair their free-flowing character, classification, or identified outstandingly remarkable values. There are 72 of these river segments on BLM-administered lands in the planning area, totaling 53,357 acres.

These river segments have different combinations of outstandingly remarkable values that overlay site-specific conditions, each of which requires unique management considerations to guarantee their protection. Because of this, all wild and scenic river corridors would not be included in the harvest land base under any of the alternatives.

Under all alternatives, limited timber harvest would be allowed if designed to have either a positive or neutral effect on a river segment's classification and outstandingly remarkable values. This would result in the protection of all designated, suitable, and eligible wild and scenic rivers under all alternatives. 


\section{Soils}

This analysis examines the effects of forest and range management activities on soil productivity that would result from the alternatives.

\section{Key Point}

- Soil productivity would be maintained or improved under all five alternatives.

Under all alternatives, long-term conservation and the productive capacity of the forest and rangeland soils across the planning area would be maintained.

The same or improved practices that were used from 1995 to 2006 under the current resource management plans (as represented by the No Action Alternative) would be used under all alternatives to provide for soil productivity. It is reasonable to assume that these practices would be implemented under all alternatives, because the management objective for soils under all alternatives is essentially the same. The primary measure of soil productivity for this analysis is the ability of the soil to grow vegetation, specifically commercial trees.

Timber harvest activities can cause soil compaction, displacement, and erosion. The duration and extent of this soil disturbance depends on numerous factors including: soil characteristics, harvest method, amount of area in yarding trails, topography, skill of the individual equipment operators, and the application of amelioration practices.

In general, soil compaction that reduces water infiltration rates and large pore space for gas and water movement constitutes detrimental soil disturbance and can last many years (Froehlich and McNabb 1984, Cafferata 1992). Soil compaction reduces tree growth, but the relationship between compaction and tree growth is complex and difficult to predict because it is dependent on many variables. For example, Miller et al. (1996) found early growth reductions of seedlings planted on compacted skid trails compared to uncompacted locations, but growth of most seedlings on compacted locations caught up to uncompacted locations after eight years.

The early findings after the first decade of the North American long-term soil productivity experiment concluded that "Forest productivity response to soil compaction depended both on soil texture and on whether an understory was present. Growth tended to be reduced by compaction on clayey soils and increased on sandy soils. Effects are attributed to loss of aeration porosity on clays and improvements in available water holding capacity on sands. Trees growing without understory competition generally were unaffected by severe soil compaction through the first 10 years. But 10 -year production generally was less on severely compacted plots if an understory was present. In time, compaction effects should be more evident in stands lacking an understory." (Powers et al. 2005)

A myriad of microbiotic organisms exist in the soil. Some aid in the decomposition of organic matter and subsequent release of plant available nutrients, some fix nitrogen from the air and make it available to plants, and some turn unusable chemical compounds into plant available nutrients. A genetically diverse thriving population of microbes is crucial to the productivity of a soil.

The effects of soil compaction on soil microbial communities and their processes are complex and not universal however. Shestak and Busse (2005) cite research that found decreases in microbial activity having no effect, or a positive response by microorganisms due to compaction. Their research on sandy loam and clay loam soils under laboratory and field conditions in the Sierra's of northern California found that they "agree with most other studies of soil compaction from the network of LTSP (long-term soil productivity) sites in North America that, so far, show tolerance or resilience by microbial communities." They conclude, "with the 
exception of poorly drained soils or those regions receiving high annual precipitation where saturation is a concern, soil physical changes associated with compaction appear to be of little consequence to the microbial community." Whether these conclusions hold up in the long term, or are valid for all soils except poorly drained ones, remains to be seen.

Ground-based yarding equipment, such as rubber tired and tracked skidders, has the potential to compact forest soils. Highly mechanized ground-based logging systems (e.g., harvester/forwarders, feller bunchers, and shovels) have become more prevalent recently in timber harvests on BLM-administered lands. However, with these systems, "... research and monitoring confirmed that despite their unique design and use, highly mechanized systems ... for logging younger and smaller timber have the potential to produce significant soil compaction" (Adams 2005).

Under all alternatives when these areas of existing compaction are encountered during future management actions, amelioration of soil compaction would be implemented, if needed, to provide for soil productivity. In some instances, implementation of the amelioration may be delayed if a subsequent entry in the relatively near future would utilize the same compacted skid trail to access the unit.

Under all alternatives, skyline and helicopter logging systems would generally be used on slopes over 35\%. These harvest methods decrease log contact with soils compared to ground-based systems by partially or fully suspending the logs over the soils. The more a log is suspended during yarding, the less the soil is affected.

The assumed area of residual detrimental soil disturbance within a timber harvest area remaining after all activities, including amelioration, would vary by logging method. Residual soil disturbance would be: $15 \%$ with ground-based logging, $3 \%$ with skyline, and $1 \%$ with helicopter.

The amount of acres that would be harvested by each logging method varies by alternative. However, when the total acres of assumed residual detrimental soil disturbance is compared to total acres harvested for each alternative, the residual detrimental soil disturbance would be about $5 \%$ of soils on BLM-administered lands in the planning area under each alternative. See Table 4-105 (Residual detrimental soil disturbance compared to total acres harvested), which shows the total acres harvested and the assumed acres that would remain in a detrimental condition after timber harvest and amelioration.

Under all alternatives, permanent roads and landings would be constructed as part of forest management activities. These roads and landings would be compacted to increase the bearing strength of the soil in order to hold the weight of trucks and equipment. Some research suggests that the growth of roadside trees may benefit from the increased light and moisture and reduced competition (Miller et al. 1989). Whether this increased growth compensates for the loss of timber production on a permanent road or landing is not known. Temporary roads and landings would have little effect on overall soil productivity because associated compaction would be ameliorated.

New permanent roads and landings would be built under all alternatives. Decommissioning of permanent roads and landings no longer needed for forest management would also occur. During the first 10 years of the plan, the net effect of road building versus road decommissioning would result in less than $1 \%$ net

Table 4-105. Residual Detrimental Soil Disturbance Compared To Total Acres Harvested During The First Ten Years

\begin{tabular}{lrrrrr}
\hline & No Action & Alt. 1 & Alt. 2 & Alt. 3 & PRMP \\
\cline { 2 - 6 } & \multicolumn{7}{c}{ (acres) } & & \\
\hline Total acres harvested & 160,500 & 204,000 & 220,100 & 288,800 & 297,700 \\
\hline Total detrimental soil disturbance & 8,400 & 10,700 & 10,800 & 15,300 & 15,000 \\
\hline
\end{tabular}


increase over current road and landing acreage under the No Action Alternative; a 2\% net increase under Alternatives 1, 2 and 3; and a 3\% net increase under the PRMP.

Prescribed fire can cause detrimental soil disturbance if the temperature and duration of a fire heats the soil at depth, such that there is a breakdown in soil structure and decrease in soil productivity. The deeper the burn, the more likely soil productivity would be impaired. "Although the most serious and widespread impacts on soils occur with stand replacing wildfires, prescribed fires sometimes produce localized problems" (Neary et al. 2005).

Under all alternatives, site preparation after timber harvest would include pile and burn (either by machine or hand) or broadcast burning. Burning piles would be more likely to create the higher temperatures that last longer than broadcast burning, increasing consumption of organic matter and volatilization of nutrients, although overall there would be fewer acres affected by pile and burn techniques. Broadcast burns for slash disposal would generally have lower temperatures and shorter duration, leaving surface soils and organic matter mostly intact; however more acres, by definition, would be affected.

Pile and burn, as well as broadcast burning, for site preparation have been implemented on BLMadministered lands since 1995 with practices and techniques designed to reduce the duration and temperature of fire. The annual amount of site preparation prescribed burning would vary from 4,800 acres under the No Action Alternative, to 10,900 acres under Alternative 2. See Table 4-1 (Estimated annual first decade levels of timber management activity by alternative). Under all alternatives, overall soil productivity would be maintained because severe depth of burning would be highly localized and small in area extent. The reason for this is that the areas immediately under the burn piles are small areas scattered around a particular unit, or are under areas of concentrated slash from harvesting.

Under all alternatives, the analysis assumes (based on experience under the 1995 resource management plans) that in the northern districts, approximately half of the acreage within regeneration harvest units would receive slash treatment, and thinning units would not receive slash treatment. The analysis also assumes (based on experience under the 1995 resource management plans) that $90 \%$ of harvest units would receive some form of slash treatment in the southern districts. The remaining $10 \%$ would not have enough slash to require treatment.

Uncharacteristic wildfire damages soils. Regardless of whether the ignition source is natural or human caused, when soil heating occurs such that there is a breakdown in soil structure, reduction or loss of organic matter and microbial species, water repellency, and surface runoff, the soil functions are impaired and soil productivity can be decreased (Neary et al. 2005).

To reduce the effects of uncharacteristic wildfire, the reduction of hazardous fuels (either through underburning or mechanical biomass removal) would occur in the planning area under all alternatives. In addition, under the PRMP, uneven-age management would be implemented in the Medford District and Klamath Falls Resource Area to reduce the occurrence of uncharacteristic wildfire. Underburning would have similar effects as earlier described for prescribed fire for site preparation after timber harvest.

Little is known about the long-term physical effects of mechanically treating vegetation for biomass removal on soils. However, machines that reduce vegetation into small pieces have the potential to compact soils (Bennett and Fitzgerald). The physical effects of mechanically treating vegetation would be similar to timber harvest activities (refer to preceding text on compaction). Although some machinery made specifically for reducing standing vegetation to woody chips on the soil surface may cause limited compaction, existing timber harvest machines that could be altered to create chips may cause detrimental compaction. However, the mechanical treatment of hazardous fuels reduces the risk of soil damage caused by uncharacteristic wildfire. 
Hazardous fuels would be treated using mechanical means under all alternatives. The methods and techniques used would be consistent with past practices, which would maintain or improve soil productivity by decreasing the effects of uncharacteristic wildfire.

Little is known about the long-term biological effects of fuel reduction and biomass removal on soils. If wood chips are left onsite, soil nitrogen would be unavailable for plant growth due to the high carbonnitrogen ratio until the woody material decomposes. However, this material is an eventual source of nutrients. Some research suggests that if the mulch layer following mastication exceeds three inches that biological damage from soil heating can occur if the mulch is burned. "Field projections indicate that up to one-fourth of treated areas with dense premastication of vegetation would surpass lethal soil temperatures during a surface wildfire" (Busse et al. 2005).

For this analysis, biomass removal for hazardous fuels and whole tree logging as a logging practice is considered as having the same effects on nutrient cycling within soils. Both practices would export most above-ground standing organic carbon off site (see the Carbon section of Chapter 3).

The importance of organic matter for site productivity is prevalent in the literature (Jurgensen et al. 1997, Rapp et al. 2000, and Hayes et al. 2005). “...The replenishment of organic matter is critical to sustained productivity of forested ecosystems. Organic carbon in forest detritus is the substrate energizing most soil biotic processes that control nutrient and water availability, aeration, and soil structure" (Powers 2002). In addition, Powers cites research that found surface sandy soils of the Sierra National Forest were depleted of plant available moisture by August, but moisture was available throughout the dry summer where logging slash had been retained. Surface organic matter acts as a mulch against solar heating and evaporation, but the mulch value would diminish as forest canopies close and transpiration dominates evaporation. This mulching effect would have more significance in the southern portion of the planning area over the long term because of the warmer drier climate.

The long-term consequences of biomass removal and whole tree logging are not known. A study to determine these long-term effects has begun recently and is called the North American Long-term Soil Productivity experiment. Combining all data from the oldest 26 sites (from the Idaho Panhandle, California Sierra Nevada's, Lake States, and Southern Coastal Plain) after the first decade, it was concluded that "complete removal of surface organic matter led to declines in soil C concentration to $20 \mathrm{~cm}$ depth and to reduced nutrient availability. However, their findings indicate that "biomass removal during harvesting had no influence on forest growth through 10 years" (Powers et al. 2005). They also concluded that "soil C inputs depend only slightly on decomposition of fresh surface residues in the forest types...studied." They further state, "that the preliminary inputs to soil C come from the decay of fine roots that remained from the previously harvested stand."

After the first decade of the North American Long-Term Soil Productivity experiment, the findings should be viewed as preliminary. The first decade look at the data was an "early glimpse and may be aberrations once a more complete data set emerges and vegetation more fully occupies our sites" (Powers et al. 2004). None of the North American Long-Term Soil Productivity data observed and used in the study came from western Oregon. However, several sites have been established within the planning area and will provide data in the future.

Western juniper removal to modify wildlife habitat, plant community composition, structure, and/or biodiversity would occur under all alternatives within the Klamath Falls portion of the planning area. The risks and significance to soils associated with burning or mechanical removal of juniper would be the same as previously discussed for hazardous fuels biomass reduction and whole tree logging. However, the machinery used can also include bulldozers to push trees over and pulling chain or cables, and the various cutting and grinding tools, as well as logging equipment. Soil disturbance can be minimal to high, 
depending on onsite soil conditions. "Higher levels of surface disturbance can increase the opportunities for weed establishment and temporarily increase erosion potential. However, disturbance of the soil may also be beneficial if applied properly when seeding is required" (Miller et al. 2005).

In the Klamath Falls portion of the planning area, summer thunderstorms are common in the semi-arid environment. Most surface overland flow and erosion is generated during these thunderstorms. The greater the plant density on any given area, the less opportunity for soil erosion. Studies in sagebrush areas have shown that over time, shrubs produce modified microclimates that cause a several-fold increase in infiltration capacity resulting in decreases in erosion compared to the soil between shrubs. Dominance of juniper on a site has been shown to decrease cover of shrub and herbaceous vegetation. Several studies have shown that cutting juniper resulted in increased shrub and herbaceous cover on sites in southeastern Oregon (Miller et al. 2005).

A study quantified hydrologic changes associated with vegetation recovery 10 years after juniper control in eastern Oregon. They found that by cutting juniper, cover was about four times greater in the cut versus uncut treatment, which resulted in the juniper woodlands rapidly producing large amounts of runoff and cut plots producing almost none. The juniper woodland runoff produced almost 10 times the sediment compared to the cut treatment. They concluded that after 10 years, cutting the juniper allowed the site to move to a hydrologically stable condition, which protected the site from even large thunderstorms (Pierson et al. 2007).

As in other ecosystems, soil carbon in the form of organic matter and soil nitrogen are crucial for vegetative growth; however, there is limited research on nutrient and carbon cycling in western juniper woodlands. There is a lack of long-term assessment of changes to soil processes as plant communities convert to juniper woodlands. In addition, the effects of juniper control treatments on nutrient cycling and nutrient capital have not been well documented (Miller et al. 2005).

Greater amounts of vegetative litter accumulate beneath juniper canopies compared to interspace soils. In most juniper woodland sites, the accumulated litter provides no nutrient value to the herbaceous and/ or shrub understory unless the trees are removed. "When trees are removed, herbaceous productivity and cover are significantly greater in canopy-influenced soils compared to interspace zones (Miller et al. 2005).

Juniper expansion into sagebrush grassland has demonstrated the potential to alter the spatial distribution of soil organic matter, carbon, and nutrients. If erosion increases as juniper woodlands develop, the potential loss of nutrients off-site in sediment will ultimately cause a reduction in community productivity (Miller et al. 2005).

Livestock cause compaction and displacement of soils where there is a concentration of animals. Livestock also exacerbate erosion if bare ground is present due to the churning action of their hooves. This hoof action can compact biological crusts, which play a role in nitrogen fixation and soil stabilization. This would typically be localized and occur around water sources, salt licks, and on the trails leading to these areas. See the Grazing sections in Chapters 2, 3 and 4 for discussions about the levels of grazing.

The rangeland health standards incorporate soil parameters that contribute to rangeland health. These include qualitative indicators for soil/site stability, hydrologic function, and biotic integrity (Pellant et al. 2005). If rangeland health standards are met, it is assumed that soil productivity is maintained.

Figure 4-187 (Status of rangeland health standards assessment) shows the acres that are meeting standards or making progress towards meeting the standards. There are 12 allotments representing about 36,000 acres (approximately $6 \%$ of the acreage available for grazing) that have not met or made significant progress towards the rangeland health standards due to livestock concerns. Actions were taken and will continue to be implemented to ensure significant progress towards the standards (see the Grazing sections in Chapter 3 and Chapter 4). 
Figure 4-187. Status Of Rangeland Health Standards Assessment

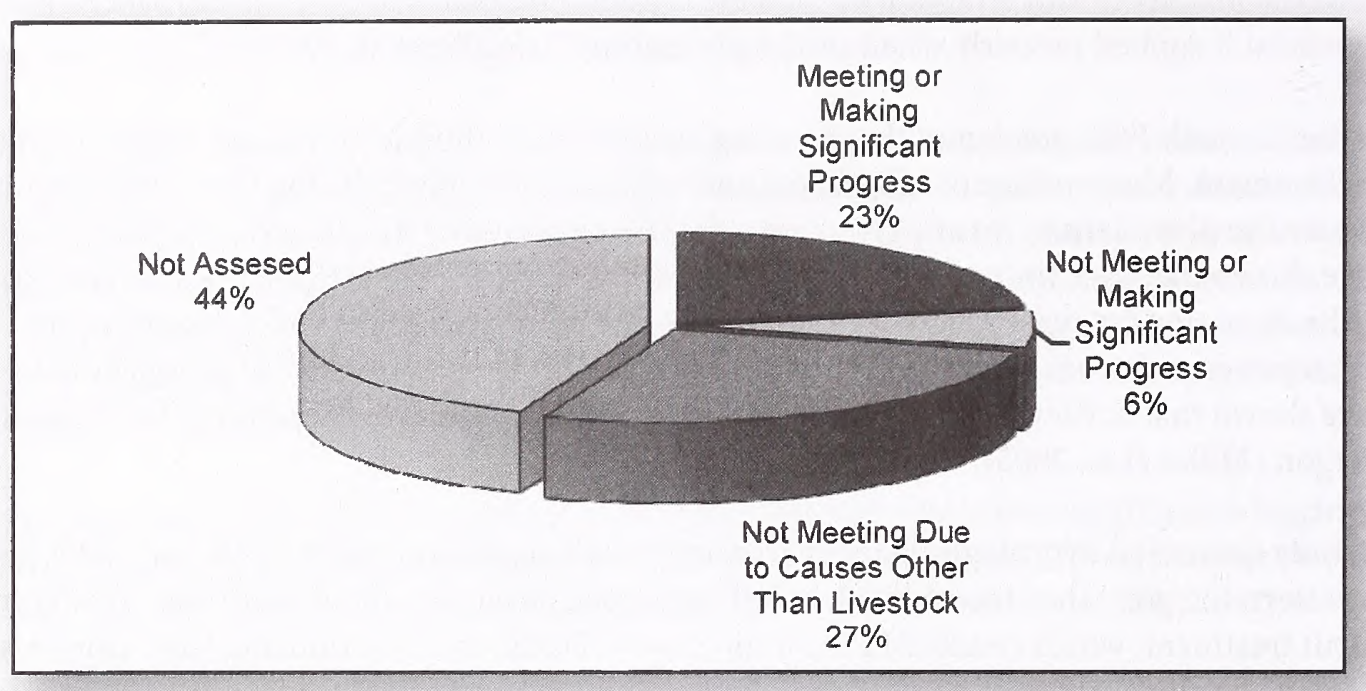

Under all action alternatives where rangeland health standards are not being met, grazing management practices would be modified to meet the standards. The nature of the modifications would be based on sitespecific circumstances.

Exposed compacted soil surfaces reduce the infiltration of rain water and snowmelt. A long, straight length of compacted soils, such as that which occurs with off-highway vehicle use, is conducive to the overland flow of water. When channelized, overland flow occurs, rills and gullies are formed, and subsequent sediment delivery to streams can occur when close enough to a water body. Currently, there are small localized areas in the planning area where this has occurred due to off-highway vehicle use.

Under the action alternatives, there would be a reduction of 330,000 acres of areas open to off- highway vehicle use. A majority of these open areas are located on steep, densely-forested terrain. This terrain is not conducive to cross-country motor vehicle travel, so off-highway vehicle use is primarily limited to existing roads and trails in these areas. Under Alternatives 1, 2, and 3, there would be 77 acres of Heceta Dunes open to off-highway vehicle use. This 77-acre area would be closed under the PRMP. In the action alternatives, offhighway vehicle use would be limited to designated roads and trails. Under all action alternatives, it is assumed that off-highway vehicle use would cause inconsequential erosion, because roads and trails would not be designated for use if they would cause erosion or sediment (see the Water section of this chapter).

Mass soil movement (including landslides, slumps, and debris flows) are natural geologic processes in western Oregon. Depending on geology and soils, the risk of slope failure changes from site to site across the planning area. Factors that contribute to slope instability include steep slopes (greater than 65\%); low soil strength; declining root strength; shallow soil depths; and high frequency, duration, and intensity of precipitation. Management actions that contribute to slope failure include timber harvest and new road construction. Sites that have a high risk of mass movement are identified under the Timber Production Capability Classification (TPCC) system and withdrawn from timber management. Although high risk areas are withdrawn from timber management to avoid slope failures, areas judged to be of lower risk have occasionally failed in the past. 


\section{Grazing}

This analysis examines the livestock grazing authorizations and the forage production in the Coos Bay and Medford Districts, and the Klamath Falls Resource Area in the Lakeview District that would result under the alternatives.

Key Points
- Under all action alternatives, there would be a decrease in livestock grazing authorizations. However,
this would not change the current level of grazing since the decrease would occur on allotments that are
currently vacant, except in the Coos Bay District.
- Under the No Action Alternative, and Alternatives 1,2 , and 3 , there would be an increase in forage
production on the west side of the Klamath Falls Resource Area and in the Medford District. The
increase would be the highest under the No Action Alternative. Under Alternatives $1,2,3$, the increase
would be the highest under Alternative 3 .
- Under the PRMP, there would be a decrease in forage production on the west side of the Klamath Falls
Resource Area and in the Medford District.
- Under all alternatives, the quantity of forage production in eastern Klamath Falls would not change
substantially.

Livestock grazing authorizations are assessed through changes in acres available for grazing including the number of allotments, animal unit months, and permittees/lessees.

As shown in Table 4-106 (Livestock grazing authorizations by district and by alternative) all of the components (acres available for grazing, number of allotments, animal unit months, permittees/lessees) of livestock grazing authorizations would either remain the same or decrease under all action alternatives.

Under all action alternatives, the amount of public land available for livestock grazing through the issuance of a grazing lease would decrease from 560,000 acres ( $22 \%$ of the planning area) to 419,000 acres ( $16 \%$ of the planning area).

In the Medford District and Klamath Falls Resource Area, the decrease occurs on allotments (in whole or in part) that are vacant and not currently grazed. This decrease would not reduce the number of allotments that have an active permit or lease. The reason for this is that the portions of allotments that are proposed for closure in part have an existing permit or lease that includes acres that are not proposed for closure to grazing, so the total number of leases is not being reduced. Only the amount of acreage that can be grazed in those allotments is being reduced. Furthermore, the allotments which are proposed for closure in whole do not have existing leases or permits.

Table 4-106. Livestock Grazing Authorizations By District And By Alternative

\begin{tabular}{|c|c|c|c|c|c|c|c|c|}
\hline \multirow[b]{2}{*}{ Grazing } & \multicolumn{2}{|c|}{ Medford } & \multicolumn{2}{|c|}{ Coos Bay } & \multicolumn{2}{|c|}{ Klamath Falls } & \multicolumn{2}{|c|}{ Total } \\
\hline & $\begin{array}{r}\text { No } \\
\text { Action }\end{array}$ & $\begin{array}{r}\text { Alts. } 1,2,3, \\
\text { PRMP }\end{array}$ & No Action & $\begin{array}{r}\text { Alts. } 1,2,3, \\
\text { PRMP }\end{array}$ & $\begin{array}{r}\text { No } \\
\text { Action }\end{array}$ & $\begin{array}{r}\text { Alts. 1, 2,3, } \\
\text { PRMP }\end{array}$ & $\begin{array}{r}\text { No } \\
\text { Action }\end{array}$ & $\begin{array}{r}\text { Alts. 1, 2, 3, } \\
\text { PRMP }\end{array}$ \\
\hline Allotments & 95 & 55 & 0 & 0 & 96 & 95 & 191 & 150 \\
\hline Leases & 0 & 0 & 4 & 0 & 0 & 0 & 4 & 0 \\
\hline Public Land (Acres) & 352,000 & 217,000 & 16 & 0 & 208,000 & 202,000 & 560,000 & 419,000 \\
\hline Active AUMs & 13,416 & 11,118 & 23 & 0 & 13,401 & 13,381 & 26,840 & 24,499 \\
\hline $\begin{array}{l}\text { Permittees/ } \\
\text { Lessees }\end{array}$ & 59 & 59 & 3 & 0 & 92 & 92 & 154 & 151 \\
\hline
\end{tabular}


In the Coos Bay District, four active grazing leases with three lessees covering 16 acres and 23 animal unit months $(0.08 \%$ of the total animal unit months authorized in the planning area) would be discontinued. See Figure 4-188 (Change in animal unit month by alternative) and Figure 4-189 (Change in the number of allotments by alternative) for a summary.

The levels of livestock grazing on U.S. Forest Service and BLM-administered lands covered by the Northwest Forest Plan have decreased since the early 1990s with some allotments vacant since the 1970 s. Under Alternatives 1,2, and 3, the quantity of forage production on the west side of Klamath Falls Resource Area and the Medford District would increase; however, the demand for grazing on the BLM (representing 14\% of the acres of U.S. Forest Service and BLM-administered lands) lands is expected to continue to decline. See Chapter 3 for the reasons for the decline in the levels of livestock grazing on Forest Service and BLMadministered lands. Under the PRMP Alternative, the quantity of forage production on the west side of Klamath Falls Resource Area and the Medford District would have a slight decrease.

Management actions needed to achieve the Standards for Rangeland Health for Oregon and Washington, resource management objectives, or other allotment-specific objectives would usually require adjustments in livestock numbers, season of use, or animal unit months, construction of range improvements, or implementation of intensive grazing systems. In the Medford District, three allotments covering 640 acres

Figure 4-1 88. Change In Animal Unit Months By Alternative

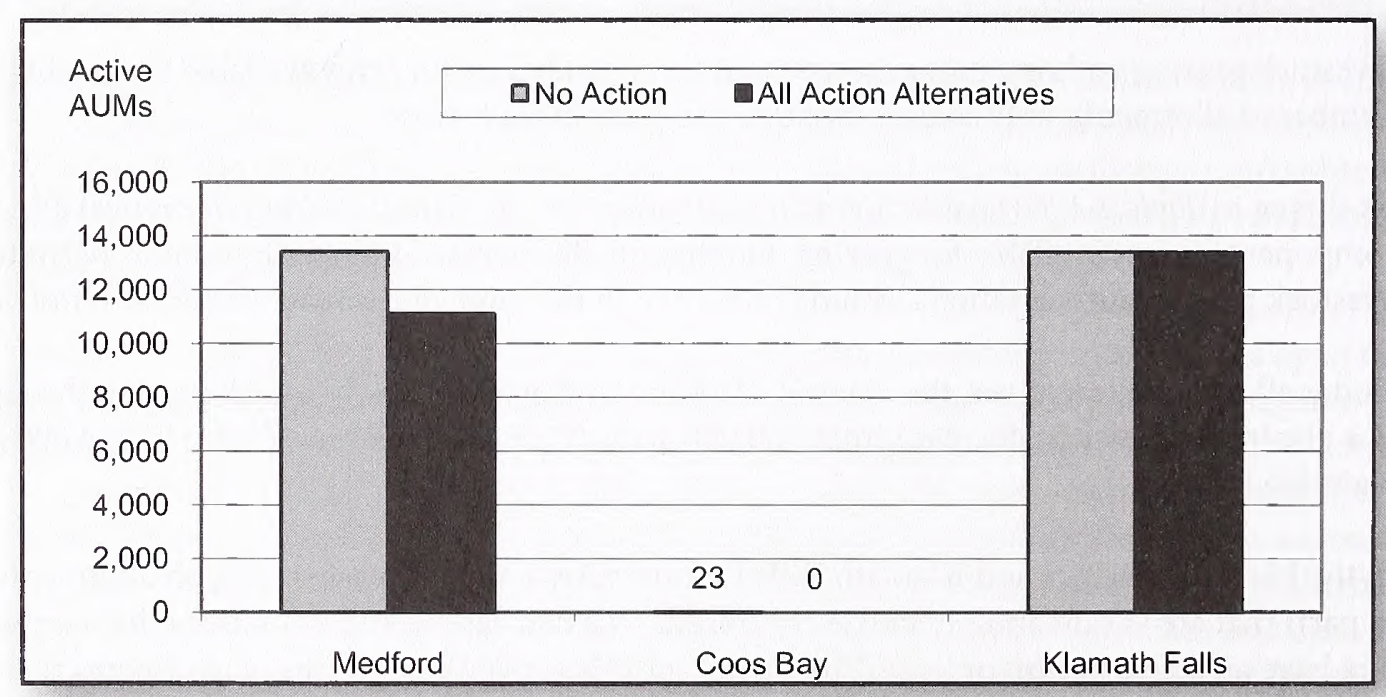

Figure 4-189. Change In The Number Of Allotments By Alternative

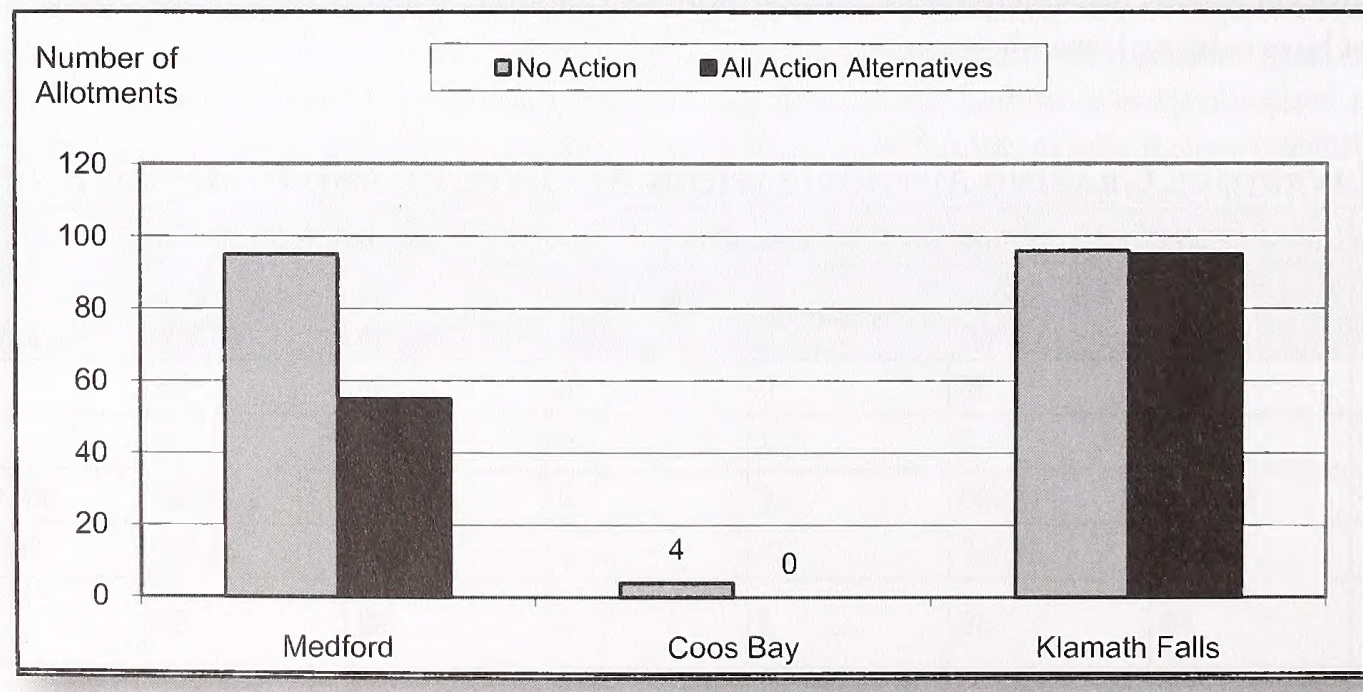


have required management actions to meet rangeland health standards since 1999. Based on past rangeland health assessments, adjustments in the next three years in the Medford District would be higher than the last eight years, because $54 \%$ of the allotments (representing $65 \%$ of the acres) have not been assessed. In the Klamath Falls Resource Area, nine allotments covering 35,404 acres have required management actions to meet rangeland health standards since 1999. Adjustments in the next three years in the Klamath Falls Resource Area would be lower than the last eight years, because more than $90 \%$ of the acres (representing $74 \%$ of the allotments) have been assessed.

Forage production is affected by changes to vegetation. Changes to vegetation can occur due to range improvements, fuels treatments, timber harvest, and management of areas of critical environmental concern.

Forage and water availability is generally adequate for livestock; however, there are opportunities to improve livestock distribution to restore riparian and upland vegetation, provide additional water sources, and protect riparian areas. Under all action alternatives, the construction of range improvements would be used to improve livestock distribution by:

- shifting grazing pressure from riparian/wetlands to uplands

- shifting grazing distribution within the uplands including areas that are not currently used

The construction of range improvements that would occur under the alternatives is shown in Table 4-107 (Range improvement construction by district and by alternative).

Under all action alternatives, the construction of range improvements that would occur under the alternatives in the Medford District would occur at approximately the same rate as those constructed from 1996 to 2006 (see the Grazing section of Chapter 3).

Under all action alternatives, the rate of range improvement construction that would occur in the Klamath Falls Resource Area would increase by $245 \%$ over the next 10 years, compared to the rate constructed during the period 1996 to 2006. There would be up to 29 reservoirs and 48 miles of fence constructed under all action alternatives within the Klamath Falls Resource Area. See Chapter 2 and Appendix M - Grazing.

Under all alternatives, the management actions that provide for the site-specific protection or restoration of habitat would exclude access (through fencing) to certain traditional watering or foraging areas. Exclusion of these areas from grazing would be so limited in number and so scattered geographically that they would not significantly limit overall watering or foraging opportunities.

Under all alternatives, the quantity of forage production in the Medford District and the Klamath Falls Resource Area would not change significantly because of non-timber management vegetation treatments (refer to Table 4-3. Estimated first decade levels of non-timber management activity by alternative). Vegetation treatments would be so scattered geographically that there would be no overall change in forage production.

Table 4-107. Range Improvement Construction By District And By Alternative

\begin{tabular}{|c|c|c|c|c|c|c|c|c|}
\hline \multirow{2}{*}{$\begin{array}{l}\text { Range } \\
\text { Improvement }\end{array}$} & \multicolumn{2}{|c|}{ Medford } & \multicolumn{2}{|c|}{ Coos Bay } & \multicolumn{2}{|c|}{ Klamath Falls } & \multicolumn{2}{|c|}{ Total } \\
\hline & $\begin{array}{c}\text { No } \\
\text { Action }\end{array}$ & $\begin{array}{l}\text { Alt } 1,2,3, \\
\text { PRMP }\end{array}$ & $\begin{array}{c}\text { No } \\
\text { Action }\end{array}$ & $\begin{array}{c}\text { Alt } 1,2,3, \\
\text { PRMP }\end{array}$ & $\begin{array}{c}\text { No } \\
\text { Action }\end{array}$ & $\begin{array}{c}\text { Alt } 1,2,3, \\
\text { PRMP }\end{array}$ & $\begin{array}{c}\text { No } \\
\text { Action }\end{array}$ & $\begin{array}{l}\text { Alt } 1,2,3, \\
\text { PRMP }\end{array}$ \\
\hline $\begin{array}{l}\text { Livestock Fences } \\
\text { Constructed (units/ } \\
\text { miles) }\end{array}$ & $\begin{array}{c}18 \\
5 \text { miles }\end{array}$ & $\begin{array}{c}18 \\
5 \text { miles }\end{array}$ & 0 & 0 & $\begin{array}{c}11 \\
19 \text { miles }\end{array}$ & $\begin{array}{c}27 \\
48 \text { miles }\end{array}$ & $\begin{array}{c}29 \\
24 \text { miles }\end{array}$ & $\begin{array}{c}45 \\
53 \text { miles }\end{array}$ \\
\hline $\begin{array}{l}\text { Reservoirs or Springs } \\
\text { Constructed/ } \\
\text { Developed (units) }\end{array}$ & 6 & 6 & 0 & 0 & 3 & 29 & 9 & 35 \\
\hline
\end{tabular}


Where vegetation treatments would occur:

- In the short term, forage production at the site level would decline following vegetation treatments.

- In the long term (5+ year), treatments would result in increased forage production at the site level and enhanced vigor of vegetation.

Off-highway vehicle use affects livestock grazing through disturbance or harassment to livestock and by the type and access that permittees/lessees use to manage livestock or conduct range improvement maintenance (see the Grazing section of Chapter 3). Under the No Action Alternative, 17 percent of areas within grazing allotments are designated as open, 79 percent are designated as limited to existing or designated roads and trails, and 4 percent are closed to off-highway vehicle use.

Under all action alternatives, all areas currently designated as open to off-highway vehicle use would be redesignated as limited to designated or exiting roads and trails in the Medford District and Klamath Falls Resource Area. This would decrease disturbance or harassment to livestock resulting from off-highway vehicle use. In the Medford District and Klamath Falls Resource area, there would be no substantial effect to livestock operators in the type and availability of access, because administrative access would be authorized as necessary to move livestock or conduct range improvement maintenance.

Under all action alternatives, the designation of off-highway vehicle emphasis areas would not substantively affect livestock grazing because the off-highway vehicle use that would be concentrated within the emphasis area would be limited to designated or existing roads and trails, and livestock would avoid these areas.

Timber management actions affect forage production through changes to vegetation structural stages. Timber harvest that results in the stand establishment forest structural stage classification would increase the amount of grasses and grass-like species that serve as forage (see the Grazing section of Chapter 3 ). The young forest structural stage classification would provide the least amount of forage.

See Figure 4-190 (Changes in structural stage abundance within lands allocated for grazing). Over the next 100 years, the amount of the stand establishment forest structural stage classification within lands allocated for grazing would:

- increase from 30,000 acres to 37,600 acres, under the No Action Alternative

- increase from 20,000 acres to 39,500 acres, under Alternative 1

- increase from 18,400 acres to 47,400 acres, under Alternative 2

- increase from 18,000 acres to 76,500 acres, under Alternative 3

- decrease from 57,500 to 23,700 acres, under the PRMP

Under Alternatives 1, 2, and 3, the increase of the stand establishment forest structural stage classification and the decrease in the young forest structural stage classification would result in a corresponding increase in livestock forage production. The increase in livestock forage production would be the highest under the No Action Alternative, which has a higher amount of lands allocated for grazing. Comparing Alternatives 1 , 2 , and 3 , the increase in livestock forage production would be the highest under Alternative 3 .

Under the PRMP, there would be a decrease in the stand establishment forest structural stage, a decrease in the young and mature forest structural stages, and an increase in structurally complex forest structural stage classification. This is because the lands allocated for grazing are within the Uneven-age Timber Management Area. This would result in an overall slight decrease in forage production under the PRMP, as shown in Table 4-108 because the Uneven-age Timber Management Area would be less productive for grazing since it would lack the stand establishment structural stage. See Table 4-108 (Changes in livestock forage production within lands allocated for grazing by alternative) and Figure 4-191 (Changes in livestock Forage Production by Alternative). 
Figure 4-190. Changes In Structural Stage Abundance Within Lands Allocated For GrAZING

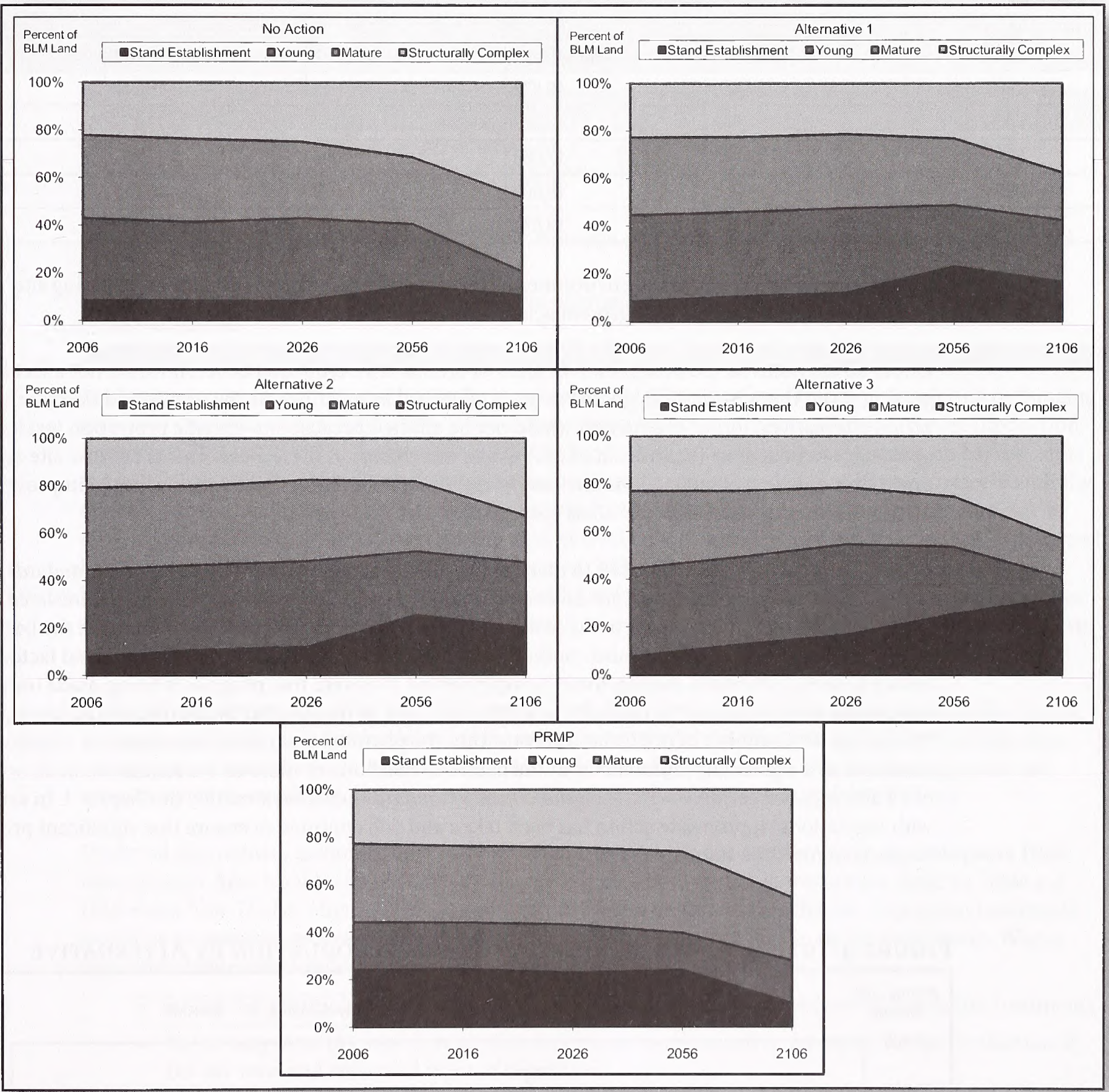


Table 4-108. Changes In Livestock Forage Production Within Lands Allocated For Grazing By Alternative

\begin{tabular}{l|r|r|r|r|r}
\hline \multirow{2}{*}{ Year } & \multicolumn{5}{|c}{ Forage Production (animal unit months) } \\
\cline { 2 - 6 } & No Action & Alternative 1 & Alternative 2 & Alternative 3 & PRMP \\
\hline 2006 & 24,620 & 16,872 & 16,853 & 16,972 & 22,150 \\
\hline 2016 & 24,582 & 17,059 & 17,127 & 17,601 & 22,192 \\
\hline 2026 & 24,400 & 17,066 & 17,006 & 17,892 & 21,863 \\
\hline 2056 & 26,223 & 18,802 & 18,920 & 19,616 & 21,787 \\
\hline 2106 & 28,950 & 19,673 & 19,867 & 22,805 & 20,447 \\
\hline
\end{tabular}

Management of areas of critical environmental concern affects forage production by applying site-specific protection (exclosures) or management actions (i.e., season of use restrictions).

Under all alternatives, the designation of areas of critical environmental concern would not affect livestock grazing. Even though areas designated as areas of critical environmental concern would decrease under all action alternatives, forage production would not be affected because site-specific protection (exclosures) or management actions (i.e., season of use) would not change in these areas. This is because site-specific protection or management actions are used to meet other allotment objectives, such as to improve livestock distribution and protect sensitive areas (i.e., riparian areas).

Grazing regulations direct the BLM to manage livestock grazing in accordance with the Standards for Rangeland Health and Guidelines for Livestock Grazing Management for Public Lands Administered by the Bureau of Land Management in the States of Oregon and Washington. The standards are the basis for assessing and monitoring rangeland conditions and trends. If livestock is a significant causal factor in the failure to meet a standard, management is implemented to ensure that progress is being made toward attainment of the standard. A total of 116 allotments (59\% of the number of allotments and leases, and $56 \%$ of the total number of public land acres within the planning area) have been assessed. Livestock was identified as a significant causal factor in the failure to meet one or more of the standards on all or portions of 12 allotments. See Table 3-78 (Rangeland health standards assessment results) in Chapter 3. In accordance with regulations, appropriate action has been taken and will continue to ensure that significant progress will be made to meet the standards.

Figure 4-191. Changes In Livestock Forage Production By Alternative

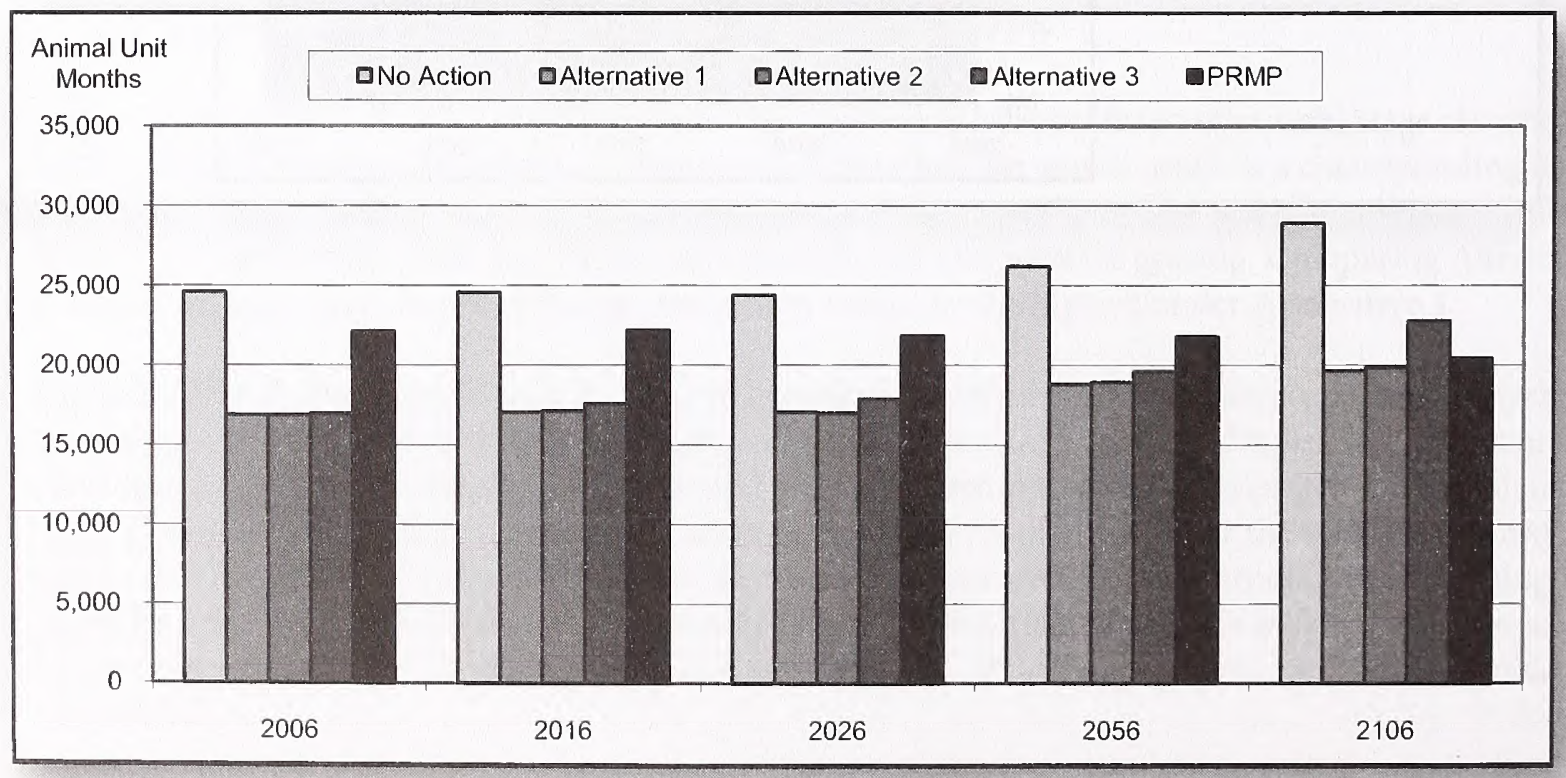




\section{Wild Horses}

This analysis examines the forage production and the appropriate management level within the Pokegama Herd Management Area that would occur under the alternatives and the PRMP.

\section{Key Points \\ - Under the No Action Alternative and Alternatives 1,2, and 3, there would be an increase in forage production in the Pokegama Herd Management Area. The increase would be the highest under Alternative 3. \\ - Under the PRMP, there would be a decrease in forage production in the Pokegama Herd Management Area. \\ - Under all alternatives, including the PRMP, the appropriate management level of 30 to 50 head would be maintained.}

Vegetation treatments affect wild horses by temporarily changing the use of traditional watering or foraging areas and changing forage production. As overstory canopy cover decreases understory forage production increases (USDA SCS 1971, Young et al. 1967). The production of forage within regeneration harvest units is greater than within thinned stands, because the understory vegetation does not have to compete with the overstory for limited resources. Over time, forage production would decline as juvenile trees continue to grow and begin to outcompete forage for the limited resources. The understory production is also influenced by successional stage and forest type (Walburger et al. 2005). The amount of forage production would be higher within a stand establishment forest than within a young, mature, or structurally complex forest. See Figure 3-150 (Forage production (represented through canopy cover) within a stand establishment forest versus a young forest) in the Grazing section of Chapter 3.

Under all alternatives, including the PRMP, wild horses would be excluded from certain traditional watering or foraging areas through fencing intended to protect or restore habitat. Exclusion of wild horses from these watering areas would be so limited in number and so scattered geographically that the fencing would not appreciably limit overall watering or foraging areas or change herd movement and distribution.

Under all alternatives, including the PRMP, the quantity of forage production within the Pokegama Herd Management Area would not substantially change as a result of vegetation treatments. Refer to Table 4-3 (Estimated Non-Timber Management Activity) in the Timber section of this chapter. Vegetation treatments would be so scattered geographically that there would be no overall change in forage production. Where vegetation treatments would occur:

- In the short term, forage production at the site level would decline following vegetation treatments.

- In the long term (5+ years), vegetation treatments would result in increased forage production at the site level and enhanced vigor of vegetation.

Under all alternatives, including the PRMP, grazing authorizations within the Pokegama Herd Management Area would remain the same. Therefore, there would continue to be adequate forage for livestock grazing, wild horses, and wildlife at the authorized levels. See the Wild Horse section of Chapter 3 for the relationship of grazing to the Pokegama Herd Management Area.

The construction of range improvements would vary between the No Action Alternative and the four action alternatives. See Table 4-107 (Range improvement construction by district and alternative) in the Grazing section of this chapter. Under all action alternatives, up to two new reservoirs and five new miles of fence would be constructed within the Pokegama Herd Management Area (see Chapter 2 maps and Appendix MGrazing). 
Forage and water availability is not a limiting habitat factor in the Pokegama Herd Management Area; however, distribution of the wild horse herd is not uniform. Under all action alternatives, construction of range improvements would improve wild horse distribution by shifting:

- grazing pressure from riparian/wetlands to uplands

- grazing distribution within the uplands to include areas that are not currently used

Off-highway vehicle use affects wild horses through disturbance or harassment. Areas designated as open to off-highway vehicle use under the No Action Alternative would present more chance for disturbance or harassment to the wild horse herd than areas designated as limited to off-highway use. However, this additional disturbance or harassment would occur on a small percentage of the herd management area, as only $8 \%$ is designated as "open to off-highway vehicle use" under the No Action Alternative, and 92 percent is designated as "limited to existing or designated roads and trails." Effects to the wild horse herd under Alternatives 1,2, and 3 and the PRMP would be minor, because the off-highway vehicle designation for the herd management area would be designated as "limited to existing roads and trails" or "limited to designated roads and trails."

Timber management actions affect forage production through changes to the forest structural stages. See Figure 4-192 (Changes in structural stage abundance within the Pokegema HMA). Timber harvest that results in the stand establishment forest structural stage classification would increase the amount of grasses and grass-like species that serve as forage (see the Wild Horse section of Chapter 3). The young forest structural stage classification would provide the least amount of forage.

Over the next 100 years, the amount in the stand establishment forest structural stage classification within the Pokegama Herd Management Area would:

- decrease under the No Action Alternative from 900 acres to 700 acres

- increase under Alternative 1 from 900 acres to 3,500 acres

- increase under Alternative 2 from 1,000 acres to 3,000 acres

- increase under Alternative 3 from 900 acres to 5,900 acres

- decrease under the PRMP from 4,600 acres to 900 acres

Under Alternatives 1, 2, and 3, the increase of the stand establishment structural stage classification and decrease in the young forest structural stage classification would result in a corresponding increase in forage production.

Under the No Action Alternative, there would be

- a decrease of the stand establishment structural stage classification

- a decrease in the young forest structural stage classification

- an increase in the structurally complex forest structural stage classification

These effects under the No Action Alternative would result in an overall increase in forage production. The increase in forage production would be the highest under Alternative 3.

Under the PRMP, there would be:

- a decrease in the stand establishment forest structural stage

- a decrease in the young and mature forest structural stages

- an increase in structurally complex forest structural stage classification

These effects would occur because the lands allocated for grazing are within the Uneven-Aged Management Area. This would result in an overall slight decrease in forage production under the PRMP. See Table 4-109 
Figure 4-192. Changes In Structural Stage Abundance Within The Pokegama Herd Management Area

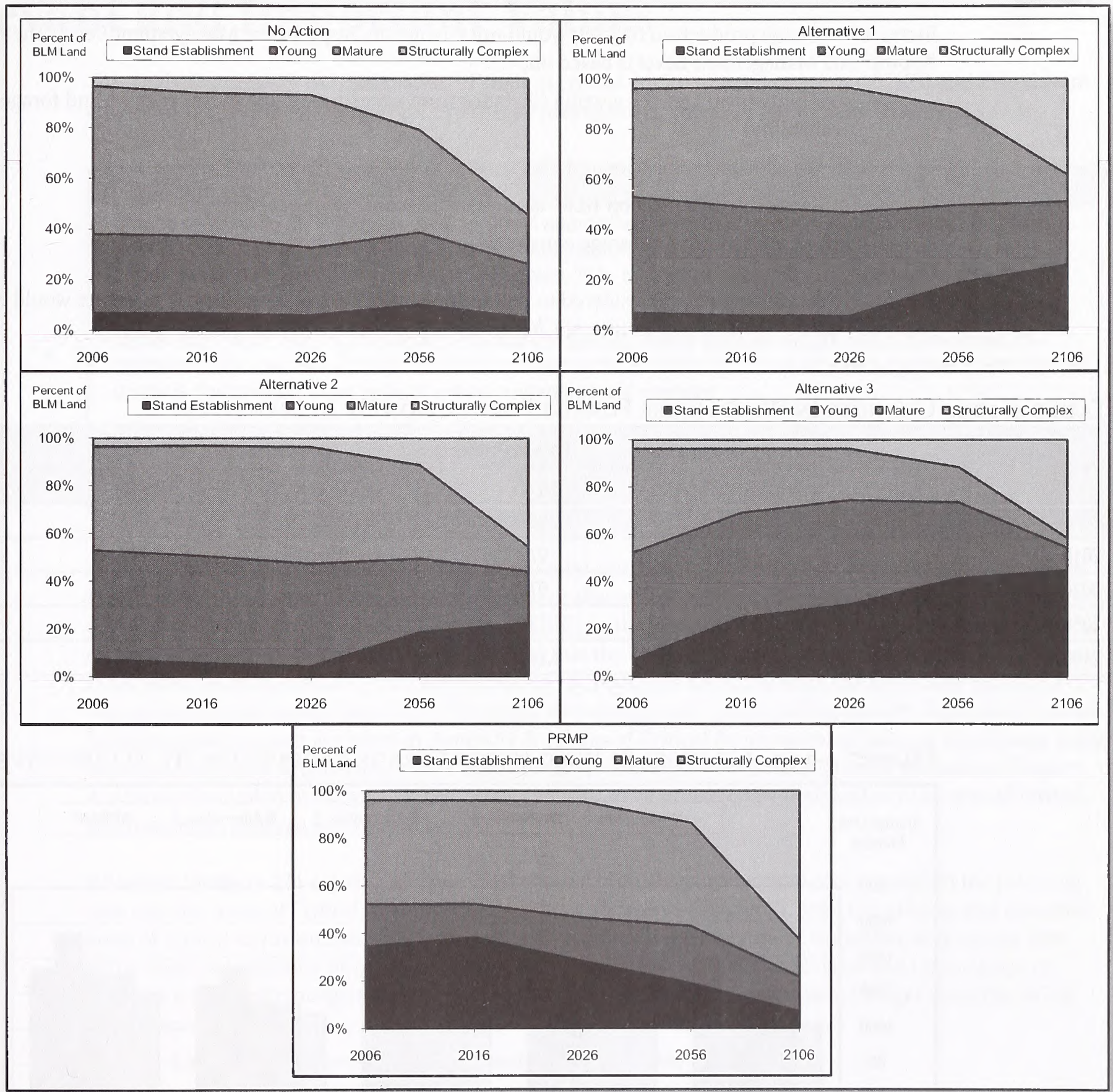


(Changes in wild horse forage production by alternative) in the Grazing section of this chapter and Figure 4-193 (Changes in wild horse forage production by alternative) below.

Increases to forage production by itself would not change the Appropriate Management Level. The Appropriate Management Level is based on:

- suitability of an area for grazing (distance from water, topography, temperature, and forage type and availability)

- forage allocations for deer and elk

- wild horse distribution on BLM-administered land and private land

- utilization (amount of forage consumed)

All of these factors would be considered to determine when changes in wild horse numbers would be required (see the Wild Horses section of Chapter 3 ).

Table 4-109. Changes In Wild Horse Forage Production By Alternative

\begin{tabular}{lrrrrr}
\hline \multirow{2}{*}{ Year } & \multicolumn{5}{c}{ Forage Production (animal unit months) } \\
\cline { 2 - 6 } & No Action & Alt. 1 & Alt. 2 & Alt. 3 & PRMP \\
\hline 2006 & 1,015 & 987 & 998 & 1,001 & 1,382 \\
\hline 2016 & 1,019 & 979 & 976 & 1,147 & 1,424 \\
\hline 2026 & 1,017 & 976 & 968 & 1,188 & 1,313 \\
\hline 2056 & 1,080 & 1,133 & 1,134 & 1,331 & 1,235 \\
\hline 2106 & 1,200 & 1,298 & 1,313 & 1,535 & 1,330 \\
\hline
\end{tabular}

Figure 4-193. Changes In Wild Horse Forage Production By Alternative

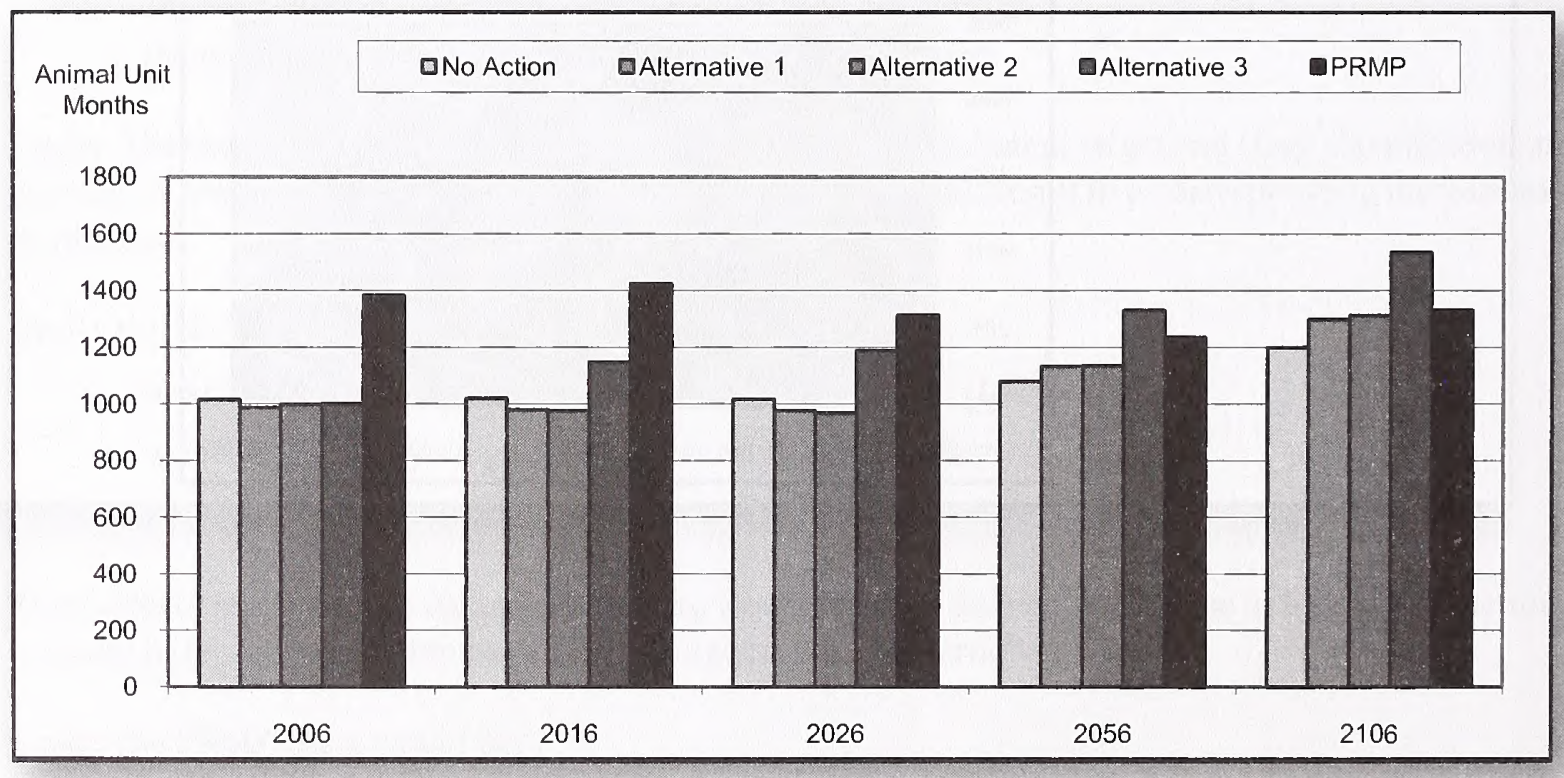




\section{Areas of Critical Environmental Concern - Relevant and Important Values}

This analysis examines the designation of areas of critical environmental concern (ACEC) and the relevant and important values that would receive special management attention under the alternatives.
Key Points
- Values that would be fully protected under all alternatives (whether or not special management was applied under a designation of an area of critical environmental concern) include any species listed under the Endangered Species Act, bald eagles, fish, migratory birds, raptors, herons, riparian and aquatic resources, and cultural resources.
- Under the PRMP and the No Action Alternative, special status species would be fully protected, in addition to the species listed in the previous key point, whether or not special management was applied under a designation of an area of critical environmental concern.
- Important and relevant values that would not be protected under some other authority or land use plan decision would be degraded or lost if special management was not applied under designation of an area of critical environmental concern.

Since designation of an area of critical environmental concern is part of the land allocation decision made in a resource management plan, it is not a resource affected by the plan. However, the different designations of Areas of Critical Environmental Concern (ACEC) in the various alternatives would have differing effects on the resources (important and relevant values) that the designations are intended to protect. Discussions of the analyses of the effects of the alternatives on the resources are included in the applicable section of this environmental impact statement. The important and relevant values associated with the areas of critical environmental concern are listed in Appendix $N$ - Areas of Critical Environmental Concern. In addition to the more thorough and detailed analysis of environmental consequences in the respective sections of Chapter 4 , a broad discussion of the various resources intended to be protected by designation of an area of critical environmental concern is provided here.

Although there are 131 existing and potential areas of critical environmental concern within the planning area (see the Areas of Critical Environmental Concern section in Chapter 3), only 122 existing and potential areas of critical environmental concern were analyzed for designation under the action alternatives. Five of the other nine existing or potential areas did not meet the criteria (i.e., relevance and importance, or the need for special management) for further consideration. The five areas that no longer meet the ACEC criteria are:

- Little Grass Mountain and Sheridan Peak in the Salem District

- Cottage Grove Old Growth and Lake Creek Falls in the Eugene District

- Iron Creek in the Medford District

There are four other existing areas of critical environmental concern that no longer require designation because they are managed under other special designations that provide protection to their relevant and important values:

- North Umpqua River in the Roseburg District is congressionally designated as a wild and scenic river.

- Sterling Mine Ditch in the Medford District is covered under the National Historic Preservation Act as eligible for listing.

- Jenny Creek and Pilot Rock in the Medford District are included within the Cascade-Siskiyou National Monument. 
Under each of the action alternatives, some areas of critical environmental concern were analyzed for designation excluding harvest land base acres on O\&C lands. Some of the original designations and nominations included only small areas of O\&C harvest land base that were included to create more logical units based on administrative boundaries or topographic features. Therefore, in some cases, the exclusion of the O\&C lands would still allow for the effective application of special management attention for the relevant and important values.

The names of the areas of critical environmental concern that would be designated under the various alternatives, their associated acres, and their important and relevant values are found in Appendix $N$ - Areas of Critical Environmental Concern.

Areas of critical environmental concern are established to protect the important and relevant values that require special management attention (see the Areas of Critical Environmental Concern section in Chapter 3). The lack of special management attention for those areas that require it would result in the eventual degradation or loss of many of those important and relevant values if those important and relevant values are not otherwise protected under law, some other authority, or a resource management plan decision.

In some instances, relevant and important values identified for a particular ACEC do not require special management attention because they would be otherwise protected under law, some other authority, or resource management plan decisions. Examples would be an ACEC in which water, fish, or species listed under the Endangered Species Act were listed as relevant and important values. Water, fish, and federally listed species do not need additional special management attention through designation as an area of critical environmental concern, because they would otherwise be protected by management direction under all alternatives or by law. Values that would be fully protected by law or management direction under all alternatives and, therefore, would not require the special management attention of ACEC designation include any species listed under the Endangered Species Act, bald eagles, fish, migratory birds, raptors, herons, riparian and aquatic resources, and cultural resources. In addition, under the No Action Alternative and the PRMP, special management under designation of an area of critical environmental concern would not be needed for special status species because the Bureau Special Status Species Policy would be applied. 


\section{Cultural Resources}

This analysis examines the damage to cultural, paleontological, and traditional use sites that would result from the alternatives.

\section{Key Points}

- The amount of damage to cultural, paleontological, and traditional use sites would vary little between all of the alternatives. Under all five action alternatives, no more than $2 \%$ of sites would be damaged per decade across the planning area.

Practices discussed in this analysis are the same or similar to those practices that have been implemented under the current resource management plans (represented by the No Action Alternative). It is reasonable to assume that these practices would continue to be implemented in a similar manner under all alternatives because the cultural, paleontological, and Native American traditional use resource management objectives of all alternatives are essentially the same.

Nearly all impacts to cultural and paleontological sites would be reduced or eliminated under all alternatives through the use of pre-disturbance site discovery methods and the application of avoidance or other protection measures. However, site avoidance would not always be possible, which would result in some incidental or inadvertent loss of sites or site values. Examples include:

- sites that cannot be entirely avoided by project redesign without eliminating the resource benefits provided by the project

- projects that cannot be relocated or redesigned (For example, a ridge saddle may be the only economic and engineering feasible location for an access road.)

- site values that are visually dependent on setting, e.g., spiritual locations and sacred sites

- sites that are not fully identified prior to ground-disturbing actions due to lack of surface manifestations or reduced surface visibility (For example, some sites are partially or entirely below the ground surface, or surface artifacts are not visible during inventory due to dense ground vegetation and thick duff cover.)

Sites are not evenly distributed across the landscape or across landforms. The range of site locations is similar for the northern and coastal areas (Salem, Eugene, and Coos Bay Districts) and for the southern areas (Roseburg and Medford Districts). The Klamath Falls Resource Area has the most recorded sites (see the Cultural Resources section on Chapter 3).

From 1998 through 2006, the number of newly discovered sites per year was also unevenly distributed:

- 2 new sites in the northern and coastal areas (Eugene, Coos Bay and Salem Districts)

- 55 new sites in the southern area (Roseburg and Medford Districts)

- 86 new sites in the Klamath Falls Resource Area

Any ground-disturbing action can damage or destroy cultural, paleontological, and traditional use resources (see the Cultural Resources section of Chapter 3). From 1998 through 2006, site damage occurred to 22 $(0.8 \%)$ out of 2,843 recorded cultural sites in the planning area. This damage resulted from timber harvest, fire and fuels management, recreation management, and off-highway vehicle use.

- Timber harvest activities damaged 10 sites between 1998 and 2006. The rate of site damage averaged one site per 7,640 harvested acres in the northern and coastal area, and one site per 9,125 
harvested acres in the southern area over the past decade. There was no damage to sites in the Klamath Falls Resource Area.

- For road construction, no sites were reported damaged in the planning area between 1998 and 2006, making a $\%$ damage rate from that activity. However, sites damaged by road construction were recorded prior to 1998 , so it is assumed damage would occasionally occur.

- Fires and fuels management activities damaged 9 sites between 1998 and 2006. The rate of site damage averaged one site per 11,052 treated acres in the southern area, and one site per 9,775 treated acres in the Klamath Falls Resource Area over the past decade. No sites were damaged in the northern and coastal area. Fuel treatments also reduce the risk of wildfires damaging sites. Although fuel treatments would reduce the risk of wildfires damaging sites, there is no quantified data on risk reduction.

- For recreation site development and use, a total of one site (in the Medford District) was damaged. Damage to one site does not provide enough data to develop a meaningful correlation between the number of recreation sites constructed or the number of acres of recreation construction and the risk of damaging cultural sites. However, it is assumed that site damage would occasionally occur.

- Off-highway vehicle use that occurs on existing and designated roads does not impact cultural sites. Use that occurs outside of existing and designated roads would potentially damage sites. The Medford District and the Klamath Falls Resource Area have each reported one damaged site. The number of cultural sites damaged is too small to demonstrate a meaningful correlation between amount of off-highway vehicle use and rate of site destruction. However, it is assumed site damage would occasionally occur.

No sites were reported damaged by other types of ground-disturbing activities in the planning area during the period 1998 through 2006. However, sites damaged by range improvements, wildfire suppression, and natural disturbance are recorded in the planning area. This damage occurred prior to 1998. Since site damage has occurred as a result of a variety of ground-disturbing activities and from natural causes in the past, it would be expected to occasionally occur in the future at approximately the same rate as in the past, that is, under the current (1995) resource management plans.

The past rate of damage is used to project the rate of damage to cultural sites that would occur under the alternatives for the first decade of plan implementation.

No data is available to quantify the impacts to paleontological resources within the planning area. These sites have been recorded infrequently with only 45 locations documented.

Under the No Action Alternative, harvest would increase in the next decade to 97,400 acres in the northern and coastal areas, which would result in $13(2 \%)$ of the sites being damaged; and to 58,800 acres in the southern area, which would result in six $(0.3 \%)$ of the sites being damaged. There would be very few or no sites damaged in the Klamath Falls Resource Area.

Under the No Action Alternative, damage to cultural sites would occasionally occur due to road construction, recreational site development and use, and off-highway vehicle use.

Under the No Action Alternative, ground-disturbing hazardous fuels treatments would occur over the next 10 years on 156,480 acres in the southern area, which would result in $14(0.8 \%)$ of the sites being damaged; and on 69,700 acres in the Klamath Falls Resource Area, which would result in $7(0.3 \%)$ of the sites being damaged. Fuels treatments in the northern and coastal area would not result in damage to sites. 
Under the No Action Alternative, total damage would occur to an average of 4 sites per year, and $1 \%$ of known sites would be damaged in the next decade. This includes:

- one site per year and $3 \%$ of sites in the northern and coastal areas

- two sites per year and $1 \%$ of sites in the southern area

- less than one site per year and $0.3 \%$ of sites in the Klamath Falls Resource Area

Under Alternative 1, harvest would occur on 122,240 acres in the next decade in the northern and coastal areas, which would result in $16(4 \%)$ of the sites being damaged. An additional 78,360 acres would be harvested in the southern area, which would result in $9(0.5 \%)$ of the sites being damaged. There would be no sites damaged in the Klamath Falls Resource Area.

Under Alternative 1, damage to cultural resources would occasionally occur due to road construction, recreational site development and use, off-highway vehicle use, other resource management actions, and natural causes.

Under Alternative 1, ground-disturbing hazardous fuels treatment over the next 10 years would occur on 156,480 acres in the southern area, which would result in $14(0.8 \%)$ of the sites being damaged; and on 69,700 acres in the Klamath Falls Resource Area, which would result in $7(0.3 \%)$ of the sites being damaged. Fuels treatments in the northern and coastal areas would not result in damage to sites.

Under Alternative 1, total damage would occur to an average of 5 sites per year, and $1 \%$ of known sites would be damaged over the next 10 years. This includes:

- less than two sites per year and $4 \%$ of sites in the northern and coastal areas

- two sites per year and $1 \%$ of sites in the southern area

- less than one site per year and $0.3 \%$ of sites in the Klamath Falls Resource Area

Under Alternative 2, there would be 126,580 acres harvested over the next 10 years in the northern and coastal areas, which would result in 17 (4\%) of the sites being damaged; and 90,410 acres in the southern area would be harvested which would result in $10(0.5 \%)$ of the sites being damaged. There would be no sites damaged in the Klamath Falls Resource Area.

Under Alternative 2, damage to cultural resources would occasionally occur due to road construction, recreational site development and use, off-highway vehicle use, other resource management actions and natural causes.

Under Alternative 2, ground-disturbing hazardous fuels treatment over the next 10 years would occur on 156,480 acres in the southern area, which would result in $14(0.8 \%)$ of the sites being damaged; and on 69,700 acres in the Klamath Falls Resource Area, which would result in $7(0.3 \%)$ of the sites being damaged. Fuels treatments in the northern and coastal area would not result in damage to sites.

Under Alternative 2, total damage would occur to an average of 5 sites per year, and 1\% of known sites would be damaged over the next 10 years. This includes:

- less than two sites per year and $4 \%$ of sites in the northern and coastal areas

- two sites per year and $1 \%$ of sites in the southern area

- less than one site per year and $0.3 \%$ of sites in the Klamath Falls Resource Area

Under Alternative 3, there would be 147,970 acres harvested over the next 10 years in the northern and coastal area, which would result in 19 (5\%) of the sites being damaged; and 126,000 acres would be harvested in the southern area, which would result in $14(0.8 \%)$ of the sites being damaged. There would be no sites damaged in the Klamath Falls Resource Area. 
Under Alternative 3, damage to cultural resources would occasionally occur due to road construction, recreational site development and use, off-highway vehicle use, other resource management actions, and natural causes.

Under Alternative 3, ground-disturbing hazardous fuels treatment over the next 10 years would occur on 156,480 acres in the southern area, which would result in $14(0.8 \%)$ of the sites being damaged; and on 69,700 acres in the Klamath Falls Resource Area, which would result in $7(0.3 \%)$ of the sites being damaged. Fuels treatments in the northern and coastal areas would not result in damage to sites.

Under Alternative 3, total damage would occur to an average of 5 sites per year, and $1 \%$ of known sites would be damaged over the next 10 years. This includes:

- two sites per year and 5\% of sites in the northern and coastal areas

- three sites per year and $2 \%$ of sites in the southern area

- less than one site per year and $0.3 \%$ of sites in the Klamath Falls Resource Area

Under the PRMP, there would be 178,900 acres harvested over the next 10 years in the northern and coastal area, which would result in $23(6 \%)$ of the sites being damaged; and 110,200 acres would be harvested in the southern area, which would result in $12(0.6 \%)$ of the sites being damaged. There would be no sites damaged in the Klamath Falls Resource Area.

Under the PRMP, damage to cultural resources would occasionally occur due to road construction, recreational site development and use, off-highway vehicle use, other resource management actions, and natural causes.

Under the PRMP, ground-disturbing hazardous fuels treatment over the next 10 years would occur on 156,480 acres in the southern area, which would result in $14(0.8 \%)$ of the sites being damaged; and on 69,700 acres in the Klamath Falls Resource Area, which would result in $7(0.3 \%)$ of the sites being damaged. Fuels treatments in the northern and coastal areas would not result in damage to sites.

Under the PRMP, total damage would occur to an average of 6 sites per year, and $1 \%$ of known sites would be damaged over the next 10 years. This includes:

- two sites per year, and $6 \%$ of sites in the northern and coastal areas

- three sites per year, and $1 \%$ of sites in the southern area

- less than one site per year, and $0.3 \%$ of sites in the Klamath Falls Resource Area

Cultural inventory programs started on the districts in 1976. The current inventory coverage ranges from $50 \%$ of the land base on Klamath Falls Resource Area, to 4\% on the Eugene District (see Table 3-84 in the Cultural Resources section of Chapter 3 for inventory coverage percentages). If inventory continues at the current rate, $100 \%$ inventory would not be completed for 30 years on the Klamath Falls Resource Area and for more than 100 years on the Eugene District, assuming all acres are eventually inventoried. Minimally, for the first three decades of plan implementation, site discovery is projected to occur as previously uninventoried land is surveyed. In the northern and coastal areas, the past rate of new site identification has been two sites each year, and the rate of damage from timber harvest is projected to range from one to two sites each year. Projecting the current rates of discovery and damage into future decades, the percentage of total sites damaged would increase. In the southern area, the rate of new site identification has been 55 sites per year, and the number of sites damaged ranges from two to three sites each year. In the southern area, the percent of sites damaged would decrease overall in future decades. In Klamath Falls Resource Area, the rate of new site discovery has been 86 sites each year, and less than one site each year has been damaged. The percent of sites damaged in Klamath Falls Resource Area would decrease overall in future decades. 
However, rates of site damage would be expected to decrease over time even in the northern and coastal area due to the following conditions:

- In subsequent decades of plan implementation, harvest will shift to second growth stands where survey and disturbance has already occurred.

- New road construction would decrease after the road system is completed.

- Stands reserved from timber harvest may never be inventoried and any sites would remain undamaged.

A summary of the cultural resource sites projected to be damaged under the alternatives during the first decade is shown in Table 4-110 (Percent of total cultural resource sites damaged under the alternatives over the next 10 years).

Adverse impacts to Native American traditional use sites include alteration of sites and site settings, loss of vehicular access to sites, and noise and visual intrusions to site setting. Disturbance or destruction of spiritual sites occurs when physical elements such as cairns, mounds or burials are damaged or removed. Adverse impacts to traditional use resources include reduction or elimination of resources such as huckleberries, bark, hazel and other resources. Competition for special forest products such as berries, bear grass, firewood or greenery contributes to the reduction of traditional resource quantities. Activities that result in the removal of competing vegetation, including timber, could provide a beneficial impact through increased growth of traditional use plants such as huckleberries and hazel.

Management actions that would affect traditional use sites and resources include any that would result in ground disturbance, alterations of plant communities, and access restrictions. These include timber harvest, road construction and road decommissioning, fire and fuels management, permitting use of special forest products, noxious weed eradication, and off-highway vehicle management.

Consulting with tribal governments and tribal members early in project planning to identify locations and resources of concern would reduce or eliminate most effects to sites and resources of interest to tribal members.

Under all five action alternatives, avoidance of traditional use sites that are identified by tribal governments within the planning area would be the preferred and most common method to eliminate or reduce adverse impacts. However, if avoidance would not be possible, other impact reduction measures would be developed in consultation with the tribal government having an identified interest. Examples of such measures include timing the management action to occur during a period of time when traditional users are not present on the site and permitting use of an alternative location acceptable to traditional users. In those instances, when tribal governments would not be able to provide traditional use site locations in advance of projects, it would not be possible to take measures to protect the site or resource of concern.

Table 4-110. Percent Of Total Cultural Resource Sites Damaged Under The Alternatives Over The Next 10 Years

\begin{tabular}{lrrrrr}
\hline Area & No Action & Alt. 1 & Alt. 2 & Alt. 3 & PRMP \\
\hline $\begin{array}{l}\text { Northern and Coastal } \\
\text { Areas }\end{array}$ & $3 \%$ & $4 \%$ & $4 \%$ & $5 \%$ & $6 \%$ \\
\hline Southern Area & $1 \%$ & $1 \%$ & $1 \%$ & $2 \%$ & $1 \%$ \\
\hline $\begin{array}{l}\text { Klamath Falls } \\
\text { Resource Area }\end{array}$ & $0.3 \%$ & $0.3 \%$ & $0.3 \%$ & $0.3 \%$ & $0.3 \%$ \\
\hline Total - All Areas & $1 \%$ & $1 \%$ & $1 \%$ & $1 \%$ & $1 \%$ \\
\hline
\end{tabular}




\section{Energy and Minerals}

This analysis examines the availability, quantity, and abundance of energy and mineral resources under each alternative relative to demand.

Key Points
- All alternatives would maintain similar levels of availability and quantity of energy and mineral resources
on the public lands.
- Under all alternatives, almost all lands would remain available for the location of mining claims under
the Mining Law:
- Under all alternatives, common varieties of rock would continue to be available from existing sites. A few
quarries may be closed, reclaimed, or potentially replaced by new sites.

Under federal law and BLM policy, all public lands are open for energy development and mineral exploration and development, unless specific lands are closed or withdrawn from mineral entry. Opportunities for new exploration for all types of minerals would be provided under all alternatives. Most of the planning area would remain open to mineral entry. Such entries would be subject to restrictions as required by law, or as a result of decisions supported by site-specific environmental analysis.

\section{Oil and Gas}

Under all alternatives, almost all lands would continue to be available for oil and gas leasing and the exploration and development for conventional oil and gas. Although prices for oil and gas are expected to continue to rise relative to the costs of exploration and development, the actual physical occurrence of oil and gas in most parts of the planning area is currently speculative.

No federal oil and gas leases have been issued within the planning area since the current resource management plans were adopted in 1995. Lands in the southern portion of the Salem District and east of the Mist gas field have the best potential to attract leasing and exploration interest for conventional natural gas.

\section{Quarries}

There are about 370 existing quarries for common variety minerals on BLM-administered lands in the planning area. It is assumed that up to 20 of these quarries would be depleted over the next 10 years and would likely be replaced by the expansion of existing quarries or the opening of new sites. Demand for common variety material is closely correlated with population growth/urban expansion and road maintenance.

\section{Mining Claims}

Under all alternatives, most lands would continue to be open for the location of mining claims under the Mining Law of 1872 (as amended). The highest levels of activity would continue to be in portions of the Medford District, followed by portions of the Roseburg and Eugene Districts. See Table 4-111 (Current claims, notices, and plans of operations within the planning area), which has district-specific information. 
Table 4-11 11. Current Claims, Notices, And Plans Of Operations Within The Planning Area

\begin{tabular}{lrrr}
\hline BLM Districts & Claims & Notices & Plans of Operation \\
\hline Salem & 129 & 0 & 1 \\
\hline Eugene & 204 & 5 & 0 \\
\hline Roseburg & 191 & 24 & 1 \\
\hline Coos Bay & 565 & 0 & 0 \\
\hline Medford & 1,427 & 100 & 3 \\
\hline $\begin{array}{l}\text { Klamath Falls Resource Area } \\
\text { (Lakeview District) }\end{array}$ & 2 & 2 & 0 \\
\hline
\end{tabular}

\section{Coal Bed Methane}

The current Coal Bed Natural Gas play on private and county lands that are south of Coos Bay may eventually extend to BLM-administered lands, although no lease nominations have been received to date. Based on the current level and location of activity, it is likely during the next 10 to 15 years that leases would be issued and that up to 77 wells would be drilled. Drilling of this number of wells would result in about 525 acres of total disturbance from the construction of access roads, drill pads, and product gathering pipelines. The location of well pads and roads for the purpose of drilling would be limited to existing roads in riparian reserves under the No Action Alternative and to Riparian Management Areas under all action alternatives. Under all alternatives, most development activity would occur on existing log landings and associated roads. See Appendix Q - Energy and Minerals for a detailed discussion of Coal Bed Natural Gas.

\section{Biomass}

The biomass opportunities that would result from timber sales would range from 5 to $10 \%$ of the standing merchantable volume of stands that would be harvested under each alternative. The analytical assumption used to derive this level is that only boles would be available for removal, as no method has been demonstrated that can consistently remove limbs economically and effectively except with ground-based, mechanized ground operations. This level would equate to between 0.35 and 0.7 dry tons per thousand board feet harvested. This analysis discusses biomass opportunities rather than actual levels of utilization under the alternatives. The basis for this discussion is that the extent of the utilization in this emerging market and industry, which has been highly variable to date, will depend on development of business infrastructure, mills and generators, overall energy costs, and market conditions that are speculative.

Several factors would interact to vary the amount of tons per thousand board feet harvested. These variables include market conditions at the time of harvest, and the location and type of stand. Other factors include the amount of nonmerchantable hardwoods, the amount of submerchantable material designated for cutting and removal in fire-prone stands, and the level of defect within a stand. Thinning would typically contain material that consists mainly of tops and submerchantable stems, whereas older stands would contain more cull material and broken pieces. In addition, with ground-based operations where the yarding of whole trees is required, the potential biomass in the limb component may be included in both the thinning and harvesting of older stands.

Topography, vegetation, and yarding systems would affect the availability of biomass. Areas suitable for ground-based equipment would have a higher recovery level. Areas of steep, dense brush would have a lower recovery level due to the difficulty of locating the material and bringing it to a landing with cable yarding systems. 


\section{Chapter 5}

Coordination,

Monitoring, and Use
of the Plan

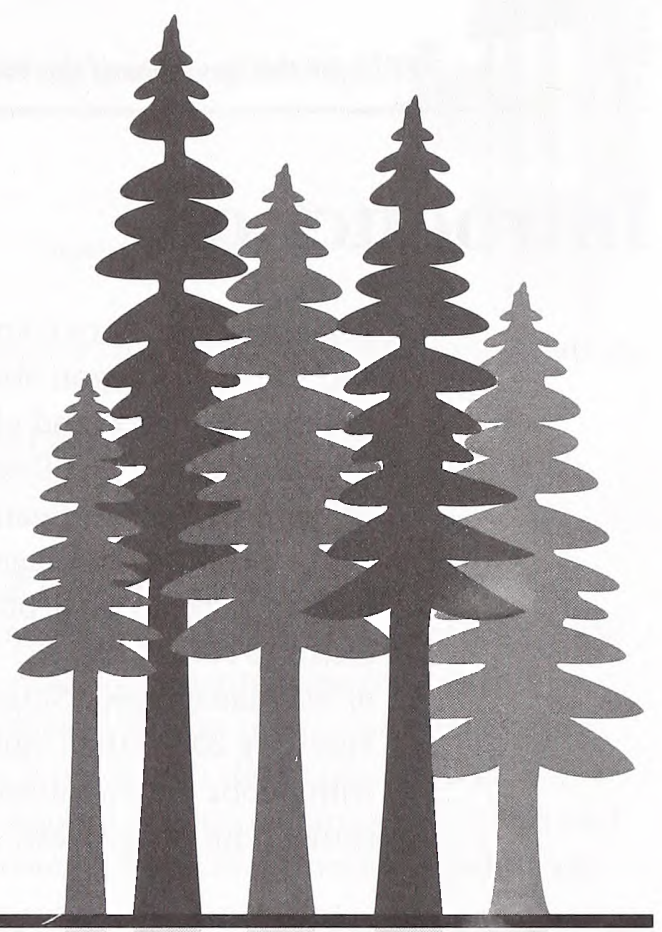

Chapter 5 describes the public participation and interagency coordination that occurred during the preparation of this Environmental Impact Statement. It also includes a list of staff involved in the Western Oregon Plan Revision. Finally, the chapter describes the monitoring plan for the Proposed Resource Management Plan and the role of adaptive management in the land use planning process.

\section{In this chapter:}

Introduction

Public Contact, Scoping, and Review of the DEIS

Protest Process.

Relationship of the PRMP to Other Agency Plans and Programs $\ldots \ldots \ldots \ldots \ldots \ldots \ldots \ldots . \ldots 65$

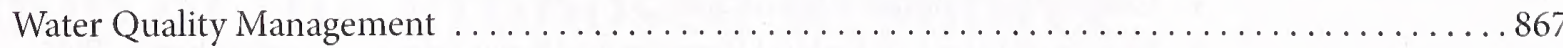

Regional Interagency Executive Committee. . . . . . . . . . . . . . . . . . . . . . . 869

Section 7 Consultation under the Endangered Species Act . . . . . . . . . . . . . . . . . . . . 869

Preparers..................................................... 871

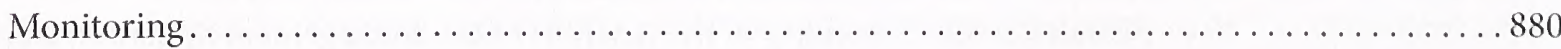

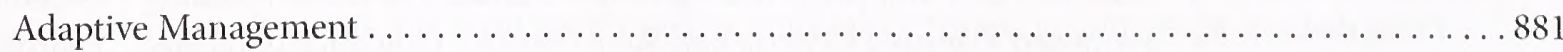

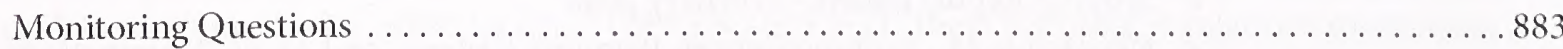

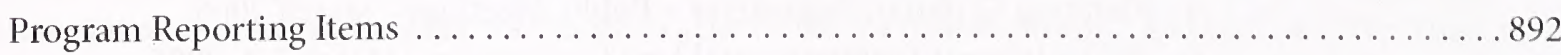

Guidance for Use of the Completed Resource Management Plans . . . . . . . . . . . . . . . . . 895 


\section{Introduction}

An interdisciplinary team of resource specialists and managers from the BLM Western Oregon districts and the BLM Oregon State Office, and contract personnel, prepared the Western Oregon plan revision. Initial preparation and planning for the plan revisions began in August 2003 when the Secretary of Interior, the American Forest Resource Council, and the Association of O\&C Counties entered into the Settlement Agreement. Plan evaluations conducted in 2004 showed that the timber harvest decisions in the 1995 Oregon resource management plans (RMPs) were not being met. A Notice of Intent, published in the Federal Register on September 7, 2005, initiated the public scoping process and notified the public of the intent to revise the 1995 Oregon RMPs with a single Environmental Impact Statement (EIS). The Analysis of the Management Situation was published in October 2005. The Planning Criteria was published in February 2006. The Draft EIS was published in August 2007. The planning process has involved many steps with public participation, as well as consultation and coordination with many agencies and organizations throughout the process.

\section{Public Contact, Scoping, and Review of the DEIS}

Public contact and scoping was conducted with direct mailings, public meetings, and internet websites. The current mailing list includes approximately 1,600 individuals and organizations. Public meetings were held in the six BLM district offices and other locations across the planning area. District and State Office personnel met with many different partnerships including: the Applegate Partnership, soil and water conservation districts and councils; watershed associations; forest protective associations; wildlife groups including Ducks Unlimited and the Rocky Mountain Elk Foundation; the Native Plant Society; environmental education groups; recreation groups including horsemen, all terrain vehicle users, and trail associations; and environmental groups including Audubon and the Nature Conservancy.

Some of the public contact and scoping activities that occurred just prior to and following the initiation of the planning process by the publication of the Notice of Intent in September 2005 include the following:

- Newsletter \#1 - Scoping - Introduction to Western Oregon Planning Revision - August 2005

- Public web page available - August 2005

- County fair booths, August 2005

- Notice of Intent in Federal Register and news release - September 7, 2005

- Scoping meetings - September/October 2005

- Scoping key contact meetings - September/October 2005

- State Director editorial boards - September/October 2005

- Economic Profile System Workshops, September/November 2005

- ACEC nomination process - Mailed to mailing list, October 5, 2005

- Analysis of the Management Situation printed - October 2005

- Newsletter \#2 - Summary of the Analysis of the Management Situation, December 2005

- State Director and Governor sign Memorandum of Understanding - December 1, 2005

- Proposed Planning Criteria and State Director Guidance published - February 2006

- Scoping Report issued - February 2006

- Newsletter \#3 - Scoping Report, Planning Criteria, and ACEC Nominations - February 2006

- Planning Criteria/Alternatives - Public Meetings - March 2006

- Public Interest Environmental Law Conference - March 3-4, 2006

- Newsletter \#4 - Planning criteria \& use of science in plan revisions - April 2006

- State-of-the-Science Forum held in Corvallis - June 15, 2006

- Newsletter \#5 - Summary of alternatives to be analyzed in the EIS - October 2006

- Newsletter \#6 - Pre-draft Environmental Impact Statement update - April 2007 
- The Draft EIS published - August 2007

- Release of Draft EIS and start of public comment period - August 10, 2007

- Launch of online web forum - August 20, 2007

- Formal public meetings; open house at district offices and on request from interested organizations and groups. - September/October 2007

- Newsletter \#8 - Comment period extended to January 11, December 2007

- Public comment period ended - January 11,2008

The five-month public comment period of the Draft Environmental Impact Statement (DEIS) ended on January 11, 2008. In response to the DEIS, the Bureau of Land Management (BLM) received almost 29,500 submissions through the web forum and through e-mail or postal mail. Comments came from across the country from private citizens, organized groups, government officials, Indian tribes, and cooperating agencies. The BLM reviewed the comments received, and with this input and in close coordination with federal regulatory agencies and other cooperators, prepared the Proposed Resource Management Plan and Final Environmental Impact Statement. Responses to substantive comments received from the public are included in Appendix $T$ of this Final Environmental Impact Statement.

\section{Protest Process}

The Assistant Secretary of Land and Minerals Management in the Department of Interior is the responsible official for this RMP revision. The Federal Land Policy and Management Act and its implementing regulations provide land use planning authority to the Secretary, as delegated to this Assistant Secretary. Because this decision is being made by the Assistant Secretary, Land and Minerals Management, it is the final decision for the Department of the Interior. This decision is not subject to administrative review (protest) under the BLM or Departmental regulations (43 CFR 1610.5-2). Because there is no administrative review, the Record of Decision will not be signed until at least 30 days after the Notice of Availability for the Final EIS appears in the Federal Register (see 40 CFR 1506.10[b]).

\section{Relationship of the Proposed Resource Management Plan to Other Agency Plans and Programs}

In addition to the plan and program coordination described above, the BLM collaborates with many other agencies in the development and coordination of their plans for areas that are within and surrounding the planning area. The BLM planning regulations call for resource management plans to be "... consistent with officially approved or adopted resource-related plans and the policies and procedures contained therein, of other federal agencies, state and local governments, and Indian tribes, so long as the guidance and resource management plans are also consistent with the purposes, policies, and programs of federal laws and regulations applicable to public lands..." (43 CFR 1610.3-2). These planning regulations promulgate the Federal Land Management and Policy Act. That Act, however, specifically provides that "insofar as they relate to management of timber resources, ..., the [O\&C Act] shall prevail." 43 U.S.C. $\$ 1701$. Thus, to the extent that there is a conflict between being consistent with other agency plans and programs and the statutory direction for managing the timber resources under the O\&C Act, the latter will prevail. Prior to the approval of the Proposed Resource Management Plan, the State Director will submit this plan to the Governor of the State of Oregon and request the Governor to identify any known inconsistencies with the state or local plans, policies, or programs. 
Table 5-1 (Plan and program coordination opportunities) identifies other federal, state, and local plans and programs considered in the analysis of effects and/or used in addressing potential cumulative effects. Because the BLM collaborates with a wide variety of federal, state, and local agencies to varying degrees, this table is not exhaustive.

Table 5-1. Plan And Program Coordination Opportunities

\begin{tabular}{|c|c|c|}
\hline Entity & Plan/Program & Common Resources or Dependencies \\
\hline \multicolumn{3}{|c|}{ County/City } \\
\hline Counties & $\begin{array}{l}\text { - Land use plans } \\
\text { - Wildfire plans }\end{array}$ & $\begin{array}{l}\text { Timber, fuels management, and payments } \\
\text { in lieu of taxes }\end{array}$ \\
\hline Cities & $\begin{array}{l}\text { - Land use plans } \\
\text { - Community wildfire protection plans }\end{array}$ & $\begin{array}{l}\text { Fuels management and communities at } \\
\text { risk }\end{array}$ \\
\hline \multicolumn{3}{|c|}{ State } \\
\hline Office of the Governor & Statewide planning goals & $\begin{array}{l}\text { Soil, timber, water, fish, wildlife, habitat, } \\
\text { economic development, recreation, and } \\
\text { energy }\end{array}$ \\
\hline $\begin{array}{l}\text { Department of Environmental } \\
\text { Quality }\end{array}$ & $\begin{array}{l}\text { - } \text { BLM water quality restoration plans } \\
\text { - Water quality management plans } \\
\text { - Total maximum daily loads (TMDLs) } \\
\text { - Smoke management plans } \\
\end{array}$ & $\begin{array}{l}\text { Streams, watersheds, air and water quality } \\
\text { standards, beneficial uses, and BLM water } \\
\text { quality restoration plans }\end{array}$ \\
\hline Department of Forestry & $\begin{array}{l}\text { - State forest management plans } \\
\text { - Forestry program for Oregon } \\
\text { - Fire plans } \\
\text { - Rules of the Oregon Forest Practices Act } \\
\end{array}$ & $\begin{array}{l}\text { Watersheds, timber, economic outputs, } \\
\text { and soils }\end{array}$ \\
\hline Department of Fish and Wildlife & $\begin{array}{l}\text { - Comprehensive Wildlife Conservation Strategy } \\
\text { (Oregon Conservation Strategy) } \\
\text { - Oregon Plan for Salmon and Watersheds } \\
\end{array}$ & Wildlife, habitat, and fisheries \\
\hline $\begin{array}{l}\text { Division of State Lands, Natural Heritage } \\
\text { Program }\end{array}$ & $\begin{array}{l}\text { - Rare and Endangered Invertebrate } \\
\text { Program (Oregon) } \\
\text { - Oregon Natural Heritage Program } \\
\end{array}$ & Special status species and natural areas \\
\hline Department of Human Resources & Public water system standards & Surface water \\
\hline Department of Agriculture & State-listed endangered species; noxious weeds & $\begin{array}{l}\text { Botanical species, noxious weed list and } \\
\text { control }\end{array}$ \\
\hline Department of Geology and Mineral Industries & $\begin{array}{l}\text { Development of oil; gas; geothermal energy; metallic and } \\
\text { industrial minerals; and sand, gravel, and crushed stone. }\end{array}$ & Lease and sales on public lands \\
\hline Department of Parks and Recreation & $\begin{array}{l}\text { - Off-highway vehicle (OHV) plans } \\
\text { - Comprehensive Outdoor Recreation Plan } \\
\text { - State Historic Preservation Office } \\
\end{array}$ & $\begin{array}{l}\text { Off-highway vehicle (OHV) trails and } \\
\text { recreation; protection of historic properties } \\
\text { and cultural resources. }\end{array}$ \\
\hline \multicolumn{3}{|c|}{ Federal } \\
\hline United States Forest Service & Land and resource management plans & $\begin{array}{l}\text { Wildlife, fisheries, habitat, streams, } \\
\text { watersheds, timber, fuels management, } \\
\text { and communities at risk }\end{array}$ \\
\hline National Marine Fisheries Service & $\begin{array}{l}\text { - Recovery plans for threatened and endangered } \\
\text { species } \\
\text { - Endangered Species Act, Section } 7 \text { (Consultation) }\end{array}$ & $\begin{array}{l}\text { Federal threatened and endangered fish } \\
\text { species and habitat }\end{array}$ \\
\hline United States Fish and Wildlife Service & $\begin{array}{l}\text { - Recovery plans for threatened and endangered } \\
\text { species } \\
\text { - ESA, Section } 7 \text { (Consultation) }\end{array}$ & $\begin{array}{l}\text { Federal threatened and endangered } \\
\text { wildlife and botanical species and habitat }\end{array}$ \\
\hline Environmental Protection Agency & Clean Water Act & $\begin{array}{l}\text { Streams, watersheds, and total maximum } \\
\text { daily loads (TMDLs) }\end{array}$ \\
\hline Natural Resources Conservation Service & Watershed plans & Streams and watersheds \\
\hline Animal and Plant Inspection Service & Pest management & Noxious weeds, invasives \\
\hline National Park Service & National rivers inventory and review & National Landscape Conservation System \\
\hline Bonneville Power Administration & Energy & $\begin{array}{l}\text { Energy, transmission corridors, and rights- } \\
\text { of-way }\end{array}$ \\
\hline Northwest Power Planning Council & Columbia River Basin & Wildlife, fisheries, and watersheds \\
\hline
\end{tabular}




\section{Water Quality Management Planning}

Section 304 of the Clean Water Act directs federal agencies to "maximize utilization of other Federal laws and programs for the purpose of achieving and maintaining water quality through appropriate implementation of plans."

Pursuant to the Clean Water Act, states are required to develop water quality standards for point and non-point sources of pollution and for developing a list of impaired waters for subsequent restoration and recovery. In Oregon, the Department of Environmental Quality is responsible for addressing water quality criteria and standards for waters of the state, and water quality limited water bodies. The Department of Environmental Quality accomplishes this, in part, through rulemaking and development of total maximum daily loads.

Pursuant to Oregon State law, the BLM is a Designated Management Agency responsible for protecting and maintaining water quality on BLM-administered lands. Designated Management Agencies are expected to implement and revise their plans as needed and to keep Department of Environmental Quality advised of their efforts. Although guidance for the resource management plan would be revised, the BLM would continue to maintain water quality in compliance with the Clean Water Act. The BLM's revised resource management plans would include the following elements to maintain water quality:

\section{Land Use Allocations}

Under the Proposed Resource Management Plan, the Riparian Management Area land use allocation would:

- provide for riparian buffers of between one half and one site potential tree, including a limited management area, on each side of stream channels.

\section{Management Objectives}

Under the Proposed Resource Management Plan, the following management objectives pertaining to water quality would be applied within the Riparian Management Areas:

- provide for the riparian and aquatic conditions that supply stream channels with shade, sediment filtering, leaf litter and large wood, and stream bank stability.

- maintain and restore water quality

\section{Management Direction}

See the Proposed Resource Management Plan in Chapter 2 for a complete description of the land use allocations and management direction that would be implemented to achieve the management objectives. The management direction applicable to the Riparian Management Areas includes:

- limits on management activity, including a near stream zone of 35 feet (intermittent streams) or 60 feet (perennial and fish-bearing streams) where thinning harvests would not occur, and a secondary stream zone where $50 \%$ canopy would be retained

- implementation of riparian restoration and road improvement activities

- a requirement to implement Best Management Practices, as needed, to maintain or restore water quality

\section{Best Management Practices}

The application of Best Management Practices is required; however, selection of individual Best Management Practices are made by BLM soil, water, fisheries, geology and other professionals during project-level analyses. Not all of the Best Management Practices will be applicable for any specific management action. Each activity is unique and Best Management Practices would be selected based on site-specific conditions.

The Oregon Department of Environmental Quality recognizes that the Designated Management Agencies already have plans in place that help prevent or control water pollution in impaired waters. Total maximum 
daily loads build on these efforts and do not duplicate them (ODEQ 2007). The BLM resource management plans serve as overall guidance documents for watershed-scale natural resource management and establish sideboards for management activities that have potential to affect water quality. Water quality restoration plans specify how restoration in a particular watershed or basin contributes to overall total maximum daily load implementation. Water quality restoration plans are used by the Department of Environmental Quality in creating an overall water quality management plan covering all lands within the area of a designated total maximum daily load.

The State of Oregon Division 42 Total Maximum Daily Load Rule (February 13, 2004) requires Designated Management Agencies to participate in developing total maximum daily loads and in preparing and implementing total maximum daily loads implementation plans. The BLM participates in total maximum daily load development and develops water quality restoration plans as a vehicle for achieving total maximum daily load compliance objectives on BLM administered lands.

The Department of Environmental Quality advises that in most instances, it will be adequate to wait for the next 5-year review of the total maximum daily load implementation plan to revise it to reflect changes (ODEQ 2007). Previously completed total maximum daily loads that include BLM-administered lands would be updated to reflect the Western Oregon Plan Revision according to Department of Environmental Quality's total maximum daily load review schedule.

The 2007 Oregon Department of Environmental Quality total maximum daily load implementation plan guidance identifies the components of an implementation plan. Table 5-2 (BLM plans and components of a total maximum daily load implementation plan) identifies the components and corresponding BLM documents that contain them.

Table 5-2. Blm Plans And Components Of A Total Maximum Daily load Implementation Plan

\begin{tabular}{|c|c|c|}
\hline Element ${ }^{\mathrm{a}}$ & Resource Management Plan & Water Quality RestorationPlan ${ }^{a}$ \\
\hline Management Strategies & $\begin{array}{l}\text { - Riparian Management Area (RMA) Land } \\
\text { Use Allocation } \\
\text { - RMA Objectives } \\
\text { - RMAActions } \\
\text { - Best Management Practices }\end{array}$ & $\begin{array}{l}\text { - Goals and Objectives } \\
\text { - Proposed Management Measures }\end{array}$ \\
\hline Implementation Timeline & N/A (Typical plans last 10 to 15 years.) & Timeline for Implementation \\
\hline Performance Monitoring & Monitoring Plan (Chapter 5 of this RMP/FEIS) & $\begin{array}{l}\text { Monitoring, Evaluation, and Adaptive } \\
\text { Management }\end{array}$ \\
\hline $\begin{array}{l}\text { Compliance with Statewide Land Use } \\
\text { Requirements }\end{array}$ & N/A & N/A \\
\hline Analyses and Information & $\begin{array}{l}\text { - Affected Environment (Chapter } 3 \text { of this RMP/ } \\
\text { FEIS) } \\
\text { - Environmental Consequences (Chapter } 4 \text { of } \\
\text { this RMP/FEIS) }\end{array}$ & Condition Assessment \\
\hline
\end{tabular}




\section{Regional Interagency Executive Committee}

The 1994 Northwest Forest Plan, Record of Decision, and Standards and Guidelines provide for coordination and review by the Regional Interagency Executive Committee of proposed changes to standards and guidelines and land allocations established under the Northwest Forest Plan and incorporated into BLM's 1995 resource management plans. With respect to plan revisions, the Northwest Forest Plan states: "Decisions to change land allocations, or standards and guidelines will be made only through the adoption, revision, or amendment of these documents following appropriate public participation, National Environmental Policy Act procedures, and coordination with the Regional Interagency Executive Committee." Although proposed revisions will be coordinated with the Regional Interagency Executive Committee, the authority to change plans remains with the individual agency in accordance with the applicable agency regulations.

The BLM coordinated with the Regional Interagency Executive Committee during preparation of the proposed resource management plan through numerous briefings, updates, and discussion opportunities. In addition, Federal agencies were invited to participate in the planning effort as members of a broader group of cooperators. The U.S. Forest Service, National Oceanic and Atmospheric Administration - Fisheries, U.S. Fish and Wildlife Service, and the Environmental Protection Agency chose to participate as formal cooperators. The Regional Interagency Executive Committee provided a memorandum (dated March 26, 2008) acknowledging BLM's completion of coordination under the above provisions.

\section{Section 7 Consultation Under the Endangered Species Act}

\section{ENDANGERED SPECIES ACT SECTION 7 REQUIREMENTS}

Section 7 of the Endangered Species Act provides statutory direction for interagency cooperation for furthering the purposes of the Act. Federal agencies achieve this cooperation both by reviewing their programs in consultation with the listing agencies for how these programs can be utilized to conserve endangered or threatened species, ${ }^{1}$ and by consulting with either the Fish and Wildlife Service or National Marine Fisheries Service (hereafter referenced as the "Services"), whichever is appropriate for the affected species, to ensure that actions authorized, funded, or carried out under their programs do not jeopardize a species or adversely modify its critical habitat. ${ }^{2}$ While both Section $7(a)(1)$ and (2) make reference to "consultation," the regulations promulgating the ESA provide direction for consultation under Section 7(a) (2), but are explicitly silent as to how to consult under Section 7(a)(1).

Under Section 7(a)(2) of the ESA, those agencies that authorize, fund, or carry out federal actions are commonly known as "action agencies." If an action agency determines that its federal action "may affect" listed species or critical habitat, it must consult with the Service(s). See 50 CFR 402.2, 402.13-14. If an action agency determines that the federal action will have no effect on listed species or critical habitat, the agency will make a "no effect" determination. In that case, the action agency does not initiate consultation with the Service(s), and its obligations under Section 7(a)(2) for that agency action are complete.

\footnotetext{
${ }^{1}$ See Endangered Species Act, Sec 7(a)(1): "All other Federal agencies shall, in consultation with and with the assistance of the Secretary utilize their authorities in furtherance of the purposes of this chapter by carrying out programs for the conservation of endangered species...". Codified in 16 U.S.C. $\$ 1536(a)(1)$

${ }^{2}$ See Endangered Species Act, Sec. 7(a)(2): "Each Federal agency shall, in consultation with and with the assistance of the Secretary, insure that any action authorized, funded, or carried out by such agency... is not likely to jeopardize the continued existence of any endangered species..." Codified in 16 U.S.C. $\$ 1536(a)(2)$
} 
The BLM has coordinated with the Services in developing the revised Resource Management Plans. As encouraged by both CEQ regulations for preparation of NEPA documents and ESA regulations, ${ }^{3}$ the agencies have reduced redundancy in paperwork by conducting this ESA coordination work integrated with their role as cooperating agencies under NEPA. Both Services were identified as cooperating agencies under CEQ regulations ${ }^{4}$ near the outset of planning for the revision of BLM's western Oregon plans. In fact, one of the express purposes for the revision of the BLM Western Oregon Resource Management Plans is for BLM to use its authorities for managing the lands it administers under the revised plans to conserve habitat needed on those lands for listed species. ${ }^{5}$ Through their coordination efforts, the agencies have met and communicated regularly and often. The development of the PRMP has been greatly influenced by these efforts. For example, the BLM increased the Riparian Management Area widths and modified the LateSuccessional Management Area locations from those in the preferred alternative in the Draft EIS, and added the Deferred Timber Management Area land use allocation to the PRMP to address input from the Services.

The BLM has satisfied its Section 7 obligations by coordinating with the Services and determining that there are no effects on a listed species or its critical habitat that would require consultation under Section 7(a)(2) of the Endangered Species Act. The BLM has examined the potential effects on listed species and designated critical habitat of revising resource management plans in western Oregon in which lands are allocated to various categories of use, each with its own management directions for planning future activities on those lands. As a result of this examination, the BLM has determined that its proposed action of revising resource management plans would have no effect for purposes of Section $7(\mathrm{a})(2)$ on these species or on critical habitat. This determination is based on the following:

- The revision of resource management plans to allocate lands to various categories of use, with associated management direction for planning future activities on those lands, would have no impact on listed species or critical habitat. The actual timing, place, and design of future sitespecific projects that would occur on these lands is not identified in the plans, and adoption of the revised plans does not alter the environmental baseline or provide a basis for a determination of "incidental take."

- The revision of resource management plans for such purpose does not create any legal right that would allow or authorize ground-disturbing activities without further agency decision-making and compliance with applicable statutes, including the ESA and NEPA. In the future when a specific project is proposed, sufficiently detailed information will be available for analyzing the effect of the project on listed species or critical habitat under Section 7(a)(2) before the BLM issues a contract, or any other form of a legal right, or otherwise approves any ground-disturbing activity. Compliance with Section 7(a)(2) may take the form of preparation of a Biological Assessment by the BLM that can result in a "no effect" determination by the BLM, a "may affect, not likely to adversely affect" determination with the Service(s)' concurrence through "informal" consultation, or a "likely to adversely affect" determination followed by "formal consultation" with the Service(s) and issuance of a Biological Opinion.

- The expertise and counsel of the regulating agencies on how the plan revisions can contribute to the survival and recovery of listed species through the direction that the revisions provide for designing future actions has already been obtained through the NEPA process, in which both Services were cooperators. Since no on-the-ground activity would be authorized in the revised plans, no incidental take could possibly take place from the act of revising the resource management plans. Requests for authorization of any incidental take permits would be made only when actual projects are proposed in the future. 
The BLM will follow the closely coordinated two-step process suggested in the ESA Consultation Handbook $^{6}$ of first consulting with the Services on how to utilize the authorities for its programs to further the purposes of the Endangered Species Act in conserving listed species and their critical habitat, and then consulting under Section 7(a)(2) on any future project-level actions "authorized, funded, or carried out" under those programs that "may affect" a listed species or critical habitat. Following this process will provide the assurance envisioned by Congress that the BLM will not be likely to jeopardize a species or adversely modify critical habitat listed for protection under the Endangered Species Act.

\section{Preparers}

\section{Steering Committee}

The nine-member Steering Committee is comprised of management staff from the BLM Oregon/ Washington State Office in Portland, the six BLM districts represented in the Western Oregon Plan Revisions, and the Coquille Indian Tribe. This committee provides leadership and direction to the resource management plan revisions process.

Members of the Steering Committee are listed below:

$\begin{array}{ll}\text { Edward W. Shepard } & \text { BLM - Oregon/Washington State Director } \\ \text { Mike Mottice } & \text { BLM - Deputy State Director, Division of Resources } \\ \text { Tim Vredenberg } & \text { Coquille Indian Tribe of Oregon } \\ \text { Aaron Horton } & \text { BLM District Manager, Salem } \\ \text { Ginnie Grilley } & \text { BLM District Manager, Eugene } \\ \text { Jay Carlson } & \text { BLM District Manager, Roseburg } \\ \text { Tim Reuwsaat } & \text { BLM District Manager, Medford } \\ \text { Shirley Gammon } & \text { BLM District Manager, Lakeview } \\ \text { Mark E. Johnson } & \text { BLM District Manager, Coos Bay }\end{array}$

\section{Key Project Staff}

Table 5-3 lists the staff who prepared the Proposed RMP/Final EIS, their specific area of responsibility, and the organization for which they work. Biographies for each staff member are included below the table.

\section{Interdisciplinary Team and EIS Team}

Tim Barnes - Geologist. Tim has a B.S. in Natural Science with Geology Emphasis from Western Oregon University and completed graduate work in geology at Portland State University. Tim has worked in the field of geology since 1994. Before joining the BLM in 2001, Tim was a Senior Geologist in private industry, completing Resource and Engineering Geology projects, resource planning, and permitting. Tim is a Registered Geologist in both Oregon and Idaho. His expertise is in oil and gas development, resource geology, and engineering geology, including landslide investigation and mitigation. Recent projects include an aggregate values study for BLM and Forest Service lands within the states of Oregon and Washington, coalbed natural gas evaluations and planning, abandoned mine drilling investigations, oceanic and dune 
Table 5-3. Key Project Staff For The Proposed Resource Management Plan And Final ENVIRONMENTAL IMPACT STATEMENT

\begin{tabular}{|c|c|c|}
\hline Responsibility & Name & Organization \\
\hline Project Manager & Richard Prather & Oregon State Office BLM \\
\hline Lead Planner, Interdisciplinary Team Leader & Philip Hall & Mason, Bruce and Girard Inc. \\
\hline Planner & Anne Boeder & Oregon State Office BLM \\
\hline Forester/Planner & Alan Wood & Oregon State Office BLM \\
\hline Writer-Editor & Kathleen Helm & Mason, Bruce and Girard, Inc. \\
\hline GIS/Data Analysis & Duane Dippon & Oregon State Office BLM \\
\hline Administrative Record Coordinator & Mary Ceciliani & Oregon State Office BLM \\
\hline Logistics Coordinator & Jerry Hubbard & Oregon State Office BLM \\
\hline Public Involvement Coordinator & Alan Hoffmeister & Oregon State Office BLM \\
\hline Vegetation/Land Use Allocation Mapping & Chris Cadwell & Oregon State Office BLM \\
\hline Areas of Critical Environmental Concern & Susan Carter & Roseburg BLM \\
\hline Cartographer & Paul Fyfield & Oregon State Office BLM \\
\hline Cultural & Fran Philipek & Salem BLM \\
\hline Ecology & Richard Hardt & Eugene BLM \\
\hline Energy/Minerals & Tim Barnes & Coos Bay BLM \\
\hline Energy/Minerals & Eric Hoffman & Oregon State Office BLM \\
\hline Fire/Air & John Dinwiddie & Medford BLM \\
\hline Fisheries & Nikki Moore & Coos Bay BLM \\
\hline Fisheries & Bill Hudson & Coos Bay BLM \\
\hline Grazing & Kim Hackett & Medford BLM \\
\hline Hydrology & Dan Carpenter & Coos Bay BLM \\
\hline Recreation & David Wash & Coos Bay BLM \\
\hline Roads, Lands & John Styduhar & Oregon State Office BLM \\
\hline Silviculture & Craig Kintop & Roseburg BLM \\
\hline Socioeconomic & Mark Rasmussen & Mason, Bruce and Girard, Inc. \\
\hline Soils & Clif Fanning & Oregon State Office BLM \\
\hline Timber & Dave DeMoss & Eugene BLM \\
\hline Vegetation/Botany & Doug Kendig & Medford BLM \\
\hline Vegetation/Botany & Claire Hibler & Salem BLM \\
\hline Wildlife & Chris Foster & Roseburg BLM \\
\hline Wildlife & Rex McGraw & Roseburg BLM \\
\hline Wildlife & Eric Greenquist & Eugene BLM \\
\hline
\end{tabular}

sand movements studies, and numerous landslide evaluations and mitigations. Tim is currently employed as the District Geologist and Western Oregon Zone Fluids Geologist, in the Coos Bay BLM District.

Anne Boeder - Planner. Anne holds a B.A. in Cartography and Geography from the University of Wisconsin and a Master of Public Administration from the University of Utah. Anne has 24 years of government service, including 13 years with the U.S. Forest Service and 9 years with the BLM. She most recently served in various leadership roles on the interagency team for the 2004 Survey and Manage Environmental Impact Statement and Record of Decision. She has also worked on both the Roseburg and Coos Bay BLM Districts.

Chris Cadwell - Forester/Resource Analyst. Chris holds a B.S. in Forest Management from Humboldt State University. Chris served on the Forest Ecosystem Management Assessment Team in the estimation of probable sale quantities. He has coordinated probable sale quantities estimations and geographic information system analysis supporting development and implementation of the BLM resource management plans in western Oregon. He is co-author of the implementation guidance for the 15 percent standard and guideline. Chris served as co-lead in developing interagency vegetation standards and served on the team that developed interagency land allocation standards for the Northwest Forest Plan area. 
He participated in the Survey and Manage Final Supplemental Environmental Impact Statements in the assessment of timber effects and development of late-successional forest. He is the state data steward for the forest operations inventory, timber production capability classifications, and land use allocations for the BLM. Chris has 25 years experience with the BLM in western Oregon and currently is employed by the BLM Oregon/Washington State Office.

Dan Carpenter - Hydrologist. Dan has a B.S. in Soil Science, from Washington State University. He has worked as a professional hydrologist for the past 25 years ( 12 with the U.S. Forest Service and 13 with the BLM) on the Oregon Coast, Western Cascades, and Great Basin in Nevada. His area of expertise includes watershed planning, modeling, and watershed restoration. His most recent assignments included working on an interagency Port-Orford-Cedar Environmental Impact Statement and environmental planning roles in the permitting of the Coos County Natural Gas Pipeline. Dan is currently employed as a hydrologist on the Coos Bay BLM District.

Susan Carter - Botanist. Susan has a B.A. in Botany and Environmental Biology from Humboldt State University. Since 2002, she has served as the District Botanist and District Weed Coordinator for the BLM Roseburg District. Previously she worked for the BLM in Bakersfield, California. Of her 19 years of botanical work experience, 18 are with the BLM.

Mary Ceciliani - Program Assistant. Mary has served as coordinator for the Administrative Record of the Western Oregon Plan Revision of the Northwest Forest Plan since October 2005. Her previous positions include working at the Oregon Federal Executive Board, where she managed all the training, coordinated health fairs for agencies during the open season, and assisted in preparation for numerous committee meetings. Mary started her career in the BLM Division of Minerals. Her BLM employment totals approximately 23 years.

David DeMoss - Forester. Dave is currently the district staff forester and district silviculturist for the Eugene BLM District. He holds a B.S. in Forestry from the University of California - Berkeley, and has 29 years experience on the Eugene BLM District in timber sales and silviculture. He served as the silviculturist on the Late Successional Reserve \# 267 Restoration Environmental Impact Statement and has experience in stand dynamics and modeling.

John Dinwiddie - Fire/Fuels/Air Quality. John's forestry education includes two years at Central Oregon Community College and completion of Technical Fire Management in 1989. John worked in private industry for two years and for the U.S. Forest Service for five years. His BLM employment totals 25 years.

Duane Dippon - Geographic Information System/Data Team Leader. Duane earned a B.S. and M.S in Forestry and Forest Economics at Purdue University and a Ph.D. in Forest Management, with a Minor in Operations Research, from Oregon State University. He served as the Forest Ecosystem Management Assessment Team co-Geographic Information System /Data Team Leader, building the geospatial database covering over 24 million acres of federal lands across the Pacific Northwest and used by the Forest Ecosystem Management Assessment Team scientists in the development of the Northwest Forest Plan. Duane began working for the BLM in 1988 to integrate the use of geospatial data, modeling, and geographic information system technology in support of federal land planning. He served as the chair or co-chair of the Interagency Resources Information Coordination Council from 1994-98 and 2003-04. He currently serves on the Oregon Geographic Information Council. Prior to joining the BLM, Duane was an Associate Professor at the University of Florida teaching Forest Management, Forest Economics, and Quantitative Methods in Natural Resources Management.

Clif Fanning - Soil Scientist. Clif holds a B.S. in Soil Science from California Polytechnic State University. He has 32 years of federal service and has been working with the BLM since 1977. Cliff previously worked in Dillon and Butte, Montana; and in Cheyenne, Wyoming. He has served on numerous planning efforts over the years and has been the Oregon/Washington state soil scientist since 1991. 
Paul Fyfield - Cartographer. Paul has been a cartographer in the BLM Oregon State Office in Portland since 2001. He earned a Master's degree in Geography from Portland State University in 2003.

Chris Foster - Wildlife Biologist. Chris is currently the District Wildlife Biologist for the Roseburg BLM District. He holds a B.S. in Forest and Wildlife Management from the University of Maine, and an M.S. in Wildlife Management from West Virginia University. Chris has more than 15 years experience working for the U.S. Forest Service and the BLM. Chris has held positions as a wildlife biologist and as a forester specializing in watershed analysis and planning.

Eric Greenquist - Wildlife Biologist. Eric is the lead wildlife biologist in the Eugene BLM District. He has a B.A. in Biology from the University of Missouri and an M.S. in Wildlife Ecology from Ohio University. During his 28 years with the BLM, Eric has worked (both in the United States and throughout the Americas) for the conservation of a variety of threatened and endangered species.

Kimberly Hackett - Rangeland Management Specialist. Kimberly Hackett has a B.S. in Wildlife Science with a Range Science Emphasis from New Mexico State University. She has worked for the BLM for 17 years. Kimberly is currently the Medford BLM District Rangeland Management Specialist. She previously worked as a Rangeland Management Specialist for 11 years in Idaho and 5 years in Nevada.

Phil Hall - Planner. Phil holds a B.S. in Forestry and a B.S. in Conservation from North Carolina State University. Phil served on the interdisciplinary team for the Northwest Forest Plan Supplemental Environmental Impact Statement (1994) and was a lead planner in developing the western Oregon resource management plans tiered to the Northwest Forest Plan. He has served on regional teams for the development of watershed analysis guides and monitoring and research. Phil has provided national level training for the National Environmental Policy Act and Resource Management Planning. Phil has a broad understanding and familiarity of BLM programs and plans, including the Northwest Forest Plan and environmental impact statements. He has 33 years of federal service, including 30 years with the BLM (1976-2006) on two BLM districts and in several resource areas. He served on special assignments to BLM's national office in Washington, D.C. and to other BLM districts in the western United States. He is now employed by a contractor to the BLM.

Richard Hardt - Ecologist. Richard has a B.A. in Natural Sciences from John Hopkins University, an M.L.A in Landscape Architecture from Harvard University, and a Ph.D. in Forest Resources from the University of Georgia. He has 11 years of experience working for the BLM and is currently employed at the Eugene BLM District. Richard's expertise is in forest ecology, planning, and the National Environmental Policy Act.

Kathleen Helm - Writer-Editor. Kathleen attended Macon Jr. College, Southern Oregon State College, and Southwestern Oregon Community College. She has 27 years experience with the BLM in reviewing, editing, and preparing environmental analysis documents, including many major complex ones: a regional Vegetative Management EIS, a land tenure adjustment in eastern Oregon, the Interior Columbia Basin Ecosystem Management Plan/EIS, the Northwest Forest Plan, and the Coos Bay BLM Resource Management Plan. She also served on the interagency Public Comment Analysis Team for the Northwest Forest Plan. Kathleen served as writer/editor preparing environmental assessments for various land management activities in western Oregon for both the Medford and Coos Bay BLM Districts. In the mid90s, she was on the interagency team preparing the Oregon Salmon Plan. From 1997 to 1999, she served as the environmental planner for the BLM Klamath Falls Resource Area, and then District Environmental Planner for the Spokane, Washington BLM Office until 2006. In both the Klamath Falls and Spokane BLM offices, she also served as a public affairs specialist. Kathleen is now employed by a contractor to the BLM.

Claire Hibler - Botanist. Claire has served as the Lead Botanist for the Salem BLM District since 2001. She holds a B.S. in Forest Management from Oregon State University and a B.A in General Biology from Humboldt State University. Claire was a founding member of, and participates on, the steering committee for the Northwest Oregon Invasive Weed Management Partnership, which spans the northwest corner of 
Oregon and part of southwest Washington. She has worked in the Salem BLM District for more than 15 years in the botany and invasive plant programs, at both the resource area and district level.

Eric Hoffman - Mining Engineer: Eric holds a B.S. in Geology from Washington State University with additional hours in environmental geology and engineering from Eastern Washington State University and George Washington University in D.C.. He has completed 37 years of government service, including 8 years with the former U.S. Bureau of Mines in Washington state and at headquarters in Washington, D.C.; 9 years with the U.S. Geological Survey at Grand Junction, Colorado; and 20 years with BLM in Oregon/ Washington. Eric's career has encompassed work on mineral resource evaluation, mined land reclamation, and Federal/Indian mineral program management. Eric is currently serving as the Acting Section Chief for the OR/WA State Office Minerals Section.

R. Alan Hoffmeister - Public Involvement Coordinator. Alan was assigned to the planning staff to coordinate and support all public involvement activities for the plan revision effort through the Draft RMP/EIS. He holds a B.S. in Forest Science from the University of Illinois. He began his government career with the U.S. Forest Service and Soil Conservation Service and has worked for the BLM as a public affairs specialist for 27 years in California, New Mexico, and Oregon. Most recently he served as the Public Affairs Officer for the BLM's Coos Bay District.

Jerry Hubbard - Logistics Coordinator. In addition to logistics duties, Jerry is coordinating public involvement activities for the PRMP/Final Environmental Impact Statement. Jerry has a B.S. in Forest Sciences from the University of Washington and an M.S. in forestry (Silviculture) from Pennsylvania State University. Jerry has held a variety of positions in BLM in Oregon: Forester on the Roseburg District, Soils/Watershed Specialist on the Medford District, Public Affairs Specialist on the Vale District, and Management Analyst in the Oregon State Office. Additionally, as part of a management development curriculum, he produced a regional economic analysis of western Oregon's timber and recreation economies for the period 1972-1986.

William F. Hudson - Fishery Biologist. Bill has a B.S. in Wildlife Management and an M.S. in Biology (Fisheries) from Tennessee Technological University. He has worked for the BLM for 25 years in the Coos Bay District. Early in his career he worked as a Resource Area Biologist, assisting in fisheries and wildlife management. Currently, Bill is the Coos Bay BLM District Fisheries Biologist and has spent the last seven years working on various Endangered Species Act consultations with National Oceanic and Atmospheric Administration-Fisheries, including local project consultations and regional consultations at the plan level for the Interior Columbia Basin and the Northwest Forest Plan. Recently, Bill chaired an interstate and interagency team that developed an Analytical Process for Developing Biological Assessments for Federal Actions Affecting Fish within the Northwest Forest Plan Area.

Douglas Kendig - Botanist/District Native Plant Coordinator. Doug has 21 years experience with the BLM and 3 years with the Peace Corps in Guatemala. He has served as Area and District Botanist and Resource Specialist for the last 11 years, representing botany, native plants, and restoration. Doug has been a resource area team member on numerous environmental assessments and watershed analysis. He holds a B.A. in International Studies from Southern Oregon University and graduate class work in Botany from Southern Oregon University and the University of Washington.

Craig Kintop - Forester. Craig is currently the District Silviculturist for the Roseburg BLM District. He holds a B.S. in Forest Resources Management from the University of Minnesota. Craig has more than 29 years experience working for the U.S. Forest Service and the BLM. He was a member of the silviculture and inventory team that developed silvicultural prescriptions and growth and yield information for the 1995 resource management plans. 
Rex McGraw - Planner/Wildlife Biologist. Rex is currently the Environmental Coordinator for the Swiftwater Field Office, Roseburg District, BLM. He earned a B.S. and an M.S. in Wildlife Biology in 1995 and 1997, respectively, from the University of Montana in Missoula, Montana. Rex has more than 10 years of experience working for the BLM. Prior to becoming the Environmental Coordinator in 2006, Rex worked in both the Coos Bay and Roseburg Districts as a wildlife biologist.

Nikki M. Moore - Fishery Biologist. Nikki is currently a fisheries biologist for the Coos Bay District BLM. She holds a B.S. in Fisheries Biology from Oregon State University. She has worked for the BLM and U.S. Forest Service for about 8 years. Nikki also worked for the National Oceanic and Atmospheric Administration-Fisheries where she completed Endangered Species Act biological opinions for local and regional projects.

Frances Philipek - Archeologist. Fran holds a B.S. and an M.A. in Anthropology from Portland State University. Fran has 28 years of government service, including 7 years with the U.S. Forest Service in Lakeview and Klamath Falls and 21 years with BLM in Idaho, North Dakota, and Oregon. Fran currently is the District Archeologist for the Salem BLM District. She is the state-wide lead for the Heritage Education and project archeology programs.

Dick Prather - Project Manager. Dick is a graduate of the Northern Arizona University School of Forestry in Flagstaff, Arizona. He served as team leader for the Final Supplemental Environmental Impact Statement for Survey and Manage in 2001 and 2004. He is a 34-year veteran of the BLM. Prior to his assignments on EIS teams, he was Field Manager in the Salem District for 18 years. He previously worked in Coeur d'Alene, Idaho and Coos Bay, Oregon as a forester.

Mark Rasmussen - Economist. Mark has a B.S. in Environmental Studies and an M.S. in Forest Economics. Since 1997, he has been a principal at Mason, Bruce, and Girard where he leads the Forest Economics and Planning Group. For 25 years, Mark's work has focused on land management planning, including economic analysis of land management policy, for federal, state, private, and tribal landowners.

John Styduhar - Senior Realty Specialist. John has a B.S. in Forestry Science from Penn State University. He has worked for the BLM as a forester, area engineer, and realty specialist for 27 years: 10 years in timber sale planning and administration, 5 years in forest road engineering and transportation management, and 12 years as senior realty specialist at the BLM Oregon/Washington State Office specializing in public land law administration and O\&C lands.

Dave Wash - Recreation, Visual Resources, Wilderness, Wild \& Scenic Rivers. Dave has a B.S. in Recreation and Park Management from Penn State University and did post baccalaureate studies in public policy and wilderness management at Colorado State University. He has 28 years experience in planning and managing outdoor recreation resources on federal lands for the Bureau of Land Management, Corps of Engineers, and U.S. Forest Service. Previous positions have involved off-highway vehicle planning and management in the California Desert Conservation Area; wilderness and National Scenic Trails management in the Sierra Nevada and Mojave Desert; visual resource analysis for large-scale mining and energy development projects; plan development and management of recreation sites; and wild and scenic river eligibility analysis. Dave currently works as the Lead Outdoor Recreation Planner for the Coos Bay BLM District.

Alan Wood - Planner/Forester. Alan holds a B.S. in Forestry from the University of Minnesota. He is a 30year veteran of the BLM and has worked in both Idaho and Oregon. Alan was a forester and Operations Chief in Salmon, Idaho, and worked extensively on fire and fuels issues. He served for 10 years as a Field Manager in the Roseburg BLM District, and most recently as a forester in the BLM Oregon/Washington State Office. 


\section{The Science Program Supporting the RMP Revision}

In support of the RMP revision, the interdisciplinary team worked with agency scientists and natural resource specialists, including three components:

- "state-of-the science" review for selected major issues and questions

- informal discussions between interdisciplinary team members and scientists

- a Science Team to review the planning criteria and draft EIS

During initial scoping, the steering committee and interdisciplinary team identified a number of issues and questions they considered relevant to the RMP revision process and that would benefit from research to synthesize current scientific knowledge. The BLM established cooperative agreements with scientists who had recognized expertise in the relevant fields to conduct "state-of-the science" reviews for these issues. "State-of-the science" review topics were:

- wildlife use of dead wood

- forest management effects on peak stream flows

- aquatic habitat management strategies

- human community resiliency

- application of landscape dynamics concepts

- young stand management

Each "state-of-the science" review synthesized published, peer-reviewed empirical and model-based studies relevant to forest management in the planning area. The "state-of-the-science" reports are available on the BLM's website at: http://www.blm.gov/or/plans/wopr/science_spring_2008.php (accessed April 2008).

In addition to having discussions with Science Team members described below, individual interdisciplinary team members conducted numerous informal discussions with other agency scientists in developing planning criteria (the analytical assumptions and analytical methodology) for the draft and final EIS. Some of the discussions are detailed here, but other informal discussions occurred throughout the development of the planning criteria and the draft and final EIS.

Scientists with the U.S. Forest Service, Pacific Northwest Research Station, assisted in developing the analytical methodology for the analysis of effects on fish. The Earth Systems Institute was contracted by Pacific Northwest Research Station to develop a wood delivery model and assist the BLM in the application of the wood delivery model to compare the potential wood contribution for fish-bearing and non-fishbearing stream channels over time between alternatives on BLM-administered lands and non-BLMadministered lands. The wood delivery model in the analysis of effects is based on research by Pacific Northwest Research Station and Earth Systems Institute scientists. The BLM was responsible for model inputs, quality control of model inputs, and interpretation of the modeling results.

Wildlife biologists with the U.S. Fish and Wildlife Service assisted in developing the analysis of effects on the northern spotted owl. These discussions provided input to development of the analytical methodology, including the habitat classification for northern spotted owls.

A Science Team consisting of scientists and natural resource specialists led by a BLM Science Team Coordinator was formed in 2005 to provide advice to the BLM about the planning criteria and draft EIS. The Science Team included:

- Doug Drake - Oregon Department of Environmental Quality Focus: Invasive plants, fish, water, fire, and soils 
- Joan Hagar - U.S. Geological Survey Forest and Rangeland Ecosystem Science Center Focus: Wildlife

- Chris Jordan - National Oceanic and Atmospheric Administration Northwest Fisheries Science Center Focus: Fish and water

- Gary Lettman - Oregon Department of Forestry Focus: Socioeconomics and timber

- Thomas Spies - Pacific Northwest Research Station Focus: Ecology, Wildlife, fire, and timber

- Fred Swanson - Pacific Northwest Research Station Focus: Ecology, fish, water, soils, and areas of critical environmental concern

- Chris Sheridan - Western Oregon BLM Science Coordinator Focus: Technical coordination, compilation, and contribution

The Science Team provided input to development of the planning criteria through meetings and informal discussions with the interdisciplinary team.

The Science Team review consisted of comments to the BLM on the draft Environmental Impact Statement by the individual team members. The scientists' comments did not represent an official position of the team members' parent agencies. The Science Team review document and further background information about the Science Team is available on the BLM's website at http://www.blm.gov/or/plans/wopr/science. php (accessed April 2008). See Appendix T (Response to Comments) for further discussion of the comments provided by the Science Team.

\section{Vegetation Modeling Team Members}

In addition, there were numerous individuals working on teams to provide the data, modeling, and geographic information that support the analysis in the document. Those individuals are:

\section{OPTIONS Team}

Kristine Allen

Chris Cadwell

Joe Graham

Mark Perdue

Don Reimer
D. R. Systems Inc.

BLM Oregon State Office

BLM Oregon State Office

D. R. Systems Inc.

CEO, D. R. Systems Inc. 


\section{Growth and Yield Team}

Mark Hanus $\quad$ FORSight Resources, Vancouver,

Washington

\begin{tabular}{|c|c|}
\hline Michael Oxford & BLM - Coos Bay District \\
\hline Alan Bergstrom & BLM - Medford District \\
\hline \multicolumn{2}{|l|}{ Frank Hoeper } \\
\hline \multicolumn{2}{|l|}{ Robert Pierle } \\
\hline \multicolumn{2}{|l|}{ Douglas Stewart } \\
\hline Steve Brownfield & BLM - Salem District \\
\hline \multicolumn{2}{|l|}{ Carolina Hooper } \\
\hline \multicolumn{2}{|l|}{ Walter Kastner } \\
\hline \multicolumn{2}{|l|}{ Daniel Schlottmann } \\
\hline Kevin Carson & BLM - Roseburg District \\
\hline \multicolumn{2}{|l|}{ Craig Kintop } \\
\hline Art Emmons & BLM - Eugene District \\
\hline Richard Kelly & \\
\hline Robert Ohrn & \\
\hline Mark Stephen & \\
\hline
\end{tabular}

William Johnson BLM - Klamath Falls Resource Area

Gregory Reddell

\section{Current Vegetation Survey (CVS)/Statistical Team}

Jim Alegria, BLM Oregon State Office

Carol Apple, Forest Service, Pacific Northwest Regional Office

\section{GIS Team}

Northrop Grumman (contractor), Oregon State Office

Eric Brewster

Maria Fiorella

Ryan Good

Eric Hiebenthal

Jeremy Hruska

Ryan Kelley

Bureau of Land Management

Duane Dippon

Craig Ducey

Jay Flora

Paul Fyfield

Dennis Glover

Dale Gough

John Guetterman

Thomas Jackson

Mark Koski

Mike Limb

Arthur Miller

Kiet Nguyen

Jeff Nighbert

Annette Parsons

Jay Ruegger

Alan Ward
Jeanne Keyes

Bron MacDougall

Bryant Mecklem

Shelley Moore

Steve Salas

Oregon State Office

Oregon State Office

Coos Bay District

Oregon State Office

Medford District

Roseburg District

Coos Bay District

Eugene District

Salem District

Klamath Falls Resource Area

Oregon State Office

Oregon State Office

Oregon State Office

Medford District

Eugene District

Coos Bay District 


\section{Ten-Year Scenario Quality Control Team}

BLM Salem District

Lisa Ball

Michael Barger

Cory Geisler

Randy Herrin

Carolina Hooper

Mark Koski

Phil Sjoding

Keith Walto

\section{BLM Medford District}

Sarah Bickford

John Bergin

Jeff Brown

Jim Brown

Dave Caulfield

Bill Freeland

Terry Garner

Dennis Glover

\author{
BLM Eugene District \\ Tom Jackson \\ Jay Ruegger \\ Dave DeMoss \\ Jack Zwiesler \\ Gary Wilkinson
}

\author{
BLM Coos Bay District \\ Terry Evans \\ Paul Fontaine \\ Paul Leman \\ Chris Schumacher \\ Alan Ward
}

Klamath Falls Resource Area.

Mike Angell

Mike Bechdolt

Mike Limb

Rob McEnroe

\author{
BLM Roseburg District \\ Bruce Baumann \\ Mark Beardsley \\ Jay Besson \\ Dale Gough \\ Jim Schwab
}

\section{Monitoring}

\section{Monitoring Plan for the Proposed Resource Management Plan}

The monitoring plan for the proposed resource management plan is carefully designed to avoid prohibitive costs and effectively answer monitoring questions and reporting levels of activities. It is not necessary or desirable to monitor every activity and management action or objective of a resource management plan.

Monitoring for the resource management plans would examine if activities are in accordance with management directions (implementation monitoring), if management objectives are being met or are likely to be met (effectiveness monitoring), and if management objectives and management actions are based on correct assumptions (validation monitoring). Most monitoring would be designed to provide information as to whether activities are in accordance with management direction.

Some management objectives and management directions in the Proposed Resource Management Plan are not measurable or quantifiable, or do not have a standard or threshold of acceptability, and therefore would not lend themselves to being addressed through monitoring questions which are almost always dependent on a quantifiable basis of measurement. The level of activity for certain management directions that do not have standards or thresholds of acceptability would be monitored in the form of a program reporting item.

In some cases, where monitoring indicates very high compliance with the plan, the frequency or interval of monitoring would subsequently be adjusted for cost and time efficiency.

Sampling or evaluation of a subset of actions would be employed to avoid unnecessary detail and unacceptable costs. Projects to be monitored would be selected on the basis of those that would yield a greater amount of information or be more beneficial. For example, a random sample may result in 
monitoring of a relatively small straightforward project that would yield limited information, whereas a more sophisticated or complex project might be available for monitoring that would yield more information or be more effective. Sampling would be done at the level of the entire administrative unit to which the resource management applies (e.g., Eugene District or Klamath Falls Resource Area).

The monitoring questions would be evaluated at each monitoring interval to ascertain if the questions, reporting, methods, sample size, or intervals need to be changed. Such changes to the monitoring plan would be accomplished through plan maintenance.

Monitoring results would be reported annually in a Monitoring Report and published as part of the Annual Program Summary. The Monitoring Report would report, track, and assess the progress of plan implementation; state the findings and conclusions made through monitoring; and serve as a report to managers and the public. Monitoring reports would also include any discussions and analysis of noncompliance and recommendations for corrective action.

The use of this monitoring plan by all BLM offices in the planning area would provide a basis for consistent and coordinated monitoring, and allow district information to be compiled and considered at the scale of the entire western Oregon planning area.

\section{Other Monitoring}

The monitoring plan for the Proposed Resource Management Plan is designed to focus specifically on monitoring the resource management plan itself and is not intended as an overarching plan that addresses all ongoing monitoring and research efforts. This monitoring plan does not attempt to address science questions or issues of a regional or interagency scale. There are many ongoing regional, interagency, and research (science-based) efforts in which the BLM participates that address these broader issues. Although these other efforts in which the BLM participates often have important implications for BLM administered lands and resources in western Oregon, they would be addressed externally from this monitoring plan.

\section{Plan Evaluations}

Plan evaluations would occur at five-year intervals. In addition to the monitoring results, many of the underlying assumptions regarding levels of activities and anticipated environmental consequences would be examined at the time of the five-year plan evaluation to determine if the plan objectives are being met or are likely to be met. The evaluation would also assess whether changed circumstances or new information have created a situation in which the expected impacts or environmental consequences of the plan are significantly different than those anticipated in the FEIS. The plan evaluation would make a finding of whether or not a plan amendment or plan revision is warranted.

\section{Adaptive Management}

Adaptive management is not a stand-alone program or process. Adaptive management for the resource management plans would be integrated into NEPA and land use planning processes. See Figure 5-1 (Land use planning, monitoring, and adaptive management). Identified outcomes for the resource management plan are described in the plan's management objectives. Resource management plan monitoring would determine if the objectives are being met or are likely to be met.

In addition to monitoring results, new information or changed circumstances would be evaluated as to whether changes in resource management plan decisions or changes in supporting NEPA analyses were warranted. Adaptive management tools and procedures that would be used to make changes in the plan in response to monitoring information, new information, or changed circumstances include: plan maintenance, plan evaluations, plan amendments and plan revisions. In addition to these planning instruments, NEPA documentation may be necessary. The NEPA procedures relevant to adaptive 
Figure 5-1. Land Use Planning, Monitoring, And Adaptive Management

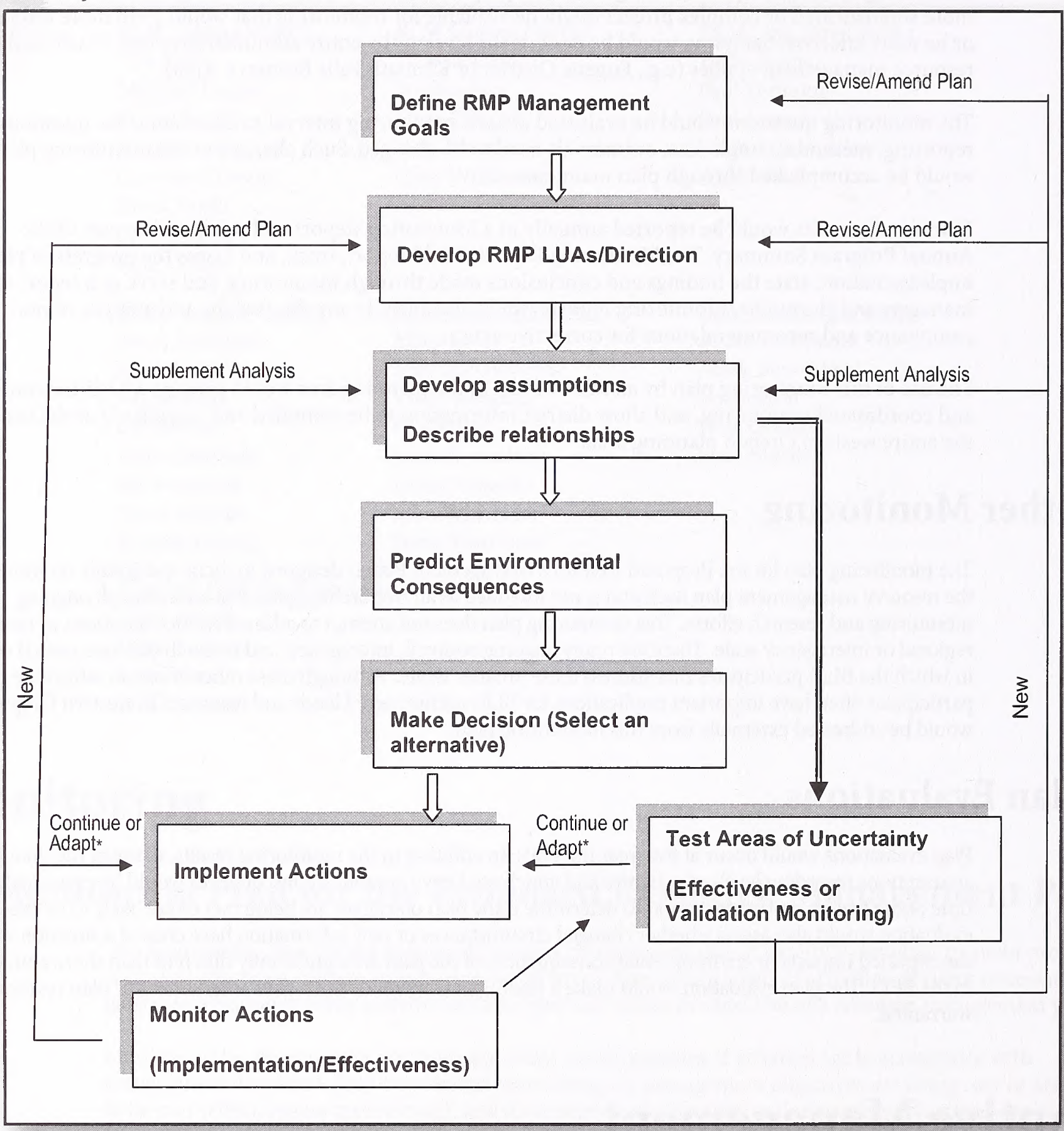

"When monitoring shows the plan is being implemented as written, continue to implement. Where management direction specifically describes the conditions where adaptation is allowable without supplementing, revising, or amending the plan, then adapt the actions. Additionally, the monitoring plan should consider the areas of uncertainty and the sensitivity of assumptions and relationships.

management would include the use of categorical exclusions, determination of NEPA adequacy reviews, environmental assessments, and environmental impact statements. Unscheduled plan evaluations could be conducted to address certain unanticipated events or new information that would call into question the underlying analysis and decisions of the plan.

In some instances, management direction contained in the alternatives provides for a range of activities or resource uses. In these cases, levels of activities or resource uses would vary within the range prescribed by the management action without the use of planning steps or NEPA analyses. The level of activities would 
be adapted within the range given by management action, depending on variation in resource needs or organizational capability.

In addition to the constraints or latitude provided by management direction for the alternatives, the ability to adapt or change management without the use of planning steps or NEPA analyses would be restricted by how much of a departure would be from analytical assumptions in the environmental impact statement. This is because the conclusions regarding environmental consequences are derived from analytical assumptions. Analytical assumptions include such things as levels or methods of activities, number of acres treated, and miles of roads maintained.

If, as a result of the need for adaptive management changes, implementation of the resource management plan would so alter the methods or levels of activities to the degree that the environmental consequences might be substantively different than those anticipated in the environmental impact statement, then formal planning steps and NEPA procedures would be required. The determination as to when formal planning steps and NEPA procedures would be required would be made through the plan evaluation process. Plan evaluations could include an overall resource management plan evaluation such as occurs at five-year intervals or a narrowly focused evaluation of a specific aspect of the resource management plan. Plan evaluations would be scheduled at five-year intervals. Unscheduled plan evaluations could be conducted to address certain unanticipated events or new information, such as a very large wildfire.

Adaptive management would also be applied by acting on information found through the monitoring questions. Adaptive management associated with monitoring would include corrective actions precipitated by findings of non-compliance. Corrective action precipitated by monitoring could range from simple changes in administrative procedures, refinements of the plan through plan maintenance, or more substantive changes through plan amendments.

\section{Monitoring Questions}

Monitoring of certain questions would not take place in the early years of implementation, because projects would not yet have been completed and, therefore, would not be ready for monitoring. Although incomplete projects may be informally examined by managers to assess progress towards implementing management actions and achieving objectives, the evaluation of incomplete projects would not be part of formal plan monitoring. Not all programs or resources have monitoring questions.

\section{Late-Successional Management Area}

M1. Monitoring Question: Has the level of northern spotted owl habitat and marbled murrelet habitat in the Late-Successional Management Areas (LSMAs) been maintained or increased?

Monitoring Requirement: Report acres of management activities and natural disturbance that have reduced the level of habitat in the Late-Successional Management Areas. Report acres of density management designed to promote development of habitat in the Late-Successional Management Areas.

Monitoring Interval: Five years.

M2. Monitoring Question: Are snags and coarse woody debris retained during thinning harvest in the Late-Successional Management Areas in accordance with the resource management plan? 
Monitoring Requirement: At least one completed thinning project in a Late-Successional Management Area. Projects must have been thinned at least five years prior to monitoring.

Monitoring Interval: Annual. Every three years if three consecutive years of monitoring show $100 \%$ compliance.

M3. Monitoring Question: Is timber salvaged after stand-replacing disturbance to recover economic value in the Late-Successional Management Areas?

Monitoring Requirement: $100 \%$ of stand-replacing disturbances over 10 acres.

Monitoring Interval: Annual.

M4. Monitoring Question: Are snags and coarse woody debris retained during salvage in LateSuccessional Management Areas in accordance with the resource management plan?

Monitoring Requirement: $100 \%$ of natural disturbance events. The entire disturbed area would not necessarily need to be evaluated. A sample or subset of the disturbed area may be evaluated.

Monitoring Interval: Annual.

\section{Riparian Management Area}

Water Quality: Surrogates for water quality would be evaluated (e.g., shade - Riparian Management Area width). In addition, water quality would be monitored through Water Quality Management Plans. Although monitoring through Water Quality Management Plans would apply to only those stream miles listed as 303(d) waters, these streams are the among the higher priority waters to be monitored.

Note: Monitoring questions M5 - M9 do not apply to Eastside non-forest lands of the Klamath Falls Resource Area; see M10-M11 for monitoring questions for Eastside non-forest lands.

M5. Monitoring Question: Is the width of the riparian management areas established adjacent to regeneration timber harvest areas in accordance with the resource management plan?

Monitoring Requirement: All streams within at least one completed timber sale.

Monitoring Interval: Annual. Every three years if three consecutive years of monitoring show $100 \%$ compliance.

M6. Monitoring Question: When thinning treatments are applied in riparian management areas along perennial and intermittent fish-bearing streams, is a minimum of $50 \%$ canopy closure retained? Are thinning treatments excluded within 60 feet on either side of the edge of the stream channel as measured from the ordinary high water line?

Monitoring Requirement: All streams treated within at least one completed thinning timber sale.

Monitoring Interval: Annual. Every three years if three consecutive years of monitoring show $100 \%$ compliance.

M7. Monitoring Question: Are thinning treatments excluded within 35 feet on either side of the edge of the stream channel as measured from the ordinary high water line of intermittent non-fish bearing streams? 
Monitoring Requirement: Up to 0.25 mile of stream within thinning projects completed within the past year would be evaluated.

Monitoring Interval: Annual. Every three years if three consecutive years of monitoring show $100 \%$ compliance.

M8. Monitoring Question: Were Best Management Practices that were identified as applicable (as indicated through NEPA decision record or contract stipulations) applied during project implementation?

Monitoring Requirement: At least three projects with identified Best Management Practices would be evaluated. Projects from any land use allocation may be selected for evaluation.

Monitoring Interval: Annual. Every three years if three consecutive years of monitoring show $100 \%$ compliance.

M9: Monitoring Question: For streams with ESA-listed or anadromous fish species, is livestock restricted from riparian areas until 30 days following the emergence of salmonids from spawning beds?

Monitoring Requirement: $100 \%$ of streams with ESA-listed or anadromous fish species within grazing allotments.

Monitoring Interval: Annual. Every three years if three consecutive years of monitoring show $100 \%$ compliance.

Note: Monitoring questions M10 and M11 apply to Eastside Non-Forest Lands of the Klamath Falls Resource Area.

M10. Monitoring Question: Has the amount of streams in proper functioning condition been maintained or increased?

Monitoring Requirement and Monitoring Interval: Monitoring and reporting would be through the use of the statewide report, Table 1 from USDI TR-1737-9 1993 (or similar), of lotic and lentic water bodies in properly functioning; functioning at risk with trend up, down or not apparent; and not properly functioning. (Note: Table 1 is available online, with instructions, at http://www.blm.gov/nstc/ library/techref.htm and is also provided below for reference purposes.)

\section{Table 1. Functioning Condition Status}

State:

\begin{tabular}{|c|c|c|c|c|c|c|c|}
\hline \multirow{2}{*}{$\begin{array}{l}\text { Habitat } \\
\text { Types }\end{array}$} & \multirow{2}{*}{$\begin{array}{c}\text { Proper } \\
\text { Functioning } \\
\text { Condition }\end{array}$} & \multicolumn{3}{|c|}{ Functional - At Risk } & \multirow[t]{2}{*}{ Non-functional } & \multirow[t]{2}{*}{ Unknown } & \multirow[t]{2}{*}{ Total } \\
\hline & & $\begin{array}{l}\text { Trend } \\
\text { Up }\end{array}$ & \begin{tabular}{|l} 
Trend Not \\
Apparent
\end{tabular} & \begin{tabular}{|l} 
Trend \\
Down
\end{tabular} & & & \\
\hline $\begin{array}{l}\text { Riverine } \\
\text { Miles } \\
\text { (Lotic) }\end{array}$ & & & & & & & \\
\hline $\begin{array}{l}\text { Nonriverine } \\
\text { Acres } \\
\text { (Lentic) }^{*}\end{array}$ & & & & & & & \\
\hline
\end{tabular}


M11. Monitoring Question: For streams with ESA-listed or anadromous fish species, are livestock restricted from riparian areas until 30 days following the emergence of salmonids from spawning beds?

Monitoring Requirement: $100 \%$ of streams with ESA-listed or anadromous fish species within grazing allotments.

Monitoring Interval: Annually for first three years of RMP implementation, and then every three years if results show $100 \%$ compliance.

\section{Eastside Forest Management Area}

M12. Monitoring Question: Are snags and coarse woody debris retained in accordance with resource management plan requirements?

Monitoring Requirement: At least one completed timber sale would be evaluated.

Monitoring Interval: Annual. Every three years if three consecutive years of monitoring show $100 \%$ compliance.

\section{Uneven-Age Management Area}

M13. Monitoring Question: Is a relative density (Curtis) of 25 and 55 (for Eastside Forest Management Area a relative density of 15 to 55) inclusive of any group selections maintained during group selection, commercial thinning, or density management conducted for the removal and sale of timber and biomass? (The overstory component of the stand would be used to measure relative density.)

Monitoring Requirement: One completed timber sale would be evaluated.

Monitoring Interval: Annual. Every three years if three consecutive years of monitoring show 100\% compliance.

\section{Deferred Timber Management Area}

M14. Monitoring Question: Has the level of older, more structurally complex, multi-layered conifer forests been maintained until the year 2023 ?

Monitoring Requirement: Report acres of management activities and natural disturbance that has reduced the acres of forest 160 years old or older. (The use of 160-year old stands is a surrogate for older, more structurally complex, multi-layered conifer forests.)

Monitoring Interval: Every five years.

\section{Timber Management Area and Uneven-Age Management Area}

M15. Monitoring Question: Has the allowable sale quantity been offered for sale within the variation provided for in the plan?

Monitoring Requirement: Report annual sale quantity offered for sale and the cumulative total since approval of the plan.

Monitoring Interval: Annual. 


\section{Timber Management Area}

M16. Monitoring Question: Has timber volume from regeneration harvest and commercial thinning been offered for sale in the quantities specified in the resource management plan?

Monitoring Requirement: Report volume of regeneration harvest and volume of commercial thinning offered for sale.

Monitoring Interval: Annual.

\section{Air}

M17. Monitoring Question: Have smoke intrusions occurred in areas designated as Class I for air quality and non-attainment occurred as a result of BLM prescribed fire?

Monitoring Requirement: Report intrusions through Oregon Department of Forestry data.

Monitoring interval: Annual.

\section{Areas of Critical Environmental Concern and Research Natural Areas}

M18. Monitoring Question: Are important and relevant values being maintained or restored?

Monitoring Requirement: Report $20 \%$ of the Areas of Critical Environmental Concern and Research Natural Areas.

Monitoring Interval: The monitoring of Areas of Critical Environmental Concern and Research Natural Areas would be rotated, providing for $100 \%$ of the areas to be monitored over a 5 -year period.

\section{Botany}

M19. Monitoring Question: Is management of species that are listed under the Endangered Species Act consistent with recovery plans and designated critical habitat?

Monitoring Requirement: At least five completed projects that "may affect" listed species would be reviewed after completion.

Monitoring Interval: Annual. Every three years if three consecutive years of monitoring show $100 \%$ compliance.

M20. Monitoring Question: Have protection measures maintained populations of BLM special status plant and fungi species?

Monitoring Requirement: At least five completed projects in which protection measures were implemented to accommodate BLM special status plant and fungi species.

Monitoring Interval: Annual. 


\section{Cultural and Paleontological Resources Including American Indian Traditional Uses}

M21. Monitoring Question: Were sites located within project areas after the commencement of grounddisturbing activities?

Monitoring Requirement: At least $20 \%$ of management activities that involve ground disturbance that have been completed within the past year would be evaluated.

Monitoring Interval: Annual.

M22. Monitoring Question: Have ground-disturbing actions avoided sites that are listed (or eligible for listing) on the National Register of Historic Places?

Monitoring Requirement: 100 percent of avoided listed or eligible sites that lie within the boundaries of a ground-disturbing project after the project is completed.

Monitoring Interval: Annually when listed or eligible sites are present and avoidance prescribed.

M23. Monitoring Question: Are sites with scientific value salvaged prior to disturbance (when disturbance cannot be practically avoided) through practices such as data recovery, including excavation, relocation, or documentation?

Monitoring Requirement: 100 percent of data recovery actions undertaken to salvage site data at risk of loss from ground disturbing management activities that have been completed within the past year.

Monitoring Interval: Annual.

M24: Monitoring Question: Are cultural and paleontological resources that are threatened by natural processes or human activity excavated and the data recovered where warranted by the scientific importance of the site?

Monitoring Requirement: 100 percent of management activities that have been completed within the past year.

Monitoring Interval: Annual.

\section{Energy and Minerals}

M25. Monitoring Question: Has the level of opportunities for the exploration and development of locatable, leasable, and salable energy and mineral resources, and for casual mineral prospecting, been maintained?

Monitoring Requirement: Report new withdrawals.

Monitoring Interval: Five years. 


\section{Fire and Fuels Management}

M26. Monitoring Question: What is the net change in fire hazard to communities at risk, and risk of uncharacteristic wildfires as indicated by changes in fire regime condition class caused by fuel treatments and timber harvest?

Monitoring Requirement: Report total acres and wildland urban interface acres of positive and negative change in fire regime condition class resulting from fuel treatments and timber harvest.

Monitoring Interval: Annual for Medford District and Klamath Falls Resource Area; semi-annual for Roseburg, Coos Bay, Eugene and Salem Districts.

\section{Grazing}

Note: Monitoring questions M27 and M28 apply only to the Medford District and the Klamath Falls Resource Area of the Lakeview District.

M27. Monitoring Question: Has the condition of public rangelands been maintained or improved compared to the baseline year of 2008 ?

Monitoring Requirement and Monitoring Interval: Grazing allotments are assigned to one of three management categories: (I) Improve (M) Maintain, and (C) Custodial. In "I" category allotments, examine trend plots every five years, determine condition every 10 years, and record utilization data every other year. In " $M$ " allotments, determine trend and condition every 5-10 years, and utilization every 5 years. Monitoring in " $\mathrm{C}$ " allotments is limited to periodic inventories and observations to measure long-term resource condition changes.

M28. Monitoring Question: Are areas disturbed by natural and human-induced events (including wildland fire, prescribed burns, timber-management treatments, and juniper cuts) rested from livestock grazing and resumed after soil and vegetation has recovered sufficient to support livestock grazing (except where grazing would either not impede site recovery, or where grazing could be used as a tool to aid in achieving recovery objectives)?

Monitoring Requirement: Ten percent of disturbance events.

Monitoring Interval: Annual. Every three years if three consecutive years of monitoring show 100\% compliance.

\section{Hazardous Materials}

M29. Monitoring Question: Has the response to hazardous material incidents included cleanup, proper notifications, criminal investigations, and site assessments as applicable?

Monitoring Requirement: 100 percent of hazardous material incidents.

Monitoring Interval: Annual. 
M30. Monitoring Question: Are hazardous materials stored, treated, and disposed of in accordance with applicable laws and regulations?

Monitoring Requirement: 100 percent of District-stored, treated and disposed hazardous materials. Monitoring Interval: Annual.

\section{Lands, Realty, Access, and Transportation}

M31. Monitoring Question: Have the acres of $\mathrm{O} \& \mathrm{C}$ lands of all classifications and the acres of $\mathrm{O} \& \mathrm{C}$ and public domain lands that are available for harvesting been reduced through disposal, exchange, or purchase?

Monitoring Requirement: Review of all O\&C lands records through the Oregon State Office. Total net change in land tenure of $\mathrm{O} \& \mathrm{C}$ lands in the planning area would be evaluated at 10 -year intervals keyed from 1998, the date of the legislation that provides for no net loss of O\&C lands.

Monitoring Interval: Three years.

\section{Recreation}

M32. Monitoring Question: Are special recreation management areas managed in accordance with their planning frameworks?

Monitoring Requirement: Report on $20 \%$ of the special recreation management areas.

Monitoring Interval: Annual. The monitoring of special recreation management areas would be rotated so that over a five-year period $100 \%$ of the areas would be monitored.

\section{Visual Resource Management}

M33. Monitoring Question: Is the level of change in character for the areas designated to be managed as VRM I, II, and III consistent with resource management plan requirements?

Monitoring Requirements: Twenty percent of activities that have the potential to affect the existing character in VRM I, II, and III.

Monitoring Interval: Annual. Every three years if three consecutive years of monitoring show $100 \%$ compliance.

\section{Wild Horses}

M34. Monitoring Question: Is the population of wild horses maintained at the appropriate management level of 30 to 50 head?

Monitoring Requirement: Population survey or census.

Monitoring Interval: Five years. 
M35. Monitoring Question: Are horses from other herd areas periodically introduced to the Pokegama herd to maintain the genetic diversity of the herd?

Monitoring Requirement: Report all introductions.

Monitoring Interval: Five years.

M36. Monitoring Question: Are water developments maintained or established to provide season-long water for wild horses within the herd management area?

Monitoring Requirement: 100 percent of water developments.

Monitoring Interval: Annual. Every three years if three consecutive years of monitoring show $100 \%$ compliance.

\section{Wilderness Characteristics}

M37. Monitoring Question: Are wilderness characteristics maintained in accordance with resource management plan requirements?

Monitoring Requirements: Report all management activities that would adversely affect wilderness characteristics to be maintained under the RMP, Wilderness Study Areas and Wilderness Areas.

Monitoring Interval: Three years.

\section{Wild and Scenic Rivers}

M38. Monitoring Question: Are the outstandingly remarkable values of designated wild and scenic river corridors (including those classified as wild, scenic, or recreational) being maintained?

Monitoring Requirements: 100 percent of BLM-authorized activities that have the potential to affect the outstandingly remarkable values of wild and scenic rivers.

Monitoring Interval: Annual. Every three years if three consecutive years of monitoring show 100\% compliance.

\section{Wildlife}

M39. Monitoring Question: Is management of species that are listed under the Endangered Species Act consistent with recovery plans and designated critical habitat?

Monitoring Requirement: At least five completed projects that "may affect" listed species would be evaluated.

Monitoring Interval: Annual. Every three years if three consecutive years of monitoring show $100 \%$ compliance. 
M40. Monitoring Question: Has seasonal motor vehicle use been restricted for deer and elk in areas identified in the RMP?

Monitoring Requirements: Review of district records.

Monitoring Interval: Annual. Every three years if three consecutive years of monitoring show $100 \%$ compliance.

\section{Program Reporting Items}

Program reporting items involve activities that are either related to: (1) certain analytical assumptions that are pertinent to non-specific management actions; or (2) analytical assumptions pertinent to the analysis of environmental consequences in the PRMP/FEIS. Not all programs or resources have reporting items.

\section{Late-Successional Management Area}

R1. Program Reporting Item: Report the acres of thinning harvest applied to promote mature or structurally complex forests in the Late-Successional Management Areas. Reporting would be annual.

\section{Riparian Management Area}

Note: Program Reporting Items R2-R5 do not apply to Eastside non-forest lands of the Klamath Falls Resource Area; see Program Reporting Items R6-8 for Eastside non-forest lands.

R2. Program Reporting Item: Report the number of fish-passage blockages that have been corrected and the number of resulting miles of stream habitat that are newly accessed. Reporting would be annual.

R3. Program Reporting Item: Report the acres of thinning and other silvicultural treatments to promote development of large trees. Reporting would be annual.

R4. Program Reporting Item: Report the miles of permanent road construction, road renovation, road improvement, and road decommissioning. Reporting would be annual.

R5. Program Reporting Item: Report the overall level of stream and riparian restoration activities (such as placement of large wood and boulders in streams, planting, thinning, etc.). Report the level of stream restoration activities in high intrinsic potential streams, or streams with high priority fish populations. Reporting would be annual.

Note: Program Reporting Items R6-R8 apply to Eastside Non-Forest lands of the Klamath Falls Resource Area.

R6. Program Reporting Item: Report the number of fish-passage blockages that have been corrected and the number of resulting miles of stream habitat that are newly accessed. Reporting would be annual.

R7. Program Reporting Item: Report miles of road restoration and road decommissioning. Reporting would be annual.

R8. Program Reporting Item: Report the overall level of stream and riparian restoration activities such as placement of large wood and boulders in streams. Report the level of stream restoration activities in high intrinsic potential streams or streams with high priority fish populations. Reporting would be annual. 


\section{Eastside Forest Management Area}

R9. Program Reporting Item: Report the acres of group selection, commercial thinning, density management, and regeneration harvest. Reporting would be annual.

\section{Uneven-Age Management Area}

R10. Program Reporting Item: Report the acres of group selection, commercial thinning, density management, and regeneration harvest. Reporting would be annual

\section{Timber Management Area}

R11. Program Reporting Item: Report the acres of stand conversion from undesirable tree species or an inadequate stocking of commercially desirable tree species. Reporting would be annual.

R12. Program Reporting Item: Report the acres of precommercial thinning, fertilization and pruning. Reporting would be annual.

R13. Program Reporting Item: Report the acres of regeneration harvest and commercial thinning offered for sale. Reporting would be annual.

R14. Program Reporting Item: Report the volume of non-ASQ timber offered for sale. Reporting would be annual.

\section{Botany}

R15. Program Reporting Item: Report the acres of activities designed to maintain or restore natural plant communities on non-forest and non-commercial lands. Reporting would be annual.

\section{Invasive Plants}

R16. Program Reporting Item: Report the acres of manual, mechanical, cultural, chemical, and biological treatments used to manage invasive plant infestations. Reporting would be annual.

\section{Energy and Minerals}

R17. Program Reporting Item: Report number of biomass utilization projects. Reporting would be annual.

\section{Fire and Fuels Management}

R1 8. Program Reporting Item: Report number of acres of hazardous fuels treatments.

\section{Grazing}

R19. Program Reporting Item: Report the findings of grazing allotments towards meeting the Standards for Rangeland Health and Guidelines for Livestock Grazing Management for Public Lands Administered by the Bureau of Land Management in the States of Oregon and Washington. Reporting would be annual. 
R20. Program Reporting Item: Report the acres of prescribed livestock grazing used to control invasive plants, reduce fire danger, or accomplish other management objective. Reporting would be annual.

R21. Program Reporting Item: Report the acres or number of range improvements. Reporting would be annual.

\section{Socioeconomic}

R22. Program Reporting Item: Report the payments to counties associated with BLM-administered lands including O\&C, Coos Bay Wagon Roads, and Public Domain lands. Reporting would be annual.

R23. Program Reporting Item: Report receipts from timber sales, special forest products, recreation and permits. Reporting would be annual.

R24. Program Reporting Item: Report appropriations; number of full time and temporary employees; and major new facility developments or improvements. Reporting would be annual.

\section{Recreation}

R25. Program Reporting Item: Report the number of service-oriented and outreach programs, including interpretation and education provided to visitors.

R26. Program Reporting Item: Report the status of development of comprehensive travel management plans for off-highway vehicle areas and off-highway vehicle emphasis areas.

\section{Research}

R27. Program Reporting Item: Provide a narrative update on status, goals, and findings of research projects in support of the management of lands and resources administered by the BLM.

\section{Special Forest Products}

R28. Program Reporting Item: Report the number of permits for harvest and collection of special forest products. Reporting would be annual.

\section{Soils}

R29. Program Reporting Item: Report the number of projects and acres in which there was greater than 15 percent of the acres treated that had detrimental soil disturbance resulting from ground-based timber harvest. Reporting would be based on evaluation of at least $20 \%$ of the total ground based timber harvest acres. Reporting would be annual. Fifteen percent detrimental soil disturbance is not a plan decision (management direction), but rather an approximate level used as analytical assumption in the FEIS. Detrimental soil disturbance in this context means areas in which the top soil has been removed, the subsoil structure severely altered and the slash deeply incorporated into the soil and which have not been or will not be ameliorated. 


\section{Wildlife}

R30. Program Reporting Item: Report number of deer and elk forage planting projects. Reporting would be annual.

R31. Program Reporting Item (pertinent to Klamath Falls Resource Area): Report acres of thinning or removal of encroaching western juniper to maintain and improve forage for big game. Reporting would be annual.

\section{Guidance for Use of the Completed Resource Management Plans}

This section provides guidance on how the plans will be implemented, evaluated, and changed by the districts.

\section{Requirement for Further Environmental Analysis}

The BLM makes many types of decisions. It is important to distinguish between land use plan decisions and implementation decisions because: (1) the administrative remedies and the timing of those remedies differ; (2) the NEPA analysis necessary to support implementation decisions is generally more site specific than the analysis necessary to support land use plan decisions; (3) the authority to make these types of decisions varies; and (4) the scope and effect of each type of decisions would be considered during the compliance and consultation proceedings required under various environmental laws.

- Land use plan decisions consist of desired outcomes (goals, standards, objectives), allowable uses (land use allocations, levels of use, restrictions on uses), and management direction necessary to achieve the outcomes.

- Implementation decisions are actions to implement land use plans. These types of decisions are based on site-specific planning and NEPA analyses. Examples of implementation decisions include: offering a specific tract of timber for sale, applying a vegetation treatment, offering a specific oil or gas lease for sale, application for a permit to drill (APDs), selling an individual grazing lease or processing a specific permit application, designating specific roads and trails as open or closed to motorized travel, or completing a specific land exchange.

These revised resource management plans only provide direction for the management of natural resources on BLM-administered lands. These plans do not authorize the implementation of any specific project-level actions. Decisions on which projects, including specific on-the-ground locations and timing of a project, will be made subsequent to the adoption of this revision to the Resource Management Plans. Decisions on specific projects will be made by BLM employees delegated to make those decisions after compliance with National Environmental Policy Act and Endangered Species Act consultation has been completed.

\section{Plan Evaluation}

Evaluation is the process of reviewing the land use plan to determine whether plan decisions are being implemented as expected, and whether the associated NEPA analyses are still valid. Based on this evaluation, a determination is made whether a plan amendment or revision is warranted. Land use plans are evaluated to determine if:

1. decisions remain relevant to current issues

2. decisions are effective in achieving (or making progress toward achieving) desired objectives 
3. any decisions need to be revised

4. any decisions need to be dropped from further consideration

5. any areas require new decisions

The plan would be formally evaluated every 5 years, or as necessitated by changed circumstances or significant new information. These evaluations would be focused on issues resulting from monitoring or new information.

The evaluation would also review major assumptions regarding the level of management activities used in the analysis of effects for the Final EIS. Much of the data needed for evaluating these assumptions related to anticipated levels of activity will have been collected through program reporting associated with the RMP monitoring plan.

Unscheduled plan evaluations could be conducted to address certain unanticipated events or new information that would call into question the underlying analysis and decisions of the plan. These unscheduled plan evaluations may examine a single or relatively narrow aspect of the RMP.

\section{Plan Maintenance}

Land use plan decisions can be maintained to reflect minor changes in data. Maintenance is limited to further refining, documenting, or clarifying a previously approved decision. Plan maintenance would not expand the scope of resource uses or restrictions or change the terms, conditions, and decisions of the approved plan. Plan maintenance may be used to adjust the annual sustained yield capacity base on updated operations inventory data.

\section{Plan Amendments}

New information, updated analyses, or new resource use or protection proposals may require amending or revising land use plans and updating implementation decisions. Re-examining existing plan decisions or the PRMP/FEIS analysis would be appropriate if new information becomes available or circumstances occur that could significantly alter the underlying conclusions of the FEIS regarding environmental consequences or the ability to achieve management objectives.

Plan amendments change one or more of the terms, conditions, or decisions of an approved land use plan. Plan amendments are most often prompted by the need to:

- consider a proposal or action that does not conform to the plan

- implement new or revised policy that changes land use plan decisions, such as an approved conservation agreement between the BLM and the USFWS

- respond to new, intensified, or changed uses on public land

- consider significant new information from resource assessments, plan evaluations, monitoring, or scientific studies

Plan amendments would follow BLM planning regulations and can be accompanied by either an environmental assessment or environmental impact statement.

\section{Plan Revisions}

Resource management plan revisions involve preparation of a new plan to replace an existing one. An RMP revision would be necessary if monitoring and evaluation findings, new data, new or revised policy, or changes in circumstances indicate that decisions for an entire plan or a major portion of the plan would no longer serve as a useful guide for resource management. Plan revisions are accomplished through the BLM planning regulations and are accompanied by an environmental impact statement. 


\section{Valid Existing Rights}

Considering the intermingled nature of the $\mathrm{O} \& \mathrm{C}$ lands in the planning area, an immense number of rightsof-way, leases, corridors, and other established legal rights have been granted over the years in establishing an effective cooperative management framework among a variety of owners. Perhaps the most extensive and unique rights are the reciprocal rights-of-way agreements with dozens of adjacent landowners established to provide for the logical, effective, and efficient development of access on the intermingled lands. Mining claims, water rights, and county roads are other examples. When implementing resource management plans, it is recognized there are some instances when actions that may occur on public lands are subject to these valid existing rights. In those cases, authorization for implementing an action may be subject to approval by the holders of valid existing rights and may not be discretionary to BLM.

\section{Management of Newly Acquired Lands}

Lands may come under BLM administration after completion of the RMP/ROD through exchange, donation, purchase, revocation of withdrawals to other federal agencies or relinquishment of Recreation and Public Purpose leases. Discretionary acquisitions (such as exchanges) would be guided by RMP/ROD "lands acquisition criteria" based on resource values of high public interest.

Newly acquired or administered lands or interests in lands would be managed for their highest potential or for the purposes for which they are acquired. For example, lands acquired within the boundary of a "special management area" with Congressional or RMP allocations/direction would be managed in conformance with management objectives and guidelines for that area. Lands acquired outside of designated special management areas would be managed in the same manner as comparable or adjacent BLM-administered lands. In western Oregon, this implies forest management activities, including timber harvest, management of the mineral estate, and standard operating procedures and pre-committed mitigation measures.

If lands with unique or fragile resource values are acquired outside of special management areas, it may be appropriate to protect those values until the next plan revision. Lands acquired adjacent to or within existing or proposed withdrawals identified in this plan that possess similar critical resource values would be proposed for withdrawal. Newly acquired lands, regardless of status, would be subject to non-discretionary access rights provided for under the terms and conditions of most reciprocal right-of-way agreements and permits.

In accordance with Section 205 (e) of FLPMA (P.L. 99-632), lands acquired by the BLM in exchange for O\&C or Coos Bay Wagon Road (CBWR) lands would have the same status and be administered in accordance with the same provisions of law applicable to those lands disposed of; and those newly acquired lands would be designated as O\&C or CBWR lands, as appropriate, and managed under the sustained yield principles as prescribed in the Act of August 28,1937 and other laws applicable to the O\&C or CBWR lands. Additionally, lands acquired using proceeds generated from the disposal of O\&C or CBWR lands under the authority of the Federal Land Transaction Facilitation Act (Public Law 106-248) would also take on the same status as the lands from which the funds were generated (O\&C or CBWR) and would likewise be managed in accordance with the Act of August 28, 1937 and other applicable laws.

Lands acquired by the BLM that take on the status of either O\&C or CBWR would require classification in accordance with the Act of June 9, 1916 as to power-site, timberlands, or agricultural lands. Lands classified as timberland or agriculture would be open to exploration, location, entry and disposition under the general mining laws in accordance with the Act of April 8, 1948. Lands acquired by the BLM under Section 205 or 206 of FLPMA take on the status of "acquired lands," and therefore would not be available for location, lease, or sale until the land is formally opened to such entry.

Land acquisitions resulting in net adjustments in the commercial forestland base may be made without adjusting the allowable sale quantity or amending the resource management plan. 
FEIS for the Revision of the Western Oregon RAPs

Chapter $5-898$ 


\section{Acronyms}

This chapter provides the main acronyms used in the document. Acronyms are used for brevity purposes and appear primarily in tables and figures.

$\begin{array}{ll}\text { ACEC } & \text { area of critical environmental concern } \\ \text { ASQ } & \text { allowable sale quantity } \\ \text { AUM } & \text { animal unit month } \\ \text { bf } & \text { board foot or board feet } \\ \text { BLM } & \text { Bureau of Land Management } \\ \text { CBWR } & \text { Coos Bay Wagon Road } \\ \text { CFR } & \text { Code of Federal Regulations } \\ \text { CHU } & \text { critical habitat unit } \\ \text { CWD } & \text { coarse woody debris } \\ \text { cfs } & \text { cubic feet per second } \\ \text { dbh } & \text { diameter at breast height } \\ \text { DEM } & \text { Digital elevation model } \\ \text { EIS } & \text { environmental impact statement } \\ \text { EPA } & \text { Environmental Protection Agency } \\ \text { ERMA } & \text { extensive recreation management area } \\ \text { FEMAT } & \text { Forest Ecosystem Management Assessment Team } \\ \text { FLPMA } & \text { Federal Land Policy and Management Act } \\ \text { FLTFA } & \text { Federal Land Transaction Facilitation Act } \\ \text { GIS } & \text { geographical information system } \\ \text { HLB } & \text { harvest land base } \\ \text { HMA } & \text { herd management area } \\ \text { IVMPency vegetation mapping project }\end{array}$




\begin{tabular}{|c|c|}
\hline $\mathrm{km}$ & kilometer \\
\hline LSMA & late-successional management area \\
\hline LSR & late-successional reserve \\
\hline LUA & land use allocation \\
\hline $\mathrm{Mbf}$ & thousand board feet \\
\hline $\mathrm{mmbf}$ & million board feet \\
\hline NLCS & National Landscape Conservation System \\
\hline NSO & northern spotted owl \\
\hline NWFP & Northwest Forest Plan \\
\hline $\mathrm{O} \& \mathrm{C}$ & Oregon and California Lands Act \\
\hline $\mathrm{OHV}$ & off-highway vehicle \\
\hline ONA & Outstanding natural area \\
\hline PRMP & Proposed resource management plan \\
\hline $\mathrm{R} \& \mathrm{PP}$ & recreation and public purpose \\
\hline RMP & resource management plan \\
\hline RNA & research natural area \\
\hline $\mathrm{ROD}$ & record of decision \\
\hline SRMA & special recreation management area \\
\hline USFS & United States Forest Service \\
\hline VRM & visual resource management \\
\hline WOPR & western Oregon plan revisions \\
\hline
\end{tabular}




\section{Glossary}

This chapter provides the definitions of terms used in this document that cannot be found in a standard dictionary.

3P fall, buck, and scale sampling

303(d) Water Quality Listing

acre

active stream channel

activity fuel

adaptive management

Adaptive Management Area
A sampling method that determines the volume and value of merchantable timber. The method starts with visual estimation of a stand using the 3P sampling method (i.e., PPP, or, probability proportional to prediction), which operates under the assumption that the probability of a tree being sampled is proportional to its predicted occurrence in a stand. The estimation is verified by cutting down a sampled tree (fall), cutting it into merchantable log lengths (buck), and measuring the logs (scale) noting indicators for defects and log grades. For managed second-growth stands, 3P sampling is generally used to develop volume tables from which stand volumes may be extrapolated. For unevenaged stands, typically containing larger and often more defective timber, $3 \mathrm{P}$ sampling is useful in determining the net volume (recovery).

Impaired waters that do not meet water quality standards, identified by DEQ, as required by the Clean Water Act.

A measure of surface land area in U.S. customary units that is 43,560 square feet, which is $1 / 640$ of a square mile (or approximately 0.4 hectares). If square, it is nearly 209 feet on each side.

The inundated area of bed and banks of a stream, from larger streamflow of one to two years.

Debris (wood chips, bark, branches, limbs, logs, or stumps) left on the ground after management actions, such as logging, pruning, thinning, or brush cutting, versus debris left after storms or fires.

A forest management methodology that continually monitors, evaluates, and adjusts decisions and management actions to improve implementation and to ensure that the goals and objectives of resource management plans are being met.

A Northwest Forest Plan term that denotes a land use allocation (or landscape unit) whose lands are designated for development and for testing technical and social approaches for achieving desired ecological, economic, and other social objectives. 
adverse modification

age classification

aggregated retention

allowable sale quantity/annual productive capacity

alternative

anadromous fish

analysis

analytical assumption

angular canopy density

animal unit month (AUM)

annual productive capacity
An Endangered Species Act term that is not specifically defined by the act but is generally accepted to denote a direct or indirect alteration of habitat that appreciably diminishes the value of an area with respect to the survival, or in some instances the recovery, of a listed species. In most instances, this standard is considered the same as, or is nearly identical, to the jeopardy standard.

A system that categorizes trees, forests, stands, or forest types by intervals of years. Age classifications differ around the U.S. by forest type (wet, dry, evergreen, deciduous, or succulent). For this analysis, the interval is usually 10 -year increments.

See variable-retention harvest system.

These terms are synonymous. The timber yield that a forest can produce continuously under the intensity of management outlined in the RMP from those lands allocated for permanent forest production.

One of several proposed management actions that have been studied and found to meet the goals and objectives of a project's purpose and need and, as a result, is suitable to aid decisionmaking.

Fish that are born and reared in freshwater, move to the ocean to grow and mature, and return to freshwater to reproduce. Includes species such as salmon and steelhead. Also see salmonid.

The scientific evaluation of the environmental impacts of proposed planning decisions. The BLM employs many types of analysis (e.g., surface, linear, raster, contiguity, and topological overlay) with a variety of data sets (e.g., inventory and GIS) and tools (e.g., physical, quantitative, data, and spatial modeling).

A judgmental decision that is based on the science and relationships of natural systems assumed to be true and from which conclusions can be drawn to supply the missing values, relationships, or societal preferences needed for proceeding with an analysis of alternatives.

A measure of shade provided by riparian vegetation. It is the density of the canopy, expressed as a percent, measured along the path of incoming solar radiation between the sun and a stream.

The amount of forage necessary to sustain one cow (or its equivalent) for one month.

An O\&C Act term denoting the volume of timber that is determined will grow in one year in a given area. Also see allowable sale quantity (ASQ), offer, and sustained yield capacity. 
Aquatic Conservation Strategy

aquatic habitat

area

\section{Area of Critical Environmental Concern (ACEC)}

\section{Area of Mutual Interest}

assessment area

at-risk species

at-risk community

authority

awarded timber sales

backcountry byways

basal area
A Northwest Forest Plan methodology designed to restore and maintain the ecological health of watersheds and aquatic ecosystems, consisting of four components: riparian reserves, key watersheds, watershed analysis, and watershed restoration.

Habitat for vertebrate and invertebrate wildlife species and vascular and non-vascular plants occurring in free water (e.g. lakes, ponds, streams, rivers, springs and seeps).

A generic forestry term that refers to the surface land included within specific boundaries and usually allocated for a specific purpose, such as a late-successional management area, a timber management area, a traditional use area, a recreational use area, or a wilderness area. Contrast with block.

Land where special management attention is needed to protect life, to provide safety from natural hazards, or to prevent irreparable damage to important values (historic, cultural, or scenic), resources (fish and wildlife), or processes (natural systems).

A defined mapped area, identified by industry, of potential petroleum development.

A subdivision of a sustained yield unit (BLM district) that has been divided by physiographic provinces.

Species that are determined by a detailed assessment to be in danger of becoming locally or completely extinct.

A group of homes or structures that exist within the vicinity of federal lands or a wildland/urban interface for which a significant threat to human life or property exists as a result of a wildland fire.

The right and power to make decisions and give orders such as the United States Congress exerts when passing legislation (e.g. the O\&C Act and the Endangered Species Act).

A sale where the government has accepted a bid from a qualified high bidder, thereby binding the government and granting specific rights to the purchaser.

A road segment designated as part of the National Scenic Byway System.

The cross-sectional area of a single stem, of all stems of a species in a stand, or of all plants in a stand (including the bark) that is measured at breast height (about 4.5 feet up from the ground) for larger plants (like trees) or measured at ground level for smaller plants. 
baseline

beneficial use

Best Management Practices (BMPs)

biological assessment

biological opinion

biomass

block
The starting point for the analysis of environmental consequences, often referred to as the Affected Environment. This starting point may be the condition at a point in time (e.g., when inventory data is collected) or the average of a set of data collected over a specified number of years. Also see analysis, environmental consequences, and inventory data.

In general, any reasonable use of a resource for a purpose consistent with the laws and best interests of the people of a state. In water use law, such uses include, but are not limited to: instream, out of stream, and ground water uses; domestic, municipal, and industrial water supplies; mining, irrigation, and livestock watering; fish and aquatic life; wildlife watering; fishing and water contact recreation; aesthetics and scenic attraction; hydropower; and commercial navigation.

BMPs are defined as methods, measures, or practices selected on the basis of site-specific conditions to ensure that water quality will be maintained at its highest practicable level. BMPs include, but are not limited to, structural and nonstructural controls, operations, and maintenance procedures. BMPs can be applied before, during, and after pollution-producing activities to reduce or eliminate the introduction of pollutants into receiving waters (40 CFR 130.2, EPA Water Quality Standards Regulation).

A biological assessment is a document that evaluates potential effects of a proposed action to listed and proposed species and designated and proposed critical habitat and determines whether any such species or habitats are likely to be adversely affected by the action. It is used in determining whether formal consultation or conferencing with the U.S. Fish and Wildlife Service or National Marine Fisheries Service is necessary (50 CFR 402.12[a] )

An opinion by the U. S, Fish and Wildlife Service or the National Marine Fisheries Service as to whether or not a federal action is likely or not to jeopardize the continued existence of listed species, or would result in the destruction of or adverse modification of critical habitat. The opinion may contain reasonable and prudent alternatives, a statement of anticipated take of listed animals, and conservation recommendations for listed plants.

Unmerchantable and waste plant materials used as a source of renewable combustible fuel. Also includes non-sawlog material ground up into fiber and used in secondary wood products.

A term that denotes an area of land that has been approved for special management, such as a northern spotted owl reserve or a fire suppression area. Contrast with area. 
board foot

Bureau Strategic Species

Bureau of Land Management (BLM)

\section{Bureau Sensitive Species}

candidate species

canopy

canopy closure

catchment

channel migration zone
A unit of measure for unfinished solid wood used by the lumber industry that is typically expressed as bf or bd. $\mathrm{ft}$. and equals the volume contained in a 1 -inch thick, 12 -inch long, and 12-inch wide board.

A special status species category established by the Oregon/ Washington BLM that includes animal, plant and fungi species that are of concern in the two states. The special status species policy (BLM 6840) does not apply to these species, and no analysis of them is required in NEPA documents. Field units are required to collect occurrence field data and maintain records. Also see Bureau sensitive species.

A federal agency within the U.S. Department of the Interior that is responsible for administering 261 million surface acres of federally owned lands in accordance with all applicable laws to sustain the health, diversity, and productivity of those lands. Most of the acreage is in Alaska and the western states.

A special status species category established by the BLM that includes those plant and animal species eligible for status as federally listed, federal candidate, state listed, or state candidate (plant) species; on List 1 of the Oregon Natural Heritage Database or approved for this category by the BLM state director; or included under agency species conservation policies. Also see Bureau strategic species.

Plants and animals for which the U.S. Fish and Wildlife Service has sufficient information on their biological status and threats to propose them as endangered or threatened under the Endangered Species Act (ESA), but for which development of a proposed listing regulation is precluded by other higher priority listing activities.

The more or less continuous cover of branches and foliage formed collectively by adjacent trees and other woody species in a forest stand. Where significant height differences occur between trees within a stand, formation of a multiple canopy (multi-layered) condition can result.

The ground area covered by the crowns of trees or woody vegetation as delimited by the vertical projection of crown perimeter and commonly expressed as a percent of total ground area.

An area drained by a stream. For research, a very small experimental watershed, oftentimes less than 100 acres.

The extent of lateral movement of a river across a floodplain toward the convex side of an original curve. 
checkerboard land ownership pattern A land ownership pattern in which square-mile sections of federal lands are typically intermixed, on the basis of alternating sections, with adjoining private lands. The O\&C lands of western Oregon are an example of checkerboard ownership. This ownership pattern resulted from the revestment back to the federal government of lands granted by the federal government to early railroad companies. The checkerboard ownership pattern of the O\&C lands creates additional access, management, and perception issues. Also see $O \& C A c t$.

clearcut

coarse woody debris

coarse woody debris classes

commercial forest land base

commercial thinning

Congressionally Reserved Areas (or Congressional Reserves)

connectivity block

connectivity / diversity block
A timber harvesting method that removes essentially all trees in an area, whether merchantable or not, producing a fully exposed microclimate for development of a new age class.

That portion of trees that has naturally fallen or been cut and left in the woods. Usually refers to pieces at least 20 inches in diameter. Also see coarse woody debris classes.

There are four classes used to describe coarse woody debris. The classes range from Class I (which has the least decay, intact bark, and a hard $\log$ ) to Class IV (i.e., the coarse woody debris has decayed to the point of nearly being incorporated into the forest floor).

Forest lands declared suitable for producing timber and having a minimum level of productivity of 20 cubic feet/acre/year. Contrast with harvest land base.

Any type of thinning producing merchantable material at least equal to the value of the direct cost of harvesting. See thinning.

Areas established by an Act of Congress or Executive Order, such as national parks, wild and scenic rivers, national recreation areas, wilderness, and national monuments.

A Northwest Forest Plan term denoting a corridor that links areas of northern spotted owl habitat. Contrast with connectivity/ diversity block.

A subdivision of the matrix land use allocation in the current Resource Management Plans that serves as a corridor for linking late-successional and old-growth forests to facilitate the movement, feeding, and breeding of late-successional and oldgrowth species. These blocks are managed to maintain between 25 and 30 percent of late-successional forest within them. Contrast with connectivity block.

Conservation, when applied to special status species, is the methods and procedures used to improve the plant and animal species biology, improve their habitat condition, and reduce threats to their continued existence. 
conservation agreement

conservation strategy

\section{Consultation}

cooperators and cooperating agencies
A non-binding document of agreement between agencies that outlines conservation goals necessary to reduce, eliminate, or mitigate specific threats to species at risk, and provides general guidance on species management.

A management plan for a species, group of species, or ecosystem that prescribes standards and guidelines that if implemented provide a high likelihood that the species, groups of species, or ecosystem, with its full complement of species and processes, will continue to exist well-distributed throughout a planning area.

A formal review between the U.S. Fish and Wildlife Service or National Marine fisheries Service and another federal agency when it is determined that an action by the agency may affect critical habitat or a species that has been listed as threatened or endangered to ensure that the agency's action does not jeopardize a listed species or destroy or adversely modify critical habitat.

Those individuals and agencies that provide qualified information to a federal agency, such as the BLM, to use in formulating resource management actions and analyzing environmental consequences. The Council on Environmental Quality regulations that implement requirements of the National Environmental Policy Act define a cooperating agency as any agency that has jurisdiction by law or special expertise for proposals that are covered by the National Environmental Policy Act (40 CFR 1501.6). BLM planning regulations [43 CFR 1610.3-15(b)] further provide that eligible Federal agencies, state and local governments, and federally recognized Indian tribes may also participate as cooperating agencies.

\section{Coos Bay Wagon Road (CBWR) lands}

The public lands that were granted to the Southern Oregon Company for construction of a military road, but subsequently revested by the United States and later incorporated into the O\&C Act.

\section{corridor}

critical habitat

crown
A strip of land that links areas in a fragmented landscape to facilitate the passage of animals, plants, people, energy, or materials between habitat or service areas. Examples are biological, recreation, transportation, and utility corridors. Biological corridors are reserved from substantial disturbance. Also see connectivity block and connectivity/diversity block.

An Endangered Species Act term denoting a specified geographic area occupied by a federally listed species, and on which the physical and biological features are found that are essential to the conservation and recovery of that species and that may require special management or protection.

The upper part of a tree that has live branches and foliage. 
crown bulk density

crown density

crown fire

culmination of mean annual
increment (CMAI)

cumulative effect

decompaction

density management

determination of NEPA adequacy (DNA)

\section{diameter at breast height}

dispersal habitat (spotted owl)
A measure of the fuel in a forest's canopy that is usually calculated by dividing the canopy volume by the weight of the needles, leaves, and smaller branches (or calculated using the height-tocrown base, tree height, and basal area values). Contrast with crown density.

A measure of the density of a tree's crown that is calculated from the amount, compactness, and depth of the foliage in the tree's crown. Contrast with crown bulk density.

Fire that moves through the crowns of adjacent trees independent of any surface fire. Crown fires can often move faster and ahead of ground fires.

The age in the growth cycle of a tree or stand at which the mean annual increment (MAI) for volume is at its maximum. At culmination, MAI equals the periodic annual increment (PAI).

The impact on the environment that results from incremental impacts of an action when added to other past, present, and reasonably foreseeable future actions regardless of which agency or person undertakes such other actions. Cumulative impacts can result from individually minor, but collectively significant, actions taking place over a period of time.

Mechanical ripping and/or tillage of roadbeds, landings and other compacted areas for the purposes of increasing infiltration and aeration.

The cutting or killing of trees to increase spacing for promoting the acceleration of the growth of remaining trees, improvement of stand vigor, or attainment of late-successional characteristics. Also see thinning, precommercial thinning, and commercial thinning].

An interim step in BLM's internal analysis process, which documents that a proposed action is adequately analyzed in an existing environmental impact statement [EIS] or environmental assessment [EA]. Where applicable, the determination also documents conformance with an approved land use plan. (BLM NEPA Handbook, 516 DM 11).

The diameter of the stem of a tree measured at 4.5 feet above the ground level on the uphill side of the stem. Also see quadratic mean diameter.

Forest habitat that allows northern spotted owls to move (disperse) across the landscape; typically characterized by forest stands with average tree diameters of greater than 11 inches, and conifer overstory trees having closed canopies (greater than 40 percent canopy closure) with open space beneath the canopy to allow owls to fly. 


\section{dispersed retention}

disturbance (natural)

disturbance, stand replacement

dominant use

effective shade

envelope curve

environmental consequences

environmental impact statement

equivalent clearcut area

even-aged management

even-aged stand
See variable-retention harvest system.

A force that causes significant change in structure and/or composition through natural events such as fire, flood, wind, and earthquake, or through mortality caused by insect or disease outbreaks.

A force that removes most or all existing trees in a forest stand through natural events such as fire, flood, earthquake, or mortality caused by insect or disease outbreaks.

A land use that is the primary purpose for the land use designation; for instance, wildlife habitat on National Wildlife Refuges or timber production on O\&C lands. Contrast with multiple use.

The proportion of direct beam solar radiation reaching a stream surface to total daily solar radiation.

A line drawn on a figure with dependent and independent variables for a collection of hydrologic studies, showing the best fit of the extent of maximum response.

The direct, indirect and cumulative effects of a proposed action or alternative on existing conditions in the environment in which the action(s) would occur. Also see baseline.

A detailed document, required under the National Environmental Policy Act of 1969, of a federal project's environmental consequences, including adverse environmental effects that cannot be avoided, alternatives to the proposed action, the relationship between local short-term uses and long-term productivity, and any irreversibly or irretrievable commitment of resource.

Method of estimating changes in streamflow response from the amount and distribution of forest cover in a watershed.

A silvicultural system that creates forest stands primarily comprised of a single age or having a very narrow range of ages.

A stand of trees comprised of a single age class in which the range of tree ages is usually $\pm 20 \%$ of rotation. 


\section{evolutionary significant unit}

facies

fifth-field watershed

fine sediment

fire control, direct

fire control, prescribed

forest

flood

\section{floodplain}

forage

Forest Ecosystem Management Assessment Team (FEMAT)
A population or group of populations considered "distinct," and hence a "species" for purposes of the Endangered Species Act, representing an evolutionarily significant unit (ESU) of the biological species. A population must satisfy two criteria to be considered an ESU. It must be reproductively isolated from other conspecific population units, and it must represent an important component in the evolutionary legacy of the species. Isolation does not have to be absolute, but must be strong enough to permit evolutionarily important differences to accrue in different population units. The second criterion is met if the population contributes substantially to the ecological/genetic diversity of the species as a whole. (NOAA Technical Memorandum NMFS F/ NWC-194).

A characteristic of a rock unit that reflects a common origin or time.

One of the classifications of watersheds used by the United States Geological Survey that identifies some of the smallest watersheds and is useful for assessing water-related issues; generally 20 to 200 square miles in size. For details about the classification of drainage areas, see http://water.usgs.gov/GIS/huc.htmi. Also see watershed.

Fine-grained soil material, less than $2 \mathrm{~mm}$ in size, normally deposited by water, but in some cases by wind (aeolian) or gravity (dry ravel).

Any treatment applied directly to burning fuel, such as wetting, smothering, or chemically quenching the fire or by physically separating the burning from unburned fuel.

Any fire ignited by management actions to meet specific objectives. A written, approved prescribed fire plan must exist, and NEPA requirements (where applicable) must be met prior to ignition.

An ecosystem characterized by stands of trees varying in characteristics such as species composition, structure, age class, and associated processes, and commonly including meadows, streams, fish, and wildlife.

Streamflow overtopping streambanks, or rising water that covers land not normally under water.

Level lowland bordering a stream or river onto which the flow spreads at flood stage.

All browse and herbaceous matter available to grazing animals, including wildlife and domestic livestock.

The 1993 presidentially assigned team of scientists, researchers, and technicians from seven federal agencies that created the report that was used as the basis for the Northwest Forest Plan. 


\section{forest land}

\section{Forest Operations Inventory (FOI)}

\section{fuell loading}

genetic gain

green tree

green tree retention

group selection harvest

growth and yield modeling

forest habitat

habitat-capable forests (spotted owl)

\section{harvesting}

harvest land base

\section{hydrophilic vegetation}

\section{hydroregion}

Land at least 10 percent stocked by forest trees of any size, and including land that formerly had such tree cover and that will be naturally or artificially regenerated.

An intensive inventory that provides managers with information regarding the age, species, stand location, size, silvicultural needs, and recommended treatment of stands based on individual stand conditions and productivity.

The dry weight of all accumulated live and dead woody and herbaceous material on the forest floor that is available for combustion, and which poses a fire hazard.

Average improvement of a specific trait in a population of progeny over the average of the parental population (for example, height growth increase).

A live tree.

A stand management practice in which live trees are left within harvest units to provide a legacy of habitat components over the next management cycle.

See selection cutting.

Simulated projections of forest stand growth and development, from which timber volume estimates and other stand attributes expected to be produced per unit area under a certain set of conditions are derived. Also see modeling.

An area containing the forest vegetation with the age class, species composition, structure, sufficient area, and adequate food source to meet some or all of the life needs (such as foraging, roosting, nesting, breeding habitat for northern spotted owls) of specific species.

Forested stands that are capable of developing into suitable habitat specifically for the northern spotted owl.

The process of onsite cutting and removing of merchantable trees from a forested area.

Those lands that are available for timber harvesting on a programmed sustained basis. Generally, a harvest land base does not include managed or other reserved lands, nonforested lands, or areas that the timber production capability classification inventory has determined are not capable of sustaining timber production. Also see timber production capability classification.

Vegetation having a strong affinity for water.

An area of similar climate and stream runoff processes. 
incidental take

incorporated by reference

intensively managed timber stands

intrinsic potential

inventory data

jeopardy

key watershed

land use allocation

landscape

late-successional forest

Late-Successional Management Area
An Endangered Species Act term denoting the taking of a species that is listed as threatened or endangered inadvertently, rather than purposely, while carrying out otherwise lawful activity. Also see take.

Documents referenced in this final environmental impact statement that are provided by the individual subject matter experts, are maintained as a part of the administrative record housed at a centralized location, and are available upon request.

Forest stands that are managed to obtain a high level of timber volume and quality per unit area by using growth-enhancing practices, such as precommercial thinning, commercial thinning, and fertilization.

A stream's inherent ability to provide high-quality habitat for salmonids.

Information collected by the use of objective sampling methods designed to quantify the spatial distribution, composition, and rates of change of forest parameters within specified levels of precision. Note: Inventories may be made of all forest resources including trees and other vegetation, fish and wildlife, etc. Also see baseline.

The endangerment of the continued existence of a species that is listed as threatened or endangered under the Endangered Species Act. Also a finding made through consultation by a federal agency under the Endangered Species Act regarding an action proposed by the agency that may cause such endangerment.

A Northwest Forest Plan term that denotes a watershed that contains habitat for potentially threatened species, stocks of anadromous salmonids, or other potentially threatened fish, or is an area of high-quality water and fish habitat. Also see watershed.

A designation for a use that is allowed, restricted, or prohibited for a particular area of land, such as the matrix, adaptive management, late-successional reserve, or critical habitat land use allocations.

A broad expanse of terrain, up to the watershed scale of 10,000 to 20,000 acres, which spans several ecosystems irrespective of ownership or other political boundaries.

A forest that is in its mature stage and contains a diversity of structural characteristics, such as live trees, snags, woody debris, and a patchy, multi-layered canopy.

A designated area outside of the harvest land base that is actively managed to protect or enhance conditions of late-successional forest base. 
Late-Successional Reserve

load

long term

mass wasting

Matrix

mature stage

mean annual increment (MAI)

merchantable

minerals, leasable

minerals, locatable
A Northwest Forest Plan term that denotes a land use allocation and has been reserved from programmed timber harvesting and designated to maintain existing or future mature old-growth, or late-successional habitat.

The amount of material entering a system, such as point source and nonpoint source pollutants. Typically measured as pounds per day and significant in relation to the volume and circulation of the water or air mass in question. Also see point source and nonpoint source.

A period of time used as an analytical timeframe; starts more than 10 years after implementation of a resource management plan, depending on the resource being analyzed. Also see short term.

The sudden or slow dislodgement and downslope movement of rock, soil, and organic materials.

A Northwest Forest Plan term that denotes a land use allocation for federal lands located outside of reserves, withdrawn areas, and late-successional areas. For the purpose of this final environmental impact statement, this term applies only to the No Action Alternative.

Generally begins as tree growth rates stop increasing (after culmination of mean annual increment), and as tree mortality shifts from density-dependent mortality to density-independent mortality.

The total cumulative quantity produced over time of some attribute of a tree or stand growth (for example, wood volume divided by the total age of the tree or stand).

Trees or stands having the size, quality and condition suitable for marketing under a given economic condition, even if not immediately accessible for logging

Generally found in bedded deposits and include oil, gas, coal, chlorides, sulfates, carbonates, borates, silicates, and nitrates of potassium (potash) or sodium and related products; sulfur; phosphate and its associated and related minerals; asphalt; and gilsonite.

Includes both metallic minerals (gold, silver, lead, copper, zinc, nickel, etc.) and nonmetallic minerals (fluorspar, mica, certain limestone and gypsum, tantalum, heavy minerals in placer form and gemstones) in land belonging to the United States that are open to citizens of the United States for exploration, discovery, and location which conveys the exclusive right to extract the locatable minerals upon receiving all required authorizations in accordance with regulations at 43 CFR 3802 for lands in wilderness review and 3809 for other public lands. 
minerals, salable

modeling

multi-layered canopy

multiple use

National Marine Fisheries Service

natural fire regime class

noncomformity

nonpoint source pollution

Northwest Forest Plan
Include but are not limited to: petrified wood and common varieties of sand, stone, gravel, pumice, pumicite, cinder, clay, and rock.

A scientific method that operates by a structured set of rules and procedures to simulate current conditions and predict future conditions. Also see analysis.

Forest stands with two or more distinct tree layers in the canopy.

A Federal Land Policy and Management Act term that denotes "... the management of the public lands and their various resource values so that they are utilized in the combination that will best meet the present and future needs of the American people; making the most judicious use of the land for some or all of these resources or related services over areas large enough to provide sufficient latitude for periodic adjustments in use to conform to changing needs and conditions; the use of some land for less than all of the resources; a combination of balanced and diverse resource uses that takes into account the long-term needs of future generations for renewable and nonrenewable resources, including, but not limited to, recreation, range, timber, minerals, watershed, wildlife and fish, and natural scenic, scientific and historical values; and harmonious and coordinated management of the various resources without permanent impairment of the productivity of the land and the quality of the environment with consideration being given to the relative values of the resources and not necessarily to the combination of uses that will give the greatest economic return or the greatest unit output." (U.S. Code, Title 43, Chapter 35, Subchapter I, $\$ 1702$ (c)) Contrast with dominant use.

A federal agency under the United States Department of Commerce that is responsible for working with others to conserve, protect, and enhance anadromous fish and their habitats.

A general classification of how fire would behave over time in the absence of human intervention.

A physical expression of a period of time of non-deposition between rock units, usually indicated by erosion characteristics, bed tilting, or missing strata of an intervening time period.

Water or air pollutants where the source of the pollutant is not readily identified and is diffuse, such as the runoff from urban areas, agricultural lands, or forest lands. Also see point source.

A 1994 common management approach for the 19 national forests and 7 BLM districts located in the Pacific Northwest ecological region and jointly approved by the Secretary of Agriculture and the Secretary of the Interior. 
nutrient cycling

ordinary high water line

overstory

partial harvest

periodic annual increment (PAI)

petroleum shows

petroleum system

physiographic province

plan conformance

plant communities

play

point source
Circulation of elements (such as carbon or nitrogen) between vegetation/organic material and soil, water and air.

Fluctuations of water in a stream or waterbody, from higher runoff of one or two years, that establish a line on the shore which is typically identified by physical characteristics.

That portion of trees forming the uppermost canopy layer in a forest stand and that consists of more than one distinct layer.

For the purpose of defining management action in Alternative 3 , partial harvest is a timber harvesting method that removes a substantial portion of the stand basal area (50-70\%) on a harvest interval that mimics the historic average return interval for a moderate or mixed-severity fire.

The difference in stand volume at two successive measurements, divided by the number of years between measurements. PAI is an approximation to current annual increment, which is not directly measurable.

A visual appearance of hydrocarbon (gas, oil, asphalt, etc.) in an exploration well, water well, coal prospect, natural spring, or seep.

A relationship of source rock and the resulting petroleum accumulation.

A region of the landscape with distinctive geographical and biological features. When physiographic provinces subdivide sustained yield units (i.e., BLM districts), assessment areas are created.

The determination that a management action is consistent with the terms, conditions, decisions, and is within the anticipated environmental consequences, of an approved resource management plan.

A group of populations that coexist in space and time and interact with one another (conifer and hardwood forest lands, oak woodlands, juniper woodlands and rangelands, chaparral, shrubsteppe lands, grasslands, serpentine, riparian vegetation, cliffs, rock outcrops, talus and overslopes, dune systems, meadows, wetlands, springs, fens, ponds, and vernal pools).

The existence of a trap that is detectable with geological, geophysical, or geochemical technology.

An origin of water or air pollutants that is readily identified, such as the discharge or runoff from an individual industrial plant or cattle feedlot. Also see nonpoint source. 
precommercial thinning (PCT)

preferred alternative

progeny test site

proper functioning condition

prospect

public domain lands

public land

quadratic mean diameter

reclamation

record of decision

(ROD)

recovery plan

recruitment habitat

regeneration
The practice of reducing the density of trees within a stand by manual cutting, girdling, or herbicides to promote growth increases or maintain growth rates of desirable tree species. The trees killed are generally unmerchantable and retained on the treated area.

A National Environmental Policy Act term that denotes the alternative in a draft Environmental Impact Statement that is preferred by the proposing agency.

A test area for evaluating parent seed trees by comparing the growth of their offspring seedlings.

The state of a riparian wetland area having the vegetation, landform, and large woody debris that are necessary for the species, habitat, and natural processes of an area.

A drillable trap that is located within a play.

Original holdings of the United States that were never granted or conveyed to other jurisdictions or never reacquired by exchange for other public domain lands.

Land that is owned and controlled by some governmental entity (federal, state, county, or other municipality).

The average diameter, at breast height, of the tree that is of average basal area in a stand. Also see basal area and diameter breast height.

Land treatment to "bring back" vegetation or functions of the land that minimize water degradation, damage to aquatic life or wildlife, flooding, erosion, and other adverse effects from surface mining operations. The process may involve backfilling, grading, resoiling, revegetation, decompaction, stabilization, or other measures.

A document required by the National Environmental Policy Act, that is separate from, but associated with, an environmental impact statement. The ROD publicly and officially discloses the responsible official's decision on which alternative assessed in the EIS will be implemented.

A plan for the conservation and survival of an endangered species or a threatened species listed under the Endangered Species Act for the purpose of improving the status of the species to the point where listing is no longer required.

A stand that is capable of becoming habitat for a designated species within a designated period of time.

(n.) Tree seedlings or saplings existing in a stand. (v.) The process of re-establishing trees on a tract of forest land where harvest or some natural event has removed the existing trees. 
regeneration harvesting

relative density

replacement habitat

resource management plan (RMP)

restoration

riparian area

road decommissioning

road improvement

road obliteration

road pullback

road stormproofing
Any removal of trees intended to assist regeneration already present or make regeneration possible.

A means of describing the level of competition among trees or site occupancy in a stand, relative to some theoretical maximum that is based on tree size and species composition. Relative density is determined mathematically by dividing the stand basal area by the square root of the quadratic mean diameter. Also see basal area and quadratic mean diameter.

A stand of equivalent habitat value to a designated species that is made available as a replacement for habitat that is lost within the same population boundary.

A BLM planning document, prepared in accordance with Section 202 of the Federal Land Policy and Management Act that presents systematic guidelines for making resource management decisions for a resource area. An RMP is based on an analysis of an area's resources, their existing management, and their capability for alternative uses. RMPs are issue oriented and developed by an interdisciplinary team with public participation. Also see adaptive management.

Land treatments intended to bring back a former condition or function.

A geographic area containing an aquatic ecosystem and adjacent upland areas that directly affect it. This includes floodplains, woodlands, and all areas within a horizontal distance of approximately 100 feet from the normal line of high water of a stream channel or from the shoreline of a standing body of water.

Stabilization of unneeded or low use roads. Depending on the restoration objective, the series of actions may involve one or several of the following: closure, restoring natural stream crossings and self-maintaining road surface drainage, erosion control, and vegetative treatments (planting), surface decompaction, and sidecast pullback or road obliteration.

Activities on an existing road that improves its original design standard. A typical improvement would add culverts and/or crushed aggregate to a natural dirt surface road.

Removing a roadbed back from the landscape and restoring the natural topography.

Removal of unstable fill materials placed on the outside edge of the road prism.

Road surface work that upgrades drainage condition on roads that will remain open for travel, but will receive infrequent maintenance. Measures intended to prevent and control erosion and sediment delivery into stream channels, and reduce risk of road failure. 
rotation

salmonid

salvage cutting

seed orchard

sedimentary basin

selection cutting

shelterwood cutting

short term

silvicultural prescription

silvicultural system

single-tree selection harvest

site class

site potential tree height

snag
The planned number of years between establishment of a forest stand and its regeneration harvest.

Fish that are born and reared in freshwater, move to the ocean to grow and mature, and return to freshwater to reproduce. Includes species such as salmon and steelhead. Also see anadromous fish.

Removal of dead trees or of trees damaged or dying because of injurious agents other than competition, to recover economic value that would otherwise be lost.

A plantation of clones or seedlings from selected trees; isolated to reduce pollination from outside sources, weeded of undesirables, and cultured for early and abundant production of seed.

A geologic structural downwarp that has been filled with eroded rock from surrounding uplands. Both marine (filled with sediment deposited in oceans) and terrestrial (filled with inflowing rivers) basins exist.

A method of uneven-aged management involving the harvesting of single trees from stands (single-tree selection) or in groups up to four (4) acres in size (group selection) without harvesting the entire stand at any one time.

A regeneration method under an even-aged silvicultural system. With this method a portion of the mature stand is retained as a source of seed and/or protection during the regeneration period. The retained trees are usually removed in one or more cuttings.

A period of time used as an analytical timeframe and that is within the first 10 years of the implementation of a resource management plan. Also see long term.

A planned series of treatments designed to change current stand structure to one that meets management goals.

A planned series of treatments for tending, harvesting, and reestablishing a stand. The system name is based on the number of age classes managed within a stand (e.g., even-aged, two-aged, uneven-aged).

See selection cutting.

A classification of an area's relative productive capacity for tree growth; commonly expressed in terms of the heights of the largest trees in a stand at a common "index" age, usually 50 or 100 yearsold. Site classes are numbered from 1 (most productive) to 5 (least productive).

The average maximum height of the tallest dominant trees (200 years or older) for a given site class. Also see site class.

Any standing (upright) dead tree. 
sold timber sale

source water watershed

special forest products

special status species

stand

stand establishment stage

standards and guidelines

stream, intermittent

stream order

stream, perennial

structurally complex stage
A timber sale for which a qualified purchaser has been established, through auction or negotiation, but where the BLM has yet to approve and consummate the timber sale contract. See awarded timber sales.

A watershed area providing untreated water, used for drinking water.

Those plant and fungi resources that are harvested, gathered, or collected by permit, and have social, economical, or spiritual value. Common examples include mushrooms, firewood, Christmas trees, tree burls, edibles and medicinals, mosses and lichens, floral and greenery, and seeds and cones, but not soil, rocks, fossils, insects, animal parts, or any timber products of commercial value.

Those species that are listed under the Endangered Species Act as threatened or endangered (including proposed and candidate species); listed by a state as threatened, endangered or candidate species; and listed by the BLM as sensitive species. Under the BLM Special Status Species policy (BLM 6840), the BLM State Director has created an additional category called Bureau Strategic Species (see glossary Bureau strategic species).

An aggregation of trees occupying a specific area and sufficiently uniform in composition, age, arrangement, and condition so that it is distinguishable from the forest in adjoining areas.

The developmental stage extending from stand initiation until stands have reached canopy closure and density-dependent tree mortality begins.

Northwest Forest Plan rules for managing the different land use allocations. For the purpose of this final environmental impact statement, this term applies only to the No Action Alternative.

Drainage feature with a dry period, normally for three months or more, where the action of flowing water forms a channel with well-defined bed and banks, supporting bed-forms showing annual scour or deposition, within a continuous channel network.

A classification system used to define stream size; based on the hierarchy of tributaries principle. Working downstream from the upper extent of stream channels in a watershed, two unbranched first-order stream channels join to from a second order, and two like second orders join to form a third order, and so on.

Permanent channel drainage feature with varying but continuous year-round discharge, where the base level is at or below the water table.

Stage at which stands develop characteristics approximating "oldgrowth" stands described in many analyses associated with the Northwest Forest Plan. 
structural legacies

structural stage classifications of forests

stumpage

suitable habitat

sustainability

sustained yield

sustained yield capacity

sustained yield unit

take

terrain

thinning

timber
The large trees, down logs, snags, and other components of a forest stand that are left after harvesting for the purpose of maintaining site productivity and providing structures and ecological functions in subsequent stands.

A scheme used to define the structural stages of forests. It uses four broad classifications (stand establishment, young, mature, and structurally complex) and multiple subclassifications to distinguish differences within classifications.

The price paid for timber on the stump. A timber purchaser pays stumpage to the BLM and then incurs the cost of logging and hauling the logs to the mill.

A stand that has the structures (physical and biological features) necessary to meet the biological requirements of a particular species.

Sustainability can be defined as using, developing, and protecting resources in a manner that enables people to meet current needs and provides that future generations can also meet future needs, from the joint perspective of environmental, economic and community objectives.

The volume of timber that a forest can produce continuously at a given intensity of management; the achievement and maintenance in perpetuity of a high-level annual or regular periodic output of the various renewable resources without impairment of the productivity of the land.

The volume of timber that can be offered for sale each year from an area based upon the consistent volume of timber that a forest can produce continuously. Also see annual productive capacity.

\section{A BLM district.}

An Endangered Species Act term that denotes the act of or the attempt to harass, harm, pursue, hunt, shoot, wound, kill, trap, capture, or collect a species listed as threatened or endangered. Also see incidental take.

A tract or region of the earth's surface or grouping of rock considered as a separate physical feature.

A silvicultural treatment made to reduce the density of trees primarily to improve tree/stand growth and vigor, and/or recover potential mortality of trees, generally for commodity use. Also see density management, precommercial thinning, and commercial thinning.

Forest crops or stands, or wood that is harvested from forests and is of a character and quality suitable for manufacture into lumber and other wood products rather than for use as fuel. 


\section{timberland}

timber production capability classification (TPCC)

trap

two-aged stand

two-aged system

understory

uneven-aged management

uneven-aged stand

United States Fish and Wildllife Service (USFWS)

United States Forest Service (USFS)

variable-density thimning (VDT)
Forested land capable of producing crops of industrial wood at a rate of at least 20 cubic feet/acre per year and is not withdrawn from timber production. (Some forest lands are not classified by the FIA [U.S. Forest Service Inventory and Analysis] as timberland because they are either unproductive or by law are off limits to harvesting [e.g., national parks and wildernesses]).

An analytical tool that inventories and identifies sites as capable of sustaining intensive timber management without it degrading their productive capacity. This tool evaluates a site's soil depth, available moisture, slope, drainage, and stability to determine site capacity for timber management activity. Sites that prove incapable of sustaining intensive timber management are typically not included in the harvest land base. Also see harvest land base.

A geologic structure that allows petroleum to accumulate and be preserved.

A stand of trees comprised of two distinct age classes separated in age by more than $\pm 20 \%$ of rotation.

A silvicultural system that regenerates and maintains stands with two age classes. The resulting stand may be two-aged, or trend towards an uneven-aged condition as a consequence of both an extended period of regeneration establishment and the retention of reserve (green live) trees that may represent one or more age classes.

Portion of trees or other woody vegetation that forms the lower layer in a forest stand, and that consists of more than one distinct layer.

A combination of actions that simultaneously maintains continuous tall forest cover, recurring regeneration of desirable species, and the orderly growth and development of trees through a range of diameter or age classes.

A stand with three or more distinct age classes, either intimately mixed or in small groups.

A federal agency under the United States Department of the Interior that is responsible for working with others to conserve, protect, and enhance fish, wildlife, plants, and their habitats.

A federal agency under the United States Department of Agriculture that is responsible for administration of the nation's national forests.

A thinning method where two or more densities of retained trees are used to promote stand heterogeneity through the development of multi-layered canopies. Provision of conditions conducive to the initiation and growth of regeneration is often an objective of VDT to encourage understory development. 
variable-retention harvest system

watershed

wetland (jurisdictional)

wetland (natural)

wildfire

wildfire, uncharacteristic

wildland

wildland/urban interface

windthrow

young stage
An approach to harvesting that is based on retaining structural elements or biological legacies (trees, snags, logs, etc.) from the harvested stand for integration into the new stand to achieve various ecological objectives. Note: The major variables in variable retention harvest systems are types, densities, and spatial arrangement of retained structures: 1) aggregated retention is retention of structures as (typically) small intact forest patches within the harvest unit; 2) dispersed retention is retention of structures or biological legacies in a dispersed or uniform manner.

All of the land and water within the boundaries of a drainage area that are separated by land ridges from other drainage areas. Larger watersheds can contain smaller watersheds that all ultimately flow their surface water to a common point. Also see fifth-field watershed and key watershed.

A wetland determination, using the Army Corps of Engineers current interagency rules, based on presence of defined wetland vegetation, soils and hydrology.

Unaltered land with natural presence and duration of water, sufficient to support wetland vegetation

Any nonstructural fire, other than prescribed burns, that occurs on wildland.

A wildfire that burns with unusual intensity and size. They are a particular concern in drier ecosystems such as sagebrushgrasslands, dry Douglas-fir, dry grand fir and ponderosa pine forests in the West where combustible fuels have accumulated.

Lands that are not dedicated to such uses as agricultural, urban, mining, or parks.

The area in which structures and other human development meet or intermingle with undeveloped wildland.

A tree or trees uprooted or felled by the wind.

Characterized by the predominance of density-dependent tree mortality and, in high density stands, a small range of tree diameters. 


\section{References}

This chapter provides a list of literature and references cited in this environmental impact statement.

Aber, J., N. Christensen, I. Fernandez, J.Franklin, L.Hidinger, M.Hunter, J.MacMahon, D.Mladenoff, J.Pastor, D.Perry, R.Slangen, H.vanMiegroet. 2000. Applying ecological principles to management of U.S. national forests. Issues in Ecology No. 6.

Adams, Darius and Greg Latta. 2007. Timber Trends on Private Lands in Western Oregon and Washington: A New Look. Western Journal of Applied Forestry 22(1) pp 8-14

Adams, Paul. 2005. Research \& Policies to Address Concerns about Soil Compaction from Ground-Based Timber Harvest in the Pacific Northwest: Evolving Knowledge \& Needed Refinements. A paper presented at Council on Forest Engineering Conference on Soil, Water, and Timber Management: Forest Engineering Solutions in Response to Forest Regulation.

Adair, Craig. 12 February 2007. American Panel Association, pers.com. Spreadsheet of North American structural panel production.

Agee, James, K. 1993. “Fire Ecology of Pacific Northwest Forests.” Island Press. Washington D.C. Agee and Skinner. 2005. Basic Principles of Forest Fuel Reduction.

Ahlgren, Clifford E. 1979. Emergent seedlings on soil from burned and unburned red pine forest. Minnesota Forestry Research Notes No. 273, 4 p. [16910]. University of Minnesota, College of Forestry. St. Paul, MN.

Alig, R.J., D. Zheng, T.A. Spies and B.J. Butler. 2000. Forest cover dynamics in the Pacific Northwest west side: regional trends and projections. Research Paper PNW-RP-522. Pacific Northwest Research Station, U.S. Department of Agriculture, U.S. Forest Service. Portland, OR

Allan J.D. 1995. Stream Ecology: Structure and Function of Running Waters. London: Chapman and Hall.

Allen, Karen and Katherine Hansen. 1999. Geography of exotic plants adjacent to campgrounds, Yellowstone National Park, USA. The Great Basin Naturalist. 59(4): 315-322. [33975]

Altman, B. 1999. Conservation strategy for land birds in coniferous forests of western Oregon and Washington, Version 1.0. Oregon-Washington Partners in Flight.

Altman, B. 2000a. Conservation strategy for land birds of the east-slope of the Cascade Mountains in Oregon and Washington, Version 1.0. Oregon-Washington Partners in Flight.

Altman, B. 2000b. Conservation strategy for land birds in lowlands and valleys of western Oregon and Washington, Version 1.0. Oregon-Washington Partners in Flight.

American Wind Energy Association. 2007. Installed \& Projected MW, Oregon Wind Energy Development.

Andersen Hal E. 1982. "Aids to Determining Fuel Models For Estimating Fire Behavior." General Technical Report INT-122. Intermountain Forest and Range Experiment Station, U.S. Department of Agriculture, U.S. Forest Service. Ogden, UT. 
Anderson, A.E. and O.C. Wallmo. 1984. Odocoileus hemionus. No. 219. in Mammalian Species. Lawlor, T.E, editor. The American Society of Mammalogists.

Anderson, D.R., J. Bart, T.C. Edwards, Jr., C.B. Kepler, and E.C. Meslow. 1990. Status Review, Northern spotted (owl Strix occidentalis caurina). U.S. Fish and Wildlife Service, Portland, OR. 95 p.

Anderson, P.D., D.J. Larson, and S.S. Chan. in press. Riparian buffer and density management influences on microclimate of young headwater forests of western Oregon. Forest Science 53(2)

Anderson, P.G., B.R. Taylor, and G.C. Balch. 1996. Quantifying the effects of sediment release on fish and their habitats. Canadian Manuscript Report of Fisheries and Aquatic Sciences No. 2346, Vancouver, British Columbia.

Andrews, H.J., and R.W.Colwin. 1940. Forest Resources of the Douglas-fir Region. Miscellaneous Publication No. 389. U.S. Department of Agriculture, U.S. Forest Service.

Anthony, R.G., E.D. Forsman, A.B. Franklin, D.R. Anderson, K.P. Burnham, G.C. White, C.J. Schwarz, J. Nichols, J.E. Hines, G.S. Olson, S.H. Ackers, S. Andrews, B.L. Biswell, P.C. Carlson, L.V. Diller, K.M. Dugger, K.E. Fehring, T.L. Fleming, R.P. Gerhardt, S.A. Gremel, R.J. Gutiérrez, P.J. Happe, D.R. Herter, J.M. Higley, R.B. Horn, L.L. Irwin, P.J. Loschl, J.A. Reid, and S.G. Sovern. 2004. Status and trends in demography of northern spotted owls, 1985-2003. Final Report to the Interagency Regional Monitoring Program, Portland, OR. September 2004. Bart, J. 1995. Amount of suitable habitat and viability of northern spotted owls. Conservation Biology 9(4):943-946. 179 p.

Anthony, R.G., S. Andrews, F. Wagner, S. Adams, L. Friar, T. O’Brien, T. Phillips and D. Strejc. 2006. Demographic characteristics and ecology of spotted owls (Strix occidentalis caurina) in the southern Oregon Cascades. Annual Progress Report. Oregon Cooperative Fish and Wildlife Research Unit, Dept. of Fisheries and Wildlife, Oregon State University, Corvallis, OR.

Anthony, R.G., E.D. Forsman, A.B. Franklin, D.R. Anderson, K.P. Burnham, G.C. White, C.J. Schwarz, J. Nichols, J. Hines, G.S. Olson, S.H. Ackers, S. Andrews, B.L. Biswell, P.C. Carlson, L.V. Diller, K.M. Dugger, K.E.Fehring, T.L. Fleming, R.P. Gerhardt, S.A. Gremel, R.J. Gutiérrez, P.J. Happe, D.R. Herter, J.M. Higley, R.B. Horn, L.L. Irwin, P.J. Loschl, R.R. Reid, and S.G. Sovern. 2006. Status and Trends in Demography of Northern Spotted Owls, 1985-2003. Wildlife Monographs No. 163.

Anthony, R.G., R.L. Knight, G.T. Allen, B.R. McCelland, and J.I. Hodges. 1982. Habitat use by nesting and roosting bald eagle in the Pacific Northwest. In: Transactions of the 47th North American Wildlife and Natural Resources Conference. pp. 332-342. Wildlife Management Institute. Washington, D.C.

Ares, A, T. Terry, C. Harrington, W. Devine, D. Peter, and J. Bailey. 2007. Biomass Removal, Soil Compaction, and Vegetation Control Effects on Five-Year Growth of Douglas-fir in Coastal Washington. Forest Science 53(5).

Arora, D. 1997. Mushrooms Demystified. 2nd edition. Ten Speed Press. Berkeley, CA. 959 p.

Ashton, D.T., S.B. Marks, and H.H. Welsh, Jr. 2006. Evidence of continued effects from timber harvesting on lotic amphibians in redwood forest of northwestern California. Forest Ecology and Management 221(2006):183-193.

Aubry, K.B. and J.C. Lewis. 2003. Extirpation and reintroduction of fishers (Martes pennanti) in Oregon: implications for their conservation in the Pacific states. Biological Conservation 114:79-90. 
Aubry, K.B. and C.M. Raley. June 2002. Ecological characteristics of fishers in the southern Oregon Cascade Range Final Progress Report. Pacific Northwest Research Station, U.S. Department of Agriculture, U.S. Forest Service. Olympia, WA.

Aubry, K.B., S.M. Wisely, C.M. Raley, and S.W. Buskirk. 2004. Zoogeography, spacing patterns, and dispersal in fishers: insights gained from combining field and genetic data. In Proceedings of the 3rd International Martes Symposium: Martens and fishers (Martes) in human-altered environments: an international perspective. pp. 211-230. D.J. Harrison and A.K. Fuller, editors. Springer Academic Publishers. New York, NY.

Bailey, V. 1936. The Mammals and Life Zones of Oregon. North American Fauna. 55:1-416.

Bailey, John D., Cheryl Mayrsohn, Paul S. Doescher [and others]. 1998. Understory vegetation in old and young Douglas-fir forests of western Oregon. Forest Ecology and Management 112(3): 289-302. [30086]

Bailey, John D. and John C. Tappeiner. 1998. Effects of thinning on structural development in 40 to 100 years-old Douglas-fir stands in western Oregon. Forest Ecology and Management 108(1998): 99-113.

Baker, D. and C. Palmer. [in press]. The Northwest Forest Plan - The first 10 years (1994-2003): implementation monitoring: accomplishments and compliance with plan requirements. U.S. Department of Agriculture, U.S. Forest Service, Pacific Northwest Region. Portland, OR.

Baker, P.J. and J.S. Wilson. 2000. A quantitative technique for the identification of canopy stratification in tropical and temperate forests. Forest Ecology and Management 127:77-86.

Ballard, Heidi. 2005. Impacts of Harvesting Salal (Gaultheria shallon) on the Olympic Peninsula, Washington:Harvester Knowledge, Science, and Participation. Ph.D. Dissertation. Department of Environmental Science,Policy and Management. University of California, Berkeley.

Banci V. 1989. A Fisher management strategy for British Columbia. British Columbia Ministry of Environment, Wildlife Branch. Wildlife Bulletin No. B-63.

Barrows, C.C. 1980. Feeding ecology of the spotted owl in California. Journal of Raptor Research 14:73-77.

Baskent, E.Z., S. Keles, and H.A. Yolasigmaz. 2008. Comparing multipurpose forest management with timber management, incorporating timber, carbon and oxygen values: a case study. Scandinavian Journal of Forest Research 23(2): 105-120.

Batchelet, D. and R.P. Neilson. 2000. Biome redistribution under climate change. pp. 18-44 in L.A. Joyce and R. Birdsey, tech. eds. The impact of climate change on America's forests: a technical document supporting the 2000 USDA Forest Service RPA assessment. USDA Forest Service Gen. Tech. Rep. RMRS-GTR-59. Fort Collins, CO. 133 p.

Bates, J., Compiler. 2007. Western Juniper control studies: EOARC research report. Eastern Oregon Agricultural Research Center February 2007.

BCMOF (British Columbia Ministry of Forests) 1995. Pruning guidebook. Forest practices code. http:// www.for.gov.bc.ca/tasb/legsregs/fpc/fpcguide/pruning/PRUNTOC.HTM

Beechie, T.J. and T.H. Sibley. 1997. Relationships between channel characteristics, woody debris, and fish habitat in northwestern Washington streams. Transactions of the American Fisheries Society 126:217-229. 
Beechie, T. J., G. Pess, P. Kennard, R. E. Bilby, and S. Bolton. 2000. Modeling recovery rates and pathways for woody debris recruitment in Northwestern Washington streams. North American Journal of Fisheries Management 20:436-452.

Beissinger, S.R. 1995. Population trends of the marbled murrelet projected from demographic analyses. In: Ecology and conservation of the marbled murrelet (C.J. Ralph, G.L. Hunt, M.G. Raphael and J. F. Piatt, editors). pp. 385-393. Pacific Southwest Research Station, U.S. Department of Agriculture, U.S. Forest Service. Albany, CA.

Beissinger, S.R. 2002. Analysis of the effect of a $10 \%$ reduction of population size on marbled murrelet population dynamics in northern California. Unpublished report. University of California. Berkeley, CA. 10 p.

Beissinger, S.R., and N. Nur. 1997. Appendix B: Population trends of the marbled murrelet projected from demographic analysis. In: Recovery plan for the threatened marbled murrelet (Brachyramphus marmoratus) in Washington, Oregon and California. pp. B1-B35. U.S. Fish and Wildlife Service. Portland, OR.

Benda, L. and T. W. Cundy 1990. Predicting deposition of debris flows in mountain channels, Canada Geotech Journal 27, 409-417.

Benda, L.E., and Dunne, T. 1997. Stochastic forcing of sediment supply to channel networks from landsliding and debris flow. Water Resour. Res. 33(12): 2849-2863.

Benda, L., D. Miller, J. Sias, D. Martin, B. Bilby, C. Veldhuisen, and T. Dunne. 2003a. Wood recruitment processes and wood budgeting. pp. 49-73. In The ecology and management of wood in world rivers. S. V. Gregory, K. Boyer, and A. M. Gurnell, eds. American Fisheries Society.

Benda, L., C. Veldhuisen, and J. Black. 2003b. Debris flows as agents of morphological heterogeneity at loworder confluences, Olympic Mountains, Washington. Geological Society of America Bulletin (September 2003), 115(9):1110-1121.)

Benda L., N.L. Poff, D. Miller, T. Dunne, and G. Reeves. 2004. The network dynamics hypothesis: how channel networks structure riverine habitats. BioScience: Vol. 54, No. 5 pp. 413-427.)

Benda, Lee, Marwan A. Hassan, Michael Church, and Christine L. May. 2005. Geomorphology of steepland headwaters: The transition from hillslopes to channels. Journal of the American Water Resources Association 41 (4), 835-851.)

Bender, L.C., G.A. Schirato, R.D. Spencer K.R. McAllister, and B.L. Murphie. 2004. Survival, cause-specific mortality, and harvesting of male black-tailed deer in Washington. Journal of Wildlife Management 68(4):870-878.

Bennett, M. and S. Fitzgerald. Mechanical Fuels Reduction. Reducing Hazardous Fuels on Woodland Properties. Oregon Forest Resource Institute and Oregon State University. Corvallis, OR.

Bentivoglio, N., J. Baldwin, T. Max, S. Miller, C.J. Ralph, M.Raphael, C.S. Strong, and C.W. Thompson. 2002. Marbled murrelet population monitoring program for Northwest Forest Plan effectiveness monitoring. Annual report. U.S. Fish and Wildlife Service. Portland, OR. 47 p.

Berris, S.N.; Harr, R.D. 1987. Comparative snow accumulation and melt during rainfall in forested and clear-cut plots in the western Cascades of Oregon. Water Resources Research. 23(1): 135-142. 
Beschta, R. 1997. Riparian shade and stream temperature: An alternative perspective. Rangelands 19(2):2528. Oregon State University. Corvallis, OR.

Beschta, R., R. Bilby, G. Brown, L. Holtby and T. Hofstra. 1987. Stream temperature and aquatic habitat: Fisheries and forestry interaction. pp. 191-232. University of Washington, Institute of Forest Resources, Contribution No. 57.

Beschta, R., M. Pyles, A. Skaugset and C. Surfleet. 2000. Peak flow responses to forest practices in the western cascades of Oregon, USA. Journal of Hydrology, 223 (2000) 102-120.

Beschta, R., J.J. Rhodes, J.B. Kauffman, R.E. Gresswell, G.W. Minshall, J.R. Karr, D.A. Perry, F.R. Hauer, and C.A. Frissell. 2004. Post-fire management on forested public lands of the Western United States. Conservation Biology 18: 957-967.

Bevis, K.R., G.M. King, and E.E. Hanson. 1997. Spotted owls and 1994 fires on the Yakama Indian Reservation. In: International Association of Wildland Fire Proceedings - Fire Effects on Rare and Endangered Species Habitats Conference, pp. 117-22. Nov 13-16, 1995. J.M. Greenlee, editor. Coeur d'Alene, ID.

Bigelow, P.E., L.E. Benda, D.J. Miller and K.M. Burnett 2007. On debris flows, river networks, and the spatial structure of channel morphology, Forest Science 53, pp. 220-238.

Bilby, R.E. and P.A. Bisson. 1998. Function and distribution of large woody debris. In: Kantor, S., ed. River ecology and management: lessons from the Pacific coastal ecoregion. Springer-Verlag: 324-346, Chapter 13. Washington, D.C.

Bilby, R.E. and J.W. Ward. 1989. Changes in characteristics and function of woody debris with increasing size of streams in western Washington. Transactions of the American Fisheries Society 118: 368-378.

Bingham, B. B., \& B. R. Noon. 1997. Mitigation of habitat "take": Application to habitat conservation planning. Conservation Biology 11: 127-139.

Birdsey, R., K. Pregitzer, and A. Lucier. 2006. Forest carbon management in the United States: 1600-2100. Journal of Environmental Quality 35: 1461-1469.

Bisson, P.A. and R.E. Bilby. 1982. Avoidance of suspended sediment by juvenile coho salmon. North American Journal of Fisheries Management 2: 371-374.

Bisson, P., R. Bilby, M. Bryant, C. Dolloff, G. Grette, R. House, M. Murphy, K. Koski and J. Sedell. 1987. Large woody debris in forested streams in the Pacific Northwest: past, present, and future. In: Streamside management: forestry and fishery interactions. E. Salo and T. Cundy, editors. Contribution Number 57. pp. 143-190. University of Washington, Institute of Forest Resources. Seattle, WA.

Bjornn, T. C., and D. W. Reiser. 1991. Habitat requirements of salmonids in streams. Pp 83-138 in W.R. Meehan, editor. Influences of forest and rangeland management on salmonid fishes and their habitats. Special Publication 19. American Fisheries Society, Bethesda, MD.

Boulanger, J., K. Martin, G. Kaiser and A.E. Derocher. 1999. Evaluating uncertainty in population trends of marbled murrelets. In: Biology and Conservation of Forest Birds; Proceedings of the Society of Canadian Ornithologists Special Science Symposium, pp. 53-62. Fredericton, New Brunswick 23-25 August, 1996. Diamond, A.W and D.N. Nettleship, eds. Society of Canadian Ornithologists Special Publication No. 1. Fredericton, New Brunswick, Canada. 
Boyd, M.S. 1996. Heat source: stream temperature prediction. Master's Thesis. Department of Civil and Bioresource Engineering, Oregon State University. Corvallis, OR.

Boyd, M. and D. Sturdevant. 1997. The scientific basis for Oregon's stream temperature standard: common questions and straight answers. Oregon Department of Environmental Quality. Salem, OR.

Bradley, R.W. 2002. Breeding ecology of radio-marked marbled murrelets (Brachyramphus marmoratus) in Desolation Sound. Department of Biological Sciences, Simon Fraser University. Burnaby, British Columbia, Canada. $86 \mathrm{p}$.

Brake, D.; M. Molnau and J.G. King. 1997. Sediment transport distances and culvert spacing on logging roads within the Oregon coast mountain range. ASAE Annual International Meeting, August 10-14, 1997. Minneapolis, MN. 12 p.

Brandt, J.P., T.A. Morgan, T. Dillon, G.J. Lettman, C.E. Keegan, D.L. Azuma. 2006. Oregon's Forest Products Industry and Timber Harvest, 2003. Gen. Tech. Rpt. PNW-GTR-681. Pacific Northwest Research Station, U.S. Department of Agriculture, U.S. Forest Service. Portland, OR. 53 p.

Brazier, J. and G. Brown. 1972. Controlling thermal pollution in small streams. U.S. Government Printing Office, EPA-R2-72-083.

Brock, R. and R. Callagan. 2006. Siskiyou Biosurvey LLC. Site Review of Fritillaria gentneri on Bureau of Land Management lands. 2006 Internal monitoring report. U.S Department of the Interior, Bureau of Land Management, Medford District. Medford, OR.

Brock, R., Callagan, R. 2007. Site Review of Fritillaria Gentneri on BLM Lands. Siskiyou Biosurvey, LLC. BLM Monitoring Report.

Brosofske, K.D., J. Chen, R.J. Naiman, J.F. Franklin. 1997. Harvesting effects on microclimatic gradients from small streams to uplands in western Washington. Ecological Applications 7(4): 1188-1200.

Brown, G.W. 1969. Predicting temperatures of small streams. Water Resources Research 5(1):68-75.

Brown, G.W. 1983. Forestry and Water Quality. College of Forestry, Oregon State University, Corvallis, OR.

Brown, G.W. and J. Krygier. 1970. Effects of Clear-cutting on Stream temperature. Water Resources Research Vol. 6, No. 4, pp. 1133-1139.

Brown, G.W. and J. Krygier. 1971. Clear-cut logging and sediment production in the Oregon Coast Range. Water Resources Research 7:1189-1199.

Brown, J.K., E.D. Reinhardt and K.A. Kramer. 2003. Coarse woody debris: managing benefits and fire hazard in the recovering forest. General technical report RMRS-GTR-105. Rocky Mountain Research Station, U.S. Department of Agriculture, U.S. Forest Service. Fort Collins, CO.

Brown, Richard T., James Agee and Jerry Franklin. 2004a. Forest Restoration and Fire: Principles in the Context of Place. Conservation Biology. August 2004. 18: 903-912.

Brown, S., T. Pearson, A. Dushku, J. Kadyzewski, and Y. Qi. 2004b. Baseline Greenhouse Gas Emissions and Removals for Forest, Range, and Agricultural Lands in California. Winrock International, for the California Energy Commission, PIER Energy-Related Environmental Research. 500-04-069F. 
Brunengo, M. J. unpublished. Estimation of snow available for melting during model rain-on- snow events. 46 pp. Washington Department of Natural Resources, Forest Practices Division. Olympia, WA.

Buehler, D.A. 2000. Bald Eagle (Halieaeetus leucocephalus). In The Birds of North America, No. 506. A. Poole and F. Gill, editors. The Birds of North America, Inc. Philadelphia, PA.

Buermeyer, K. R. and C. A. Harrington (2002): Fate of overstory trees and patterns of regeneration 12 years after clearcutting with reserve trees in Southwest Washington. Western Journal of Applied Forestry 17: $78-85$.

Burger, A.E. 2001. Using radar to estimate populations and assess habitat associations of marbled murrelets. Journal of Wildlife Management 65:696-715.

Burger, A.E. 2002. Conservation assessment of marbled murrelets in British Columbia, a review of biology, populations, habitat associations and conservation. Pacific and Yukon Region. Canadian Wildlife Service. $168 \mathrm{p}$.

Burnett, K. M. 2001. Relationships among juvenile anadromous salmonids, their freshwater habitat, and landscape characteristics over multiple years and spatial scales in Elk River, Oregon. Ph.D. Dissertation. Oregon State University, Corvallis, OR.

Burnett, K.M. and D.J. Miller. 2007. Streamside policies for headwater channels: an example considering debris flows in the Oregon Coastal Province. Forest Science, 53: 239-253.

Burnett, Kelly M., Gordon H. Reeves, Daniel J. Miller, Sharon Clarke, Ken Vance-Borland, and Kelly Christiansen. 2003. A first step toward broad-scale identification of freshwater protected areas for Pacific salmon and trout in Oregon, USA. In: Aquatic protected areas: What works best and how do we know? J.P. Beumer, A.Grant and D.C. Smith, editors. Proceedings of the world congress on aquatic protected areas, Cairns, Australia and North Beach, WA. Australian Society for Fish Biology.

Burnett, Kelly M., Gordon H. Reeves, Daniel J. Miller, Sharon Clarke, Ken Vance-Borland and Kelly Christiansen. 2007. Distribution of salmon-habitat potential relative to landscape characteristics and implications for conservation. Pacific Northwest Research Station, U.S. Department of Agriculture, U.S. Forest Service. Corvallis, OR.

Burroughs, E. and J. King. 1989. Reduction of soil erosion on forest roads. General Technical Report INT264. Intermountain Research Station, U.S. Department of Agriculture, U.S. Forest Service,

Burroughs, E.R., G.R. Chalfant and M.A. Townsend. 1976. Slope Stability in Road Construction. A Guide to the Construction of Stable Roads in Western Oregon and Northern California. United States Department of the Interior, Bureau of Land Management, Oregon State Office. Portland, OR.

Bury, B. 2005. Stream Amphibians. in Riparian zone forest management and the protection of biodiversity: a problem analysis. pp. 23-27. Sarr, D.A., D.C. Odion, D.E. Hibbs, J.Weikel, R.E. Gresswell, R.B. Bury, N.M. Czarnomski, R.J. Pabst, J. Shatford, and A.R. Moldenke (editors.) National Council for Air and Stream Improvement, Technical Bulletin No. 908. Research Triangle Park, NC. 107+ pages.

Bury, R.B. and C.A. Pearl. 1999. Klamath-Siskiyou herpetofauna: Biogeographic patterns and conservation strategies. Natural Areas Journal 19:341-350.

Busby, Posy, Peter Aldler, Timothy Warren, and Frederick Swanson. 2006. Fate of live trees retained in forest cutting units, western Cascade Range, Oregon. Canadian Journal of Forest Research, 36: 2550-2560. 
Busing, R.T., A.M. Solomon, R.B. McKane, and C.A. Burdick. 2007. Forest dynamics in Oregon landscapes: evaluation and application of an individual-based model. Ecological Applications 17(7): 1967-1981.

Buskirk, S.W. and R.A. Powell. 1994. Habitat ecology of fishers and American martens. In: Martens, Sables and Fishers: Biology and Conservation. pp. 283-296. S.W. Buskirk, A.S. Harestad, M.G. Raphael, and M.G. Powell, editors. Cornell University Press. Ithaca, NY.

Busse, M.D., K.R. Hubbert, G.O. Fiddler, C.J. Shestak and R.F. Powers. 2005. Lethal soil temperatures during burning of masticated forest residues. International Journal of Wildland Fire 14(3).

Busse, M.D., S. E. Beattie, R. F. Powers, F. G. Sanchez, and A. E. Tiarks 2006. Microbial community responses in forest mineral soil to compaction, organic matter removal, and vegetation control. Canadian Journal of Forest Research 36: 577-588.

Bustard, D.R. and D.W. Narver. 1975. "Preferences of juvenile coho salmon (Oncorhynchus kisutch) and cutthroat trout (Salmo clarki) relative to simulated alteration of winter habitat." Journal of Fisheries, Resource Board Canada 32:681-687.

Cafferata, P. 1992. Soil Compaction Research. In: Forest Soils \& Riparian Zone Management: The Contributions of Dr. Henry A. Froehlich to Forestry. Skaugset A., editor. Forest Engineering Department, Oregon State University. Corvallis, OR.

Callihan, Robert H., Timothy S. Prather and Francis E. Northam. 1993. Longevity of yellow starthistle (Centaurea solstitialis) achenes in soil. Weed Technology 7: 33-35. [24469]

Campbell, S, and L. Liegel. 1996. Disturbance and Forest Health in Oregon and Washington. Gen. Tech. Rep. PNW-GTR-381. Portland, OR: U.S. Department of Agriculture, Forest Service, Pacific Northwest Research Station. $121 \mathrm{p}$.

Carey, A.B. 2000. Effects of new forest management strategies on squirrel populations. Ecological Applications 10:248-257.

Carey, A.B., S.P. Horton and B.L. Biswell. 1992. Northern spotted owls: influence of prey base and landscape character. Ecological Monographs 62(2): 223-250.

Carroll, C., W.J. Zielinski, and R.F. Noss. 1999. Using presence-absence data to build and test spatial habitat models for the fisher in the Klamath Region, U.S.A. Conservation Biology 13(6):1344-1359.

Carson, Sue D. 2003. Modeling genetic gain in growth in New Zealand: 1 986-2003. In: Cherry, Marilyn L., and Glenn T. Howe. editors. Genetics and growth modeling workshop: Pacific Northwest Tree Improvement Cooperative. Proceedings of a workshop; 2003 November 496. Vancouver, WA.

Castellano, M.A., E. Cazares, B. Fondrick, and T. Dreisbach. 2003. Handbook to Additional Fungal Species of Special Concern in the Northwest Forest Plan. General Technical Report PNW-GTR-572. Pacific Northwest research station. USDA, U.S. Forest Service and USDI, Bureau of Land Management.

Castro, J.M., and Jackson, P.L. 2001. Bankfull discharge recurrence intervals and regional hydraulic geometry relationships: patterns in the Pacific Northwest, USA. Journal of the American Water Resources Association 37(5): 1249-1262.

Cederholm, C.J., L.M. Reid and E.O. Salo. 1981. Cumulative effects of logging road sediment on salmonid populations in the Clearwater River, Jefferson County, Washington. In: Proceedings, conference on salmon spawning gravel: A Renewable Resource in the Pacific Northwest? Water Research Center Report 39. 
Cederholm, C.J., R.E., Bilby, P.A. Bisson, T.W. Bumstead, B.R. Fransen, W.J. Scarlett and J.W. Ward. 1997. Response of juvenile coho salmon and steelhead to placement of large woody debris in a coastal Washington stream. North American Journal of Fisheries Management 17:947-963.

Chamberlain, J., R. Bush, and A. L. Hammett. 1998. Non-timber forest products, the other forest products. Forest Products Journal. 48(10):10-19.

Chamberlain, T.W., R.D. Harr and F.H. Everest. 1991. Timber harvesting, silviculture, and watershed processes. American Fisheries Society Special Publication 19:181-205.

CH2MHill; Western Watershed Analysts. 1999. FEMAT riparian processes effectiveness curves: What is science-based and what is subjective judgment? Prepared for the Oregon Forest Industries Council by: CH2MHill, Portland OR. and Western Watershed Analysts, Lewiston, ID.

Chan, S., P. Anderson, J. Cissel, L. Larsen and C. Thompson. 2004. Variable density management in Riparian Reserves: lessons learned from an operational study in managed forests of western Oregon, USA. Forest Snow and Landscape Research 78(1/2):151-172.

Chan, Samuel, David Larson, Kathleen Maas-Hebner, William Emmingham, Stuart Johnston, and Daniel Mikowski. 2006. Overstory and understory development in thinned and underplanted Oregon Coast Range Douglas-fir stands. Can. J. For. Res. 36: 2696-2711.

Chapman, D. and K. McLeod. 1987. Development of criteria for fine sediment in the Northern Rockies ecoregion. U.S. Environmental Protection Agency. Seattle, WA. 279 p.

Charnley, S. 2006. Socioeconomic Monitoring Results, Volume II: Timber and Nontimber Resources. Northwest Forest Plan-The First Ten Years (1994-2003). General Technical Report PNW-GTR-649 Vol. II: 29-33. Pacific Northwest Research Station, U.S. Department of Agriculture, U.S. Forest Service. http://www. treesearch.fs.fed.us/pubs/22374

Chen, J., J. F. Franklin, and T. A. Spies. 1992. Vegetation responses to edge environments in old-growth Douglas fir forests. Ecological Applications 2:387-396.

Chen, J., J. F. Franklin, and T. A. Spies. 1993. Contrasting microclimate among clearcut, edge, and interior of old growth Douglas-fir forest. Agriculture and Forest Meteorology 63: 219-237.

Chen, J., J.F. Franklin and T.A. Spies. 1995. Growing-season microclimatic gradients from clearcut edges into old-growth Douglas-fir forests. Ecological Applications 5: 74-86.

Chen, Jiquan, Gordon Smith, [and others]. 1996. Initial response of understory plant diversity and overstory tree diameter growth to a green tree retention harvest. Northwest Science 70(1): 24-35. [26579].

Christner, J. and R. D. Harr. 1982. Peak streamflows from the transient snow zone, western Cascades, Oregon. In: Proceedings of the 50th western snow conference. Fort Collins, CO: Colorado State University Press: 27-38.

Cissel, J. H., F. J. Swanson and P. J. Weisberg. 1999. Landscape management using historical fire regimes: Blue River, Oregon. Ecological Applications 9:1217-1231.

Clark, R. N. and G. H. Stankey. December 1979. The Recreation Opportunity Spectrum: A Framework for Planning, Management, and Research. General Technical Report PNW-98. Pacific Northwest Forest and Range Experiment Station, U.S. Department of Agriculture, U.S. Forest Service. 
Clarke, Sharon E., Kelly M. Burnett and Daniel J. Miller. 2008. Modeling streams and hydrogeomorphic attributes in Oregon from digital and field data. Journal of the American Water Resources Association. Vol. 44, pp. 459-477.

Climate Impacts Group. 2004 (updated August 2004). Overview of Climate Change Impacts in the U.S. Pacific Northwest. University of Washington. Seattle, WA. Available online at: http:// www.ef.org/ westcoastclimate/D_PNW\%20impacts.pdf

Coastal Landscape Analysis and Modeling Study (CLAMS) website: http://www.fsl.orst.edu/ clams/ download/posters/ip_poster3.pdf

Cocksedge, Wendy. 2006. Incorporating non-timber forest products into sustainable forest management. An overview for forest managers. Royal Roads University, Victoria, B.C. Canada.

Cockle, K.L. and J.S. Richardson. 2003. Do riparian buffer strips mitigate the impacts of clearcutting on small mammals? Biological Conservation 113(2003):133-140.

Cohen, W.B., T.A. Spies, R.J. Alig [and others]. 2002. Characterizing 23 years (1972-95) of stand replacement disturbance in western Oregon forests with Landsat imagery. Ecosystems 5:122-137.

Cole, E.K. 1996. Influence of limited access roads on Roosevelt elk in the Oregon Coast Range. M.S. Thesis. Oregon State University. Corvallis, OR.

Cole, E.K., M.D. Pope and R.G. Anthony. 1997. Effects of road management on movement and survival of Roosevelt elk. Journal of Wildlife Management 61(4):1115-1126.

Collins, B. 1995. Riverine gravel mining in Washington state, physical effects with implications for salmonid habitat, and summary of government regulations. Report prepared for: U.S. Environmental Protection Agency. Completion report prepared for: Grant X-000694-01-0.

Compton, J.E., M.R. Church, S.T. Larned and W.E. Hogsett. 2003. Nitrogen export from forested watersheds in the Oregon Coast Range: the role of N2-fixing red alder. Ecosystems 6: 773-785.

Congalton, Russell G. and Kass Green. 1999. Assessing the accuracy of remotely sensed data: principles and practices. Lewis Publishers, USA

Connelly, J.W., S.T. Knick, M.A. Schroeder and S.J. Stiver. 2004. Conservation assessment of greater sagegrouse and sagebrush habitats. Western Association of Fish and Wildlife Agencies. Cheyenne, WY.

Cook, J.G., L.L. Irwin, L.D. Bryant, R. Riggs, and J.W. Thomas. 1998. Relations of forest cover and condition of elk: a test of the thermal cover hypothesis in summer and winter. Wildlife Monographs No. 141

Cook, J.G., L.L. Irwin, L.D. Bryant, R. Riggs, and J. W. Thomas. 2004. Thermal cover needs of large ungulates: a review of hypothesis tests. In: Transaction of the Sixty-ninth North American and Natural Resources Conference. March 16-20, 2004. Spokane, Washington. J. Rahm, editor. Wildlife Management Institute, Washington, D.C.

Coombs, Eric M., Janet K. Clark, Gary L. Piper and Alfred F. Cofrancesco, Jr. 2004. Biological Control of Invasive Plants in the United States. Oregon State University Press. Corvallis, OR. Copeland, S. 2005. Fire Effects on Selected Rare Plants of the Siskiyou Mountains, Oregon. A senior thesis submitted to the Department of Biology, The Colorado College. 
Copeland, S. 2005. Fire Effects on Selected Rare Plants of the Siskiyou Mountains, Oregon. A Senior Thesis submitted to the Department of Biology, The Colorado College.

Cordone, A.J. and D.W. Kelley. 1961. The influences of inorganic sediment on the aquatic life of streams. Reprint from California Fish and Game. Vol. 47, No. 2. [155k]. California Department of Fish and Game, Inland Fisheries Branch. Sacramento, CA. 41 pp.

Council on Environmental Quality. 1997. Environmental Justice Guidance Under the National Environmental Policy Act.

Courtney, S.P., J.A. Blakesley, R.E. Bigley [and others]. 2004. Scientific evaluation of the status of the northern spotted owl. Sustainable Ecosystems Institute. Portland, OR.

Courtney, S.P., A.B. Carey, M.L. Cody, K. Engle, K.E. Fehring, J.F. Franklin, M.R. Fuller, R.J.

Gutiérrez, J.F. Lehmkuhl, M.A. Hemstrom, P.F. Hessburg, S.L. Stephens, L.A. Sztukowski \& L. Young. 2008. Scientific review of the Draft Northern Spotted Owl Recovery Plan and reviewer comments. Sustainable Ecosystem Institute, Portland, OR.

Cram, Douglas, S., Terrell T. Baker and Jon C. Boren. 2006. Wildland Fire Effects in Silviculturally Treated Vs. Untreated Stand of Arizona and New Mexico. Research Paper RMRS- RP-55. Rocky Mountain Research Station, U.S. Department of Agriculture, U.S. Forest Service. Fort Collins, CO.

Cude, Curtis G., 2007. Accommodating Change of Bacterial Indicators in Long. Term Water Quality Datasets. Journal of the American Water Resources Association, vol. 41, Issue 1

Cullen, S.A. 2002. Using radar to monitor populations and assess habitat associations of marbled murrelets within the Sunshine Coast Forest District. Ministry of Water, Land and Air Protection. Surrey, British Columbia, Canada. 25 p.

Curtis, Robert O. 1982. A simple index of stand density for Douglas-fir. Forest Science (28)1: 92-94.

Curtis, Robert O. and David D. Marshall. 1986. Levels of growing stock. Cooperative study in Douglas-fir. Report No. 8 - The LOGS study: 20-year results. Research paper PNW-RP-356. USDA Forest Service. Portland, OR.

Danehy, R.J., S.S. Chan, G.T. Lester, R.B. Langshaw, and T. Turner. 2007. Periphyton and macroinvertebrate assemblage structure in headwaters bordered by mature, thinned, and clearcut Douglas-fir stands. For. Sci. 53:294-307.

Davis, Kevin Q. 2006. Association of O\&C Counties to County Board of Commissioners. 17 August 2006. Portland, OR.

Davis, R.J. Personal communication to Eric Greenquist, January 29, 2008. Discussion of the unpublished results of an analysis of fire hazard and risk to high quality northern spotted owl habitat in western Washington and western Oregon, prepared by R.J. Davis, National Forest Service, J. Lint, Bureau of Land Management, E.N. Rybak, National Forest Service and J. Thrailkill, U.S. Fish and Wildlife Service.

Deal, R.L. 2006. Red alder stand development and dynamics. in: Red alder-a state of knowledge. pp. 44-54. Deal, R.L. and C.A. Harrington, editors. 2006. General Technical Report PNW-GTR- 669. Pacific Northwest Research Station, U.S. Department of Agriculture U.S. Forest Service. Portland, OR.

DellaSalla, D., S. Reid, T. Frest and J. Strittholt. 1999. A Global Perspective on the Biodiversity of the Klamath-Siskiyou Ecoregion. Natural Areas Journal 19:300-319. 
Denman, K.L., G. Brasseur, A. Chidthaisong and others 2007. Couplings between changes in the climate system and biogeochemistry. Pp. 499-587 in IPCC. Climate Change 2007: The Physical Science Basis. Contribution of Working Group I to the Fourth Assessment Report of the Intergovernmental Panel on Climate Change. Solomon, S., D. Qin, M. Manning and others, Eds. Cambridge University Press, Cambridge, UK and New York, NY.

Dent, L. F., and J. B. S. Walsh. 1997. Effectiveness of riparian management areas and hardwood conversions in maintaining stream temperature. Oregon Department of Forestry, Forest Practices Technical Report Number 3. Salem, OR.

Department of Energy (DOE). 2007. Technical Guidelines: Voluntary Reporting of Greenhouse Gases (1605[b]) Program. Office of Policy and International Affairs. http://www.pi.energy.gov/ enhancingGHGregistry/documents/January2007_1605bTechnicalGuidelines.pdf (accessed March 2008).

DeSanto, T.L. and M.F. Willson. 2001. Predator abundance and predation of artificial nests in natural and anthropogenic coniferous forest edges in southeast Alaska. Journal of Field Ornithology 72(1): 136-149

Dewey, Steven A. 1991. Weedy thistles of the western United States. In: Noxious range weeds. Westview Special Studies in Agricultural Science and Policy. pp. 247-253. [23552]. James, Lynn F., John O. Evans, Michael H. Ralphs, and Dennis R. Child, editors. Westview Press. Boulder, CO:

Dillar, 1909, 1914, as found in Weissenborn, A. E., 1969, Mineral and Water Resources of Oregon: State of Oregon Department of Geology and Mineral Industries, Bulletin 64, 468p. and Maps

DiLucca, M.C., J.W. Goudie and S.C. Stearns-Smith. 2004. Variable retention yield adjustment factors for TIPSY. Extension Note No. 69. British Columbia Ministry of Forests, Forest Science Program. Victoria, British Columbia, Canada.

DiTomaso, Joseph M. and Kohn D. Gerlach, Jr. 2000. Centaurea solstitialis. In: Invasive plants of California's Wildlands. 101-106. [40301]. Bossard, Carla C., John M. Randall, and Marc. C. Hoshovsky, editors. University of California Press. Berkeley, CA.

Dixon, G.E. (compiler). 2003. Essential FVS: A user's guide to the forest vegetation simulator. Internal Report, 193 p. Forest Management Service Center, U.S. Department of Agriculture, U.S. Forest Service. Fort Collins, CO.

Dolloff C. A. 1986. Effects of stream cleaning on juvenile coho salmon and Dolly Varden in southeast Alaska. Transactions of the American Fisheries Society 115:743-755.

Dolloff, C.A. and M.L. Warren, Jr. 2003. Fish relationships with large wood in small streams. In: The ecology and management of wood in world rivers. pp. 179-193. Gregory, S.V.; Boyer, K.L.; Gurnell, A.M. editors. American Fisheries Society. Bethesda, MD.

Donald, William W. 1994. The biology of Canada thistle (Cirsium arvense). Reviews of Weed Science 6: $77-$ 101. [37298].

Donato, D.C., J.B. Fontaine, J.L. Campbell [and others]. 2006. Post-wildfire logging hinders regeneration and increases fire risk. Science 311: 352.

Doyle, Kathleen M., D.H. Knight, D.L. Taylor [and others]. 1998. Seventeen years of forest succession following the Waterfalls Canyon Fire in Grand Teton National Park, Wyoming. International Journal of Wildland Fire 8(1): 45-55. 
Dugger, K.M., F. Wagner, R.G. Anthony and G.S.Olson. 2005. The relationship between habitat characteristics and demographic performance of northern spotted owls in southern Oregon. The Condor 107:863-878.

Dunbar, D.L., B.P. Booth, E.D. Forsman [and others]. 1991. Status of the spotted owl, Strix occidentalis, and barred owl, Strix varia, in southwestern British Columbia. Canadian Field Naturalist 105:464-468.

Duncan, S. 2002. Postfire Logging: Is it beneficial to a forest? Science Findings Issue 47. Pacific Northwest Research Station, U.S. Department of Agriculture, U.S. Forest Service.

Duncan, S. and J. Ward. 1985. The influence of watershed geology and forest roads on the composition of spawning gravel. Northwest Science 59: 204-212.

Dunne, T. and L. B. Leopold. 1978. Water in environmental planning. 818 pp. W.H. Freeman and Co. San Francisco, CA

Dunne, T., J. Agee, S. Bessinger [and others]. 2001. A scientific basis for the prediction of cumulative watershed effects. The University of California Committee on Cumulative Watershed Effects. Report No. 46. University of California Wildland Resource Center.

DuRoss, C. B., Blakely, R. J., Wells, R. E., 2002, Geologic Cross Sections through the Roseburg 30' X 60' Quadrangle: New Constraints from Potential Field Modeling: Geologic Society of America Abstracts with Programs, V. 34, p. 32. as provided by Wells, R. E., 2008, Personal Communications with Ray E. Wells, Geologist; United States Geologic Survey. March 12, 2008.

Ehinger, Paul F. \& Associates. 2005. The change in mill ownership and log demand since 1999 and its impact on western Washington timber supply. Sept. 5, 2005.

Ehinger, Paul F. \& Associates. 2006. Forest Products Industry, Western Oregon: Analysis of industry by log processing capabilities, species, log diameter requirements and constraints limited by mill equipment and mill configuration.

Ellestrand, N and D. Elam. 1993. Population genetic consequences of small population size: implications for plant conservation. Annual review. Ecological Systems: 24:217-42.

Energy Information Administration 2007. Annual Energy Outlook 2006 with Projections to 2030, Release Date December 2005. http://www.eia.doe.gov/oiaf/aeo/pdf/aeotab_13.pdf

Espinosa, R. 2007. USDI, BLM, Roseburg District. personal communication with Christopher Foster. Everest, F.H., F.B. Lotspeich and W.R. Meehan. 1982. New perspectives on sampling, analysis, and interpretation of spawning gravel quality. In Acquisition and utilization of aquatic habitat inventory information, editor N.B. Armantrout, pp. 325-333. Western Division, American Fisheries Society. Portland, OR.

Everest, Fred H. and Gordon H. Reeves. 2007. Riparian and aquatic habitats of the Pacific Northwest and southeast Alaska: ecology, management history, and potential management strategies. Gen. Tech. Rep. PNW-GTR-692. Portland, OR: U.S. Department of Agriculture, Forest Service, Pacific Northwest Research Station. $130 \mathrm{p}$.

Everest, F.H., R.L. Beschta, J.D. Scrivener, K.V. Koski, J.R. Sedell and C.J. Cederholm. 1987. Fine sediment and salmonid production - a paradox. In: Streamside management and forestry and fishery interactions. pp. 98-142. E. Salo and T. Cundy editors. College of Forestry Resources, University of Washington, Cont. 57. Seattle, WA. 
False-brome Working Group. (n.d.). Retrieved January 25, 2007 from: http://www.appliedeco. org/FBWG. htm

False-brome Working Group Newsletter. January 2004. Retrieved January 25, 2007 from: http:// www. appliedeco.org/BRSYweb/finalJan2004newsletter.pdf

Federal Register. 1980. U.S. Fish and Wildlife Service. Listing the Oregon Silverspot Butterfly as a Threatened Species with Critical Habitat. Vol. 45, No. 129: 44935-44938.

Federal Register. 1990. U.S. Fish and Wildlife Service. Endangered and threatened wildlife and plants; determination of threatened status for the northern spotted owl; final rule. Vol. 55, No. 123: 26114-26194.

Federal Register. 1992a. U.S. Fish and Wildlife Service. Endangered and threatened wildlife and plants; determination of critical habitat for the northern spotted owl; final rule. Vol. 57, No. 10: 1796-1835.

Federal Register. 1992b. U.S. Fish and Wildlife Service. Endangered and threatened wildlife and plants; determination of threatened status for the Washington, Oregon and California population of the marbled murrelet. Vol. 57, No. 191: 45328-45337.

Federal Register. 1993. U.S. Fish and Wildlife Service. Endangered and Threatened Wildlife and Plants; Determination of Threatened Status of the Pacific Coast Population of the Western Snowy Plover; Final Rule. Vol. 58, No. 42: 12864-12874.

Federal Register. 1996. U.S. Fish and Wildlife Service. Endangered and threatened wildlife and plants; final designation of critical habitat for the marbled murrelet. Vol. 61, No. 102: 26256-

26330 .

Federal Register. 1999a. Endangered and Threatened Wildlife and Plants; Proposed Rule to Remove the Bald Eagle in the Lower 48 States from the Federal List of Endangered and Threatened Wildlife. U.S. Fish and Wildlife Service. Vol. 64, No. 128: 36454-36464.

Federal Register. 1999b. National Marine Fisheries Service. Designated Critical Habitat; Central California Coast and Southern Oregon/Northern California Coasts Coho Salmon. 64(86):24049.

Federal Register. 10 December 1999c. U.S. Fish and Wildlife Service. Final rule on listing Fritillaria gentneri, Vol. 64, No. 237: 69195-69203.

Federal Register. 25 January 2000. U.S. Fish and Wildlife Service. Endangered and threatened wildlife and plants; endangered status for Erigeron decumbens var. decumbens (Willamette daisy) and Fender's blue butterfly (Icaricia icarioides fenderi) and threatened status for Lupinus sulphuerus ssp. kincaid ; Final Rule. Vol. 65, No. 16: 3875-3890.

Federal Register. 2003. U.S. Fish and Wildlife Service. Endangered and Threatened Wildlife and Plants; Final Rule to Remove the Douglas County Distinct Population Segment of Columbian White-Tailed Deer from the Federal List of Endangered and Threatened Wildlife. Vol. 68, No. 142: 43647-43659.

Federal Register. 2004. U.S. Fish and Wildlife Service. Endangered and Threatened Wildlife and Plants; 12-month Finding for a Petition to List the West Coast Distinct Population Segment of the Fisher (Martes pennanti). Vol. 69, No. 68: 18770-18792

Federal Register. 2005a. U.S. Fish and Wildlife Service. Endangered and threatened wildlife and plants; 12month finding for petitions to list the greater sage-grouse as threatened or endangered; proposed rule. Vol. 70, No. 8: 2244-2282. 
Federal Register. 2005b. U.S. Fish and Wildlife Service. Endangered and Threatened Wildlife and Plants; Designation of Critical Habitat for the Pacific Coast Population of the Western Snowy Plover; Final Rule. Vol. 70, No. 188: 56970-57018.

Federal Register. 2 November 2005c. U.S. Fish and Wildlife Service. Endangered and threatened wildlife and plants: designation of critical habitat for the Fender's Blue Butterfly (Icaricia icarioides fenderi), Lupinus sulphureus ssp. kincaidii (Kincaid's Lupine), and Erigeron decumbens var. decumbens (Willamette Daisy). Proposed rule. 70:66492-66539.

Federal Register. 2005d. National Marine Fisheries Service. Endangered and threatened species: designation of critical habitat for 12 evolutionarily significant units of West Coast salmon and steelhead in Washington, Oregon, and Idaho. 70(170):52630.

Federal Register. 2006a. U.S. Fish and Wildlife Service (USFWS). Endangered and threatened wildlife and plants; removing the bald eagle in the lower 48 states from the list of endangered and threatened wildlife. Washington, D.C. Vol. 71, No. 32: 8238-8251.

Federal Register. 2006b. USFWS. Endangered and threatened wildlife and plants: 12-month finding on a petition to delist the Pacific Coast population of the Western Snowy Plover. Vol. 71, No. 77: 20607-20624.

Federal Register. 2006c. USFWS. Endangered and threatened wildlife and plants: designation of critical habitat for four vernal pool crustaceans and eleven vernal pool plants, Final rule. Vol. 71, No. 28: 7118-7166.

Federal Register. 2006d. Endangered and threatened wildlife and plants: designation of critical habitat for the marbled murrelet. Vol. 71. No. 176, pp. 53838-53591.

Federal Register 2008. National Oceanic and Atmospheric Administration. Endangered and Threatened Species: Final Threatened Listing Determination, Final Protective Regulations, and Final Designation of Critical Habitat for the Oregon Coast Evolutionarily Significant Unit of Coho Salmon; Final Rule. Vol. 73, No. 28.

Ferns, M.L. and D.F. Huber. 1984, Mineral resources map of Oregon: State of Oregon Department of Geology and Mineral Industries geological map series GMS-36, Map.

(FEMAT) USDA Forest Service, USDC National Oceanic and Atmospheric Administration, USDC National Marine Fisheries Service, USDI Bureau of Land Management, USDI Fish and Wildlife Service, USDI National Park Service, and Environmental Protection Agency. 1993. Forest ecosystem management: an ecological, economic, and social assessment. Report of the Forest Ecosystem Management Team.

Field, C.B., L.D. Mortsch,, M. Brklacich, D.L. Forbes, P. Kovacs, J.A. Patz, S.W. Running and M.J. Scott. 2007. North America. Pp. 617-652 in IPCC. Climate Change 2007: Impacts, Adaptation and Vulnerability. Contribution of Working Group II to the Fourth Assessment Report of the Intergovernmental Panel on Climate Change, M.L. Parry, O.F. Canziani, J.P. Palutikof, P.J. van der Linden and C.E. Hanson, Eds., Cambridge University Press, Cambridge, UK.

Findholt, S.L., B.K. Johnson, D.Damiran, T. DelCurto and J.G. Kie. 2004. Diet composition, dry matter intake and diet overlap of mule deer, elk and cattle. In: Transaction of the sixty-ninth North American and Natural Resources Conference, March 16-20, 2004, Spokane, Washington. J. Rahm, editor. Wildlife Management Institute, Washington, D.C.

Findlay, S., G.E. Likens, L. Hedin, S.G. Fisher, and W.H. McDowell. 1977. Organic matter dynamics in Bear Brook, Hubbard Brook Experimental Forest, New Hampshire, USA. Journal of the North American Benthological Society, Vol. 16, No. 1 [43-46]. doi:10.2307/1468230 
Fitzgerald, Stephen A. 2002. Fire in Oregon's Forests: Risks, Effects, and Treatment Options. Extension Forestry Program, Oregon State University. Corvallis, OR.

Ford, R.G., G.K. Himes Boor, B.E. Sharp and J.L. Casey. 2002. Estimates of bird impacts resulting from the M/V Kure/Humboldt Bay oil spill of November 5, 1997. Final draft report prepared for California Department of Fish and Game. Office of Spill Prevention and Response. 71 p.

Forest Health Technology Enterprise Team. 1997. Killing them softly: Using natural enemies to combat exotic weeds. Update Team. Spring 1997. Retrieved January 26, 2007: http://www.fs.fed.us/foresthealth/ technology/ news/Spring97.html

Forman, R.T.T. 1995. Land Mosaics: The Ecology of Landscapes and Regions. Cambridge University Press, New York, NY.

Forsight. 2006. How to handle non-uniform stand density (clumpiness) in ORGANON. The FORsight Resource (3)3: 1-2. FORsight Resources LLC. Vancouver, WA

Forsman, E.D., E.C. Meslow and H.M. Wight. 1984. Distribution and biology of the spotted owl in Oregon. Wildlife Monographs 87:1-64.

Forsman, E.D., I.A. Otto, S.G. Sovern, M. Taylor, D.W. Hays, H. Allen, S.L. Roberts and D.E. Seaman. 2001. Spatial and temporal variation in diets of spotted owls in Washington. Journal of Raptor Research 35(2):141150.

Forsman, E.D., R.G. Anthony, J.A. Reid, P.J. Loschl, S.G. Sovern, M.Taylor, B.L. Biswell, A. Ellingson, E.C. Meslow, G.S. Miller, K.A.Swindle, J.A. Thrailkill, F.F. Wagner, and D. E. Seaman. 2002. Natal and breeding dispersal of northern spotted owls. Wildlife Monographs No. 149.

Forsman, E.D., R.G. Anthony, E.C. Meslow and C.J. Zabel. 2004. Diets and foraging behavior of northern spotted owls in Oregon. Journal of Raptor Research 38(3):214-230.

Forsman, E.D., J.A. Reid, M.S. Koranda, J.S. Mowdy and A.L. Price. 2006. Demographic characteristics of northern spotted owls (Strix occidentalis) on the Tyee Density Study Area, Roseburg, Oregon: 1985-2006. Annual Progress Report. U.S. Department of Agriculture, Forest Service, Pacific Northwest Research Station, Oregon Department of Fish and Wildlife, Oregon State University, Corvallis, Oregon.

Forster, P., V. Ramaswamy, P. Artaxo, T. Berntsen, R. Betts, D.W. Fahey, J. Haywood, J. Lean, D.C. Lowe, G. Myhre, J. Nganga, R. Prinn, G. Raga, M. Schulz and R. Van Dorland. 2007. Changes in atmospheric constituents and in radiative forcing. Pp. 129-234 in IPCC. Climate Change 2007: The Physical Science Basis. Contribution of Working Group I to the Fourth Assessment Report of the Intergovernmental Panel on Climate Change. Solomon, S., D. Qin, M. Manning, Z. Chen, M. Marquis, K.B. Averyt, M. Tignor and H.L. Miller, Eds. Cambridge University Press, Cambridge, UK and New York, NY.

Foster, S.C., C.H. Stein and K.K. Jones. 2001. A guide to interpreting stream survey reports. P.A. Bowers, editor. Information Reports 2001-06. Oregon Department of Fish and Wildlife. Portland, OR.

Franklin, J.F. 2004. Sudden Oak Death. Appendix 8. In: Scientific evaluation of the status of the northern spotted owl. Courtney, S.P., J.A. Blakesley, R.E. Bigley, M.L. Cody, J.P. Dumbacher, R.C. Fleischer, A.B. Franklin, J.F. Franklin, R.J. Gutierrez, J.M. Marzluff, and L. Sztukowski. Sustainable Ecosystems Institute. Portland, OR.

Franklin, J.F. and C.T. Dyrness. 1988. Natural Vegetation of Oregon and Washington. Oregon State 
Franklin, A.B. and R.J. Guitierrez. 2002. Spotted owls, forest fragmentation, and forest heterogeneity. Studies in Avian Biology. 25: 203-220.

Franklin, J. F.; MacMahon, J.A. 2000. Messages from a Mountain. Science. 288: 1183-1185

Franklin, J.F. and R. Van Pelt. 2004. Spatial aspects of structural complexity in old-growth forests. Journal of Forestry, April/May: pp. 22-28.

Franklin, Jerry F., H.H. Shugart and Mark E. Harmon. 1987. Tree death as an ecological process. Bioscience, Vol. 17, pp. 550-556.

Franklin, A.B., D.R. Anderson, R.J. Guiérrez \& K.P. Burnham. 2000. Climate, habitat quality, and fitness in northern spotted owl populations in northwestern California. Ecological Monographs 70(4):539-590

Franklin, J. F., D. B. Lindenmayer, J.A. MacMahon, A. McKee, J. Magnusson, D.A. Perry, R. Waide. D. R. Foster. 2000. Threads of continuity: ecosystem disturbances, biological legacies and ecosystem recovery. Conservation Biology in Practice. 1: 8-16.

Franklin, J.F., T.A. Spies, R. Van Pelt, A.B. Carey, D.A. Thornburgh, D. Rae Berg, D.B. Lindenmayer. M.E. Harmon, W.S. Keeton, D.C. Shaw, K. Bible and J. Chen. 2002. Disturbances and structural development of natural forest ecosystems with silvicultural implications, using Douglas-fir forests as an example. Forest Ecology and Management 155: 399-423.

Franklin, J.F., D.R. Berg, A.B. Carey and R.A. Hardt. 2006. Old-growth conifer forests. In: Restoring the Pacific Northwest: the Art and Science of Ecological Restoration in Cascadia. pp. 97-121. D. Apostol and M. Sinclair, editors. Island Press. Washington, D.C.

Franklin, Jerry F.; Mitchell, Robert J.; Palik, Brian J. 2007. U. S. Department of Agriculture, Forest Service Northern Research Station, General Technical Report NRS-19. Natural Disturbance and Stand Development Principles for Ecological Forestry.

Freidman, S. 2007. USFWS Botanists. Personal communication with Douglas Kendig. USDI, BLM. Medford, OR.

Froehlich, H.E. and D.H. McNabb. 1984. Minimizing Soil Compaction in Pacific Northwest Forests. In: Forest Soils and Treatment Impacts. Stone, E.L., editor. Proceedings of Sixth North American Forest Soils Conference. June 1983. University of Tennessee Conferences. Knoxville, TN.

Frost, E.J. and R. Sweeney. 2000. Fire Regimes, Fire History and Forest Conditions in the Klamath-Siskiyou Region: An Overview and Synthesis of Knowledge. World Wildlife Fund. Ashland, OR.

Furniss, R.L. and V. M. Carolin. 1977. Western Forest Insects. Miscellaneous Publication No. 1339. 654 pp. U.S. Department of Agriculture, U.S. Forest Service.

Furniss, M., T. Ledwith, M. Love, B. McFadin and S. Flanagan. 1988. Response of road-stream crossings to large flood events in Washington, Oregon and northern California. Six Rivers National forest, Pacific Southwest Region, San Dimas Technology and Development Center, U.S. Department of Agriculture, U.S. Forest Service. San Dimas, CA.

Furniss, M. J., T. D. Roelofs and C. S. Yee. 1991. Road construction and maintenance. In: Influences of forest and rangeland management on salmonid fishes and their habitats. American Fisheries Society Special Publication 19: 297-323 
Gallo, Kirsten, Steven H. Lanigan, Peter Eldred, Sean N. Gordon and Chris Moyer. 2005. Northwest Forest Plan - the first 10 years (1994-2003): preliminary assessment of the condition of watersheds. General Technical Report PNW-GTR-647. 133 pp. Pacific Northwest Research Station, U.S. Department of Agriculture, U.S. Forest Service. Portland, OR, 133 p.

Ganskopp, D. and M. Vavra. 1987. Slope use by cattle, feral horses, deer, and bighorn sheep. Northwest Science 61(2):74-81.

Global Invasive Species Database. Issg Database: Ecology of Euphorbia esula. June 26, 2005. Retrieved July, 2006 from: http://www.issg.org/database/species/ecology.asp?si=83\&fr=1\&sts

Goheen, E.M., E.M. Hansen, A. Kanaskie, M.G. Williams, N. Oserbauer and W. Sutton. 2002. Sudden oak death caused by Phytophthora ramorum in Oregon. Plant Disease 86:441.

Golightly, R.T., P.N. Hebert and D.L. Orthmeyer. 2002. Evaluation of human-caused disturbance on the breeding success of marbled murrelets (Brachyramphus marmoratus) in Redwood National and State Parks, California. 61 pp. Bureau of Land Management, National Park Service, U.S. Fish and Wildlife Service, U.S. Geological Survey, California Department of Fish and Game, and California Department of Parks and Recreation. Arcata, CA.

Gomez, D.M. and R.G. Anthony. 1996. Amphibian and reptile abundance in riparian and upslope areas of five forest types in western Oregon. Northwest Science 70(2):109-119.

Gomez, A., R.F. Powers, M.J. Singer, and W.R. Horwath. 2002. Soil Compaction Effects on Growth of Young Ponderosa Pine Following Litter Removal in California's Sierra Nevada. Soil Science Society of America Journal 66:1334-1343.

Gomi, T., R. C. Sidle, and J. S. Richardson, 2002. Understanding processes and downstream linkages of headwater systems. BioScience, 52, 905-916.

Good, T.P., R.S. Waples and P. Adams (editors). 2005. Updated status of federally listed ESUs of West Coast salmon and steelhead. U.S. Department of Commerce, National Oceanic and Atmospheric Administration. Technical Memo. NMFS-NWFSC-66, 598 p.

Gottlieb, S. 1993. Habitat Utilization and Population Characteristics of the Pokegama Wild Horse Herd. B.S. Thesis. State University of New York, Purchase.

Graham, R.T, Sarah McCaffrey and T.B. Jain. 2004. Science Basis for Changing Forest Structure to Modify Wildfire Behavior and Severity. General Technical Report RMRS-GTR-120. Rocky Mountain Research Station, U.S. Department of Agriculture, U.S. Forest Service.

Grant, Gordon E., Sarah L. Lewis, Frederick J. Swanson, John H. Cissel, and Jeffrey J. McDonnell 2008. Effects of forest practices on peak flows and consequent channel response in western Oregon: a state-ofscience report for western Oregon and Washington. Gen. Tech. Rep. PNWk-GTR-760. U.S. Department of Agriculture, Forest Service, Pacific Northwest Research Station, Corvallis, OR.

Greenberg, Joanne and K.F.Welch. 1988. Hydrologic Process Identification for Western Oregon. 18 pp. Hydrologic Services Co. prepared for Boise Cascade Corporation.

Gregg, MA., J.A. Crawford, M.S. Drut and A.K. DeLong. 1994. Vegetational cover and predation of sage grouse nests in Oregon. Journal of Wildlife Management 58(1):162-168. 
Gremel, S. 2000. Spotted owl monitoring in Olympic National Park: 2000 annual report. U.S. Department of the Interior, National Park Service, Olympic National Park. Port Angeles, WA.

Gremel, S. 2005. Factors controlling distribution and demography of northern spotted owl in a reserved landscape. M.S. thesis. University of Washington.

Guitierrez, R., M. Cody, S. Courtney and D. Kennedy. 2004. Assessment of the potential threat of the northern barred owl. Chapter 7. In: Scientific evaluation of the status of the northern spotted owl. Courtney, S.P., J.A. Blakesley, R.E. Bigley, M.L. Cody, J.P. Dumbacher, R.C. Fleischer, A.B. Franklin, J.F. Franklin, R.J. Gutierrez, J.M. Marzluff, and L. Sztukowski, editors. Sustainable Ecosystems Institute. Portland, OR.

Gurevitch, J., S. Scheiner and G. Fox. 2006. The Ecology of Plants. Second Edition. Sinauer Associates Inc.

Haerter, J. 2007. Personal Communications on 23 February 2007 with Jim Haerter, Oil and Gas Program Lead, USDI BLM, California State Office, Sacramento, CA.

Hagen, C.A. 2005. Greater sage-grouse conservation assessment and strategy for Oregon: a plan to maintain and enhance populations and habitat. Oregon Department of Fish and Wildlife. Salem, OR.

Haggerty, S.M., D.P. Batzer, and C.R. Jackson. 2004. Macroinvertebrate response to logging in coastal headwater streams of Washington, U.S.A. Canadian Journal of Fisheries and Aquatic Science: 61: 529-537.

Halferty, M. 20 February 2007. Personal Communications with Peggy Halferty, P.E, Environmental Manager, Methane Energy Corporation.

Hall, J.D. and Lantz, R.L. 1969. Effects of logging on the habitat of coho salmon and cutthroat trout in coastal streams. In Symposium on salmon and trout in streams. Edited by T.G. Northcote. Institute of Fisheries, Univ. British Columbia. pp. 355-375.

Hamer, T.E. and S.K. Nelson. 1995. Characteristics of marbled murrelet nest trees and nesting stands. In: Ecology and conservation of the marbled murrelet. C.J. Ralph, G.L. Hunt, Jr., M.G. Raphael, and J.F. Piatt, editors. Gen. Tech. Rep. PSW-GTR-152, Pacific Southwest Research Station, U.S. Department of Agriculture, U.S. Forest Service. Albany, CA.

Hamer, T.E., S.G. Seim and K.R. Dixon. 1989. Northern spotted owl and northern barred owl habitat use and home range size in Washington: preliminary report. Washington Department of Wildlife. Olympia, WA.

Hamer, T.E., D.L. Hays, C.M. Senger and E.D. Forsman. 2001. Diets of northern barred owls and northern spotted owls in an area of sympatry. Journal of Raptor Research 35(3):221-227.

Hann, D.W. and C.-H. Wang. 1990. Mortality equations for individual trees in southwest Oregon. Research Bulletin 67. Oregon State University, Forest Research Laboratory, Corvallis, OR. 17 p.

Hann, David W. 1992. Letter to Robert Lewis, BLM Medford District. 6 July 1992. On file at the Roseburg BLM District, Roseburg, OR.

Hann, David W. 1998. Extending southwest Oregon's dominant height growth equation to older ages. Research Contribution 18. Oregon State University, Forest Research Laboratory. Corvallis, OR. 16 p.

Hann, D.W. and M.L. Hanus. 2001. Enhanced mortality equations for trees in the mixed conifer zone of southwest Oregon. Forest Research Lab., Oregon State University, Corvallis, Oregon.

Research Contribution 34.34 p. 
Hann, David W. 2005. ORGANON user manual: Edition 8.0. Department of Forest Resources, Oregon State University. Corvallis, OR. 130 p.

Hann, David W. and John A. Scrivani. 1987. Dominant-Height growth and site-index equations for Douglas-fir and Ponderosa pine in southwest Oregon. Forest Resource Lab Research Bulletin 59. Oregon State University, College of Forestry. Corvallis, OR.

Hann, Wendel, Doug Havlina and Ayn Shlisky. 2003. Interagency and The Nature Conservancy fire regime condition class website. U.S. Department of Agriculture, U.S. Forest Service, U.S. Department of the Interior; The Nature Conservancy; and Systems for Environmental Management [frcc.gov].

Hanley, T.A. 1984. Habitat patches and their selection by wapiti and black-tailed deer in a coastal montane coniferous forest. Journal of Applied Ecology 21:423-436.

Hansen, Malin J., and Anthony P. Clevenger. 2005. The influence of disturbance and habitat on the presence of non-native plant species along transport corridors. Biological Conservation 125 (2): 249-259.

Hardy, Colin C. and Stephen F. Arno. 1996. The Use of Fire in Forest Restoration. General Technical Report INT-GTR-341. Intermountain Research Station, U.S. Department of Agriculture, U.S. Forest Service. Ogden, UT.

Harmon, M.E. 2001. Carbon sequestration in forests: addressing the scale question. Journal of Forestry 99(4): 24-29.

Harmon, M.E. 2006. Atmospheric Carbon Dioxide. pp. 20-29 in Forests, Carbon and Climate Change: A Synthesis of Science Findings. Oregon Forest Research Institute. 182 p.

Harmon, M.E., K. Bible, M.G. Ryan, D.C. Shaw, H. Chen, J. Klopatek, and X. Li. 2004. Production, respiration, and overall carbon balance in an old-growth Pseudotsuga-Tsuga forest ecosystem. Ecosystems 7: 498-512.

Harr, R. D. 1976. Hydrology of Small Forest Streams in Western Oregon. General Technical Report PNW55. Denver Service Center, U.S. Department of Agriculture, U.S. Forest Service. Denver, CO.

Harr, R.D. 1981. Some characteristics and consequences of snowmelt during rainfall in western Oregon. Journal of Hydrology 53: 277-304

Harr, R.D. 1986. Effects of clearcutting on rain-on-snow runoff in western Oregon: a new look at old studies. Water Resources Research. 22: 383-392.

Harr, R. and B. Coffin. 1992. Influence of timber harvest on rain-on-snow runoff: a mechanism for cumulative watershed effects: Interdisciplinary approaches to hydrology and hydrogeology. American Institute of Hydrology. pp. 455-469.

Harr, R.D.; McCorison, F.M. 1979. Initial effects of clearcut logging on size and timing of peak flows in a small watershed in western Oregon. Water Resources Research. 15(1): 90-94.

Harr, R., R. Fredriksen and J. Rothacher. 1979. Changes in Streamflow Following Timber Harvest in Southwestern Oregon. Research Paper PNW-249. Pacific Northwest Research Station, U.S. Department of Agriculture, U.S. Forest Service. 22 p.

Harr, R., W. Harper, J. Krygier and F. Hsieh. 1975. Changes in Storm Hydrographs after Road Building and Clear-Cutting in the Oregon Coast Range. Water Resources Research, 11(3): 436-444. 
Harrington, C.A. 2006. Biology and ecology of red alder. In: Red alder-a state of knowledge. pp. 21-43. General Technical Report PNW-GTR-669. Deal, R.L. and C.A. Harrington, editors. Pacific Northwest Research Station, U.S. Department of Agriculture, U.S. Forest Service. Portland, OR.

Harrington, C.A. and S.H.Schoenholtz, Editors. 2005. Productivity of Western Forests: A Forest Products Focus. General Technical Report PNW-GTR-642 August 2005.

Harris, D.D., L.L Hubbard and L.E. Hubbard. 1979. Magnitude and Frequency of Floods in Western Oregon. Open-File Report 79-553. U.S. Geological Survey. 35 p.

Harris, C.C., W. McLaughlin, G. Brown and D. Becker. 2000. Rural communities in the inland Northwest, an assessment of small communities in the interior and upper Columbia River basins. General Technical Report NPW-GTR-477. Pacific Northwest Research Station, U.S. Department of Agriculture, U.S. Forest Service. Portland, OR. 120 p.

Hartman, G.F. and T.G. Brown. 1987. Use of small, temporary, floodplain tributaries by juvenile salmonids in a West Coast rain-forest drainage basin, Carnation Creek, British Columbia. Canadian Journal of Fisheries and Aquatic Sciences 44:262-270.

Hartman, G.F., J.C. Scrivener and M.J. Miles. 1996. Impacts of logging in Carnation Creek, a high-energy coastal stream in British Columbia, and the implication for restoring fish habitat. Canadian Journal of Fisheries and Aquatic Sciences 53 (Supplement 1):237-251.

Hayden et al. 1991. In: Washington Forest Practices Board. 1997. Standard methodology for conducting watershed analysis, Ver. 4.0. Online: http://www.dnr.wa.gov/forestpractices/watershedanalysis/manual/ hydrology.pdf. Washington State Department of Natural Resources. Olympia, WA.

Hayes, J.P., S.S. Chan, W.H. Emmingham, J.C. Tappeiner, L.D. Kellog and J.F. Bailey. 1997. Wildlife responses to thinning in young forests in the Pacific Northwest. Journal of Forestry 95: 28-33.

Hayes, J.P., J.M. Weikel and M.P. Huso. 2003. Response of birds to thinning young Douglas-fir forests. Ecological Applications 13:1222-1232.

Hayes, J.P., S.H. Schoenholtz, M.J. Hartley, G.M. Murphy, R.F. Powers, D. Berg, and S.R. Radosevich 2005. Environmental consequences of intensively managed forest plantations in the Pacific Northwest. Journal of Forestry. March 2005.

Hayner, personal communication. 2007

Haynes, R.W., D.M. Adams, R.J. Alig, R.J., P.J. Ince, J.R. Mills and X. Zhou. 2006a. (Draft) The 2005 RPA timber assessment update. http://www.fs.fed.us/pnw/about/programs/hnri/index.shtml

Haynes, Richard W., Bernard T. Bormann, Danny C. Lee and Jon R. Martin, technical editors. 2006b.

Northwest Forest Plan - the first 10 years (1994-2003): synthesis of monitoring and research results. General Technical Report PNW-GTR-651. Pacific Northwest Research Station, U.S. Department of Agriculture, U.S. Forest Service. Portland, OR. 292 p.

Healy, M. C. 1991. Life history of chinook salmon (Oncorhynchus tshawytscha). Pages 311-394 in C. Groot and L. Margolis, editors. Pacific salmon life histories. UBC Press, Vancouver, BC, Canada.

Healy, Evelyn and Joseph DiTomaso. February 20, 2002. Yellow starthistle information, Weed research and information center (producer). University of California. Davis, CA. Retrieved January 29, 2007 from <http:// wric.ucdavis.edu/yst/biology/yst_fact_sheet.html> 
Hebert, P.N. and R.T. Golightly. 2003. Breeding biology, and human-caused disturbance to nesting of marbled murrelets (Brachyramphus marmoratus) in Northern California: progress report 2002. Unpublished draft report. Department of Wildlife, Humboldt State University. Arcata, CA.

Heckman, Charles W. 1999. The encroachment of exotic herbaceous plants into the OlympicNational Forest. Northwest Science 73(4): 264-276. [36188]

Helms, John A. (ed.). 1998. The dictionary of forestry. Society of American Foresters. 210 p.

Herter, D.R. and L.L. Hicks. 2000. Barred owl and spotted owl populations and habitat in the central Cascade Range of Washington. Journal of Raptor Research 34(4): 279-286.

Hess, R., 2001, Nevada Oil and Gas Well Map: Nevada Bureau of Mines and Geology, Map. http://www. nbmg.unr.edu/lists/oil/map color.jpg

Hessburg, Agee, and Franklin. 2005. Dry forests and wildland fires of the Inland Northwest USA: Contrasting the landscape ecology of the pre-settlement and modern eras.

Hibbs, D.E. and A.L. Bower. 2001. Riparian forests in the Oregon Coast Range. Forest Ecology and Management 154: 201-213.

Hicks, B. J., J. D. Hall, P. A. Bisson and J. R. Sedell. 1991. Responses of salmonids to habitat changes. American Fisheries Society Special Publication 19:483-518.

Hickman, J., editor. 1993. The Jepson manual: higher plants of California. University of California Press. Berkeley and Los Angeles, CA.

Hitchcock, C.L. and A. Cronquist. 1973. Flora of the Pacific Northwest. University of Washington Press. Seattle, WA.

Hogan, C. 1991. Snowy plover and human activities at Damon Point, Washington, May 1 to June 10, 1991. Unpublished report to the Washington Department of Wildlife. Olympia, WA. 10 p.

Holaday, S. 1992. Summertime water temperature trends in Steamboat Creek Basin, Umpqua National Forest. MS thesis. Oregon State University. Corvallis, OR.

Holloran, M.J. and S.H. Anderson. 2005. Spatial distribution of greater sage-grouse nests in relatively contiguous sagebrush habitats. The Condor 104:742-752.

Hooper, Douglas R. 1973. Evaluation of the effects of flows on trout stream ecology. Emeryville, Cal: Pacific Gas and Electric Company, Dept. of Engineering Research

Hoover, C.M., R.A. Birdsey, L.S. Heath, and S.L. Stout. 2000. How to estimate carbon sequestration on small forest tracts. Journal of Forestry 98(9): 13-19.

Hoover, C.M. and S.L. Stout. 2007. The carbon consequences of thinning techniques: stand structure makes a difference. Journal of Forestry 105(5): 266-270.

Horn, R., J.Vossbrink, S.Peth, and S.Becker 2007. Impact of modern forest vehicles on soil physical properties. Forest Ecology and Management 248 (2007) 56-63.

Hoshovsky, Marc. 1986. Element Stewardship Abstract for Cystisus scoparius and Genista monspessulamus: Scotch broom and French broom. The Nature Conservancy. 1815 North Lynn Street, Arlington, VA. 22209. 
Hosten, P.E., G. Hickman, and D. Schuster. 2007. Recent and historic changes (5 to 30 years) in plant community composition in the Cascade-Siskiyou National Monument, southwest Oregon. USDI Bureau of Land Management, Medford District

Houston, R.A. 1997. Bedrock Geology of Bacona 7.5 Min. Quadrangle, Columbia County, Oregon, Senior Thesis. 36 pp. Unpublished. Advising Professor Dr. Alan Niem. Department of Geosciences, Oregon State University. Corvallis, OR.

Houston, R. 14 December 2005. Personal Communications with Bob Houston, Petroleum- Geothermal Geologist, Oregon Department of Geology and Mineral Industries. Interagency Tour of Drill Sites, Coos Bay, OR.

Houston, R. February 2007. Personal Communications with Bob Houston, Petroleum-Geothermal Geologist, Oregon Department of Geology and Mineral Industries.

Huff, M. 1995. Historical and current forest landscapes in eastern Oregon and Washington part ii: linking vegetation characteristics to potential fire behavior and related smoke production. General Technical Report PNW-GTR-355. Pacific Northwest Research Station, U.S. Department of Agriculture, U.S. Forest Service. Portland, OR

Huff, M., P. Jodice, J. Baldwin, S. Miller, R. Young, K. Ostrom, C.J. Ralph, M. Raphael, C. Strong and C. Thompson. 2003. Draft Marbled murrelet effectiveness monitoring northwest forest plan 2002 annual summary report. $29 \mathrm{p}$.

Huff, M.H., M.G. Raphael, S.L. Miller, S.K. Nelson and J. Baldwin (technical coordinators). 2006. Northwest Forest Plan - The first 10 years (1994-2003): status and trends of populations and nesting habitat for the marbled murrelet. General Technical report PNW-GTR-650. Pacific Northwest Research Station, U.S. Department of Agriculture, U.S. Forest Service. Portland, OR.

Hutchison, Max. 1992. Vegetation management guideline: Canada thistle (Cirsium arvense (L) Scop.). Natural Areas Journal 12(3): 160-161. [19441]

Hutto, R.L. 2006. Toward meaningful snag-management guidelines for postfire salvage logging in North American conifer forests. Conservation Biology 20(4): 984-993.

Hyatt, Timothy L. and Robert J. Naiman. February 2001. The Residence Time of Large Woody Debris in the Queets River, Washington, USA. Ecological Applications, Vol. 11, No. 1: 191-202.

Ice, G. 1978. Reaeration in a turbulent stream system. PhD thesis. Department of Forest Engineering, Oregon State University. $174 \mathrm{p}$.

Ice, G. 1985. Catalog of landslide inventories for the northwest. Technical Bulletin Number 456, National Council of the Paper Industry for Air and Stream Improvement. New York, NY. 78 p.

Ice, G.G., D.G. Neary, and P.W. Adams. 2004. Effects of wildfire on soils and watershed processes. Journal of Forestry 102(6): 16-20.

IMST (Independent Multidisciplinary Science Team). 1999. Recovery of Wild Salmonids in Western Oregon Forests: Oregon Forest Practices Act Rules and the Measures in the Oregon Plan for Salmon and Watersheds. Technical Report 1999-1 to the Oregon Plan for Salmon and Watersheds. Governor's Natural Resources Office. Salem, OR. 
Intergovernmental Panel on Climate Change. 2007. Climate Change 2007: The Physical Science Basis. Contribution of Working Group I to the Fourth Assessment Report of the Intergovernmental Panel on Climate Change. Solomon, S., D. Qin, M. Manning, Z. Chen, M. Marquis, K.B. Averyt, M. Tignor and H.L. Miller, eds. Cambridge University Press, Cambridge, United Kingdom and New York, NY, USA.. 996 p.

Irwin, L.L., D. Rock and S. Rock. 2004. Adaptive management monitoring of spotted owls, 2004 annual progress report. National Council for Air and Stream Improvement, Inc. Vancouver, WA. 47 p.

Isaacs, F.B. and R.G. Anthony. 2005. Bald eagle nest location and history of use in Oregon and the Washington portion of the Columbia River Recovery Zone, 1971 through 2005. Oregon Cooperative Fish and Wildlife Research Unit, Oregon State University. Corvallis, OR.

Isaacs, F.B. and R.G. Anthony. 2007. Bald eagle nest locations and history of use in Oregon and the Washington portion of the Columbia River recovery zone, 1971 through 2006. Oregon Cooperative Fish and Wildlife Research Unit, Oregon State University, Corvallis, OR

Iverson, R.M. 2000. Landslide triggering by rain infiltration. Water Resour. Res. 36(7): 1897-1910.

Iverson, R. M., M. E. Reid and R. G. LaHusen. 1997. Debris-flow mobilization from landslides. Ann. Rev. Earth Planet. Sci., 25, 85-138.

Jackson County, 1989-Ammended 2004, 2006, Jackson County Comprehensive Plan, Section 11-Energy Conservation Element: Jackson County State of Oregon, 26 p.

Jackson, C. R., C. A. Sturm and J. M. Ward. 2001. Timber harvest impacts on small headwater stream channels in the Coast Ranges of Washington. Journal of the American Water Resources Association. 37(6): $1533-1549$.

Janisch, J.E., and M.E. Harmon. 2002. Successional changes in live and dead wood carbon stores: implications for net ecosystem productivity. Tree Physiology 22: 77-89.

Jensen, Mark E. 1991. Ecological classification and cumulative soil effects. In: Proceedings- -management and productivity of western-montane forest soils. Harvey, Alan E. and Leon F. Neuenschwander, compilers. 1990. April 10-12; Boise, ID. Gen. Tech. Rep. INT-280. 218-223. [15985]. Intermountain Research Station, U.S. Department of Agriculture, U.S. Forest Service. Ogden, UT.

Johnson, M.G., and R.L. Beschta. 1981. Seasonal variation of infiltration capacities of soils in western Oregon. Pacific Northwest Forest and Range Experiment Station, Corvallis OR. PNW-373 1981.

Johnson, R. 2000. Tree improvement in the Pacific Northwest. In: Rose, R.; Hasse, D.L. Proceedings: advances and challenges in forest regeneration. Oregon State University, Corvallis, OR

Johnson, D.H. and T.A. O'Neil. 2001. Wildlife-habitat relationships in Oregon and Washington. Oregon State University Press. Corvallis, OR.

Johnson, Randy and David Marshall. 2005. Modeling genetic gain in established Douglas-fir plantations. 18 January 2005 (unpublished). Pacific Northwest Research Station, U.S. Department of Agriculture, U.S. Forest Service. Corvallis, OR.

Johnston, A. 2002. Northern spotted owl survey and monitor report. U.S. Department of the Interior, National Park Service, Crater Lake National Park. Crater Lake, OR. 
Jones, J. and G. Grant. 1996. Peak Flow Responses to Clear-Cutting and Roads in Small and Large Basins, Western Cascades, Oregon. Water Resources Research, 32(4):959-974.

Jones, J.A., F. J. Swanson, B.C. Wemple and K.U. Snyder. 2000. Effects of roads on hydrology, geomorphology, and disturbance patches in stream networks. Conservation Biology 14(1):76-85.

Jones, Eric T., Rebecca J. McLain and James Weigand, eds. 2002. Nontimber Forest Products in the United States. Lawrence: University Press of Kansas. 445 p.

Jones, Eric T. and K.A. Lynch. 2007. Nontimber forest products and biodiversity management in the Pacific Northwest. Forest Ecology and Management 246 (2007) 29-37

Jules, E.S. 1998. Habitat fragmentation and demographic change for a common plant: trillium in old-growth forest. Ecology 79(5):1645-1656.

Jull, Mike. 2001. Wind damage and related risk factors for interior Douglas-fir leave trees in Central B.C. In: Windthrow assessment and management in British Columbia; Proceedings of the windthrow researchers workshop in Richmond, British Columbia, Canada. January 31-February 1, 2001. Compiled by S.J. Mitchell and J. Rodney.

Jurgensen, M.F., A.E. Harvey, R.T.Graham, D.D.Page-Dumroese, J.R.Tonn, M.J.Larsen, and T.B.Jain 1997. Impacts of Timber Harvesting on Soil Organic Matter, Nitrogen, Productivity, and Health of Inland Northwest Forests. Forest Science 43(2) 1997.

Kadrmas, Tina and W. Johnson. 2002. Managing Dyer's Woad. Fact sheet FS-02-097, University of Nevada Cooperative Extension.

Kanaskie, A., M. McWilliams, K. Sprengel and D. Overhulser. 2005. Swiss needle cast aerial surveys, 1996 to 2005. In Swiss Needle Cast Cooperative: Annual Report 2005. pp. 9-11 Oregon State University. Corvallis, Oregon. http://www.cof.orst.edu/coops/sncc/sncc05.pdf

Kanaskie, A., E. Goheen, N. Osterbauer, E. Hansen, M. McWilliams and B. Woosley. 2006. Phytophthora ramorum in Oregon forests. Spring 2006 Meeting of the California Oak Mortality Task Force: Phytophthora ramorum - A Management and Research Update. Carmel, CA. http:// nature.berkeley.edu/comtf/ html/2006_meeting_agenda.html

Karraker, N.E., and H.H. Welsh, Jr. 2006. Long-term impacts of even-aged timber management on abundance and body condition of terrestrial amphibians in northwestern California. Biological Conservation 131(2006):132-140

Karr, J.R., J.J. Rhodes, G.W. Minshall, F.R. Hauer, R.L. Beschta, C.A.Frissell and D.A. Perry. 2004. The effects of postfire salvage logging on aquatic ecosystems in the American west. BioScience 54: 1029-1033.

Kauffman , J.B., W.C. Krueger, and M. Vavra. 1983. Impacts of cattle on streambanks in Northeastern Oregon. Journal of Range Management 36:683-691.

Kaye, T. 2002a. Effects of Cattle Grazing, Insect Interactions and Population Ecology of Snake River Goldenweed (Haplopappus radiatus). Final Report prepared for BLM Vale District and Institute of Applied Ecology, OR. 32 pp.

Kaye, T. 2002b. Lomatium cookii Population monitoring in the Illinois Valley, Josephine County, Oregon. Annual progress report prepared for the Medford BLM on long-term monitoring. BLM, Medford, OR. 
Kaye, T., 2007. Personal communication, Executive Director, Institute for Applied Ecology, Corvallis OR. Occurrence loss to species with 20 or fewer sites.

Kaye, T. 2008. Personal communication. Invasive plants (Brachypodium sylvaticum) and adverse effect to rare fungi and terrestrial lichens and bryophytes.

Kaye, Thomas, 2003. Invasive Plant Alert: False-brome (Brachypodium sylvaticum). False-brome Working Group. Institute For Applied Ecology. Retrieved January 25, 2007 from: <http://www. appliedeco.org/ Reports/BRSYbrochureSmall.PDF>

Kaye, T. and M. Kirkland. 1994. Population biology of Lomatium bradshawii. Unpublished report for the Eugene District, Bureau of Land Management and the Oregon Department of Agriculture. Eugene, OR.

Kaye, T.N., Brandt, A., and Mazzu, L. 2005. Effects of the Biscuit Fire on Frasera umpquaensis on the Medford BLM.

Kaye, T. and A. Thorpe 2006. Lupinus sulphureous ssp. kincaidii (Kincaid's lupine) and Icaricia icarioides fenderi (Fender's blue butterfly) in the Eugene Wetlands: Population monitoring, reintroduction success, and an evaluation of experimental treatments. Annual Progress Report. U.S. Department of the Interior, Bureau of Land Management, Eugene District. Eugene, OR.

Kaye, T.N., R.J. Meinke, J. Kagan, S. Vrilakas, K.L. Chambers, P.F. Zika and J.K. Nelson. 1997. Patterns of rarity in the Oregon flora: implications for conservation and management. In: Conservation and management of native plants and fungi. Kaye, T.N., A. Liston, R.M. Love, D. Luoma, R.J. Meinke, and M.V. Wilson, editors. Native Plant Society of Oregon. Corvallis, OR.

Kaye, Thomas N., Pendergrass, Kathy L., Finley, Karen, Kauffman, Boone J. 2001. The effect of fire on the population viability of an endangered prairie plant. Ecological Applications, 11(5), Pp. 1366-1380. The Ecological Society of America

Kaye, T.N., Brandt, A., and Mazzu, L. 2005. Effects of the Biscuit Fire on Frasera umpquaensis on the Medford BLM.

Keller, E.A., and F.J. Swanson. 1979. Effects of large organic material on channel form and fluvial processes. Earth Surface Processes. 4:361-380.

Kellman, M. C. 1969. Plant species interrelationships in a secondary succession in coastal British Columbia. Syesis 2: 201-212. [6589].

Kelly, E.G. and E.D. Forsman. 2004. Recent records of hybridization between barred owls (Strix varia) and northern spotted owls (S. occidentalis caurina). Auk 121:806-810.

Kelly, E.G., E.D. Forsman and R.G. Anthony. 2003. Are barred owls replacing spotted owls? The Condor 105:45-53.

Kelly, M., D. Shaari, Q. Guo and D. Liu. 2005. Modeling risk for SOD nationwide: what are the effects of model choice on risk prediction? General Technical Report PSW-GTR. Pacific Southwest research Station, U.S. Department of Agriculture, U.S. Forest Service. http://nature. berkeley.edu/comtf/pdf/KellyetalSOD222-05.pdf

Kennedy, R.S.H. and T.A. Spies. 2005. Dynamics of hardwood patches in a conifer matrix: 54 years of change in a forested landscape in Coastal Oregon, USA. Biological Conservation 122: 363-374. 
Keppeler, E. and R. Ziemer. 1990. Logging effects on streamflow: water yield \& summer low flows at Caspar Creek in northwest California. Water Resources Research 26(7): 1669-1679.

King, James E. 1966. Site index curves for Douglas-fir in the Pacific Northwest. Weyerhaeuser Forestry Paper No. 8. Weyerhaeuser Company, Forestry Research Center. Centralia, WA. Knighton, David. 1984. Fluvial Forms and Processes. Edward Arnold, Baltimore, Maryland. Knorr, J. and E. Martin. 2003. Forest Plan Effectiveness monitoring. Klamath National Forest sensitive plant program, FY03. Unpublished Results. USDA USFS, Klamath National Forest. Yreka, CA.

King, J.G. 1989. Streamflow responses to road building and harvesting: a comparison with the equivalent clearcut area procedure. Res. Pap. RP-INT-401. Ogden, UT: U.S. Department of Agriculture, Forest Service, Intermountain Research Station. 13 p.

Knorr, J. and E. Martin. 2003. Forest Plan Effectiveness monitoring. Klamath National Forest sensitive plant program, FY03. Unpublished Results. U.S. Department of Agriculture, U.S. Forest Service, Klamath National Forest. Yreka, CA.

Kochendorfer, J. N. and J. D. Helvey. 1984. In: Washington Forest Practices Board. 1997. Standard methodology for conducting watershed analysis, Ver. 4.0. Washington State Department of Natural Resources. Olympia, WA. Online: http://www.dnr.wa.gov/forestpractices/ watershedanalysis/manual/ hydrology.pdf

Kondolf, G.M., G.F. Cada, M.J. Sale and R. Felando. 1991. Distribution and stability of potential salmonid spawning gravels in steep boulder-bed streams of the eastern Sierra Nevada. Transactions of the American Fisheries Society 120:177-186.

Krankina, O.N., and M.E. Harmon. 2006 pp. 78-91 in Forests, Carbon and Climate Change: A Synthesis of Science Findings. Oregon Forest Research Institute. 182 p.

Kremsater, L.L. and F.L. Bunnell. Testing responses to forest edges: the example of black-tailed deer. Canadian Journal of Zoology 20:2426-2435,

Kruckeberg, A.R. 1984. California serpentines: flora, vegetation, geology, soils and management problems. University of California publications in Botany, vol. 78. University Press. Berkeley, CA.

Kvenvolden, K. A., Lorenson, T. D., Niem, A. R., 1995, Natural Hydrocarbon Gases in the Coast Range of Southern Oregon: United States Geological Survey Open-File Report 95-93. 19 p.

Lamarche, J. and F. Lettenmaier. 2001. Effects of forest roads on flood flows in the Deschutes River, WA. Earth Surface Processes and Landforms 26:115-134.

Lamberson, RR., B.R. Noon, C. Voss and K.S. McKelvey. 1994. Reserve design for territorial species: The effects of patch size and spacing on the viability of the northern spotted owl. Conservation Biology 8(1):185-195.

Landres, P.B., P. Morgan and F.J. Swanson. 1999. Overview of the use of natural variability concepts in managing ecological systems. Ecological Applications 9: 1179-1188.

Lank, D.B., N. Parker, E.A. Krebs and L. McFarlane-Tranquilla. 2003. Geographic distribution, habitat selection, and population dynamics with respect to nesting habitat characteristics of Marbled murrelets (Brachyramphus marmoratus). Center for Wildlife Ecology, Simon Fraser University. Vancouver, British Columbia, Canada. 
Larson, W.E. and F.J. Pierce. 1996. Conservation and enhancement of soil quality. In: The Soil Quality Concept. The Soil Quality Institute, editors. United States Department of Agriculture, Natural Resources Conservation Service.

Latterell, J.J., and Naiman, R.J. 2007. Sources and dynamics of large logs in a temperate floodplain river. Ecological Applications 17(4): 1127-1141.

Lauten, D. J., K. A. Castelein, E. Seckinger and E. P. Gaines. 2006. The distribution and reproductive success of the Western Snowy Plover along the Oregon Coast - 2005. The Oregon Natural Heritage Information Center. Corvallis, OR.

Law, B.E., D. Turner, J. Campbell, O.J. Sun, S. Van Tuyl, W.D. Ritts, and W.B. Cohen. 2004. Disturbance and climate effects on carbon stocks and fluxes across western Oregon, USA. Global Change Biology 10: 14291444.

Lawson, P. W., E. Bjorkstedt, M. Chilcote, C. Huntington, J. Mills, K. Moore, T. E. Nickelson, G. H. Reeves, H. A. Stout and T. C. Wainwright. 2004a. Identification of Historical Populations of Coho Salmon (Onchorhynchus kisutch) in the Oregon Coast Evolutionarily Significant Unit. Review Draft. Oregon Northern California Coast Technical Recovery Team. 129 p.

Lawson, P.W., E.A. Logerwell, N.J. Mantua, R.C. Francis, and V.N. Agostini. 2004b. Environmental factors influencing freshwater survival and smolt production in Pacific Northwest coho salmon (Oncorhynchus kisutch). Canadian Journal of Fisheries and Aquatic Science 61: 360-373.

Lee, P., C. Smyth and S. Boutin. 2004. Quantitative review of riparian buffer width guidelines from Canada and the United States. Journal of Environmental Management 70:165-180.

Lehtonen, A. R. Makipaa, J. Heikkinen, R. Sievanen, and J. Liski. 2004. Biomass expansion factors (BEFs) for Scots pine, Norway spruce, and birch according to stand age for boreal forests. Forest Ecology and Management 188: 211-224.

Lemieux, Paul M., C Lutes and D.A. Santioanni. 2004. Emissions of organic air toxics from open burning: a comprehensive review. Progress in Energy and Combustion Science 30: 32. online: http:// www. sciencedirect.com

Lennartsson, T. 2002. Extinction Thresholds and Disrupted Plant-Pollinator Interactions in Fragmented Plant Populations, Ecology, 83(11):3060-3072.

Leopold, Luna. 1994. A view of the river. By the president and fellows of Harvard College. ISBN 0-67493732-5

Leopold, L.B., M.G. Wolman and J.P Miller. 1964. Fluvial Processes in Geomorphology. W.H. Freeman. San Francisco, CA.

Leppig, G. and J. White. 2006. Conservation of Peripheral Plant Populations in California. Madrono Vol. 53, No. 3:264-274.

Leskiw, T. and R.J. Gutiérrez. 1998. Possible predation of a spotted owl by a barred owl. Western Birds 29:225-226.

Lewis, J.C. and G.E. Hayes. 2004. Feasibility assessment for reintroducing fishers to Washington. Washington Department of Fish and Wildlife. Olympia, WA. 70 p. 
Lewis, Robert A. and Robert Pierle. 1991. Adoption of an ORGANON mortality adjustment for green tree retention and for long rotations. Unpublished Internal Report. U.S. Department of the Interior, BLM, Medford District Office. Medford, OR.

Lienkaemper, G.W. and F.J.Swanson. 1987. Dynamics of large woody debris in streams in old-growth Douglas-fir forests. Canadian Journal of Forest Research 17: 150-156.

Lindell 2006. USDI, BLM, Medford, OR. personal communication.

Lindenmayer, D. B., and J. F. Franklin. 2002. Conserving forest biodiversity: a comprehensive multiscaled approach. Island Press, Washington, D.C.

Lindenmayer, D.B. and R.F. Noss. 2006. Salvage logging, ecosystem processes, and biodiversity conservation. Conservation Biology 20(4): 949-958.

Lindenmayer, D.B., D. Foster, J.F. Franklin, M. Hunter, R. Noss, F. Schiemegelow and D. Perry. 2004. Salvage harvesting after natural disturbance. Science 303: 1303.

Lindsey, W. 2006. Rangeland Management Specialist, USDI Bureau of Land Management, Klamath Falls Resource Area. Personal communication.

Lint, J. (technical coordinator) 2005. Northwest Forest Plan - the first 10 years (1994-2003): Status and trends of northern spotted owl populations and habitat. General Technical Report PNW-GTR-648. Pacific Northwest Research Station, U.S. Department of Agriculture, Forest Service. Portland, OR. 176 p.

Lint, J. 2007. Personal communication 5 Nov. 2007 with J. Lint, Wildlife Biologist, U.S. Department of the Interior, BLM.

Lint, J., B. Noon, R. Anthony, E. Forsman, M. Raphael, M. Collopy and E. Starkey. 1999. Northern spotted owl effectiveness monitoring plan for the Northwest Forest Plan. PNW-GTR- 440. Pacific Northwest Research Station, U.S. Department of Agriculture, U.S. Forest Service. Portland, OR.

Lisle. 1981. In: Streamside Management: Forestry and Fishery Interactions. Contribution 57. 1987. pp. 3997. Salo, E.O and T.W. Cundy editors. University of Washington, Institute of Forest Resources. Seattle, WA.

Lisle, T.E. 1989. Sediment transport and resulting deposition in spawning gravels, north coastal California. Water Resources Research 25(6): 1303-1320.

Litton, C.M., J.W. Raich, and M.G. Ryan. 2007. Carbon allocation in forest ecosystems. Global Change Biology 13: 2089-2109.

Lloyd, D., J. Koenigs and J. LaPerriere. 1987. Effects of turbidity in fresh waters of Alaska. North American Journal of Fisheries Management. 7:18-33.

Log Lines Log Price Reporting Service. 2006. Log Price Reports. Mount Vernon, WA.

Long, J.N., and J. Turner. 1975. Above-ground biomass of understory and overstory in an age sequence of four Douglas-fir stands. The Journal of Applied Ecology 12(1): 179-188.

Long, C. J., C. Whitlock, P. J. Bartlein and S. H. Millspaugh. 1998. A 9000-year fire history from the Oregon Coast Range, based on a high-resolution charcoal study. Canadian Journal of Forest Research 28: 774-787. 
Luce, C. 2002. Hydrological processes and pathways affected by forest roads: what do we still need to learn? Hydrol. Process. 16: 2901-04.

Luce, C. H. and T. A. Black. 2001. Effects of traffic and ditch maintenance on forest road sediment production. In: Proceedings of the Seventh Federal Interagency Sedimentation Conference, March 25-29, 2001, Reno, NV. pp. V67-V74. (180 kb)

Luginbuhl, J.M., John M. Marzluff, Jeffrey E. Bradley, Martin G. Raphael and Daniel E. Varland. 2001. Corvid survey techniques and the relationship between corvid relative abundance and nest predation. Journal of Field Ornithology 72(4): 556-572.

Magnusson, Mark, U., Donald L. Wyse and Joseph M. Spitzmueller. 1987. Canada thistle (Cirsium arvense) propagation from stem sections. Weed Science 35: 637-639.

Magoon, L. B., 1992, The Petroleum System-Status of Research and Method, 1992 as found in Ryu, I. C., Niem, A. R., Niem, W. A., 1992, Schematic Fence Diagram of the Southern Tyee Basin, Oregon Coast Range, Showing Stratigraphic Relationships of Exploration Wells to Surface Measured Sections: State of Oregon Department of Geology and Mineral Industries Oil and Gas Investigation 18, Maps, cross sections and $46 \mathrm{p}$.

Maguire, D., D. Waring, K. Cromack and J. Boyle. 2000. Trends in soil and foliar nutrients across a range in Swiss Needle Cast severity. In: Annual report to the Swiss Needle Cast Cooperative. pp. 79-84. Oregon State University. Corvallis, OR. <http://www.cof.orst.edu/coops/sncc/sncc00.pdf $>$

Maguire, D.A., D. B. Mainwaring and C. B. Halpern. 2006. Stand dynamics after variable-retention harvesting in mature Douglas-Fir forests of Western North America. Allgemeine Forst und Jagdzeitung. 177: $120-131$.

Manley, I.A., A. Harfenist and G. Kaiser. 2001. Marbled murrelet telemetry study on Queen Charlotte Islands/Haida Gwaii. Ministry of Environment, Lands and Parks. Smithers, British Columbia, Canada. 24 p.

Marshall, D.B., M.G. Hunter and A.L. Contreras. 2003. Birds of Oregon. Oregon State University Press. Corvallis, OR.

Martin D.J. and L.E. Benda. 2001. Patterns of instream wood recruitment and transport at the watershed scale. Transactions of the American Fisheries Society: Vol. 130, No. 5, pp. 940-958.

Marzluff, J.M. and M. Restani. 1999. The effects of forest fragmentation on rates of avian nest predation and parasitism. Unpublished report. College of Forest Resources, University of Washington. Seattle, WA.

Maser, C. 1998. Mammals of the Pacific Northwest: From the Coast to the High Cascades. Oregon State University Press. Corvallis, OR.

Mason, R. S., Erwin, M. I., 1955, Coal Resources of Oregon. United States Department of the Interior, Geological Survey Geological Survey Circular 362, 7p.

Max, T. A., H. T. Schreuder, J. W. Hazard, D. D. Oswald, J. Teply and J. Alegria. 1996. The Pacific Northwest Region vegetation and inventory monitoring system. Research Paper PNW- RP-493. 19pp. Pacific Northwest Research Station, U.S. Department of Agriculture, U.S. Forest Service.

May, C.L. 2002. Debris flows through different forest age classes in the central Oregon Coast Range. Journal of the American Water Resources Association 38(4): 1-17 
May, C.L. and R. E. Gresswell. 2003. Large wood recruitment and redistribution in headwater streams of the Oregon Coast Range, U.S.A. Can. J. of Forest Res. 33: 1352-1362.

May, C.L., and R. E. Gresswell. 2004. Spatial and temporal patterns of debris-flow deposition in the Oregon Coast Range, USA. Geomorphology 57: 135-149.

May, D., 2005, Personal Communications with David May, Geologist and Vice President, Methane Energy Corporation. Interagency Tour of Drill Sites, Coos Bay, Oregon, December 14, 2005.

McComb, W.C., K. McGarigal, and R.G. Anthony. 1993. Small mammal and amphibian abundance in streamside and upslope habitats of mature Douglas-fir stands, western Oregon. Northwest Science 67(1):1715.

McComb, W.C., M.T. McGrath, T.A. Spies and D. Vesely. 2002. Models for mapping potential habitat at landscape scales: an example using northern spotted owls. Forest Science 48(2): 203-216.

McCullough, D.R. 1960. An ecological study of the Columbian black-tailed deer in a logged environment. M.S. Thesis. Oregon State College. Corvallis, OR. 63 p.

McCune B. and L. Geiser. 1997. Macrolichens of the Pacific Northwest. 386 pp. Oregon State University Press. Corvallis, OR.

McDade, M.H. 1987. Source area of coarse woody debris in small streams in western Oregon and Washington. M.S. thesis. Oregon State University. Corvallis OR.

McDade, M.H.; F.J. Swanson, W.A. McKee, J.F Franklin and J. Van Sickle. 1990. Source distances for coarse woody debris entering small streams in western Oregon and Washington. Canadian Journal of Forest Research 20: 326-330.

McDonald, Philip M. 1976. Shelterwood cutting in a young-growth, mixed-conifer stand in north-central California. Research Paper PSW-117. Pacific Southwest Forest and Range Experimental Station, U.S. Department of Agriculture, U.S. Forest Service. Berkeley, CA.

McGarigal, K. and B.J. Marks. 1995. FRAGSTATS: spatial pattern analysis program for quantifying landscape structure. General Technical Report PNW-351. Pacific Northwest Research station, U.S. Department of Agriculture, U.S. Forest Service.

http://www.umass.edu/landeco/research/fragstats/fragstats.html>

McIver, J. D. and L. Starr, technical editors. 2000. Environmental effects of postfire logging: literature review and annotated bibliography. General Technical Report PNW-GTR-486. Pacific Northwest Research Station, U.S. Department of Agriculture, U.S. Forest Service. Portland, OR.

McIver, J.D. and R. Ottmar. 2007. Fuel mass and stand structure after post-fire logging of a severely burned ponderosa pine forest in northeastern Oregon. Forest Ecology and Management 238: 268-279

McLain, Rebecca J. and Eric T. Jones. 2005. Nontimber forest products management on national forests in the United States. PNW-GTR-655. Pacific Northwest Research Station, U.S. Department of Agriculture, U.S. Forest Service. Portland, OR. http://www.treesearch.fs.fed.us/pubs/21091

McLendon, Terry. 1992. Factors controlling the distribution of Canada thistle (Cirsium arvense) in montane ecosystems: Rocky Mountain National Park, Colorado. Annual Report: NPS Contract Number CA 1268 1-9002; Reporting period 17 April 1991 - 30 April 1992. Unpublished report on file with: Rocky Mountain Research Station, Fire Sciences Laboratory, U.S. Department of Agriculture, U.S. Forest Service. Missoula, MT. 36 p. 
McNeil, W.J. 1966. Effect of the spawning bed environment on reproduction of pink and chum salmon. U.S. Fish and Wildlife Service Fishery Bulletin 65: 495-523.

McShane, C., T. Hamer, H.Carter, G. Swartzman, V. Friesen, D. Ainley, R. Tressler, k. Nelson, A. Burger, L. Spear, T. Mohagen, R. Martin, L. Henkel, K. Prindle, C. Strong and J. Keany. 2004. Evaluation report for the 5 -year status review of the marbled murrelet in Washington, Oregon, and California. Unpublished report, EDAW, Inc. Seattle, WA. Prepared for the U.S. Fish and Wildlife Service, Region 1. Portland, OR.

Meehan, William R. 1991. Influences of forest and rangeland management on salmonid fishes and their habitats. USDA. American Fisheries Society Special Publication 19. Bethesda, MD.

Megahan, W. 1972. Subsurface road interception by a logging road in mountains of central Idaho. In: Watersheds in Transition: [350-356]. S. C. Csallany, T. G. McLaughlin and W. D. Striffler, editors. Colorado State University. Fort Collins, CO.

Megahan, W. and W. Kidd. 1972. Effects of logging and logging roads on erosion and sediment deposition from steep terrain. Journal of Forestry 70:136-141.

Megahan W. and D. Molitor. 1975. Erosional effects of wildfire and logging in Idaho. In: Watershed Management Symposium; 1975 August. Logan, UT: American Society of Civil Engineers Irrigation and Drainage Division: 423- 444.

Megahan, W., J. Ptoyondy and K. Seyedbagheri. 1992. Best management practices and cumulative effects from sedimentation in the South Fork Salmon River: an Idaho case study. In: Watershed Management: Balancing Sustainability and Environmental Change. Pp. 401-414. R.J. Naiman, editor. Springer-Verlag. New York, NY.

Meier, Gretchen and T. Weaver. 1997. Desirables and weeds for roadside management - a northern Rocky Mountain catalogue. Report No. RH WA/MT-97-8115. Final Report: July 1994 - December 1997. [29135]. State of Montana Department of Transportation, Research, Development, and Technology Transfer program. Helena, MT. 145 p.

Meinke, R. 2007. OSU. Site management plan for Mimulus evanescens (Disappearing Monkeyflower). Lakeview District, BLM (Klamath Falls R.A.). 14 p.

Meleason, M. A., S. V. Gregory and J. Bolte. 2002. Simulation of stream wood source distance for small streams in the western Cascades, Oregon. General Technical Report PSW-GTR-181. Pacific Southwest Research Station, U.S. Department of Agriculture, U.S. Forest Service.

Menges E., 2000. Population viability Analyses in Plants: Challenges and Opportunities. Tree Vol.15, No. 2, Feb. 2000.

Menke, C. and T. Kaye. 2006. Population Monitoring and Effects of Grazing on Calochortus greenei on the Cascade-Siskiyou National Monument. Annual progress report. BLM, Medford District. Medford, OR.

Methane Energy Corporation. 14 December 2005. Interagency tour of drill sites, Coos Bay, OR.

Meyer, J.M. March 2007. Personal Communications with Jack Meyer, Geologist, Northwest Natural Company.

Meyer J.S., L.L. Irwin and M.S. Boyce. 1998. Influence of habitat abundance and fragmentation on northern spotted owls in western Oregon. Wildlife Monographs 139. 
Meyer, C.B., S.L. Miller, and C.J. Ralph. 2002. Multi-scale landscape and seascape patterns associated with marbled murrelet nesting areas on the U.S. west coast. Landscape Ecology 17:95-115.

Michigan Department of Environmental Quality. 28 December 2001. Land and Water Management Division, Hydrologic Studies Unit.

Miles, Patrick D. 14 July 2006. Forest inventory mapmaker web-application version 2.1. North Central Research Station, U.S. Department of Agriculture, U.S. Forest Service. St. Paul, MN. [Available only on internet: www.ncrs2.fs.fed.us/4801/fiadb/index.htm]

Millar, C., R. Neilson, D. Bachelet, R. Drapek, J. Lenihan. 2006. Climate Change at Multiple Scales, pp. 30-60 in Forests, Carbon and Climate Change: A Synthesis of Science Findings. Oregon Forest Research Institute. $182 \mathrm{p}$.

Millar, C.I. and W.B. Woolfenden. 1999. The role of climate change in interpreting historical variability. Ecological Applications 9:1207-1216.

Miller, D. 2003. Programs for DEM analysis. Landscape dynamics and forest management. General Technical Report RMRSGTR-101CD [CD-ROM]. Rocky Mountain research Station, U.S. Department of Agriculture, U.S. Forest Service. Fort Collins, CO.

Miller, Ronald E. "Regional and Interregional Input-Output Analysis." In Methods of Interregional and Regional Analysis, by Walter Isard, Iwan J. Azis, Matthew P. Drennan, Ronald E.

Miller, Ronald E., and Peter D. Blair. 1985. "Input-Output Models at the Regional Level." Input-Output Analysis: Foundations and Extensions. Englewood Cliffs, N.J.: Prentice-Hall, Inc.,

Miller, R.F. and R.J. Tausch. 2001. The role of fire in juniper and pinyon woodlands: a descriptive analysis. pp. 15-30. in: Proceedings invasive species workshop: the role of fire in the control and spread of invasive species. Galley, K.E.M. and T.P. Wilson (editors). Miscellaneous Publication 11. Tall Timbers Research Station, Tallahassee, FL.

Miller, D. and L. Benda. 2005. Terrain resource inventory and analysis database: Landscape analysis tools for watershed scientists and planners. Earth Systems Institute, Ver. 1.1. Seattle, WA.

Miller, D.J., and Burnett, K.M. 2007a. Effects of forest cover, topography, and sampling extent on the measured density of shallow, translational landslides. Water Resour. Res. 43 (W03433).

Miller, D.J. and K.M. Burnett. 2007b. A probabilistic model of debris-flow delivery to stream channels, demonstrated for the Coast Range of Oregon, USA, Geomorphology

Miller, Sidney Salzman and Erik Thorbecke. 1998. Aldershot, England: Ashgate. pp. 41-124.

Miller, R.E., G.W. Glendenen and D. Bruce. 1988. Volume growth and response to thinning and fertilizing of Douglas-fir stands in southwestern Oregon. Gen.Tech. Rept. PNW-GTR-221. U.S. Dept. of Agriculture, Forest Service, Pacific Northwest Research Station. Portland, OR. 38 p.

Miller, R.E., W. I. Stein, R.L. Heninger, W. Scott, S.N. Little, and D.J. Goheen. 1989. Maintaining and improving site productivity in the Douglas-Fir region. In: Proceedings of a symposium. Maintaining the long-term productivity of Pacific Northwest Forest Ecosystems. March 1987. Perry, D.A. and others, editors.

Miller, R.E., W. Scott, and J. W. Hazard. 1996. Soil Compaction and conifer growth after tractor yarding at three coastal Washington locations. Canadian Journal of Forest Research 26: 225-236. 
Miller, G.S., R.J. Small and E.C. Meslow. 1997. Habitat selection by spotted owls during natal dispersal in western Oregon. Journal of Wildlife Management 61(1):140-150.

Miller, D., C. Luce and L. Benda. 2003. Time, space, and episodicity of physical disturbance in streams. Forest Ecology and Management. 178:121-140

Miller, R.F., J.D. Bates, T. J. Svejcar, F.B. Pierson, and L.E. Eddleman. 2005. Biology, Ecology, and Management of Western Juniper. Oregon State University, Agricultural Experiment Station, Technical Bulletin 152, June 2005.

Moeur, M., T.A. Spies, M. Hemstorm, J.R. Martin, J. Alegria, J. Browning, J. Cissel, W.B. Cohen, T.E. Demeo, S. Healey and R. Warbington. 2005. Northwest Forest Plan - The first 10 years (1994-2003): status and trend of late-successional and old-growth forest. General Technical Report PNW-GTR-646. Pacific Northwest Research Station, U.S. Department of Agriculture U.S. Forest Service. Portland, OR.

Montgomery, D. and J. Buffington. 1997. Channel reach morphology in mountain drainage basins. Geological Society of America Bulletin 109: 596-611. From: Stillwater Sciences/NCASI.

Montgomery, D. R., J.M. Buffington, R.D. Smith, K.M. Schmidt and G. Pess. 1995. Pool spacing in forest channels. Water Resources Research 31:1097-1105.

Montgomery, D.R., J.M. Buffington, N.P. Peterson, D. Scheutt-Hames, and T.P. Quinn. 1996. Streambed scour, egg burial, depths and the influence of salmonid spawning on bed surface mobility and embryo survival. Can. J. Fish. Aquat. Sci. 53:1061-1070.

Montgomery, D.R., E.M. Beamer, G.R. Pess, and T.P. Quinn, 1999. Channel Type and Salmonid Spawning Distribution and Abundance. Canadian Journal of Fisheries and Aquatic Sciences 56(3):377-387

Montgomery, D. R., B.D. Collins, T.B. Abbe and J.M. Buffington. 2003. Geomorphic effects of wood in rivers, In: The Ecology and Management of Wood in World Rivers, edited by S. V. Gregory, K. L. Boyer, and A. Gurnell. American Fisheries Society Symposium 37, [21-47]. Bethesda, MD.

Monsanto, P.G., and J.K. Agee. 2008. Long-term post-wildfire dynamics of coarse woody debris after salvage logging and implications for soil heating in dry forests of the eastern Cascades, Washington. Forest Ecology and Management 255: 3952-3961.

Morken, I. and R. Ziemer. 1998. Publications related to Caspar Creek. In: Proceedings of the conference on coastal watersheds: the Caspar Creek story, 6 May 1998; Ukiah, California. Robert R. Ziemer, technical coordinator. General Technical Report PSW GTR-168. [137-149]. Pacific Southwest Research Station, U.S. Department of Agriculture, U.S. Forest Service. Arcata, CA.

Mote, P. W., E. A. Parson, A. F. Hamlet, K. N. Ideker, W. S. Keeton, D. P. Lettenmaier, N. J. Mantua, E. L. Miles, D. W. Peterson, D. L. Peterson, R. Slaughter, and A. K. Snover. 2003. Preparing for climatic change: the water, salmon, and forests of the Pacific Northwest. Climatic Change 61:45-88.

Muir, Patricia S. 2004. An assessment of commercial "moss" harvesting from forested lands in the Pacific Northwestern and Appalachian Regions of the United States: How much moss is harvested and sold domestically and internationally and which species are involved? Department of Botany and Plant Pathology, Oregon State University. Corvallis, OR. 80 p.

Muir, P.S., R.L. Mattingly, J.C. Tappeiner II, J.D. Bailey, W.E. Elliott, J.C. Hagar, J.C. Miller, E.B. Peterson and E.E. Starkey. 2002. Managing for biodiversity in young Douglas-fir forests of western Oregon. Biological Science Report USGS/BRD/BSR-2002-006. U.S. Geological Survey, Biological Resources Division. 76 p. 
Muir, Patricia S., K. N. Norman, K. G. Sikes. 2006. Quantity and value of commercial moss harvest from forests of the Pacific Northwest and Application regions of the U.S. The Bryologists Vol. 109, Issue 2, pp. 197-214.

Murphy, M.L. and J. D. Hall. 1981. Varied effects of clear-cut logging on predators and their habitats in small streams of the Cascade Mountains, Oregon. Canadian Journal of Fisheries and Aquatic Sciences. 38:137145 .

Murphy M.L. and K.V. Koski. 1989. Input and Depletion of Woody Debris in Alaska Streams and Implications for Streamside Management. North American Journal of Fisheries Management 9:427-436.

Murphy, M.L. and W.R. Meehan. 1991. Stream ecosystems. American Fisheries Society Special Publication 19:17-46.

Murphy, M.L., et al. 1986. Effects of clear-cut logging with and without buffer strips on juvenile salmonids in Alaskan streams. Canadian Journal of Fisheries and Aquatic Sciences 43:1521-1533.

Myers, J. M., C. Busack, D. Rawding and A. Marshall. 10 May 2002. Identifying historical populations of Chinook and chum salmon and steelhead within the Lower Columbia River and Upper Willamette River evolutionarily significant units. Draft report to the co-managers from the Willamette/Lower Columbia River Technical Recovery Team, Northwest Fisheries Science Center, 2725 Montlake Blvd. E., Seattle, WA 98112.

Naiman, R.J and R.E. Bilby, editors. 1998. River Ecology and Management: Lessons From the Pacific Coastal Ecoregion. Springer-Verlag. New York, NY.

Naiman, R.J., T.J Beechie, L.E. Benda, D.R. Berg, P.A. Bisson, L.H. McDonald, M.D. O’Conner, P.A. Olson and E.A. Steel. 1992. Fundamentals of ecologically healthy watersheds in the Pacific Northwest coastal region. In: Watershed management: balancing sustainability and environmental change, pp. 127-188. Naiman, R.J., editor. Springer-Verlag. New York, NY

Naiman, Robert J., C.A. Johnston and J.C. Kelley. December 1998. Alterations of North American Stream by Beaver: How Animals Shape Their Ecosystems. BioScience. Vol. 38, No. 11:753-762.

Naiman R.J., R.E. Bilby and P.A. Bisson. 2000. Riparian ecology and management in the Pacific Coastal rain forest. BioScience 50:996-1011.

National Wildfire Coordination Group. 2001. Smoke Management Guide for Prescribed and Wildland Fire. PMS 420-2. National Wildfire Coordinating Group, National Interagency Fire Center

NatureServe. 2006. NatureServe Explorer: An online encyclopedia of life [web application]. Version 4.7. NatureServe. Arlington, VA. Available http://www.natureserve.org/explorer. (Accessed: July 12, 2006).

Naugle, D. E., C. L. Aldridge, B. L. Walker, T. E. Cornish, B. J. Moynahan, M. J. Holloran, K. Brown, G. D. Johnson, E. T. Schmidtmann, R. T. Mayer, C. Y. Kato, M. R. Matchett, T. J. Christiansen, W. E. Cook, T. Creekmore, R. D. Falise, E. T. Rinkes, and M. S. Boyce. 2004. West Nile virus: pending crisis for greater sagegrouse. Ecology Letters 7: 704-713.

Nawa, R.K. and C.A. Frissel. 1993. Measuring Scour and Fill of Gravel Streambeds with Scour Chains and Sliding-Bead Monitors. American Fisheries Society, North American Journal of Fisheries Management. 13:634-639.

Neary, D.G., K.C. Ryan, and L.F. DeBano, editors. 2005. Wildland fire in ecosystems: effects of fire on soils and water. General Technical Report RMRS-GTR-42-vol.4. Rocky Mountain Research Station, U.S. Department of Agriculture, U.S. Forest Service. Ogden, UT: 
Neiland, Bonita J. 1958. Forest and adjacent burn in the Tillamook Burn area of northwestern Oregon. Ecology 39(4): 660-671.

Nelson, Cara and Charles B. Halpern. Edge-related responses of understory plants to aggregated retention harvest in the Pacific Northwest. Ecological Applications, Volume 15, Issue 1 (February 2005) pp. 196-209

Nelson, S.K., M.H. Huff, S.L. Miller and M.G. Raphael. 2006. Marbled murrelet biology: habitat relations and populations. Chapter 2 In Huff, M.H., M.G. Raphael, S.L. Miller, S.K. Nelson, and J. Baldwin (technical coordinators). Northwest Forest Plan---The first 10 years (1994-2003): status and trends of populations and nesting habitat for the marbled murrelet. General Technical Report PNW-GTR-650. Pacific Northwest Research Station, U.S. Department of Agriculture, U.S. Forest Service. Portland, OR.

Newton, V.C. Jr. 1969. Subsurface Geology of the Lower Columbia and Willamette Basins, Oregon: State of Oregon Department of Geology and Mineral Industries Oil and Gas Investigations No. 2, Cross-sections and Maps. 121 p.

Newton, V.C. Jr. and R.E. Stewart. 1965. Oil and Gas Exploration in Oregon: State of Oregon Department of Geology and Mineral Industries. Miscellaneous Paper 6, maps and $32 \mathrm{p}$.

Newton, V. C. Jr., Kulm, L. D., Couch, R. W., Braman D., Pitts, G. S., Atta, O. V., McKeel, D. R., 1980, Prospects for Oil and Gas in the Coos Basin, Western Coos, Douglas, and Lane Counties, Oregon: State of Oregon. Department of Geology and Mineral Industries Oil and Gas Investigation Number 6, 74p.

Nickelson, Thomas E. 2001. Population Assessment: Oregon Coast Coho Salmon ESU. Oregon Department of Fish and Wildlife Information Report 2001-02. Northwest Region Research and Monitoring Program. 47 p.

Nickelson, T. E., J.W. Nicholas, A.M. McGie, R.B. Lindsay, D.L. Bottom, R.J. Kaiser and S.E. Jacobs. 1992. Status of anadromous salmonids in the Oregon coastal basins. Oregon Department of Fish and Wildlife. Portland, OR. $83 \mathrm{p}$.

Niem, A.R. and W.A. Niem. 1990. Geology and Oil, Gas, and Coal Resources, Southern Tyee Basin, Southern Coast Range, Oregon. Open-File Report O-89-3. State of Oregon Department of Geology and Mineral Industries. $44 \mathrm{p}$.

Niem, A.R. W.A. Niem, M.W. Martin, M.M. Kadri and D.R. McKeel. 1985. Correlation of Exploration Wells, Astoria Basin, Oregon: State of Oregon Department of Geology and Mineral Industries Oil and Gas Investigations No. 14, maps and 8 p.

Niem, A.R., P. D. Snavely, Jr., and W. A. Niem. 1990, Onshore-Offshore geologic cross section from the Mist Gas Field, Northern Oregon Coast Range, to the Northwest Oregon Continental Shelf: State of Oregon Department of Geology and Mineral Industries Oil and Gas Investigation 17, 46 p. + Appendices and Maps.

Nierenberg, T. and D. Hibbs. 2000. A characterization of unmanaged riparian areas in the central Coast Range of western Oregon. Forest Ecology and Management 129 (2000):195-206.

Niewendorp, C., 2008, Personal Communications with Clark Niewendorp, Mineral Resources Geologist; State of Oregon Department of Geology and Mineral Industries, February 19, 2008.

Noggle, C. C. 1978. Behavioral, physiological and lethal effects of suspended sediment on juvenile salmonids. Zoology. University of Washington. Seattle, WA. 
Nonaka, E. and T.A.Spies. 2005. Historical range of variability in landscape structure: a simulations study in Oregon, USA. Ecological Applications 15(5):1727-1746.

Norris, D. and J. Shevock. 2004a. Contributions Toward a Bryoflora of California: I. A Specimen- Based Catalogue of Mosses. Madrono, Volume 51, No. 1, pp. 1-131.

Norris, D. and J. Shevock. 2004b. Contributions Toward a Bryoflora of California: I. A Specimen- Based Catalogue of Mosses. Madrono, Volume 52, No. 2, pp. 133-269.

Noss, Reed F., Jerry Franklin, William Baker, Tania Schoennagel and Peter B. Moyle. February 2006. Ecological Science Relevant to Management Policies for Fire-Prone Forests of the Western United States. Society for Conservation Biology Scientific panel on Fire in Western U.S. Forests.

Nuzzo, Victoria. 2000. Element stewardship abstract: Cirsium arvense. In: Weeds on the web: The Nature Conservancy wildland invasive species program. Retrieved September 2006 from http://tncweeds.ucdavis. edu/esadocs/cirsarve.html [2001, July 01].

Ohmann, J.L., M.J. Gregory and T.A. Spies. 2007. Influence of environment, disturbance, and ownership on forest vegetation of coastal Oregon. Ecological Applications 17:18-33.

O'Keefe, T.C. and R.J. Naiman. 2006. The influence of forest structure on riparian litterfall in a Pacific Coastal rainforest. Canadian Journal of Forestry Research. 36:2852-2863.

Olmstead, D.L. and M.P. Alger. 1985. Mist Gas Field: Exploration and development 1979-1984: Oil and gas investigation 10. Oregon Department of Geology and Mineral Industries. 36 p.

Olmstead, D.L., V.C. Newton Jr. and R.E. Stewart. 1989. Hydrocarbon exploration and occurrences in Oregon: Oil and gas investigation 15. Oregon Department of Geology and Mineral Industries. 74 p.

Olson, D.H., J.C. Hagar, A.B. Carey, J.H. Cissel and F.J. Swanson. 2001. Wildlife of Westside and High Montane Forests. pp. 187-212. In: Wildlife-habitat Relationships in Oregon and Washington, Johnson, D.H. and T.A. O’Neil (managing directors). Oregon State University Press. Corvallis, OR.

Olson, G.S., E.M. Glenn, R.G. Anthony, E.D. Forsman, J.A. Reid, P.J. Loschl and W.J. Ripple. 2004. Modeling demographic performance of northern spotted owls relative to forest habitat in Oregon. Journal of Wildlife Management 68(4):1039-1053.

Olson, G.S., R.G. Anthony, E.D. Forsman, S.H. Ackers, P.J. Loschl, J.A. Reid, K.M Dugger, E.M. Glenn and W.J. Ripple. 2005. Modeling of site occupancy dynamics for northern spotted owls, with emphasis on the effects of barred owls. Journal of Wildlife Management 69(3):918-932.

Olson, Deanna H.; Van Norman, Kelli J.; Huff, Robert D. 2007. The utility strategic surveys for rare and little-known species under the Northwest Forest Plan Gen. Tech. Rep. PNW-GTR-708. Portland, OR: U.S. Department of Agriculture, Forest Service, Pacific Northwest Research Station. 48 p.

Oregon Department of Agriculture (ODA). 2001. Reintroduction of the Red Root Yampah (Perideridia erythrorhiza). Final Report to the BLM: Roseburg, Medford, and Lakeview Districts, Klamath Resource Area and Winema National Forest. $41 \mathrm{p}$.

ODA. 2005. Prepared by Kelly Amsberry and Robert J. Meinke. Reintroduction of the Red Root Yampah (Perideridia erythrorhiza). Final Report for 2004 to the BLM: Roseburg and Medford Districts. 18 p. 
ODA. 2007. Noxious Weed Control, French broom. Retrieved 1/26/2007. http://egov.oregon.gov/ODA/ PLANT/WEEDS/profile_frenchbroom.shtml

Oregon Employment Department, Oregon Labor Market Information System (OED OLMIS). 2006. http://www.qualityinfo.org/olmisj/OlmisZine

Oregon Department of Environmental Quality (ODEQ). 1998. Oregon's 1998 Water Quality Status Assessment Report: Section 305(b) Report. Portland, OR.

ODEQ. 2004a. Web page for temperature limited water-bodies in Oregon. www.deq.state.ok.us/ WQDnew/305b_303d/

ODEQ. 2004b. Water Quality Assessment. Section 305(b) Report.

ODEQ. 2006. Water quality assessment- Oregon's 2004/2006 integrated report database. [Online: http:// www.deq.state.or.us/wq/assessment/rpt0406/ search.asp]

ODEQ. 2007a. TMDL implementation plan guidance for state and local government designated management agencies. May 2007.

ODEQ. 2007b. Evaluation of the Western Oregon Plan Revision (WOPR) - Draft Environmental Impact Statement (DEIS) Alternatives for Stream Temperature.

Oregon Department of Forestry (ODF). 1999. Storm impacts and landslides of 1996: Final report. Forest technical report No.4.

ODF. 2003. Determination of rapidly moving landslide impact rating. Forest practices technical note, Number 6, Version 1.0, September 1, 2003.

ODF. 2005. Swiss needle cast and the H [harvest] \& H [habitat] Model (Draft 3/3/05). Unpublished internal report.

ODF. 2006. 2005 Timber harvest reports. November 2006. http://egov. oregon.gov/ODF/STATE_FORESTS/ FRP/2005MENU.shtml\#Harvest_Data

Oregon Department of Forestry and Oregon Department of Environmental Quality. 2004. Sufficiency analysis: A statewide evaluation of forest practices act effectiveness in protecting water quality [Online] http://www.deq.state.or.us/wq/nonpoint/docs/suffanalysis.pdf

Oregon Department of Fish and Wildlife (ODFW). 2003a. Oregon's mule deer management plan. Portland, OR.

ODFW. 2003b. Oregon's elk management plan. Portland, OR.

ODFW. 2005a. Oregon conservation strategy. Salem OR.

ODFW. 2005b. The importance of beaver (Castor Canadensis) to coho habitat and trend in beaver abundance in the Oregon Coast Coho ESU. ODFW (7) Beaver final report, Part 4.

ODFW. 2006. Oregon conservation strategy. Salem, OR. 
ODF and Oregon Department of Environmental Quality. 2004. Sufficiency analysis: a statewide evaluation of Forest Practices Act effectiveness in protecting water quality [Online] http://www.deq.state.or.us/wq/ nonpoint/docs/suffanalysis.pdf

Oregon Department of Environmental Quality. 2007. Evaluation of the Western Oregon Plan Revision (WOPR) - Draft Environmental Impact Statement (DEIS) Alternatives for Stream Temperature.

Oregon Department of Geology and Mineral Industries. 1985. Oregon administrative regulations (OAR): http://arcweb.sos.state.or.us/rules/OARS_600/OAR_632/632_010.html; accessed March 2007.

Oregon Department of Geology and Mineral Industries. 1999. Oregon administrative regulations (OAR): http://arcweb.sos.state.or.us/rules/OARS_600/OAR_632/632_010.html (accessed March 2007).

Oregon Department of Geology and Mineral Industries. 2003. Mist gas field production figures 2002 and mist gas field map 2003: Open-file report O-03-01. Tables and maps.

Oregon Department of Geology and Mineral Industries. 2006. Unpublished. 7 February 2006. Oil and gas program and geothermal program draft report submitted to governing board. $14 \mathrm{p}$.

Oregon Department of Geology and Mineral Industries. 2007a. Mist gas field production, 2006. http://www. oregongeology.com/sub/oil/MistProduction2006.xls

Oregon Department of Geology and Mineral Industries: 2007b. Mist gas field production, 2006 and historic. http://www.oregongeology.com/sub/oil/oilhome.htm

Oregon Employment Department. Oregon labor market information system (OLMIS) http:// www.olmis. org/olmisj/OlmisZine

Oregon Natural Heritage Information Center (ONHIC). 2004. Rare, threatened and endangered species of Oregon. Portland, OR. 105 p.

ONHIC. 2006. Database. September 2006. Portland, OR.

ONHIC. 2007. Rare, threatened and endangered species of Oregon. Portland, OR. 100 p.

ONHIC. 2008. Rare, threatened and endangered species of Oregon. Portland, OR. 101 p.

Oregon Parks and Recreation Department (OPRD). 2003. Oregon statewide comprehensive outdoor recreation plan, 2003-2007.

OPRD. 2004. Draft habitat conservation plan for the Western Snowy Plover. Salem, OR. Oregon State University. 2000 Online: http://www.ocs.orst.edu/pub/maps/Precipitation/Total/ States/OR/or.gif]

Oregon Watershed Enhancement Board (OWEB). 1999. Oregon watershed assessment manual. Available from OWEB, 775 Summer St. NE, Ste\# 360, Salem, OR. 97301, or online at: www.oregon.gov/oweb/docs/ pubs/OR_wsassess_manuels.shtml\#OR_watershed_assessment_manual

Orr, E.L. and W.N. Orr. 2000. Geology of Oregon, 5th Edition. Kendall/Hunt Publishing Company. 254 p.

Outcalt, Kenneth Wayne and Edwin H. White. 1981. Phytosociological changes in understory vegetation following timber harvest in northern Minnesota. Canadian Journal of Forest Research. 11: 175-183. 
Packer, P. 1967. Criteria for designing and locating logging roads to control sediment. Forest Science 13(1): $1-18$.

Page, G.W., J.S. Warriner, J.C. Warriner and P.W.C. Paton. 1995. Snowy Plover (Charadrius alexandrinus). In The birds of North America, No. 154 (A. Poole and F. Gill, eds.). The Academy of Natural Sciences, Philadelphia, PA, and The American Ornithologists Union, Washington, D.C.

Page-Dumroese, D.S., and M.F. Jurgensen. 2006. Soil carbon and nitrogen pools in mid- to late-successional forest stands of the northwestern United States: potential impact of fire. Canadian Journal of Forest Research 36: $2270-2284$

Page-Dumroese, D., M.Jurgensen, W.Elliot, T.Rice, J.Nesser, T.Collins, and R.Meurisse. 2000. Soil quality standards and guidelines for forest sustainability in northwestern North America. United States Department of Agriculture, Forest Service, Pacific Northwest Research Station, PNW-RP-494.

Pappajohn, S. 2002. Personal communication with Steven Pappajohn, principal of Geo Trends-Hampton International, Incorporated. Interagency meeting. 27 August 2002. Salem, OR.

Pappajohn, S. 2005. Personal communication with Steve Pappajohn, President and Director of Methane Energy Corporation, Director of Cascadia Energy Corporation. Interagency tour of drill sites. December 14, 2005. Coos Bay, OR.

Pappajohn, S. 2007. Personal communication with Steve Pappajohn, President and Director of Methane Energy Corporation, Director of Cascadia Energy Corporation. 21 March 2007.

Parendes, Laurie A. and Julia A. Jones. 2000. Role of light availability and dispersal in exotic plant invasion along roads and streams in the H. J. Andrews Experimental Forest, Oregon. Conservation Biology. 14(1): 64-75.

Park, C.S. 1993. SHADOW stream temperature management program. U.S. Department of Agriculture, U.S. Forest Service, Pacific Northwest Region.

Park, C.S. 2005. Personnel communication with Dan Carpenter.

Pashley, D.N., C.J. Beardmore, J.A. Fitzgerald, R.P. Ford, W.C. Hunter, M.S. Morrison and K.V. Rosenberg. 2000. Partners in flight conservation of the land birds of the United States. American Bird Conservancy. The Plains, VA.

Pearson, R.R. and K.B. Livezey. 2003. Distribution, numbers, and site characteristics of spotted owls and barred owls in the Cascade Mountains of Washington. Journal of Raptor Research 37(4):265-276.

Peck, M.E. 1941. A manual of the higher plants of Oregon. Binfords and Mort, Portland, OR. Illustrated flora of the Pacific states, Abrams, 1960

Peery, M.Z., S.R. Beissinger, B.H. Becker and S.H. Newman. 2002. Marbled murrelet (Brachyramphus marmoratus) demography in Central California: 2001 Progress report. Prepared for the California Department of Fish and Game, U.S. Fish and Wildlife Service, and California state parks.

Peery, M.Z., S.R. Beissinger, S.H. Newman, E.B. Burkett and T. D. Williams.2004 Applying the declining population paradigm: diagnosing causes of poor reproduction in the marbled murrelet. Conservation Biology 18(4):1088-1098. 
Pellant, M., P. Shaver, D.A. Pyke and J.E. Herrick. 2005. Technical Ref. 1734-6 (Version 4). Interpreting indicators of rangeland health. USDI, BLM

Perakis, S.S., D.A. Maguire, T.D. Bullen, K. Cromack, R.H. Waring and J.R. Boyle. 2006. Coupled nitrogen and calcium cycles in forests of the Oregon Coast Range. Ecosystems 9: 63-74.

Perry, D.A. 1998. The scientific basis of forestry. Annual Review of Ecology and Systematics 29:435-466.

Peterson, D.L., M.C. Johnson, J.K. Agee, T.B. Jain. D. McKenzie and E Reinhardt. 2005. Forest structure and fire hazard in dry forests of the western United States. General technical report PNW-GTR-628. Pacific Northwest Research Station, U.S. Department of Agriculture, U.S. Forest Service.

Petzet, A. 22 January 2007. Special report: water issues overshadow Powder River coal gas play. Oil and Gas Journal online, Volume 105, Issue 4. http://www.ogj.com/currentissue/index. cfm? $\mathrm{p}=7 \& \mathrm{v}=105 \& \mathrm{i}=4$

Piatek, K.B., C.A.Harrington, and D.S.DeBell 2003. Site preparation effects on 20-year survival and growth of Douglas-Fir (Pseudotsuga menziesii) and on selected soil properties. Western Journal of Applied Forestry 18(1) 2003.

Pilz, David, Lorelei Norvell, Eric Danell, and Randy Molina. 2003. Ecology and management of commercially harvested chanterelle mushrooms. Gen. Tech. Rep. PNW-GTR-576. USDA USFS. Portland, OR.

Pilz, D., R. Molina and J. Mayo. 2006. Effects of thinning young forests on chanterelle mushroom production. Journal of Forestry.

Pilz, D., R. McLain, S. Alexander, L. Villarreal-Ruiz, S. Berch, T. L. Wurtz, C. G. Parks, E. McFarlane, B. Baker, R. Molina, and J.E. Smith. 2007. GTR-710, 07-007 Ecology and management of morels harvested from the forests of western North America. USDA, USFS. Portland, OR.

Poage, N.J. unpublished. BLM Western Oregon late-successional and old-growth conifer data (1983 - 1991). On file at Eugene District, BLM. Eugene, OR.

Poage, N.J. 2000. Structure and development of old-growth Douglas-fir in central western Oregon. Ph.D. dissertation. Oregon State University. Corvallis, OR. 164 p.

Poage, N.J. and J.C. Tappeiner. 2002. Long-term patterns of diameter and basal area growth of old-growth Douglas-fir trees in western Oregon. Canadian Journal of Forest Research 32 (7): 1232-1243.

Poggi, D., A. Porporato, L. Ridolfi, J. Albertson and G. Katul. 2004. The effect of vegetation density on canopy sub-layer turbulence. Boundary-Layer Meteorology 111: 565-587

Pollock, M.M., M. Heim and R.J. Naiman. 2003. Hydrologic and geomorphic effects of beaver dams and their influence on fishes. pp. 213-234. In: The ecology and management of wood in world rivers. Gregory, S.V., K. Boyer, and A. Gurnell, editors. American Fisheries Society, Bethesda, MD.

Poole, A. and F. Gill, editors. 2002. The birds of North America. Nos. 1-716. Philadelphia, PA

Powell, R.A. and W. J. Zielinski. 1994. The scientific basis for conserving forest carnivores: American Marten, Fisher, Lynx, and Wolverine in the western United States (Chapter 3 Fisher). General technical report GTR RM-254. Rocky Mountain Forest and Range Experiment Station, U.S. Department of Agriculture, U.S. Forest Service. 
Powers, R.F. 2002. Effects of soil disturbance on the fundamental, sustainable productivity of managed forests. USDA Forest Service PSW-GTR-183.

Powers, R.F., F.G.Sanchez, D.A.Scott, and D.Page-Dumroese. 2004. The North American long-term productivity experiment: coast-to-coast findings from the first decade. United States Department of Agriculture Forest Service Proceedings Rocky Mountain Research Station -P-34.

Powers, R.F., D.A.Scott, F.G.Sanchez, R.A.Voldseth, D.Page-Dumroese, J.D.Elioff, and D.M.Stone 2005. The North American long-term productivity experiment: Findings from the first decade of research. Forest Ecology and Management 220 (2005) 31-50.

Proctor, Bernadette D. and Joseph Dalaker. 2002. Current population reports, pp.60-219. Poverty in the United States: 2001. U.S. Census Bureau.

Ralph, C.J. and S.L. Miller. 1995. Offshore population estimates of marbled murrelets in California. pp. 353-360. In: Ecology and Conservation of the Marbled murrelet. Ralph, C.J., G.L. Hunt, Jr., M. G. Raphael, and J.F. Piatt, editors. General technical report PSW-GTR-152. Pacific Southwest Experimental Station, U.S. Department of Agriculture, U.S. Forest Service. Albany, CA.

Ralph, C.J., G.L. Hunt, Jr., M.G. Raphael and J.F. Piatt. 1995. Ecology and conservation of the marbled murrelet in North America: an overview. pp. 3-22. In: Ecology and conservation of the marbled murrelet. General Technical Report PSW-GTR-152. Pacific Southwest Experimental Station, U.S. Department of Agriculture, U.S. Forest Service. Albany, CA.

Raphael, Martin G. and Randy Molina, 2007. Conservation of rare or little-known species. Island Press, Washington D.C. 375 p.

Raphael, M.G., D.E. Mack and B.A. Cooper. 2002a. Landscape-scale relationships between abundance of marbled murrelets and distribution of nesting habitat. Condor 104(2), 331-342.

Raphael, M.G., D.E. Mack, J.M. Marzluff and J.M Luginbuhl. 2002b. Effects of forests fragmentation on populations of the marbled murrelet. Studies in Avian Biology 25:221-235.

Raphael, M.G., B.M. Galleher, J.H. Huff, S.L. Miller, S.K. Nelson and R.D. Young. 2006. Chapter 5: Spatially explicit estimates of potential nesting habitat for the marbled murrelet. In: Northwest Forest Plan---The first 10 years (1994-2003): status and trends of populations and nesting habitat for the marbled murrelet. Huff, M.H., M.G. Raphael, S.L. Miller, S.K. Nelson and J. Baldwin (technical coordinators). PNW-GTR-650. Pacific Northwest Research Station, U.S. Department of Agriculture, U.S. Forest Service. Portland, OR.

Rapp, V., Editor. 2000. First approximation report for sustainable forest management in Oregon. Oregon Department of Forestry, April 2000.

Rapp, Valerie. 2004. Western forests, fire risk and climate change, PNW Science Update, Issue 6. Http:// www.fs.fed.us/pnw

Rashin, E., C. Clishe, A. Loch and J. Bell. 2006. Effectiveness of timber harvest practices for controlling sediment related water quality impacts. Journal of the American Water Resources Association. Paper No. 01162 .

Rasmussen, Mark. 2006. Personal communication. 25 August 2006. Notes of meeting hosted by the American Forest Resources Council. Eugene, OR. 
Rasmussen, M.C. and W.J. Ripple. 1998. Retrospective analysis of forest landscape patterns in western Oregon. Natural Areas Journal 18(2): 151-163.

Reeves.2005. Powerpoint presentation. From website: http://www.blm.gov/or/plans/wopr/science/ scienceforum2.php.

Reeves, G.H., F.H. Everest and J.R. Sedell. 1993. Diversity of juvenile anadromous salmonid assemblages in coastal Oregon basins with different levels of timber harvest. Transactions of the American Fisheries Society 122:309-317.

Reeves, G.H., L.E. Benda, K.M. Burnett, P.A. Bisson and J.R. Sedell. 1995. A disturbance-based ecosystem approach to maintaining and restoring freshwater habitats of evolutionarily significant units of anadromous salmonids in the Pacific Northwest. American Fisheries Society Symposium 17:334-349.

Reeves, G.H., D.B. Hohler, B.E. Hansen, F.H. Everest, J.R. Sedell, T.L. Hickman, and D. Shively. 1997. Fish habitat restoration in the Pacific Northwest: Fish Creek of Oregon. pp. 335-339. In: Williams,J.E., C.A. Wood, and M.P. Dombeck. Watershed restoration: principles and practices. American Fisheries Society. Bethesda, MD.

Reeves, G.H., K.M. Burnett and E.V. McGarry. 2003. Sources of large wood in the main stem of a fourthorder watershed in coastal Oregon. Canadian Journal of Forest Research 33: 1363-1370.

Reeves, G.H., P. A. Bisson, B.E. Rieman and L.E. Benda. 2006. Postfire logging in riparian areas. Conservation Biology 20(4): 994-1004.

Reid, L. M. 1981. Sediment production from gravel-surfaced forest roads, Clearwater Basin, Washington. Fisheries Research Institute. College of Fisheries, University of Washington. Seattle, Washington. FRI-UW8108 .

Reid, Leslie M. and Thomas Dunne. 1984. Sediment production from forest road surfaces. Water Resources Research 20(11):1753-1761.

Reiter, M. and R. Beschta. 1995. Effects of forest practices on water in cumulative effects of forest practices in Oregon: Literature and Synthesis. Forest Engineering Department, College of Forestry, Oregon State University. Corvallis, OR. 185 p.

Ricca. M.A. 1999. Movements, habitat associations, and survival of Columbian white-tailed deer in western Oregon. M.S. Thesis. Oregon State University. Corvallis, OR.

Ricca, M.A., R.G. Anthony, D.H. Jackson and S.A. Wolfe. 2003. Spatial use and habitat associations of Columbian white-tailed deer fawns in southwestern Oregon. Northwest Science 77(1):72-80

Rich, T.D., C.J. Beardmore, H. Berlanga and P.J. Blancher. 2004. Partners in flight North American landbird conservation plan. Cornell Lab of Ornithology. Ithaca, NY.

Richardson, H.W. 1972. Input-output and regional economics. John Wiley and Sons: New York, NY.

Ripple, W.J., K.T. Hershey and R. Anthony. 2000. Historical forest patterns of the central Oregon Coast Range. Biological Conservation 93:127-133. 
Ritchie, Martin W. 1999. A compendium of forest growth and yield simulators for the Pacific Coast states. General Technical Report PSW-GTR-174. 59 pp. Pacific Southwest Research Station, U.S. Department of Agriculture; U.S. Forest Service. Albany CA:

Ritchie, Martin W. 2006. Users guide and help system for CONIFERS: a simulator for young mixed-conifer stands version 3.00. Pacific Southwest Research Station, U.S. Department of Agriculture, U.S. Forest Service. Albany, CA.

Ritchie, M. W. and D. W. Hann. 1985. Equations for predicting basal area increment in Douglas-fir and grand fir. Oregon State University, Forest Research Laboratory, Research Bulletin 51.9 p.

Rizzo, D. M. 2003. Sudden Oak Death: Host plants in forest ecosystems in California and Oregon. Sudden oak death online symposium. Online: www.apsnet.org/online/SOD

Rizzo, D. M., M. Garbelotto, J.M. Davidson, G.W. Slaughter and S.T. Koike. 2002. Phytophthora ramorum as the cause of extensive mortality of Quercus spp. and Lithocarpus densiflorus in California. Plant Disease 86: 205-214.

Robichaud, P.R., J.L. Beyers and D.G. Neary. 2000. Evaluating the effectiveness of postfire rehabilitation treatments. General Technical Report RMRS-GTR-63. Rocky Mountain Research Station, U.S. Department of Agriculture, U.S. Forest Service. Fort Collins, CO.

Robison, M. Henry. 1997. Community input/output models for rural area analysis. Annals of Regional Science. Vol 31(3):325-351.

Robison, G.E. and R. L. Beschta. 1990. Identifying trees in riparian areas that can provide coarse woody debris to streams. Forest Science Volume 36, No 3:790-801.

Robison, E. G., J. Runyon, and C. Andrus. 1995. Cooperative stream temperature monitoring: project completion report for 1994-1995. Prepared for: Oregon Department of Environmental Quality. Oregon Department of Forestry. Salem, OR.

Robison, G.E., Mills, K.A., Paul, J., Dent, L., and Skaugset, A. 1999. Storm impacts and landslides of 1996: final report. Oregon Department of Forestry. Forest Practices Technical Report. 4.

Roche, Cindy Talbott and Ben F. Roche, Jr. 1988. Distribution and amount of four knapweed (Centaurea L.) species found in eastern Washington. Northwest Science 62(5): 242-253.

Roloff, Gary, J. Stephen, P. Mealy, Christopher Clay, Jeff Barry, Curt Yanish and Leon Neuenschwander. 2005. A process for modeling short and long term risk in the southern Oregon Cascades. Forest Ecology and Management $21 \underline{1 \text { (2005) 166-190. http://www.sciencedirect.com }}$

Romero, Nicolas, Roberts E. Gresswell and Judith L. Li. 2005. Changing patterns in coastal cutthroat trout (Onchorhynchus clarki clarki) diet and prey in a gradient of deciduous canopies. Canadian Journal of Fisheries and Aquatic Science. 62:1797-1807.

Roni, P. 2001. Responses of fishes and salamanders to instream restoration efforts in western Oregon and Washington. Report to Bureau of Land Management on project completion, Interagency Agreement No. 1422H952-A98-3007. National Marine Fisheries Service, Northwest Fisheries Science Center. Seattle, WA. $132 \mathrm{p}$.

Rooney, B. 22 June 2006. Oregon's forestry and logging industry: particularly important to rural areas. Oregon Employment Department. 6 p. 
Rosenberg, D.K., K.A. Swindle and R.G. Anthony. 2003. Influence of prey abundance on northern spotted owl reproductive success in western Oregon. Canadian Journal of Zoology 81:1715-1725.

Rosgen, D.L. 1996. Applied river morphology. Wildland Hydrology, Pagosa Springs, CO.

Rothacher, J. 1973. Does harvest in west slope Douglas-fir increase peak flow in small streams? Pacific Northwest Forest and Range Experiment Station, U.S. Department of Agriculture, U.S. Forest Service. Portland, OR.

Rowland, M.M., M.J. Wisdom, B.K. Johnson and J.G. Kie. 2000. Elk distribution and modeling in relation to roads. Journal of Wildlife Management 64(3):672-684.

Rowland, M.M., M.J. Wisdom, B.K. Johnson and J.G. Kie. 2004. Effects of roads on elk: implications for management in forested ecosystems. In: Transaction of the sixty-ninth North American and Natural Resources Conference held March 16-20, 2004, in Spokane, Washington. J. Rahm, editor. Wildlife Management Institute, Washington, DC.

Ruddell, S., R. Sampson, M. Smith, R. Giffen, J. Cathcart, J. Hagan, D. Sosland, J. Godbee, J. Heissenbuttel, S. Lovett, J. Helms, W. Price and R. Simpson. 2007. The role for sustainability managed forests in climate change mitigation. Journal of Forestry 105(6): 314-319.

Rykken, J.J., S.S. Chan, and A.R. Moldenke. 2007. Headwater riparian microclimate patterns under alternative forest management treatments. Forest Science 53(2)

Ryu, I. C., A. R. Niem, W. A. Niem. 1992, Schematic fence diagram of the Southern Tyee Basin, Oregon Coast Range, showing stratigraphic relationships of exploration wells to surface measured sections: State of Oregon Department of Geology and Mineral Industries Oil and Gas Investigation 18. Maps, cross sections and $46 \mathrm{p}$.

Ryu, I. C., A.R. Niem, W.A. Niem, R.E. Wells and P.O. Hales. 1996. Oil and gas potential of the southern Tyee Basin, Southern Oregon Coast Range. Oil and gas investigation 19. State of Oregon Department of Geology and Mineral Industries. Cross sections and $141 \mathrm{p}$.

Sandberg, D.V., R.D. Ottmar and J.L. Peterson. 2002. Wildland fire in ecosystems: effects of fire on air. General Technical Report RMRS-GTR-42-Vol. 5. Rocky Mountain Research Station, U.S. Department of Agriculture, U.S. Forest Service. Fort Collins, CO.

Schemske, D.W., B.C. Husband, M.H. Ruckelshaus, C. Goodwillie, I.M. Parker, and J.G Bishop. 1994. Evaluating approaches to the conservation of rare and endangered plants. Ecology, 75(3) pp. 584-606.

Schmidt, Karen, J.P. Menakis, C.C. Hardy, W.J. Hann and D.L. Bunnell. 2002, Development of coarse-scale spatial data for wildland fire and fuel management. General Technical Report RMRS-87. Rocky Mountain Research Station, U.S. Department of Agriculture, U.S. Forest Service. Missoula, MT

Schoenberger, M. D. Meyer and A. Perry. 1982. The effect of soil disturbance on growth and ectomycorrhizae of Douglas-fir and western hemlock seedlings: a greenhouse bioassay. Canadian Journal of Forest Research 12: 343-353.

Schuett-Hames, D., B. Conrad, A. E. Pleus, and K. Lautz. 1996. Literature review and monitoring recommendations for salmonid spawning gravel scour. TFW Ambient Monitoring Program. TFW-AM9-96001. Olympia, WA. 
Schuett-Hames, D.E., N.P. Peterson, R. Conrad and T.P. Quinn. 2000. Patterns of gravel scour and fill after spawning by chum salmon in a western Washington stream. North American Journal of Fisheries Management 20:610-617.

Scientific consensus statement on the likely impacts of climate change on the Pacific Northwest. Oregon State University, October 12, 2004. Available online at: http://www.ef.org/westcoastclimate/E_OSU\%20 Consensus\%20Statement.pdf

Seaber, P., F. Kapinos and G. Knapp. 2007. Hydrologic unit maps. U.S. Geological Survey, Water Supply Paper 2294. Online: [http://pubs.usgs.gov/wsp/wsp2294/]

Sedell, J. R. and C.N. Dahm. 1984. Catastrophic disturbances to stream ecosystems: Volcanism and clear-cut logging. In: Current Perspectives in Microbial Ecology. M.J. Klug and C.A. Reddy, editors. Michigan State University, East Lansing, MI. and American Society of Microbiology, Washington, DC.

Sedell, James R. and Judith L. Froggatt. 1984. Importance of streamside forests to large rivers: the isolation of the Willamette River, Oregon, U.S.A., from its floodplain by snagging and streamside forest removal. Verhandlungen International Verein Limnologie 22: 1828-1834.

Sedell, J. R. and K.J. Luchessa. 1981. Using the historical record as an aid to salmonid habitat enhancement. pp. 210-223. In: Acquisition and utilization of aquatic habitat inventory information. N.B. Armantrout, editor. Proceedings of symposium, 28-30 October 1981. Portland, OR. 376 p.

Sedell, J. R. and K.J. Luchessa. 1982. Using the historical record as an aid to salmonid habitat enhancement. In: Acquisition and utilization of aquatic habitat inventory information. [210- 222]. N.B. Armantrout, editor. American Fisheries Society, Western Division. Bethesda, MD.

Seiger, Leslie. 1991. Element stewardship abstract for Polygonum cuspidatum: Japanese knotweed, Mexican bamboo. The Nature Conservancy. 1815 North Lynn Street, Arlingon, VA. 22209. http://tncweeds.ucdavis. edu/esadocs/documnts/polycus.rtf Retrieved September, 2006.

Sensenig, T.S. 2002. Development, fire history, and current and past growth of old-growth and younggrowth forest stands in the Cascade, Siskiyou and Mid-Coast Mountains of southwestern Oregon. Ph.D. Dissertation. Oregon State University. Corvallis, OR.

Sessions, J., P. Bettinger, R. Buckman, M. Newton and J. Hamann. 2004. Hastening the return of complex forests following fire: the consequences of delay. Journal of Forestry 102: 38-45.

Sheley, Roger L.; James S. Jacobs and Michael F. Carpinelli. 1998. Distribution, biology, and management of diffuse knapweed (Centaurea diffusa) and spotted knapweed (Centaurea maculosa). Weed Technology. $12(2): 353-362$.

Shestak C.J., Busse, M.D. 2005. Compaction alters physical but not biological indices of soil health. Soil Science Society of America Journal 69:236-246 (2005).

Sidle, W. C., 1981, Potential hydrologic effects of developing coal and other geoenergy resources in Oregon: A review. United States Geologic Survey. Water Resources Investigations 81-1014 Open File Report USGS/ WRI-81-1014 TI85 901332, 37 p.+ maps.

Sigler, John. W., T.C. Bjornn and Fred H. Everest. 1984. Effects of chronic turbidity on density and growth of steelheads and coho salmon. Transactions of the American Fisheries Society. 113: $142-150$. 
Simpson, William T. 1993. Specific gravity, moisture content and density relationship for wood. Gen. Tech. Rep. FPL-GTR-76. Madison, Wisconsin: USDA, Forest Service, Forest Products Laboratory. 13 p.

Skaugset, Arne. 1997. Review of Earlier Soil Compaction Studies: A paper presented at a Society of American Foresters conference on understanding and managing soil compaction to maintain ecosystem productivity. Bend, OR.

Skaugset, A., and M. M. Allen. 1998. Forest road sediment and drainage monitoring project report for private and state lands in western Oregon. Forest Eng. Dept., Oregon State University, Corvallis, OR. http:// www.oregon.gov/ODF/PRIVATE_FORESTS/docs/fp/RoadSediment.pdf

Skog, K.E. and G.A. Nicholson. 2000. Carbon sequestration in wood and paper products. pp. 79-88 in L.A. Joyce and R. Birdsey, tech. eds. The impact of climate change on America's forests: a technical document supporting the 2000 USDA Forest Service RPA assessment. USDA Forest Service Gen. Tech. Rep. RMRSGTR-59. Fort Collins, Colorado. 133 p.

Smith, W.P. 1987. Dispersion and habitat use by sympatric Columbian white-tailed deer and Columbian black-tailed deer. Journal of Mamma logy 68(2):337-347.

Smith, J. 2004. A synthesis of potential climate change Impacts on the U.S. Pew Center on global climate change. Arlington, VA.

Smith, J.E. and L.S. Heath. 2004. Carbon stocks and projects on public forestlands in the United States, 1952-2040. Environmental Management 33(4):433-442.

Smith, J.E., L.S. Heath, K.E. Skog, and R.A. Birdsey. 2006. Methods for calculating forest ecosystem and harvested carbon with standard estimates for forest types of the United States. Gen. Tech. Rep. NE-343. Newtown Square, PA: U.S. Department of Agriculture, Forest Service, Northeastern Research Station. 216 p.

Smithwick, E.A.H., M.E. Harmon, S.M. Remillard, S.A. Acker and J.F. Franklin. 2002. Potential upper bounds of carbon stores in forests of the Pacific Northwest. Ecological Application 12(5): 1303-1317.

Sobota, D.J., Gregory, S.V., and Van Sickle, J. 2006. Riparian tree fall directionality and modeling large wood recruitment to streams. Canadian Journal of Forest Research 36: 1243-1254.

Soll, Jonathon; D. Kruezer, K. Strauss, and J. Dumont. 2007. Sandy River riparian habitat protection project report 2006. The Nature Conservancy. The global invasive species initiative. Retrieved January, 2007 from http://tncweeds.ucdavis.edu/moredocs/polspp03.pdf

Sorenson, D. L., M. M. McCarth, E.J. Middlebrooks and D.B. Porcella. 1977. Suspended and dissolved solids effects on biota: A review. EPA-600/3-77-042. U.S. Environmental Protection Agency, Environmental Research Laboratory. Corvallis, OR. 64 p.

Speich, S.M. and T.R. Wahl. 1995. Marbled murrelet populations of Washington - marine habitat preferences and variability of occurrence. pp. 313-326 In: Ecology and conservation of the marbled murrelet. C.J. Ralph, G.L. Hunt, Jr., M.G. Raphael, and J.F. Piatt, editors. General Technical Report PSWGTR-152. Pacific Southwest Research Station, U.S. Department of Agriculture, U.S. Forest Service. Albany CA.

Spies, T.A. 2004. Ecological concepts and diversity of old-growth forests. Journal of Forestry April/May: 1420. 
Spies, T.A. 2006. Maintaining old-growth forests. Chapter 6 in R.W. Haynes, B.T. Bormann, D.C. Lee, J.R. Martin, tech. eds. Northwest Forest Plan - The First 10 Years (1994-2003): Synthesis of Monitoring and Research Results. General Technical Report PNW-GTR-651. Pacific Northwest Research Station, U.S. Department of Agriculture, U.S. Forest Service. Portland, OR.

Spies, T.A. and W.B. Cohen. 1992. An index of canopy height diversity. COPE Report 5(3): 5-7.

Spies, T.A. and J.F. Franklin. 1988. Old-growth and forest dynamics in the Douglas-fir region of western Oregon and Washington. Natural Areas Journal 8:190-201.

Spies, T.A. and J.F. Franklin. 1991. The structure of natural young, mature, and old-growth Douglas-fir forests in Oregon and Washington. In: Ruggiero, L.F., K.B. Aubrey, A.B. Carey, and M.H. Huff, technical coordinators. Wildlife and Vegetation of Unmanaged Douglas-fir Forests. pp. 91-109. General Technical Report PNW-285. Pacific Northwest Research Station, U.S. Department of Agriculture, U.S. Forest Service. Portland, OR.

Spies, T.A., K.N. Johnson, K.M. Burnett, J.L. Ohmann, B.C. McComb, G.H. Reeves, P. Bettinger, J.D. Kline and B. Garber-Yonts. 2007. Cumulative ecological and socioeconomic effects of forest policies in coastal Oregon. Ecological Applications 17(1): 5-17.

Sproule Associates, Inc. 2004. Letter report to John Carlson, Geo Trends-Hampton International from Leslie S. O'Connor, U.S. Manager and John P. Seidle, Senior Reservoir Engineer; date May 3, 2004. (Used with written permission of Methane Energy Corporation, February 14, 2007). 8 p.

Sproule Associates, Inc. 2005. Letter report to John Carlson, Director, Torrent Energy Corporation from Leslie S. O'Connor, U.S. Manager and John P. Seidle, Senior Reservoir Engineer; date June 17, 2005. (Used with written permission of Methane Energy Corporation, February 14, 2007). 26 p.

Sproule Associates, Inc., 2006, Letter report to John Carlson, Director, Torrent Energy Corporation from Leslie S. O'Connor, U.S. Manager and John P. Seidle, Senior Reservoir Engineer; date April 12, 2006. (Used with written permission of Methane Energy Corporation, February 14, 2007). 4 p.

Staebler, G.R. 1963. Growth along the stems of full-crowned Douglas-fir trees after pruning to specified heights. J. of Forestry 61(2): 124-127

Stallman, J., R. Bowers, N. Cabrera, R. Real de Asus and J. Wooster. 2005. Sediment dynamics in the upper McKenzie River Basin, central Oregon coast range. American Geophysical Union \#H51E-0411.

Stein, W.I. 1955. Pruning to different heights in young Douglas-fir. J. of Forestry 53: 352-355

Steinblums, I.J., H.A. Froehlich, and J.K. Lyons. 1984. Designing stable buffer strips for stream protection. Journal of Forestry 81(1):49-52.

Stephens, Scott Lewis. 1998. Evaluation of the effects of silvicultural and fuels treatments on potential fire behavior in Sierra Nevada mixed conifer forests. Forest Ecology and Management 105(1998) 21-35)

Sterns, M.A., J.S. McIver and G.A. Rosenberg. 1990. Investigations of the western snowy plover at the Coos Bay North Spit and adjacent sites in Coos and Curry Counties, Oregon. Report to the Oregon Department of Fish and Wildlife, Nongame Program. 33 p.

Steventon, J.D. and N.L. Holmes. 2002. A radar-based inventory of marbled murrelets (Brachyramphus marmoratus), northern Mainland Coast of British Columbia. Prince Rupert Forest Region, British Columbia Ministry of Forests. 40 p. 
Stewart, R. E., and V. C. Newton, Jr. 1954, Revised by Newton Jr., V. C., 1965, Oil and Gas Exploration in Oregon: State of Oregon Department of Geology and Mineral Industries Miscellaneous Paper 6, 43p. and Maps

Stewart, K. and U. Mallik. 2006. Bryophyte response to microclimatic. Edge effects across riparian buffers. Ecological Applications, 16(4), 1474-1486

Storck, P., T. K. Kern and S. Bolton. 1997. Measurement of differences in snow accumulation, melt, and micrometeorology between clearcut and mature forest stands. University of Washington, Department of Civil Engineering. Presented at the Western Snow Conference. Banff, Alberta, Canada.

Strang, R. M., K.M. Lindsay and R.S. Price. 1979. Knapweeds: British Columbia's undesirable aliens. Rangelands 1(4):141-143.

Strathers, R.J., T.P. Rollerson and S.J. Mitchell. 1994. Windthrow handbook for British Columbia forests. Working paper 9401. British Columbia Ministry of Forests. Victoria, British Columbia, Canada.

Stone, M. K. and J. B. Wallace. 1998. Long-term recovery of a mountain stream from clear-cut logging: the effects of forest succession on benthic invertebrate community structure. Freshwater Biology 39: 15 1-169.

Strong, C.S. 2003a. Decline of the marbled murrelet population on the central Oregon coast during the 1990s. Northwestern Naturalist 84: 31-37.

Strong, C.S. 2003b. Marbled murrelet abundance and reproductive indices in Oregon during 2002. Unpublished report. 14 pp. Oregon Department of Fish and Wildlife, and U.S. Fish and Wildlife Service. Portland, OR.

Strong, C.S. and T.M. Carten. 2000. Marbled murrelets at sea in Oregon: status of abundance and reproduction during 1999. Draft final report to the Oregon Department of Fish and Wildlife. Portland, OR. $17 \mathrm{p}$.

Sullivan, K. and S. Duncan. 1980. Sediment yield from road surfaces in response to truck traffic and rainfall. Weyerhaeuser Technical Report 042-4402/80. Weyerhaeuser Company, Technical Center. Tacoma, WA.

Sullivan, K., T. Lisle, C. Dollof, G. Grant and L. Reid. 1987. Stream channels: the link between forests and fish. In: Streamside management: forestry and fishery interactions. Contribution Number 57. E.O. Salo and T.W. Cundy, editors. University of Washington, Institute of Forest Resources. 39-97. Seattle, WA.

Suring, L.H. 1975. Habitat use and activity patterns of the Columbian white-tailed deer along the lower Columbia River. M.S. Thesis. Oregon State University. Corvallis, OR. 59 p.

Suring, L.H. and P.A. Vohs, Jr. 1979. Habitat use by Columbian white-tailed deer. Journal of Wildlife Management 43:610-619.

Suttle, K.B., M.E. Power, J.M Levine and C. McNeely. 2004. How fine sediment in riverbeds impairs growth and survival of juvenile salmonids. Ecological Applications, 14(4): 969-974 by the Ecological Society of America.

Swanson, F. 1981. Fire and geomorphic process. In: Proceedings, fire regimes and ecosystems conference. Dec. 11-15, 1979. Honolulu, HI. General Technical Report WO-26. U.S. Department of Agriculture, U.S. Forest Service. Washington, D.C. 
Swanson, F., R. Fredriksen and F. McCorison. 1982. Material Transfer in a Western Oregon Forested Watershed. In: Analysis of coniferous forest ecosystems in western United States. [233-266]. R. Edmonds, editor. US/IBP Synthesis Series 14. Hutchinson Ross Publishing Co. Stroudsburg, PA.

Swanson, F, R. Graham and G. Grant. 1985. Some effects of slope movements on river channels. In: International symposium on erosion, debris flow and disaster prevention: Proceedings: [273- 278]. 3-5 September 1985. Tsukuba, Japan.

Swanston, D. N. 1991. Natural Processes. American Fisheries Society Special Publication 19:139-179.

Swanston, D. and F. Swanson. 1976. Timber harvesting, mass erosion, and steepland forest geomorphology in the Pacific Northwest. In: Geomorphology and engineering: [199-221]. D.R. Coates, editor. Dowden, Hutchinson, and Ross, Inc. Stroudsburg, PA.

Swift, L.W. Jr. 1986. Filter strip widths for forest roads in the southern Appalachians. USDA Forest Service, Southeastern Forest Experiment Station, Coweeta Hydrologic Laboratory, Otto, NC

Tappeiner, J.C., D. Huffman, D. Marshall, T.A. Spies and J.D. Bailey. 1997. Density, ages, and growth rates in old growth and young forests in coastal Oregon. Canadian Journal of Forest Research 27: 638-648.

Tarboton. D.G. 1997. A new method for the determination of flow directions and upslope areas in grid digital elevation models. Water Resources Res. 33(2):309-319.

Taylor, G.H. and R.R. Hatton, 1999. The Oregon Weather Book. Oregon State University Press, Corvallis, Oregon. $240 \mathrm{p}$.

Taylor, A.H. and C.N. Skinner. 2003. Spatial patterns and controls on historical fire regimes and forest structure in the Klamath Mountains. Ecological Applications 13(3): 704-719.

The Nature Conservancy; U.S. Department of Agriculture, U.S. Forest Service; and the U.S. Department of the Interior. 2005. LANDFIRE Rapid Assessment Modeling Manual, Version 2.1. Boulder, CO.

The Nature Conservancy. The Global Invasive Species Initiative. Weed Alert!: Brachypodium sylvaticum (Huds.) P. Beauv. (slender false-brome, false brome). Retrieved January 25, 2007 from: http://ncweeds. ucdavis.edu/alert/alrtbrac.html

Theirrault, Shannon. 2001. Wildfire Smoke: a guide for public officials.

Thomas, R. and W. Megahan. 1988. Peak flow responses to clear-cutting and roads in small and large basins, western Cascades, Oregon: A second opinion. Water Resources Research Vol. 34, No. 12, [3393-3403].

Thomas, J.W., E.D. Forsman, J.B. Lint, E.C. Meslow, B.R. Noon and J. Verner. 1990. A conservation strategy for the northern spotted owl. A report by the Interagency Scientific Committee to address the conservation of the northern spotted owl. U.S. Department of Agriculture, U.S. Forest Service and U. S. Department of the Interior, U.S. Fish and Wildlife Service, Bureau of Land Management, and National Park Service. Portland, OR. 427 p.

Thomas, J., J. Franklin, J. Gordon and N. Johnson. 2006. The Northwest Forest Plan: Origins, Components, Implementation Experience, and Suggestions for Change. Conservation Biology, Vol. 20, No 2, pp. 277-287.

Thorpe, A.S. and T.N. Kaye. 2006. Experimental habitat manipulation of wayside aster (Aster vialis). Institute for Applied Ecology, Corvallis, Oregon and USDI BLM, Eugene District. 
Thrailkill, Jim. Personal communication to Eric Greenquist, June 28, 2007.

Titus, R. G. and H. Mosegaard. 1992. Fluctuating recruitment and variable life history of migratory brown trout (Salmo trutta L.) in a small, unstable stream. Journal of Fish Biology Vol. 41, No. 2, pp. $239-255$.

Titus, Jonathan H.; Scott Moore, Mildred Arnot and Priscilla J. Titus. 1998. Inventory of the vascular flora of the blast zone, Mount St. Helens, WA. Madrono. 45(2): 146-161.

Torrent Energy Corporation. 2005. Coos Bay Basin Project: Webpage: http://www.torrentenergy. com/s/ CoosBayBasin.asp

Toth, S. 1991. A road damage inventory for the upper Deschutes River basin. Timber-Fish- Wildlife Report. TFW-SH14-91-007.

Treyz, George I. 1993. Regional Economic Modeling: A Systematic Approach to Economic Forecasting and Policy Analysis. Boston, MA: Kluwer Academic Publishers.

Tripp, D.B., and V.A. Poulin. 1986. The effects of logging and mass wasting on juvenile salmonid populations in streams on the Queen Charlotte Islands. British Columbia Ministry of Forests and Lands, Land management report 45, Victoria, Canada.

Tschaplinski, P.J. and G.F. Hartman. 1983. Winter distribution of juvenile coho salmon (Oncorhynchus kisutch) before and after logging in Carnation Creek, British Columbia, and some implications for overwinter survival. Canadian Journal of Fisheries and Aquatic Sciences 40:452-461.

Turner, Nancy J. 1999. Time to burn: Traditional use of fire to enhance resource production by aboriginal peoples in British Columbia. In: Indians, fire and the land in the Pacific Northwest. pp. 185-218. Boyd, Robert, editor. Oregon State University Press. Corvallis, OR.

Turner, Monica G., William H. Romme, Robert H. Gardner and William W. Hargrove. 1997. Effects of fire size and pattern on early succession in Yellowstone National Park. Ecological Monographs 67(4):411-433.

Tweten, R.G. 1992. Narratives of final critical habitat units for the northern spotted owl in Oregon. Administrative record. U.S. Department of the Interior, U.S. Fish and Wildlife Service. Portland, OR.

US $109^{\text {th }}$ Congress, 2005, Energy Policy Act of 2005: United States Public Law 109-58, 119 Statute $594-119$ Statute 1143

U.S. Army Corps of Engineers. 1956. Snow hydrology-summary report of the snow investigations. North Pacific Division. Portland, OR. 473 p.

U. S. Army Corps of Engineers. 1998. Runoff from snowmelt. Engineering Manual EM 1110-2- 1406. online: [http:/www.usace.army.mil/publications/eng-manuals/em1110-2-1406/c-5.pdf]

U.S. Census Bureau. 2000-2006. DP 1 Profiles of general demographic characteristics and DP 3 profile of selected economic characteristics.

U.S. Department of Agriculture (USDA). Soil Conservation Service. 1971. Guide to range condition class and/or forage quality for the Siskiyou and Klamath Land Resource Areas. Jackson County, OR.

USDA, Pacific Northwest Research Station, U.S. Forest Service and Oregon Department of Forestry. 2002. Land conservation and development, and agriculture: forests, farms and people - land use change on nonfederal land in western Oregon, 1973-2000. 
USDA USFS. 1982. Aids to determining fuel models for estimating fire behavior.GTR-INT-122, Intermountain Forest and Range Experiment Station. Ogden, UT.

USDA USFS. 1987. Wood handbook: wood as an engineering material. Agricultural Handbook No. 72. USDA, Washington, DC.

USDA USFS. 1988. Final supplement to the environmental impact statement for an amendment to the Pacific Northwest Regional Guide. Pacific Northwest Region. Portland, OR.

USDA USFS. 1991. Draft environmental impact statement on management for the northern spotted owl in the national forests. U.S. Department of Agriculture, Forest Service, Pacific Northwest Region.

USDA USFS. 2002. Restoring complexity: Second-growth forests and habitat diversity. Science Update, Issue 1, May 2002. USDA USFS PNW Research Station, Corvallis, OR; Peter Gould, PNW Research Station, Portland, OR.

USDA USFS. 2005a. Pacific Northwest region invasive plant program: preventing and managing invasive plants. Final environmental impact statement. Volume 1.

USDA USFS. 2005b. Letter from L.E. Friedman, Director, Resource Planning and Monitoring to Forest Supervisor. 28 July 2005. Colville National Forest and Forest Supervisor, Okanogan and Wenatchee National Forests.

USDA USFS. 2006a. Northwest Forest Plan: The first ten years. Socioeconomic monitoring results. General Technical Report PNW-GTR-649, Vol. III, pp. 37-76. Pacific Northwest Research Station.

USDA USFS. 2006b. Modeling genetic gain in established Douglas-fir plantations. Research proposal; submitted by Randy Johnson, PNW Research Station, Corvallis, OR; Peter Gould, PNW Research Station, Olympia, WA; and David Marshall, Weyerhaeuser Company. http://www.fs.fed.us/pnw/about/programs/ rmp/Agenda2020-collaboration.shtml

USDA USFS. 2006c. Considering communities in forest management planning in western Oregon. Donoghue E., N. Sutton and R. Haynes. General technical report PNW-GTR- 693. Pacific Northwest Research Station.

USDA U. S. Forest Service (USFS) and U.S. Department of the Interior (USDI), Bureau of Land Management (BLM). 1993a. Pacific Yew, final environmental impact statement, record of decision.

USDA, U. S. Forest Service; Umpqua, Willamette, and Rogue-Siskiyou National Forests; and USDI BLM; Medford and Eugene Districts. 1993b. Conservation Strategy Frasera umpquaensis (Green Gentian or Umpqua swertis).

USDA U.S. Forest Service; Mt. Hood and Willamette National Forests; and USDI, BLM; Salem District. 1994a. Conservation strategy for Aster gormanii.

USDA U.S. Forest Service and USDI, BLM. 1994b. Final Supplemental Environmental Impact Statement on Management of Habitat for Late-Successional and Old-Growth Forest Related Species Within the Range of the Northern Spotted Owl. February 1994. Washington, D.C.

USDA USFS and USDI BLM. 1994c. Record of decision for amendments to Forest Service and Bureau of Land Management planning documents within the range of the northern spotted owl; standards and guidelines for management of habitat for late-successional and old-growth forest related species within the range of the northern spotted owl. April 1994. 
USDA U.S. Forest Service; Umpqua National Forest; and USDI, BLM; Roseburg and Medford Districts; and USDI, USFWS. 1995. Conservation agreement for Calochortus umpquaensis (Umpqua Mariposa Lily).

USDA, U.S. Forest Service; Winema, Shasta-Trinity, Modoc and Lassen National forests; USDI, BLM; Lakeview, Burns and Spokane Districts; USDI USFWS; Klamath Basin National Wildlife Refuge; and California Department of Fish and Game. 1996a. Conservation strategy for Rorippa columbiae (Columbia cress).

USDA, U.S. Forest Service; Umpqua, Mt. Hood, Willamette and Rogue River-Siskiyou National Forests; and USDI BLM, Roseburg, Eugene, Salem and Medford Districts; and U.S. Army Corps of Engineers, Willamette Valley Project. 1996b. Conservation Strategy for Cimicifuga elata (Tall bugbane).

USDA, U.S. Forest Service and USDI Bureau of Land Management. 1997. Survey and manage draft management recommendations - Bryophytes. Installment 1. IM OR1997-027 Transmittal IM. Unpublished report. On file with: Regional Ecosystem Office, P.O. Box 3623, Portland, OR. 97208

USDA, U.S Forest Service and USDI Bureau of Land Management. 1998. Management recommendations for vascular plants. Unpublished report. On file with: Regional Ecosystem Office, P.O. Box 3623, Portland, OR. 97208.

USDA, U.S. Forest Service and USDI BLM. Interagency Wild and Scenic Rivers Coordinating Council. December 1999. The Wild and Scenic River study process.

USDA, U.S. Forest Service and USDI Bureau of Land Management. 2000a. Management recommendations for lichens, Version 2.0. IM OR2000-042, Transmittal IM. Unpublished report. On file with: Regional Ecosystem Office, P.O. Box 3623, Portland, OR. 97208

USDA, U.S. Forest Service and USDI Bureau of Land Management. 2000b. Management recommendations for lichens, Version 2.0. IM OR2000-042, Transmittal IM. Unpublished report. On file with: Regional Ecosystem Office, P.O. Box 3623, Portland, Oregon 97208.

USDA, U.S. Forest Service and USDI BLM. 2002. Results of landscape level protocol survey of survey zones 1 and 2 for marbled murrelet. A memo from T. Riley, USFS, and R. Wenker, BLM, to K. McMaster, USFWS. March 4, 2002.

USDA, U.S. Forest Service and USDI BLM. July 2003. Gerber-Willow Valley Watershed Analysis. Klamath Falls, OR.

USDA, U.S. Forest Service and USDI, BLM. 2004a. Final supplemental environmental impact statement to remove or modify the survey and manage mitigation measure standards and guidelines in Forest Service and Bureau of Land Management planning documents within the range of the Northern Spotted Owl.

USDA, U.S. Forest Service and USDI, BLM. 2004b. Final Supplemental Environmental Impact Statement: Management of Port-Orford-Cedar in Southwest Oregon. Portland, Oregon.

USDA, U.S. Forest Service and USDI, BLM. 2004c. The Healthy Forests Initiative and Healthy Forests Act Interim Field Guide.

USDA, U.S. Forest Service and USDI, BLM. 2004d. Biscuit Fire recovery project final environmental impact statement. Rogue River-Siskiyou National Forest and Medford District, BLM. Publication \#R6-RR-SNF06/2004. Medford, OR. 
USDA, U.S. Forest Service; Siuslaw National Forest; USDI, BLM; Coos Bay District; USDI, National Park Service; Redwood National Park; and Redwood State Park, CA. 2004e. Conservation Strategy for Pink Sandverbena (Abronia umbellata ssp. breviflora).

USDA, U.S. Forest Service and USDI, BLM. 2005a. Draft Rapid Assessment Reference Condition Models. Available online at: http://www.reo.gov/ecoshare/news-issues/ram-issues.asp

USDA, U.S. Forest Service and USDI, BLM. 2005b. Northwest Forest Plan temperature TMDL implementation strategies. U.S. Forest Service, R-6 Regional Office and BLM Oregon State Office. Portland, OR.

USDA USFS Umpqua National Forest, USDI BLM Roseburg District, and U.S. Fish and Wildlife Service. 2006. Programmatic conservation agreement for Kincaid's Lupine (Lupinus sulphureus spp. kincaidii) in Douglas County, OR.

USDA USFS Six Rivers and Rogue-Siskiyou National Forests; USDI BLM Medford and Coos Bay Districts, and USDI USFWS Arcata and Roseburg Field Offices. 2006. Conservation agreement for Hastingsia bracteosa, H. atropurpurea, Gentiana setigera, Epilobium oreganum, and Viola primulifolia ssp. Occidentalis and serpentine Darlingtonia wetlands and fens from southwestern Oregon and northwestern California.

USDA and USDI. 2006a. Protecting people and natural resources. A cohesive fuels treatment strategy.

USDA and USDI. 2006b. Surface operating standards and guidelines for oil and gas exploration and development. BLM/WO.ST-06/021+3071. Denver, CO. 84 p.

USDA and USDI 2007. Surface Operating Standards and Guidelines for Oil and Gas Exploration and Development (The Gold Book). BLM/WO.ST-06/021+3071, Bureau of Land Management. Denver, Colorado. $84 \mathrm{p}$.

USDA USFS, USDI BLM. 2007. Conservation assessment for fungi included in Forest Service Regions 5 and 6 sensitive and BLM California, Oregon and Washington, special status species programs. July 2007. Authors: Kathleen Cushman and Rob Huff.

USDA, Natural Resources Conservation Service. August 1995. RCA III effects of sediment on the aquatic environment: potential NRCS actions to improve aquatic habitat working paper. No. 6 Janine Castro and Frank Reckendorf. Department of Geosciences, Oregon State University. Corvallis, OR.

U. S. Department of Commerce, Bureau of Economic Analysis. 2006. Regional accounts data. November 2006. www.bea.gov/bea/regional/data.htm.

U. S. Department of Commerce (USDC), National Oceanic and Atmospheric Administration (NOAA). 2005. Fisheries Office of Protected Resources. Pacific Salmonids: Major Threats and Impacts website: http:// www.nmfs.noaa.gov/pr/species/fish/salmon.htm

USDC and NOAA, National Weather Service. 1973. Precipitation-frequency atlas of the western United States, Volume X, Oregon. Atlas 2, 43 plates. Prepared by J.F. Miller, R.H. Frederick and R.J. Tracey. Silver Spring, MD.

USDC NOAA, and National Marine Fisheries Service (NMFS). 1996. Making Endangered Species Act Determinations of Effect for Individual or Grouped Actions at the Watershed Scale. August 1996. http:// www.nwr.noaa.gov/1habcon/habweb/habguide/matrix_1996.pdf 
USDC NOAA, National Marine Fisheries Service. 1997. Biological Opinion and Conference Opinion. 18 March 1997. Implementation of Land and Resource Management Plans and Resource Management Plans. Northwest Region.

United States Department of Interior (USDI) and Department of Energy (DOE). 2003. Opportunities for near-term geothermal development on public lands in the western United States. Barbara C. Farhar, Ph.D. and Donna M. Heimiller. April 2003. Technical report. Table 1 (DOE/GO-102003-1707)

USDI BLM. 1960. Statistical Appendix to the Annual Report of the Director, Bureau of Land Management to the Secretary of the Interior for the fiscal year ended June 30, 1960. USDI, BLM. Manual Handbook H-1741-1 - Fencing.

USDI BLM. Manual Handbook H-1741-2 - Water Developments. USDI BLM. Manual Section 8110.42. Management Use Categories.

USDI BLM. 1970. Public Land Statistics.

USDI BLM. April 1979. Wilderness Proposed Initial Inventory. Roadless Areas and Islands Which Clearly Do Not Have Wilderness Characteristics in Oregon and Washington.

USDI BLM. August 1979. Wilderness Review, Initial Inventory. Final Decision on Public Lands Obviously Lacking Wilderness Characteristics and Announcement of Public Lands to be Intensively Inventoried for Wilderness Characteristics in Oregon and Washington.

USDI BLM. March 1980. Wilderness Review, Intensive Inventory. Final Decision on 30 Selected Units in Southeast Oregon and Proposed Decisions on other Intensively Inventoried Units in Oregon and Washington.

USDI BLM. November 1980. Wilderness Inventory. Oregon and Washington. Final Intensive Inventory Decisions.

USDI BLM. 1985. Manual 3031-Energy and mineral resource assessment, Release 3-115, June 19, 1985.

USDI BLM. 1986. Timber Productivity Classification - TPCC Handbook 5251-1

USDI BLM. 1991. Summary of the Analysis of the Management Situation, for the Salem, Eugene \& Coos Bay (January, 1991), Roseburg \& Medford (February 1991) District Office Resource Management Plans.

USDI, BLM. 1993. Process for assessing proper functioning condition. TR 1737-9 1993.

USDI BLM. 1994a. Salem District Proposed Resource Management Plan/Final Environmental Impact Statement.

USDI BLM. 1994b. Eugene District Proposed Resource Management Plan/Environmental Impact Statement.

USDI BLM. 1994c. Roseburg District Proposed Resource Management Plan/Environmental Impact Statement.

USDI BLM. 1994d. Coos Bay District Proposed Resource Management Plan/Environmental Impact Statement.

USDI BLM 1994e. Medford District Proposed Management Plan/Environmental Impact Statement. 
USDI BLM. 1994f. Klamath Falls Resource Area Resource Management Plan/Environmental Impact Statement.

USDI BLM, Coos Bay District. 1995. Conservation Strategy for Phacelia argentea.

USDI BLM. 1996a. Partners Against Weeds: An Action Plan for the Bureau of Land Management. Washington, D.C.

USDI BLM. 1996b. Topsy/Pokegama Landscape Analysis. Lakeview District, Klamath Falls Resource Area. Klamath Falls, OR.

USDI BLM. 1996c. BLM Manual Supplement Handbook 5400-2. Special Forest Products Procedure Handbook Series. BLM Oregon State Office, Portland, OR. 83 p.

USDI BLM. 1997. Standards for rangeland health and guidelines for livestock grazing management for public lands administered by the Bureau of Land Management in the states of Oregon and Washington. August 12, 1997.

USDI BLM. $2001 \mathrm{a}$. Inventory and monitoring system: current vegetation survey field procedures. 16 January 2001. Natural Resource Inventory Oregon/Washington. 173 p.

USDI BLM. 2001b. Release 6-121. 19 January 2001. BLM Manual 6840 Regulations - Special Status Species Management.

USDI BLM. 2001c. North Bank Habitat Management Area/ACEC Record of Decision, Habitat Management Plan and Monitoring Plan. Roseburg District, BLM. Roseburg, OR.

USDI BLM. 2001d. Reasonably Foreseeable Development Scenario for Oil and Gas Development in the Buffalo Field Office Area, Campbell, Johnson, and Sheridan Counties, Wyoming. Wyoming State OfficeReservoir Management Group. 25 p.

USDI BLM. 2002a Pokegama Wild Horse Herd Management Area Plan. Lakeview District, Klamath Falls Resource Area. Klamath Falls, OR.

USDI BLM. 2002b. Western Oregon Transportation Management Plan, 1996. Updated 2002

USDI BLM. 2003. BLM-Instructional Memorandum No. OR-2003-054. 25 March 2003. Oregon/ Washington Special Status Species Policy.

USDI BLM. 2004a. New River Area of Critical Environmental Concern Management Plan. Coos Bay District, BLM. North Bend, OR.

USDI BLM. 2004b. Timbered Rock Fire Salvage and Elk Creek Watershed Restoration Final Environmental Impact Statement. Medford District, BLM. Medford, OR.

USDI BLM. 2004c. Implementation of special status species policies for the former survey and manage species. BLM information bulletin no. OR-2004-145. $4 \mathrm{p}$

USDI BLM. 2004d. Implementation of special status species policies for the former survey and manage species. BLM information bulletin no. OR-2004-145. $4 \mathrm{p}$

USDI BLM. 2004e. Implementation of the 2004 record of decision to remove survey and manage mitigation measure standards and guidelines. BLM information bulletin no. OR- 2004-121. 
USDI BLM. 2005a. Draft vegetation treatments using herbicides on Bureau of Land Management lands in 17 western states. Programmatic environmental impact statement. Washington, DC.

USDI BLM. 2005b. North Spit Management Plan. Coos Bay District, BLM. North Bend, OR.

USDI BLM. 2006a. County budget data for FY2005 - BLM Western Oregon Plan Revision. Portland, OR.

USDI BLM. 2006b. Unpublished rare plant database: GeoBob. Portland, OR.

USDI BLM. 2006c. Recreation management information system. Data retrieved from http:// rmis.blm.gov/

USDI BLM. 2007a. Geographic information system (GIS) data layers. Oregon State Office. Portland, OR.

USDI BLM. 2007b. Instruction memorandum no. OR-2007-072. Update to Oregon/Washington BLM State Director's special status species list.

USDI BLM. 2007c. Final Vegetation Treatments Using Herbicides on Bureau of Land Management Lands in 17 Western States Programmatic Environmental Impact Statement. Volume 1: Abstract, Executive Summary, and Chapters 1 through 8.

USDI BLM. 2007d. Draft environmental impact statement for the revision of the resource management plans of the western Oregon Bureau of Land Management districts of Salem, Eugene, Roseburg, Coos Bay, and Medford district, and the Klamath Falls Resource Area of the Lakeview District. U.S. Department of the Interior, Bureau of Land Management, Portland, Oregon.

USDI BLM. 2007e. Record of decision. Vegetation treatments using herbicides on Bureau of Land Management lands in 17 western states. Programmatic environmental impact statement (PEIS). Reno, NV.

USDI BLM. 2007f. Final Biological Assessment Vegetation Treatments on Bureau of Land Management Lands in 17 Western States. Reno, NV.

USDI BLM. 2007. Unpublished BLM Special Forest Products Database. BLM Oregon State Office, Portland, OR.

USDI BLM. 2008, Geographic Information System (GIS) Data Layers, Oregon State Office, Portland, OR.

USDI BLM, Roseburg District and U.S. Fish and Wildlife Service (USFWS), Roseburg Field Office. 2004. Conservation Agreement for Calochortus coxii (Crinite Mariposa Lily).

USDI BLM Medford District, USFWS, and The Nature Conservancy of Oregon. 2004. Draft conservation agreement for Limnanthes floccose Howell ssp. pumila (Dwarf Woolly Meadowfoam).

USDI USFWS. 1983. Columbian White-Tailed Deer Recovery Plan. Portland, OR.

USDI USFWS. 1986. Recovery plan for the Pacific bald Eagle. Portland, OR.

USDI USFWS. 1990. McDonald's Rock-cress, (Arabis mcdonaldiana Easwood) Recovery Plan. Portland, OR. $40 \mathrm{p}$.

USDI USFWS. 1990. Endangered and threatened wildlife and plants determination of threatened status for the northern spotted owl; final rule. Federal Register 55(123):26114-26194.

USDI USFWS. 1992a. Draft recovery plan for the northern spotted owl. Pacific Region. 662 p.

References - 979 
USDI USFWS. 1992b. Endangered and threatened wildlife and plants; determination of critical habitat for the northern spotted owl; final rule. Federal Register, Vol.57, 10:1796-1838. January15, 1992.

USDI USFWS. 1993. Lomatium bradshawii (Bradshaw's lomatium) Recovery Plan. Portland, OR. 47 p.

USDI USFWS. 1996. Water Howellia (Howellia aquatilis) Recovery Plan. Helena, MT. 52 p.

USDI USFWS. 1997. Recovery plan for the threatened marbled murrelet (Brachyramphus marmoratus) in Washington, Oregon and California. Region 1. Portland, OR.

USDI USFWS. 1998a. Recovery Plan for the Threatened Nelson's Checker-mallow (Sidalcea nelsoniana). Portland, OR. 61 p.

USDI USFWS. 1998b. Recovery Plan for the Endangered Western Lily (Lilium occidentale). Portland, OR. $82 \mathrm{p}$.

USDI USFWS. 1998c. Recovery Plan for the Applegate's Milk-vetch (Astragalus applegate). Portland, OR. $41 \mathrm{p}$.

USDI USFWS. 2000a. Recovery Plan for the Golden Paintbrush (Castilleja levisecta). Portland, OR. 51 p.

USDI. USFWS. 2000b. Endangered and threatened wildlife and plants; endangered status for Erigeron decumbens var. decumbens (Willamette daisy) and Fender's blue butterfly (Icaricia icarioides fenderi) and threatened status for Lupinus sulphuerus ssp. kincaid; Final Rule. 50 CFR Part 17, Federal Register, Vol. 65, No. 16: 3875-3890. Jan. 25, 2000.

USDI USFWS. 2001a. Western Snowy Plover (Charadrius alexandrinus nivosus) Pacific Coast Population Draft Recovery Plan. Region 1. Sacramento, CA.

USDI USFWS. 2001b. Oregon Silverspot Butterfly (Speyeria zerene hippolyta) Revised Recovery Plan. Region 1. Portland, OR.

USDI USFWS. 2003a. Recovery Plan for the Rough Popcornflower (Plagiobothrys hirtus). Portland, OR. 60 p.

USDI USFWS. 2003b. Recovery plan for Fritillaria gentneri (Gentner's fritillary). viii +89 p. Portland, OR.

USDI USFWS. 2003c. Recovery Outline for Lomatium cookii (Cook's Lomatium) and Limnanthes floccosa ssp. grandiflora (Large-flowered Woolly Meadowfoam). Portland, OR. 19 p.

USDI USFWS. 2003d. Website for Lost River and Shortnose suckers. Created by: Oregon Fish and Wildlife Office. http://www.fws.gov/oregonfwo/EndSpp/FactsFish/LRsucker.htm http://www.fws.gov/oregonfwo/ EndSpp/FactsFish/Shortnose.htm

USDI USFWS. 2003e. Estimates of distances at which incidental take or murrelets and spotted owls due to harassments are anticipated from sound-generating, forest-management activities in Olympia National Forest. U.S. Department of the Interior, Fish and Wildlife Service, Lacey, Washington.

USDI USFWS. 2004a. Northern spotted owl five-year review: summary and evaluation. Portland, OR.

USDI USFWS. 2004b. Marbled murrelet 5-year review process. Region 1. Portland, OR. 
USDI USFWS. 2005a. Recovery Plan for Vernal Pool Ecosystems of California and Southern Oregon. Region 1. Portland, OR.

USDI USFWS. 2005b. Draft (November 2005): The USFWS 40\% rule based on the current science on the northern spotted owl; an update. Portland, OR. $8 \mathrm{p}$.

USDI USFWS. 2005c. Endangered Species Program. Critical habitat: What is it? December 2005. URL: http://www.fws.gov/endangered/pdfs/listing/Critical Habitat 12 05.pdf (accessed March 2008).

USDI USFWS. 2006a. Recovery Outline for Lupinus sulphureus ssp. kincaidii (Kincaid's lupine). Portland, OR. 23 p.

USDI USFWS. 2006b. Draft Recovery Plan for Listed Species of the Rogue Valley Vernal Pool and Illinois Valley Wet Meadow Ecosystems. Portland, OR.

USDI USFWS, Roseburg Field Office. 2006c. Personal communication from Lynn Gemlo, copy of latest state of the species section for the northern spotted owl.

USDI USFWS. 2007. Endangered and threatened wildlife and plants; proposed revised designation of critical habitat for the northern spotted owl (Strix occidentalis caurina); proposed rule. Federal Register 72(112):32449-32516. June 12, 2007.

USDI USFWS. 2007. Draft: Smoke effects on northern spotted owls. Portland, OR.

USDI, USFWS. 2007. 5- Year Review Summary and Evaluation Golden Paintbrush (Castilleja levisecta). Lacy, Washington. $37 \mathrm{p}$.

USDI USFWS. 2008a. Final recovery plan for the northern spotted owl (Strix occidentalis caurina). Portland, OR. 142 p.

USDI USFWS. 2008b. Final rule on the critical habitat of the northern spotted owl.

USDI USFWS, USDI BLM, and USDA USFS. 2007. Methodology for estimating the number of northern spotted owls affected by proposed federal actions. Oregon Fish and Wildlife Office, Fish and Wildlife Service, Portland, Oregon.

USDI, U.S. Geological Service. USGS web page for suckers: http://wfrc.usgs.gov/research/ fish\%20 populations/STShively2.htm and http://www.fws.gov/pacific/bulltrout/final/pdf/BT combined revised100605.pdf

USDI, U.S. Geological Survey. 2007. Mineral Commodity Summaries.

United States Environmental Protection Agency (U.S. EPA). 1998. Final Guidance for Incorporating Environmental Justice Concerns in EPA's NEPA Compliance Analyses.

U.S. EPA. 2000. The history of drinking water treatment. Office of Water, EPA-816-F-00-006.

U.S. EPA. 2007. Inventory of U.S. Greenhouse Gas Emissions and Sinks: 1990-2005. U.S. Environmental Protection Agency. Washington, D.C. 
U.S. Global Change Research Program, National Assessment Synthesis Team. 2001. US National Assessment of the Potential Consequences of Climate Variability and Change Educational Resources. Regional Paper: Pacific Northwest. U.S. Climate Change Science Program/U.S. Global Change Research Program. Washington D.C. Available online at: http://www.usgcrp.gov/ usgcrp/nacc/education/pnw/default.htm

United States International Trade Commission. 2006. http://www.usitc.gov/

University of Washington (E. Salo and T. Cundy, editors). 1997. In: Streamside management: forestry and fishery interactions. Institute of Forest Research No. 57-1987, Chapter 2. E. Salo and T. Cundy, editors. College of Forest Resources, University of Washington. Seattle, WA.

Vance, Nan C., Melissa Borsting, David Pilz and Jim Freed. 2001. Special forest products: species information guide for the Pacific Northwest. General Technical Report PNW-GTR-513. Pacific Northwest Research Station, U.S. Department of Agriculture, U.S. Forest Service. Portland, OR. http://www.treesearch. fs.fed.us/pubs/3075. 169 p.

Vander Schaaf, D., M. Schindel, D. Borgias, C. Mayer, D. Tolman, G. Kittel, J. Kagan, T. Keeler-Wolf, L. Serpa, J. Hak and K. Popper. 2004. Klamath Mountains Ecoregional Conservation Assessment. The Nature Conservancy. Portland OR.

Van Sickle, J. and S.V. Gregory. 1990. Modeling inputs of large woody debris from falling trees. Canadian Journal of Forest Research 20: 1593-1601.

Verts, B.J. and L.N. Carraway. 1998. Land Mammals of Oregon. University of California Press. Berkeley, CA.

Vessely, D.G. and W.C. McComb. 2002. Salamander abundance and amphibian species richness in riparian buffer strips in the Oregon Coast Range. Forest Science 48(2):291-297.

Vessely, D., W.C. McComb, J.M. Weikel and D. Bigger. 2001. Wildlife and coarse-filter biodiversity assessment. In: Umpqua Land Exchange Project Multi-Resource Land Allocation Model Handbook. Umpqua Land Exchange Project. Portland, OR.

Wagner F. F. and R. G. Anthony. 1999. Reanalysis of northern spotted owl habitat use on the Miller Mountain study area. Final report for step 1: Identification and evaluation of northern spotted owl habitat in managed forests. Oregon Cooperative Fish and Wildlife Unit, Oregon State University, Corvallis, OR.

Wagner, E., E. Hansen, S. Leavengood, J. Punches and S. Bowers. 2003. The Big Log Project. Wood Science and Engineering. Oregon State University. Corvallis, OR. 101 p.

Walburger, K., T. DelCurto and M. Vavra. 2005. The effects of herbivory and timber harvest on understory production in northeastern Oregon. Papers presented at Range Field Day. Union, OR.

Walker, G. and P. King. 1969. Geologic map of Oregon: U.S. geological Survey, Map 1-595.

Wallace, J.B., S.L. Eggert, J.L. Meyer and J.R. Webster. 1997. Multiple trophic levels of a forest stream linked to terrestrial litter inputs. Science. 277: 102-104.

Wallin, D.O., F.J. Swanson and B. Marks. 1994. Landscape pattern response to changes in pattern generation rules: land-use legacies in forestry. Ecological Applications 4:569-580.

Ward, J. W. Jr. 1990. Spotted owl reproduction, diet and prey abundance in northwest California. M.S. Thesis. Humboldt State University. Arcata, CA. 
Ward, J. W. Jr., R.J. Gutiérrez and B.R. Noon. 1998. Habitat selection by northern spotted owls: the consequences of prey selection and distribution. The Condor 100:79-92.

Warren, Debra D. 2006. Production, Prices, Employment and Trade in Northwest Forest Industries. Pacific Northwest Research Station, U.S. Department of Agriculture, U.S. Forest Service. Portland, OR.

Washburne, 1914, as found in Olmstead, D.L., Newton Jr., V.C., Stewart, R.E., 1989, Hydrocarbon Exploration and Occurrences in Oregon: State of Oregon Department of Geology and Mineral Industries Oil and Gas Investigation 15,74p.

Washington State Department of Natural Resources (DNR). 1997a. Standard methodology for conducting watershed analysis, version 4.0, Appendix C - Hydrologic Change. online: [http://www.dnr.wa.gov/ forestpractices/watershedanalysis/manual/]

Washington State DNR. 1997b. Surface Erosion Module vs. 4.0. Online: [http://www.dnr.wa.gov/ forestpractices/watershedanalysis/manual/hydrology.pdf]

Washington State DNR. 2005. Definition and Inventory of Old Growth Forests on DNR-Managed State Lands. Olympia, WA.

Watershed Professionals Network, 1999. Oregon watershed assessment manual. June 1999. Prepared for the Governor's Watershed Enhancement Board.

Watterson, Nicholas A. and J. Jones. 2006. Flood and debris flow interactions with roads promote the invasion of exotic plants along steep mountain streams, western Oregon. Geomorphology 78 (2006) 107 123.

Weaver, W. and D. Hagans. 1996. Aerial reconnaissance evaluation of 1996 storm effects on upland mountainous watersheds of Oregon and southern Washington. Pacific Watershed Associates. Arcata, CA.

WeedMapper Team, Dept. of Rangeland Resources, Oregon State University. Copyright 2004a. Retrieved July, 2006 from: http://www.weedmapper.org/maps.html

WeedMapper Team, Department of Rangeland Resources, Oregon State University. Copyright, 2004b. Retrieved September 5, 2006 from: http://www.weedmapper.org/eues.html

WeedMapper Team, Dept. of Rangeland Resources, Oregon State University. Copyright, 2004c. Meadow knapweed (Centaurea pratensis Thuill., non Salilsb.). Retrieved January 25, 2007: http://www.weedmapper. org/cede5.html

WeedMapper Team, Dept. of Rangeland Resources, Oregon State University. Copyright, 2004d. Spotted knapweed (Centaurea maculosa auct. non Lam.). Retrieved January 29, 2007 from: http://www.weedmapper. org/cebi2.html

Weir, R.D. and A.S. Harestad. 2003. Scale-dependent habitat selectivity by fishers in south-central British Columbia. Journal of Wildlife Management 67:73-82.

Weisberg, P.J. and F.J. Swanson. 2003. Regional synchroneity in fire regimes of western Oregon and Washington. Forest Ecology and Management 172:17-28.

Weissenborn, A. E., 1969, Mineral and Water Resources of Oregon: State of Oregon Department of Geology and Mineral Industries, Bulletin 64, 468p. and Maps 
Wells, R. E., Jayko, A. S. Niem, A. R., Black, G., Wiley, T., Baldwin, E., Molenaar, K. M., Wheeler, K. L., DuRoss, C. B., and Givler, R. W., 2000, Geologic map and Database of the Roseburg 30 X 60 ' Quadrangle, Douglas and Coos Counties, Oregon: United States Geological Survey, Open-File Report 00-376, Map and $55 \mathrm{p}$.

Wells, R. E., 2008, Personal Communications with Ray E. Wells, Geologist; United States Geologic Survey. March 12, 2008.

Wemple, B.C. 1994. Assessing the role of logging-access roads in two large forested basins in the western cascades of Oregon. M.S. thesis. Oregon State University. Corvallis, OR.

Wemple, B.C. 1998. In: Jones, J.; F. Swanson, B. Wemple and K. Snyder. 2000. Effects of Roads on Hydrology, Geomorphology, and Disturbance Patches in Stream Networks. Conservation Biology. 14(1):76-85.

Wemple, B.C. and J. Jones. 2003. Runoff production on forest roads in a steep mountain catchment. Water Resources Research 39(8):1220.

Wemple, B.C., J. Jones and G. Grant. 1996. Channel network extension by logging roads in two basins, western Cascades, Oregon. Journal of the American Water Resources Association 32(6):1195.

Westerling, A.L., H.G. Hidalgo, D.R. Cayan and T.W. Swetnam. 2006. Warming and earlier spring increase western U.S. forest wildfire activity. Science 313(5789): 940-943.

Western Wood Products Association. 2006. 2005 Statistical Yearbook of the Western Lumber Industry. Portland, OR.

Whiteaker, L. 2007a. personal com. Botanist, ACEC Interdisciplinary Team Member, Western Oregon Plan Revision, Klamath Falls, OR.

Whiteaker, L. 2007b. personal com. Botanist, Klamath Resource Area. Cattle effects to rare species.

Whitney, L.W. 2002. Ecological Relationships Between Columbian White-tailed and Black-tailed Deer in Southwest Oregon. M.S. Thesis. Oregon State University. Corvallis, OR.

Wigmosta, M.S., L. Vail, and D. P. Lettenmaier, 1994: A distributed hydrology-vegetation model for complex terrain, Wat. Resour. Res., 30, 1665-1679.

Wiley, T. 2006. Personal Communications with Tom Wiley, Geologist, State of Oregon Department of Geology and Mineral Industries Southwest Oregon Section Leader.

Wiley, T., 2008, Personal Communications with Tom Wiley, Geologist, State of Oregon Department of Geology and Mineral Industries Southwest Oregon Section Leader. March 11, 2008

Willard, E. Earl; Ronald H. Wakimoto and Kevin C. Ryan. 1995. Vegetation recovery in sedge meadow communities within the Red Bench Fire, Glacier National Park. In: Fire in wetlands: a management perspective: Proceedings, 19th Tall Timbers fire ecology conference, November 3-6; 1995. pp. 102-110. Cerulean, Susan I.; Engstrom and R. Todd, editors. Tall Timbers Research Station. Tallahassee, FL.

Williamson, Richard L. 1973. Results of shelterwood harvesting of Douglas-fir in the western Cascades. Research Paper PNW-161. Pacific Northwest and Range Experimental Station, U.S. Department of Agriculture, U.S. Forest Service. Portland, OR. 
Wimberly, M.C. 2002. Spatial simulation of historical landscape patterns in coastal forests of the Pacific Northwest. Canadian Journal of Forest Research 32:1316-1328.

Wimberly, M.C. and J.L. Ohmann. 2004. A multi-scale assessment of human and environmental constraints on forest land cover change on the Oregon (USA) coast range. Landscape Ecology 19: 631-646.

Wimberly, M.C., T.A. Spies, C.J. Long and C. Whitlock. 2000. Simulating historical variability in the amount of old forests in the Oregon Coast Range. Conservation Biology 14(1):167-180.

Wind Energy Resource Atlas of the United States. 2007. Chapter 3: Regional Summaries, the Northwest Region, Oregon and Washington Coast.

Winter, L.E., L.B. Brubaker, J.F. Franklin, E.A. Miller and D.Q. DeWitt. 2002. Initiation of an old-growth Douglas-fir stand in the Pacific Northwest. A reconstruction from tree ring records. Canadian Journal of Forest Research 32:1039-1056.

Wipfli, M.S., J.S. Richardson and R.J. Naiman. 2007. Ecological Linkages Between Headwaters and Downstream Ecosystems: Transport of Organic Matter, Invertebrates, and Wood Down Headwater Channels. Journal of the American Water Resources Association. 43 p.

Wisdom, M.J., N.J. Cimon, B.K. Johnson, E.O. Garton and J.W. Thomas. 2004a. Spatial partitioning by mule deer and elk in relation to traffic. In: Transaction of the Sixty-ninth North American and Natural Resources Conference held March 16-20, 2004, in Spokane, WA. J. Rahm, editor. Wildlife Management Institute. Washington, D.C.

Wisdom, M.J., B.K. Johnson, M. Vavra, J.M. Boyd, P.K. Coe, J.G. Kie, and A.A. Ager. 2004b. Cattle and elk responses to intensive timber harvest. Pp. 727-758, in Transactions of the 69th North American Wildlife and Natural Resources Conference held March 16-20, 2004 in Spokane, WA. J. Rahm, editor. Wildlife Management Institute, Washington, D.C.

With, K.A. and T.O. Crist. 1995. Critical thresholds in species' response to landscape structure. Ecology 76(8): 2446-2459.

Witmer, G. and M. Wisdom. 1986. Some important elk-forest habitat relationships for western Oregon and Washington. In: Proceedings of the 1986 Western States and Provinces Elk Workshop held March 17-19, 1986 in Coos Bay, Oregon. Eastman, D.L., editor. Oregon Department of Fish and Wildlife. Portland, OR.

Woltemade C.J.; Potter, K.W. 1994. A watershed modeling analysis of fluvial geomorphologic influences on flood peak attenuation. Water Resources Research. 30(6): 1933-1942.

Woodbury, P.B., J.E. Smith and L.S. Heath. 2006. Carbon sequestration in the U.S. forest sector from 1990 to 2010. Forest Ecology and Management 241:14-27.

Wright, K., K. Sendek, R. Rice and R. Thomas. 1990. Logging effects on streamflow: Storm runoff at Casper Creek in northwestern California. Pacific Southwest Forest and Range Experiment Station, U.S. Department of Agriculture, U.S. Forest Service. Arcata, CA.

Wringler, N.H. and J.D. Hall. 1975. Effects of logging on water temperature and dissolved oxygen in spawning beds. TransAmerican Fisheries Society 104(1):111-121.

Yaeger, J. Scott. 2005. Habitat at Fisher Resting Sites in the Klamath Province of Northern California. Thesis presented to Humboldt University. Arcata, CA. 
Young, J.A., D.W. Hedrick and R.F. Keniston. 1967. Forest cover and logging--herbage and browse production in the mixed coniferous forest of northeastern Oregon. Journal of Forestry 65: 807-813.

Zabel, C.J., K.M. McKelvey and J.P. Ward, Jr. 1995. Influence of primary prey on home-range size and habitat-use patterns of northern spotted owls (Strix occidentalis caurina). Canadian Journal of Zoology 73:433-439.

Zabel, C.J., J.R. Dunk, H.B. Stauffer, L.M. Roberts, B.S. Mulder and A. Wright. 2003. Northern spotted owl habitat models for research and management application in California. Ecological Applications 13(4):10271040 .

Zenner, E. 2000. Do residual trees increase structural complexity in Pacific Northwest coniferous forests? Ecological Applications 10(3): 800-810.

Zenner, E.K. 2005. Development of tree size distributions in Douglas-fir forests under differing disturbance regimes. Ecological Applications 15(2): 701-714.

Zielinski, William J., Neil Duncan, Emma C. Farmer, Richard L. Truex, Anthony P. Clevenger and Reginald Barrett. 1999. Diet of Fishers (Martes Pennanti) at the Southernmost Extent of their Range. Journal of Mammalogy 80(3):961-971, 1999.

Zielinski, William J., Richard L. Truex, Gregory A. Schmidt, Frederick V. Schlexer, Kristin N. Schmidt and Reginald H. Barrett. 2004. Resting Habitat Selection by Fishers in California. Journal of Wildlife Management 68(3):475-492.

Ziemer, R. R. 1981. Storm flow response to road building and partial cutting in small streams of Northern California. Water Resources Research 17(4): 907-917.

Ziemer, R. R. 1998. Proceedings of the conference on coastal watersheds: the Caspar Creek story. 6 May 1998; Ukiah, California. Pacific Southwest Research Station, U.S. Department of Agriculture. U. S. Forest Service. Albany, CA. 149 p.

Ziemer, R. R. and E.T. Keppeler. 1996. Hydrologic consequences of logging second-growth redwood watersheds. Conference on coast redwood forest ecology and management. Humboldt State University. Arcata, CA. 


\section{Index}

303(d) listed streams $\quad 10,337$

A

ACEC 11, 27, 43-46, 621

Adaptive management $\quad 7,881$

Administratively Withdrawn Area 27

Air quality 408

Allowable sale quantity $\quad 37,40,571-575$

Anadromous fish 362

Annual program summary 139,881

A reas of concern (Northern Spotted Owl) 286

B

Bald eagle 310-312, 710-713

Best Management Practices 867, Appendix I

Biological Assessment 870

Biological Opinion 870

Biomass 861

Bull Run Watershed 25-26

C

Cascade-Siskiyou National Monument 25-26

Clean Air Act 408

Clean Water Act $\quad 10,336$

Climate change 488

Coal bed methane 467, 861

Columbian white-tailed deer 326,697

Communication sites 59

Conservation needs (Northern Spotted Owl) 286-298, 645, 660, 661-667, 668-679, 680-683

Consultation 19

Cooperating agency 15,16

Coos Bay Wagon Roads 3, 12

Coquille Forest $\quad 16-17,148.158$

Coquille Tribe 16,17

County payments $237-238,547,549,561$

Critical habitat $5,9,298,315,365$

Cumulative effects 485

\section{D}

Deferred Timber Management Area 37

Deer management areas $327-329,698,705$

Direct and indirect effects 485

\section{E}

Early-successional forests 206

Eastside Forest Management Area 24, 35-37, 577

Effective shade Summary lv

Elk 7050710, 326, 328-330 
Elk management areas 329-330, 705-710

Employment 247-250, 546, 550-559

Endangered Species Act $\quad 9,869$

Existing old forest 514

F

FEMAT 202, 211, 216

Fire regime $394-400,807$

Fire resiliency $401,806,808$

Fire hazard 401

Fisher 318-321.713-720

Fish productivity 801

Forest fragmentation 214

G

General Landscape Area 158

Geothermal energy 467

H

Habitat groups 271

Hardwood stands 214, 724-726

Harvest land base $516,517,575,583$

High intrinsic potential $\quad 367,368,803-804$

I

Indian tribes 16

Instream restoration 803

$J$

Jordan Cove Energy Liquid Natural Gas Terminal and Pacific Connector Gas Pipeline 451, 487

$\mathbf{L}$

Land birds $321-325,721-735$

Land tenure zones 57,58

Land use allocations $\quad 24,139,140,148,158$

Large wood model $\quad 372,779$

Late-successional forests 202, 505

Late-Successional Management Area 24, 28, 140, 148, 158

Listed fish species 362

M

Marbled murrelet $\quad 28,299,-307,684-697$

Mature forests 206

Mitigation 495-497

Monitoring 880

Mt. Hood Corridor 25, 36, 63, 409

Mule deer 327, 698

$\mathrm{N}$

National Energy Policy 469

National Environmental Policy Act 15

National Landscape Conservation System 24, 25, 621, 835

Natural disturbance $\quad 490-493$ 
Nonharvest land base $\quad 519,577$

Northern spotted owl $\quad 5,19,28,283-298,644-681$

Northwest Forest Plan 10-year monitoring $\quad 480$

O

O\&C Act $3,6,8,10,12,233$

O\&C lands 13, 193-197, 239

Off-highway vehicles $\quad 61,62,621$

OPTIONS model 482, Appendix R

ORGANON growth and yield model 482, Appendix R

Oregon listed species 315

Oregon Smoke Management Plan 408

Owl activity centers 162

$\mathbf{P}$

Pacific Crest National Scenic Trail 25, 26, 63

Peak flow 355-357, 753-759, 800

Port-Orford cedar root rot $19,41,218$

$\mathbf{R}$

Rangeland health $\quad 435$, Appendix M

Reasonably Foreseeable Mineral Development Appendix Q

Reference analyses $\quad 484,573-574$

Research natural area $\quad 440-441$

Rights-of-way 59, 450-452

Riparian Management Areas 24, 32-37, 140, 148, 158

S

Sage Grouse $306-310,744-745$

Salvage $32,494-495,616$

Secure Rural School and Community Self Determination Act 236-237, 545

Sediment delivery $343,347,385,799$

Settlement agreement 4

Soil compaction 430

Source water watersheds $\quad 360-361,778$

Special status species $261-269,315,746$

Stream temperature $336,388,801$

Structural stage classifications $\quad 206-211,502-516,584$

Sudden Oak death 490

Survey and Manage 5, 18-19

Sustained Yield Units 483

Swiss needle cast 214

T

Temperature standards for fish species $\quad 388-389$

Temporary use permits 451

Timber Management Areas 24, 37, 39, 140, 148

Timber Production Capability Classification (TPCC) 348

Traditional use sites 448,855

Travel management plans 453 
$\mathrm{U}$

Uneven-Age Management Areas 24, 37

Utility corridors 59,60

V

Visual resource management classes $\quad 425$

W

Water quality $20,334,867$

Western Snowy Plover 311-315, 743

West Nile virus 285

Westwide Energy Corridor Project 486

Wildland urban interface 50-51

Wind energy 468

Y

Yaquina Head Outstanding Natural Area 25, 26

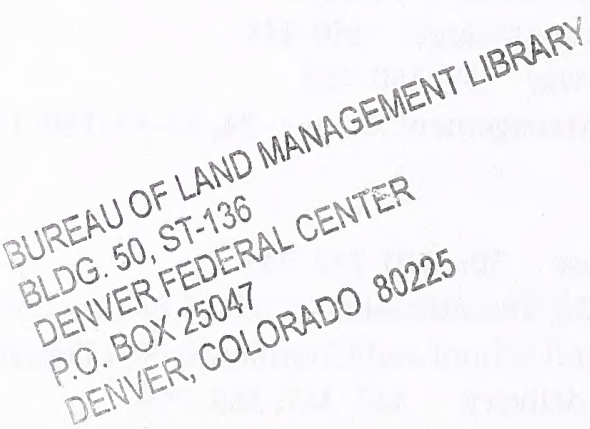

Table of Contents - 990 




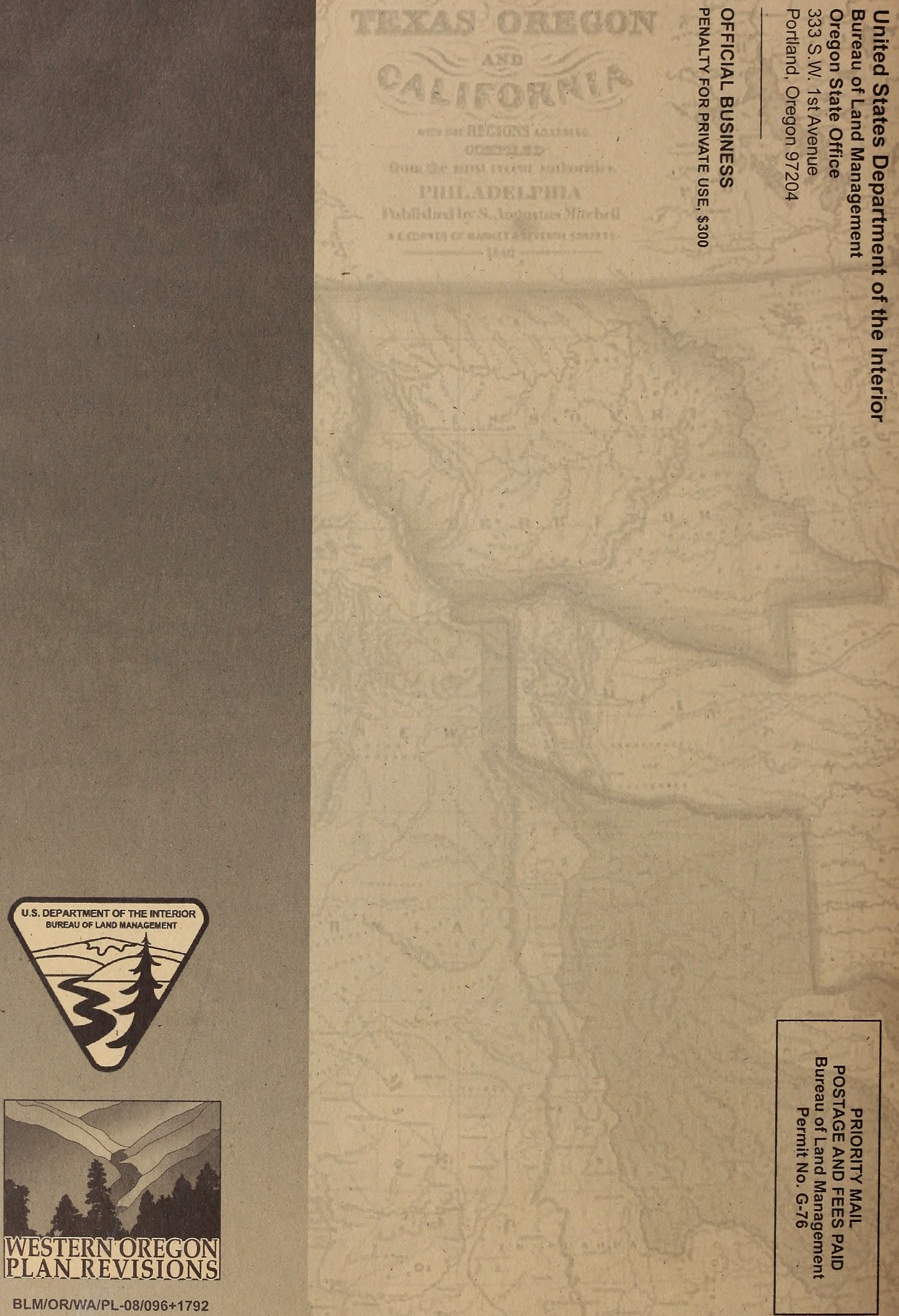